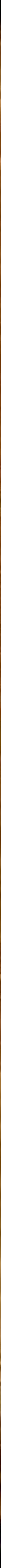




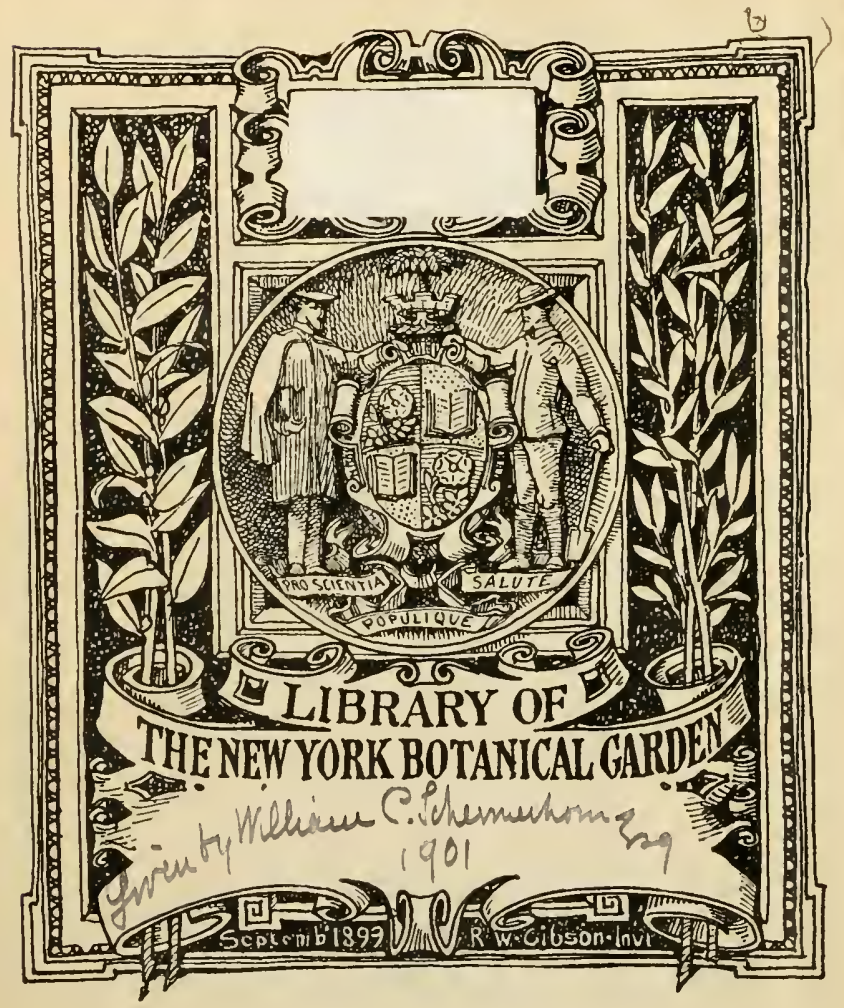

R. FRIEDLÄNDER \& SOHN Buch hand I u Berlin N.W.6. 11. Curisirasse 11 


\section{Denews}

RUEW YORO BOTANICAL GARDEN 



\section{FLORA LIPSIENSIS S I S T E N S}

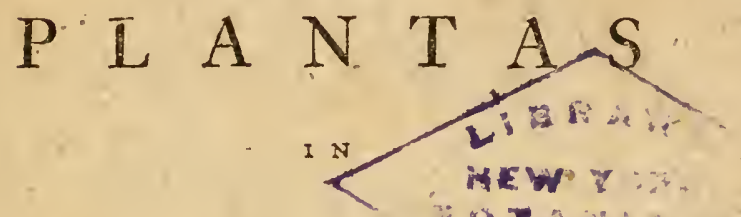
A G R I S

\section{I R C V L I L I'P S I C I}

TAM SPONTE NASCENTES QVAM FREQVENTIVS CVLTAS

$S$ E C V N D V M

$S$ Y S T E M A S E X V A L E REVISVM ATQVE EMENDATVM

DES C R I P TAS

$\Lambda$

IOANNE CHRISTIANO GOTTLOE ${ }_{11}^{\text {R A V M GARTEN }}$

AED. BACC.

Gum Tabulis IV. aeri incifis.

L I P $S$ I A E

IMPENSIS SIEGFRIED LERRECIIT CRVSII

$$
\begin{aligned}
& \text { c. I I I C C X } \\
& \text { ? }
\end{aligned}
$$




$$
\begin{array}{r}
4+4 \\
4= \\
4:
\end{array}
$$




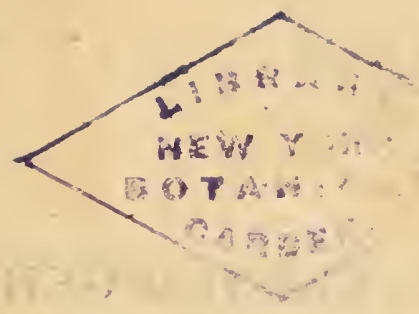

\title{
V I R I S
}

MAGNIFICIS, ILLVSTRIBVS, EXPERIENTISSIMIS, AMPLISSIMIS ATQVE DOCTISSIMIS

\section{FACVLTATIS MEDICAE LIPS IEN S IS}

\author{
A DSESSORIB V S.
}




\section{IOANNI CAROLO GEHLERO}

THERAP. P. P. OFD. FAC. MED, DECAN, ACAD. DECEMVIRO MAI, ET MIN. COLLEG. COLLEGIATO CIVIT. LIPS. POLEATO SOC. OEC. LIPS. MEMBRO HONORARIO.

\section{CAROLO CHRISTIANO KRAVSE}

PHILOS. ET MED. DOCTORI FACVLT. MED. SE. NIORI ANAT. ET CHIRVRG. P. P. EXTRAORII-

NARIO MIN. PRINC. COLLEG. SENIORI.

\section{IOANNI GOT'TLOB HAASIO}

ANAT, ET CHIR. P. P. ORDIN. MED. FACVLT. ADSESSORI SOCIET. OECON. LIPS. MEMBRO HONAR. ET SOC. REG. SCIENT. GOTTING. SODALI. 


\section{ERNESTO PLATNERO}

PHYSIOL. P. P. ORDINAR. FACVIT. MED. ADSESSORI ACAD. DECEMVIRO MAI, COLLEG. PRINC. PRAEPOSITO NATION. SAYON. SENICRISOCIET. OECON. LIPS. MEMR. HONOR.

\section{IOANNI EHRENFRIED POHLIO}

MED. DOCT. PATHOL. P.P. ORDIN. FACVLT. MED. ADSESS. SIREN. PRINC. ELECST. SAX. CONSIEIAR. AVL-ET ARCHIATRO SOC. OEC. LIPS.

MEMB. IIONOR.

\section{ADAMO MICHAEL, BIRKHOLZ}

PIIIOS. ET MED. DOCTORI FACVLT. MED. ADSESSORI COLLEG. MAI. PRINC. COLLEGIATO. 


\section{CHRISTIANO FRIDERICO L VDWIG}

PATHOL. P. P. SVBSTIT. HISTOR. NAT. P. P. EXTRAORD. FAC. MED. ADSESSORI PRAEFECT. LIPS. PHYSICO RROVINCIALI SOC. OEC. LIPS. MEMB. HON. SOC. AGRICVLT. PARIS. ET ACAD.

REG. SCIENT. MONSPELIENS. HALENS. ET NAT. CVRIOS. CORRESPONDENTI.

\section{ERNESTO BENIAMIN THEO- PHILO HEBENSTREIT}

PHIL. ET MED. DOCT. FACVLT. MED. SVBSTIT. SOC. OECON. LIPS. MEMB. HONOR. NAT. CVRIOS. HALENS. ET MVSEI PARIS. SODALI SOC. REG. SCIENT. GOTTING. ET SOC. AGRICVLT. PARIS. CORRESPONDENTI. 



\section{$\mathrm{FANCCE}$ \\ FLORAM LIPSIENSEM \\ IN}

PVBLICVM AC PERENNE PIETATIS SENPITER NAE

MO N V M E N T V M 2 '

GRATISSIMAE MENTIS

TESSERAM PERPETVAII

D. D. D.

AVCTOR

10. CHRISTIAN. GOTTLOB BAMGARTEN AED. EA C C, 


\section{LECTVRIS BENEVOLIS.}

1. Irabuntur forfitan multi, poft celeberrimorum Virorum, bóngeri, schregeri aliorumque curas, me hominem noum, illisque nominibus, et doctrinae copia, et auctoritate, longe inferiorem, ad floRaE LIPSiENsis adumbrationem animum appuliffe. Ego vero non ita fum arrogans, vt meis qualibuscunque laboribus gloriae palmam. Viris illis eripere audeam; neque ignoro, quam difficile fit in laboris abaliis paene confecti repetita pertractatione lectorum reprehenfionem non incurrere, ne dicam, gratiam promereri. Quae cogitatio, cum ab incepto negotio tantum non me deterruerat, alia tamen fuerunt, quae animum meum confirmarent et in aliquam fpem erigerent. Cum enim per quinqué, et quod excurrit, annos, "ex quo tempore in ILrystris, pohli Patroni mei fumme Venerandi fcholis, hiftoriam plantarum addifcere coepi optimique Praeceptoris exemplo fidaque inftruCione incredibili illius fcientiae amore me accenfun captumque fenfi, frequentiffmis in agrum Lipfienfen finitimasque regiones excurfio-

nibus 
nibus florae dona curiofe perquifuerim et inueftiganerim, non exiguum plantarum numerum paffin inueni, quarum nullam mentionem eiusdem argumenti fcriptores fecerunt. Quas plantas, fi prioribus florae lipsicae indicibus adderem, non ingratum Viris doctis laborem me fufcepturum effe confidebam. Neque tamen in eo Iubfiftere voluj, vt plantarum a me Linfare colleEtarum indicem fpicilegii adinftar antecefiorum meorum fcriptis adiccrem. Cum enim omnes propemodum nofiri temporis Botanici LINNAEI fyftema vnice fequantur, percommodum videbatur, omnem plantarum Lipjenfum enumeratio. nem fyitematis illius ordine adornare. BOEHMErvs enim, etfi incredibili ftudio, nec fatiș laurandis obferuationibus de Flori Lipfienf alias optime meritus, plantas IIPSIENSES fecanduim methodum b. LvDwigir doetiffme excogitatam expofuerit; vfui tamen Tironum labor illius Viri grauifinus nunc minus accommodatus effe vidètur. ScHREzErvs autem non exigum plantarum numerum BOERMERIIANo indici adiecit; et, qui huncfecutifunt, KNOELIVS, IAHNIVS, ESCHENsachivs, libellis fingularibus dinitias noftras anxerunt. Denique HeDwigrvs cryptogamias Lipfare plantas égregiis et numerofis obferuationibus illuftrauit. At eorum gratia, qui botanicam in hac Academia edifcunt, optabile erat, vt, quaecunque Virorum illorum induftria, vel nouiter detę? 
detexit, vel accuratius definiuit, in vnum librum continuumque ordinem congererentur et contribuerentur. Qui enim plantarun colligendarum caufa per agros camposque fuburbanos circumcurlitat, his valde moleftum eft multos libros libellosque fecum gerere, iisque promifcue euolvendis tempus perdere.

His igitur caufis permotus non incongruum effe putaui, fi plantarum omnium Lipfienfizm enumerationem nouo integroque opere retractarem. Quodfi in haud exiguo Florae lingen/is fcriptorum numero wea fama in obfcuro fit, nobilitate et magnitudine eorum, nomini officient meo, me confoler.

In Plantarum Liplienfum numero non modo cas, yuae in agris mihi proxinis crefcunt, verum ctiam paullo remotiorum locorum prouentus vsque ad duorum milliarium et dimidii quaquauerfum ab vrbe difantiam complexus fum. Et quamvis hoc inprimis curandum eflet, vt plantae inquilinae accurate determinarentur, nolui tamen eas filentio praeterire, quas olim peregrinas ex remotis terris allatas, vel natura caloris frigorisque aeque patiens, vel diutuma cultura noftro coelo affuefcit.

In Claffibus plantarum conftituendis IINNaEvi fecutus fum, ita tamen, vt THVNenglI exemplo, quod ante wiLdenovivm et TrMmrm fecutos effe video, Gynandrian, Monoccian, Dise- 
cian et Polygamiam eiecerim plantis, a LINNAEO fub his claffibus comprehenfis in reliquas claffes

- contributis. Nominibus autem illis, Gynandrinc, Monoecixe etc. in fingulis claffibus eos ordines di1tinxi primarios, ad quos illae planta pertinent, Jgitur' in fingulis claffibus plantas Flori 'Hermaphrodito, Styloftemonoide, Thalamofiemonoide, Monoclino, Diclino, Polygrmoide, in fingulos ordines feparatini difpofui.

In Graminum recenfu genera, ad tertiam uinNaEl claffem pertinentia, Gideret methodum, characere a figura numeroque calycis et corollae defumto, amplexus fum. - Proinde vniverfam hanc plantarum, tribus antheris praeditarum, familiam in tres cohortes défribui. Hi vero funt : Giamina calamaria corolla defituta,- calyce vniualui, vel quinqueualui; fiore amentaceo, hermaphrodito, vel monoclino:' wamiculata flore feffili pedicellato, hermaphrodito vel polyganoide: Spiccta denique florefeffili denticulis fuperftructo, tantum hermaphrodito.

Ex Vmbellifercmm numero alias cum CRANa zro fecundum feminum figuram, alias fecundúm Inuolucrorum numerum, difribui, aliquoties tamen ab lroc ordine paullifper deflexi. Non ignoro multos nunc effe, qui involucrorum numerum et figuran conftantem et in fingulis plantis immutabilem efie negent, me vero his affentire multiplex. obferuatio non patitur.

Filices 
Filices ex linnaei fententia defcripfi. In Mufcis autem hedWigivm et WiLdenovivm : in $\mathrm{Al}$ gis WIGGERSM, hORMANNVM et WILDENOVIVM, qui Lichenes, quos haud iure vnico gencre LiNNAEvs comprehendere annifus eft, in pluragenera, partim e forma externa, partim plerumque e fructu, vt charactere confante, diuidere ftuduerunt; in Fungis denique WIGGERSVM, ва.TSCHIVM, WiLdeNovivm et Rothivm maxima ex parte fecutus fum, ita tamen, vt his poftremo loco diRtis HeDWIII ORefporas adiecerim.

Nomina generica, exceptis is cryptogamicis, ab 11l. b. IInNaer impofita, fere omnia fervaui. Nonnulla tantum genera a IINNAEANis feparaui et fecundum wiggersi fententiam, ob proprias notas characterifticas, fingularibus nominibus infigniui. Sic v. c. ob calycem quadrifidum et corollanr tecrapetalam Oxycoccum e Vacciniis calyce quadriphyllo et corolla monopetala inftructis, feiunxi et huic generi a b. schortero nomen feci. Porro e genere Lamii et Galiop/idis, quas plantas Celebr. portıchrvs optime de- fcripfit, nonnullas fpecies feparaui, in quibus Faux Corollae dentibus deftituta eft, et ex his cum wiggerso Pollichiare genus conftitui.

Synonyma Auctorum omnia enumerare nolui, ne nimis longus effem vidererque ea exfcripfiffe, quae Celebr. вовнmervs et schregervs in 
fuis libris iam citarunt. Igitur ex his felectiffma tantum appofui. In Cryptogamia autem, quae magna adhuc difficultate laborat, numerofrora Synonyma e multis Auborum, qui hne locum nuper illuftrarunt, libris, adieci. Illis autem plantis, quas Antecefores mei in fuis libris non habent, ex veteribus tantum; e. g. e casparis bavhini Pinace, pauca fynonyma addidi easque fimul figura ftellulae notaui."

Vt plantace viuae cum depictis comparari poffint, icones valde bonas Blackrẹellianas; ob expofitas plantarum medicas virtutes; avgrstra QVIRINVM RIVINVM, ob icones nitidiffimas et valde accurate fculptas; e recentioribus autem Floran Danicam et Florain Aufriacan, ob tabulas optime expreffas et coloribus viuis ad naturam proxime accedentibus pictas; SCHеVCHzervм fparfim, sCHRERERVM et leERSivm contra femper, ob accuratifimas graminum defcriptiones delineationesque; skvirivm ob diffeetiones plantarum accuratas fubtilesque; KerNervm, ob plantas oeconomicas; denique dILlenIVM, vaIILANTIVM, SCHAEFERVM, HEDWICIVM, HOFMANNVM, ватsсніvм aliosque, ob egregias defcriptiones artificiofasque delineationes, allegaui.

Nomina pharmaceutica, deinde germanica, gallica anglicaque, tam generibus, quam fpeciebus addere ftudui. Nonnullis tamen plantis 
cryptogamicis nomina non adieci, cum deftituerer libris, ex quibus illa exfcribi potuiffent.

Loca, vbi nafcuntur plantae noftrates, citavi ea, quae roehmervs, schrebervs, Jannivs aliique iam recenferunt, tum ea, vbi Ill. roulrvs plantas nonnullas mecum beneuole communicatas, primum detexit, denique ea, in quibus a me repertae fuerunt. Praeterea, quod Celebr. sовiMervm et Schrenervis feciffe video, naturamfoli defcripfi, in quo fingulae plantae proueniunt. Caeterum illa plantarum loca, quae vrbi vel pago vicinia et propriis nominibus infignita funt, proprie indicaui; contra plantis vbique magna in copia crefcentibus, propria locorum nomina non adieci; dénique vel iis, quae in agris fub dio et in ambulacris publicis vulgatiffime coli folent, atque noftro folo ita adfuetae funt, it nunc pro fpontaneis haberi poffint; vel quoque illis, hinc illincue in fyluis dumetisque nuper plantatis, locum in hoc libro effe concédendum putaui. His autem locis plantarum natalibus femper tempus florendi, earum durationem et fructus maturitatem a me obferuatam, fubiunxi.

Denique defcriptiones et obferuationes, eas tamen pauciores, ne liber mole fua nimis laboraret, nec lectoribus effet moleftus, fparfim addi$\mathrm{di}$, et his plantarum vfum, et medicum; et oeconomicum, hactenus cognitum, notare non. omifi. 
Me quoque hand paruam apud Tirones gratiam initurum exiftimaui, fi Terminos Botanicos, quortm maximam partem b. LINsaevs conftituit, cxplicatos et ordine partium plantarum -difoofitos, exhiberem, et fimul in tabulis nonnullis felectiores quasdam plantas a Dextemimo CAPIEvx accurate delineári pingique curarem.

Tandem omnibus Praeceptoribus meis atque Patronis, inprimis gehiero, pohlio, rappio, hebenstreitio, lvdwigio, . кühNio, eschensachro, Viris Illufrribus, Excellentiffmis Experientiffmisque profida doetrina, confilis, librisque' beneuole milhi communicatis, decentifimas perfoluo gratias; quibus quantum, tum in vniuerfa vita mea Academica, cum in hoc libro condendo debeam, nunquam animus meus excidere patiar.

Caeterum nihil magis in yotis habeo, quam, vt meam qualemeunque operam non inutiliter in hoc' libello conficiendo doctis rerum arbitris collocaffe videar. Daban Lisfac IV. die Octobris. MDCCXC. 
AVCTORES, QVI'DE PLANTIS LIPSIENSIBVS IN VNIVERSVM VEL SPARSIM SCRIPSERVNT.

\section{1) Pavla ammanni Supellex Botanica f. Enume-} ratio plantanm, quale non follum in horto anedico, fed etiam in aliis circa Vibem viridiariis etc. progerminare fulent. Lipf. I 6́75. \&mai. In quo plartae fecundim alphabethum cum fynonymis propriis fine locis tamen natalibus adiectis enumerantur.

2) avcrstus girings Rivings Decamus Facultat. Misd. olin Lipfienfis, qui methodum fimpliciffimam a toris fabrica regularitateque fumere tentauit, magnum opus fufcepit, et nouam plantarum methodum iconibus ornare voluit. Edere ergo incepit Lipfae anno 1690. Fol. Ordinem plantarn?n, quae funt flore irregulari monopetrilo. Quem fecutus eft anno I691. Orto plantrimu, quae funt fore irregulari tetrapeialo, et déinde $\mathbf{x} 699$ prodiit Ordo plantamm, quae funt fore irregulari pentapetalo. Tabulas contra, quae Ordinem fiom hexapetalormu irregularium comprehendunt diu a celeberRimo viri morteb. LVDWIGLYs, qui aeque, ac HEBENSTrEITIVs, 


\section{8}

Decam Fucult. Med. ólim Linglenfes, multo indefeffo. que labore plantas in Circulo noftro prouenientes disquifuerunt atq̣ue in fuis fcriptis fideliter defcripferunt, edidit. Plantas multas e noftra terra prouenientes nitidifime delineauit.

3) Christiani lvdwigit welschin Bafis Botanica. f. Brenis ad rem herbarian Manuductioetc. Lipf. 1697. 12 mo. Huic autem libello Catalo. gum plurimarum plantarum in noftro Climate crefentium adiecit et ordine alphabetico cum folis nominibus absque loco natali plantas indicat.

4) davidi wippacheri $M$. D. et Practici olin Lipfenfis Flora Lipfienfis bipartita. Lipf. I726. $8 \mathrm{~min}$. In qua nomina plantarum obfcura et imperfecta, immo quoque erronea, enumeratur et loca earum natalia cum florendi tempore vitaque plantarum, indicantur.

5) alberti halleri Flord Iénenfis henrici bernhardi rvppir, etc. Ien. 1745. 8. Exiguam plantarum noftro folo repertarum copian continet Flora.

6) AVG. 
6) ave. frieder. Waltheri Mied. Doct. $\approx$ Prof. Medic, quondam Lipfienfis Catalogus plantorum exoricanm indigencrumulye, quas in horto coluit. Lipf. x732. 8. et Eiusd. Defgratio plantitum, quas hortus complectitur eti. Lipf. 1735.8. In his duobus libris plantas tam rariores, quam vulgares, alphabethico ordine, cum meris nomibus enarrat.

7) IоH. Gottifie Gleditschi Methodis Fungorum, etc. Berol. 1753. $8 \mathrm{~min}$. Eft libellus praeftantifitimus et in aeternum vsque vtiliffimus. Continct enim magnum Fungonim numerum, apud nos vigentium, quos optimis grauiffmisque defcriptionibus, obferuationibus felekiffinis et locis natalibus fpeciatim reete indicatis, auxit.

8) georg. ivdolphi boemieri $M . D$. ac Prof. Therap. hoc tempore Wittebergenfis Flora Lipfac indigena. Lipf. 1750. 8mai.

9) christiani daniel schreberi $M$. D. ac Prof. hoc tempore in Academ. Erlang. Oberuationes de Phafco etc. Lipi. I770. 4. Subfequente anno edidit Spicilerium Florae Lipfire. 8mas.

10) rritder. avg. Gottu. KNorle Epifol, in qua Plantas Venenatas Vmbelliferas indicit. Lipi. 1771.4 .
$b \approx$
AVG。 
11) $\triangle Y G$ GRID. GVIL. ERN. JAHNiI de plantis circa Liplam mper imentis Epiftola. Lipf. 1774.4.

12) Io. Min. rechensach Dijput. Obfematiomun Botaniarmun etc. Lipf. I78\% 4. Vbi de plantis noftratibus agit, ibidem loca natalia indicat.

I3) D. Io. neDwan Deferintio it adumbratio microfconico-anditica Mufromus Frondoforum, nec non aliorum veretantizm e claffe cryptoganica Linnaei nowomm dubiisque rexatonum. Tom. I. et II. Lipf. I $787-1789$. Fol. De plurimis cryptogamicis plantis locorum nacalium mentionem facit.

I4) 10. CHRIST. GOTt L. Bavagarten Serbum Lipficum. Simpes pracprimis cxoticas circa Vrocu plantatas continct. Lipf. I790. 8 . 


\section{TERMINORVM TECHNICORVM}

IN HOC LIBRO OCCVRRENTIVM

$\begin{array}{lllllllllll}E & X & P & L & I & C & A & T & I & O\end{array}$

b 3 



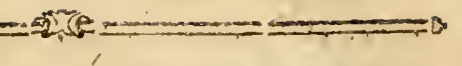

$P_{1}$ vafculis in vafculis renitentibus et loco-motiuitate deftitutum, - qua de re vera humorum circulatio in Plantis nulla deprehenditur. Caeterum, it Animalia, nuptiis propagantur, crefcunt, irritantur, fruetificant et duplici componuntur falfantia, quarum vna eft corticalis, altera medullaris. Partes autem, plantas conftituentes, praecipue funt fequentes.

\section{IR A D I X.}

Eft Organum plantae nutriticium, fine quo ea vivere, eleuari ac fuftentari non poteft. Conftans Canse dice defcondente Radiculisque.

A. Radicula eft pars radicis fibrofa, in quam terninatur Caudex defeendens, ct qua Radix nutrimentum haurit pro vegetabilis fuftentatione.

B. Caudex defcendens eft Radix ipfa fic dieta, quaso fub terra fefe tenfim fubducit et Radiculas profert. Dein ob variam ftruluram a Botanicis Radix diuerfis diftin. Ca eft rominibus fequenti modo,

Anmua, intra annum emortura.
Biemis, quae primo anno vegetat, et altero floret fi. mulque perit.

Perennis, quae productione nouarum germinarum per $\}$ a) Vita plurimos annos regerminat; vt Viola odorata; Gle-
choma hederacea etc. 
Rotunda, quae anģulis plane orbata eft: e. g. Cyclamen; Crocus zcruns.

Onata, cuius diameter longitudinalis fuperat transuerfalen, bafi fegmento circuli circumfcripta, apice anguftiore: vt Orchidibus quibusdam.

Fiufiformis, quae eft fimpliciufcula, oblenga, crafla, verfus bafin fenfim attenuata; v. c. Dusucus; Pafiraca. Pracnorfa, quac deorlum truncata, nec acuto arice terminatur; vt Scabioja juccifa; Plantago.

Palinata, vbi longitudinaliter in plures lobos fubacqua-

les diuiditur verfus ortum : vt Orclis latifolia, macu. listi.

Teficulata, eadem ac Jupra ouata, nonnullis Orchidum fpeciebus propria.

b) Figura, $\{$ Fafciculat.', quae partibus carnofis plus minusue productis, ad radicis ortum immediate munitis, conftat; vt Orchis abortiua: Ophris Nidias Auis.

Tuverols, ex fubrotundis carnofis compolita corporibus $i ;$ in fafciculum collectis. Spiraca Filipcudula; Solanum tuberofum.

Gramlata, dicilur ea, quae corporibus fphaericis carnofis adhaeret radiculis filofis; ficuti Saxifraga gra. mulata.

Bulbofa, dicitur ea, ex cuius fuperficic inferiori vel ba. ? fi fibrillulac modo emittuntur et quae radix aliter, : Bubus dicitur, qui quoad fubfantiaa triplici módo a Botanicis diftinguitur; nempe,

Bulbus, qui eft hybernaculum plantae ex rudimentis foliorum praeteritorum, vel

Solidus, qui fubftantia carnofa, intus indivifa coninua conftat; vt Radix Allii Sativi et Tulipoe, vel 
Tunicatus ex lamellis bubofis, fibi fuprincumbertibus concenticis compofitus; vt Radix Cepae, vel denique

Squamofus, qui fquanis imbricatis confructus eft;

v. c. Litii Albi liodix. Perpondiculeris, quae recta defcendit.
Horizontalis, quae fib tera transterfim extenditur: vt Iris.

Obliqua, quae a perpendiculari aut horizontali linea dificedit.

Repers, quae longe fub terra excurrit, ct hinc inde no. ves furculos profert demititque, vt Trisicum re. pens.

Simplex, quae non fubdiniditur.

Fibrafa, radiculas tenues numerofas emittens.

Compofita 1. Ramofa, quae in ramos fibrofos laterales fubdiuiditur.

Dentata, dicitur ea, cuius articuli denticulis exiguis reChis breuibus confructi funt; vt Dautra, Articulata, quse geniculis intercipitur et vel hinc inde intermediis incrafatur; vi Conullaria Polygonatun; O.xalis Acctojella.

Tenera, quae fibrillulis minutifimis, facile defructibilibus, confist.

Compacta, fubfantia folida donatá.

Fariacea, quae fubfontian farinae ed inftar intuscontinet.

Carmofa, quae interne pulpa folidiufcula fucculenta re(i) Strustura

c) DiraAione. plera eft.

Succulnta, quae humoribus copiofioribus pisedita eft. Lignea, quae humoribus fiperfivis carct, et denfifimis fibris adp:effs conftat.

e) Subfanc tia. 


\section{II. $T R V N C V S$.}

Communiter ea pars planta dicitur ${ }_{5}$ quae e radi. ce exfurgit, et flores cum fructificaticne plus minusue fuftinet. Sunt ártem diuerfis Truncorum diuerfa et propria nomina fequentia:

I. Caudcx, dicitur Trancus perennis, fquamolus et corticatus Arboribus, Fruticibus Suffruticibusque proprius.

2. Caulis, dicitur is, qui per annum durat, et fo. lia, flores cum fruetu profert, vt in Herbis.

3. Culmus, ef Truncus Graminibus proprius, qui eleuat folia cum fruaificátione, plerumque genicularus aut enodis, annuus, fifulclus aut fpongiofus, vel ex foliis cenuolutis compofitus. Europaei annui omnes.

4. Scapis, appeliatur Truncus vniuerfalis, qui fioreș tantum fuftinet absque foliis.

5. Frondis folium referens. Filibus.

6. Surculizs, perennis, qui tenuis, vix lignofus, fo. liofus et Muscis Frondofis proprius.

7. Lova, dicitur Truncus perennis, qui ex filis metis confat foliisque caret, vt Lichcnibus filamentofos; Infucore; Conforua.

8. Stipes plerunque annuus ế aphyllus, quibus rami frons et frętificatio in vnum confuunt, vt Filiç.bus, Fungis. Stipes autem Fungortm eft vel farctus, aut fifulofus; vel annulatus, aut nudps.

Trunci differunt inter fe vario modo.

fHerbaceus, dicitur, cuius Caulis non lignofus et qnotannis aut biennis perit.

Duratione. \{Fruticofur, audit C̈aulis, fi planta feu firṕs caulem per hyemem feruet, ramis vero quotannis marceicat; fiL cuti Solanum dulcamara. 
Suffruticolus, eft Truncus perennis, qui plures ab rna? radice duriores hurnilioresque caules protrudit.

Arborcus, qui perennat et ex caudice fimplici gemmife- Duratione.
ro conftat.

Praefens aut mullus. ve Carliza acaulis.

Teres f. rotundatus, qui cylindricus et absque angulis. Semiteres, qui hinc planus, illinc conuexus.

Comipreffus, cuius latera duo oppofita fere plana funt.

Anceps, in medio vtrinque conuexus; latere vero vtroque acuminatus gladium anceps referens. Angulatus, qui pluribus, quam duobus angulis longitudinaliter notatuś eft.

Acatangulas, qui angulis fcindentibus gaudet. Obtufangulatas, margine angulato obiufo inftructus. Obfolerangulus, vbi anguli vix manifefte confpiciuntur.

Triquetrus, cuius latera inter angulos plana funt. Trigonitis, cuius latera inter angulos conuexa obfervantur.

Simplex, nullis ramis infruetus. Ramofus, ramis lateralibus praeditus. Ramis $\int_{\text {f }}$ arfis absque ordine Caulem reftien. tibus. oppofitis, fi duo rami ex codem plaņo

Ramortm Diwisio

\section{$\{$ axillis prodeunt.}

altersis, cum vnus polt alterum tan. quam per gradus exit.

diftichis, fi vtrinque e regione folum oriuntur. 
Ramorum. Diuifio.

Ramis

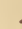

$\left\{\begin{array}{l}\text { Ramis } \\ \text { Ramorum. } \\ \text { Diuifio. }\end{array}\right.$

Confertis, cum ita copiofi rami, in totum occupant Truncum, vix relieto fpatio.

patalis, vi ad angulum re?tum, aut quafi reâum cum caule locati funt

$\{$ Rami.

verticillatis, cum plures quam 2 verticillstion truncum ambiunt. fafciculatis, cun rami furfum quafi in [. fafcicula elecrantur. -

Subramofus, dicitur is, qui ramis pauciffimis lateralibus - inftructus eft.

Ramofiffimus, vbi rami numerofi absque ordine cumulati funt ce collocati.

Lacuis, fuperficie aequali donatus.

Striatus, longitudinaliter lineis impreffis aut prominulis notatus.

Sulcatus, fulcis profundis, latis, excauatis cxaratus.

Glaver, fuperficie lubrica f. polita et nada inftructa.

Scaber, corpufculis rigidiufculis prominentibus exafpeSuperficie. $\{$ ratus. Cannabis; Humulus.

Muricatus, corpufculis fubulatis, mollibus, non pungertibus, munitus.

Tomentofus, villis intertextis vir contpicuis obteetus, vade frepius albidus: piantae narinae et faepe cam. pefros ventis expofitae, vt Anemojic Pulfatilla; Verbafun Thapu $r_{22 s}$.

Villofus, pilis longionibus rarioribus, mollibus, confpicuis pubefcens, vt Tewcriwn Chamaepythis. 
Hirfutus, qui pilos profert longiores, magis confpicuos, rariores et rigidiorcs.

Hifpidus, fetis rigidis adfpe:fus.

Vrens, fimulis adurefius. Vrtica urens.

Aculeatus, aculeis inftructus.

Spinofus, fpinis armatus, vt Prunus Spinoja, Crataegi variae.

Papillofus, corpuícalis pilocrafioribus, pellucidis, capitulo faepius terminatus.

Apingllus, i. e. qui foliis caret.

Foliofits, folia gerens.

Nudns, qui deftituitur foliis, fquamis, ftipulis absque excrelcentibus.

Squamofus, foliolis fquamas referentibus donatus.

Imbricatus, foliis vel foliolis, vno alte:um tegentibus, 'vel vno altero inftar tegulorum incumbenti- $\}$ veftitu.

bus.

Vaginatus, foliorum vaginis cinetus; ficuti Gramina et Vimbelliferae.

Alatus, vbi fecundum caulis longitudinem folii pagina vna aut vtraque, decurrit. Verbafum Thapfus: Cardusi.

Plenus, qui nulla cauitate gaudet, fed plene faretus eft.

Fiftulofus, intus cauus, nec farctus.

Rigidus, nimis,flexilis et facile frangens.

Articulatus, geniculis aut internodiis interceptus.

Debilis, minus profunde radicatus, hine facile decum- $\}$ Struaura.

bens, nifi aliquo fulcro fuftentetur.

Filiformis, aequali vbique crafitie donatus.

Annulatus, ad, origines foliorum annulo quafi cir1-

हीus.

Erectur 
Erecius, fitu perpendiculari adfcendens.

Declinatus, prius adfcendens, dein terram verfus fe fle-

Ctens; fiexionis angulo patentillino inftar carinse na. viculae. Potentilla aurea.

Adfcendchs, qui cum quadam cauitate fucceffue ab horizonte fuperiora verfus recedit.

Obliquus, a perpendiculari aut horizontali linea difce. dens.

Incuruatus f. inflexus, dum primum crectus, deinde arcuatus.

Reclizatus, arcuntim verfus terram. -

Niztans, apice extrorfum reflexus.

Difüus, ramis absque ordine patentibus. Funaria officinalis.

Striclus dicitur is, qui plane eft erectus, perpendicularis, nee minime flexuofus.

Laxus libere, vel ex debilitate, in arcum Acxilis, ant Directionc. $\{$ nutans.

Procmmbens, debilis horizontaliter terrae innitens.

Dccumbens f. Profiratus, bafi cecumbente erełus. fupter terram extenfus.

Repcrus, radiculas hinc et inde exerens procumbendo fuper terram. Potentilla Anferina.

Stolonifer, turiones ad radicom emittens. Potentilla reptans; Aizgn.

Sarmentofus, qui propagines fteriles, foliaceas, filiformes et fubrepentes cum geniculis radicantibus profert. Vitis finifera.

Radicans, ramis radices proferens, Hedera Helix.

Cyrrhifer, cirrhos emittens, v. Lathyritus.

Scandens, adfcendendo ad alia corpora tentaculis fele fuftentans. Clematis Vitalba.

Volubilis, qui fpiraliter adfcendit per ramum alienum, 4 aut dextrorfum 1, contra folis motum, vt Conuolusulus; 
phafeolus: atut finiftorfum f. fecunciun Solem vulgo, ficuti Humuias; Lonicera.

Linearis, eft lunulae longitudo ab vnguis radice verfus? viguruem extenfa.

Vnguiculatus, lineae.6 vel vncia dimidia.

Pollicaris, eft longitudo aut diameter extimi articuli pollicis.

Palmaris (vnciae 3) diameter 4 digitorum transucrforum parallelorum 'dempto pollice.

Spithaneus (vnciae 7), qui aequat fpatium inter api- ? cem pollicis indicis extenfum.

Dotrantalis (vncise 9) aequans fpatium inter apicen pollicis et digiti minimi extenfum.

Pedalis (vnciae 12) qui comprehendit fpatium a flexura cubiti ad bafin pollicis.

Orgyalis (pedes 6) valens hexapodam, feu humanam altitudinem menfuram inter manus expanfas.

Menfira. a) fecundumlongitudinem.

Exprimitur fimili notiflimo v. c. pollicis, capitis humani.

b) fecundum crafitiem.

Vniflorus, bi-tri-multiforus, feu fore vnico, duobus, tribus vel pluribus ornatus.

Paniculatus, ramis varie tubdiuifis, floribus numerofis: Erigeron canadenfe.

Spicatus, cuius rami fpicas ipfas vel fpicaeformes flores gerunt.

Monophylus, di-tri-polyphyllus, vbi Caulis feu vnico, duobus, tribus vel pluribus veftitus foliis.

\section{F O L I V M.}

Eft productio fubftantiae plantae corticalis, parenshymate abundans, in paginam faepius attenuats, 
attrahens praeparansque humores. Folia autem quaclam fimplicia funt, compofiza alin; illa áppoliontur, quorum petioli aut nerui medii in vrican lis. perficion extenduntur; haec contra dicuntur, quorum periolus plura, quam rnum, profert folis. In omni folio confideratur, prauter numerum etiam tubftantia, figura, directio, fuperficies, smbitus, infertio, fitus, etc. Sunt itaquze folia.

Radicalia, quac immediate e radice prodeunt; Caulina, quae e caulc enafcuntur; Ramea, e ramis.

Axillaria, quac ex axillis, fcilicet inter ramum ct cau-

a) Ortu. $\{$ fira.

len, ex anguio fupra prodeunt; Subarillaria, in.

Floralia, quae ad florum exortum inferuntur, vel et ipfis pedunculis adhaerent, perfifrentia fua a bracteis deciduis diftincta.

Seminalia, qune antea Cotyledones fuerunt, atque ex

$\checkmark$ femine emergunt, caduca.

Solitaria, ubi vnicum cx ecdem loco enafcitur.

Binati, foliolis tantum luobus.

b) Nuncro. Temata, foliis tribus ex eodem plano, vt $L y f$ machia.

Fafciculata, fi plura diftincta ex eodem puncto prode.

$\checkmark$ unt.

Orbiculata, quorum diameter longitudinalis et transverfalis acqualis, peripheria circinnata.

c) Circum-

Subrotuda, quorum figura orbiculato proxime accedit.

Ouata, quorum diameter longitudinalis fuperat transverfalem, bafi fegmento circuli circumferipta, apice vero eodem anguftiore. 
Oualia f. Ellipticn, quorum latitudo eft fere tertia pars fua longitucinis, f. qune ex orbiculato-oblonga vtraque extremitate rotundata aequali proedita funt.

Parabolica, quorum diancter longitucinalis fuperat transuerfalem et a bafi furfum angufatur in femiovaturn.

Oblonga, quorum diameter longitudinalis aliquoties fuperat transuerfalem, et vtraque extremitas fegmento circuli eft anguftior.

Ozato-oblonga, Ouata ad oblongam figuram accedentia.

Linearia, aequali vbique latitudine, interdum vtraque extremitate tantum angufantur.

Lanceolaza, quorum latitudo vix fexta pars eft totius longitudinis.

Lanceulcto-ouata, vbi lanceolata ad ouatam figuram fubaccedunt.

Ouato-linceolata, ouata ad lanceolatam figuram accedentia.

Capillacea, tenuifima fere ad inftar capili.

Setcicea, fetum referentia.

Accrofa, eadem, quae Linearia, periffentia plerumque bafi articulatione ramo inferta, vt in Pine, Iunipero, Taxo etc.

Subulara, ad bafin linearia verfus apiceın fenfim attenua-

ta.

c) Circuin-

feriptione. ta.

Teretia, quae maxima ex parte cylindricam formam habent.

Semiferetin, vna parte explanata, altera conuexa. Triangularia, angulis tribus prominentibus: inftructa. 


\section{3 구}

TERMINORVM TECHMICORVM.

d) Angulis

\section{Triquera, quae tribus lateribus longitudinaliter planis} funt praedita.

Selioicsea, rhombea funt $\mathrm{ex}$ it angulis, quorum laterales

4 minus a bafi difant, quam reliqui.

Peltara, quorum petioli inferuntur folii difco, non màrgini.

Cordata, funt ouata bafi excauata angulis pofticis deftituta feu cordis formam infuli referentia.

Reniformia, ambitu rotundaia, bafi excifa et in latitu. clinem magis, quam in longitudinem extenfa.

Lunata, apice contiexa, bafi concaun, breuia, lobis la-

e) Figura. $\{$ teralibus acuminatis, infrueta.

Carinata, nauiculae in modum concaua.

Emarginata, apice cxcauata.

Sagittata, triangularia bafi finu excauata, angulis po. ficis acutis.

Haftata, tringularia bafi lateribusque excauatis, ramis

$\checkmark$ patulis. Rumex Acetofella.

fntegra, indiuifa, finu omni deftituta. Ergo his oppo. nuntur fequentia :

Partiza, ad bafin fere divifa, vnde 2-3- múltipartita a numero partium oriuntnr.

Fifja, diuifa finubus linearibus, marginibus rectis, vtpote $2-3-4-5-$ et multifida.

f) Ambitu. Lobata, vbi funt diuifa in fegmenta profundiora et latiora, quorum numerus conftituit Folia $2-3-4$ et 5 - lobr.

Palmata, diuifa vltra medium in Lobos plurimos fub. aequales bafi cohgerentes.

Digitara, fegmentibus anguftioribus, digitos aemulantibus, fere ad bafin vsque productis, et petiolo fimplici $\mathrm{f}$ indiuifa legmenta adnectuntur plura.

a) Quoad 
a) Quoad Sinus fcilicet difcum foliz in partes fe-

cantes.

Lyrata, quae funt transucrfm diuifa in lacinias, ita, vt fuperiores fint maiores, inferiores remotiores. Incija, in fegmenta angufa inaequalia.

Laciniata, variefecta in partes, partibus itidem indeterminate fubdiuifis.

Pinnatifida, transuerfim diuifa in lacinias horizontales oblongas.

Runcinata, funt pinnatifida, lobis antice conuexis, poftice transuerilis: Leontodon Taraxacum.

Sinuata, quae lateribus finus dilatatos admittunt.

B) Quod Marginem f. extremam oram folii ad latera, intaćlo difco folii.

Spinofa, quae margine exeunt in acumina duriora, rigidicre, pungentia.

Duntata, quas acumina horizontalia, folii confiftentia, Spatio remota habent.

Serrata, margine incifo: omnibus incifuris extremitatem refipicientibus.

Duplicato - ferrata, incifuris iterum incifis.

Crenata, margine incifuris fine refpectu extremitatis fecto, vnde acute f. obtufe-crenata, duplicato-crenata, crenis iterum crenatis.

Cartilagiznea, quorum margo cartilagine, a fubftantia folii diuerfiflima, firmatur.

Ciliata, quorum margo fețis parallelis longitudinaliter obvallatur, e. g. Thymus Serpilluni.

Lacera, quae margine varie diuifa funt fegmentis difformibus.

Erofa, finuata finubus minimis obtufis laciniisque inaequalibus inftusta,

f) Ambitu.

$$
62
$$

Re. 
f) Ambitu. $\left\{\begin{array}{c}\text { nubus circuli fegmento inferiptis, terminatur. } \\ \text { Integerrina, quae margine per totum ambitum integer- }\end{array}\right.$ rimo.

Acuta, quae terminantur angulo acuto.

Acuminats apice fubulato terminantis.

Cufpiclata, ncruo in acumen rigidum exeuntia.

Mucronata, prioribus fimilia, fed acumine longiore. pungente infructa.

Cirhofia, quae terminantur Cirrho.

g) Apice. Obtufa, intra fegmentum circuli terminantia.

Retufa, in finum obtufum excurrentis.

Praemorsa, quae obtufiflimá terminantur incifuris inaequalibus.

Emarginata, quae terminantur Crena. Vnde acute vel obtufe enarginata.

Truncata, linea transuerfali definentia.

Nitentia, quae giabritie lucente funt praedita.

Lucicla, vitri ad inftar, maiore praecedentis gradu glaberrima, et quafi illuminata.

Laetia, quorum fuperficies aequales funt absque omni pube pilofo, fetofa eadem funt Glabra.

Nuda, excrefcentiis pilofis, verrucofis, fpinofis etc. deftitura.

h)Superficic $V$ enofa, vafis difcurrentibus multifarian diuifis praedita. Qua de re oriuntur fequentia.'

๔) Auenia, venis deftituta.

ß) Rugofa, cum venae foliorum contractiores. euadunt quam difcus, vt interiecta fubftantia adfcendat.

r) Lacunofa, quae foueas inter venas interiectas habent. Lich. pulmonarius. 
d) Bullata, fubrtantia folii quaí in veficulas ele? vata.

Nenuofa, 'vbi vafa fimplicinima absque ramulis longitudinaliter extenduntur a bafi verfus apicem. Iterum quoad diuifionem et magis minusue praefentiam diverfa, et funt:

a) Trineruia, quae folummodo 3 vafis gaudent et f. p.

ß) Triplincruia, cum 3 vafa fingula ftatim alia 3 (h)S.ppericie apice fuo exporrigunt.

r) Eneruia, quae huiusmodi valis carent.

8) Lineata, quae lineas diftinetas exhibent, neque tam profundas, nec eminentes.

ह) Stviata, lineis fuperficialibus excauatis parallelis infcripta.

छ) Sulcata, angulis numerolis totidemque interiectis finubus longitudinaliter exarata.

Punftata, punß̧is excauntis adfperfa.

Papilloja, punctis veficularibus carnofis te ła.

Papuloja, quae tuberculis laepe coloratis, faretis exafperata funt.

Vifcida, humore tenaci oblinita.

Villofa, pilis mollibus te $ł$ a.

Tomentofa, villis intertextis vix confpicuis obdußa.

Sericea, pilis adpreffis, mollifimis nitidis confpicuis tecta.

Lanata, pilis incuruatis imbricatis, quafi tela araneae induta, v. c. Saluia.

Barbata, pilis villisque parallelis, fere fafciculatis, inPtar barbae hirci obfita.

Pilofa, vbi pili diftincti elongati tegunt fuperficien.

Scalra, quum punctis eminentibus rigidiufculis per folii difcum fparguntur. 


\section{8}

terminozvar technicorvm.

Hifpida, fetis rigidis fragilibus difcum folii exafpe.

i) Vefitu. $\{$ Strigofa, aculeis lanceolatis rigidis in fuperficie. Aculeata, cum Aculei pungentes rigidi occupant $\checkmark$ difum.

Plana, quae vtramque paginam vbique parallelam ge. runt.

Canaliculata, ex fulco profundo fecundum totam longitudinem excauata in dimidiatum fere cylindrum.

Concaua, cum margo folii arctior, quam vt difcum cir-

k) Expan- $\left\{\begin{array}{c}\text { cumfcribat, vnde deprinitur difcus. } \\ \text { flune }\end{array}\right.$

Plicaza, difco plicis ácutis alternatim Rexo, anguiis dependentibus adf́cendentibusque. Alchemilla.

$V$ voduluta funt, cum difcus folii verfus marginem con-

vexe adfcendit defcenditque. Scolopendriun.

Crifpa, margine luxuriante, vi Difcus elladar maior,

qua de re vndulata fiunt. Lèvidium; Naftuit.

Seffilia, quae immediate Cauli vel Ramo absque petiolo infident. Opponuntur his

Petiolata, quae petiolo ad bafin inferuntur.

Peltata, fi petiolus difco folummodo interitur, vt $H y$ drocotyle, Nizmphaca.

Amplexicaulia, $\mathfrak{i}$ bafis folii vtrìnque ambiat latera Caulis transuerim. Semiamplexicaulia gradu modo diffe-

1)Infetione. $\{$ runt ab illis.

Perfoliata, quae bofi transuerfim Caulem ?per totum cingunt vt Lonicera Caprifol. Bupleurun.

Confluentia, quae ad bafin inter fe colıerent.

Vaginentia, bafi formante tubum, caulen vel culmum veftientia. Sicuti Gramina et plantae vmbelliferae.

Decisrentia eadem, quae alata, quae bafí folii deorfum

L fecundum caulis longitudinem extenduntur.

Alaprna, 
Altcria, cum vnum poft alterum tanquam per gradus? circa Ramum oritur.

Oppofita, vbi a per paria decufiatim e regione colloca. ta funt.

Decu!fata funt oppofita, vt planta verticaliter infpectu folia 4- fariam vergant.

Verticillata, pluribus quam 2 folis ex codem plano horizontali prodeuntibus caulem ambeuntia.

Fafciculara, vbi plura foliola ex vno eodemque puncto progrediuntur. Larix:

Sparfa, quae absque certo ordine conftituta funt. Conferta, quse ita funt copiofa, vt ramos occupent totos, vix relisto fpatio.

Remota, fpatio a fe inuicem diftentia. lis opponuntur

Approximata, quae ad fe inuicem proxime accedunt. Twbricata, guando parallele fuperficie recta: fibi inuicem -incumbunt et fe quo ad pariem tegunt. Itunip.crus.

n) Directione

Erefta, quae ad angulum acutifimum cauli obfident. Obliqua, cum bafis caulem, apex horizontem refpicit. Fritillaria.

Aduerfa, cun fuperficics fuperior non coelum fed horizontcin fpeciat.

Adpreffa, cum difcus folii approximatur Cauli. Inflcxa, apice furfum, dein verfus caulem flexo. Recurua f. reflexa, apice deorfum, dein verfus Caulem (m) Situ. refiexo.

Reclirata, deorfum verfus petiolum flexa, ve arcus fit bafi inferior, apice defcendente.

Reuclata, quae deorfum reuoluuntur.

Dependentza f. pendula, quae recte terram fpectant. Adfungentin, arcuatim erecta, feu primum declinata, vorfus apicem demum ereßta. 
n) Directio-

Obreria, quorum bafis anguftior, ita, vt bafis concipiatui.

Refipinata, cum folii Juperficies terram, et inferior colum fpectat.

submerfa f. denerfa, intra aquac fuperficiem abfonne. $\{$ dita.

Natautia, quee fuperficiei aquae natant. Nymphara. Horizontalia, quac ad angulum rectum a caule difeedunt.

Radicata, que radiculas demittunt ex fubfantia ipfus folii.

Aombranacea, quac inter vtramque fuperficiem nulla accedente pulpa licatent.

Scariofu, fubftantia ficca arida, tatu fonors.

Gibba, quae vtraque fuperficie conucxa mediante co-

b) Subftan- $\left\{\begin{array}{l}\text { piofiori pulpa. } \\ T \text { tabrlofa, }\end{array}\right.$

ria $\{$ Tubulofa, interne funt caus.

Puipofa, quae interne molli pulpa repleta funt. Sedum. Camoja, quae interne firmior fere fucculenta pulpa referta lint.

Compreffa, quae a lateribus marginalibus comprimuntur, vt fulstentia foii maior fiat, quam Dificus.

Compacta, fulstantia firma folidaque confantia.

p) Duratio- Decidua, fi ante fructus maturitatem cadere folent.

ne $\{$ Caduca, ante vel ttatim poft explicationem Floris eúa$\checkmark$ nefcunt.

q) $\mathrm{Compun-S}$

fitione. $\{$ Compolita, Secundum vero gradus compofitionis diffe$\checkmark$ runt fequenti modo:

numero. «) Binata, vbi petiolo adnectuntur foliolá bina.

в) Termaia, - - - - terna.

r) Quinata, - - - - quina. 
Digitata, cum petiolus fimplex apice anncitit foliola tigura. plura.

Pedata, cum petiolus bifidus latere tantum interiore adnectit foiliola.

Pinnata, petiolo fimplici lateribus adnectente foliola plura. Quae vario modo differmnt et conftituunt fequentia:

a) Alrupte pimata, nec Cirrho, nee folioio terminato, eadem ac Pinnulis fine pari.

ß) Alternatim pinnata, vbi pinna maior foliolis alternis minoribus gaudet.

r) Articulate pimata, vbi folia pelioli communi articulato donata.

d) Cirrhofe pinnata, cum pinnata Cirho terminantur.

*) Decurfiue pinnata, vbi pinnata foliolis decurrentibus per petiolum.

Ђ) Duplicato pialiata, cum petiolis lateribus adfigit folioia pinnata.

n) interrupte pinnata, vbi Folia/foliolis ruptis, pinnata foliolis alternis minoribus gaudent.

2) Oppofite pinnata, vbi pinnata foliolis oppofitis collocata 1unt.

1) Triplicato pimata, cum petiolus communis ad. figit plura foliola bipianata.

Decompofita, cum petiolus communis diuiditur in plures fimplices, qui item petiolos plures gerunt. Haec avtem funt:

a) Bigeninata, cum petiolus dichotono apicibus adnectit foliola qquatuor.

b) Riomata, cum petiolus gerit 3 folia ternata, cadem ac duplicato-ternata

c) $B i$ - 
c) Bipinnata f. duplicato - pinnata cum petiolus ad. figit foliola pinnata.

Supradecompofita, fi petiolus femel ramificatus iterum in alios ramos fubdiuifos adnectir plurima foliola et Secundum variam ramorum diuifionem audiunt:

a) Tergenina f. triplicato-bigcnina, cum petiolus trifidus vtroque apice foliola duo fert et infuper foliola 2 ad diuaricationem petioli communis.

b) Triterizata cum petiolusadfigit 3 foliola biternata.

c) Tripinnata $\int$ tripilicato-pinnata, cum petiolus communis adfigit piura foliola bipinnata.

\section{F $\quad$ V L C R A.}

Aiiis quoque Adminicula funt partes illae, quae plantis tutelae aut aptiori fuftentationi inferuiunt. Hodic autem decem fpecies numeratur: I) Petio. la, 2) Stipula, 3) Cirrhus, 4) Inuolucrum, 5) Spstha, 6) Seta, 7) Pubes, 8) Arma, 9) Bractea, 10) Pedunculus.

I. Petiolus $\mathrm{f}$. fulcrum fuftinens folium, nec frußtficátionem, vario differt modo, et quidem:

2) Magnitu- Brassis, nondum folii longitudinem attingens,

dine.

Mediocris, longitudine folii.

Longus fupervis

(Longifnums fuperans aliquoties) longitudinem folii.

Breuiffinus, qua magnam partem non attingit folii lon. gitudinem.

b) Figura. $\left\{\begin{array}{l}\text { Linsearis, aequali,vbique latitudine. } \\ \text { Alatus, qui lecundum longitudinet }\end{array}\right.$

4 Alass, qui lecundum longitudinem foliatus eft. 
Clanatus, verius apicem incraflatus. Menbranaceus, complanatus more folii. Feres, Semiteres, Triqueter. 1 b) Figura.

Canaliculatus, fupra fulco profundo longitudinaliter excauatus.

Iiffertus, perpendiculariter ramo infidens. Adnatus, quando bafi latiori ita cohaeret, ve absque la-? ceratione caulis epidermidis auelli nequeat. Decurrens, Alatus, Amplexicaulis; Vaginans. Appendiculatus; ramentis foliaceis ad bafin infructus. J

Erectus, patens, adfurgens, resuruatus.

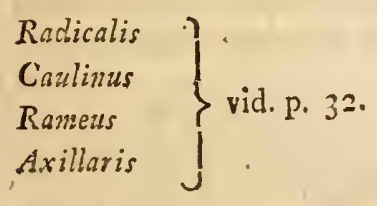

\section{Glaber. \\ Nudus. \\ Pubefccus. Articulatus. Aculeatus} Spinofas, fpinis lenio:ibus indurefcentibus pugentibusque armatus.

2. Stipnla eft Folioium vnum aut duplex bafi petiolorum vei paffim pedunculorum adnätum. Sunt autem fequentes.

Caducae, quae ante foliorum cafum cadunt. Decidua, fi cum foliis cadunt. Perfifzertes. 
3.Rat, durarionis.

4 Rat ambi

\begin{tabular}{l|c} 
5.Rat. figu- & tac; laciniatae, fifue. \\
Setaccac; lanceolatae; fulbuh
\end{tabular}

rae,

tus. ¿ genues.

Catcrales, ad latus petioli aut pedunculi.

Extrafoliacere, fi extra folii ortum) exifunt.

7. Rat. fitus

Oxpofitifoliaceae, fi vtrinque foliorum oppofitorum pe-

i tiolis adhaerent, aut fi folia e regione opponuntur.

3. Cirrins eft Vinculum filiforme, fpirale, quo planta alicui corpori alligatur: Vitis; Lathi. rus; Vicin; Pifum; Plafeolus. Eft:

a) Axillaris, qui exala inter folium et ramum oritur.

b) Foliaris, ex fubfantia folii enatus plerumque ex ipfius apice.

c) Ptiolaris, qui petiolo inferitur.

d) Peduncrilaris, ex pedunculi bafi progrefius.

4. Spatha eft Membrana, cuius bafis ampiectitur pedunculum vaum pluresue, et quoad numerum, directionem et figuram diuerfa. Qua de re numerantur :

Viffora, 2-3- ct multiflora.

Monophylla, 2-3-polyphylla.

Pinna, concann, conuoluta, longa, bresis, etc.

Erectit, declinata.

5. Seta audit Filamentum, quod Mufcorum capfulas fuftinet. Haec autein eft, vel 
Terminalis, vel Lateralis; vel

Solitarie, vel Adgregata; vel

Breuis, vél Longa.

6. Pubes funt Organa mutua ad tutclam externarum ä̈ris iniuriarum, aut liquoris alicuius feparationem $\in t$ excretionem deftinata. Huc pertinent.

Scabrities, quae funt tubercula, aut verrucae exiguae, rigidiufculae.

Pili, funt duêtus excretorii plantae filiformes, molles, valde fieziles, elaftici tamen, fimplices vel râmófi.

Laina, funt Satulae longiores, molles, tenuiorés, quae ad inftar telae araneae plantas obtegurit, easque a nimio aeftu defendunt. Verbacum Thapjus.

Tomentun, eft excrefcentia pilofa, fetulis breuioribus, mo!libus intertextis vix conlpicuis conftans. Poquthus alba.

Barba, eft excrefcentia e pilis parallelis, prolixis compofita.

Villus, pitis longe tenerioribus breuioribusque inftructus.

Strigae, excrefcentiae fetofae, rigidae, declinatae, inftar linguae felis.

Setae, funt excrefcentiae pilis fimiles, fed rigidae, inflexiles, erectee. Huc autem numersntur:

I) Simplices, continuo fecundum longitudinem extenfae.

2) Ramofae, alias rurfus diuifas exerentes.

3) Hamofae, apice reflexae, et animalibus facile adhaerentes.

4) Plumatae, inftar plumae ex vtroque latere oppofito alias fimplices f. rachi communi adnectentes.

5) Stel- 
5) Stcllatae, fi fetae fimplices fetam communem ambiunt.

Hami, funt mucrones acuminati apice fimplici arcuation reflexi, quibus quaedam plantarum partes adhaerent animalibus praetereuntibus. Loppa, Geum vrbanum.

1) Glochidus, funt fetae apice duplici angulate reflexae: infiar cufpidis teli retrorfun dentati.

2) Triglochides, funt glochides tricufpides.

Papilla, funt glandulae humorem excernentes, variis plantarum partibus infidentes, qua de re fecundum locum occupantes appellantur

Foliaceac, in foliis fitae; vt Salix alba.

Stipulares, in ftipulis.

Petiolares, in petiolis.

Pedunculares, in pedunculis.

Praeter has partes commemoratas reperiuntur Glandulae bracteis, calyce, corolla, Raminibus, ftylo, frigmate et geminibus. Cacterum fecundum earum f . guram dicuntur capitatae, cylindraceae, rotuxdatac, ouatae, lanceolatae, lenticulares, conicae; et denique ratione fuperficiei: pellucidae, coloratae vel excoloratar.

Vtriculi, funt vafcula replets liquore fecreto. $V i$ cofitas, qualitas humoris tenacis.

Glutinofitas, fi humor craffus et tenax partes oblinat Ceraftium vifcofum; Senecio vi/cofus.

7. Arma lunt excrefcentiae rigidae laedentes, quibus ab animalium tactu defenditur planta. Nempe

a) Aiculci, funt múcrones pungentes plantae cortici tantum 2dfixi. Rofa.

b) Fur. 
b) Furcae funt aculei ramofi, vbi plures bafivniti funt: hinc bifidae, trifidae. Berberis.

c) Spinae funt mucrones e fubftantia ipla lignea protrufi, rigidi, acuti. Prunus Spinofa. Sunt: terminales, in apicibus ramorum, foliorum; axillares, inter folium et ramum ortae. calycinae, ex ipfocalyce, eius laciniis foliolisve enatae;

foliares ex foliis, fimplices.

d) Stimulae, funt mucrones puncturas inflammatorias efficientes, vnde pruriginofae euadunt partes, Vritca.

8. Bractea, foliolum aut 1quams flori fubiacens. Colore et Figura a caeteris recedens. Tilia, Saluia, Funaria bulbofa. Nempe

2) colore (Coloratae.

b)figura. Coma, conftat bracteis, quae caulem terminant magnitudine.infigni. Fritillaria Imperial.

c) numero. Vna, duae, plures.

d) dura-(decidua. tione. perennis.

9. Peduncultus eft fulcrum folummodo fuftinens frugtificationem, nec folia. Eft enim :

Partialis, aliis quoque pedicellus appellatus, vnicam fuftentat plerumque fructificationem, vel ex alio communi enatus eft.

Communis, qui plures fructificationes luftinet.

Variat autem: a) Numero, b) Loco, c) Situ, d) Directione, e) Menfura, f) Structura. 
48 TERMANORVM TECHNCORVM.

SNullus, tunc oritur flos fefilis.

a) Numero Solitarizs, vbi vnicus eft in loco.

Gemizatis, qui duplex in endem loco.

- $\begin{aligned} & \text { Radicalis, immmediate ex ipfa radice exfurgens. } \\ & \text { Caulinus, ex caule: rameus, ex ramis. }\end{aligned}$

Caulinus, ex caule: rameas, ex ramis.

Petiolaris, ex petiolo enatus. .

Cyrrhiforus, promens vna cirrhum. Vitis.

Terminalis, qui ramum vel caulem terminat.

Axillaris, qui inter axillas foliorum et caulis enafci-

b) Lueo.

Oppofitifolinceus, qui folio e regione opponitur. Solanum Dulcamara.

Laterifoliaccus, ad latus bafeos folii locatus; vt Symb- phytum.

Inserfoliaceus, cum inter folia oppofita alternatim collocatur. Afclepias Vinceronicum.

Suprafoliaceus, qui lupra folium egreditur.

Aliernus. Sparjus.

c) Situ. $\{$ Aggregatus, Oppofitifoliaceis.

Verticillatus, fi plures quam duo in eadem altitudine

$\measuredangle$ caulem ambiunt.

Adpreffus.

Cernuus, cum apice incuruatur, vt Flos verfus latus alterum vel terram nutet... Bidens cernua. Carduns mutans.

d) Directio- Erętus, qui fitum perpendicularem habet.

ne. $\quad$ Patens, fi continuo magis a fe diuergunt plures ex eodem loco producti.

Coarctatus, cum plures pedicelli culmo approximantur.

Reclinazus, vbi arcuatim defcendit.

Wutans, apice extrorfum rcflexus.

Pendu. 
Pendalis, terram verfus perpend:cularem, habens dire? Cionem.

Flaccidus, debilis ita, vt a proprio focis pondere dependea.

Adjcendens, qui primum paulo declinatus, demun reßa

d) Directione.

furfum fertul:

Strifus, omnino perpendicularis fine flexura.

Flexuofus, qui a flore ad fiorem fiectitur. Aira flexuofa. Retrofraclus, vi quafi ad dependentiam redaclus.

Breuis. Breniflmus.
Longus. Longifjimis (relpectu ad floris magnitudinem). c) Meniuis.

Teres. Triquczer. Tetragowus.

Filifornis, qui tentris eft et aequaliter crafius, ita, vi filum aemuiet.

Atrenuatus, verfus apicem f. florem parum tenuior factus.

Incraj)ati, qui apicem verfus fenfim máiorem acquirit "molem.

Clauatus, prope fiorem clause ad infar incrafstus. Nutus, qui bractsis, foliis, fquamis aut quadim pubis specie caret.

Squamofis, fquamis adtperfus.

Foliatus, foliis tectus.

Braftcatur, bręeis inftructus.

Geniculaus. Articulatus.

\section{INFLORESCENTIA.}

Eft modus, quo flores pedunculo plentae anneatuntur, graduali modiffcatione féandit, et fic eft vel Solitarius, qui pedunculo rnico fimplici, bifido, 3 - fido etc. conftat; dehinc pedunctulus $1-2-3-$ florus etc., vel contrá Aggregatus, qui ex pluribus foliis conftat, et figuram quandam format. 
a) Loco, , Diclini, vbi mares a feminibus plone feparati funt, ita, vt vterque domicilium proprium in diftinto indiui- duo obtineat.
Polygamoides, vbi in eadem fpecie florum inuolucra fta- mina cum pittillo, dein quoque mares vel feminas includunt.

Flores fimplices, intra Perianthium aut Corollam vnicum receptaculum conftituentes.

Flores compo.fiti, cum flosculi feffiles plures receptaculo communi integro et perianthio communi continentur, fimulque antheris in cylindrum connatis infructi funt. Sicuti in Symgenefia. Sunt autem rurfus :

b) Compofitione.

I) Ligulati (f. Semiflosculofi tovrN); qui Corollulis flosculorum omnibus planis imbricatis verfus ambitum expanfi funt compofiti.

2) Tukulofi, Corollulis flosculorum omnibus tubulatis fubrequalibus conftantes.

3) Fadiati, fi Corollulae difci tubulofae, in Ambitu contra, flosculi difformes funt, et quidem in ambitu fosculis:

a) ligulatis.

b) tubulofis. Cantaurea.

c) Juburdis, Artemifia. 
Solitarii, feparati loco a reliquis in eodem caule ad? ftantibus.

Vnici, folummodo in codem caule.

Eini, Termi, cac. cowiofi, vbi totidem fosculi ante fibi

(b) Compoadfident in eadem ferie. Daphne. Mezereman.

Terminales, ad npicem Caulis $f$. Rami politi. Latcrales, fi lateri Caulis adfixi funt. Vinilaterales f. fecundi, vbi flores omnes ad vnum id:nque latus inferentur.

$S_{p a r} h$, fi plures absque ordine egrediuntur. Seffiles, pedunculo deftituti. Pedunculati contra pe. dunculo inftrati:

Erecti, qui ferme perpendiculariter coelum refpiciunt.? Cermi, vbi pedunculi apice ita incuruatifunt, vt flores - verlus latus alterum vel Terram nutent. Bidens cernua.

Nutantes, qui terrain magis refpiciunt, quam antece: (d) Directiodentes. - Carduns nutans. Verticales, perpendiculariter terram verius direçi. Horizontahs, qui limbo fuo horizonti paralleli funt.

ne.

\section{II.}

Modus florendi aggregatus is audit, qui ex pluribus, foliis .conftat, et dehine: Vafciculum, Verticillum, Capitulum, Paniculan, Strobilun, Anentum, Spican, Corymunm, Thyrfum, Racemum, Cyman et Vinbellam format.

I. Fascicylvs, cum Flores ex eodem loco in direcione ere ta parallela paucis pedunculis fimplicibus infident. Dianthus barbatus.

II. verticilevs, vbi Flores ex alis foliorum caulem annuli ad inftar ambiunt; hine plantae hacce fo. refentia 
refeentia donatac Verticillatae, ad quas praeprimis $D i$ dyzamia L. pertinet, appellantur. Sunt autem:

1) Sifjilis, fi flosculi pecunculo carerit et immediate caulo affident.

2) Pedunculatus, vbi fores eleuantur pedunculis.

3) Nudtis, inuolucris bracteis etc. deftitutus; contra atutem.

4) Lracteatus, bractea infruetus, et

5) Innolucratas, inuolucro quodan munitus.

6) Confertus, qui conftat flosculis plurimis denfe areteque coniuntis:

7) Sparfus, vbi plures verticilli absque ordine pro. gnafcuntur.

8). Horizontulis, aequori paralleli.

9) Supraarillaris, vbi plures flosculi peduncuiati, vel feffiles, ex codem centro ambitu aequali prodeunt.

10. Difans, qui pedunculis remotis inftuctus eft.

HII. CA.pitvivm, Flores in funmo caule, autramis ex eodem plano multi, feffiles aut pedunculis fimplicibnsimpofiti. Eft:

a) Subrotundum, accedens figurae fphaericae. Allii fpecies.

b) Globofuni, ab omni parte roinndatum.

c) Dimidiatum, ab vnolatere rotundum, ab altero contra plonum.

d) Foliojum, cui foliola vel accumbunt, vel interferta funt, et contra.

c) Nudum, foliolis deftitutun.

IV. PAnicvla, vbi fores fparfi pedunculis dinerfe diuifis et fubdiuifis gaudent. Gramina plurima, e. g. Pánicun, Milizin, etc.

Conge/ra, floribus copiofioribus inftrueta,' 
Denfa, eft maior gradus praccedentis.

Diffufa, cum laxe dingaricantis pedicelli angulis? rectis f. obtufis.

Spicata, in fpicam fere degenerans.'

Parula, pedunculis pedicellisque vndique difperffs, fioribus remotis.

Coarćtata 1. contracta, cum peáicelli fere paralleli fibi exiftunt.

Diuaricata, cum fruce diuaricantur pedicelli ad anģulum rectum.

V. AMENTVM, vbi flores fquama molliori aut foliacea diftinguuntur, et fquamis axi medio communi adhaerentibus, corollis vero nulliş, inftrueti funt; vt in Salice, Coryjlo, Iuglande, etc.

VI. strobrlvs, vbi fores fquama rigida, coriacea vel lignea diftinguuntur, petalis carent et fqnamis axi medio communi adíxis gaudent; vt in Pino.

VIr. sirca, vbi flores feffiles pedunculo communi fimplici adfixi funt. Sequente autem modo diuerfa eft.

1) Simplex, quando flores folitarii adfident vni cidem-? que pedunculo, vt in Graminibus, Vcronicis etc.

2) Compofita, vbi fpicillis pluribus ex pedunculo communi enatis conftantes.

3) Interripta, alternatim nulla, aut faltem multurı per interualla anguftata.

a) Cumpofrione.

Inica, wbi tum in caule format caulem monsofachion. Multac in caule eodem contra caulem polyftachion.

Outata, ad figuram oui accedens. Vontricofa, fi vtraque extremitate angurtior, mediointu- $\}$ c) Iigura.
mefcat corpore. 
c) Figura.

Cylindrica, fi rotunda per totam longitudinem craffa fit. Inbricata, fi fosculis vno lateri incumbentibus confa:

- Eigura. $\{$ ta fit.

Articulata, internodiis geniculato. Carcx pulicaris. Linearis, eft compretia aequali vbique latitudine.

e) Luco.

Sccunda, floribus omnibus ad vnum latus verfis conftans.

Dificha, foribus ad vtrumque latus focctantibus in$L$ ftrufa, vnde 4-6-ficha, a numero ordinis.

d) Situ. $\left\{\begin{array}{l}\text { Ciliata, interiectis ciliis f.pilis exfantious munita. } \\ \text { Comosa, foliolis tenuiftimis terminata. }\end{array}\right.$

Foliacen, foliolis in ea dilperfis.

VIII. CORYMzVs fit ex Spica, dum finguliflores pe. dunculos proprios habent, fitu eleuato proportionali. Simplex, dum. pedunculi finguli non fubdiuduntur. Compofinus autem, cum pedunculi primores, alios plures minores 'gignunt, fitu feruato eodem.

IX: Tuyrsvs eft paniculae coarctatae fpecies in formam ouatam.

Nildus, deftitutus foliis f. Squamis; contra. Foliaceus, follis vertitus.

$\mathrm{X}$. RACruvs, pedunculo communi in plures ramos diuifo ita, vt in vno plano nunquam conueniant. Differt sutem fequente modo:

a) Compori-

3) Simplex, pedunculo ramisque indiuifus. tione.

b) Compolftus, pedunculo ranisque lubdiuifis, Cherropodium viride; Vit is vinifera. ne

Erecius, Dependens, Pendulis. 
Flaccidus.

Laxus.

Nudus, foliis deftitutus, contra Foliaceus, foliis suetus.

XI. crma (f. Fzos cymofiss) eft receptaculum diuifum in pedunculos, quorum fupremi omnes ficuti in vmbetla ex eodem centro, inferiores contra f. pofteriores (pcdicclii) non ex eodem centro, fed rage prodicunt; vi Sambuctus nigra et Elululus; Solanum Dulcanza. ra; Viluralum Opulus etc. Haec autem Cyma eft, vel Nuda, quae inuolucris brafieisque caret. Sicuti Cormus Sanguinea, vel

Bractenta, bracteis inftructa, vel Ramofa, in ramos fubdiuila. Sedum albaim

$$
\text { vel }\left\{\begin{array}{l}
\text { trifida: Scdum acre } \\
\text { tripartita: Sambucus Ebalus } \\
5 \text {-partita: Sambucus nigra. }
\end{array}\right.
$$

XII. vMBELLA (f. Flos vinbellatus) eft receptaculum diuifum in pedunculos, omnibus eodem centro exeuntibus, ambitu formato aequali. Cornus mafcula; Variat autem hoc modo:

Simplex, vmbella, vbi receptaculum fic femel diuiditur, in pedunculos. Sanicula, Eryngium.

Compofita, vbi omnes pedunculi communes fubdiuiduntur in vmbellulas. Daucus, Cicuta, Eupitorbia, Efula.

Vinuerfalis, quae alias vmbellulas pedunculis primoribus gignit.

Partialis (S.'Vubllula), vbi aliae Vubcllulae pedunculis fecundariis 1. pofterioribus in fident.

Prolifera, it in vmbella fimplici vnus alterue peduncu-

lus progignit vmbellulam. Afclepias Vincetoxicumb 


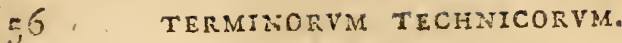

- Concaua, dirco deprefía.

Faftigiata, erecta, difco planiffimo ad horizontem pa.

b) Tigma. $\{$ Conuexa, dilco in fphacrae fegmentum elato.

Radiata, fi petala exteriora verfus fita in embitu difformia, vel maiorafunt. Heracleum; Tordylium; Can-

calis.

s) Directio-\{ Nutans, praecedenti contraria. Solanum nigmun.

Cerma, crectam inter et nutantem media ad latus res. git. Chaerophyllum temulim.

\section{ERV CTIFICATIO.}

Ef Vegetabilium pars temporaria generationi dicata, antiquum terminans, nouum incipicns. Ef autem duplex:

a) Simplex, quae confiat floribus feparatis.

ß) Compofita, flosculis confans pluribus, qui eidem receptaculo infident. Sicuti sYNGenesia Linn.

Ad partes generationem perficientes abfoluentes. que communiter numerare folemus Frorem et Frvc. TVM.

FLos autem eft Thalamus nuptialis Vegetabilium, qui forma atque fabrica tenera ab omnibus plantae partibus facillime diftinguitur et fructui femper antecedit.

FLORIs partes, quae nunc diligentifime examinan. dae funt, partin effectiales, partin contra accefjoriae.

I. Partes floris effentiales conftiturit Antheran ct Gernen, Guae partes in omnibus plantis adefic depent.

1) AN- 
1) Antrera enim conftst fubrantia feminali insscula et fubtilifima, memoranulis communibus proprisque inuoluta, quae matura exploditur.

Antheras vero diuerfo modo differmst, et quidem funt:
3) Vuilocubarcs.
2) Biloculares.
3) Trilocialires.
4) Multiloculares.

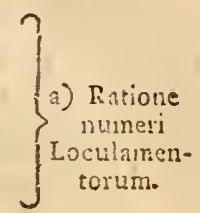

Loculi funt concamerationes f. caua difflato polline in corpore Antierae confpicua. Diflinktae, vt vna alteri nulla fui parte cohaereat; ficuti Floribus plerisque.

Connatac, vbi plures in vnum 'corpus concreta funt. Clafjis sYNGENESIA. Linu.

Laterales, lateribus filamentorum adfixae. Paris. Verjatiles, quae parte laterali nedia apici flamenti incumbunt, cacierum contra liberae funt et mobiles. Sn?uia; Tulipa; Gramina. Siffics, quae filamentis carent.

b)Colnacliounis.

EreEtae.

Pendyilae.

c) Directionis.

Integrae.

Bifilae.

d) Diuifioris.s.

Didzyae, duobus globulis difinctis, latere connatis conftantes. Rercurialis.

Globo,ae. Subulutce. Sagistatae. Bicorszcs, apice bifido porrecto cornum ad inftar. Arifatata, quae arifta terminaniur. Spiralcs, cohleae in modum factae. 
Dehifcentes, vbi Antherarum valuulas rumpunt atque fele reflectunt fumque Pollen veficulare fupra. f) Explofio-
nis. Stigma fparrunt. Quod negotium partium ad fucti-

ficationem pertinentium aliis audit Anthefis.

Operculerae contra funt Antherae Mufcis propriae, quae epiftomio clsufae funt et temporefructificationis con4 tra hoc abiciunt.

opxacvlvi auten eft Membrnna, q̧uee Anthorae Orificim fupra cilis claudit et ealyptran totan yel ex parte tegit. Varias sutem adfumit figuras. Nempe reperitur:

Obtufum, Conicum, Subulatim, Arcuatum, Recum, Obliquini etc.

Pollen eit Purnis floris, globulos plurimos minimosque refcrens, snthera inclulus, - humore aetherco 1 . valde tenui rumpendus, atomosque elafticos eiaculans. Ob figuras funs varie liudit:

Globus echinatus; ad inftar echini f. erinacei mucronatus. Helianthus

perforatus: Geranizm.

didymus, figura Scroti animalis, leui fulco fubbipartiti. Symplaytum.

rotatus: dontatis. Malua.

angulatiss. Viola.

reniformis. Narciffus.

conuolutus. Borrago.

2) GERMEN, eft Rudinentum Fructus immaturi in Hore, atque eft vel:

I) Superuni, Corolla inclufum, vel cuius piftillum abit in f́ructum ex mente rovrner. Paris, Prumus Cerajus, Berberis etc. vel

2) Inferm, quod infra Corollam pofitum eft, vel cuius calyx abit in fructum $\mathrm{ex}$ mente TOVRNEF, vel denique 
3) Sefjili, difico eiẹatum.

Omne autem GeRiMeN infuruetum ef Stigmate.

Stigma eft eflentialis illa pars Germinis, quae Auram feminalem malcuiam excipit; attenuat et germini communicat, vitum inchoet.

Stigmata autem funt nunero, figura et Lupetficie diuerfa, et quidem.

Simplex. Paris.

Dinifum, vel $2-4-5-$ - partitum etc. Perforatum in medio cauitate conftructum:

Capillare. Rumer Acctofa.

Capitatum globis terminatur. Vinca.

Globofuni (idem ac prius), Primula.

Ouatum. Gentiana.

Orbiculatum. Berberis, Lythrum.

Peltatam l. clypeatun, globis, quafi mallé fuperne intus complanatum. Niyzphaea. Papauer.

Coroulalatum. Erica.

Cruciforme. Parralis.

Truatcatum. Lathraca.

Enarginatum. Circaea. Cynoğlo/fum.

Oblique deprofinin. Aetaea.

Bilanellatum, globus comprefius et longitudinaliter bifidus.

Concaunin. Viola.

Carialiculațm. Colshicunt.

Angulatum trimgulare. Lilium.

Striatuu. Papaner.

tetragsanm. Erica, etc.

Pubefens. Cucubalus.

Barbatum. Vicia, Lathyrus.

(b) Figura. 
d) Directio-3

Reuolutum. Dianthus, Taraxacum.

Flexum finifts orjum, Silcuc.

ne

dextrorfum, Cucubalus.

Obliquum.

Terminale.

Laterale.

Denique autem aut Stylo caret, áut contra illo clevatur: dehine vel Seffle, aut Pcdunculatun.

II. Partes Fioris accelforiae, quae non in omni Planta deprehenduntur, et quibus natura effentiales ornauit et muniuit, funt Inuolucra, IveEtarium, Filamentum, Stylus, Difcus.

involvera autem Flcum funt Calyx et Corolla.

CALYX eft cortex Plantae in fructificatione prae. fens, qui X Species conftituit, fcilicet I Perianthium. II Inulucrum. Inl Glunam. IV Arifan. $V$ Ancsutum. VI Spatham. VII, Calyptram. VIII Scutellam. IX Scyplaum et $X$ Voultian.

I. PERIANTHIVM, calyx fruatificationis contiguns, et quidem triplex:

\&) Fructiffcrtionis, famina germenque includens.

ß) Floris, ftamina absque grermine continens.

y) Fructus, germen absque faminibus fouens.

1) Proprium autem dicitur, quod vnice $\alpha$, aut $\beta_{3}$ aut $\gamma$, fufinet, atque confibuit fequentes fpe cies:

a) inonophyllum, conftans foliolo vnico, bafi inntegro, vel limbo faepius diuifo etc.

polyphyllism contra, foliolis f. fegmentis plúribus confans.

b) fif 
b) fiffum eft monophyllum, plus 'minusue ad mediam partem verfus bafin diaifum, finubus linearibus totidemque marginibus cretis.

$2-3-4-5-$ etc. multifichnn, eiusdem fpeciẹs funt.

Partituin eft quoque monophyllum diuifum, vt fiflum, fed vilra medium, faepe fere vsquic ad bafin, laciniis tamen in baft manifefte ctiannum cohae-1 rentibus.

bi-tri- et muli ipartitum.

inregrim eft I- phyllum indiuilum, finu orni defitutum, prioribus contrarium.

c) tubulofun, quod caum ad cylindri feu fiftulae figuram accelit.

patcns, cuius laciniae dinergunt, aut limbus late eft expanfus.

refiexum laciniis aut limbo.

inflatum, caum inftar veficae inflatae tume. fcens.

d) abbrettiatum, longitudinem tubi (Corollae) non attingens.

longum, longitudine tubi(Corollae); mediocre.

obtufun, acutum.

(pinofim, fpinis
aculcatum, aculeis ) armatum.

aequale, inaequale, labiatam.

2) Commune, dicitur, quad plures flosculos continet includitque. Sicuti adgregatak, yt Scabiofa, Taraxacum.

imbricatum, fquamis $\mathrm{f}$ foliolis calycinis variis imbricatim fuper impofitis conftans, Hieracium, Lachuca, Jquarrofum, eft Imbricatum, quod contra fquamis vndique dinaricatis patentifimis conftat. Onopordon, Conyza.

fcario- 
I fariofum, imbricatum fquamis apice f, margine membrana acutis, arida fonora. Chryfanthemnm.

fquamofum, ex fquanis vndique diuaricatis, patentiffmis confruçum. Carduur, Hclianthus.

calycularum, visi féries foliolorum (Squamarum) breuiorum diftincta exterius bafin calycis cingit. Diann thus, Crepis.

turbinatum, obuerfe conicum if. teres, et verfus apicem attenuatum.

II. Involvcrvm, Calyz Vmbellae a flore feparatus. Eft quidem

$\left.\begin{array}{ll}\left.\begin{array}{l}\text { inizerfale } \\ \text { partiale } \\ \text { proprium }\end{array}\right\} \text { fubiectum } & \begin{array}{l}\text { iniuerfali } \\ \text { enilibet fori. }\end{array}\end{array}\right\}$ vmbellace.

nonophyllum etc. polyphyllum.

dimidiatam, ab altero latere deficiens.

III. GLYMa, Calyx Graminum confans valuis amplexantibus.

- Valuae funt láminae f. fquamae omnino ficces, aguam pluuiamque eludentes prorfus; cacterum papyraceae frmitatis, oblongae plerumque.

a) vniflora, vnicum includens flosculam. Panicun, Phalaris.

biflora, fi duos flosculos continet.

multiflor, fi plures, quam duos, includit. Tritict:ms.

b) unitialuis, fi flos tegitur valua vnica praeter valvas corollaceas.

bi. multiualuis, fi valuae duae pluresue fori eidem adftent. Sicuti 6-valuis in Hordeo.

c) colorata, coloris altericis, quam viridis herbacéi. giabra, hifpida. 
IV. ARIST.1, ent Mucro fubulatus, qui Glumae infidet, atque, eft

a) nutica, fi mucrone fubulato caret:

- ternizalis, cum arifta ex valuae apice prodit. dorfalis, quae parti externae conuexae, feu dorfo valuae adfidet. Auezza.

b) tecta, quae fibrarum ducto recto extenditur. Agroftis SpicaVenti.

- tortilis ad inftar contortifunis. Alsena. geniculaia, articulatione inftrueta. Agroft. cainina. articulata, internodiis geniculata. Stipa. . recuruata,extroríum arcuatim flexa.

V. Amentvm, eft Calyx a Receptaculo communi fililiforni, fquamis paleaceo-gemmaceis diftinctus. Inglans-

fquamofum, fi flosculi fquamis fuffulti. Carpinus. mudum, fqusmis deftitutum.

VI. spatha, Calyx membranaceus, fpadicem referens, longitudinaliter tuptus; vel eft vagina longitudinalis fifa, membraracea, rugofa, fere femper arida.

vniualuis, conftans folio vnico, latere longitudinaliter fifro. Arum, Narciffis, Leucoium.

biualuis, conftans vagina profundius in duas lacinias filia.

- dimidiata, quae exhibet valuam vnicam a bafi ad apicem longitudinaliter hiantem, inftar oui lon. gitudinaliter dimidiati.

imbricata, membranulis variis imbricatim fuperimpofitis conftans.

I-6- multiflora.

VII. calyptra, Calyx Mufcorum cuculatus, anthed rae. fuperimpofitus. 
resta, perpendiculariter $\left.\begin{array}{l}\text { horizontalis, horizontaliter } \\ \text { oúliqua, oblique. }\end{array}\right\}$ incumbens.

VIII, scvtella Calyx Licheribus quibusdan proprius, orbiculatus, concauus margine vndique elevate.

Segrilis, nullo pedunculo inftrueta. Scutcllaria carpirea.:

concaus. Scutell, cacrulefcons. creinlata.

IX. scyprns, Calyx Lichenum coralloideonum, conftans ftipite bafi attenuato, fuperne dinatato excauato.

A. vouva, Calyx Fungi membranaceus, vndique la. certs.

npiroxiniata, ad pileum proxime accedens. remotifima, a pileo fpatio recedens.

conotia of Ininolucrum rooris internum $f$. liber plantre in rloke prefens, eftque monopetala, Tubo et Limbo, vel polypetala, Vrgue et Lamina conftans.

Petalum, Pars Corollac in plures dinifac eft tegmen Floris corollaceum. Partes huius Petali funt:

I) Tibus, Corollac I-petalae pars inferior tubu. - lofa. Lonicera, Primula Veris.

3) Vuguis, Corollae polypetalae pars inferioradfixa. Saponaria.

Limbus, Corollae I - petalae pars fuperior dila. tata.

4) Laciniae, funt partes Corollae, in quas limbus finditur.

Lamina, Corollae polyperalae pars fuperior patula, lats. 
A. Monopetala, dum Corolla bafi ita adhasret, vt lacinis altera absque alterius dilactratione vix auferri quest: aut nexus faltem fub diruptione laciniae vnius ab altero fatis confipiciatur. Veronica.

fiffo, $2-5-f i t a$.

partita, 2-maltit-partita.

a) Regularis, limbo in fegmenta aequalia diuifo. Haec autem iterum

a) Hypocrateriformis, cuivs limbus planus tubo elongato impofitus.

B) Infundibulifomis, cuius limbus adłcendens co. nicus tubo elongato impoints

y) Rotata, cuius limbus planus, partibus patens, nullo f. breniffirno tubo impolitus.

8) Campanulata, tubo nullo, ventricofa, linbo campanse formam referente.

ह) Globofa, quae figura prope globum refert. $V a c$. cisiun. Myrtillas.

b) Irreşalaris, limbo in fegmenta inequalia diuifo; quae denuo

a) Subacqualis, fegmento vno alione alkerius figurae aut magnitudinis, qualis occurrit in Veronica etc.

6) Rungers 1. Labiata, limbo irregulari in 2 fegmenta inaequalia, Labia dicta, partito.

$\left.\begin{array}{l}\text { Labium fup rius } \\ \text { Labium inferius }\end{array}\right)$ audit ( $\begin{aligned} & \text { Galea. } \\ & \text { Barba. }\end{aligned}$

Riztus, eft hiatus inter duo Labia Corollae ringen. tis.

Faux, eft histus inter lacinias Corollae vbi tubus terminatur.

Palatum, apopliyfis labii inferioris Snperiora verfus, quo rikus occluditur. 
y) Perfonata, eft Corolla ringens fegrrentis inaequalibus binis inftucta, quorum fuperius galeae effigien minime repraefentat, Astirrininum Listaria, Euphtafia.

B. Polizpetala, quae e $2-4-6-$ et pluribus petalis conftat et quidem eft $2-3-4-5-6-$ et poly. petala a numero petalorum deriuanda.

a) Reguloris, quae petalis aequalibus conftat. Sicuti

a) cruciata $f$. cruciformis, quae petalis 4 aequalihus gaudet. Ciaffis Tetradynamic Linn.

B) -patentiffma limbo horizontali. Anthericum. '

b) Irregularis, cuius petala insequalia funt. Haec denuo eft triplex, nimirum,

*) Papilionacea (a Mapilione volitante fic dicto Toumefortio), eft irregularis, $4-$ petala, conftans :

3) Vexillo, petalo fuperiore adfcendente.

2) Carina, petalo inferiore cymbiformi, quae includit ftamina et piftillum, et ad vnguem faepe bifida.

3) Alis, petalis lateralibus folitariis.

B) Anomata, petalis inaequalibus innominatis conftans: in Aconito tamen petalum fuperius dicitur Galea: at in Delphinio, Antirrininis nonnullis etc. pars poftica tubulofa appellatur Calcar, quod NeEtarium IINN.

y) Innequalis, vbi partes non magnitudine, fed proportione refpondent, vt regularis flos euadat. $B u$. zomas

C. Compofita, cum flosculi feffiles plures receptaculo communi integro et periantlio communi continen. tur, fimulque antheris in cylindruın connatis inftrusti lunt.

a) $L i$. 
a) Ligulata (femiflosculofte tovRner.), dum co:ollulae flosculorum omnes planae, yerfus ambitum contra expanfae funt.

b) Tubalofa (fiosculofa tovRnep:), cum corollulae' fingulae tubulofae, fubaequales funt.

c) Radiata, corollulis difici tubulofis, ambitus vero ligulatis difformibus compofita.

D. Apetala, vini Corolla nulla in nonnullis floribus deprehenditur, et tunc Flos dicicur apetalus.

II. NECTARIVM, eft Organum accefforium a calyce et corolla diftinctum, luccum melliferum floris proprium continens et fecernens, in vniuerfum autem mire ftruetura eorum variat, et quidem!

a) Campanulatum. Narcifus.

b) Cornutum. Aconitum.

Nectarium autem eft vel,

proprium, quod calyci, receptaculo communi, aut germini adnatum, fed ab his diftinetum eft. Delphinium Conjolida.

calcaratum, cornu inftar poftice prominens; in Orchidibus.

petalinum, quod in quadem ipfius petali parte refidet: Lamiun Ramunculus et Fritillaria.

III. Fil.anentym, pars Floris eleuans adnectensque Antheram, organum genitale mafculun. Filamenta autem fecundum numerum, firuram, infertionem et proportionem diuidi folent fequente modo:

a) Diftincta, quae inter fe non cohaerent:

1) Monoftemonis eft fructificatio, fi vnicum fila-? mentum in fingulo receptaculo fruetificstionis, aut fioris tentum obferuatur, vt Claffis Monan-

a) Numero. dria Lisw., aliis Monoftemonis. 
2) Ninuso: \{

2) Diflenonis, fi famina duo adlunt; ficut Diandria L., aliis Difemonis.

i) Ifoftcmonis (f. Icolondria linN.), vbi ftamina 20 1) vel plura non receptaculo, fed calycis lateri interno b) Iufertions $\{$, adinectuntur.

2) Polygamonis (Polyandriz LINNo), vbi famina receptaculo inferuntur a 20 ad plurima in eodem flore.

1) aequalia magnitudine.

2) inhequalia aliquot maioribus vel minoribus, et quidem

a) vbi enim 2 longiora, et 2 breuiora obferuantur, tune Clafis Didynamia LINN.

c) Proportione.

ब) Cohacfio-

ne.
B) funt autem $f_{c} x$ ftamina in fingulo flore, et quorum $\div$ longiora, 2 autem oppofita breuiora Claflis Tetradynamia L.

3) irregularia, magnitudine, directione, figura diverfa. Lonicera Periclymenum.

4) longiffima refpectu Córollae f. Calycis in apebreuijlina) talis.

b) Connata, vioi plura ftamina filamentis in vnum, vel plura corpora funt coalita. Si enim

a) Stamina filamentis in vnum corpus modo cannata funt, tunc Clarr. Monadelplia L.

B) Stamina autem filamentis fere omnia, excepto vnicolibero, in vnum corpus coalita, tunc Clar. Diadelphia L.

y) Sunt ftamina filamentis in 3 vel plura corpora fafciculatim connexa, tunc exiftit Clarr. Polysadelphia LiN. Et denique

d) Stamina antheris in cylindrum coalita, contra filamenta funt libera, Claft. Syngenefia LiNN. exfurgit.

c) Se- 
c) Separata, vbi mares cumfeminis in cadem domo, fed a menfa et toro feiunda funt, feu ftamina $e_{t}$ piftilla in fingulo flore feparatin in eadem planta reperiuntur, Monoccia.

Remota, vbi mares a feminis plane feparata funt 1 . ftamina in planta diuerfa a piltilis proganfeuntur. Divecia.

Intermixta, vbi in eadem ftirpe famina cum pifil-e) Situ. lis, vel ftamina, vel piftilla feparatin habitant. 10 .

- lyzamia.

Capillaria, inftar capilli tenuia, fecundum losgitu? dinem totam aequaliter crafia. Plantago. Phy tcuma.

Plana, quae compreffa membranae inftar tenuia et la. ta funt. Orwithogalum, Allium Porrum.

Foliace, foliis intertincts.

Cunciformic, fenim verfus bafin angulata. Thali. Etrun.

Spirclia, quae fpirae ductum fequuntur. fubulata: cnarginata.

tricufpidata, latiora, fed apice trifida. lurfuta, lanam rigidiulculam induta. Verbafann Thapjus.

ŚTYLYs eft pedunculus figmetis, germini impofitus, et quoad numerum, figuram, proportionem, divifionem '́t dirễionem quoque diuerfus.

Exulumero fylozum, aut, fi defunt, ex numeroftio- a) Numero. matum linnaevs Ordines Clafíum $f$. fubdiuifiones, in Monog. Dig. etc. Polygyniam petiit, qui patet ex Syltemate Sexuali. 
b) Figura. $\left\{\begin{array}{l}\text { cyjlindricus, inftar fcipionis, teres. } \\ \text { angulatus; fibulatus. Geranium. }\end{array}\right.$

iclawatus Juperne. Leucoium vernum.

capillaris, flliformis.

flongifimus. Campanula.

breuifjinitus.

tione.

nullus. Papauer, Tulipa.

acqualis, crafític, Lamium.

YVuus. Plwres.

d) Diuifione $\left\{\begin{array}{l}\text { Sifuivus, angulo acutifimo. Polygonum Perficaria. } \\ \text { bifus. }\end{array}\right.$ dichoronius, angulo patento recto bifariam diuifus. urifidus. Campanula. -4-5- fidus ctc. Geraniuns.

e) Directio-\{Rectus. Curuus.

ne Yobliquus. Inclinatus.

- Frvcrvs eft illa pars plantae, cuius partes in Pericarpio, Semincet Recepticulo confiftunt.

\section{PERICARPIVM.}

Vifcus Plantae, grauidum feminibus, quae matura dimitrit. Oritur autcm hoc ex germine ampliato, et in variis plantis diuerfinima gaudet figura et confiftentia; dehinc Frustus diuerfis qüoque nominibus Capfulae, Siliquae, Leguminis, Arilli, Strobili, Nucis, Drupae, Baccse, Cyfrae, Pomi, intignitur.

I) Capfula eft pericarpium inuolucro vnico cauo conftans, apice, latere, bafi dehifcens, fouens femina non futuris, fed alio loco, adfixa. 
Capfulae antein partes funt Valuac, Locula, Septum, Columinula.

ж) Valuac funt fegmenta illa, in quae Capfula dini. ditur, dum femina matura dimittit, et iuxta horum numerum appellatur, Capfula $2-3-5-$ ctc. multi-valuis.

B) Lockla 1. Loculamenta funt camerae femina recondentes, in quas capfula interse a fepo diuiditur.

Iuxia horum numerum dicitur $\mathrm{Cap}_{2} \cdot \mathrm{2}^{-3-4-}$ et rultilocularis.

y) Sep:un, aliis diffepimenoun, eft prries, quo fructus interne diftinguitur in concaméationes plu. res, et quidem eft

vel parallelem, vel contrariumi.

8) Colimaula 1.' Columella, eft pars Capfulae, quas a receptaculo adicendit et in centro parietes internos cum feminibus connectit.

sircumfciffa audit Capfula, quae transuerfim media fere parte in hemifpaetia 2 denilit. Hyofcyamus, Plantago.

elaftica, valuulas cum impetu fubito disiicit. didyma, irghtuta.

dicocca S. 3 - cocca, fi capfula $2 \mathrm{rel} 3$ nodis protube-

rat intusque in $2-3$ locularnenta diuiditur.

giono $-2-3$ et polyy forma dicitur, quae vnicum feu plura femina foutentia continet.

2) Siliqua, eft pericarpium 2 - value affigens femina fecundum vtramque futuram: conftat valuis et diffe. pimentis.

Diffepincritum eft vel, parallelum latitudine et diametro transuerfali ad valvulas accedens; Draba; vel, irassilerfon anguftius vbi valvulae cocretatae enadunt concaune. 
Siliqua ftrięe d'citur, cum longitudo notabiliter fupe. rat latirudinem.

Silicula, fi vix fuperat.

Siliqua autem diuerfa eft: quoad figuram

coimpreffo, lateribus oppofitis proxime ad fe inticem accedentibuis. Thiajpi.

cordata: Lepidium. Obcordata: Thlafpi burfa Paforis. lanccolata: Ifatis.-triquetra.

tetraëcira 4 lateribus longitudinaliter planis: Eryfimzun.

tovulafit, eminentiis hinc inde gibba, Raplanus.

Cocliterriza.

articulata, fi toruli aequaliter filiquam armbiunt, yt intcrualla anguftiora aequalia relinquant: Kaplanius.

- 3) Legunciz. Efi Pericarp un biualue, in quo Semina fechndum futuram alreram tnntum adtixa, $v t$ in Pifo. Et quidem eft:

1) Ouatum, cuius diameter iongitudinalis fuperàt transuerfalem, a figura bafi fegmento circuli circumfcripta, apice vero eadem anguftiore.

2) Rotundiatum, quod angulis carct. 'Aftragalus.

3) Teres, quod maxima $\epsilon x$ parte cylindricum eft: Lorus.

4) Rhonbeum, cuins t latera pasallela aequalia. Ononis.

5) Turgidwm, infar veficàe cauum repletum feminibus. Gunifta; Cicer.

6) Yuflatum, infär veficae cauum, nec repletum. Colutea.

7) Spirale, quum Legumina deorfun fpiraliter inuolvuntur. Medicago.

8) Contortum, cum fpiraliter contorquetur. Medics. go fatiua; Spiraea Vlmaria.

9) Ari- 
9) Articuintum, perinterualla snguftatun. Corozilla; Hedufarum.

Vuiloculare. Pleraeque Plantae e Diadalyhia. LinN. Bilocsilarc. Afragalus.

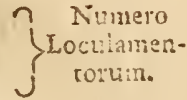

4) Arillus. Eft Pericarpium inuolucro proprio vnico Semina extrorfum circumdante confans, isque:

1) Simplex Copfularis.

Succulentus. Euonzymus.

Cornojus.

Subcarnofus. Rofae.

Cartilagineus. Cinnoglofjum.

2) Compofitus, Hecizjara pleraque.

5) Strobilus. Pericarpium imbricatum, ex Amento . coarctato fatum, fquanis induratis. Ef

Convideus, vel

Globofus.

6) Nux. Inuolucrum duplex: neutrum dehifcens; $e x$ tersum dempvin ficcum; internum oficum. Anygdalus, Iaylans.

7) Drupa. Inuolucrum triplex; externum membranacelim; internum fucculentum in plerisque; intįun coriaceum, nec denifcens, Prunis, Cerafus exc.

8) Bacca. Inuolucrum duplex, neutrum dehifcens: exterium membranaceum aut fubligneum: intermum fucculentum aut carncium. Cucurvitaccae et Bacciferne. Eft autem:

a) Seminum numero.

- mono-di-iri-ctc. polyjperma.

b) Loculamentis I-2-3-et multilocularis. 
recutita, ad inftarglandis ferme praeputio te to Taxus.

9) Cyfa. Inuolucrum triplex: externum membranaceum: intermun carnofum fucculentumque : intimum coriaceum non dehifcens.

a) Iigura. $\left\{\begin{array}{l}\text { Turbinatum, obuerfe conicum. Pyrus communis. } \\ \text { Globofani. Pyrus Malus. }\end{array}\right.$
b) Numern
$\begin{aligned} & \text { Loculamen. } \\ & \text { torum. }\end{aligned}$

\section{SE M E N.}

Eft pars regetabilis, decidua, polline foecundante viuificata, plantam noum et parenti fimilem proferens: ac locum aptum fèmina nacta, tunc figurae variac quoad numerum, figuram, fuperficiem, loculos et confiftentiam exiltunt.

Semen autem conftat Tunicis, Corculo, Cotyledone et Hylo.

a) Tunicae funt inuolucra cotyledones obducentia, numero et ftructura diuerfa.

b) Corculum eft nouae Primordium plantae intra Semen, hilo proximum, et conftat:

Plumula, parte Carculi fquamofa adfeendente. Roftello, parte Corculi fimplici defcendente.

c) Cozyledoncs lunt foliola ferninalia corculum inaolventia, quae abforpto humore eum låtant, danec propriae vitae viribus aliqueat: et funt Acotyledones, vbi nulli omnino extant Cotylodones fub feminis Germinatione: Filicibus, Fungis. Monocotyledones, vnico Cotyledone germinantes: Graminious, Orichideis, Liliis. 
Dicotzlenodes, foliis teminaibus duobus fub Seminis germinatione. Plerisque plantis: Pifo, PhafeoTo etc.

Polycotyledorses, Plantis paucifimis. Sicuti Pinu, Lino.

d) Hilum $f$, cicatrix externa feminis ab ciusden adhse. fione in fructu reliate, quo cotyledoncs hauriunt nutrimentum.

Senen ipfum eft vel teetum, pericaipio inclufum: vnde planta Angiofperma (áyyor 1. x'ryebry', Vas et блtqua, Semers); vel

mucizm, fi femen fponte fua illico vifui pateat: vnde planta euadit Gymuo/perna. Eft auteni duplex; nempe aut

1) Muticum, nullo alio corpore terminatum; in Graminibus, - Plnntis compofitis nonnullis etc., aut

2) Coronatim calyce in' Vimbollifieris.

a) Corona, ef calyculus adhaerens, quo volitat, $€ x$ perianthio floris. Scabiofa.

b) Pappus, Corona pennacea pilofaue, quo volitat Semen et quidem eft:

a) Simplex, radiis pluribus indivins in orbem po. fitis. Hieracium.

Sefjilis, Semine absqug fipite adhaerens.

Stipitatus, fi aden filum, eleuars connectensque pappum et Semen. La Eiuca.

Capillaris, radiis 1. filis fimplicibus infruetus. Sonchas.

B) Compofitus, radiis $\int$ pilis ramóis infructus.

Palcaccas, confans lamellis linearibus apice femi. num adfixis. Bidenzs.

Plamojus, villofus pennis compofitus. Tragopogon. 
Arifarus, arifae forms apparens. Tagetcs, Helianthus.

Nutlus, Artemifia;'Bellis; Cichoreun.

c) Couda, femen flo terminstum. Aripa geniculate, articulatione inftucta. Agroft. caniria.

Arifa pilofa; Clenatis Vitalba. Arifta plumena: pilis pennatis Semen terminans. Geum riuale.

d) Hamus, appendiculus feminis, quo animalibusprae: tereuntibus adhaeret.

triglochis: fotis tricufpidatis femen, coronatus. Azyofotis I ampula.

- incumus, arifa vncinata infuructus. Gcun urbanum.

e) Nucleus, ipfom femen in offoa capfula f, nuce reconditum. In Drupis.

Semen autem eft

a) Nunero. $\{$ mono-di etc. polyypermwm.

gyinnociyfpermum, femen nudum geminum.

- (Cordiforme $)$ a figurâ cuiuscunque Amilis.

b) Figura. Echinatum, a fimilitudine animalis aculeis f. fpinis rectis oundique homidi.

Orbiculatums.

c) Superficie $\int$ Scabrum. Lacue. Glabrum. Rugofun etc.

d) Confi- Ooncunt. Lithospermum. trentil. \{Callofins. Cartilaginetsm. 


\section{RECEPTACVLVM.}

ER bafis, cui fructificationis partes funt adfixae; $\epsilon t$ quidem eft :

a) Proprium, quod partes vnius tantum fructificationis colligit.

๙) Frućificationis, fori et fructui commune.

ß) Floris, bafis; vbi floris partes absque germine affiguntur.

r) Fructus, bafis Fructus remota a foris Receptaculo.

8) Semizum, bafis, qua femina intra pericarpium' afliguntur.

b) Communs, quando fosculos plures ita connectit, vt quibusdam exemtis irregthlaritas exiftat; et fuperficiei figuraeque ratione differat.

Nudum, pilis, fetis, paleis deftitutum. Taraxacum. Punctatum, punctis adfperfum, caeterum nudum. İillofum, villis veftitum. Artenifia; Abfinihium; Car: duns.

Pilojum, pilis obfeffum.

Setofum, obuallatum fetis. Arctium Lappa. Centaurea.

Cyanus.

Paleaceum, infructum paleis: Cichoreum, Authemis; Achillea Millefolium. Palea, eft lamella innata linearis, flosculos diftin-
gens.

Planum fuperficie. Achillaea Millefolium. Conuexum, fuperficie ad fegmentum Sphaerae acceden. te eleuatum. Matricaria Chamomilla. Subriatum.

Ouatum. Globofism. Conicum fuperficie in conum elata. Bellis. 
8) Directio- $\left\{\begin{array}{l}\text { Simples. } \\ \text { Compofitans. }\end{array}\right.$

a) Vmbella eft Receptaculum ex codem centro eion. gatum in pedunculos filiformes proportionatos.

B) Cyma, Receptaculum ex centro eodem vniuerfali, particularibus vero vagis, elongatum in pedunculos faftigiatos.

7) Spadix, Receptaculum palmae, enatum intra Spa. tham, in ramulos fruetificantes diuifum.

a) vniforus, multiflorus.

b) Simplex, non diuifus. rannofiss.

\$) Racizis, Receptaculum filiforme flosculis longitu. diualiter adnectens in Spicam.

\section{HYBERNACVLVM.}

Pars plantae includens herbam embryonem ab externis iniuriis. Eftque vel

a) Bulbus, Hybernaculum plantae e rudimento folio. rum practeritorum.

a) Tuiticatus, bulbus tunicis nunerofis veftitus. Cipa.

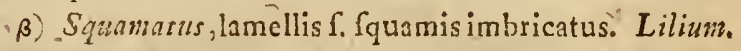

g) Solidus, carnofus, intus dinif́s. Tulipa.

d) Articulatus. Adowa, Lathraea.

b) Gemma; eft Hybernaculum plantae ex rudimentis foliorum futurorum. a) Origine. $\left\{\begin{array}{l}\text { petiolaris, e petiolorum rudimentis. } \\ \text { ftipularis, e ftipulis confecta. } \\ \text { corticalis, e corticis ramentis. Arboribus. } \\ \text { radicalis, e bafiradicis. Herbis. } \\ \text { caulina, in caulis quadam parte fitu: Suffrubicibus, Fruti- } \\ \text { cibus et Arboribus, }\end{array}\right.$ 
foliaris, folia, nec flores floralis, flares, noñ folia communis, et folia et flores.<smiles>CCCCCCCCCCC</smiles>

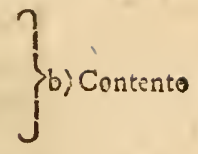

3

\section{S T A T I O.}

1) Clima comprehandit regionem terre ratione longitudinis, latitudinis et altitudinis geographicae. boreala comprehendit Europan Septentrionalem a Lapponia ad Lutetiss Parifiorum.

2) Solum, fundus, cui innafcuntur plantae.

Lacufre, Lacuum Aqua dulcis pura, adeo profunda, vt Gelu fundum non tangat.

Palufive, Aqua minus profunda, Luto laxo refertum greltr obnoxia et aeftate ficcefcens.

Inundatum, hịeme repletum aqua, aeftate putridum, exficcatum, imbribus interdum fuffufum.

Vliginofum, fpongiofum, aqua putrida laborans, colo. nis inuifum, nec legetis, nec foeni prouentui aptum.

Fluniale, quod aquam puram, fubfrigidam, motu agitatam alueo detinet.

Fontanuni, ex quo aqua gelida, puriffma fcaturit.

Caefpitofum, refertum humo mixta Sphagno, teêum tuberibus, aqua linofa cinctum.

a) AQVO: SVM.

Nemorofium ad radices montium, inter lucos, humo? fpongiofa tectum; vmbrofum femper, exhalans continuo aërem humidum, ventis minus expofitum, plantas vernales, frigoris et caloris impatientes alens.

Syluaticun, vmbrofum terra fabulofa fterili referturn.
VMBRD. SYM, 
c) $\mathrm{CANPE}-$

Arucnfe, confiat aquis requictis.

Pratcufe, hethis luxuriat, campis depretis, conuallibusque conftat, et quidem $\in \mathbb{R}$

a) fertile

b) exfuccum

c) humidinfculum.

Cultum in hortis, terra fubacta, mixta, fertilifims, promouens plantas Hortulanis inuifas, intcr Olera luxuriantes.

Ruderale, iuxta domos, habitacula, vias et plateas.

Agrefte, quod terra fubacta laeta goudet.

Verfurarum, quae funt margines agrorum, tanquam 'prata fercorata confideranda.

Fimetorum, ex ftercore animalium congefto.

CGlabretum, eleuatum ficciffima arida planiuscula a fole d) Monta. arefacta.

Rupcfré, Petrarum fiffuris, nurisque praeruptis, aridiffinisque conftans.

3) Loca natalia funt aut comminnia (quae funt notilli. ma), aut fingrtarla, quaé cint fequentia:

1) Lacus, Collectio Aquarum ex fluuiis minoribus, rinis, fontious.

2) Flumen, Aqua mobilis ex pluribus riuis in vnum alueum confluentibus.

3) Riuus, Aqua mobilis ex pluribus fontibus fimul vnitis.

4) Fons, Aqua mobilis ex vario aqueo coadunato.

5) Pifcina, Aqua minus mobilis, pura.

6) Foffa, Aqua fagnans impura.

7) Stagnum, fundo limolun et aqua quieta repletum.

3) Palus, liumo lutof laxa, aqua impura, ftagnanteque ficcelcit.

9) Lit. 
9) Littus, folum lacui, aut Rumini proximum.

10) Collis, Telluris fuperficies modice eleuata.

11) Mons, fabulólus, aricis, ferilis, telluris fuperficie magis eleuata.

12) Sylua, Arboribus denfe confita tellus, terra fabu- lofa ftirili referta.

13) Nonus, vid. Solnm nemorofum.

14) Fruticctum, Fruticibus

15) Arboretnm, Arboribus ) confita tellus.

16) Quercetum, lumo fterili nec fpongiofa refertum et Qucrubus maxime confitum.

17) Alnerum, lolo Spongiofo tectum, vmbrofum, Alnis plerumque infructum.

18) Saltus, Syluorum locus eleuatus, vmbrofus, fquálidus.

19) Campus, Locus apricus ventibus expofitus, ficcus, afper.

20) Aruum, conftat agris requietis.'

21) Agar, terra fubaeta, fertili, frugifera gaudet.

22) Verfura, agroium margo.

23) Pratum, herbis iuxurians, campis deprefis convallibusque conftat.

24) Pafcumm, differt a pratis, quod ferilius, ficcius et magis fabulofum eft.

25) Hortus folo culto, fertilifimo, deliciofo gaudet.

25) Fimetum, ex ftercore arimalium congeftum.

27) Ruderatun, locus incultus iuxta domos et vias.

4) Terra plantis fauens, funt Humus, Arena, Argilla et Creta.

I) Humus tenuiffima, atra, fpongiofa, phlogiftica, et plantis alimentum praebet primarium.

2) Are. 
82 TERMINORVM TECHNICORVM. EXPLICATIÓ.

2) Arena, ficca, friabilis, fiticulola; eft a) mobilis, b) farinacea, c) vulgaris, d) falualofa.

3) Argilla, tenax, tempeitate' humida vnetuofa, 'ficea et igne contra indurata.

4) Creta in collibus ficcifimis aridiffimis.

5) Compofita ex his enumeratis intermixta; multiplex. 


\section{CLASSES GENERVM.}

Claffis I.

MONA N D I A.

MONOGYNIA,

\section{A. FLORE HERMAPHRODITO.}

Cal. I - phyllus. Cor. o. Stig. bifidum.

Cal. fuperus, breuifimus, minimus. Cor, o. Stan. firmate infertum Stignn. fimplex, Sen. vnicum, 2. Hippufubrotundium.

\section{B. FLORE MONOCLINO.}

\$ Cal. o. Cor.2- petala. Petala incurua lunulata. Fi- 3. Callitrilam. incuruum, longum. Siyl. 2. Capf. 2-locula- che. ris, 4- fperma, fulcis exarata.

o Cal. et Cor. o. Anthera fphaerica, germini inferta. 4. Chara. Filam. 0:

ㅇ Cal. 3-4- phyllus. Cor. O. Stigm. 5- fidum. Serr. 1. 
II.

\section{DIA N D R I .}

MONOGY

\section{A FLORE HERMAPHRODITO.}

5. Lign-

a) Fiores $\mathrm{I}$ - petali, inferi, regulares.

frum. Cor. infundibuliformis, 4- fida. Antí, longitudine fe, re corollae. Bacc. pulpofa, 3 vel 4-fperma.

6. Syringa. Cor. 4- fida, rotata: laciniis oustis. Stigm. 2-fidum. Cap.. 2 - locularis.

b) Hores I- petali, inferi, irregulares.

a. Seminibus capjula zectis.

7. Veronica Cal. 4-partitus. Cor. rotata; limbo 4- partito; lacinia infma anguniore. Capf. 2 - locularis, obcordsta.

8. Pingui-Cal.2- labitatus, 5- fidus. Cor. ringens, calcarata. cula. Caps. I- locularis.

9. Vtricu. Cal. 2 - phyllus aequalis. Cor. ringens, calcarata, laria. Cays. I - locularis, plura femina includens.

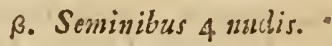

10. Verb6- Cal. 5-7-gonus ae friatus denticulis 5-7-breuina. bus, excepto denticulo fuperiore intermedio trunca. to. Cor. Lubaequalis curua: limbo femi 5-fido. Stam. in exoticis 2, in noftrate paffim 4. Srigm. capiratum. Cap. 2 - locularis. Sem. 4 calyce immutato continentur.

i1. Lyco. Cor. I- petala, 4- fida, fuuregularis: lacinia vnica, pus. emarginata. Stam. diftantia. Stigm. fubulatum. Sem. 4 retula in calyce aperto nidulantia. 
Cor. ringens, inaequalis. Filam. trónsueffe pedicello 〔2. Saluia. affixa. Seni 4. Neítar, 4. fubrotunda carneo-flaua.

\section{2) Flores fupcri.}

Cal. 2-phyllus, fuperus. Cor. 2-petala, obrorda- I 3.Circaea ta. Capf. pilofa, 2-locularis, biualuis, 2-fperins.

\section{I G Y I I A.}

Cal. Glum. 2- valuis, 1 - fora, oblonga.' Cor. 2-x.4. Antho. valuis, ariftata. Sen. I. nudum. Neftar, 2, obtule, xanthum. concaua.

\section{B. FLORE STYLOSTEMONOIDE.}

Cal. c. Cor. 5 - petala irregularis: Petala fuperiora 15. Orclibs. in galeam vergentia, 6 -tum inferius vario modo dividitur in calcar fatis longum cornuforme terminatur. Stam. Filam.2, breuiffima, albida. Antherae ouatac viridefcentes, vel purpureae. $P i f t$ - $-\left\{S_{t y l}\right.$. breuiffmus. Stign. fimp!. obtulum. Nectariam pone floręn in cornu pendulum, labio plaño.

Cal. o. Nectar. breuiffimum ferotiforme, labio plano. 16. SarySim. plurim. fcobiformia.

rizin.

Cal. O. NeEtar. Labium fubtus carinatum. Stam. Fil. 0. 17.Ophrys Antherac 2.

Cal. O. Nectar. Labium ouatum, fubtus gibbum, trifi- I8. Seradum. pias.

\section{FLORE MONOCLINO.}

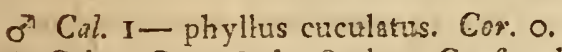

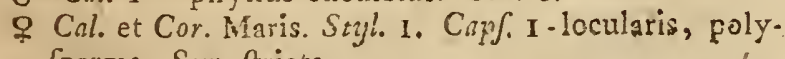

19. Lemna. fnerma. Sem. ftriata.
D. FLORE 


\section{CLASSES GENERVM. \\ D. FLORE DICLINO.}

20. Salix, e Cal. Squamae Amenti I - florae. Cor. c. Nectar. giandula in centro floscuii. Stam. 2-5.

9. Amcat. Cal et Cor. Maris. Styl. 2- fidus. Canf.2-valuis, 1- locularis. Sem. pappofa.

\section{E. FLORE POLYGAMOIDE.}

21. Fraxi- $\sigma^{7}$ Cal. ct Cor. O. Stani. 2. Pifl. I. Sonr. I. laneeolatum nus. alatum.

o Cal. Cor. Pifi. Sem, vt in hermaphrodito.

\section{IIII.}

T R I A N I R I A.

MONOGYNI $\Lambda$.

$\begin{array}{llllllllllllll}S & E & C & T & 1 & O & I\end{array}$

\section{A. FLORE HERMAPHRODITO.}

๙. Flores fuperi complezi,

22. Vale- Cal. o. Cor. I - petala, 5- fida, infundibuliformis; rima. tubus calcaratus, aequalis, 1. ringens. Stann. $\mathrm{I}-4$ Sem. 1. coronatum. Flores hermaphroditi, dioici.

B. Flores inferi completi.

23. Poly- Cal perfiftens, 5 - phyllus: foliolis 2 alternis minorichemaiti. bas. Cor. o. Scm. I, memprana tenuiffima veftitum.

\section{$\%$ Fiores fenperi incompleti.}

24.Gladio. Cor. 6- partita, ringens; petalis tribus fuperioribus lis. conuergentibus. Stam. adfendentia. Stigm: 4- fidum, concauum.

Cal. 
Cal. fpathaceus. Cor. 1 - petala, 6-partita; laciniis 25 . Iris. alternis reflexis, quarum 3 maiores reflexae, e bafi pilofae aut glabrae, ouato-obtulae; 3 minores et anguftiores. Stigm. 3; petaliformia, reflexiufcula, apice laciniata ac crilpa, fubtus conna:a. Capf. $3-$ locularis.

\section{T R I G.Y N I A. \\ Flores fimplices inferi.}

a) completi.

Cal. 5- phyllus. Cor. 5- petala, calyce longior. 26. Holo. Caps. I - locularis, apice dehifcens 3 -valuis, po- ftem. lyfperma.

b) incompleti.

Cal. 2- phyllus. Foliola ouata, obtufa. Cor. I- peta.27. Montin la, irregularis. Caps. 1 - locularis, 3-valuis.

\section{SEC T I O II.}

\section{A. GRAMINEAE. S. CALAMARIAE.}

\section{A. FLORE HERMAPHRODITO.}

\section{O NOGY N I A.}

2) Floribus glumofis, inferis; Glumis tantum calycinis.

Cal. I-glumis: glumis paleaceis, fafciculatis. Cor.0. 28. Schaea Senr. I, fubrotundurn, inter infimas glumas. nins. Cal. I- glumis: glumis paleaceis, diftiche imbricatis. 2y. CypoCor. o. Sem. I, nudum, triquetrum, vel fubrotun- rus. dum, planiufculum. 
30.Scitpus Cal. I - glumis: glumis paleaceis, vndique imbricatis. Cor. o. Sem. I, imberbe, triquetrum, villis caly. ce breuioribus inftructum.

31. Erio- Cal. 1-glumis : glumis paleaceis vndique imbricatis. phoram. Cor. o. Sem. 1, triquetrum, lans longifina cinctum.

\section{B. S P I C A T A.}

q) Floribus glumofos, inferis; Glumis tantum corvllaccis.

- 32, Nardus Cal. o. Cor. 2 - valuis: Valua exteriore lanceolata, carinata, ariftata; inferiore acuminata. Sem. 1. lanceolatum, corolla adnata tectum.

\section{I G Y I I A.}

I. Paniculata.

a) Gramina calycibus 2 - valuibus, vnifloris, vagis.

33. Phala- Cal. 2- glumis, aequalis, glumis carinatis, corollam ris. includentibus.

34. Alopen Cal. 2- glumis," aeqqualis, carinatus, lanceolatus. Cor. curus. 1- valuis, apice ririfa longa terminante.

35.Milium Cal. 2- glumis; glumis tubacqualibus, ventricofis. - Cor. 2 - valuis, ouata, breuiffima: valunla altera minore. Stigm. penicilliformia. Sem. vnicum fpletsdore praeditum:

36. Agro- Cal.2- glumis, aequalis: glumae lanceolatae acutae, fis. corolla longiores. Cor.2-valuis. Valuula exterior modo mutica, modo ariftata. Stigm. longitudinaliter hifpida. Sem. 1, glabrum.

37. Stipa. Cal. $=$ - glumis, acuminatus, vniflorus. Cor. 2 - valvis: Valunla exteriore arifta terminali longiffima, bafi articulata.

b) Gra- 
b) Gramina calycibns:2- valuibus, biforis, vagis.

Cal.2-glumis, aequalis, acutus. Cor. 2- valuis: 38. Aira. altera valuula faepe ad bafin ariftata. Flosculi 2 , rariffine rudimento tertii foris.

$C_{a l}, 2-$ glumis, aequalis, obtufus. Cor. 2-valuis, 39. Melica. mutica. Sem. I, ouatum, acutiufculum. Rudimentuni tertii floris inter flosculos.

$\mathrm{C} a l .2$ - glumis comprefius: Glunae lanceolatae, mu- 40. Dactycronatae: altera Giuma meiori ćarinata. Flosculi 2 lis. vel 3 , absque interiecto rudimento. Cor. 2 - valuis; aliero valuula apice ariftata.

c) Gramina calycibus triualuibus, anifloris,

$$
\text { vagis. }
$$

Cal. 3- glumis: duse maiores muticae aut ariftatae, 4 I Panicum tertia dorfalis, minima. Cor. 2- valuis. Valuula exteriore ouata, obtuliufcula conuesa; interiore plana et eodem gaudet figura. Sem. I, fubrotundum.
d) Gramitita calycibus biualuibus; Spiculis multifloris, vagis.

Cal. 2- glumis, muticus, ouatus, scuminatus, multi- 42. Poa. florus. Cor. 2-valuis: Valuulis acutiufculis margine feariofis. Spicilla ouato-oblonga.

Call-2- glumis, cordatus, concaus, obtufus. Cor. 43. Briza. 2 - valuis, murica, inaequalis. Spiculae cordatae, diffichae.

Cal. 2-- glumis, fubulaius, acrminatus. Cor. oblonga, 44. Feftuea valuulis mucronatis: altera faepe ariftata ex apice. Spicul. oblongae, teretiufculae.

Cal. 2- glumis, oblongus, acuminatus. Cor. 2 -valvis, inaequalis, maiore bifida, ariftsm infra apicem emittente. Spic.oblongae, multiflorse, tereres, difti. chae. Sem. 1 , onatum.

Cal, 2- glumis, lanceolatus, azutus. Cor. oblonga, 46. Auers. aitera, valuula dorfo vel bafi ariftata, arifts tortili in medio geniculato. Spiculae diffulae, multiforae. 
47.Arundo Cal. 2 - glumis, oblongus, acuminatus. Cor. bafi la. nuginofía. Sem. lana cinctum. Flosculi congefti, lana cinaii.

48. Cyno- Cal. 2-glumis, linearis, acuminatus. multiflorus. furis. Rec. commune vnilaterale, fpiculas obiongas colligens, multiforum.

49. Phleun Cal. 2 - ghumis. linearis, truncatus, apice bicufpidato, fefilis. Cor. 2 - valuis perianthio minor, mutica, inclufa. Sem. r.

\section{Spicata.}

e) Spica diftinEta, receptaculo fubulato, den-

50. Elymus $C_{6}$ l. 2- glumis, stgrgegatus, multiforus. Spiculae gुeminae.

51.Lolium. Cal. 2- glumis, linearis, fixus, rnchi oppofitus, multiforus. Cor. inaequalis. Spiculae diftichae, inuticae vel ariftatae-Sen. 1, oblongum

52. Secale. Cal. $2-$ glumis, biforus. Cor gluma ariftata.

53. Triti-Cal.2-glumis, ouatus, fubtriftorus, feffilis. Cor.2cunk. glumis, valuulis fubrequalibus. Flos obtufiufculus, acutus. Receptaculi bafis callola.

54. Hor- Cal. 6- phyllus, 3-florus. Flosculi laterales faepe dewn. mafculi.

\section{B. FLORE MONOCLINO.}

\section{Calamariae.}

55. Cařcx. o Amentum I- florum, fpicatum 'glumis. Cor. o.

\& Cal. et Cor. vt in mare. Strgm. 3: Sim. 1, triquetrum, intra nectarium. Nectar. inflatum, tricenta-

56. Spar. \& Amem. fubfphaericum. Cal. 3- phyllus. Cor. o.

ganizms. of Ament. Cal. Cor. maris. Stign. 2 - fidum. Drupa exficer, I-leu 2-fperma.

57. Typha, $\sigma^{\circ}$ Ament. cylindricnm. Cal. 3-phyllus, minimus, fetaceus. Cor. o.

+ Ament. 
o Ament. cylindricum infra mafculos. Cal. copillaris, pappofus. Cor. c. Styl. I. Sem. I, infidens pappo capillari.

\section{FLORE POLYGAMOIDE.}

$$
\text { ×. Calyce } \mathrm{I} \text { - floro. }
$$

万 Cal. biglumis, I- florus, oblongus, muticus feu 58. Anariftatus. Cor. bufi ariftata: arifta tortili, recusua dropogon. perfiftente. Stain. 3. Styl. 2. Senl. I.

o $C_{2} l .2$ - valuis, pedunculatus. Cor. mutica, fecunduim Linnaevis O. Stam. 3.

$$
\text { B. Calyce } \mathrm{I}-3 \text { floro. }
$$

Cal. Communis $2-$ glumis, $2-3-$ forus.

59. Holcus.

o Cor. biualuis, mutica. Stam. 3. Styl. 2. Scm. I.

o Cor. biualuis, altera valuata infra apicen arifa rigida. Stan, 3 .

\section{IV.}

\section{T E T R A N D R I A.}

MONOGYNIA.

\section{A. FLORE HERM APHRODITO.}

a) Flores I - petali, monojpermi, Juperi. Aggregatae.

Cal. communis polyphyllus; proprius duplex; exter. 6o. Scabio. nus membranaceus, internus 5 - partitus. Cor. 4 - fa. f. 5- fidre. Rec. paleaceum, eleuatum, ouatum. Seni. oblonga, coronata, inuoluta.

Cal. ecmmunis polyphyllus, foliofus; proprizs vix ma- 6I. Dipfanifeftus Cor. 4- fidae. Rec. conicum, paleaceun. cus. Sem. columnaria,

b) Flo- 
b) Flores 1- petali, nonocarpi, inferi.

6. Centun. Cal. 4- partitus, corolla longior. Cor. 4- fuda, roculiss. tata, patens. Filam, breuin. Capj. 2-locularis, circunfcifia, polyfperma.

6. Planta- Cal. 4- partitus, conolia breuior. Cor. 4- fida, rotago. ta, limbo refiexo. Filan. longifima. Capf. 2-locularis, polyfperma, ouata, transuerfaliter dehifens.
c) Flores $\mathrm{I}$ - petali, monocarpi, fuperi.

64. Sangai- Cal. 2- vel 3- phyllus, hypocarpius. Cor plana, 4forba. partita, epicarpia. Capf. $4-$ gona, bilocularis, polyfperma.
d) Flores - petali, fruftibus gèminis, comratis, fuperi. Stellatae.

65. Galium Cor rotate, plana, profunde \&- partita, tubo breuifimo. Recept. 3 dentatum. Fructus fubglobofi, glabri aut hifpidi.

66. Afperu. Cor. infundibuliformis, limbo obtufo; tabo longiore. la. Fruet. baccati, fubylobofi.

67. Sherar- Cor. tubulofa infundibuliformis, limbo acuto. Cal.6dia." dentatus, Frual. oblongi, coronati. Sem. 3- den. tata.

\section{e) Flores tetrapetali, Superi.}

68. Trapa. Cal. 4- partitus. Nectar. corone fimile - Nux arma. ta pinis 4 validis conicis, oppofitis.

69. Comus. Cal. minimus, 4- dentatus, deciduus. Cor: 4-petala, regularis. Pet. oblongo-lanceolata, cruciatim pofita. Drap. nucieo 2 - loculari.

\section{f) Flores apetali, inferi.}

7o. Alche- Cal. femi - 8 - fidus, cuius 4 laciniae maiores, ouatomilla. acuminatae. Cor. O. Styl. bafi germinis inferitur. Sem. I, cotdatum ${ }_{2}$ calyce inclitium. 
Cel. I- phyllus, 8- fidus. Cor. O. Styl. I bafi germi- - i. Apha. nis inferitur. Sem. vnicum nudum calyce inclufum. nes.

\section{I G Y N I A.}

Cal. 5- gonus, 4-5- fidus. Cor. I - petala, ouata, 72. Cufcure $4-5$ - fida regularis. Petala ouata, acuta. Stigm. fimplicia. Capf. 2- locularis, $2-3-4-$ fperma, et carnola.

\section{T E T R A G Y N I A.}

Cal. o. Cor. Pet. 4, fubrotundà, integra. Anth. fere fel- 73. Potafiles. Stigmata obtufa. Styl.o. Sem. 4, nuda, angula- :inogeton. ta, mucronata.

Cal. 4- phyllus. Cor. 4- petala. Perala calyce mi- ?. Sagina. nora, onata, obtufa, integra. Capf: 4- locularis, 2 - valuis, bis - vel polyfperma.

\section{B. FLORE MONOCLINO.}

8 Cal. 4-phyllus. Cor O. NeEtar. centrale, vrceola-75. Vrtica. tum.

우 Cal. 4-phyllus; foliol. 2, oppofitis, exiguis. Cor. 0. Stign. villofum. Sem. 1 , ouatum, nitidum.

O Ament. cylindraceum, fquamis 3-fidis, 3-fioris. 76. Betula. Cor. 3-vel 4- partitae, patentes, 4- ftemones.

\% Ament. imbricatum. Squamis fubtrifidis, 2- floris. Cor. 0. Styl. 2. Sem. 2, 3, vtrinque membrana alata.

\section{FLORE DICLINO.}

$\delta$ Cal. 4-partitus. Cor. O. Filamenta ó. Antherae ca- 77.Vicums. lyci adnatae.

\$ Cal. 4- phyllus, fuperus. Cor. o. Styl. o. Stigm. obnfum. Bacc. I - tperma. Sesin compreffa, cordata.

78. Cal. 2 - partitus. Cor. O.
o. Cal. 2 - fidus, deciduus. Cor. O. Biftill. I. Bacc. 1.. phas. fperma: arillo truncato. 


\section{FLORE POLYGAMOIDE.}

79. Paric of Cal. 4-phyllus 4-fidus. Cor. 0. Stam, 4. Styl. I. taria. Sen. i luperum ouatun.

of Cal. Cor, Styj. Senis. vt in hermaphrodito.

$$
\begin{aligned}
& \text { PENTA N D R I A. } \\
& \text { MONOGYNIA. }
\end{aligned}
$$

\section{A. FLORE HERMAPHRODITO.}

a) Flores $x-$ petali, infori. Germinibus 4- ternis, nudis. Afperifoliae.

80. Echizun Cal. 5- partitus. Cor. campánulata, irregularis', fauce nuda : laciniis fuperioribus longioribus. Sem. 4 nuda, feabra.

81. Pulmo- Cal.5- dentatus, prismatico-quinquangularis. Cor.innaria. fundibuliformis, fauce nuda. Sent, 4, nuda, fubrotunda, fplendentia.

82. Livia- Cal. profunde $5-$ partitus. Cor. infundibul. 5 - fidus. forcranm. Laciniis ouatis, obtufis, aequalibus, fance plicats, perforata, nuda. Sem. 4, nuda, dura, golabra, aut fcabra.

83. Sym-Cal. 5- partitus. Cor. limbo tubulolo-ventricolo: faupizytum. ce claufa radiis lubulatis, conniuentibus. Sem. 4 , acuta, conniuentia.

84.Borago. Cal. 5- partitus. Cor. rotata: fauce claufa radiis obtufis emarginatis. Sem. rugola.

85. Lycop. Cal. 5- partitus laciniis lanceolatis. Cor. infundibul. fis. tubo curasto, fauce claufa 1quamis 5 conuexis. Sen. 4 .

86. Afprrb-Sal. 5- fidus, fruztiferus, cempreflus; lamellis finuago. tis, plano-parallelis. Cor. infundibul, tubo erecto, fauce claufa, fquamis 5 , conuexis. 
Cal. 5- partitus. Cor. infundibul. fauce claufa fquanu- 87 . Cynolis 5 conuexis. Capl 4 depreffee, interiori latere fty- glofjum. lo affixae, 1 - ipermae. Sem. G. aculeata.

Cal. 5- fidus. Cor. infundibul. tubo bafi prismatico; 83. Arichufauce claufa fquamulis 5 conuexis, oblongis. Sem. J.. 4 oblonga obtufa.

Cal. ádbalin profundo 5 - fidus. Cor hypocraterifor- 89. Myojomis, 5- fiảa;' emarginata: fauce claufa 5 fquamulis 'tis. coloratis. Scm. \& ouata, acuminata, giabra aut pilofa,

b) Flores I- petali, infcri. Germinizus cap. fuliferis.

Cor. regularis rotata. Filam. inferne hirfuta, baficon. 9o. Ana. nata. Stigm. capillatum. Capj. golobofa 1 - locula. gallis. ris, polylpermis, circumfeifa.

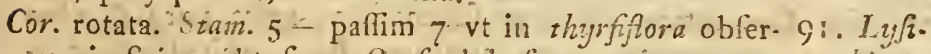
vaui. Stigni obtufum. Capf. globofa, mucronata, I-- machia. locularis, to valuis.

Cal. 5 - gonus fubcampanulatus, ore 5 - dentato. Cor. 92 Pirmon. - hypocrateriformis, tubo cylindrico, fauce peruia; la. ore patulo. Stign. globofum. Capf. 1 - locularis, apice dehifcens polyfernia.

Cal. 5- gonus. Cor. hypocraterif. fauce coaretata, 93. Andro. glandulofa : laciniis integris. - stzgm. globofum. taps. face. I - locularis, globofa, polyfperma.

Cal. profunde 5- partitus. Cor. hypocrateriformis. Fi- 94. Hotto. lam. laciniis corollae oppofita, tubo corollae inpofi. nia. ta, Stigm. globofum. Canj. I - locularis, orbicularis, polyfperma.

Cal. profunde 5- fidus. Cor. I - petala infundibulif., 95. Menyinterne pilofa. Stign. 2- fidum. Caps. 1 - locularis anthes. polyfperma.

Cor. campanulata, 5- plicata; limbo integro vel paulum crenulato. Stigm. 2. Caps. 2 - et pleruinque $3-96$. Eomuol.
locularis. Sem. 4 , angulofa.

Cal. tubulofus pentagonus, deciduus. Cor, infundibulif. 97. Datura pentagona, limbo plicato acuminato. Stigm. bilamel. latum. apf. 2-locularis, 4- valuis, polyfperma. plus minusue fpinofa.

Cal. 


\section{CLASSES GENEXVM.}

98. Hyo. Cal. I - phyilus s - fidus, perfitens Cor. infundibufcyamus. lif. I - petalo, inaequalis. Stom. inclinata. Szigm. capitatum. Capj. 2- locularis, operculata.

99: Nico- Cor infundib. limbo plicato. Stame ad latus corollae fle., tiana. xa. Stigm. cmarginatum. Capl. 2 - locularis, spice dehifcens.

100. Ver. Cor: rotata, inaegualiter 5 - fida. Stam. inclinsta fae-3 bafcum. " pius plumofa. Stigan.. obtufum. Cap. 2-locularis, 2- valuis, polylperma.

20I.Vinca. Cor. hypocraterif. lacinis 5 extrorfumlatioribus. Stigm. duplex, vnum alteri fuperimpofitum. Folliculi 2, erecti. Sem. plura, oblonga, fulcat:, remota, nuda. Nectar- fubrotunda, carnol Germinis longitudine.

c) Flores I- peiali, inferi. Germinibus bacciferis.

102. Sols Cor. rotata. Antherae fubcoalitae, apice poro gemino num. perforatae. Stigm. obtulum. Bacc. orbiculares, 2loculares, polyfpermae.

103. Atro-6or.5- fida, regularis campanulata. Stam. extrorfum pa. arcunta et filementa verfus apicem cum antheris nutantur. Stigm. diftans, incuruatum. Bacc. globofa, 2- locularis, polylperma.

d) Flores I - petali, fuperi. Germinibus cap. fuiliferis.

104. Samo-Cal. 5- fidus: laciniis latiufculis acutis. Cor. rotata: lus. laciniis 5, fubrotundis, obtufis, aequalibus; tubo breui; fauce fquamulis, 5 , hreuiffimis, fetaceis. As. therae 5 : filamentis breuibus. Stigm. copitatum. Caps. globofa, I-locularis, 5 -valuis, polyfperma.

105. Phy-Cor. corniculata, ad bafin fere 5 - pertite. Stigm. 3 teuma. fidum. Câf. 3-locularis, polylperma. 106. Cam- Cor. campanulata, fundo corollae valuulis 5 Ataminifepanula. ris. Stigm. 3 - partitum. Cap $\int_{3}-\int_{.} 5$ - locularis, poris lateralibus dehifcena. 
e) Flores 1 - petali, fuperi. Germinibus bac-
ciferis.

Cal. 5- dentatus, minimus. Cor. I- petala, inaequa- 107. Lo. lis, bilabiata: latiun inferits fimplex, obtufum; nicera. fuperius in lacinias + obtufas' diuiditur. Stigns. capitatum. Bacc. 2- locularis, polyfperma, fubrotunda.

f) Flores 5- petali, inferi. Germin. bacciferis.

Cal.o. Cor. campanulata, tubulofa, externe rudis, in. 108. Rham. terne colorata, 4-5- fida. Squamae oris conni- nus. ventes Stamina munientis. Stigm, diulum. Bacc.fubrotunda, 1 - locularis, 3-4-vel polyfperma. Flores hermaphroditi, aut dioici.

Cal. 4-vel 5- partitus. Cor. 5- plerumque 4- rog. Euopetala, patens. Stan. faepius 4, paffim 5. Bacc. cap- mymus. fularis, 5- gona, 5-locularis, colorata. Semb.arillata.

Cal. 5-dentatus. Cor. Petala apice cohaerentia, faepe rlo. Vitis. emarcid3. Bacc. 5- fperma. Senn. femibilocularia.

g) Flores 5--petali, fupcri. Germ. bacciferis.

Cal. 5-fidus, ventricofus: laciniis fubrotundis, obtu- III. Ribes. fis, apice refiexis, coloratis. Pctala et Staiit. calyci inferta. Stylus bifidus. Bacc. I-locularis, polyfperma.

Cal. Inuolucr. vmbella minima. Cor, Petalis 5 - vel 6, y I2. Hede. oblongis, crafis, coriaceis. Stigm. fimplex. Bacc.calyce cineta, globofa, 3-vel 5- fperma.

sa.

h) Flores apetali, inferi.

Cal. I- phyllus, 5 - partitus: laciniis ouato-obtufis, Ir3.Glaus reuolutis. Cor. o. Capf. fubrotunda. - locularis, 5-1.6-valuis, .5- fperma.

\section{i) Flores apetali, fuperi.}

Cal. I- plyyllus, naminifer. Cor. O. Nectaria fliformia 114. The calyci inferta, erecta. Sem. I, intra calycem, fubro. Sium, tnndum, coropatum.

DIGY: 


\section{I G Y N I A.}

a) Flores I- pezali, inferi.

II5. Afcle-Cor. rotata, regularis, 5- fida, reflexa. Nectariis pias. $\quad 5$, ouatis, concauis, corniculum exferentibus. $F i$ lamcnta breuifima, corpuf́culo-conico-obtufo cealefcentia. Folliculiz, oblongi. Sem. pappofa, receptaculo membrana affixa.

116. Gen-Cor. 1 - petala, inferne tubulola, 4-5- fida, varie tiana. figurata. Styl. o. Stign ouata. Capf. 1-locularis, 2 - valuis, polyfperma. Receptricula 2, longitudinalia.

b) Flores apetali.

117. Che Cal. 5 - phyllus, 5 gonus, foliolis concauis. Cor. 0. nopodium. Styjl.2- partitus. Sem. 1, lenticulare, intra calycem.

I18. Besa. Cal. 5- plyyllus. Cor. O. Sen. I, reniforme, intra fubftantiam bafeos calycis.

119. Her- Cal. I - phyllus 5- partitus; laciniis aequalibus, niaria. ouatis, a'cutis. Stam. 10; 5 fterilia. CapJ. 1 - iperma. Sesn. tectum, ouatum, glaberimum.

120. Vilmus Cal. I - phyllus 5- fidus, comprefius, coloratus. Cor. o. Filamenta 4 vel 5 , vitra forein. Stigm. villofa. Caps. comprefra, rotunda, 1 - fperma, alata.

c) Flores vmbelliferi; 5- petali, Superi, difpermi.

๙. Vmbellis fimplicibus. 'Habitu imperfecto deliquefcente.

321. Eryn-Inuolucr. rniucrale polyphyllum longum; partiale pagutm. leaceum. Flores capitati. Sem, 2, perianthio coronata. Receptaculum commune conicum."

122. Hy- Vmbella parua prolifera. Inuolucro 4-phyllo. Petala drocozyle. 5, integra, ouata, acuminata, Styl. 2. Sem.2, orbicu. lato - comprefia, glabra. 
ß. Vmbellis compofitis. Habitu perfecto.

A. Fructu tecto plicis, fetis aut lanugine.

$V m b$. conferta, fubcapitata. Inuolucr. vnizuerfale 3-123. Saniphyllum aut polyphyllum; partiale polyphyllum: cula. foliolis fubulatis. Petala aequalia, obtufa, inflexa, bifida. Flores fubumbellati difci abortantes. Sern. muricata.

Inuolucr. polyphylla longitudine fere radiorum. Petala 124. Atha. inflexo-cordata, fere aequalia, emarginata. Sem. 'outo - oblenga, introrfum conuexa, ftriata, lanugimanta. nofa.'

Inuolucr. polyphylla, pinnatifida. Vmbell. fruetifera, I25. Dauaetate concaua euadit. Flor. radiati, irregulares, fer- cus. tiles.' Sent. fubouata, 4- gona, pilis hilpida aut nuda.

Inuolucr. integra. Petala inflexo emarginata. FruEtus 126. Caufetis vndique hifpidis. Flores Mares et Hermaphro- calis. diti.

B. Fruciu audo, Julcato, coftato, aut ftriato.

Inuolucr. vniuer. $\mathrm{I}-$ phyllum, rarius 0 ; partiale con- $127.0^{\circ}$ ftanter polyphyllum. Flor. radiati, difco ferili. Peta- nanthe. $l a$ inaequalia bifida. Semb. fubouara, perianthio fulcata et pillillis coronata.

Inuolucr. vnituerfal. vel o, vel polyphyllum; partiale fim-128. Pell plex, breuiffimum. Petala aequalia integra. Flor, cedanum. flosculofi; difco nunquain abortiuo. Sem. ouata, vtrinque in medio Atriata, margine alata.

Inuolucr. partial. dimidiata fubtriphylla, Flor. fubuni-129.' Coformes, fertiles. Pet. cordata, emarginata. Sem.fub- nium. globoła, gibba, 5- ftriata, fecundum longitudinem latitudinemque crenulata.

Inuolucr. polýphyll. Flor. flosculofi, hermaphroditi. I 30 . BuPet. inuoluta. Sem. fubrotundo, compreffa, ftriata. pleurum. Inuolucr, vtraque polyphylla; vniuerfale reflexum. Flor. I31. Sium. vniformes, hermaphroditi. Pet. cordata, leuiter incifa. Sem. fubouata, ftriata (absque alis et coftis). 


\section{-C. Frictu alato: ala marginali.}

132. Hera- Inuolucr. partiale polyphyllum caducum. Flor radinti; cleum. difco nunquam abortante. Petalis difformibus infeso emarginetis. Sem. eliiptica, marginata, compreffa, leuiter in dorfo friata.

133. Tor Innoliser. fimplicia, longa. Flor radiati, fertiles. Senn. diglium. orbiculata, crafli, ala marginali crenata.

13.5. Soli- Inuolucr. vnitserale polyphyllum, refiexum; partiale num. polphyll. patens. Petala cordata, aequalia, emarginata. Flor. uniformes, fertiles. Sem. fubouata, compreffa, in medio 3-5 friis eleuata, margine alsta.

135. Lafer-Inuolucr. vtraque polyphylla, parua. Petala inflexnpisıum. cordata emarginata. Flor. flolculofi, fertiles. Sem. oblonga, dorfo-conuexa, alis menuranaceis alata.

I36. Angc-Vmbella vniuerf. multiples rotunda; partial. globola. lica. Inuolucr. vaiuer. $2-5-$ phyllum, paruum; partiale 8- vel polyphylium. Flor. Alosculofi, fertiles. Corollac aequales: petalis incuruis apice emarginatis. Sem. ouata, angulata, marginata, in dorfolulcis 3 longitudinalibus exafperata, alata.

\section{भ. Inuolucris partialilus: nullo vniuerfali.}

137. Cori-Inuolucrum vniuerfale vix I - pliylium, plerumque o; andrum. partiale 3-phyllum, dimidiatum, lineare. Vmbella vniuerfal. radiis paucis: partal. pluribus. Flosculi difci abortiui, Jtyli diftantes. Stign radii capitata. Sem. 'fubglobofa, laeuia absque ftriis et fulcis.

r38. Acthu-Inuolucell dimidinta, 3-vel 4- phylla, pendula. Flor. 'fa. flosculofi, fertiles. Sem. orbicularia, 4 fulcis diftinctis exarata, inde Fructus 8- gonus.

132. Scan-Innoluc. partiale 5-plyyllum Flor. radiati; difco faedix. pe mafculo. Cor. Petala cordata, inaequalia integra aut marginata. Styli erecti. Scm. elongata, glabra, friata, roftrata.

140. Chae-Inwolucell. 5-10- phylla et plura, reflexa, concaua. rophyllum. Flor. flosculof, difco faepe abortiuo. Pet. inflexa, cordata. Styli reflexi. Scm. oblonga, fuperne atte'nuata, extrorfum concaua, leuiter ftriata, nitentia. 
Inuolucr. aniuergle o; partiale polyphyllum, foliol. scu- I + r. Pheltis. Flor. flosculoli, fertiles. Petal. acuminata corda-landrium. to-inflexa. Styli recurui, perfiftentes. Sicm. ouata Jaeuiter $10-$ firiata, carinata perianthio et piftilis.

Vmbellae globofae. Inuolucell. polyphylla, linearia. I +2. Sefili. Flor. flosculof, fertiles. Sem. ousta, extrorfum concaua, frista.

$V$ mbell. vniuerfalis et partialis radiis pluribus, fubro- 143 Cicuta tundis. Insolizc partialia polyphylla, fetofa. Pctala ouata infexa. Sem. fubouata, ventricofa, friata.

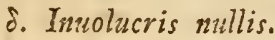

Flor. flosculofi, fertiles. Cor. Petal. integra lanceolata, $14, p_{0}$ pltiapice inuoluta. Sem. elliptica, compreffo-plana, mai- naca. gine circts.

Flor floscul. fertiles. Cor petala lanceolata, apice in-145. Aneflexa. Senz. fubounta, comprefla, marginata, friata. thum. Cor. petal. carinata, inflexo-emarginata. Flor. flosculo- r ifo Caram fi, fertilcs. Sem. ouato-oblonga, gibba, fulcata.

Vnbel. vniwerf. radiis pluribus; partial. adhuc pluribus. 147. $P$ inbFlor. fubradisti, fertiles. Cor. petala inflexa, emargi- pinslla. nata. Siyli erecti. Stigm. fubglobofa. Sem. ouato-oblongra, 5 ftriis eleuats.

Vmbell. vniner risdiis paucioribus; pert.pluribus. Flor. 148 Apium flosculofi, fertiles. Cor. petal. aequalia, inflexo-inci-

fa. Sem. minuta, ouata, friata.

$V$ inbell. uniuerf. conuexa; partial. plana. Flor fiosculofi, 149. Aegofertiles. Cor. petala aequalia, femibifida in apicem podium. vacatum abeuntia, cordata. Styl. corollulae longitudine. Sem. ouato-oblonga, gibba, Ariata.

\section{T R I G Y N I A.}

a) Flores Juperi.

Cal. 5 - partitus, minimus. Cor. -rotata, 5- fida. I50. Vi. Stigm. obtula. Bacc. I- foerma. Eurnum!. 
15I. Sanl Cal. 5- partitus breuifimus, Cor. rotata, concaus, bucis. 5- fida. Styl. o. Stigm. obtufa. Bacc, 2- vel 3fperma plerumque.

b) Flores inferi.

152. Rhus. Cal. 5- partitus. Cor. 5-petala. Styl. O. Bacc. Ifperma.

153. Sta- Cal. 5- partitus. Cor. 5- petala. Cap $\int_{3} 3$ - locularis, pliylea. $\quad 3-$ gona, I- fperma, inflata. Scm. bina, offea, glo154.Alfine. Cal. 5 - phyllus. Cor. petalis 5 aequalibus, Styl. o. Caps. $\mathrm{x}$ - locularis, 3 - aut 6 - valuis, poly. fperma.

\section{TE T R A G Y N I A.}

155. Par. Cal. 5-partitus: laciniis oblongis acutis, Cor. pet. 5 rafjia. aequalibus, fubrotundis, concauis, ftriatis. Filam. 5, breuia. Styli fere nulli, Neclar. 5, cordata, ciliata, glandulofa; glandulis pedicellatis. Cap.. 4- gona, 4-valuis, 1-locularis.

\section{P E N T A G Y N I A. \\ a) Flores aggregati inferi.}

156 Statice Cal. communis imbricatus; proprius I- phyllus. integer, plicatus, raritrme infundibuliformis. Cor. 5petala, vnguibus ftaminiferis. Sem. I, nudurn, ouatum, nitens, intra perianthium perfiftens.

B) Calyce 3-phyllo. Flores inferi.

157.Linum Cal. 5- phyllus, paraus, acutus. Cor. 5- petala, infundibuliformis. Cap. globofa, 5- valuis, 8-vel 10-locularis. Sem. folitaria, ouata, fplendentia, 


\section{P O L Y G Y N I A.}

* Floribus fimplicibus, 5-pctalis.

Cal. I - phyllus, 5- fidus. Cor. pet. 5, fubrotundis, 158 . Dro. obtufis, integerrimis. Caps. I- locularis, apice 5 - Jera. valuis, polyiperma.

$$
\text { ** Calyce 5-piryllo. }
$$

Cor. 5- phyllus, fupra bafin adnatus. Nestar. 5 ligu- 159. Myyo. lata, petaliformia. Recept. longiffimum. Styl, breuil- furus. fimi aut nulli. Scm. numerofa, oblonga.

\section{B. FLORE MONOCLINO.}

$\sigma^{\top}$ Cal. $3-\int_{.5}$ - phyllus, coloratus. Cor. 0. Stam. 160.Ama$3-$ f. 5 . ranthus.

of Cal. et Cor. vt in mare. Styl. 3. Cap.. I - locularis' 1- fperma, 3- roftris, horizontaliter dehifcens.

\section{FLORE DICLINO.}

\section{a) Digynia.}

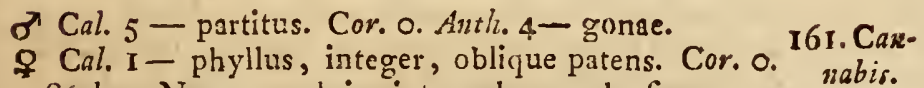
Sfyl. 2. Nux 2- valuis, intra calycem claufum.

$0^{T}$ Cal. 5- phyllus. Cor. O. Filantenta breuifrima. I62 Humu-

+ Cal. 4- phyllus. Cor. O. Styl. 2. Sem. I, intra caly ${ }^{162 ~ l u s . ~}$ cem foliofum, fubrotundum.

\section{B. Tetragynia.}

ò Cal. I- phyllus, 5- partitus. Cor. o.
o Cal. 4 - fidus, inaequalis, perfiftens; Cor, o. Styl. ${ }^{6} 3$. Spi-
nacia. 4. Semb. I, intra calycem induratum, 
YOA * CLASSES GENERVM.

D. FLORE POLYGAMOIDE.

164. Atrit o Cal. 5- phyllus, 5-gonus, perfiftens. Cor. ó. glex. Stam. 5. Styl. 2 - partiti. Sem. I, orbiculatum, depreffum, intra calycem.

2 Cal, 2- phyllus.. Cor. Styl. Sem. hermaphroditi.

\section{I.}

\section{H E X A N D R I A.}

MONOGYNIA.

\section{A. FLORE HERMAPHRODITO.}

a) Flores calyculati, calyce corollaque initruati,
bacciferi.

165. Eerbe- Cal. 6- phyllus, inferus. Cor. Petal. 6, regularia ad bsris. fin glandulis 2 neetariferis notata, fubrotunda, obtufa, integra. Stigu. capitatim. Bacca oblong̀a, 2fperma.

b) Flores fpathacci. Calyce mullo.

16C. Leu- Cor. fuperá, campaniformis, 6- partita, apicibus incoium. ciaftata. Stano aegualia. Stigmi. iimplex.

167 Galan-Car. funera 6- petala; petalis 3 exterioribus oblongis, thus. concauis, interioribus 3 minoribus, emarginatis. Stigrit. fimplex.

168. Nar. Spatiza propria. Cor. fupera, 6 - petaia, adhaerens.' cifjus. NeCtar.infundibuliforni-campanulatum, I - phyl- lum, epicarpium. Stam, tubo neearii inlerta. Stign. fimplex.

160 Allin $\mathrm{Cal}$. proprius nullus. Spath. multifora. Cór. infera, campanulats, 6- petala. Capj.3-gona, 3- loculatis, fupera. Seim. fubrotunda. Petalis ouato-lanceolatis feriflibus. Vubella congefta. Stam. modo finpliciter 
pliciter fubulata, modo alternation 3 - fida, aut in bulbos aut capfulas excrefcens.

Cor. 6 - partita, companulata, epicarpia. Stan. longa, 1 70 Hemedeclinata. Stigm. 3 - gonum.

rocallis.

c) Flores mec perianthio, nèc foatha inferucti, nudi' inferi.

Cor. infera, 6- vel modo 4- fida, mox campanulata, I 7 !. Conmox infundibuliformis vel rotata. Bacc. globola, 3- valiaria. locularis, 3-vel polyfperma. Sem. folitaria.

Cor.infera, 6- petala, oblonga, obtufa, patens. Stign. I $i=$. A:?3 - gonum. . Filamenta glabra aut hirfuta. Caps. thericum. ouata, trifulca, 3-locularis, poiyfperma.

Cor. infera, 6- petala, fellaeformis, bafi erecta, fupra 173. Omi. medium patens. Filam. totidem fubulata aut emar- thogalmu. ginata, alterna bali dilatata. Stign. obtufum. Cay. angulofa, 3 - locularis, 3 - valuis. Sem. fubrotuilda.

Cor. infera, 6 - petals, patens, decidua. Filam. filarefe- I $7 \%$ Scilla. rentia. Stigm. fimplex.

Cor. I - petala, 6 - partita, campaniformis, erecta. 175. A/paStam. filiforma petalis inferta. Styl. "breuilimus. ragns Stigm. punfum prominens. Bacc. globofa, 3-locularis $6-$ fperma.

Cor. infera, 6- petala, campanulata. Nectarinn fouea I 7ó Tritittupra vngues cuiuslibet petali. Stignn. 3- plex. ' laria.

Cal. o. Cor. 6- petala campanulata. Petalis erectis, I faepe reflexis, baficanaliculato - tubulofis, barbatis aut nudis. Stigm.3-gonum. Cap. 3- locularis, 6 ful. cis exarata. Sem. plurima, plana.

Cos. infera, 6- petala, campannlata, decidua. Styl. o. 178Tulipa Stigm. 3- lobum.

d) Flores in Jpadicem fimplicem, nudum, congefti.

Cal. o. Spad. ex margine folii cylindricus, fiosculis te- I gofeorus ctus. Cor. 6- petala. Pctal. obtula rhomboideaintus caua. Styl. o. Stign. punetam prominens. Capl: 3 - locularis, 3 - fperma. 


\section{e) Flores apetali.}

J80. Iuncus Cal.5 - phyllus, perfiftens: foliolis lanceolatis. Cor. . Stigm. 3 , villofa, inflexa. Capf. ouata I - locularis, 3 - valuis, triquetra, 3- aut polylperma.

181. Peplis Cal. campanulatus, ore i2-fido. Cor. O. Styl. I, breuis. Stigm. capitatum. Canf. fubrotunda, 2 - locularis, polyfperma.

\section{T R I G Y N I A.}

182. Col- Cal. fpathacea, tubo longiffino. Cor. I- petala, reguchicum. laris, tubo radicato, 6-partita. Stigm. canaliculata, Caps. ouata, inflata, 3- locularis, polyfperma.

183. Tri- Cal. 3- phyllus. Petal. 3, calyciformia. Styl. o. Stigm. glochin. $\quad 3$ : 6 . Capj. 3- aut 6 - locularis, bafi dehifcens. Sem. I in quolibet loculamento.

184. Ru- Cal. 3-phyllus. Cor. 3- petala: petalis conniuenmex. tibus. Styl. 3 germini infidentes. Sem. I triquetrum. Flores hermaphroditi aut diclini.

185. Cal. 6- phyllus foliolis lanceolatis apice flaccidis, obScheuchze rufis. Cor. o. Capj. 3-6fubrotundae, inflatae, I ria. fpermae, apice dehilcentes.

\section{P O L Y G Y N I A.}

186 Alisana Cal. 3 - phyllus perfiftens. Cor. 3 -- petala: petalis fubrotundis, obtufis, patentifimis. Capf. 6, vel plurimae, polyfpermae.

\section{B. FLORE STYLOSTEMO- NOIDE.}

187. Ari-Cal. o. Cor. I- petala, bafi ventricofa, tubo cylindrafolochia. ceo, 6- gono, limbo lingulato, inteorro. Styl.'o. Pift. 6- gynum. Capf. 6- locularis, infera, palyfperma. Sem. angulofa, compreffa. 


\section{VII.}

\section{H E P T A N D R I A.}

MONOGYNIA.

Cal. 7- phyllus. Cor. rotata 7 - partita, aequalis, I88. Trien. ftellata. Stign. capitatum. Bacca I-locularis, ficca, talis. dehifcens, ftylo perfiftente.

Cal. 1- phyllus, 5- dentatus, ventricofus. Cor. 4- I8\%. Ac/cuvel 5- petala, inaequalis, calyci inferta. Cape. 3- lus. locularis, 2 - Sperma.

\section{VIII.}

\section{O C T A N D R I A.}

MONOGYNIA.

\section{A. FLORE HERMAPHRODITO.}

a) Flores completi, fuperi.

Cor. 5 - petala, inaequalis. Cal. 5 - fidus, inferus, 19c. Tro. calcaratus. Cap. 3-locularis, I- Sperma.

paeolum. Cal. 5- fidus. Cor. 5- petala. Styl. 2- fidus. Caps. rgr. Acer. I-2-1.3- Ppermae, alatee.

Col. 4- fidus, fuperus: laciniis erectis corollatis. Cor. 192. Epi4-petala. Stanina cum ftylo erecta aut declinata. lobium. Capf. oblongs, linearis, 4-locularis, 4-valuis, polyfperma. Seni. pappofa.

Cal. 4- phyllus: foliolis lanceolatis reflexis, tubulo- r93. Oenofus, deciduus. Cor. 4- petala. Cape. infera, 4-lo- thera. cularis, 4- valuis, polyfperma. Sem. angulata, nuda.

Cal. 4- phyllus, fuperus, breuifimus, truncatus. Cor. 194.Vacri$x$ - petala, fubrotunda, vrceolata 5 - fida. Filam. niutis.

8-10, receptaculo inferta. Antherae bicornes. Bacca globofa, vmbilicata, quadrilocularis, polyfperma,

Cal. 
I95. Schol-Cal.4- fidus, fuperus, breuifimus. Cor. 4- petals, lera. regularis: laciniis reflexis. Filamenta 8 , purpurafeentia, conniuentia. Antherae flauae, 2- partitae, tubulorae. Stylus cum Stignate obtufus. Bacca polyfperma,

196. Erica. Cal. 4- phyllus, coloratus. Cor. I- petala, 4- fida, bafi ventricofa. Filamenta capillaria, receptaculo inferta. Anth. bihdae conniuentes. Stign. capitatuin, - , 4- gonum, 4- fidum. Capf. Lubrotunda, $4-10$ crilaris, polyfperma.

b) Flores incompleti, inferi.

$-$

197. Dawk-Cor. I- petala, 4- fida, regularis, infundibuliformis, ne. limbo aequali Cal. o. Stam. breuifima, inclufa. Bacca I-locularis, I-Iperma, cannofa aut ficca.

\section{T RI G Y I A.}

198. Poly- Cal. 5- partitus, coloratus, corollinus. Cor.o. Stamigonmi. num numerus variabilis. Sem." 1 , triquetrum, nudum,

\section{TE T.R A G Y I A. -}

199.Adoxa Cal. 2 - fidus, inferus, planus; foliolis ouatis obtufiusculis. Cor. 1 - petala, 4- aut 5-fida, laciniis ouatis, acutis, fuperis. Staminnm et Stylorum numerus variat. Bacc. globulof, , $-5-$ locularis inter calycem et corollam. Sem. folitaria.

2co. Paris. Cal. 4 - phyllus. Cor. 4 - petala, perfiftens, petalis fubulatis fere fetaceis. Bacc. 4- gona, 4- locularis, polyâperma.

$201^{\prime}$ Elati-Cal. $4-5-$ phyllus. Cor. 4 - petala, fubulata. Cap). ne. 4- loçularis, 4- valuis, depreffa.

\section{B. FLORE DICLINO.}

202. Popu- $\sigma$ Amentum commune cylindricum, laxe inbricatum hiss. fquainis vniforis, planis, margine laceris. Cor. o. Nct. turbinatum, tubulatum, obliquum, integrum. Stank. 8-16, breuiffima,

S:Ament. 
ㅇ Ament. Cal. et Cor. maris., Styl.o. Stign. 4-fidum. Copf. ouata 2 - locularis, 2 - valuis, polyfperma. Sem. multa, pappofa.

\section{IX. \\ E N N E A N D R J A. -}

HEXAGYNIA.

\section{A. FLORE HERMAPHRODITO.}

Cal. o. Inuol. 3- phyllum vmbellatum. Cor.6-peta- 203. Buto. la: alternis maioribus. Carff. 6. polyfpermae.

mins.

\section{B. FLORE DICLINO.}

of Cal. 3- phyllus. Cor. 0. Stam. 5-9, I0-15. An 204. Mer. therae didymas, globofae. curialis.

of Gal. et Cor. maris. $\mathrm{Ne}$ ¿l. 2. fubulata. Styl. 2, reflexi, hirfuti. Caps. fubrotunda, didyma, 2-locularis, I - sperma.

o Spatha $2-$ phylla, tritora. Cal. 3 - fidus. Cor. 205. Hy. 3 - petala. Stan. 9-12. Filamentis 3 interioribus drocharis. ftyliformibus.

\% Cal. et Cor. vt in mare. Styl. 6. Capy. 6- locularis coriacea, polylperma, infra receptaculum. Sem. mi. nutiflima. 


\section{$\mathrm{X}$. \\ D E C A N D R I A.}

MONOGY NIA.

\section{A. ELORE HERMAPHRODITO.}

a) Floribus 5-petalis: Fruetu $\mathbf{I}-$ capfulari.

a) Calyce I - phyllo.

206. Ruta. Cal. 5- partitus. Cor. petala eoncaua. Germ. punctis 10 melliferis cincum. Cap\% 5- fida, 5- locularis, polyfiperma.

$20-$ Pyrola Cal. 5- partitus, perfiftens. Cor.5-pctala. Filamenta recta aut incurtuata. Antheris bicornibus. Stylus rectus aut incuruatus. Capf. 5- locularis, angulis dehilcens, polyfperma.

208 Ledum Căl. 5- fảus, minimus. Cor.5-partita, plana. CápS. 5- locularis, polyfiperma, bafi dehifcens.

Floribus 5 - petalis: Frultu multicapfulari.

в) Calyce 5-phyllo.

209.Mono- Cal. corollinus, 10-phyllus; foliolis ereetis, bafi extropa. cauatis, melliferis. Cor. O. Cap?, ouata 5-locularis, 5- valuis, polyfperma. Semina minima, fetacea, inftar farinae lerratilis.

210. Di- Cal. 5- phyllus, tubulofus, bafi nudus. Cor. 5- peEłammus. tala: Petalis inaequalibus, vnguiculatis. Filam. declinata, glandulis ornata. Capf. $5, \mathrm{I}$ - loculares, 2values, oblongae. Sem. arillata.

\section{1 G Y N I A.}

a) Flores apetali.

2ir.Scle- Cal. I-phyllus, 5-fidus, periftens. Cor. O. Caps. rantibus. ouata, tenuifima, in fundo caly cis. Sem. 2, extrorfum, conuexa.

$\mathrm{C} a$ l. 
Cal. 5- fidus, coloratus, patens, laciniis ouatis. Cor. 212. Chryo. Stam. 8- f. 10. Caris. I-locularis, bicornis, po- Sofplenumm. lyfiperma.

b) Flores 5-petali, fracta unicapfulari.

Cal. 5- partitus, laciniis oblongis. Cor. 5- petala. 2I SaxiCaps. I- locularis, birofris, polyfiperma.

fraga

Cal. I - phyllus, 5- dentatus, campanulatus, ftria. 214. Gyp. tus. Pet. ouata, fere feffilia. Cerr. fubglobofa, I- Jophila. locularis, 4- valuis, polyfperma.

Cal. I - phyllus, 5 - fidus, tubulofus, bafi nudus. 215. SapoCor. Petala 5, bali denticulata, aut nuda, vnguibus longioribus. Capf. longitudine calycis cylindraceoventricofa, I- locularis, polyfperma.

Cal. 1 - phyllus, cylindricus, longus, in 5 -denticu- 216. Dianlos acutos diuirus, frietus, bafi + fquamulis cinctus. thus. Cor. Pet. 5 vnguiculata, obcordata, crenata. Caps. cylindrica, I- Incularis, polýperma.

\section{T R I G Y N I A.}

2) Flores 5- petali, fructu 3-capfulari, calycibus znozrophyllis.

Cal.5-dentatus, inflatus, campaniformis. Cor. Pet. 5, 217 . Cucubifida aut ferrata, vnguiculata, ad faucem nuda vel bahus. denticulata. Capos: 3 - locularis, acuminata, polyfperma, Sem. reniformia.

Cal. 5-dentatus, clauatus, plus minnsue ventricofus. 218. Silene. Cor. Petala 5 , faepe bifidn, varia vnguibus inftrueta, denticulis ad faucem coronata. Caps. cylindrica, 2locularis.
b) Flores 5-petali, fructu I-loculari, ca. lycibus 5-phyllis.

Cal. 5-phyllus, patens. Cor. 5 - petala. Petalis re- 219. Aregularibus, integris, obtufis. Nect. 0. Capf, ouata, I- naria locularis, polyfiperma. 
2=0.Stella-Cal. 5 - phylins, patens. Cor. Petala 5 , regularia, bi- ria. fida, bipartita, patentia. Stull.3. Cap.ouata, I-locularis, 6-valuis, polyfperma.

\section{P E N T A G Y N I A.}

a) Flores 5- peiali, fructu 3-capfulari, calycibus $\mathrm{I}$ - phyjllis.

221. Lych-Cal. I - phyll. 5 - dentatus, fubrotundus, inflatus. wis. Cor. 5 - petala, vngue longitudine calycis, limbo plano, fubbifido. Caps. fubouata, 5- locularis, polyfperma.

b) Fru\&u I - capfulari.

221. Agro-Cal. I- phyil. 5- dentatus, coriaceus. Cor. Petala 5, fíma. obuerfe ouata, obtufa, integra autemarginata, vnguilata. Capf. oblongo-ouata, I - iocularis, 5-valvis, polyfperma.

c) Fructu I - loculari, calycibus 5 - phyllis:

223. Suer Cal. 5- phyllus. Cor. Petala 5, regularia, obtufa, integila. gra. Capf. fubrotundo-ouata, 1-locularis, 5-val. vis, polyfperma.

224. Cera-Cal. 5 - phyllus, patens. Cor. Petala 5, 2 - partita,

frum. regularia, calyce-minora aut maiora. Caps. obtufa I- locularis, polyfperma, apice dehifcens.

d) Fructu 5-capfulari, calycibus $\mathbf{1}-$ phyllis.

225. Oxalis Cal. I - phyllus, 5- partitus. Cor. 5- petala, vnguibus cohaerens. Capf.5-cufpidata, 5 -gona, locularis. Sem. angulofa.

- e) Fructu multicapjulari, calycibus i-phyllis.

226.Secum Cal. I - phyllus profunde 5-partitus, acutus. Cor: Petala 5 lanceolata, aequalia. Nét. Squamà 5 ad ba. fin germinis. Cap. plerumque 5 , acuminat2e, introrlum dehifcentes, polylpermae. 


\title{
$\mathrm{XI}$.
}

\section{DODECANDRIA.}

\author{
MONOGY NIA.
}

Cal. 2 - phyllus, inferus. Cor. 5- petala. Petalis 227. Por obtufis bifidis. Stanı. 8-15. Cap $\int$ I - locularis, po. tulaca. lyfperna, circumfcifla. Stzgmata 6, Stylum longitudine aequantia.

Cal. I - phyllus cylindraceus, tubulatus, ftriatus, $6-228 . L y$. I2 - dentatus: denticulis alternis minoribus. Cor. thruhs. Perala 4 feu 6 , calyci inferta. Caps. 2- locularis, polyfperma. Filamenta 6 longiora, 6 breuiora calycem longitudinis aequantur, reliqua eminentia. - In Lythro Hyffopifolio modo 6 Filamenta numerantur.

\section{I G Y N I A.}

Cal. duplex, internus 5- fidus, paruus, externus duo- 229. Agrio bus foliolis mucronatis. Pet. 5 ftellatim patentia. Fi- monia. lanenzta plerumque $\mathrm{I} 2$ in noftrate numeraui. Styl. 2. Sem. I $f_{0} 2$, nuda in fundo calycis.

\section{T R I G Y N I A.}

Cal. I- phyll. 4 f. 6-fidus, laciniis anguftis, perfi-230. Kefedaftens. Petala inaequalia; alia integra, alia laciniata. NeEt. glandula fupremi petali. Stam. I I-I6, f.plurims. Styl. 3-5. Caip. I - locularis, apice lians. Cal. 1 - phyilus ventricolius rugolus. Pet. $4-f .5$ giluba, 23 I. Eutruncata. Filam. I 2 et plura. Styl.3. Caps. fubrotun- phorbia. da, tricocca, ftylo elongato pendens. Omnes fere laetefeunt.

\section{O D E A G Y N I A.}

Cal. 12 - partitus, concauus, acutus. Cor. 12 - peta. 232. Sem. la; petalis lanceolatis, concauis, acutis. Capj. I2, perkiumm. compreffae, breues, polyfpermae. 


\section{XII.}

\section{C O S A N D R I A.}

MONOGY NIA.

a) Floribus completis, fuperis.

333. Phila.Cal. I - phyllus, profunde 4-partitus: laciniis owadelphus. to-acuminatis paffim denticulatis. Cor. $4-$ petala, regularis, rotato-campanulata. Petalis ouatis, integris, concauis. Stum. 24, thulamo femiglobofo haerentia. Sryl. 4. Cap. 4- locularis, polyfperma.

b) Floribus corrpletis, inferis.

234. Pru- Cal. I- phyllus, 5-fidus, inferus, laciniis concauis, nus. obtufis, Cor. 5 - petala. Drup, nucleo comprefio 2 valui, integro.

235 Amyg-Cal. inferus, 5 - fidus. Cor. 5- petala. Drupa nuce dalus. $\quad 2$ - valui, foraminulofá.

\section{I G Y I A.}

236. Cra- Cal. 5 - fidus, fuperus, concauus, parens. Cor. Pet 5 taegus. fubrotunda, concaua. Stzl. 2-3-5. Bacc. carnofa, fubrotunda, vmbilicata, 2 - fperma.

\section{T R I G Y N I A.}

237. Sor- Cal. 5 - fidus, fuperus. Cor. 5 - petala. Bacc. vnibilibus. cata, 3 - fperms.

\section{P E N T A G Y I A.}

a) Floribus completis, calycibus Juperis.

$238 \mathrm{Mejpi}$ Cal. 5- fidus, fuperus. Cor. 5- petala. Bacc, vmbililus. cata, 5 . IO- fperma.

Cal. 
Cal. 5- fidus, fuperus, Cor petalis 5 fubrotundis. Po- 239. Pyrus mum vinbilicatum 5-loculare, polyfpermum. ,

b) Floribus complet is, calycibus inferis.

Cal. I - phyllus, profunde 5 - fidus, laciniis acutis. 240. SpiCor. petalis 5 fubrotundis. Capf.plures oblongo-acu. raer. minatae, 2-values, polyipermae.

\section{P O L.Y G Y N I A.}

Cal. x - phyllus, 5- fidus, vmbilicatus, carnofus, 24 I. Roja. collo coarstatus. Cor: 5 - petala. Filan. plura ad nonaginta. Sem. plurima, lanugine obferra intra calycem baccatum recondila.

Cal. I - phyllus, 5- fidus, laciniis oblonge lanceola- 242. Rubus tis patentibus. Cor. petaits 5 obtufis regularibus. Bacca compofira ex acinis fubrotundis, I- loculari. bus, in capitulum collectis:

Cal. 8- fidus, laciniis alternis minoribus. Cor. 4- pe- 243. Tortala; petalis obouatis obtufis. Sem. 8 fubrotunda, mentilla. mutica, nuda, thalamo paruo exfucco affixa.

Cal. I - phyllus, 10 - fidus, laciniis alternis anguftio- 244. Fra ribus. Cor. petalis 5. Sem. plurima, ousto-acumina- garia. ta, receptaculo ousto, carnofo, deciduo affixa.

Cal. 1 - phyllus, 10- idns, laciniis alternis minori- 245.Potenbus, reflexis. Cor. petalis 5 lubrotundis. Sem. pluri- tilla. ma, nutica, fubrotunda, receptaculo exigúo non fuccofo immerfa.

Cal. I - phyllus, I0-fidus; laciniis minimis, linea- 246. Geums ribus. Cor. Petala 5 limbo fubrotundo; vngue fublongo anguftato: Sem. plurima, hilpida, caudata, plumofa.

Cal. 10- fidus, coloratus, perfiftens, laciniis alternis 247. Cominoribus inferioribus. Petala 5 minima, acuminata. narum. Sem. numerofa, acuminata, Thalamum inedulem perfiftentem tegentia. 


\section{XIII.}

\section{P O L Y A N D R I A.}

MONOGXNIA.

\section{A. FLORE HERMAPHRODITO.}

a) Flores fimplices, completi, 4-petali.

248. Papa-Cal. 2- phyllus, caducus, foliolis ouatis. Styl. o. ver. Stigm. peltatum, planum, radiatum. Capf. I- locularis, rotundo-ouata, hifpida aut glabra, receptaculis feminum diftincta, ftigmate coronata, 'foraminibus pluximis dehifcens.

249. Cheli- Cal. 2- phyllus, foliolis ouatis, concauis, deciduis. donium. Styl. o. Stigm. 2- fidum. Siliq. I- locularis, 2valuis, polyfperma, linearis.

250.Altaea Cal. 4- phyllus. Cor. 4-petala, caduca, germinis bafi inferta. Bacc. 2- locularis, feminibus plurimis femiorbiculatis, difticho pofitis, foeta.

\section{b) Flores 5-petali.}

251. Ciftus Cal. 5-phyllus: foliol. 2 minoribus, 3 maioribus. Caps. plerumque multilocularis, in nofirate $\mathbf{I}-10$. cularis, triualuis, polyfperma.

252.'Tilin. Cal.5- partitus, deciduus. Capj. globola, coriacea, 5- locularis, 5- valuis, bafi dehifcens. Sem. 1 adolefcens, reliqua 4 fterilia.

\section{c) Flores polypetali.}

253: Nymn-Cal. 4 f. 5- phyllus: foliolis craffis intus coloratis. phaca. Cor. polypetala; petalis $5-20-30$ ornata. Anth. laterales. Stigm. peltatum, radiatum. Bacc. carnofa, multilocularis: in lutea magis conica; in alba plus globola. 


\section{I G Y N I A.}

Cal. 5 - phyllus. Cor. 5 - petala. Styl. 0. Germ, 2-5, 254. PacoCip. polysperma, feminibus coloratis.

nia.

\section{T R I G Y I A.}

Cal. O. Cor. 5- peiala, inaequalis. Nectar. I - ᄃ. $2-255$. Del. phyllum, bifidum, feffile, poftice coronatum. Cap. phinium. j. fubulatae, I- values. Sem. plura, angulata.

\section{P E N T A G Y N I A.}

Cal. o. Cor. 5 - petala, aequalis. Nectar. 5 , corniculata, 256. Aquiinter petala. Capf. 5 cylindraceae, acuminatae, $I-$ legia. values.

Cal. o. Cor. Petala regularis, obtula vel fubrotun- $25 \%$. Nigelda, patentis, in angufum terminantia vnguem, ve- la. nofa. Nett.8 (Lvowig); 5 (LrNnaevs); bilabiata, intra corollam. Capj. 5 1. 10. corniculatae, connexae, poly!perinae.

\section{P O L Y G Y N I A.}

a) Flores incompleti, calyce nullo.

Cal. o. Cor. petalis 4 1.5. NeEt. O. Sent. plurima, cau- 258 Clema data.

Cal. o. Cor. petalis 4 f. 5. Nect. c. Cap. I - 1perma, 259. Thalifriata aut alata, non dehifcentia, ecaudata, oblon- Elrum. ga. Sem. plur. fubmutica, nuda.

Cal. o. Petala 5, decidua. Nect. o. Styl. o. Cap\}. plur. 260.Caltha polyfpermae.

Cal. o, excepta Hepatira, I - phyllus: foliolis 3-261. Ameconcauis. Cor. $6-9$ - petala. Nect. o. Sem. plura, mone. varia.

Cal. o. Cor. polypetala, decidua. Neet. plura, plana, 26?. Trolbafi pirforata. Copf. plur. ouatae, I- fpermae.

lius. 
b) Flores fmplices, completi, calycibus inftrueti.

253. Ka. Cal. :- phyllus, caducus. Pet. 5 vnguve porrecto ad munculus. finguli petali vnguem, inftrucis. Styl. O. Sem. plua, irregularia, nuda.

264. Fica. Cal. 3- phyllus. Cor.polypetala. Petalis vngue nectavia. rifero infruetis.

2654donis Cal. 5- phyllus. Cor. $5-8$ - petala $f$. polypetala. NeEt. o. Styl. o. Sem. plurima, angulata corticata.

\section{B. FLORE THALAMOSTEMO. NOIDE,}

266.Arum. Cal. fpath. I - phylla, cuculata, colorata, perfiftens. Spadix fupra nudus, inferne piftilliferus, medi fta. mineus. Filam. O. Styl. o. Liscc. polylperriac, ftiligerae, rotundae.

\section{FLORE MONOCLINO.}

26-. Sagit or Cal. 3- phyllus. Cor. petalis 3 fubrotundis. Stam. 3aria. 24 et plura.

of Cal. et Cor. Maris. Styl. multi, valde breues. Sem. plurima, oblonga, marginata.

268. Cera. or Cal. niultipartitus. Cor. O Stam.16-20. Filanen. tophyllam. tis breuifimis. Antlzeris in glomerem congeftis.

26 Myrio o Cal. et Cor. Maris. Styl. O. Sem. I, nudum.. ploylhun. dueis. Stain. 8 .

\& C.r. $\$$ - pliyilus. Cor. O.. Piff. 4. Styl. O. Capf. 4, connatae, monofperinae.

270. Pote- of Cal. 2-3-3-phyllus coloratus. Cor. 4-partirimm. ta. Stam. $20-50$.

\& Cal. maris. Cor. 4- partita, limbo reflexo notata. Styll. 2. Stignz. penicilliformia. Bacc. labio corollae indurato 2 - fperma. 
o Ancint, fubrotundum. Cal. I- phyllus, plumofus, 271. Fagus. 4-5- fidus. Cor. 0. Stam. 4-8-i2.

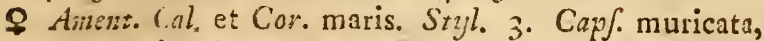
4- valuis. Sem. 2, carnofa.

o. Cal. 4-6- fidus. Cor. 10. Ament. laxum. Stan. 272. Qucr5 - 10.

\& Cal. I- phyiliz, integerrimus, fcaber. Cor. o. Styl. 2-5. Nus: ouata, coriacea.

o Anemt. imbricatum fquamis I- floris. Cor. 6-273. Itupartita. Stam 18 circiter. glans.

9 Fl. congefti. Col. 4- fidus, inferus. Cor. 4-par- cus. tita. Drupa oualis, coriacea

o Ament. cylindricum: fquamis $3-$ fidis, 1 - Aloris, 274. Cory. conftans, imbricatum. Cor. O. Stam. 6- 10 plura- lass. que.

ㅇ Cal. 2-phyll. margine lacerus. Cor. o. Styl. 2. Nux ouata, acuminata, I - fperma.

o Ament. globofum, fubfquamnfum. Cor. vix manife-275. Platafta. Anther. filamentis circumnatae. ilus.

\& Ament. vt in Mare. Cor. polypetala. Styl. I. Stignt. recuruum. Senz. fubrotunda, ftylo mucronata, bafi pappora.

8 Cal. Ament. cylindraceum, imbricatum: fquamis 276 . Carpifuperne latioribus I- foris, margine ciliatis. Cor.o. nus, Stam. 8-20.

8 Cal. 6- fidus. Cor. vt in mare. Germ. 2, ouata in. tra fingulam fquamam. Styl. 2. Nux ouata, nngulo. $\mathfrak{f a}_{2} 1$ - fperma, calyce excepta,

\section{XIV.}

D I D Y N -A M I A,

\section{A. GYMNOSPERMAE.}

\section{a) Flores verticillati. Calyces 5 二 fuli et multi- dentati.}

Cal. 5- dentatus, angulatus; aculeis terminatis. Cor. 277. Leoringens: labio fuperiori villofo. Anth. polline femi- nurus. nali nitido adfperfae.

$$
\text { h4 Cal. }
$$


278. Gleco. Cal. cylindricus 5- fidus, friatus, minimus. Cor comma. preffa: Iabio fuperiori erecro, femibifido; inferiori trifido, obtufo. Antherae per paria in fornem crucis conniuentes.

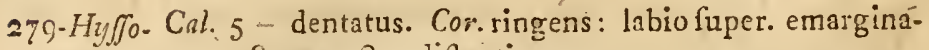
ints. to. Stam. recta, diftantia.

28\%. Men. Cal. campanulatus, 5-fidus. Cor. 4 - fida, fubaequa-

tha. lis : lacinia fuperiore latiore emarginata. Filam. ereCta, diftantia.

281. La- Cal. 5-dentatus, ouarus, bractea fuffultus. Cor. La. vandula. bium fuperius denticulis 2 approximatis. Stan. intra tubum ccrolla longioribus.

282. Teu. Cal.o - phyllus, 5- fidus, acutus: denticulis 5 fucriun. perioribus maioribus. Cor. tubus breuis, fauce incuruata. Lab. Juperius o, inferius 5-fidum: laciniis fuperioribus profunde bipartitis, dentatis. Sem. fubrotunda.

283. Ainga Cal. femi 5- fidus: denticulo fuperiori minore. Cor. lab: fuperius denticulis 2 approximatis, faminibus breuioribus, Sem. + calyce conduntur.

234. Beto- Cal. 5-dentatus, ariftatus. Cor. lab. Suqeriori planiunica. fculo, tubo cylindraceo. Sern. 4 in fundo calycis.

285. Lumi-Cal. I - phyllus, fuperne patens, ariftis 5 acutis. Cor.

wim. ringrens: lab. fuperius integrum, fornicatum; infer. bilobum; fauce vtrinque dente fetaceo terminata.

286. Polli- Cal. 5 - dentatus. Cor. labium fuperius integrum, forchia. nicatum, fauce dentibus deftituta.

287Goleop Cal. 5- dentatus, denticulis ariftatis. Cor.'ringens. fis. Lab. Juper. fornicato, ferrato: inferiori lacinia media crenato, fauce vtrinque denticulo cauo, obtufiuscu. lo, enittente. Sem. bis 2 - angulofr.

288. Sta- Cal. profunde 5 - fidus; denticulis, acutis in fpinulas chys. terminantibus. Cor. ringens. Lab. Juperius fornica. tum; inferins 3 - fidum, lateribus reflexum. Stam. deflorata verfus latera inflexa. Sem. 4 fubrotunda.

289. Nepe- Cal. irregulariter 5 - dentotus. Cor, ringens tubulofa.

ta. Lab. inferius laciniis lateralibus rehexis; media concaula crenata. Stam. approximata. Senl. oblong?.

290. Satu Per. 5- dentatum. Cor.5 - fida, fubaequalis. Stam. reia. remota. 
Cal. poculiformis 5- 10 - dentatus, Io- ftriatus. 291. BalloCor. ringens. Labio fuperiori fornicato, integro ta. crenato; inferiori 3 - fido,

Cal. tubulatus, $10-$ Ariatus, rigidus. Cor. ringens, 292. Mar. Lubliamforpcrius eretum, lintare 2- fidum. Scm.4-- mbium. oblonga.

\section{b) Calyces bilabiati.}

Cal. breuis, cylindraceus, obtulus, 2- fidus, inte-293. Scllgerimus, poft florefcentiam claufus, fquamula in- tcllaria. cumbente acutus. Cor. ringens, emarginata, tubus' b. fi inflexus.

Cal. 2 - fidus, faux villis claufa. Lab. Juperius 3-; in- 294. Thy. ferius 2- dentatum: denticulis infimis rectioribus, mus. fupremis magis reflexis.

Cal. 2 - phyllus; fubaequalis. Cor. laciniis fubaequa-295. Ocylibus. Filamenta bina bafi procenumemittentia.

Cal. I - phyllus Ariatus, 2 - labiatus: labio fupcriori 296. Pruplano truncato; inferiori anguftiori, erecto, femibi- nella. fido. Filam. apice bifurcata, altero spice antherifera. Sem. bis a fubrotunda.

Cal. $2-5-$ fidus. Strobilus $4-$ gonus, fpicstus, ca- 297. 'Orilyces coligens. Cor. laciniis fubaequalibus.

Cal. 2- labiatus. Lab. fuperius in denticulos 3 ; inferius 298. Clinoin 2 fifum. Imolicr. multifetum aut lineare, caly- podium. ces colligens et verticillis fubiectum.

Cal. angulatus, -1cariolus, 2 - labiatus, labio fuperio- 299. Melif- . re adicendente. Cor ringens, inaequaliș: labii infe- $\int a$. rioris lacinia media obcordata.

\section{B. A NGIOSPERMAE.}

Flores fimplices inaequales $\int$. Perfonati.

๙. Calyces 2-frali.

Cap.. I - locularis. Cor. fubaequalis 4 - fida. Glandula 300. Orojub bafi germinis.

banche.
h 5
B. $\mathrm{Ca}$ - 


\section{B. Culyces 4-fidi.}

301. La. Cal. 4- fidus, amplus, villolus. Cor. perfonata. Gland. thraea. lub germine. Capj. I - locularis, elafica, polyfperma.

302. Eu- Cal. .1- fidus, cylindricus, Anth. inferiores baî femiphrafia. fpinofac. Capf. 2 - locularis, ouato-oblorga, polyfiperms.

303. Rhi-Cal. ventricoius, compreffus- Car. labium fuperius enarnanthus. ginarum vel tenue, probofcidem elephantinam refeferens; inforizis tribus laciniis. Anth. bifidae, hirfutaé. Capj. 2 - locularis, obtufa, comprefia, - polyfperma.

30f. Me- Cor. perfonata. Labio fupcriori comprefio, margine relamplyrum. plicato; inferiori 3-dentato; fauce aut aperta, aut tuberculis claufa. Cap/: 2 - locularis obliqua. Sem. 4 gibba.

\section{r. Calyces 5 - frdi.}

305. Limo-Cor. campanulata, 5- fida, aequalis. Cap $\int . x-$ locufclla. laris, $2-$ valuis, polyfperma.

306. Scro-Cor. fubglobofa, relupinata, 5 - fida. Cap९. 2 - loculaphularia. ris, 2 - valuis, fubrotunda, acuminata, polyfperma. 30\%. Digi-Cal. 5 - partitus. Cor. campanulatá, 5 - fida, deortalis. fum ventricola. Stam declinata. Capjouata, bilocularis.

308.Antir Cor perfonata: bafi gibba f. calcarata, nectarifera. rhinum. Cans. 2 - locularis, irregularis, polyfperma.

309. Pcdi. Cor. perfonata : Lab. Superiori fornicnto integro, obtufo,

cularis. incifo, pafin acuto, in roftum terminante; inferio-, ri 2 - partito; medio anguftiore lacinia. Caps. $2-10$ cularis, obliqua, inucronata. Sem. tunicata, angulola. 
$\mathrm{XV}$.

\section{TETRA D Y N A M I A. A. SIL I C VL OSAE.}

a) Silicula apice integra.

Cal. 4-phyllus. Cor. 4-petala, cruciata: petalis bi- 310. Dra. fidis, integris aut emarginatis. Silic. ouali oblonga, ba. polyfperma: valuulis planiu!culis, diffepimento parallelis. Styl. o. Sem. fubrotunda, plura.

Silic. turbinata, ouata, valuulis concauis, fylo conico 31 1. Myaterminath, loculo vel polyfpermo. Styl. perfiftens. grum. Sem. Lubrotunda. Cal. 4 - phyllus, fugax. Cor. palfim patens.

b) Silicula apice emarginata.

Sil. orbiculata, emarginata, polyfperma:, valuulis naui- 3 I2. Iberis cularibus carinatis. Cor. irregularis: petal. 2 exteriorabus maioribus, 2 interioribus minoribus.

Silic. ftylo plus minus eusdenter infructa, $2-\operatorname{locula}-313$. Alys: ris: valuulis hemifphaeria horizontali dehifcentibus. fus.

Filam. 2 breuiora introrfum bafi denticulo notata.

Cor, petala modo integra, modo emarginata.

Silic. modo lata, comprefla, verrucofa, ariftata, mono-3 $3_{4}$. Coch fperma: modo globofa, leuiter comprefia, frilifera, learia 4- pperma. Styl. breuis. Stigm. capitatum. Cal. 4-phyllus.

Silic. oúato-cordata, 2 - vel pelyfperma: valuulis ca- 3 I5. Lepirinatis, difiepimento contrario.

dium.

Cal. 4 - phyllus, patens. Styl. paruus. Silic. varians, 316.-Thla. vel obcordata, vel triangularis, 2 - lccularis, poly- $\int p i$. fperma: valuulis nauicularibus, marginato-carinatis. 


\section{B. S I L I Q V O.SA E.}

a) Calyce clauso, plus minusne longitudinaliter conniucute.

317. Ra- Siliq. teres, tornfa, fubarticulata. Glandulac a; 2 inter phanus "Iftamina breuiora et piftilum: 2 inter ftamina lon. giora et calycem. Styl. vix vllus, breuis, capitatus. Sex. fubrotunda.

3IS. Eryfí. Siliq. columnaris, tetragona, polyfperma. Gland.4 nemun. Etriferae inter foliola calycis. Styl. breuifimus. Stıgm. capitatuṇ.

319. Chei-Cal. claufus foliis 2 gibbis. Siliq. compreffa, apice bifranthus. da. Germ. vtrinque dentieulo glandulato. Sem. plana.

320.Hcfpe- Cor. per. oblique flexa. Gland. intra ftamina breuiora. ris. Siliq. ftigmate bafi bifurcato apice conniuente.

32 I. Arabis Cal. faepe coloratus," gibbus: foliol. binis ouato-oblongis, acutis; 2 linearibus erectis. Gland. 4 melliferae, intra foliola calycis. Siliq. compreffa, linearis, Atylo breuifimo obtufo inftrueta, polyfperma.

323.Brafj-Siliq cylindracea. Gland. 4 nectariferae; 2 intra ftamica. na breuiora: 2 extra longiora. Sem. globofa, plura. 322. Tur Siliq. longiffima, angulata, $4-$ gona: angulis 2 obfole. ritis. tis. Cor. petalis erectis.

\section{b) Caljace pofus minnsue hiante.}

324. Ifatis. Siliq. lanceolata, compreffa, decidua, 1 - locularis, 1 - fperma, 2-valuis: valuulis excauatis nauicularibus. Styl. breuis. Stign. cepitatum.

325. Car- Siliq. fubcompreita, elantice dehileens: valuulis per ma. damine. turitatem reuolutis. Styl. o. vel,breuis. Stigm. capitatum, integrum. Sem. plura, rotunda.

326. Sina- Cor. vnguibus erectis, laciniis patentibus. Gland. 4 nepis. Etariferis; binis inter ftamina breuiora et piftilum: 2 inter ftrmina longiora et calycem.

32--Sifym-Silig. teres, dehifcens, valuulis minus recuruatis, mabrinm. gis rectinsculis. Styl. o. aut breuiffmus obtufus. Cal. et Cor, patentes. Sem. plura. 
XVI.

\section{MON A D E L P H I A}

D EA A N D I I .

\section{A. FLORE HERMAPHRODITO.}

Monogya. Cal. 5 - phyllus f. 5 - fidus. Cor. petalis 5 32?. Geraoblongis vel fubrotundis: vnguibus longioribus aut nium. breuioribus. Filam. bafi connexa. Statr. 5-10. Stigm. 5. Capf. 5- cocca, in roftrum terminans.

\section{P O L Y A N D R I A.}

Polygyn. Cal. dupl, extern. 3 fidus. Styl. multifidus. 329. LauaCiarf. loculis $2-$ fpermis, verticillatis. Polyg. Cal. duplex; exterior 3-phyllus, acutus: inte- 330. Malua rior I - phyllus, lemi 5 - fidus. Copf. arillis I fpermis, verticillatis, pluribus.

Cul, duplex; extcrior 6 - fidus, arillis pluribus $\mathrm{I}-33$ 1. Alcea. fpermis verticillatis.

Cal. duplex I-phyllus; exterior 8-9- fidus: inte- $33=\mathrm{Al}$ rior femi 5 - fidus; arillis plurimis, $1-$ fpermis, thaea. verticillatis.

\section{B. FLORE MONOCLINO.}

$\sigma^{7}$ Amént. fquamofum, hians. Cal. 4-phyllus. Cor. 333.Pinus. o. Stam. plurima intus florefcentis.

o Cal. ftrobilus, Iquamis 2- fioris, modo fimplicibus, modo duplicatis. Cor. o. Piff. I. Nux ala mem. branacea.

\section{FLORE DICLINO.}

o Ament. conicum: fquamis 10,1 - floris. Cor. 0.334 . IuniStum. 3, 4, 5, paflim 8, 9, globofa, coalita. 
o Cal. 3 - partitus. Cor. petalis 3. Styl. 3. Baccae in. ferae fubrotundae, carnolae, 3 - fpermac.

335. Taxus 8.9 Cal. 4 - phyllus. Cor. O. Anther. peltatae, 8fidae. Stzyl, O. Stigm. I. Bacca I-fperma, recutita. Seni. 1.

\section{XVII.}

\section{A D E L P H I A.}

HEXANDRIA.

Flores fimplices, ringentes.

336.Fuma-Cal. 2- phyllus, deciduus, aut nullus. Cor. ringens, ria. 4 - petala, bafi globofa nectarifera. Filam. 2 , bafi membranacea, fingula. Antheris 3. Frustus varius, rotundus, aut oblongus, I- vel polylpermus.

\section{O C T A N D R I A.}

337. Poly- Cal. $3-5-$ phyllus, perfiftens: foliolis 2 alaeformigala. bus coloratis. Cor. ringens. Filam. connata. Caps. obcordata, compreffa, $2-$ locularis.

\section{E C A N D R I A.}

Flores fimplices, papilionacei, legumbizo fi.

(a. Staminibus omnibus connexis.

1) Stigmate imberbe.

338. Geni- Cal. 2- labiatus. Vexill. oblongum, friatum, emargifra. natum, deorfum reflexum, a carina remotum. Stiguis. inuolutum. Legum. 1 - permum, breue, tugidiusculum.

339. Lupi- Cal. 2- labiatus, faepe appendiculatus. Anth. 5 oblonnus. $\quad$ gae et 5 alternae, fubrotundae. Legum. coriaceum, polyfpermum.

Cal. 
Cal. $\mathrm{x}-$ phyilus, ventricolus, 5 - dentatus; denticu- $3 \%$. A lis insequalibus. Iogrem. fubrotundum, calyce turgi- thyllis. do inclufum.

Cal. I- phyllns, 5- partitus, laciniis linearibus. Ve 341. Onoxill. coidatum, ftriatum. Lesum, rhombeum, turgi- . nis. " dum, villofum, fefile. Sem. pauca. Filam. in membranam coalefcentia absque fiftura.

Cal. 5- fidus: laciniis 2 fuperioribus breuioribus. Styl. 3\$2. Pifum tribus angulis infructus, fupra carinatus, pribefcens.

2) Sigmate pubefcente.

Cal. I - phyllus, deorfum productus bilobiatus, fuper- 3n3. Sparne profundus, pateis, 5-dentatus, in Genifa. Fi- 'inisb. lain. carinae adhaerentia. Legum. compreffum, fubpolyfpermum.."

Cal. 2 - labiat. $\frac{2}{3}$. Carima cam ftaminibus fyloque fpi- $3+4 . P h a-$. raliter torta. Seolus
R. Staminibus (inferioribus) connatis, decimo (fu- premo) libero.

\section{1) Stigmate pubefcente.}

Cal. I - phyllus, tubulofus, bafi obtufus, 5 - denta- 345. Oro. tus: denticulis 3 inferiorilus rectis longioribus, binis bus. fuperioribus breuioribus. Styl. linearis, teretiufculus. Siliq. longa, teres, I - locularis, plurima femina includens.

Cal. 5 - fidus: lacin. 2 fuperiores breues, inferier lon-346 Lagior. Styl. planus, fuperne latior, fupra villofus, thyrus. Stigm. villofum. Siliq. cylindracea; longa, compreffa. Sem. globofa.

Cal. 5 - fidus. Styl. latere inferiore transuerfe barba-347. Vicia tus. Stigm. obtufum. Siliq. longa, femina fubrotunda includens.

Cal. 2- labiatus, 5 - fidus. Legumen infiatum, futura 348. Colufuperiori ad bafin dehifcens.

tea.

Cal. dentatus: denticulo lupremo fubemarginato. $V_{\ell-349 .}$ Robixill, fubrotundum, réflexo-patens.

nia.

2) Stig- 
2) Stigmate imberbi

๙. Leguninibus vnilocularibus, poly.jpernis.

350. Cicer. Cal.5- filus, longitudine corollae: laciniis 4 fuperioribus vexillo incuntbentibus. Legan. rhomboidale, inflatum, $2-$ fpermum.

35 I. Cyti-Cal. 2- Iabiatus. Legumen bari attenuatum, pedicellajus. tum, obtufum.

352.Lotus. Cal. regulariter 5- fidus, tubulofus. Cor. Vexill. fub'rectun deflexum, gracili inftructun petiolo. Carina bipes, in roftrum acutum terminans. Legum. longum, cylindricum, friatum, farctum.

353. Gale. Cal. 5- dentatus, aequalis. Legument lineare, teres,

ga. Atriis oblique transuerfis.

$354^{\text {Erum }}$ Cal. 5 - partitus, longitudine fere corollae, aequalis. Legum. oblongum, teres, nodofum vel planum.

35.5. Tri. Cal. 5 - fidus. Legumb. vix calyce longius, $1-f$. polyfolium. Spermum, deciduum.

\section{ß. Leguminibus fubbilocularibus.}

356. Aftra. Cal. irregulariter 5-dentatus, compreffus, tubulatus. galus. Legun.rotundatum, gibbum, 2-loculare. Cor. Vexillo longo plicato margine reflexo: Alis inferis anguftioribus, apice in hanum abeuntibus. Carina emarginatà, longitudine alarum ant iis paulo breuior.

35\%. Glyci-Cal.2- labiatus, 5- fidus. Legumen oblongum, 2ne. loculare. Carinae Vexillum reflectens. Stamet $S_{t y l}$ Ipiraliter intorta.

\section{$\gamma$. Leguminibus articulatis.}

358. Hedy-Cal. 5 - fidus irregularis. Vexillo longo emarginato. farum .Alis re Legum. articulis 2-f. pluribus, I- fpermis, echinatis. Sem. reniformia.

359. Coro-Cal. I - phyllus, 2- labiatus: denticulis fuperioribus nilla. 2 connatis. Legum. longifimum, cylindricum, ad fingula femina oblonga contractum. 
Cal. 2- labiatus, 5- dentatus: denticulis fere regu- 360 . Ornilaribus. Legum. arcuatum, teres, fubulatum?, thopus.

Cal. paruus, 5-dentatus. Legumen compreflo-mem-361. Hiphranaceum, altera futura enarginaturis ad medium pocrepis. vsque excifa.

Cal. 5- dentatus: denticulis fere reguleribus: imo $362:$ Medi. longiffimo, Caeterum vexillo vltra carinam et alas cago. eminente, emarginato, marginibus inflexis. Alae oblongae ouatae, hamatae. Carina bifida, ousta, roftro carens. Piftill. incuruatum e carina elaftice ex. filiens, eandemque deflectens. Ligum, membranaceo. compreffum'et falcatum cochleatumque. Sem. plura reniformia.

XVIII.

\title{
P O L Y A D E L P H I A.
}

DOLYA NDRIA.

Cal. 5- partitus, inferus. Cor. Pet. 5 aequalitus, el- 363. Hylipticis, patentibus. Filamenta plnima in faciculis pericum. 3-5 bati connata. tyl. 3-5, Capp.oblonga, coni ca, $1-2-$ f. 5 - locularis, polyfperma:

\section{$\mathrm{XIX}$}

\section{S Y N G E N E S I A.}

\section{A. FLORE HERMAPHRODITO.}

\author{
A E Q VAIIS.
}

a. Flores Semiflosculi, corollulis vnifornibus, ligulatis.

Cal. cylindraceus cályculatus. Rec. fubpaleaceum. Cor. 364. Ci. 5- dentata. Papp.5- dentatus, obfolete pilofus. chorium. 
${ }_{3} 65$ Hijo Cal. imbricatus, bafi ventricofus. Rec. paleaceun. Cor. chacris. 5- dertata, Papp. plumofus, aut fimplex fipitatus.

366. Tra- Cal. fimpl. laciniis 8 - 12 bafi coalitis. Recept. nudum. gopogon. Papp. plumofus, ftipitatus.

36\%. Picris Cal. imbricarus calyculatus. Recept. nudum. Sem. transverfin fulcata, pappo pulmofo coronata.

363. Tara-Receptatulum conuexum, nudum, Cal. oblongus caly. xacrin. culatus duplici foliorum ferie. Pappus fipitatus, plumolus.

369. Leon-Cal. imbricatus, fquamis linearibus parallelis, laxis. todon. Rec. nudun. Papp. plumolus, feffilis aut fipitatus.

370. Scor-Cal. imbricatus: íquamis margine membranaceo. Rec. zonera. nudum. Papp plumolus.

37 I Crepis Cal. duplex calyculatus: fquamis patentibus, deciduis ; interioribus conniuentibus lacinis. Rec. nudum. Papp. pilofus, ftipitatus aut feflitis.

372. Chon-Cal. fimpl. cylindraceus, polyphyllus, calyculatus: drilla fquamis breuifimis adpreffis. Kec. nudum. Sem. nuticata, pappo capillari. longe ftipitoto.

373. Pre. Cal. fimpl. cylindriformis, calyculatis, 8-ro- phylnanthes. lus: figuamis breuifimis adprelis. Recept. nudun. Papp. capillaris, yel fipiratus, vel feffilis.

374. Lactu. Cal. imbricatus, fubconico - cylindriformis: fquaca. 'mis margine membranaccis. Rec. nudum. Sem. laevia, puppo pilofo, fripitato donata.

375.Hicra. Cal.imbricatus, cylindrico-ouatus. Rec.nudum. Papp. cium. teffilis, capillaris.

376. Sorz-Cal. imbricatus, bafi ventricofus. Recept. nudum. Sem. chus. pappo fimplici, fefili, pilofo infructa.

377. Lap-Cal. calyculatus, angulatus: fquamis bafeos 6 minimis, fana. tubi 8 linenribus. Recept. nudum. Sem. cylindraceo -3- gona.

378. Iyjo-Cal. 10- phyllus, bafi ventricofior: fquamis lanceoSeris. latis, bafi breuiffimis. Rcc. nudum. Papp. pilofus ant nudus, calyculo coronatus. 
B. Corollulis uniformibus, tubulofis.

* Floribus capitatis.

Cal. imbricatus, hemifphaericus, radiatus: fquanislon- 379. Carligis, nitidis, colnratis; extcrioribus femipinnatis, " na. multifidis, ramofis; intericribus planis, radium efformantibus. Recept. paleaceum fo fcifum. Sem. villola.

Cal. imbricatus, fubrotundo-ouatus; fquamis ramofo-380 Cnicus fpinofis, calyculatusi fquamis maximis. Corollul. hermaphrodirae, aequales. Sem. calycis thalamo villofo infixa, pappo coronsta.

Cal. imbricatus, globofus: fquamis apice hamato-in-38r. Arflexis. Recept. paleaceum. Papp. capillaris, bre- Etiun. vis.

Cal. dilatatus, imbricatus fquamis carnofis, apice acu-382. Cyna tis foliolo oblongo, emarginato, fpina terminato. $\mathrm{ra}$.

Cal. imbricatus, ventricofus, ouatus: fquamis imbrica-383. Cartis, fpinolis. Recept. pilofum. Pnpp.plumofus, fef- duus. filis.

Cal. ventricofus, imbricatus: fquamis fpinofis. Recept. 384. Ono- nudum, fauofum. Papp. capillaris.

pordon.

Cal. imbricatus, fubcylindricus: fquamis acuminatis in- 385. Serraermibus. Recept. nudum. Papp. plumofus. tula.

\section{* Flores Difcoides.}

Cal. oblongus, imbricatus: fquamis lanceolatis, rectis, 386 . Eupafloribus adpreffis. Recept. nudum. Styl. Longiffimus, torium 2- partitus. Papp. feffilis.

Cal. imbricatus, multifidus. Cor. compolita aequalis : 387 Bidens propria infundibuliformis, Recept, paleaceum. Papp. arifis rectis, fcabris. 


\section{S V P E R F L V A.}

๙. Floribus difcoideis; Corollulis difformibus tubulofis.

388. Arte- Cal. imbricatus: fquamis rotundatis, obtufis, connimifia. ventibus. Cor, radii nullae, difici tubulofae. Recept. nudum. Papp. $\mathrm{O}$.

389. Tana- Cal. hemifpharicus, imbricatus: fquamis acutis. Cor. cetum radii lineari-ligulatae 3 - fidae. Recept. nudum, Pàpp. o. Sem. nuda.

390. Cony- Cal imbricatus fubrotundus: fquamis apice afterum feza. $\quad$ re in modum patentibus. Cor. radii 5 - fidae. Reccpt. nudum. Papp. pilnfis.

391. Gna- Cal. imbricat fquanis fubrotundis vel oblongis, marphalium. gine membranaceis, nirentibus, coloratis. Cor. radii 5- fidae. Papp. plumofus.

\section{B. Floribus radiatis; Corollulis difformibus: :ubulofis in Difco, lingulatis in Radio.}

392. Bc llis. Cal. polyphyllus, hemifphaericus: fquamis aequalibus; Recept. conicum, nudum. Sem. obouata, compreffa. Papp. o.

393 Matri-Cal. łraemifphaericus, inbbricatús: fqusmis linearibus,

caria. fubaequalibus. Recept. conuexum, nudum. Papp. o. 394. Chry Cal. henifphaericus, imbricatus:- Fquamis interioribus janthsmum margine feariofis: intimis in membranas pellucidas. terminatis. Recept. conuexum, nudum. Papp. o. 395. Arnica Cal. mulsifidus, imbricatus, radio multo breuior. Filam. rodii 5 antheris deftitutạ. Recept: nudum. Papp. pilofus.

396. Inula. Cal. imbricatus. Antherae bafi bifetae. Recept. nudum. Papp. pilofus, fimplex.

39-. Erige- Cal. oblongus, cylindricus: fquamis imbricatis, ereetis. ron. Cor. radii lineares, anguftifimae. Recept. nudum. Pappo. capillaris.

398. Soli:, Cal. polyphyllus: fquamis imbricatis, conniuentibus. dago. Cor. radii 10, pauciores remoti. Recept. nudum. Papp. pilofus. 
Cal. fimplex, acqualis: polyphyllus. Recipt. nudum. 399.' CinePapp. fimplex, capillaris.

raria.

Cal: cylindricus, calyculatus, multifidus: fquamis api- 400 . Senece fphacelatis. Recept. nudun. Papp. pilofus, fim- cio. plex.

Cal. cylindraceus: fquamis aequalibus, fubmembrana-sor. TufJceis. Recent. nudum. Papp. pilofus.

Cal. imbricatus: fquanis interioribus patulis. Cor. ra. $\$ 02$. After. dii 10. plurcs patentiores. Recepjt. nudum. Prpp. plumofus, fimplex.

Cal. 1- phyllus, tubulafus, 3-- dentatus. Radius 5-- 403. Tageforus. Recept. nudum. Papp. ariftatus.

tes.

Cal. polyphyllus, fimplex. Keccpt. nudum. Fl. difci toł. Hele. ․ Cor. 5 - dentatae. Fl. racii o. Cor. 3-fidae. nizm. Papp. 5- dentatus.

Cal. hemifhaericus: fquamis imbricatis fubaequalibus. 405 . Anthe Recept. paleaceun, Florun difcus conuexus. Fapp. mis. pilofus.

Cal. ouato - oblongus, imbricatus. Cor. radii 5-10. 405 . AchilRecept. paleaceum. Papp. O.

Cal. ouato-cylindricus, fquamis imbricatis tectus. Kec. 40 ? Zinnid paleaceum. Difci Coroll. 5- fidae. Papp. ariftatus. Rad. 5- florus, perfiftens. Sem. mutica.

\section{F R V S T R A E A.}

Cal. imbricatus, rotundus: fquamis variae frgurae, 4.88. Cenmox aculeatis, ciliatis; mox nudis. Keccpt. villofum taurea. ast fetolurn. Papp. pilofus.

Cal. polyphyllus, fquamis duplici ferie. Recept. coni- 409: $R u d$ cunn. Rade 2-3- florus. Papp., 4 arifis corona- - beckia. tris.

Cal. eręus, polyphyllus: fquamis duplici ferie; exte-410. Corioribus patentibus.

reopjis.

Cal. imbricatus, fquarrofus. Recept, paleaceum, Papp. 4qI I. Heliariftatus.

aisthus. 


\section{N E C E S S A R I A.}

4I2.Filago Cal. imbricatus. Ftosculi anguftiflimi, inter calycis fquamas pofiti. Recept. nudum. Papp. o.

413.Calcn- Cal. timpl. polyphyllus: fegmentis fubaequalibus. Corollulue Radis tridéntatae; Difci 5- Ridae. Recept. nudum. Papp. o. Centralia Semina membranacea, alia abortiua, alia cordato-comprefia; Radii Semina incuruata vel cymbiformia echinata.

\section{MONOG A M I A.}

4I4. Iafia. Cal. communis ro- phyllus: foliolis alternatim imbriwe. catis fibi incumbentibus, horizontaliter patentibus; proprius 5-dentatus, fuperus, perfiftens. Cor. 5petalae, regulares. Cap. 2 -loculares, polyfpermae. 415. Viola. Cal. 5-'phyllus. Cor. Pet. 5 inaequalibus, infimo bafi in calcar obtufum terminarite. Amh. 5 , in tubum coalitae. Capf. fupera oblonga, trigona, 1 - locularis, 3 - valuis, femina plura includens.

416. Impa. Cal. 2 - phyllus, minimus, caducus. Cor. Petal. ple. tiens. rumque $4, \mathrm{p}$ affim 5 inaequalibus. Nictar. cuculatum, cornutum. Anth. bafi dehifcentes. Caps. fupera Ilocularis, 5- valuis, elaftice e latere defiliens. Sem. fubrotunds.

\section{B. FLORE MONOCLINO.}

417. Mc. $\sigma^{7}-9$ Cal. 5-fidus. Cor.5-partita, venolo-rugofa. mordica. Filim. 3 antheris, linearibus duplicibus biauritis in duobus fimplicique vniaurita in tertio. Styl. 3 - fidus. Pomum 3-:laculare elaftice defiliens. Sem.marginata.

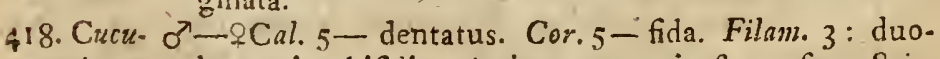
mis. bus apice bifidis. Anth. communis flexuofa. Stigmatibus tribus. Styl. 2 - partitus. Pomum 3 - loculare. Sem. arguta. 
6- C Cal. 5-dentatus. Cor.5- fida. Filamenta 3: 419 Cucur. antheris communibus fexuofis. Styl. 3 - fidus, ftig- bita. mate communi flexuofo. Pomum 3- loculare, feninibus margine tumidis.

$8^{x}-\subsetneq$ Cal. $1-$ phyllus, 5 - dentatus. Cor. profunde 420 . Bryo. 5-partita. Filam. 3, duobus. Antho gemina, tertia nia. fimp:ici. Styl. 3-- fidus. B̈acc. globofa, polyfperma. Flos diclinus paffim apud nos obferuatur.

\section{XX.}

\section{R Y P T O G A A M I A.}

\section{I. \\ F I L I C E S.}

a) Fruetificationes fpicatae.

Spic. ouato-oblonga, multiualuis. Fruetificationes pel- $42 \mathrm{I}$. Equitatae, bafi dehifcentes.

Spica articulata, lingulata, difticha. Capf. $\mathrm{x}$ - locula. $422 \mathrm{O}$ \% $\mathrm{hio}$. pibus, membranaceis, transuerfim dehif́centibus. Sem. gla/jum ouata, minima, pulueris ad inftar.

Spica racemofa: fimplex aut ramola, pedunculata vel 4.23. Osfelfilis. Caps. globofae, plurimae, 2-values, ob- munda: longae, fecundum lengitudinem horizontaliter dehifcentes. Sem. minima, puluerulenta. .

Spica diuerfa: alia fterilis, latior; alia fruétifera, angu- 424. Struftior. Capj. $\mathrm{x}$-loculares, membranaceae, tenuiffimae, thiopteris. Sem. I, globofum. 'GLEDITSCY.

Spica oblonga: fquamis imbricatis. Fruftificat, 2-425. Lycovalues, elaftice defilientes.

b) Frualificationes frondofae in pagina infe- riore.

Frons varie' figurata. Fruetificationcs fubtus totam te; 426 . Acron gentes, fefliles, accumulatae in vnuın acervum. ftchum 
4.2\%. Poly-Fronss integra vel diuifa. Fructificat. in aceruulos fubpódium. rotundos vel seniformes per difcum frondis auerfam difrubutae.

428. Afple-Frons integra vel ouato dinifa. Fructificat. in lineas fub-nimm. " parallelas difco frondis fubieztas et oblique decur- rentes. Capf. fubgiobofae, I-loculares. Sem. I. nudum, exiguum, lubrotundum.

429. Pteris Fructificationes in lineam marginalem ad frondes et nervum digeftae. Cap $\int$ globolae, 1 - values, membra. naceae. Sem. I lubrotundum, exiguum.

M V S C I.
A. Frondofi.
a) Periftomate rullo.

430. Phas- Capjula operculata: operculo nunquam abfedente. ciinz.

b) Periflomate nudo.

43. Sphag- Periftoma nudum.

min. $\sigma$ Rami fuperiores in clauae formam terminans.

432. Hed. Perift nudum. Flos Mafc. gemmitormis, alaris, monoi, wigia , eus.

433. Gymb-Perift: nudum. Mafc. Flor. difciformi, dioico. noftomun.

c) Perifzomate figurato; fimplici ordine.

«. Periftomate dentato: dentibus integris.

434. Tetra- Periff. fimplici ordine: dentibus 4 integris, pyramidaphis. litus Majc. Flor. capituliformi dimorpho. 435úplach-Perift. fimpl. 3 - dentatum: theçae apophylis abconiman. ca vmbraculiformisque. Majc. Flos difciformis. 
Perift. fimpl. 6 dentibus angußis, ere etiufculis, Mafc. $436 \mathrm{Lecr} f \mathrm{i} \mu$ Fios gemmiformis e foliorum alis.

Pcrift. fimpl. dentes I6 latiuseuli refexi. Mafe Flore $43-$ Grimin lummitate difciformi. mia. Perift. frmp dentibus 16 integris. Mafc. Fl los s fummi- 438 W cifia - tate capituliformis, dioicus. Pcrift. 16 - dentatum: dentibus reflexis, interpofitis $\$ 39$ Orthoprocefulis fimbriatis, conniuentibus. Flos Mafe. trichnm. gemmiformis et capituliformis.

Perif. fimplex: dentibus 32 integris, apicibus mem. 440. Poly: brana adglutinata. Mafc. Flos difciformis.

\section{ß. Dcnticulis bifidis.}

Perift. fimplex: dentibus 16 bifidis, longis, ereetis. 44r. TriMafc. Flos in alis foliorum gemmiformis.

chofonism. Pcrift. funpl. dentibus 16 breuioribus, inflexis, fiffs. 442.- Fifjt. Mafc. Flos in foliorum alis gemniformis. dcys. Pcrift. fimpl. dentibus 16 breuioribus, infexis, bifidis. $4.33 \mathrm{D}$ icra Mafc. Flos capituliformis.

num.

\section{\%. Denticulis ciliatis tortilibus.}

Perift. finpl." ciliata: ciliis fpiraliter conuolutis. Mafc. 444 TortuFlos gemmiformis monoicus.

Perift. fimpl. ciliato. Flos Nafe. capituliformis, dioicus. $4+45$ barbo-

d) Periftonate figurato; ordine duplici.

ж. Periftamate dentâto ciliato.

\section{J. Dentibus apice liberis.}

Perift. duplex: ixterm. dentatum; dentibus I 6 ciliisque 416 Neckeapica liheris. Ma/c. Flor. gemmiformi dioico. ria. Periflextern. dentibus 16 acutis: interiore ciliis vni-447.Lesken formibus. Majc. Flos gemmiformis dioicus.

Perift. cuserm. dentato: dentibus 16 acutis; inter. cilis- 448. Hyp

to: ciliis e membrana difformibus. Mafc. Flos gem. nilm, miformis dioicus, 
449 Bryum Pcrift. extern. dentibus 16 acutis: intern. é memhrana carinata ciliis diffornibus. Mafc. Flos capituliformis dioicus.

45c. Mni. Perift. extern. dentibus 16 acutis: intern. e membrana um. ciliis difformibus. Mafc. Flos difciformis dioicus.

\section{Dentibus apice cohaerentibus.}

45I. Koel: Perij. extern dentibus 16 ppice cohasrentibus obliquis: rututra. intcrn. ciliis totidem membranaceis planis. Mafc. Flore dif́ciformi dicico.

\section{ß. Periftomate dentato membranaceo.}

452 Webe- Perift. extern. dentibus 16 acuminatis : intern membrara. naceo carinato cum et absque ciliis. Flore herma. phrodito.

453. Bar- Perift. duplex: extern. dentibus 16 cuneiformibus: intramia tern. membranaconica plicato-carinata, in aperturain lacinulatam conniuens. Flos androgynus.

454. Bux- 8-qMafc. Flos difcoideus. Perift. extern. dentibus 16 baùnia. truncatis; intern. membranaceo plicatum.

\section{\%. Periftomate dentato reticulato.}

455.Fonti-Perift. extern. dentibus 16 pyramidatis: intern. reticunali: lato. Mafc. Flore in alis foliorum gemmiformi. 456 Mcesia o'-QMajcul. Fios difciformis. Perift. extern. dentibus 16 curtis : intern. reticulatum.

\section{B. Hepatici.}

457. Inn- Cap . pedunculi folitaria, 4 - valuis.' Sem. filis elanticisgermannia. infurucio. 458. Mar $8-\$$ Reccptaculum peltatum inferne feminiferum, chantia. multicsplulare. Capf. 4 - valuis. Sem. filis elafticis praedita. 


\section{I .}

\section{A L $: G$ A E.}

a) Terreftes.

Capf. biualuis, linearis; valuulis feminiferis. Sent. co. 459 Antho. lumnulae filiformi adhaerentia.

$\sigma^{2}$ - Capf. cordiformis. Sent. fubrotunda frondi im- 460 Blafia. inerfa.

8 -

Receptaculain feminum oblongum, psltiforme.

46r.Riccia

Receptaculua feminum fubrotundum, fibconuexum, frepius ematrinatum, feutiforme.

Receptaculuan ferinum in veficulas protuberantes et ma- 464 ., Reticulas albas eleuatum. Corpus varie lobatum, late cularia expanlum.

Recept. feminum peltatur. Corpus fimplex vel imbri- $465 . \mathrm{Vm} b i$. caturn depreffurmque.

licuria.

Recept. feminum tuberculofum. Corpus fintulofum, fae- 466. Cla pius ramofuin.

donia

Recept leminum in verrucas eleuatum.

467. $r \mathrm{cr}$.

Recept. Seminum tuberculis Iquamofis vel carneis inftru¿ium.

ruscakiz. $46+\frac{T}{2} b$.

Recept. ferninum cruftaceo-tartareum, patellaeforme eleuatrim.

Recept. feminum in orbiculas eleuatum, Corpas ex me tha bircularia. 469. Scu+70. Vsuea ris filis leu funiculis, teretibus plerumque folidis rigidisque conftans.

Recept. feminum inbricatum. Corpus cruftis tartareis 47 r. Pfora. inftruktum.

Puluis fubtilifimus per lentem a iglebis varie formatis 472 . Lepra. conftans.

Fibrae fimplices, per lentem ex lanugine valde tenui conftantes. 
b) Aquaticue.

474. Con-Fibrae fimplices vel ramofac, capillares, longinimá, ferua. modo teretes, modo reticulofae, paffim globolae. 475. Vlua. Fruftificationes in membrana diaphana.

\section{V. \\ F V N G I.}

a) Semina Fungosum externa in fuperficie inferiore mem. branae Funginz tcgeritis, aut lamellas, aut uubas formantis, aut Apophyfinu adinftar prodeun- tis, recondita.

4-6. Aga-Pileus fuperficic inferiore in duplicaturas membranaceo. ricus. lamellatormes centro ad ambitum difpofitas. Pleo - feffili vel ftipitato. Sem, vel margini vel fuperficiei totius lamellae affixa.

477. Bole- Pilezs fuperficic inferiore in tubis, cauernulis aut poris tus. argregatus.

478. Hyd-Pilczs in protuberantiis elongatis fola femina ferentimusin. bus.

b) Semina Fungorum in fuperficie fuperiore, corpus aut conuexim, aut concaumm, referente, externa, apparentia.

479. Phal-Pilezs intus laeuis, exterius rugofus et reticulorum adlus. inftar difpofitus.

480. Hel- Pileus ex plicis turbinatis confans. Capfulae lavella. tentes. -

47 I Peziza Fungus concauus, cyathiformis vel infundibuliformis, ftipitatus absque fructificationibus vifibilibus. Sem. minutiflima pulueris ad inftar elaftice explodens. 
Fungus concauus, planus, reflexus, e thecis feminali- 482 . OEtobus membrancfis ve plurimum femina $5-8$ foecuin- Jpora. da ferentibus, conftans.

Fungus patellaeformis. Sem. in fuperficie externa per 483 . Poro: puncta minutifima eiaculans.

nia.

c) Semina in tota Juperficie corpus oblongum formante, externe fita.

Fungus glaber faepius clauaeformis. Fruatificationes 484 . Clauainuifibiles. ria.
d) Semina in cano peculiari recondita atque mem. brana diaphana inaoluta.

Fungus volua difcedente flis'reticulatis factus, femina- 485. Steque nuda elaftice eiaculans. menitis.

e) Semina in corporis ipsusus fubftantia inclusa, et

vel $\alpha$. Orificio quodam Juperiora verfus aperto effun-

Fungus fucco membranaceo globofo vel ouato-fubro- 486. Lycotundo inftructus, feminibus filo inftructis, interne ex perdon. toto repletus.

Fungus voluatus capiulam globolam eiaculans.

Fungus lphaericus feminibus ecaudatis faretus, per po- pobolus. ros in fupetficie fparfos faepius emittens. 488. Splaeria.

\section{vel ß. Explofione membraniulae diffracta ad latera emittenda.}

Fungus gelatinofus partibus fructificantibus in illo laten- 489. Tré tibus. molla. 


$$
142 \text { GLASSES GENEKRM. }
$$

490. Mu- Subftantia mollis in púluerem capituio inclulum $\mathrm{fa}$ cor. tilcens.

491. Embo- Snbftantia cellulofa, pulueifora, nullo corrice tecta. 492 Moni- Fungus granulofus filamentis adfixus. lia. Subftantza mollis butyracea, in atrum et fuliginofum

493. Fuli-
go. puluerem dilabens. 


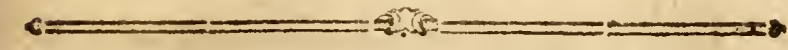

\section{Cla tris is.}

MON A N D.R I A.

MONOGYNIA.

\section{A. FLORE HERMAPHRODITO.}

I. SALICORNIA. LiNs. Gen. 10. Glasfchmalz' Germ. Glafswort Angl. Soude Gall.

. Salicornia patula, articulis apice compreffis, emar- herbacea. ginato bifidis. LinN. Syft. p. 52. sсикев. Spicil. p. 39. n. 961. BLAKw. tab. 598. Flor. Dan. tab. 303. SC KVHR tab. 1 .

Krautartiges Glaskraut, Scekrappe, Meerfalzkraut. Germ. Herbaceous Glajszert. Angl. Salicot ou Soz. de. Gall.

Créfcit copiofe ad falinas Ketfchauienfes et ad Deidiz. Floret Iul. et Aug. Annua.

V Jus. Ex hac planta Soda fic dicta, qua vtuntur ad vitra et fapones conficiendos, praeparatur. Infuper haec etiam acetariae ad inftar commedi poteft, et Angli Belgique hanc herbam oleo et pipere acetoque conditam cupide edunt. Planta quoque'a pecoribus expetita.

\section{HIPPVRIS L. G. II. Tannenwedel, Schaft- halm. Germ.}

2. Hippuris foliis otonis fubulatis. IINN. Syf. p. 53. vulgari JанN Epift. gratul. n. I. Flor. Din.' tab. 87. sckvhr tab. 1.

Gemeines Kannenkraut, Tannenwedel. Germ. Common Horfetail. Angl. Peffè d'eam. Gall. 
In locis agiofis paludofisque copiofe ad Rnap. pindorf, an Rande des reicbs, et' alibi freưuens. Flor. Míai. Iun. Perennis.

Ob huits plantae afperitatem tornatores et ferinarii vtuntur ad vartas partes polierdas. Oues herbam figiunt; capri contra auide deuorant.

\section{I G Y I A.}

yerna.

3. Callitriche foliis fuperioribus oualibus, floribus androgynis. LINN. Syit. p. 53. воEHM. n. 2.7. (fub Sicllaria) Flor. Dan. teb. 129. sCKvir tab. 1.

Frïhjuhriger IValferftern, geftirnter IVafjerfenchel. Germ. Vernal Starivort. Angl.

In foriculis et locis tagnantibus vbique; e. g. autunmalis. himter den Kohlgärten, in folliculis ad Gohlis. Flor. initio Veris. Annua.

4. Callitriche foliis omnibus linenribus, apice bifidis, foribus hemaphroditis. LiNe. Syft. p. 53. n. 2. вогнм. n. 240. (fub Sicllarza).

Callirr. foliis oppofitis oblongis, firctibus quadrifariam dehifcentibus. Gmel. Sibir. III. tab. I. fir. 2.

Herbfaceaferftern, fcimalblïtriges Linfenkraue. Germ. Autumnal Starvort. Angl.

In forficulis pratorum et fragnantibus vbique. Fl. dubia. Aug. ad tempus autumale vsque.

5. Callitriche foliis fuperioribus oualibus, caulinis linearibus apice bifidis. Horm. Obferuat. Bot. n. i.

Stcllaria intermedia. WIGGERS Primit: Holfat. 11. $A$.

Stellaria foliis omnibus fubrotundis. воЕнм. n. 24 . Germ.

Ziecifelinafter Walferftern, f. Sumpfieaferftern.

In iiscem locis cum priori, praecipue bey Reid. niz. Fl. vernali tempore. 


\section{B. FLORE MONOCLINO.}

4. CHARA L. G. Ir2\%. Armleuchter. Germ.

6. Clara caulibus laeuibus, frondibus interne denta- vulgaris. tis. LinN. Syft. p. 839.n. 2. SCHREe. Spic. p. 62. n. 1009 . Germ.

Gemcincr: Armleuchter; Finkendes Wafjorfchafthea. In foflis.pratorum Schocnfolticorum et Abtnaundorf; in ferobibus limolis paludofis nach Gonnezviz, et in pifcinis ad Parnet. F1. Iul. Aug.

Odor huius herboe eft foetidus.

7. Chara caulibus aculeis capillaribus confertis. IINN. hifpicia. Syft. p. 839 .n. 3. Fl. Dars. tab. I54.

Struppigter Armleuchtcr. Gem.

In locis inundatis, e. g: bei dem Brandvorwerke IL. roнl detexit, et pifcinis ad Lindcuthal paffim. Fl. Iun. lul. Annua. 
4

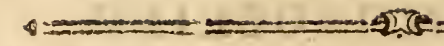

\section{Clarlis II.}

\section{I A N D R I A}

MONOGYNIA.

\section{A ELORE HERMAPHRODITO.}

a) Flores 1 - petali, inferi, regulares.

5. LIGVSTRVM L. G. 18. Rheinweide. Germ. (Prinet. Angl. Troëne. Gall.

vulgars. S. Liguftrum folis lanceolato-ouatis, fubacutis.

Liguffrum :algive. LINA. Syft. p. 56. говHM. n. 2. ELACEW. t. I42. SCKVHR t. 2. MIIL. t. 162 .

Rain- f. Spanifche-IVeicien, Miundholz. Eifenbeerbatm. Gemeiner Hartricgel. Germ. Common Priuet. Angl. Troërse commun. Cinll.

Ad fepes frequens, unn das Brandvorwerk, in der Allce vor dem Grimmifen Thore e: Hällijchen Pfortchca; porro quoque in multis hortis circa Lipfiam fitis. Et in fyluis elatioribus, c. g. in Bicniz copiofe etc. Fl. Iun. et Iul. Baccae maturefeunt autumno. Frut. $V$. Ex baccis atramentum confici poteft. vid. TRAG. et r.rNn. Flores apibus pabulum gratum. Fru. tex ad fepes et hortorum ambulacra ornanda idoneus optimusque. Folia funt amara, adfringentia, quae in ferbuto diarhoeaque valde laudantur.

6. SYRINGA L. G. 22. Spanifcher Hollunder, f. Flieder. Grm. Lilac Angl. et Gall.

vmlgaris. 9: Syringa foliis outa - cordatis, integris. LrNN. Syft. p. 57. вовнм. n. I. (fub Lilac) SCKVHR t. 2.

Var. 
Var. a flo:e aibo.

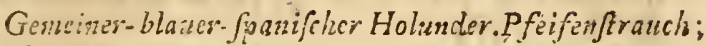
Huck ant dic Magd: wor. aer isblïhender Hollunder. Germ. Common blue Lilac, var. White Lilac. Angl. Queuë de Ręrazd ou Lilac, et var. Lilac a fleurrs blass. ches. Gall.

In hortis vbique et ad fepes hortorum frequens. Fl. Mai Frut.

$V f$ Flores apibus pabulum. Nationes orientales aliique e rnmis fiftulas tabacorum conficiunt. Scriniarii lignum ad res laeuigandas adhibent.

10. Syring foliis outato-lanceolatis, integerrimis.

Syringa perfica foliis lanceolatis integris. LINN. perfica. Syft. p. 5\%. Mmr. Dict. t. 164. fig. 1 .

Lilac Liguftri folio Tourio.

Perfifcher Flieder mit dem Raineeridenblatte. Germ. Perfian Tasmine Angl. Lilac de Perfe. Gall.

Patria huic fpeciei propria eft Perfia, ex qua in Europam iam diu translata eft et cafiz in Propugnaculo Grimenfi, bei der Paftei hinter der Soldatemeohnung, fponte nunc crefcere videtar. Praeter hunc locum in Serto circa vrbem et in hortis vrbanis rufticanisque culta. Fl. Maio et Iunio.

ObF. Frutex valde minor, tenerior Syringa vulgari. Rami angulati ita vno latere conuexi, altero contra plani et quafi profunde fulcati; cneterum cortice cinereo - albefcente cincti, magisque folioli. Lignum paulo durins. Folia ex Axillis ramorum progredientia, compofita, pinnata: luperio a romea 4 paribus conftantia atque in foliis duobus Cirshiformibus terminantur Foliola ougto - lanceolata únon plane lanceolata), integerrima illis Ligultri ferefimilibus oblcure-viridefcentia. Corolla, vt. in S. vulgari, quoad figuram, infuper carneo praedita colore et minus odorata.

b) Flores inferi 1 - petali irregulares.

7. VERONICA I. G. 26. Elrenpreis. Germ, Speed.

well. Angl. Veronique. Gall.
$*$
Spicarae.

1I. Veronica fipicis terminalibus, foliis ternis inaequa- maritima.

$$
\mathbf{A}^{-} 3 \text { liter }
$$


liter ferratis. unN. Syft. p. 58. n. 4. вотнм. n. 95 . Fl. Dan. t. 374 .

Mecrarands Ehrenpreis; blaner Weiderich. Germ. Maritime Specdrvell. Anọ!. Vironique des mêrs. Gall.

In pratis, e. g. inn Rofonthals, nach Lindenau, Gonneteriz. Fl. Aug. et Septembr. Perennis.

$V \int$. Folia infufo theiformi inferuiunt.

Sclireberi, 12. Veronica fpiciś terminalibus, elongatis, -foliis femper oppofitis, cordato-lanceolatis, oblongis, duplicato-ferratis, apice acuminatis. T'ab. I.

Veronica longifolin fpicis terminaiibus, foliis oppofitis lanceolatis ferratis, acuminatis. LINN. Syft. p. 58. n. 5. schreb. Spic. p. 10. n. 903. cranz II. p.'334. n. 2.

- Langblïtterichter Ehrempreis. Germ. Long-leaued Speedzoll. Angl. Veroiniguc à fenilles longues. Gall.

In pratis et nemoribis, e. g. in Rofenthale, ad Rafchwitz, nach Lindenan. Fl. Iun.-Aug. Perennis.

Obf. Haec planta in locis humidioribus maiori - habitu gaudet, eiusdemque folia funt modo latiora, modo angufiora, laete vel obfcure virefcentia. Flo- res apibus pabulum, et oues herbam recentem val. de quacrunt.

Spicara 13. Veronica fpicis terminalibus; foliis oppofitis, crenatis; caule adfcendente fimpliciflimo. LINN. Syrt. p. 58. n. 7. Eовн n. 96. Fl. Dan. to 52. Veronica Orchider. CRANz. II. p. 333 . n. I.

Zugéfpizter Weiderich. Wiefen-Ehrenpreis. Germ. Uprigit Spiked Male Speedwell." Angl. Veronique ì epis. . Gall.

Ad fyluarum margines frequens, e. g. ant der Pleiffe in Rofenthale, in Z Z chocherfchen Holze, hinter der Ziegellcheine, et alibi. Fl. Tun. - Aug. Annua.

$V f$. Flores apibus pabtilum, et herba a nonnullis' medicis corricis loco Peruuiani in febribus tertiani adhibetur. 
I4. Veronica fpicis lateralibus pedunculatis; foliis op-offinalis. pofitis ; cal?'eprocumbente. IINN. Syft. p. 58. n. Io.

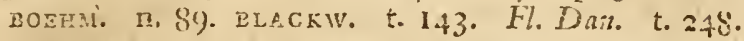
SCKVHR. t. 3 .

Feronica fcapis fpicatis, foliis oppofitis, ouatis, ftrigofis, caule procumbente, ftolonifero. IINA. Hort. Cliff. ก. 8 .

Gebrïachlicher Erenpreis; Heil aller IV it ; Grundheil. Germ. Mal-Specduell of the Shops. Angl. Dero. siguc sulle, vulgaive, ou officinalo. Gall.

In fylunticis, e. g. im Univerfitäts-, Livkeler., Zfchoclierfchen et Gonatceiner Holac; quoque in pratis nack Lindenau, copiofe. Fl. Iun. - $\Delta u g$. Perennis.

Vf. Planta eft amara, adfiringens, vulneraria, tonica, petoralis et vulgo thei fuccedaneum praebet. Cineres huius fal commune continent. Decolum cum vitriolo infpifatnm atramentum exhibet. Infu. per plebs hac herba in multis rebus fupertitiofis vtuntur.

\section{** Corymbofo-racemofac.}

35. Veronica racemo terminali fubfpicato, foliis ouatis, ferpyllifolia. glabris, crenatis. IINN. Syft. p. 59. n. 17. CRANz. II. p. $3+2$. n. 10. военм. n. 90. Fl. Dan. t. 492.

Var, $\propto$ ) Ver. ereẑta fyluéftris.

ß) Ver. minima, repens.

2ü̈ndelblättriger Ehresipreis, Germ. Paul's Beto$n y$, or finoath Speedzell. Angl. Veronique Serpoline. Gall

In pratis, pafcuis vbique. Var, $\alpha$ ) in pratis mon: tofisque frequens. $\beta$ ) in loco fteriliori, e. g.agris, yor dean Schönfelder Pfortchen. Fl. April, Maio. Annua.

Vf. Apes hanc laepius freçuentant et a floribus copiam me!lis maiorem cera reportant.

16. Verouica racemis lateralibus, foliis ouatis planis, Eeccabunga caule repente. LINN. Syft p. 59. n. 18. воEHMan. 85 , BLACXw. t. 48. fig. I. Fl. Dan. t. 51 I.

Var. a) Ver. Beccabunga mino:.

$A_{4}$. Pharm.


Pharm. Bcccabungae herba.

Buchbungen; Wajjerfalat. Germ. Brooklime. Angl. Beccabongue, ou Crelfon aquatique. Gall.

In fofis et fcrobibus, bei Lindenau, Leut fch, Eh. renberg, Gunndorf etc. et ad riuulos fere vbique, praeprimis, micht weit von Gcfundbrunnen. et copio. fiffime in folliculis verfus Stcteritz. Flor. tota fere aeftate. Perennis.

$V \int$. Vis eiusdem difcutiens, antifcorbutica, dehinc humores mundificat et vrinam promout. In culinis acetariae loco adhibetur et ibidem more cibabariorum oleraceorum praeparatur. Equi ouesque hanc refpuunt.

nagallis 2quatica.

17. Verouica racemis lateralibus, foliis lanceolatis ferratis, caule erecto. IINN. Syft. p. 59. n. I9. воЕнм. n. 84. - BLACrw. t. 4 is. fig. 2.

Waffergauchacil, fchmalblätrrige Bachbungen. Germ. Long-lcancd Water Specduell. Angl. Beccabongueà feuilles longues Gall.

In paludofis et fofficulis nach Schönfeld zu, etiam in pratis mach Lindenau et Grasfeld copiofe. Fl. Maio - Septembr. Perennis.

$V \int$. Haec faepe variat quoad magnitudinem, ita, vt hinc maior, illinc minor deprehendatur. Ouibus et auibus praecipue aduerfa.

feutellata. 18. Veronica racemis lateralibus alternis: pedicellis pendulis; foliis linearibus, integerrimis. LINN. Syft. p. 5\%. n. 20. CRANZ. II. p. 343. n. I2. ВОЕНM. n. 86 . Fl. Dan. t. 209.

Schiliförniger \&. fchmalblätrichter Ehrenpreis. Germ. Nerrow-leaued Water Speedwell. Angl. Vero. nique à écuffons. Gall.

In locis inundatis et fofficulis, ad viam inter Lin. denau et Klenzfchocher; in fofficulis ad pratorum margines polt Gunndorf, bei dem Gefundbrunnen et Univerfitätsholze; porro etiam in pratis Schönfeldin cis. Fl. Iun. Iul. Annua.

Teucrum. 19. Veronica racemis lateralibus longifimis; foliis oustis, rugofis, dentatis, obtufufculis; caulibus procumbentibus. LINN. Syft. p. 59. n.21. вовнM. n.87, Pharm. Veronicae Tcucrii Hierba. 
Edler Ehrcupreis; fulfcher Gundermamn. Germ. Veronique Teucriette, ou Grofle Germandrée. Gall. Norrow-leaued wald Gernander. Angl.

In p:atis et nemorofis valde frequenter in Rofenfenthale et alibi. Fl. Iun. et Iul. Annua.

Obf. Quae amat varietates et ratione habitus et coloris corollae diuerfas. Ceterum hace vi aperiente et adftingente gaudet atque a nonnullis loco potus theiformis adhibetur. Apibus et auibus minoribus prodert.

20. Veronica racemis lateralibus; foliis oblongo-ouatis proftratm ferratis; caulibus proftratis. IINN. Syft. p. 59, n.23.

JAHIN n. 2.

Var. $\alpha)$ flore carneo.

ß) flore caeruleo.

Geftreckter Ehrenpreis. Germ. Proftrate Speedruell. Angl.

Crefcit auf dem Lämmerberge ad Sckopam et mihi 'aufs den Rofenthaler Wiefen occurrit. Fl. Mai. - Iul. Perennis.

21. Veronica racemis lateralibus; paucifloris, calyci-montana, bus hirfutis; foliis ouatis, rugofis, crenatis, petiolatis; caule debili. LINN. Syft, p. 59. n. 25. SCHREB. p. 10. n. 904 .

Berg-Ehrenpreis. Germ. Mounitain Speedzell. Angl.

In locis valde vmbrofis v. c. im Rofenthale; auf dern Bieniz. Fl. Maio.

22. Veronica racemis lateralibus; foliis ouatis feffilibus, rugofis, -dentatis; caule debili, bifariam pilofo. LiNN. Syft. p. 6o. n. 26. говнм. n. 88. - Fl. Dan. t. .4 .4 .

Gamandcrartiger Elureipreis; blauer Wiefen. Eh. renpris; Frauenbis. Gern. Veronique chenctée. Gะ!l.

Vy. Apes interdum hanc reuifunt, et herba in medicina pro potu theiformi a nonnullis medicis pafo fim piaefcribitur.

23. Vironica racemis lateralibus; foliis cordatis, rugo- latifolia. fis dentatis; caule ftricto. LINN. Syft. 'p. 6n. n. 30. CRANZ. II. p. 348. n. 15. вОЕНM, n. 88.

$$
\text { A } 5 \text { Breit. }
$$

Chamae. drys, 
Breitblättrichar Ehrenpreis; Sufansonkrast. Ferm. Broad-leawed wild Germander. Angl. Véronigate if fuilles larges. Gall.

Inter fruticeta im Rofenthale et alibi. Fl. Mai. Iun. Anuua.

\section{*** Pedunculis vnifloris.}

agreftis. 24. Veronica floribus folitariis, foliis cordatis, incifis, pedunculo breuioribus. LINN. Syft. p. 6o. n. 32 . военм. п. 91. - Fl. Dan. t. 449.

Acker-Ehrenpreis; blauer Vogelnieier. Germ. Ger. mander Speediell. Angl. Véromaque rnfiququ. Gall.

In agris frequens. Fl. April. Ma!. Annua.

$V \int$. Pabulum ouibus.

5. wenfis. 25. Veronica foribus folitariis; folitis cordatis, incifis pedunculo longioribus. irns. Syit. p. 6o. n. 33 . вовнм. п. 94. Fl. Dan. t. 5 I5.

Feld-Ehwenpreis. Germ. Specdwell Chichwed. Angl. Véronique des champs. Gall.

In pratis et agris neglectis paffimque cultis. Fl. vernali tempore Annua.

$V \int$. Pabulum ouibus gratum.

hederaefolia 26. Veronica floribus folitariis; foliis cordatis, planis, 5 - lobis. LINN. Syft. p. 60. n. 34. CRANz. II. p. 350. n. 18. военм. n. 92. - Fl. Dan. t. $42 \%$.

Epheublätrichter - Ehrenpreis; kleiner Gunder. mann. Germ. Ivi-leaued Specdreell, or Snall-henbir. Ang-1. Véronique ì feuilles de Lierre. Gall.

In agris inter fegetes fere vbique. Fl. April. An, nua.

Obf. Varietas flore pallidiori cum hac propria fpecio immixta faepe deprehendi, nunquam vero illa flore tota pallida mihi occurrit. - V . Oues hanc herbam guftent.

t:iphyllos. 27. Veronica foribus folitariis; foliis digitato-partitis, pedunculis calyce longioribus. LiNN. Syft. p. 60. ת. 35. военм. n. 43. - Fl. Dan. t. 627 .

Var. I) foliis digitato - 5 - fidis.

Dreiblätricluter-Ehrenpreis; blaue Hünerroute. Germ. Trifid Speedueell. Angl. Véronique digitée. Gall. 
In agris cultis copiofe, ibique etiam/varietas, intermixta. Fl. April. Annua.

28. Vercnica floribus folitariis; foliis digitato-partitis, verna. pedunculis calyce breuioribus, Lins. Syft. p. 60. n. 36. SCHKER. p. 11. n. 905. - Fl. Dan. t. 252.

Frïhjöhriger-Ehrenpreis, Händleinkraut. Germ. Vernal Speedreell. Angl.

In apricis, aridis ad templum St. Theclac et $G i$. ckerlingsberge. Fl. toto vere. Annua.

8. PINGVICVLA L. G. 33. Fettkraut. Germ. Buttérw ort. Angl. GrâRette. Gall.

29. Pingaicula nectario cylindraceo lóngitudine petali. vulgaris, Liñ. Syf, p. 65. военiм. n. 83. Flor. Dan. t. 93.SCKVHR. t. 3 .

Gemeines Fettkraut; Fettblatt; Schmeereur ; BergSninkel. Germ. Connzon Butterzert; or Yorkfhire Sanicle. Angl. Grallette connmune. Gall.

In palcuis vdis, im Zfchocherfchen Holze paffim. Fl. Iun. et Iul. Perennis.

\section{VTRICVLARIA L. G. 34. Wafferfehlauch. Germ.}

30. Vtricularia nectario conico; fcapo paucifloro. vulgaris. inn. Syft. p. 65. schree. p. 10. n. 902. Fl. Dall. t. 138. SCKVHR. t. 3 .

Gemeiner Wafferjchlauch; Leichenkraut; Waffergarbe. Germ. Lert:ibulaive. Gall.

In ftagnis pratorum Schocnfeldicorime et in locis inundatis; e. g. in alneto ad Schönfeld. Flor. Iun. et Iul. Perennis.

Olf. Diftinguitur ab Vtricularia minori fpinulis cavillaribus minimis in margine foliorum. SCHREB.

B. Scminibus 4. mudis.

20. VEREENA L. G. 35. Eifenkraut; Eiferich. Germ. Vervain. Angl. Verveine. Gall.

31. Virbena tetrandra, fpicis fliformibus paniculatis; officinalis. foliis multifido laciniatis; cáule folitario. LnNN. Syft. 
p. 67. n. 16. воЕнм. ก. 133. 2LACXW. t. 41 . Fl. Dan. t. 628. sскVнR. t. 3 .

Pharm. Verbenae Herba.

Gebröuchliches Eifenkraut; Eijerhart; wilder EiSerich; Sthalkraut; Taubenkrant; Kazzenblut. Germ. Great Vervain. Angl. Verveine. Gall.

In ruderatis ad vias publicas, bei den Kohlgärten, Leurfeh, Gundorf. copiofe in pago Plaufigetc. Fl. Iul. et Aug. Perennis.

$V \int$. Radices in condimentis cucumerum immixtae has faciunt fapidiores, Olim haec herba pro medicamento magico habebatur.

11. LYCOPVS L. G. 36. Wolfsbein. Germ. Water Horehound. Angl. Licope. Gall.

Zuropaeus. 32. Lycopus foliis finuato ferratis. LiNn. Syft. p. 67. CRANZ. II. P. 32\%. ВOEHM. ก. 82. - SCKVHR. t. 4 . Europöifcher Wolfsfuss; Sparfaden; Sumpf $\mathfrak{l}$. Wafferandorn. Germ. Marrube des marais ou Licope. Gall. European Warer Horehound. Angl.

Ad fuuios frequens, nach dem Rofenthale et in rivulis nicht weit von dem Gefundbrunnen; porro in pifcina vor Parneck mihi occurrit. Fl. Iun. - Aug. Perennis.

Vf. Herba exficcata et cum vitriolo co ta nigro colore inficit corpora, quo confilio cingari ad colorem furuum cuti condonendum adhibent. Recens herba pecoribus pabulum.

12. SALVIA L. G. n. 39. Salbey. Germ. Sage. Angl. Sauge. Gall.

pratenfis. 33. Saluia foliis cordato oblongis crenatis: fummis amplexicaluibus verticillis fubnudis; corollis galea glutinofis. LINN. Syft. p. 69. воEHм. n. 81. BLACKW. t. 258 .

Pharm. Hormini Fol. Sem.

Römrche, türkifche, wilde, IVald, IViefenfalbcy; Muskazeller i Scharlachkraut. Germ. Meadow Sige or Clary. Angl. Ormin des prés. Gall. 
In pratis et collibus ficcis, im Bieniz auf dem Berge. Fl. Iun. et Iul. Perennis.

$V$ f. Flores apibus pabulum gratum. Herba inprimis ouibus obnoxia. Coriis parandis apta. Cereuifiae condonat vim temulantem. Semina odorem fua. viffmum fpirantia.

\section{c) Flores fuperi.}

13. CIRCAEA L. G. 25. Hexenkraut. Germ. Enchanters Night hade. Angl. Circée. Gall.

34. Circaea caule erecto, racemis pluribus, foliis oua- Iutetiana. tis. Linn. Syft. p- 58. военм, n, 250. Fl. Dan. tab. 2 IO. SCKVHR. t. 2. a.

Gemein Hexen S. Stephankraut, Waldklette. Germ. Common Enchanters Night/ hade. Angl. Circée Herbe de St. Etienne, out Herbe des magiciennes. Gall.

In fyluis, maxime ims Ro/enthale; Gonnewitzer, Zfchocherifchen et Kleindölziger Holze. Fl. Iun. Aug Perennis.

Nomen Circaea habet a Circe, propterea, quod fructus eiusdem fe veftibus affigunt, ficuti Circe fuis incantamentis facere folebat. Apes neceffitate coaEti hanc quaerunt. Chomelius cataplasma emolliens e foliis parauit, quod ad condylomata venerea tollenda felici exhibuit fucceffu.

35. Circaea caule ramofo, deprefto, foliis cordatis, alpina. dentatis, nitidis, glabris. Rotr. Tent. Fl. Germ. T. I. p. 13 .

Circaea alpina caule proftrato, racemo vnico, fo-' liis cordatis. Linn. Syft. p. 58 . eschenb. Obferv. Bot. p. 15. n. 5. Flor. Dan. t. 210.

Alpen Hexcnkraut; kleines Berg - Hexenkraut. Germ. Mountain Enchanters Night Shade. Angl. Circée des Alpes. Gall.

In locis vmbrofis et fyluaticis, humidis et fteriliffimis, in der Diibenfchen Heide, ante paucos annos ESCHENBACHIVS cum SEGNizio detexerunt.

Obf. Cel. escheneachivs fimul hanc fpeciem accuratius defcripfit atque caulem, quem LiNNAEvs et 
'Iil. MVRraivs proftratum reperierunt, contra erectum atque exceptis nodo inferioribus eius articulis,

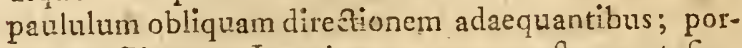
ro tam Circaean Latesianan, quam noftram, et fimplici et compofito racemo faepius obferuauit. Folia in noftra funt cordata, fplendentia, longifime petio. lata.

\section{I G. Y N I A.}

I4. ANTHOXANTHVM L. G. 46. Ruehgras.

Gorm. Springgirafs. Angl. Flouve. Gall.

odoratum. 36. Anthoxantum fpica oblonga ouata; flosculis fubpedunculatis; arifta longioribus. LnNN. Sylt. p. 73. EовнM. n. 597. SCHREB. Agroftogr. p. 49. Tab. V. Fl. Dan. t. 666 . scкvнr. t. 4 .

Wahres Ruchgras; gelbes Ruchgras. Germ. Virnal, or? Springgras. Angl. Flouve odorante. Gall.

In pratis copiole, inprimis im Rofenthale, in pratis Schoenfeldicis aliisque plurimis pratis copiofiffime. F1. Mai. - Iul.

$V \int$. Pabulum equis ouibusque pergratum. Eft

- vere aroma foeni, quod etiam ob gratum odorem inter puluerem fternutatorium a nonnullis commi. cetur.

\section{B. FLORE STYLOSTEMONOIDE.}

\section{O R C H I D A E.}

15. ORCHIS L. G. I094. Ragwurz: Germ. Foolftones. Angl. Orquis. Gall.

* Calcare lóngiusculo.

Sambucina. 37. Orchir bulbis oblongo-ouatis, apice obtufis, nectarii cornu conico; labio ouato trilobo, bracteis ouato-lanceolatis, floribus paulomaioribus. Tab.II.

Orchis Samburina bulbis fubpalmatis erectis, ne-. etarii cornu conico, labio ouato fubtrilobo bractè 
Iongitudine florum. irns. p. S1O. JAcQ. Fl. Auftr. IL, tab. 108.

Orchis radicibus palmatis, brafteis coloratis, labello circum ferrato, trilobato, lobo medio emarginato. HALl. Hift. II. p. I 42 , n. 1280.

Ragveurz mit dem Holliuzder Geruche. Germ. Aufrian handed Elder Orchis. Angl.

In locis pratisque montofis et fylvaticis, e. g. in 'den Hegeholze' bei Kriphäne; porro in monte lic dicto Bieniz paftrn. Flor. Máo et ineunte Iunio.

Obf. Bulbus biennis apice fibrillulis fortioribus obtufis, pollicis longis, donatus, fubrotundo-obfcure compreffus; alter innior magis concicus et apice nudus, obtufus. Ceterum fupra Ballbi bafin 8 fibrofis radiculis, fuperiora verfus. currentibus obfefius. Canlis varie longus, erectus, angulo-tres, fimplex. Spica ouata laxa terminans Folia radicalia bina femi vaginantia, reliqua caulina +-5 amplexicaulia patentia; omnia oblongo-lanceolata, $1-3$ pollicis longa, integerrima, laete viridia, glabra. Petala 5. fuperiora: tribus conniuentibus; duobus lateralibus contra patulis et reflexis. Labello laterribus réflexo, ferrulato, leuiffime bifido; medio emarginato. 'Calcar mediocre, terres, crafium, emarginatum. Corolla viriải-flaua; barba intus puntis crocęo-purpureis notata. Stipulae ouato-fanceolatae, femi incuruae, floribus paulo maiores, vel paffim longitudine florum.

38. Orchis bulbis palmstis patentibus, nectarii cor- naculata. nu germinibus breuiore: labio piano, petalis dorfalibus. LINN. Syft. p:8IO. n. 37. воЕнм. n. 5 I 5 . Var. I. vaillant, Paril. t. 31. fig. 9. 10. hall. Fl. t. 32 .

Orchis maculata radicibus palmatis; canle plerumque folido; labello trifido galea reuoluta. Hatl. Orch. 14. Cranz. Stirp. II. p. 492. n. I I.

Pharm. Palnatae Radix.

Geflëcktes Knabenkraut; Hëndelkrautreeiblein. Germ. Fonale Handed Orchis" Angl, Germ. Orquis tacheté. Gall. 
In pratis humidis, e. g: in pratis Schoenfeldicis 'copiofe; porro in Univerfitätsholze, ibique fyluis confinibus. Fl. Mai. et Iun.

Vf. Ouibus pabulun.

katifolia. 39. Orchis bulbis fubpalmatis rectis, nectarii labio trifido, lateralibus reflexo, cornu germinibus breuiore, bracteis flore longioribus. LiNn. Syft. p. 8IO. n. 34. РОЕНM. n. 5 I 5 .

Orchis radicibus palmatis, caule plerumque fiftulofo, bracteis maximis, galea lateribus reuoluta. CRANZ. II. p. 493. n. I2. BLACKiv. t. 405 .

Breitblättrichies Kabbenkraut; Venusblums; rosher Wiefeng'ukguk. Germ. Male Handed Orchis. Angl. Germ. Orquis à feuilles larges, oü des prés. Gall.

In pratis paludofis, e. g. in pratis Schoenfeldicis et poft Tauchanin. Fl. Mai. Iun.

noriophora. 40. Orehis bulbis indiuifis, neettarii labio trifido reflexo crenato: cornu breui, petalis conniuentibus. IINN.' Syft. p. 808. n. 21. schreb. Spicil. Append. n. 1 169. Fl. Dan. t. 224.

Orchis cimicina radicibus fubrotundis, galea conniuente, labello trifido reflexo, cranz. II. p. 498. n. 13

Stinkendes Stendelkraut; Bocksknabenkraut. Germ. LefferLizard Flower. Angl Orquis fetide, ou punaisGall. In nemorofis et auf der Wieje an Bieniz, ILl. poHLrvs in Zfehochrijchen Holze, rarius; porro quo: que in Bienitz et ins verfflogenen Holze paffim reperi. Flor. Iun. Iul. cisert.

Olf. Labium trifidum ferratum. Odore cimi-

Morio.

41. Orchis bulbis fubrotundis, galeae petalis lineatis, labello ampliter trifido, crenato, medio fegmento emarginato. CRANZ. II. p. 49\%. n. I4. BOEHM. ก. 512 .

Orchis bulbis indiuifis, nectarii labio $\mathrm{A}$ - fido, crenulato: cornu obturo adfcendente, petalis obtufis conniuentlbus. LIN N. Syft. p. 3OS. n. 23. VAIrLANT. Parif tab. 3 l. fig. 13.14 . hall. Flor. t. 33. Fl. Dan. tab. 253 .

Pharm. Salep Radix. 
Knabenkraut; Gemeine Raguvur; Salepretwrel; Heniathseurzel. Germ. Female Foolftones. Angl. Orquis fencile, ou bouffor. Gall.

- In pratis frequentillime. Fl. Maio. Perennis.

Olf. Flores interdum colore pallidiow, palfim rubro deprehendi. Radix eft lubricans, valde nutri. cia aphrodifiaca. Labium trifidum, medio emarginatum. Petala obtufa lineari lanceolats.

42. Orchis bulbis indiuifis, necturii labio 4 - lobo mafcula. crenulato: cornu obtufo, petalis dorfalibus reflexis. LINN. SyIt. p. 80\%. n. 24. ВOEHM. n. 5 II. BLACKW, t. 53. vaILI. t. 3 1. fig. I2. Fl. Dan. t. $45 \%$. SEGv. ver.t. 15. tig. 4.

Mômuliche Ragzenrz; Narrenhoden. Germ, Male Foolftoncs. Angl. Orquis male. Gall.

In pratis Schoenfeldicis pafim et Syluis frequens. Fl. Iun. Iul.

43. Orchis bulbis indiuifis, neêarii labio 5- fido, militaris, punctis fcabro, peralis confluentibus. Lins. Syft. $p$. 3Og. n. 2万. вOEHIM. ก. 510.

Orchis radicibus tubrotundis, labello quadrifido, laciniis anterioribus latiulcuis; pofterioribus remotis fere conuergentibus GMEL. 1. 24 .

Orchis Riuini bulbis fubrotundis, fpica conica, petalis conniuentibus, ne tarii-labio trifido, lacinia media productiore bifida. Govan. illuftr. 74 .

Orchis mafcula Rivin. Hex. t. I 5 .

Var. Orchis militaris mäior TovRn. Inft. 438. tab.

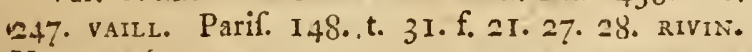
Hex t. 16 .

Kriegerifche Raguenrz. Germ. Man Orchis. Angl. Orquis militaire ou capette. Gall.

In pafcuis hintcr Wolkwitz, et pratis lumidis am Univerfitiitsholze, et alibi. vaz. in pratis bei dem Biqsitz et Kleindölzig. Fl. Iun. Iul. Perennis.

** Calcare longifino.

44. Orchis bulbis indiuifis, nectarii labio lanceolato, bifolia. integerrimo: cornu longiflimo; petalis patentibus. 
IiNN. Sylt. p. 808. n. 15. воEнM. n. 520. (fub Satyrio) - SEGV. t. 15. f. 10.

Pharm. Satzrii Radix.

Zireiblättrichte Ragtura; weiffes Knabenkraut; Fuchshï.llein; Bifanknabenkrant; Nachtviole. Germ. Common B̈utterfin Orchis. Angl. Orquis bifeaille, ou blanc. Gall.

In fyluaticis locis nemoribusque, im Univerfitätshotze, Gundorfor Holzc, et aliis fyluis adiacentibus copiofe. Fl. Mai. Iun. Perennis.

Obf. Labium lanceolatum. Petala alba patentia.

$V \int$. Vis radicis narcotica, aphrodifiaca. Qua de re veteres contra fierilitatem, porro tabidis fenibusque valde commendarunt. Flores purpurafcentes, noEtu fuaucolentes; apibus pabulum.

a nopica. 45. Orchis bulbis palmatis, neetarii cornu fetaceó germinibus longiore; labio 3 - fido, petalis duobus patentiflimis. LINN. Syft. p. 810. n. 29. вовнм. n. 514. Fl. Dan. t. 224. HALl. Flor. t. 29.

Stechfiegenartige f. Schneckenförnige Ragzeurz. Germ. Red Handed Orchis. Angl. Orquis giraflée. Gall.

In pratis nemorofis paffin, in Univerfitätsholze, anno praeterito reperi, et in aliis fyluis copiofe. Fl. Mai. Iun. Perennis.

16. SATYRIVM L. G. I095. Stendelkraut. Gem. Satyrion. Angl. Satiraine. Gall.

viride. 46. Satyrium bulbis palmatis, foliis oblongis obturis, - mectarii labio lineari trifido: intermedia obfoleta. IINN. Syft. p. 8II, n. 6. CRANz. Infit. Tom. I. pag. 443. n. 2. военM. n. 513. (fub Oichidej hall. Fl. t. 26. Fl. Dan. t. 77 .

Griines Stendelkraut; Bocksgeilen. Germ. Frog Satyrion. Angl. Satiraine grenouillezte. Gall.

In pafcuis et ericetis ad Meckern et IVahren, porro iuxta $S$ clienditz, vt et in Sylua Acadcmica mihi occurrit. Fl. Iun. Iul. Perennis. 
17. OPHRYS L. G. 1096. Knabenkraut. Germ. Ophrife. Gall. Twayblade. Angl.

Calcare nullo.

a) Labillo integro.

47. Ophrys bulbis adgregatis, oblongis; caule fubfo- fpiraliso liofo, floribus fpirsili-fecundis, nectarii labio indiuifo, crenulato. LINN. Syft. p. BI2. n. 3. CRANz. Inftit. II. p. 473. n. \%. (fub EpipaEtide) товнм. n 5 I6. (lub Helleborine) H.aLL. Fl. t. 38 . SEGV. ver, t. 8. fig. 9. GMel. Sib. 11. p. I3. tab. 2. fig. I. Flor, Dan. tab. 387.

Gezenndenes Kubenkraut. Germ. Triple Ladies Traces. Angl. Ophrije en Jpirale, Gall.

In fyluis montofis im Linckler Holze, auf der Wic. Je dextiorfum, den Linckler Holze gegeñ über ILL. POHLIVs reperit; item anten zuifchen dem Dieniz und der Wiefe crl. bоeнmervs, nec non ipfe. Porro quo-, que copiofe crefcit in pratis bei Stetteritz ibidemque pafuis. Fl. Inl. Aug. Perennis.

\section{в) Labello bifido.}

48. Ophrys bulbo fibrofo, caule bifolio, foliis ouatis, ouata, netarii labio bifido. i.nN. Syt. p. 613. n. 5 . CRANZ. II p. 248. n. 8. ЕOEHM. n. 521. LOBEL. icon. p. 302. Fl. Dain. t. 13\%。

Var. a) foliis tribus.

Pharm. Bifolii Herba.

Eirundblïtriges Knabenkraut; Genibeines Zueiblatz: Rattenfchwanz. Germ. Conimon Treayblade. Ang!. Ophrife double-ferille. Gall.

In fyluis montofis et pomariis, in der Leimgrube, im Bieniz, ad Rückmarsdorf, in Jylua Academica paffim. Fl. Mai. Iun. Perennis.

49. Ophrys bulbis fibrofo-faf́ciculatis, caule vaginato Nidus Auis. aphyllo, neetarii labio bifido. LINN. Syft. pag. 812.

n. I. CRANz. p. 475 . n. 9. BOEHM. ก. 522, IIALL. Fl.

t. 37. Nidus Amis. tovrn: p. 438 . 
- Vogeinefl; Waldknabenkraut; Wurm f. Vogeluews; Margendreher. Germ. Bird's Neft. Angl. Ophrife nitu do oifean. Gall.

in nemoribus vmbrofis, inter arborum radices, e. g. im Unitverfizätshoize paffin quoque in Gunndorfer et Gonncroitzer Holze reperi. Fl. Mai. Iun. Perennis.

18. SERAPIAS I. G.' 1097. Stendelwurz. Germ. Baftard Hellebore. Angl. Elleborine. Gall.

latifolia. 50. Serapias bulbis fib:ofis, foliis / ouatis amplexicaulibus; floribus pendulis. LINN. Syft. p.8I 4. n. I.

Serap. caule multifloro et multifolio. LiNN. Cliff. 429. еоенм. n. 518. (lub Helleborine). Hall. Flor-t. 40. Fl, Dan. t. 8 II.

Breitblattriges Sicndelkraut; falfche Niefewurz; Zymbclblume. Germ. Elléborine à feuilles larges. Gall. Braad-leaved Baftard Hellebore. Angl.

In fyluis montoisque locis, im Univerfitätsholze et Bieniz. Fl. Mai. Iun. Perennis.

Oly. Spica multiflora, longa, Petioli oblongi. Folia femiamplexicaulia.

lungifolia. 5r. Serapias bulbis fibrofis, foliis enfiformibus ferfilibus, floribus pendulis. LINN. Syf. pag. 8I5. n. 2. Вовна: ก. 519. (fub Helleborime) - Hall. Flor. tab. 39.

Epipaet is paluftris caule foliofo multiforo, label. 10 articulato vomeriformi : floribus pendulis. CRANz. P. II. pag. 462 . n. 3. tab. I. fig. 3. Fl. Dan. (ab. $26 \%$.

Langblintrige Stendeheurz; IVicjendiegel. Germ. Long-leaved Baftard Hellebore. Angl. Elléborine à feuilles longues. Gall.

In pratis vliginofis bei Rückmarsdorf hinter dem Sandberge; porro in pratis nicht weit von Kleindölzig paffim. Fl. Iul. Aug.

miffolia. 52. Serapies bulbis fibrofis, foliis enfiformibus diftinctis, bracteis minutifimis, floribus erectis: nectarii labio obtufo petalis breuiore. LINN.Syft. p. 8I5.n. 3 . 
Epipactis alba caule foliofo paucifloro, labello articulato, obtufo labro reflexo. CRAsz. Auftr. P. II. p. 460. n. 2. t. I. fig. 4. a.

Helleborine latifolia, floribus magnis, paucis albisque. Boenim. n. 51\% hald. Fl. tab. 4I. Fl, Dan. tab. 506 .

Schnerdformige Stendelwursel. Germ.

In fyluaticis graminofis, im Univerfitätsholze. F1. Mai. Iun. Perennis.

53. Serapias bulbis fibrofis, foliis enfiformibus, flori- rubra. bus erectis: nętarii labio acuto. Linn. Syft. p. 816.

n. 5 .

EpipeEt is purpurea caule foliofo, pauciforo, labello articulato roftriformi, acuto, cranz. $\Lambda$ uftr. p. $45 \%^{\circ}$

n. I. t. I. fig. 3 .

Helleborine longifolia foribus magnis paucis purpurcis. Iralz. 274 .

Gall.

Rothe Stendeleeurzel. Germ. Elleborine rouge.

In fyluis montofis crefcit, e. g. im Gundorfer et KKleindölziger Holze anno praeterlaplo inueni. Fl. Maio et Iun. Perennis.

Obf. Flores funt magni, purpurei. Faux Corollae pallida. Labellum longius acutum, ferratum, lineis vndulatis. Antherae purpureae. Fruetus erecti.

\section{FLORE MONOCLINO.}

19. LEMNA L. G. I I30. Wafferlinfe; Entengrüin. Germ. Ducks Meat. Angl. Canillée, Ğall.

54. Lemıa foliis petiolatis lanceolatis. LINN. Syft. pæog. trifulca 840. вовнм. ก. 854 .

Entengrün; Waferlinfe. Germ.

In forfis ftagnantibus et pifcinis omnibus fere vḅique copiofe. Fl. Inl. Aug:

Obf. Caulis complanatus, proliferus, femper de. cuffatus.

55. Lemna foliis feffilibus vtrimque planiufculis, radici- minor. bus folitariis. LINN. Sylt. p. 840. воЕнм. n. 855 .

$$
\text { B } 3 \text { Pharm. }
$$


Pharm. Lentis palufiris Herba.

Kleine Wafferlinfe. Germ. Small Ducks Meat. Angl, Lentille d'eau: Gatl.

In aquis quietis vbique. Fl. Iun. Iul.

$V \int$. Anatum cibus gratifimus.

zibba. 36. Lemna foliis feffilibus fubtus hemifphaericis, radicibus folitariis. L1NN. Syft. p. 84 . n. 3 .

In foffis, lacubus aquisque quietis, bei Altranftidt copiofe et alibi. Iun Iul.

Obf. GERARDYS hanc pro varietate Lemnae mino. ris laabet.

polyrrhiza. 57. Lemna foliis fefillibus, radicibus confertis. LINN. Syft. p. 84I. schreb. Spic. pag. I I4. n. 1099. Icoń. Roef. inf. 3. t. 73. 74. f. 12. t. 94.

Vielum:liclute IVafferline. Germ.

In foffis tagnantibus inter duas priores immixtam faepius vidi. Fl. Iun. Iul.

\section{FLORE DICLINO.}

20. SALIX L. G. I20I. Weide. Germ. Willow-tree, or Sallow. Angl. Saule. Gall.

a) Foliis glabris ferratis.

monandra 58 . Salix foliis ferratis glabris, lineari-lanceolatis, fuperioribus obliquis. поғм. Hiftor. Salic. p. I8. Tab. I. f. I 2. T. V.' f. I.

Salix (purpurea L.) foliis ferratis glabris: lanceo: latis, inferioribus oppoftitis, LINN. Syft. p. 879, n. I2. SCHREB. Spic, p. 69. n. 1024 .

- Gemęine rothe Weide; Hagenueide; purpurothe Weide. Germ. Pourple or Red Willow. Angl. Ofier rougge des vignes. Gall.

Ad ripas et foffas circa vrbem paffim. Fl. April. Capr. Maio maturefcunt.

Obf. Haec fpecies ifui Cynipis falicis maxime expofita, qua de re Rofae fic dictae Salicis in ea obfervantur. Caeterum valde vtilis eft ad fepes et ripas muniendas, porro crates corbesque ex ea confici porfunt, 
59. Snliv foliis oblongo lanceolatis ferratis glabris, flo--triandra. ribus triandris, WILDEN. prodr. Berol. n. 9. LINN. Syft, p. 879. n. 2. SCHRED. p. 68. n. 1022. нOFM. Hiftor. Salic. p. 45. 'T. IX. f. $1-4$.

Mandciuerde; Bufchueide; Bachereide f. gemeine Korbueide. Germ. Snouth, or Triandrous Willowe. Angl. Saule ì trois étamines. Gall.

In humidis locis ad ripas fluminum; e. g. an $\mathrm{der}$ Pleiffe, et ad ripas foffarum copiofe. Fl. April.

$V \int$. Cortex huius leniter adftringens et amarus. Decurt. huius aquofum cum vitriulo martis nigro inficit colore. In febribus tertianis a nonnullis cortex cum opimo euentu eft adhibitus.

6o. Salix foliis ouatis, acutis, ferratis, glabris, floscu- pentandra, lis pentandris. IINN. Syft. p. 879. n. 3. SCEzEg. pag. 68. n. 102r. Wild prodr. Berol. n, 10.

Pharm. Salicis loureae Cortex.

Fünfuninnige Wcide; bittere f. Baunzwollen. Weide; Lorbecrartige-f. Fanlweide. Gcrm. Swect-fcentedt or Bay-leaved Willore. Angl. Saule rouge. Gall.

Ad oras Pliffae paffun et in falicetis vbique im. mixta. Fl, April. Maio. Capf, Oztobri maturefcunt.

$V \int$. Ob copiam maiorem melliginis, quae in hac fpecie facpe deprehenditur, apes falutant flores. Pappus pro bombycis fuccedaneo fubftituitur. Salix ad ambulacra fepesque idonea.

6r. Salix foliis ferratis, ouato lanceolatis, acutis, fu- vitellina. pra glabris: ferraturis cartilagineis, worm. Hiftor. Salic. p. $5 \%$ Tab. XI. XII. f. $I-3$.

Salix Vitcllina foliis ferratis, ouatis, acutis, glabris: ferraturis cartilagineis; peticlis callofo punetatis. LYNN. Syft. p. 879. n. 6. вовн.M. n. 70I.

Gelbe Weide; Dotterneeide; Goldweide. Germ. Yellowe or golden Willowe. Angl. Sante Ofier, on Bois jaune. Gall.

Ad vias et ripas Elyftri et Lupac. Fl. Mai. Cap. Iu. nio marurefcunt.

Vf. Cortex iuniore in aetate lutefcens, adultus cinereo-luteus, faporis amari, adftringentis. ExtraÊtum amasum febrifuga vi, ficuti plures falices, gauB 4 dere 
dere; CEL. HOFMANNis putat. Ex pappis papyrum ruden fragilemque scrabervs confecit. Lignum huius flexile od ligamina ruficorum, ad corbes taciendos vitesque vinciendos, valde vile.

mygdalina, 62. Salix foliis ferratis, glabris, lanceolatis, petiolatis; ftipulis trapeziformibus. LINN. SyAt. pag. 879. n. 7. BOЕнM, 12. 697 .

Mandel-1. Pfirfichuecide. Germ. Almond-leaved Willow. Angl. Saule ì feuilles d'Amindier, ou 'Bullain. Gall.

Ad fepes hortorum et inter faliceta frequens. Fl. April. :

fragilis. 63. Salix foliis ferratis, glabris, ouato-lancenlatis; petiolis dentato glandulofis. LiNs: Syft. p. 879. n. 10. SCHRE. Spic. p. 6\%. n. 1020 .

Pharm. Salicis fiagilis Cortex.

Bruchueide. Rofs-Sprock-Knackerzeide. Germ. Crak Willow. Angl, Saule caflant. Gall.

In aquolis locis vbique. Fl. Aprili.

Babỵlonica. 64. * Salix foliis ferratis, glabris lineari lanceolatis, r.3. mis pendulis. LINN. Syft p. 879. n. II. 'GMEL. Sib. III. p. 309. t. 3- fig. 2 .

Salix oricntalis, flagellis pulchre deorfum penden. tibus. TOVRn. Coroll. $4 \mathrm{I}$.

Salix Arabica foliis atriplicis C. B. P. p. 475 .

Morgcalandifche Hangcl- Babylonifche Thranenweide. Germ. Babylonian, or Wieping Willowe. Angl. Saule plcurcux. Gall.

Ex Oriente, vbi proprie fponte crefcit, in Europam transportata eft. Apud nos in locis publicis parim occurrit, vtpote fpecimina nonnulla in Cocmeterio Si. Iormis ante multos annos et ruperrime in Serto polt montem Schneckenberg fic diktum, culta, reperi. Praeter hace loca in multis hortis fuburbanis colitur. Nondum flores emittere vidi. Hyemes noftrates ven hementiffmos haud facile perfert.

Inelix. 65. Salix foliis ferratis, glabris, lineari lanceolatis: fuperioribus oppofitis obliquis. IINN. Syft. p. $89 \% \cdot \mathrm{n}$. I3. ВОЕНM, ก. 699 . 
Bach-Sandieecide; braune Weide; Heck- f. Rofensueicle. Geãm. Kofe or Ycllowe dreayf Willow Angl. Saule Hélzce. Gall:

Ad omnes fere publicas vias frequentifime. Fl.April.

Obf. Folia magis lineari -lanceolata, quam lanceolato-linearia. Flores monandri.

b) Foliis integerininis villofis.

66. Salix foliis integerrimis vtrinque villofiś, oboua- aurita. tis, apendiculatis. t.rNn. Syft. p. 880 . n. 22 sCFrRez. Spicil. p. 69. n. 1025. nofM. Hift. Salic. p. 30. - Tab. IV. f. I. 2. Tab. V. f. 3 .

Die kleine rundblattrige Werftreeide; Salbeyreeide; geölurte. Weide. Germ. Round-leaved IVillowe. Angl. Saule ì oreilles. Gall.

Ad pratorum foffas et in pratis ipfis humidis. Fl. Mai. Capf. Iun. maturefcunt.

67.* Salix foliis integris, ouatis, acutis, fuprafubuillo- arenaria, fis, fubtus tomentofis. LiNN. Syft. p. 880. ก. 25 .

Salix pumila foliis vtrinque candicantibus et lanuginofis. C. B. P. p. 474. GMeL. Sib. I. p. 164. t. 36. tig. 1 .

Kleiner rauher Bruch-WViefenwerft; kleine Silberweeide. Germ. Sand Willow. Angl. Saule des Sables. Gall.

In pratis paludofis ad fofficulas, e. g. ad pagum Wölkau; porro quoque in nemoribus vliginofis, arvis et agrorum limitibus, pafinin. Fl. Aprili, Maio.

Obj. Filnnenta 2 alba. Anth. flauxe. Germ. lanceolatum, pubefcens. Styl. 2. breuiffimi, ex brunno: nigricantes. Stign. fimplicia, obtufa. Scm. pappofa. 68. * Salia foliis integerrimis lanceolatis, fubtus villo- incubacen, fis nitidis, ftipulis ouatis acutis. zINN. Syft. p. 880 . n. 26 .

Niedrig kriechende Mattcnueide. Germ. Saule nichear. Gall.

In pratis vliginofis et arenofis humidis bei Belgers. hayn; Pomfen; Holzhaufenz; porro inter Litzen et IVeifenfels in agrorum limitibus alibique fparfim mihi occurrit. Fl. Aprili.
B 5
c) Fo. 


\section{c) Foliis fubferratis viliofis.}

saprea, 69. Salig foliis ouatis rugofis fubtus tomentofis, vndatis, linperne denticulatis. LINiN. Syft. p. 880 . n. 30. воент. n. 700 . horn. Hift. Salic. p. 25. Tab. III. f. I. 2. Tab. V. f. 4. Flor. Dan. t. 245 .

Var. a) Salix foliis oblongis, fubtus villofis, inferioribus excauatis; fuperioribus integris IINN. Flo Lapp. p. 293 . n. $36 \%$.

b). Sal. foliis integerrimis, ouato lancèlatis, fubtus fericeis iulis ouatis. Hall. Hift. $165 \mathrm{I}$.

Pharm. Cort. Salicis Capreae.

Rundblättrige Sohl-Sahl-Seilweide; grofse Werftweide; Geifsevcide; Palmenzeidle." Germ. Broad round lenved Sallowe or Common-Sallvir. Angl. Saule Marcean, ou Saule à fouilles rondes et larges. Gall.

In dumetis, ad fepes hortorum et ad foffas. 'Fl. April. Capf. Maio maturae.

Vf. Cortex eius a Cel. grnzio in febribus laudatur. Ramulorum cortice biennium ad pelles varias manicarum perficiendas in Danio vtuntur. Caeterum fila lintea colore tingit nigro. Carbones huius ligni ob conceprionem ignis citifimam ad pulueris tormentorum praeparationem adhibetur. Flores apibus pabulum. Folia pecora auide deuorant,

viminalis. 70. Salix foliis fúbintegerrimis, lanceolato-linearibus, longiffimis, acutis, fubtusfericeis, ramis virgatis. LiNN. Syft. p. 890. ก. 3 I. BOEIIM. n. 698. - HOFM. Hift. Salic. p. 22. Tab. II. f, I. 2. T. V. f. 2.

Band-Haar-Fifcher-1, Seilweide; Krebs.-Ufer-Korbzeide. Germ. Ofier Willowe, Akigl. Zenigole. Gall.

In humidis ad ripas copiofifline. Fl. April. Mą. Capf. Iun. maturae.

alba. 7I. Salix foliis lanceolatis, acuminatis, ferratis, vtrinque pubefcentibus: ferraturis infimis glandulofis. LINN. SyAt. p. 880 , n. 33. вовнM. ก. 696. ногм. Hiftor. Salic, p. 4II. T. VII. et VIII. fig. I. 2. TơRN. t. 590. BLACKW, t. 327 .

Pliarm. 
Pharm. Salicis albae Folia, Semen et Cortex.

Gemeinc Weide; reeiffe Weide; Silberveide; Korb. zeeidc. Germ. Common or wehite Willoze. Angl. Saule blanc ordinaire; ou commun. Gall.?

In locis humidis, viisque publicis et hortis copio. fe, et ad fopes hortorum haud infrequens. Fl. April. Maio: Capl Iun. maturefcunt.

Vf. Cortex adfringens eiusque decotum putsedini refiftens. Iuniorun ramulorum cortex contra febres intermittentes et lumbricos ab haRTMaNNo aliisque commendatur. Lappones decoctum contra dolores colicos adhibere folent. Extratum corticis medii in pulmonibus vlceratis leudatur. Cortex in cupreo vale coctus lanea et fericea fanguinco, acdito alumine, cinnamomeo inficit colore HofMans. Porro quoque fertur, hano fpeciem in regionibus calidioribus Mannam exfudare. In foliis fpuma alba obferuatur.

\section{E FLORE POLYGAMOIDE.}

i1. FRAXINVS L. G. I273. Efche. Germ. Arh Tree. Angl. Frêne. Gall.

72. Fraxinus foliolis ferratis, floribus apetalis. LiNN. excelfior" Syft. p. 918. вовнM. r. 7ro. (fub Orno) BLAKW, tab. 328. CRAM. t. 8 .

Pharm. Fraxini Lignum, Cortex, Folia, Se. mina.

Gemeine Efche; Wald f. Edel Efche. Germ. Contmon $A \int_{h}$. Angl. Frêne trés:élevé, ou nudiflore. Gall.

Ad fepes paprorum, v. c. bei Eitritfch, et circa do. mos pagorum frequens. Fi. Aprili. Arbor.

Obj. Arbufculas iuniores toliis vtrinque grlabris, masgine integerrimis fupra obfcure viridibus, in horto Lechriano vidi.

Vf. Semina huius arboris in Pharmacopoliis fub nomine Linguae Asis referuantur. His vero feminia 
bus vis diuretica, antipleuritica et aphrodifiaca attribuitur. Lignum adftingens, et Corticis decolum, cum Gentianae radice et Sale abfynthii, loco Corticis Peruuiani, contra febres laudatur. Ligno tenui, duro, architecti, tornatores et fcriniarii ad inftrumenta fabricanda vtuntur. Ob incrementi celeritatem praeciptse in loco spto diligentius coli meretur. Arbores vero alias hermaphroditae; Femineae contca, aliae, deprehenduntur. 


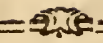

\section{Claffis III. \\ T'R I A N D R, I A}

MONOG Y NIA.

\section{$\begin{array}{llllllll}S & E & C & T & I & O & I\end{array}$}

\section{A. FLORE HERMAPHRODITO.}

a) Flores fuperi, completi.

\section{VAlerianA-L. G. 48. Baldrian. Germ. Va- lerian. Angl. Valeriane. Gall.} 73. Valeriana floribus triandris dioicis, foliis pinnatis, dioica.
integerrimis. LINN. Syft. p. \$O. n. 4. вовнм. n. $9 \mathcal{E}$. BLAKw. t. 484. Fl. Do\%? t. $68 \%$.

Var. «) Val. Mas paluftris minor.

- B) Val Foem. paluftris inodora, parum laciniata, foliis fubrotundis.

Unehelichsr Baldrian; Wiefen-Baldrian; kleiner Sumpf-Baldrian. Germ. Marls Valerian. Angl. Va leriane des marins. Gall.

In pratis humidis et fpongiofis, e. g. in pratis Schoenfldicis copiofe, inprimis Mares.inueniuntur et alibi copiofe. Fl. Maio. Perennis.

VJ. Plebs herba acetariae loco vtitur. Pabulum pecoribus gratum.

74. Valeriana fioribus triandris, foliis omnibus pinna- officinalis. tis. LINN. Syft. p. 80. n. 5. BOEHM. n. 97. BLACKW. t. 271. Fl. Dane t. 570 . sc xvHR.t. 5.

Var. Valer. folitis anguftioribus.

Pharm. Valerianae Sylueftris Radix. 
Gebrauchlicher Baldrian; Katzentheriak; Magdalenenzentrzcl. Germ. Great Wild Valerian. Angl. Valeriane fanvage. Gall.

In pratis paluftribus, frequentifime in pratis Scloconfeldicis et Gerberweafer; porro in pratis ad Sclileufig et poft Gundorf. Var. im Bieniz ct quidem in colle prata verfus faepius mihi occurrit. Fl. Iun. Iul. Perennis.

$V \int$. Ab ouibus herba deuoratur; equi contra hane, refpunt. Felium radix eft amafia. Radix etiam contra vermes commendatur.

a) olitoria. 75. Valeriana Locu/ta foribus triandris, caule dichotomo, foliis linearibus, fructu fimplici. LINN. Syft. pag. 80. n. 16. var. $\alpha$.

Val. (olitoria) foliis lanceolatis integris, fruetu fimplici. ninn. Cliff, 16. военм. n. 99. - Flor. Dan. tab. 738 .

Ackerbaldrian; Ackerfalat; Limmerlattich; Schafmiuler; Sonnenzeirbel; Feldkrappe; Niifschcnfalat; Rapunzchen. Germ. Doucctte ou Mache, Gall.

Inter fegetes et in aruis auf dem Gickerlingsberge; hinter der Leimgrabe; porro in propugnaculo inz grinumifchen Zwinger. Fl. Maio. Annua.

Aues et oues auide quaerunt. Herba quoque praebet acetariam bene fapidam.

b) dentata. 76. Valeriana Locufta, caule dichotomo, foliis oblongis, fubferratis; feminis corona tridentata. HALl. 666. n. 2. (fub_Valerianella) LiNn. Syft. p. 80. n, 16. var. E. dentata.

Gezîhnter Ackerbaldrian; Spater Lämmerlattich.

In agris inter fegetes nach Gonnewitz; poft Wolckwizz; ad Wölkau; Sechaufen etc. frequenter reperi. Fl. Iul. Aug.

b) Flores inferi, completi.

23. POLYCNEMVM L. G. 59. Knorpelkraut. Germ.

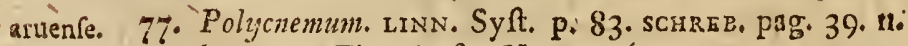
962. JACQ. Flor. Auftr, V. 4. t. 365 . Acker. 
Ackerknorpelkraut; Klcinkanpferkraut. Germ, Po. bycieme des champs. Gall.

In apricis aridis, am Bieniz, et anf dem Sandberge ad Nauendarf eic. anno praeterito mihi quoque oc. currit. Fl. Iul. Aug. Annua.

B) Flores fuperi incompleti.

24. GLADIOLVS L. G. 63. Schwertel. Gcrm. Gladiole. Angl.

78. Gladiolus foliis enfiformibus, floribus diftantibus, communis, LINN. Syft. p. 86. вовнм. n. IOO. SCK'VHR, t. 6.

Genteiner f. rother Schwertel; Siegwurz; Allermannshannifch. Germ. Common Gladiole, or Corn. Flag. Angl. Giayeul. Gall.

In pratis pinguioribus et fubhumidis hinter Kleindölzig nicht reeut von dem Bientz, paffim mihi occurrit. Fl. Iun. Iul. Perennis.

$V \int$. Caritate annonae graffante radix loco panis commedi poteft. Flores apibus pabulum. Nomen germanicum Allermanusharnifch plantae ab hominibus fuperftitiofis attributum eft propteres, quod imaginant homines, hanc herbam fecum ferentes, vulnerari non polfe.

25. IRIS L. G. 65. Schwerdlilie. Germ. Gladwyn. Angl. Flambe. Gall.

* Barbatae (quarum petala patentia pilis inftruuntur).

a) Foliis enfiformibus.

79. Iris barbata foliis, enfiformibus, glabris, foliatis germanica. breuioribus, 'fcapo multifloro. Linn. Syft. p. 89. n. 9. вовнм, n. 4. вLACKW. t. 69.

Pharm. Ireos Noftratis Radix.

Teut fche Schwerdlilie; geneine blaue wilde Schwerdlilie; Violenweurz. Germ. Common German Iris. Angl. Iris vulyaire ou Flambe. Gall.

In pratis vliginofis, rarius inter Linderiau et Leut fch; porro etiam in maceriebus, v. c. in pago fic dicto Kleindölzig. Fl. Mai. Iun. Perennis. 
Vf. Radix acris, purgans et pellens vulgo contra Hydropem adhibetur. Corollae viridi colore tingunt cxpreffo fucco, cum alumine cocto, pro fcriptura. LINN.

$$
\text { ** Inberbes. }
$$

a) Foliis cufiformibiss.

pfeud. Aco- 80. Ir is imberbis, foliis enfiformibus, petalis alternis rus. figmate minoribus. LINN. Syft. p. yo. n. I8. Бовнм. n. 3. BLACKw, tab. 261. Flor. Dan, tab. 494. sckvHR, teb. 5 .

Pharm. Acori paluftris Radix.

Gelbe Wafferfchuerdlilie; Ackerueurz; falfcher Kal- mus. Germ. Water Flag, or Y clloue Flower de Luce. Angl. Lris jaune desipris ou Flambe d'cau. Gall.

In foris locisque paludofis nach Pfaffendorf; im $R$ ofenthale, in fofficulis vor Schönfeld, nach den Gerberwiefen zu; ad ripam fuminis die Bare bei Grasfeld; copiofe- Fl. Mai. Iun. Perennis.

$V \int$. Vis radicis adftringens, purgans. Pictoribus colorem Aauum exhibet et fuccus coriis tingendis aptus. Pecora hanc refpunt.

\section{b) Foliis lincaribus:}

Sibirica. 91. Iris imberbis, foliis linearibus, fcapo fubtriforo tereti, germinibus trigonis. lins. Syft, p. 9r. n. 33. sCiree. p. I. n. 5. - Iris. BOEIM. n. 5. JACQ. Fl. Auftr. t. 3 .

- Sibirifche Schuecrdlilie; blauer Schrecrtel; Wiefenfcineverdilie. Germ. Siberian or Low Yellowe Iris. Angl. Iris de Sibérie. Galll.

In pratis humidis am Bieniz et in pratis zwifchen Grofischocher and dem Walde copiofe; fperfim quoque im verfchloffenen Holze. Fl. Maio, Iun. Perennis. 


\section{$T R I G \quad Y N I A$.}

\section{HOLOSTEVM L. G. i io. Spurre. Germ.}

82. Holoften floribus vmbellatis. LINN. Syft, pag. vmbellatum 129. 11.4 .

Alfine vimbellifera, foribus claufis. вовнм. n. 3\%9. SCKVHR. t. 16.

Doldenformige Spurre; Nelkengras. Germ. Spanifh Plamanu. Angl.

In locis ficcioribus et aggeribus, fatis frequenter ad vism nach dem Gickerlingsberge et ad parietes hortorum aufferiualb des Thores nach Gonnezeitz, nach der Leimgralbe $\approx u$.

Obf. Flores primum rubello virides, deinde albi, siarcidi, collapfi; apice petalorum cienulato. Stam. 4 , vel 6 paffim numeraui.

\section{MONTIA L. G. 10\%. Montien. Germ.}

83. Montia foliis oblongo-ouatis, fubcarnofis; pedun-fontana, culis vnifloris, fructiferis, deflexis. MoеNcr. Haft. $\mathrm{i}, \mathrm{n}$. IO9. LiNn. Syft. p. 126. LEYs. 11. 134. Fl. Dan. t. 131 . Quellnontien; Waffrbirzelkraut. Germ.

Praeprimis amat riuulas clariores, puriores, vbi maior euadit; nec arua humidiufcula relpicit, ibiminor apparet, vti id ad agrorum margines, wor dem Teiche nach Schönfeld; porro infra ad Tenulum St. Theclae et in agris poft pagum Kriphaene primum mihi nccurrit in magna copia. FI, exeunte Aprili in Autumnum vsque. Annua.

Obf. Caul. teres, tenellus, laeuis, a bafi in ramos oppofitos diuifus : Rami iterum oppofiti, vel fimplicibus pedunculis fatis diftinctis $3-5$, vel pluribus fáciculatim, paflin alternatim oppofitis terminantes. Fol. oppofita, feffilia, oblongo-lanceolata, fíprema ouata, acutiufcula, omnia integerrima, glabra, ex glauco-viridia. Flores parui, albi. Petala albido-flavefeentia. Antherae paruulae, Aause. Pift. Styl. 3 . longitudine corollae. Stign. obtufa, alba et pubefcentia. Sem. fubrotunda, flaua, plura. 
$4=$

\section{S E C T I O II,}

I. GRAMINEI. S. CALAMARIAE.

A. FLORE HERMAPHRODITO.

MONOGY NIA.

๙) Flores glumofi, inferi; Glumis tantum calycinis.

28. SCHOENVS L. G. 7I. Knopfgras. Germ. Choin, Gall.

* Culmo tereti.

Mariscus., 84. Schoenis culmo tereti, foliis margine dorfoque aculeatis. unNo. Syft. p. 95. n. I. вовнn. n. 6540BLACr:w. t. 316.

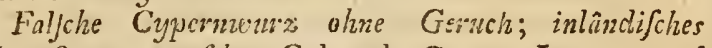
Knorffgras; teutfcher Galsand. Germ. Long-rooted. Baftard Cyperas. Angl. Choin marisque. Gall.

In locis viginolis et paluftribus, e.g. in pratibus Schoen. feldicis, porro anf den Gerberwiefen; anf der Wiefe Ruckmarfchdorf gegen ïber etc. Fl. Iul. Aug.

$V \int$. Gramen paludibus profundis et celpitofis ap. tum. Foliis rufticani ad domos tegendos vti poffunt. ** Culmo triquetro.

compreffus. 85. Schocintes culmo fubtriquetro nudo, fpica difticha, inuolucro monophyllo. LINN. Syft. pag: 9I. n. 10. LEERS Fl. Herb. n. 32. t. 1. f. x.

Zuffommengedriicktes Knopf gras. Germ. Compreffed Baftard Cyperus. Angl.

In viiginofis et pratis paludofis, e. g. auf der Ruckmarfch́lorfor Wiefe, porro anf der Wiefe unten am Bie. niz, praeterito anno iuueni copiofe. Fl. Iun. Iul. 
86. Schoezus culmo fubtriquetro foliofo, fioribus fafci-albus, culatis, foliis fetaceis. LINN. Syft. p. 96. n. I3. schreb. Spic. pag. 6I. n. ICO8. Fl. Dan. tab. 320. sckvhr. tab. 7.

Weifcs Kaopfgras; recifo falfelue Cyperterus. GermWhite flowering Rufli-grafs. Angl. Choin blanco Gail.

In paludibus circs Lipfiam olim Burjerius inuenit; mihi quoque in pratis ante pagum Schoenfeld occurrit. Fl. Aug. Septembr.

29. CYPERVS L, G. r2. Cypergras, Germ. Souchet. Gall.

87. Cyperus culmo triquetro nudo, vmbella 3. phyl- fauefens, la, pedunculis fimplicibus insequalibus, lpicis con-

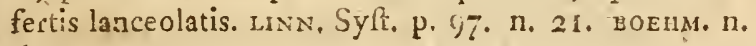
6.9. - sCrvir. t. 7 .

Gelblichtes Cypergras. Germ. Yellow Cypêrus. Angl. Souchet jaunâtrye. Gall.

In inundatis locis verfus Schoenfeld atque circa pagum Proliftheide et alibi frequens." Fl. Iul. - Septembr.

IJ Cel. svccovivs hoc gramen inter pabula pecorunı retulit.

88. Cyperus culmo triquetro nudo, vimbella trifida, pe. fuicus dunculis fimplicibus inzequalibus, fpicis confertis linearibus. Lins. Syfi. p. 97. n. 22. Еовнм. n. 619.Fl. Dan. tab, 179. LeERs Fl. Herb. tab. I. fig. 2. sckver. tab. 7 .

Schwarzbraures Cypergras; klcine zentfche Cypernsewrz. Germ. Brozez Cyperus. Angl. Souchet brun. Gall.

In paludofis et pratis Spongiofis; porro circa pifcinas et lacus thinzer der Mïlle bei Sclzönfeld atque verfus Abtnamndorf. Fl. Iul. Aug. Perennis. fufcis.

Obf. A priori diftinguitur fpicis angutioribus et 
30. SCIRPVS. L. G. 73. Binfengras, Germ. Scirpe. Gall.

9) Spica nnica.

articulatus. So. * Scirpus culmo tereti, nudiufculo femigeniculato; capiculo glomeratn, Jaterali. LiNn. Syft. p. 98.11. 3 . Gelenkigtes ininfengras. Germ.

In locis paludofis et inundatis copiofe hinter denz Gerberzelefon, porro in parcuis graminibus tenuioribus veftitis, e. g. zwifchen Linderaus et Kleinzfcho. cher et ad Parncck. Fl. Iun. - Aug. Perennis.

palutris. 9o. Scirpus eulmo tcreti nudo, tpiea fubouata, imbricats, terminatrice. IinN. Syf. p. 93. n. 4. вовнм. n. $65+$. LeERS t. I. f. 3 . Fl. Dan. t. 273 .

Sumps Binfengras. Germ. Club Rufh. Angl. Ion. quine ou Yonq is maffe. Gall.

In pratis paludolis fere vbique freguentifime. FI. Maio. Perennis.

VJ. Suibus pabulum deliciofum; oues autem hoc fugiunt.

capiatuss. 91. Scirpous culıno tereti, nudo, fetiformi, fpica fúb-

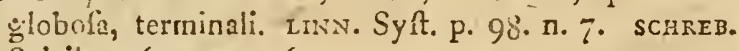
Spicil. p. 60. n. 1006.

Kopftragcindes Binjcugras. Germ.

In limo humido ed ftognorum margines ad Schönt. fill, Lindeizau, Lentfcie, Panneck, et in locis inundatis ipfisque exfiecatis. Fl. Iul. Aug. Perenne.

acicularis. 92. Scirpuls culmo tereti, nudo, fetiformi f fica ouata, biualui; ferninibus nudis. uIsN. Syft. pag. 98. n. 8. Eozina, n. 650. - Fl. Dan. t. 287.

Spicsförmiges 1. Nadclförmiges Binferzgras. Germ. Leaft upriglut Club Rujh. Angl. Scirpe en aiguille. Gall.

In pratis verfus Schönfold, anf den Gerberwiefen, in locis inundatis, pafcuis fublhumidis et circa pagos. Fl. Iul. Aug.

b) Culno tereti polyffachio.

lacuftris. 93. Scirpus culmo tereti nudo; fpicis ouatis pluribus pedunculatis terminalibus, LINN. Sylt. P. 99. n. 10. вовнM. ก. 652.

Kaneel- 
Kamcelfrolı; Teich- f. Seebinfengras; gro/se Pferde f. Weygierbinfon. Germ. Bull Rizh. Angl. Scirpe des étangs. Gall.

In ftagnis et pifcinis maioribus, zwifchen Leutjch et Parneck, in der Bahre nach Schünfeldau, bei Pomfen et alibi. Fl. Iun. Iul. Perennis.

$V \int$. In Succia pro boum equorumque pabulo et tiguris tegendis clitellisque infarciendis valde aptus.

94. Scirpus culmo nudo fetaceo, fpica terminali feffili. fetaceus.

LINN. Syft. pag. 99. n. I 4. SCHREB. Spicil. p. 59. n. I005. LEeRS t. I. f. 6. Fl. Dan. t. 3 II.

Borftenartiges Binfengras; Moosbinfen. Germ. Leaft Rufh. Angl.

In locis paludofis agrorum ad Schocnfeld et circa Atagna ad Lindenthal. Fl. Iul. Aug. Perennis.

c) Culmo triquetro. Panicula nuda.

95. * Scimpus culmo triquetro nudo, fpica oblonga, con-glomeratus. gefta terminali : fub Ipicis folium trigonum fere horizontale. scor. Carn. ed. 2. p.47. n. 63.

Bïfchelfürmiges Binfengras. Germ.

In fofliculis et inundatis ad viam nach der Vogelzeiefe et ad Parneck; quoque in Rofenthale et quoque auf den Gerberzeiejcn, nuperrime inueni. Fl. Iun. Iul. Perennis.

d. Culmo triquetro; Panicula foliofa.

96. Scirpus caule triquetro; panicula conglobata, folia- inaritimus. cea fpicularum Iquamis trifidis: intermedia fubulata.

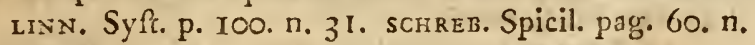
ICOT. ICKVHR. t. 8 .

Var. a) Scirp, maritimus, fpicis omnibus fefilibus. culatisque.

B) Sciro maritimus, fpicis fefrilibus pedun-

Ufer-Binfengras; runder wilder Waffergalgand. Geim. Rotund-rooted Baftard Cyperus. Angl. Scimpe maritime. Gall. 
In follis pratisque ad Schörjeldet inprimis ad Ketfchant. Var. a in locis necioribus. $\beta$ ) in locis humidis temper deprehenditur, Fl: Iunio in Angufum vsque Perennis.

Vf. Radicas nodofae fiscatae et in farinam redactae pauperibus pro pans inferuire poftunt.

Gyldaticus, 97. Scirpus culmo triquetro foliofo; vmbella foliacea; pedunculis nudis, fupra decompofitis; fpicis confertis. LINR: Syft. p. IOO. n. 33. БOEHM. n. 657. Fl.Dan. t. 307. LEERS t. I. fig: 4 .

Waldbinfongus : falfcher Miliz; Hirfegras; Bufchgalgano. Germ. Mille Caperus Grafs. Angl. Scirpe des bois. Gall:

In locis aquofis pratisque humidis fere vbique. Fl. Iun. Inl. Perenis.

Vf. Hoc gramen fyluas reddit foecundiores. Co. medicur ab equis; a fuibus non.

3r. ERIOPHORVM. L. G. 74. Dinngras; Woll- . gras. Gem. Cottengras. Angl. Chenuelle. Gall.

wolyin- 98. Eriophomm culmis teretibus; folis planis; 1picis chion, pedunculatis. IINN. Syft. p. 102, n. 2. воzнiм. n. 655. (lub , Linagrofo): : Leers tab. I. fig. 8. SCKVkr. tab. 8 .

Vieljahriges Dünngras; Batumreollengras; Flachsgras. Germ. Chonuclle ou Linaigrette paniculće. Gall.

In pratis paludofis, praeprimis in pratis Schocnfolelicis copiofe; porro ouf den Wicfeu bei dem Ge* fundbrinnen, lisuter Planfig; bei T'auche etc. copiofe. F1. Iun. Iul. Perennis.

If. Lana pro cateplasmatibus in combuftionibus vfurpatur. Chirothecis, puluinaribus, ellychniis pannis, chartis, pileis, pappis, inferuit.

\section{Syicata.}

B) Flores glumof, infori; Glumis tantum corolla. ceis. 
32. NARDVS. L. G. 75. Borftengras. Gern. Matweed. Angl. Nardet. Gall.

99. Nardus fpica fetacea reeta fecunda. inNn. Syft. pag. ft:iota.

102. ก. 2.' вовнім. n. 598. \&CiR:E. Agroftogr. p. 65.

tab. 7.LEERS t. I. f. 7 . SCKVHR. t. 9 .

Steifes 1. Atarrendes Borfengras; haarformiges Pfrienengras. Germ. Small Matweed. Angl. Narden ferré. Gall.

In locis ficcis et elatioribus, in der Leimgrube, poft Schönfel:t, in Univerfititsholze, bei Pomen. Fl. Iun. Iul. Perenne.

- $0 . b 5$. Vbi hoc gramen crefcit, folum fterile ind: cat. Sabulofis locis tegendis vtile. Caeteruiu e pra. tis exftirpandura.

\section{I G Y I A.}

I. Paniculata.

*) Gmmina calycitus 2 - valisibus, vniforis, vagis.

33. PHALAKIS. L. G. 80. Glanzgras. Germ. Canarygrafs. Angl. Gr. Phalaris. Gall.

ioo. Phalaris panicula fubouata fpiciformi, glumis ea-canarjentis. rinatis. LINN. Syft. p. I03.n. 2. EOEHM. n. 599. SHREB. Agroft. p. 83. t. 10. fig. 2. LEERS t. 7. f. 3 .

Pharm. Canarienge Sem.

Canarienglanzgras; Canarienfamen. Germ. Canarygrafs. Angl. Fhalaris des Canaries, ou Graine de Canarie. Gall.

In agxis circa Lipfiam paffim. Fl, Mai. Iun.

Vf. Paiulum ouibus gratum: Pafferes canaricnfes femina valde amant. Seminum farina pani et cibis inferuiens.

IOI. Phalaris panicula ablonga ventricofa ampla. LINNa arundinacea

Syft. p. 104. n. 8. военм. n. 600. Fl. Dañ. tab. 259.

LEERS t. 7 . . . 3. SCKVHR. t. 9.

Rohrartiger Glanzgras; Ripdstrausgras. Germ. Red Canny. Grajs. Angl. Phalaris rofeau. Gall.: 
In fubhumidis et foffis poft Lindenthal, in pratis hinter Kleincölzig, quoque vero mu Univerfitätsholze fparfim inueni. Fl. Mai. Iun. Perenne.

$V \int$. Pecora culmis iunioribus auide vefcuntur. Varietas:foliis pictis argenteis in' Horto medico, Lehriano culta. Gramen infuper tećtis rufficanis inferuire poteft.

plleoides. 102. Phalaris panicula cylindrica fpiciformi, glabra paffin viuipara. LiN. Syft. p. IO4. n. 5. - Gramen typlioides, fpicis purpurafcente foliacea. scruevciz. Gram. 6-.Fl. Dan. t. 53 r.

Lifchartiges Glanziras; folfches Lifchgras; Rau-pengras. Gerui. : Cyliwdrical fpiked Canary Grajs. Angl. Phalaris pléócde. Gatl. a

In muris limofis pagorum v. c. ad Parneck, Klcindölzig, mihi occurrit. Fl. Iun. Iul.

\section{ALOPECVRVS. L. G. 84. Fuchsfchwanz. Germ.} Fox-tail grafs, Angl. Vulpin. Gall.

pratentis. 103. Alopecuris culmo fpicato, erecto; glumis villofis; corollulis muticis. LIN s. jyft. p. IOO. n. 3. њOEHM. .604. scHRER. Algroft. p. 133.t. 19. f. 1. LEERS t. 2.f. 4. scrivik. $t$ I I.

Wiefenfuchssclureanz; Kolbengras; Taubgerfte. Germ. Meadou Fax-tail:grafs. Angl. Fulpiu des près. Gall.

In pratis fyluaticis, e. g. in Refenthale valde frequens, in pratis Schocnfildicis, bei Lcutfch, Plaufig, Stetteritz, Kleindölzig, Schörzau, et alibi valde vulgaris. Fl. Iun: Iul.

Obf. Culturam liuius graminis Angli commen-
dant.

2greftis. 104. Alopecurus culmo fpicato eręto, glumis laeuibus. LINN. Syft. p. IO4. n. 4 .

Gramen fpicatum fpica cylindracea tenuifima longiore et breuiore. TovrN. pag. 522. n. 82. 83 . sCHreb. Agroft. p. 140. t. I9. f. 2. Fl. Dan. tab. 697. LEERS t. 2. f: 5 .

Ackerfuchsfchwanz, klein Fuchsfanert. Germ. Iointedarifta or Field Fox-tail grafs. Angl, Vulpin des Chanzps. Gall. 
In folo limofo, e. g. in agris nach dem Gefundbrunazen zul faepius et palim hinter Tauche deprehendi. Fi. Mai. Iun.

105. Alopecurus culmo fpicato infracto, corollis muti-genicularus. cis. LiNn. Syft. pag. iO8. n. 5. вовнм. n. 603 - Fl. Dan. t. $6 \%$. LEERS t. 3. f. 7 .

Knicfürmiger Fuchsfchwanz; klein Fluttgras; krie. chend Spiesgras. Germ. Flote Fox-tail grafs. Arigl. Vulpin genouillé. Gall.

In locis inundatis valde, copiofe im Rofenthale in pratis Schoenfẹldicis aliisque multis et fere vbiquẹ. Fl. Mai, Iun-

Obf. Ouibus pabulum obnoxium Gleditfchius refert.:-

35. MILIVM. L. G. 85. Milisgras f. Hirfengras.

Germ. Millet-Grafs. Aingl. Millet. Gall.

106. Milium floribus paniculatis difperfis muticis. effurum.

LINN. Syft: p. IO9. n.,5. BOEHM. n. 609. LEERS t. 8.

f. 7 . SCKVHR, t. I I.

Milisgras; Fladdergras; Waldhirfe. Germ. Scaterect-flozeered Millet-Grafs. Angl. Millelot épars. Gall.

In fyluis vmbrofis, im Rofenthale, Univerfititts: holze, poft Leut fch et im Bieniz. Fl. Mai. Iun.

,Vf. Tinias et alia infecta pellit.

36. AGROSTIS. L. G. 86. Strausgras. Germ. Bent-grafs. Angl. Eternue. Gall.

a) Arifatae.

107. Agroftis petalo exteriore arifta rectá ftricia longif- fpica venti. fima, panicula patula. LINN. Syft. pag. I10. n. I. zoen. n. 6io. Flor. Dan. tab. 853 . leers tab: 4. fig. I.

Acler-Strausgras;, Feld- S. Santgras; Windâliee. Germ, Silky Bent-grafs. Angl. Eternuté ćrentće. Gall. 
In agris inter fegetis copiofe vor den Schönfelder Pförtcheri, in pratis et ad aggeres der Pleifie anf den Wege vor deni Brandworwerke, porro in agris ficcoribus arenofis verfus Gonazereitz, anch den Gefuadbruitwen $\approx$, et alibi. Fl. Itan. ivil.

VS. Recens gramen pạbulumbonum; in adultiore attate gingiuas laedit. Culmi cafis ftramineis tegendis orbibusque conficiendis apti. Succus fpicularum externarum colore tingit viridi. Caeterum hoc gramen eft vitium agrorum.

arundinacea I08. Agroftis panicula oblonga, petalo exteriore bafi villofo ariftaque torto calyce longiore. LinN. Syft. p. IIO. n. 6. SCHREB. Spicil. p. 46. 11. $975^{\circ}$

Rohrartiges f. Jchilfig Strausgras; Dillengras. Germ, Arundinaccous Bent-grafs. Angl. Eternue rofeau. Gall].

In nemoribus, in Bieniz et Univer/itatsholac frequenter, in Rofenthale rarius. Fl. Iun. Iul. P'erenne.

$\therefore$ Obj. Culmi adeo flexiles funt, vt ex is orbes ftramineos ftragulaque conficere poffimus. Infuper calmi fiftulae hauriendo fumo tabaci inferuientes iisdem purgare folemus. Calmuci cafas his operiunt.

rubra, 109. *Agrcfits paniculae parte inferiore forente paten. -2 tifima, petalo exteriore glabro, arifta terminali, tortili, recurua. Linn. Syft. p. I10. n. 9.

Rothes Strausgras. Gernı. Red Bent-grafs. Angl. Eistrute rouge. Gall.

In locis fterilioribus, e. g. in der Sandgrube, auf den Bieniz, copiofe mihi occurrit. Fl. Iun.

canina. 110. Agroftiscalycibus elongatis, petalorum arifta dorfali recurua, culmis proftratis fubramofis. LiNN. Syft. p. INO. n. I3. SCHREB. Spicil. pag. 47. n. 976. LEERS n. 52 . t. 4. f. 2 .

Hundsfirausgras; braunes odes liegendes Strausgras. Germ. Browen Bent-grafs. Angl. Etemue genouillée. Gall.

In agris arenofis et ad eorum margines hinter Schönffld horrosque olẹraceos, et ad viam nach L $₫ u t$ fch, alibique, Fl. Iul. Aug. 
Obf. Similis Agrofit capillari, fed vt plurimum proftratis culnis faepe bali repentibus ab illa difinguitur.

\section{b) Muticas.}

III. Agroftis panicula ramulis patentibus muticis, cul- ftolonifera, mo repente, calycibus aqualibus. LINN. Sy?t. p. III. л. I6. военм. n, 6I I. Flor. Dan. t. 56 . LeERs tab. 4. fig. 6.

Auslaufendes Strausgras. Germ/ Creping Bent-grafs. Angl. Eternute traçante. Gall.

In verfuris ficcis et pratis, e.g. ad Templum St. Theclae et in foffis ad viam mach Sichönfeld Fl. Iun. Iul.

I 2. Agroftis panicula capillari patente, calycibus fu-capillaris, bulatis aequalibus hifpidiufculis coloratis, frosculis muticis. LiNn. Syft. p. 11 1. n. 17. schreb. Spicil. p. 48. n. 978 . - stilling. Fl. mifc, t. 3. Fl. Dan. tab. 16.. LEERS t. 4. f. 3. sckVIR. t. 12.

Hanrförmiges Strausgras; Berghirfe. Germ. Fine Bent-grals. Angl. Eternue chevelue. Gall.

In pratis, ad margines fluminum, v. c. an der Pleifge bei dem Brandvorwerke, in verfuris pomarisque et fere vbique copiofe. Fl, Mai. - Iul.

Obf. Hace fpecies quoad magnitudinem variat; nam in locis humidis valde maiorem, quam in ficcis, deprehendi.

Vf. Eft pabulum valde gratum atque Lichenes eruit.

I13. Agroftis panicula laxa, calycibus muticis aquali-alba. bus, culmo repente. IINN. Syft. p. III. n. 19. ВоEнM.

n. CO2. - LEERS n. 55. t. 4. f. 5.

Weiffes Strausgras. Germ. White-Bent-grafs. Angl. Eternue blanclar. Gall.

Obf. Haec poiius Agrofois capillaris effe videtur varietas. Crefcit in pratis et fubhumidis copiofe cum priori immixta. Fl. Mai. - Aug.

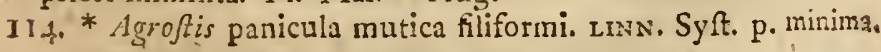

- IIJ. n. 21 .

Gramen minimum paniculis elegantiffimis. C. B.P. II. ก. 6 . 
Sehr kleines Strausgras, Germ. Snal Bent-grafs. Angl. Eternue mnneur. Gall.

In locis framinibus veftitis arenofis ad viam nach Lindenthal, etism in Bieniz. Fl. spril._-iul.

vinealis. I15. Agrofis calycibus coloratis, petalorum arifa dorfali longitudine fere calycis, culmis adfcendentibus. SCHREB. Spicil. p. $4 \%$ n. $97 \%$. c. Syn, SCHEVCHz.

Bergftrausgras. Germ.

In ficcioribus et aridis ad Schönfeld; porro ad Templum St. Theclac. Fl. Iun. Iul.

Obf. Ab Agro i. carina, fpiculis dupl. maioribus, diftinguitur. Varietas ariftis ad lineae longitudinem in Pineto ad Lindenthal aliisque in locis Ill. schrebervs de texit.

\section{STIPA. L. G. 96. Pfriemengras. Germ. Etiepe. Gall,}

pennata. I 16. * Stipa ariftis lanatis. IINN. Syft. pag. I2I. LEYs. - Hallenf. n. 72 .

Gramen fpicatum ariftis pennatis. TovrN. p. 5 I 8 .

Gefiedertes Pfrienengras; Marienflachs; federreiches Stransgras; Sandfedern. Germ. Feather-grafs. Angl. Etieqse empennée. Gall.

In locis arenofis elatioribusque bei Sckcuditz atque poft hanc vrbem, porro bei Pomfen ante plures annos reperi. Fl. Mai. Iun. Perenne.

iuncea. II S. Stipa ariftis nudis erectis, calycibus femine longioribus, folipis intus laeuibus. LxNN. Syft. pag. I 21 . ก. 2 .

Feftuca glumis vnifloris, ariftis longiffmis nudis. тоенм. п. $64 \%$ c. Syn. Gmel.

Bingenartiges Pfricmengras; Nadelhaber; Sandpfricmen: Germ. Stipe joncicre. Gall.

In apricis et afperis. Fl. Iun. Iul.

sapillara. $118 . *$ Stipa arifis nudis curuatis, calycibas femine longioribus; foliis intus pubeficentibus. IINN. Syft. p. 121. n. 3 .

Stipa ariftis nudis flexuofis, calyce femine longiore, HALL. Helv. n. 1513 . 
Zartes Pfricinengras; Nadclwacht. Germ. Stipe ou Etiepe capillaire. Gall.

Ad viam publicam poft Altranfïdt, verfus KetSchau paffim; porro in vinearum collibus circa Nauenburg copiofe. Fl. Iulio et Augufto.

Olf. A priori valde differt, foliis angulatis, rigidioribus, breuioribus, minus fabris, latere fuperiore magis explanatis, paululum pubefcentibus. Calyce fpadiceo et ariftis breuioribus adultioribusque varie curuatis.

в) Calycibus 2-valuibus, bifloris, vagis.

38. AIRA. L. G. 87. Schmelengras. Germ. Hairgrafs. Angl. Erbin ou Canfe. Gall.

\section{* Muticae.}

119. * Aira panicula oblonga, fecunda, mutica, imbrica- arundinacea ta, foliis planis. Linn. Syft p.' 3 It.

Rohrartiges Schmclengras. Germ. Anundizaceous Hair - grafs. Angl. Erbin rofeau. Gall.

In nemoribus, in Univerfitätsholze, rarius, praeterito anto inueni. Fl. Iun. Iul

120. Aira panicula patente, floribus muticis laeuibus, aquatica. calyce longioribus, foliis planis. LINN. Syft. p. I12. n. 3. schired. Spicil. p. 79. n. 98: Fl. Dan. t. 38r. Var. a) fpiculis 6 - floris, flofeulis valde remotis.

Wafferfchnelengras; Quellgras; fiffes Waffergras; Wafferhirfe. Germ. Water Hair-grafs. Angl. Foin ou Erbin aquatiguc.

In pratis et forfis fallis ad Ketfchau. Var. $\alpha$ ) in ficcis locis et ad vias inundatas, in pratis hinter den Winklerifchen Garten, et in fofficulis hinater den Kohlgärten. Fl. Iun. Iul.

\section{** Ariftatae.}

121. Aira foliis planis, panicula patente, petalis bafi caefpitora. villofis ariftatisque: arifta rect breui. LisN. Syft. 
paz. I 2. n. 6. :военм. n. 6I5. Fl. Dan. tab. '240, LEERS t. 4. f. $\mathrm{S}$.

Rafenfcimelen; glänzende Schmiclen; Ackerfchniclen; Ackervielzgras. Germ. Turfy Hair-grafs. Angl. Erbin des gasons. Gall.

In pratis humidis et agris inter fegetes. Fl. Iun.

Vf. Pabulum ouibus maxime gratum. Vfilagini facpe of expofita.

flexuofa. I22. Aira foliis fetaceis, culmis fubnudis, panicu'a divaricata, pedunculis flexuofis. LiNn. Syft. p. 1i2.n. 7. sehreb. Spic. pag. 50. n. $98:$ Fl. Dan. tab. $157^{\circ}$ SCHREB. Agroft. p. 57. ^. 30. LeERS t. $5 . \mathrm{f} .1$.

Drath- f. gebogene Schmelen; Silbertocksbart; Bufcheraldgras. Germ. Erbin tortieus. Gall.

In ncmoribus, im Univerfitätsholze, in Holze ah der Ziegelfcheune bei Meisdorf. Fl. Iun. Perenne.

uontana. 123. * Aira foliis fetaceis, paniculata angutata; fosculis bali pilofis ariftatis: arifta tortili longiore, LINNo Syft. p. 112. n. S. LEers n. 61. t. 5. f. 2 .

Ecrgfchnelen. Gem. Mountain Hair-grafs. Angl. Foinin des Montagnes. Gall.

In locis montolis im Bieniz et fparfin auf dem Gickerlingsberge inueni. Fl. Iun.

canefcens. 124. Awa foliis fetaceis: fummo fpathaceo paniculan interne obuoluente. LINN. Syft. p. 112. n. I1.SCHRES. Spicil. p. 3०. n. 9S2. - sckvin- t. 12.

Graues Schnclengras; Silbergras. Germ. Grezy Hairgrafs. Angl. Erbin blanchâtre. Gall.

In aruis atenofis um den Bicriz copiofe, nach Scliönfeld, etiam be i demBranderoreerke fparfim. Fl.Iun? Iul. Annuum.

Vf. Gramen fenellum ouibus pabulum gratum. Radicibus huius Coccionellam germanicam tenere fertul.

praccox, 125. Aira foliis fetaceis: vaginis angulatis; foribus paniculato-fpicatis; flosculis bafi aritatis. LINN. Syft. p. 112.n. 12. - Fl. Dan. t. $3 \% 3$.

Frïhes Schnclangras. Germ. Early Hair-grafs. Angl. Foin précoce. Fall.

in locis arenofis humidis an dem Rancle des Uni. verfitïtsicolies, niclit reeit von dem Fürjerlianle magna 
in copia reperi, porro ad Templum Gomeneitz, in Bieniz et polt Taucliam, "auf dem Sandberge. Fl Mai. Iun.

126. Aira foliis fetaceis, panicula diuaricata, floribus caryophylariftatis diftantibus, Linn. Syft. pag. 1 I2. ก. I3. SCHKE. p. 50. 1. 983. Fl. Dan, t. 382. STILling. fl' mifc. t. 5. LEERS t. 5. f. 2.

Nolkenartige Schmelen; Klein' Nägleingras. Germ. Silver Hair-grafs. Angl. Erbin oenlleté. Gall.

In agris arenofis vertus Schoenfeld, ad T'emplum St. Theclae; hinter dem Bieniz; poft Taucham auf den Schwarzbergen, frequenter. Fl. Mai. Iun.

VJ. Odor huius graminis tineas pellit.

127. Aira foliis planis, panicula contraeta, floribus pe- caeru!ca.

dunculatis muticis conuoluto fubulatis. LINN. Fl. Suec. 67. Ei. Spec. Pl. 95. scrizeb. Spic. pag. 48. n. 979. - Flor. Dan. t. 239. sckvir. tab. I3. Mclica caerrslaer.

Blaue Schmelen. Germ. Purple Hair-grajs. Angl. Erbin blewe. Gall.

In nemoribus fubhumidis im Univerfitätsholze inveni, et in pratis paludofis vbique. Fl. Mai. Iun.

Vf. Pabulum a pecoribus expetitum.

39. MELICA. L. G. 88. Perlgras. Germ. Milic-Grafs. Angl. Meiique. Gall.

128. Melica flosculi inferioris petalo exteriore ciliato. ciliata.

LINN. Syft. p. I12. n. 1. вовнм. n. 6́3.

Gefranztes f. Wimperfpelzigt-Perlgras. Germ, Ciliated Melic-Grajs. Angl. Melique ciliée. Gall.

Ad muros et in pratis fyluaticis, in Rofenthale. Fl. Mai. Iun.

129. Melica petalis imberbibus, panicula nutante fim- nutans. plici. LINN. Sytt. pag. 112. n. 2. вовнM. n. 6I4. SCHREB. Agroit. p. 62, t, 6, f. 2.

Ueberhïngendes Perlgras. Germ. Common MelicGrafs. Angl. Melli- brandillant ou Melique penchée. Gall.

In fyluis elatioribus, in Univer f̌tîtsinolae, Bieniz. Fl. Mai. Nug. Perenne. 
40. DACTYLIS. L. G. 92. Knaulgras; Hundsgras. Gern. Cocks-Fooi-Grafs. Angl. Dactile. Gall.

glomerata. 130. Dactylis panicula fecunda glomerata. LINN. Syft. p. 116. n. 2. вовпім. ก. 638.' (fub Cynofuro) -

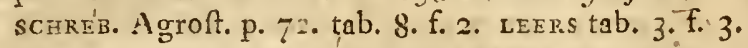
SCKVHR. t. 14.

Gemcincs Knaulgras; Strausgras; rauhes Hundsgras. Germ. Rough Cocks-Foot. Angl. Dactile pelotonné. Gall.

In pratis vliginolis des Rofenthals; in pratis Schocnfeldicis, in pomariis, nemoribus pratenfibus aliisquel gramineis locis fere vbique. Fi. Iun. Iúl. Obf. Calyx 4 -phyilus.

Vf. Pabulum equis gratum. Canibus vomitoriun inferuiens.

\& Calycibus $3-\frac{1}{-}$ valuibus, vatuula tertia dorfali,

41. PANICVM. L. G. 82. Hirfegras. Germ. PanickGrafs, Angl. Panic. Gall.

* Spicata.

verticilla- I3I. Panicum Spica verticillata, racerhulis 4 - ternis, tum. inuolucellis vnifloris bifetis, culmis diffufis. LINN. Syft. p. 105. n. 2. scirreb. p. 43. n. 970.

Qnirlförniges Hirfegras; Ǩleb- f. Knotengras; Wildenannsgras. Germ. Verticillate Panick-Grafs. Angl. Panic verticillé. Gall.

In agris et aruis hortorum cultis copiofiffime. Fl. Iul. Aug.

glaucum. I3 - Panicun fpica tereti, inuolucellis biforis fafciculato - pilofis, feminibus vndulato - rugofis. linn. Syfto p. 105. n. 4. SCHREв. Spic. p. 44. 11.972. - Eiusd. Agroft. T. II. p. 2I. t. $25^{\circ}$

Eifcngraucs Hirfegras; Fömich; veilder Hirfe. Gern. Glaucous Panick. Angl. Panicette ou Panic glauque. Gall.

In agris poft mefièn vbique. Fl. aeftate. Annuum. 
13. Panicun fpica tereti, inuolucellis bifloris, fafcicu-viride. lato-pilofis, feminibus neruofis. LINN. Syft. p. 105. n. 5. SCHREb. Spicil. p. 44. n. 97 I. - LEers n. 40. t.j2. f. 2.

Gr fincs Hirfegras; Fönnich; Schwadengras. Germ. Green. Panick-Grafs. Angl. Panic vert. Gall.

In muris argillaceis, agris et ad tramites frequenter. Fl. Iul. Aug.

$V \int$. Hoc et praecedens pabula bona et dulciá

Obf. Simillimum Panico verticillato, fed habitu molli, nec afpero, ab illo differt.

134. Panicum fpicis alternis coniugatisque, fpiculis fub-Crus Galli. diuifis, glumis ariftatis hifpidis', rachi quinquangulari. LiNN. Syft. pag. 105. n. 8. воEHM. n. 606. LEERS n. 41 .'t. $2:$ f. 3 .

Var. $\alpha)$ Pan. fpica dinifa, ariftis brenioribus.

ß) Pan. fica ariftis longifimis armata.

Granaigtes f. Hahnenfiufsiges Hirfegras; Entengras. Geim.' Loofe Panick-Grafs. Angl. Panic Pieid de Coq. Gall:

Ad foftas et in pratis, pomariis et agris cultis bei den Kohlgärten. Var. $\beta$. in agris inter fegetes nach den Straffenhiïufern. Fl. Aug. Septembr.

135. Panicum fpicis digitatis, bafi interiore nodofis, fanguinale. flosculis geminis muticis, vaginis foliorum punctatis. inn. Syft. p. 106. n. I3. schreb. Spicil. p. 45. n. 973 Fl: Dan. t. 388: scirreb. Agroft. p. 119.taj. I6. SCKVHR. t. 10.

Bluthirfe; Himmelelthau; Krötengras. Germ. CooksFoot-Panick-grafs. Angl. Panic-Manne, ou Sanguin. liall.

In agris cultis frequens et locis arenofis fparfim. Fl. Iul. Aug:

Obf. Saepe fpicis luxuriantibus varietates multas exhibet. Vf. Ex feminibus alica bene fapida conficitur. Pabulum ouibus gratum.

\section{** Paniculata.}

136. Panicum panicula laxa flaccicla; foliorum vaginis miliaceur. hirtis, glumis mucronatis, neruofis. IINN. Syft.pag. 106. n, 2.4. 
Pharm. Mulii Semina.

Haushalitungshirfe. Germ. White, or Yellow Millet. Angl. Panic Millet. Gall.

$\mathrm{In}_{\mathrm{s}}$ agris colitur et paffim inter fegetes fponte na. :5. fcentem inueni. Fl. A eftate. Semina Aug. maturefcunt. Hoc gramen in Oftindia fponte crefcit. In oeconomia valde vilie.

§) Calycibus biaialuibus, fpiculis nultiforis, vagis.

42. POA. L. G. 89. Rifpengras. Germ. Meadow- Grafs, Angl, Paturin f. Poherbe. Gall.

aquatica. 137 : Poa paniculata diffufa, fipiculis 6 - floris, linearibus. LINA. Syft. p. I13. n. I. BOEHM. n. 633. LEERS n. 73. t. 5 . f. 5 .

Wafier-Ripengras; Viehgras. Germ. Red Mca. dore'-Grals. Angl. Poherbe d'eau, ou Paturin aquatique. Gall.

In pratis fubhumidis, et foffis nach Pfaffendorf; - hinter den Koklgaivten; in pratis Schoenfeldicis et Ger. berreviefen; in folliculis hinter Schönf́ld et fere vbique etc. Fl. Iun. Iul.

Obf. Omnium graminum, quae in Europa crefeunt, maximum. VJ. Tenellum ouibus pabulum haud ingratum et foenum praebet delicatum.

trithalis. 138. Poa panicula difrufa; fpiculis trifloris bafi pubelcentibus, culmo erceto tereti. Linis. Syft. p. Irz. n. 3. BOEFM. ก. 630. - LEERS n. 66. t. 6. f. 2.

Dreiblüthiges Rifpcrigras; gemeines Viehgras. Germ. Common Meadore - Grafs. Angl. Pazurin vultaive, on Poherbe des friches. Gall.

In pratis copinfe, maxime in horto Fregiano et ad vise vbique. Fl. Mai. Iun.

$V j$. Pabulum oues valde nutriens.

anguftifoliti. i 39. Poa panicula difufa, fpiculis 4-foris pubefcen. tiibus; culmo eresto tereti. Lmin. Syft. p. II3. n. 4 . воLIM. n. 631. - LeERS. I. 67. t. 6. f. 3. sCKVHR. tab. 13 . 
Sinalblâtriges Rijpoingras; Birdgras" der. Englânder. Germ. Narrow-leaued or Fold Mead grafs. Angl. Patum à feuilles étrbites. Gall.

In hortis, pratis et.lyluis im Gundorfer Holze. FI. Iun. Tul.

Obf: Antherae flauae. Panicula oblonga, adpreffa, quafi imbricata.

140. Poa panicula diffufa, fpiculis 5 - floris glabris, pratenfis. cuimo erecto, tereti. I.INN. Syft. pag. II3. n. 5. POEHM. n. 632. - LEERS n. 68 . t. 6 . $\mathrm{f}$. 4 .

Wiefen, Rifpengras; gemein Viehgras. Germ, Great Meadow-Grass. Angl. Poherbe des près. Gall.

In pratis humidis, e. g. auf den Gerber-und Schönfelderwiefen. Fl. Mai. Iun.

Obf. Antherae caeruleae. VJ. Pabulum pecoribus valde gratum et falutare.

141. Poa panicula diffufa, angulis rectis; fpiculis ob- annuar tufis, culmo abliquo compreffo. Lixs. Syit. p. II 3 . n. 6. воEHM. n. 629. LEERS n. 70 . t. 6. f. 1 . STILIING. Fi. Mifc. t. $\%$.

- Fahriges f. Sommer. Rifpengras; Klein rothes Viehgras. Germ. Annual Meadore-grafs. Angl. Paturin anmuel. Gall.

Ad tramites et in locis fterilioribus vbique. Fl. tota aeftate. Perenne.

Vf. Pabulum ouibus aliisque commune.

142. Poa panicula diffufa, fpiculis fubtrifloris pube- paluftris. fcentibus, foliis fubtus fcabris. IINN. Syft. p. II 3.n.

9. SCHRER. Spicil. p. 55. n. 993.

Suntif-Rifpengras. Germ. Marlh Meadore-Grafs. Angl, Poherbe des marais. Gall. Iun.

In vdis pratorum Schoenfeldicorum. Fl, Maio

143. Poa panicula attenuata; fpiculis fubbifioris mu- nemoralis. cronatis fcabris; culmo incuruo. LINN. Syft. p. II 5. n. 26. schreb. Spicil. p. 53. n. 994. Flor. Dan. t. 749 . IEBRs t. 5 . f. 3 . var. a.

Hain-Rijpengras; Walduiehgras. Germ. Wood Meadow grafs, Angl, Paturin des bois. Gall. 
In omnibus nemoribus, e.g. im Rofentiuale, in dem Holze bei Meckern, Gonnewitz, im Sommerfelder Holze; inb Bieniz, frequens. Fl. Iun. Iul, Perenne.

Obf. Spiculae bi- 3 flore, graciliores, quam Poae reliquae.

critzata. 144. Poa panicula fpicata, calycibus fubpilofis fub 4floris, pedunculo longioribus, petalis ariftatis. LINN. Sylt. p. $115 \cdot$ n. 3O. SCHREB. Spic. p. 54. n. 992. Fl. Dan. t. 25 I. LEERS t. 5. f. 6.

Kammförmiges Rifpengras; wolligt Viehgras. Germ. Crifted Meadoze - grafs. Angl. Paturin à crête. Gall.

In ficcioribus elatioribusque vbique auf dem $G i$ ckerlingsberge, auf dem Thonberge $u$. dem Wege nach Pomfen hin, copiofe. Fl. Iun. Iul.

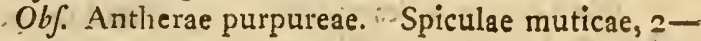
vel 3 - florae.

\section{* Panicula Jecunda.}

comprefta. 145. Poa panicula coarctata fecunda, culmo obliquo compreffo. LINN. Syft. p. 115. n. 24 . вовнм. n. 635 . Fl. Dan.t. 742. LEERS t. 5. f. 4 .

Zufammengedrücktes Rifpengras. Germ. Creeping Mendow - grafs. Angl. Paturin applati. Gall.'

In tectis, muris pagorum limofis, v. c. ad Schön. feld, Leutch, Parneck, Gunndorf, Stetteritz, Wolk. reitz, Belgershayn etc. et alibi; porro etiam in, agris ficcioribus elarioribusque vbique. Fl. Mai. - Iul.

Vf. Pibulum ouibus maxime gratum.

bubola. 146. * Poa panicula lecunda patentiufcula, fpiculis quadrifloris. LiN. Sy't. p. I15. n. 23.

Poa foliis bulbofis, panicuia diffufa, locuftis $4-$ floris, folliculis fubuillofis. H.in . Erumerat. $214 \cdot \pi$. 9. $\beta$.

Knolligtes' Rifpengras; Schalottengras; Läuchelgras. Germ. Bulboje Meadow-grafs. Angl. Paturin bulbeux. Gall.

In collibus et locis elatioribus, in der Sandgrube, anf dem Gickerlingsberge et im Bieniz faepius vidi. Fl. Mai, Iín. 
Obf. Culmi bafi tuberofa. Vf. Pabulum ouium egregium.

43. BRIZA. L. G. 90. Zittergras. Germ. Quakinggrafs. Aigl. Amourette. Gall.

147. * Eriza fpiculis triangulis, calyce flosculis lonminor: giore. IinN. Syft. pag. 115. военм. n. 647. var. schinz. t. a. f. 9. a.

Kleines Zintergras; Hafenohr; Iungfernhaar. Germ. - Smal Quaking -grafs. Angl. Petitc Amouretse. Gall.

In collibus ficcioribus auf dem Gickerlingsberge et bei dem Pulverthurme, paffim mihi occurrit. Fl. Mai. Iun.

Ill. goehmervs c. Hallero hanc fub fequentem vt varietatem comprehendunt.

148. Briza fpiculis ouatis, calyce fosculis breuiore. :Linn. Syft. p. 115. n, 3. военм, n. 647. Fl. Dant. t. 258. LEERS t. 7. f. 2. SCKVHR. t. I4.

Mittleres, Zittergras; Flittern; Wiefenflittergras; unfer lieben Frauenflacks. Germ. Middle 2uakıng. grafs. Angl. Amourette tremblante. Gall.

In pratis Schoenfeldicis aliisque locis ficcioribus, auf. deni Gickerlingsberge, in der Leimgrube, bei dem Pulverthurme, ad Tempplum St. Theclae, et in hortis pratenfibus etc. Fl. Mai. Iun.

44. FESTVCA. L. G. 95. Sch wingel. Germi. Féfcuegrafs. Angl. Fétuque. Gall.

* Panicula Jecunda.

149. Feftuca panicula fecunda coartata ariftata, culmo ouina. tetragono nudiusculo, foliis fetaceis. ins. Sỳt. p. 118. n. 2. Военм. 634. SC'Hrez. Spicil, p. 156. n. 614. stilling. fl. mifc. t. 8.

Var. a) Gramen ariftatum radiculis nigricantibus. LOES. Pruf. n. 21. LEERS n. 74. t. 8. f. 4. $\beta$.

Schaffchieingel; Schafgras; hart Gras; kleiner Bocksbart. Germ. Sheep's.Fefcue-grafs: Anigl. Fétuque des moutons, ou petit foin. Gall.

$\mathrm{D}_{3}$

media.

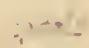


In locis, ficcioribus um dis Oberholz, faepiusque in muris circa pagos. Var. a) a!m Bicniz auf der Anhöhe. Fl. Mai Iun. Perenne.

Obf. Spiculae 4-vel 5 - florae. Vf. Pabulum ouibus primarium et gratum, et in Anglia praécipue commendatur.

nubra, 150. Fefuca panicula fecunda fcabra ; f́piculis fexforis. ariftatis : fiosculo vltimo mutico; culmo lemitereti. IINN. Syft. p. I18. n. 3. SCHREE. Spicil. pag. 57. n. 998. STIRLING. f. mifc. t. 9. LEERS t. 8. f. I.

Rother. Schuingel; rother. Bocksbart. Germ. Purpole - Fefcue-grajs. Angl. Féruque rouge. Gall.

In locis ficcioribus, pafin in der Sandyrube, auf dem Gickerlingsberge erc. Fl. Iun. Iul. Perenne.

Obf. Feftucae ounae fimilis; fed maion habitu et foliis latioribus, ab illa differt. Color tempore maturitatis in rubrum abiens.

- Vf. Pabulum ouibus gratum et femina pecoribus deliciofa.

șuriurcula. I5t. Feftuca panicula fecunda oblonga, fpiculis oblongis lacuibus; foliis fetaceis. LiN". Syft. p. II8. n. 6. SCHkEB. p. 5\%. n. 997. Fl. Dan. E. 848 .

- Hurter Schuingel; langficlseliger Borftchuingel. Germ. Hard Fefcue-grafs: Angl: Fétuque durette, ou Feugeróli. Gall.

In pratis ficcioribus ad Templum St. Theclice paffim. Fl. Iun, Iul. Perenne.

Obj: Spiculae 5 - vel 6-forae, ablongae.

elatior. I52. Feftuca panicula fecunda erefta, fpiculis fubariftatis: exterioribus teretibus. LINN. Syft. p. 118. n. 8 . schreb. Spicil. p. 58. n. 1003 . Eiusd. Agroft. p. 34. t. 2. LEERS.t. 8. f. 6.

Wiefen-f. erhabner Schieingel. Germ. Meadow or Tall-Fefcut-zrafs. Angl. Fétuque elevée. Gall.

In pratis, ertilioribus locisque graminofis vbique. F1. Inn - Aug.

Obf. In folo humido pinguique ftaturam maio. rem adquirens fpiculas 6-II floras fert. VJ. $\mathrm{Pa}$ bulum equis pecoribusque optimum. 
153. Fefuca panicula fecunda fpicata ftricta, fpicis ob- arundinacea longis, ereitis, paucifloris, ariftatis; calycibus anguftatis. Gmel. Sibir. I. p. 3. schrer. Spicil. p. 57. n. 1000 .

Rohrartiger Schwingel. Germ. Reed Fefcue-grajs. Angl. Féruque rofeau. Gall.

In prato accliui humido, hinter dens Bieniz nicht weit. z'on Kleindölzıg. Fl. Iur. Iul. Perenne.

154. Feftuca panicula fpicata, calycibus minutifimis myurus. muticis; for. feabris; ariftis longis. IINN. Syft.p. I18. n. 9. SCHRED. Spicil. p. 58. n. 1002.

Mäufejchwanzartiger Suingel. Germ. Fétuque Queve de Rat. Gall.

In agris hinter den Kohlgärten,nach Schönfeld zu, et in limitibus agrorum, un den Bieniz, etiam in der Sandgrube. Fl. Iun.

Obj. Spiculae 5-5-florae, diftichae.

155. * Feftuca panicula fecunda, nutante, fpiculis quin- nemorea. quefloris, glabris, ariftaris, foliis radicalibus fetaceis; culmeis planis, longiffimis, fcabriufculis. LEYs. Fl.Halenf. n, 102.

Hain - Schwingel. Germ. Wood Fefcue-grafs. Angl. Fétuque des bois. Gall.

In locis nemorofis, e. g. im Univerfitätsholze, Gunndorf et Sckcuditzer Holze. Fl. Iun. Iul. Perenne.

156. Feftuca panicula laxa, fpiculis feptemfloris, difti- pratenfis. chis; glumis villofis. REYGER p. 5 I. n. 5 .

Feftuca foliis hirfutis, latiulculis; fpiculis paniculatis, 5 - floris, ariftatis, glabris. HaLl. Hift. n. 1435. schreb. Spicil. pag. 57. n. 999. Leers tab. 8. fig. I. c.

Wiefenfchwingel. Germ. Meadote Fefue-grafs. Angl. Fétuque des près. Gall: Iul.

In pratis fertilibus fubhumidis vbique. Fl. Iun.

Obf. Hoc gramen cum Feftuca elatiori faepe confunditur. 


\section{Panicula cequali.}

decumbens. 157. Feftura panicula erecto, fpiculis fubouatis muticis, calyce fosculis maiore, culmo decumbente. LINN. Sylt. pag. I I9.' n. 13. schreb. Spicil. p. 58. n. 1001. Fl. Dan. t. 162. LEERS t. 7. f. 5 .

Niederliegender Schwingel; Haferfchwingel. Germ. Snuall Fefcue-grajs. Angl. Fétuque inclinée. Gall.

In pratis ficcioribus ad Abtnauendorf; im Bicniz. auf der Anhöhe; in nemorofis, v.c. im Bieniz et Uniucrfitätsholze, valde frequens; in pineto ad Lindenthal paffim et alibi. Fl. Iun. Iul.

Obf. Spicula calycis exterior longior; interior brevior et anguftior. Spiculáe 3-5 florae.

fluitans. I58. Feftuca panicula ramola ereta; fpiculis fubleffilibus, teretibus, muticis. LıN. Syft pag. I19. n. i5. вогнм. n, 643; $F l^{\prime}$. Dan. t. 237 . stililing. milc. t. 20. SCHREB..Agroft. p. 37.t. 3. LEERS t, 8, fig. 5. E SCKVHR. T.' 15.

Mannalchioingel; wilder, Schwade ; frankfurter Scheradengrïtze; fchlcfifcher Reis. Germ. Flote Fefcuegrafs. Angl. Fétuque flottante, ou Manne de Pruffe. Gall.

In paludolis, folfis et inundatis vbique, e. g. im Rofcnthale copiofe, hinter Schönfeld, poft pagum Scherbig in fofficulis bei Wölkau, bei Lindenau et alibi. Fi, Mai. Iun. Iul.

Obf. Semina flaua, valde nutrientia. Grana Mannae fic dicta, e quibus Alica Feftucae, quae in cibum a nonnullis recipitur fapidifimum, et fi ad farinam redigatur in panis, placentarum etc, praeparatione; conficitur, caeteris cerealibus parum cedunt. Porro pabulum equis, praecipue fuibus gratum.

45. BROMVS, I. G. 92. Trefpe, Germ. Bromegrafs. Angl. Droue. Gall.

* Arifta dorfaili fub apice petali exterioris.

lecalinus. 159. Bromus panicula patente, fpiculis ouatis, compreffis; glumis nudis diftinctis; ariftis fubulatis, brevioribus, flexuofo - rectis. потн, I. p. 47, n, I. 
Bromus panicula patente, Ipiculis cuatis: ariftis rectis, feminibus diftinctis. LiNn. Sy,ft. p, 1:9, n, 1. BOEHM. n. 640. - LEERS t. II. f. 2.

Var. Bromus fpiculis fubmuticis.

Roggen Trejpe; gemeine Trefpe.Germ. Spradingpanicled Brome-grajs. Angl. Scigle Droue. Gall.

In agris fecalinis et auenaceis copiofo; tice in muris; etiam im Bieniz. Fl. Lun. Iu!.

Obf. Annnnae caritate graflante vulgo frumentum. Attamen fegeti immixtum pansin amarum et ingratum, et refertur edentes primum quafi tenulentos redderc. Tenellum granen, ouibus equisque pabulum. Paniculae colore tingunt viridi Coloni inprimis Yftadienles, LINN.

160. Bromus panicula erectuscula, fpicis outis pube- mollis. fcentibus: ariftis reftis: foliis molliffme villofis. IINN. Syft. p; I 19. n. 3. sCireb. Agroft. p. 6o. tab. 6. LEERS t. 1I. f. I. SCKVHR. t. 16.

Bromius panicula erecta, coarctata. вовні. n. $6+2$.

Wciche Trefpe; Trefpgras. Germ. Smooth villofelcaved Brome grafs. Angl. Brome maliet. Gall.

In arenolis ficcioribus, muris et ad vias frequentiflime. Fl. Iun. Iul.

Obf. Geniculis crafforibus fubtus magis hirfutis; vaginis ftriatis; panicula breuius pedunculata, a priori, facile diftinguitur.

Vf. Pabulum bobus ouibusque falutare.

16r. Bromus panicula diffufa; fpiculis terctibus, fubu- inermis...tg latis, muticis ariftatisue. r.EYs. n. I08. LiNs. Syft. p. I 19. n. 6. SCHREB. Spicil. p. 59. n. 100\%. (fub $F_{e-}$ fuca $\left.\int_{p c c i o f a}\right)_{0}$ - Eiusd, Agroft. p. 97, t. I3.

Fcftuca Leyferi locuftis teretibus, multifloris, glumis femi membranaceis, breuiter ariftatis. мöNch. Haff. I. p. 41, n. 82 .

Queck-Trcjpe. Ferm.

In margine editiori fragni ad Altranftädt III. sCHREs, olim inuenit. Fl. IUn. Iul.

Ol.f. Rad, repens, prouti Triticum repens.

162. * Bromus panicula nutante fcabra, fpiculis villo- afper. fis, ariftatis; foliis 1cabris. LinN. Sylt. p. I19. n. 8 . LEYS. ก, 110. 
Feftuca graminea nemoralis latifolia mollis. EAVH, Pin. 9. theatr.' 14.4.

Raucher Trefpe. Germ.

In agris inter fegëtes paflim. Fl: Iun. Iul.

fterilis. I63. Bromus panicula patula, fpiculis oblongis diftichis, glumis fubulato ariftatis. Linv. Syft. p. I20. n. 10. LIERS n. 83. t. II, f. 4 .

Taubtrefus; Mü̈ufe-Taub-Hafer. Germ. Bromse férile. Gall. Iun.

In muris tectisque, ad fepes vbique. Fl. Mai.

aruenfis. If $4^{*}$ * Bromus panicula nutante, fpiculis ouato - oblongis, Linn. Syft. pag, I20. n. II. LEYs, n, XI2. Fl. Dan. t. 293. LeERs t. II. f. 3.

Ackertrefpe, Germ. Corn Brome-grafs. Angl. Droue des champs. Gall.

In actris, agrorum terminis et ad fepes, vulgaris. Fl. Iun. lul.

tetorum. 165. Bromus panicula nutante, fpiculis linearibis. IIINN. Syft. pag.' I 20. n. I3. LEYS. n. II3. SCHREB. Spicil. p. 56. n. 995. LEERS n. 58. t. I0. f. 2.

Dachtrefpe; Sandtrefje. Germ. Brome des toits. Gall.

In collibus ficcis auf den Stadtzeällen, in muris limofis circa pagos vbique. Fl. tota aeftate.

Obf. Tota planta faepius coloris obfcure rubri cum rufo mixti.

giganteus. I66. Bromus panicula nutante, fpiculis quadriforis: ariftis breuioribus. LINN. Syft. P. I20. n. I4, LEYS. n. I14. LEERS' $\mathrm{n}$. 86. t. 10 . $\mathrm{f}_{f} \mathrm{r}$.

Bromis panicula nutante, fpiculis lanceolatis : ariftis longis fléxuofis. Scrireb. Agroft. p. 88, tab. 1 I. SCHREB. Spicil. p. 56 . n. 996.

Filticritejpe; grof.e 1. Waldtrefpe. Germ. Tull Brome-grafs. Angl. Brome gigantesque. Gall.

In nemorofis vmbrofiffimis, in Rofenthale, Univerfitä̈tsholze, Rahnitz, Gunzadorfor et Kleindölziger Holze; porro quoque in collibus circa vrbem, frequens. Fl. Iun. - Septembr.

Obf. Panicula valde laxa. Pedicelli bini, longo fpatio nudi. 
Vf. Pabulum pecoribus, deliciofum, et ter quaterve fecari poteft.

** Ariftis tcribiralibus, apicibus petalorum ohfoletis.

I67. Bromns culmo indiuifo, fpiculis alternis, fubfefi- pinnatus.

libus, teretibus, fit arifaris. Imin. Sylt. p. I20. n. 22. BOEHM. n. 639. Fl, Don.t. 164. LeERs tab. IO. fig. 3 .

Bromus pinnatus fpiculis feffilibus, culmo indiuifo, arifis folliculi gluma breuioribus. Pollich. Pal. I. p. $117 \cdot$ n. 117 .

Gefiederte Trefpe; Zittertrefpe. Germ. Spiked Brome-grafs. Angl. Brome empenné. Gail.

In fyluis montofis, im Bieniz. Fl. Iun. Iul.

$\mathrm{O} b \int$. Spiculae teretes, villulofae, ariftatae.

\section{AVENA. L. G. 97. Hafer. Germ. Oats. Angl. Avoine:}

768. Alina paniculata, calycibus bifloris; flosculo her- elatior. maphrodito fubmutico; mafculo ariftato. LINN. Syit.

p. I2I. ก. 2. ВОЕНM. ก. 627 .

Auena calycibus bifloris panicula laxe fpicata, pedunculis prioribus fafciculatis. GVETT. p. 182, var. $\beta$. Fl. Dan. t. 165. schres. Agroft. p. 25. t. I. LEERS t. Io. f. 4. $\alpha-\delta$. SCKVIR . t. I $\%$ Holcus auenaceus calycious 2 - foris, arifta floris mafculi dorfali refracta. wiGg. Primit. 72 . n. 775 .

IV iefen 1. hoher Hafer; franzöfifch Raygras. Germ. Oat-graas. Angl. Avoine clevée, oz Fromental. Gall.

In pratis fyluaticis copiole im Rofenthale, auf dem Gickcrlingsberge, in Bieniz, in vinetis poft Taucham, zintcn am Fufse des Minnebergs ctc. in agris inter fegetes et in collibus circa vrbem, praecipue zreifchen dene Thoniaspförtchen und dem Schlossthore. Fl. Iun. Aug.

Vf. Pabulum equis, pecoribus optimum. Sues radices auide deuorant. Seminum farina vim nutrien. di continet. 
fatiua. 169. Auera paniculata, calycibus difpemis, feminibus laeuibus, altero ariftato. ins. Synt. pag. 122. n. 6 . BOEIIM. 11, 626. BLACKW. t. 222 .

Var. a) Auena vuigoris niwra.

Pharm. Aucna cxcorzichta.

Gemeiner fo zeiffer Hicfer; Ireter-Hafer; var. a) fchrearzer Hafer. Germ. HFite or Black Oats. Angl. Avoine cultivée, oublanche, on noire. Gall.

In agris feritur et paffun in agris fecalinis crefcit. Fl. Iun. Iul.

$V \int$. In Norwegia ex farina panis Fladenbrod fic dictus coquitur.

orientalis. 170. Auena panicula coarctata fecunda, -1piculis biforis horizontalibus parallelis, feminibus laeuibus. schrè. Spicil. p. 52. n. $98 \%$.

Türkifcher f. ungarifcher Hafer. Germ.

Obf. Ante paucos annos haec introducta, nunc in Auestae fativae agris fparfim occurrit. Fl, Iun. Iul. Annuum.

ttrigofa Ret- 171. Auenae panicula oblonga, fubnutante, fécunda; zii. flosculis geminis apice biariftetis, dorfo arifta geniculata.' RETz. Obferv. BOTt.' Fafc. I. pag. II. n. I3. SCHREB. Spicil. p. 52. n. 988 .

Auessa frvigofa paniculata, calycibus biforis, flosculis pedicellatis apice biariftaris, dorfo arifta genicu-

lata. RETz. Flor, Scand. p. 20. n. 130.

Sp:tzhafer; grauer Hafer. Germ.

. Inter Auenam fatiuam et Hordeum pafim crefcit. Fl. Iun. Annuum.

Ob. Ill. SCHREBERVs paniculam dicit contractam, e contrario IIl. RETzivs iure meritoque fubuutantem. 'Pedunculi I-4 fori, fcabri. Gluma corollina, maturo femine nigro. 'Semen altero apice barbatúm. Culmus et folia nuda. Statura prioris, fed panicula ramis psullo laxioribus fpiculis gracilioribus, ab illa differt.

Lonffingia- I72. * Auena panicula contra ta, fosculis binis; altena. ro pecunculato, apice biariftatis, dorfa arifta refiexa. LOEFFL. LINN. Sylt, Edit, keicit. Tom. I. pag. z22.

n. 5; 
Aucra . dabia paniculata, calycibus fubtriforis: floseulo infino terminali arifta ere ta, reliquis apice biariftatis, dorfali arifta reflexa. LEERs. Herborn. p. 41. n. 89. T. IX. f. 3 .

Löflingifchor Hafer. Germ.

In agris elatioribus arenofis auenaceisque inter fegetes nach Schönau, Nauendorf, Rïckmarsdorf et Klcindölzig praeterito anno reperi. Fl. Iun. Iul.

Obf. Culmi fpithamaei, 2 - pedales; erect, tenues, glabri. Folia raaicalia fauca, anguftifima, breuia, glabra. Folia culmea leuiter ventricofa; quafi fubulata, fubafpera, Panicula pauciflora, coaretata. Cal. exterior 5 - neruius; interior flosculis duplo longior, 7 neruius.

173. Anenis paniculata; calycibus trifloris; flosculis fatua. onnibus eriftatis; receptaculis barbatis. LINN. Syrt. p. 122. 2. 8 sCHRE. Spicil. p. 53. n. 989. Eiusd. Agroft. p. 100. 1. 15. LEERS t. 9. f. 4.

iNind-Schiorarater; ixilder-taub-Bruchhafer. Germ. Bearted Oat-grajs. Angl. Suoine follette, ou Averon. Gall.

In agris inter fegetes copiofe. Fl. Iun.

Obf. Semina pecora non guftant. Hoc gramen frumento valde obnoxium, qua, de re poft matiem eradicandum.

174. * Auena fubfpicata, calycibus fubtrifloris bafi pilo- pubefcens.

fis, foliis planis pubefcentibus. LINN. Syft. p. I22. n. 10. - LEeks n. 91, t. 9. f. 2.

Harigter Wiefenhafer. Germ. Kough Oat-grafs. Angl.

In pratis paffim in Rofenthale et in pratis ad Kleindölzig inueni. Fl. Iun.

Obf. Panicula fernipedalis, coarktata; florens patula, multiflora. Spiculae teretes, minores, quam in congeneribus, 3-4-florae. Flosculi bafi pilofi, 5-neruii, calycis longitudine. Folia vtrinque tactu mollia, fuperficie fuperiore pilis albis ct mollifimis obfelfa.

I75. Auena panicula laxa, calycibus triforis breuibus, Aauuefcens. flosculis omnibus ariftatis. InN. Syit. p. 122. n. 12. 
SCIREE. p. 54."n. 991. LEYS. n. 94. SCHREB. AgroR. p. 6. t. 9. iEERs t. 9. f. 3 .

Goldhafer; gelber Hafer. Germ: Yellozo-Oat. Angl. Aroine jazuntre, cut Avenclle blorde. Gall.

In locis hecioribus elationibusque feitwairts Pfaffenchorf vor der erfeni Wachbleiche dextrorfun nah Gohlis, porro auf den Gickerlingsberge, quoque in pratis fyluaticis in Rofenthale copiofe; auf der Vogelwie$\int e$, in agrorum verfuris bei den Brandiorzeerke, et inter Meckern atque Lindenthal etc. Fl. Iun. Inl.

Obj. Panicula fiaucfens angufta, coaretata mox calycibus 2 -floris, $\operatorname{mox} 3-4$ - floris. Semina flauefcentia.

Vf. Pabulum pecoribus bene fapidum.

pratenfis. 176. Anena fubfpicata, calycibus quinquefloris. LINN. Syft. p. I22. n. 19. воEнM. n. 628. SCHREs. Spicil. p. 53. n. 990. - LEERS n. 92.t. 9. f.'1.

Tivenhafer; Achrenförniger Hajer. Germ. Meadow Oat-grafs. Angl. Aucuztte argentée, ou Aivoine lies prìs. Gall.

In pratis ficcioribus et dumetis, in Bieniz, auf dicn IViefor nach don Gouncwitzer Schanzen et alibi frequens. Fl. Iun. Iul.

Obf. Panicula fpicata, contracte, paucifora. Arifta dorfalis longior, verficolor: dein tortilis nigro et albo colore variegsta.

\section{ARVNDO. L. G. 99. Schilf S. Rolnr. Geruz.} Reed-grafs. Angl. Rofeau. Gall.

phragmites. 1\%7. Arundo calycibus quinqueforis, panicula laxa. LINN. Syft. p. $\mathrm{I}=3 ;$ n: 3. EOEHM. n. 624. LEYS. n. 95. IEERS n. 94 . t. 7. f. I.

Gemeines Rolur; Scluilf; Pfeifen f. Deckrolur. Germ. Common Resd-grafs. Angl. Rofcum vulgairè. Gall.

In forfis fere omnibus et lacubus: praecipue in dew Gerberneaffer, in der Pleijfe, Bahie, pilcinisque p'urimis et alibi. Fl. Iul. Aug. Perenne.

$V f$. Tetis foreisque hortorum aptum. Foeni fuccedaneum. Gyplariis pro bafi. inferuiens. 'Panicu- 
lis puellae vtuntur corymbi ad inftar. Ponicula viridi inficit colore. Pecoribus nocet. SCIREB.

r73. Arundo calycibus vniforis, panicula ereta, foliis epigeios.

iubtus glabris. LrNe. Sylt. p. 123.n. 4. SCHRED. Spicil. p. 52. n. 986.

Land f. Hiigel Schilf. Germ. Small Reed-grass. Angl. Petit Rofeau. Gall.

In verfuris hinter Gohlis et Lindenthal, an Bieniz. Fl. Jul. Aug. Perenne.

Obj. Panicula coarctata, aequali, a priore diftinguitui. Pabulum praebet in locis ficcis.

179: Anundo calycibus vniforis laeuibus, corollis lanu. Calamagro. ginofis, culmo ramofo. LINN. Sylt. pag. I23. n. 5 . BOzHм. n. 625. LEYs. n. 96. - Fl. Dan. t. 280.

Wiefenjchilf; Rohrgras; grofses Rohrgras; Federgrat. Germ. Branched Reed-grafs. Angl. Rofeau laineux, oul Lefcice. Gall.

In falicetis et dumetis ad vias; in pratis' aquofis rach Scliōnfeld, in locis ftagnantibus bei Pfajjendorf et alibi frequens. Fl, Iul. Aug.

Ob. Differt ab antecedente, panicula tenuiori, breuiter acuminato, calycibus framineis.

Dog's Tail-grafs. Angl. Crételle. Gall.

ftis.

\section{VJ. Pabulum in paludibus praertans. LINN. \\ VJ. Pabulum in paludibus praertans. LINN.}

180. Cynofurns bracteis pinnatifidis. IINN. Syft. p. I I6. criftatus.

n. I. BOEHM. n. 637 . LeYs. n. 102. Fl. Dan. t. 238.
schres. Agroft. p. 69. t. 8. f. I. stilling. Fl, mifc.

t. II. LEERS t. 7. f. 4. SCKVHR: t. I5.

Gemeines 1. gefiederter Kammigras. Germ. Crefted. Dog's Táil-grafs. Angl. Crételle. Gall.

In pratis zm Rojenthale, et pratis Schoenfeldicis copiofe, parfim in humidis, auf der Viehreide nach dem Zfchocherfchen Holze; porro in locis-ficcioribus auf dem Gickerlingsberge; ad Templium St. Theclae; in Bieniz; vor dem IVindmühlentiore nach den Straffenhâufern und dem Gefundbrunueni zu; et alibi in verfuris elatioribus. Fl. Mai. Iun." -

$V \int$. Oues hoc gramine libenter vefcuntur. 
caeruleus. I8!. Cynofurus brafteis integris, fpicis fubouatis. LINN. Syft. pag. II . n. 4. военм. n. 636. LEYS, n. 130. JACQ. Mifc. Vol. II. p. 66: Icon. rar.

Blaues Kasnmgras. Germ. Blue Dog's Tail-Grafs. Angl. Crítelle bleı. Gall.

- In montofis ferilioribus auf den Bicniz, porroauf den Sawibergen ior Rïcknarsdorf et Nauendorf pal- Fin. April. Mai.
11. SPICA TA.
a) Spicaterctiufcula, floribus vagis.

49. PHLEVM. L: G. Liefch gras. Germ. Cat's Tail-grafs. Angl. Fleau, ou Maffette. Gall.

pratenfe. I82. Phleun fpica cylindrica longifima ciliata, culmo 3 ere?to. LINN. Syft. pag. 10\%. n. 1. вовнм. n. 60i. : SCIREB. Agroft. p. 102 . t. T.4. KERN. B II. p. III. t. 196. LEERS Herborn. t. 3. f. I. SCKVHR. t. IO.

1. Wiejenliefchgras; Tivintheusgras dev Engländer; Wicjonfuchsfcherina. Gern. Timothis-grafs, or Mea- doze Cat's Tail grafs. Angl. Mafjette qu: Fleau des près. Gall.

. In fyluis praten fibus; im Rofenthat?, bei Sommerfeld, Grasfeld, Grasdonf, ad Temipluni St. Theclae, in verliuris verfus Schönfcld et alibi frequens. Fl. Iun. Iul.

Ef pobulum optimum ab Anglis maxime cultum. Attam bo bobs, ouibus caprisque aduerfum.

nodnfum, 183. Phleum fpica cylindrica, culmo adicendente; foliis obliquis; radice bulbofa. LrNN. Syrt. p. 108. n. 3. BOEIM. n. 602. LEERS t. 3. f. 2. SCHREB. Agroft. t. I 4. f. 3. 4. Fl. Dan. t. 390 .

Kizotigtes Lifcligras. Germ. Bulboje Cat's Tailgrajs. Angl. Fleau noueux. Crall.

In veriris ficcioribus, arenofis elatioribusque, in der Sandgmbe, bei din Straffenhinufern, et ad viam - verfus Sckeuditz alibique frequens. Fl. Iun. in Auguftum vsque. 
Obj. LinNaEvs hoc cum priori coniunxit et Ill. SCHRERERv omnes Plulei fpecies in vuicam redigere 1tuduit.

b) Spica difticha: Receptaculo fibulato, dentato.

50. ELYMVS, L, G. I02. Hargras. Germ. Wheat-grafs. Angl. Einine. Gall.

184. Elymus fpica nutante, arcta, fpiculis re tis inuolu- caninus. cro defticutis : infmis geminis LINN. Syft. p.125. n.

5. LEERS t. 22. f. 4. SCKVIIR. t. I9.

Triticum caninum radice perenni, fpica fubnutante, fpiculis erectis, ariftis longifimis. sСнкев. Spicil. p. 51 . n. 483 .

Hundshargras; Hundereeizen; rothe Qucckenenuzel. Germ. Bearded WVheat-grafs. Angl. Elime des fables. Gall.

In vmbrofis copiofe in Rofenthale, Univerfitiatsholze, in pratis hinter Reichels Garten aliisque nemoribus. Fl. Iun.

a85. * Elymar f́pica erecta, fpiculis bifloris, inuelucro Europaeus. aequalibus. Linn. Syft. pag, 125. n. 8. wigg. Primit. Holf p. I $\mathbf{I}$.

Hordeum $\int_{p}$ icis rigidis cylindricis, calycinis, glumis ariftatis. He.L. Helv. n. 1527 .

Hordeum cylindricum. MvrR, prodrom. Goetting +3 .

Europäifches Haargras; Roggengras. Germ. Eline d Europe. Gall.

In fyluaticis locis im Univerfitätsholze rarifime mi. hi occurrit anno 1788. Fl. iul. Aug.

5I. LOLIVM. L. G. 101. Lolch. Germ. Darnel, Angl. Ivroi. Gall.

186. Lolium fpica mutica, Tpiculis compreffis multiflo- perenne. ris. Linn. Syft. p. 124. n. I. вовнм. n. 64\%. Fl. Dan. t." 7 40. SCHREB. Agroft. II. p. 79. t. 37. LEERS t. 12. fig. I. «. 
Austanernder Loich; WViefen-Jïffer-Lolch; Wintcrtrefri ; Dinkelffelzen; Taubenleorn. Germ. Red Darncl-grafs. Angl. Pain-vin; Liroic vivace, ou Fauffe IErazic Gall.

Ad femitas, verfuras vbique, in palcuis, pomariis. Fl. Tun. Iul.

Vf. Pabulum equis tantummodo bonum. In pratis Angioram practans paluulum.

remuleatum 18\%. Loliwn fpica ariftata, fpiculis comprefis mulifioris. LINA. Syft. p. 127. ก. 3. вовнм, ก. 646. Fl. Dan. t. 106. schier. Agroft. II. pag. 74. t. 36. LeERS tab. 12. f. 2. SCKvHR, t. I5.

Taumellolch; Sominerlolch; Tollgerfac; Tollkorn; Schueindelhafer; Sominertrefp; Toeborichi Twalch; Timitkemeaizcn. Germ. Damul. Angl. Iuroie eniwrante. Gall.

In agris fecalinis et hordeis iter legetes maxime vor denn Schönfelder Pfürtchin etc. Fl. Iun. Iul.

Olof. Hominibus animalibusque obnoxium et venenum Guftata femina temulentiam ét fere caecitatem inducunt. LiNN. Interdum fomina cereuiliis temulentis inprudenter adduntur

\section{SECALE. L. G. 103. Roggren. Germ. Rye. Angl. Seigile. Gall.}

cereale. 188 . Secale glumarum ciliis fcabris. Linn. Syft. p. 125. n. 1. вовім. ก. 618 .

Var. a) Secuic hybémum maius, foliis latioribus. BLACEW. t. 424. KERN. B. II. p. 95. tab. 158. SCKVHR. tab. 19 .

B) Secale vernum minus, foliis angúftioribus.

Winter-und Sommerroggen; Konn; Iohanniskern; Aergyptifilues E. Terufalemskon. Germ. Common Rye. Angl. Suigls commun. Gall.

Gbj. Hoc gramen in Creta et Siberia fponte crefcete fertur. Farina feminum pani in Europa inferuit; porrocx is fpiritus frumenti, qui rufticis nectar eft, defillatur. Semina tofta potus Caffere fuccedateun pauperibus. Emplaftum de crufta panis diuerfino. de vfurpatur. 
53. TRiTICVM. L. G. 105. Wcizen. Germ. Wheat, Angl. Froment, Gall,

\section{a) Annua.}

180. Triticum calycibus quadriforis, ventricofis, gla- aefium. bris, inbricatis, arifatis. Linn. jyft. pag. 126. n. 1 . BOEKiM. ก. ́r19.

Triticum arifatum f. ariftis longis. BLACKw. t. 40 . f. 15 .

Sommenecizen. Gern. Blé tremois on Froment d'été. Gisl.

In agris feritur. Fl. Iun.

ฐoo. Triticum calycibus quadriforis, ventricofis, lae- hibernum. vibus, imbricatis, fubmuticis. LINN. Syrt. p. I26. n. 2. БОЕНM. 620.

Triticum ariftis carens. BLACKW. t. 40. f. $I-3$.

Pharm. Amylum.

IV antmecizen. Germ. Stard. Angl. Frohnent d'hi. yer. Gall.

Seritur in agris. Fl. maturius priori.

$V \int$. Farina pani, placentis, cerenifiae, fpiritibus etc. inferuiens. Vftilagini frepius expofitum.

\section{b) Percnnia.}

99r. Triticun calycibus quadriforis, fubulatis, acumi- tepens, natis; foliis planis. LINN. Syft. p i27. n. I1. гоEHM. n. 621. BLACKW. tab. 537. (fub Gramine canino). Fl. Dan. t. 74 S. schreb. Agroft. P. II. p. 24 tab. 26. f. I. III. SCKVHR. $t 20$.

Pha:m. Graninis minoris Radix.

Quecken f. Hundsgras; Grasuuruel. Gern. 2uichgrafs, or Couchgrafs. Ang!. Fromcut rampant, ou Chiendent officinal. Gall.

In agris et cultis frequens, in verfuris, hortis, porro ad lepes et muros fere vique, c. g. in l'oetcngange; in Serto bei dem Sclneckinberge erc. Fl. Iun. Iul.

Obf. Herba et radix canibus vomitum excitunt, In annonse caritate radix exficca, pani inferuit. . In non. nullis regionibus fuccus ex radicibus exprinitur ad 
apes pafcendos. 'Radix exficcata vi nutriente, mundificante purganteque gaudet. Agricolis inuifum.

54. HORDEVMI L. G. 104. Gerfte. Gernn. Barley. Angl. Orge. Gall.

vulgare. 192. Hordenn fosculis omnibus hermaphroditis ariftatis': ordinibus duobus erectioribus. LrNN. Syft. p. 125. n. I. BOEHM. n. $\quad=0$. - rLACKW, to 423 . SCHINz. t. 13. f. 16. a. Horderm coelefte polyftychum hybernum. вовим. n. 623, Var.

Pharm. Hordcain mundanin f. perlatum, f. Sem. excorticata.

Genzeine f. vierzeilige Gerfe; kleine Gerfte. Germ. Common Barley. Angl. Orge vulgaire, ou Efcourgeon. Gall.

diftichon. 193. Hordeum flosculis lateralibus mafculis muticis, feininibus angularibus imbricatis. IINN. Syft. p. 125. n. 3. - BLACKW. t. 223 .

Zweizeilige f, grojse Sommergerfie; Zicgelgerfte. Germ. Long-eared Barley. Angl. Orge diftique, ou Pamelle. Gall.

Hue duae fpecies, praecipue pofterior in agris circa Lipfiam et pagos feruntur. Illa floret Iunio, haec Iul.

Obf. Hondeum difichon ad Samaram Tatariaefluvium fponte crefcere fertur.

hexaftichon. 197. Hordeun fiosculis omnibus hermaphroditis ariftatis, feminibus fexiariam politis. ins. Syft. p. 125 . ก. 2 .

Sechszeilige Gerfe; Rothgerfee. Germ. Square, or Bear-Big Barley. Angl. Orge quarrée; ou groffe Orge. Gall.

Pafim in agris cultis inter Hordeum vulgare mihi occurrit. Fil. aeftate.

murinum. 195. Hordeun fiosculis la'eralibus mafculis ariftatis; inuolucris intermediis, ciliatis. LINN. Syft. p. I $26 . \mathrm{n}$. 7. воEнM, n. 6:2. Fl. Dan. t. 629. SC KVHR. t. 19. Mänjegcrfte; Taulgerfte; Katzenlorn. Germ. Orge des murs. Gall. 
In ruderatis et ad muros tramitesque copiofe. Fl. Mai. Iun.

VJ. Pabulum onibus. Gled.

y96. Hordeum Aosculis lateralibus, fterilibus, filiformi- fecalinum. hus, ariftatis, dorfo glabris; inuolucris fetaceis fcabris. sCHREB. Spicil. p. 148. n. 1167.

Taube-Mâjegerfac; Korngras, Germ. Orge Seigle. Gall.

In ficcis verfus Ket fchau. Fl Mai. Iun.

Obf. Ab Hordeo nurino, foliismollioribus, pilofis; fpica minori tenuinrique, inuolucris minoribus, minime cilitatis, differt.

\section{B. FLORE MONOCLINO.}

\section{Calamariae.}

55. CAREX. L. G. 113\% Riedgras. Germ. Carex. Angl. Caret ou Laiche. Gall.

$$
\text { * Spica unica fimplici. }
$$

197. Carex fpica fimplici androgyna, fuperne mafcula; pulicaris, feminibus refexis teretibus, ouato acuminatis.

Carex pulicaris. LINN. Syft. p. 8+2. ก. 3. ВОЕнм. n. 6-3. LEERS t. 14. f. 1 .

Flühriedgras. Germ. Flea Carex. Arigl. Caret pu. cicr. Gall.

In pratis paludofis, im Rofenthale et in pratis Schocnfeldicis etc. frequens. Fl. Mai. Iun.

\section{** Spicis androgynis.}

198. Carex fpicis compofitis, fpiculis androgynis, oua- arenaria. to - acutis; inferioribus remotioribus, foliolo lon, giori inftuatis, culmo triquetro. LINN. Syft. F. 843 . n. 8. BOEI1M. 11. 67+. - Fl. Dan. tab. 425. LEERS n. 706. t. 14 .

Pharm. Rad. Graminis maioris f. Caricis-arenariae.

$$
\text { E } 3 \ldots \text { Sani- }
$$


Sandriedgras; teutfcla Scfaparill. Germ. Sea Carex. Angl. Caret fablin Gall.

In locis vliginolis ante pagun Schönfcli pafim. Fl. Mai. Iun.

Obf. Stigma 2-fidum, fpiculàe feffiles. Radix recens vulnerata odorem Teiebinthinae venetae fimiIen fpargens: faepius toco Saffaparillae a Pharmacopolis venditur.

dificha, 19\%. Carew fpica conpofita fubdifticha, fuiculis cuatis fubinbricatis androgynis, folio longiori inftrutis, culmo triquetro. Leys. ת. 937. SCHREb. Spicil. p. 63. ก. 6-1.

Cratex diffichafpica compofita, fpiculis ex fubro. tundo-ountis, numerofis, confertis, in fummo faepe cohatrenibus, feffilibus, androgynis, nudis.Pollich pal. Tom. II. p. 562. n. 8-5.

Zuecifeitiges Riedgras Gern. Caret diffique. Gall.

In fyluaticis in Rofcnthale, Gonnereitaer Holze, alibique. Niv. Mai. Inn.

Obf. Differt a priori, fpicis remotioribus, fpiculis fubdifichis magis obtufis, bractea fpica longiori et foliis anouftioribus.

leporina. 200. Carcev fpica compofita, fpiculis ouatis, fefflibus, approximatis, alternis, androgynis, nudis. LinN. Syft. p. S43: n. IO. BOEMM. n. 667. LEYS. n. 938. LEERS n. 707. f. 6.

Hafenricdgras. Germ. Naked Carex. Angl. Caret des lieures. Gall.

In pratis liumidis in Rofenthale copiofe et in pratis Schoenfeldicis, etiam auf den Wiefen nach Lindenau; et ad viam publicam nach $W_{V}$ ölkauet in fofficulis vbiq̣ue. Fl. Mai. un.

vulpina. 201. Carex f́pica fupra d.compofita, inferne laxiore; fpiculis ouatis andrngynis, gुlomerais. LINN. Syft.p. 843 n. 11 . EOFHM. n. 6ú6. LeYs. n. 940. LeERS n. 7०8. Tab. 14. f. 5. Fl. Dan. t. $30 \%$

Fuchsriedgras; Waficrcyperngras. Germ. Greas Carex: Angi. Caret des Renards. Gall.

In paluftribus, in $R$ efentlale; in forfis inundatis circa pag s vbique in $v$ is publicis haud infrequens; prae. cipue nacti Düben et Pomfin zu. Fl, Mai, Iun, 
Obf. Culnus craftus, firmus, triangularis; ftigna 2- fidum.

202. Caren fpica compofita, difticha, nuda; fpiculis brizoides.

androgynis, oblongis, contiguis, culmo nudo. LANN. Syf. pag. 84. ก. 12. schaEd. pag. 63. n. 675 . BOEIM. ก. 675 . LEYS n. 941.

Zittergrasininliches Ricdgras. Germ. Rough Carex. Angl.

In nemoribus vmurofis im Rofenthale, Streitiolze et anf dun Gorbcreiefen. Fl. Iun.

203. Carex loica compofita, dificha, nudiufuia: fpi- praecor. culis contiguis, androgynis, teretibus, erectis, culmo fuperne nudo. LEYs. n. 939. sCHREB. Spicil. p.63. n. 1010 .

Frïlzatiziges Riedgras. Germ. Early Carex. Angl.

In locis graminofis ficcioribus, in horto Reichclian no, im bieniz, ad Gonncweitz beider Kirche, ad Gautfch et alibi. Fl. Mart. April.

204. Carex fpiculis fubouatis, feffilibus, remotis an muricata. drogynis, caplulis acutis diuergentibus, fpinofis. LINN. Syft. pag. 843. n. 13. BOEHM. n. 672. LEYS. ก. $9+2$.

Carex municata fpiculis fubouatis feffilibus remotis androgynis, fuperne mafculis, inferne femineis, capm fulis acutis bicufpidatis. WILD. Prodr. Berol, n. 94.

Zugefpitztes Ricdgras. Germ. Prikly Carex. Angl. Caret hériffé. Gall.

In riemorofis humidis areifchan dem Schanbergifchnu Hölzgen, et ad Lindenau. Fl. Mai. Iun.

205. Carex fpiculis feffilibus, remotis androgynis, loliacea. carfulis ouatis, teretiusculis, muticis, diuaricatis. IINN. Syft. p. $8+4$. n. 1.4. scureb. Spic. p. 6.7. n. IOII.

Lolchartiges Ried'gras. Germ. Iun.

In vois and der Ziegclforonme bei Meisciorf. Fl. Mai. 206. Carex fpiculis ouatis, fubfeffilibus, remotis, an- remota, drogynis: bracteis culmum aequantibus. InN: Sylt. p. 8it.n.15.SCHREE. p.64.n.1012. - LEERS n. 710. Fl. Dan. $53^{-0}$.

Entemite Segge f. Riedg:as. Germ. Long-leaved Carex. Angl. Caret écarté. Gall. 
In nemoribus humidis vmbrofisque, im Rofenthale, Gonnewitzer, Gautfcher Holze. Fl. Mai. Iun.

Obj. Spica breuis. Stigna bifidum Folia carinata. elongata. 20\%. Carex fpiculis oblongis, tefil bus, remotis, androgynis, caplulis ouatis, acutis. LiNn. Syft. p. 8.44 . n. 16. вовнм. n. 676 .

Lenges Riedgras. Germ. Long-fpicked Carex. Angl. Caret alongé. Gall.

In pratis humidis et fylueftribus im Rofenthale, porro inter Grofszfhocher eiusque fyluam Fl. Mai. Iun.

Obf. Spica vniuerfalis oblonga 8-To-fiora. Capiuia roblonga, obfoleta trigona, in apicem longum produsa.

paniculata. 208. Carcx racemo compofito; fpiculis androgvnis. Linn. Syft. p. 844 . n. I8. MICH. gen. 68 . t. 33. f. ?•

Carex fpica paniculata, androgyna; culno tiquetro; fpiculis feffilibus, ouato acuminatis, вовнм. n. 674 .

Quaftenformiges Riedgras. Germ. Panicled Carex. Ang1. Caret en panicalc. Gall.

In paluftribus fyluaticisque frequentifime in Rofenthale, Strzitholae. F1. Mai. Iun.

*** Splicis fexu diftinctis; femine is felfilibus.

Anua, 209. Carex fpicis confertis, fubfeffilibus, fubrotundis; mafcula lincari; captulis acutis, recuruis. LiNN. Syft. p. 8.44 n 21 . BoEHai. n. 768. LeERS n. 714. t. I5. f. 6. (male expreffa).

Gelbes Riedgras. Germ. Yellow Carex. Angl. Caret jaune. Gall.

In pratis humidis et Incis fpongiofis, an dem Eutritzfcher Graben, nach Gohlis, in pratis Schoenfeldicis atque auf den Rofenthaler WViefen. Fl. Mai. Iun.

Obf. Stigma trifidum. Capfulae ventricofae, friatae, in apicein oblongum bifidun terminantes.

digitata. 210. Carcx fpicis linearibus, erectis; mafcula breuiore inferioreque; bracteis aphyllis, capfulis difantibus. LINN. Syft. pag. 8\$4. II. 23. BOEHM. n. 670. LEYS. n. 946. LeERS n. 715 . t. 76. f. 4 .

Fin- 
Fingerförmiges Riedgras. Germ. Digitated Cared. Angl. Cartet digité. Gall.

In locis nceliuioribus, campeltribus, an Bieniz. Fl. Atril. Maio.

211. Carextpicis fenineis fefflibus, fubfolitariis oua-montana. tis mafulise approximatis; culmo nudo; capínlis pubefeentibus. LINN. Syft. p. $84.4 \cdot$ n. 24 . SCHREB. Spicil. p. 65. n. 1014. LEYS. n. 947. LeERS n. ? I6. t. 16. f. 6. Fl. Dail. t. 4 4t.

Bergriedgras. Germ. Mountain.Carex. Angl. Caret 'des montagnes. Gall.

In acliuibus am Bieniz et ad aedem St. Theclar. Fl. April Maio.

Oly. Spicula mafcula terminalis erecta, oblonga; fquamis fufcis, obtulis, neruoluteo. Spiculae, foemineae duae (rarifime vna) approximatae, feffiles, ouatae, breuiores, panciflorae et maturitate nigrae. Capfulae fubtrigorae, gibbae, pilis albidis obfitae. Culmi fpithamaei, fubnudi, laeucs, filiformes.

212. * Carex fpica nafcula oblonga, femineisfeffilibus filiformis. inferiore folio preprio breuiore. LINN. Syft. p. $8+5$. n. 25. LEERS R. gI8. t. I6. f. 5 .

Haarformige Sigge. Germ. Filiform-Carex. Angl In locis nemonlis, im Rofenthale pafim mili occurrit. Fl. April,Maio.

Obf. Spica macula terminalis. Spicae femineae 2-3- approxmatne, oblonigae, breues, feffiles; fquamis fufcis, oblongis. Capfulae fubhirfutae, confertae.

213. Carex fpicis femineis fubpedunculatis; capfulis tomentofa.

fubglobofis tomentofis. LrNs. Syft. pag. 847. n. 25 . SCHRE. P. 65. 8. 1015. LeYs. 11. 948. LeERS n. 717 .

t. 15 . f. 7 .

Wclligtes Ridgras. Germ.

In nemoribu's elatioribus, anf dem Bicniz. "Fl. Mai. Iun.

Olf. Folia radicalia, angufta, fubcarinata, fuperne fcabra, inferne leviter pubefcentia. Capfulae $15-20$, fubglobofac, albido - villofie, in apicen bifidum breuem produktae. 
"**** Spicis fexn diftindtis; femineis pedunculatis.

limofa. 214. * Carex fpicis ouatis pendulis: mafcula longiore erectiore, radice repente, LINN. Syft. p. 845. $\pi .32$. LEYS. n. 953. LEERS n. 7 I9. t. I5. f. 3. Fl. Dah, tab. $6+6$.

Schlamm - Riedgras. Germ.

In pafcuis et locis limofis bei Kleindölzig praeterito anno mihi occurrit.

pallefcens. 215. Carex fpicis pendulis; mafeula eręa, femineis ouatis, imbricatis; capfulis confertis, obtufis. LINN. Syft p. 8.45. n. 34. SCHREB. Spicil. pag. 66. n. 1016. LEERS n. $72 \%$. t. $15 . \mathrm{f} .4$.

Blaffes Riedigras. Gern. Pale, Carex. Angl. Caret patle. Gall.

In fyluaticis fuhhumidis ad Gautch, Rafchreitz, Meisdorf, ibidemque in pratis et ad fepes ad Abtnaundorf. Fl. Mai.

Obf.' Stigma 3 fidum. . Capfuiae confertae, oblongae, trigonae, obtufiffunac.

panicca. 216. Carex fpicis pedunculatis, erectis, remotis; femineis linearibus; capfulis obrufusculis, inflatis. LiNN. Syft p. 8.5.5. n. 35. Schree. pag. 66. n. $101 \%$. LEYS. n. 955. LeERS n. 722. t. 15. f. 5. Fl. Dan. tab. 261 .

Brodriedgras; Fennichegge. Germ. Pink Carex. Angl Caret panifet. Gall.

1. In piatis fpongiofis et vliginofis fere vbique, bei Kleindölsig; im Rofenthale. FL Mai. Iui. Perennis.

Obf. Spica mafcula oblanga fuperne plerumque Anribus femineis. Spicse fenineae $2-5$. Capfulae ventricofae, obtufae, bidentatae.

5eudo-Cy-2I - Carex fpicis pendulis; mafcula erecta lineari ; feírus: mineis geminatis cylindricis pendulis, capfulis fulca. tis, mucronatis. WILDEN. Prodr. Berol. n. 105.

Carex lpicis pendulis, pedunculis geminatis. IINN Syft p. 845. n. 37 . вовнM, n. 663 .

Falfch Cyperngras. Germ, Bafard Carex. Angl, Caret Eaux. Souchet. Galla 
In ftognis ad viam nach Schönfeld; foitzeïrts Pfaffendorf auf desn. Irege mach Gohlis, porro in foltis circa pagum Probftheide et alibi frequens. Fl.-Mai. Iun.

Oif. Spicae femineae folitariae $2-5$, rarifime 6 , cylindriformes. Stigma 3-fidum. Caplulac ouato - oblongae, glabrae, fulcatae, mucronatae, spice bifidne.

218.* Carcx ficis ereßtis, cylindricis, ternis, fubfeffli- caefpitofa. bus: mafcula terminali, culmo triquetro. LiNa. Syft. p. $845 \cdot \pi \cdot 38$. LEYS. n. 95\%. WILDEN. n. 10. ' Tab. II, tig. 5 .

Rafenriedgras. Germ. Turfy Carcx. Angl. Caret gazon. ' Gall.

In losis caefpitofis hei Kleinz/chocher,' porro nach dem Bieniz zu, bei Belgershayn, Poinen paffin. Fl. Aeftate.

Obj. Stigma modo trifidum obferuaui.

219. Carex fpicis remotifinis, fubfefflibus, bractea difans, vaginali; capfulis angulatis, mucronatis. IIEN. Syft. p. 845. n. 39. SCHREB. Spicil.p. 67. n. 1019.

Getheilte Segge. Germ. Loofe Carex. Angl. Caret écarté. Gall.

In pratis fubhumidis; hinter den Bieniz; im Ro. Senthale; in pratis nach Schönfeld. Fl. Mai.

Obj. Spicis magis diftantibus, breuiter pedunculatis; capfulis acutis, a priore differt. Stigma?fidum.

220. Carex fpicamafcula oblonga, femineis ferioribus, humilis, remotis, fubpedunculatis, paucifloris, culmo foliis breuiore. SCHRE. Spicil. pag. 6j. n. 1013. LeYs. n. 952.

Niedriges Riedzras. Germ.

In locis accliuioribus, an Bieniz. Fl. April. Maio.

221. Carex fpicis pendulis, maicula erecta, femineis pendula. cylindraceis, pedunculo longioribus; capfulis acuminatis, hlvs, Angl. 382. schreb. pag. 62. n. 669. BCän. ก. 669 .

Ilangendes Riedgras. Germ. Pendulous Carex. Angl. 
Ad foflas paludesque campeftres, hinter dem Brandvorwerke er Gonmcreitz. Fl. Iun. Iul.

fyliatica. 222. Carex fpicis pedunculatis pendulis: mafcula erecta; femineis filiformibus, laxis, pedunculo brenioribus; capfulis ouatis, ariftatis, furcatis. LeYs. 11. Q62.

Carex fpicis pendulis: mafcula ereita, femineis filiformibus, pedunculo breuioribus; capfulis ouatis, diftantibus. hvds. Angl. 353. schreb. Spicil. p.62.n. 66r. вогнм. n. 66r. Fl. Das. t. 704.

Carex veficaria culmo longifimo, fpicis tenuibus, remotis. LIN S. 'Syft. Ed. REICH. Tom. IV. p. II 4.

Waldriedgras. Germ. Wood Carex. Angl. Caret des bois. Gall.

In nemorolis vmbrofis, in Rnfenthale, Kanirfch, in Zjchocherfchen-Gunndorfer-Gonnewitzer. Unwver $\int_{2}$ tâtsholze etc. Fl. Maio.

Obj. Stigma 3 - fidum. Capfuiae 3 - quetrae, giabrae, ventricofae; apice bifido.

****** Spicis fexu diftinctis: mafculis pluribus.

acuta. 223. Carex fpicis mafculis pluribus, femineis fubfentlibus; capfulis obtufiafulis. ImN. Syft. pag: $3+5$. n. 41. BOEHM. n. 665. Letrs n. 723 . tab. 10 . f. I.

Var. a) Carex acuta nigra foliis anguftioribus fpica nigra. fpica rufa.

B) Carex acuta rufa, maior, foliis latioribus,

Spitziges fchrearzf. fchrearzbrannes Riedgras. Germ. Great broad-leaved brown Carex. Angt. Caret aigas noir, out Lniche noive Gall.

In pafcuis humidis et fterilioribus anf dem Wege nach Altran? ädt ; im Stadutgraben zuifchen den grimmifchen und hällifclen Thore. Var. \&) In pratis humidis in Rofenthale, in locis paludofis et fofis vor Merfcurrg copiofe et var. $\beta$ ) in locis paludofis forlisque in Rojenthale, anf dem Wege nach Schön feld, uicht weet von den Teiche copiofe, et alibi. Fl. April. -Iun. 
Olf. Stigma 2-fidum. Var. o) differt culmo fpithamaco, lpicis omnibus atris, magnis approximatis et feminea faepius modo vnica. Var. $\beta$ ) culmo $2-3$ pedali, fpicis omnibus rufis, minus approximatis; femineis plerumque duabus, paffim tribus.

224. Carex fpicis malculis pluribus; femineis pedun-velicaria. culatis; capfulis inflatis, acuminatis. LINN. Syft. p. 845. 11. 42. roehM.n.662. leers n. 724. Fl. Dam. tab. $-6 \div 7$.

Biafenfegge. Germ. Greater Bladder Carex. Angl. Caret ićliculaire. Gall.

in paluftibus, e. $g$. in alneto bei Schönfeld; in fofficulis ad Probtheide frequenter, bei Pfafjeszdorf; Wetteritz, pafim et alibi. Fl. Maio..

Ubf. Stigma 3 fidum; fpicae feminege 3, remotae, oblongre.

$V f$. Pabulum bobus gratum.

225. Carex fpicis remotis; mafculis pluribus, femineis hirta.

fubpedunculatis, erestis; capfulis hirtis. LiNN. Syft. p. 846. n. 43. SCHREB Spicil. p. 66. n. IOI8. LeERS n. 725 . t. 16. f. 3. Fl. Dan. t. 379 .

Ranches Riedgras. Germ. Hairy Carex. Angl. Caret hériffé. Gall.

In campis arenofis ad vias nach Gonnewitz, in Bie. niz et aliis in locis copiofe. Fl. Mai. Iun.

Olf. Stigrna 2 et 3 fidum. Spiculae mafculae 23 , fefliles, oblongae; feminaae 2, remotae, ere స̂ae, peciunculatae et fquama modo nudae et lcues, reliquae partes plantae villis albidis obfitae.

\section{SPARGANIVM. L. G. II32. Ygelsknofpen.} Germ.

226. Sparganium, foliis erectis lanceolatis, neruo ele- ereftum. vato. WILD. Prodr. Berol. n. I 6.

Sparganium foliis erectis triquetris. LINN. Syft. p. 841. BOEHM. ก. 677. LEERS n. 726.

Aufrechte Ygelknofpe f. Degenkraut. Germ. Ruban deau. Gail.

In folfis, pifcinis ad Nauendorf bei der Kâmmerei; porro ante pagum Gothe et fere vbique, et ad littora

Plifiae, 
Pliflac, hinter den Brandiomecrle und auf den Wege mach Grofs $\approx$ felocker, et in folliculis proturum, porro in Gorberwafer frequens. Fl. Iun. - Aug.

VJ. Pabulum bobus gratum; fluuios et lacus pa. catos reddit.

\section{TYPHA. L: G. II I. Roinrkolbe. Germ. Mafte. Gall.}

latifolia. 227. Typha foliis fubenfiformibus, fpica mafcula femineaque approximatis. iINN. Syft. p. 84 I. воEнм. n. 678 . LeYs. ก. 965 . Fl. Dan. t. 645 .

Breitblattrichte Roiurkolben; Pumpkeulen. Germ. Maffe d'cau. Gall.

In omnibus fere pifcinis praeprimis prope Nauendorf beider Kanmerei, ante pagum Gothe t in ftagnis frequens, e.g. inder Prellheide. Fl. Iul.Aug. Perennis.

Vf. Pappo pauperes implentculcitras.

anguftifolia. 228. 'Typiza foliis femicylindricis, fpica mafcula femineaquic remotis. LinN. Syft. p. 84I. n. 2.-Fl. Dna., เ. 815 .

Typila paluftris claua gracili et minor. вовнM. $\mathrm{n}$. 678. var. 1: et 2 .

Schmalblütrichte Folben; Teich f. Lifchkolben. Germ.

In iisdem locis cum priori, praecipue in pifcinis ad Lindenthal, Gundorf, Elsrenberg et Gonnewitu, Nanendorf, Gothe; in tyluis paludofis in der Prell-" heide etc. Fl. Iul. Aug. Perennis.

Vf. In regionibus nonnullis foliis vtnntur victores ad doliorum circulos firmandos. 


\section{FLORE POLYGAMOIDE. Paniculata.}

¿) Calyce $\mathrm{I}$ - floro.

53. ANDROPOGON. L. G. :25 I. Barbon. Gall. Blutgras. Germ.

229. Andropogon fpicis digitatis piurimis, flosculis fef- Ifchaemin. filibus: ariftato muticoque, pedicetlis lanatis. IINN. Syit. p. yo.4. n. 23. SCHRER. Spicil. p. 45. n. 974. Ei. Agroft. P. II. p. 66. t. 33. JACQ. Fl. Auftr. V. VI. t. 384 .

Weifjes Blutgras. Germ. European. Andropogon. Angl. Barúnz veitu. Gall.

In locis eleuatis gramineis, iuxta vias publicas poft Altranfadt ad ftagnum atque muros Coemetcrii in paruis elatioribus ficcisque copiofe; prope Deidizpal. fim. Fl. a Iulio in ferum Autumnum vsque.

B) Calyce $2-3$ - floro.

59. HOI.CVS. I. G. II52. Rofsgras, Germ. Indian Nillet. Angl. Houque. Gall.

230. Holcus glumis bifloris nudiusculis: fosculo her- mollis, maphrodito mutico; mafculo arifta geniculata. LINN. Syft. p. 905 . n. 6. schieb. Spicil. p. 5\% n. 98 \% (fub Aira) Leers n. 769. - schreb. Agrolt. p. 149. tab. 2o. f. 2 .

Weiches f. kriechendes Ro/sgras. ${ }^{-}$Germ. Houque molle. Gall.

In locis arenofis, ferilioribus nemorofisque, im Bieniz, Oberholze; in pratis ad Abrnauendorf. Fl. Iun. Iul.

Obf. Folia lata, plana, laeuia, fupra villis rarisinftructa, Calyx inaequalis, ouatus, argute acuminatus, comprefius, erectus.

231. Holcus glumis bifloris villofis: fiosculo herma- lanatus. phrodito mutico; máculo arifta recuiua. IINN. Syft.

p. 905. 
80 CLASSIS III. TKIANDKIA. POLYGAMOIDE.

p. 905. n. 7. вокнм. n. 616. (fub Aira) Lгекs n. 770 . SCIIREB. Agroft. p. I4.5. t. 20. f. 1.

Wolluchtes Rofsgras'; Pferdegras. Germ. Meadoze. Snft-grafs. Angl. Houque laineufe. Gall.

In pomariis, pratis humidis, in Rofenthale, in pratis Schoenfildicis, anf der Rückmarsciorfir und andern Wiefen, frequens. Fl. Iun. Iul.

Ol.,. Folia lata, plana vtrinque molliffimis villis obfita. Calyx 2- florus, obtufe ouato-acurus, glumis maioribus, obiongioribus, pubefcentibus, magis coloratis, carina fetis patulis diftinctioribus ciliatis. - VS. Foenum praebęt bonum. 


\section{Claffis IV.}

T, E T R A D R I A

MONOGYNIA.

\section{A FLORE HERMAPHRODITO.}

a) Flores $\mathbf{I}$ - petali, monofpermi, fuperi:

A GGREGATAE.

60. SCABIOSA. L. G. i2 r. Scabiofe. Gsrm,-Seabious, Angl. Scabieule. Gall.

* Corollulis quadrifidis.

232. Scabiofa corollulis 4 - fidis aequalibus, caule fuccira. fimplici, ranis approximatis, foliis lanceolato-ouatis. LINN. Syf. p. 144. n. \% BOEHA. n. 159. BLACKW. t. 142. Fl. Dani. t. 279 .

Var. «) Scabioja foliis hirfutis) C. B. P 269.

B) Scabiofa foliis glabris I. et II.

r) Scabiofa flore carneo in album vergente.

Pharm. Succifae f. Morfus Diaboli Radix, Herba. Abbifs-Scabiofe; Telifils Ablifs f. Anbis. Germ. Devil's-Bit; Snooth Suctifa. Angl. Scabzeufe fuccife; Mors dit diable, out Remors. Gall.

In pratis ad Schönfeld. Var. a) in pratis pott pagos Gunndorf et Klcindöizig inueni, et var. $\beta$ ) auf dem Gickerlingsberge. Fl. Iul.

Obf. Caulis teres, ftriatus; pilis hirfutis obfitus. Folia in medio leuiter ferrata.

$V \int$. Folia viridi colore et radix luteo tingunt. Flores apibus pabulum, et herbabobus, capris, ouibus, gratum. 
thenfis, 233. Scatiofa corollulis - fidis radicantibus, folii in. firtoribus pinnatidis, incifis; caulinis, dentatis;

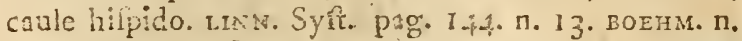

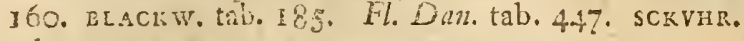
tab. $2=$

Pharm. Scabiofic Kadix, Herba, Flores.

Acherfabioje; Apofteriblaut; Glicderling g; Grindkraut Nonaenklepvel; blane Formofe; Tivinzenbllume. Germ. Fich-Scabious. Angl. Scabicufe des chailips. Gail.

In pratis Schüncleldicis et ad agrorum margines poft urbern Tancian fic dictam verfus vineta, aliisque in locis copiofe. Fl. Iul. Aug. Perennis.

ObJ. Receptaculum villofum, villis 12-24. cas!itis. Folia radicalia, pinnatifidı, fubintegra, pilis fiabris obfita.

Vf. Radix vim diluendi adftringendique habens. Pabalum pecoribus amabile. Flores apibus. Herba lanam colore tingit viridi.

\section{** Corollullis quinquefidis.}

solunicaria, 234. Scabiofa corollulis 5-fidis, radiantibus; foliis radicalibus ountis, creratis; caulinis pinnatis, feta-

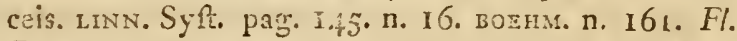
D.n. t. 3 ! 4 .

Illein Apoftemkrant; Tanbenfabinfe. Germ. Leffer Ficlle Scabious. Angl. Grand Scalierle colombaire. Gall.

In montofis, ficcioribus, im Bieniz et anf dem $\mathrm{G} i$ cherlingsberge; porro in Alneto ante Schönffel. Fl. Iul. Ang. Biennis.

Obf. Color corollae caeruleus. Folia radicalia, paflim inter,errima: caulina pinnata, fetacea; interdum linearia, integerriua, ouata, longe petiolata.

tenuifolia. 23.5. Scabiofa corollulis fubquinquefidis radiantibus; foliis radicalibus bipinnatis, angutis; calinis pinratis, linearibus; petiolis perfoliatis. Roтn. Fl. Germ. P. ¿. p. 59. n. 6 .

Scaliofa ochrolenca corollulis 5 -fidis radiantibus; foliis!bipinnatis linearibus. LINN. Syft. p. 146. n. 32 . 
EOEFM, B. I62. JACQ. ODferv. III. f. 72 . et 74. KERN. p. 109. f. $_{1} 193$.

V\&r, a) Scab. Hore ochroleuco.

B Scab. flore caerulco.

Golblichte 1. wohlvicherde thïringifche Scabioje. Germ. Kellow German Scabious. Angl. Scabieufe it feuilles étroits. ou jaunâtre Gall.

in inontofis campeftribusque in via ad Meckern; inter Euteritfih et IFeltcrirfch, auf dean Sandberge zor Nauendorf et Rückmansdorf. Var. $\beta$ ) $2 m$ Bieniz palim. Fl. Iul. Aug. biennis.

$V \int$. Pabuium ouibus delicatum.

61. DiPSACVS L. G. r20. Karten. Germ. Teazel. Angl Cardiaire. Gall.

236. Dipfacus foliis fefflibus ferratis, paleis recuruatis. fullonum. IINN. SYR. p. $143 \cdot$ n. 1. BOEH., n, 158. BLACKW, t. 50 SCKVHR. T. 2 I.

Webcriartcn f. Karterfchen; Ticlumacherdiftel; grofse reilde Rartendifiel. Germ. Fullus Teazel. Angl. Charcon à Bonntetier; on Cinardon à Foulon. Galt.

' In ruderatis et ad follas auf dch IFige nacle der grïnen Schenke, hinter den Taubinen bei dem Anger; auf dor Pfingfreriefe etc. Fl. Iul. Aug. Perennis.

237. Dipg facus folits connacis fimuatis. LIN Sy t. pag. Iaciniatus. 1.43. n. 3. BOEHM. n. 158. var. I. JaCr. Flor. Auftr. V. 5. t. 403 .

Gejchliziblïtrige Kartch. Germ. lagged-leaved Teazel. Angl. Chardon, ou Cardere à feulles de. cozpées. Gall.

In dumetis et ad fepes' paftim. Fl. Iun. Iul. Perennis.

Obf. Quoal magnitudinem cum priori conuenit.

238. Dipfacus foliis confuentibus et aculeis rigidiori-fatius.

hus; floribus paliidis. гогнu. n. I38. var. 2 .

Zahme TVeberdifuel; wahre Tiartetfchen; Y Yelkonf; Frau Venusbad. Germ. Culzized Teazel. Angl. Cardere cultizée. Gall. 
In pratorum marginibus port Gumersdorf, nach der Bürgeraue, et in multis hortis crefcit. Fl. Iul. Aug. P.rennis.

VJ Flores'apitus pabulum. Capita plantae echinata pectinis dd inftar fullonibus infertiunt. Aquam toliis contentam contra lenes ocu rum morbos laudat EOERHAVIVS.

pilofias. 239. Dipjacus folia petiolatis appendiculatis. LrnN. Syft. p. 143 . n. + . Boens. n. 157 JaCn. Flor. Auftr. V.III. t. 48 . BLACKw.t. ? 2. Virga paftoris.

Haarigte Kartendiflel i., kleine munde Kartendifel. Germ. Stepherds Staff. Angl. Cardere velue, ou Vorge ì Pafteur. Gall.

Ad fepes et in pratorum marginibus poft Lcut fch et Parneck; porro in horto Bofiano hinter dem Colfeehazuje. Fl. Iul. Aug.

b) Florés $\mathrm{I}$ - petali, monocarpi, inferi.

62. CENTVCVLVS. L. G. 151." Kleinien. Germ. Baftard Pimpernel. Angl.

minimus. 240. Ceintznculis foliis fuperioribus alternis, ouatis: inferioribus oppolitis. LINN. Syft. pag. 158, SCHREB. Spicil. p. 5. n. 892. LEYs. n. 142. Fl. Dan. tab. 177. sckviri. t. 24.

Kleinfor Centunkel; Rlinker. Germ. IVhite-flowew ring Baftard Piminernel. Angl.

In agris arenofis vilique, anf dem Gickerlingsberge; in montofis locis ante pagum Inockau, porro bęi Mark- et Altranftadt; beim Oberholze, alibique. Fl. 1ul. Aug.

\section{PLANTAGO. L. G. 148. Wegerich. Germ. Plantain. Gall.}

maior. 24. I. Plantago foliis ouatis, glabris; fcapo tereti; Ipica , fosculis imbricatis. LinN. Syft. p. 155. военм. n: 18. blackw. tab. 35. a. Fl. Dan. tab. 46 r. a. sckVhr. tab. 23 .

Var. 
TETIR A DRIA. AO NOGYNIA.

Var. a) Plantago latifolia:glabra minor. C. B. P. 189.

dentatis.

B) Plantago caule maximo, folio finuatovel ferratis.

r) Plantago caule pumilo, foliis integerrimis

Pharm. Plantaginis liztifoliac Herba, Radix, Se. mina.

Grojser Wegerich f. Wegctritt; Schafzunge. Germ. Common broad leaued plantain. Angl. Plantain large, ou ì bouquet. Gall.

In verliris, pratis ficcis, pomariis, ad femites ybique. Fi. per totam aeftatem.

Vf. Pabulum pecoribus. Flores apibus et femina pafteribus canarienfibus deliciae. Succus vel decoctum contra tabem laudatur. Semina in dyfenteria.

242. Plantago foliis ouato lanceolatis, pubefcentibus, media.

fpica cylindrica, feapo tereti. LINN. Syft. p. 155.n.3. schreb. Spicil. p. 4. n. 890. Fl. Dan. t. 581. a.

Var. a) Plantago latifolia hirfuta minor. C. B. P. 189.

Mittlcre Wegebreitc; klciner f. teeiffer Wegtritt. Germ. Plantain moyen. Gall.

In ambulacris et ad vias cum priori vbique. Fl. Maio Iun.

Obf. Folia ouato - oblongo-lanceolata, bafin verfus ferrata, pilis feabris obfita. Scapus nudus, teres, hirfutus. Spica breuior, craffior et denfior. Antherae violaceae. Pratis valde obnoxia.

243. Plantago foliis lanceolatis, fpica fubouata nuda, lanceolata. feapo angulato. LiNN. Syft. p. 155. n.6. вогнм.n. 19. Fl. Dan, t. 437 . var. $\beta$.

Var. a) Plantago foliis feptemneruiis, pedunculo longillimo.

b) Plantago foliis quinqueneruiis, paulo latioribus, maioribus. BLACKw. t, 14. minoribus.

c) Plantago foliis trineruiis, anguftiffmis,

Pharm. Plantaginis minoris Herba. 
Spitziger Wegetwitt;'Hesuds- I. Rnfsribbe; fiebenfüf-1. dreinasigter Wegbreit. Germ Narsote-licued Plaitain, or Ribieort. Angl. Plantain Lancéolée. Gall.

In pratis, pomariis, verfuris et nontofis frluis valde vulgaris. Var. a) in horto Bofino, b) inn Rofenthaic, e) in ficcioribus, in der Obfallec vor Schlcufig et im Bicnia ctc copioíe. Fl. aetate.

Vf. Pabulum ouibus aliisque gratum. Succus cxpreffus recens vnguentum exhibet vulnerarium. In radicibus huius Coccionela germanica habitace fertur. Cacterum eaeden vires ac Plontagitis maiolis.

maritima. 244. Plantago foliis femicylindraceis integerimis bafi lanatis, fcapo tereti. LiNN. Syft. p. 156.n. I2. schíreb. p. st. n. \$91. Leys. 11. 1.66. Fl. Dan. t. 243 .

Mccrucgetritt; Sceflrandswegerich. Germ. Plantain des marais. Gall.

In falinis locis, e. g. ad Kerfchan iterum magna in copia reperi. Fl Iul. ad Autunnum vsque.

Obf. Folia crafra, linearia, glauca, baí parum lanata.' Anthrrae fiauae.

Vf. Pecoribus praeftans pabulum. Folia iuniora oleo et ace to condita acetariorum ad inftar in regionibus nonnullis inferuiunt

Gubulata. 245.* Plantago foliis fubulatis, triquetris, ftriatis, fcabris; fcapo tereti. LINN. Syft. p. 156. n. 14. LEYS. n. 120. MORAND, t. 60. f. 5 .

Pfricnenförmiger IVegerich; kleiner Kröhenfus; Schze cinekreffe. Germ. Subulated Plantain. Angl.

- In locis arenofis fainisque ad Ketfchau nuperrime inueni. Fl. Iun. Iul.

c) Flores monopetali, monocarpi, Juperi.

64. SANGVISORBA. L: G. n., I52. Wiefenknopf; Sperbenkraut. Germ. Burnet. Angl.

Aficinàlis. 246. Sanguiforba fpicis ouatis breuibus, foliolis cordatis bоенim. n. 16. LiN. Syft, n. 158. Fl. Dan. tab. 97. SCKVHR, t. 24.

Pharm, 
Plarm. Pimpisellate Italicae Radix.

Gebrauclubiclicr IFiefezzknopf f. Bibernell; grofse f. falfclue Bibernil ; Blatliraut ; Blutropfen; Herrgotsbïrtcin; tentflue Theriakuntal. Germ. Common or Englif! anild Bumet. Angl. Pinprenelle. Gall.

In pratis ficcis humidisque fere vbique, praecipue anf den Wiefen hinter Reichels Gartcn, auf den Rofentlualer, Lincwanater et Gumndorfer Wiefen. Fl. Iul. - Septenis.

Vf. Pabulum pecoribus ouibusque falátare. Herba etism coriis parandis apta. Radix vulneraria et tonica in dyfenteria et pulmonum vlcaribus laudatitน.

d) Flores monopetali; frustibus geminis, connatis, fimperis.

S T E I, L A T A E.

65. GALIVM. L. G. I32. Labkraut. Germ. Ladiesbeditraw. Angl. Caillelait. Ğall.

* Fructibus glabris.

247. Galinm folis quaternis, obouatis, insequalibus, paluftre. caulibus diffufis. LiNN. Syft. p. I5O.n. 2, вовн1M. n.9. Fl. Dan. t. 423 .

Sumpflabiraut; Sumpfiealdfroin; weis Magenkraut. Germ. White' Marfh Ladics-beciftrave. Airgl. Caillelait des marais. Gail.

In pratis vmbrofis fyluaticisque, in alneto ad Schönfeld, in Bienitz et alibi copiofe. Fl. Iun. Iu!. Annunm.

Obf. Folia caulina femper inaequalia, valde ohtufa; inferiora interdum quina, vel fena; fuperiora, femper 4 - terna; floralia bina, paffim terna. 24. Galina foliis fubquaternis, linearibus laeuibus; montanum, caule debili feabro, feminibus glabris. LiNN. Syrt. p. I5O. ก. 3. ВОЕHM. n. I2. LEYS. R. 149.

Eerglablinaut; Bergröthe. Germ. Mountain Lañiest bedifrare. Angl. Caillelait des montagnes. Gall, 
In nemoribus montofis, anfidem Bieniz fpsrfim mihi occurrit. Fl. Iun. Iul.

Obf. Folia ad bafin caulis quaterna vel quina latiora; fuperiora oćtona. tenuiora, in apicem acutum definentia; fuprema quina et quoque fena. Synonymun, quod Cel. eostrmervs huc citauit, potius ad Galium glaucum reducendum.

viginofum. 249. Galinn foliis fenis lanceolatis, retrorfum ferratoaculeatis, mucronatis, riegidis, corollis fructu naioribus. LINN. Syft. p. 150. n. 6 SeHREk. p. 3. n. 887.

Moraflabliraut; klein weifjes Meicrkraut. Germ. Marjh Goofe-grafs. Arigl.

In pratis paludofis vbique, v c. ad Schönfili, Lindenau, Kleindölisig etc. Fl. Iun. Iul.

Obj. Folia linesria apice breui acuta; inferiora quaterna; internedia fena; fupiema octona et quina.

fpurium. 250.* Galiun foliis fenis lanceolatis, carinatis, fcabris, retrorfum aculcatis, geniculis fimplicibus, fructibus glabris. LINN.'Syft. p. $150 . n$. 7. LEYS. n. I24.

Unichices Labliraut; Baftardklebrich. Germ. Caille. lait Aparine. Gall.

In ayris arenolis inter fegetes paffin mach Gonnezeitz, ct in agris hinter dcn Gerberzeiefen. Fl. Iun. Iul.

Obf. Hoc Galium ab alis pro varitate Galii Aparines habctur; fed ab illa diftinguitur, caulibus.mi-' noribus, vix pedalibus, difiufs, tenuioribus; geniculis aequalibus, nudis; foliis inferne fenis; fuperne quaternis; frutu glabro, vel hifpido.

veium. 25I. Galiun foliis oftonis linearibus fulcatis, ramis flo. ribus breuibus. LINN. Syft. p. 150. n. 12. воEHM.n.8. BLACKW. t. '35. SCKVAlR. t. 23 .

Pharm. Galii litei Herha et Flores.

Wahres Labkraut; geller Butterficl; Glied-Lab-Meyerkraut; "uner lieben Frauenbett-Wald-Stroh. Germ. Common Yclloze Ladies -bedftrawo, or Cheefe Rennct. Angl. Caillelait joune. Gall.

In pratis et ad vias publicas frequenter. Varietatem ve. ro floribus pallidis, foliis fenis paulo latioribus, in alne- 
to ad Schönfeld nuperrime inueni . Fl. Iun. Iul. Perenne.

Oof. Folia caulina linearia, fulcata, acuta; inferiora otona; fuperiora decena plurimaque; foralia quina, vel fena.

Vj. Comae coagulo lactis mifcentur ad cafeos conficiendos.

252. Galitm foliis octonis ouato-linearibus, fubferra- Mollugn.

tis patentifimis, mucronatis, caule flaccilo, ramis patentibus. LiNn. Syf. p. 150. n. 13. BOEHM. n. 11 . BLACKw. t. 169 . Fl. Dan. t. 455.

Weifies Labkraut; Grofs if Schmalftemncyerkraut; ueiffes Wraldftroh. Germ. TVhite Ladies-bedftraze; on Great bafart Madder. Angl. Caillelait blanc ou Petit Mugnet. Gall.

In pratis et ad fepes fparfim. Flor. Iun. Iul. Perenne.

Ob. Caulis angulofus, glaber; folia caulina latiora, quam in Galiis antecedentibus, glabra, fupralaete viridia, fubtus glauca, integerrima; inferio:a decena; intermedia lena et oftona; foralia bina, rninora, anguftiora. Flos albus.

Vf. Pabulum pecoribus falutare. Radix rubiotinctoria.

253. Galinm foliis octonis laeuibus, fubtus fabris: fo- fyluaticum.

ralibus binis; pedunculis capillaribus, caule laeui. LINN. Syit. p. 1 ío. n. 14 . schree. Spicil. p. 2. n. 13. BOEHM. 11. 3. KERN. B. II. p. 106. t. I83.

Waldlabliraut; grofs Waldancifer. Germ. Wood Ladies - bedfravo. Angl, Coillelait des bois. Gall.

In fyluis montofis, im Univerfotïtsholze, im Bieniz, in fyluis ad Sonimerfold, Zuenke, in der Kiimmerei bei Naucndor 5 in dem Verhaue etc. copiofe. Flor. Iun. Iul. Perenne.

Obj. Caulis teres f. fubquadrangularis, ereftus. Folia intęrdum fena, faepius ótona. Corollae albae laciniis latiffmis acutis. - Hanc herbam pro Matrifilua phamacopeos imperitos laepius vendere, II'. SCHRERERVS inonet.

Vf. Radix pulchro rubro tingit colore. 
glaucum. 254. Galium foliis oftonis linearibus fubtus gुlancis, pedunculis elongatis dichotomis, fummo caule floriferis, caule glauco laeti. LINN. Syft. pag. 151 n. I8. SCHREB. Spicil. p. I. n. 12. BOEIM. n. I2. ESCGENB. Oiferv. Bot. p. 2r. л. 9. Fl. Dan. t. 609. JAcé. Flor. Auftr. Vol. I. t. \&r. var. $\beta$.

Eifengraues Labkraut. Germ. Glaucous Ladies - bedArawe. Angl.

In montofis auf dem Bieniz paffim, et rarifime prope Wehliz et Rochlitz Cel. ESCHENB. ante multos annos inuenit. Fl: Iun. Iul. Perenne.

2fpcrum. 255. Galium foliis lineari lanceolatis, fenis nouenisque, lubafperis ariftatis rolt. n. 15I. (Galium figlueftre).

Galizm folits feptenis cauleque inferne pubefcentibus, panicula ramis frictis dichotomis. senreb. Spicil. p. $3 \cdot 11.888$.

Reuclucs Labkraut. Germ.

In locis ficcioribus montofisque ad Lindenthal, am Bieniz ctc. Fl. Iun Iul.

Obf. Canl. debilis, angulatus, decumbens, Folia caulina media plerumque feptena, paffim nouena Iinearia, apicem verfus paullo latiora; inferiora fena: infima quina; cacterum integerrima, apice pariter in fpinulam paruamabeuntia, brigidiufcula, laeteviridia, glabra. Fiores albi.

\section{** Fructibus hifpidis.}

borale. 256. Galium foliis quaternis lanceolatis, trineruiis, glabris, caule erecto, feminibus hifpidis. linN. Syft. p. I5I. n. 2I. ВОEHM. ก. IO. LEYS. ก. 157.

Mitterä̈clütich Labkraut; glatte wilde Wiefenrüthe. Germ. Crofs-zeort Madder. Angl: Cazllelait dis Nord. Gall.

In nemorofis, inz Rofenthale, in Bieniz, Skendi. zer Holze. Fl. Mai. Iun

Obf. Canl. quadrangularis, erectus, glaber; folia omnia quaterna; quoad magnitudinem inaequalia, plerumque lanceolata, leuiter acuta, glabra, trinervia, paffim 5 - neruia. - 
If. Flores apibus et herba pecoribus pabulum falutare Radiz rubro tingit colore.

257. Golinum follis fiperioribus nouenis, mediis dece-Aparine.

nis et infrioribus oftonis, lanceolatis, carinatis, fcabris, retrorfun aculeatis, geniculis villofis, fuctu hifpido.

Gulme Aporine foliis octonis lanceolatis, carinis fcabris retrorfum aculestis; geniculis villofis, hifpidis. LINN. SyP p. 151. n. 25. zOEয1M. n. 6. BIACKIV. t. 30 . Fl. Dant t. 495 .

Vai. o) Foliis omnibus fenis, habitu tenuiori.

Klcblerat ; Zaunreis; kleine Kletten; Betolersin̈re; Nabelfanzen. Germ. Cleavers. Angl. Grateron on Riéble. Gall.

Ad fepes pagorum et in cultis nemoribusque f:equentiffime, c. g. ims Referithale etc. var, in agris inter fegetes vor dem Schönfolder Pförtchenctc. Fil. Iun. Iul.

Flores parui, albi, ad ramorum apicem fafciculntim pofiti, pedunculis fublongis inftrueti. Fol.6--3--na, obverfe lanceolata f'cabra.

VS. Pabulum bobus, capris et anferibus. Semina Cafiease fuccedaneum pauperibus. Radix rubro tinctoria. Ad discutiendas itrumas cum Axungia trita laudatur herba.

258. Galium folis quaternis, ouatis trineruiis, margi rotundifone aculeato-ciliatis, feminibus hifpidis. 'schreb. Spicil. p. 2. n. 886 . sckviR. p. 73. n. 235. fub Afperula laewigata.

Rundblistriges Lab- ., Mazyerkraut. Germ. Round leaued Madder. Angl.

In fyluis vmbrofis in Bieniz; in der Bürgerau; in verfchlofjenen. Holze; in Univerfitätsholze; in der Diilenflhen Heide. Fl. Iun. Iul.

\section{ASPERVLA. I.. G. I 28. Waldmeifter 1 Mayer-}

kraut. Germi. Woodroof. Angl. Aparinette. Gall.

259. Afperula foliis oftonis lanceolatis, florum fafcicu-odorata. lis pedunculatis. LINN. Syft. pag. I48. n. I. BLACKW.

t. 6c, f. 1. et 2. Fl, Dam, t. $\$ 39$. sckvir. t. 23 .

pharm. 
Pharm. Marvifyluae f. Hepaticae ftellatae Herba.

IVohlriechendir Waldneifter; Herafreude. Germ. With fwect, or white flowers Woodroof. Angl. Afpcrule odorante; Hepatique, cht Reine des bois. Gall.

In fyluaticis montofis, fparfin hinter dem Bieniz confpexi porro in der Dübenflizen Heide an der Wittealerger Landfarafse copiofe. Fl. Mai. Iun.

$V f$. Odore fasucolenti pellit tineas. Vinum bene odoratum reddit et delicatum. Pabulum praecipue vaccis. Radix rubro inficit colore.

aruenfis. 260. Afpcrula foliis fenis, floribus feffilibus terminalibus acigregatis. LiNN. Syft. pag. 148. n. 2. вовнм. n. 15 .

Ackermayterkraut; kleines blaues Sternkraut. Germ. Biue Wociroof. Angl. Afperule des cilamps. Gall.

In agris et aruis hinter den Gickerlingsberge et alibi. Fl. Mai. Iun. Annua.

Obf. Folia fioralia numerofa, margine ciliis obfita, caulina intermedia quina, fena vel feptena; inferiora modo lena. Fruetus glaber.

$V$. Radix rubro-tin Etoria.

tinctoria. 261: * Afperula follis linearibús, inferioribus lenis: inter nediis quaternis, caule flaccido, floribus plerisque trii dis. LINN. Syft. p. I49, n. 6. LEYS, n. 160. SCOP. Ca1 ․ n. $1+9 \cdot$ (Galiun tinctorium).

Firbonder Waldnacifter; zecis Mayjerkraut. Germ. Swedifh IVoodroof. Angl. Cinanchine. Gall.

In fyluis elatioribus ani Bicniz paffm praeterito anno deprelicndi. F1. Mai. Iun.

Obf. Flos albidus, paffim carneo-albidus. Caulis quadripedalis, quadrangularis, debilis, flexuofus. Folia linearia obtufe acuta; infima fena; intermedia quaterna; fuperiora floraliaque bina; haec breuiora, illa longiora.

Vf. Pabulum ouibus. Lanam et fila lintea rubro tingit colore; dein quoque rubiae tinetorum loca vfurpatur.

cynanchica, 262. Afpernla foliis quaternis linearibus: fuperioribus oppofitis; caule erecto, fioribus quatrifidis. LINN. Syft. p. 149. n. 8. SCHRER. p. 3. n, 889.

Pharm. 
Pharm. Herba Cynarchica.

Brâunęentrel; Kleine Fürberröthe f. Waldncifter; weïrgend Mayerkraut. Germ. Squinancy - weort. Angl. Garance de chien; nu Herbe is l'efquinaneie. Gall.

In verfuris, gramine tenui veftitis, ficcis ad KetSchatr. Fl. Iul. Aug.

Quoad vfum in arte tinctoria cum Rubia tinctorum conuenit.

\section{SHERARDIA. L. G. I2 - Sherardien. Germ.}

263. Sherardia foliis omnibus verticillatis, fenis, lan- aruenfis. ceolatis, floribus vmbellatis, feflilibus.

Sherardia foliis omnibus verticillatis, floribus terminalibus. LinN. Syft. p. 148. sCKvirR. T. 22.

Afperula foliis lenis, femine dentato. вовнм. n. I4. Fl. Dan. t. 439 .

Sherardskraut; Ackerröthe; Ackerfernkkraut. Germ. Little Field Madder. Angl. Shcrarde des champs. Gall.

In agris cultis ad Gohlis, Eutritfch, hinter Altranftält alibique. Fl. Iul. Aug.

Flores ex violaceo in rubellum vergentes, Anth. violaceae $3-4-$ pluresque ad caulis ramorumque apicem fafciculatim feffiles, extrorfum foliis verticillatis cincti.

\section{e) Flores tetrapetali fuperi.}

68. TRAPA. L. G. I65. Stachelnufs. Germ. Macre. Gall.

264. Trapa petiolis foliorum natantium ventricofis, nu- natans. cibus quadricornibus, fpinis patentibus. LINN. Syft. p. 163 n. 2. вовнм. n. 255 . SCKVHR. t. 25. Pharm. Aquaticae Nucis Fruetus.

Schwiminende Stachelinufs, Spitz- f. Waffermufs; Icfuitermufs f. Mütze.; See- f. Weihernufs; Wafferkaftanien. Germ. Iefuit's - Nut, or Water Calthrops. Angl. Chatuignes d'eau; Macre d'eau; Trufles d'eau ou Triboule. Gall. 
In fuuiĺs et aquis limofis, porro in picinis ad $L$ int deuau, Parneck, Eharenberg, Wölkan, in Gerbonenf. jer. etc. Fl. Iun. Perennis.

$V \int$. Nucleus farinaceus pani aptus. Radicem effe venenofan, nonnulli audores autumant. Folia equis pabulum.

69. CORNyS. L. G. 155. Cornelbaum. Gorm. Dogwood. Angl. Cornouiller. Gall.

* Inuolucirtae, vmbellatae.

mafcula. 265. Cormus arborea, vinbelis inuolucrum aequantibus. LINN. Syłt. p. 1 59. n. 2. EOEIIM. n. 258. BLACKW. t. I2 I. UERITIER Corn. n. 4. SCKVHR. t. 24.

Pharm. Comi Fruens.

Gomener l: ahmer Kornelbaun; Romelizskirfcke; Horlsken-Dorlen - Thierlsin - Fürneical-Horlizenbanz; Ruthbcerfrauch. Germ. Cornelian Cherry-trec. Angl. Coumouiller-mal, on ordinaire. Gall.

In hortis priuatis et rufticis, in dew Alllee zwifchen dem grimuifchen whd hillifechen Thore atque in fepibus hortisque valde frequens. Fl. Febr. Fruetus Aug. et Sept. maturefcunt. Frut.

If. Flöes apibus pabsilum. Fruetus edules, robo:antes. Frutex fepibus viuis aptus et ambulacra ornat. Lignuan durifinum. Indos ex hoc fagittas fabricari refertur.

\section{* Nudae cigmofue.}

fanguinea. 266. Corntts ramis rectis, foliis ouatis concoloribus, cymis depreflis. Hcrizier Corn. n. 5 .

Comus fanguinca arbo ed, cymis nudis, ramisereatis. Lisin. Syft. p. 159. n. 3. вовнм. n. 257. Fl. Dan. t. 4 .

Wilder Romelbaum; wilde Dürlizen; Härtern; Hindsberfircuch, Teufelsmettcon; Rotibeinhols; Hartriegel. Germ. Common Degreood or Blocdy Tuiz. Angl. Cournouiller fonguin. Gall: 
In fyluis e. g. imi, Rofenthale, in dcr Kimmereibei Nauendoif, in dumetis fure omnibus frequens et.ad

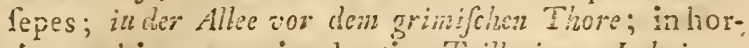
tis multis, e. $\mathrm{g}$. in hortis, Trilleriano, Lchriano, Winkleriaro etc. Fl. Mai. lun. Frutex.

Vf. E baccis oleum exprefium pro lucernis in Italia praccipue agro Tridentino inferuit. Ligno duro buxi loco tornatorés et laniones ad verucula vtuntur. 267. * Comnts ramis recuruatis, foliis lato-ouatis, fuo-alba. tus canis, cymis depreffis. Heritier r. 7. Sert. Lipl. p. :8. n. 20. PALL. Rufi: j1. t. 34.

C. albe arborca, cynis nudis, ramis recuruatis. LINN. Syft. p. I 59. DV ror Harbh. I. p. 165.

C. fylueftris fructu albo. Amm. Ruth. 198. tab. 32 . MiLl. ic. t. 10\%.

C. tartarica arborea, foliis oblongo-ouatis neruofis inferne albis, floribus corymboís terminalibus. MILL. dict. n. 7 .

In dumetis polf pagum Stötteritz prope hortum Wcifinnm; arf der linful prope hortun ad paoum Grojsteolkau, paffim practerea in hortis plurinis fubvrbanis et quoque in Sertr nuperrime culta. Frutex autem fponte crefcit in Sibiria et America feptentricnali. Floret apud nos bis e? pafim ter anno. Ramuli confpicui verfus Autumnum et maxime Vexcolore pracàiti funt pulcherrime rubro.

f) Flores apetali, inferi.

70. ALCHEMIILA. L. G. I77. Sinau; Frauenmantel. Germ. Ladies mantle. Angl. Pied de Lion. Gall.

268. Alchemilla foliis lobatis, palmatis, ferratis, LINN. vulgavis,

Syft. p. 166. eosma. n. 551. BLACitw. t. 72. Fl. Dan

t. 693 . scKVHR. t. 26.

Pharm. Alchemillae Radix, Herba.

Geneiner Sintau; Löreentappe; Alclesniftenkraut; Francnmantel; unfor lieben Frauennachtmantel. Germ. Common Ladies mante. Angl. Pied de Lion sulgaire. Gall. 
In pafeuis et fyluaticis fpongiofis ac graminofis im Rofenthale et Streitholze alibique. Fl. Mai. Iun. Perennis.

$V f$. Pabulum pecoribus optimum. Coriis parandis apta. Decocta huius herbae Alchemiftae fuper. ftitiofi vfurpantur.

\section{I G Y N I A.}

71. APHANES. L. G. 178. Ohmkraut. Germ. Parsley - Piert. Angl.

aruenfis. 269. Aphanes hirfuta foliis tritobatis; lobis tripartitis et bipartitis. LeERs. Herborn. n. I22. fub Alchemilla Aplanes.

Aphanes arienfis. Lisw. Syft. pag. 167 . вовнм. n. 552. scikvHR. t. 26.

Ackerohnkraut; klein Frauen- f. Maricnmäntelchen. Germ. Perchepier. Angl.

In agris inter fegetes hinter Bofens Garten, in iisden locis elatioribus bei dim Gickeslingsberge; in agris veríus Gonncevitz, valde frequens verfus Gohlis, Eutritfch et alibi. Flor. Iun. Inl. Annua.

Obf. Quanta controuerfia quaasd ftaminum numerum, inter omnes fere botanicos fit, conftat. Alii enim modo vnicum, ad quos sCrvilirivs et timmivs pertinent: alii, et fere plurimi, 4 , iure meritoque ffarcunt. Si fides milsi fit apud naturae curiofos, fateor, partibus ciusdem mafculinis, toties per lentem examinatis, me faepius \& ftamina obferuaffe, quamquam etiam modo vnicum, modo duo ftamina, paffim vidi.

Vf. Planta aperiens vrinam excitat et menftrua re. tenta proulocat.

72. CVSCVTA. L. G. 182. Seide. Germ. Dodder. Angl. Goutte. Gall.

Suropaea. 270. Cufcuta funiformis, floribus fefflibus, quadrifidis. LINN. Syft. p. 16\%. воEнM. n. 20. BLACKW. tab. 554 . Fl. Dan. t. 199. sckVir. tab. $2 \bar{l}$. 
Ciefita Europaea floribus feffilibus, confertis, quadifidis. retz. Fl. Siand. Piodr. n. 180.

Pliam. Ciffutae l. Euithymi llerba.

Envopiziche Seide; Filzkrant; Tenfelszwirn; finmurotzer Ranken; Tlachaufauger; Franewhanr. Germ. Grater Dodder. Angl. Cujante vulgaire.

Parafitica in Hunule, Lupulo et fiuticibus variis. Flor. I un. lul. Arinua.

Olo. Lini agris et lupuletis obnoxia: herba tingit colore purpurafcente.

\section{T E T R A G Y N I A.}

73. POTAMOgetoN. L. G. 186. Saamkraut. Germ. Pondweed. Angl.' Epi d'eaux. Gall.

27r. Potamogeton foliis oblongo-ouatis, petiolatis na- natans. tantibus. LiNn. Syft. pag: 165. n. I. вогнм. n. 26 I. SERN. B. II. P. 104.t. 1SO. SCKVHR. t. 28.

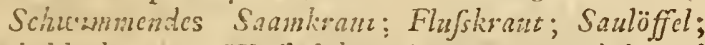
Secluoldenkrant; Wijerlah. Germ. Broad-leaned Pond-zeed. Angl. Epi d'enu flotant. Gall.

In Atagnis, tollis, hinter deri Brandvorzerke etc. Fl. Mai. Iun.

VJ. Pabulum fuibus gratum et faginat. Pifces quoque eo delectantur:

272. Poiamogiton foliis cordatis amplexicaulibus. perfoliatum LINN. Syft. p. 168. n. 2. schreb. Spicti. p. 20. n. 9??: Fl. Dan. t. $19 \%$

Durchffochnes Saankraut. Germ. Perfolinted Pondweed. Ingl. Epi c'eau perfolié. Gall.

In fluuiis, e. g. in der Bahre bei Grasfeld, in paludihus aqua repletis ante pagos plurimos, e. g. ad Hohenholig, Grendetz, IVölkau, in pifcinis, e. g. ante Sclzörzfì. FI. Míd. Iñ.

273. Pontanogeton foliis lanceolatis planis in petiolos lucens. definentibus. livis. Syft. p. 169. n, 4. вовmM. n, 262. Fl. Dan. t. 19i.

Lenciatendes Saamkraut; Hechtlack. Germ. Longleaued Pondweed. Angl. Epi d'ean luifant. Gall. 
In pifcinis ad Lentfch, Pomeck; porro ad Grojsditz, Troilatin, in der Peiffe etc. F. Iun.

Olf. Folin venis reticulata, firiis obliquis decufa. ta, pellucida.

erifum. 27\%. Potannorcton folis lanccolatis, alternis oppofitisue vadulatis ferracis. InN. Synt pag. IE9. ח. 5. вовнм. n. 250.1

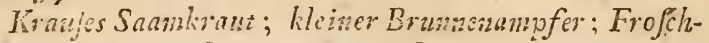
lat:ich.Germ. Grater IVatcr-Cultrops. Angl. Epi dicau orecults. Gall.

In funis in dor Pleife, in pifcinis, e. $g$. ior Schönfeld, Wulkan. Fl. Míai.

pe\{̂inatum." $=75 .^{*}$ Potamogeton folli; letaces, parallelis, approxi. matis, diftichis. Lins. Syf. p. 169. n. 8 .

Kanmjurmig Sanmkrawt. Germ, Fannel-leaued Poudseeed. Angl. Epi 'deau pectiné. Gall.

In foltis et fuuis, in der Pleiffe, inueni. Fl. Iun.

fetecum. 275. Potamogeton follis lanceolatis, oppofitis, acuminatis. LiNn. SyR. p. 169. n. 9. BOEIIM. n. 260.

Borftenformiges Saamkrant. Grm.

In Auuiis, in as? Pleiffe. et alibi. Fl. Mai. Iun.

graminetum. 27\%. Potanogeton foliis lineari-lanceolatis, alternis, ferfilibus, Ripula latioribus. tinn. Syrt. p. 169. n. 10.

Var. I:otamogeton heterophlyllum foliis fubmerfis linearibus feffilibus natantibus lanceolatis petiolatis. SCHREb. Spicil. p. 21. n. 928. Fl. Dan. t. 222. $\beta$.

Grasartiges Saankrant Germ. Grafs-leaucd Poudweed. Angl. Epi d'eau graminé. Gall.

In foffis vbique. Var. in ftagno ad Lindenthal Ill. scirreg. inuenit. Fl. Iul. Aug.

marinum 278 . Potainogeton foliis linearibus alternis diftinctis in-

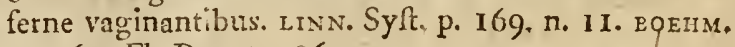
n. 263. Fl. Dan. t. 186.

Mcerfaankraut. Germ. Epi d'ean des ners. Gall.

In pifcinis ad Leut fch, Parmeck aliisque. Fl. Iun: Iul.

pufilum, 279. Potamogeton folis linearibus" oppofitis alternisque diftintis bafi paientibus, caule tereti. IINN, Syft. p. 160. n. 12, LEYS, n. 177. EOEHM. 12, 264. 
Fleines-Saankraut. Germ. Snall Grass-leaued Ponduece. Angl. Epi-deau linaive. Gall.

In iisdern locis cum priuri. Fl. Iun.

Ob. Caulis crpiliaceus, teres. Folia capillaria, inferiora oppolita. fuperiora alterna. Semina gibbofa, obtufi.

\section{SAGINA. L G. 188. Vierling f. Maftkraut.}

Gern. Sagine. Gail.

280. Sagina ramis procumbentibus, petalis breuifimis. procunIINN. Sylt. pag. 169. n. I. BOEHM. n. 385. sCKVHR. bells. tab. $: \because$.

Var. fo) Sagma floribus, apetalis.

Gefreckter Vierling f. Meflkraut; klein Vogelkraut mat Grasblattern. Germ. Sagine ranipante. Gall.

In locis ficcioribus, firrilioribus, in der Sandgrube, hinter 7 anche auf den Sand-und Schzearzbergen, porro auf den Minneberg etc. copiofe. Flor. Iun. Iul. Annua.

281. Sagina caule erecto vnifioro triflorcue. LiNN. Syft. erecta,

p. 1Cit. 11.3 Fl. Dan. p. 845.

Aufrechtes Mafkkraut. Germ. Sagine droite. Gall.

In locis ficcioribus, arenolis, am Bieniz faepius mihi occurrit; ad Templum St. Theclae, in Coemeterio ad Gonmerentz copiole; etiam in muris limofis. Fl. April, Maio.

\section{B. FLORE MONOCLINO.}

\section{VRTIC.A. L. G n. i r.4\%. Neffel. Germ. Nettlé. Angl. Ortier. Gall.}

282. Vrtica foliis oppofitis oualibus. LINN. Sylt. p. 849 . vrens.

n. 6. военм. ก. 6\%о. Fl. Dan. t. 680.

Pharm. Vrticae minoris Herba.

Brennende Neffel; Eiterneffel. Germ. Ortie griéche ou brillunte. Gall".

In nemoribus, dumetis, ad forfas et fepes valde vujgaris et fere vbique. Fl. Iun. Iul,

$$
\text { G } 2 \text { Olg. }
$$


Oif. Pultos meleagridum herbam recentem confcilan commedere, refert rivs. Vetnali rempore in iufula ct olerum loco recipitur.

dioica. 283. Vrtica folis oppolitis cordatis, racemis geminis. IINN. Syft. p. 8.49. n. 7 . BOFHM. n. 679. BLACKw. t. 2. Fl. Dar. to $-\therefore 6$.

Pharm. Viticac maioris Rad. Herb. Sem.

Zueibâfige Neffil; Broneffel; grofse Neffel.Germ. Great, or Common Nittle. Angl. Ortic grunde. Gall. In fyluis vmbrofis humidisque, dumetis, ruderatis; tofilis et ad fepes frequentifine in Rofentiall: vor dem Schönfelder Pfortchen, linter der Milchinfol et alibi, Fl. Iul. Aug:

$V f$. Iuniori actate, maxime vernalitempore, in olcre coquitur. Herba exficat: prbulum ouibus faimtare. E par: ncinymate linum ap*um conficitur. SCHAEFERVS papyrum e cortice conficere docuit.

76. BETVLA, L. G. r 4.7. Birke. Germ. Birch, ou Alder-Tree. Angl. Bouleau ou Aune. Gali.

alba. 281. Fetula foliis ouatis, acuminatis, ferratis. LINN. Syft. p. 8.48. n. I. вог̈M. n. 6、3. SERT. Lipf. 11, I1. ¿LACKV. t. 240 . CRAM. t. 10 .

Pham. Betulae Lignum, Epidemis, Folia, Lympha.

Geneinc weiffe Birke; Mien; Wunnebrum. Ferm. Common Birch-Trie. Angl. Bonicau blanc. Gall.

In nemoribus, copiole : im Univerfitätsolse, bci Kriphäne imHcregraje; bciMachermetc. nunc quoque in Serto poftergaftulum piantata, et alibi. Fl. spril,Maio. Arbo:.

VJ. Folia luteo tinEtoria, exficcata onibus pabulum. Cortex crafior apud Lapones in rfu, quo coriarii retia pircatoria rubro tingunt colore, et pro orbiculis vuntar. Liber integer detractus et epiftomio firnatus pro lagenis Sibixienfibus. Lignum durum, album, tenax ad manubria cultrorum, rotas, trahas et reliqua conticienda, ruflicis inleruit. Carbones foco praefantifrinos Metallurgi et Chemici, adhibent. Vernali tempore, antequam folia prorumpunt, $\mathrm{ex}$ arbore, 
bore, costice incifo, aqua fillat limpidifima, quae contra calculurn, raben et forbutum laudatur. Fo. lia cum aqua et alumine coeta et proccipitata luteum exhibent colorem.

285. Betula folii fubrotundis, glutinofis, glabris, ob- Alnus. tufe crenatis, pedunculis ramofis. wil DEN. Prodr. Berol n. 230 .

Betula Alnu pedunculis ramofis. Linn. Syft. p. $849^{\circ}$ n. 6. товHM. n. GY2, CRAM, t. 12.

Betula foliis glabris, rotundis, rotunde crenatis, fpongiolis ad neruorum angulos. H.aLL. Hif.II.n.1630.

'Pharn. Alni Co:tex et Folia.

Gomeine Eller; Erle; Otterbaum. Germ. Common Aldor. Angl. Boulcan Aune, ou Aunt à feuilles roudes et d'un verd foncé; Vergne. Gall.

In Serto inter ergaftulum et hortum Cur $i$ ii in ne. moribus humidis, dumetis et pratis copiole ante et poft Schünfeld, in ZJchocherfchen Holze, im Rofenthale et circa plurimos pagos etc. Fl. Aprili.

Obj. Curculio Alni huic arborivalde ob noxia.Carbones in noftratibus regionibus vfitatiflimi.Lignum fub aqua percane, qua de re ad equilia contignanda maxime vtitur. Tornatores ad varia inftumenta conficienda ashibent.- Cortex nigro tingit colore, dehine a pileariis gallarum loco vfurpatur.

\section{FLORE DICLINO.}

\section{7\%. VISCVM. L. G. I209. Miftel. Germ, Mifiel. Angl. Gui. Gall.}

286. Vifcum foliis lanceolatis obtufis, caule dichoto- album, mo, fpicis axillaribus. linN. Syft. p. 883. BOEнM. n. 6SI. BLACKW. T. I 8 \%.

Pharm. Vifci querni Stipites.

IVidfer Miftel; Eichenwiftcl; Knifter; Mairentacken. Germ. Miftletoe. Angl. Gui de Chêne. Gall. 
In variis arboribus parafitica : e. $g$. in Pyro fyluefri, Salice maximeque in Quercubus, vidi. Flor. Mátio.

Vf. Specificum contra epilcpfian landatur. Ex baccis praeparatur vilcus ad aues capiendas.

78. * HIPPOPHAE. L. G. I2 10. Sanddorn. Gem. Sea. Buck-Thorn. Angl. Chalef. Gall.

Rhaunoides $287^{\circ}$ * IIPpophaE foliis lanceolatis. LinN. Syft. pag. 88.4

Wcidenblattriger Sandkreuzdom; Mcerkreux. dom; Finnifche Bcercis; rothe Schlehen. Germ. Sea Buck-Thorn, or Sallowe-Thorn. Angl. Rhamnoides a feuilles de Saulc. Gall.

In dumetis quaí fponte crefcéntem vidi, v. c. ad Stötterizz poft hortum Weifianum; in Infula inter pifcinas ante hortum ad $W_{0} l_{k} a u$. Aliter vero in plurimis hortis fuburbanis et in Serto frutex frequenter cultus. Fl. Aprili et Maio.

Patria vero huius fruticis funt America feptentrionalis et Europa auftalis, e. g. Skecia, Pruflia, Helvetia, Anglia etc. Folia anguftifima, lanceolata, fubtus cinereo-argentea, fupra viridis, glabra, margine reflexa. Rami cortice fplendefcente colore gaudentes. Baccae verfus autumnum maturae, fluuae, auAterae.

\section{FLORE POLYGAMOIDE.}

79. PARIET:RIA. L. G. Glaskraut. Germ. Pellitory, Angl. Parietaire. Gall.

officinalis. 289. Parietaria foliis lanceolato-ountis, pedunculis dí chotomis, calycibus diphyllis. I.rNN. Syft. pag. 908. военм. ก. 550. вLACK w; t. I56. Fl. Dan.t. 521 .

Pharm. Pariciariae f. Helxines, Hexba. 
TETKANDRIA. POLYGAMOIDE. IO3

Gcreöhnliches Glaskraut; St. Pcterskraizt; Rcblunnkraut. Gernn. Pellitory of the Wall. Angl. Pariétajre efficinale. irall.

Ad muros, in grimmifchen Zwinger verfus $P$ Portam St. Petri et inter fruticeta bei dor Milchinfel Fl. Iun. Iul. Perennis.

Vf. Herba afpera vafis metallicis mundificandis ap. ta. Inter herbas 5 emollienteseft. In clyiferibus alvuum laxat, voget.

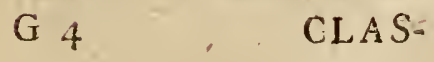




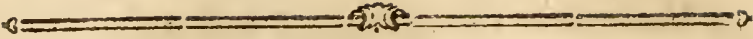

Claffis $V$.

P E N T A I D R I A

MONOGYNIA.

\section{A. FLORE HERMAPHRODITO.}

a) Flores monopetali, infori; gerninibus quaternis mudis.

\section{A S P E R I F O L I A E.}

80. ECHIVM. L. G. 203. Otter- . Natterkopf. Germ. Viper's Buglofs. Angl. Vipérine. Gall.

vulgare. 289. Echinm caule tuberculato hifpido, foliis caulinis lanceolatis, hifpidis, foribus fpicatis lateralibus. LINN. Syft. p. I9O, n. I2. вOEHM. n. I5I. BLACKW. t. 299. Fl. Dan. t. .4 45 . sCKVHR. t. 32 .

Var. 1) Fiore rubro. BL.ACKw. t. 299. f. I.

2) Flore violaceo et rubro.

3) Flore albo.

Gemeiner Natterkopf; Schlangenhaupt; Frauenkrieg; weilde blaue Ochfenzunge. Germ. Common Vipers Bugloß. Angl. Vipérine commune; Herbe aux Viperes. Gall.

In collibus circa vrbem praeprimis in pomoerio Grimmen.i et paflim ibidew in Serto nach dem IWeinnaipfchen $\approx u$ : porro in ruderatis ficcis ad vias $\approx u i f$ chen Plagevitz et Kleinzschocher, in pago ipfo auf der. Anhöhe hinter der Brauer Wohnang; poft Altranftadium prope Coemeterium : copiofe in agris elatioribus hinter Kriphâne. Fl. Iun. Iul. 
$V \int$. Flores apibus gratifimi.

SI. PYLMONARIA. L: G. I90. Lungenkraut. Germ. Lungwort. Angl. Pulmonaire. Gall.

290. Pulmonaria foliis radicalibus, onato inceolatis, anguftifoli: inferius decurrentibus. Eовнм. n. 30. L1Niv. Syft. p. 18 . 11. 1. Fl. Dan. t. 483 .

Schualblattriges Langenkraut. Germ. Nimrouleaued Lung-zeort. Angl. Pulmonaire i feutles étroits. Gall.

In fyluis montofis, in Bieniz. Fl. April. Maio. Perennis.

291. Pulmonaria foliis radicalibus ouato-cordatis, fca- oficinalis.

bris. LINN. Syft. p. 187.n. 2. BOEHM.n. 29. SCKVIR.t. 30 .

Var. 1) foliis maculofis. el.ACKW. t. 379. Fl. Dan. t. 482. SCKVHR. f. cit.

Plarm. Pulnonariae Maculofae Herba.

Gebräuchliches Lungenkruut; Hirgch- I. Kohmangold; Fleckenkraut; unscr lieben Frautin Milciknant. Germ. Spotted Lung-wort or Buglojs Cowjtips. Angl. Pulmonare. Gall.

Floret in fyluis et inter frutices, in Rofonthale. Variet. autem frequentiffime in fyluaticis in Z Zchocherfchen, Kleindölziger, Schanbergifchen Holze aliisque. Fl. April. Mai. Perennis.

Obf. Cal. I - phyllus, quinquedentatus, pentagonus, cyathiformis, glandulis purpureis inftructus, extrorfum fetulis obfefis; interius glaber. Cor. I-petala; infundibuliformis; tubo cylindriformi, calycis longitudine; limbo quinquefido, femicirculari, erecto-patente. Stan. Filam. 5 , aequalia, in fauce breaiffrma. Antherae ereßtae, verticillatac, conniuentes. Pift. Germ. 4: ftylus filiformis, concauus, calyce breuior minorque; ftigma obtufum, emarginatum. Sem 4 - fubrotunda, obtufa. Folia radicalis et caulina fefflia; fcabra, paffim maculata vel non maculata. Caulis pentagonus, fetis veftitus. Pedunculus vniforus, ex apice caulis egrediens. $R a-$ dix horizontalis, fibrillis fparfin inftructa. 
Vf. Flores apibus pabulum praeftans et pecora fere omnia fefe delectant. Folia tenella acetariorum ad inftar in culinis praeparantur.

82. LITHOSPERMVM. L. G." I93. Steinfame, Gim. Gromwell. Angl. Gremil. Gall.

officinale. 292. * Lithofpermum feninibus laeuibus, corollis vix calycem fuperantibus, foliis lanceolatis. LINN. Syft. p. 185 . n. I. LEYS. n. I8I.

Pharm. Lithofpermi f. Milii-folis Semina.

- Gobrïuchlicher Steinjaame; Marienthränen; Waldhirese; wilder Thce. Germ. Great upright Gronuell. Angl. Grénil, ou Herbe aux perics. Gall.

In agris fecalinis inter fegeres, et in fyluaticis locis, im Gonneveitzer et Rafchreitzer Holzo inueni. Fl. Mii. Iun.

Vf: Semina annonae caritate pani inferuiunt. Radicis cortex rubro tingit colore. Omnia pecora, exceptis capris, hanc refpuunt.

aruenfe. 293. Lithofpcrimun feminibus rugofis, corollis vix calycem fuperantibus. LINN. Syft. p. 185. n, 2. вовнм. n. 23. BLACK v, t. 43 6. Fl. Dan. t. 456.

Ackerfeinfaame; Blutkraut; Feldhirfe; Schminkze'urzel; roth Perlkrant. Germ. Baftard Aikanes. Angl: Grenil fauvagc ou champêture. Gall.

In agris inter fegetes fere vbique copiofifime. Fl. Ap:i1. Maio; et tempore autumnali ruirfus floret. Annus.

$V \int$. Folia iuniora pulmentis apta. Radix rubrotinctoria. Fuallae Finncis et Norlandicis pigmenti loco cosmetici radices recentes leniter lotas adlibent. IINN.

83. SYMPHYTVM. L. G. I97- Beinwelt. Germ. Comfrey. Angl. Confoude. Gall.

officinale. 291. Symphytum foliis ouato-lanceolatis, decurrentibus. LINN. Syft. p. IS7. вогнм. п, 28. BLACKw. Łab. 252. Fl. Dan.t. $66_{4}$. 
Var. a) Flore purpureo. sckvin. t. 30.

Plarm. Confolidae Maioris had. Herh. Flores.

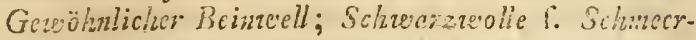
zourz; Schmolz-Beineeurz. Germ. Grande Confonde is fleurs blancin's et paurpres; ou loreille dene. Gall. "

In pratis humidis et ad fontis, nach Schönfeld: in nenoribus, e.g. in Rofuntale; bei Grasfeld; Platfig; bei Eutritfch; auf den Gerberevicfenitic. et alibi frequens. Var. a) in Horto Mcdico, Lchriano et oliis mihi occurrit. Fl. Mai. Iun.

Vf. Flores apibus pabulum gratum. Herba coriis parandis haud inepta. Rad. procataplasisatibus emollientibus difcutientibusque.

84. BORAGO. L. G. 200. Borretfch. Germ. Borage. Angl. Bourrache. Gall.

295. Borago foliis omnibus alternis, calycibus patenti- officinalis. bus. LINN. Syft. p. I88. n. I. EOEHM. n. 21. ELACKW.

t 36. SCKVHR, t. 3I. KERN, p. 99. t. 16\%.

Var. a) Fiore albo.

Pharm. Boraginis Herba et Flores.

Gemeiner Borretfch; Herzblïmlein; Wohlgemuth.

Germ. Borrage. Angl. Bourrache. Fall.

In reiectamentis hortorum, pafim in Poetengange, in hortis copiofe. Fl. Iun. Iul. Annua.

$V \int$. Flores apibus valde grati.

85. LYCOPSIS. L. G. n. 202. Krumnhals; Wolfsgeficht. Gein. Wild Buglofs. Angl.

295. Lycopfis foliis lanceolatis hifpidis, calycibus fore- aruenfis. fcentibus eręis. lins. Syft. p. 189. n. 5. вовгM. n.

n. 24. (fub BuglofJo). BLACXIv. t. 231 . SCKVIR. t. 3 !。 Ackerkrummhals; Feld-Oclufezzmge; IVolfsgeficht; Liebâugel. Germ. Small reild Buglofs. Angl. Face de loup ou Gripe des champs. Gall.

in agris arenofis inter fegetes, nach den Straffenhäufern, ad viam nach Gonneveitz: porro in iisdem locis poft Taucham nach den Wrinbergen alibique. Fl. a. vere in autumnum vsque, 
Obf. Planta ex toto hifpida.

pulln. $29^{-*}$ * Lycop/is foliis integreirimis, caule erecto, calycibus fructefcentibus, inflatis, pendulis. urvi. Syft. p. 188. n. 2. LEYS. n. 185.

Branner oder fchworzer Irmmulials. Germ. German will Bugloss. Angl. Gripe notre. Gall.

In marginibus agronum stenoforum ad Gonnewitz et Schöntcld pafiim vidi. F]. Mai. Iun. Perennis.

\section{6. * A SPERvgO. I. G. n. 201. Scharfkraut. Germ.} Smal wild Bugiofs. Angl. Rapette. Gall.

procumbens 298 . A Afpcrizo calycibus fructus compreffis. LINN. Syft. pag. 188. LEYS. n. 187. Fl. Dant. tab. 552. scKVHR, tab. 31 .

Bugioffum fylv, caulibus procumbentibus. C. B. P. $257 \mathrm{~V}$.

Geftrecktes Scharfkraut; grols Klebkraut; Schlangentiugel; teutfcher Berufstoand. Germ. Great Goofegrafs. Angl. Rapctie ou Port-finille. Gall.

In ruderatis, ad fepes, paftim ad pagos Borstorf, Mockau ct alibi praeterito anno inueni. FJ. Maio.

Obf Coules ranofr, angulofi, procumbentes. Folia fubpetio ata, ouata, fetofa. Floribus caerulaeo-violac is. Calyx maturus ctim pede anferino conueniens.

Vf. Folia tenella pro spinachia inferuire poffunt. Pabulum ouibus.

87. CYNOGLOSSVM. L. G. 195. Hundszungé. Gcrm. Hound'stongue Angl. Langue de chien. Gall.

officinale. 299. Cymogloffum ftaminibus corolla breuioribus; foliis lato-ianceolatis, tomentolis, feffilibus. LINN. Syft. p.

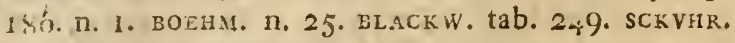
tab 30 .

Pharm. Cynanglolf Rad. Herba.

Geluäuchiche Hundsaunge; Licbäugel; Venusfin. ger. Geru. Common Hound'stongue. Angl. Cinoglofe ou Langue de chien. Gall.

In ruderatis ad fepes circa pagos p'urimns, e. g. ad Gonnewitz, Gaut fh; porro in collibus circa vriem, prae- 
precipuc inter portam Grimmenfen et Hulensem. Fl. Mai..Iun.

Vf. Capri modo hanc herban comedurt. Odor virulentus pediculis aduerfus. Planta vim habens naycoticam. Externe in cataplasmatibus ad ambufta vfurpatiur.

300. Cynogloffin ftaminibus corollam aequantibus. Apenni-

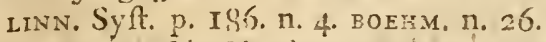
num.

Apenninifche Hunds $\approx$ unge. Gern. Apcmine Hounds Tongue. Angl.

In horto Bofano copiofe, porro an dem Damme bei dens Gonnewitzer Teiche. Fl. Maio.

88. ANCHVSA. L. G. I94. Ochfenzunge. Gem. Bighlofs. Angl. Bụgloríe. Gall.

301: Anchufa foliis lanceolatis, fpicis imbricatis fenun- ofricinalis. dis LINN. Syf. p. 185. BOEHM. n. 22. BLACKW. tab., 5co. Fl. Dan. t. 572. sckvir. t. 29.

Pharm. Bugloffi Rad. Herba, Elores.

Gebräuchliche Ochfenzunge; Augenzier; BanernBorretfcin; rotlue Hindsaunge- Germ. Common, or Great Buglo/s. Angl. Buglone ordinaire. Gall.

In horto Bofiano frequens et in pratis, auf der Funk kalurig pafim. Fl. Mai. Iun. Biennis.

$V /$ Flores pabulum apibus optimum. Folia tenera ad olera in culinis vfurpantur. Sucius ex herba recenti expreffus cum alumine cotus viridi tingit colore.

89. MYOSOTIS. L. G. n. I92. Mausohr; Vergifs mein nicht. Gernu. Miofotide. Gall.

302. Muofotis calycibus oualibus, acuminatis, hirfu- fempinites tifimis, tubo corollae longioribus, foliis ouato-lan- a) mrucnit i. ceolatis вотн. Fl. Germ. I.p. 8\%.

Myofotis feminibus laeuibus, foliorum apicibus callolis. I.INN Syft. p. I84. BOEнM, n. 32. (fub Helio. tropio, Fl. Dan. t. 583 . 
Scorpionartig-klein Ackernaufëhrchen; rauch Maifeohr. Germ: Fidd Moufe-ear Scorpion Grafs. Angl. Scorpione des Champs; Orille de Souris. Gail.

In agris et aridioribus locis vbique. Fl. pe: totam Aeftatem.

fcorpinides. 303. Mygotis calycibus oualibus, obtufis, glabris, tub) palultis. bo corollae aequalibus, toliis lanceolatis. Rdтr. Flor. Germ. Tent. I. p. 8\%.

Myofotis folis glabris. minn. Hort. Cliff. 46.

Hcliotropiun folis glabris. вовнu. n. 31 .

Sumpf-f. glastes Minufeohr; Vergijs mein nicht; Scorpiomangold. Germ. Murfh Moufe-ear Scorpioizgrafs. Angl. Scorpioze de Marais. Gall.

In fyluis paludofis vbique, copiofe im Rofenthale, Goincre'ztzer, Gautfcher, Zfchocherfcinen Holze etc. Fl. Aeftate tota.

Obj. Hacc facpe variat ratione habitus et coloris forum, modo minor, modo maior; hinc flore albo; illine carneo, praecipue an Rofenthale deprehenditur.

Lappula. 304. Myofotis feminum aculeis glochidibus, folit lanceolatis pilofis. LiNn. Syft. p. 185. n.4. BOsHM. n. 27. Fl. $D a a_{2}$ t. 692.

Klettenartiges Maufeolur; Scorpionfchroanz; kleine Hundszunge. Germ. Litzle, Blue Hound's Tongue. Angl.

in muris limofis, locis argillofis, in der Leim- und Sandgrube etc. Flor. tota Aeftate. Annua.

b) Flores monopetali, inferi; germinibus-cap. suliferis.

90. ANAGALLIS. L. G. 220. Gauchheil. Germ. Pimpernel. Angl. Mouron. Gall.

aruenfis, a) phoznicea.
305. Anagallis caule procumbente, foliis ouato-lanceolatis, calycis fegmentis lanceolatis. WILDEN่, Prodr. Bcrol. n. 256.

Anagallis foliis indiuifs, caule procumbente. rinN. Syft. p. 196. вовнм. n. 33. BLACKW, tab. 43 Fl. Dan. t. 88. schvis, t. 36 . 
Anagallis flcre phoeniceo. C. B. P. 252 .

Pharm. Anagallidis Herba.

Rother Gauchlacil; Moyger- 1. Hünerdarm; Mönfegedamue; Vogelkraut; Heil aller Welt. Germ. Red, or Larg-leaved Piminernel. Angl, Mouron à fezrs rouges. Gall.

In agris inter fegetes vbique. Fl. Iun. Iul. Annua.

306. Anagallis caule procumbente, folits ouato-lanceolatis, corollis ferratis, calycis foliolis lubulatis. aruenfis. b) caerulea. schrer. Spicil. p. 5. n. 893. wildri. Prodr.Berol.n. 257. BLAC:W. t. 147 .

Blaner Ackergauchlacil. Germ. Blue flower'd Pimpernel. Angl. Mouron à fleurs bleues. Gall.

In agris ficcioribus, e. g. an Gickerlingslerge et vor den Schönfelder Pfortchen, paftim mihi occurrit. Fl. cum priori.

91. LYSIMACHIA. L. G. 219. Lyfimachie; Weiderich. Germ. Loofe-frive. Angl. Percebone. Gall.

\section{* Pedunculis multifloris.}

307. Lyfimachia paniculata, racemis terminalibus. vulgaris.

LiNn. Syft. p. 195. n. I. вовнм. n. 35. BLACKiv, tab. $27 \%$. Fl Den. to $6 \times 9$.

Var: $\alpha)$ Ly.fim. foliis binis cruciatim pofitis.

ק) Ly/2mn. foliis omnibus quaternis, minoribus.

y) Liyfin. foliis omnibus ternis maioribus.

bus quaternis.

8) Lifin. foliis fuperioribus ternis, inferiori-

Gemeine Lyfimachie; grofser gelber Weiderich; gelb Weidenkraut; Efswourzel. Germ. Yellow Willow Herb or Loofe Strife. Angl. Corneille. Gall.

Ad ripas et paludes in nemorofis, in Rofontiale, in pratis hinter Gunndorf, frequens. Va: $\alpha$ et $\beta$ in der Prellheide in locis humidioribus; in iisdem locis in der Kämmerci bei Nauendorf copiofe. $\gamma$ et $\delta$ ) ins Rofenthale, porro quoque in pratis hinter Ehrenberg, ad riuulam nach der Nötzfcher Mühle zu etc. reperi. Fl. Iul, Aug. Perennis. 
$V \int$. Herba Aauo tingit colore lanam.

thyrfifora. 308. Liyfinaclia racemis lateralibus pedunculatis. IINN. Syft.p. 195. 11. 4. BQEHM. n. 35. F7. Dan. tab. 517.

Strausförnige Luflmachie; Wafferneicerich. Germ. Tuficd Loofe Strifi. Angl. Lyfimaque. Thijriflore. Gill.

In fofis paindibusque vor Pfoffendarf, bei Gohlis, olin BOEHME? insenit. In riuulis pratorum bei Klcindülaig et rerfus trölkait, nuper repesi. Fl. . Iun. Iul! Perennis.

Obf. Folia integerr'ma feffilia, fubtus pilis nolliffmis obferfa, racemis longiora. Flores paffim lexfariam diuifi. Stam paffin 7 numeraui.

\section{* Pedunculis unifloris.}

nemorum. 309. Iyfrinachia feliis ouatis acutis; foribus folitariis: saule procumbente. IrN Syft. p. 196. n. 8.Fl. Dan.t. 174.

Hain Lijfinachie; gell' Ganchheil; gelber Hïhner. darn; gelbes Grundheil, Waldbibcrncli. Gesm. Yellowe Pimprernel of the Woods. Angl. Lyjimaque des Foréts. Gall.

In nemoribus humidis, im Gonnereitzer, Zfchocherfchen, Sckcuditzer Hoize, porro in der hïmnere, in der Prellheide etc. paffum vidi. Flor. Maio Iun. Perenris.

Numnula- 310 . Iyfimachia foliis fubcordatis, floribus folitaris; ria. caule repente. IINN. Syft. p. 196. n. 9. военм. n. 36. zLACKw. t. 542. Fl. Dair. t. 493 . sскVHR. t. 36 .

Pharn. Nummulariae Herba.

Wiefengcld; Pfenuighant; klcin Schlongen-Gold. Natter- oder Mond raut; lireifend Wundkraut. Germ. Greater Willowe Herb; Yellowe Money-Wort or Herb Tivo-ponce. Angl.- Nummuiaire ou Herbe aux écus. Gall:

In locis nemorofis humidisque, in GonnenvitzerRafchuitzer, Zfchocherfchon, Sommerfelder, Macherfchen Holze, inder Kïmmeri, in riuulis beider Nöetzscher Mülale etc. Fi. Iun. Iul. Perennis. 
V. Herba cum infúo oliofo curculiones necat.

92. PRIMVLA. L. G. 2ro. Schlïfelblume. Germ., Primrofe. Angl. Prìmevére, Gall.

3It. Primula foliis crenatis, rugofis, mollibus; saly-veris cibus villafis, inflatis, pentagonis, dentatis. RETZ, a) ofticinalis. Obferv. Bot. Falc. II. p. IO. n. 13.

Primula veris foliis dentato rugofis; limbo corollarim concano. LiNN. Sytt. pag. 192. ni I. var. $\alpha$. вОенM. 11. 39. БLAKN. t. 226. Fl. Dan. 433. scKVHR. t. 33.

Pharm. Primulae ueris f. Paralyfeos Radix, Herba, Flores.

Viclblumige, wohlvicchende, gebräuchliche Schliuffelblume; Himmelsfihliiffol; Gichiblume; Faften-1. Lerchenblume; St. Peterfchlüffel. Germ. HoJe-and, HoJe Coreflip. Angl. Primevere, Primerole, ou Herbe à la Paralyfie. Gall.

In protis ficcioribus bei Gonnewitz, am Bienizetc. F1. April. Maio. Perennis.

Obj. Limbus corollae concauus.

$V f$. Flores pabulum apibus; Folia tenella fuccedaneum Theae et acetaria praebent fapida. Infuper funt mollia, nutrientia, corroborantia et pulmenti ad inftar coquuntur. Flores vinum efficiunt fragans et iucundum. E contrario Radix cereuifiam.

312. Primula feapis multiforis; exteruribus foribus veris nutantibus ; corollarum limbo plano. Roтн Flor. Germ. $\beta$ )elatior.

P. I. p. (;O. LINN. Syft. p. 192. n. I. var. $\beta$. воЕнM. n. 38. schreb. Spicil. pag. 5. n. 38. Fl. Dan. tab. 434.

Wilde, frïhzeitige, grofse Waldfchliiffelblume; Faftenhandfchih, Hoflerchen, Ofterblumen. Germ. Oxflip. Angl. Primvere elevée. Gall.

In fyluis humidis pratisque copiofe, im Rofenthale, in Univerfitätsholze hinter den Förfterhaüfe etc. Floret cum priori.

Obf. Limbus corollae planus.

3r3. Primula pedunculis radicalibus vniforis, feapo veris n. 110 . 
Primula veris acaulis fcapo nullo. uiNN. Syft. pag. I92. n. 2. val. \%. schreb. Spicil. pag. 5. n, 38. var. BLAEKw. t. 52: Fl. Dan. t. 192.

Stammlofe Schlivfsclblume. Germ. Common Primrofe. Angl. Premiere fans tige.

In nemoribus, in Rofenthale, quoque am Bieniz. parrim. Vernali tempore viget.

\section{3. * ANDrosaCE. L. G. 209. Mannsharnifch f. Mannsfchild, Germ.}

elongata. $31+*$ Androjacae foliis lanceolatis dentatis; vmbella trunifera elongata; corollis calyce ongulato. breuioribus. RrTz. Obferv. Botan. Fafe. II, pag, 10. n. 14. JACQ. Obferv. 1. 42. Eiusd. Flor. Auftr. Vol. IV. tab. 330 .

Ancroface elongata foliis fubdentstis, pedicellis longifimis; corollis calyce breuioribus. LINN. Sy?. p. 192. n. 2. LEYS. n. 197. SCKVHR. t. 33 .

Verlängerter Mannsharnifch. Germ. Long Pedicled Androface. Angl.

In agris elatioribus ficcioribusque, e. g. bei Stahmetn, Modelzeitz et $S c k c u d i t z$ praeterito anno inueni. Fl. April. Annua.

94. HOTTONIA, L. G. 2!6. Hottonie $f$ Wanterveil. Germ.

paluftris. 3 I 5 . Hottonia pedunculis verticillato multiforis. LINN. Syrt p. 194. вовIM. n. 37. Fl. Dan.t. 487.scrvhr. tab. 34 .

Sumpflnottonie; Wafferuiole; Waferfeder; WafSergarbe; Wafferfenchel. Germ. Water Vonlet. Angl. Plumelle des marcis. Gall.

In paluftribus et tcrobibus in Rofentlale, bei Pfaf'fentorf, Gohlis, Eutritfch, Tauche, in nemoribus in der Prellheide inter Alnos et alibi valde frequens. Fl. Nai. Iun, Perennis. 
95. MENIANTHES. L. G. 215!' Zottenblume. Germ. Menianthe, Gall.

3I6. Menganthes foliis ternatis, corollae laciniis margi- trifoliata ne inegris, fuperne barbstis. вотн. Flor. Germ. peg. 91 .

Menyonthes foliis ternatis. LiNn. Syft. p. I94. n. 4 .

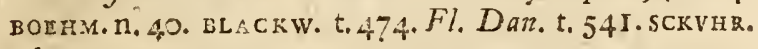
tab. 35 .

Pharm. Trifoliz fibrini l. aquatici Rad. Herba.

Dreiblattrige Zottenblume; Fieber I Bitterklee; Bieberklee; Scharbocksklee; Dreiblatt; Monatsblume; Ziegenklappen. Germ. Marfh Trefonl; or Buck-bean. Angl. Trefle d'eau. Gall.

In paludofis et foltis ad Schönfeld und dem Gerberwaffer aliisque locis. Fl. Mai. Iun. Perennis.

$V \int$. A pauperibus Humuli loco in Vplandia ad cereuifiam praeparandam adhibetur. Radices puluerifitae cum faina cerealium mita, caritate annonae grafante in regionibus borealibus pani inferuiunt. Lrnn. Amoenit, p. 515. Vermes necat puluis cum infufo.

96. CONVOLVVLVS. L. G. 23r. Winde. Germ. Bindweed. Angl. Liferon, Gall.

317. Comuoluulus foliis fagittatis vtrinque acutis, pe-artienfis. dunculis vnifloris, calyce nudo. WILDEN. Prodr. Berol. n. 262. LINN. Syft. p. 200 , n. 1. BOEHM. n. 49. Fl. Dan. t. 459 .

Askerwindé; Erd-Feld. Weisle-Weingartenwinde; Teufelsdarm. Germ. Common perennial Bindweed. Angl. L2 feret. Gall.

In agris aruisque cultis vbique. Flor. Iun. Iul. Perennis.

Planta rufticis odiofa.

318. Comoluulus foliis fagittatis poftice truncatis, pe- repiun. dunculis, tetragonis, vnifloris, bracteis cordatis calyce longioribus. WILDEN. Prodr. Berol. n. 263. LINN. Syft. p: 200. n. 2. вовIM. n. 50. EKACKw. tab. 38. Fl. Dan, t, 758. sckver. t, 38 . 
Pharm. Conuolurli maioris albi Herba.

Zunneinde; grafie Heckenvinde; Bär-Weifsewinde; Battlersfeil; teurfche Sckanmonie. Germ. Large white Bindweed, or Bear-lind. Angl. Grard Liferon, ou Liferon des haïs. Gall.

Ad fepes, dumeta hortorum vbique. Fl. Iun. Aug. Perennis.

97. DATVRA. L: G. 263. Stechapfel. Gemb. Thornapple. Angl. Ponme épineufe. Gall.

Stramoniun 31\%. Datura pericarpiis fpinofis, ereetis, ouatis; foliis ountis, glabris. LrNw. Sy?t. p. $220 . n$. 2. BorIm. n. 42. (fub Stramonioj blackw. t. 313 . Fl. Dan, tab. 436. sCKVнR. t. 43 .

Pharm. Daturae Semina et Stramonii Herba.

Gemeiner Stechapfel; Dorn- I. Rauchapfel; Dollkraut. Germ. Common Tkorn sipplé. Angl. Sirumoine ou Endormze. Gall.

In ruderatis circa pagos, bei Gonnereitz, um das Schreerkésdorfifche Guth, in pago Kriphine dicto, in der Alee et alibi paffim. F1. Iun. - Septembr.

Ob/. et $V \int$. Planta fufpecta et Rupefaciens. Necat apes. Oues reipuunt. Sues leminibus deuoratis pereunt. Extr. a Cel. Stoerkio et Groeding. in mania, epilepfia, laudatum elt.

98. HYOSCYAMVS. L. G. 264. Bilfenkraut. Germ. Henbane. Angl. Juisquiame. Gall.

niger. 320. Hyofcyanus foliis amplexicaulibus finuatis, floribus feffilibus. LINN. Syft. pag. 220. n. I. вовнм. и. I54. elackw. t. 550. Gled. Naturgefch. p. 73 . Tab. V. SCKVFR. t. 44 .

Pharm. Hiyofcyani Radix, Semina, Herba.

Schuearzes Bilfenkrauz; Biljenfaame; Schlaftrunk; , Zankkraut; Zankteufil; Hünergift f. Tod; Zigeuaerkorn; Prophetenkrant; Teufelsauge. Germ. Black Henbayize. Angl. Fusquiame noir; ou Potelée. Gall. 
In neglectis, ruderatis et ad vias bei dem Gerichte, an den Kohlgurten, nicht zeeit von der Leingrube et alibi frequens. Fl. Iun Iul. Perennis.

Obf. et $V f$. Planta odorem grauenlentem fpirans, caput grauefcens, venen of valdeque obnoxia. Oues, anferes et pullos necat. - Pifces a feminibus fupefa. Ci et porci paralyfi a fficti. Folia interdum fuccedaneum Nicotianae. Cingari feminibus ad magicas artes exercondas vtuntur. Succo ex hac herba re. centi expreffo peilere fertur lectorum fulcra fublito cimices.

99. NICOTIANA. L. G. 265. Taback: Germ. Tobacco. Angl. Tobac. Gall.

321. Nicotiana foliis lanceolato-onatis feffilibus decur-Tabacum. rentibus, foribus acutis. LiN. Sy凡t. pag. 221 . n. I. ВОЕНM. n. 43. BLACKW. t. 146. SCKVHR. t. 44 .

Pliarm. Tabaci Herba, Semina.

Gemeiner Taback; großblâttriger Taback; das hcilfane Kraut; Heil aller IVelt. Germ. Virginian Tobacco. Angl. Nicotiane, ou Tabac common à grandes feuilles; Herbe Sainte. Gall.

Seritur bei Stötteritz, nach Probftheide zu, et in multis hortis paffun. F!. Iul. Aug. Annua.

Vf. Planta narcotica. Cum foliorum cineribus imuo!umli pelluntur." Coriis parandis apta.

322. * Nicotiana foliis petiolátis, ouatis, integerrimis; ruttica.

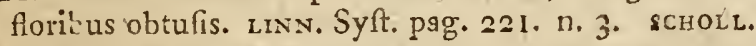
Barb. p. 273. n. 24.

Kleiner wilder Taback; türkijcher, banesn, gemeiner, engli/cher. Taback; Königinnkrauit. Germ. Common englifl Tobacco. Angl. Tabac i la Reine; Herbe à l.Ambajjadeur. Gall.

In iisdem locis cum antecedente frequenter colitur. Fl. aeftate. 
100. VERBASCVM. L. G. 262. Königskérze, Fa. ckel. Germ. Mullein. Angl. Bouillon. Gall.

Thaphus. 323. Verbafan foliis decurentibus vtrinque tomentofis, caule fimplici. LINN. Sylt.p. 2 Ig.n. I. воEнм. ń. 152. в LACKW. t. 3. et 502. bene. Fl. Dan. tab. 63I. SCKVGR. t. 42.

Pharin. Verbafci Herba, Flores.

Wollkraut; Kerankrant; wolligte Königskerze; Barenfackel; Feld-f. Ofterkcrze; Fackclkraut; Fackelblumen; Himnelsbrand. Germ. Leaved or Great white Mullcin. Angl. Bowillon blans male, ou Molene. Gail

In ruderntis, verfuris, auf dem Whalle circa vrbem -. copiofe bei den grinmifchen Zevinger, in muris copiofe, hinater den Kohigürten ctc. Flor. Iul. Aug. Perénnis.

Vf. Flores apibus pabulum. Rad. puluerifata contra pulmonum morbos pecorum adhibetur. Pifci feminibus deglutitis temulenti. Flores flauo-tinctorii.

Lychnitis. 324. ${ }^{*}$ Verlafcum folis cuneiformibus, oblongis. IINN. Syft. p. 219 . n. 5. JeERs Herborn. n. 150. LEYs. n. 206. WIL D. Prodr. Brrol. n. 265

Kleiz IVollkrait; faubigte Kexzen; weiffes IVollkraut; Mottcnkraut. Germ. Hoxry Mullein, or white flowered Mullein. Angl, Bouillon Lychnite. Gall.

Ad vias, fepes et in ferilibus, ficcis et coemeteriis pagorum frequens. Fl. Iun. Iul. Perennis.

Obf. Cutul. ramofus. Folia radicalia longe petio. 'lata.' Flor. flati et pafin albi.

nigrum. 325. Verbafem foliis oblongo cordatis, petiolatis. LINN. Syft. p. 219. 11. 6. BOEHM. n. I53.

1, Pharm. Verbafci Radix, Flores.

Schwarze Berzen; Brannwurz; fchwarzes Wollkraut. Germ. Sage-leaved Black Mullein. Angl. Bouillon noir. Gáll.

In falicetis et ad riuulorum margines hintcr Schönfeld, auf dem Gickerlingsbergc, ad fofliculas dichte hinter Eutritich etc. et alibi. Fl. Iun. Aug. Biennis.

* VJ. Planta florefcens mures pellit. Apes frequenter reuifunt. 
326. * Verbafcum foliis amplexicaulibus, oblongis, gla-Blattaria. bris, pedunculis folitariis. uIN . Sytt. p. 219 . n. 8 . IEYS. n. 2OS. SCFOLL. Hor. Barb. n. $172^{\circ}$

Schaben-f. Mottenkraut; Edelkraut; Rattẹnkraut. Germ. Yellow Motin Mullein. Angl. Heibe aux Mites. Ga!l.

In locis arenofis fterilioribusque bei Kleinzfchocher, et in Coemeterio bei Altranftaidt et alibi paffum.

Necar cimices.

101. VINCA. L. G. 322. Sinngruin, Ingrün. Germ. Peris inckle. Angl. Pervenche. Gall.

327. Vinca caulibus procumbentibus; foliis lanceolato-minos. oustis; floribus pedunculatis. LINN. Syft. p. $252 \mathrm{n}$. I. EOEHM. ก. 4 I. RLACKW. tab. 59. SCXHH. tab. 5 I. insle.

Var. a) Filore alto.

Pharm. Vincae Pemincae Herba.

Kleines Sinngriin; Wintergrïn; Todtenkranz; Iung fer skrone; Magdepalme. Germ. Common green I'crizeinkle. Angl Pervenche. Gall.

In fyluis denfioribus, in Uiziverfitiitsholze copiofe. Varietatém ibidem paffim anto praeterito vidi. Fl. Mai. Iun. Perennis.

$V \int$. Planta adftringens in Gargarismatibus pafim adhibetur.

c) Flores monopetali, inferi; Germinibus bacciferis.

102. SOLANVM. L. G. 269. Nachtfchatten. Germ. Night-Thade. Angl. Morelle, Gall.

328. Solanum caule inermi frutefcente flexuofo; foliis Du':amara. fuperioribus haftatis, racemis cymofis. LINN. Syft. p. 223. ก. 5. воЕHм. n. 54. BLACKw. tab. 34. Fl. Dan. tab 607 .

l'liarm. Dulcamarae Stipites.

Hinfchlu- f. Hirfchkraut; Alpranken; Mäuleholz; Bitterjüs; IValduachtfchatten; reilde Stickueur: Germ. Woody Night finad or Bitterfereat. Angl. Dou$\mathrm{H}_{4}$ 


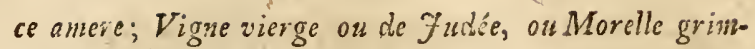
pante. Gall.

In fepibus et.ad ripas Autiorum, im Rofenthale, ad folficulas in den-Poetengange, hinter den Gerbcreiefeni; verfus Stötteriız, Borsderf, Machern, Eutritfch, Kriphänéetc. Fl. Iun. Iul. Baccae Septembri maturae. Perennis.

$V \int$. Ramis ad vincula cantharorum vtuntur eorum confectores. Baccae arti tinctoriae aptae. Canibus et ouibus funt venenum.-

tuberofum. 329. Solanum caule inermi herbaceo, foliis pinnatis in. tegerrimis, pedunculis lubdiuifis. LiNn. Syft. p. 224. n. 23. военм. n. 52. вLACKW, tab. 539. a ct b, et 587 .

Knollichier Nachtfchaticn; Erdâfel; Erdtuffel; Knollen; Kertoffeln; Tartoffeln; Patatten. Germ. Connon Paratoes, or Taupinambours. Angl. Pomme de terre, Truffe ou Battate de Virginie. Gall.

In agris et hortis oleraceis copiofe coluntur. Fl. Iul. Aug.

Obf. Variat mirifice. Flos videlicet deprehenditur modo colore pallido, modo caerulaeo, violaceo aut puipureo. Porro qioque radix quoad figuram, magnitudinern et coioren diuerfa. Aliae enim orbiculares, aliae oblongae contra, aliae coniferae; et aliae ratione coloris funt pallide luteo, carneo, rubro ac deniquue albo praeditae colore. Qua de re varia nomina in linguã vernacula accipiunt.

$V \int$. Radix hominibus cibus et nutrimentum; pecoribus faginatio. Ex bulborum tarina anylum, puluis odoratus, cafeus, fpiritus etc. conficitur.

vulgatum. 330. Solanum caule inermi, herbaceo; ramis teretibus hirfutulis: foliis ouatis, glabris, racemis nutantibus, baccis et acinis nigris.

Solanum nigrum caule inermi herbaceo; foliis ouatis dentato-angulatis, racemis diftichis nutantibus. LIIN. Syft. pag. 224. n. 20. BOEHM. n. 53. BLACKw, tab. 107. Fl, Dan. tab. 460 . sckver, tab. 46.

Pharm. Solani nigri Herba. 
Gemeiner fchwarzer Nachtfhatten; Sau- .. Alpkraut. Germ. Common Nighthede. Angl. Morelle à fruit noir. Gall.

In cultis et ruderatis vbique, proecipue auf des Wällen circa vibem. Fl. Iun. Iul. Annua.

Obf. Planta fufpecta. Sues, vitulas, snates etc. necat.

33r. * Solanum caule inermi, herbaceo, ramis tereti-villofun. bus villofis; foliis ouatis, angulofis, villofis; baccis nigris; acinis luteis.

Raucher Nachtfchatten. Germ.

In ruderatis ad fepes, in ambulacris ct collibus circa vrbem copiofe. Fl. Aeftate.

Planta odore mofchi praedita. Qualitas virofa.

I03. ATROPA. L. G. 266. Tollkraut. Germ. Dwale. Angl. Belladonne. Gall.

332. * Atropa caule herbaceo, foliis ouatis integris. Belladonna. LINN. Syft. p. 22 I. n. 2. BLACKW. t. 564. Fl. Dan. t. 758. J.1en. Flor. Auft. Vol. IV. t. 30g. KERN. p. 104. t. 179. SCKVHR. t. 45.

Pharm. Bellae Donnae Folia, Baccae.

Gimeines Tollkraut; Tollkirjchenkraut; fchöne Mädchen S. Frau; Teufels-1. Wolfskirfche; Irr-Wuthf. Schlafbere. Germ. Common Deading Night fhade, or Dwale. Angl. Belladonne. Gall.

In fyluis elatioribus, paffim in fylua Academica mihi occurrit, in dumetis et ad fepes hortorum pafim; porro in multis hortis circa Lipfiam. Flor. Iul. Aug. Perennis.

Planta tota venenofa.

$V \int$. E foliis aqua defillata in Italia puellac -pigmenti cosmetici loco vtuntur; pictores etiam colore tingunt viridi. 


\section{d) Flores monopetali, fuperi; Germinibus capplis- liftoris.}

I0千. SAMOLVS. L. G. 238 . Samoskraut f. Pungen. Gern.

Valerandi. 333.' Samolus caule minus ramofo, foliis crafis, 'carnofis integerrimis; caulinis obtufo-cordatis; radicalibus obuerfo-ouatis.

Samolus Valeraindi. Linn. Syft. p. 212. sChreb. Spicil. p. 8. n. 898 . Fl. Dan. t. I89. sc KvHr. t. 40.

Sanolus Valerandi folio oblongo. walth. Hort.p. 162.

Samolus Africanus folio rotundiore. Id. 1. c. tab. 23 .

Samoskraut; Strandpungen; rundblättrige Wafferpimpinelle. Germ. Long-leaved Brookzeeed, or Rcundlenved Water Pimpernel. Angl. Mouron d'eau. Gall.

In riuulis falfis ad Ketfchau valde frequens. Flor. Iun-Aug:

Obf. Icon, quam Cel. waltuervs in fuo libello delineari curauit, noftrae fpeciei valde affinis. Nec igitur dubito, illam plantam, in Africa nafcentem noftrae effe potius varietatem, quam fpeciem propriam. Si ob caulem magis ramofum firmioremque, qui in planta Africana obferuatur, foluminodo novatn confitituere velimus fpeciem, tunc ex diuifrone plantarum in fpecies Chaos exifteret. - Bracteae lanceolatae. Cal. glaber 5 - fidus. funt.

Vf. Folia amara falfa pro acetariis inferuire pof-

195. PHYTEVMA. L. G. 236. Rapunzel. Germ. Kandpion. Angl. Phitevme. Gall.

orbicularis. 334. Physeama capitulo fubrotundo, foliis ferratis, radicalibus cordatis. LiN. Syft. p. 2I r. n. 4. BOEHM. n. 156. (fub Rapunculo) JACQ. Flor. Auftr. V. 5. tab. .437 .

Kieisnnnde Rapunzel. Germ. Round headed Horned Rampion. Angl. Phitevme, ou Raiponfette ìt têtes. Gall. 
In fyluis et pratis montofis bei Gunnderf, frequenter auf den Wiefon hintir Grojs- und Kleindölzig, in Bicniz. Fl. Mai. Iun. Perennis.

Obf. Caulis ercetus, fimplex, fpicam vnicam terminalem gerens. Spica fubgolbola, ouata, caerulea. Semina flauo-fufca, ouata.

335. Phytcnina fpica oblonga, capfulis bilocularibus, fpicata. foliis radicalibus cordatis, LINN. Syft. pag, 212. n. 5 . Fl. Dan. tab. 362. KERN. pag. 93. tab. 153. SCKVIIR. tab. 39 .

Var. Phyteuma foliis maculis nigris notatis, fpica duplici et flore quadrifolio, interdum violaceo.

Achrentragende Rapunzel; Waldrapunzel; weiffe Rapunzel; Taubenkropf. Germ. Spiked Rampion. Angl. Raiponfette ou épi. Gall.

In fyluis, am Bieniz et Univerfiriitsholzc. Fl. Mai. Iun. Perennis.

Obf. Spica longior, quam in priori, cylindrica, albo-flauefcens. Fructus 2 - fidus, bilocularis. funt.

IJ. Folia et radix ad olera et acetaria in vfu

106. CAMPANVLA. L. G. 234. Glocken. Gcrm. Bell-flower. Angl. Campanule. Gall.

a) Foliis laeuioribus anguftioribus.

336. Canpanula foliis radicalibus reniformibus; cauli- rotundifolia nis linearibus. linn, Synt. p. 206. n. 4. SChreb. Spicil. p. 7 . n. $89 \%$.

Rundblâttriges Glöckchen; Wicfen-Gras- 1. Milchglöckcisen. Germ. Common fmall round-leaved Bellflower. Angl. La petite Campanule. Gall.

In pafcuis ficcioribus gramincisque, ad viam qua itur verfus Gonnervitz, um den Bieniz, nach Silönfeld; in colle Templi $S t$. Theclae; in pratis hinter Reichels Gorten, auf den Brücken nach dem Kuhthurme $\approx u$. Flor. Mai. ad Septembr. vsque.

$V f$. Sarcus ex corolla expreffus coeruleum et flavum exhibet colorem, Pabulum ouibus valde gra. tum.! 
patula. 337. Campanula foliis frietis; radicalibus lanceolato. oualibus; panicula parula. LiNN. Syft. p. 206. n. 5 . schreb. Spicil. p. 6 n. 894 . Fl. Dan. t. 373.

Weitblumige r. fchweedyche Glocke. Germ. Field Bell-Flower. Angl. Campanule touffue. Gall.

In pratis vbique. Fl. Iun. Iul Perennis.

Obf. Flores exigui, parui. Cal. ad laciniarum ba. fin denticuln hiuido. Caules :amofi.

Rapunculus 33 \%. Campamula foliis indulatis: radicalibuslanceolatooualibus: panicula conretata. LiNN. Syft. p. 206. n.6. вовнм. n. 48 . Fl. Dan. t. 855. sCKvнR. t. 49 .

Rapunzel; kaulblättriges Glöckchèn; Fürwitzlein. Germ. Rampion, or Efculent-sooted blue Bell-flower. Angl. Raiponfe. Gall. Aug.

In pratis et locis aridioribus. Flor. Mai. - Iul. -

Obf. Caul. angulatus, hirfutus. Folia parum plicota, leuiter fcabra.

$V \int$. Radix od olera et acetaria.

perficifolia. 339. Campanzila-foliis radicalibus obouatis; caulinis lanceolato-linearibus, fublerratis feffitibus, remotis. LiNN. Syft. p 206. n. 7. EOEHM. n. 4.4.

Var. Campanula flore albo, foliis parum latioribus.

Pfirfichblättrige Glocken; große Schmalblättrige Waldglocke; Waldcynizbel; holue Waldrapunzel f. Glockenblumse. Germ. Peachleaved Bell-fluwer. Angl. Campanulc à feuilles de pêcher. Gall.

In filuis montofis, in b̈ieniz frequens. Fl. Iun. Iul. Perennis.

VJ. Flores apibus pabulum praeftans.

$$
\text { b) Foliis fabris, latioribus. }
$$

Rapuncu- 340. Campanula foliis cordato-lanceolatis, caule ramoloides.

fo: fl.ribus fecundis fparfis; calycibus reflexis. LINN. Syft. p. 207. n. 23. SCHREE, Spicil. pag. i7. n. 896.

Rapunzclartige Glöckchen; wilde Milchglocken. Germ. Rampioin-rooted Dell-fiower. Angl. Caimpanüle raiponfette. Gall. 
Ad fepes in editioribus über Markkleberg, im Rofen. thale et aliis fyluis ad Plifiam; porro in multis hortis. Fl. Iun.-Aug.

$V \int$ Radicem efle efculentam referunt Clufius et Dodonaetss.

34I. Campanula caule angularo, foliis petiolatis, caly. Tracheliun. cibus ciliatis, pedunculis trifidis. IINN. Syft. p. 208.

n. '28. вовFlм, ก. 45 .

Var. a) Campanula flore albo.

1 Neffelblättrige Glocken; gemeines Halskraut;'Huck. blatt; Zapfenblatr. Germ. Great blue Throatwort, or Canterbury Bells: Angl. Campanule gantelle, ou Gantelée à fleur bleu; Gant de Notre-Dane Gall.

In fyluis frequens, in Rofenibale, Zfchocherfchen, Kleindülziger Holze aliisque, et ad lepes copiofe etc. Var. im Kleindülziger et Scheuditzer Holze nuperrime reperi. Fl. Iun. Iul. Ang Perennis.

$V \int$. Radix efculenta et folia tenella oleribus etacetariis apta.

342. Campamula caule angulato, fimplici: floribus fef-glomerata. filibus. capitulo terminali. LIN Sy ft. p. 208. n. 29. вовнм n. 46.

Gehäufte f. Büfchelglöchchen; kleines Halskraut. Germ. Lelfer Throatzeort. Angl. Campanale conglomérée. Gall.

In pratis montofis, aridisque et fyluis, im Univerfitütsholze, in Bieniz an der Wiefe, etiam auf dem Altranftidter Kirchhofe fiequenter reperi. Fl. Iun. Iul. Aug. Perennis.

Pratis obnoxia. Pecora herbam refpuunt.

343. Campanula hifpida, capirulo terminali, foliis lan. Ceruicaria ceolato-linearibus, vndulatis. LINN. Syft. p. 208. n. 30. schreb. Spicil. p. 6. n. Xొ5. Fl. Dan. t. 787 . Gerin.

Halskrautglöctichen; Genick - 1. Zïpfleinkraut.

In fyluis, e. g. im Bieniz, Oberholze, ad Oeltfchaus Störmthal et Univerfitâtsholze, porro in Coemeterio Altranfiadienfi. Fl. Iul. - Aug. Perennis.

VJ. Radix alba, fapida et leniter roborans. 
*** Capfulis obteklis, calycis finubus refiexis.

Spculum 344. Campanula caule ramofifimo, difufo, foliis ob: Veneris, Jongis fubcrenatis; floribus folitaris, capfulis prismaticis. LinN. Syft. p. 209. n. 46. schrez. Spicil. p. 145. ก. -1162.

Frauen- 1. Venusfpiegel; fünfeckichte Veilchen. Germ. Venu's Looking-glaß. Angl. Mirette, ou Miroir de Venus. Gall.

Inter fegetcs pafim. Fl. Iun.-Aug.

Obf. Galli radicem, quam Doucette appeliant, acetariorum ad inftar lubenter comedunt.

\section{e) Flores nonopetali, fuperi: GERMINIBVS B A C CIFERIS.}

107. LONICERA. L. G. 250. Lonicere. Gem. Honey" fuckle. Angl. Chevre-feuille. Gall.

* Periclymena, canle volubili.

Caprifolium 345. * Lowicera floribus verticillatis, terminalibus, feffilibus; foliis fummis connato-perfoliatis. LIN . Syft. p. 215 . scop, Carn. I. p. 152. Poli. Pal. I. n. $217^{\circ}$ JACQ. Flor. Aufr. V. 4. t. $35 \%$.

Periclymenum perfoliatum. C. B. P. p. 302.

Ceißblatt; durchueachenes italienifches f. welfches Geißsblatt; Speck-IValdilie; Felngerjelieber; Waldwinde; Zannling. Germ. Italian Honeyfuckle. Angl. Chevre-feuille cultivé. Gall.

In dumetis ac fepibus et hortis fuburbanis paga. nisque valde frequens. Flor. Maio. - Iulio maturat baccas.

Obf. Frutex volubilis, longus, teres. Rami op. pofiti. Folia coniugats, inferiora, ouata, obtufa, connata, fumma orbiculata, integerrima. Baccae fubrotundae, fucculentae, ex rubro in flauum colorem vergentes, glabiae, apice puncto nigro notatae. Sem. 4-5, rotunda, glabra. 
346. * Lonicera capitulis ouatis imbricatis terminali-Periclyme bus: foliis omnibus diftinctis. LINN. Syßt. p. $216 . n$, num. 4. SERT. Lipf. n. 49. SCKVHR. t. yо.

Var. «) Lonic. foliis omnibus integerrimis, petio. latis, oppofitis.

ß) Lonic. foliis finuofis vel querinis.

r) Lonic. foliis finuofis variegatis.

Pharm. Caprifolii Stipites, Herba.

Gemeine Lonizere; wildes gemeines Geiffblatt; Georgenrofen; teutfcher Fel nger jelicber; Rofe von Fericho. Germ. Wild Honey-fuckle. Angl, Che'ure-fuille d'Allenagne. Gail.

In dumetis ante pagum Großreölkau auf drr Inful; porro in plurimis hortis fuburbanis et paganis haud infrequens. Fl. Iun. et Iul. Frut.

Vf. Flores vrinam cient. Baccae dulces purgante vi gaudent. Floyer. - Infufum cum vitriolo martis nigro tingit colore.

** Chamaeceraja: pedunculis bifloris.

347. * Lonicera pedunculis bifloris, baccis diftinetis, tatarica. foliis cordatis, obtufis. LiNN. Syft. pag. $216 . \mathrm{n} .8$. JACQ. Mifc. Vol. III.

Chamaecerafizs fructu gemino rubro, foliis glabris cordatis. Amm. Ruth. 184.

Tartarifche Hecienkirfche. Germ. Tartarian Honeyfuckle. Angl. Chevre-feuille de Tartarie. Gall.

In dumetis auf der Inful ante horrum ad Großsieöli kau; in Serto unten an Graben ergaftulum verfus paffim; fed frequentius in hortis fuburbanis, e. $g$. Winkleriano, Trieriaño, Lehriano etc. Fl. Maio et Iunio.

Hic autem frutex proprie in Tataria nafcens ob infignem Corollae colorem ornat fruticeta e $t$ fepibus vivis humilioribus valde aptus.

348. * Lonicera pedunculisi bifloris, baccis diftindis, Xylofteum. foliis integerrimis, pubefcentibus. LINN. Syft. p. 216. n. 9. Fl. Dan. t. 808 .

Die gemeine Heckenlirfche; Hunds-Ahlirfche; Teufels Fliegenkirfche; Bohrholz; Vogelbeere; Spießbeerholz:Fiedelrümpfchen; Teufelsmarterholz; Seelenholz; Zweckholz; Frazenholz. Germ. Fly Honewfucile. Angl. Cheore-feuille des buiffons; ou Camerifier. Gall. In 
In fyluis humidis et ad fepes hortorum pagano. rum frequens. Flor. Maio. Baccae Aug. maturefcunt.

Vf. Lignum tabaci fifulis aptun; Herba pabulum capris gratum. "Friurex fepes viuas reddit denfiores. Bзcca vehementer purgant et in magna copia fumtae vomitum excitant.

\section{f) Flores 5-petali, inferi: GERMINIBVS BACCIFERIS.}

108. Rhamnus. J. G. 284 . Wegdorn. Germ. Buckthorn. Angl. Nerpran. Gall.

* Inermes.

Frangula. 349. Rhammus inermis, floribus monogynis, hermaphroditis; foliis integerrimis. IINN. Syft. pag. 234. EOEHM. П. 51. BLACK W. tab. 152. DV HAM. Arb. I. p. 245 . t. 100. Fl. Dan. t. $2 \% 8$. CRAM. t. 43 . SCKVHR. t. 4 6. Fol. male picta.

Pharm. Frangulae Cortex.

Unbewährter IVegdorn; Faulbaum; Zapfenholz; Hundslausbaum; Grindholz; fchwarze Erle; Schießbece; Pulverholz; Stintbaum. Germ. Blac. Berrybearing Alder. Angl. Bourdaine ou Aulne noir baccifere. Ga!l.

In nemorofis humidis, im Zfchocherfchen Holze; hinter dem Gexberwaller; auf dem Wege nash Schönfeld; im Rofenthale; in ambulacris, e.g. 1n der Allee et in multis hortis. Flor. Mai. - Iul. Baccae maturefcunt Aug.

$V \int$. Baccae, fub nomine Graine d'Avignon, viridi, cortex contra luteo tingunt, colore. Tinctura baccarum cum bafi aluminis trita, format colorem vulgo Stilde-Grain dictum. Duhamel. Smolandi ad vincula cantharorum hunc feligunt. Carbones ad pul. verem pyrium praeparandum adhibentur. 


\section{** Spinofi.}

350. Rhamnus fpinis terminalibus, floribus quadrifidis catharticus. dioicis; foilis ouatis, cąule erecto. LINN. Syft, pag. 232. ก. 1. БOEHA. n. U9, ELACKW. t. 135. CRAM. t. 35. Dviam. Arb. II. pag. 21 . t. 50. Fl. Dan. tab. 850 .

Pharm. Spinae Ceruinae Baccae, Cortex.

Purgiruder liegdorn; Kreuzdorn; Rhein-f.Kreasbeere; Hirfchdom; Dintenbeerftrauch; Awifulbeerdorn. Germ. Conmon Purging Buckthorn. Angl. Noirnmu, Bourguepine: Gall.

Inter fruticeta et in nemoribus nach dem Rofentia. le et Schönfald, porro in plurimis hortis etc. Flor. Maio.

$V \int$. Frutex fepibus pulcherrimis, altis, viridibusque aptus. Cortex luteo purpurafente. Baccae autem viridi tingunt colore, et cum alumine costae fuccum viridem Verd-de - Vefjie, i. e. Saftgrïn dictum exhibent. Syrupus e baccis praeparatus leniter et tarde purgat.

109. EVONYMVS. L. G. 201. Spillbaum. Gim. Prickwood. Angl. Fufain. Call.

35 r. Enonzm foribus fubquadrifidis; fruatibus apte- Europaeus, ris: foliis ouatis, acutis, ferratis. WILDEN. Prodr. Berol. n. 283 .

Ezonymus Europaclis foribus plerisque quadrifidis; foliis feflilibus acutis. LiNм. Syft, p. 238. n. 4. вовнм.

n. 353 . SCKVHR. t. 48 .

Euonymus vulgaris pedunculis alaribus, petalis ob. longis, frutibus glabris. scop. Carn.

Europ ifcher Spillbailm; Pfaffenlizitchen; Pfaffenmütze; Zueeck-1. Schufterlola; Spulbaum; Haneklötchen; Rotinkihlgenbrot. Germ. Conimon Spindlee Tree. Angl. Fufain de bois; ou Bonnet de prètre. Gall.

Ad fepes, in dumetis vbique; in der Allee et in multis hortis. Fl. Mai. Inn. Frut.

Obj. Plerumque flores et frusus quadrifidi, paffim quinquetidi. 
Vf. Adfepes humiliores; puluerem pyrium vtilis. Lignum flauefcens, durum, rigidifinum, inftrumentis, e. g. fufis, colis etc. corficiendis aptum. Baccae pediculos nccạnt, et a tinétoribus in vlum vocantur.

I10. VITIS. L, G. 30.5. Weinftock, Germ. Vine, Angl. Vigne. Gall.

vinifera. $352 .{ }^{*}$ Vitis foliis lobatis finuatis nudis. LINN Syft. p. 244. blacxw. to 153. вave. Pin, 299. Vitis vinifera.

Pharm. Vitis Folia. Pafrulae mainres. Vinum.

- Gemeiner f. coller Vicinftock; is tinrebe; Traubenftock; Weintrauben. Germ. Common Grapes. Anglo Vigne cultwée; Raifin de Dame. Gall.

Habitat in Orbis 4 partibus temperatis. Praeprimis in noftro Circulo paftum in magna copia reperitur, e. g. in'dem Weinnupfchen vor dem grimmifchen Tho-

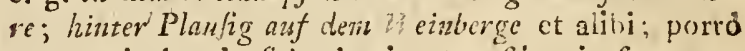
quaque in hortis fuburbanis et rufticanis frequ ns. Fl. Maio Iunio. Baccae maturae exeunte Septembre et initio Octobris.

Vfus eft notifimus.

\section{g) Flores 5-petali, fuperi: GERMINIBVS BA C CIF ERIS.}

III. RIBES. L. G. 30r. Krausbeere; Inhannisbeerftrauch, Germ. Currant. Angl. Groffieillier. Gall.

$$
\text { * Ribefáa, inermia. }
$$

tubrum. 353. Ribes inerme, racemis glabris, pendulis, floribus planiulculis. LINN. Syft. p. 242. n. 1. вовнм. $n .236$. BLACKW: tab. 285 . f. I. et 2. et var, fructu albo f. 5 . SCKVHR.' t. 48.

Pharm. Ribium rubrorum Baccae.

Rother Iohannisbeerflauch; Riebefelffrauch Germ. Common Sur Curranzt. Angl. Grofezllier à grappes et à fruit rouge. Gall. 
Inter fruticetaet ad fepes hortorum ipfisque in hortis. Fl. April. Mai. Frut.

$V \int$. Flores apibus pabulum. Baccae conditae in deliciis habentur. F baccis cum Saccharo non depurato et aqua fiigida q. f. Vinum praeparari poteft, pulcherrime colore Kermfiano amoenum. Roob eiusdem cum faccharo praeparatum in febribus putridis valde aeftimabile.

354. Ribes incrme, racemis pilofis; Aoribus oblongis, nigrum. LINN. Syf. p. $2+3 \cdot n$ 4. ВОЕнм. n. 355. BLACKw. t. 285. F. 6. Fl. Dais. t. 556 .

Pharm. Ribum nigrormu Baccac conditae, Rob. Stipites, Herba tenella.

Sterarze Iohannisbiere; Bocksbeere; Inngfrauftrauch; Stinkblume; Rocisbcerenftrauch. Geym. Common blak Cirrant. Angl. Grofjeillier à fritit noir ou Caffier. Gall.

Inter frutices in Rojenthale, et ad forulas an deve klcinen Kohlgärten etc. Fl. April. Frut.

$V f$. Folia tenella, recentia et ciriffime in aqua calida infufa, mox ficca!a, fuccedanea fun Theae Chinen-, fi. Baccae in nonnallis regionibus eduntur et l.a. fermentatae Spiritum ardentem largiuntur. A ve. reribus hae baccae pro veneno habitas. Boues dySenteria febriii baccis deuoratis, afthiguntur.

** Groffulariae aculeatae.

355. * Ribes ramis aculeatis, petiolorum ciliis pilofis, Grofularia. baccis hirfutis. IINN. Syft. p. 243. n. 7. BLACKw. t. $27 \%$.

Grofularia fpinofa fatiua, dvizas, Fruit. I. p. 270. t. 2. f. 1. 2.

Gemeine Stachelbere; laarige Gartenfachelbeere. Germ. oofeberry. Angi. Groffeilleer blanc. Gall.

In dumetis, ad hortorum lepes paffim; in hortis contra valde vulgaris. Fl. Aprili et Maio. Baccae Iulio moturae.

Hic autem frutex in Heluetia vulgatinimus radicibus propsgans hinc et illine varie coloraras fert bac. cas, quae non folum crudae eduntar cum fapore, fed 
et g:ofiae in embammata coquuntur. Baccac maturae, caute ficcatae in furno, gratun faporem aciululum conciliant iusculis.

Vua crifpa. 356. Ribes racenis aculeatis, baccis glabris, pedicellis brątea monophylla. cisis. 5 ft. pag. 243. n. '8. BоEнM. ก. 357 . BLACKw. t. $27 \%$. Fl. Dan, t. 546.

Glatce Siaciclbere; Kloferbere; Chriftohren; Hecken- f. Stüchbere. Germ. Wilt prikley Gofeberry. Angl Groffeillior des haics, ou épineux fauvage; oit Gadelier. Gall.

In hortis, dumetis, areis vbique. Flor. Aprili. Frut.

VJ. Baccae immaturae vario modo in cibis; maturae et eciuntur et in vitreis vafis claufis aceto condiuntur. Infuper fermentatae fpiritum ardentern dant.

\section{HEDERA. L. G. 304. Epheu. Germ Ivy. Angl. Lierre. Gall.}

Helix. 357. Hedera foliis ouatis lobalisque. LINN. Syft. pag. 243. BOIHM. n. 352. BLACKW, t. 188. CRAM, t, 45 . SCKVHR, t. 49.

Var. $\alpha$ ) repens.

ß) arborea.

Pharm. Hedirae arboreae Lignum, Folia; Baccae.

Genteiner Eplieu; Maldeppig, Mouerewig; Mauerpfan; Wintergrün. Germ. . Great common Ivy-tre. Angl. Licre ordinaire Gall.

Prior terram fyluarum teret vbique, praeprimis in Rofenthale, quibus in locis rarifime floret, quade re a bavnixo Hedera fterilis app dlata eft. Altera contra cuin fuis farmentis fixe adhaeret srboribus atque muris. Fl. April. et Mai. Baccae vero aeftate fubfequente maturefeunt.

Ob. Varietates foliis ex viridi et pallido aut luteo variegatis in Kortis paffim occurrunt.

$V J$. Hederae foliis clauos pedum extrahi poffe, olim exiftimauit Rucrius. Ob fnliorum frporem et refinae naturam b. Scopolizss putauit hanc plantam efle vulnerariam. 
358. * Hedera foliis quinatis, ouatis, ferratis. LrN sy. Sy. quinquefo243 n. 2. DV Ror Harbk. I. 38. n. 302. lia.

Fünfül'ttriger f. amerikanifcher 'Eplueu; Tungfernwein; wilder Wcin. Germ. American foy or Virginiun Creeper. Angl. Lieme d'Anerique. Gall.

Sponce proprie nafcitur in America feptentrionali. Apud nos ad muros et in hortis. paffim reperitur. Sic quoque ad nuros limofos poft hortum Weifianim ad Stöttcritz mihi occurrit. Praeter haec loca ad Horti menici murum et in aliis hortis crefcit. Flor. Aeftate.

Olf. Racemi 3- fidi bis dichotomi, vltimo vmbellati. Cal. breuiffinus, obrufe dentatus, apice rubicundus. Petala oblonga, obtúfa, apice fornicata, viridia. Glandula receptaculi calyce altior, germen ciugens crenis aliquot. Stam: filiformia, corolla paulo breuiora. Styl. I. longiudine ftaminum. Germen fuperum ietra-pafim polyfpermum. Numerus finrum variat $4-5-$ sCireB. Folia verfus Autumnum rubro gaudent colore.

h) Flores apetali, inferi.

113. GLAVX. L. G. 3I4. Milchkraut. Germ, Milkwort. Angl.

359. Glaux foliis alternis, ellyptico-oblongis. LINN. maritima.

Flor. Lapp. 72. Eiusd. Sylt pag. 24y. JaHN. n. 4. Fl. Dan. t. 548 . sckvнr.t. 50 .

Milch-Salz-S.Mutterkraut; Schiel-Seemelkraut; 'Vogelkraut mit Koriander Saamen. Germ. Sea Milk. wort, or Black Salt-wort. Angl. Glaux du bord de lì mer. Gall.

In folo falfo; v. c. ad falinas Ketfchanicnfes, olim Celeb. Knolle detexit, ibidenque quoque nuperrime reuifi magna in copia. Fl. Mai. Iun.

Obf. Calyx perfiftens campanulatus, viridis; port maturitatein vero albo vel rubro variat colore; dehinc nonnulli pro corollula habuerunt calycem. 
II4. THESIVM, L. G, I 5. Leinblatt; Flachskraut. Germ.

Linophyl- 360. Thefintm panicula foliaces, foliis lnearibus. LiNN. lum.

Syft. p. 219. Бовтім. n. 353. SCrink, t. 5 I.

Bergflachs;-gemeines Leinkrait. Germ. Flax-leaved Thefinin, or Baftard Toad-Flax. Angl. Théfie à feuilles de Linz. Gall.

In collibus gramine veftitis, am Bieniz fparfim. Fl. Maio-Iul. Perennis.

Obf. Caulis ereetus ramofus; Flores quadri-fed paffim quinquefidi. Cal.4-5- fidus. Stam.paf$\operatorname{fim} 4$.

\section{I G Y I I A.}

a) Flores mionopctali, inferi.

115. ASCLEPIAS. L. G. 3:3. Afklepiade f. Hundskohl. Germ. Swallow-wort. Angl. Dompte, venin. Gail.

Vinceroxi- 36r. Afclepias foliis cordato-ountis, bafi fubpilofis; sum. caulo erecto: floribus fafciculatis, wILDEN. Prodr. Berol. n. 29 r.

Afclepias Vincetoxicum foliis ouatis bafi barbatis, caule erecto, vmbellis proliferis. tinN. Syft. p. 259 . ก. 16. говнM. n. 56. BLACKw. t. 96. Fl. Dañ. t. 849. scKVHR. t. 35. f. b. (non optima).

Pharm. Hirundinariae f. Vincetoxici Radix, Herba.

Weiffe Aefculapie; gemeine Schrealbenzeurs; Giftwender; Giftwurz; St. Lorenzkraut. Germ. Common White Swallowe-zert. Angl. Tane poifon; Dompteverin ; Vincpoifon. Gall.

In nemoribus montofis, paffim in Bieniz. Flor. Iun. Iul. Perennis.

Vf. Plantam gelu taßtam equi comedunt. Pappus pro vomite. Radix prouocst exanthemata. 
116. GENTI ANA. L. G. 352. Genzian f. Enzian. Grrm. Fellwort. Angl. Gentiane. Gall.

* Coróllis 5 fidis fibcampanifornibus.

362. Gentiana corollis quinquefidis, campanulatis, op. Pneumopofitis, pedunculatis; foiits linearibus. LINN. Syft. p. nanthe. 264. ก. 7. вовнм. n. 55. Fl. Dan. n. 269.

Grof.Ser 1. fchmalblattriger Herb/t Enzian; Lungen. blume. Germ. Calathian Violet. Angl. Gentiane marais. Gall.

In locis humidis, auf der Wiefe Rïckmarsdorf gegen ïber; auf der Wiefe hinter Kleindölaig copiofe; hinter der Schönfelder Mühle paflim. Fl. Iun.-Aug. Perennis.

** Corollis 5 fidis, infundibiliformibus.

363. Gentiana corollis 5 fidis infundibiliformibus; cau- Centaurium le dichotomo: piltillo fimplici. rinN. Syft. p. 268. n. 2. вовнм. n. 57. fub Centaurio. BLACKw. t. 452. Fl. Dan. t. 617. SCKvir. t. 4.9.

Var. «) Gentiana corollulis 5 fidis infundibiliformibus, caule breuiffimo, ramofifimo. Gerard.

B) Gentiana minima flore albo; foliis minori. bus, craffio:ibus, carnofis.

Pharm. Centaurii minoris Herba, Flores.

Taufengüldenkraut; Fieberkraut; Erdgalle; Bieberkraut. Germ. Leffer Centaury. Angl. Gentiane Centazirée, ou petịté Centaurés. Gall.

- In pratis ficcioribus bei der Funkenburg, in der Obftallee bez Leutfch. porro in fofficulis humidiuscu. lis hinter Schleufig, Gunndorf, Ehrenbergetc. Var. ß) ad Salinas Ket fchauienfes deprehendi, Fl. Iun.-Aug. Bicnnis.

$V \int$. Planta valde amara, tonica, antifebrilis, folidorum laxitatern corrigens, fluida diluens, excretoria promouens, dein contra febres remittentes cum fucceffu adhibetur, atque paffin cortici peruuiano fub. Atituitur, Pediculi decocto necantu:.
b) $F l 0$ - 
b) Flores apetali.

1I7. CHENOPODIVM. L. G. 337. Gänfefufs. Germ. Gool-Foot. Angl. Patte d'oie.

* Foliis angulatis.

Bonus Henricus.

364. Chenopodizm foliis triangulari fagittatir, integerrimis, fpicis compofitis, aphyllis, axillaribus. I.1NN. Syf. p. $30 \%$. вовнм. n. $55 \%$. BLACKw. t. 311 . Fl. Dan. t. 579 . SCKVHR. t. 56 .

Phrm. Boni Henrici Herba.

Guter f. ftolzer Heinvich; Hackenfchaar; englijch Bengelkraut; wilder Foldfpinat; Lämmeroluren; L.mmerkraut; Allgut; Hundemelde. Germ. Common Eng. lifh Mercury, Good Henry or Allgood. Angl. Patte, d'oie Bon-Henri. Gall.

In ruderatis, ad vias, nach den Hüufern der Kohlg rten et circa pagos vbique. Fl. Mai. Iun.

Vf. Turiones Afparagi inore praeparantur. Folia in folo pirigui culta vernali tempore fapida acetariis inferuiunt. Radix exhibetur ouibus phthifi affictis.

vibicum. 365. * Chenopodium foliis triangularihus fubdentatis, racemis confertis, frichifimis, cauli approximatis longifimis. I.INN. Sylt. p. $261, n .2$.

Stadtgañfefuf. Germ. Upright Blite. Angl. Paite d'oic des villes. Gall.

In vrbibus et pagis ad domos, in der Allee ante portam Grimmenfen et in vrbe Taucha dicta bei der Kirche mihi occurrit etc. Fl. Aug.

rubruin. 366. Chenopodium foliis cordato-triangularibus, obtufiulculis dentatis; racemis erectis compofitis, fubfoliofis, caule breuioribus. Linn. Syft. pag. 261. n. 4 . вовнм. ก. $56 \mathrm{I}$.

Pharm. Atriplicis Sylueftris Herba.

Rother Ganfefuls; Nennfpitzen; Schueintodt; Sau. balg; Miftmelde. Germ Sharp-leaved Goofe-foot. Angl. Patte d'oie raugeâtré. Gall.

Ad vias, in locis ruderatis vbique, Flor. Mai. Iun. Annua, 
Ol. Infufum aquofum cum vitriolo martis fulco tinuit colore.

36-. Chencprodium foliis ouatis, nitidis, dentatis, acu- murale.

tis; recemis ramofis, nudis. LINN. Syft. p. z6́r. 1. 5 . schreB. Spicil. p. 40. n. 964.

Mauer Gänfefus. Germ. Common Goofe font, or Sow-baze. Angl. Patte d'oie des muraillis. Gall.

In ruderatis, auf den Whalle, et circa pagos in muris.

368. Chenopodium foliis rhomboideo-triangularibus, album.

elofis, poftice integris: fummis oblongis; racemis ereatis. unN. Syft. pag. 26I. n. 7. вовнм. n. 562 . Fl. Dant. t. 553 .

Weiffer Günfefus; Scheis- f. wilke Melde. Germ. Common Orache. Angl. Patte d'oie blanche., Gall.

In agris cultis frequenter. Flor. Iun. Iul. Annua.

$V \int$. Folia vere ad olera.

369. Chenopodium foliis rhomboideis, dentato finualis; viride.

racenis ramofis fubfoliatis. LINN. Syft. p. 262 . n. 8 . BOEIM. ก. 559 .

Grïner Günefues; gemeine grïne Melde. Germ. Grecn Blite. Angl. Patte d'oie verte. Gall.

In agris fere omnibus inter fegetes atque olera frequentiflima; porro etian ad inuros ante portulam Schoenfeldicam et alibi. Fl. Iun, Iul.

$V \int$. Folia olerum loco vernali tempore inferviunt.

370. Chenopodian foliis cordatis angulato-acuminatis, hybridum. racemis ramolis nudis. $\mathrm{lN}$. Syft. pig. 262, n. 9 . ВОЕНМ. n. 560 .

Unïchter Günfefuß; Schweinemelde; breitblättrichter Pitzer; Sautodt. Germ. Maple-lcaved Blite. Angl. Patte d'oie hybri,ze. Gall.

37. Chenopodium foliis ouato-oblongis, repandis; ra glaucum. cemis nudis, fimplicibus, glomeratis. LiNN. Syft. p. 262. n. 14' ВОЕНM. n. 563 .

Eifengrauer Gifefuß; geftreckte Mclde. Germ. Oak-leaved Blize. Angl. Patte d'oie glauque. Gall.

Ad domos et fineta copiofe. F1, Iul. Aug., 
** Foliis integris.

Vuluaria, 372. Chenopodium foliis integerrimis, rhomboideoouatis; Horibus conglomeratis, axillaribus. LINN. Syft. pag. 252. n. I8. гоЕнм. n. 558. вLACKw. tab. I00.

- Pharm. Vuluariae Herba.

Stinkendor G nefefuß; Stinkinelde; kleine Miftmolde; Bocksmelde; Buhl.Schaam-Mauzenkraut; Bocks Wiihlkraut, Stunkende Hure; Fotzcnkraut. Germ. Stin'ing Orach. Angl. Patte doie fétide, on Arroche fauvage. Gall.

In ruderatis et ad fepes murosque, bei dem Weinn. pfchen; ad fepes hinter Gunndorf etc. Fl. Iul, Aug. Annua.

Obf. Hircorum odorem fpargit. Contra malum hyftericum haec laudarur in electuariis.

polyrper- $3: 3$. Chenopodiun foliis integerrimis ouatis, caule demum. cumbente, cynis dichotomis aphyllis axillaribus. LINN. Syft. p. 262 . n. 15. вовнм. n. 564 .

Vielfaamiger Gänfefuß;; Fifchmelde. Germ. Roundleaved Blite, or Allfecd. Angl. Patte d'oie graincufe. Gall.

In viis publicis vbique. Fl. Iul. Aug. Annua.

$V \int$. Efca pifcibus gratifima.

maritimum. $37+^{*}$ Chenopodiun foliis fubulatis, femicylindricis. LINN. Syft. p. 262. n. 18.

Seeftrands Ganfefuß. Germ. White Glaßwort. Angl. Blanchette. Gall.

In locis falfis ad Ketfchau, quoque bei dem Dïrrenberge paffim nuperrime inueni. Fl. lul.

I! S. BETA. L. G. 33\%. Mangold. Germ. Beet. Angl. Poirée. Gall.

vulgaris. 375 . Beta foribus congeftis. LINN. Syff. p. 262. n. I. БOEHM. n. 5 55. BLACKW. tab. 235. SCKVHR. tab. 56 , Beta foribus têrnis. IINN. Syft. p. 262. n. 2.

Vas, $\beta$ ) Radice rubra. 
Platm. Betae rubrae Herba, Radix.

Genciner Mnzgold; Sommerbeete; var. o)rothe Rïben; $\beta$ ) reciffe Ruben. Gcrm. Great red Beet. Angl. Poirée on Bette vulgaire, $\beta$ ) Poirée rouge, ou Bctte. razte. Gall!

In hortis oleraceis copiofe coluntur. Flor. acfate. Annuae.

Varietas $\alpha$ ) Calycis foliolis bafi dentatis, radicernbra $\beta$ ) Calycis foliolis bafi inermibus; radice alba, vel pallido-flaua.

In culinis radix notiffima tempore autumuali et hyberno, Elixantur videlicet radices recentes in aqua et in taleolas tranfuerfales deinde fecantur, poftea aceto, cum pauxillo aquae diluto, immittuntur. E puluere radicis ope alcoholis vini et digeftione Saccharum purifinum extraxit Marggraf.

II9. HERNIARIA. L. G. 336. Bruchkraut. Germ. Rupture - Wort. Angl.

376. Hemiaria herbacea, tota glabra, glomeratis mul- glabra, fifloris. L1NN. Syft. p. 261. БоEHM. n. 569. BLACKW.t. 529. Fl. Dart. t. 529. SCKvHR. t. 56.

Pharm. Horniariae Herba.

Glattes Bruch- f. Harnkraut; Taufendkorn. Germ. Smooth Rupiurewort. Angl.

In locis fterilicribus, arennfis, um Pfaffendorf, ouf dem Mcckerfchen Berge, auf den Willen bei der Sandgrube hinter der Scharfrichterei et alibi copioíe. Fl. Mai. Iun. Annua.

377. * Herniaria tota hirfuta, glomerulis pauciforis. hirfuta. i.Al. Hift. I. p. 256. LINN. Syft. p.261. л. 2. вовнм. n. 569. Var. Herniaria hivfluta Syn. eоerh, polt. Palat. I. ก. 24 . Rотн. Fl. Germ. II. p. 200.

Rauches Bruchkraut. Germ. Herniaire vclue. Gall.

Habitat in folis arenofis elatioribusque pafim. Fl. cum priori.

Obf. Praecedenti valde fimilis, fed caule, foribus ac foliis hirfutis, et colore magis obfcures viridi, ab illa differt, 
120. VLMVS. L. G. 345. Ulmbaum; Rüfter. Germ. Ein-Tree. Angl. Orme. Gall.

campentris. 378 . Vlmus foliis duplicato-ferratis, bafi inaequalibus, foribus fubfeffilibus, conglomeratis. WILDEN. Prodr. Berol. n. 205. LINN. Syft: p. 265. BOEIM. n. 570. cram. t. 5. Fl. Dan. t. 632. SCKveir. t. 51-n. 2.

Pharm. Dlmi Cort x.

Leimbanm; Rauchlinde; Feldulmbaum; gemeine, breitbl trrige Rüfter; fchwarze Rüfter; Fliegenbaum. Germ. Coninnon rough, or broad-leaved Elin-tree. Angl. Orme fauvage. Gall.

In fepibus, fyluis et nerribus, im Rofenthale, Univerfitätsholze, bci Gohlis, Gonnezeitz, multisque in aliis pogis. Fl- Mart. April. Arbor.

$V \int$ Folia ouibus bobusque pabulum; Cortex ra. dicis in hydrope, fcabie inueterat : humida ficcaque laudatur a Cel. Lyffons. In ambulacris arbor gratiffina. In liorwia puluis corticis a pauperibus ad panem coquendum adhibetur.

c) Flores vmbilliferi: 5- petali, fuperi, difpermi.

1) Vmbellis fomplicibus. Habitu iuperficto, deliquefente.

121. ERYNGIVM: L. G. 354. Mannstreu; Elend.

Girm. Seaholly. Angl. Panicaut. Gall.

campente. 379. Eryngium folits rndicalibus amplexicaulibus pinnato laciniatis, inuoluc is fere fubulatis capitulo longiuribus. CRANz. II. p. 229. n. 17. LINN. Syft. pag.

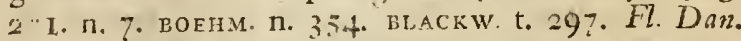
tab. 5 f. JACQ. Fl. Auftr. Vol. Il. tab. 155. sскvHR. tab. 59 .

Pha!m. Eryñgii Rad. Herba.

Fcldmannstrun; Elend-Damn-Radendiftel; BrachDonnér-Kraup-Laufilifes..Germ. Conmon Eryngo. Angl. Chadon roland; Chardon à cent tîtes, ou $P$ amicaut. Gall. 
In campeftribus ad Burkhaufen, Kleindölzig, auf dem Sandbcrge vor Nautendorf, bei Ruckmarsclorf etc. Fl. Iul.-Sept. Perennis.

$V f$. Rad. ad radices aperientes minores pertinens diuretica. Turiones vernali tempore acetariorum loco eduntur.

122. HYDROCOTYLE. L. G. 335. Waffernabel. Germ. Water - Nabel - Wort. Angl.

380. Hydrocotyle foliis peltatis, repando-crenatis, vm- vulgaris. bellis quinqueflolis. LINN. Syft. p. $2-1$ n. I. JAHN. n. 5. Rоти. Flor. Germ. pag. 135. Fl. Dall. tab. yo. SCKVHR. t. 59 .

Gemeiner Wafernabel; Venusnabel; fchildförmiges. Sumpfinabolkraut. Germ. Common Warer Nabel-zeort. Angl. Ecuelle d'eau. Gall.

In pratis $v$ dis ad alnorum radices bei Schönfeld; porro poft Gunndorj am Graben :ll. poн sws ince it. Ego quoque in alnetis, bei Schadebach, ina der Prellheide auf dem Tiefenfecr und den Tafchepliner Antheile in locis paludofis inter Alios in magna copia nuper reperi. Fl. Iun. Iul. P.rennis:

Obj. Planta valde acris; aues, hac deuorata, inflommationibus aliisque fymptomat.bus grauioribus affliguntur.

2. Vmbellis compofitis. Habitu perfecio.

A. Fructu tekto plicis, fetis aut lınugine.

123. SANICVLA. L. G. 356. Sanikel. Germ. Sanicle. Angl.

38I. Sànicula foliis radicalibus fimplicibus, flosculis Europaea. omnibus feffilibus. LiNN. Syft. pag. 272 . вовнм. n. 495. вLACKW, tab, 63, Fl. Dan. tab. 283. sскVH及. tab. 60.

Pharm. Saniculae Herba.

Euro. 
Europaifcher Sanickel; Berganickel; Traniçel; Heil aller Schaicn. Germ. Conmon Sanicle. Angl. Sanicle. Gall.

In fyluis et nemoribus vmbrofis, in Univer-fintisholze; im Linkler Holzé etc. Flor. Miai.-Iul. Perennis.

I24. ATHAMANTHA. L. G. 369. Hirfchwurz. Germ. Spignel. Angl.

Ceruaría. 382. Athamantha foliis pinnatis decuftatis incifo - angulatis, feminibus nudis, liss. Syft. $p$ 279. n. 2. вовнм. n. 7 6. JaCQ. Flor. Auft. Vol. I. t. 69.

Selinum (ceruaria) foliis cartilsgineis, infcrne appendiculatis, circum ferratis, ferris denticulatis. CRANz. II. p. 167. 11. 5. Tab. III. f. 1.

Gcmeine f. fchwarze Hirfchwurs 1", fchwoarser Enzian; Hirfchpeterlein; Hirfchheil; Bergperterfilic; Vielgut. Germ. Larger parfley-leaved Mountain Carrot. Angl.

In montofis, im Bieniz an der Wief, in agris elatioribus hinter dem Machorfcheńn Holze etc. copiofe. Fl. Iul. Aug. Perennis.

Obf. Fol. duplicato - pinnata; foliola oblonga, obtufa, 3-5-folia; dentato-ferrata; ferraturis in mucronem definentibus.

Oreofeli- 383. Athamantha foliolis diuaricatis. LINn. Syft. p. 279. num.

n. 5. JACQ. Flor. Aufr. Vol. I. t. 68. scKvir. tab. 64 .

Athamantha foliis triplicato-pinnetis : foliolis lanceolatis, trifidis integerrimis, diuaricatis. WILDEN. Prodr. Berol. n. 324 .

Selinum (Oreofelinum) foliolis coft refracta, diuaricatis, caule asquali fubnudo. cranz. p.i69. n. 6.

Pharm. Oreoselini Radix, Herba.

Gelbhirfchwurz f. kleine Bergpeterfilie; Augenueurs. Germ. Black or Broad-leaved Mountain or ftone Parfley. Angl. Perfil de montagne. Gall.

In pafcuis montolis, auf den Gickerlingsberge, im Bieniz, in hortis oleraceis. Fl. Iul. Aug. 
125. DAVCVS. L. G. 364. Vogelneit; Möhren. Germ. Carrot. Aingl. Carotte. Gall.

384. Daucus inuolucris pinnatifidis, petiolis fubtus Carota. neruofis, feminibus hilpidis. cRaNz. pag. 227 . n. 4 . LINN. Syft. p. $277 \cdot$ n. 333. ЕОЕНM. n. 496. BLACKW. t. 546. Fl. Dar. t. 723. schvir. t. 61 .

Daucus Carota inuolucro vniuerfali pinnatifido, Alosculo centrali nullo. WIgGers Primit. n. 233.

Var. $\beta$. radice fatius.

Pharm. Dauci fyltieftris Semina.

Dauci fatiui Rodix, Sernina.

Gemeine f. wilde Möhren; Mohrenkïmmel; Vogelneft. Germ. Common wild Carrot. Angl. Carotte jau. vage. Gall.

In campeftribus et pratis Schoenfeldicis. Var. $\beta$. in hortis colitur. Fl. Iul. Aug. Annua.

Obf. Rad. Dauci' Satiuae quond colorem variat, lutea vel alba. Eftapida et in Tuffi infantus, Phithifi et contra vermes fuccus recenter expreffus laukatur. Caeterum in culinis frequens ad cibos multos praeparándos adhibetur.

385. * Daucus inuolucro vniuerfali pinnatifido, floscu- mauritani-

lo centrali fterili carnofo. wilden. Prodr. Berol. n: cus. 319.

- Daucus Mauritanicus feminibus hifpidis, flosculo centrali fterili carnofe, receptàculo communi hemifphaerico. Linn. Syft. p. $277 \cdot$ ก. 2.

Caucalis carnofa вотн. Flor. Germ. I. p. IÍg. II.p. 305 .

Mauritanifche Möhren. Germ. Great Spanifh Car. rot. Angl.

In pratis Schoenfeldicis et auf den Gerberteiefen, paffim vidi. Flor. Iul. Semina maturat Augufto.

Differt a priori caule hifpidiore; innolucro vniuerfali vmbella breuiore; inuolucris partialibus tridentatis: flosculo centrali in Vinbella communi, maiore, atropurpureo, carnofo, fterili imperfęto. Rotr. 
126. Caucalis. L. G. 362. Haftdolde; Klestenkerbel. Germ. Baftard Parfley. Angl. Caucalier. Gall.,

Daucoites. 386. * Caucalis feminibus ouato-oblongis, angulis 1 dorfalibus 4-diftentibus hilpidis, foliis giabris, bafi coltaque pilofis, inuolucellis dimidiatis. Rотн. Fl. Tom. 1. p. 119. II. p. 305 .

Caucalis vmbellis trifidic, aphyllis, vmbellulis 3 fpermis, 3-phyllis. LINN. Sylt. p. 276. JACQ. Fior. Auftr. V. II. t. 157. Echinop/iora. Riv. t. 24.

Caucalis leptophylla laciniis foliorum peranguftis; feminum vncis rigidis. CRANz. Auftr. p. 225 .

Möhronartiger Klettenkerbel. Germ. Carrot-leaved baftard Parfley. Angl.

In agris elatioribus inter fegetes, copiofe in vineis ad Naumburg et in agris inter Ducum C rotam verfus Tauchanet Eulenburg frequenter reperi. Fl Iulio et Augunto.

grandifiora. 38\%* Caucalis feminibus ouatis, coftis d rfalihus approximatis quatuor; aculeis diffufis, petalis exterioribus maximis, Rотн. Flor. Germ. P. I. pag. 120. II. pag. 307.

Caucalis grandiflora inuolucris finglis pentaphyllis: foliis vnico dupio maiore. LINN. Sylt, p. 275.1 . LEYS. Hal. n. 264. JACQ. Fl. Auftr. V! 1. t. 219.

Caucalis aruentis echinata magno fore. C. B. P. p. 152.

Großblumigter Klettenkerbel. Germ. Large-flowering baftard Parfley. Angl. Caucalier ì grandes ficurs; grandi Gironille. Gall.

In agris oleraceis inter fegetes, e.g. in hortis oleraceis et agris bei Sellerhaufen, Stötteritz etc. paffim. Fl. Iul. Aug. Semina maturat Septembri.

Leptophylla 388 * Caucalis feminibus femicylindricis: angulis dorfalibus obfoletis aculeis diffufis fcabris, foliis vndique pilofis." коти 1. c. P. I. p. I20. II. p. 308

Caucalis inuolucro vniuerfali fubnullo, vmbella bifida, inuolucellis pentaphyllis. LINN. Syit. p. I $76 . \mathrm{n}$. 6. Caucalis humilis JACQ. Hort. V.2. t. 195. Caucalis procumbens, RIV, pent. t. 332. 
Caucalis aruenfis echinata paruo flore fructuque. C. b. P. p. 152 .

Kleinbläitrichter Klettenkerbel. Germ. Fine-leaved Bafard Párflez. Angl. Cazcalier à fuilles -ítrozts. Gall.

In hortis oleraceis inter olera et praprimis inter Doucum Carotam haud infrequens, Fl. Iulio et Auguito.

B. Frudu nudo, fulcato, coftato aut friato.

12\%. OENANTHE. L.. G. 382. Rebendolde. Germ. Water Dropwort. Angl.

380. Onanthe ftolonifera-foliis caulinis pinnatis, fili- fiftulorn, formibus fiftulofis. INN. Syft. pag. 285 . BOEHM. n. 494. Fl. Dan. t. 346. Riv, Pent. t. 66. Oenanthe.sckVir.t. 70 .

Röhren Rebendolde; Wafferfeinbrech; Wafer Filipendel; Driißsurs; Tropfieurz. Germ. Common water Droprevort. Angl. Ocranthé aquatique. Gall

In riuuis et folfis bei dem Gesbeneaffer; bei der Nötzfcher Mïhle; in pratis vliginolis tei Schadebach, Borsciorf etc. Fl. Iun. Iul.

\section{PÉVCEDANVM. L. G. 370. Haarfrang.}

Gorm.

390. Peucedanum foliis quinquies tripartitis, filiformi- officinale. bus, linearibus, cINN. Syft, p. $=80$. вовнм. n. 479. SCKVHR. t. 13.

Pharm. Pencedani Radix.

Geveöhlicher Hanfrong; Sanfenchel; Schueefelwur. Germ: Common Hoys Fentel. Angl: Fenonil de pore; 2ueue de punrcen. Gall.

In protis pinguicribus montofisque, nach Rafeh* witz, auf den H'iefen bei. Schleufig, Großs. et Kleina zfchocher. Fl. Iun. Iul. Perennis.

391. Pencedanum folinlis pinnatifilis; lacinis oppafr. Silaus. tis, inuolucro vniuerfali diplyylo. LIN . Syft. $\mathrm{p} 280$. 
n. 5. вовнм. n. 480. JACQ. Flor. Auftr. V, r, t, 15. RIV. A. $57^{\circ}$ 'Sefeli pratenfe.

IHefenharfromg; Roßkümmol; unîchte Bärwetrz. Germ. Meadoze Sefol.. Angl. Fonouil des près. , Gail.

In pratis auf der Pfingfueiefe; bei Schlewfig; Sommerfid; Plaufig; Sellcribufen etc. Fl. Iun. Iul. Percninis.

Obf. Caul. angulato-ftriatus. Folia lanceolata. Flores lutei, dein aisefcentes. Fruecus tribus frriis vtrinque fuleatis, tubis diuaricatis reflexis, fligmate fémen contingente.

129. CONIVM. L. G. 369. Schierling; Tollkraut: Gim. Hemlock. Angl.

naculatum. 392. Conium feminibus friacis, caule ramofifimo, maculato, glabro; foliolis pinnatifidis. LinN. Syít. p. $27 \AA$. BOEHM. n. 5 CO. BLACKW. t. 45 T. et 573 . f. a $\in$ t b. JA, . Flor. Auftr. V. 1. tab, 56. Cicuta riv. tab. 74. scrive. tab. 62. figura male exprella et coloribus picta.

Pharm. Conii f. Cicutac Terreftris f. Vulgaris. Herba.

Gefleckter großer Schierling r. Apocheher-WienerSchierling; Tïterich; Zugenlratt; Ziegundill; Vogeltodt; weilde Peterfilie; Teufels-Katzenpeterlein. Germ. Greater Hesilock or Common Loifinous Hemlock.,Angl. Grande Ciguë. Gall.

Ad fepes et in humidis locis bei den Kohlgärten, in dumetis zwifchen der. Funkenburg und der Ziegeljcheune etc. copiofe. Flor. Mai. Iun. Annua, paffim Bieunis.

Obf. Cañlis 3-5- pedalis, erectus, ramofifimus, rotundus, levirfme'fulcatus, glaber, fifulnfus, glaucoobductus halitu, maculis notatus pnipureis exiguis. Folia lerrata, radicalia valde maiora, fupradecompofita. Carlina multo minora. Petioli longi fiftulof, glabri, crafli, terete-compreffufculi, maculati. Vmolla vainerfalis irregularis, radiis $10-$ 12 , patens; particularis fimilis, radiis 10-15. Involucrim 
solucrum $3-5$ phyllum, foliolis ouato-lanceolatis; acuris, b fi coalitis, ina qualiums, reflexis. Imolucella !-2 jhyli:, patentia, faepius + - tid. Flosculi aequales, fertiles Cor. Petala alua iregulariter reflexo-cordata, irregularia. Scm. duo, fubglobofa, gibba, furcata, latiribus comprefia.

Planta valde fufpect. atque hominibus pecoribusque lethalis. Extraet in multis $\mathrm{g}^{-1}$ andulorum etc. morbis a Cel. stoenckio laudatum eft.

130. BVPLEVRVM. L. G. 25 \%. Hafenöhrchen. Germ. Hare's Ear. Angl. Oreille de Lievre. Call.

393. Buplumum foliis ouatis perfoliatis, inuolucris vniner- romndifofaibus nullis cranz. Azift.p. 202 n. 10 LINN. Sy t.

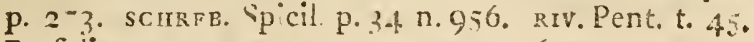
Perfilista. BLACEw. t. 95. sCKVir. t. 60.

Pharn. Perfoliati Herba, Semina.

Rundlinitriges Divicheachs; Hafcröhrchen; SchooßI'undkraut; Bruchueuris; Stopfloch G rm. Common Tharoug zuax. Angl. Percefciille; Oroille de Lieure. . Gall.

In agris inter fegetes ad Alstmanewdorf et verfus Eulcnbrerg glin Ill. sснвев. inuenit. Ego quoque in ho tis inter Olera paltim vidi. Fl. Iul. A g.

$39+$ * Bupleurun vibellis compofitis fimplicihusque, fenicompocaule ramolo, leuiter flexuofo; foliis fimplicibus, al- fitum.

ternatis, lanceolatis, $b=1$ fetula obductis.

Bupleurum foniccmpofitum. LinN. Syft. pag. 273 .

n. $\%$.

Hall zufammcngefetztes Hafenöhrlein. Getm. Spa. nifh Hare's ear. Angl.

In pratis ad Salizas Ketchanienes.

Obf. Vinbellac terminales et axillares, vnizerfales 5-6 radiis, pluribus compofitae; partiales $1-3-4$ radiis. Sim, rigida, minima.

395. * Bupleumun caule proftrato, foliis linenri-lanceo- tenuifimum latis, vmbellis fimplicibus, alternis pauciforis. вотн. Fl. Germ. P. I. p. 226 .

Bupleurum vmbellis fimplicibus, alternis, penta. phylis, fubtrifloris. LINN. SyR. p. 274, n. 12 . LEYS. n. 283.

K 2

Kilei- 
Kileines f. Jehr zarzes Hafenohrlein. Germ. Leaft Ha. re's-ear. Angl. Huplcure menu. Gall.

In locishyeme inundatis bei Belgershain, Pomfen nuperrine letexi. Fl. Iul. Aug.

Ol\%. Inuolucrum $3-5$ phylium, breue. Inuolucella capillaia, breuia. Vmbelluiae axillares, mininae.

\section{SIVM. L. G. 378. Merk. Germ. Water Parfnep. Angl. Bèrle. Gall.}

latifolium. 396. Simm folis pinnotis, foliolis acute dentatis, femiribus firiats, caule flltutofo. KNOLTE prg. 13. ก. 2.

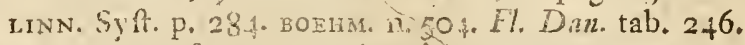
jace. Fl. Aufer. V. I. t. 6\% Gium. riv, t. $7 \%$.

Coriandium latifolim caule argute angulato, fo. liis lavis pinnatis, ferratis. Cranz. I. p. 212 . n. 5 .

Brcitblittrichter Merk; Wafferfrofcheppig; Weyher-Frefchpeterleiss; großer 'italforpafinak. Germ. Common Water Parfnep. Angl. Berle à fezilles larges.

- Gall.

In locis paludofis nach Pfaffendorf, in alneto nach Schörfeld, in riuula nach der Nötz/cher. Mïhle, et alibi vbique Fl. Iul. Aug. Perennis.

Obf. Radicem huius venenatam indolem habere, Knollius refert.

anguntifo- 397 , Sium foliis pinnatis: foliolis aequaliter argute fer. lium. ratis: impari trifido, vmbellis lateralibus oppofitifoliis. ROTH. Fl. Gèrm. p. $127^{\circ}$

Sium folis pinnatis, vmbellis axillaribus peduncu. latis, inuolucro vniuerfali pinnatifido. IINN. Syft. p. 284. n. 2. SCHRER, Spicil. p. 35. n. 505.

Schmalblättraluter Merk; Wafferpeterlein; Waffer. morelle. Germ. Common upright Water Parfnep. Angl. Berle à feuilles étroits. Gall. -

In pratis ad Abmauendorf, Schönfeld, hinter dem Bieniz maxime ibidem in forficulis copiofe etc. Fl. Iul. Aug, Perennis.

nodiforum. 398. Simm foliis pinnatis: foliolis incifo dentatis: im. pari-tripartito, vmbellis lateralibus, oppofitifolis, lefrilibus pedunculatisque. Ror H. Flor. Germ. p. 127. 
IINN. Syft. p. 284. n. 3. повнм. n. 505. Sium minus. RIV. P.nt. tab. 7 S. Apium Sium. cranz. I. pag. 215 . ก. 5

KI iner Eppich; krichender Walereppich; Wafermerk. Germ. Creeping Trater Parfinep. Angl. Berle marécayeutc. Gall.

In ruulis et paludofis, beim Bieniz. Fl. Iun. Iul. Perennis.

399. Sium foliis pinnatis: floralibus ternatis, IrNv. Sifarum. Syrt. p. 284. n. 4. гогнM. n. 503. scKVHR. t.69. Sifarum. Riy. Pent.

Sifarum germanorum. C. B P. r 55 .

Zuckereeural; Zuckerrïbcheì; Gierlcin f. Görlein; Gritzel. Germ. Skirrets. Ang-l. Cherui; Racine fucrée. Gall.

In agris et hortis oleraceis inter plantas culinas haud infreguens et paflim ibidem in cultis agris inter fegetes. Fl. Iulio et Augufto. Sem. exeunte Auguto et Septembri matura.

Radix recens et ficca continet Saccharum. In cu. linis radices recentes iusculis inçoquuntur.

400. Sium filiolis linearibus decurrentibus connatis. Falcaria. LiNN. Syf. p. 284 . ก. 8. воEHM. n. 506 . JACQ. Flor. Auftr. Vol. III. tab. 257. Falcaria riv. tab. 48. Sefeli (Falcaria).-Cranz. I: p. 208 . n.6.

Sichelformiger Merk; Sichelkrau:; Sichelmöhuren; Feld-oder Ackerbacillen; faule Grete. Germ. Pereñnial Bifhop's-ivied. Angl.

In agris et ad femitas pafim, bei Lindcran, etiam pafrim arf dem Altranftadter Kirchhofe, unc dem Brandvoreerke. Fl. Iul. Aug. Perennis.

- C. FruEtu alato; ala marginali.

132. HERACLEVM. L. G. 375. Heilkraut. Germ. Low - Parfnep. Angl. Berce. Gril.

40I. Heracleum foliolis pinnatifidis laeuibu's, floribus vniformibus. LINN. Syft. pag. 282 . воEнM. n. 474 . Sphondylium. SCKVAR, t. 67, BLACKW. t, 540. Sphondylium RIv. t. 4. 
Pharm. Brancae $V r \sqrt{2}$ 1. Sphondylii Herba.

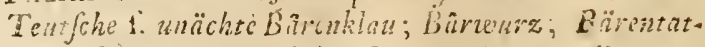
ze; Bartfch; Porft; Kelwpfinas. Germ. Common haing Cowe Parfinep; Brank Ur/ine; or Bears Brecch. Angi. Berce ou Fraufe Branc-U.fine. Gall.

In pratis et pafcuis humidioribus copiofe, e. g. in pratis Schounfelticis, ad fóficulas uei Gomacwitz, verfus Lindenau etc. Fl. Iul: Aug. Perennis.

alpinum. 402.* Híraclem foliis fimplicibus, floribus radiatis. IINN. Syft. p. 283. n. \% JAIN. n. 5.

Alpen-Heil rant. Germ. Mountain Coze-Parfyep. Angl Berce des Alpes. Call.

In pratis vdis ad Krappendorf Cel. JAHN olin invenit, milhi autem nondum occurrit. Flor. Iul, Aug.

33. TORDYUIVM. I.. G. 36i. Zirmet; Drehkraut. Cerm. Hart-Wort. Anzl. Tordile. call.

namum. 403. Tordylimm vmbellis confertis radiatis, foliolis lanceolatis incifo fematis: IINN. Syft. p. $275 \cdot$ n. 5. JAcQ. F1. Auftr. V. 2. 5. 1 , 2.

Tortislium. Riv. Pent. r.

Caucalis maxima, Sphondylii aculeato femine. C. B. P. Is.

Grojer Zirnet; großes Drch raut. Germ.

In Europae aútralis dumetis et ad vias proprie fpontanea: apud nos in hortis oleraceis aliioque palfin occurrit. Fi I un. Tul.

Anthrifus. 404. Tortylium vmbellis confertis, foliolis ouato-lanceolatis, pinnatifidis. LINN. Syft. p. 275. त. 6. CRANz. I. p. 226. 12. 3. ВОЕНM. n. 407 .

Geneiner Zirnet; Heckendrehkraut; Hec'enkerbel; Schafkerbel; Bettellïufe. Ge,rm. Red Flozered Baftard. Parfley. Angl. Caucalier äpre, ou Tordile authrlyue. Gall.

Ad fepes et in ruderaris frequens, auf den Hofpitalfeldern; ad fepes bei ter Leingrule, et in nemoribus in Rofinthale, circa paguan Gonnezvitz etc. Flor. Iun. Iul. Annua, 
134. SELINVM. I. G. 368. Oelfenich et Silge. Germ. Milky-Parfley, Angl.

40.3. Selinum corollulis explicatis, foliis onato-laticeo- fyluefire.

latis, femine oblongo, plano. Craxz. I. p. I77.n. II. Tyfelinum RIv. Pent. t. ig.

Selinum radice fufformi, multiplici, ftylis ereetis corollis explicatis. IINN. Sytt. p. 278. вовнм. n. 47\% KNOLLE D. 14. 1. 2. BLACKW. t. 556́. JACC. Fl. Aufti. V. 2. t. 1,2. SскVнR. t. 63.

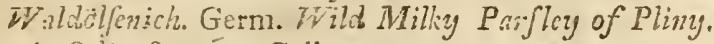
Angl, Seline fouvrige. Gall.

In pratis hunidis vmbrolis, himter Schönfeld; in Rofenthale; in der Preillueide etc. Flo:. Iun. Iul, Percrnis.

Obf. scxvirr reßte monet, differentian hnitrs fpeciei et fublequentis a rajicibus non efe fumencam. Pluries cnm hasc et fequentem reperimulipicimo. do diuifan in fibrillulas.

Succus lactefcens e radice eft acertimus. Cs et fuu es hoc inflammantur.

4c6. Selinmm caule laeui, fubiaßefcente, radice vnica, paluftc. foliis quadruplicato - pinnatis linearibus. wiz D. Prodr. Berol. n. 321. kNoll. p. 14. n. I.

Selinum fublafefcens, radice vnica. Lins. Syft. p. 278. n. 2. вOEHM. n. 478. CRANz. I. pag. 172. n. 8. Tab. 10. f. s. Fl. Dan. t. 25\%. Ty frelinum angutifol. RIV. t. 20.

Pharm. Rad. Oclsnitii f. Tylfelini.

Sumpfolfenich; Alftuch; 'reilder Eppich; MIilchpeterling. Germ. Marfh Milky Parfley. Angl. Perfil. des marais, ou Perfil laitenx. Gall.

In alnetis et locis paludonis ad Schönfeld, an dem Gerberwaffer et alibi. Fl. Iun. Iul.

Obf. Foliis multo angufti ribus a priori differt.

Vf. Lappones Tabaco deficiente radicem mafticare foient. IINiv.

$40 \%$. Selinum caule fuicato acutangulo, inuolucro vni- Caruifoliun verfali caduco, pififtellis fruZuis reflexis. CRANz. Auftr. Ginelini. I1. p. 126. ก. 5. LIN⿴囗 SyR. p. 2-8. ก. 4. воEHM. ก: 4.3. GMEL. Sibir. I. p. 204. T. 48. F\%. Dan. t. 667. $\mathrm{K}$ JAC $\Omega \cdot$, 
JACQ. Flor. Auftr, tab. 16. Angelica tenuifolia Rrv. Pent.

Selinnm caule fulcato, acutangulo, fo!iis triplicato pinuatis; pinnis latiufculis, fimplicibus trifidisque; foliolis apice mucronatis. WhDEN. Prodr. Berol, n. 322.

Karuenblättrichter Oelfenirh; Rofifenchel; Kümmelfige; fonblattrige Engeluurz; Wieferölsnich. Germ. Carazeay-liaved Mil y Parfley. Angl. Selina à feuilles de Cherwz. Gall.

In pratis et fyluis humidis im Z fchocherfehen Holze. Fl. Iun hul. Pesennis. tis.

Obf. Scm. comprefto - plana, trifulcata; fulcis ala-

135. LASERPITIVM. L. G. 374. Laferkraut. Girm. Lafer - wort. Angl, Lafer. Gall.

felinoides, 408. Laferpitium foliolis pinnatifidis connatis: laciniis fuboppolitis neruis petiolisque hifpidis. CRANz. I. p. 182. ก. 3 sснRed. Spicil. p. 35. n. 498. (fub Laferpitio prutenico).

Laferpitiun prutenicum foliis lanceolatis integerrimis; exrinis coalitis. LINN. Syft. pag. 281 . n. 7. вотнд. n. 498 . J廵. Fl. Auftr. V. 2. t. 153. Laferpitium minus. Rrv. t. 23.

Preuffifhes Laferiraut; Hein-klebrige f. kleine Hirfclueurz; falfche Molurribe. Germ. Daucoide La. fer-wort. Angl Lafer de Prufje Gall.

In nemoribus fubhumidis, im Bicniz, et in prato hinter dew Bieniz, in Oberholze, in pratis inter Ocltfchau et Kemliz frequentiffme, et in iisdem locis bei Iriphione et Schadebach. Fl. Iul. Aug.

136. ANGELICA. L. G. 379. Angelick; Bruft f. Engelwurz. Germ. Angelique. Gall.

sylueftris. 409. Angelica foliolis aequalihus ouatn-lanceolatis, ferratis LINN. Syft. p. 284. вовнм, n. 472. sCKYHR. tab. 68. RIY. Pent. Angelica t. 17 . 
Pharm. Angelicae fyliceffris Radix.

Wold-Brufteura; wilde Angclick; Wicfen - WaldIraffer zei de Engelueva; wilde Luftururz; Heiligegeiftwar. Germ. Wild Angelica. Angl Angelique fouvage; Herhe à Geraird; Pied de Chêrre. Gall.

In pratis humidis ad Eutrit/ch, bei den Gerberwaffer, neben dem Poetcngange, in fofficuli pratornm et in Alnetis bei Borsdorf. Fl. Iul. Aug. Perennis, etc.

3. Inuolucris partialibus; nullo vninerfali.

137. CORIANDRVM. L. G. 386. Coriander. Germ. Coriandre. uall.

410. Coriandrum fructibus globofis. unN. Syf. pag. fatiuum. 28 - sckver. t. 7 . Coriandrum riv. Pent.

Coriandrum maius. C. B. P. 158.

Phatm. Coriandri Semina.

remeiner Coriander; sahner Coriander; Schwindel örner; Wanzenslill. Germ. ( reater or cultivated Coriandrr. Angl. Coriandre cultuvé. Gall.

In hortis oleraceis aliisque frequenter occurrit; paffim quoque in finctis et ruderatis. Flor. Aefiate.

VS. Panem confeturi, Ruricolae Sieciae, huius femina paftac crebro immifeere folent. BERG.

138. AETHVSA. L. G. 385. Gleifs. Germ. Fool's Parfley. Angl.

4II. Aethufa caule diftorto, inuolucellis dimidiatis, Cynapium. pendulis. CrANz. I. p. 21 I. n. 3. (fub Coriandro).

Acthufa foliis pinnatis, foliolis profunde laciniatis, planis, laete-virefcentibus, ferninibus fubrotundis, friatis, caule g;abro, viridi, ramofo. KNOLLE p. 1 I. Aethufa foliis conformibus. LinN. Sylt. pag 246 . воEHM. n. 5Ó1. BLACKW. t. 51\%. SCKVHR. t. 72. CYnapium. RIv. t. 76 .

Gartengleis; kleiner Schierling; Hundspeterlein; tolle Peterfilic. Germ. Leffer Hemlock, or Fools ParfFlez̧. Angl. Petite Cigué. Gall.

K 5

In 
In cultis et agris oleraceis inter Apium Petrofeli. man frequens; ad fepes hortorum et in dumetis parfim. Fl. Mai, Iun. Annua.

Planta venenata hominibus lethalis. Saepius in culinis Apii petrofelini loco folia huius imprudenter adhibentur. Anferes etiam necat.

Olf. Difinguitur ab Apio petrofelino; caule ad radicem fufco, foribus albis, calyce reflexo barbatoque et odore alliaceo.

139. SCANDIX. L. G. 387. Kerbel. Germ. Shephereds Needle. Angl.

odorata, 4T2. Scandix feminibus fulcatis angulatis. LiNN. Syft, pag. 206. n. I. JACC. Flor. Auítr. V. 5. app. tab. 37.

Myrrhis maior, Cicutaria odorata. C. B. P. r6́o.

Pharm. Cerffolii Hifpanici Herba.

Wohlviechender Terbol; finanifcher, fchweizer, zoclJcher, Mumhenkerbel, Anishcrbel. Germ. Szecet Cicely. Angl. Cerfizil mafqué. Gall.

In Italia, Auftria et Heluetia fponte crefeit, in nofratibus hortis copiofe reperitur. Fl. Iun. Iul.

Folia apud nos insculis incoquntur. Semina recentia difocta oleribus admifta bene fapidum praebent cibum.

PectenVere- 113. Scandix foliis omnibus tenuinme diulfis, femine ris., roftrato longifimo. Bonga. n. 48\%. Lind. Syft. pag. 287. n. 2. CRANz. I. pag. 189. (fub Claneropizyllo). Fl. D,an tab. 84t. JACQ. Flor. Anltr. V. 4. tab. 263. Scandix. RIV. t. 37 .

Nadel-f. Hechelkerhel; Hechelkanm; Hirtennadel; Schnabl ratu; Schnabinohren; Venusfiel. Germ. Common Shepherd's Neelle; Venus's Comb. Price. nelde: Storksbile. Angl. Grandent; Aiguille de Berger, ou peigne de Vonus. Gall.

In agris inter fegetes nach den Straßenhâufern żu, copiole et alibi. Fi. Mai. Iun. Annua.

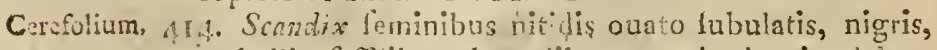
vmbellis feflibus lateralibus, caule laeti, glabro. _ IINN. Syft, p. 231 . n. 3. CRANiz. I. p. 191. n. के liub 
Chaeroplujll.) военм. n. 49?. вLACKw. t. 236, jace. Flor autr. V. 4. t. 3yo. sesvaro, t. 73. Cerefolium, riv. Peat.

Gurenkerlel; gemein Kerlel raut. Germ. Common, o:- arein Cizeruil. Angl. Cerf́euil commun. Gall.

In agris et hortis oleraceis, in demboctengangc et ad epes hortorum oleracentum, in pomaris, interdum tp nnte crefcit. Fl. Mai. Fun.

Vf. Folia efculenta cocta in iusculis ; porro qnoque ad panatelias placentasque fapidiores gratioresque reddend.s adhibentur.

425. Scandi: f:ninibus ountis hifpidis, corollis vaifor- Anthrifus. mibus, cau'e laeui. IINN. Syf. p. 287 . n. 4. EOrEM. n. 493 . JAce. Flor. Auftr. V. 2. t. 154. Fl. Dan. t. \$63. Cauculis folit Chaerefolii. RIV. t. 34 .

Blctien'erlel, Efelskerbel, Efclspeterfilic. Germ. Rough-Seeded, zeild Chervil. Ingl. Scandix horiffé. Gall.

In pagis Schönfeld, Sellerhaufen, Siötteritz ad fepes et in omnibus fere pargis fparfim. Fl. Mai. Iun. Annua.

ObJ. Inuolucrum faepius I - phylium, paftim vero $3 \frac{5}{5}$ phyllum. - Inuolucella femper 5- phylla: foilolis lanceolatis, acuminatis, ciliis longiffmis obfitis. Semina ouat:, hípida.

140. CHAEROPHYLLVM. L. G. 388. Kälberkropf

f. Kern. Germ. Wild Chervil. Angl. Cerfeuil. Gall.

416. Chaerophylln!m caule laeui, ftriato, geniculis tu-fylueftre, midiulculis, feminibus laetibus, non ftriatis; nigris. IINN. Syft. p. 289. CRANZ. I. P. Iy2. n. 5. BOEHM. n. -19I. JACQ. Fl. Auftr. V. 2. t. 149. scrvir. t. 73 . Cerefo:ium fylueftre. Rrv. Pent. t. 44 .

Pharm. Cicutariae Hierba:

if aldkälberkropf; wildcr Kerbel; Tollkerbel; Schere; Bujchmöhren. Germ. Shmnoth-feeded Chervil, or Wild Cecely; Cowneed. Angl. Corfenil fauvage. Gail.

In pratis humidis et fyluaticis im Rofenthale fre." quenter, aliisque in fyluis: etiam in der. Leingrube pafrim. Fl. Mai. Iun. Annua,

Planta 
Planta valde fufpecta; vbi crefcit, folum fertile et foecundum isdicnt.

VJ. Luteo et viride colore tingit. LINN.

bulbofum, 4i7. Caerophyllum caule lacui; geniculis tumido, bân hirto; feminibus hirtis, biariftatis; radice bulbofa, carnofa. LINN. Sylt. p. 288. n. 2. CRANz. I. p. ISq. n. 7. вовнм. n. 289. JACQ. Fl. Auftr. V. I. t. 63. Myrr. his foetens. RIV. Pent t. 50.

Zwiebelartiger f. knollichter Käiberkropf; Erdcafanie; Rübenkerbel; Peperle; Peperlein; Pimperlinpimp. Germ. Kinotty Chervil; or Touberous Myrrh. Angl. Cerfouil bulbeux. Gal!.

Ad fepes fere vbique.' Fl. Mai.-Iul.

Obf. Radices in nonnullis regionibus comeduntur. Clufius autem ob dolores crpitum, quos inducunt, effe venatas putat. Pharmacopoei Crnii macnlati loco, hanc hibbam ignorantiae caufa ad extractum cumponendum adhibent.

temulun. 4I 8. Chaerophyllwn caule maculato, fabro; geniculis tumidis, vmbellis floridis, declinatis. CRANz, I. pag. 190. n. 3. IINN. Syft. p. 288 . n. 4. воEнM. n. 488. JACQ. Flor. Auftr. V. 1. tab. 65. Myrrhis. Riv. Yent. t. $49^{\circ}$.

Scandix temula. wigg. Primit. n. 236.

Schieindelkalberkropf; beraufchender Kälberkern; Tammolkerbel. Germ. Spottea zeild Chervil. Angl. Cerfeuil penché. Gall.

Ad fepes et in dumetig, locis vmbrofis et humidis; e. g-hiniter dan Kohlgârten. vor dem Poetengange etc. copiofe. Fl. Mai. Iun. Pérennis.

Obj. Caulishirfutus, teres, fulcatus, ramofifimus. Folia radícalia compofita, pinnatifida; laciniis latioribus integris; caulina minus compolita; laciniis tenuioribus, paucioribus, pafim dentatis, faepius integris. Sem. 8 - fulcata, glabra.

Planta venenata.

hirfutum.-4Ic. Chacrophyllum caule aequali; foliolis incifis, acutis; frudibus biarifaris. LINN. Syft. pag. $28 \%$ - n. 5 . CRANz. 1. pag, 19\% n. 6. kOEHM, n 490. JACQ. Flor. $\therefore$ siuftr. 
Autr. V. 2. t. I 48 . Myrrhis paluftris. RIv. tah. $5 \mathrm{I}$. bona.

Zottichter raucher Kälberkropf; Bergkerbel; Bergfihierling; Croßuedendiunk. Germ. Hainy wild Chervil. Angl.

In nemoribus ad riuulos et folfas in Rofenthale frequens; in Zfchocherfchen, Gonneveitzer Holze; in dumetis copiofe etc. Flor, Mai. Iun Perennis.

420. Chaerophyllum caule aequali, foliois incifis, femi- aureum.

nibus colorotis, fulcatis muticis, linN. Syft. p. 288 .

n. 8. JACQ. Fl. Auftr. V. I t. 64 -

Myrrhis minor. C. B. P. 160 .

GolxgelberKälberkern S.Kälberkropf. Germ. Gold - co. loured-feeded Clzervil. Angl. Cerfeuil. doré. Gall. In hortis oleraceis inter Scandicem Cerefolium immixta haud infrequenter reperitur; paffin vero in ruderatis et reiectamentis hortorum occurrit. Fl. Maioe Iunin.

Pianta tota aromatico gaudet odore $\epsilon$ pabulum pecoribus falutare.

141. PHELLANDRIVM. I. G. 393. Peerfat; Pferdefaamen; Würzerling. Cerm. Hemlock. Angl.

421. Phellandrium foliorum ramificationibus diuarica-aquaticum. tis. LINN. Sy R. p. 296. CRANz. I. p. 200. n. 6. Liguficum phellandrium, EOEHM. 11. 507. BLACKW. tab. 570. scrvHR. t. 71. Phellandrium. RIV. t. 64.

Pharm. Phellandrii Semina.

Wafjerpeêfaat; Sanmeikraut; IVaffer-Roß-Fenclicl; Wützerling. Germ. Water Hemlock. Angl. Phellandrie aquatique; Fenouil d'eau; Cıguë d'eau. Gall.

In foffis et paluftribus fere vbique. Fl. Iul. Aug. Perennis.

Pabulum bobus egregium, equis vero lethale et paraplegiam efficit LINN. In variis morbis Semina laudantur. 
I4ุ2. SESELI. L. G. 39̣o. Sefel; Bergfunchel. Germ.

faxifragum. 422. Sefeli caule filiformi diuaricato, foliis duplicato ternatis linearibus, vmbellis fubfexfid"s. InNw. Sylt. p. 259. n. 10. вовнм. n. 486 . Pimpinella tenuitolia. RIV. t. 83. bene.

Stcinbrechjefol. Germ. Saxifrage Sefeli. Angl.

in collibus apricis, ad templiun $S t$. Theche. Flor. Iul. Aug. Aninua.

143. CICVTA. L. G. 38.4. Wïterich. Germ. WaterHemlock. Angl. Cicutaire. Gall.

virofa. 423. Cicuta vmbellis oppofitifoliis, petiolis marginatis, obtufis. LINN. Syßt. p. 286. воEHM. n. 502. вLACK $w$.

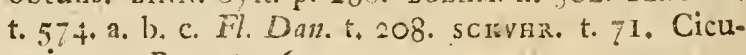
taria. Riv. Pent. t. 76.

- Pharn. Cicutae aquaticae Herba.

Giftiger Wüterich; Scherte; Wafferfchierling; Parzenkraut. Germ. Long-leaved Water-Hemlock. Angl. Cicutaire aquatique. Gall.

In paludolis et ad fuuiorum ripas, an den Gräben rach Schönfild et alibi. Fl. Iun. Iul Pernnis.

Planta fumme venenata hominibus et bobus, lethalis: caoris conira falutaris et gratus eft cibus, vt Lucretius ait. Wepferts in trost fuo funefa hominum, qui hanc guftarunt, exempla commemorat.

4. Inuolucris nullis.

I44. PASTINACA. L. G 392. Paftinak. Germ. Púrfncp. Angl. Parnis. Gall.

fatiua, 424. Pafinaca foliis pinnotis, lanceolatis, bafi femitrilobis. CRAivz. Fofe. III. p. 161. n. 2. Selinum Paftinaca offic.

Paftinaca foliis finmpliciter pinnatis. LrvN. Syft. p.

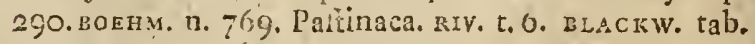
374. sckvir t. 76. 
Paftinacn fatius a) foliis fimplicite' pinnatis, cuatis, dentato ferratis, bain tri-vel faltem temi - 3-lobis.

lanceolatis, integris.

B) foliis oppofío pinnatis; pinnis

Pharm. Paftinacas Radix, Semina.

Gcmeiner Paftinak; wilde, weiffe Möhren; HirchHaninelsmöhren; Balftcrnaken. Germ. Wild Parfnep. Angl. Panais, ou Paftcrude. Gall.

In pratis copiofe auf den Girberwiefen etc. In collibus circa vrbem; in propugnaculo inter Portam St. Petri et Grimnenfom; in dem ausgefüllien Graben vor dcn hallijchers Thore and Pförtchen. etc. Flor. Iul. Ang.

Obf. Cantis 5-pedalis, ramofus, fulcarus, hirfutus aut glaber. Vaginulae 2, femiamplexicaules, hirfutulae, apicem verfus femialatae, acuminatae. Folia caulina magis impari pinnatifido-laciniata; laciniis 5, oustis et pafim lanceolatis, vel vno latere, vel duo. bus ferratis, vel integris; radicaliu ouata, difincte pinnata, dentato-ferrata, bafi trilobata; lobis inaequalibus, adeo vi vno latere longior ancecedat. Involucrum vniuerfale et partiale, nulla.

Radix fatiua in hortis colitur. Rad. per fe costam, aut cum aceto rleoque conditam remedium effe antifebrile putat Geoffroy:

425.* Paftinaca foliis pinnatis: foliolis bafi antica exci- Opopanax.

fis. LINN. Sylt. p. 200 . 11. 3.

Panax Paftinacae foliis. Morif. Hift. 3 , f.9. tab. I7. fig. 2 .

Pharm. Opopanacis Gummi.

Guwmipafinack; Panaxgummi.Germ.

Sponte crefcit in Europa auftrali, e. g. in Italia, Sicilia, Gallia etc. apud nos in hortis oleraceis aliisque colitur.

I45. ANETHVM. L. G. 394. Dill, Germ. Dill. Angl. Anet. Gall.

426. Anethum fiuctibus compreffis. LIN Syst. p. 290. graueolens. BOEHM. 几. 47 Q. SCKVHR. t. 77 .

Pharm, 
Phorm. Anethi Herba, Flores Semina.

Gemeine Dill; Till; riechendes Dillivaut; Hoch. kraut; Kïnmerlngshratit. Germ. Common Dill; Garden-Dill. Angl. Anet; Anctte à odeur forte. Gall.

In agris oleraceis, paffm fponte crefcit, praecipue autém colirur. Flor. Iul. Aug. Annua.

Vf. Herba culinaris ad cucumeres, cafeos et olera condienda, vtilis.

Foeniculum $427 .^{*}$ Anethum fructibus ouatis. IIN Syft. p. 29r. n. 3. BLACKw. t. $2 \times$ s. Foeniculum Riv. Pent.

Phorsn Feniculi dulcis Rad.'Herb. Semina.

Fenchel; gemoiner Fenchel. Germ. Common Fennel. Angl. Fenoull conmun. Gill.

In Europa auftrali, praeprimis in Hijpania et Germania, fpónte naficitur.

In noftratibus sutem reginnibus inter olera pafim occurrit: maxime autem in hortis oleraceis aliisque fuburbanis colitur. Fl. Iul. Aug.

Apud nos femina duntaxat cullinaria funt.

\section{CARVM. L., G. 395. Karve 1. Kümmel. Germ.} Caraways, Angl. Carvi. Gall.

Carui. 428. Carum pinnis coniugatis, pinnis circa coftam fefe decufiantibus. cranz. Fafc. III. p. 218. Apium Carvi. LINN. Sylt. pag. 291. воEHM. n. 482 JACQ. Flor. Auft. V. to t. 393. sckvir. t. 77 . Carum. Riv. Pent.

Pharm. Carui Semina.

Gememer - Feld - IVicfen-Speifekümmel; Mattenkïminel; Fifchkarve; Garbe. Germ. Cararesys. Angl. Cunin des près. Gall.

In pratis et campis, auf den Rofenthaler et Leut. fcher Wiefen, auf der Pfurrwicfe bei Kriphäne ctc, et in hortorum pratis. Fl. Mai. Iun Annua.

Vf. Radices pro Paftinacae radicibus comedi porfunt. Folia tenclla iusculis incoquuntur. Semina carminatiua in Colics flatulenta vtili=. Capterum Semina frequenter in Lufatia inferiori praeprimis in fpiritus 
fpiritus frumenti deftillatione adhibentur et pani acidiufculo haec addere conf́ueti.

I47. PIMPINELLA. L. G. 396. Bibernel. Germ. Burnet Saxifraye. Angl. Boucage. Gall.

429. Pimpinella caule friato, glabro; foliis pinnatis, Saxifraga. glabris; mdicalihus foliolis fubrotundis, argute dentatis; caulinis bipinnatis, linearibus wilden. Prodr. Berol. n 3 ?

Pimpinclla foliis pinnatis: foliolis radicalibus fubrotandis; fummis linearibus. LINN. Syft. pag. $22 \mathrm{I}$. KERN. p. 101. t. 172. SCKVHR. t. 78. Pimpinella RIV. Pent. t. 70. вовнм. n. 483 . Var.

Pharm. Pimpinellae Nofiratis f. Albae Rad. Herba, Semina.

Kleine ueeifie Bibernell; Pfefferzenrzel; Bóckspeterlein; teutfche Theriakzour xifrage. Angl. Petite Bouquetine; petite Pimprenelle; oul Boucage. Gall.

In collibus apricis, arenofis, pafcuis, vulgaris. Fl Iul. Aug.

430. Pimpinella foliis inferioribus fimpliciter pinnatis, magna. latis lubcordatis, auriculatis; fuperioribus fub-bipinnatis. RETz. Falc. III. Obf. Bot. pag. 29. no 45. var. $\beta$.

Pimpinella magna foliolis omnibus lobatis, impari triiobo. LiNn. Syft. pag. 291 n. 2. вовим. n. $4 \times 3$. Jace. Flor. Auftr. V. 4. t. 396. Pimpinella flore rubro. Riv. Cl. pent. irr, t. So.

Grofe, zeeiffe Bilemell. Germ. Great Burnet Saxi frage. Aagl. Grande Bonquetine; Boucage majeure. Gall.

In pratis nemorofis, humidiufeulis hinter dem Bravdrorwerke auf den Wege nach Großzschocher et alibi. Fl. Iun. Inl.

43 * Pimpinella foliis omnibus pinnatis; foliolis radi- media. calibus fubcordatis, fobtrilobis; ferratis: caulinis incifo angulatis." RETZ. Fafe. III. Obl. Bot. p. 30 var. 8. Pimpinella pinnis fubrotundis circumferratis. вов НМ. П. $48 \mathrm{I}$. 
Pinpinella nicdia. Riv. 1. cit. tab. 81. male.

Pimpinella faxifraga. BLACEw. Tab. 472 .

Mittel Bibcracll. Germ.

In locis ficcioribus, arenofis nach Schönfeld ad remplum St. Theclae verfus Taucham ctc. F1, Iun. Iul.

ininoi. 432. Pimpinclla foliis radicalibus fubrotundis, caulinis linearibus. Retz. Fic. IIl. Obferv. Bot. p. 30. var, $\varepsilon_{\text {. }}$ Pimpinella pinnis laciniatis, fuperioribus tenuifimis. вовнм. n. 485 . Fl. Dan. t. $66 \%$

Pimpinella Saxifraga minor crifpa. Morif. Vmb. tab. 5 .

Pimpinclla nigra. wis D. Prodr. Berol, n. 348 .

Pharm. Pimpinellac nigrae Radix.

Schuarze 1. kraufpe Bibernell. Ge:m. Boucage noire. Gall.

In locis gramine tenui ve@titis, nach den Kohlgarten $z u$; porro bei dcm Pulverthurme et fere vbique. Fl. Iun. Iul.

Tabernarios et deftillatores Francofurtenfes hac radice vit ad vitae aquam coeruleo tingendam colore, Hurnifch refert.

148. APIVM. L. G. 397. Eppich R. Peterlein. Germ. Smallage, or Parfley. Angl. Ache Perfil. Gall.

graueolens. 433. Apium foliis caulinis cuneiformibus, vmbellis ferfilibus. LINN. Syft. pag. 292. n. 2. вовHM. n. 509. Blackw. t. 443. Fl. Daiz. tab. 790. sckvilk, tab. 78 . Apiuin. kiv. Pent.

Pharm. Apii Rad. Herba, Semina.

Stinhender-Eppich; Walfereppich; Waffermorellen; Schellern; Hepfen; farriciechender Häpfen; ir alferpetcrlein; wilder Selierie. Germ. Common Snallage. Angl. Ache; Celeri. Gall.

In paludofis parfim; in fofficulis ad Ketfchau bei den Gradierh.ujcrn copiofe. Flor. Iul. Aug. Perennis.

Rad. fylueftris venenatam indolem habens. Equi hanc respunt. Rad. fatiua fic dicta Zellerie, in hor- 
tis olemceis priuatisque, frequenter colitur, et bene fapida.

434. Azium foliis caulinis linearibus, inuolucellis $\mathrm{mi}$ - Patrofelie: nut:s. Livis. Syft. prg. 292. n. I. eozhm. n. 508. num. CRanz. Auft. Fafc. III. p.215. Apium fatiuum. Riv. Pent.

Phrm Pctrofelini Radix, Herbn, Semina.

Peterlein; gineine Pcterfilie; Peterling; Petcrfilieneurzel; Gazancppich. Germ. Common Parfley. Angl. Perfil commun. Gall.

In agris et hortis oleraceis valde frequens: $p$ firm quoque in propugnaculo Grimmenja auf der Mauer reperi. Fl. Aeltate.

V. In culinis radices recentes carnium iusculis in coquuntur. Infuper Petrofelino condiuntur pifces, olcro, carnes.etc. Auiculis eft yenenum, vt BERGivs plurimique obferuarunt.

I 49. AEGOPODIVM. ' ¿. G. 398. Strenzel; Gurifch. Germ. Afh - weed. Angl.

435. Aegopodium foliis caulinis fummis, ternatis. Poengratia. LiN N. SyR. p. 292. вовim. n. 47z. Fl. Dan. t. 0;0. SCIVAR. t. 7\%. Podigraria. RIv. t. 46.

Liguficun Podagraria, 1adice repente. Cranz. Fafc. III. p $200^{\circ}$

Aegopodinm folis inferioribus biternat's, fefili: bus; cauinis fupericribus ternatis, Necker. gallob. p. 152.

Gemeiner Strensel; Zipporieinkraut; Geisfuß; Gerfch; Urifch; Zicgentraut: klcine faljche Argelik. Germ. Gout-wort; weild Mafter-wort; wild dugcli. $c a$, or Herb à Gerard. Angl. Pied de chêure; Petite Angélizise. Gall.

In locis fubbumidis et nemorofis, im Poetcitgange, ad foras nach Schönfeld; in dumecis et in fere omni: bus nemoribus, et quoque in multis hortis frequen: ter. Fi. Mai. Iun.

VS Pabulum pecoribus egregium, Vernali tempore folia in olere coliiguntur. 
$16+$

CLASSIS V.

\section{T R I G Y N I A. \\ 3) Flores Superi.}

150. VIBVRNVMriL. G. 400. Meh'-f. Schlingbaum, Schwolken. Germ. Marfh-Flder. Angl. Viorne;

Obier. Gall.

Opulus. 136. Vibumim folis lobatis, petiolis glandulofis. LINN. Jyft. p. 294. ก. 4 BOEHM. n. 58. SERT. Lipl. n. 10\%. Fl.' Dan. t. 66 I. scKvHR. t. 8 !

Var. B) Viburnum Opulus rofeum. IINN, var. $\beta$.

Sambucus aquatica, flore globolo pleno. C. B. P. 456 .

Sunpf-Hirgh-Rofen-Waferholder; Sehnee'allenbaum; Droflelberen; wilde Gelderrofe; Baumrofe; Kalinthen;"Kalinesz; Kalinkenbaum; Galinen; Kalinkenholz; Gimpelholz; Kaninchenheere; Kalkbcerenbauni; Waldholunder; Gänfe. Wafjerflicder. Var. $\beta$ ) Ballrofen. Germ. Marfl-Elder. B) Gueldr-Rofe. Angl. Viome Obier; $\beta$ ) Rofe de (ueldres; Obier fte. rile; Pelote de Neige; Caillebot. Gail.

In fyluis humidioribus, in Rofenthale; im Univerfitâtsholze; ad margines nemorum, e: g; hinter der-großen Funkenburg ad Plifam copiole; in fepibus, dumetis vbique et in pratis Schocufeldicis, nich weit von der Bahre. Var. $\beta$ ) in hortis vbique et in Serto etc. Fl. Mai. Iun. Baccas maturat Septembri. Frut.

Vf. Baccas Ruffi et Poloni edere folent. Linnum pro pećtinibus textorum inferuit. Eramis durioribus Tabaci fiftulae confici poffunt.

15I. SAMBVCVS. L. G. 402. Hollunder; Flieder, Germ. Elder. Angl. Sureau. Gall.

Ebulus. 43\%. Sambucus cymis tripartitis ; Aipulis foliaceis, cauie herbaceo. Liñ. Syt. pag. 295. вбEнм. n. 60. SERT. Lipf, n. 90. BLACIKW. tab. 488 . M1LL, tab. 226. sCKVHR. t. 83 . bene. 
Pharm. Ebuli Radix, Cortex internus, Folia, Flores, Baccae, Semina.

Attich; Zwerg 1. Niederhollinder; Kraut-1. Sommorho'der; Acker-Feld-rother Holder; Hirfchfchwansol Germ. Common Dwarf-Eldur; Waluert, or Danezerort. Angl. Sureau Hichle ou Yéble; petit Sureaus. Gall.

Ad ripas Pliffae poft hortum IVinklerianun; Trierianum; Fregianum etc. ad fepes bci den Peterfchiefsgraben; ad riuulam zuach der Nötzfcher Millule zu; porro circa pagos Tzfchepline, Wölkau; Nauendorf bei der Knmmerei, hei Machem cic. et in multis hortis fuburbanis paganisque. Fl. Iul. Frut.

$V \int$. Decotum Corticis amarum haufum vomitum fortem cam alui purgatione facit. Folia horreis inmilia mures pellere feruntur. Baccae cum aceto et alumine cocruleo tingunt colore fila lintea et coria. Scmina in aqua macerata Otam dant exprefium. Berg. Infuper quoque in Podagra er Ifchiade laudantur.

438. Sambucus cymis quinquepartitis, foliis pinnatis, nigra.

foliolis fulcatis, ferratis, caule arboreo. LINN. Syft. p. 295. n. 4. BOEHM. n. 59. BLACKiw. t. I5 I. DVHAM. Arbr. II. p. 253. t. 65. Cram, tab. 32. Fl. Dan. tab. 345 .

Pharm. Sambuci, Cortex interior, Folia, Flores, Baccae, Samina.

Geneiner f. fchrearzer Hollunderbaun; Fliederbaum; Flieder;.Schibiicn; Holderbaum; Holderfranch; Kesken; Alinornbaunz; Schetcliken. Germ. Comunon Elder-tree; Black-berried Elder. Ang!. Sureau conmun; Sureau à fruit noir. Gail.

in fyluis et nemoribus, im Rofenthale paffim, in Querceto verfus Altranft.dt copiofe, in Sylua Academita aliisque fyluis; indumetis fere vbique; in hortis et ad corum fepes valde frequens.- Fl. Mai. Iun. Baccae Septembri inaturefcunt. Arbor.

Vmbra huius Arboris eft fufpeta et hominibus obnoxis. Flores exficcati vfitatinmi fub forma Theae in varis morbis exanthematicis bibuntur. Baccae recentes, quae gallinas necant, addito faccharo, cum vel fine aromatibus lege artis fermentatae 
Vinum praebent naufeofum Berg. Cum baccis quoque vina rubro-fanguineo tinguntur colore. Lignum durm et fiamm bucci loco tornatores feligunt. $\mathrm{H}$ ec arbor valde vtilis hyeme proeterlapho geticidio valde infeftata $e f$ in nctratibus $r$ gionibus.

laciniats. 43\%. * Sambucus cymis 5 - partitis, foliis bipinnatis; pinnis ternatis, foliolis lancelatis, incifis, caule arboreo. RETz. Obf. Bot. Fafic. III. p. 3O. LINN. Syft. p. 29 h. n. 5. SERT. Lipf. n. $9 x$.

Sambucus laciniata. Mrl. DiEt.

Petcrfilionbl trichter Hollunder. Germ. Parcliy= leaved Elder. Angl. Surcau ì fouilles lacintées, ou de Perfile. Gall.

In dumetis fed raro, e. g. poft pagum Stötteritz prope hortum if cifinum vnicum reperi fpecimen; porro qunque frequentior occurrit in hortis plurimis fuburbanis etc. Fl. Iunio.

\section{b) Flores inferi.}

I52. * RHVS. L. G. 399. Sumach. Germ. Sumach. Angl. Sumac. Gall.

Coriaria, 440. * Rhus foliis pinnatis, elliptico-oualibus, obtufe ferratis, fubtus pilofis.

Rhus Coriaria foliis pinnatis, obtufiuscule ferratis oualibus, fubtus villofis. LINN. Syft. pag. 292. BLACKW. t. DVHAM. Arbr. II. p. 2 IS, t. 52.

Pharm. Sumach Folia, Flores, Baccae.

Gerberfumach; Firberbaum; Hirfchhornbaum; EfJigbaum; Sumach; Smack. Germ. Coriars Sumach; Elm-leaved or Tanner's Sumach. Angl. Sumac des Corroyeurs, ou d'Europe; Rouvre des Corroyeurs. Gall.

In hortis et ad hortorum fepes circa plurimos pagos valde frequens; porro quoque in hortis fubura banis et in Serto reperitur. Fl. Iun. Iul. Arboy.

Obf. Ramiteretes, villis denfis obferfi. Folia compofita 8-12-psribus conftantia absque foitolo caulem terminante. Foliola pafliminf:ra a!terna-in oppofita, faepius folummodo oppofita, elliptico - oualia obtufus- 
cule ferrata, fuperne obfcure viridia, inferne tomentofis coltis diftinetis inftructa. Coftae autem verfus mar. ginem in $2-3-4-$ furcas terminantes, villis denfis minutiffmis tectse.

Vf. Baccae olim in condimentum cibi adhibitae fierunt, nunc obfoletae in culinis. Attamen Turcis vfuales, qui carnes ipfis condiunt, vel lolis, vel fale et Allio mixtis. Cortex caulis pannos flauo inficit colore. Cortex radicis coriis parandis aptus et rufo tingit elegante colore.

153. * STAPHYLEA. L. G. 404. Blafennufs; Pimpernufs. Germ. Eladder-Nut-Tree. Angl. Staphillier;

Néz-Coupé. Gall.

44.r. * Staphylea foliis pinnatis; (floribus digynis trigy pinnata. nisue). IINN. SyR. p. 296. LEYS. n. 318. LEERS Herborn. n. 23 1. SERT. Lipf. n. 98 . SCEVHR. t. 84 .

Piftacia fylueftris. C. B. P. 40 r.

Gemeiner Pimpermißßrauch; gefiederte Pimperauß; Klappernuß; Blafennuß; Todtcnkopfoaum; wilde Piftacien S. Zirbelniijfle. Gcrm. Common Bladder-Nut. Angl. Staphillier ailé; Néz-Coupé; Baguenaudiérà Pater Nofter; faux Piftuchier. Gall.

In dumetis, ad fepes et in horto Bofano hinter dem Coffechanfe paffim; in aliis hortis fuburbanis frequentior. Flor. Maio et Iunio. Fruftus maturi Septembri.

Obj. Folia compofita 5-7-pluribusue conftantia, ouata. Styli $2-$ paffim 3 . Capf. $2-3-$ locularis.

Fructus vomitum excitant et capitis dolores indus cunt.

I5 4. ALSINE. L. G. 411. Vogelkraut; Hünerdarm, - Germ. Chickweed. Angl. Morgeline. Gall.

442. Alfne petalis bipartitis, foliis ouato-cordatis.media, IINN. Syft. p. 198. BOEHM. n. 378. BLACKW. t. 164: Fl. Dan. t. 525. schver. t. 85 . 
Pharm, Alfines Herba.

Hüncrdarm; gemeines Vogelkraut; Hïncrbiß; Hünermyrrhe; Hünerfalbe; Meyer; kleiner Meyer; M ufegedime; Mivfezetrig. Germ. Common Chickzeed; Henbit. Angl. Morgcline. Gall.

in aruis et cultis vbique; porro in muris limofis et arbribus vetuftatis paffim. Flor. per toram fere aefratem.

$V j$ Folia et femina auiculas, praeprimis Paferes Canarienfes, nutriunt.

\section{TETRA G Y N I A.}

155. PARNASSIA. L. G. 415. Einblatt. Germ.

paluftris, 443. 'Pamafjia. LINN. Syft, pag. 299. вовHM. n. 35 I. Fl. Dan. t. $8+8+$ sckverr. t. 86 .

Pharm. Hepaticae albae Herba, Flores.

Sumpfeinblatt; Sampfparmaffcrgras; Waffer-reeiffe Leberblune; Hermblüncl; necijes Studenteuröslein. Germ. Grafs of Parnaflus. Angl. Parnaffie de marais; Chicndent du Parnalfe. Gall.

In pr tis Schoezifeldicis et Corionum copiofe; in iisdem locis prope psgos Kriphäne; Wölkau'; Machern; Sommerfeld etc. Fl. Iul. in Septembrem vique. Perennis.

Vf. Flores foenifecium indicant. Sapor plantae amarus. Decost foliorum et radicis a nonnullis in Ophthalmia commendatur. Contra Cardialgiam coquitur planta curn cereuifia.

\section{P E N T A G Y I A.}

a) Flores aggregati, inferi.

156. STATICE. L, G. 418. Wiefenkraut; Grasbłume. Gorn. Thrift, Angl.

Armeria. 444. Statice fcapo fimplici, capitato, foliis linearibus. L.NN. SyAt. p. 300, вOEHM, n. 358. SCKVHR, t. 87. 
See-Meemelke; Nelkenartiges Wiefenhrant; Grasbluznc; Sundnäglein. Gem. Sea Pink, or Sin GellyFlower. Angl. Gazon diEfpagne oil d'blinpe. Galí.

In pafcuis ficcis, fabulofis et collibus nin Gicker. lingsubrge, aci viam nach dem Gejundbrunnen $\approx u$, ad Templum St. Thcclae; ad viam verfus Schünfeld et in aliis elstioribus gramine vefitis abunde. Fl. Iunio in Septembrem vsque. Perennis.

\section{b) Flores 5 - petali, inferi.}

I5\%. LINVM. L. G. 4I9: Flachs. Germ. Flax, Angl, Lin. Gall.

\section{* Foliis alternis.}

445. Linim calycibus capfulisque mucronatis, petalis vitatificrenatis, foliis lanceolatis alternis, caule fubfolitario. mum. LINN. Syft. p. 302. вОЕHM. n. 36I. BLACKW. t. 160.

Pharm. Lini Satiu Semina.

Gewölunlicher -jâhriger - wilder Flachs f. Lein, Germ. Conmon cultivated Flax or Manured Flax. Angl. Lin diufage ì filer. Gall.

Ad verfuros et in der Allee bei den Weinnâpfchen, pafim porro in agris inter fegetes; praeprimiș autem a ruricolis colitur. Fl. Iun. Iul.

Vfus Oeconónicus notilimmus. Ex oleo Lini incolae tractus Sibiriae circa Newjanfle parant Vernicem, quam variis vtenfilibus cupreis, ferreis ligneisque, vt vafculis pro Thea, pateris etc. imponunt. Compofitionem et methodum applicandi docuit Cel. Pallas *) Oleum Lini in praxi vfitatifimum.

\section{** Foliis oppoftis.}

446. Limum foliis oppofitis, ouato-lanceolatis, caule catharticum, dishotomo, corollis acutis. L1NN. Syft. p. 303 n. ig.

$$
\text { L } 5 \text { ВоЕнМ. }
$$

*) Vid. Reife durch verfchiedene Provinzen des ruffifllen: Reichs. T. II. p. 187. 
воЕнM. n. 362. вLACKw, tab. 368. Fl. Dan. tab. 85 I. SCKVHR. t. 87.

Pharm. Lini Cothartici Herba.

Purgirflachs; Berglein; kleiner veilder Lein; kleiner hivefenflachs; Leinkraut. Germ. Purging or Mountain Flax. Angl. Lin pirgatif. Gall.

In pratis montofis pinguibusque bei dem bieniz; in pratis Schoenfeldicis; bei Schadebach; Kriphäne et fere vbique. Fl. Iunio in Septembrem vsque. Sem. Sept. et ORtøbr. matura.

Infufum herbae recentis cum vitriolo martis nigro inficit colore. Eft planta valde amara aluum absque incominodo laxat.

Radiola. 4.47. Linum foliis oppofitis, caule dichotomo, floribus tetrandris tetragynis. LiNN. Syft. pag. 303. n. 20. schreb. Spicil. p. 28. n. 942. Fl. Dan. t. 178 .

Viertheiliger f. Sehr kleiner Flachs; kleinfes Taufendkorn. Gern. Leaft-Rupture:-Wort, or All-Seed. Angl, Lin mulriflore: Gall.

In aruis et pratis labulofis frequens, e. $g$. auf dem Bieniz, ad Tomplum St. Theclae; in agris areno. fis verfus Schönfld. Fl. Jul. Aug Annua.

Obf. Cal. 4- phyllus. Petala s, erecta, exigua, obtula. Siam. 4. Antherae exiguae, fubrotundae, flauae. Caulis erectus, vncialis altior, teres, filiformis. Folia oppofita, feffilia, ouata, acuminata, integerrima.

\section{P O L Y G Y N I A.}

Floribus fimplicibus 5 - petalis.

$$
\text { a) Calyce I - phyllo. }
$$

158. Drofera. L. G. 42 I. Sonnenthau. Germ. Sundew. Angl.

rotundifolia 448. Drofera fcapis radicatis, foliis orbiculatis. IINN. Syst. p. 304. n. 3. BOE FM. n. 359. BLACKw. tab. 432 . SCKVHR. t. $8 \%$.

Pharm, 
Pharm. Ror is Solis Herba.

Rumdbl terichter Sonnenthau; Sindan; Iuagferriblüthe; unfers Herrgottslöffcl; Bauernlöffclkraut; edler Wiederton. Girm. Common Rofa Solis, or SunDew. Anct. Roflolis ì feulles rondes. Gall.

In pratis mentofis, viginotis inter Miffcos, e. g. bei Schadebach valde frequens: porro um die Fustenburger Teiche olin Cel. Bonmanes detexit. Fl. Iul. Aug. Perennis.

Obf. Cal. I- phyllus 5- fidus, gisber. Stam.5. Styli 6 - pafim 7-8. Stigmara fubrorunia, albs. Germen ouatum. Capfulae 6-8- locularis. Sem. plurima, cylindrica, glabra, membranula retiformi inclufa. Caulis erectus, fimplex, teres, nudus, exrufo-rubellus, fplendens, fpicam ramofam gerens. spica fecunda, apice incurua $16-20$ floribus infurucia. Folia radicalia in cefpitem congeruntur, inferne glabra, fuperne et margine pilis rubicundis quafi rore adfperfis obferfa.

$V \int$. Herba ouibus obnoxia. Planta valde acris, veficans, fuccum exfudans, verrucas tollere dicitur.

449. Drofera foliis oblongo-ouatis, fcapis radicatis. longifolia. RINN. Syft. pag. 304. n. 4. BOEHM. n. 360. sCKVhr. tab. $8 \%$.

Langblättrichter Sonnenthan; kleiner Sonnenthau; Hermlöffelkraut. Germ. Long - leaved Rofa Solis. Angl. Roffolis à ferilles longées. Gall.

In iisdem locis cum priori paffim reperitur. Fl. Iul, Aug. Perennis.

Obf. A priori differt: Caule breuiori, foliis obverfe lanceolatis, obtufis, multo longioribus; pericarpio breuiori et craffiori; germine angulato, ftigmate $2-3-$ dentato. licliqua cum priori conue. nientia.

Vf. Folia vtriusque femper humiditate madentia homines fuperfitiofi collignnt ad varias artes magi. cas. 


\section{B) Calyce $5-$ phoyllo.}

159. MYOSVRVS. L. G. 426. Mäufefchwanz, Germ. Moufe-Tail, Angl.

minimus, 450. Myofurus foliis integerrimis, linearibus. IINN. Sylt. pag. 308. вовнм. n. 420. Fl. Dan. tab. 406. SCKVHR. t. 83.

Kleinfter Mänfefchreanz; Mäzfçchwânzchen; Mäufegras; Herrnzippel; Nünmelzellen. Germ. Small Moufe-Tail., Angl. Qucue de Souris. Gall.

In agris arenotis bei. Stötteritz; Probftheide; Meisciorf etc. porro auf den Streitcamme et in muris vbique. Fl. Maio Iun. Annua.

\section{B. FLORE MONOCLINO.}

160. AMARANTHVS. L. G. I I 57. Taufendfchön. Germ. Amaranth, or Flower-Gentle. Angl. Ama-rante. Gall.

Elitun. 451. Annaranthus glomerulis lateralibus, floribus trifidis, foliis onatis, retulis, caule diffufo. LINN. Syft. p. 8.4. n. 11 . BOEIM. n. 68 .

- Mayerart!ges Taufondfchön; Kleiner Mayer; Mayeramaranth; Mayerhahnenkamm; zeilde Mrl he. Germ. Leaft, or Snall white Blight; Strawberry-Spinach. Angl. Blette commune; Blcte d'Europe. Gall.

Ad fépes vor dem "Perersthore, bei Lindenau etc. et inter olera in hortis cultisque frequens. Fl.Iul. Aug. Perennis.

Obf. Radix valde repens ruricolis, inuifa. Folia oleruin ad inftar edunt pauperes. Semina more milii coquuntur.

C. FLORE - 


\section{FLORE DICLINO.}

161. CANNABIS. L. G. 1220. Hanf. Germ. HempPlant. Angl. Chanvre. Gall.

452. Cannabis foliis digitatis. LrNN. Syf. pag. 886. fatiua. военм. n. 704. ELACKW. 'tab. 322. a. Fem. et 322. b. $M a f c$.

Cannabis erratica.)

Cannabis fatiua.

C. B. P. p. 320 .

Pharm. Cannabis Semina.

Gemeiner f. veilder Hanf; mein Fimmel; tauber Hanf; grïner S. fp:ter Hanf; Büflling. Germ. Male or Fomal Hemp. Angl. Chanure mâle ct fonelle; Chenevis cultivée. Gall.

In agris inter fegetes paffm; maxime autem in agris hoitisque culta. Fl. Iúl. Annus.

Obf. Scminibus plaraeque auicolae vefcuntur, pinguefcunt et bene fe habent; qua de re nullam qualitarem narcoticam retinere pofiunt., Poloni ex Geminum farina praeparare folent pultes, quas lubenter comneclunt, KasmpF. Perfae olim putarunt, haec emina, friata et commefta, venerem volde ftimulare fimulque fterilitatem inducere. olearivs. 'Folia et pollen in Perfia totaque India vi narcotica gaudent et laetitiam inducunt. Noftra autem Cannabis odorem frarcit mitiorem narcoticum:

$V f$. Oeconomicus, vt $L i n i$, et ad funes, vela alia: que lintea vtilis.

262. HVMVI.VS. L. G. I22т. Hopfen. Germ. HopPlant. Angl. Houblon. Gall.

453. Humulus. irnn. Syft. pag. 886. вовнм. n. 703. Lupulus.

Cannabis Lupulus Scop. Carn. II. p. 263. n. 1219.

Lupulus mas.

Lupulus femina.

C. B. P. p. 298 .

Pharm. Lupuli Radix, Turiones, Coni f. Strobuli. 
Gemeiner Hovfen; wilder Hopfen; Strauch-Bufch. Waldiopfin. Germ. Witl Hinps; Hop Niole and Female. Angl. Houblon mile et feraclle; Houblon rulgatэi. Gall.

In fepious et dumetis feitwärts Lindenaul ad pifcinam verius Leutfci, ad fepes hinter dem "Thonberge; er circa plurimos pagos; in nemoribus quoque, e.g. in Rofinthale et alibi copiofifime. F1. Iul. Aug. PI. parafirica.

Cbj. Cal. maris 5 - fidus. Flores maris alares, race: mofi, albidi. Cor̈. 0. Antherae 5. Stipulue 2 - 4, cordatae, bifidae. Caules longi, fcandentes et fe conuoluentes, angulofi, aculeis ornati, minutifimi. Folia oppofita, petiolata, $3-5-10 b a$, cordata, icabra, ferrata.

$V \int$. Topiariis ad ambulacra viua. Turiones primo vere prorumpentes Alparagi loco, quos ad lautitiam magriates edere folent adhibentur, fapidi grata maritie. Coniexficcati omni cerezifia imponuntur, quibus hae ab acore praeferuantur. Caules aqua macerati, in filamenta, ficuti Camuliz, a fe inuicem leparari pof. fint.

163. SPINACIA. L. G. I21\%. Spinat. Gcm. Spinach. Angl. Epinard. wall.

oleracen. 45 . Spinacia fructibus fefrilibus. Linn. Syft. pag. 886. вовiн. n. 705. SCHOt.L. Barb. p. 304. n. 150.

Pharm. Spinaciae Herba recens.

Kohlartiger Spinat; Spinat; Gartenfpinat; Crint kraut. Germ. Prikly, or Seeded Spinach. Angl. Epis mard commun, cultizé ou mâle. Gall.

In hortis oleraceis et agris inter fegretes bei Sellerhanen, Stötterita, et alibi paffim mihi occurrit. Fl. aefite. Annua.

Obf. Patria vero huius nondum nota eft. Caeterum herba olis vernale vfitatifimum et faiuberrimum. Nonnulli oecononi folia huius viridia, coelo fereno colligentes in furno tepido, feu in ä̈re ficco, lente torrefaciunt atque in virm hyemaiem fic conieruore folent.

D. FICRE 


\section{FLORE POLYGAMOIDE.}

IG4. ATRIPLEX. L. G. I260. Melde. Germ. Orach. Angl. Arrocine. Gall.

455. * Atriplex caule herbaceo, foliis incanis, ferratis, rofea.

fructibus quadrangularibus, dentatis.' Linn. Syrt. p. 909. n. 3.

Atriplex fylueftris, fructu rofeo compreffo. C. B.

p. 119 .

Rofenrothe Melde. Germ.

In ruderatis ad pagum Kctfchau et alibi frequens. Fl. Iul. Aug.

45\%. Atriplex caule erecto herbacẹ, foliis triangulari- hortenis, bus. LINN. Syft. p. 909. n. 7. ВОена. n, 556. вLACKW.

tab. 99.

Var. $\beta$ ) A. tota fanguinę.

Pharm. Atriplicis Satiud̆e Herba.

Gartcnmeldc; weiffe Gartennelde; Zuclerinclde; zahme Melde. $\beta$ ) blatrothe Garteimelde. Germ. Gardin Orach; white Dracke; $\beta$ ) Red Garden Orach. Angl. Arroche cultivée, oul des jardins; Bonne Dame; Follete des jardins; $\beta$ ) Arrocke rouge. Gall.

In ruderatis prope hortos oleraceos et ad pagos, maxime autem cum var. $\beta$ ) in hortis ipfis oleraceis frequenter occurrit. Fl. Iul. Aug. Annua.

$V \int$. In culinis coquuntur folia tempore aeftiuo cum Cerefoilo, Allio fiftulofo, carnibus, in iufculum oleraceum fpiftum.

457. Atriplex caule herbaceo, foliis deltoidibus denta- laciniata. tis, fubtus argenteis. LinN. Syft. p. 909. n. 8. вовнм.

n. 555 . Angl.

Getheilte .. gefchlitzte Melde. Germ. Faggéd Orach.

In locis fterilioribus, in der Allee, in der Sangrube pafim; in hortis oleraceis et ad Salinas Ket fchauienJes etc. Fl. Iul. Aug. Annua.

458. Atriplex caule herbaceo, calycinis valuulis femi- haftata. neis magnis deltoidibus, finuatis. Lis. Syft. p.909.

n. 9. ВОЕНМ. n, 554 . 
I 6 Classis V. PENTANDRIa, POLygamolde.

- Spreßblittrige S. fpontonartige Melde. Germ. Wild Orach. Angl. Arroche haftée. Gall.

In ruderatis, cultis et circa pagos ad fepes frequéns. Fl. Iul. Aug.

patula. 459. * Atriplex caule herbaceo patulo; foliis fubdeltoideo-lanceolatis; calycibus feminum difco den.atis. InN. Syft p. io 0 n. no.

Atriplex angufto oblongo folio. C. B. P. p. $=19$. Weit ausgebreitete Meldid. Germ. Narrov-leaved Orach. Angl. Arroche ćtaléc. Gall.

- In ruderatis, fimetis tthortis inter Olera et ad vias fepesque liaud infrequens. Fl. Iul. Aug. Annua. 


\section{$\begin{array}{lllllllll}H & E & X & A & N & D & I & A\end{array}$}

MONOGYNIA.

\section{A. FLORE HERMAPHRODITO.}
a) Flores calyculati, calyce corollaque inftrueti, bacciferi.

I65. BERBERIS. L. G. 4\%6. Sauerdorn; Sauerrach. Germ, Barberry. Angl. Epine Vinette. Gall.

460. Berleris pedunculis racemofis, fpinis triplicibus, vulgaris.

fuliis ciliatis. LINN. Syft. pag. 343. SERT. Lipli. n. IO. BLACKw. tah. 165. MLL. t. 63. KERN. p. ico. t. 169. Berleris dumetorum. mil. Fig. tab. 63. DVHaM. Arb. I. p. 9-. t. $; 8$.

Phirin. Berberidis Cortex, Baccae, Semen.

Gtmeiner Sauerrach 1. Sauerdorn; Berberizendorn; Berlisbeeren; Efjigdorn. Germ. Common Barberry, or Stipe redgebufch. Angl. l'Epine-Vinette Gall.

In fepibus et dumeris vulgaris, paffim etiam in der Allee vor dem grimmifchen Thore nunc plantata, et in miltis hortis. Fl. Mai. Iun. Frutex.

VJ. Baccae pro acetariis colliguntur. Cortex radis is inficit cur a flauo colore apud Polnnos: et lixivio maceratus luteo tingit coiore. Succus baccarum citri loco ad potum fic dictum Punt fch. inferuit. $L$ gno duro tornatores vtuntur. In culinis fuccus Berberidis viualis. 
178
b) Flores fpatzacei.
Colyce nullo.

156. LEVCOIVM. I. G. 43 Knotenblume. Germ. Great Snowdrop. Angl. Perce-neige. Gall.

vernum. for. Letucoitun fpatha vrifora, ftylo clanato. LrvN. Syft. p. 316. вовнм. n. 528 . JACQ. Flor. A uftr. V. 4. t. 312 . Sє Y'VHR. \{. 89 .

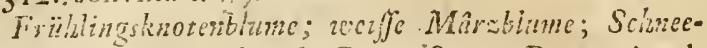
Glöchchen. Germ. Jconal Great Snow-Drop. Anglo Perce-stige. Gall.

In filuis copiofe im Rofenthale ctc. Fl. Febr. Mart. Perennis.

Vf. Rad. interne afunta vomitum excitat.

\section{7. * GLANTHVS. L G. 433 . Selneeblume . Sshneetropf. Germ. Daffodill, Angl.}

nimlis. 262. * Grlantlus vniforus, petalis altennis, cordstis, brenioribus. 11arl. Helvet. n. 125 * LinN. Syyt. pag. 316. 'JACQ Flur. Nuftr. 330. V.4. tab.3I3. SC KVHR. $8 \%$

Sclinecllumie; Schucetröpfchen. Germ. Sitoze-Drop. Angl:

In hortis ad fepes vbique fponte crefcit. Fl. Febr. Mart. Perennis.

168. * NARCISSVS. L. G. 43.5. Narcife. Germ. Daffodil. Angl. Narciffe. Gall.

poéticus. 463. * Niarciffus fpatha vnifora, nectario rotato brevifimo feariofo crenulato. IINN. Syft. p. 3i6. 11. I. Narcilus albus, circulo purpureo. C. B. P. pag. 48. 54.

B) Narcifius medio purpureo multiplex. Id. pag.

Dichter Narciffe; genneine f. weiffe Narciffe. Geim. Poetic Daffiodil. Angl: Narciffe des Poütes. Gall.

Habitatin Gallia Narbowenfi, Italia et Germania: In hortis noftratibus maxime colitur. Fl. Mai. Iun. Perennis. 
464. * Narciffus fpatha vnifora, nectario campanulato, preudo-Narereits, crilpo aequante petala ouata. Linn. Syit. p. cilís. $3 I^{-} \cdot$ n. 2.

Nracifus luteus fylueftris, duplici $f$. triplici tubo aureo. C. B. P. p. 54 .

B) Na:cirfus flore pleno. Cluf. Hift. 1. p. 50.

Unïchte $f$ geameine gelle fo zeilde gelle Narcifle. Germ. Common Yellow Daffodil. Angl. Narcife Jau. vage. Gall.

Habitat in Galliae, Anglize, Italiae, Hifpanias et Germaniae nemoribu in ririmi-que: Apud nos valde rugga: is in hortis ruft canis et fere ornibus fuburbanis. Fl. Aprili et Main. Rad. bulbola perennis.

169. ALLIVM. L. G. 442. Lauch; Knoblauch. Germ. Gariik. Angl. Ail. Gall.

\section{* Folia caulina plana. Vunbella capfalifera.}

465. Allium caule planifolio vmbellifero, ftaminibus Porrum, triculpidatis, radice tmaicats. IINN. Syf: p. 32 I.n. 2 . Eiusd. Hort. Vpl. p. .7. n. 4 .

Allium ftaminibus alterne trifidis, foliis gramineis, floribus fphaerice congeltis, radice tunicata, caule aćminato. Ifalt. Opulc. p. 348. n. 6 -

Pharm, Porri Semina.

Lauch 1 Porrey. Germ. Common Leek. Angl. Porreau, on Poireau. Gill.

In lyluis ficcioribus et arenofis rariflime in Bieniz anno 17.88 . vidi; in hortis autem oleraceis cultum frequentius. Fl. Iun. Iu!.

IV. Decotum Pori olim laudatur in calculis. Vhus praeprimis culinaris.

\section{** Folia caulina plana. Tmbelta bulbifera.}

466. Allizim cqule planifolio bulbifero, bulbo compofi- fatinum,

to, ftaminibus tricufpidatis. LrNN. Syft. pag. 3ะ2.

ก. 12.

Allium ftaminibus aiterne trifidis, foliis gramineis, capite buibifero, radicibus in vnum buibum congruenti- 
bus. Hazl. Opufe. p. 33 I. n. X. Ei. Helv. II. p. 4. t. 15. f. 9 .

Plarm. Allii Radix.

Gemeiner I. zahner Knoblauch. Germ. Common Garlic.. Angl., Ail wulnaire Gall.

In hortis et agris oleraceis Lipfiae confinibus copiofe. Fl. Iun. Iul.

VI. Nautis maxime prodef hoc allium. Bergins quo.que vidit plures codem curatos, quas Quattana vexauerat. Galinis faluberrimum eft et a Pauonibus maxime expetitum. Bergius.

Scorotopra- 467. Allium caule planifolio, bulbifero, foliis crenulafun. tis, vaginis ancipitibus, ftaminibus triculpidatis. LINN. Sy R, p. 322. n. 13. SCHRER. Spicil. pag, $3 \%$ n. 958.

Allium ftaminibus alterne trifidis, capite bulbifero, faipo ante maturitatem contorto. HaLL. - 2.

Grasinuch; Rockenbollen; Schlangenlauch; Feldknoblauch. Germ. Rocambole. Angl. Ail Rocambole. Gall.

In fyluis, in Rofenthale; Kanitfch; in pratis an dor alten Pleife, etiam in der Scheibe, Flor. Iun. Iul.

Obj. Corollae purpureae. Stamina pallida. Spatha enfiformis. Odor et fapor panlo mitior Allio fa- tiuo, fed quoad vires cum priori conuenis; in condimenta ciborum ingreditur bulbus. I ac sutem et butyrum inficit. In Gothlandia et Oclandia inter olera coquenda vfurpatur.

carinatum. 468. Allumi caule planifolio, buibifero, ftaminibus fubulatis. LINN. Syft. p. 322. n, 15. SCHREB. Spicil.p: p. 37 . n. $95 \%$.

Alliwn inodorum, vmbella bulbifera, vagina bicorni, foliis carinatis, haĹl. Opufcul. p. 391 . n. 27. f. 2 .

Berg-Waldknoblauch; wilder Knoblauch; WaldBergateiclel; Bergfchnttlouch; wilder Schnittlanch; gefchinacklofer Lauch. Germ. Carinated-leaved Gur. lick. Angl. 
In fyluaticis montofis; in colle ad Markleberg in. ter virgulta ad viam cauam, in horto Bofiano pafím. Fl Iu! Aug.

Obj Odor plantae tritae, omnibus fpeciebus mitior et quấi rapaceus; in foliis omnino mullus odor.

\section{*** Folia canlina teretia. Vmbella capfitifera.}

469. Allium caule teretifolio, bulbifero, ftaminibus vineale. iricufpidatis. L1NN. Sylt. p. 322, n. 23. HALl. Helvet. ก. 1221 . Eiusd. Opuic. p. 33 ก. 4. вовнм. ก. 530. Weinlauch; Hundslanch; Hands f. rother Knoblauch; Ackerknoblauch. Germ. Crone Garlick. Angi. Ail des ungues. Gall.

In fyluis humidioribus, e. g. in ZfolocherfchenSckenditzer - Gonnezeitzer-Gautz/chr - Holze, indcm Holze hinter Nötajcli an der Prellheide etc. porro in dumetis inter prata der Fun ienburg tuad dur Zicerlfchenne copiofe; bei Lindenali et in agris, pratis paftim ; in vineto bei Plaufig et in vineis dictis poft Taucham verfus montem Minneberg dißtuin etc. Fl. Iun. Iul. Perennis.

$V \int$. Pabulum vaccis et cibus alaudarum Lipfienfium. Lac et butyrum ingrato alliaceo colore inficit.

470. Allium caule teretifolio, bulbifero, foliis fcabris, oleraceum.

Semiteretibus, fubrus fulcatis, ftaminibus fimplicibús. LINN. Syft. p. 323 . n. 24. scitreb. Spicil. p. $37^{\circ}$ n. 530. HALl. Opuíc. p. $38 \%$ n. 26. Tab. I.

Kohlartiger Knoblizch; Kohlknoblatich; Gemïslauch. Germ. Wild Garlick:- Angl? Ail Sauvage ou verdâtre. Goll.

In pratis an deralten Pleife inter virgulta etc. Flor. Iul: Autig.

-Qbjo Caulis 2--3-pedalis, heuis. Spatha biphylla, oblonga fubutata. Folia caua.

$V \int$. Tempore vernali pro olere in regionibus monnullis colligitur.

47r. * Allinm fcapo nudo tereti, foliis fubulatis, vm- afcalonicum bella globofa, ftaminibus tricufpidatis. IINN. Sylt, p. $323 \cdot$ n. $27 \cdot$ 
Cepa fterilis, C. B. P. P. 72 .

Afcalonifche Zuiebel; Schaloticn; Ifchlanch; Efchläuchel, Schaloztcnkablauch f. Zuticbel. "Germ. Scallion or Efcallion; Efcitaiot. Angl. Ail de Palcfíne; Efchalottes. Gall.

Colitur virique in hortis. Sponte crefcit in Polaefina. Fl, Aefrate. Kodix in culinis frequenter vfur patur ad carnem fapidiorem reddendam.

**** Folia radicalia. Scapus nudus.

Cepa. 4:2. Allium ferpo nudo inferne ventricnfo longiore, foliis teretibus, lín. Syft. p. 323. n. 35. rOEHM. n. 532. Hall. Opufe. p. 361 . XXIV.

Var. a) Cepa vulgaris, flovibus et) tunicis purwarafentibus. candidis.

ß) Cepa floribus et tunicis) C.B.P.p. 7 I.

Pharm. Cepae Radix.

Gemeine Zuiebrl, gelbe, rothe f. weiffe Sommersuicbel; Bolien; Zipollen. Var. a) gemeinte. rothe

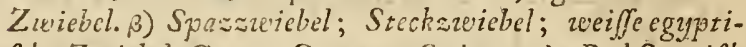
sche Zueiebel. Germ. Common Onion; $x)$ Red Spanifh Onion. B) Winte Egyptinn Union. Angl. Oignon rouge; Cibouille. Gall.

In hortis oleraceis aliisque maxime colitur. Flor. Iun. Iul.

Cepae yfus notiffimus et valde frequens in culinis. Certe, condimentum fatis praeftans. Confervatur bene Cepa, fi in falfugine maceratur et deinde in aceto vini coquirur.

fifulofum 473. Allium, fcapo nudo adaequante folia reretia ventricofa. LinN. Syft. p. 323.n. 38. HaLl. Opufe, p. $36 \%$ XXVII. воEHM. n. 533 .

IVinterzwiebel; Scleiß 1. Spaltzwiebel; Schnitt. zwiebel; alliferzu'iebel. Germ. Long or IVelch Onion; Ciboule; St Omer Onion. Angl. Ail fifuleux; Ciboule nnuéc: Ciboule commane des jardins; $\mathrm{C}$. boule de St. Facques; Oignette. Gall. 
In hortis vidque colitur. Flor. Aeftate. Perernis.

Vf. Bulbi huius tempore verno etaefiuo fubfituuntur faepe Cepae fectili. Folia iusculis oleraceis incoquuntur.

474. Allium lenpo nudo, ancipiti; foliis linearibns, ca-angulofum.

naliculis, fubtus fubangulatis: rmbella taftigiata. IINN. Syft. p. 323. n, 30. IIALl. Enum. p. 297. n. I. Eiusd. Opufc. p. 370 . n. XXIX. гоEHa. ก. 535. JAck. Flor. Aufr, V. 5. t. 423.

Wiefenlauch; eckichzer Lauch; kleincr Berglauch; klcines Nariffenlauch. Germ. Narcifjus-leaved-Garlick. Angl. Ail anguleux. Gell.

In pratis humidis paffim et in fyluis, e. $g$. $i m$ Zfchocherfchen Holve etc. Fl. Iul,--Septembr. Perennis.

475. Alliun f́capo nudo, triquetro, foliis lançeolatis, urfinum. petiolatis, vmbella fattigiata. LiNN. Syft. p. $323^{\circ} \mathrm{n}$. 33. rOEIIM. n." 536. HAll. Helvet, n. 1228. Eiusd. Opufc. p. 379. n. XXXII. Fl. Dan. t. 757. KERs. p. Iix.t I9\%.

Bürenlauch; Zigeuner I. Waldknoblauch; Ranifch; Ram fer; Rameel; Ramper; Lachenknoblanch; Ranifch; Rinjen. Ferm. Ranfou. Ang-l. Ail petiolé, ou dours à Ail des bais. Gall.

In fyluis copiofifime in Rofenthalc et alibi. Flor. Mai. Iun. Perennis.

Sapor in late et butyró percipitur. Lithuanis pro panacea et theriaca efle fertur. Incolae Kimtfchatka contra fcorbutum adinibent herbam. Talpis muribusque hoc effe aduerfum fertur.Lac quidem vitia. tur, fi a vaccis pafcitur.

476. Allizm fcapo nudo adaequante, folia tereria, fubu-schoenopralata, filifoimia. LiNN. Syft. p. $32+$ n. 32 . восни, n. fum. 53 a' sckvitk. 't. $9 \%$ :

Graslauch; Schinittlauch;-Iohannislauch; Iacobslauch; Schnitzareiebel; Brislazch. Germ. Scalion; Efcallion; Efhalion; Cives. Angl. Ail Ciboulette vivace; Cive d'Angleterre. Gall.

In piatis fiecivibus et ad fepes hortorum paffim: in hortis vero frequantius. Flor. Iun, Iul. Perennis. 
$V \int$ Embammatibus incoquitur ad varias pifcium fpecies. Nonnulli crudum in particulis minimis confcifum edunt vna cum pernis fuillis anferibusque faiitis.

170. * HEMEROCALLIS L. G. 46\%. Tagb'ume; Lilienaftodil. Germ. Day-Lily. Angl. Hénerocalle. Gall.

Haua. 477. * Hemerocallis foliis linear $\mathrm{-fubulatis}$ carinatis, corollis flauis. LINN. Syft. p. 334. n. 1. JACQ. Hort. V. 2, t. 139 .

Lilium luteum, afphodeli radice. C. B. P. pag. 80.

Var. ß) Lilio-Afplodelus luteus minor. Tourn. Inft. 232 .

Gelbe Affodillilie, Tagfchöne. Germ. Day-Lily. Angl. Hémeroculle junne. Gall.

In hortis haud infrequens. Fl. Mai. Inn. Rad, tuberofa, perennis.

Habitat proprie in pratis vliginofis Hungariae et campis Sibiriae. Gaudet Corolla duplominore flaua, petalis ad later nec nudatis, nec venofis, ftylo incurvo, odore florum grato.

fulua. 478. * Hemerocallis foliis lineari-fubulatis, carinatis, corollis fuluis. LiNn. Syft p. 339, n. 2 .

Lilium rubrum Afphodeli radice. C. B. P. p. 80.

Rothgelbe f. feucrgelbe Tagblume. Germ. Red DayLily. Angl. Hémerocialle fafranée.

In hortis fere vbique copiofe colitur. In China et Heluetia habitat. Fl. Iun. R`d. tuberofa, perennis.

Obf. Differt a priori : Corolla duplo maioce, floribus fuluis, peralis magis ref xo vndulatis venofisque et habitu plantae multo maiore.

Quia flores in liac et priori fpecie explicantur ple. rumque nodu et témpore meridiano praeterlapfo exarefcunt, hoc genus Tagfchöne germanice appellauit

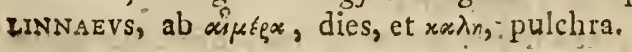


HEXANDKIA. MONOGYNIA.

c) Flores nec perianthio nec jpatha infructi, nudi, inferi.

17 I. CONV ilLARiA. L. G. 459. Zauken; Maiblume. Gcrm. Lily - convally. Angl. Muguet. Gall.

*) Lilium Conuallium Tourn, Corollis campamulatis.

4-9. Commallaria fcapo nudo. LINN. Syf. pag. 334. maaais. BOEHM, n. 62 BLACKw. t. $70 . F$ Dan. t. 854.

Phrm. Lilii, Conuallium Fiores.

Mniblüuchen; Springauf. Germ. Lilly of the Valley. Angl. Lis des vallées, ou Muquet dès bois. Gali.

In nemorofis copiofe et multis hortis, im $R$ ? fenthale, fy ua Academica etc. Flor. Mai. Iun. Perennis.

Vf. Capris, ouibus pabulum. Folia cum calce viridi tingunt colore durabili.

* Polygonata. Tourm. Corollis infundibuli. formilus.

480. Connallaria foliis alternis amplexicaulibus, canle Polygonaanc piti, sedunculis axillaribus, fubunifloris. L1NN. tuin. Syft. p. 334 . n. 5. вовнм. n. 61. Fl. Dan. tab. 377 . EL C K K. t. $25 \mathrm{I}$.

Pharm. Sigilli Salomonis Radix.

Weisweurz; Gelenkwurz; Schninkwurz; Salo. monsfiegel. Germ. Common Solomons Seal. Angl. Sceau de Salomon. Gall.

In fyluis humidis wn Rofenthale, im Sommerfelder * Mricherfchen Holze, in der Kämmerei, in dem Nötzfcher Holze etc. in alneto ad Schönfeld etc. Fl. Mai. Iun. Perennis.

$V \int$. Rad.annona vrgente pro pane, qui tunc fufcus fit et fapore fubgiutinofogaudet, inferuit. Cosmeticis et medicamentis vulnerariis adfociatur. 


\section{6}

multifora. 431.* Conuallaria foliis alternis amplexicaulibus, caule tereti; pedunculis axillaribus, multifloris. L1NN. Syft. p. 334. n. \%. Fl. Dan. tab. 192. вовнім. 11. 6I, Var.

Polygonatum latifolium maxinum. C B. P.

Vieiblühende Zauken; Weiswurz. Germ. MangFloreered Solomons Scal. Angl. Grand Genouillet. Gall.

In fyluaticis, in Rofenthale et im Walde ad Rafclow witz. Fl. Iun. Iul. Perennis.

*** Smilax. Tourn. Corollis rotatis.

bifolia. 482. Conuallaria foliis cordatis, floribus triandris, ínn. Syft. p. 335. n. 11. военм. n. 256 . Fl. Dan, t. $29 \mathrm{I}$.

Var. Conuallaria foliis ternis.

Zweiblättrige Zauken; Einblatt. Germ. Two-leaved Convallaria or Leaft Lily of Valley. Angl. Mugueret. Gall.

In fyluis, im Univer,itiuts - et Gunndorfer Holze; in der Känmerę, in der Prellhcide eà. Var. etiam inb Univcrfinätsholze praeterito anno paffun mihi occurrit. Fl. Mai. Iun. Perennis.

172. ANTHERICVM L. G. $43 \div$ Zaunblume; Spinnenkraut. Giml. Spiderwort. Angl.

ramofum. -33 . Anthericum foliis planis, fcapo ramofo; corolic $\therefore$ planis pitilla ere to LINN. Syft.p. 330.n. 5. воEнM.

- n. 526. JaCQ.Flor. Aufr. V. 2. t. 16 r

Weiffer Wiedirion; nftiges SpinnenkrautiGerm. $\therefore$ Branching Spiderceort. Angi. Phalangive rameufe; on - du petit Lis à hampe romeufe. Gall.

In montofis fyluaticis im Bieniz amb Berge. Flor. Mai. Iun. Perennis.

Likago. 484. Anthericum folits planis, caule fimpliciffimo; corollis plani, piftillo declinato. Linn. Syft. p, 330, n, 6. schred. p. 36. n, 526. Fl, Dan. t. 616. 
Erdfnimenhlrant; Sandlilie. Germ. Singh-falked Spidarivort. Angl. Phalangere is epi, ou du petit Lis ì lannipe. Gull.

In locis montofis, in Bieniz copiofe. Fior. Mai. Iun. Pei: nnis.

Olf. Scapo fimplici a priori diftinguitur.

17?. ORNITHOGALVM. L. G. Vogelmilch; Milchftern. Gorm. Bird's-Fout Angl. Churle.

$$
\text { Gall. }
$$

* Staminibus omnibus fubulatis.

485. Onnithogalun fcapo angulofo, diphyllo, pedun- Iuteum, culis vmbeilatis fimplicibus. unN. Syf. p. 32\%. 1. 2 . военм. n. 5.2. Fl. Dan. t. 378.

Gelber IVilchftern; Stemblume; Haferfchnirgel; Stcrn aus Bethlehen; Acherazeicbel; Feldzuricbil; Ziegenlauch. Germ. Dogs-onion, or Yellow Stir of Betleficen. Angl. Orniz̧ogale-jaune. Gall.

In aruis humidis et ad fyluarum margines nach den Rolenthale; in pratis hinter den Kohlgärten etc. Fl. Mart. April. Perennis.

Obf. Coro!lam Linnaei nibil aliud, quam Calycem efre, puio. Nam fi connexum huius cum pedunculo coniderare velimus, balin foliorum cum eiusdem parenclymate aretam coniun tionem habere, obferua. bimus. Sic Perianthium fexphyllum, perfiftens et dupliciter coloratum: interna pagina flawo, externa viridi gaudet colore.

VJ. In annonae caritate pro pane venditur. LiNs. Amoenit. I. p. 518 .

486. Grithogalum fcapo angulato, diphyllo; pedun- minimum, culis vmbellatis, ramofis. LiNn. Syft. pag. $227: \mathrm{n} .3$. sCHREB. Spicileg. pag. 35. I1. 527. b. Fl. Dan. tab. 612.

Kleinfter Haferfchmirgel. Germ, Leaft Yellow Star of Bethlehem. Angl. Ornizagale très-petit. Gall.

In fyluis, im Rofenthale; porro auf der Milehinfel et alibi cum praecedenti mixta crelcit. Flor. Aprili. perennis. 


\section{8}

Obf. Parnm differt a priori.

narbonenfe, $48 \%$ * Ornthogalum racemo oblongo, filamentis lanceolatis membranaceis, pedunculis foribus patentibus.' IINN. Syft. p. 327 . n. 5.'

Ornithogalum maius fpicatum, fore albo. C. B. P. p. ๆo.

Narbonifcher Vogelfern. Germ. Spicked Star of Bethlehesn zehite a zehite fouer. Angl. Ornitogale de Narbonne. Gail.

Habitat in Germaniae, Galliae et Italiae agris: apud nos paffim in pomariis et hortis quafi fpontanea occurrit. Fl. Mai. Iun.

\section{**. Staminibus alternis, emarginatis.}

vmbellatum. 188. Ornithogalum foribus corymbofis, pedunculis feapo altioribus; filamentis bafi dilatatis. LINN. Syft. p. 328. n. 12. воЕнм. n. 525. JACQ. Flor. Auftr. V. 4. t. 343 . scKVнr. t. 94 .

Doldenartige Vogelmilch; weiffe Feldzwiebeln; - Stemblümlein ; Ackeræueichel. Germ. Common Star of Bethlehen. Angl., Ornitogale à bouquet, ou Dame d'onze henies. Gall.

In locis gramine veftitis, in Rofenthale auf den IViefen hinter den Lazarthe, in Horto Bofiano hinten bei der Mauer et in aliis hortis paffim. Fl. Mart.Iun. Perennis.

Obf. Scapus fubtere , fiftulo fus, glaber, viridis, inferiona verfus expallido in viriofcentem vergens. Virbella in corymbun digefta. Spatha minuta, in fetam abiens. Cor. c. Cal. 6- plyyllus : foliolis fquamiformibus 1. ouato-oblongis, intus albelcentibus; tribus exterioribus paulo mainuibus et dorfo viriclibus, margine contra albidis. Stam. Filamenta fubulata, glabro, tria emarginata. Antherae flauae. Stigh. 3quetrum, obtufum; àlbefcens. Rad. bulbofa folida, ex minoribus - bulbis cminentibus componitur. Fol. $5-7$ e radice fafculi ad inffar egredientia bafique ccmmuniter in mcmbranam coeuntia, omnia linearia, integerrima, laete viridia, extus conciexa, intus 
canaliculata, fria pallida fecundum longitudinem or. nata.

174. * SCILLA._. G. 452: Meerwiebel f. Mäufezwiebel. Germ.

489. Scilla floribus lateralibus alternis fubnutantibus, amoena.

fcapo angulato. LINN. Syft. p. 328. n. 5. JACQ. Flor. Auftr. V. 3. t. 2 I8. sckvHR. t. 9.1.

Sternhyazinth-Meerzwiebel; fchöne Scille. Germ. Byzantine or Borrye-flozered Star Hyacinth. Angl.

In horto Bofiano olim culta nunc fpontanea, et in pornariis paffim. Fl. Mai. Aprili. Perennis.

175. ASPARAGVS. L. G. 457. Spargel. Germ. Sperage. Angl. Afperge, Gall.

490. Afparagus caule herbaceo, tereti, erecto, foliis le- officinalis. taceis, fripulis paribus. LINN. Syit. p. 332. Bozrm.

n. 538. BLACKw. t. 33\%. Fl. Dan. t. 305.

Pharm. Afparagi Radix, Semina.

Gewöhnlicher 1. wilder Spargel; Wiefenfpargel; Waldppargel; Afpars; Korallenkraut. Germ. Wild Sperage. Angl. Afperge ordinaire: Gall.

In nemoribus pafin, in pratis ad falinas Ketfchasvienfes, in agris autem oloraceis, e. g. in den Kohlgarten etc. maxime colitur. Flor., Iun. Iul. Per. ennis-

VJ. Radix aperiens. Turiones in magna copia co. mefi milum cruentum producere poffunt.

176. * FRITILLARIA. L. G. 444. Kronblume f. Kaiferblume. Germ. Fritillary. Angl.

491. Fritillaria racemo comofo inferne nudo, foliis integerrimis. LINN. Syft. p. 324. n. 1. KNIPI. Cent. III. Corona Inperialis. n. 39 .

Gezeöhnliche Kaiferkrone. Germ. Crown Imperial. Angli Cournnue Imperiale. Gill.

Obf ExOriente vnde Conftantinopoli et inde inEuro. pam reliquam tranfportata. Tota planta recens naufe ofa, acris. 
acris. Florum nectare dulci Turcse ad vomitum movendum, foeminae ad toetum excludendum, viuntur. Apes hoc inebriantur.

177. LILIVM. L. G. 443. Lilien. Gcrm. Lily. Angl. Lis. Gall.

candidum. 492.* Lilium foliis fparfis, corollis campanulatis : intus glabris. LIN Syft, $p 224$ n. I. RLACKw, t. I 1 . Lilium album, flore ereto, vu gare. C. B. P. pag. 76.

Pharm. Lilii Albi Flores, Anther'c.

Llie; geneine S. weife Lilie. Germ. Common white Lilly. Angl. Lis blanc, ou commun. Gall.

In hortis et pemariis valde copiofe reperitur. Fl. Iun. [ul. Perennis.

$V \int$. Planta in Oricnte proprie nafcitur, cuius fores odorem exhalant penetrntem, coput grauntem. atque temulentiam inducentern. Rad. bulbofoIquanofa.

buibiferum. $49{ }^{*}$ Lilizm foliis fparfis, corollis campanulatis ereais; intus fcabris. IINN, Syft. p. 324. 2. 2. Jace. Fl. Aultr. V.3. t. 226.

Lilium purpureo-croceum maius. C. B. P. p. 76 .

Fenerlilie; Goldlilic; goldgelbe Lilze. Germ. Oran. - ge or Red jumple Lilly. Angl. Lis bulbitere ou aurangé. Gall.

In hortis frequenter colitur; habitat autem in Iaponia, Italia, Aufria, Sibiria et rermania.

$V \int$. Radix buibofo-fquamofa in Iápnnia, Rolia, Tataria etc. pro cibo inferuit et ibidem Saranna appella:ur.

Martagon. 494. Lilium foliis verticillat's, floribus reflexis, corollis reuolutis. LINN. Syft. pag. 324. вовHм. n. 527. JACQ. Fl. Auftr. V. 4. t. 351. KERN. p. 96. t. $16 \mathrm{I}$.

Pharm.' Afphodeli kadix.

Feldlilien; Haidenlilien; Berglilien; wilde Goldueurz; türkifcher Bund. Germ. Old Martagon, Turk's law, or Martagon Lily. Angl. Lis SaHvage; Martagon. Gall. 
In fyluis montofis et vmbrofis, in Bieniz paffim ac in liortis. Fl, lun. Iul. Perennis.

$V \int$. In Sibiria, tefte gMeinivo, radix editur. In vino coéta menfes et rrinam prontoutet et etian in dentitione difficiliore radix laudatur.

I 8 . * TVILIPA. L. G. 4े 48 . Tulpe; Tulipane. Gom. Tulip. Angl. Tulipe. Gall.

495. * Tulipa flore fubnutante, foliis lanceolatis. Sylueftis.

Liñ. SyRt. p. 325 . n. 1. Fl. Dan. t. 375 . 63.

Tulipa minor lutea Italia et Gallica. C. B. P. pag.

Wilde woluliechende 1. europaiifche Tulpe. Germ. Wild Tulip; Early Szeer-fcented European Tulip. Angl. Tulipe jauvage. Gall.

In Italia, Gailia, Sibiria et nonnulis Grmaniae regionibus fponte crefcit; apud nos in hortis inter fequentem occurrit et ob gratum ocorem ab hortulanis maxime colitur. Fl. Maio er Iunio.

A fequente differt: Caule altiore; foliis anguftio. ribus; floris colore fubtus virefcente; peralis acutioribus; fcapo verfus florm inflexo et ante fiorefcentiam nutanie; filamentis praeprimis bafo valde attenuatis et fuprabafin hirfutis floreque mogis odorifero LINN. Calmuccos bulbofam edere radicem refert PALLAS.

496. * Tulipa flore ereto, foliis ouato-lanceolatis. Gesneriana. LINN. Syft. p. 325. n. 2.

Tulipa Turcarum. Cord. Hit. 2 I3.

Gemeine 1. Gartentulpe; Tulipane. Germ. Common or Turkifh. Tulip. Angl. Tulipe des Fardiniers. Gall.

In hortis fere omnibus valde vulgaris. Fl. Maio et Iunio.

E Cappadocia adlata circa annum 1559. In Rofila quoque fponte crefcit. Huius varietates innumera. hiles et elegantifimae ornant Maio Curioforum hortos.

$V \int$. Bulbi cocti cum oleo pipereque adfumti fapidi et falutares funt. Parkinf.

d) $F / 0$. 
d) Flores in jpadicem fimplicem, nudum congefti.

179. ACORVS. L. G. 468. Kalmus. Germ. Flag, or Rufh. Aingl.

Calamus. 497. Acoris. Linn. Syft. p. 339. воEHM. n. 57I. GORz. 288. c. fig. BLACK W. t. 453 .

Pharm. Calami Vulgaris Radix:

Gemeiner odor Geweürzkalmus. Germ. Szeret. Scanted Flag. Angi. Calanus aronatique; ou Fonc odorant. Gall,

In ftagnis et pifcinis vbique, im Gerberweafjer. Fl. Iun. Jul. Perennis.

Vf. Radix refoluens, ftomachica. Cacheet: ci abfti- nere debent. Afthmatici pituitofi ea vti poflunt. Rad. in puluerem redacta Aromatu'n indicoraw foccedaneum efie poteft. Rad. fpiritui frumenti Sueciae 1 incolae imponunt. LINN.

\section{e) Flores apetali.}

180. IVNCVS. L. G. 472 . Dinfen; Simfen. Germ. Jonc. Gall.

* Culniis nudis.

conglome- 498. Iuncus culmo nudo, ftricts, capitulo laterali, flnratins

ribus triandris, onatis, obtufis. LINN. Syft. p. $3+0$. n. 2. вовHM. n, 578. LeERS n. 261 t. $13 . \mathrm{f} \mathbf{1}$. Kopflimfen; glatte Bimfen; vunduöpfige Bimen; Rutfchen. Germ. Fonc congloméré. Gall.

In locis vliginofis et ad ferobes, hinter den Gerberwiefen, ad pifcin $m$ bei Lundenau, Leutfch etc. Flor. Iun. ful. Perennis.

Oly. Caul. I-2 pedales, eresti, fticti, teretes, glabri. Folia rara. Stamina faepius 3, rariffime 6 obferuaui. Semina acutiufcula, pallida.

$V f$. Corbibu's maffis aptus eiusque medulla ad ellychnia candedarum. Indicat folum fubtus aquofum. 
499. Inncus culmo nudo, fricto, panicula laterali, la-effufus. xa, floribus ouatis, obtufis. LiNn. S; ft. p. 3\$0.n. 3 . BОЕНM. n. 577. LEERS n. 262. t. I3. f. 2.

Flatterbinfen; Flatter-Senten; Bufch-Krötegras. Germ. Fonc vulgaire, ou tpars. Gall.

In paludibus; iuxta lepes circa plurimos pagos; ad vias vdas vbique et in indem locis cum priori copiofe. Fl. Iun. Iul, Perennis.

Obf. Floribus paniculatis, non capituliformibus, a priori differt. Folia porro insiora. Stam. 6 paffim 3 . Sem. lutea.

$V \int$. Medullam huius et prioris fpongiofam thecis pro ornatu Sueci adglutinant. LINN. Amoen. I. pag. 518. Ad corbes plecte:2das vtilis.

500.* Tuncus culmo nudo, fricto, apice membranaceo, infexus, incuruo, panicula laterali. LINN. Syft. p. $340, \mathrm{n}, 4$. LEYS. n. 353. LEERS n. 263 . t. 13. f. 3

Gehogene Binfen. Germ. Fonc recourbé. Gall.

In Incis vliginofis ad fortas bei Kleinpößnau, Merkrostz, Reiduitz inueni. Fl. seltate.

Obf. Panicula laterali maiore; pedunculis et pedicellis longioribus, omnibus furfum modo deuergentibus; culmo longiore, cnnefcente, rigidiore et apice poft furefcentiam incuruato; petalis lo gioribus, fubulatis interioribus 3 reliquis paulo breuioribus, a priori facile diftinguitur.

50I. Iuncus culmo nudo, filiformi, nutante; panicula filiformis. laterali, pauciflora, fimplici. LINN. Syft. p. $3: 10$. n. 5. SCHREB. pag. +2. n: 967 . LEERS. n. 264. tab. I3. fig. 4 .

Fadenförnige Binfen. Gall. Fone fliforme. Gall.

In paludofis turfofis ad Schönfeld, Meckerí, bei Schadebach etc. - Fl. Iun. Iul.

Obf. Culmi phures, femipedales, infirmi, filiformes, ftriati, bafi fquanati. Panicuia fimplex, pauciflora, breuiter pedicellata, in medio culmi prorum. pens.

502. Iuncus culmo nudo, rigido, foli's fetaceis, capitu-fquarofus. lis glnmeratis, aphyllis. LiNn. Synt. pag. 3\%0. n. 7. вогнм. п. 580. Fl, Dan. t. 430 . 

Gail.

Sparrichte Binfen. Gérn. Fonc rude au toucher.

In graminofis, ad fepes paffim et in riunlis humidisque bei den Ziegelficumen und der Vogelwiefe co. piole. Fl. Iun. Iul. Perennis.

Obf. Folia patentia, terrae adprerra, rigida, falcein eludentia. Inuitum colonis gramen et folum indicat vliginofum turfolum valde ferile.

** Culmis foliolis.

articulatus. 503. Inncus foliis nodofo-articulatis; petalis obtufis,

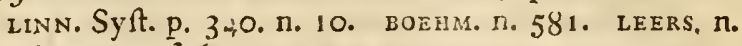
265. t. 13. f. 6 .

Gegliederte Binfen; Gliederfenden. Germ. Fone ar. ticule. Gall. .

In pratis paludofis, auf den Cerber-et Rofenthaler IViefen, bei dent Gefundbrunnen, copiofe etc. Fl. Iun. Iul. Perennis.

Obf. Folia radicalia $\mathbf{I}-2$ pedalia, compreffo-te. retia, caua, nodolo-articulara; culmra bif ris; alterna, recta, radicalibus fimillima. Panicula terminalis. Flores capitari, exigui, axillares et terminales.

bulbofus. 504. * Iuncus culmo indiuifo, fubcomprefo: foliis linearibus, canaliculatis: panicula terminali, brictea fua breuiore, corollis capfulisque obtufis. вотн. Fl. Gc:m. p. 155. LINN. Syit. pag. 34l. n. I1. LEERS. n. 266. t. 13. f. 7. Fl. Dan, t. 43 I.

Zwiebelartig: Binfen; kleine Sommerbinfen; Zwiebelkrötengras. Germ. Fonc bulbeux. Gall.

In pratis humidis, in Rofentizale, auf der Wiefe vor Schleufig paftim mihi occurrit. Flor. Iun. Iul. Perennis.

Obf. Radix bulbofa fibrillulis tecta. Panicula erecta, inaequalis, maturo fructu coryınhofa. Stigmata petalis longiora. Sem. fulua, pellucida.

bufonius. 505.- Iuncus culmo dichotomo, foliis angulatis, floribus folitariis fefflibus. LINN. Syft. pag. 341 . n. 12. BOХHM. n. 579. LEERS. n. 267. t. 13. f. 8 . 
Krötenbinfen; kriechendes Krotengras; Poggengras. Germ. Fonc des crapauds. Gall.

In fyluis et agris humidis inter fegetes copiofe vor et hanter Leut fch in agris pon pagum Kriphäne; ad Zf.hepline; Nauendotf; Gothe etc. atque in agris oleraceis, ad Schörnfelld. Fl. Iun. Iul.

\section{*** Capfulis trifpermis.}

506. Inncus foliis planis, pilofis: corymbo ramofo. pilofus. Linv. Syft. pag. 341 . n. 17. воен.. n. 583. Fl. Dan. t. 77I. LEERS. n. 268 . t. 13 . f. 10.

Var. a) Gramen hirfutum anguftifoliúm maius. $C$. B. Prodr. 16. вовн.м. n. 584 .

B) Gramen hirfutum latifolium minus. C. B. Theatr. 102. ВОЕН11. n. 585.

Haarige Binfen 1. Krötengras; Bufchgras. Germ. Fonc velu. Gall.

In locis ficcioribus, fyluaticis et elatioribus, ians Bieniz, Univerfitä̈sholse. V:sr. *) in Rofenthale, hinter Leutfch. B) in locis arenofis accliuioribusque auf denn 'Wege nach Schönfild, im Bieniz et alibi. Fl. April. Mai. Iun.

Obf. Culmi I- 2 pedales, erecti, teretes, foliis obfeffi. Folia vaginantia, lineari-lanceolata, plana. Corymbus vmbellatus: pedunculis $5-9-11$, finplicibus, vni-feu 3 floris, integris, paffin bifidis. Caps fubhaemilpherica 1 - locularis, 3 - valuis. Semino tria flauefcentia.

507. Iuncus foliis planis, fubpilofis, corymbis folio niueus.

breuioribus, floribus fafciculatis. uinn. Syft. p. 34 . n. I\%. BOEIM. ก. 586 . LEERS. n. 269. tab. 13. fig. 9.

- eiffe I Schneebinfen f. Krörenkraut. Germ: Fonc argenté. Gall.

In fyluis puffm im Rofenthale, et nemoribus bei Plagreitz et Leutfch; zn Lin eler Holze; im Bieniz; in Hegigrafe bei ririphiät etc. Fl. jun. Iul.

Obf. Corymbi fibconuexi, erecti, poft forefcentiam nutantes. Flores fafciculati, folitarii, purpureomaculati. 


\section{-196 CLASSIS VI.}

campeftris. 508. Izmcus foliis planis fubpilofis, fpicis fefrlibus pedun. culatisque. tinn. Syft. p. 3.1. n. 19. 20EHM. n. 582. Var. a) Iuncus fpica folitaria racemofa, erecta. GMEL: I. t. 17. f. I.

Fildbinfen; haariges Zypergras; Hungerbrodt; Himnclbrodt; Hafenbrodt. Germ. Fonc des champs. Gall.

In campis ficcis fere vbique, nach Schönfeld, ad Templum St. Theclac, in montofis locis. Var verfus Taucham. Fl April Ma?.

$V \int$. Pabulum ouibus primariun. Capituli florum et Semina gaudent fapore dulci et ab infantibus Silefia. cis in deliciis habentur.

\section{I. PEPLIS. L. G. 492 . Peplis; Zipfelblume. Germ.}

Portula. 509. Peplis caulibus repentibus, foliis obouatis, coniugatis, integerrimis. котн. Fl. Germ. p. 158.

Peplis folibus apetalis. LINN. Jyft. p. 345. BOEHM. n. 523. Fl. Dan. t. 64 .

Portula' ineyrich; unächter Portulak; Wafjervogelkraut; Zipfelkraut. Germ. Water Purslane. Angl. Pourpiere. Gall.

In locis Atagnofis et fofficulis hinter Gunndorf, Eh. renberg, in Unuverfitätsholze. Flor. Iul. Aug. Annua.

Obf. Petalis paffim infruta: et quidem conftane ter obferuaui + laneeolata, apice obtura, albida.

\section{T R I G Y N I A.}

182. COLCHICVM. L. G. 492. Zeitlole; Herbf. blune. Germ. Colchique. Gall.

autumnale. 510. Colchicum folis planis, lanceolatis, erectis. LrNN: Syft. p. 349. ЕОEHM. n. 63. BLACKW. t. 566. STOERK, Lib. de Colch. tab.

Pharm. Colchici-Radix recens. 
Horbf f. Wiefen Zeitlofe; Michael f. Herbftblunne; Lichtllume; wilder Safran; Mottenfafran f. Kuhdut rè; nackude Hure f. Inngfer: IHundshoden; Spinnblume; Betzlersläufe. Germ. Common Meadoze-Saf. fran. Angl. Colchique combnnize f. Mort, au chien Gall.

In pratis humidis copiofifime im Rofenthale, in iisdem locis unf dem Behomot bei Kriphänie valde com. munis, porro quoque in pratis ad Wetteritfch. Cel. тrTivs copiofe reperit. - Fl. fub fine Aug. in Oeto. brem vsque.

Obf. Caulis tubulofus, triangularis, bafi fquamis veftitus. Cor. l'etala 6-paffim 5-8. Stam. 6, rariffime 5. Stig:t ata incuruata. - Planta valde acris fufpecta, praecipue radix vomitus efficit maximos et poftea mortem inducit. STOERKIVs extractum $\mathrm{Hy}$ * dropicis commendat. Infurum florum inebriat. Folia fubrubro tingunt colore et pecorum pediculos necant. Oxymel, ex hac radice petitum, in vfu eft. Ex radice recenti Amylum album, friabile, poft lotionem faepe repetitam, non acre obtinuit $\mathrm{Cel}_{\text {s }}$ BERGIVS.

183. TRIGLOCHIN. L. G. 488. Dreizack; Krötengras. Germ. Trofcart. Gall.

5II. Triglochin foribus trigynis, capfulis fublineari-paluftre, bus, trigonis, trilocularibus. LINN. Syft. p.348. n. I. воEнM. n. 25 I. LEERS. n. 2.72. tab. 12. f. 5. Fl. Dan. t. 490 .

Sumpfdreizack, klein Binfengras. Germ. Trofcart des Marais. Gall.

In paluciofis pratis, auf den Schönfelder Wiefen, bei Schadebach, frequens. FI. Iun. Iul.

Obf. Radix biennis, bulbofa, fibris filiformibus, flauefcentibus inftrueta. Stam. $1-3$ - rarifime 6 . Stigmata, 3 , acuta, perfiftentia.

Vf. Gramine hoc boues, equi, capri prae aliis de. destantur. 
maritimum.512. Triglochin foribus hexagynis, eapfulis ouatis, hexagonis, hexalocularibus. LINN. Syft. p.348.n.2. scineв. Spicil. p. 926. Fl. Dan. t. 306.

Seeftrandgras. Germ. 'Trofcart maritime. Gall.

In locis falfis ad Ketfchau, ibidem in siuulis pratisque copiofe quoque reperi. Fl. Iun. - Aug. Perennis.

$V \int$. Boum quoque pabulum delicatiffinum.

184. RVMEX. L. G. 485. Ampfer. Germ. Dock. Angl. Patience. Gall.

* Flores hermaphroditi: valuulis granulo notatis.

Patientia. 513** Rumex floribus hermaphroditis; valuulis integerrimis, vnica granifera, foliis ouato-lanceolatis. LINN* Syrt. p. 346 . n. I.

Lapathum fatiuum antiquorum. Munting Aardgew. t. 692 .

Lapathum fatiuum. BLACKw. t. 489 .

Pharm. Patientiae Rádix.

Zahmerf, Garten-Ampfer; dasKräutleinPatientia; englifcher Spinat; Mönchsrhabarber; Geduldkraut. Germ. Patience cultivée; Parelle des jardins; Surette; Rhabarbe des moins. Gall.

In Italia proprie fponte crefcit: Apud nos vbique in hortis colitur. Fl. Iul. Aug. Perennis.

$V \int$. Rad. recens vernali tempore vtiliter addi poteft apozematibus iusculisque medicatis. Folia recentia in culinis per totam aeftatem vfurpantur et initio veris inter prima olera obueniunt. Vtilis haec planta perennis, frigoris et foli patiens.

fanguineus, $5 \mathrm{I} 4$. * Rumex floribus hermaphroditis: valuulis integerrimis; vnica granifera; foliis cordato-lanceolatis. LINN. Sylt. p. 346. n. 2. LEYS. n. $36 \%$.

Pharm. Lapathi Sanguinei Radix, Herba

Bluthrothe Grindzeurz; Blutampfer; rothblïttrige Mengeheurz. Germ. Bloody Dock. Angl. Patience rouge, ou Sang de Dragon. Gall. 
In locis cultis inter olera et ad hortorum fepes fponte parim. Fl. Iul. Annua.

515. Rumex floribus hermaphroditis: valuulis inte-crifpus. gris, graniferis: foliis lanceolatis, vndulatis, acutis. IINN. Sy?t. p. 546. n. 5. военм. n. 574. Var. 1.

Kraufe Grinducurz; kraufer Ampfer; Butterampfer; Olzmblâtiter; krausblâtrige Mengelwurz. Getm. Curled Dock. Angl. Patience frifée. Gall.

In pratis et nemoribus humidisque ad pagos et vias copiofe. Fl. Iun. Iul. Perennis.

$V J$. Succus recenter exprefius in fabie laudatur. Semina contufa dyfenteriam tollere feruntur. Semina aẽre ficcata in annonae caritate pani inferuiunt Sueciae et Norwegiae.

516. Rumex floribus hermaphroditis; valuulis denta- maritimus. tis, graniferis; foliis linearibus. LiNN. Syft.p. $346 . n$. 9. SCHREB. p. 41. n. 966.

Meerampfer; fchmalblättrige Grindwurz. Germ. Patience muritime. Gall.

In locis humidis et ftagnis ad Lindenthal, Burg* hanfen ad Salinas Ketfchauienfes atque bei dem dürren Berge. Fl. Iun. Iul.

517. Rnmex floribus hermaphroditis: valuulis dentatis, acutus graniferis; foliis vndato-oblongis, acuminatis. IINN. Syft, p. 346. n. II. BовнM. n. 575. BLACKW.t. 49 I

Pharm. Lapathi Acuti Radix, Herba, Semina.

Spitzblattrichter Ampfer; wilde Rhabarber; Pferdeampfer; halbe. Gahle; Streifururz; Bubenkraut; Hungir Lendcnkraut; Zitrcruurz. Germ. Sharp poinsed Dock. Angl. Patience fauvage; Parelle; ou Rénea bre. Gall.

In pratis humidis, foffis vbique. Fl. Iun. Iul. Perennis.

518. Rumex floribus hérmaphroditis: valuulis integer conglomerimis, nblongis, graniferis; foliis lanceolatis, fubundulatis. rotн. Fl. Germ. p. 160. военм. n. 576 . Gall.

Gehäufter Ampfer. Germ. Patience congloméré.

In ftagnis, in der Sandgrube. Fl, Iul. Aug. Perennis. 
obtuffolius. 519. Rumex foribus hermaphroditis: valuulis dentatis, granifesis; foliis cordato-oblongis, obtufufculis crenulatis. LINN. Jyft. p. 347.n. 11. SCHREs. Spicil. p. 41. n. .965.

Stunipfolättrige Grindizeurz; kleiner Amnfor; Butterampfer. Germ. Patience vulgaire. Gall.

In 1yluaticis locis, im Rofenthale, in ambulacris. Fl. Iul. Aug. Perennis.

Pecora hunc refpunt.

** Flores hermaphroditi: valuulis granulo deftitutis.

açuaticus 520. Rumex floribus hermaphroditis: valuulis integerrimis, nudis; foliis cordatis, glabris, erectis. LINN. Syft p. 347. n 15. BOEHM. n. 574. LBACKW. t. 262. et 490 .

Pharnı. Herbae Britannicae Radix, Herba.

Wafferampfer; Mönnichs - Rhabarber; Waffermangold; Grindururz; Docken 1. Pockenblãtter. Germ. Watcr Dock. Angl. Patience aquatique ou d'ean. Gall.

In follis vbique: nach Schönfeld, an den Gräben hinter den Gerberweiefen, et ad ripas fluuiorum, ander Balure, Pleiffe vbique etc. Flor. Iun. Iul. Perennis.

fcutatus. 52r. Rumex foribus hermaphroditis, foliis cordato: haftatis, caule tereti. LINN. Syft. pag. $347 \cdot$ n. 20. BLACKw. t. 306.

Acetofa rotundifolia hortenfis. C. B. P. paga II4.

Pharm. Acetofae rotundifoliae Herba.

Rundblättrichter Sauerampfer; franzöfifcher Sauerampfir; Agrefampfer. Germ. Round-leaved Sorrel; French Sorrel. Angl. Ofeille franche ou ronde Paticn. ce à écufions. Gall.

In hortis inter Olera er in reiectamentis hortorum paffim, maxime autem in hortis colitur. Fl, Mai. Jun, Perennis. 
Vf. Ob gratam aciditatem et faporem ab Anglis, Gallisque, reliquis 'Acerofae fpeciebus pracfertur et valde colitur. In fcorbuto laudatur herba.

\section{*** Flores diclini.}

522. Rumex floribus dioicis: foliis oblongis, fagittatis. Acetofa. LINN. Syft. p 378. D. 27. воЕHM. ח. 5\%2. BLACKW. t. 230 .

Pharm. Acetofae Noftratis' Radix, Herba, Se. mina.

Großer f. wilder Sauerampfer; Saucrlamp; Sauerfenf; Wiefenfauerampfer. Germ. Common, ur Meadow Scrrel. Angl. Patience Ofeille ou Ofeille des près; Ofealle commune. Vinette, ou Saliette. Gall.

In pratis et hortis vbique. Flor. Mai. - Iul. Per. ennis.

Obf. Calyx Maris patens; Foeminae contra reflexus.

VJ. Succus ex hac herba recenti expreffus eft faporis aciduli, cum fale tartari debilius efferuefci, et fi fubfidentia depuratur, dein infpiffatur, Sal effentiale praebet. Lac acetofatum in Lapponia ex herba preeparatur. Contra fcorbutum in Groenlandis, vbi fimul cum Ccchlearia commifceri folet, laudatur. Semina in annona graffante pani inferuiunt. Rad. exficcata, coßta, pulchro rubro tingit colore. Folia recentia iusculis, olerious incoquuntur. Si fuccus citri ad. ditur, fapidiora euadunt.

523. Rumex foribus dioicis; foliis lanceolato-haftatis, Ácetorella, IINN. Syft. p. 348. n. 28. BOEHM. n. 573. вLACKW.

t. $30 \%$.

Var. a) Rumex foliis lanceolatis, anguftioribus, radice repente.

b) Rumex minima foliis non lanceolatis.

Spieß-Feldampfer; Ackerjauerampfer; kleiner Sauerampfer; Schafampfer. Germ." Sheeps Sorrel. Angl. Patience petit Ofeille; Ofeille des brebis; Suretre des brebis. Gall.

In agris arenofis lapidofisque maxime auf den Schönfelder Aeckern cum varietatibus, et fere vbique in lòcis ficcis fterilioribus. Fl. April. - Iun, 
Agris molefta. - Vires easdem habet, quas priores.

135. SCHEVCHZERIA. L. G. 487. Scheuchzerie.

\section{Germ.}

paluftris: 53. Scheuchzeria foliis carnnfis, femiteretibus, braEteis morophyllis, fpathaceis. unN. Syft. p. $3 \div 8$. wilden. Prodr. Berol. n. 4II. военm, n, 587. (fub Iunco). Fl. Dan. t. 7 6.

Sumpf Scheuchzcrie. Germ. Leffer flowering Rufh. Angl. Fonc fluri. Gall.

In locis paludofis ad Schönfeld, in pratis vliginofis bei Schadebach. Fi. April. Maio.

\section{P O L Y G Y N I A.}

186. ALISMA. L. G. 495. Frofchlöffel. Germ. Water Plantain. Angl.

Plentago 525. Alisma foliis ouatis, acuris; fruetibus obtufe trisquatica.

gonis. LINN. Sylt. p. 350. военм. n. 252. Fl. Dan. tab. 561 .

Waffer-Frofch-Wegcrich; gemeiner Frofchlöffel; großer irafjerwegerich; Waldbart; Frofchiraut. Great Water Plantuin. Angl. Plantain d'eau. Gall.

In aquolis ad forfos frequens hinter den Kohlgär. ten, in foficulis nach Sclionfeld, et in ftagnofis in der Leímgrube copiofifine etc. Flor. Iun. - Aüg. Perennis.

Hanc plantam vaccis aliisque lethalem effe, auctores referunt.

Vf. Vcficas excitat.

B. FLORE 
HEXANDRIA. STYIOSTEMONOIDE. 203

\section{B. FLORE STYLOSTEMONOIDE.}

187. * ARISTOLOCHIA. L. G in II. Ofterluzey. Germ. Birthwort. Angl. Ariftoloche. Gall.

5:6.* Ariftolochia foliis cordaris, caule erecto, forihus Clematitis. axillaribus confertis. LINN. Syft. p.825. LEYs. n. 926 . BLACKW. $t 255$.

Pharm. Ariftolochiae Vulgaris Radix.

Genieine kleine Ofterlizey; Holzueurz. Germ. Creepeng Birthwert. Angl. Ariffoloche clematite. Gall.

In horto Bofiano fponte crefcit. Fl. Iun. - Aug. Vf. Externe puiuis carnes abfumit fungofos, ca; riei refiftit viceraque fanat. 


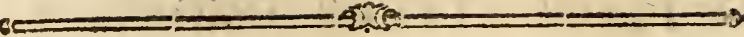

Claffis VII.

HE P T A N D R I A.

MO NOGY NIA.

188. TRIENTALIS. L. G. 496. Schirmkraut. Germ.

'Europaea. 527. Trientalis foliis lanceolatis, integerrimis. LINN. Syft. p. 352. вовнм. n. 64. Fl. Dall. t. 86. квоск. Flor. Silef. T. I. p. 596 . t. 53 .

Europâiches Schirmhraut; Stcribliumlein. Germ. Chickweed-flozeered Winter-green. Angl.

In locis fyluaticis vmbrofis, ferilibus, paffim ims Univerfitâtsholse; in der Kinmerei bei Nauendorf; in der Prollheide. Fl. Mai. Iun.

189. AESCVIVS. L. G. 498. Rofskaftanie. Gorm. Horfe Chefnut. Angl. Maronnier. Gall.

Hippo-ca- 528. Aefculus flotibus heptandris, patentiffmis, racea. ttanum, mofis. LINN. Syf. p. 352. воEHM. n. 457. CRAM. to 23. B. I. 2.

Pharm. Hippocaftani Cortex.

Gemeine Roßkaflanie; oftindifche wilde Kaftanie; Vervirkaftanie. Germ. Comnzon Horfe Chefinut. Angl. Maromier dInde; Chataigne de cheval. Gall.

Habitat proprie in Oriente, vnde Europae innotuit non ante 1550 ; sunc autem ad vias et circa vrbem in der Allec; in hortis plurimis circa Lipfam copione, et in pagis fere omnibus valgaris. Flor. Mai. Iun. Arbor. 
Olf. Corollis pentapetalis, non tetrapetalis, patentilifmis, aequalibus differt ab Aefculo Pautio.

Vf. Amylum infipidum et inodorum, acre, tenuiffimum ex frustibus maturis conficitur, et pabulum equis, ceruis gratum. Flores apibus pabulum. Folia ouibus, capris, bobus et ceruis pabulum Ci:neres exhibent lixiuium vtile. Corricem huins arboris cortici pertuiano fubfituere annifus eft $Z$ anichelli. 


\section{2. \\ Claffis VIII. \\ O C T A N D R I A.}

MONOGXNIA.

a) Flores completi, fuperi.

190. * TRDPAeOlvM. L. G. soi. Indianifche Krefle. Germ. Indian Crefl. Angl. Capucine. call.

maius. 529. * $T_{\text {ropacolum foliis peltatis fubquinquelobis, peta- }}$ lis obtufis. LinN. Syft. p. $35 \mathrm{I}$. n. 2 .

Cardamindum ampliore folio et maiori flore. Tournef. Inft. p. + o.

Viola indica fcandens, nafturtii fapore, maxima odorata. Herm. Lugd. 628. t. 629.

Pharm. Nafurtii Indici Herba, Flores virentes.

Großse indianifche Kreffe; Kapuciner reffe; gelber Ritterfporn. Germ. Indian Creß. Angl. Grand Capucine; Crelfon d'Inde. Gall.

Habirat in Peru, vnde cura Beuerningii in Europarn $168+$ translatum. Apud nos hofpitatur fub dio et in hortis valde colitur. Fl. Aeftate. Annua.

Olif. Filia b. Linnaei prinuın obferuauit fores noctu lucefcere. Flores faporem odoremque Sifynbrii Naffurtii aemulantes in acetariis adbibentur. Baccac condiuntur aceto.

I9I. ACER. L. G. 1266. Mafsholder; Ahorn. Germ. Maple - Tree. Angl. Erable. Gail.

Pfeudo-pla- 530. Acer racemis pendulis, foliis quinquelobis, obturanus. fis, inácqualiter ferratis. WILdeN. Prodr. Bezol. n. 435. 
Acer foliis :- lobis, acute ferrati, frorum raceno compofito, pendulo. DV ROI. Harbk. It p. SER.T. Lipt. n. 2.

Acerfoliis quinquelobis inaequaliter ferratis, floribus racemolis. LiNe. Syft. p. 911, n. 3. воEнM. n. 364 . DVHAM. Arbr. I. t. 36 . f. 1.

Gementer, großer, weiffer, un chter Ahorn; Waldefche; Milchbaurn; Spillenholz; große Majern; Efchdorn, Germ. Greater Maple-tree; Sycomore-tree. Angl. Erable blanc ou de montagne; Sycrmore. Gall.

In nemoribus, e.g. im Rofenthale, in der Prellheide etc. in dumetis nach Gunndorf et ad pagos bei Eutritz/ch, Wetteritz/ch, Sechaujen, Klein- $\epsilon$ G Großreöl. kau etc. et in hortis fuburbanis haud infrequens. Fl. Maio. Aıbor.

$V \int$. Iignum album, durum, fcriniariis et tornatoribus ad difcos, cochlearia, cantharos, inftrumenta mufica, menfas, tellas variaque vtentilia. Folia ftiaminis loco et pecoribus pabulum. Succum ex arbore deftillantem aquae locn cereuifis addunt Angii.

53 [. * Acer corymbo timplici e ecto: foliis 5 lobis, platanoides. denratis: dentibus acuminatis. wilden. Prodr. n. 436.

Acer platanoides foliis quinquelobis acuminatis, acute dentatis, glabris, floribus corymbolis. LiNN. Syft. p. 912 n. 11. SERT Lipf. n. S.

Lehne; Lölnne; Lemne; Leinbaum; Breitlehne; Spitzahorn; Jpitzblätrichter Ahorn; pohlnifchier f. norwegifcher. Ahorn; tent/cher Zuckerahorn; grojser Milchahorn; Weinhlatt; Breitúlatt. Germ. Norway. Marle. Angl. Erable Planavier. Gal!.

In nemoribus pafimet ad pagos plurimos: in der Allee verfus Ergaftulum atque in multis hortis fuburbanis, e. g. in Horto Lehriano; Richteriano, Trierzano et Wmkleriano ett. FI. Naio. Arbor.

VJ. Lignum tenax et durum, dehinc variis rebus ad oeconomiam pertinentibus conficiendis valde aptum. Succus in foliis contentus acris et $a b$ infectis intactus relinquitur. 
campetre. 532. Acer corymbo tripartito erecto, foliis quinquela bis, integerrimis: lobis inferioribus emarginatis. wiLd, l. c. n. $437^{\circ}$

Aicr campeftre foliis lobatis, obtufis, emarginatis: L'INN. Syft. p. 912. n. I3. вовHM. n. 363. cRAM. tab: 39.

Kleiner teutfcher 1. Feldahorn; Mavellen; Weislöber; Elpern; Aplern; Appeldören; gemeiner Maßholder; kleiner Milchahorn; Weisbaum; Weifseper; Bienerbaum. Germ. Snal or common Manle; Leffer Maple; Whaten-tree; Striped Sycomore. Angl. Erable commuz ou des bois; petite Erable. Gall.

In nemoribus et fyluis, e. g. inn Rojenthale, im - Zfchocherfchen Holze copiofe; porro in Macherfchen, Univorfitâtsholze; in der Kâmmerei bei Nauendorf; in dor Prillherde aitf den Zjchepliner Antheile etc. in campeftribus locis parrim et alibi.Flor. Aprili et Mai. Arbor.

192. EPILOBIV́M. I. G. 507. Weiderich; Unliolden. kraut. Germ. Willow Hierb. Angl. Neriette.

Gall.

\section{* Staminibus declinatis.}

anguftifo- 533. Epilobium foliis fparfis lineari lanceolatis; floriliun. bus inaequalibus. LiNN. Syft. p. 35\%. n. I. вовнм. n. 297. Fl. Dan. t. 289 .

Schmalblittriger Weiderich; franzöfafche Weide: "Wcidenröslein; Eberkraut; Feuerkraut; St. Antonikraut; Bergfchoten; willder Oleander; Unholdcinkrout. Germ. Rofe Bay IVillow Herb, or Fronch IVillow. Angl. Nériette Antoine; petit Laurier-Role; Herbe de St. Antorne; Epilobe'à feuilles étroits Gall.

In riuulis et fyluis in Klein- et Grofisolziger Holze. Fl. Iul. Aug. Perennis.

$V \int$. Pappus faminum bombycis loco nuper connmendatus 'eft. Kaảix fub terra craffos exferit turiones, qui Afparagi turionuin more praeparari pofunt. Foliorum infufum epotum, Rufls vfitatum, inebriat. 
Meduilam caulium inter cupedines Camtfchadalorum non infimum obtinere locum refert $G$ mel.

** Staminibus ereetis, regularibus, petalis bifidis.

534. Epilobium folis ouato-lonceolatis, femismplexi-grandiflocaulibus, hirfutis; caule ramofiffino, villofo, radice rum. repente вотн. Flo: Germ. p. 1 óm.

Epilobium (hirlucum) foliis oppofitis, lanceolatis, ferracis, decurrentibus, amplexicaulibus. tINN Syit.

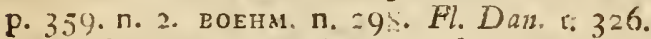

i. rofsblühender, fteifbarftiger f. raucher teiderich; Feuerkraut; Wafferviolen. Germ. Large-flowered Hairy IV̈illow Herb. Angl. Neriet velu. Gail

Ad folfas, in der Pleife, an der Ocheneechre, hinter, dem Brandvoreverke; porro in der Leimgrube, ad pifcinam bei den efundbrunnen, in pago Stötteritz circa pícinas e.g. in pifcinis horti Weifiani copioliffime et in foltis beî der Wiesz unten anz Bie. miz etc. Flor. Iul. Aug. Perennis.

Ob. Folia ferrata, vtrinque -tąu molliufcula, feffilia femidecurrentia ouato-lnnceolata, acumine dentato termin ntia; hirfuta, fuprema alterna; relicua oppolita. Flores folitarii magni, ex purpureo-rubri. $\mathrm{P}$ tala limbo bifida. Antherae flauae. Stigm. 4fidum ex albido - flauefcens.

Vf Pappus B mbycis loco vt prior. Pabulum ouibus, capris, bobus.

535. Epilobium fuliis oppofitis lanceolatis, ferratis, fef-paruiforum filibus, cauleque villofís. SCHREB. Spicil.pag. I 46. n. I 6 \%. REz. Fior. Scand. Prodr. n. 40 \%. Eiusd. Fafc. I. Obf. Bott p. I6. n. 42. Fl. Dan. t. $347^{\circ}$

Kleintlümigter Weiterich. Germ.

In locis humidis ad Schönfeld, Abtnauendorf, poft Altranftidt etc. Flor Iun. Iul. Perennis.

Obf. Nonnulli pro varietate prioris habent.

536. Epilobiun foliis oppofiti:, ouatis, dentatis. LrNs. montanum.

Syft. pag. 359. n. 4. вовнм. n, 299. Fl, Dan. tab. 565. 
Bergzeiderich; glatier Schotenweiderich; Bergun. holdenkraut. Germ. Smooth-leaved Willow Herb. Angl. Epilobe de montague. Gall.

in locis accliuioribus inter frutizes et.in dumetis denfioribus vbique. Fl Iun. Iul. Perennis.

Obf. Folin glabra. Flores pallidi.

tatragonum. 537. * Epilobinn foliis lanceolatis denticulatis, imis oppofitis; caule tetragono. LiNn. Syft. p. 35y. n. 5 . IEYS. n. $3^{-\%}$.

Viereckichter Weiderich; vierwinklichtes Unholden. kraut. Germ. Nasroze-leaved IVillow-Herb. AnglEpilobe à quatre Paris. Gall.

In fyluis montofis paffin-am Bieniz vidi. Flor. aeftate.

paluitre. 53\%. Eilobium foliis oppofitis, lanceolatis, integerrimis; petalis emarginatis, caule ere Co. LinN. Syft. p. 359. n. 6. SCHREB. Spicil. p. 22. t1. 931. Fl. Dan. t。 347.

Epilobium foliis ellipticis integerrimis.

Sumpof 1. Torfiecidericla. Germ. Margh Willow Herl. Angl. Nerict des, marais. Gall.

In pratis paludofis at Abtnamendorf; ad piscinam vor Parneck, inter Delitz und Meisdorf. Fl, Iul. Aug. Perennis.

rofeun. 539. Epilobium foliis oppeffitis alternisque nuato-lanceolatis, petiolatis, lerratis, glabris. schréb. Spicil. pag. 14. n. 1165. RE'r2. Piod?. Flor. Scand. n. 703. Eiusd. Fafe. I. Obferv. Bott. p. 16. n. 42. LEYs.n. 380. KROKER, ก. 589.

Rofewother Weiderich. Germ.

In issdem locis, vbi Epilobiun paruiflonim floret et copiofe ad parietes in dent Thomaszzeinger reperitur. Fl. Iul. Aug. Perernis.

Caulis fubteres, fiperiora verfus a-gonus, gia. ber et verfis finem, villis candidis obductus. Folia inferiora oppofita, longius petiolata, ounta, ferrata, acuta, glabra; reliqua praeprimis fuprema caulis alterna, breuius petiolata, ninora, magis onato-lanceolata et villis candidis mollibus obfeffr. Flores exigui, parui. Petala ex rofeo in album vergentia. Germ. 4- gonum, pilis albis denfiffimis obdustum. 
Pro varietate Epilobii montani Ill. ReTzuvs habet propter ilius affinitatem, atque ftigmate clausto, indiuifo, ab illo tasitum differt.

5 A. Epilobium foliis oppofitis alternisque lanceolatis, obfcurum. glatris terratis, bafi decurrentibus. schreb. Spicil.p. 147 n. 1166.

In locis humidis ad fofias hiner. Kleindölzig; bei Nautentorf an der Kïnmerei etc. Flor. cum prioribus. Prennis.

Defcriptio schregeri huic aptifima.

193.* OENOTHERA. L. G. 505. Nachtkerze; Onagra. Germ. Tree-Primrofe. Angl.

541. Oenothera foliis ouato-lanceolatis, planis, caule latifolia. muricato villofo. IINN. Syfr. pag. 353. Oenz, biennis scop Carn. n. 452 . Fl. Dant t. $4+6$.

Lyfimachia lutea, corniculata. C. B. P. 245.

Onagra latifoliá. Tourn. 302.

Zuevijährige Nachtkcrze; franzöflfche f. Spanifche Raninzel; Gartemapanzel ; Weinlulune; Nachtfchlïfjelulume; gehörnter Weiderich; gelbe Rapunzel. Germ. Common biennial Tree-Primofe; Broad-leaved Tree Primrofe; Night Primrofe; Angl. Herbe aux ânes; Onagre; 7 ambon des jardiniers. Gall.

in Virginia iponte crefcir, vnde circa 620 in Europam translata, nunc in Germania quoque fpontanea et apud nos prueprimis in horto Bofiano fponte cre. fcit et in multis aliis hortis vrbanis et rufticanis co. piofe reperitur. Fl. Iun.-Aug. Biennis.

V\%. Radix cocta, oleo et fale confecta lactum inftar hyemis verisque tempore comeditur. Silefii radicem Rhaponticam appellant.

194. VACCINIVM. I., G. 523. Preufelbeere, Germ; Billberry. Angl, Airelle. Gall.

* Foliis deciduis.

542. Vaccinium pedunculis vnifloris, foliis ferratis, Myrtillus. ouatis, deciduis, caule angulato, LiNN. Syft. p. 362.

$$
\mathrm{O}_{2} \text {. }
$$


вов пIM. n. 68. B LACKW. tab. 463. cram. tab. 49. 1. 2 。

yharm. Myrtilii Baceac.

Gimeine Heidclvecre, blaue 氏. fchwarze Beere; Pi: ckelhcere.' Germ. Blach Whorte or Billbory. Angl. Airclles Myrulles; Baics de l'Airelle; Lucette; RaiSon des bois; Manvets Bluets. G.iil.

In fyluis denforibus et pinaftretis copiofe $i n U_{n z}$ verfitis- und Gumdorfer Holze, in der Prellheide wnd Kämmerei paffim. Fl Mai. Iun. Perennis.

Vf. Saccae maturaefapidae, vefrigerantes, adfringentes! Si enim in nimia copia affumuntur, tune obfructiones lethales fequi pontur. Exficatse in iusculis quoque et in panatellis infarciendis vfurm pantur. Infuper colore purpureo et rubro tingunt vina, et pabuluin tetraonibus, perdicibus, gallinis, phafianis praebent egregium.

\section{** Foliis femperuirentibus.}

Vutis Idea. 543. Vaccinium racemis terminalibus, nutantibus; foiiis oboutris, reuolutis, integerrimis fubtus punctatis. linn Sylt. p. 363. n. I3. BoenM.n.67. Fl, Dan。 t. 40. CrAm. t. 49. f. 3 4.

Pharm. Vitis Ideae Baccae.

Preufelbeeren; rothe Heidelbeeven; Raufch-Grander. Kronsbere; Kreu-PraußBbeeren; Krausbceren; Kronsbercinfaude; wilder Buxbaum; Steinberen; Germ. Red Whorts, or Worthle-Berries. Angl. Airelle rouge. Gall.

In fyluis locisque opacis, im Univerfitätsholze etc. Flor. Mai Iun. Perennis.

Vf. Baccae acidulae in regionibus feptentrionalibus cibo inferuiunt. Baccae recentes cum fac haro citrique cortice condiuntur et in variis morbis acuris falurares. Porro et iis Rob et gelatina praeparatur, quae in culinis vfitatifima lunt. - Vinum ex hifce baccis probe maturis paratur, addito faccharo, fermentatione vinora. 
195. * SCHOLLERA. Rotr. Moosbeere. Germ. Cran-berry. Angl. Cannebeige. Gall.

544. * Schollera foliis ouatis, integerimis, reuolutis, Oxicocsus. crúlibus repentibus, filiformibus, nudis. r.rnN. Syft. p. 363. n. Ia fub Vaccinio. Al. Dan. t. 50. WILDEN. Prodr. Berol. n. 428. Rотн. Flor. Gerni. P. I. pag. 170 .

Sumplieere f. Hiibelbeere; Moosbeere; Kranichbeere; Fonnbere; Affen-Prellbeere; Raufchgrün; Gichtkraut. Germ. Cranberry or Moorberry. Angl. Canneberge; Coujinet des marais. Gall.

Pharm. Oxycocci Baccae recentes.

In locis humidis er mufcofis, paffm in Univerfitätsholae; in der Dïbenfchen Haide frequens. Flor. Mai. Jun.

$V \int$. Baccae aufterae cum faccharo praeparatae in menfis Suecorum iucundus eft cibus. Mel Oxycocci grate acidum eft confiftentia fere Oxymellis, in febribus laudatur a medicis Suecicis vid. Pharın. Suec.

196. ERICA. L. G. 524. Heide. Germ. Heath. Angl.
Bríyere. Gall.

545. Erica antheris ariftatis, bicornibus; corollis cam-vulgaris. panulatis fubaequalibus, mediocribus; calycibus duplicatis; foliis oppolitis fagittatis. LINN. Sytt. p. 36: говнм. n. 65. El. Dan. t. 67\%

Erica rulgaris criftata: foliis oppofitis fagittatis. THVNB. Diff. de Erica 11. 7 \%.

Var. a) Evica vulgaris flore albo.

Pharin. Ericae Herba.

Hemeine Heide; Rehheide; weiffes Heidekraut. Germ. Commor Heath, or Liny. Angl. Bruyere. Gall.

In campis fylueftribus, pratis fterilioribus bei dem Gefundurunen, hinter Schönfeld, nach Mlockau an; im Lutieler et Univerfititsholze etc. Flor. Aug. Septembr. Perennis.

Vf Prata reddit fteriliora. Pabulum apibus valde egregium, et mel copiofintime praebet. Vbi enim 
haec planta ibi mel rufrum, vbi vero deef, album euadit Oel. 30. I24. - Decolum foliorum lithontripticum remedium veteribas. Ad menfes pellendos in multis regionibus adhibetur. In Anglia folia et caulis fummitates lupuli loco cereuifiae adduntur. In Smolandia ouibus et capris fubfternitur herba. IrNN. Amoen. I. p. 519 . In Silefia oues et equi foliis turionibusque vefcuntur. KROKER.

b.) Flores incompleii, inferi.

197. DAPHNE. I. G. 526. Zeiland. Germ. Kellcrhals. Angl. Sarvu. Gall.

Mezerem. 545. Daphne Roribus feffilibus ternis caulinis, foliis lanceolatis deciduis. LINN. Syft.pag. 37I. EOEHM. n. 66. BLACKw. t. 582. Fl. Dan. t. 268.

Pharm. Laurcolac Cortex. Coccumnidii Semina..

Geneiner Kellerhals; Schallkraut; Seidelbaft; Zeidelbaft; Sïß-WVlfshafi; Bergefeffer; fallcher Pfefferfrcauch; Brenzzeurz; Rehieere; Elendsblut. Germ. Mezercou. Angl. Bois genti, ou Mezereon. Gall.

In filuis vmbrofis et ficcioribus paffim, im $U_{n i}$ verfitätsklze; auf den Kuabeinberge bei Pforte ecc. Fior. Mart. $\Lambda$ prii. Baccae Iил. Iul. maturae. Firut.

Baccae autem pecora, lupos, canes vulpesque necant: apes fugiunt fores et frutex per totum fufpeRus. Flores fuaroolentes, ftupefacientes. Aues folumímodo baccas fine periculo deglutire feruntur. Cortex cuti applicatus facit veficulas et recenter de. rafus contra ferpentum ictus imponitur'a Suecis Mulierculae ruri baceas propinant in morbis rebellibus faepe cffectu de'eterio. 


\section{T R I G Y N I A.}

198. POLYGONVM. L. G. 537. Knöterich; Wege-

tritt. Germ. Knotgrals or Biftort. Angl. Renouée ou Biftorte. Gall.

* Biftorta, fpica anica.

547. Polygonum caule fimplicifimo, monoftachyo; fo- Biftorta.

liis ouatis in petiolun decurrentibus. LINN. Syf. p. 376. n. 2. вОЕНM. ก. 592, BLACKW. t. 254. Fl. Dant。 t. 421 .

Pliarm. Biftortae Radix.

Schlangen-f Gift-Krebszenrz; Ottcr-f. Natterwurz; blïhende Hirfchzunge; Drachenu'urz; Schlangenkraut; Ginfeampfer. Germ. Greater Biftort, or Snakeweed. Angl. Grande Biflorte; Renoúe Bifrorte; Biftorte à épifeul., Gall.

In pratis praecipue vliginolis vbique, frequentiline in Rojenthale, auf den Gorber - und Schönfelder Wie. Sen etc. Fl. Mai. Iun. Perennis.

$V \int$ Flores apibus pabulum et herbam animalia quadrupedia, exceptis equis, deuorant. Radix cruda et cofta in Ruffia etc. editur. In vino decoeta vas cillantes firmat dentes.

** Perficariae; piftillo bifido aut famina mi. nus octo.

548. Polygonum floribus pentandris, femidigynis; fpi-amphibiun.

ca ouata. LinN. Syit. pag. $377 \cdot$ n. 6. вовнм. n. 566 . Fl. Dan. t. $2 \$ 2$.

Var, a) Polygonum aquaticum, natans, foliis cbtu. fis, glaberrimis. tiffmis, $f$ abris.

B) Polygonum terreftre, erectum, foliis acu-

Fíchfelknözerich; klein Wrafferflöhkraut. Germ. Peremial Arswart. Angl. Perficaire amphibie. Gall.

In pifinis et ftagris, $\alpha$ ) boi Linilenau, Leutfch, hinter Nauendonf etc. viuique. B) In pratis et agris patrim. Fl. Iun. Iul. Perennis. 
Hydropiner. 549. Polygonum floribus hexandris, femidigynis; foliis lanceo atis, ftipulis fubmuticis tinn. Syitt. pag. 37 . n. \%. воЕнM, n. $: 6 \%$ BLACKiw. t. 49.

Pharm Perficariae vrentis H:rba.

Walferpfeffer; Bitterling; Scharföhkraut; WafSerblat; Pfausenfpiegcl; Pfauenkraut; Flihpfeffer. Germ. Sharp Arsinart; Watter Pepper:Angl.Perficaire âcre; Poivre deau; Curage. Gall

In paludofis et fofis an dem Gerberwaffer; in foffis bei den Kohlgïrten, Reidnitz, Sellerhaufen, Rücknarselorf et Lindenau, et in agris fubhumidis paffim, Fl. Iun:'ul. An!sua.

VT Planta corrofiua, acerrima, cosmetica, luteo colore tinctoria.

Perficaria. 550. Polygonun foribus hexandris, digynis; fpicis ouatis, oblongis, foliis lancéolatis, ftipulis ciliatis. LINN. Syft. p. 377. n, 10. ВOEHM, n. 567. вLACKW. I18. Fl. Dan. t. 702 .

Var, «) Floribus candidis, foliis anguftioribus.

B) Fo iiis maculatic, latioribus.

Flöhkraut; fleckiges Flöhkraut; Pfirfichkraut. Germ. Spotted Arsmart. Angl. Perficaire douce: Gall.

In locis humidis et multis agris. Var. a) in agrorum-maroinibus inter fegetes inte portulam Schoenfeldicam et portam. Grimmenfens, nach der Milchinfel zu, et in iisdem locis verfus Comewitz dextrorfum. , B) In pircinis et forfis bei Lindenau et alibicopiofe. Fl. Iun. Iul.

Vf. Luteo colore pannos laneos álumine imbutos inficit. LINN.

orientale. 551. * Polygonum floribus heptandris digynis, foliis oustis, caule erecto, ftipulis hirtis hypocrateriformieus. LIN sy syt. $p, 377$. ก. 12.

Perficaria orientalis, nicctianae folio, calyce iorum purpureo. Tournef. Coroll. 38. Coninel. yar. 43. tab. 4 रे.

Morgenlïndifcher Kïzöterich. Germ. Oriewtal Arsmart. Angl. Perficuite orientale. Gall. 
Habitat in India: apud nos folummodo in omnibus fere hortis valde colitur. Fl. Iulio in Septombrem vsque.

VJ. Semina auibus pabulum pergratum. Foliis tenellis Sues auide vefcuntur.

*** Polygona, foliis indiuifis, floribus octan. dris.

552. Polygonum fioribus octandris, trigynis, axillari-auiculare. bus; foliis lanceolatis, caule procumbente, herbaceo. IINN. Syft. pag. 378 n. 15. военм. n. 589. BLACKw. t. 3I 5. Fl. Dan. t. 803 .

Var. a) Polygonum foliis anguifis, breuibus.

B) Polygonum foliis oblongo-linearibus.

Pharm. Centunnodiac Herba.

Vogelknötrich; Megelauf; Iungferntritt; Wegetritt; Wegegras; Blutrarbe; Blutkraut; Blutgras; Angerkraut;Zehrgras; Taufendknoten; Tcnnegras; Unvertritt. Germ. Common Knotgrafs, or Centeftode. Angl. Herbe de St. Innocent; Trainafje commun; Renouće des oifeaux. Gall.

In plateis, ad agros, fepes, in verfuris et viis publicis vbique. Fl. Iun. in autumnum vsque.

Obf. Calyx modo viridi, modo rubello colore, quoad loca diuerfa, deprehénditur.

$V f$. Semina autumnali tempore a pantribus et columbis auide quaeruntur et quoque in annonae caritate hominibus pro pane iníeruire poffunt.

Planta autem in folo humido crefcens ouibus ma: xime nociua, Boehm.

\section{***** Helxines, foliis fubcordatis.}

553. Polygonum foliis cordato-fagittatis, caule ere?̣tius- Eagopyrum. culo, inermi, feminum angulis aequalibus. LiNN. Syft. p. 379. n. 2\%. вовнм. n. 590.

Pharm. Fagopyri Semina.

Heideion; genteiner Buchweizen; Blent.e. Germ. Buck Theat. Angl. Blue noir; Seigle Vellar; Sarrafin. Gall. 
In agris inter fegretes paffin ante portulam Schönfeldicam, praecipue autem bei Mockau. Fl. Iun. Iul. Aug: Annua.

VJ.Planta recente et ficca pecora vefcuntur.Seminum farina pan? inferuit in Lufutia inferiori et popana ex his ibidcin coquuntü e: inter alinenta confuetamemorantur. Cortices feminum inter tecta hyben naculorum Belgae collocant. LINN. In culinis coquunturf fmina ex. corticata cum aqua in puitem, vel cum lacte in pul. mentum. Herbam ficcam refpuunt equi, edunt con. tra Boues, fed Oues inde contaminantur. Scart.

Conuoluu- 554. Polygonum foliis cordatis, caule volubili, angulalus.

to, floribus obtuiusculis. LINN. Syf. p. 379. n. 28 . военм. n. 591. Fl. Wan. t. 344 .

liildes Heidekorn; Vogelange; Heidelwinde; Schwarz- 1. Buchwinde. Germ. Black Bindreed. Angl. Blé noir Lifiron, on Sarrafun grimpant. Gall.

In agris cultis oleraceis, hortisque frequens. Fl. Iul. Aug Annua.

Obf. Planta agris noxia.

- Vf. Semina hominibus et auibus éfculenta, etherba a pecoribus_quaeritur.

dumetorum 555. Polygonm foliis cordatis, caule volubili, laeui: floribus carinato-alatis. LINN. Sy f. pag. 3-9. n. 30 . schrer. Spicil. p. iz. n. 9 8. Fl. Dan. t. 756.

Vogelaurage; große Bubenwinde; Bufchheidelorn. Gcrm. Clining Buckwheat of the Thichets. Angl. Blé noir dés hẩes. Gall.

In lepibus dumetisque frequens in Streitholze, in der Kanmerei bei Nauendorf etc. Flor. Iul. Aug. Ana nua.

\section{T E T R A G Y N I A.}

199. ADOXA. L. G. 5 `3. Bifankraut. Germ. Adoxe. Gall,

Mofchatlli- 55\%. Adpoxa foliis plerumque ternatis, lobatis, unNN. na, Sylt. pag. 381 . вогім. n, 0\%. Fl. Dan. t. 94. 
Kleines Bifamkraut; 'Bifamhahnenfuß; Waldrauch; Bifamkraut. Germ. Holloweroos; Mufk-Crowefoot; Touberous Mofchatel. Angl. Fleur Mufcuéc; Mofcatelize à feuilles de Funetcrie bulbenje. Gall.

Ad fepes, maxime circa arborum detruncatarum radices, in locis paludofis hinter den Kohlgârten nach Schönfcld $\approx u$, auf den Eutrizfcher Wiefent, in der Prellheide intra Alnos; et quoque ad riuulos nemorum verfis Nöszfchetc. Flor. toto vere. Perennis.

Cbf. Capitulum tetra gonum $\mathrm{ex}$ is floribus verticillatis compofitum: Flore terminali vnico 4 fido, cetandro, tetragyno. Cal. bifido; flo. ribus lateralibus $4-5$ fidis, decandris, pentagynis. Cal. paffim 3 fido. - Tota planta Mofchi odorem fpargit.

200. PARIS. L. G. 542. Einbeer. Germ. Oneberry. Angl. Pairiette. Gall.

557. Paris foliis quaternis, ouatis. LINN. Syft. p. 38I. quadrifolix, BOEHM. n. 302. BLACKW. t. 286. Fl. Dalt. t. 139.

Pharm. Paridis Herba, Baccae.

Vielblittrige Einbeer; Wolfsber; Sternkraut; Venusficgal; Fichstraube. Germ Frue-love, One-Berry, or Herb Paris Angl. Horbe à Paris, ou Raifinde Renard; Etrangle Lonp. Gall.

In fyluis praecipue imi fofcnthale etc. Flor. Mai. Iun. Perennis.

Obf. Foliis ternis et quinis paffim mihi occurrit. - Planta narcótica, et baccas galinis aliisque auibus lethales, GESNERvs refert; hominibus autem mouere ventriculi fpasinos et vomitus.

\section{I. ELATINE. L. G. 544. Elatine f. Hendel,}

\section{Gerni.}

558. Elatine caule repente, dichotomo, ramofifimo, Hydropipe: folis oppofitis. LINN. Syft. p. 381. schres. Spicil. p. 22. n. y32. F\%. Dani. t. I 56 .

IVaferpfeffer; pacrbl.ttrichte Elatine. Germ. Op̣pofite-leaved Elating. Angl. 
Ad pifcinas bei Lindenax, hinter Kriphine, bei Nanemdorf étc. Flor. aeftate. Annua.

Alinaftrum. 559. Elatine caule ere.to, fimplici, foliis verticillatis. IINN. Syft. p. 38 I. n. 2. BOEHM. n. 3O1. vaILl. Parif. 6. t. 1. f. 6.

II a ferkrouel; wirbelformige Elatine. Germ.

In paludiburs exficcatis aquoficgu: ftagnantibus" hinter dem Liniler Hölzchen, bei Plaufig. Flor. Iun. Iul. Perennis.

\section{B. FLORE : DICLINO.}

202. POPVLVS. L. G. 127\$. Efpe; Afpe. Germ. Poplar - Tree. Angl. Peuplier. Gall.

siba 560. * Populus foliis fubrotundis dentato-angulatis; fubtus tomentolis. LiNn. Syf. p. 889 . n. I. DVHAM. Arbr II. t. $3^{6 .}$

Populus altrs máoribus foliis. C. B. P. p. 429 .

Theiffe 1. Silberpappel; werffer Albeerbaum; "Teißbaum; Bcllbaum; Heilgen-؟ Götzenholz.Germ. White l'oplar: Abele-tree. Angl. Peupliev: blanc, mâle ous femcile; Grifaille de Hollande; Ipreau; Franc-picard; Aubel, ou Orme blanc. Gall.

In tolo hi:mido et locis fyluaticis pafim, in pagis ante domos et circa pagos haud infrequens; in hortis p'uris is fuburbanis et in Serto quoque nuper plant ta. Fl primo vere.

Arbor pulchra ob folia fubtus albifima a vento facile "gitats p aebet fpectrculum, ac fi nine recta êfet, dehine Ambulacra ornat, Folia capiris, ouibus equisque prbu um bonum.

tremula.-561. Populus foliis fubrotundis, dentato angulatis vtrinq̨ue glabris. LiNN. Syft. p. 889. n. 2. вовнM. n. 70". BLACKW. T. 2.48. CKAM. t. '3.

Efche, 1. Afche; Flatterefpe; Zitterpappel; lybifche Panpil. Germ. Afpen Tree, or Trembling Poplar. Angl. Peuplier Tremble- Gall. 
In pratis fyluaticis et ad flunionum ripas, in $R_{0}$ fenthale; hinter der Funkenburger Wiefe ad Pliffae ripam; porro in nemoribus, im Gonnezeitzer, Macherfchen, Zfchocherfchen Holze, in der Tämmerei, in der Prellheidc, atque in aliis filuis; pafim quoque in der Allee et ad varios multos pagos. Flor. Mart. Arbor.

Obf. Radicibus reptantibus praedita, - Fol. pabulum equis et ouibus preebent tgregium. Cortex primarius eft Caftorum cibus, et vilidis eiusdem fumus gryllos pellit. Lignum ad clitellas, ia!a lactea, amphoras alisque elaboratur. In foco lignum comburitur, minus calefacit.

562. Populus foliis deltoidibus, acuminatis, ferratis, nigra. LINN. Syft. p. 889. n. 3. вовнM. в. 706. BLACKW. t. 248. CRAM. t. II.

Pharm. Populi Oculi (Gemmae retius).

Schwarze Pappel f. Efpe; Pappelbaum f. Pappelteeide; Schwarzer Alberhaum; Surbache; Sarbaum: Bellenholz. Germ. Black Poplar. Angl. Peuplier noir. Gall.

Ad prata, in fyluis, ad ripss foffarum, fluuiorum, pifcinarum, copinfe bei Parneck, Gunndorf, im Rofenthale; in Ambulacris ante pagos plurimos, ad fepes hortorum rufticorum, in pafcuis fere vbique et alibi. Fl. Mart. April.

Vf. Arbor ambulacris maxime vtilis. Ex gemmis vnguentum populeum praeparatur. Rufí parenchyma corticis loco, Subere pro epiftomiis adhibent. Gmel.

563. * Populus foliis rhomboidiformibus, diftincte cre "Italica. natis, longe petiolatis, alternis. SERT. Lipf. $n$. 72.

Populus nigra DV Rot Harblk. P. II. pag. 14I, var. ß. italica. 
222 CLASSIS VIII. OCTANDRIA. DIClino.

Italienifche f. lombardifche Pappel Germ. Lombar dey Poplar. Tree. Angl. Pezplier d'Italie ou de Lonbardie. Gall.

In Italia habitat, vnde circa $1770^{\circ}$ in Saxonian translata eft. Apud nos hofpitatur preeprimn's circa 'vrbem in Ambulacris magnis, porro in Ambulicroante pagum Keifchan et alibi; atque in permultis hortis, e, g. in Horto Trieriano, Win leriann, Lehriano et in aliis etc, fuburbanis paganisque. Fl, vernali tempore.

Olf. Differt a priori, ftatura paulo minori; trunco magis ramolo pyramidem referente; ramis multo fexibilibus; folits anguftioribus, obfcure viridibus, magis filendentibus; ligno albidiore, fibris tenuioribus intertexto; cortice magis albefcente, verfus finess rami laete viridefcente. 


\section{Claffis IX. \\ EN N E A N D R I A}

H EXAG Y N I A.

\section{A. FLORE HERMAPHRODITO.}

203. BVTOMVS. L. G. 530. Wafferlifch.

Germ.

564. Butomus foliis longis, triquetris. LINN. Syft. p. vinbellatus. 385. вовнм. n. 254. Fl. Dan. to 604..

Doldenformiger Wafferlifch; Wafferviole; Blumenbinfen; Kameelheu. Germ. Flowering-RuSh, or Water Gladiole. Angl. Fouc flewri. Galt.

In ftagnis zerifchen Pfaffendorf und der Wachsbleiche an dem Wege nach Goblis copiofe et ad fiuuios in Gerberzeafer; in foffis nach Lindenau, hinter der großen Funkenburg, ${ }^{2 n}$ der Bahre in pifcinis bei den Gefundbrunnen, Schönfild, Plaufigg; Sominer. feld, Tauche etc. Fl. Iul. Aug. Perennis.

\section{B. FLORE DICLINO.}

204. MERCVRIALIS. L. G. I230. Bingelkraut. Germ. Mercury. Angl. Mercuriaie. Gall.

565. Mercurialis caule fimpliciffmo, foliis fcabris. perennis. Iinn. Syft. p. 890. вовHM. n. 709 . Fl. Dan. t. 400.

Vieljähriges Bingelkraut; weibliches und minnliches Bingel hraut; Speckmelde. Germ. Doy's Mercury. Angl. Mercuriale des bois, ou de montagne. Gall. 


\section{C.LASSIS IX. ENNEANDRIA. DICIINÓ.}

In alnetis et faludofis vmbrofis, hinter Neufcher. bitz, in Streitholze. Fl. Mai. Iun. Perennis.

Plantá fulpecta, - vomitoria, valde purgans; Atupefaciens.

annua, 566. Mercurialis caule bracchiato, foliis g'abris, floribus fpicatis. IINN. Syft.p. 709. n. 3. BOEHM. n. 708. BLACKW. t. I62.

Pharm. Mercuinolis Herba.

Fähriges Bingelkraut. Germ. French Mercury Angl. Mercuriale male et femelle, ou Foirole. Gall.

In agris et locis ruderatis, bei den Kohlgärten; in locis humidis ad Gumbarf, et ad muros in grimmifchen Zuinger nach dem Petersthore zu, mihi paffim occurrit. Fl. per totam fere aeftatem.

205. HYDROCHARIS. L. G. I 23 I. Plompen. Germ. Morraine. Gall.

Morfus Ra- 567. Hydrocharis foliis cordiformibus, orbiculatis, nanae.

tantibus. Linn. Syft. p. 890. военм. n.695. Fl. Dan. t. 878 .

Frofchbiß. Germ. Moraine grenouillette. Gall.

In forfis limofis. fluuiis, in dem Graben vor Pfaffendorf, in der Pleife bei Schlenfig, in pifcinis bei Kriphäne; Nauendorf bei der Kaminerei; Gothe etc. valde frequens et alibi. Fl. Iul. Aug. 


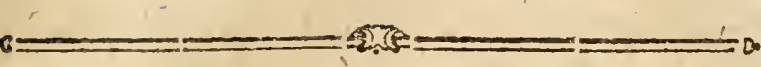

\section{Claffis $\mathrm{X}$. \\ D E C A N D R I :}

MONOGYNIA.

\section{A. FLORE HERMAPHRODITO.}

*) Calycibus I - phyllis. Floribus 5-- petalis. Frustu,
I-capfaliori. 206. RVTA. L. G. 56: Raute Germ. Rue. Gill.

568. * $\mathrm{R}_{u t a}$ foliis decompofitis, lateralibus quadrificis. graueolens.

LINN. Sift. p. 39\%. ELACKW, t. 7.

Rura fylueftris maior. C. B. P. p. 336.

Pharm. Rutae Herba, Semina.

Gemeine Raute; Wein-1: Gartenroute; Starkrie. chende Raute. Germ. Garden Rue. Angl. Rue des jardins, out Rue à odeur forte Gall.

In Eulopa auftríli et Oriente hahitat: apud nos in muris, ad fepes hortorum et in vinetis verfus Vaumburg yafim: maxime autem in hortis, rutticanis et oleraceis. Flor. Iunio in Auguftum vsque. Perennis.

$V \int$. Ex herba recente tantulum olei obtinetur, e feminitus contra longe plus. Sem Rutae veteribus Romanis fuerunt culinaria atque inter reliqua aromata cibicondimentum effecerunt, pariter ac ipfa herba ficcata, vel recens, vt tradit apicivs COEIIVs, 


\section{6}

207. PYROLA. L. G. $: 99$. IVintergrün. Germ.

Wintergreen. Angl. Pirole. Gall.

rotundifolia.56̧. Pyrola faminibus adlcendentibus, piftillo declinato. uins. Syft. p. 408. военм. n. 465. Fl. Dan. t。 110.

Pharm. Pyroine Hesba.

Rundblättriges Wintcrgrün; Waldmangold. Germ. Comurnon or Round leaved Wintergrein. Angl. Pirole à finilles rondes. 'jall.

In hamidis vmbrofis, paffim bei dem Gcfundlbrunnen, et in fyluis, im Univerfitätsholze copiofe. Flor. Iun. Iul. Perennis.

minor. 570.* Pyrola foribus racemofis difprefis; ftaminibus pintilloque ere:tis. LINN. Syft.' p 408. n. 2. вогнм。 n. $465 .$. var. 3. Fl. Dan. to 5.5 .

Kleines Wintergrïn. Germ. Leffer Wintergrcen. Angl. Petite Prole. Gail.

In tyluis apricis et vinbrofis, paffim im Univerfitütsholze, Fl. lun. Iul Perennis.

fecunda. 57. Pypola racemo vnilaterali. LINN. Syft. p. $408 \cdot$ n. 3. BOEHM. n. 466. Fl. Dan. t. $\div 6 \%$.

Einfeitiges Wiutergriin. Geim. Tenderer Winter. green. Angl. Pirole ondulcée. Gaill.

Habitat in fyluis cum prioribus. FI. Iun. Iul.

vimbellata 572 . P'zrola pedunculis fubumbellatis. LiNN. Syft. p. $40 \hat{\sigma}$. ก. 4. BOEнM ก. $46 \%$.

Doldenförmiges Wintergrün. 'Germ. Umbellated IVinter-green. Angl Pirole arbiffeaz. Gall. Iul.

In fyluis fparfun in Univerfinatsholze. Flor. Iun.

vniflora. 573. Pyzrola feapo vnifloro. uinn. Syft. pag. 409. n. 6. воені. n. ‡6*. Fl. Dan. t. 8 .

Einhlitiges Wintergrïn. Germ, One flowered Winter-gretn. Angl. Pirole à une fleur. Gall. Iul.

In iisdem locis cum praccedentibus. Flor. Iun. 
208. LEDVM. L. G. 59r. Kühnroft; Porfch. Germ. Wild Rofemary. Angl.

574. Ledun foliis lineari-lanceolatis, fubtus ferrugi-paluftè. nco tomentofis, farninibus corolla longioribus. ReTz. Prodr. Flor. Scand. n. 435. LINN. Syft. pag. 402. Schreb. Spicil. pag. 28. n. 43. DVhamel Arb. I 3 .

Ledum foliis fparfis linearibus margine reuolutis, fubtus rubiginolis; floribus decandris. Jace. Collect. Vol. I1. p. 4.2. n. XVII.

Pharm. Rosmavini Sulueftris Herba.

Sumpfkithnroft; Porjt; Porfch; Pooft; Zeitheide; weiffe Heide; Bienenhutide; wolde Rosmarin; Mutterkrant; Mottenkraut; Kienpoft. Germ. Small wild Roj-mary; or Marfh C.ftus. Angl. C'2fte à feuilles de Rosinarin. Gall.

In nemoribus, in der Diibencchen Heide trequentiffime. Fi. Iun. Iul.

$V J$. Flores apibus pabulum optinum. Herba graueolens, narcotić, pecorum pediculos necat, et odor penetrans caput grauetcit, tineas necat, cimicesque fugare fertur. In regionibus nonnulis pro Lupulo in cereuifia conficienda adhibetur, quae temulentian inde et cephlylgiam scitat. Decostum eiusdem in thriticis et rheumatic doloribus apend viefios ficicum euentu adhibetur. Ol um deftillatum hetulino additum coria Ruflolum (luchten) diftinguit. Infuper ex herba lixiuium, quod coriis parandis valde aptum eft, conficitur.

(B) Calycibus 5-phyllis.

209. MONÓtROPA. L. G. 583. Ohnblatt. Germ. .

575. Nonotropa floribus lateralibus octandris, termina-Hypopithys. li decandro. LiNn. Syif. pag. 402. военм, n. 300. Fl. Dan. t. 2,52.

Fichten-Spargel; Banmuarzelfauger;" Ohnblatt; Waldfonmerieuri, Germ. European Monotropa. Angl. 
In fyluis vmbrofis, im Bieniz; im Univerfitaitsholze; et quirque in der Prellicerde, int.r Pinus dicht an den Holazeege a"echts nach Dïben zun nuper detexi Flor. Mai. Iun. Perennis.

Pianta parafitica radicum Pinus fylueftris et gbietis. - Odore gaudet grato. Color totius plantae fordide fnuus.

b) Flores 5- petali; Fruâtu multicapfulari.

210. * DICTAMNVS. L G. 566. Diptam. Germ. Dittony. Angl. Dictam. Gall.

albue. $5 \%$ 6. * DiEtamus foliis pinnatis, caule fimplici. uINN. Syft. p. 39\%. BLACKw. t. 75. MILL. t. 123. JACQ. Fl. Aufr. V. 5. t. $\div 28$.

Dictamnus albus valgo Fraxinella. C. B. P. pag. 222.

Pharm. Dictamni albi f. Fraxinellde Radix.

IVeiffer Diptan; Spccht-Acfchcreeurzel. Germ. White, or Baftard Dittony. Angl. Diptam blanc. Gaill.

In Europa auftrali: v. c. in ltalia, Gallia, Germania habitat; apud nos cont 2 in hortis plurimis colituir. Fl. Iun. Iul. Pereńnis.

VJ. Cel. Stoerkius *) tincturam e radice recenti paratson et qunque puluerem radicis dofi i- " et 9 cafibus vfum eiusdem confirnat, vt anthelminthicum et emmenagogum praeftantifinum.

\section{I G Y N I A.}

\section{a). Flores apetali.}

211. SCIERANTHVS. L: G. 6II. Knauel. Germ. Knawel. Angl.

amius. 577. Sclerantlaus calycibus fructus patulis. IxN. Syft.

p. 415. воEнM, n. 595. Fl. Dan. t. 504. Scle:

*) Vid. Lib, de Flanmula Ionis, Diâtamno albo etc. 
Scleranthas annums laciniis calycis patulis, acutis viriảibus, WILDEN. Prodr. Berol. n. 467.

Einjähriger Knaucl; 'Knörich; Knzötcreln; zeild Iohanniskrant; kleiner IVegetritt. Germ. Common Ger. man Knot-graß, or Knazeel. Angl, Knavel annuel. Gall.

In agris inter fegetes vulgaris. Fl. aefate.

Obf. Fotia fubcainofa, viridia, linearia; Alosculi exigui, parui. Calyx acutus, viridis. Stam. 5- ro pafim numeraui.

578. Scleranthus calycibus fructus claufis. uINN. Syft. perennis.

p 415. 1. 2. sснлев. Spicil. p. 43. n. 969. Fl. Dan.

t. 563 .

Scleranthus perennis laciniis calycis erectis, obtufis albido emarginatis. wilden. Prodr. Berol. n. 468.

Pharm. Polygoni cocclferi Herba.

Vieljahriger h́nauel; Iohannisblut. Ferm. Perenuial, Knarel. Angl. Knavel vivace. Gall.

In collibus arenofis, an Bieniz et alibi. Fl. Iun. Iul.

Obf. Folia plura. Flosculi maiores: Calyx obtufior, viridi-albus, vnicum femen faepius contia nens.

\section{I2 CHRYSOSPLENIVM. L. G. 607. Milzkraut;}

Germ. Golden Saxifrage. Angl. Saxifrage dorée.

$$
\text { Gall. }
$$

579. * Chryfofpleniun foliis oppofitis, caule tetragono. oppofitifor LINN. Syft. p. \$II. RоTH. Fl, Germ. I. p. 172. Leys. - lium.

n. 4 I . Fl. Dan, t, 36 .

Saxiraga rotundifolia aurea. C. B. P. p. 309.

Kleines Goldmilakraut; Milzkraut mit gegenüberfehenden Blättern Germ. Common Golden Saxifrage. Angl. Dorine à feulles oppofées ou Saxifrage dorée. Gall.

In fyiuis et nemoribus paludofis vmbrofisque, 'e. g. in der Prellizeide intra Alnos pafrim; im Machem flien et Otzeruifcher Holse. Fl. Aprili. 
Obf. Caulis erectus priori minor, tetragonus, glaber. Fol. oppofita femiorbiculata, obtufe finuata, minora.

altrnifo- 580. Chryjofplenium foliis alternis. LINN. Syft. p. $41 \mathrm{r}$. lum. вовнм. 11. 5:8. Fl Dan t 66.

Pharm. Chrufojpleniti Nofurtii petraci Herba.

C: ̈̈ldenfteinbrech; rauches Mondirant; Buttcrblune; Goldveilclien; Steinkvoffe; großses Milzkrant; Güldennilzkrant. Germ. Alternnie-leaved Golden Saxufrage. Angl. Dorine ì feuilles alternes, ou Creffon des Roches. G.11.

In locis humidis, vmbrofis ad atborum Alni Salicumque radices, anf den Wiefen zwifchen Gohlis et Eutrits $/ \mathrm{cl}$; in Alneto bei Mockau; im Sonimerfelder ct Machergchen Holze etc. Fl. Mart. Aprili.

Obf. Stamina , 10, 12 obferuaui.

$V j$. Fiores apibus pabulum egregium.

- Herba cum Oleribus cocta vehementem excitat vonitum.

b) Flores 5- petali; fructu vnicapfulari.

2I3: SAXIFRAGA, L. G. 603. Steinbrech. Germ. Saxifrage Angl. et Gall.

* Foliis indinifis, caule foliojo.

granulata 58\%. Saxifraga foliis caulinis reniformibus, lobatis, caule rainolo, radice granulata. LINN. Syfr. p. +13 . n. 27. воЕнм. ก. 372. вLACKW. t. 56 . Fl. Dan. tab. 514 .

Pharm, Saxifragae albae Radix, Herba, Flores, Semina.

Rörniger 1, weiffer Steinbrech. Germ. White Saxifrage or Sengreen. Angl. Saxifrage blanche ou gremue. Gall.

In locis graminibus fere deftitutis et collibus, auf den Gickerlingsberge, auf dem Wege nach Schönteld, et alibi. Fl. April. Mai. Perennis. 
** Foliis lobatis, caulibus erectis.

582. Savifraga foliis caulinis reviformibus, trifidis, tridanylites alternis, caule erecto, ramofo. LiNN. Syf. p. 414 . n. 3.2. BOE HM: n. 373 .

Dreafungriger S kleiner Steinbrech; Sundpeinbrechkraut: dreifuigeruchte Dachhauswurs; Händlcinkraut; Frujchtatzen, Germ. Saxifrage tridactile ou cunciforme. Gall.

In locis vliginofis et fubhumidis, agris, aruis, auf der Wiefe bei Riickmarsdorf, porro in muris vor den Windmiihlenthore IUl. PoHLIVs reperit. Fl. April. Maio. Annua.

Vf. Herba vt Portulaca in Acetariis inferuire potent.

214. GYPSOPHYLLA. L. G. 6r2. Gipskraut. Gernb.

583. Gypfophylla foilis linearibus, planis; calycibus muralis. aphyllis; caule dichotomo, petalis crenatis. LINN. Syft. p. +16. n. 10. вовнм n. 3 I.

Mauergypskraut; kleine Mauernelke. Germ. Annual Gyploptisilia. Augl.

In aruis et muris vbique frequens, Flor. Aug. Septembr.

2I5. SAPONARIA: L. G. 613. Seifenkraut. Germ: Sope-wort. Angl.

584. Siponaria calycibus cylindricis; petalis integris, ofticinalis, foliis ouato-lanceolatis. LINN. Syft. p. 416. BOEHM. n. 309. WrLden. Prodr. Berol. n. 470. BLACKw. tab. I1 2. Fl. Dan. 1. 543.

Phorm Sapanariae Radix, Herba, Semina:

Geüönl ches Seifunkraus; Speichelueureel; Seifen-

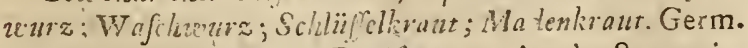
Common Sopereonrt; Bruifererort. Angl. Saponairs offi inale on Lampetze, Gall.

In locis vinbr-fis, p.fim inter Plagwitz et Kleinsfchocher au durEljter; cum flore pleno bei den Straf- 
Jenhinferz frequenter reperi. Flor. Ful. Aug. Perennis.

Vf. Pollen antherarum purpureo tingit colore. Radix valclé repens, hortis molefta.

Vaccaria. 585. Saponavia calycibus pyramidatis, quinquangularibus; foliis ouatis acuminatis fefilibus. LINN. Syf: p. 416. n. 2. Бовнм. n. $3^{\circ} \mathrm{O}$.

Getreidefeifenkraut; Kuhkraut; wilder Waid; Karthenferbiunean; Erdueeil. Germ. Corn Sope-wort. Angl. Sazonaire blé de-vache. Gall.

In agris inter fegetes bei Comeroitz pafim. Flor. Iun. Iul. Annua.

216. DIANTHVS. L. G. GI 4. Nelke, Germ. Pink. Angl. Oeillet. Gall.

\section{* Flores aggregati.}

barbatus. 586. Dianthus foribus aggregatis, fafciculatis, fquamis calycinis ouato-fubulatis, tubum aequantious, foliis lanceolatis. Linn. Sylt. p " 417.

Bartnelke. Germ. Sweet Willian. Angl. Ocillet bavipu. Gall.

In locis humidis, graminofis er fterilioribus, auf der Wicfe hmter Klcindölzig, etiam auf der Ruckmarsdorfer Wicfe, porro auf den Aeckern vor Nanndorf. Fl. Iul. Aug. Perennis.

Carthufa- 587. Dianthus floribus fubaggregatis, fquamis calycinorum. nis, ouatis, ariftatis, tubum fubaequantibus, foliis trineruiis. LINN. Syft. p. 417 . n. 2. вовнм. n. 366 .

Pharm. Tunicae fylueftris Flores.

Steinnelken; rothe Feldnelken; wilde Karthoufer f. Domiernelken; wilde Grasblumen. Germ. Oeillet des Chartreux, ou des montagnes, ou ronge. Gall.

In locis gramine veftitis paflim. Fl. Iun.Iul.Per. ennis.

Armeria. 585. Dionthus foribus aggregatis, fafciculatis, fquamis calycinis, lanceolatis, villofis, tubum aequantibus. LINN. Syft, p. 41\% n. 4. вOEHM, n. 363. Fl. Dan. t. 230. 
Muthuille; wilde Bartnelke; Thiernàgelein; wilde Pechnelken. Germ. Deptford Pink. Angl. Oeillet velit. Gal.

In pratis nemorofis et fyluis im Rofenthale, im Bicwiz. Fl. Iun. Iul. Annua.

5i9.* Dianthus floribus aggregatis, capitatis, fqua- prolifes. mis calycinis ouatis, obtulis, muticis, tubum fuperantibus. Linn. Syft. pag. $41 \%$ n. 6. Fl. Dan. tab. 221.

Kleine üilde Nelken; einjahlige Bartnelke der Engländer; fproffcirde Nolke; Kopfnï̈glein. Germ. Annual Sweet Willian. Angl. Oeillet prolifere. Gall.

In campis ficcis et elatioribus, ad margines agro. rum nach Schönfeld zu inueni. Fl. Iul. Aug.

** Flores folitarii, plires in eodem caule.

590. * Dianthus floribus folitariis fquanis calycinis fub-Caryophyl ouatis breuifimis, corollis crenatis. LINN. Syft. pag. lus. 41: n. 8. BLACK w. t. 85 .

Pharm. Tanicae Flores.

Gemeine 1. Cartennelie; Grasklume; Nägelein; Giroffeln. Germ. Garden Gilli-Flozer; Clove InlyFloweer. Angl. Oillet des Ficuriftes; irofflée. Gall.

Colitur vbique in hortis. Fl. Iun. in Augufum vsque. Perennis.

Varietates innumerabiles hortos decorant et f́pelta. culum Curioforum praebent gratifimum.

Infufi aquofi cum Spiritu Vitrioli fanguineus fit color. Cum Vitriolo martis ftatim nigrefcit. BERGIVs.

59I. * Dianthus Aoribus folitariis; fquamis calycinis lan- detoideş ceolatis, binis ; corollis crenatis. LINN. Syft.p. $419 . n$. IO. Fl. Dan. t 577 .

Deltaformige Nelke;-kleine Grasnelke; Heidenelke; Iungfernelke; "Feldnelie; Feldnelie mit klcinen Kelchfchuppen. Germ. Pink. Angl, Oeillet rampant, ou couché Gall.

In collibus, pafcuis: bei Riickmarsdorf auf dem Berge; an Biewiz; in agris cor Nauwdorf. Fl. Iul, Aug. 
plumarius, $54 \approx$ * Diantluzs foribus folitariis, fuuanis calycinis tubonatis breuifinis, corollis multifilis fauce pubef́entibus. LINN. SyRt p. 1 I . n. I5. SCHOLL, Suppl. Fi. Barb. n. 043 .

Caryophyllus fylueftris flore laciniato fine corniculis od ro. C. B. P. p. 2 ia.

Federnelke. Germ. Wild Pins of the Forefts. Angl. Ceillet frangé. Gali.

Ad fepes bortorum et in pomariis paffim; fre. quentius autem in hortis fere cmnibus. Fl. Mai. Iun. Perennis.

fuperbus. 503. Dianthus foribus paniculatis: fquamis calycinis breuioribus acuminatis, corollis multifido-capillaribus, caule erecto. LINN. Syf. $p+12$ n. 16 . вовн. ก. 3 (5.5. El. Dan. t. 578. JACQ. Ob. t. 25. KERN. Hag. $10^{-}$. t. $18 \%$.

Hohe Federnelken; Pfau-folze Nolken; Bu, chnelke; Prachtreike; Mutherille; Hochmuth. Germ. Superb Pink. Angl., Ocillet fupirbe, ou Mignardife. Gall.

In locis graminofis humidisque pratis; nuf der Wiefe hinter Kleizedölati, anf den Schanzen hinter Schönfolt, porro copiole in pratis ad Linderhayn cum Gentiana Pneunonanthe copiole. Flor. Iul. Aug. Perenris.

\section{*. $\quad$ *** Caule vaifloro, herbaceo.}

arenarius, 594. Dianthus caulibus fubuniforis, fqumis calycinis, ouatis, obtufis; peralis multifitis, foliis linearibus. LINN. Syft p. 41 i. n. 17. еовнм. 13. $36 \%$

Sandnelke. Germ. Stone-Pink. Angl. Ocillez desfables. Gall

In locis Aerilioritus, arenofis, elatioribus fere whique hinter din Gerbomeiefin, auf den Bergen bei Wleckeris, im Bieniz etc. Flor. Iul. Augufto. Annua, 


\section{T R I G Y N I A.}

a) Flores 5-petali, tructu 3-capfulari, calycibus monopingllis.

21\%. CVCVBALVS. L. G.615. Taubenkropf. Germ.

Camillet, call.

595. Cucubalus calycibus campanulatis, petalis difan- bacciferus.

tibus, pericarpiis coloratis, ramis diuaricatis, LINN.

Sy ft. p. 419. вогна. n. $3 \% 9$.

Bcerentragender Taubenkropf; Hecken - f. BufcíHïnerdarm; groliser f. Schevarser Hünerbiß: Germ. Bcrry-bearing Clickweed. Angl. Cucubale à baies. Gall.

In fepibus vmbrofis auf-den Gonneveitzer Schanzen. Fl. Iun. Iul. Perennis.

596. Cucubalus calycibus fubglobofis, glabris,' reticu- Behen:

lato-venofis, capfulis trilocularibus, corollis fubnudis. LiÑN. Syft. p. 419. n. 2. воEHM. ก. 39- Flor. Dant: t. $\times 5=$.

Pharm. Behen albi Radix.

Wild Serfonkrant; reciffes Marienröslein; fchmaler, gemeiner 1. reerffer Behen; Speyßßpettel; Spielglätte; Wandelkraut; Inuggefellen'nopt; , lied raut; Wiederfoßß; Schónmrösle; Schachtkrant. Germ. Spatling Popply or Bladder Campion. Angl. Camillet, ou Béen blanc. Gall.

In fyluis montofis, frequenter in Bieniz; porro in der Dïlbenfchen Heide. Fl. Mai. Iun,

218. SILENE. L. G. 6I6. Leimkraut; Feldkerze, Germ. Campion. Angl. Cornillet. Gall.

* Floribus lateralibus confertis.

597. Silene petalis bifidis, floribus lateralibus, fecun- nutans. dis, cernuis: panicula nutante. Lins. Syft. p. $4=0$. n. 9., BOEIIM. n. 395. Fl. Dan. t. 242.

Lychais trigynis fecundis, pariculatis, pendulis, petalis conuolutis, bifidis. scop. Carn. p. $503 . n$. 
Weiffe Klebnelke; weiffer 1. wilder Wiederftoß; 2ecuß 1. wild Frauenröslen; ;iberluangendes Lcinkraut; - Irandelliraut. Germ. Broad-leaved mountain Campion. Angl. Cornillet penché. Gall.

In dumetis variis, hinter den Kohlgärten, im Uni. werfititsholze, in Kleindelziger et Sckewdizer Holze, in Bienizetc. Fl. Iun, iul, Annua.

\section{* Floribus ex diciotonia caulis.}

notiflora. 598. Silene calycibus decemangularibus; dentibus tubum aequanibus; caule dichotomo, petalis bifidis. IINị. Sy ft. p. 42r. n. 23. Scireb. Sp cil. pag. 31. n. $9+9$.

Nachthlühendes Lein'raut; wild Nacht-Marierröslein. Germ: Night-flowering Catch-Fly. Angl:

In nemcribus vmbrofis ad Gonnewitz, Gautfch. Fl. Iun. Iul.

Armeria. 599. Silene fleribus fafciculatis, faftigiatis, foliis fuperioribus cordatis, glabris, petalis iutegris, LINN. Syft. p. $1: 2$. n. $3 \%$ Fl. Dan. t. 5.59 .

Lychnis vifcofa purpurea latifolia lneuis. C. B. P. p. $=0$ :

Nelkenartige Silene. Germ. Broad leaved Campion, or Lobel's Catclifly. Angi Cornillet Oeillet. Gall.

in hot tis inter olera paffrm: in hortis aurem fub- urbanis e rufticanis fiequentius; in ruderatis et reiect mentis hinc et illinc, fed raro. Flor. Maio et Iunio.

b) Flores 5-petali; fructu monoloculari, ca. lycibus 5 -phigllis.

\section{AREN+RI4. L. G. Gr8. Snndkriut. Germ. Chick weed. Angl. Sabloniere. Gall.}

mineruia. 600. Arewaria foliis ouatis, acutis, petiolatis, neruofss. LINN. Syft. p. $+23 \cdot$ n. 5. scHREs. spicil, pag. 29, n. .944: Fl. Dan. t. 329 . 
Dreinerviges Sandkraut. Germ, 'Plantain-leaved Chick-zeed. 'Ang'. Sablonere ì trois nerutures. Ga!l.

In nemoribus humidis, vmorofss et dumetis, co. pioliffime im Rofentlule, in Zfchocherfehen Holze, ins Bieniz, in pint to ad Lindenthal et in pratis humidis ad Abinanezdorf. Fl. Mui Iun. Annun.

601. Arenaria foliis fubouatis, acutis, feffilibus, corol- ferpyilifolia lis calyce breuioribus. LinN. Syit. pag. 723. n. 9 . вовнм. ก. 383 .

Thümianbintrriges Sandkrant; Kleiner Hïhnerlißß. Germ Leaft Chicizeed. Angl. Sabloniere à feuilles de Serpolet. Gill.

In pratis et agris in der Leimgrube, in agris vor den Schönfelder Pfortchen. Flor. Maio Iunio. Annua.

602. Arenaria foliis filiformibus, fipulis membranaceis rubra. vaginantibus. L1NN. Syf. pag. 124. n. 12. - вовнм. n. sili.

Arenaria caulibus proftratis, frliis oppofitis, filiformibus, internodiis duplo breuioribus, calycibus capfulis aequalibus. rотн. Flor. Germ. p. 159.

Rothes Sandikraut; kleines Spergelkraut. Germ Pur. ple-flozecred Chic uiced, or Spurrey. Angl. Sabloniere rouge. Gall.

In arenolis campeftribus et agris hinter Leuifch etc. Fl. Iun. Iul. Aug:

603. * Arenaria cauibus proftratis, folis oppofitis, li- marina. nearibus, fubulatis, carnofis, longitudine internodioim, calycibus capfula dimidio breuicribus. Alfne (maritina) foliis fubcarnofis longitudine intermedioram. linn. Hort. Cliff. 173. schreb. Spicil. p. 29. n. 38I. var $\beta$.

Meerfandkraut. Germ. Sea Spurrey. Angl. Sablo- niere des marais. Gall.

In locis arenofis et falfis, ad Gunnèrsdorf paffim et ad fälinas Kétfchauienfes in magna copia inueni.Fl.Iul. Aug. 604. * Arenaria folis futulatis, caule paniculato cap- tenuifolia: fulis eretis, petslis calyce breuioribus, lanceolatis. LiNn. Sylt. p. 424. n. 20. Fl. Dan. t. 389. 
Var. a) Aremaria vifcola, schres. Spicil. p. 20. n. 945. iub Alfine vifcofa.

Schmalblättriges Sandkraut. Germ. Finc-leaved Chick-reech. Angl. Sablonizere à feuilles itro:ts. inall.

In murris ad Rlcin- et Grofdölaig mihi occurrir, var, in colle ad Tcmplum St. Theclac. Fl. Aprili.

220. STEllaria. L., G. 6 i 7 . Sternpfianze; Meierich. Girn. Stirchwort. Angl. Stelaire. all.

nemorum 605 . Stellaria foliis cordatis, petiolatis, panicula pe-

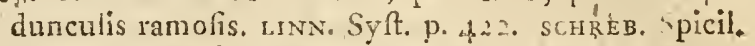
p. 30. n. 946 fub Alfine. Fl. Dan. t. $3-1$.

Waldmeicrich 1, holer Vogelmeicr. Germ. Stellaire, ou Etcilée des bois. Gaill.

In nembribus humidis im Kofenthale, Univcrfitäts. und Zfchocherfichen Holse; auf der Wiefe ad Linden. thal. Flor. Mai inn.

eichotoma. 606. * Stellaria fuliis ouatis fefflihus, caule dichotomo, foribus folitariis; pedunculis fruetiferis reflexis LINN. Sy.ft. p. 122. n 2.

Zweithcilige Stemptanzc. Gesm.

In locis montofis, frevilioribus nach Schörafeld et quoque an Bicnis fecimina pauca, mihi occurrerunt. Fl. Iul. lug:

Holoftea. $60 \%$. Stellaria foliis lanceolatis, ferrulatis petalis bifidis. Linn. Syft. p. 422. n. 4 . Bовна, n. 376 . Fl. Danl. to 698.

Grofes Augcatroftgras; Grofinelkcnmezger; Inng. ferngris; Grasblument f. Blumengras. Gurm. Stelluire graminée. Gıll.

in pratis et fylnis, in Rofenthale et alibi. Flor. Mai. inn Pt rennis

graminea. 608 Strllaria foliis lineribus integerrimit, floribus paniculatis inn. Syft. p. +72 . n. 5. вовим. n. 375 .

Var. «) Stcllaria maine.

a Siellaria minor. Fl. Dan t. $47 \dot{4}$.

2) Stellaria minima foliis lanceolatis. Fl. Dan.

t. $5^{15}$.

Yriascrtiges Steminant; kein, Blumengras; grasblättrigzr Hiincrdaril, Meyer. Gèm. Etoilée. Gall. 
In pratis paludofis. Var. o) e. g. imi Rofenthale $\beta$ ) ad vias publicas, et in alneto et intra firuticeta naclz Schönfeld, $\gamma$ ) ad fepes et in tectis. Flor. Mai. Iun. Perennis.

60i). Stellaria caule diffufo, procumbente, ramofifimo, viliginora. foliis lanceolatis, baticiliatis, anguftioribus, pedunculis terais, lateralibus: intermedio vniforo; lateralibus dichoromis, paucitloris: noтн. Flor. Germ I. p. 19. военм. n. $37 \%$ mviray. Prodr. defe. Stirp. Goetting. p. 55 .

Sumiffternkrout. Germ.

In locis paludolis vmbrofis in dem Univerfititsholze hinter dem Forfterhaufe. Fl. Mai. Iun.

\section{P E N T A G Y N I A.}

a) Flores 5- petali; fruktu tricapfulari; calycibus monophyllis.

22x. LYCHNIS. L. G. 636. Lichtröslein; Wiederftofs. Germ. Lainprette. Gall.

610. * Lychnis floribus fafciculatis faftigiatis. LiNs. chalcedoniSyft. p. 435. n. I. ca.

Ly

Chalcedonijches Lichtröslein; Ierufalcmsblune; Zinnobcrblume; brennende Licbe. Germ. Scarlet Lychnis. Angl. Lamprette croix de Maluhe. Gall.

In Ruffia tota proprie crefcit; apud nos in hortis vbique occurrit. Fl. Aeftate.

$V \int$. Floribus amoene rubris ornat hortos.

6II. Lychnis petalis quadrifidis, fruatu fubrotundo. Flos Cuculi. IINN. Syft. p. 35. n. 2. воEнM. n. 391. scop Cain. p. 304 n. 8. Fl. Dan, t. 590.

Guclucksblume; Fleifch- ᄃ. Gauchblume; GúckucksSipeichel; Gauchnelken; Pechblume. Germ. Raggect Robin; Meadnw Pink; Cucknw-Flower; IVild william. Angl. Lamprette dechirée, ou à Coucou. Gall. 
In pratis humidis copiofe ad Schönfeit, im Rofeñ thale, auf der Wiefe bei Ruckmarsdorf et hinter Klcindölzig. Fl. Mai. Iun. Perennis.

vifcaria. 612. Lychnis petalis fubintegris. LiNe. Synt. p. 435, n.

6. вовнм. n. 390.

Pech-Theer-1. Klebenelke; Klebwiederftoß; Mückenfang; wildes, purpurrothes Marienroslen. Germ. German Catch-Fly. Angl. Lamprizte visqueufe, ou bout bonnoife Gall.

- In montolis auf dem Gickerlingsberge, auf der Anhöhe an Bienitz paflum; in fofliculis bei ScehauJen, ad riuulam bei Nözzciz. Flor. Iun. - Aug Perennis.

divica. 613. Lychnis foribus dinicis, petalis emarginatis; foliis oustis, acutis. LinN. Syft. p. $4,60, \mathrm{n}$. 9. Bовнм. r. 392. scor, Carn. pag. 505. n. 10. Fl. Dan. tab. 492.

Saponaria dioica. WILDEN. Prodr. Berol. n. 472.

.Var. a) Floribus a bis.

- Lychnis fylueftris alba fimplex. C. B. P. p. 204 , BOEHM. n. 393.

B) Floribus hermaphroditis.

Pharm. Saponariae albae Radix

Morgenvölein; wilde rothe Veilrögcl; je lïnger, je frezundlicher. Germ. Batchelor's-Button. Angl. Lanbprette dioique, ou Lychnis fauvage. Gall

In fyluis et prais, in Zjchocherfchen Holze, hinter Nenfcherbitz. Var. $\alpha$ in pratisfyluisque, paffm im Kleindälziger Holze mihi occurrit. Var. $\beta$ ) inter frutices bei Pfaffendorf. Fl. Iun. Iul.

** Flores 5-petali: b) Fruetu 2-capfulari.

222. AGRO jTEMMA, I. G.635. Raden. Germ. Cockle; Angl. Agroftemme. Gall.

Githago. 6I A. Agroftemma hirfuta, calycibus coroliam aequantibus, petalis integris, nudis. LiNs. Sylt. pag. 435 . военi. n. 396. Fl. Dan. t. 5:6.

Pharm, Lolii officinarum Semina. 
Kornaden; Radenkornelken; Kornnägelein; fchrearzer Ackerkiimnel. Germ. Com Campion; Comnon Cokle. Angl. Agrofteme des Blés on Nielle dés bleds. - Gall.

In - sgris inter fecale vbique. Flor-Iun. Iul. Anกนa.

Obf. Semina frumento mixta panes intrant: infuper aluum laxare et vrinam promouere, feruntur. 615. * Agrofemina tomentofa, foliis onato-lanie.latis, coronaria. petalis einarginatis corunatis ferratis. LINN. Syft. $p$. 435. n. 2.

Lychnis coronaria diofcoridis fatiua. C. B. P. pạ̧. 203.

Garten-Kronraden; Sammetnelke; Veximelke; Sanmetröslein; Marienröslein. Germ. Rofe Campicn. Angl. Coquelourde des Fardiniers. Gill.

In hortis vbique et ad fepes hortorum, in pomariis et ruderatis raro. Fl. at ftate. Perennis.

*** Flores 5-petali : c) Fructu 1- locula: ri, calycibus 5 - phyllis.

223. SPERGVLA. L. G. 638. Spark. Germ. Spurrey. Angl, Efpargoute. Gäll.

6I6. Spergula foliis verticillatis, fioribus dccandris, aruenfis. Lints. Syft. p. +37 . вовнM. n. 386 . HAMEL cult. 6. p. 149.t. I.

Acker/park; Spurre; teutfcher, weiffer, weilder Spergel; Marienglas; Spurgeift; Nettelkamm; Kzöo. terich; langer Knebel; Länfegras. Germ. Corn Spurrey. Angl. Spargoute des champs Gall.

In aruis et agris interfegetes, copinfe hinter Lentfch; Parneck, Kriphinne et' fere vbique. Flor. Iun. Itul. Annua.

61 7. Spergula floribus pentandris, foliis verticillatis, fe- pentnndra. minibus margiñtis acutis. LINN. Sy ft. p. 437 . n. 2 . sCHREB. Spicil. p. 3I. n. 947. (fub Alfinze).

Spergula vernalis foliis verticillatis, leminibus mar. ginatis: margine diaphano-albo. wILDEN. Prodr. Berol. n. 489 . 
Fünfmänniger Spergel. Germ. Small Spurrey.Angl. Spargoutc ă cinque étamines. Gall.

In agris arenofis, paftim nac.h Schönfeld, et alibi. Fl. Aprili.

Olf. Flores, quos examinaui, faepiffime filamentis ro-, rarius - infructi.Simillina SpergulaeAruen${ }_{i}$; differt veronbilla, habitu tenuiori, tota g'abra, pari modo vernali viget tempore et mox fugit; feminibus orbiculatis, compreffis nigris. - Haec planta a capris, ouibus, equis, fuibus et bobus, vt Cel. вовнм. obleruauit, auide deuoratur.

nodora. 618. Spergula foliis oppofitis, fubulatis, laeuihus, cau. libus fimplicibus LINN. Syft. p. $+37 \cdot$ n. 3. BOEHM. n. 382. Fl. Dant. t.' 96.

Knöterich; knotiger Spark; kleiner weiffer Spergel. Germ. KnottedSpurrey, or Englifh Marjh Saxifrage. Angl. Spargoute noneufe. Giall.

In pratis et arenofis locis, auf deni Schönfelder Wiefen etc. Fl. Iun. Iul.

224. CERASTIVM. L. G. 637. Hornkraut. Germ,

Moufeear Chichweed. Angl. Oreille de Sou. ris. Gall.

* Capfulis oblongis.

vuigatum. 6I9. Ceraftium foliis onatis, petalis calyci aequalibus, caulibus diffufis. uinN. Syft. p. 436. n. 2. военм. n。 387.

Gemeines Hornkraut. Germ. Narrow-leaved Moufecar Chickrweed.. Anglo. Ceraifte vulgaire. Gall.

in locis graminofis, pratis, hortis fere vbique. Flo Mai. Iun. femidecan- 620. Ceraftium foribus pentandris, petalis emargina*
drum. tis. LINN Syft. p. 436. n. +. вовнм. n. 384 .

Halbze'zenmanniges Hornkraut. Germ. Leaft Moufeear Chickiveed. Angl. Ceraifte pentandre. Gall.

In apricis et locis gramine tenui veltitis, paffim verfus Schönfold, Fl. April, Mai. Annua. 
621. Cerafinm erectum, villofo-vifcofum, petalis caly-vifcofun. ce breuioribus. LINN. Syf. p. 436.n. 3. SCHREz. Spicil. p. 33. n. 948

Klcbrichtes Hornkraut; Ackeryogelkraut; raucher Hüncrdarm. Germ. Broad leaved Vijcous Moufe-ear Chickre'ced. Angl. Coraifte visguteux. Gall.

In pafcuis et aggeribus ad vias nach Merjeburg, Dclitfch. Fl. Mai. Iun.

622. Ceraftium foliis lineari-lanceolatis, obtufis, gla. aruene.

bris; corollis calyce maioribus. Lin. Syft. p. 436 .

ก. 6. вовнм, n. 3 к6. Fl. Dan. t. 626 .

Ackernhornkratit; Steinbrechueiblein; falfcher zeeiffer Steinbrech; weiß Nelkengras; Herzgras; HerzröJeigen. Germ. Com Moufe - ear Chiclizeed, or Wild Sea Pink Angl. Coraifte des champs. Gall.

Ad viss publicas et agrorum margines, nach dem Gickerlungsiverge, ad Gohlis alibique. Flor. April. Maio.

\section{* Capjulis fubrotundis.}

623. Cerafium foliis cordatis, feffilibus; floribus foli-aquaticum. tariis, tructibus pendulis. LINN. Syft. p. 436 . n. 13 . BOEHM. n $37 \%$.

Waferhornkraut; großer weeiffer Meyer; groß.. Vo. gclkraut. Germ. Marhs Moufe-ear Chickueed. Angl. Ceraifte aquatique G.sil.

In locis paludofis et foffis vbique, in Rofenthale, Gonnewitzer Schanzen, in fofticulis nach den Straljen. hîuforn. Flor Iun. Iul. Porennis.

\section{d) Fructu 5-capfulari; calycibus snonophyllis.}

225. OXALIS. L. G. 63,4. Sauerklee; Mälerkraut, Germ. Wood Sorrel: Angl.

* Foliis ternatis. Ssapo radicali.

624. Oxalis fcapis vnifloris, foliis ternatis, foliolis ob-Acetofella. corciatis pilofis. LINN. Sylt. p. 432, n, 5. вовнм. n. 78. BLACKW. t. 308 , 
Pharm. Acerofullae Herba.

Wiilfes Sauermilcrkraut; Herz-Guckgucks-HafenHee; Gauchllee; geneiner Sauerliee; Hafen RoßBuchampfer; Guckguck-Gauch-Buchbrod; Allcluja. Gerur. Common „. ooct Sorrel, or Acid Trefoil. Angl. Ofelle furuage; Pain ì Coucou, ou la petit Alleluja. Gall.

In opacis et vmbiofis nn dem Eutritfcher Graben, et in fyluis in Rofenthale copiofe. Flor, April. Mai. Perennis.

VJ. Folia ad acetaria. Sal ex is eductum in fpiritu acri folutum ad maculas in linteis et lanificiis ex atramento concepras delendas vfurpatur. Folia conniuentia humidam indicare tempeftatem et fereno coelo dependere, refert 111 . LINN.

\section{** Foliis caulinis alternis.}

corniculata. 625. Oxalis caule ramofn, Biffulo; pedunculis vmbelJiferis. LinN Syt. pag. 434. n. 20. вовнм. n. 71 . Fl. Dan. t. $3^{-3}$.

Gelber gchörnter Saierklee f. gelbes Mälerkraut. Germ. Trailing Yẹllowe reood Sorrel. Angit. Alleluja à fleme jante. Gail. nua.

In agris cultis et hortis vbique. Fl. Mai. Iun, An-

226. SEDVM. L. G. 629. Fetre Henne; Zumpenkraut. Germ. Orpine; Stone-crop, Angl.

Orpin, ou Joubarbe. Gall.

\section{* Planifolia.}

Telephium. 625. Sedum foliis planiulculis, ferratis; corymbo folio. fo, caule erecto. LINN. Syft p. 229. n. 2. вовнм. n. 409. вLACKw. t. 19r. Fl. Dan. t. 686.

Pharm. Telephii 1. Fabariae; f. Crafulae maioris Radix.

Mutterkraut; Holzsueang; gemeines Zumpenkraut; fette Hewne; Schmcereeruz; fettes Wundkraut: Donnerkraut; großes Bruchkraut; Kutaben-1. Wolfskraut; 
St. Iohannispflanze; Gefchweulfkrant; Fotzenzzeang; Germ. Orpine, or Live-long. Angl. Orpin, Reprife; ou Foubarbe des vignes. Gall

Maxime iuxta fepes, auf dem fickerlingsberge, bei Mockan, Stömthal etc. et in multis hortis rufticanis. Fl. Iul. Aug. Perennis.

Obf. Flores 5 - nectariis intrueti, in quibus apes nutrimentem fum quaerunt. Foliarecentia, leniter contufa atque aceto vini immilfa, tunc clauis impofita hos emolliunt tolluntque.

\section{** Teretifolia.}

62\% * Sedum foliis fubulatis, fparfis, bafi folutis, infe reflexum. rioribus recuruatis. IINN. Syft. p. $\$ 30$. n. 11 .

- Zurückgebogenes Zumpenliraut; gelber Manerpfeffer; gelbe Fettchenne. Germ. Y cllow Stoue - Crop, or PrickMadam. Angl. Foubarbe réféchie; Raifinet. Gall.

In muris copiofe, rarius auf dem Bieniz. Flor. Iun. Perennis

628. Sedum foliis fubulais quinquefarie confertis, bafr rupefte. folutis, floribus cymofis. zinN. Sy?t. pag. 430. n. i2. EOEHM. ก. 4 I 3 .

Felfon-Zunpeskraut; fetse Berghenne; kleine Hauszerurz. Germ. Roch Stone-crop. Angl. Foubarbe des rochers; Orpin des rochers. Gall.

In montolis ficcis auf dem Gickcrlingsberge, am Bioniz. "Fl Iun. Iul.

629. * Sidum foliis oblongis, obtufis, teretiufculis, albuin.

feflilibus patentibus, cyma rañofa. LINN. Sytt. pag. 430. n. 15. Fl. Dan. t. 66.

li eiffe fette Henne; Dripinatan. Germ. White Sto-. ue-crop. Angl. Petite Foubarbe; Trique blanche, ou Trique-Madame, Fall.

In muris limofis, an der Kapolle bei' den Kohlgär. ten elibi Fl. Iun. Iul.

630. Sedum foliis tubouatis, adnato-feffilibus, gibbisacre erectiufculis aliernis; cyma trifida. IINN. Syft $\mathrm{p} \cdot+30$.

n. ', SOFHM '

Pharı. Sedi minoris f. vermicularis Herba. 


\section{CLASSIS X. DECANDRIA. PENTAGYNIA.}

Scluarfes Zumpisukrazit; fcharfir Mauerpfeffier; Stcine. pfeffer; NießBuwrz; Katzen- f. Hünertr ubchen; kleiner Donncrbart; klein Hausuerarzelmännlein. Germ. Common Wall Stone-crop, or Wall Pepper. Angl. Vermiculaire brûlante. Gall.

In muris et tectis frequens, etiam copiofe in Reichels Garten hinten and der Wiefe: in, Horto Bofuno untern bei dem altcn Gewä̈hslanfe ett. Flor. Iun. Iul. Perennis.

fexangutare. 63 r. Sedum foliis fubouatis, adnato-fefilibus; gibbis erectiusculis, fexfarian imbricatis, LINN. Syft. pag. 430. ก. 17. ВОЕнм. ก. 412.

Sechszeinklichter Mauterpfeffer S. Schmernenirz; gelinder Mauerpfeffer; Kleine Hauszevurz; Niefliraut; Mauertrifubel. Germ. Infippid Stone-crop. Angl. Foubarbe ì fix angles. Gall.

In muris et teetis fparfim. Fl. Iun.

Obf. Priori fimillimum; fed ab illo differt, fapore mitiori; caule fimplici; foliis quafi ternatis ; fioribus paucioribus. 


\title{
Claffis XI. \\ DODECANDRIA
}

\author{
MONOGYNIA.
}

22\%. PORT.VLAEA, L. G. 659. Portulack. Ge\%m. Portulac. Angl. Pourpier. Gall.

632. Portulaca foliis cuneiformibus, foribus feffilibus. oleracea.

IINN. Syft. pag, 145. БовHM. n. 885. ELACKN, tab. 287.

Pharm. Portulacae Herba.

Wilder 1.knhlartiger Portulack; Burzelkraut; Ackerburzel. Germ. Wild, or Garden Purflnuze. Angl. Pourpier fauiage. Gall.

In agris oleraceis fponte crefcit paffim et maxime ibidem colitur. Fl. Iul. Aug.

$V \int$. Folia ad acetaria et in iusculis recepta. Caules quoque crudi condiuntur cum aceto, fale, pipere et lauri foliis, et fic per hyemen feruari poffunt.

228. LY.THRVM L. G. 660. Partike; Blutkraut.

Geru. Partike Loofe Strife. Angl. Salicaire. Gall.

633. Lythrun foliis oppofitis, cordato-Ianceolatis; falicaria.

Horibus picatis, dodecandris. LinN. Syft. pag. 446 . BLACKw. t. 520. гоEHM. n. 530. Fl. Dan. t. 6-1.

Pharm. Salicariae f. Lufinachiae purpureae Herba, Flores.

Wcidenkraut; brauner \& rother Weiderich; blauer Fuchsfcheans; gemeines Blutkraut. Germ. Purplefpited Loofe. Strife; Willow Herb. Angl. Salicaire zulgaire. Gall,

$$
\text { Q } 4
$$


Ad fuuiorum ripas, vor den Rofenthale an der Pleife, in falicetis et nemoribus paludofis inter Gonucze itz, Rafchreitz, Fitch, Gaut fch, in aquis ftagnantibus boi Gothe, Nauendorf, Kriphine ctc. Fl. Iul. Aug. Perennis.

Obf. Plan:a multis in hortis noftratibus priuatis circa pifcinas, e $g$. in Horto Trieriano, Lchrianio ob colorem fioris pulchrum plantata eft. - Curculionibus sdu rfa. Pabulum ouibus, capris, bobus, equis grstum. Fiores apibus; coriis quoque parandis vtilis. Gled. Herba laudatur a Cel. IAEN in diarrheis et dytenteriis, a laxitate ortis, annofis et protafis.

Hyfopifolia , 634. Lythrum foliis alternis lineqritous, floribus hexandris. Linn. Syft. p. 447. 11. 14. военм. n. 540. JacQ. Fior. Auft V. 2. t. I 23 .

Var. a) Lythran foliis anguftioribus.

a Lijthrum floribus a bis.

Yfopblätrige Purtik f. Blutkrant. Germ. HyMop. leaved Loofe Strife. Angl. Salicaire à fouilles d'Hyfope. Gall.

In locis ftignofis, fubhumidis hinter Parneck; in Unizerfizâtsholze; porro an der Landftrafe zwifchen Lïtzen und Markranftädt; iuxta vias publicas zrvifchen Markranftädt und Weiffenfels anno 1788. vidi. Var. ad agrorum margines poft pagurn Kriph $n e$ et in pagro ipfo am Schmiedeteiche copiofe. $\beta$ ) In pratis bei Schadebach. Fl Iul. Aug. Perennis.

\section{I G Y N I A.}

\section{AGRIMONIA. L. G. 663. Odermennig. Germ.} Agrimony. Angl. Aigremonie. Gall.

Eupatoritin 635. Agrinnonia follis caulinis pinnatis : impari petiola. to, fruetibus hifpidis. LiNN. Syft. p. 447. вовнм. n. 703. BLACK w: t. 21 . bene. Fl. Dan. t. 588.

Pharm. Agrimoniae Herba.

Gemeiner.Odermennig 1. Adermennig; Bruchkrut; Brucluenrz; Beerkraut; Frsnizkraut; Königshrant; Klettenkraut; Leberkletten; Steinwurzel; Heil aller Welt. 
Welt. Germ. Common Agrimony, or Grecks Eupatory. Angl. Aigremonie Gall.

In pratis, Schoenfeldicis; bei den Kuhthurm; bei den Gefundbrumnen; ad colles quoque bei dem Pulverthurme et in dumetis vbique et quoque ad vias frequens Fl. Iun. Perennis.

$V \int$.infufun radicis in febribus apudCanadenfes valde aeftimatur. Kalm.

Obf Herbs coriis praeparandis apta. Aues et capri modo hac herba vefecintur. Boues et Equi contra hanc refpunt. Pratis inuif.

\section{T R I G Y N I A.}

230. RESEDA. L. G. 564. Wau; Harnkraut. Germ. - Baftard Rocket. Angl.

636. Refeda foliis lanceolatis, integris, bafi vtrinque Iutcols. vnidentatis ; calycibus quadrifidis. LINN. Syft.p. $4 ; 8$. schree. Spici!. p. $3 \%$. n.95\%. elack w, t, 283. Fl. Dan. t. 864. KERN. p. 106. t. 185.

Wau; Waude; Gaude; Fârócrevau; Fârbergras; Streichkraut; Gilbkraur; Harn-Stark-Hexenkraut. Germ. IVild Hoad 1. Dyer's weed. Angl: Réféda jauriffant; Goude, ou Herbe à jauniv. Gall.

In ruderatis, auf den. Staduzällen circa vrberi, porro in pomariis. Fl. lul. Aug.

Vf Herba citrino eleganter tingit colore praefertim fericum; porro lanas albas lutco; caeruleas, vt commune, viridi colore.

637. * Refeda foliis pinnatis, floribus tetragynis, caly-alba. cibus fexpartitis. LIN Syft. p. 448. n. 7 .

- Refeda inaxima. C. B. P. p. 100.

Weiffe Rejeda. Germ. White Doyer's-zeed. Angl. Réféda blanc. Gall.

In Hifpania et Monfpelii habitat: apud nos in collibus circa vrbem pausa fpecimina nuperrime vidi; in hortis autem fuburbanis haud infrequenter colitur. Fl. Iunio in Augufum, vsque. 
lutвa. 638. * Refeda foliis omnibus trifidis: inferioribus pin. natis. LiNn. Syft. p. 448. n. y. JACC. Fl. Auftr. V. 4 t. 353 .

Refeda vulgaris: C. B. P. p. 100.

Gelber f. gemeiner il au; gelbes Harnkraut; fian fche Rauten. Germ Common Lellow Woad. Angl. Réféda jaune, ou Herbe Maure. Gall.

In ruderatis et reicetamentis hortorum paffim in locis montofis boi Weifjenfels, et in hortis fuburbanis culta. Fl. un. in $A$ ug. vsque.

odocata. 639. * Refeda foliis integris trilobisque, calycibus flo. rem aequantibus. IINN. Sytt. p. +19. n. I2.

Refeda foliis integris, floribus odoratis HALL. Goetting 95 .

Wohlriechende Refede. Germ. Garden, or Odorant Refeda. Ingl Réféda odorant. Gall.

Ex Aegypto in Europam olim venit et ob fuauiffimum odorem in noftratibus hortis maxime colitur. F1. per rotam aeftatem.

231. EVPHORBI 1. L. G. 665. Euphorbien f. Teufelsmilch. Germ. Spurge. Angl. Titimale.

\section{Gall.}

* Vmbella trifida.

Peplus. 640. Euphorbia vmbella trifida, dichótoma; inuolucellis ouatis; foliis integerrimis, obouatis, petiolatis. IINN. Syft. p. +51 . n. 31. BоIIM. n. -8.0

Runde Euphorbien; Wolfswilch. Germ. Petty Spurge. Angl. Tithymale des vignes.

in cultis oleraceis et hortis paffim. Flor. $\Lambda u g$. Septembr. Annua.

Pecoribus obnoxia.

exigua. 641- Euphorbia vmbella trifida, trichntoma, inuolucel is lancenatis; foliis linaribus, acutis; partialibus dichotomis diphyllis. LINN. Syft. p. 451 . n. 33 . военм ก. 73 Fl. Dant. t. 592

Kleine Wolfsmllch Germ. Dwarf Spurge. Angl. Petit Tithymizale. Gall. 
In aruis nach den Gonnezeitzer Schanzen; ad viam nach Lindenan et in agris inter fegetes frequentifime. Fl. Iul. - Septembr, Annus.

Obf. Petala lunata. Fructus glaber.

** Vmbella quadrifida.

642. Euphorbia vmbella quadrifida: dichotoma, foliis Lathyris, oppofitis integris. LiNN. Syft. p. $451 . n, 36$.

Lathyris maior. C. B. P. p. 293.

Pharm. Cataputiae minoris Semina.

Springkraut; Springkörner; Purgierkörner; Treibkörner; breizblattrige ir olfsmilch; Caraputia; Springze'unzel; Kretzkraut; Schleijskraut. Germ. Epurge.Gall.

In hortis et cultis copiofe reperitur; paffirn ad fepes hortorum et inter olera fpontanea. Flor. Iul. et Auguft.' Perennis.

In vernacula lingua Spring- $f$. Treibkörner appellantur femina, quia capfulae per maturitaten cum impetu diffliunt. Seminum vfus internus caute admitendus magis fuperfluus.

\section{*** Vinbella quinqueficla.}

643. Euphorbia vmbella quinquefida; bifida, inuolu-dulciso cellis fubouatis, foliis lanceolatis, obtufis, integerrimis. LINN. Syft. p. 452 . n. 43. БUеHM. n. 80. SCOP. Carn. 432.

Siiffe Euphorbie; Wald f. Suiffe Wolfsmilch. Germ. Sweet Spurge. Angl. Tithymale doux. Gall.

In fyluaticis vmbrofis, in Univerfitäts. et Gonnewitzer Holze; in Horto Bofiano et quidem ad fepes intra arbores hinter den Caffeehanfe copiofe. Fl. Mai. Iun. Perennis.'

Obf. Petala integra, Fruetus muricatus, ruber. Ceterum recens minus acris, dúlci gaudet fapore; exfiçatus nigro inftruetus colore.

644. Eupizorbia vmbella quinquefida, trifida, dichoto- heliofcopia ma, inuolucellis obouatis, foliis cuneiformibus, ferratis. LINN. Syft. p. $453 \cdot$ n. 52. BOEHM. n. 77 . Fl. Dan. \$. 725 . 
Sonnenwendige Euphorbie; Milchkraut; Hundsmilch; Sonnemerrbel. Germ. Sun Spurge, or Wart Wort. Angl. Tithymale Reueille matin. Gall.

In inultis agris copiofe hunter Bojens Garten nacls den Stralfenhäufern $\approx t$, atque in multis hortis rufticanis vbique. Fl. Iun. - Aug. Ámnua.

Haec in Suecia ab ouibus deuorata, diarrhoeam c xcitat; non vero in bobus tamen carnem odore ingrato inficit.

platyphyllos 645. Euplizorbia vmbelln quinquefida, trifida, dich $\$$ o. ma, inuolucellis carina pilofis, foliis ferratis, lanceolatis, capfulis verrucofis. LINN. Syft. p. 453. n. $59 \cdot$ scireb. Spicil. p. 8. n. goo. scop. Carn. p. 431. n. 3. JACQ. Flur. Auftr. V. 4. t. 376.

Breitblättrige Euphorbie. Germ. Broad-leavid Spurge. Ancl.

Ad Margines ftagnorum nd Burghanfen, Ketjchau; Frankcnhein et alibi Mcrelurgum verfus. Fl. Aug. Septembr. Annua.

\section{**** Vmbella multifida.}

Efula. 6 6. Euphorbia vmbella nultifida; bifida, inuolucellis 1ubcordatis, petalis fubbicornibus, ramis fterilibus, folis vniformibus. LINN. Syfr. p. 453. n. GO. schreb. Spicil-p. \%. n. yor BLACKw. t. 163 .

- Pharm. Efulae Herba.

Efelskraut; Efelsmilch; Teufelsnilch. Germ. Pine Spurge, or Leffer Efula; German Spurge. Angl. Efule, ou'Hirbe au lait. Gall.

In locis accliuioribus, arenofis, anf der Straffe hinter Taucha, ad viarn kurz vor Sckeuditz; in locis montolis vor Meckern et alibi. Flor. Iul. - Septembr. Perennis.

Radices in maiore dofi exhibitas vomitus conciliare - c rbitfmos Ledel refert : et planta tota abuomini applicata critpus totum intumu he fphaceloque orto mifere periife aegrum commemorauit. scopos. 
647. Euphorbia vmbella multifida, dichotoma, inuolu- Cypariftiss. cellis fubcordatis, ramis fterilibus, foliis fetac is, caulinis lanceolatis - LiNN. Syft. p. 354 , n. 62. воEнM. n. -6. JACQ. Flor. Auitr. V. 5: t. 435 .

ZuprefJenartige Euphorbie 1. Wolfsmilch. Germ. Tithymale des champs; petite Efule. Gall.

In campis et ad fepes auf den : ickerlingsborge, vor Meckern unten an den Bergen paflim etc. Flor. Mai. Iun Perennis.

648. Euphorbia vmbella multifida, fubtrifida, bifida; paluftris inuolucellis ouatis; foliis lanceolatis, ramis fterilibus IINKN. Syft. pag. 45 †. ก. 6 , BOEIM. $\mathrm{n} .75$. Riv. teir. 230. Efula paluftris. Fl. Dan. t. 866.

Pharm. Efulae Radix, Cortex, Herba.

Sumpf-Wolfrmilch; große Teufelsmilch. Germ. Greater Efula, or Marjh Jparge. Angl. Tithymale des marais; Grande Efule. Gail.

In pratis et forfis piludofis, auf dem Schambergifohen Wiefen, bei Kle indölzig etc. et in hortis paffim. Fl. Iun. Iul, Perennis.

\section{O D E C A G N I A.}

232. SEMPERVIVVM. L. G. 66\%. Hauslaub. Germ. Houfe-leek. Angl. Joubarbe. Gall.

649. Semperaiunm foliis ciliatis, propaginibus patenti- tectorum. bus. LINN. SYft. p. +55 . n. 3. BОЕНM. n. 412. LEYS. n. $47^{2}$. BLACKw. t. 366. Fl. Dan. t: $60 \mathrm{I}$.

Pharm. Semperuiui'. Sedi maioris Herba.

Gemeine f. große Hauswurz; Hauslaub; DachHauswurz; Dutzblume; Wunderbar; Donnerbart; Donnerblatt; Donnerkraut; Immergrïn. Germ. Com-

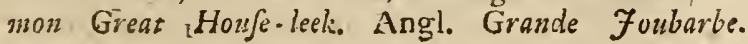
Gall. 
254 C.LASSIS XI. DODECANDRIA. DODECAGYNIA.

In muris, tectis et parietibus pagorum vbique, et in horris. Fl, Iun.-Aug. Perennis.

Obf. Herba acido auftera, aquofa, vi refrigerandi adfringendique gaudet. Folia comprefta oím cum fucceftu adhibebantur ad ganglia tollenda. Folia leniter contufa ad clauos pedum exfirpandos viurpantur vulgo. Succus ex foliis expreftus in aubuAtis laudatur et cum melle Aphthis fuccurrit. 


\section{Claffis XII. \\ I C OS A N D R I A.}

MONOGYNIA.

a) Flores completi, fuperi.

233. * PHILADELPHVS. L. G. 66́\%. Pfeichenfrauch; Orangenblume. Germ. Mock-Orange. Angl.

650. * Pliladelohus foliis fubdentatis. Lisv. Syßt. p.colonarius, 468. SERT. Lipf n. 62.

Pharm. Philandelphi Flores.

Wohlriechendir Pfeichenftrauch: Röluren- 1. Flöten. batum; wilier weiller Iasmin. Germ. White Syringa, or Mock Orange. Angl. Syringa à fleurs blanches; Philadelplue odorant. Gall.

Ad tepes hortorim rufticorum, in dumetis poft Hortum Weifianum ad Stötteritz, in Infula iuxta Hertum ad Großwölkau et in multis hortis. In Sirto quoque verfus Ergaftulum. Flor. Mai. Iun. Frutex.

b) Flores completi, inferi.

234. AMYGDALVS. L. G. 674. Mandel- 1. Pfirfchenbaum. Germ. Almond or Peach - Tree. Angl. Amandier, ou Pêcher. Gall.

651. *'Amygdalus foliorum ferraturis omnibus acutis, Perfica. floribus feffilibus foli ariis. LinN. Syft. p. 462. n. I, DV Ror Hárbk. I. p. 56. BLACKw. t. 101

Perfica molli carne et vulgaris. C. B. P. p. 440 . 
Pharm. Perficae Flores, Nuciei. .

PJufchenbaum; Pfrfichbaum. Germ. Common Peachtree. Angl. Amandier Pêcher: Pêcher ordinaire Gấl.

Regio, vbi haec arbor in Europa fp nte crefcit, nondum nota. Apud nos vioique valde colitur. Fl. Aprili et Maio.

In hortis varietates perplurimae reperiuntur. Flo. res vehementer purgant, lumbricos expellunt et obfructiones referant. Vogel.

\section{PRVNVS. L. G.575. PAaumen. Germ. Plum- Tree. Angl. Prunier. Gall.}

Padus. 652. Prunus floribus racemofis, foliis deciduis, bafi fubtus biglandulofis. LinN. Sylt. p. +62 . вовHM. n 349 . SERT. Lipf. n. 75. Fl. Dan. t. 205. Cram t. 41. KERN, B. II. $\mathrm{p}$ I10. t. 10.5 .

Pharm. Padi Baccae.

Vogelkirfche; Traubcn-Al-Ohl. f. Elalirfche; Hüneraugenbeere; Jcheanze Weide; Haarholz; Pabfzeeide; teutjeher Drachenbaun; unächter Faulbanm; Tolpelgensbum; Elzenbawn; Altbaum: Olthaum; El/cnbeerbaum; Stinkbaum; Wafjerfchlinge: gemein Lusienholz. Germ. Wild Clufter-cherey, or Birds-cherryPadus. Angl. Cerifier à grappes, dont le frnit n'eft. pas mangeable ou bois de St. Lucie, ou Puticr. Gall.

In fyluis, praccipue im Rofenthale, um Pfaffendorf: nunc etian pafim, in der. Allee vor dem grinimifchen Thore, et in multis hortis circa vrbem. Flor. April. Mai. Arbor.

Vf. Baccae ingratae, naufeofae a nonnullis fale adfperto auide edunrur. Folia recentia Capris Equis jue naufeofa. Surculi flexiles ad manubria Sc'opetorum flagella et fiftulas tabocinas adhibentur. Ligmam leue flexileque ad manubrium bombardarum.

virginiana. 653. * Prumus foribus racemofis, foliis deciduis bafi antice glandulofis. LINN. Sylt. p. 462. n. 2. DV ROI Harbk. II. p. I9I. SERT. Lipl. n. 76 .

Cerafus fylueftris, fructu nigricante in racemis longis pendulis Phytolaccae inftar congeftis. Dvram.Arb. 5 . 
Virginifche Traulankirfche f. Vogelkirfche. Germ. Virgininn Birb-Cherry, or Clufier Cherry. Argl. Corifier de Virginie. Gall.

In dumetis vaffin, e. og. auf der Infit ante Hortum fpiendidum ad Großreölkate reperi; porro in

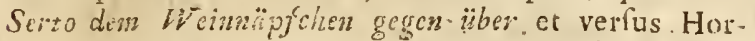
tum Richrerianzmi atque in maltis hortis fuburbanis. Fl. Iun. et In! Arbor:

Habitat propric in Virginia et Carolina.

Obf. Trumcas ţo pedum magnitudinem acquirenz. Foila ouato-lanicolat, ferrato-dentata, gla. berrima, laete vindis, fplendelcentia. Petioli fuperne glandulis norati. Flos albus et illis Prrnace Padi fimilia Fruetus parui, primum virid s, dein ex purpureo nigrefcentes. Lignum album ftris rubris intertextum.

Vf. Fruecus faporis dulcis gratique et praebentfpiritum fuauifrmum. I.ionum in Foco et ad varia vtenfilia conficienda valde aptum.

654. Prnnus vmbellis fuhpedunculatis, foliis ouato- Cerafus. lancenlatis, gyahris, conduplicatis. I.INN. Syft. pig. 463. n. 12. BOEIIM, 11. 4 CO. BLACK W. to 449 .

Var. I) Cerafus carne tenera etaquofa.

2) Cerafus acidifima fanguineofucco.) C.B.P. ittlina.

3) Cerafus racemola hortenfis. p.4.50. aultera. Cerafis fatina, aeftate continue fiorens ac ${ }^{\prime} \in \ln s$. frugefcens. Dvнas Arb Fruit. Tom. I. p. 179. n. 9. PI. 7 .

4) Cerafus pumila (foliis onatis eglandulofis) pumila.

C. B. P. p. 450. Rvpr. !enenf. p. 135.

5) Cerafus hortenfis flore pleno. C. B. P. p. luxurians. 450. SERT. Lipf. n. $7 \%$

Pharm. Ceraforum Rubrorum Fructus, Nuclei, Gummi.

Cemeiner Kirfchbann; wilde Kivche; I) Glaskirfche; 2) kleine fanre Firrche, Bloderkirfche; 3) die ftets bliihende Kirfche; 4) Zuęrgkirfche; Erdueiel. fel ; 5) geneiner Kirfchbaun mit gefillticr Blume Germ. Common Cherry. Tree or Kentifli Cherry. 3) All Soints, or Montily Cherry; 4) Dwarf Cherry; 5) Darble 
forering common Cherry - Tree Angl. Prunier Ceri. fie. Cerife dont la chair eft molle et aqueuje: 2) Cerife ì fruit tris aigres à fuc rouge; 3) Cerife à grappes; Cerifît de la Touffaint ou de St. Martin; Cerifizer tardif; ;) Cerife i fruits pumiles; 5) Cerife à flenrs doubles. Gall.

in nemoritbus et fyluis paffim, ad fepes hortorum, in artis: varietates contra vbique in hortis er faepius an pagos atque in ipfis pagis Ambulacra forment. Va d) in fepibus hor orum et dumetis haud infre. quens. F1. Maio. Fructus Iulio et ineunte Augufto maturi. Arbor.

Praeter has varietates commemoratas innumerabiles quoque obferuantur in horis fere omnibus magnis et vinetis ad Nazmburg.

Vf. Cerafi fruetus recentes vel ficcati in culinis notiffimi. - Condiuntur enim Saccharo, vini aceto et per hyemen fic feruantur: Insculis quoque faepius incoquuntur et valde delicatum fragranternque exhibent cibum. Placentse cerafinge, quas praeprimis piftores noftrates componint coquuntque, plurimorum gulas titillare folent. Fructus maxime acidi fitim exftingunt et febrium ardores demul. cent.

auium. 655. Prunus vmbellis fefflibus, foliis ouato lanceolatis iubtis pub.feentibus, conduplicatis. urNs. Syft. p. 463. n. 13. BLACKW. t. 425. CKAM. t. 16.

Pharm. Ceraforum Nigrorum Flores, Fructus.

Gemeine fchrearze Vogelkurfche; wilder füfer Wald. kirfchbaum; Holz- f. Haferkirfchens; Wafferbeeren; Kaszbeerenbaun ; Zuiefelbeerenlaum; Weichfeln. Germ, Common red wild. C'herry, Tree, Mazzard. Angl. Merifier; Prunier des nfeaux. Gall.

In fyluis et nemoribus paffim. Flor. Mai.

$V f$. Baccis deliciant aues. Has baccas necafle Tetraones b. LINN. vidir in horto academico Vpfalienfi. Ligno fcrinisrii vtuntur ad infrumenta fabrificandr.

domefica. 656. Prumus pedunculis fubfolitariis, foliis lanceolatoouatis, conuolutis, ramis muticis, LiNs. Syf; pag. 
463. n. 15. ЕOEHM. ก. 402. ELACKI, t. 305. CRAM, tab. 20.

Var. I) Pruna pirns, praecoria.

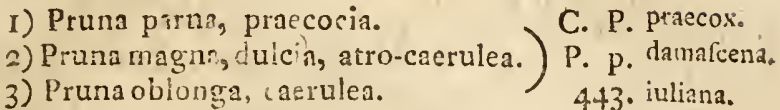

3) Prunab 4.3. iuliana.

4) Prunus fructu medio, oblongo, cereo. cerea.

Dунам Fruit. II. p. I t. t. 20. f. 3 .

5) Pruna ex flauo rufefcentia mixti fapóris Erignola. gratilfina. C B P. p. 4.43 .

Pharm. Pruna Gallica maiora et minora $\beta$ ) Pruna Damajecna.

i cuneiner P Paumcnbaum; Zwetz'chen; 1), die kleine friihe Pflaume; Hundspjlaume; Spilling; 2) grofe violette Damafcener-Pflaume; 3 ) die Inlianspflaume; 4) de Katharincupflaume; Mandelpflaume; S) Pruselle; Brunclle; brignolerpflaume. Gern. Commoz Piume-tres; 1) White Primordian; 2) Creat Da. majk Violet; 3) The St. Iulian; 4 The St. Catharunc: 5) T/se Brignole. Angl Prunier Domeftique; I) Fannhâtiue; Prune de Catulogne; 2) Gros Damas Violet de Tours; 3) Prune de St. Iulian; 4) Prune de St. Catharine; 5) Prune de Brignole. Gail.

In fepibus, dumetis, hortis vbique et quoque ante domos rufticorum: varietates in hortis frequentes. Fl. Iun. Fruct. initio Septembr. maturi.

Obf. Prineolse in Gallia parantur communiter e Prunis. Brignolenfibus enucleatis et compreflis. Fructus in Culinis et apua pifores maxime in vfu. Ceterum aceto vini condiuntur et fic per longum tempus confervari pollunt.

657. * Prunus pedunculis geminis, foliis ouatis fubuil- infititia. lofis, conuoluris, ramis fpinofis. LiNN. Syft. p. 463. n. 16. BLACKw. t. :0\%.

Zahme Schlehe; Hafurfchlehe; Kriechelbazm; Kriechen; Krecken; Zipparten; Augufpplaumen. Germ. Black-Bullace-Tree. Angl. Grand Prunier fativage. Gall.

In fepibus et dumetis fiequens. Fl. Mai. Inn. $V \int$. Fructus aceto conditi menfae inferuiunt. 
fpirola. 653. Pranus pedunculis folitariis, foliis lanceolatis glabris: ranis fpinolis, LINN. Sytt: p. 455 . n. I7. вовнм.

n. +O I. ELACKw, t. 94. CRAM. t. 34 :

Pharm. Acacioe Noftratis.f. Pruneoli Jylueftris Flores, Corten, Frußius.

Schrearzdorn; Schlehendorn; Schlehenhecken;' wilde Kriechcln; whlde Pfanmon; tcutfohe Akazie. Germ. Black-Thorn, or Winter Crcke, or Sloe-Tree, Chrifmas Plum. Angl. Prunellier faurage; Epine noi. re. Gall.

In lepibus, dumetis, vor dem Rofenthale, Pfoffendorf, ad fepes bi der Milchinfel et nach der Limgrube; in fylua Academica aliisque in locis. Fl. April. Frut.

Vf Frutex ad fepes viuas aptus. Baccae vino Gallico inditae idem fragrantifimum reddunt lapijiffimumque. Radicem contra calculos renales HevcheRvs primus commendauit. Frukus porro lero autumno, poft incetum figus nocturmum, rite natu. refcunt. si weftas calidn antecefirt, latis fapidi fiunt. Lignum durum, tenax, dentibus prato:uni variisque inftrumentis aptun tornaiores finia ii et adhibent. Cortex, quo pecora vefcuntut, cum ilumine co Ans. rubrum, fruetus immaturi cum vitriolo contra, nigrumex. hibent conftantem colorem.

\section{I G Y N I A.}

236. CRATAEGVS. I.. G. 678. Hogedorn. Germ. Beamiree, or Wild Scrvice-Tree. Angl.

Alifier. Gall.

torminalis 659. * Crataegus foliis cordatis, feptangulis: locis infimis diuaricatis. L1NN. Syit. pag. 46 . n. 2. LEYs. $n$. 419. SERT. Jip1, n. 22. cMaM. t. 17. Fl. Dant. 798. JACQ. Flor. Auntr. V. . t. 4.43 .

Mehlbece; Adlers-Arls-Darmbeere; Elzheren; Elritzen-Atlasbeerin; Efchrijfel; wilder Sperber. baum. Ferm. TVild Service trec; Maple-leaved Service. Angl. Alifier desbris, ou ì feuilles decoupées; Sorbier Torminale; Tormigné; Aubépine ; Sorbier. Gall. 
In nemoribus et fepibus frequens. F!. Maio.

VT. Baccae paffim eduntur.

660. Crataegus foliis obtutis fubtrifidis, ferratis. LINN. Oxyacantha

Syft, p. 40, n. 9. вовим. n. 404. SER'T. Lipf. n. 24. BLACKW. t. 129. CRAM. t. 33. Fl. Dan. t. 634. JACG. Flor. Auftr. V. 3. t. 292. f. 2, kERN. B. Ii pag. II 1 . f. 198 .

Pharm. Oxyacarsthac 1. Spinae albae.Folia, Flores, Baccae.

Wcisclun ; gemeiner Hagedorn; Hage- f. Hundidorn; Chriftom; Mehldorn; Mehlnofen; Mehlfaßgcn; Mihloum; Mehlheere; Mehlplatten; Mehlfeifcher:; Möllcrbrod; unfer liebcu Frauenbirnlein; Hageäpfl, Germ. Common White-Thom, or Hazethorn. Angl. Epine bianche; Noble Epine, on Aubépine des Inies. Gall.

In fepibus et dumetis pluribus, in der Allce, hinter den Straffenhizufern; etiam in fyluis, in Rofenthale, inn Sommorjelder - Macherfchen-Univerfitätsholze, in der Kämmerei bei Nawendorf frequens. Flor. Maio. Frut.

Vf. Frutex fepibus vtiliffimusetc. Lignum ad rotas molendinarias, manubria malleorum aptum. Baciae, auibus pabuluin et diarrhoeae refiftentes. In Heluetia ex is potus, cereuifiae aemulans, praeparatur. Pauperes baccas crudas edunt in Germania.

\section{T R I G Y N I A.}

237. SORBVS. L. G. 679. Speierling: Quitfelibeerbaum. Germ. Quicken, or Service-Tree. Angl. -Sorbier. Gall.

66r. Sorbus foliis pinnatis vtrinque glabris. LINN. Syfr. aucuparia.

p. 465 . военМ. п. 405 . SERT. Lipf. n. 93. BL.ACK!..

t. 172 . CRAM. t. 18.

Pharm. Sorbi Aucupariae Baccae.

Vogclfpeicrling; Vogelbecrbaum; Abrefche; Eberefche; Quitfhern; Quitfchbeêrenbaum; Eberefchbaum; Ebfchen; ioulder Sperberbaun; Arfchröfel; Areffel. Germ, Quicken-Tree; Quickbéam; Roan-Tree; $\mathrm{R} 3$ Mout? 
Mountain Afh. Angl. Sorbier fauvnge, ou Sorbier des chaffeurs, ou des Oifeleurs, on Cochêne, Covnier, Coretzicr, Sounbier; Sornier, Harlajier, Branfis Gall.

In fyluis areisque, pustur quoque in der Allee et hortis priuatis; im Lehifchen, Winklerifchen et 7 rierifchen Garten. etc. Fl. Mai. Iun. Arbor.

$V f$. Baccis gallinae, turdi, panleres aliaeque aues vefcuntur, dehinc pro laqueariis aucupun inferviunt. Folia pecoribus pabulum. Lignum $m \cdot n$ fis fabrificandis, radiis rotarun, temonibus, manubriis fiftularum tabacinarum, valde aptum. Nodofi baculi ex hocce ligno a rufticis nte parantur. Radix pro manubritis cultrorum; cochlearibus etc. Succus baccarum purgans. Baccae colligi debent ante frigus inceptum et bene ficcri. Homines fuperftitionis pleni incantari fihi imaginantes, e ramis flectunt coronam eamque infigunt parte vencficio tąta; qua ratione melius is cire factum putant.

\section{P E N T A G Y N I A.}

a) Fioribus completis; calycibus fuperis.

238. MESPILVS. L. G. 6 I. Mifpeln. Germ. MedlatTree. Angl. Neflier. Gall.

Pyracantha. 662. * Mejpilus fpinof, foliis lanceolato-ouatis, crenatis, calycibus fruetus obtufis. LINN. Sy ft. p. 466. n. I. DV ror Harbk. I. p. Ar3. SERT. Lipf. n. $57^{\circ}$

Oxyacantha Diofcoridis 1. Spina acuta, pyrifolio.

C. B. P, p. 4₹4.

Der immergriinende Dorn. Germ. Evergyeen Thon, or Pyracantha. Angl. Nefflier Buiffon ardent. Gall.

In duinetis, fed raro v. $c$, in Infula ante Hortum ad Grojizeöilkau et in Serto nunc plantata copiole ad collem wo man zur Hintergalfe gelut et in hortis fuburbanis frequens. Fl. Iun. Iul. Frutex.

germanica. 663. Mefpilus inermis, foliis lanceolatis fubtus tomentofis, foribus folitariis, feffilibus. Linn. Syft. p. 466 . ВовнM. ก. 416 . SERT. LIPf. n. 58 BLACKW. to 154 -

Pharm, 
Pharm. Nefpili Fruetus, Semina.

Genucizer Mifpelbaun; Mefpeln f. Hefpeleinbaum. Germ. Comminon, or Dutch Medlar. Angl. Neflier connum des bois. Gall.

In fyluis ct frut:cetis, auf dem Gickerlingsberge et in inultis liortis frequens. Fl. Maio. Arbor.

VJ. Folia et racemi coriis parandis apta. GLED. Fru• ctus, quamdiu arboibus infidet, femper immaturus, qui de ie decerptus collocatur fuper ftramenta ad matura dum., In Gallia fructus Saccharo condiuntur et-addito butyro, cum vino faccharoque frigun. tur.

664. * Mejpilus inermis, foliis ouatis, integerrimis: Cotoneafter. fubtus tomentofis. LINN. Syft. p. 466. n. S. DV RoI Harbk I. p. 420. SERT, Lipf, n. 59. Fl. Dan. t. 1 I2. CRANz, t. 2. f. I.

Chamae Mefpilus cordi. C. B. P. p. 452.

Zivergmiffelbaun mit dunkelrother Frucht; wilde Qurtten; Bergquittcn. Germ. DuvarfQuince; Baftard Quince-Tree. Angl. Neffier de Gesner. Gall.

In montibus et locis rupeftribus bei Pforte Cel, D. Ludwig ante paucos annos inuenit et egro quoque bei Pforte auf dem Knabenberge et in muris Scholam munientibus vidi; porro quoque in Infula ante llortum Wolkanicnfem, in Serto et plurimis hortis fubur. banis. Flor. Maio et lunio. Baccae rubrae maturae Autumno. raui.

Obf. Saepius modo 3 ftylos et $3-4$ femina nume.

239. PYRVS. L. G. 682. Birn- et Apfelbaum. Germ, Pear, or Apple. Angl. Poirier, ou Pommier.

665. Pyrus foliis oblongo-ouatis laeuibus, laeuiter Pyraiter. dentatis; floribus vmbeliferis : fructubreuiter pedunculato. wiLD. n. \& 7 .

Pyrns fyinefris. C. B. P. p. 439: DVHaM Arbor. T. I Pl. $\$$.

Pyrafir; wilder Birnbaum; Feld-Holabirnen; Waldbirnen; Saubirnen; Knotelbaum; Höltgen; Hu- 
zeln. Germ. IVili Pear Tree. Angl. Poirier fauvage. Gäll

in fyluis, in Rofenthale, in Univerfitütsholzealiisque et in aruorum marginibus paftim; purn ad fepes hortorum rufticanorum, in Zfchocherjchen Holze, in

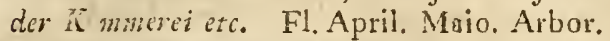

$-V \int$. Flores praccipum apibus pabulum. Fruaibus fues bene figinantur. Lignum tenax, durius quam fequens et inftrumentis opificum conficiendis vald aptum. Caeterum Pyrus Pyrafter eft omnium. fatiu rum mater: Potum ex his fruetibus pracparatum milerimum vocat Hallerus.

communis. 666. Pyrzs foliis ferratis, laeuibus; pedunculis corymbofis. LINN. Syft. p. 466 . BOEHM. n. 4I . BLACKw, t. 453 .

Gemeiner Birnbaum. Germ. Cultivated Pear-Tree. Ang!. Poirier cultivé. Gall.

In hortis, ambulacris circa pagos et in pagis ipfis valde frequens. Omnes varietates, quarum recenfet Millervs in fuo Dictionari, magis ad horticulturam pertinent, quapropter illos huc commemotare mitto.

Vf. Eduntur Pyri fructus maturi crudi it cocti. Si enitn ex arbore decerpuntur falubriores, qua.n fi diu confervantur. Vfus culinaris notifimus. malus fylue- 667 . Pyrus foliis acuminatis, fubtus hirfutis, pedun-
ttris. culis vmbelliferis fubfeffilibus. - BLACKW. t. 178 . CRAM. t. 19.

Malus fylueftris. C. B. P. p. 433 .

Wilder Apfelbaum; Wald C. Holzapfel; Sauẫfel. Germ. Crab Tree, or Wilding Apple. Angl. Ponmier faurage. Gail.

In fyluis, in Rofentliale, nunc etiam paffim in der Allee vor dem grimmifchen Thore. Flor. cum prinri.

$V \int$. Haec arbor proxime poft Crataegum quoad duritiem lignilad rotas molendinarias valde idonea. Flores egregium apibus pabulum. Fruztus fuibus.

Malus. 668: Pyrus foliis ierratis, vinbellis feffilibus, LINN. Syft. p. 4 (I6, n. 3. БOEHM, n. 418 . 
Pyrus foliis ferratis, pomis bafi concauis. LINN. Fl Suec. 164. n. 432.

Var. «) Malus fatica, fructu fubrotundo, viridi $\propto$ )prafomila ferrugineo. Toum nft p. 635 .

в) Malus pomis redolentibus, acido-dulcibus. $\beta$ ) BorsdorSchwenk. Silel. p. 303 . feriana.

Pharm. x) Poma Rentium. B) Pona Borsclorferiana.

Zahmer Anfolbaum; Gartenapfelbaum; geneiner Kọchanfel Germ. Common Apple Tree; a) French Rennet; B) Borsclorferian Apple-Tree. Angl. Pommier caltivé; a) Reinette franche; $\beta$ ) Ponnme de Borsdery. Gall.

Hae et permultae aliae varietates, quas praeteream, in hortis noftratibus et praeprimis var. $\beta$. in pago borsdorf dicto, coluntur, et apud nos indeliciis prae aliis habentur. Porna huius varietatis maturefcunt autumni initio. Poma autem reliquarum ratione qualitatis, faporis, coloris et pro diuerfis maturatationis temporibus in infinitum variant.

$V \int$. In culinis valde vulgaria funt omnium poma varietatum et eduntur aut coßta, aut affata, vel quoque frequentius cruda. Gelatina ex pomis decorticatis et probe cnucleatis praeparatur coctione cum aqua pura in pritem redactis, tum expreffione fucci, addito Saccharo. Syrupus inprimis pomorum Bordorferianorum pergratus in tuffi laudatur. E pomis maxime aufteris modo maturetis; Spiritus extrahitur pariter, ac vini fpecies conficitur, quam Viniln $P_{0}$ maceum (i. e. Cidre) appellare folemus. Poma cruda, fub fera vefpera comefta, multum ad euphoriam conferunt, facillime digeruntur, aluum leniter laxant, fcorbuto refiftunt et imıo quoque, vt refertur, calcu. lorum genefin retinere poffunt.

669 . Fyrus foliis integerrimis, floribus folitariis. LINN. Cydonia, Syft, p. $46 \%$. n. 6. Вовнм. n. 419. JACQ. Fl. Auft. V. 4. t. 342 .

Var. a) Cydonia foliis oblongo-ouatis, fubtus to. ' $\alpha$ ) oblonga, mentofis; pomis oblongis bafi productis. MILL. I. RLACXW, to I37.
R 5
B) $\mathrm{Cy}$ - 
B) naliformis.

Var. $\beta$ ). Cydonia foliis ouatis fubtus tomentofís, pomis roturtioribus. Mill. 2. DVHaM Arbr, et Ar-

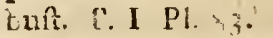

$\mathrm{Ph} ı \mathrm{rm}$. Cydoniae Frufus, Succus, Cortex, Semina

Gemeiner Quittenbaum; a) Quittenbirne; Birnquitte; B) Aepfillquitte. Germ. Quince Tree; $\alpha)$ Pcar Quince; $\beta$ ) Apple Quince. Angl. Coignafficr ou Coignicr connnn; $\alpha$ ) Coignaffier oblong, ou Femelle; Coudounier; $\beta$ ) Coignafjier nêle, ou pomme. G:ll.

In tepibus dumetisque paffm; in hortis autem frequentius. Fl. Mai. Arbor humilis. Poma Octobre matura.

Vf Poma in culinis vftatiffima et vel coquuntur, vel aromatibns condiuntur. Gelatina f. miua e fucco, vti e ponis vulgaribus, paratur. Poma var. $\beta$. coctione colore magis rubro gaudent et ad condimenta aptiora.

b) Floribus completis; calycibus inferis.

240. SPIRAEA. L. G. 686. Spierftoude. Germ. Spiraea. Angl. Spairelle. Gall.

* Fruticofae.

falicifolia $6 \%$ * Spiraca foliis lanceolatis, obtufis, ferratis, nudis, floribus riemolis, LINN. Syft pag. 471. n. 2. SERT. Lipi n. $9 \div$ KEKN B. II. p. 94. t. 155 . DVRAM. Arb. T. II P!. $7:$

Weidenblattrige Spierfaude. Germ. Willowe-leaved Spiraea Angl.

In haris mult's, praecipue in horto Bofiano nune fponte ce elci, in aliis, ne mpe hortoLehriano, Winklerianoct Trieriano, etc et ad finficulas bi ider erfen Wachsbleiche prope hortum Pfaffendorf gegen üler; et in Int:la ante hertum Woelkauienfem; palfun in Serto plantata "FI iun. Frurex.

alba. $677^{*}$ * Spirce folii loncela is acutis, apice ferratis, Horitu diplicito-racemofis. DV Ror Harbk. II. pag. 430. SERT, Lipl, n. 95 .

Weißs , 
Weifillizilende Spierfande. Germ. Whithe Flowe. ring Spiraca. Angl, Spirée ì Fliur blanclie. Gali.

Hebitat proprie in America pientrionali : fed palfim in clumeris noftratibus, e. g. in Infula suxtaHortum ad Grofleölkau reperitnr: porro in Serto copio. fe nunc cultus frutex et in omnibus hortis iplendidis fulubanis etc. Flor. Inlio in Septembien vsque.

Obf. Differt a priori, foliis magis longioribus, verfus apicem paullo latioribus, longe petiolstis, rarius dentatis, laete viridibus. Racemus lasus: Petaia alba. Hic frutex oi tulchos flares et folia pulchre laete viridia ornat fruticeta e: ambulacra.

672. * Spiraea foliis lobatis, ferratis: corymbis termina- Opulifolia. libus. LINN. Syft. p. $47^{2}$. n. 11 . DV ROI Harbk. II. p. 436. SERT. Lipf. n. 97 .

Spiraea Opuli foilo. Tourn. Int. 6r8.

Spierfaude mit Wachholderblättern. Germ. Gelder-Rofe-leaved Spiraea, or Nine Bark. Angl. Bois ì fept écorces. Gail.

In Virginia et Canada habitat. Apud nos quoque in dumetis v. c. in Infula ante pagum Grof.srë̈lkau et ad Stötteritz poft hortum Wrifanum; in Serto et multis hortis haud infrequens. Flor. Maio et Iunio.

Hyemes facile perfert noftretes et in omni folo crefcit. Flores inodori corymbun formantes. Petala albida. Stamina pallida. Antherae rubellae.

\section{** Herbaceae.}

673. Spiraea foliis interrupte pinnatis: foliolis lineari- Filipandula. lanceolatis, interrupte ferratis, glaberrimis; floribus cymofis. LINN. Syft. p. 472 . n. I.\}. ROEHM. n. 542. BLACKw. t. 46?. Fl. Dan. t. 635.

Pharm. Filipendulae 1. Saxifragae rubrae Radix, Herba.

Erdeicheln; Tropfwurz; Weinblume; Haarftrang; Wildgarben; rother Steinbrech.j Germ. Dropwort. Angl. Filipendule, Gall. 
In pratis montolis, auf dem Gickerlingsherge, an!f den Wiefcn binter ' unindorf, und, bei Rückmarsdorf; auf dem Behomot bei Kriphüne, polt Tauchann unten an Minneberge etc. Fl. Iun. Iul. Pétennis.

Obf. Herbam refpuuntequi Matzufch. Radices tuberofae ficcatae et in farinam cortufae, panem vicarium praehent efulentum. Radices-fues in delicis habent; fed prata deprauant, qua de re sradicand:̈e. Siflores in lacte elixantur, grato fapore lac inbuunt.

Vhnaria. 6\%4. Spiraea fo iis interrupte pinnatis: foliolis ouatis, bilerratis, fubtus canis, floribus cymofis. LIN . Syft. pag. 472 . ก. 15. вовнм. ก. 421 . вLАCKW. tab. 465 . Fl. Dain. t. $5+1 \%$.

Pharm. Caprinae f. Vlmariae Radix, Herba.

Iohennis-f. Geisuedel; Geisbart; Schweulftkraut; Mâdefïß; Màl f. Mâikraut;'Wiefenkönigunn; Kranñ lraut; Winmlvaut. Germ. Ouecn of the Meadows; Neadne Swect. Angl. Omitúre, on Reine des près. Perite barluc dc Chevrc; Vignette. Gall.

In pratis humidis, un Eutritjch et Schönfeld, in dumetis fere onnibus hinter dem Brandvoreerkenach Zfchocher, im Zfchochorfchen Holwe, im Rofentinale Icilicet hinter der Funkenburger Wiefc; in dumetis - ibidem inter haec prata et verius Lateritia et alibifrequens. Fl. Iun. Iul. Yerennis.

VJ. Sub feriis ruft:corum pasimento infternitur, vt aërn puificet gratumque exciret odorem. LINN: Herbe tinctoria. Capri auide herbam deuorant, equi et pecora contra fugiunt.

\section{P O L Y G Y N I A.}

24I. ROSA. L. G 687. Rofe. Germ. Briar or RofeTree. Angl. Rofier. Gall.

* Germinibus fulglobofis.

Eglanteria. 675. * Rofa calycihus femipinnatis : germinibus globofis, gl bris: ped nculis petiolisque hifnidis glandulofis caule acul is fparfis cuiluis: foliolis fubrotundis ferraturis glandulofis. DV RoI Harbk. II.p. 337. 
Rofa Eglanteria germinibus globolis pedunculisque giabris, caule aculeis fparfis, rectis, petiolis fcabris, toliolis acutis. LiNs. SyR. p. $472, \mathrm{n} .1$.

Rofa fylueftris foliis odoratis. C. B. P. pag. 483 .

Weinrofe; wohlviechende Roje. "Germ. Common Szeet Biar. Aingl. Rolier Eglantier. Gall.

In $f$ pibus hortorum rufticanorum, et in dumetis, fed rarius: in hortis autem fuburbanis intıa fru ces arboresque exoticas valde frequns; in Serto pafin. Fl. Iun. et Iul, Frut.

Obf. Folia 5 pallim quoque 7 foliolis conftantia, fubo: biculato.ousta, dentata, glabra, fubtus lanugine rubella obte?ta. Petioli pilis et globulis glandulofis inftruti. Pedunculi hilpidi. Calycis fegmenta fecundurn petalorum longitudinem taepe integra et margine lanugine albida obferfa. Cor. r'utula parua, enarginata, albido-carnola (nec flana), et bene \{uaueolentia. Fruetus globofus, paffim quo. que pilofus, et fi maturus tunc nigro imbuitur culore. Folia et Petala huius odorem fpirgunt fusuiffinum. Saepius verofiutex falfe confulus elt cum Rofa lutea. MIILL.

676. * Roja germinibus fubglobnfis aculeatisque, acu- rubiginofa. leis recuruis, foliis fubtus rubiginofis. LINN. Syft. p. 473. n. 2. JACQ. Fl. Auftr. V. 1. t. 50.

Rof fpinis aduncis, foliis fubtus rubiginolis. HALL. Flor: $\mathrm{riO}_{3}$.

Rofffarlige Rofe. Germ. Eglantine, or Sweet Bitar. Angl. Rofier rouillé. Gall.

Ad fepes et in dumetis pafim: porro in Horto Bofiano oben bei dem Gezvïchslanufe fub arboribus et in perplurimis hortis fuburbanis. Fl. Exeunte Maio et Iunio.

Obf. Rami aculeis longis fparfis obfefli. Folia e 7 foliolis ouatis, acuminatis, ferratis, cmpofiı. Petioil aculeis minutiflimis reflexis obtecti. Flores ex aurantio purpurei odorem cimicum fere fimilem exhs. lant, folia contra pergratum. 
Lutea. $677^{*}$ * Rofa calycibus femipinnatis : germinibus globo. fis redunculisque glabris, foliolis ouatis, glabris, ferratis, ferraturis p.tiolisque villofis glandulofis: cru. le aculeato., DV ror Harbk. II. p. 34.4 .

Rola lutea fimplex. C. B. P. p. 453.

Var. $\beta$ ) Rofa lutea multiplex. C. B. P. 1. c.

Die gelbe cinfache Rofe. $\beta$ ) Die gelbe gefüllte Rofe. Germ. Single yellow Rofe. B) Double yellow Rofe. Angl. Rofier äflour jaun fimple et var. double.

In lepibus dumetisque fparfim: in horto Bofano in isclem locis cum pioni et in horto Lehriano, Winkleriano, Tricriano etc. frequens. Fl. Iun.

Obf. Radix, vt in priori repens. Rami aculeis copiofis rufis obfeffi. Folia e $5-7$ foliolis confantia.

cinnamomea 678. * Rofa calycibus integris: germinibus globofis pedunculisque glabris, caule aculeis ftipularibus, petiolis fubinermibus. LINN. Syft. p. $+73 \ldots \mathrm{n} \cdot 3$.

- Rofa odore cinnanomi. C. B P. p. $44_{3}$.

Zimmtrofe. Germ, Cinnamon Rofe. Angl. Roficr à odeur de cannelu. Gall.

In Europa auftrali proprie crefcit: apud nos autem in fepibus paffim et copiofe in hortis perplurimis. Fl. Maio. Frut.

Obf. Folia communiter ? foliolis fupra glabris, fubtus tomentotis, conftantia. Corolla fimplex; faepius luxurians, purpures, odore cinnamomeo.

fpinofifima. 679. Rofa calycibus integris: germinibus globolis 'olla. bris: pedunculis hifpidis: caule petiolis aculentifinis: foliolis lanceolato-ouatis, ferratis glabris. DV $=$ nor Harbk. II. p. 339 .

Rofaypinofiflma germinibus globofis, glabris, pe* dunculis hifpidis, caule peciolisque aculeatifinis. Linn. Syft. p. 473 , n. 6. воEHм. n. 47 r. Fl. Dan. t. 398.

Erol-Feld-Haber-fachlichte Rofe; Marterdonn. Germ. Divarf or Whice, Scoth Rofe; Burnet-leaved Rofe. Angl. Rofier trìs-épineux. Gall.

Ad agrorum terminos, in dumetis fepibusque, ad Tempinm St. Theclac et in hortis plurinis. Fl. Iun. et Iul. Frut. 
Obf.' Frut. ereßtus humilis, bipedalis altior, fpinis latis vaiidis armatus, inter quas ipinulae mino:es molles Alexilesque confertim pofitae funt. Rami alterni diusgentes fpinulis nollibus, flexibilibus, denfifm is obferi. Folin pinnata: foliolis $7-9$ paruis, fere fuborbiculatis, fublefilibus, inpari petiolsto, yerratis, laete viridibus, glabris. Stipulae foliorum margine pilis capitatis ciliatae. Segmenta Calycis 5, lanceolata, acuminata, integerma. Cor. $5-r$ petaIa: Petalis fubrotundis obrufis, integerrmis vel apice leuifme emarginatis, albidis, odoratis. Bacca fubglobofa, glabra, femina plurins continet et mituritatis tempore nigra euadit.

680. * Rofa cnlycibus femipinnatis: germinibus gtobo-villofa. tis pedunculisque hifpidis, caule periolisque culeatis: foliolis oustis tomentofis. DV kor Harbi. II. pag. $34 \mathrm{I}$.

Rofa rillofagerminibus globofis, aculeatis, pedunculis hifpidis, caule aculeis fpinofis, petiolis aculeatis, foliis tomentofis. LINN. Syft. p. $+7+$. n. 9. JAHN. n. 7 .

Rofa fylueltris pomifera maior. C. B. P. pag. $48+$.

Großs Hagenlattenrofe: grojse f. zeilde Haznbuttentragende Rofe; die rauchblättrige Rofe mit der großen Frucht. Germ, Greater zeild Apple-bearing Roje. Angl. Ro.fer velu; Elegantier hériffon; Grand Rofier à gros fruit epineux. Gall.

In locis arenofis elatioribusque auf, dem GickerlingsbergeCel. JaHnivśs reperit et quoque in vinetis dietis poft Taucham palfm alibique et in plurimis hortis.Flor. Iun. Frutex.

Obf. Cal. Sigmenta 2 ouata integra, 3 femipinna. ta, fubtus pilis breuibus eminentibus hifpida. . Cor. 5- petala: P talis ex orbiculato-cordatis, obtufis apice emarginatis, laete rubris. Pedunculi pol icem longi, hifpidi e ramorum apice folitarii, aut duo coniunctim iuxta fe in vicem prodenntes, finguli vnifori. Stzl. vix vllus; ftigm. capitarun, fufcum. Bacea ouata, punfulis fparfi eminemtibus fcrbriufculae rel glabrae. Fol. alterna pinnata feptena, fumma fioralia 
ternata; pinnis oppofitis ferflibus, ouatis, acutiusculis, acute dentatis, vtrinque mollibus, pallije viridibus. Frutex et rani foinis fatis validis acutiflumis oblefi. Flores alste euolutionem extus rubelli.

prouincialis. $68 \mathrm{r}$. ${ }^{*}$ Rofa calycibus fenipinnatis, germinibus globofis; pedunculis petiolisque hifpidis: foliis ouato-acuminatis fubtus vilolis, ferraturis glandulofis. DV ror Harbli. II. p. $3 \pm 0$.

Rofa purpurea. C. B. P. p. 484.

Var. $\propto)$ Rofa prouincialis maior fore pleno ruberrimo. HoRт. Angl. t. 18. BLACKw. t. 78 .

ß) Rofa bafilica ex albido colore et rubello variegata. Dvham. Arb. 12. M1:L. Pl Tab. 221. 2.

Provinarole; Knopf-f. Kohlme a) gefillte Pro. winzroje; $\beta$ ) roth und zectsgefreifte Rofe; hnnte Rofe; Tag- und Nachtrofe. Gem. Provence Rofe: Cab. bage Rofe; $\alpha)$ Provenice double Rofe; $\beta$ ) York and Lancafter Rofe. Angl. Rofier de Provence; B) Rofier à fleur mi-partie de rouge et de blanc. Gall.

In fepibus et dumetis palnn et frequentius in hortis cum varietatibus. Fl. funio.

Frutex $3-4$ - pedalis, ranis facile propagatur. Folia 5- enis foliolis craflis, acute ountis, conftnntia, fupra laete viridibus et glabris, fubtus vero venis fortioribus et villofis inftruata. Petioli pedunculique aculeis minutiffmis armati. Cal. Segmenta modo integerima, modo lacinis plurimibus excifa. Cor. finplex latte viridis et magna: plena magis laete rubra et parua. Cor. vero petalis variegata iemipiena, led mar 1 ior, quam Cor. fimplex. Infuper Flores omnes odo. rem fortem et bene fuaucolentem fpargunt.

femperui- 632. * Rofa germinibus glohofis pednnculisque hilpirens. dis: caule petiolisque aculearis: foliolis lanceolatis fubcarnofis perennantibus, DV ROI Harbk. I1. pag. 358 .

Rofa femperuirens germinibus globolis pedunculisque hifpidis, caule petiolisque aculeatis, floribus fubumbellatis. LiNn. Syft. $\mathrm{P}$ ? $\mathrm{n}$. 1 .

Rofa mofchata femperuirens. C. B. P. p. 482. DiLL. Elth. Tab. 245. f. $31 \%$ 
Immergrïne Rofe: Germ. Ever-green Mufk Rofe. Angl. Rofier toujour verch, ou à fleur musquéce. Gall.

In hortis plurimis vulgaris et paffim ad fepes hor. torum. Fl. Iun. et Iulio.

Obf. Radix valde repens. Rami procumbentes. Folia e $5,-7$ foliolis acute oblongis, dentatis, oblcu- " re viridibus, compofita. Odor florum pergratus.

\section{** Germinibus ouatis.}

683. * Rofa calycibus femipinnatis germinibus onatis centifolia. peduncuhsque hifpidis: caule hifipido aculeato: petiolis glandulofis, foliolis o uatis ferratis, fubtus pilofis. DV Ror Harbk II. p. 367.

Rofa centiforia germinibus ouatis pedunculisque hif́pidis, caule . hilipido, sculeato, petiolis inermibus. LinN. Sylt. p. 474. n. 1 I.

Rola mutiplex media. C. B. P. p. 482.

Zentifolienrofe; hundertblättrige Rofe; roth gefüllte wohlriechende Rofe. Germ. Dutch handred.leaved Rofe. Angl. Rofier de Provins, ou it cent feuilles. Gall.

In hertis fere omnibus et dumetis vulgaris. Flos. Iunio:

Obf. Frutex 3-4-pedalis. Folia 3-5- nata : foliolis maioribus, quam in antecedentibus, ouatis, duplicato-dentatis: fupra laete viridibus et venoforugofis, fubsus ex viridi pubefcentibus, venulis et pilis notatis. Denticuli foliorum ex fuico - viridefcentes. Petioli punctulis eminentibus rubris obfeffi Pedunculi hilpidi et glandulis rubris notati, Flores pallido-fanguinei.

684. * Rofa calycibus femipinnatis: germinibus ouatis Damafema. turgidis pedunculisque hípidis: caule petiolisque aculicatis: frliolis oustis acuminatis, fubtus fubuillo. fis. DV RoI Harbk. Ii. p. 370.

Pharm. Rnfae Damafcenae Flores.

Damafcenter Rofe. Germ. Damafk Roje. Angl, Rofier de Demafce. Gall.

In hortis vbique occurrit. Fl. Iunio. 
Obj. Folia $3-5$-nata : foliolis ouato - acuminatis, denticūlatis, fupra olıfcure viridibus glabrisque, fubturs autem $\mathrm{p}$ lidioribus et paululum tomer ofis. Frectus crafe ouatus, acuieis rubris obfeffns. Cal Seg. mente pinnatifida, refiexa. Flores pergratum exhalan. tes odarem.

VJ. Communiter condiuntur falc culinari fores re. cenfer ficcati, vnde odor permanet. Aqua deftilata Rolarum in adfectibus oculorum trequenter adhibetur.

Gallica, 685.* Rofa calycibus femipinnatis, germinibus ouatis - pedunculisque hifpidis: caule petioiisque hilpidoaculeatis : foliolis ouatis, fubtus villofis. DV ROr Harbk. Il. p. 363 .

Rofa gallica germinibus ountis pedunculisque hifpidis: caule petiolisque hifpido - aculeatis. IINN. Syft. p. 474. n. 13. BLACKIi, t. 82.

kofa rubra multiplex. C. B. P. pag. 48I. Dviras. Arb. T. II. P1. 55.

Phasm. 'Rojac rubrae Flores.

Eligrofe; rothe f. Apotheckerrofe; Zuckerrofe; Sammetrofe. Germ. Gallican, or Red Rofe. Angl. Rou ficr de France. Gall.

In hortis vbique. Fl. Iunio.

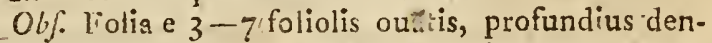
tatis, fubrus tomentofis venofisque; fupra contra laete viridibus et glabris. Calycis fegmenta 3 modo pinn:tim lnciniata; omnia autem expanfa, concaua et margine lanuginofo ornata. Bacca ouata pilis fufcis hifpidis cincta. Flores ex pallido rubri odorem gratum hahent.

canina. 686. Rofo calycibus femipinnatis villofis : germinibus ouatis pedunculisque grtabris: periolis lubhifpidis: foliolis ouatis mucronatis. DV Ror Harbk. II. pag. 359 .

Rofa canina germinibus ouatis pedunculisque glabris, caule petiolisque aculeatis. LinN. Syft. p. 474 : n. 16. вовн., n. 450 . вт.АСКW, t. S. СRAM, tab. 36. Fl. Dain. t. 535 .

Pharm, 
Pharin. Rofac jylueftris Flores.

Cynoriati Fruaus, Semina.

Bedeguar Fungus.

Hunds-Heckroje; gemuze wilde Role; Feldrofe; Horn-Dorni Zaunrofe; Hagedomrofe; Rofendorn; Hngcbutron; Hanebutten; Hannbuttcn, Hanthötgen; Hainhocken; Wiegenfrauch; Vilepen; Hancllojigen; Argchkiczeln; Airfhkratzehn; Schlafkunz; Schlafkanz. Cerm. Common woild Birar; Dog's Rofe; Hep-tree, or Hep-bufh. Ang-1. Rofier canin; Eglantier fauvage; Gratcal oul Ciniromodor. Gail.

In sepibus et dunetis, bei den Pulucrthuma, ad fepes bci dem fanlen Anger nicht weit von dem Tüulchen etc. ad viam publican verlus Eutritfch; pon Taucham et ibidem in vineis frequens; porro in plurimis hortis rufticanis etc. Flor. Main et Iunio.

Obf. Fruzex wiagnus, crafus, fpinis validis aduncis obfefius. Fol. alcene pinnata; pinnis $5-7$ oppositis fubfeffil:bus, imperi coftan terminante, omnibus caeterum ouato-acuninatis, acute dentatis, fuperne laete-inferne paliideviridibus, glabris. Stipulac tagitratne, glabrae, ciliatae. Calyc.fegmenta lanceolata, 2 integra, 3 femipinnata, e ramortum apice folitarii. Bacca ouata, fplendens, glabra, maturitate ex fanguinso-purpur»a, is plursque femina includit.

Vf. Baccae bene maturae, ficcatae et probe exacinatae coquuntur in isculis palato gratis. Baccae additis pafrulis maioribus coetze, dein cum carne bubulina in patinis difpofitae, fuauifimam exhibent" panaceam ruricolis Lufatize inferioris. Infuper ex his baccis paratur decoftum aņuofum, faturatum, aditis parfulis, pruneolis et faccharo, quod, colatione inftituta, menfis imponitur. Folia coriis parandis apta.

68\%. * Rofagerminibus ountis glabris, pedunculis ceu- nendulina. leque hifpidis, petiolis inermibus, fructibus pandulis. LINN. Syft. p. 2 4. n, 19. DV Ror Harbk. II. pag. 369. Dill. Hort. Elti. t. 245 . f. $317^{\circ}$

Die Refe mit hürgenden Fräichten. Germ. Longfruized Rofs. Angl. Rofier ì fruit quendant. Gall. 
In fyluis uburbanis paffin; in fepibus, dumetis et hortis fere omnibus frequens. Fl. Exeunte Maio et Innio.

Ob. Frutex $5-7$ - pedalis, aculeis validioribus armatus. Petioli aculeis deftituti. Pedunculi cum fruCibus verius terram nutant.

alba. 688. * Rofa calycihus fermipinnatis, germinibus ouatis, glabris. pedunculis hifpidis: caule ptiolisque villofis aculeatis: foliolis ougtis, fubtus villofis. DV ROI Harbk. 11, p. 3\%, ILACKw. t. 73 .

Var. $\beta$ R Rola fiore p'eno.

Pharm. Rofae Albae Flores.

Weifle Rofe; $\beta$ ) reeilfe Rofe mit gefüllter Blume. Germ. Common wehite Role; $\beta$ ) white Rofe white a double Flozeer. Angl. Rofier blanc; $\beta$ ) Rofier à fleur blanche double. Gall.

In fepibus, dumetis hand infrequens; in hortis autem fere omnibus circuli lipfienfis valde vulgaris. Fl. Maio Iun.

Obf. Folis e 5 foliolis minoribus, excepto fupreno maiore reliquis, compofia. Foliola fint ouata, profundius ferrate, inferne venis eminentibus notata, lanugine albidiufcula obducta, fuperne contra valde oblcure viridia. Stipulae in apicem duplicem partitae, raro dentatae. Calycis fegmenta reflexa, pinnatifida, pilis hifpidis rubefcentibus teata. Flos pallidus, fimplex, faepius plenus. Bacca ouata, glabra.

242. RVBVS. L. G. 688. Bromm- S. Himbeerftrauch.

Germ. Rafpberry ot Bramble. Angl. Framboi-

fier. Gall.

* Frutejcentes.

idaeus. 689. Rubus foliis quinato-pinnatis ternatisque, caule aculeato, petiolis canalicularis. Linn. Syft. pag. 475 . BOEЕM. $n$ i $4 \%$

Rubus foliis ternatis quinatisque conta plerumque inemi, tructu rubio, villofo. cranz. Stirp. Auftr. p. 8I. BLACKw. t. 28 y. Fl. Dan. t. 788 .

Pharm. 
Pharm. Ruli Idaei Folia, Fructus.

Himberenflrauch; Himbeere; Homberc; Hohlbeeve; Himmellwemen; Hanberftrauch; rothe Bronbec. ven. Germ. Common or Prikin, or Red Rajpberry. Bufh, or Hind berry. Angl. Ronce Framboifbere; Framboifier du Mont-Ida. Gall.

In locis elatioribus, arenoîs, im Univerfitâtsholze; in dumetis et ad fepes hortorum etc. frequens. Flor. Mai. Iun. Perennis.

$V \int$. Baccae fapidiffmae vinum reddunt gratum, et vario modo condiuntur.

690. Ruvus foliis ternatis fubnudis: lateralibus bilobis, caefius. caule aculesto tereti. LINN. Syit. p. 475. n. 7. DOEIM.

ก. $4+9$.

Pharm. Rubi Caefii Baccae.

Bocksbere; Ackerbeere; Fuchs - Tauben - Krazbeere; die kricchende blane Brombere; Acksirombere; Ackerbremen. Germ. Small Bramble, or Deweberrybufih. Angl: Ronce rampante, ou bleuâtrc. Gall.

In agrorum limitibus, izz und linter der Leimgribbe, bei dor Tabacksmühle, nach deas Schanzen. Flor. Iun Perennis.

Obf. Frutex nimis reptans agris maxime molentus et obnoxius.

$V f$. Baccae vinum reddunt fapidiTimum: crudae et conditae in deliciis habentur.

691 . Rubus folis quinato digitotis ternatisque, caule fruticofus. petiolisque aculeatis, LxNN. Sytt. pag. 475. n. 8. BCEHM. n. 74 \& BLACKw. t. 4.5 .

Pharm. Rulin Fruticofi Baccae.

Große of Chwarae Bromm-1. Kratabere; Bremenfrauch. Ralumbecren Germ. Common Branble, or Blackberry. bufl. Angl. Ronce commune, ounrire; Mures de Renard; Cathrinette des Bois. Gall.

In fyluis, im Univerfititsholze, Gonnewitzer, Zfchocherfchen Holze etc. et in ncmoribus im Rofenthale et ad agrorum limites. Flor. Maio Iunio. Frut.

Vf. Sepibus viuis aptus. Succus chartam coerule fingit colore. In nonnullis Galliae regionibu-loc ad vinum album rubro tingendum colore adhibetur. 
Carbones ex hoc ligno pulueri pyrio apti fammam celerem dant.

odoratus. 692.* Rabus foliis fimplicibus ( 5 - lobis inaequaliter ferratis), carale inermi multifolio, multiforo. LINN. Syft p. 475. n. io. ov kor Harbk. II. p: 379 . SERT. Lipf, n. 89. Mr.t. 6. Tab. 223.

Woblriechendier Himmbcerfrauch. Germ. Firginian Flouering Rafpberry. Angl. Framboifier à flcurs odorantes. Gall.

Sponte nafcitur in Canada, Penfiluania et Virginia : aplid ros paflim in dunetis nunc occurrit, e. g. in Infula prope hortum ad Großlë̈lkau; in Serto nicht zeert von cum Weinnipfchen atque untcn an Graben verfus Collegium rubrum et Ergaftulum etc. denique in plurimis hortis. Fl. Iunio in Septembrem vsque.

\section{** Herbacei.}

faxatilis. 693. Kubus foliis ternatis, nudis, flagellis reptantibus, herbaceis. linn. Sytt. p. 476. n. 17. schrez. Spicil. p. 33. n. 3. Fl. Dan. t. 134.

Felfen Brombecre; Steinbeere; kriechende Brombeere; Bruntfluken. Germ. Stone Bromble. Angl. Ronce des roches. Gall.

In fyluis montofis, ferilibus, in Oberholze, porro in Univerfitiitsholze, nicht wecit ion dern Haufe, palfim. Fl. Mai, Iun. Perennis.

Vf Baccae a pueris legruntur comedunturquie ct Rufi, qui has cum melle mifcent, fermentatione pers fecta, fpiritum accipiunt.

243. TORMENTILLA. L. G. Gor. Biutwurz. Germ. Tormentil. Angl. Tormentille. Gall.

s5e̊x. 694. Tormentilla caule erectiusculo, foliis feffilibus. LINN. Syft, p. 479. вOERM. n. 306. BLACKW, t. 445 . Fl. Dan. \&. 598 .

Fragaria foliis quiriatis, calyce oftofido, flore tetrapetalo. CRanz, Fafe. I. p. 80.

Pharm, 
Pharin Tormentillae Radix, Herba.

Aiffechte Tormentill; Blut-1. Ruhrkraut; Tórmentilinutiz; Rothwurz; Hüner-Birk-Nabcheurz; Heiz. Germ. Wild, or upright Tornentil. Angı Tormentille. Gall.

In protis fyluaticis, im Rofenthale, bei Lindenauls in der Kanmerei, im Hegégraje bei Kriņäne, in pratis loc Scizadebach etc. in Bieniz, in pratis Schoenfoldicis. Fl. tun. Iul. Perenuis.

VJ. Radix fues faginat, porro coriis parandis apta, et a Japponibus ad pigmentum rubrum radix mafticata adhibetur. LINN. Flor. Lapp, 113 .

244. FRAGARIA. L. G. 689. Erdbeere. Govm. Strawberry. Angl. Fraifier. all.

695. Fragaria flogellis reptantibus, foliis ternatis, fru-vefca. Etu eduli. LINN. Syfr. pag. 476. Бовнм. n. 423 . BLACKW. t. -7 .

Var. a) Fragaria fruêu albo.

B) Fragaria fruetu rubro.

Pharm. Fragariae Herba, Fructus.

Wald-1. gemeine Erdbeereflanze; Knackerbeere; Erdbeerkraut; Walderdbeere; rothes Befingkraut. Germ. Common Strazesherry. Angl. Fraifier comman. Gall.

In pratis, paicuis nemoribusque, in der Leinngru. be, im Univerfitatsholze, inir Bicniz et alibi. Fl. Mai. Perennis.

Fragaria in hortis culta folo pingui baccas grandiores profert, minus vero fapidas, acidiores. Baccae apud nos vfratifimae in culinis. Eduntur crudae vel vino, aut lacte commixtae.

696. Fragaria caule decumbente, ramis floriferis, laxis. ftérilis. IINN. Syit. p. +76. ก. 9 .

Potcrtilla foliis ternatis, petalis albis, fubrotundis. Bовнм. ก. 3209.

Uneßbare, unfruchtbare Erdbeere. Germ, Barren Strazeberry. Angl. Fraifier fterile, Gall. 
In iisdem locis cum priori reperitur.

Obf. Flageliis haec deftituta.

245. POTENTILLA. L. G. 690. Grinfing . Fün :blatt. Germ. Ciaquefoil. Angl. Quintefeuile.

\section{Call.}

\section{* Foliis pinnatis.}

Anferina. 697. Potentilla foliis pinnatis, ferratis, caule repente, pedunculis vnifforis. LINN. Sytt. p. $47 \div, \mathrm{n}, 2$, BOEHM. n. 422. BLACKW. tab. 6. Fl. Dant. tab. 544. KERN.

B. Il. p. 95 t. $15 \%$

Pharm. Anjerinae Radix, Herba.

Gánferich; Gänfekraut; Günfefutter; Gânfegarbe; Grïnfing; Silberkraut; wilder Rlueinfarm. Germ. Wild Tanyy, or Silver-ueced Moorgraß. Angl. Argentine fauvigge. Gall.

In pafcuis et ad vias vbique copiofe. Fl. Mai. Iun. Perennis.

$V \int$. Hace prata reddit fterilia. Radix faporis dulcis in nonnullis regionibus Paftinacae ad inftar comeditur.

Lupina. 698. Pctentilla foliis pinnatis, caule dichotomo, decumbente. IINN. Sytt. pag. 477. n. IO. вогнм. n. 431 .

Zurückgebogeñer Grïnfig. Germ Supine Cinquefoil. Angl. nis,

In agris oleraceis et ad Gohlis. Flor. Iun. Peren-

** Foliis digivatis.

sef:. '699. Potenzilla foliis feptenatis, lanceolatis, ferratis, vtrinque fubpilofis, caule ere ?o. LINN. Syft. p. $477^{\circ}$ n. IO. вовнм. n. 427. JAHN. n. 8. JACL. Fl. Auftr, V. 4.t. $38 \dot{3} 3$.

Gerader Gänferich. Germ. Yellow upright Cinqusfoil. Angl. Potentille droite. Gall.

In locis gramine veftitis, auf dem Gickerlingsberge. F]. Tun, Pẹrennis 
700. Potentilla foliis quinatis cuneiformibus et cunei- argentea. formiter incifis, fubtus tomentofis: caule firmo, erecto. cranz. Fafc. Il. pag. 73. n. 5. (fub Fragaria). LIN. Sy R p. 477. n. 17. BOEHM, n. 430.

Silberblättriger Grünfing; Silberkraut; aufrecht Fünffingerkraut; falfcher Gänferich. Germ. Silverry Cinquefoil. Angi. Potentille argentée. Gall.

In ruderatis, collibus, locis arenofis vbique fre. quens, etiam in muris linofis haud infreanens. F!. Mai.Iun. Parennis.

*** Foliis pinnatifidis.

701. * Potentilla foliis radicalibus quinatis acute ferratis, verna. retulis, caulinis ternatis, caule declinato. LiNN. Syft. p. 478 . n. 17. Fl. Dan. t. 114.

Potentilla foliis quinatis, obtule in apice ferratis, petalis cordatis. HALL. Helvet. Hift. II. pag. 4S. n. 1110.

Fragaria foliis ternatis quinatisque fubtus canis, caulinis ternatis. cranz. Fafc. I. pag. 74. Täb, I. fig. I.

Frïhlings Potentille; kleines frïhjähriges Fünffingerkraut; Bergfünfingerkraut. Germ. Sprng Cinquefoil. Angl. Potentille printaniere. Gall.

In apricis anf den Gickerlingsberge, in Bieniz, dichte vor Marliranftadt; in montolis locis circa vrbem IVeifjerifils etc. Fl. fub initio veris.

702. Potentilla petiolis et foliis quinatis, caule pro- alba. cumbente fere altioribus, flore albo. CRANz. Fafc. II. p. 75. n. 10. (fub Fragaria).

Potentilla foliis quinatis apice conniuenti-Cerratis, caulibus filiformibus procumbentibus, receptrculis hirfutis, linn. Syft. p. 478 . n. 2 I. вовнм. n. 428 . JACC. Flor. Auftr. V. 2, t. I 5 .

Weijler glatter Günferich. Germ. White Cinquefoil. Añgl. Potentille blanche. Gall.

In fyluis montofis pafim im Bieniz. Flor. Mai, Iun. Perennis, 
reptans.' 703. Potentilla foliis quinatis, caule repente, pedunculis vnifloris. LinN. Syft. p. 479.n. 26. вовнм.n. +26. BLAC Kw. t. 454 .

J'harm. Pentaphylli f. Onianquefolii Radix, Herba. Kriechendes Fünfingerlirout; Funflilat; Handblatt. Germ Creping Cinquefoil, or Fire-leaved Graß. Angl. Quintefenille. Gall.

In locis arenofis praeprimis vor dem IVindmühlens. thore nací den Straffenhânfern $\approx u$ et in humidis vbique frequentiflime, in muris quoque paffim. Fl. Jun. lul. Perennis. bus.

VJ. Planta vulneraria, adltringens in Gargarismati-

246. GEVM. L. G. 692. Märzwnz f. Garaffel. Germ, Avens. Angl. Bendồte. Gall.

vrbanum. 704. Geum foribus erectis, frutibus globofis villofis, ariftis vncinatis, nudis, foliis lyratis. LINN. Syft. p. 480. n. 2. вов̈m. ก. 433. cRanz. Fafc. II. pag. 69. BLACKw. t. $253 . \mathrm{Fl}$. Dant. t. 672. .

Pharm. Caryophyllazac Radix, Herba.

Nelkenzeurzel; Nägleinteurad; Benediktenkraut; Benedikteneurz; Märzueurz; Garaffel; Hajenauge;. Ygelkraut; Sanunundenkraut. Germ. Common Avens, or Herb-Bemet. Angl. Benoite, ou Cariopilillée. Gall.

In locis vmbrofis et humidis, in alneto ad Schönfeld, in dumetis bei dem Gc/undbrunnen; in fyluis, v. c. im Rofenthale, Plagzeitzer und Zfchocherfchen Hob$z e$, et ad fepes paftim. F1. Mai. Iun. Perennis.

$V \int$. Pabulum bobus, capris, ouibus, equis, fuibus grarum. Radix vino et cereuifiae addita cariophylli odore ea imtruere et ab acefcentia praeferuare dicitur. Radix quoque nuper a Cel. Bvchiave laudata eft in febribus intermittentibus, vt remedium, febrifugum praeftontilimum.

nutus. 70.5. Geun foribus nutantibus, fructu oblóngo: aritis piunofis torris Cranz. Fafe, Il. p. 70. n. j. воEHM. n. 432 . Fl. Dan. t. -27 .

Geum riuale. Lisis. Syft, p. 480 . n. 5.

Pharm. 


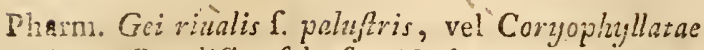
aquaticar; Bendictae figlaeftras Herba.

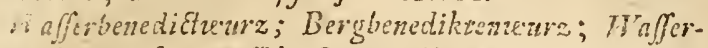
veuracl; Wiefengaraffel. Germ. Liater Avens. Angl. Benoite aiquatique. Gall.

In locis palude fis fyluaticis, in alneto ad Schönfeld; indumetis hinter den Kohlgärten; in fyluis e.g. im Mecherfchen, Comereitzer, Zfchocherfiheu Holze; et in nemoibus, in Kofenthale, Sommerfolder Holze etc. Fl. Misi. Lin. Perennis.

$V \int$. Hane radicem frepe quoque curafe febres intermittentes, etian protralas, nonnulit referunt in Aitis Acaden. Scient. Stockh. Vol, XVIII. pag. 118. feqq.

247. COMARVM. L. G. 664. Siebenfingerkraut. Germ. Comaret. Gall.

706. Comarum foliis pinnatis, petalis calyce minoribus. paluftre, LINN. Syft. p. 487 .

Potentilla calyce colorato, petalis maiori, вогнм.

n. 42.5 .

Siebenfingerkraut; purpurrothes Fïnfingerkraut; Sumpfgânfekrant; Blutauge. Germ. Red Marhh .Cinquefoil. Angl Comaret ou Potentille rouge. Gall.

In pratis vliginofis et humidis ad margines alneti szach Schönfeld; ibidemque in ipfis pratis paffim. TI. Mai, Iun. Perennis. 


\section{Claffis XIIT.}

P O L Y A N D R I A

MONOGYNIA.

\section{A. FLORE HER MAPHRODITO.}

a) Flores fimplices, completi, 4- petali.

248. PAPAVER. L. G. 70ษ Mohn. Gern. Poppy. Angl. Pavot. Gall.

* Capfulis hifpidis.

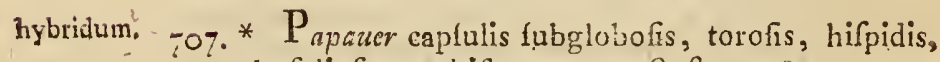
caule foliofo, multifloro. Linn. Syft. p. $48 \%$.

Un chter 1. Baftard Mohn. Germ. Round roughheaded Poppy. Angl. Pavot hibride, Gall.

In agris inter fegetes paffim. Flor. Iun. Iul. Annuum.

Obf Capfulá ouptae; torulis canaliculatae, fetis incuruis rigidis, furfum fpetantibus' denfe armatae. Setae caulinae adpreffae. Folia caulina ternato-pinnatifida.

Argẹmone. 708. Papazter capfulis clauatis, hifpidis, caule foliofo, multiforo linN. Syf. p. 489. n. 2. SChree. Spicil. p. 23 n 93.3. Fl. Dan. t. 467 .

Keelenförmiger Mohn; kleiner Mohu; Argemonröslein Sandnohn. Germ. Long rough-hea-deed Poppy. Angl. Pavot à maffue. Gall. 
In agris inter fegetes vulgare. Flor. Iun. Iul. Anกนun.

Obf. Folia hirfuta pinnata; pinnis profundius laciniaris. Caules pede altiores, pilis denfis minutifimisque tecti. Capfulae oblongae, pilis hifpidis furfum fieetantibus obfefae. Flores ex fanguineo purpu. rei.

\section{* Capjulis glabris.}

709. Papauer capfulis glabris, globofis, caule pilolo, Rhoeas. multifloro, foliis pinnatifidis incifis. LINN. Jyft. pag. 490. ก. 5. ВОЕНM. n. 303. BLACKW. t. 2.

Pharm. Papaueris Erratici f. Rhoeadis Herba, Flores.

Klapprefen; Klatfchrofen ; falfche Kornrofen; Flitfchrofen; roiher Mohn; wilder Mohn; Schnallen Germ. IVild or Red-Field Poppy. Angl. Coquelicot des jardins; Pavot fauvage, ou rouge; Confanous. Gall.

In agris cultis praecipue arenofis copiofifime. Fl. Iun. Iul. Annuum.

Obf. Calyx 2-pliyllus, hirfutus, mox deciduus. Petala 4, regularia, fubrotunda, obtula, integra, purpurea, verfus bafin ftriis nigris notata. Caul, erectus, teres, ex rubello-viridis, hilpidus, pilis patentibus obfeffus. Fol alterna, lanceolata, apice in fjinulam paruam abeuntia, pilofa, pinnatifida, obtufa, dentata. Pedunculi longi, hifpidi, I- flori. Styl. 3. Stigma radiatum violaceo-purpureum. Capf. obverfe ouata, glabra, maturitat ex albido-flauefcens. Sem. plurima, tubrotunda, fulca, glabra.

Vf. Folia tenelia in Irlandia in pulmentis adhibentur edunturque. Flores in infufo, puluere nut extrasto vtilifime dentur in morbis pectoris. Semina fomnum ciere leruntur.

710. Papauer capfulis oblnngis, glabris, caule multi- dubium. foro, feris adpreffis, foliis pinnatifidis incifis. LINN. Syit. p. 490. n. 6. scareb. Spicil. p. 23. n. 934. JACQ. Flor. Auttr. t. 25. 
Rothe Klatfchrofen; Feldmohn; Ackermohn, Kornroferz. Germ. Long Jnooth - headed Poppy. Angl. Pavot doutcux. Gall.

In agris minus fertilibus inter fegetes. Flor. Iun. Iul. Annuum.

Obj. Fol. fere bipinnata, hirfuta, pinnis acute in. cifis. Coulis firmis ex denfis piiis obfellius, contra verfus terram magis patentibus. Capf. oblonga, giabre, figmate radisto tecta. Sem. numerola, lubroturka, fulca.

somniferum 71r. Papaucr calycibus capfulisque glabris, foliis amplexicaulibus incifis. . LINN. Syft. p. 490 . n. 7 . BOEHM. 1. 304. cKanz. Fafc. II. p. 133. n. 2. BLACKW. tab. 482.

Var. a) Papauer feminibus aibis.

b) Papauer feminibus nigris.

Pharm. Papaucris Alb Herba, Semina, Capitula. Var. b) Papautis Nigri Semina, Capitula.

Gemeiner Mohar; jchlafmacheader Moln. Vor; a) zeeiffer 1. Gartenmohn. b Schwarzer Mohn; zahner Feldmohn. Germ. Common Garden, or White or black Poppry. Angl. Pavot des boutiques, ou des jardins. Var. a) Pavot blanc, b) Pavot noir. Gall.

In agris cultis paffim fponte, fed maxirre in lortis oleraceis et agris colitur. Flor. Ae?tate. Annuum.

Vf. E capitibus huius fpeciei imptimis vas a) fauciatis lac ftillat, quod, poft exficestionem perf ctam, Opium audit. Praeftantifimum vern eft Opium album, Maflak, dictum, quod carifimun eft et ah iplis magnatibus in patria expetitum; dehine rarifisue ad nos fertur. Thebaictim contra Opinm, nobis officinale, vulgatifimum eft in Oriente, plebis vfui inprimis inferuiens. Paratur enim fola contufione et expreffione capitum Papaueris, fubfequente inf́piffatione fpontanea in aëre libero. Seminibus Papaueris omnino ineŕc vim paregoricam, faepius obferuaui in iis, qui in magna'copia his víi funt. Attamen vero his leminibus Gallinae vefcintur impune, et ab talis, Polonis, Silefiacis et Saxonibus etc. cibis farinaceis 
naceis admifceri folent. Semina enim trita, deinde pane albo commixta atque in turundarum formam redacta, quibus deniqu lac et Syrupus communis infundi folet, cibum exhibent iucundiffimum (Molnnpillchacn) puellis Lufatiae inferioris ad li a ducenda conuenientibus. Flores apious, pabulum fuauifimum.

249. CHELIDONIVM. L. G. 603. Schöllkraut. Germ Celandine. Angl. Eclaire. Gall.

712. Chelidonian pedunculis vnnellatis, lobis fubro- maius, tundis, caule pilofo. LinN. Syft. p. 489. вовнм. n. 305. вL.ACKW. t. 9I. Fl. Da12. t. 542.

Pharm. Chelidonii Maioris Radix, Herba.

Großes Schöllkrant; Gillkraut; Scliollzeurz; BlutMay-Schwalbenkraut; Schwalben-Gold-Lichtueurz; Goticsgabe; Herrgottsblatt. Gern. Common Greater Celandine. Angl. Grande Chélidoine, ou ćclaire. Gall.

In ruderatis ad fepes vbique. Flor. per totam fere aeftatem.

250.* ACTAEA. L. G. 700. Chriftophskraut; Schwarzwurz. Germ. Bane-berries. Angl. Chriftophoriane. Gall.

713. * Actaer racemo ouato, fructibus baccatis. LiNn, fpicata. Syft. p. $488 . F l$. Dan. t. 498.

Pharm. AEtaeae Radix.

Aelorcuformige Schwarzeurz; Chriftophwura; Chriftophelskraut; heidnifch Wondkraut; fchuearze Niefiseurz; Wolfswurz; Schwarzkraut. Germ, Conzmon black-berried Herb Chriftopher. Angl. Herbe de St. Chriftophlc. Gall.

- In fyluis vmbrofis, paffim in fylua Academica nuper mihi oceurrit. Fl. Mai. Iun. Perennis.

$V \int$. Herba capri et oues velcuntur. - Baccae a nonnullis fufpectae et venenatae funt habitae.

b) Flo- 
b) Flores 5 - petali.

25 T. CiSTVS. L. G. 72 s. Ciftenröslein. Ferm. Little Sun-Flower. Angl. Cifte. Gall. Helinnthe- 7r4. Ciftus fuffruticoitus, procumbens; ftipulis lanceo-
mum.

latis, folis cbiongis, reuolutis, fubpilofis inN. Syft. p. 5CO. воEнм, n. 398. (fub Helianthemo). Fl Dan. t. 101 .

'Sonncngünzel; Sonnenblïnlein; Sonnenröslein; Hei-1 denylop 1. Schmuck; Elijabethblïnzchen; Ciftenröslein. Germ. Yellowe diuerarf $\mathrm{C}_{2} \mathrm{ftus}$, or Jittle Sunfozerer. Angl. Cifte, Héliantéme, ou Flcur du Soleil. Gall.

In pafcuis et pratis, am Bicniz unten auf der Wiefe copiofe. Fl, Mai Iun. Perennis.

252. TILIA. L. G. 7 17. Linde. Germ. Lime - tree. Angl Tilleul. Gall.

vulgaris, 7I5. Tilia foliis acuminatis, ferratis, fubhirfutis, fructibus quadrangularibus fubpilolis. MILl. Dict. n. 2. DV ROI Harbk. II. n. 261. SERT. Lipf. n 10:。

Tilia Europica, floribus nect rio deftitutis. IiNN. Syft: p. 493. вовпि. n. 397. ВLAСKw. t. 469. СКАM, tab. 9.

Var. «) Tilia femina foliis maioribus.

Pharm. Tiliae Cortex, Flores, Carbo.

Europiifche Linde; gemeine f. weiche Walperlinde; breitblattrige 1. große Linde; Sonmerlnde; frïhe Linde. Germ. Common Lime, or Linden-tree. Angl. Tilleul. Gall.

In aruis et campeftribus. Var. o) in der Allce et in multis hortis; in nemorihus $2 m$ Rofenthale, im Sommerfelder Holze étc. pagisque ante domos paffim. Fl. Iun. Iul. Arbor.

Vf. Arbor in ambulacris et fepibus praeftantifima; foliis floribusque Suaueolentibus vmbraque grata. Cortex aqua maceratus funibus maffisque conficiendis aptus. Carbonibus pictores ad proeludia figurarum vtuntur. Lignum leue, giabrum, dehine 
ad fimulacra a fculptoribus, ad calcearia a futoribus. Eft autem porofum, qua de re ad vafa liquores continentia ineptum.

716. Tilia foliis cordatis acuminatis inaequaliter ferra- cordata tis, fruatibus 5-locularibus, tomentofis. Mu.. Diê. ก. I. SERT. Lipf. n. 10.5.

Tilia femina folio minori. C.B.P. pag. 426. LrNN. Syít. Pl.Ed.R.T. II. p. \%33. n. 1. var.

Havte Linde; Kleine, Stein, Jp̈̈te Linde; Berg.Wald. Winterlinde; fchmalblittrige Linde. Germ. Common greén-twigged Lime. Angl. Tillealt. Gall.

Crefcit cum priori. Fl. Aug. Septembr.

\section{c) Flores polypetali.}

\section{NYMPHAEA. I. G. 709. Seeblume; Seero. fe. Germ. Water Lily. Angl. Nénufar. Gall.}

717. Nymphaea foliis cordatis integerrimis, calyce lurea. pentaphyllo maiore. LINN. Syf. p. 491. воEHM. n. 544. BLACKw. t. 497 ? a. b.

Pharm. Nyinphaeae liteae Radix, Flores.

Gelbe Seeblume f. Rofe; Waflerlilie; Wafjertulipane; gelbe Liafjerthme; Weyherroje; Nixblume; Plumpen; Kannenplumpen; Mummeln; gelbe Seekandel. Germ. Yelloze Water Lily. Angl. Némufar jaune. Gall.

In aquis t'agnofis, follis, pifcinis et fuuiis vbique, maxime im Gerberwafjer. Flor. Iunio Iulio. Perennis.

$V$ f. E radicibus foliisque fues pinguefcunt. Fumo tineae et grylli domeftici pelluntur. Flores coris parandis apti.

718. Nimphaea foliis cordatis, integerrimis, calyce alba. quadrifido. LINN. Syft. pag. 491. вовHM. n. 5.5. Blackw. tab. 493. a. b. et 499. Radix. Fl. Dan. tab. 603.

Pharm. Nymiphaeae albae Radix, Flores.

Weiffe Seepuppe r. Seerofe; zeeiffe Weyherrofe; weiffe Wafjerblume; weiffe Seekandel; ţaffermijhre; Herkuleswurz; Waffertulpe; Kollerieurz; Wajjer. 
mänachen. Germ. White Water Lily. Angl. Nénufar Glanc. Gall.

In iisdem locis cum priori, maxime in fluuio Bahre fic dieto, nacin Schönffeld, et in Plifia nach Groß. ajchocher etc. Fl. lun. Iul. Perennis.

\section{I G Y N I A.}

254. PAEONIA. L. G. 737. Pfingftrofe; Gichtrofe. Germ. Peony. Angl. Pivoine. Gall.

of ficinalis. 719. * Paeonia foliolis oblongis. Linn. Syft. pag. 502. scholl. Barb. p. 285 . n. 70.

4) femina x) Paeonia foliis difformiter lobatis. mazl. Helvet. 3II. BLACKW. t. 65.

B) mafcula

B) Paconia foliis lobatis ex ouato-lanceolatis. HaLL. Helvet. 3 I I. BLACKW. t. 245 .

y) Paconia flore pleno.

Pharm. Paconiae Radix, Flores, Semina.

Pfingftrofe; gebr uchliche Gichtrofe f. Paeonien; Bungenrofe; Königsblunie. Germ. Cfficinal Peony; Male or Fenale Peomy Angl. Pivoine Male ou Fimelie. Gall.

In hortis praeprimis colitar, fed parfin in Horto Bofiano var. y) nune quafi fpontanea fycta eft. Fior. Maio et Iunio. Peremis.

Vf. Radices recrnies maxime var. a Amylum ex. hibent album, mite et hene glutinolum. Radix infuper iaudatur in Epilepfia, eclamplia infantum, tuffi conuulfiua et mentruis retentis etc.

\section{T R I G Y N I A.}

255. DELPHINIVM. L. G. 736. Ritterfporn. Germ. Larks Spur. Angl. Delphinette. Gall.

Confolida 720. Delphiniun neciariis monophyllis, caule fubdiuifo. LINN. Syft. p. O3. вовнM. ก. 54. вLACKW. t。 26. Fl. Daito t. 683. KERNo B, 1I. p. 94, t. 154 .

Pharm. 
Pharm. Confolidae Regalis f. Calcatrippae Flores, Herba.

Feld-Korn-Ritterfporn; Ritzerfpiel; Spornblume; Leqcichklauen; Hornkïmmel. Ferm. Wild LarksSpur, or Rozal Confount. Angl. Dauphin des blcs; Delphinette Royale, nu Pied d'Alouette. Gall.

In.agris inter fegetes fecalinas, maxime bei der $T o$. buksmühle et verlus Stötieritz, porro poft pagum Kriph ne, alibique etiam frequens. Fl. Iun. Iúl.

Obf. Haec quoad colorem valde variat, nam hine for. albo aut cerneo. illinc rubro aut purpureo de. prehenditur: et in hortis faepius fore pleno varie colorato.

Vf. Succus recentcr expreffus viridi et cum alumine mixtus caeruleo tingit, colore. Sicci flores Tabaco admifcentur, vt gratior appireat magis, quam eu dat. unN. Flores apibus pabulum falutare.

72.* Delphinum netariis monophyllis, caule fimpli. Aircir。 ci. LINN. Sy ft p. 50, . n. 2 .

Confolida Regalis hortenfis, fore maiori vel minori, fimpici vel multiplici. C. B. P. p. 142 .

Einjähriger Ritter-fporn ohne Seitenzweige; könig. licher Ritterfporn; zahmer f.- Gartenritterjporn; grof: Se Sporenblume. Germ, Royal Larks-fpur. Angl. Dauphin mitivé. Gall.

In omnibus hortis fuburbanis rufticanisque; paffim in pomaris, hortis oleraceis, ad lepes etc. Flor, Aeftate.

Hortos ob varios colores eleganter ornat haec planta.

\section{P E N T A G Y I I A.}

256. AQVILEGIA. L. G. 74I. Akeley. Grrm. Columbines. Angl. Ancolie. Gall.

722. * Aquilegia nectariis incuruis. LINN. Syf. p. 505 . vulgaris, WILDEN. Prodr. Berol. n. 568. LEYs. 5.527. BLACKW. t. 409. Fl. Dan. t. 695 .

Pharm. Aquilegiae Herba, Flores, Semina, 
Gemeiner Akeley; Glockenblinne; infer lieben Framo enhandffichlo. Germ. IVild or Garden Columbines. Angl, Ancolie vulgaire. Gall.

In nemoribus et ad fepes paffim; in hortis contra varie ludit. Fl, Mai. Iun. Perennis.

257. NIGIL.C.A. L. G. 742. Schwarzkỉmmel; Nardenfaame. Germ. Fennel-Flower. Angl.

Nielle. Gall.

Damafena. 723.* Nigella floribus inuolucro foliofo cinctis. urNN. Syft. p. 506. n. 1 .

Nigella anguftifolia, flore maiore, fimplici, caeru= leo. C. B. P. p. 145 .

Damafcenifche Xigelle; fransöfifcher Schzearzküm. mel 1. Nardenfanme; Iungfer in Grafe; Schabab. Germ. French Fennel Flower. Angl. Nielle de Dama. feene. Gall.

In hortis oleraceis paffim: frequentius in hortis fuburbanis rufteanisque. Flor. Iul. et Auguft. Annua.

fatua. 724. Nigella piftillis quinis, capfulis muricatis, fubro. tundis, foliis fubpilofis. LinN. Syft. p. 506. вовнм. n. 414 .

Pharm. Nigellae S. Melanthii Semina.

Zahmer 1. römifcher Schwarakiümmel; fchwarzèr Coriander; Spargenfanme; die Braut in Haran. Germ. Cultivated Fennel-Flower. Angi. Nielle cultivée. Gall.

In hortis oleraceis et agris paffim. Flor Iun. Iul. Annua.

$V \int$. In Oriente haec Lemina pani infperguntur do. meftico, vti apud nos Semina Carui.

arueris. 725. Nigella piftillis quinis, petalis integris, capfulis turbinatis. LINí. Syft. p. 506. вовнм. П. 415.

Ackernardenfaame; teuifche Kornnigelle; Schwarz. kiummel; Ledichtblume. Germ. German Corn Nigella. Angl. Nielle des champs: Toute Epice. Gall.

In agris inter fegetes ad Gohlis et in hortis olera. ceis. Fl. Iun. Iul, Annua. 
IOLANDRIA. POLIGYNIA.

Vf. Rufici feminibus ad cibos condiendos vtuntur,

\section{PO I Y G Y N I A.}

a) Flores incompleti; calycibus - nullis.

258. CLEMATIS. L. G. 754. Waldrebe. Germ. Climber: Angl. Clematite. Gall.

726. Clcmatis foliis pinnatis: foliolis ouato-lanceolatis eredt. integerrimis, caule erecto: foribus pentaphyllis tetrapetalisue. IINN. Syft. pag. 5\%2. вогнM. n. 309. Fl. Dalt. t. 291 . KeRN. t. 184 .

Pharm. Flammulae Iouis Flores, Herba.

Aufrechtfelaesde Waldrelie. Germ. Upright White Climber. Angl Clématite droitc; Ilammule; ou Her. be aux gue:x. Gall.

Ad lepes hortorum oleraceorum et in multis hortis fuburbanis etc. Fl. Iun. Iul. Perennis.

259. THALICTRVM. L. G. 755. UnRtetkraut;

Wiefenraute. Germ. Meadow Rue. Angl. Pigamon. Gall.

-27: ThaliEtrum foliolis lanceolato-lincaribus, integer-anguftifo-

rimis. LIN⿴. Syft. pag. $513 \cdot$ n. 12. воEнM. n. 308. lium. JACQ. Hort. V. 3. t. 3 .

Schnalblittriges Unfetkraut f. IViefenwaute. Germ. Narrow leaved Meadoze Kue. Angl. Talitson à feuil. les étroites. Gall.

In pratis et locis padudofis faepius ad foffas hinter Gunndorf; in pratis bei Lindenhayn intra frutices co. piofe. Fl. Iul. Perennis.

728. Thalistrum caule foliofo fulcato, panicula multi- flaum plici erekta. LiNn. Syft. pag. 5I3. n. I f. ВОЕнм. n. $30^{-}$.

Pharm. ThaliEtri Radix.

Gelbe f große Wiefenraute, f. falfcher Rhaborber; Heilblatt Germ Great Meadow Rue. Angl. Piganon jaune; Talitrón commun; la Rue des près. Gall. 
In pratis bei dem Kuhthume und der Vogelwiefe et in dumetis inter prata der großen Funkenburg atque Lateritiam.

$V f$. Flores apibus pabulum et folia quoque luteo tingunt colore. Radix per os aflumta vrinam flauo tingit colore.

260. CALTHA. I. G., -6I. Dotter f. Schmalzblu. me. Germ. Marfh Marygold. Angl. Populage. Gall.

prifuftis. 729. Caltha flore fimplici, foliis fubrotundis, crenatis. Linn. Syf. pag. 519. военм. n. 446. Fl. Dan. tab. 668 .

Dotter-f. Kuhblume; Butterblume; Schmergeln; Schmalz-Bach-Mattentlume; Goldurefenblume; teutfche Kapern. Germ. Ycllow-flowered Marfh Mary. gold. Angl. Populage des marais, ou Souci de Marais. Gall.

In pratis humidis verfus Schönfeld; in Rofenthale; in pratis Coriorum, bei Pfaffendorf; in Alnetis, nemoribus et aquis fagnantibus vbique. Fl. Aprili et iterum Autumno. Perennis.

Obf. et $P f$. Boues hanc non tangunt. Floresnondum euoiuti Capparidum loco praeparari folent.

26r. ANEMONE. L, G. 75I. Windblume; Küchen. fchelle. Germ. Wind flower, or Palque-flower. Angl. Silvie, ou Coquelourde. Gail.

* Hepaticae. Flore fubcalyculato.

hepatica. 730. Anemone foliis trilobis integerrimis. zINN. Syf.p. 509. Cranz. Fafc. II. p. 121. sCHRER. Spicil. p. 33. n. 960. BLACKw. t. 207. Fl. Dan. t. 610.

Pharm. Hepaticae Nobilis Herba, Flores.

Lcberkraut; edel Lcberiraws; Gïldcnlloc; Leber. blume; Hevzlraut; fchrear z Blatterkraut. Grun. Bhue Hepacica. Angl. Hepatique des jardizzs, ou Tregle hefatique. Gall. 
In fyluis vmbrofis elatioribus in Oberholie bei Oeltjchan Ill. schres. olim detexit; ego quoque paffin $\imath m$ Bienzz, et nuperrime auf dem Knabenbergebeb Pforte copiofe reperi. Fl. Aprili.

Obg. Varietates nonnullae apud nos in hortis plue rimis reperiuntur.

** Pulfaitliae. Pedunculo inuolucrato, feninio. bus ecaudatis.

731. Anemone pedunculo inuolucrato, petalis rectis, Pulfatilla, foliis bipinniatis. LINN. Syft. p. 570. n. 7. вовнм. n. 543. CRAsz. Fafe. I1. p. I23. Fl. Dan. t. I53.

Pharm. Pulfatillae Herba.

Küchenfchelle; Ofterblume; Beizuurz; blawe $\mathbf{t}$ grofse Küchenfchclle; Wcinkraut; Tagefchlaf; graue, berg Mandel-Schlottenblume; Muttcrblusie. Germ. Conmon bluc Pafque - Floveer. Angl. Pulfatille; Coquelourde ou Herbe au vent. Gall.

In campis montofis, ficcis et fterilioribus, anf denz Sandberge am Bieniz, in pafcuis elatioribus poft pa. gum Kriphine verlus Tiefenfee. Flor. Mart. April. Perennis.

Vf. Succus corollae viridem, exhibet colorem atrimenti loco adhibendum. Hérba caprae ouesque pafcuntur. Pan. Suec.

732. * Anemoné pedunculo inuolucrato, petalis apice pratenlis. reflexis, foliis bipinnatis. CRANz. Fafc. II. pag. 123 . IrNe. Syft. p. 510. 11. 8. Fl. Dan. t. 611.

Pharm. Puljatillae nigricantis Herba.

Wiefenteindblume f. Jchuearze Küchenjchelle; kleine Ofterólume; Biß- 1. Bizzblume; kleine Bißu'urz; Wiefen Animone. Germ. Smal blackifh flnuered Pas. que Flozver. Angl. Anemone, ou Silvie des près. Gall.

In pratis humidis ad Schönfeld et auf den Roferna shaler Wiefen: Fl. Aprili.

$V$ f. Herba a Sroerkio in oculorum affectibus laudea tur. 
*** Anemonoidear. Flore mudo, fenimibus ecauds. tis.

fylue?tris. 733: * Anemone pedunculo nudo, feminibus rotundis, hirfutis, muticis. LINN. Syft. p. 510.

Waid Kuchenfchelle f. Windillume; weiffe große Windrofe; Windröslein. Gtrin. , ood. Amenione. Angl. Anémone fauvage. Gall.

in nemoribus montofis, pafim im Bicniz anno praeterito inueni. Fl. Maio.

nemorofa. 334 . Anemone feminibus acutis, foliolis incifis, caule vnifloro. Linn. Syft. p. 511, n. 23. вовнм. n. 548. Fl. Dan. t. 549 .

Anemone nemorofa alba. CRANz. Fafc. II. pag. $12 \mathrm{I}$.

Plarm. Ranuntuli Albi Flores.

Hainevindhlume; Storchllume; Waldhähnchen; weeiffe Windblune; weiffer Waldhahnenfuß; veriffe Apriblusne. Germ. Common White or wood Anemone. Angl. Silvie blanche, ou Arémone des bois. Gall.

In nemoribus frequens; im Rofenthale, im $\mathrm{Ma}$ cherfchen Holze, in der Kanmmerei bei Nauendorf; in der Prellheide auf dem Tiefenfeer Antheile etc. Flor. Mart. April. Perennis.

Obf. Petalorum corollae numerus in hac fpecie eft dinerfus: mox fex, moxfeptem vel nouem deprehendi. Folia fub initio in tres membranas concauas abeuntia, pofrea digitata, incilo ferrata. Caulis rotundus, fparfin fetis obfeffus. Pedunculus tenuis, mollis, pilis inftru?us. Radix horizontalis, longa, tenuis, fibrillulis ornata. Herba bobus excitat dyfenteriam, dehinc e campis exftirpanda.

Lanuncu= 73.5. Anemone feminibus acutis, foliolis incifis, petalis loides. fubrotundis, caule fubbiforo. tinn. Syft. p. 3ri.n. 15. военая. n. 547. Fl. Dan. t. 140.

Gelbes Waldhänchen; kleines Goldhânchen. Germ. Yellew Wood Animone. Ang!. Siluie jaune. Gall.

In pratis et fyluis, copiofe zm Rofenthale, Zfchocherffhcn, Goincesitzer Holaz etc. et alibi, Fl. April. Má. Perennis. 
Obf. Variat pedunculis $\mathbf{I}-3$ floris. Corolla contra petalis $+-8-10$; er numero faminum.

262. TROLLIVS. L. G. 758 . Troll - f. Engelblume. Girm. Globe Ranunculus. Angl.

736. Trollius corollis conniuentibus, nectariis longitu- Europaeus. dine ftaninum. IINN. Syt. p. 518. говн1. n. 519. 27. Dan. t. 133 .

Enropioifche Engelblune; Dotterblume; gefiillte Bergratuinkel; Alpen Hahnenfuß. Germ. European Globe, Flowery Globe Crozefoot, or Trollfower. Angl. Tiolle globulcux. Gall.

In pratis humidis hinter Kíleindölzig; bei der Schönzfelder Mühle; in Hogegrafe bei Kriphine, ibidem auf dem Behomoz. Fl. Iun. Iul.

b) Flores fimplices, completis calycibus inftructi.

263. Ranunculus. L. G. 75\%. Hahnenfuts. Germ. Butter-Cups; Crowfoot. Angl. Rénoncle. Gall.

* Foliis fimplicibus.

73\%. Raninculus foliis ouato-lanceolatis, petiolatis, Flammula, caule declinato. einn. Syft. p. 515 . военм. n1. 444. Fl. Dan. t. 572 .

Var. «) Ranunculus foliis integerrimis.

ß) Ranunculus foliis fubdentatis.

Kleiner Sumpfhahnenfuß; Egelkraut; klein Sweer. kraut; Gichthraut. Germ. Small Crouffoot, or Leljer Spear-Wort. Angl. Rénoncle petite; Douve. Gall.

In pafcuis et locis vliginnfis, nach der Leimgrube; porro in pratis Schoenfeldicis et alibi. Flor. Iun. Iul. Perennis.

VJ. Galli hac herba ob acritatem fummam vtuntur pro veficatoriis. "Pecora et iumenta refpuunt.

738. Ranunculus foliis lanceolatis, caule erecto. LINN. Lingua. Syf. p. 5I5. ก. 3. Еовнм. n. 475.Fl. Dar. t. 754 . 
Großer grasblättriger Sumpfliahnenfif $\$$ I. Speerhahacnfüs. Germ. Great Spearwort, or Large Crowefoot. Angl. Rínoncle grand Douve. Fall.

In locis paludofis, unter an Gickerlingsberge, et in foflis nach Schörfeld, ibidemque ipfis in pratis, etiam iisdem in locis ad Lindenati. Flor. Iun. Iul. Perennis.

auricomus. 739. Ranumetulus foliis radicalibus fubreniformibus, tripartitis, acute crenatis; caulinis digitatis, linearibUS. LEYS. ה. $54 \%$.

Ranunculus foliis redicalibus reniformibus, crena. tis, incifis; caulinis digitatis linearibus, caule multifioro. Linn. Syft. p. 516 . n. 15. CRANiz. Fafc. II. p. 112. ก. 3. вовнм. ก. 442. Fl. Dant. ิ. 665.

Goldgelber Hahncufuß; Waldfchmergel; fïfer 1. wohlriechcadcr Waldhahnenfuß $\beta$; Goldhôhale in. Germ. Sievet - fccated Woot Crowefoot. Angl. Rénoncule printamniére, ou des bois. Gall

In pratis et fyluis, partim in Ro,enthale et Univerfit:tsholze. Fl. Mai, lun.

Seelerat1s. 740. Ranunculus foliis inferioribus palmatis, fummis digitatis, fruetu oblongo impatiente. IINis. Syft. pag. 516. n. i\%. воFHM. n. Ұ41. CRANz. Faf́. II. p. III. pLACKw. t. $25 \%$. Fl Dani t. $5-0^{\circ}$

Gleifblunen; Gift- S. brennender Wafferhahnenfuß; böjer Hahnenfuß ; Frofchpfeffer; Wafjereppich. Germ. Rénoncule de marais. Gall.

In paludibus et aquis ftagnantibus fere vbique, e. g. in der Allee, in der Leingrube, hinter den Kohlgärtent, bei Reidnitz und nach Sellerhaulen zu; in aquis quietis ad pngum Stötteritz, porro in ruderatis pafim alibique frequens. Flor. Mai. - Iul. Annua

Obf. Planta acerrima, et tefte b. Gledizychio, ore adfumtá, grauiffma excitat fi mptomata. Mendici plantn pedibus inp fita vice ra fibi excitare folent, qquibus ad unndinas fe praeparant. 
4T. Ranunculus calycibus retrofexis, pedunculis fulca-bubofus. tis, caule ereêro multiforo, folitis compofitis, radice fimplici, globola. IINN. Syft. p. 5I7. n. 3O. вовMM. ก. 438. Cranz. Fafc. II. pag. I14. Fl. Dan. tab. 551 .

Rïbon- f. Zuiebellahnenfufi; Brennkraut; Drïswur: Tarbenfis.s. Germ. Round:rooted Crowfoot. Angl. Rénonicule bulbeufe, Crcnouillez. Gall.

In pneus, protis, fyluis et elstioribus, hinter den Windmiihlcathore, auf dcm Fuf.ytege nach den StrafJenhäufcrn, ad viam nach Entritfch ctc. Fl. Mai. Iun. Perennis.

743. Ranuraculas calycibus patulis, pedunculis fulcatis, 'repens frolonibus recentibus, foliis compontis. LINN. Syf. p. 517, n. 31. LOEHM. n. 439. CRANz. Fafc. II. pag. I 4. BLACKW. t. 3 I.

IVieferi- . kriechender Hahnestuß; iteyher- 1. Krälucnfuss. Germ. Creeping Croufoot. Angl. Réroncule grenouillêre, ou couchée; Bouton d'ar. Gall.

In pratis, hortis et agris copiofiflime. Flor. Mai. Iun. Perennis.

Obf. Radix fiorofa, repens. Caules late procum. bentes, repentes. Cal. laeuis.

741. Ranumculas cslycibus patulis, pédunculis fulcatis, polyanthecaule erecto, foliis multipartitis. IrN . Syft. p. 517 . mus. n. 32. SCHREB. Spicil. p. 32. n. 952.

Vielblïmigter Halunenfußs; Butterblimehen. Germ. Réncucule bajjunet, on à plufieurs fleurs. Gall.

In pratis ad Gaut/ch, Z fchocher, Lindenau, in folo fteriliori, in Sylua Academica. Flor. Iun. Iul. Perennis.

Obf. Diftinguitur a lubfequente, ftatura multo maiore, foliis magis profunde et acutius diffectis, plane glabris; petiolis paullulum fulcatis, fapore mitiore.

74.5. Ranunculus calycibus patulis, pedunculis tereti- acris. bus, foliis tripartito-multifidis; fummis linearibus. IINN. Syf. p. 517. n. 33 .

Ranunculus caule eręto, multifloro, foliis pentago. nis, lobis fefflibus. вовнм. n. $437^{\circ}$

Pharm. 
Pharm. Ranunculac Herba.

Gemeiner Wiefen-f. fchaifer, brennender Hahnzenfuß; - Schmalzblïmchen. Germ. Upright Crowfoot. Angl. Rénoucule bafjin oú âcre. Gall.

In pratis, pafcuis et tyluis frequens, im Roferthaie, auf den'Schönfelder Wiejen, et fere vbique. Fl, Mai. Iun. Perennis.

Obf. Caules pilis minimis hirfutis arcte adpreffis. Calycis foliola fatis pilofa, bafi foluta, nec ọdnata.

VS Herba Bones et Equi vefcuntur.

lanuginofus 745 . Ranunculas calycibus patulis, pedunculis teretibus, caule petiolisque hirtutis, foliis trifidis, lobatis, crenatis, lanuginofis. Livn Syft. pag. 517. n. 34. вовнм. n. 24. Fl. Dait. t. 97.

Ranunculus foliis tripartitis, acute ferratis, lanuginofis. ĆRANz. Fof. II. p. IIS.

Wolligter f, Seidenhahnonfus?; Birkhahnenfußs. Germ. Rén:oncle velue. Gall

In fyluis pofim; im Rofenthale; in Sonmerfolder. et Univerfithtsholze. Fl. Mai. Perennis.

arwenfis. $7 \div 5$. Ranunculus ferminibus aculeatis, foliis fuperioribus decompofitis, linearibus. zinn. Syft. p. $518 . \mathrm{n}$. 37. говIIM. n. 443 . Fl. Dan. t. 719 .

Acker. Fcld-1. Stachelhahnenfußß. Germ. Rénoncule des champs. Gall.

In agris inter fegetes frrquens, ouf den Aeckembei dem Pulverthurme etc. Fl. Mai, Iun. Annua.

haterophyl- 747. Ranunculus foliis fubmerfis capillaceis: emerfis relus. niformi peltotis. LEYS. n. 5.55 .

Ranunculus aquatilis LiNN. Syft. p. 518. n. 44. et ed. R. 11. 667. var, $\alpha$. CRANz. Faff. II. p. 118.' 'воEHM. n. 43 4. Fl. Dant. t. 37 6.

Hahnenfuß mit viel geftalteten Blärtern; Wafferleberkraut Germ.

In forfis et riuulis vbique, im Gerberweaffer, in pio fcinis bei Plaufig, Segeritz et in fluuiis etc. Fl. Mai. Iun. Perennis.

aquathis, 749 Ranunculus foliis omnibus capillaceis, laciniis die -vergentibus. eExs. n. 556. Wirden. Prodr. Berol. n. $59 \mathrm{I}$.

Ranu12* 
Ranunculus aquatilis. LinN. Syft. ed. R. Ii. p. 668. var. $\gamma$. ВоЕнM, n. $: 235$.

Wafjerhalunenfiłß. Germ. Rénoncule d'eau, ou aģuasique. Gall.

In forfis, fluuiis pifcinisque, e. g, in Gerberwaffer, bei Großditz, Plaufig etc. Fl. Mai. Iun.

749. Ramunculus foliis omnibus capillaceis: laciniis pa-Ruuiatilis. rallelis longiflimis. LEys. n. $557^{-}$wilden. Prodr. Berol. n. 592 .

Ran̈unculus aquatilis. "ziNN. Syft, ed. R. II. p. 668. var. $\delta$. вOEI:M. n. 436 .

Wafferfenchel; Flußhahnenfuß; Haarkraut. Germ. Resoncule des rivicres. Gall.

In fluuiis in der Pleiffe et Elfter. Flor. Maio Tunio.

264. * FICARIA. Feigwarzenkraut. Germ.

Pilewort. Angl. Eclairette. Gall,

750. Ficaria foliis cordato-angulatis, petiolatis, gla- ranunculoibris, nitidis, caule vnifloro, radice tuberofa. des.

Ranunculus Ficaria. L1NN. Syft. pag. 515. n. IO. вовнм. n. $5 \div 6$. fub Ficaria. Blacrw. t. 5 I.

Pharm. Chelidonii Minoris Radix, Herba.

-Scharbock f. Feiguarzenkraut - I. zurz; kleines Schöllkraut; Pfaffen I Bieber Hödlein; Pfennigfalat; Mäufebrodt; Blatterkraut; klein Sclizealbenkraut; wild Löffelkraut; Scinnalzfterublume; Erdgerfte. Germ. Lefler round leaved Celandine, or Pile-wort. Angl. Petite Chélidoine; ou petite Eclairetie; petite Scro. phulaire; Herbe aux Hemorrhoides. Gall.

In pratis et locis vmbrofis, im Rofenthale copiofe, un Pfaffendorf; in hortis humidis. Fl. April. Maio. Perennis. tur.

$V \int$. Folia vernali tempore pro olere colligun- 
265. * ADONIS. L. G. 756. Alonisröslein; Teufels: augen. Germ. Plicafant's Eye; Red-Maithes. Angl.

Adonis. Gall.

seftiualis. 75r. * Adonis foribus pentapetalis, fructibus ouatis. IINN. SyA. p. 5 ! 4. LEYS. n, 318.

Wuldes Adonisröslein; Tenfelsangen; braine Mäg. del; Feldrösel; rothe Kamillen; Roralblünel; Acker-i: Klapperröfel; Sommer-Adonis; Feld. f. wilde Adonis : Fenerröfel. Germ. Yellow flowered Alony. Angl. Adonis d'été. Goll.

In agris inter legetes paffim, bei Gohlis et Eutritfch, porro bei Schönau, Nauendorf etc. Fl. Mai. Iun. Annua.

Obf: Numerus petalorum frequenter variat; mox enim $5, \operatorname{mox} 7, \operatorname{mox} 9$, etc. numeraui.

autumnaliś. 752. * Adonis fioribus octopetalis, frußtibus, fubcylindricis. LINN. Suft. p. 5 12. n. 2. LEYS. ก. 559

Herbft Adonistöslein; Margarethenblininchen. Germ. Common Pheafant's Eye, or Red Maithes; Red Morocco. Angl. Adonis d'Automne. Gsll.

In aruis inter fegetes pafim bei Eutritfch, bei der Hoizenleine, gïldenen Goffe et Störmthal etc. quoque in hortis cum priori frequens. Fl., Iul- - Septembr. O'j. Flores purpurei. Petals ouato-rotunda. Rami faepiffme foriferi.

\section{B. FLORE THALAMOSTE- MONOIDE.}

266. ARVM. L. G. TIT9. Aron, Germ. Waike-Robin: Aingl. Gouet. Gall.

maculatum. 753. Arum acaule, foliis haftatis integerrimis, fpadice clauato LINN. Syft. p. 828. BOEHM, n. 596, ELACKW. t. 228. Fl. Dan. t. 505.

Pharm. Ari Radix, Herba. 
Geflecker Aron; Zehrwurael; Magenwarz; teutScher Ingber; Kallotuß; klein Schlangtnkraut; Pfaffenblut; Frefisturz; Iohauniskraut; Kuhuurz; ESelsokren. Germ. Common Wake robin. Angl. Pred de Vexu. Gall.

In fy!uis vmbrolis, im Rofenthale, in Zfchocher. fchcn Holze copiofe p.tc. Fl. Mi. Perennis.

$V \int$. Radix hinc illincque editur, et BERGIVs e radi. cibus vetuatis et farinofis insculum parauit perinde fapidum ac a Sagu, odore pulmenti triticei.

\section{FLORE MONOCLINO.}

267. SAGITTARIA. I. G. I 164 . Pfeilkraut. Germ. Arrow-Head. Angl. Fléchiére. Gall.

754. Sagittaria foliis lagittatis, acutis. LINN. Syft. pag, fagittaefolia. 856. Вовнм. 11. 660. Fl. Dan. t. 172.

Pfeillhâttriges Pfeilkraut; großes Pfeilkraut. Germ. Common Arrow. Head. Angi. Fléchiére, ou Fleche d'eau. Gall.

In agris Ragnantibus, pifcinis, bei dem Gefundbrunnen. lici Gothe, Nauendorf, Kriphäne, Groj- et Kleinwolkau, Güldengo/fe; et in fluuiis minoribus bei Lindenau, Leutfch, Kleinzfchocher etc, vbique. Flor. Iun. Iul. Perennis.

Chinenfes Sagittariam ferunt, vt bulbum pro culina obtineant, quem copiofe edere folent.. $P$. OSBECK.

268. CERA TOPHYLLVM. L. G. I 162 . Wachsblatt.

Germ. Pondweed. Angl.

755. Ceratophyllum foliis dichotomis dentatis: inferio- demerfum.

ribus linearibus: fuperioribus inflato-tubulofo-denfiffimis, capfulis roftro longitudine aequalibus. ROTr. Flor Germ. p. 40 ?.

Ceratophyllum foliis dichotomo-bigeminis, fructibus trifpinofis. LINN. Sy?t. p. 836, воЕнM, n. 688. 
Untergetauchtes Wachsblatt; Wafferhosmpflanze;

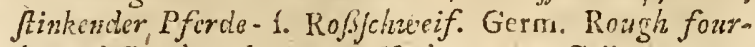
horned Pondweed. Angl. Hydre cornut. Gall. Iul.

In folfis, aquis et pifcinis natat vbique. Fl. Iun.

fubmerium. 756. * Ceratoplayflum folis dichotomis dentatis; inferioribus fubinilato-tubulofis; fuperiouibus cspillaribus approximatis, capfulis acumine breui obtufo. RoTr. Fl. Germ. p. $\angle 0^{\circ}$.

Ceratophyllim foliis dichotomo - trigeminis, fruetu mutico, LINN. Syft. p. 856 .

Ganz untergetauchtes Wachsblatt $\Upsilon$. Hornblatt. Germ. Smooth eight-horned Pondzeed. Angl.

In foffis et lacubus, praeprimis in pilcinis bei Par: neck, Großueölkanl et poft pagum Kriphäne, porro in der Bahre et Pleiffe vbique. Fl. Iun. Iul.

269. MYRIOPHYLLVM. L. G. II63. Federballf. Kraut. Germ. Water Milfoil. Angl.

fpicatum. 757. Myriophyllum caule ramofo, fpicis terminalibus nudis interruptis; floribus bracteatis, foliis pinnatis capilaribus. wirden. Prodr. Berol. n. $4 i 6$. LinN. Syft. p. 856. вовнм. n. 593. Fl. Dant. t. 68 I.

Aehrenformiger Federball; Teichfenchel; Wafferfuchsfchuoanz; Waffergarn; Saufaamen. Germ. Spicked Water Milfoil Angl. Volant d'eau. Gall.

In foffis, ftagnis pifinisque, in den Teichen bei dem Gerberwajfer, bei Parneck etc. Flor. Iul. Aug.

verticilla- 758. Myriophyllum, caule fimplici; foribus verticills. tum. tis, foliis pinnatis; pinnis linearibus carnofis. wrLDEN. Prodr. Berol, n. 447. IINN. Syft. p. 856. вовнм. n. 594 .

Wirbelartiges Federkiaut S. Teichfenckel; Saan. kraut; Saufaamen. Germ. Verticillated Water Mil. foil. Angl.

In iisdem locis cum priori, Fl. Iun. Iul, 
270. POTERIVM. L. G. I16\%. Bechtrblume; Megelkraut. Germ. Burnet. Angl. Pimprenelle.

Gall.

759. Poterium inerme, caulibus fubangulofis. IINN. fanguiforba. Sytt. p. $857^{\circ}$

Sanguiforba polyanthera, foliolis ouatis, fpica brevi. BOEHM. $n$ i

Pharm. Pimpinellae Italicae Herba, Semina.

Gemenne Bechorblume; fchwarze i. kleine Bibernoll; italienifche Bibirnell: rauches Blutkraut; Sperberkraut. Ger!n. Common Burnet or Stone parsley. Angl. Petite Pimprenelle, ou Pimprenelle d'Italie. Gall.

, In pafeuis et apricis vbique: auf den Bergen bei Meckern, auf dem Gickerlingsberge. Flor. Iulio et Augufto.

$V \int$ Folia ad acetaria. Herba pabulum pecoribus falutare.

27I. FAGVS. L. G. II -O. Buche. Germ. Beech-tree. Angl. Hêtre. Gall.

760. Fagus foliis ouatis, vndulatis, obfolete ferratis. fyluatica.

LINN. Syft. p. 859. BOEmM. n. 693. CRAM. tab, 3. v. GLEICHEN. Abbild. T. 17. DV ROI Harbk. I. pag. 230 .

Pharm. Fagi Frustus.

Wald-Majt-Trag-Roth Winter-und Sommerbuche; Bucheckern. Germ. Beech tree Angl. Hêtre des Forezs, ou Fouteau, Fau ou Foyard. Gall.

In fyluis, im Kofenzhale, im Meckerfchen Holze alisque nemoribus. Fl. April. Mai. Arbor.

Vf Glandes annonae caritate pani inferuiente: cephalslgiam et temulentian inducunt. Toftae fuccedaneum Careas; caeterum his g!andibus porci pinguefcunt la do laxo. Lignum fib aqua diutius dirar, qua de re ad nauium carinas aptum. In foco mạxime calefacit. Cincres metallurgicis, vitriariis, faponariis vtiles: Cortex et Folia coriis praeparandis spta. 
272. QVERCVS. L. G. I Í68. Eiche. Germ. Oak. Angl. Chêne. Gailh.

Robur. 76r. Quercus foliis metiolatis, deciduis, oblongis, fuperne latioribus. "finubus acutioribus angulis obtufis, fuctibus feflilibus. LINN. Syft. pag. $85 \pi$. DV ROr Harbk. II. p. 237. KERN. B. II. p: 103. t. 178.

Quercus latifilia mas, quae breui pediculo eft. C.

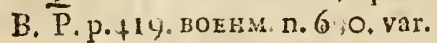

Gemeine Winter Stein-Berg-Harz-Roth- 1. Eiseiche, Traubeneiche. Gern. Common Oak-tree. Angl. Chêne Rouvre ou Chêne commune. Gall

in fyluis fere omnibus circa Lipfiam fitis, et ante rufticorum domos, atcue in $\mathrm{p}$ : gis ipfis paffim Arobulacra format. Fl. Mai. Arbox.

$V \int$. Sues his glandibus optime pingues fiunt. Cortex et cupulae fiuctus coriis parandis praeitantiffina. Lignuin durum, tenax a Cantharide deftruitur, et Teredine nauali laeditur. Infuper vtilifimum ad aedíicia, Carinas nauiun, prela, voluulos, rotarum radios, aratra, fepimenta, ciftas fepulcrales, dolia, fellas, menfas et varia inftrumenta etc. Cortex fuccedaneum corticis Peruuiani pauperibus.

femina. 762. * 2uercus foliis deciduis, fubpetiolatis oblongis obtuís, pinnato-finuatis: fructibus fubfolitariis longe pedunculatis. pv rol Harbk. Il, pag. 240. котн. Flor. Germ. I. p. 408. BОЕнм. n. 6yO. BLACKw. tab. 487 . CRAM. t. 2.

Quercns cum longo pediculo. C. B. P. pag.
420 .

Snmmereiche; Aufteicize; Hafeleiche; Stieleiche; Waldeiche. Germ. White long Foat Stalks to the Acorn. Angl. Chêne à grappes. Gall.

Pharm, Quercus Cortex, Folia, Glandes, $\mathrm{Cu}$ pulae.

In fyluis fere omnibus, praeprimis in der Kämme. rei bei Nauendorf; im Meckerfchen sommerfelder Holze; im Rofenthale; in Querceto vor Altranftïdt etc. valde vulgaris. 
POLYANDKIA. MONOCLINO. 307

VJ. Eglandibus Soda praparari poteft. Lignivfus idem eft ac prioris.

\section{IVGLANS. L. G. I I69. Wallnufs, Germ. Walnut - Tree. Angl Noyer. Gall.}

763. Inglans foliis oualibus, glabris, fubferratis, fub- Regia. aequalibus. tinn. Syft. pag. 858. вовни. n. 692. scholl. App. Flor. Barb. p. 302, DV Ror Harbk. I. p. 323. BLACKW. T. 24. CRAM. t. 22.

Var. a) luglans fruktu maximo. C. B: P. pag. 417. C. B. P. l. c.

b) Iuglans fruêtu tenero è fragili putamine.

c) Jugians putamine durifimo. Tourn. Inftitut.

d) Iuglans bifera.

e) Iuglans fruetu Serotino., $4{ }_{4}$ I . P. P.

Pharm. Imglandis Nuces, Diffepimentum, Cortex viridis.

Gemeiner Wallhulßbarm; we? fche $N u \beta$; a) Schafnuß; Kobernuß; Pferde- $1 . R o \beta n u \beta$; b) die diunnSchaaligze $N u \beta$; Meifennu $\beta$; c) Steinzus $\beta ;$ Grübelnu $\beta$; d) der aweimal in Iahre tragende Naßsbanm; e) die fpôte WVallnußß f. Iohannisnußs. Germ. Common Walnut-tree; a) Large Walisut; b) Tender Shelled Walnut; c) Hard-fhelled or French-IValnut; d) Tweice-bearing Walnut; e) Late ripe Walnut. Angl. Noyer ordinaire, ou Royal; a) Noix de Fauge; b) Noix Mefanges; c) Nozx it fruits dures; e) Nozer à fruits tardifs, ou dc la St. Fean. Gall.

In Perfia proprie habitat, ex qua iam diu in Euro. pam Arbor rranslata eft. Apud nos in hortis fuburbanis rufticanisque, in pagis ante domos et ante pa. gos Ambulacra format palfim, e. g. ad Ketfchau, vbi fere-omnes hyeme dirifimo 1788 ad 99 nunc funt dernortuae etc. Fl. Maio. Fruatus Septembr. et ineunte OStobri maturant. fentus.

Obf. Arboris magnae rmbra fufpecta obftupefacit 
VJ. Olcum ex nucleis decorticatis paratum pifto. ribus vtile., Vt Anthelminthicum contra Taeniam commendatur. Nuclei cum aqua triti, in emulfionem abeunt. Extractum ex Dipis recentibus immaturis paratum praeftans qroqu: anthelminthicum. Aluum purgat et'lumbricos firul pelit. Drupae porro immaturae condiun ur cum Saccharo, aromatibusque. Drupis immaturis fpiricus frumenti infunditur a ruricolis, quo, vt ftomachico, vtuntur. Nuclei maximi tofti pro Checalsta, vel Caffea inferuiunt in nonnullis $r$ gicnibus Folia et Cortex Druparum exterior viridis obfcure viriden exhibent coloren durabilem.

27\%. CORYLVS. L. G. II 72. Hafelfaude; Hafelnufsfrauch. Germ. Hafel-Nut, Angl. Noifertier. Call.

Aueliana. 764 . Corylus fipulis ouatis, obtufis. LINN. Syft.pag. 859: BOEHM. N. 69T. DV RO1 Harbk. I. P. 173. WILDEN. Prodr. Beroi. n. $43 \%$.

Corylus fylueftris. C. B. P. p. 418. BLACkw. tab. $29.3^{\circ}$

Var. a) Corylus fatiua, fructu rotundo, maximo. b) Corylus fructu oblongo, ouato. p. 4 I8.

C. B. P.

Pharm. Coryli Lignum, Vifcum, Puluis: Auellanae Nuces.

Gcmeine, wilde Hafelftuude; Waldhajelftrauch; a) die grobe holl adifche 1. Jpanifche $N u /$; Zellerruß ; b) Mandelnuß. Germ. Wild Hazel-Nut; a) Spanifh Nut; Larg Cob Nut; b) Long Nut. Angl. Noifettier des bois, ou Coudrier; a) Avelline à fruit rond; b) Longuette, ou Avelline à fruit long et blane. Gall.

In fyluis frequens, praecipue in Rofenthale et Univerfitätsholse; in der Kammerei bei Nuuendorf; in dumetis et intra fepes viuas iusta pagos paffim. Varietstes autem modo in hortis coluntur. Flor. Mart. April. Frut.

VJ. Sepibus maxime praeftans. Nuces in deliciis habentur, Rami virides frumenti corruptionem 
suertentes, ad virgulas diuinatorias, corbes carbonum, cribra, vincula doliorum, etc. Carbones a pictoribus, fculproribus et aurifabris ad praeludia figurarum. Folia capris ét flores apibus pabulum.

265. * Corylus ftipulis oblongis, obtufis, ramis ere- inaxima. ktioribus. MILL. 2. DV RoI llarbk. I. p.176.

Var. a) Corylus fatiua fructu oblongo) rubente. C. B. P.

b) Corylus fructu oblongoruben-) p. 418 . te, pellicula alba tecto.

Lambertsnuß; Bartnufs; a) rothe Lambertsnufs; Blutuufs; rothe Ruhrmufs; b) zeeiffe Lambertsnufs. Germ Filbert Nit:tice; a) Red fkinned Filbert; b) White fkinned Filbert. Angl. Noifettier cultivé; a) Noifettier franc, ou à fruit rouge; b) Noifettier is fruit long, couvcrt d'une pellicule blanche. Gall.

In hortis valde frequenter occurrunt. Flor. cum priori. Drupae paullo ferius maturefcunt, quam priores.

Obf. Differt haec fpecies ab antecedente: Ramis magis ereetis, ftipulis oblongis et calyce cylindriformi drupas includente, verfus apicem minus lacinia. to Drupae, fi terra imaittuntur, femper gignere folent truncos ipfis proprios, nec vinquam degenerant. Nuclei omnium optimi et fapidifimi,

275. * PLATANVS. L. G. II73. Platanus.

Germ. Plane-Trce. Angl. Platane.

Gall.

766. * Platomus foliis lobatis. zinN. Sy§t. p. 859. ח. 2, oecidentalis. DV Ror Harbk i1. pag. I 3 . DVHAM Arbor. T. II. Pl. 35. SERT. Lipf. n. 69. 
Nordunerihanifcher Platanus; Wafferbuche. Germ. American or Virginian Plane-tree; Large Button Wond. Angl. Platane d'Occident ou de Virginue; Cotionier. Gall.

Habitat proprie in America feptentrionali. Apud nos ad pifcinas et in'lucis huinidis yaffim ante multos annos plaitata eff, e. g. ad pifcinam prope pagum Grofswölkau di:tum, et nunc in Scrto non procul a porta Grimmenfi, et quidèm ante montem Schneckenterg dictum, et, verfus Ergaftulum; porro in multis hortis. Fl. Iunio. Arbor.

Obs. Arbor celeriter crefcit et in omni folo prouenit. Cortice frunci exteriore in adultis denudatur quotannis. Truncus fenfin $60-80$ pedum altior fit et $3-4$ pedum craflus. Fol. aiterna, late expanfa, multilobata, acute dentata, fuperne laete viridia, inferne pallidiora et coftis eminentibus tomentofisque inftructa, longe petiolata:

276. CARPINVS. L. G. 1 I7r. Spindelbaum. Gern. Hornbeam. Angl. Charme.

Gall.

Betulus. $76 \%$. Carpians fquamis ftrobilorum planis. LINN. Syff. p. 859 . вовнм. n. 6 .9. ру воI Harbk. I. pag. 124, BLACKW, t. 293. CRAM. t. 4.

Spindeibaum ; gemeine Hain - Hagen - Stein - Wei/sbuche; Hornbaum; Rollholz;. Flegelholz; Hartholz; Zaunbuche. Germ. Common Hornbean. Angl. Charme ordinaire. Gall.

In fyluis frequens, ins Rofenthale, UniverfitâttsZ fehocherfchen-Kleindölziger Hölzern; multisque aliiș in Syluis. Flor. Aprili, Maio. Arbor, 
POLYANDRIA. MONOCLINO. 3 II

VS. Haec Arbor fepibus viuis, maxime in hortis valde communis et praeftans. Vernali tempore aqua fillat. Cortex luteo tingit colore. Lignum album, duriffimum et tenuifimum a tornatoribus, feriniariis, opificibusque fr"quenter adhibetur ad varia vafa vterfilia atque inftrumenta conficienda. 


\section{A. GYMNOSPERMAE.}

a) Flores verticillati. Calycibus 5 - fidis et multiden-
tatis.

277. LEONVRVS. L. G. 780. Löwenfchwanz;

Wolfstrayp. Germ. Lions 'Tail. Angl. Leonare. Gall.

Cardiaca. 768. Leomurus foliis caulinis lanceolatis, trilobis. LínN Syft. p. 538. вовна, n. 115. BLACKw. t. 17 I. Fl. Dan. t. 727 .

Pharm. Cardiacae Herba

Wolfsfufs 1. Wolfstrarp; Herzkraut; Herzgefoan; -Herzgefperr, Löwenfchwanz; wild Mutzerkraut. Germ. Englifh Mothervert. Argil. Agripaume, ou Cardiaque. Gall.

Ad fepes et in ruderatis, in Poetengange, etiam in Horto Bofiano. Fl. Iul. Aug. Perennis.

Marrubia- 769. Leonurus foliis ouatis lanceolatisque ferratis; cafrum. "lycibus feffilibus, fpinofis. LiNn. Sy ft. p. 538 . n. 3. SChreb. Spicil. p. I2. n. 908. Jace. Flor. Auftr. V.5. t. 40.5 .

Faljcher unächter Wolfstrapp; rother Andorn: böhmifcher Lözerenfchwanz. Germ. Bohenian Lion'se Tail. Angl.

In ruderatis et collibus circa vrbem; in fyluaticis locis inter frutices, 'hinter dem Lazarethgarten; porro in Rofenthale. Fl. Iul. Aug. Perennis, 
DIDYNAMIA. GYMNOSPERMAE.

279. GLECOMA. L. G." ־३ Gundeirebe, Germ. Turnhoof. Angl. Terrette. Gall.

27c. Flecoma foliis reniformibus, crenatis. LinN. Syft. hederacea p. $=34$. ILAcrw. t. 225 . Fl. Dlan.t. -89 .

Chrmacilenia caulibus procumbentibus, radicatis, foliis cordiformibus, petiolatis. повнм. n. 131 .

Var. Clecoma foliis punctato-albis.

Pharm. Hederae Torreftris Herba.

Epheuartige Gundel-1. Grundrebe; Donnerreben; Gundevinann; Erdepheu. Germ. Ground Ivy. Angl. Lierre terrefter. Gall.

In locis hunidis fyluaticisque, vor und in den RoSenthale, bei Pfaffendorf, in Lindenauex Holze, et fere vibique. Fl. April - Iun. Annua.

Oly. Planta herbas proximas lente expellit et prata denudat. LINN.

Vf. Flores apibus pabulum, et ad cereuifiam clarificandam dolio immittitur herba ab Anglis.

279. HYSSOPVS. L. G. 76\%. Yfop. Germ. Hyfop. Angl. Hifope. Gall.

27 I. * Hylyopus fpicis fecundis, foliis lanceolatis. officinalis. LINN. Syft. p. 529. вLACKW. t. 296. JACQ. Flor. Auftr. V. 3. t. 254 .

Fharm. Hufjopi Herba, Semina.

Gewölunlicher Y Yop. Germ. Officinal Hyfop. Angl. YJfope ordinaire. Gall.

In hortis cultis paffim, praecipue in Horto Bofia no var. flore albo quotannis mihi obuiam venit, Fl. Iun. Iul.

280. MENTHA. L. G. 77 I. Münze. Germ. Minto Angl. Menthe. Gall.

* Floribus oblongo - ouatis.

772. Merztiza fpicis ouato-oblongis, foliis oblongis, fylueftri? fersatis, feffilibus, fubtus tomentofis, ftaminibus co-

$$
\mathrm{V}_{\mathrm{i}} 5 \text { rolla }
$$


rolla longioribus. LINN. Syft. p. 532. n. 2, вовнM. n. 881. BLACKw. t. 292.

Pharm. Menthae i. Longifoliae Sylueftris Herba.

Wilde 1. Rofsmiinze; Rofbalfan; Herzenstroft. Germ. Common White Mint. Angl. Menthe Jauvage. Ga!l.

In locis vliginchis bei den Kohlgärten, et in plúrmis fyluis. Fil. Iul. Aug. Perennis.

viridis. 7. 3**Mentha fpicis oblongis, foliis lanceolatis, nudis, ferratis, leflilibus, faminibus corolla longioribus. LINN. Sy?t. p. 532 . n. 4. LEYS. n. 566 .

Grüne Münze; Froucmmïnze; englifche f. römifche Mïnze. Germ. Spear-Min*. Angl. Menthe Romaine. Ga!!.

In locis fylunticis et humidis paffim, im Kleindölzigcr Holze nach Skenditz zu. Fl. Iul. Aug.

Obf. Hacc fortior ef, quam $M$. fylueftris, minus grata, fapore debiliori, quam M. Piperita, ideoqueil. ii pirfim fubftitui poreft.

rotundifolia $7.4 . *$ Mentha picis oblongis, foliis fubrotundis, rugofis, crenstis, feffilibus. LINN. Syft. pag. 532. n. 5 . LEYS. ก. :32.

Rundbl,trige Münze; Pferdemïnze. Germ. Roundleaved Mint. Angl.Menthe à feuilles rondes, ou Menthafre. Gall.

Ad foffas et fluuiorum ripas bei den Gefundbrunnen paffim $r$ peri. Fl. Iul. Aug.

$V \int$. Summitates tinnitum aurium et furditatem tollere refert HAzLERvs.

\section{* Floribus capitatis.}

crifa., 775. * Mentha floribus capiatis, foliis cordatis, dentatis, vndulatis, felfilibus, ftaminibus corollam aequanti.us LiNN. Syft p. 32. n. 6.

Mentha crifpa. Riv Monop. t. :7•

Pharm. Menthac Crifpae Herba.

Kraufemüuze; Gartenmünze; Münzhalfam; krauSer Baifam; Braunheilig. Germ. Curled Mint. Angl. Menthe frifée, Gall. 
DIDYNAMIA. GYMNOSPERMAE. $3 I 5$

In Sibiria et Germania habitat: in hortis autem noftratibus et agris olfraceis haud infrequenter occurrit. Flor. Iul. in Autumnum vsque. Perennis.

Vf. Flores apibus pabulum haud infimum.

776. Montha floribus capitatis, foliis ouatis, ferratis, aquatica. petiolatis, ftaminibus corolla longioribus. Livin. Syft. p. 532: n. 8. вОЕНМ. ก. 128. BLACKW. t. 32. Fl. Dañ. t. 673 .

Pharm. Menthae aquaticae Herba.

Wafjermizinse; Bach-Kröten-Fifchmïnze; Wafferpolei; Rofsbaifan; wildes Katzenkraut. Germ. Water-Mint. Angl. Baume, ou Menthe aquatique. Gall.

In aquofis foffis et locis ftagnofis vbique. Flor. Iul. Aug. Perennis.

*** Floribus verticillatis:

777. * Mentha floribus verticillatis, foliis ouatis acutius- fatiua. culis, ferratis, ftaminibus corolla longioribus. LINN, Syft. p. 532. n. 10. Fl. Dan. t. 794 .

Mentha crifpa verticillata. C. B. P. p. 227.

Zahme Mïnze; gemeine Kraufeniünze. Germ. Marfh or Sweet Mint. Angl. Menthe cultivée. Gall.

In pratorum fofficulis vel pratis humidis, bei Schadebach paflim et in hortis oleraceis. Flor. Iul. in Septembrem vsque.

778. * Mentha foribus verticillatis, foliis ouatis, acutis, gentilis ferratis, ftaminibus corolla breuioribus. LINN. Syft. p. 533 . n. II. LEYS. n. 570. Fl. Da11. t. 736.

Willè, grofse Münze; Balfan-Oranien-f. Pomeranzennünze; Gartenbalfan; rothe Gartenmünze; $B a$ filienmïnze. Germ. Red Mint. Angl. Baune des jardins. Gall.

In agris humidis Ill. ponlıvs primum vidit, et mihi in forfis ad Delitz paftim occurrit. Fl. Augufto in Septembrem vsque.

Obj. Menthae aruenfi valde fimilis, fed minus hir futa; corellae infima lacinia acuta. 
Vf. Folia virentia faturae herbariae immifentur a quibusdam et cruda eduntur.
aruenfis. $7 \%$. Mentha foribus verticillatis, foliis ouatis, acutie, ferrstis, ftaminibus corollam aequantibus. LiNn. Syft. p. 533. BOEHM. n. I 29. ELACK w. t. 131. Fl. Dan. tab. 51.

Pharm. Menthae Sylueftris Herba.

Ackcrmünze; Korn-Fcld-wilder Poley f. kleine Bachmünze. Germ. Corn Minz, or Water Calaminth. Angl. Monthe des champs. Gall.

In agris et aruis hum:dioribus bei dem Gerberwaffer nach Schönfeld $z u$; porro in pratis, agris neglectis, er circa foffas fere vbique. Flor, Iul. Aug. Perennis

Vf. Prohibet lactis coagulationem, menfes pellit, Bubones mammarum tollit.

Pulegiun. $78 \%$. Mentha floribus verticillatis, foliis ouatis, obtufis, fubcrenatis, caulibus fubteretibus repentibus, ftaminitus corolla Inngioribus. IINN. Syft. p. 533 . n. 16. SCHREB. Spicil. p. 12. n. 909. BLACKW. t. 302.

Pharm. Pulegii Herba.

Polei; Poleimünze; Herzpolei; Flöhkraut. Germ. Common Penny-royal, or Pudding Grafs. Angl. Pouliot. Gall.

In locis inundatis ad Leutfch, Parneck. Flor. Iul. Aug.

281.* LAVANDVLA. L. G. 769 . Lavendel. Germ. Lavender. Angl. Lavande. Gall.

Spica. 78r. * Lauandula foliis feffilibus lanceolato-linearibus, margine reuolutis, $f$ ic inter upta, nuda, LINN. Syft. p. io n. 1. BLACKW. T'2

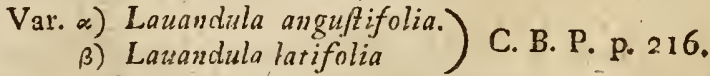

Pharm Lauandulae Herba, Flores

Gemeiner S Spiklavendel; Spike; fchmaler C. breite blïtrichter Lavendel Girm. Common Lavender. Ingl, Lavande Femelle ou commune; Spic ou Afpic. Gall. 
DIDYNAMIA. GYMNOSPERMAE, 3I?

In Europa auftrali sponte crefcit. Apud nos in hortis oleraceis aliisque valde frequens. Fl. Aeftate. Perennis

$V \int$. Planta aromatica paffim ad condimenta adhibetur.

282. TEVCRIVM. L. G. 764. Gamander, Germ. Germander. Angl. Ivette. Gall.

782. * Teucrium foliis multifidis, floribus lateralibus Botiys. ternis, pedunculis. LINN. Syft. pag. 525. LEYs. n. 574 .

Teucrium foliis multifidis, verticillis dimidiatis. SCHRED: Vert. Vnil. p. XXXII, n. 20.

Iva mofchata, folio multifido. RIV. Monop. tab. 24.

Traubengamander. Germ. Fagged-leaved Ground Pine. Angl.

In agris negletis montoís paflim mihi obuiam venit et quoque auf den Acckern nach Schônfeld. Fl. Iun. Iulio.

Obf. Caul. palmaris, pedalis, valdé ramofus. Fol. muitifida, petiolata, anbitu e cord to-ouara, recurva: laciniis $2-5$ - fidis, integris, obtufis Verticilii folio breuiores, 6 - 8 -- flori. Caly. $x$ bafi valde gibbus. Cor amoene purpurea, medio aiba, punctis rubris confperfa, dorfo marginata.

VS. O.lore aromatico gratoque gaudet planta. Lanam inbuit colore ingrato e fufco-cereo; cum alumine autern elegantem fufcum exhibet colorem.

783. Teucrium foliis trifidis linearibus integerrimis, flo- Chanaepi-

ribus fefflibus, lateralibus, folitariis, caule difufo. tys. IINN. Syft. p. 525. n. 4. BLAC Kw. t. 80. Fl. Dan. t. 75.3 .

Bugula foliis trifidis, floribus fparfis in alis folio. rum. BOEHM. n. 101.

Pharm Chamaepityos Herba.

Slagkraut; Feldcypreffe; Fe länger je licber. Germ, Common Ground I'ine. Angl. Teette Gill.

In loco renofo et frbulofo pafim in fylua ad Zzeinauendorf. Fl. Iul. Aug. Annua. 
Obf. Rad. lignofa. Caul. b:fi perennes, tetrago* ni, rubelli, fcabriufculi. Folia oppofiti, Iubptrojata, bafi acuta, integerrima, verlus apicem profitide trifida: foralia fere feffilia, onat, bafi $r$ rundar: integerrina. Flores aiares tolitarii, $5-7$ in verticitis fingulis. Cal. 5-gonus, 5-dentatus, pilofus. Cor. filamenta ad faucem punetulis purpurukcentibus notata.

Vj: In Scorbuto, Epilepfia, Arthritide, herba olim eft laudata. Porro hane herbam morb!m boum ouumque putridum fanafe, Eraljauola refert.

Scorodonia. 784. Teucrium foliis cordatis, ferratis, petiolatis, racemis lateralibus fecundis, caule erecto. Linn. Sylt. p. 527. n. 23. SCHREB. Spicil. p. I3. n. yoin. Ei Vericill. p. XXXVIIIl. n. 35. BLACK,.t. 9. Fl. Dan. tab. 405 .

Scorodonia. RIv. Monop. t. 22.

Skorodonie; Waldfkordienkraut. Germ. Wood Sage. Angl. Sauge fauvage. Gall.

In locis elatioribus, arenofis, ad Templun St. Theclae, atque in der Tieghatz bei Dïhen. Fl. Iuri. Iul. Perennis.

Obf. Caul. erectus, bafi paullulum incurnatus, 4 - gonus, geniculatus, ramis opp-fitis. Folia coniugata, cordato-ouata, obtufiufcula, vel denticulis minus acutis notata, vtrinque viliofa; foralia minuta, fubrotunda, integerrima, vtrinque acuta, in mucronem definentia. Spica racemola, fecunda, fummitate caulis ramorumque egrediens. Calyx bilabiatus, glaber. Labium fuperius fubrotundum. denticulo vnico inftuetum; inferius denticulis 4 gaudet. Cors tubus parum incuruus, albidus, ftriis purpureis fuperne pistus.

Scordium. 785. Teucrium foliis oblongis, feffilibus, dentatn-ferratis, floribus geminis, axiliaribus, peduncu'atis, caule diffufo. LiNn. Syft. p $52 \%$ n. 25 . SCHREb. Verticill, p: XXXVII. n, 29. RIV. Monop. tab. 21. b.n. BuACKw. t. 475. Fl. Dan. t. 593. GLED, Naturg. der cinhein. Pfl. P. 191. T.X. 
Teucriun foliis feffilibus ferratis, nollibus, floribus ex alis binis. вовнм. n. IO7.

Pharm. Scordii Herba.

Skordien; Skordienkraut; Lachenknoblauch; Wajferknoblauch. Germ. Water Germander, or Garliknander. Angl. Chamaras ou Germandrée d'eau. Gall.

In pratis paludofis, auf der Wiefe finiftrorfum verfus Kuhthurm, porro etiam vor Jem Streitholze, in fepulchreto ad Sommerfeld. Flor. Iul. Aug. Peren. nis.

Vf. Pabulum bobus, capris: Herba graueolens lac alliacio inficit odore. Fomenta putredini et gangrenae refiftere feruntur. In febribus intermittentibus maxime laudatur herba.

786. * Teucrium foiiis cuneiformi-ouatis, incifis, cre-Chamaedrys natis, petiolatis, foribus ternis, caulibus procumbentibus, lubpilofis. IrNe. Syft. P. 527. LeERs Herborn. p. 442. BLACKW. t. 80 .

Teucrium Chamaedrys foliis oblongis profunde ferratis, verticillis dimidiatis, caulibus procumbentibus, pilofis. schreb. Verticill. p. XXXII. n. 21.

Pharm. Chamaedryos Herba.

Gewöhnlicher Gamander; Bathengel; edel Gamanderkraut; Bergfkordien. Germ. Common Germander. Ang:. Petit Chêne, ou Germandrée. Gall.

In locis montofis ficcioribus, rarius auf dem $\mathrm{Gi}$ ckerlingsberge: auf der Anhöhe dęs Bieniz inueni. Fl. Iun. Iul.

Vf. Planta vulneraria. Folia enim cum oleo vulneribus impofita haec fanant. Flores apibus pabulum. Herba tinctoria.

\section{AIVGA. L. G. 763. Fünfel. Germ. Bugle. Angl. et Gall.}

78\%. Aiuga tetragono-pyramidalis villofa, foliis radica- pyramidalis, libus maximis. LinN. Syft. p. 525 .

Aiuga pyramidalis caulibus fimplicibus erectis, foliis oblongis dentatis. scHrez. Verticill. pag. XXIII.

n. 3 . 
Bugula foliis angulofe, dentatis, caule fimplici. hall. 635 , военM. n. 103 , вLACK w, tab. 64. f. 2. Fl. Danl. t. 185.

Eusula montana. Riv. Monop. t. IłO. f. 2.

Pharm. Confolidae Miedıae Herba.

Pyjranidenförmiger Günfel S. blauer Günfcl; Stcin-1. Berggünfel; cuile Brauncllen; Bronzikraut. Germ. Moun. tain Bugle, or Sicklevert. Angl. Bugle pyramidale. Gall.

In pratis et nemoribus ficcis, auf dem Gickerlingso berge, unten bei den Mecker/chen Bergen, in den Macherfchen Holzc, in dem Holze bei Nötzfch, pafim. Fl. Mai. Iun. Perennis.

Obf. Caules folitarii, vel plures, ftolonibus deftituti, denfe villofi. Fol. oblong:, dentata, obtufa, pafim ouata, vel lanceclata; flnralia ouata, ferrata, reliqua verfus terram trilobs, vel faepius dentata, villofa. Cor. tubus breuior, quam in fubfequente, al, bidus, ftriatus, d nique coeruleus euadit. Flores in verticillisidenfis ponuntur: $6 \cdot 8$ in fingulo verticillo fores feffiles funt ad foliorum alas. Flos albus vel purpureus.

- reptans. 788. Aiuga caule fimplici ereeto, ftolonibus repentibus, foliis ouatis crenatis. sснгев. Verticill. Vnilab. pag. $\mathrm{XX}$ I. n. 2 .

Aiuga reptans glabra, ftolonibus reptantious. LINN. Syft. p. 525 .

Bugula foliis ouatis, inter flores ftipatis, flagellis repens. HALl. 634 . говHM. ก, IO2. BLACW, tab, 64. fig. '.

Bugula. Riv. Monop. t. I40.

Var. a) 'Aiuga flore-albo.

6) Ainga flore purpureo.

Pharm. Bugulac Herha.

Günzcl f. Günjel: fchleichender Goldgünfel:. Wiefcre. gïnfel; Heilkrâutlein. Germ. Crecping Bugle. Angl. Bugle, ou petite Confoude. Gall.

In,pratis humidis fyluaticisque locis, copiofiffime in: Rofonh hale, Univerfitäts- et Gonncwitzer. Holze, auf den Schönfelder, Gerber, Lindenauter Wiefen et alibi frequens. Fl. Mai, Im, Perennis. 
DI DYNAMIA. GYMNOSPERMAE., $32 I$

Ob. Canlis erectus, glaber, non ramofus, 4-gonus, geniculatus, inter folia tubuillolus, tener et fucculentus: inter caulis hafin et radicis apicem ftolones fteriles, foliofi, in terra repentes egiediuntur. Fol. radicalia in celpitem congetia, parum obuefe vel oblongc ouata, fubpetiolata, obtufa, crenata, glabra: fluralia fubrotunda, obtufa, integerrima, margine cilisto fubrubella, leuiter pubefcentia, bafi ciliata. Verticili e foribus $8-12$ conflati, villofi : inferiores remotiores, fuperiora verfús denfus iuxta fe inuicem imponuntur.

- Vf. Flores lruius et prioris pahulum apibus bo. num. Folia bobas pabulum: Equi autem refpuunt herbam.

284. BETONICA. L. G. 776. Betonien. Germ. Betony. Angl. Betoine. Gall.

739. Betonica fpica interrupt2, corollae labii lacinia in-oficinalis.

- termedia emarginata. LiN , Syet p. 535. военм, n. 120. вцACKw. t. $46 . F l$. Dan. t. 426 .

Var. a) Betonica flore albo.

B) Bezonica flore purpureo.

Pharm. Betonicae Herba, Flures.

Gcreöhnliche f. brawne Betonien. Germ. Wood Becony. Angl. Betoine vulgaire, Gall.

In pratis ficcis et fyluaticis, anf den Wiefen nack den Kuhthurm, hinter Gunndorf, et in tiusdem $f_{y} \mid-$ va, porro in Rofenthale etc. Flor. Iut. Aug. Perennis.

285. LAMIVM. i. G. 774. Taube Nefiel; Bienen. faug. Cerm. Archangel. Angl Lamion, ou Archangélique. Gall.

790.* Lamiun foliis cordatis, acuminatis, verticilis maculatum. decemfloris. LINN. SyRt.p. 532. LEERS n. 448 .

Gefleckte taube Neffel; rother Bisnenfaug. Germ. Italian Dead - Nettle. Angl.

Ad folfas et fepes im Rofenthale inter frutices paffim mihi occurrit. Fl. Vere et Aeftate. 
Obf. Planta recens inebrians; ficca fternutatoria.

albun. 791. Lanilum foliis cordatis, acuminatis, ferratis, petiolatis, verticillis vigintiforis. LINN. Syf. pag. $59+$.

Laminn foliis difeetis, cordatis, acutis. вогнм. $\mathbf{n}$. 10.4. BLACKIV. to 33. Fl. Dan. to 9.r.

Pharm, Lamii. Albi Herba, et Galeopfidis f. Vrticae movtuae Flores.

Si eiffe taubc Neffel C. Bienenfaug; Wurmneffel; weifler Eras?gel. Germ. White Archangel. Angl. Or. tie hlanche, ou Archangélique. Gall.

In ruderatis, cultis, prinahi's, dumetis et ad muros fepesque vbique frequens. Fl. April. ad Aurumnum vsque.

Vf. Cum Vitica lïsque prime Vere in oleribus coctum edirur. In funse albo iacdacur. Caeterum flores apibus pabulum valde egregiom.

purrureum. 792. Laminm foliis cordatis, obrutis, petiolatis. LinN. Syft. p. 534. n. 6. вовнм. л, 106. BLACKw. tab. I82, Fl. Dan. t. 523 .

Rothe taube Neffel; kletine Todtenneffel: IVanzenkraut. Germ. Purple Archangel. Angl. Lanier rouge. Gall.

In agris cultis, nemoribus et ad fepes vbique. Fl. cum priori.

Vf. Flores apibus pabulum. Folia tenella Vere cum oleribus coquuntur in Laplandin ef Lulatia inferiori. Huius et prioris herba oues vefcuntur.

286. * POLlichiA. roтr. Fl. Germ. I. p. 254. Hohl. zahn, Germ.

amplexicau-793. Pollichia calycibus inermibus, corollae labio infelis. riore bifido, foliis caulinis feffilibus, rotundatis, incifis; radicalibus petiolatis, cordato-lobatis. Wind. Prodr. Bernl. n. 6ra.

Lamium (amplexicaule) foliis foralibus feffilibus, smplexicaulibus obtufis. İNN. Syft. pag, 534, n. 7 . воЕसМ. n. 105, Fl, Dan. t. 752., 
DIDYNA MIA. GYMNOSPERMAE. 323 ,

Klezne todte Ackerncfel mit "Gundelrcbenblättern. Germ. Creat Henbit. Angl. Lamie à fenilles jans pétiole. Gall.

Ii faris et aruis frequens. Flor. Iun. Iul. Annua.

794. Pollichia calycibus pungentibus, corollae labio Galcobdo inferiore trifidn, foliis omnibus cordatis, dentatis, pe. lon. tiolatis. WILDEN. Prodx. Berol n. 613 .

Galeopfis (Galcobdolon) verticillis fexfloris: inuo= lucro tetraphyllo. LINN. Syft, pag. 535. вовцM. n.

I 10.

Var. x) Foliis maculatis.

Gelbe tau'se Nolfel; gelbe Thaldncffel; gelber Hohlzahn; Goldneffel. Germ. Yellow Nettle Hemp. Angl. Ortie morte if fleur joune; Lamier jaune. Gall.

In nemoribus vmbrofis, copiofifime im Rofenthale cum varietate; in agris humidis ante Portam Halenfin verfus Schönfeld et in dumetis; ad riuuloram margines, in falicetis pratisque variis. Flor.Iun. Iul. Annua.

$V$ J. Flores apibus pabulum.

287. Galeopfis. L. G. 775. Katzengefichte, Hohl. zahn. Gorm. Hedge Nettle. Angl.

Gileopfie, Gall.

795. Galeop ${ }_{25}$ verticillis omnibus remotis, calycibus Ladanum.

campanulatis, pubefcentibus: dentibus lineari fetaceis, diuergentibus longioribus.

Galeopfis internodiis caulinis aequalibus, verticillis omnibus remntis, calycibus inermibus. LINN. Syft. p. 534. вогнм. n. 108. wilder. Prodr. Berol.n. 610.

I.adanum fegetum, folio latiore. RIv. Monop. tab. $2+$.

Var. ๔) Folis anguftifoliis.

- B) Foliis latifoliis.

Acker Andorn; klein Berufkraut; rothes Feldalyffenlerant; bloue raube Neflel; Kormeuth; Feldkatzengefichte; kleine Hanfneficl; var. fchmal- oder breit. $\mathrm{X} 2$ 


\section{4}

blättricher Hohlzahn. Germ Narrow-leaved All-heat. Angl Corpaudine des champs. Gsul.

In arti, agris, requietis, vor dent Scliönfelder Pförtchen et bei Eutritfch, copiofe. Flor. Iul. Aug.

Tetrahit, 796. Guleopfis internodiis caulinis fuperne incraffatis, verticillis fummis tubcontiguis, calycibus ventricofis; dentibus longiffimis fetaceis, aequalibus. LinN. Syft. p. $535 \cdot$ n. 2. воени. n. 109 . котн. Fl. Germ. I. p. 2 is

Cannabis Spuria. Riv. Monop, t. 44 .

Var. a) Galeopfis wulgaris flore albo et flauo.

B) Galeopjis vulgaris flore albo et purpu. reo.

8) Galeopjis vulyaris corolla flaua, labio infesiore maculața.

Großse gelulicht f. röthlicht weiffe Hanfueffel; Ackeraefjel; bunte taubs Nelfel; wolder Hanf; großer Hohliahn. Germ. Hemp leaved Dead Nettle Angl.

In agris inter fegetes ante portan Halenfin verfus Schönftld, et ante portulam Schoenfeldicam; porro in aruis cultis et fyluis ceduis, haud infiequens. Fl. Iul. et Aug.

cuizabina. 297. * Galeop/is verticillis fummis fubcontiguis, calycibus tubulofis: dentibus paullo brevioribus, lineariba, insequalibus, tribus maioribus. вотн. Flor. Germ i. p. 234.

Galcopsis Tctrahit, $\beta$ ) LIN s. Synt. R. 3. p. 5 I. Aechte Hanfneffel; Jchnalbl trichtes Katzengeficht. Germ.

In dumetis et fyluis vbique. Flor. Inl. Aug. Pers ennis.

288. STACHYS. L. G. 77-. Bulkiskraut; Rofspo. lei. Gern. Bafe Horchound. Angl. Stachie. Gall.

fyluatica. 799. Stachys verticillis fexforis, foliis cordatis', petiolatis. LINN. Syft. p. 53 s. n. I. BOEHM, n. II2. BLACKW. tal). 2.1.

Pharm. Galeopfidis Herba. 
Wald Bulkiskraut; große ftiukende taube Neffel; todte IValdnefjel; Scharlachneffel; Stïck-Heckizeffel; Gottesvergeß. Germ. Hedge Nettle. Angl. Lamier des bois; Orticr morte des bois. Gall.

In remoribus denfioribus, im Rofenthale, Gonnezeitzer, Rafchueitzer, Zjchocherfchen Holze; in pratis fyluaticis, et ad fepes circa pagos, . Flor. Iun. Iul. Perennis.

Vf Herba luteo-tinctoria. Caules praeparati ficuti Cannabis. ad tomentum vfurpari poffunt. Flores pabulum apibus.

799. Stachlys verticillis fubfexfloris, foliis lineari lan-paluftris. ceolatis, femiamplexicaulibus, fefrilibus Insx. Syft. p. $5\{5$. n. 2 .

Stachys verticillis fpicatis, foliis fubhirfutis, ellipticis, a hafin cinarginatis. БOEHM. 11. 113 . ВLACKY. t. 273 .

Sumpf Bulbiskrant C. Uratner Wafferandom; Sumpf Polci. Germ. Marfh Stachyss, or Clozen All-heait. Angl. Panacée des Labourears. Gall. .

In fyluis paludofis et ad ripas forfarum fuuiorum. que, et in arris humidis paffm, im Rofenthale, in alnero ad Schonfeld pafim. Flor. Iul. Aug. Perennis.

Obf. Agris inuifa. Sues tamen radices huius quaerunt et agros effodiunt.

80s. Stachys verticillis multiforis, foliozum ferraturis germanica. imbricatis, caule lanato. L1iN. Syft. p. 535. n. A.

Stachys foliis oblongo-cordatis, floribus verticillatis воент. n. ils. Fl. Dan. to 189 . JACe. Fior. Aufir. V. \& t. 3! 9 .

Wolligtes Bulkiskraut; rother, Berg, grauer, grof, Ser, kriechendar Andorn; Feidandorn; teut fcher Andorn. Germ Gernan Bafe Hore-hound. Ang. Staquis des Allemands, ou a Epi flcuri. Gall.

In agris montofis, ficcioribus, circa. Riecknarsdorf. Fl. Iul. Aug. Perennis.

So i. * Staclyys verticillis fubfpicatis, foliis cordato el-refta. lipticis, crenatis, fcablis, caulibus aufcendentibus. IINN. Syft pag. $\div 3^{6}$. wilden. Prodr, Berol. n. 6í8. JAce. Flor. Auftr. Vol. 4. t. 359.

Pharm. 
Pharm. Sideritidis.Herba.

Aufirchies Bulkiskraut f. Roßpolei. Germ. Staquis étroit. Gall.

In locis montofis, fterilioribus paftum an Bienizet bei R̈̈̈kmars dorf mihi occurrit. F!. Iul. Aug. -

annu.. 802. Stachys verticillis fexforis, foliis ouato-lancenlatis, trineruils laeuibus, petiolatis, caule crecto. LINN. Syft. p 536. n. ió.

Bctonica foliis inte: diffitos verticillos longioribus, ellipticis ferratis. воEнM. n, 121. JACQ. Ficr. Auftr. Vol. 4. t. 360 .

Zeifigskraur; Bade-Gliedkraut; Iudenkrant; gelber Andorn; kleine gelbe Sommerbetonc; Rlcin Berufskraut. Gern. Anmual German Field Betony. Angl. Staquis anmual. Gall.

In agris et aruis inter fegetes $\mathrm{et}$ in hortis oleraceis. Fl. Iul. Aug Annua.

aruenfis, 803. Stachys verticillis fexforis, foliis obtufis, nudiusculis: corolis longitudine calycis, coule debili. LINN. Syft. p. $53^{0}$. n. 1\%. SCHREe. Spicil. pag. 12. n. $90^{\circ}$.

Kleiner nzcaiviger Feldandorn. Germ. Amual Englifh upright Ground Ivy. Angl. Staquis des champs. G.ill.

In agris fubhumidis verfus Stätteritz copiofe, et hinter den Gerberwicjen wach Schönfeld, bei Trache. zau. Fl. Iul, Aug.

389. NEPETA. L. G. 768 . Katzenminze. Girm. Cat-Mint, or Nep. Angi. Cataire. Gall.

Catara, 804. Nepeta folibus fpicatis, verticillis fuppedicillatis, foliis petiolatis, cordatis, dentato-ferratis. LaNN. Syft p. 529 .

Catari a foliis cordatis, petiolatis, verticillis fpicatis. вовнм. ก. 123. BLACKw. t. 455. Fl. Dan. tab. 580

Nepetha. kIv. t. 52 .

Pharm. Nepetae 1. Catariae Herba. 
DIDYNAMIA GYMNOSPERMAE.

Gezeöhnliche Katzenmünze; weiffer Dorant; $K a$. zzenferz; Katzenbaljam; Ratzenmünze; Maricnftein; Katzennelfel; Katzenkraut; Berg-1. Steinmïnze; Stcimeffel. Germ. Common Cat-Mint. Angl. Herbe aut Chat. Gall.

- In fepibus et circa pagos frequens, in hortis et. ism oleraceis mihi obuian venit. Flor. Iun. Iul, Per* entis.

VS. Herba felibus fuavifima.

290. SATVREIA. L. G. 765. Saturei. Germ. Savory. Angl. Sarriette. Gall.

805. Satureia pedunculis bifloris. InN. Syf. p. 528. n. hortenhs.

5. воЕнм. n. 124, BZACKW. t. 419 .

Satureia hortenfis. C. B. P. P. 218.

Pharm. Satzuciae Lerba.

- Rohncmiraut; Gartenzfop; Pfefferkraut. Germ. Summer, or Gorden Savory. Angl. Sarriette des jardins; Sardrée; Savorée. Gall.

In hortis guafi fpontanea; in agris oleraceis frequens paftimque in ruderatis. Flor. Iul. Aug. An. nua.

$V \int$. In culinis frequenter herba adhibetur pro ciborum condimentis.

29I. BALLOTA. L. G. 7\%. Zahnlore. Germ. Black Horehound. Angl. Ballore.

Gall.

806. Ballota foliis cordatis indiuifis, ferratis, calycibus nigra.

acuminatis. LLNN. Syft. pag. 537. вовнм. n. 122.

BLACKw. t. 136 .

Var. e, Ballota flore albo.

Pharm: Marrubit Nigri Herba.

Stinkender 1. fihtearier Andorn of Zahnlofe. Germ. Wonlly Stinking Hore honnd. Ansi. Ballote noire, ou Marribe puent. Gall.

In inderatis, ad vias, frequenter ante portulam Schöujelobicam: in Moeniis, et ać fepes murosque, bei $\mathrm{X}_{4}$ dem 
den Pulvertiurme. Var. ante portam Halenfem. Fl. Iun. Iul. Perennis.

Vf. Panacea eft herba in pecorum morbis apudGothlandos Hyftericis planta commendanda. Apes fiores frequentiline quaerunt.

292. MAKRVBIVM. L. G. 779. Andorn, Germ. Horehound. Angl. Marrube. Gall.

vulgare. $80 \div$. Marrubilm dentibus calycinis fetaceis, incinatis. LINN. Syft pag. :3\%. BDEHM, n. I2\%. BLACKiv. tab; 479 .

Pharm. Marrubii Albi Herba.

Genciner f. ueiffer Audorn; weiffe Leuchte; Mutterkraut; Marobel; Helfkraut; Lungenkrant; Goztesucrgeß; veilder Tamrand; Gotteshitlfe, Germ. Common, or White Horchound. Angl. Marrube blanc. Gall.

in agris pagorum, ficcioribus locis, ipfis in pagis, ad vias publicas, bei dem Gerichte, et ad fepes frequens. Fl. Iun. - Aug. Peremnis.

Oly. Planta a veteribus Medicis magni aefimata fuit, aunc vero plane obfoleta. 'In Afthmate humido I. H. LANGr herbam laudat.

b) Colyces bilabiati.

293. SCVTELLARIA. I. G. 792. Heim- א. Schildkraut. Germ. Skull-cap. Angl. Toque. Gall.

galericulata. 808. Scutellaria foliis cordato-lanceolatis, crenatis, foribus axillaribus. LinN. Syft. pag. 546. n. 6. Fl. Dan. t. 63\%.

Cafjida toliis lanceolatis, ferratis; foribus binis. BОЕнМ. ת, II 8 .

Scutellaria. Riv. Monop. t. 76.

Gemeines Helmkraut; Fielierkraut; blau Schildkraut; Fleckenkraut. Germ. Hooded Willow-Herb. Angi!. Toque ou Cinasurée bleue. Gall.

Ad foflarum ripas, bei dem Cefundbrunnen, et in falicetis, hinter dem Brandvorwerke etc. Fl. Iun.Aug. Perennis. 
DIDINAMIA. GYMNOSPERMAE; 329

Sog. Scutellaria foliis integerrimis, inferioribus hafta. haftifolia. tis, fuperioribus fagittatis. LINN. Syft. p. 54- $\mathrm{n}, 7 \cdot$ voenM. n. I lo. fub Cafjida.

Scutellaria folio non ferrato. RIv. Monop. t. $7 \%$.

Spiefblätriges Helwikaut f. fpontonlliittriges Schildtraut. Germ. Suedifh Skuli-cap; Hooded Drillow-herb. Angl. Toque à fir de fleche. Gall.

In paludofis opacisque cum priore floret. Perennis.

294. THYMVS. L. G. 785. Thimian. Germ. Thyme. Angl, Theim. Gall.

8ıo. Thymus floribus capitatis, caulibus repcntibus, Serpyllum. foliis planis, obtulis, bafi ciliatis. IINN. Syft. p. 541 . BОЕн1M. ก. I 25 .

Var. 1) vulgare. BLACKw. t. 2 II.

2) citracum.

3) hirfutum.

4) album.

Pharm. Serpylli Flores, Herba.

Feldquändel; Feldkïmmel; wilder Thimian; Hünerkohl; wilder Polei; grojser, citronen, raucher, weiffer Quândel. Germ. Comnon Mother; or wild, lemon, hear, white-Thyme. Angl. Serpelot. Gall.

In aridis apricis vbique, Var. 1) maxime in hortis; 2) in der Leingrube; 3) ad vias publicas ziach Schonfeld, an Bieniz; 4) in locis elatioribus, arenofis, nuf den Gickerlingsberge palim, etc.

Vf. Pabulum ouibus, capris et apibus gratum.

8Ir. * Thymus ere tus, foliis renolutis ouatis, floribus vuigaris, verticillato-f picatis. LiNN. Syft. p. 542. n. 2.

Pharm. Thymi Herba.

Gereöhnlicher Thimian; römifcher oder zeelfcher Qnändel. Germ. Common Thyme. Angl. Theim vul. gaire Gall.

In hortis vrbanis, oleraceis, rufticanis valde fre. quens et quafi indigenus, Flor. Iun. - Aug. Per, ennis. 
Acinos. 8r2. Thymas foribus verticillatis, pedunculis vnifioris, caulibus erectis, fubramolis, foliis acutis, ferratis. LINN. Sylt. p. 542 . n. 4. EOEHM. n. I 26 .

Bergbafilien; Steinzolei; Bergthimian; wilder Kirchilop. Germ. Comsnon Englifh wild Bafil. Angi. Pcizt Barilic fauvaye. Gall.

In locis arenofis, elatioribus, auf dem Sandberge am Bienz et in plurimis Coemetcriis elatioribus. Fl. Iun. Iul.

\section{5. * OCYMVM. L. G. 790. Bafilie. Germ. Bafil. Angl. Bafilic. Gall.}

Bafilicum. 813* Ocymum foliis ouatis, glabris, calycibus ciliatis. IINN. Syft. p. 5\$5. n. 6. BLACKW. t. 10 4 .

Ocymum caryophyllatum maius.

Var, $\infty)$ Ocymum caryophyllatum maxi-|C. B.

в) Osymum latifolium maculatum $\left.f_{.}\right\} \begin{aligned} & \text { P. } p \text {. } \\ & \text { crip m. }\end{aligned}$

225 .

r) Ocymum viride, foliis bullatis. C. B.P. p.

Pharm Baflici Herba, Senina.

Geneine Bafalie; Bufilienkrant; Baffilicuns; Hermkraut. Gerin. Steert fcentcd Bafil. Angl. Bafilic; Frambafin da Pérru. Gall.

In ndia et Perfa habitat. Apud nos in hortis vald frequenier reperitur varietatibus pluribus Annua.

$V \int$ in culinis gra:a eft herba pro cibi condimentc. Folia in ins:ulis lul enter dunt Galli.

minimur. 314. * Ocymum foliis ouatis integerrimis. LIN , Syft.

P. 5 . 5 . ก. 7 .

Ocrimum minimum, C B. P. p. 226.

Kleinfe Bafilie; das kleine biafilicum. Germ. Bufh Biffil; Leugt Rafil. Angt. Petıt Bafficic. Gall

In Zeyin!la habit $t$ : copiole qu que apud nos in horris culitur. For. Iul, in Septembrem vsque. Annua

Obf. Vires easdem ac prior habet. 
DIDINAMIA, GYMNOSPERMAE, 33 I

296. PRVNELLA. L. G. Braunelle. Germ. Selfheal. Angl. Brunelle. Gall.

815. Prunella foliis omnibus ousto-oblongis, ferratis, vulgais. petiolatis, calycibus labio fuperiore truncero, fubtridentato. linn. Syft. p. $5 \div 7$. BOEHM. n. 116. Brunella. RIV. Monop. t. 29. BLACKW. ¿. 24 .

Pharm. Prunellae f. Confolidae minoris Herba.

Gemeine Braunelle; Gottheil; Braunheil; St. Antoniasliraut Germ. Common Selfheal. Angl. Brunelle commune Gall.

In pratis poft Hortum Winklerianum et Reicheliamum etc. in pafcuis et fyluis vbique, praecipue $2 m$ Rofentialc, Z Zchocherfchen Holze etc. Fl. Iun.-Aug. Perennis.

816. Prunella foliis omnibus ouato-oblongis, latiori- grandiflora. bus, ferrulatis, calycis labio fuperiore profunde trilobo.

Prunclla foliis integris, vix dentatis, fpica foliis maiore. HALI. 637. BOEUM, n. 117 . JACQ. Flor. Auftr. Vol. 4 . t. 377 .

Prunella caerulea magno flore. C. B. P. pağ. $26 \mathrm{I}$. IINN. Spec. Pl, II.p 837. vai. $\beta$.

Var. a Prunella flore caerulaeo.

Großblïhende Braunclle. Germ. Greatcr Flozered Self heal. Angl. Branelle à fleurs grands. Gall.

In pratis, copiofe hinter Kleindölzig, porro anf der Riickmarsdorfer Wiefe paffin reperi. Flor. Iul. Aug. Perennis.

817. * Prunclla foliis ouato-oblongis, petiolatis: fu- laciniata. premis quatuor lanceolatis, dentatis. LINN. Syff. p. 547. Leys. n. 605. ' Jace. Flor. Auftr. Vol. 4. tab. 378.

Aufgcfchlitzte Braunelle. Germ. Fagged-leaved Sclfheal. Angl. Brunelle ì feuilles iaciniées. Gall.

In pratis et fyluis montolis, rarius an Bicziz un. ten auf der Wiefe nuperrime inueni. Flor. cum grioribus. 
29\%. ORIGANVM. L. G. -84. Doften; Wohlgemuth. Germ. Origanys. Angl. Origan. Gall. heracleoti- 818 * Origanum fpicis longis pedunculatis aggrega-
cum. tis;'bracteis longitudine calycum. irns. Sylt. pag. $5+1$ n $\$$

Or:ganum heracleoticum, Cunila gallinacea, Plinii C. B. P. p. $2: 3$.

Gemeiner Wntcermajoran; iscracleotifche Dóften; unichter Majoran; wilde Dofin. Germ. Winter Szect Marjoran. ìngl. Marjolaine d'Hyver; Grande Marjolane Gal!.

In Graecia habitat, ex qua olim in Europam eft translata. Apud nos in hortis oleraceis pafitin colitur. Fl. Aeftate in Autumnum. dos.

$V f$. Folia in culinis adhibentui ad cibos condien-

vulgare. 819. Origanun 1picis fubrotundis, paniculatis, conglomeratis, bracieis calyce longioribus, ouatis. LINN. Syft. p. 541. воEнM. ח. 132.

Origanum. Riv. tab. 60. Elackw. t.280. Fl. Dan, tab 6:8.

Pharm. Origani Vulgaris Herba.

Gemeine Dofen; "ohlgenuth; Felddofteñ wilder Orant. Germ. Common wild Origanum. Angl. Origan vulgaive; ou füüuge Gall.

In nemoribus montofis, paffim im Bieniz. FL Iul, A ug. Perennis

Vf. Lanam ruhro vel purpurafente tingit colore. The f cetdaneum : vt citius inebriet, additur cere. vifiae fermentanti a eftgothis.

Maiorạna. 820. Origanum foliis oua'is, obtufis; fpicis fubrotundis compritis pubef entibus. LINN. Syt. pag-541. $\Omega$. 11. BLACKiv. t. 19.

Ph rm. Masoranae Herba.

Geüönlichor f zahmer Majoran; Sommermajoran. Germ Common Suret Mirjoran Ang. Marjolaine commune ou frunche. Gall.

VJ Eft optimum et praeftantifinum Germanorum aroma. 
DIDYNAMIA. GYMNOSPERMAE. 333

298. CLINOPODIYM. L. G. :83. Wirbe!doft. Germ. Field-Bafil. Angl.

82r. Clinopodium capitulis fubrotundis, hifpicis, bra-vulgare.

Ateis fetaceis. LINN. Syft. p. 541. BOEнM. n. : 30.

Clinopodium. RIv. Monop. t. +3 .

Gemener Wirbeldoft; Hauptrojt; Buttfufs; falfcher Waldpolei. Germ. Common Ficld-Bafil. Angl. Grand Bafilic fauvage. Gall.

In tyluis moniofis, copiofe im Bientia, in Gunndorfer Holze; an dem Graben bez dey Gonnewitzer Sclanne; ad margines pratorum ad Stötterizz verfus praedium Weifantunn. Fl. Iul. Aug. Perennis.

299. MELISSA. L. G. 786. Meliffe f. Mutterkraut. Grrm. Beaulm. Angl. Melifie. Gall.

822. * Meliffa racemis axillaribus verticillatis; pedicel-officinalis. lis fimplicibus. $\ln$. Syft. p. 524. n. I.

Pharm. Meliffe citrinae Herba.

Gemenne Meliffae 1. Mutterkraut; Cistonenkrant. Germ. Cosmon Beaum. Ang]. Meliffe, ou Citronelle. Gall.

In hortis fere omnibus copiofe. Flor. Aeftate.

\section{B. ANGYOSPERMAE.}

Flores fimplices inaequales f. Perfonatas.

a) Calyces bifidi.

300. OROBANCHE. L. G. 841. Sommerwurz; Hanfmännchen. Germ. Broomrape. Angl. Orobanche, Gall.

823. * Orobanche caule fimpliciffimo, pubefcente, fta- maior. minibus fubexfertis. IINN. Syft. pag. $573 \cdot n$. 2. LEYS. n. 609 . 
Orobanche caule fimplici, fipula vnica, calyce $4-$ fido. HALL Hift. n. 2y5. Orobranche. Riv, Monop. et t. 88 .

Grofse Sommereurz; Hanfwürger; böfer Heinrich; Löwenffhwanz. Germ. Great Broomrape. Angl. Grande Orobanche; Herbe aux Taureaux. Gall.

In agris teriiuribus et pratis ficcis, et in nemoribus montofis, paffim auf den Bienir, atque in agris inter legetes bei Rüchmarsdorf et Nauendorf anno 1788. detexi. Fl. Iun. Iul.

\section{B) Calyces quadrifuti.}

\section{I. LATHRAEA. L. G.. 80I. Schuppenwurz. Germ.}

fquamaria. 824. Lathraea caule fimplicitimo, corollis pendulis: labio inferiore trifido. LiNn. Syft. pag. 550. n. 4. BOEIM. n. 134. ELACKW rab, 1 O. GLED, Naturgefcil. der einh Pfl. p. z4n. Tab. XIII.

Pharm. Squamariae 1 Dentariae Radix.

Schuppenweurz; Schnappereurz; Ohnblatt; Maiwurz; St. Georgenlivant; Kaalkraut; Zahnkraut; Schwanmkraut. Germ. Thootwort; Lingwort. Angl. Grande Dentare; Clandeftine ì fleur's pendantes. Gall.

In locis opacis et humidis, in ulneto ad Schönfeld, ad alnorum radices, an dem Gonncreitzer oder Streitholze, in Univerfitatsholze, an Bieniz paffun mihi occurrit. Fl. Mart. April, Perennis.

\section{EVPHRASIA. L. G.799. Augentroft. Gern.} Eye bright. Ang!: Eufraife. Gall.

officinalis. 825. Euphrafia foli:s ouatis, lineatis argute dentatis. LiNN. Syft. p. 549. n. 2. воEнM. n. I+8. BLACKw. t. $42 \%$

Euplirafia. RIV. Mnnnp. t. 132.

Var. ux) Euphrafin miunr non ramofa.

Pharm, Euphrafiae Herba. 
Gereöhnlicher Augentroft; Angendienf; Hirakraut; lichter Tag; Tageleuchte. Germ. Eyebrimht of the Shops. Angl. Euphraßie ordinaire. Gall.

In pratis et pafcuis humidis fere vbique, auf den Schönfelder, Rofenthaler, Lincuenauer Wiejen etc. var. in locis steritioribus, nach dem Univerfitütsholze Fl. Iul. Aug. Annun.

826. * Euphrafia foliis cordato-ouatis, acute ferratis; rubra. calyce obrufe denrato, caule magis ramofo. -

Rother Augentroft. Germ.

In locis ficcioribus elatioribusque hinterLindenau auf dem Walle; porro vor Meisdorf et alibi. Flor. Iul. Aug.

Obf. Haec autem proxime accedit ad fequentem; fed diftinguitur habitu toto trifti; caule maiore flexuolo; magis rsmoío, rarius finplici, pilis denfioribus obfeffo; foliis ouatis, dentibus acutioribus longioribusque notatis, paullulum hirfutioribus; calyce maiore et obtufe dentato ; cornlla ex albido rubra, vel totá rubella et denique loco natali. Iila enim humida et plurinis graminibus ventita amat loca; haec autem modo arida, fteriliora et arenofa. Caeterum gaudent caules floribus ad vnum lntus vergentibus.

827. Euphrafia foliis linearibus omnibus ferratis, odontites. Linn. Syft. p. 550. n. 4. Бовнм. n. 142. Fl. Dall. t. 65.5 .

Brauner Augentroft: wild Tag und Nacht; Zahntroft. Germ. Euphraife tardive irall.

In agris hinter dem Gerberne affer; auf den Aeciern nach Schönfild, hinter den Kohlgärten copiole, et ibidem ipfis in pratis. Fl, Iul. Aug. Annua.

828. * Euphrafia foliis linearibus ferratis: fuperioribus lutea. in egerrimis. LINN. Syft. p. 550. n. $40^{\circ}$ LeYs n. $6 r+$ JACQ. Flor. Auftr. Vol, 4. t. 398. Odontites flore lu. teo Riv. Monop. t. 41.

Geiber Augentroft. Germ. Yelloze Ezebright. Angl. Euphraife jaune. Gall.

In locis elatioribus et -fterilioribus; e. g. in collibus, hinter Lindenau, nach Rafchreitz zu; porro vor Meisdorf et alibi frequens. Fl. Iul. Aug. 


\section{$336 \quad$ CLASSIS XIV.}

303. RHINANTHVS L. G. 798. Hahnenkamm,

Germ. Elephant's Head. Angl. lihinanthe. call.

Crifta Galli.829. Rhinasthus corollarum labin fuperione compreffo,

breuiore, calycibus giabris. pollich. Palat. n. 5 i 9 . LINN. Jyft. pig. $54 \%$ n. 3. WILDEN. Prodr. Berol. n. 633 .

Rhinanthus foemina corollarum labio fuperiore breuiore comprefto, calyce glabro. $\mathrm{Sco}^{2}$. Carn. pag, 480. Crifta Galli. Riv t. 92.

Ale ¿torolophus calycibus glabris; foliis inter flores latioribus. BOEIM. n. 139.

Hahnenkamn; Klaffer; Wiefenklapper; gelber Rodel; Lânfekraut; klingender Hans. Germ. Crête de coq, ou Pediculaire janne. Gall.

In pafcuis et pratis vbique. Fl. Iun. Iul.

Aletorulo- 830. Rhinanthis corollarum labio fuperiore compreffo, phus. breuiore, calycitus villofis. Pollich. Palat. n. 580.

Rhinanthus mas calycibus villnfis; auriculis galeae terminatis, nectario rotundato. scop. Carn. Alectorolophus calycibus hirfutis, foliis inter flores latioribus, ВОЕнм. n. 138 .

Glitjch; Wiefcnrodcl; Rodclkraut. Germ.'

In pratis humidioribus, auf den Rofenthäler, Lin. denuner, Leutfcher Wiefen, bei dem Gefundlrunnen. Fl. cuin priori.

304. MELAMPYRVM. L. G. Soo. Fleifchblume;

Kuhweizen. Germ. Cow - Wheat. Angl. Blé noir. Gall.

criftatum. 83 r. Melampyrum f́picis quadrangularibus, brałeis cordatis, comp ctis, denticulatis, imbricatis. LINN. Syf. p. 550. SCHREB. Spicil. p. 13. n. 910. Leys. n. 616

Nelampyrum crifatum. RIv. $t, 8 \mathrm{I}$. 
Kammtragende Fleifchblume. Germ. Crefied CowWheat. Angl. Melampire à crête. Gall.

In nemoribus elatioribus, et fterilibus, im Bieniz, in Univerfitätsholze et alibi. Fl. Iul. Aug.

832. Melampyrum fpicis conicis laxis, bracteis dentato- aruenfe.

fet.seis, coloratis. LINN. Sylt. p. 550. n. 2. LEYs. n'. 617.

Melampyrum aruenfe. RIV. Monop. t. 79.

Mclampyrum fpica denfa, longiori, foliis inter florem laciniaris, adlcendentibus вовнм, n. I +1 .

Ackerficifchblume; Kuh-oder Wachtelzeeize; Mohrenzeizc; Schrearzieeize; Acker-purpurrother Kuhweize; St. Petersblume. Germ. Purple Core: Wheat: Horle flower. Angl. Melampire des champs; Bléd no:r; Rouge Herve; Blé de rache. Gall

Obf. Semina panem reddunt caerulefcentem et aınarum, nec tamen noxium.

83.3. Melampým floribus fecundis lateralibus, bracteis nemorofum. dentatis; fummis coloratis ferilibus, calyce lanato. LINN. Syft. p. 5 50. 11.3 .

Meiampyrum fpica laxifina, foliis inter flores laciniatis, patentibus. военм. n. 140. Fl. Dan. tab. 30.5 .

Melampyrum nemorofum. Riv. Mnnop. t. so. -Hanfleifchblume; Tag und Nacht; Ochfenweize. Germ. Blue Coze-Wheat. Angl. Melampire violet. Gall.

In nemoribus, copiole in dem Meckerfchen, Gonnewitzer, Rafchwitser Holzeetc. Fl. un. Iul. Annua.

Obj. Coma foliorum violacea : fubtus lucente fulvo florum colore lucos vmbrofos ita exhilarat haec planta, ac fi aulam ipfius Florae aut Aurorae intrares.

834. Melampyrnm floribus fecundis lateralibus; foliis pratenfe. coniugationibus remotis, corollis claufis. LINN. Sylt. p. 5:0. n. 4. SCHREB. Spicil p. I3. n. 9 II.

Wiefenkuhweize 1. Fleifciblume; gelber Waldhirfe. Germ. Meadow Cow-Wheat. Angl. Melampire des près. Gall. 
In vmbiofis locis ad Lindenthal, Breitenfeld, in Bicnza et aliis nemoribus circa Lipfiam pofitis. Fl. Iun. Iul. Annua.

Obf. Corollae rubellae ad labium fanguineae ob. feruantur.

$V \int$. Sues Semina fedulo inquirunt, ef mufcum effodiunt. Vbi planta copiofiffima, ibi etiam butyrum maxime omnium luteum et praeltantifimsm. LINN. Lapp.

fyluaticum. $83^{\circ}$. Melampyrum floribus fecundis, lateralibus, foliis coniugationibus remotis, corollis hiantilus. LINN. Syft. pag. 550. n. 5. schreb. Spicil pag. 14. n. 912. Wilden. Prodr Berol. n. 638. Fl. Dan. t. 45.

Waldkuhreeize. Germ. Wild Core-Wheat. Angl. Melampire des bois. Gall.

In fyluaticis, montofis, in Bienis, Oberholze paffím. Fl. Iun. Iul. Annua.

Obj: Differt a priori, corollis breuioribus, flauis et hiantibus.

\section{y) Calyces quinquefidi.}

305. LIMOSELLA. L. G. 837. Sumpfkraut, Germ. Plantaginelle. Gall.

aquatica. 836. Limofella foliis lanceolatis. IINN. Syft. pag. 5 I2. bоeнi. n. 35. leys. 11. 620. Wilden. Prodr. Berol. n. 549. Fl. Dan. t. 6y.

Plantaginella. halc. Ienenf. pag. 23. tab. 6. fig. 2. Gall.

Waferfumpfkraut. Germ. Linofelle aquatigue.

In locis inundatis et Aagnofis, bei dem Lindentha. ler Hölzgen, bei, Schönfeld copiofe. Flor. Iun. Iul.. Annua. 
DIDYNAMIA. ANGYOSPER MÁE. 339

306. SCROPHVLARIA. L. G. 81 + Braunwuz.

Germ. Figwort. Angl. Scrophulaire.

Gall.

837. Scrophularia foliis cordatis, trineruiis, caule obtu- nodola fangulo. linn. Syft. pag. 560. n. 2. вовна. n. 149. kiv. Monop. t. jof. feq. BLACR . t. $87^{\circ}$

Pharm. Scroplulariae Foetidae Radix.

Knotige Branmenrz; Sau urm-Feiguarzentenrz; Kuntenkraut; Sauknoten, fchwarzer, bratur Nachtfchatten Germ. Great Figreori; Common Knoblyrooted Figzerv. Angl. Grande Scrophulaire. Gall.

Ad lepens et ripas forfarum, porre in fyluis, im Rojenthal, in folliculis pratorum bei Kleindölzig etc. Fl. iul. tug. Perennis.

VS Decocto herbae lauantur Sues fcabiofi. Segtt. Flores pabulum apibus pergratura.

838. Scrophularia foliis cordatis obtufis, petiolatis, de-aquatica. currentibus, caule membranis angulato, racemis t $r$ minalibus. LINN. Syft. p. 560 . n. 3 . воЕНM. n. 156 . BiACKw. t. 86. Fl Dan. t. 507.

Pharm. Scropluulariac squaticae Herba.

Wafler Braunzeurz f. falfche $W$ afferbetonie; zeei er Nachtfchatten. Germ. Water Betony, or Figwort. Angl. Scrophulaive aquatique; Betoine d'eau, ou Her. be dil fiege. Gall.

In humidis ad folias, bei dem Bieniz hinter Klcin- . dölzig copiofe. Fl. Iun. Iul. Perennis.

839. * Scrophularia folits cordatis: caulinis ternis pe-vernalis. dunculis axillaribus, folitariis, bifidis. LINN. Syft. p. 560. n. 11. wilden. Prodi. Berol. n. 647. Fl. Dan.

t. $4 \mathrm{I}$.

Scrophularia fore luteo. Riv. Monop. t. 186

Früjảhrige Branmevirz. Germ. Yellow or Vernal Figwort. Angl. Scrophulaire jazine Gall.

Ad fepes et in locis aquofis, pallim vor dem Roferm. thale inueni. Fl. initio veris. 
3०\%. * DIGITALIS. L. G. 816 Fingerhut. Germ. Fox-glove. Angl. Digitale. Gall.

purpurea. 840. * Digitalis calycinis foliolis ouatis, acutis, coroliis obtufis: labio fuperiore integro. LinN. Syft. pag. 562 . n. 1 .

a) Digitalis purpurea, folio afpero. C. B. P. p. 243 .

B) Digitalis alta folio afpero. C. B. P. p. 244 .

Pharm Digitalis purpureae Herba.

Rother Fingerhut. Germ. Red Flowered Fox-glove. Angi. Digitale rouge. Gall.

Habitat in Europa auftraliore. Apud nos in hortis frequenter occurrit. Fl. Iun. Iul. Perennis.

- ferruginea. $34^{\prime} . *$ Digitalis calycinis foliolis nuatis obtufis, patentibus: corollae labio inferiore b:rhato. Linn. Syft.p. $56 \therefore$. n. 6 .

Digitalis anguftifolio flore ferrugineo. C. B. P. p. S4t. Rir. Monop t. 96 .

Roffarbiger Fingerhut. Germ. Iron coloured Foxglove. Angl Digizalc rouillé. Gall

In Falia proprie hobitat Apud nos contra in reiectamentis hortorum paffim occurrit, et fic in $P_{0}$. nocrio Grimmecnfi auf der Paftei nuperrime reperi. Praeterea in hortis fplendidis, e. g. in Winkleriano fub arboribus frequenter crefcit. Fl. Iul. et Augufto. Perennis.

Olf, Caul. ftrictus, laeuis, $6-7-$ pedalis. . Fol. feffilia, oblongo-lanceolato-ouara, laeuia, lineis albidis longitudinalibus notata, integerrima. kacemus e fingulis alis fupremis erectus. Bracteae lineari-linceolatae, reflexae. Pedunculi breuiffimi, folitarii. Calyc. foliola fuperiora 3 appioximata. Cor. ventricofa, inferne gibba, 'crlyc multo longior, pubefcens: laciniis 2 fuperioribus obfoleris; lateralibus acutis; infima longiore, pilis molifilinis obfeflax Stam. flexuofa, 4. Styl. longitudine floris. 
DIDYNAMIA. ANGYOSPERMAE. 34 I

308. ANTIRRHINVM. L. G. 8os. Orant; Do-

rant. Germ. Toad-flax, or Snap-drogon. -

Aingl. Mufle de veau. ciall.

* Foliis angulatis.

842. Anthirrhinum foliis cordatis, quinquelobis, alter- Cymbalaria. nis, caulibus procumbentibus. LiNis. Syft. pag. 584 . SCHREE. Spicil. p. I \& ก. 9I3. LOB. n. 615.

Cyintralaria. RIv. Ord. t. $\$ 5$.

Zymbcl-Nabel-Flachskraut mit dem Epheublatte. Germ. Ivy-leaved Toad flax. Angl. Cimbalaire ordinaire, Muflici if feuilles de Lierre Gall.

Ad muros in dem Bofifchen Garten, et in muris Templi St. Pauli valde copiofe. Fl. Iul. Aug.

Obf. Succus ex herba recenter expreflus admifceri Aquse Tophanae falfe fertur.

843. Antirrlinum foliis haftatis, alternis, caulibus pro. Elatine. cumbentibus. LINN. Syft. p. 554. n. 3. вовнM. ת. I +7 . BLACKw. t. 170. Fl. Dan. t. $\$ 26$.

Erdwinde. Germ. Tellow Sharp-pointed Fluellin, or. Female Speedwell. Angl. Velvote, ou Elatine; Muflier auriculé. Gall.

in aruis et agris, bei der Leimgrube. Fl. Iun. Iul. Annua.

844. Antirrhinum foliis ouatis alternis, caulibus pro- fpurimm. cumbentibus, LinN. Syit. pag. 554. "n. 4. военм. n. 146.

Falfcher Orant; rundblittrichte Erdwinde. Germ. Round-leaved Fluellin. Angl. Velvotte femelle, ou Mufle de Veau des bleds. Gall.

In aruis et agris ad pagum Z/chöfen porro bei Mockau, Gonnewitz et verfus Rhöthe. Fl. Jun. - Aug: Annua.

** Foliis alternis.

845. Antirrlinum foiis plerisque aiternis, lanceolatis, minus. obtufis, caule ramofifimo. LiN . Syft. pag. $55^{6}$. n, 28. 
Antirrlinum foliis longis, obtulis, vifcidis, cauls eręto ramofiffimo, calcare breui. вовнм. n. 1.74 . Fl. Dan. t. 552 .

Linaria aruenfis minima. RIv. Monop. t. 84.

Kleiner Orant; Hunndsfchädel; kleine Kalbsnafe, klcine BerufkrautGerm.Leaft Toad - flax. Angl. Petit Muflier de Veau. Gall.

In agris et muris paftm. Fl. Iun. Iul.

Linaria. 846. Antirrhinum foliis lanceolato-linearibus, confertis, caule eresto, fpicis terminalibus feffilibus floribus imbricatis. LINN. Syft. p. 557. n. 33. вовнM. n, 143. BLACKW. t. II5.

Linaria. RIV t. 82.

Var. $\beta$. A. caule humiliore, foliis minoribus, anguftioribus: floribus dimidio minoribus.

, Pharm. Linariae Herba.

Lein-1. Flachskraut; Frauen-Marienflachs; wilder Flachs; leinkrantiger Orant; ScheiSkraut; Katharinen-Lann-Stallkraut. Germ. Common or Lavge yellow Toad-flax. Angl. Linaire ordinaire; Lin Sauvage. Gall.

In collibus circa vrbem, ad fepes hortorum et in agrorum marginibus, bei Gohlis: poft hortos oleraceos et in pafcuis hinter Markranftadt. Fl. Iun.-Aug. Perennis.

$V f$. In Suevia haec ob odorem graueolentem ad mufcas e domo abigendas adhibetur, et lacti recenti herb immiffa infecta occidere folent Swrolandi.

*** Foliis oppofitis.

*aenfe. $8470^{*}$ Ansirrhinum foliis fublinearibus: inferioribus qua. ternis, calycibus pilofo-vilcidis, floribus spicatis, caule erecto. LINN. Syft. p. 556 n. 7. T.EYs. n. 626. Ackerorant. Germ. Corn bline Toad-flax, Angl, Muffe de Veau des champs. Gall.

In agris arenofis, Aterilibus, bei Schönan, Nauendorf et Rürkmsarsdorf inceni. Flor. Iun. - Aug. Annua. 
DIDY NAMIA. ANGYOSPEKMAE. 343 **** Corollis ecaudatis.

848. * Antirrlinum corollis ecaudatis, floribus fpicatis, mains.

calycibus rotundatis. LiNn. Syft. pag. 35\%. n. 4.0. LEYS. ก. 629 .

Antirrhintir maius alterum folio longiore, C. B. P.

p. 211.

Antirhinum. RIv. Monop. t. 8I.

Pharm. Antirrhini Herba.

GroßSes Löwenmaul; Kalbsuafe Garm. Greater Snap. Dragan. Angl. Mufle de Veau; Oeil de Chat; Täte de Veau; Gueule de Vean; Mouron violet. Gall.

in ruderatis pafim ; in collibus circa vrbem. Va. rietates contra in plurimis horris valde freciuenter oc. currunt. Fl. per totam Aeftatem.

Obf. In Perfia, vbi haec planta fponte crefcit, e fe. minibus exprimitur Oleum egregium, quod Turcice Kunjchut Iagi, Perfice autern Kantjchut Roge audit, et ibidem butyri loco comeditur.

849. Antirrhinum corollis ecaudatis, foribus fubfpica. Orontiun. tis, calycibus corclia longioribus. LINN. Syft.p. $55 \%$. n. 41. BOEHM. ก. 1.45 .

Antirhinum aruenle. RIV. t. 81. optime.

Hunt'skopj; Kalbsnaje; Orant; Teufelsỏsnd; wild Löreenmanl; Todtenliöpfe. Germ. Leaft Snap-Dragon. Angl. Muflier rubicond. Gall.

In eruis inter fegetes, bei den Kohlgârten, ad Schönfeld ctc. Fl. Iun. Iul. Annua.

309. PEDICVLARIS. L. G. so 4. Läufekraut; Rodcl,

Germ. Rattle or Loufe - wort.' Anghl. Pediculaire. Gall.

850. Pedicularis caule ramolo; calycibus criftatis, cal- paluftris lofo-punftatis: coroliis labio-obliquis. IINN. Syft. p. 5.11 . n. I.

Pedicularis caule ramofo, eręto, calyce, bifido, Zовнм. n 136. Fl. Dan. т. 225.

Pedicularis, RIv, t. 92. 
ว 44 CIASSIS XIV. DIDYNAMIA. ANGYOSPERMAE.

Pharm. Pedicularis aquaticae Herba.

Sumpfrodel; Linufekraut. Germ. Marfh Loufewort. Angl. Pediculaire des marais. Gnll.

In pratis humidioribus, copiofifime in pratis Schoenfeldicis et alibi. Fl. Iun. Iul. Annua.

Obf. Pratis inuifa et pabulum pecoribus ingratu!n. fyluatica. 851. Pedicularis caule ramofo, calycibus obinngis, angulatis, laeuibus, corollis labio cordato. Linn. Syft. p. 5 I I. n. 2.

Pedicularis caule ramofo, procumbente, floribus fparfis obtufis. вовнм. n. 13i.

Pedicularis minor. RIV. t. 9I.

Waldrodel; Waldläufekraut; Hundskoth. Gern. Red Rattle or Louje-wort. Angl. Pediculaire des bois. Gall.

In pratis, pafcuis fyluaticis et humidis, im Gonnereitzer, Zfchocherfchen Holze etc. Fl. Iun. Iul. Annua. 
TETRA D Y N A I A.

\section{A. S I L I C V L OS A E.}

a) Silicula apice integra.

310. DRABA. L. G. 864. Hung̉erblümchen. Germ. Drave. Gall.

852. Draba feapis nudis, foliis fubferratis, filicula fty- verna.

lo deftituta. LinN. Syft. p. 585. Cranz. Fafc. I. pag.

II. ВОЕНM. n. 295 .

Frühjahliges Hungerblünchen; klein Tüjchelkraut; Ferm Contmon lihithlon-graß. Angl. Drave printaniere. Gall.

In aruis, campis fterilifimis, agris incultis et hortis vbique valde frequens. Flor. April. Maio. Annus.

3II. MYAGRVM. L. G. 860. Leindotter. Germ. Gold of Pleafure. Angl. C'ameline. Gall.

853. Myagram filiculis obouatis: pedunculatis, poly-fatium." fpermis. LINN. Syft. p. 584. n. 7. вовнм. n. 265.

Var. Myagrum foliis auriculatis flore et femine minore.

Dotterkraut; Flachs 1. zalinier Leindotter; großer Leindotter; kleiner f. teutfcher Finkenfaanen; Oelfaament. Germ. Conmon Gold of Pleafure. Angl. Cameli. ne cultivéé; Sefame d'Allemagne. Gall.

In agris inter fegetes paffim. Var. in muris et agris inter Linum verfus Merfeburgum. Fl. Iun. Iul. Annua. Y 5 . 
Old. Linicolis inuifa pienta. In Germenis fevitur ad oleum exprincndum in medicina, culina, oeconomia vitle. Gотт. Semina pro Sefami feminibus faepius venduntur. Caeterum femina cibus quoque Anferibus gratus. SCHWENRF.

panicula- 854. Myagran diliculis lentifołmipus, orbiculațis, punโุum. chato-rugofis. LINN. Syft. p. 589. n. 4. SCHREB. Spicil. p. 21 . n. 924 . Fl. Dant t. 20,4.

Bïfchelförmiger Dotzer; kleiner Leindotter; wilder Dotter; Finkenananez. Germ, Paniculated Gold of Pleafur Angl.' Cameline paniculée. Gall.

In agris pafim, vor dem Schönfelder Pförtchen mihi occurrit, et in locis humidis gramina veftitis e. g. vor Pfaffendorf ad fluuii ripam paffim. Flor. Iun. I ul. Annua.

Obf: Capr. 2-locularis, lentiformis et punztis eleuatis adfperfa.

b) Silicula apice emarginata.

312. IBERIS. I. G. 868. Bauernfenf; Schleifenblume. Grain. Candy - Tufft. Angl.

nudisaulic. 855. Iberis herbacea, follis finuatis, caule nudo fimplici. LINN. iyft. p. 589 .

Iberis foliis pinnatis, caule nudo, non ramoío. Bовнм. n. 292. Fl. Danz. t. 323 .

Sandbaucrnfenf;; Steinireffe; Heide-Sand-Bergzeilde Kreffe; Kleine Iberpflanze; kloine Schleifenblume. Germ. Rock. Creß3. Angl.

In agris arenois ad viam nach Schônfeld; hinter clean Bieniz; der Rücknarsitorfer. Wiefc gegen über. Fl, Mart. Aprili. Annua.

3I 3. ALYSSVM. L. G. 869. Steinkraut. Germ. Madwort. Angl. Alyfon. Gall.

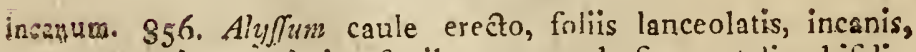
in! gerrimis, floribus corywbofis, petalis bifidis.

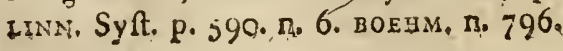


TETRADY A IA. SILICWLOSAE. $3+$ ?

Beftailbtes Steinkraut; veeiß Schildbefeinkraut; vereffe Weglereffe; weiffer Bauernfenf. Germ. Leaft annual Maduort. Angl. Alyffon vivace. Gall.

In elatioribus arenofis ferilioribusque ad viam mach Kückmarsdorf et Nauendorf copiole etc. Flor. Iul. Aug. Perennis.

$85 \%$ * Aly $\int u m$ caulibus herbaceis, faminibus omnibus calycinum. dentatis, calycibus perfifentibus. u1NN. Sylt. fag. 590. n. 8. LEYS. ก. 6;2. WILDEN. Prodr. Bero!. n. 660. JÃ̄. Flor. Aufr. V. 4. t. 33 S.

Teutfhes Steinkraut. Gism. Large anmul Mad. wert. Angl. Alyfon bouclier. Gall.

In campefribus ficcis paflim, bei Kleindölzig, vor Ileinzchocher. Fl. Iun. Iul.

314. COCHLEARIA. L. G. 867. Löffelkrajt. Germ. Scurvy-grafs. Angl. Cuillére. Gall.

858.* Cochlearia foliis radicalibus cordato-fubroturdis, onsinzis. caulinis oblnngis finuatis. L1NN. Syft. p. 588 . n. I. sickw. t. 227 . Fl. Dan. t. I 35 .

Cochlearia folio fubrotundo. C. B. P. p. I 10.

Pharm. Cochleariac Herba.

Gebräuchliches Löffelkraut; Scharbockskraut. Germ. Common Scurvy-gra!s. Angl. Herbe aux Cuillers. Gall.

Iri agris oleraceis et hortis haud infrequens. Flor. Aeftate.

$V \int$. Planta inter medicamenta antifcorbutica primaria, ndeoque in hortis frequentiffme colitur. In Islandia herba in minims partes diffecatur, et cum lacte acidulato, vel eius fero, more olerum editur; condiunt quoque fale culinari in magnis doliis et per hyemem feruant. Oues illam quidem auide edunt et valde pinguefcunt, fed caro naufeofo inficitur fapore. Olaffen.

859. Cochlearia foliis pinnatifidis, caule depreflo. Coronopus. IINN. Syft. p. 588. sçreb. Spicil. pag. 22. n, 930. ELACkw, t, I20, Fl, Dan, t, 202, 
Krähenfiußartiges Löffelkraut; Krähenfuß; Schreeinskreffe: Hirfchhorn. Germ. Sreine's Creffes; Crowesfood or Bucks-horn. Angl. Cnsme de Cerf deschamps, ou Paed de Corneille; Ambrofelle fauvage- Gall.

In viis vor dem Ranftidter Thore, an der Ziegelfcheinne, auf der Vogclivicfe, in der Leingrube ctc. FI. Iun. Iul. Perennis.

Armoracia. 8óo. Cochlearia foliis radicalibus lanceolatis, crenatis, caulinis in ifis. LinN. Syft. p. 588. n. 0. вовнM. n. 29). BLACKW. t. 41 s.

Pharm Amoraciae Radix virens.

Merrettig; Kreen. Germ. Horfe Raddifl. Angl. Grand Raifint fauvage. Gall.

In humidis et reieztamentis hortorum fponte ad ripas fluminum et fofas, bei den Kohlgärten; auf der groffen Funkenburg; ad fofficulas bei Sellerhaufen; praecipue autem apud nos in agris cleraceis colitur. Menfe Martio feritur, et fublequente anno floret Iun. Iul. Perennis.

$V \int$ Armoracia in Germania in larga quantitate cul., carne coquitur menfisque inponitur. Angli contra copiofe pilibus eam addere folent. Succus re. centr: expreffur 1 Ce defpumaro commixtus exhibet egregium puellarum cosmeticum.

\section{LEPIDIVM. L. G. 865. Kreffe. Germ. Dittander. Angl. Paffarage. Gall.}

fatiuum. 86r. Lepidiun foribus tetradynamis; foliis oblongis, mulifidis. LINN. Syft pag. 586. n. 9." BLACKW. tab. 23.

Pharm Nafturtii Nortenfis Herba virens, Semina. Zahme Gartenkreffe. Germ. Garden Dittander, or Garden Creß3. Angl. Creffon alénois, ou Nafitor. Gall.

in hortis intr olera vhique cultum; paffim f́ponte ad hortorum fepes. Fl. Iun. Iu!

Vf. Vernali tempore pro acetariis adhibetur herba. 
862. Lepidium foribus diandris, apetalis, foliis radica- ruderale libus dentato pinnatis, ramiferis, linearibus, integerrimis. IInN. Syft. pag. 58\% n. I6. Fl. Dan. tab. 184.

Nafturtiun foliis imis multifidis, fuperioribus integris, peranguftis. Вовнм. 11.293.

Stinkkreffe; Hundeferge; klein Befenkraut. Germ. Narrow-leaved Wild Creß, or Dittander. Angl. Creffon des rumes. Gall.

In locis arenofis et ruderatis vbique, bei der Leim. grube; ad muros limolos bei Fregs Gutze copiofe etc. Fl. Iun. Iul. Annua. tur.

Obf. Cimices odore graui ingratoque pellere fer863. * Lepidium floribus diandris tetrapetalis, foliis Iberis. inferioribus Inceolatis, ferratis; fuperioribus linearibus integerrimis. LINN. Syft. p. 53\% n. 18. JAHN . n. \%. BLACKIV, t. 3:2.

Pharm. Tberidis Herba.

Iberpflanze; europäifche Kreffe. Germ. Dittander called Iberis. Angl. Creffon Iberide; Palferage. Gall.

In ruderatis ad muros prope officinam lateritiam Meistorfienfem et in agris oleraceis. Flor. Iul. Perennis.

\section{THLASPI, L. G. 866. Täfchelkraut. Germ. Mithridate or Treacle Muftard. Angl.}

864. Thlajpi filiculis orbiculatis, foliis oblongis, den-aruenfe. tatis, glabris. LiNn. Syft. pag. 581 n. 2. воEнM. n. 284. BLACKw. t. 68. Fl. Dan. t. 793 .

Pharm Thlajpeos Semina

Ackertafchelkraut; groß Täfchelkraut; Bauernkreffe; Pfemigkraut; breiter Bauernfenf. Germ Field Treacle Muftard, or Penny Creßs. Angl. Thlafpi de monnoyer, ou à la larges filiques. Gall.

In aruis et agris inter fegetes valde frequenter, nach der Leimgrule. Fl. April. Mai. Annua.

Oly. Boum lac, buryrum, carnes, ingrato fapore inficere refert $D$. HASTROM. 
865. Thlafpi filiculis fubrotundis, foliis fagittatis den. tatis incanis. LINN. SyR. p. 587. n. 6. вовHM. n. 2yo. BLACKW. t. 409 .

Feldtäfchelliraut; Feldtafche; Seckelfenf. Germ. Mithsidate Muftard, or Buftard Crck. Angl. Thlajpi champêtre. Gall.

In agris, locis argillofis, campertribus fere vbique. Fl. April. Msio. Annua.

montanum. 866. * Thlafyi filiculis obcordatis, foliis glabris: radicalibus fubcarnofis, obouatis, integerrinis, caulinis amplexicaulibus, corollis calyce maiorihus. LINN. Syft. pag. 587. n. 7. Jace. Flor. Auttr. Vol. 3. tab. 237.

Bergtifchelhraut. Germ. Mountain Mithridate Mufard. Angl. Thlafpi des montagnes. Gall.

In locis elatioribus ficcioribusque, in Bieniz paffim, et in agris bei Kleindölzig et Rückmarsdorf. Fl. Míi. Iun.

Bura Pafto- 86́7. Thlajpi filiculis obcordatis, foliis lanceolatis, ra. ris.

dicalibus pinnatifidis dentatis, caulinis. fogittatis. IINN. SyAt. p. 586. n. 11. BOEHM, n, 291. BLACKW. t. 5. Fl. Dann. t. 729 .

Var. a) Thla $j$ i foliis finuatis.

↔) Thlafwi foliis integris.

Pharm. Burfae Paftoris Herba.

Hirtentëfchelkraut; Dachskraut; Seckelkraut; Gârıfekreffe;- Blutkraut; Beutelfchneiderkraut. Germ. Shoperd's Purle. Angl. Tabouret, ou Bourfe à Berger, ou à Pafteur. Gall.

In agris, cultis, ruderatis, muris limofis et ad vias vbique. Flor. ab initio Veris in Autunnum vsque.

Vf. Pabulum ouibus falutare, 
TETRADYNAMIA. SILIQVOSAE. 35 T

\section{B. SILI Q V O S A E.}

a) Calyjé claujo plus minusue iongitúdinaliter connziveste.

317. RAPHANVS. L. G. 886. Retrig. Germ. Radirh. Angl, Raifort, Gall.

868. Raphanus frliq̨uis teretibus torofis bilocularibus. Satiuns.

LINN. Sylt. p. 603 . n. r. вовIM. n. 268.

Vár, «) Raphanus minos oblongus, C. B. P.

- p. 96 .

ß) Raphazus maior oblongus. BOERH. II, II.

x) Raphants maior orbicularis vel

rotundus. C.B.P.

d) Khaphanus niger maior rotun- 1. c.

Pharm. Raphani Nigri Radix.

Zahmer Rettig; Knoll-f. Rantrettig. Var. a) $R a$. dieschezi; Monarsradieschen; Raphanellen; $\beta$ ) großer weiffer Rettig mit langen Knollen; Sommer. 1. Waffer. retzig ; v) großer weiffer Rettzg mit runden Knollen; d) fchearzer f. Winterrettig. Germ. Common Radifh. Angl. Raifort commune; a) Radis; $\delta)$ Ramenas out Rammelas. Gall.

In China proprie habitat, ex quo olim in Euro. pam venit. Hae autem varietates enumeratae com: muniter coluntur in agris oleraceis et hortis fere omnibus fuburbanis rufticanisque. Var. $\alpha$ ) quoque in locis pratenfibus graminofis humidioribusque vor Pfaffendorf und der Wachsbleiche, atque in Poëzengange dietam tparfin reperi. Fl. Maio in Auguftum veque. Rad. perennis.

Vf. Succo acri, abftergente, aperience, fatus gignente pellenteque, ac vrinam mouente, bulbus featet; dehinc contra Scorbutum et calculos laudatur. Caeterum in culinis vfitatifimus et inter acetaria alecata in nonnullis regionibus commifceri folet. Bulbi quoque crudi cum fale et pane frequentiffme eduntur. 
Rhaphani-86o. Raphasus filiquis teretibus, articulatis, laeuibus, ftrum. vnilccularibus. LINN. Syft. p. 603 . n. 3. говнм. n. 267. Fl. Dan, tab. 678. KERN. B. 1I. pag. 98 tab. I66.

Ac errettig; Heidenrettig; Ackerkohl; wilder $\mathrm{f}$. Bauernfcnf; Schöndefenf; Hederich!. Heiderich. Germ. Corn Foinued-podded Charlock. Angl. Rapiftre ou Raifort fauvage. Gall.

In agris arenofis inter fegetes, praeprimis inter Hordeum et Auenum et haud intrequenter inter Se. cale vhique. Fl. Mni. in Aug. vsque Annua.

Obf Exficcatam plantam hyeme bobus, prae ipue Vaccis faluberrimum pabulum exhibere, docuit Cel. Krinitz. Hominibus certe innoxium alimentum pratbere herbam, experientia locuit, qua de re b. Linn. morbum Raphaniam dictun ex feminum fa. rin pari immixta falfe deriuauit. Oues et equiher. ba iubenter vefcuntur.

3I8. ERYSIMVM: L. G. Hederich. Germ. Hedge Muftard. Angl. Tortelle. Gall.

officinale. 870. Eryfimum filiquis Spicae adpreffis, foliis runcinatis. LiNN. Syft p. 595. BOEHM. n. 273. BLACKw. tab. 28. Fl Dant. t. 5 lio.

Pharm. Eryfimi Herba.

Gerë̈̈lnlicher Hederich; Wegefenf; Kreuzkraut. Germ. Common Hedge Muftard. Angl. Vélar, ou Tortelle. Gall.

Iuxta muros, atque in plateis et ruderatis, ad fepes et vias publicas vbique, e. g. mach Lindenau, in der Le?mgrube, an den H ufern der Kohlyärten etc. Fl Iun. Iul.

Barbarea. 87 . Eryfinum foliis lyratis, extino fubrotundis; filiquis obloicte tetragonis. LINN. Syit. pag. 596. n. 2. вовнм. n. 2-9. fub Sifymlio.

St. Barbenkraut; Walferfenf; Winterkreffe; $\mathrm{Ha}$ bichtskraut Germ. Wintercrefs, or Rocket. Angl. Herbe de St. Barle; Barbarine d'Orient; Herbe au charpentier; Lulienne jaune. Gall. 
Ad fofias et vias vbique; bei der Leimgrube et ad ripas fuuiorum frequens. Flor, Mai, Iun. Perennis.

VJ. Editur cruda in Satura herbaria. Per totam hyemem folia legi poflunt fub niue, vbi virent. Planta antificorbutica.

872. Eryfimum foliis fimplicibus, cordatis, retufis. Alliaria. LINN. Syft. p. 596 . n 3. воЕнм. n. 28I. fub Sifymbrio. BLACKW. t. 372 .

Leuchel; Knoblauchshederich; Ramfchelzerurzel; Raufchueurzel. Germ Tack by the Hidge, or Sauce Alone Angl. Alliare; Hérbe des Aulx. Gall.

Ad fepes paffim et in fyluis frequens, praecipue in RoSenthale, im Zfihocherfchen, Sommerfelder-und Streitholze; porro etian pallim im Poetengange. Fl. Mai. Iun. Perennis.

Obf Singulais alliacius odor in hac planta. Dum enim Vaccae hac vefcuntur, lar fapore Alii imbuitur. Folia primo Vere intilltibus et fallamentis addi folent in nonnullis regionibus. "Semina excitant fternutationem.

873. Eryfimum caule ramofifimo, foliis lanceolatis cineiranthoi obliquis repando dentatis, filiquis patulis. LINN. Syit. des. p. 647. n. 5. вовнм. n. 287. fub Turvite. Fl. Dan. r. 73 I. JACQ. Flor. tuftr. t. 23 .

Lackblumartiger Hcterich; Levcojen; langfchötiger Leindotter; Schotendotter. Germ. Tortelle à fletsrs dis Girofier. Gall.

n pratis bei der Ziegelfcheune, und nach dem Kuhthurme. Fl. Iun. Iul.

Obj. Herba agris inuifa.

319. * CHEIRANTHVS. L. G. 879. Lackblume; Lev. coje. Germ. Stock Iuly Flower, or Gilliflower. Angl. Giroflier, bu Violier. Gall.

874. * Cheiranthus foliis lanceolatis, acutis, glabris, Cheiri. ramis angulatis, caule fruticolo LiNN. Syft. p. $597^{\circ}$

n. 6. BLACKW. t. $1 \% 9$.

Leucoium luteum vulgare. C. B. P. p. 203. 
Pharm. Cheiri Flores:

Gelbe Vioie f. Veilchen; gemeiner Lack; golden Lack. Germ. Cominon Yellowe Wallforeer. Ang! Girofticr, ou Viotier janis. Gall.

In Europa auftrai habitat. Apud nos paffm in muris et tecti-p peffin reperitur, fed frequentius in hortis fere omnibus colitur ibidemque multiforie ludit coloribus egregiis. Flor. Aprilí et Maio. Perennis.

incanus. $875{ }^{*}$ Cheiranthus foliis lanceolatis, integerrimis, obtufis, incanis: filiquis apice truncatis, caule fuffruticolo. LinN. Syft, p. 597, n. 11 .

Leucoium incano folio, hortenfe. C. B. P. p. 200, ก. $1,2,-5,5,6,7$.

Ausduaernder Levcoje. Germ. Stock Gilliflozeer. Ang! irofier blanc. Gall.

In Hifpuniae maritimis habitat: in noftratibus hortis valde vulgaris, vbi coloribus pluribus variat. Fl. exeunte Vere in Aefiatem vsque. Perennis.

annuus.' $8760^{*}$ Cheiranthus foliis lanceolstis, fuhdentatis, obtufis, incenis: filiquis cylindricis apice acutis, caulo herbaceo Livn. Sytt. p. $59 \%$. n :

Leucoium incanum minus. C. B. P. p. 200.

lähriger Levcoje. Germ. Ten weecks. Stock Iuly-Flo. wer. Angl Girofier annucl Gall

In hortis cum priori reperitur. Fl. Aeftate.

320.* HESPERIS L. G. 881. Nachrviole; Wendelblu. me. Germ. Dame's - Volet. Angl. Itliane.

\section{Gall.}

mattonalis.877.* Hefperis caule fimp'ici, ereeto, foliis ouatoiancenlatis, denticulatis, petalis inucrone emarginatis. LiNN. Syft. p. 5 i).

Pfingftviole; Frauennachtviole; Matronalviole; $M a$. tronenblume. Germ. Common Garden Rockct. Angl. Iuliemne, ou Iuliane; Caffolette. Sall.

In Horto Bofiano fponte crefcentem inueni pafim. Fl. Iun, Iul. 
TETRADYNAMIA. SIIIQVOSAE. $35 \bar{J}$

32I. ARASIS. L. G. 882. Gänfekraut. Grm. Baftard-, Tower Muitard. Angl.

878. Arabis foliis lanceolatis petiolatis, integerrimis. Thaliana. linn. Syft. p. 599. военi. n. 250 . wilden. Prodr. Berol. n. is6.

Thalijches Gänfekraut; kleiner Thurnfenf; Thurmkoill. Germ. Codded Moufe-ear. Angl.

In ngris inter fegetes et in hortis circa Gohlis. Fl. Iun. Iul. Annua.

322. TVRRITIS. L. G. 883. Thurmkraut. Germ. Tower Muftard. Angl. Tourette. Gall.

874. Turritis toliis radicalibus dentatis, hifpidis; cau- glabra.

linis integerrimis ampexicaulibus. Lins. Syft. pag.

600. военм. п. 283 . F\%. Dan. t. 809 .

Glatres Thurmkvaut; Senfkohl; Waldkohl. Germ. Smoozh Touver Muftard. Angl. Tourette liffe. Gall:

Ad fepes paffim, porro auf dem Gickerlingsherge, in pratis ante pagum Gohlis, nach Mechern, et in $\mathbf{s}-$ netis dictis poft Tauckam. Fl. Mai. Iun. Perennis. 880. Turritis foliis omnibus hifpidis, caulinis amplexi- hirfuta.

caulibus. LINN. Syft. p. 600. n= 2. военм n. 2 : $=$

Raucher Thurmkohl. Germ. Rough Tower Muftard. Ang!. Touretre velue. Gail.

In locis humidioribus vmbrofisque, anf cier Wiefe nâch Rückmarsdorf. Fl. Mai. Iun. Perennis.

323. BRASSICA. L. G. 884. Kohl. Germ. Cabbage. Angl. Choux. Gall.

* Stylo obtufusculo.

88 I. Braflica radice cauleque tenui; foliis caulinis vni- campetris. formibus, cordatis, feflilibús. LINN. Syft. p. 60I.n. 3. F. Dan.t. 550 .

Wilder Durchwachs; Feldkohl; wilder Konl; Waldkehl; Kniitzen. Germ. Perfoliate Yellore-foree? red Cabbage. Angl, Chou champêtrte. Gall. 
In agris inter legetes et hortis oleraceis fparfim. F!. Mai. Iun. Annua.

Obf. Corolla flauefcens: Folia radicalia lyrata, Iubhilpida ; caulina laeuia.

Napus. 882. Braffica radice caulefcente, fuffformi. Lins. Syft.

p. 6о1. вогнм. ก. 270. BLACKW. t. 224.

Pharm. Napi Semina.

Rübraat; Rübjen; Oelfaamen; wilde Stockrüben. Germ. Wild Navew; Colefeed or Colewert. Angl. Navet fauvage. Gall.

In agris inter fegetes et ad ripas Pliffae nach dcm Rofenthale rarius vidi: maxime autem in noftris regionibus colitur. Flor. Vernali tempore et Aeftate. Annua.

Radices fapidifimae coluntur in hortis. Oleum ex feminibus exprimitur. In culinis hae radices in aqua elixsntur et iuxta carnes eduntur, incoquuntur quoque iqusculis.

Rapa. 883. Brafjica radice caulelcente, orbiculari, depreffa, carnufa, LiNi, Syft. pag. 60i. n. 7. вовнм. n. 271 .

Var. $\alpha$ ) Braffica radice fufiformi.

B) Braffica radice orbiculata.

Phàm. Rupue Semen, Radix.

eiffe Rüben; Halmrüblein. Var. a) lange Rü. ben; $\beta$ ) runde Rüben. Germ. Common Turnep. Var. a) Long-rooted Turnep; $\beta$ ) Round Turnep. Angl. Rone. Var. $\propto$ Navet commun blanc long; $\beta$ ) Navet commun blanc rond. Gall.

In $\mathrm{g}$ is, et campis hortisque frequenter culta, paffim in aruis inter fegetes. Fl. Aeftate.

$V \int$. Rapae, primum in aqua elixatae, dum mollefcunt, et poltea cun lacte in pultem costae, nutrim ntum pratbent mite, edulcorans, faluberrimum, facillimae digeftionis, nec flatuienturr. Ruri crudae eduntur. Syrupus Raparum debet effe recenter paratus. 
TETRADYNARIA. SILIQVOSAE. 357

884. Braffica radice caulefcente, terete, carnofa. Linn. Oleracea. Sy?t. p. 60I. n. 8. вовнм. n. 269.

Var. «) Braffica capitata ferotina comprefla maior. $\propto)$ Oler. SPIELM. p. 33 . alba.

ß) Eraffica praecox, capite oblongo. SPIELM. $\beta$ ) Oler. p. $3 \mathrm{I}$. pyramidalis.

III.

y) Braffica alba et viridis C. B. P. pag. ) Oler.

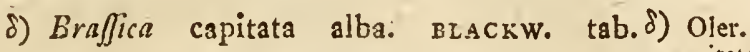
231.
ह) Braffica capitata rubra. Id. ibid.
ह) Oler.
६) Brafjica alba crifpa. C. B. P. p. II I.
६) Oler.
ท) Braffica laciniata rubra. Sdbauda.
C. B. P. Hift. II. n) Oler. laciniata.

p. $83^{2}$.

\section{2.}

9) Bralfica angufto Apii folio, C. B. P. pag. 9) Oler.

6) Braffica oleracea Sabellica non capitata. b) Oler: SPIELM. p. 36. var. 2. Selenilia.

x) Braffica fimbriata. C. B, P. P. 112. KERN, x) Oler. p. 97 . t. 163.

Sabellica.
ג) Braffica cauliflora. milz. Dict, $n, 83$.
i) Oler.

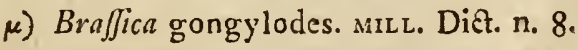
Botrytis.

b) Brafjica radice napiformi. мil. Dict, $v$ Oler.

ก. 2 .

Napobraftica

Pharm. Brafficae Rubrae Semina.

Kohl; gemeiner 'Kohl; Kraut; a) weiffer Kopfkohl; weeiffer Blattkohl; weilfes Kraut; großerbraunfchiceigifcher Kopfkohl; ordentlicher großer platter Weißkohl; groß Mittelkraut; Kappus; ß) fpitz- 
Frühkraut; fpitz Engelbergerkraut; Schwaberkraut; Zuckerhutformiger Kohl; Wondclfathter Kogflohl;

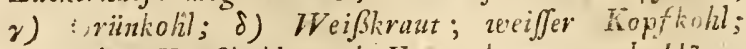
E) rother Kopfkohl; roth Kappuskraut; roth hinupzerkraut; ל) Savoyer Kohl; weiffer Wirringhohl; Wirfing; n) blaucr Schnittkohl; 9) Braunkohl; Krauskolal; Federkolal; brawsychweigijcher Hauskohl; Blïnafchekohl; . ) grïner Wirfing; Herzkohl; Pörfchkohl; krauler Kopfkohl; x) Schneckenkoills

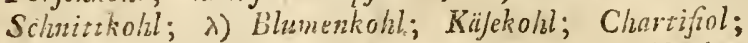
$\mu^{\prime}$. Kohibabi; Kohlrïben ïber der Erde; "Kolalritibe; Kohlrabi unter der Erde; Klunverrüiscn. Germ. Conmonn, or Sea Cabbage; a) Common White Cabbage; B) Sugar-loaf Cabbage; \&) White Curled Savoy Cabo bage; $\varepsilon$ Red curled Cabbage; 9) Sibcrian Borecale; x) Canlifower; $\lambda$ ) Tournep-Cabbage; $\mu$ ) Tonrneprooted Cabbage. Argl. Chou Pommé; a Chou Ponnmé blanc: Chou blanc de Strasbourg; r) Chou Ponsmé verd; \&) Chou Ponmé blanc; E) Cloou Pommé rouge; ;) Chou de Milán ou de Savoye; n) Chou brutin; 9) Chou de Milan frifé pointu, ou à tére lon-

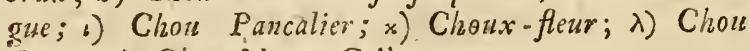
Rave; $\mu$ ) Chon Naver. Gall.

In agris oleraceis et hortis vbique omnes varietates enumeratae copiofe coluntur. Flor. Aeftate.

Obf. Var, $\alpha$, Ob folis crafinora et minus infipida apud nos in foro Vingo venditur. $\beta$ ) Ad Feftum St. Ioannis caput perficere tolet. S) Hanc varietatem in albam redire obferuauit REICHARD. \&) Ex Italia in reliquos Europae regiones olim diffurfa eft. Haec et fequens foliis megis aut minus profunde fr nuatis magis aut minus crifpatis vacie ludit. 9) $\mathrm{Ex}$ huius feminibus interdum procreant fpecimina minus hullata minusque fimbriata, magis glauca, caput rotundum formantia, çune Argentoratenfibus Grünkohl nominari (ol:t, ve seres.m. refert. - x) Braf. fica caulifora verfus finem Seculi XVII. in Germaniam ex Italia primum eft transinta, teftibus $\mathrm{He} / \mathrm{fio}$ et reichardo. d) Huins autem Autores Seculi XVI. iam priman faciunt mentionem. 
Vf. Braffica Sabauida eft magis tenera et fapida, quam alba. Braljica rabra pris cibo magis tenera et minus flatulenta. Sapidior tamen fir, il capitikus minutim confectis, et in butyro, clixatis, dum molle. fcunt, addatur ius carniun, cum pauxillo piperis albi et Salis culinaris, atque ita ebulliat, vt in pultem vertatur, etrunc acetum vini addatur. Brafjicae Botrytios capita omnium Braficae fpecierum fapidifima et tenerrima, dehinc frequentifime in opulentiorum mentis occurrunt. Porro quoque in vfum culinarem commode ficcari poteft Brafjica Botrytis. Methotum autem ficcandi docuit Cel. I. G. EIsrn *) Iiraffica Sabellica in vehementiflino gelu rigefcit, fub niue tamen virefcit. et luccofa quam primum regelatur. Brafjica Napobrafjica nuerit principio fuo laccharato. Radices tius finduntur in taleolas, et iu. ri carnium incoquuntur. Panem infuper pro plebe fatis fapidum, ex hac radice parauit sTRANDBERG. Amylum ex hac radice extrahere non potuit $\mathrm{Cel}_{4}$ BERGIVS.

\section{** Eracae, Siliquis Stylo enfiformi.}

885. * Braffica foliis runcinatis, caule hifpido, filiquis Erucaftum. laeuibus fylo enfiformi. LiNN. Syft. pag. 601. n. 12 .

Eruca fylueftris maior iutea, caule alpero. C.B.P. p. $9 x$.

Wilde Rauke; Raukeln; wilder Kohl. Germ, Rough Stalked yellow: wild Rocket.' Angl. Roquette fawvage. Gall.

In agris arenofis inter legetes paffim et in hortis et nleraceis inter Olera. Flor. Iunio in Auguftum vsque Annua

Herba in Acetariis olim adhibita nunc obfoleta. Pabulum bobus falutare. Apes defectu aliarum modo hanc quacrunt.

$$
\mathrm{Z}_{4} \text { - b) } \mathrm{Ca} \text {. }
$$

*) vid. Untericht von der allg?meinen Krïuter-und Wursela trockyung. Reval. 1773 . 
b) Calyce plus minusue hiante.

324. ISATIS. L. G. 88\%. Waid. Germ. Woad. Angl. Paftel, Gall.

tindoria. 886. Ifatis foliis radicalibus crenatis; caulinis fagittatis, filiculis oblongis. LINN. Syft. p. 604. вовнм. n. 266. BLACKW. t. 246 .

Färber Waid; Scharte. Germ. Common Dyer's Woad. Angl Paftel. ou Guéde. Gall.

In agris inter fegetes pallim ad Abtnawendorf, vbi colitur; ibidemque ad muros sarius reperi, porro in hortis paffim. Fl. Mai, Iun. Biennis.

Obf. Non procul ab Erfordia Ifatis colitur arti tinctrriae aptiffima optimaque. In Rofjae vrbe Korfchimaan, tefte parlas, officina, vbi Ifatis adhibetur ad tingenda lintea et lanuginofa, exftat. Proprie lano lutes imbuit durabili colore; contra addito calce cacrulaeo; et cum Vitriolo ex pallido-viridem colorem exhibet. De methodo IJatiden tinftorians colendi praeparandique, confuli poteft astrvc. *)

\section{2.. CARDAMINE. L. G. 876. Schaumkraut;}

Gauchblume. Germ. Ladies Smock. Angl. Creffon. iall.

impatiens $88 \%$ Cardamine foliis pinnatis, incifis, ftipulatis; floribus apetalis. IINN. Syft. pag. 594. n. 9. вовнм. n, 25\%. Fl. Dan. t. 235.

Empfiniliche Wiefonkreffe f. Gauchblume; Springkrefje. Germ. Impatient Ladies-Smock. Angl. Cardamine fenfible. Gall.

In pratis fyluaticis', copiofe im Rofenthale, Streite holze. Fl. Miai. Annua.

hirfuta. 888. * Cardamine foliis pinnatis, floribus tetrandris. I1N. Syft. P. 594 . n. 12.
Nafturtium aquaticum minus. C. B. P. p. 104.

Rauche

") Memoir, pour l'hifsaire de Languedoc. p. 523. feq. 
TETRADINAMIA. SILIQVOSAE. 36 I

Rauche 1. zottige Gánchblume. Germ. Hairy LadiesSmock. Argöl. Cardamine velue, Gall.

In hortis inter Olera peffim et in nemoribus humidis, im Rofinthale nach der Bürgeraue zu ncnnulla fpecimina nuper reperi. Fl. Iunio.

889. Cardanine foliis pinnatis, foliolis radicalibus tub- pratenfis, rotundi, caulinis, lanceolatis. LINN. Syft. p. $594 . \mathrm{n}$. 33. EOEHM. $\mathrm{n}$ 281. BLACKW, t, 223.

Wiefenkrefe; Wiefenfchaumkíaut; branne wilde Krefje. Germ. Common Ladies. Smuck. Angl. Crefjon des près. Gall.

In pratis omnibus humidis, im Rofenthale, auf den Gerber, Schönfelder, Lindenauer Wiefen etc. copiofe. Fl. Mai. Iun. Perennis.

890. * Cardamine foliis pinnatis, axillis ftoloniferis. amara. LINN. Syft. p. 594. n. 14 .

Nafturtium aquaticum maius et amarum. C. B. P. p. 104.

Bitere Bergkreffe f. Schaumkraut. Germ. Bitter Creß, or Ladies.Smock. Angl. Cardamine amere. Gall.

In nemoribus vmbrofis humidisque, im Rofenthale, ad Pliffae ripam et forlas paffim nuper inueni. Fl. Iun. et Iulio.

326. SINAPIS. L. G. 885 . Senf. Germ. Muftard. Angl. Moutarde. Gall.

89r. Sinapis filiquis multangulis, torofo- turgidis, laeui- aruenfis. bus, roftro ancipiti longioribus. LiNN. Syft. p. 602. вовнм. n. 272. Fl. Dan. t. 753 .

Ackerfenf; wilder Senf; taljcher Hederich; fchwarser Feldjenf; Schuttenf; Ackerkohl; Röddick; Triller. Germ. Field Muftard. Angl. Moutarde des champs. Gall.

In agris inter fegetes vbique. Flor. Maio I unio. Annua. 
alba. 392. Sinapis filiquis hifpidis: roftro obliquo longifimo enfiformi. LINN. S) Rt.p. C2. 11. †.

Sinapis Apii folin. C. B. P. p. 99.

Woiffer f. englifcher Senf. Germ. White Muftard. Angl. Moutarde blanche. Gall.

In ogris inter fegetes, preprimis bi Braffica $\mathrm{Na}$ pus feritur, et in agris oleraceis. Flor. Aeftate. Anriua.

Vf. Folia ad acetaria vtilia. Herba pabulum pecoribus valde bonum.

nigra. 893 * Sinapis filiquis glabris raceno adpreffis, LiNN. Sygt. p 602. n. 5. LEYs. n. 675 .

Pharm. Sinapeos Semina.

Schwearzer Senf Germ. Black Muftard. Angl. Moutarde noire; Senevé. Gall.

In ruderatis et ad vias pafime Fl. Iun.

327. SISYMBRIVM. L. G. 87\%. Rauke. Gcrm. Water- Crefs. Angï. Creffon. Gall.

* Siliquis declinatis brenibus.

Nafurtium. 894. Sifymbrium filiquis declinatis, foliis pinnatis,-folioli, Jubcordatis LINN. Syft. p. 594. BOEHM. n, 277. blackiw. t. (10. Fl. Dan, t. 6yo.

Pharm. Nafturtii aquatici Herba.

Brumnen-Born-Wafferkreffe Germ. Water Creffes. Angl. Creffon de Fontane ou d'cau. Fall.

Ad $\mathrm{ri}$ ulos, fontes foffasque puriores vbique, bei Ruickmarsdorf an der Wiefe etc. Fl. Iun. Iul. Perennis

Vf. Folia pro olere vernali tempore colleguntur, $\mathrm{H}$ rba ntifcorbutica.

fyluefre. $89 \div$. Si/ymbrizm filiquis declinatis oblongo ouatis; fo. liolis lanceolatis ferratis. LiNn. Syft. p.g. 59 t: n. $20^{\circ}$

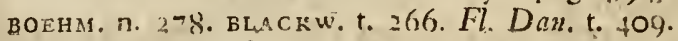

Walt f. Wagferrauke. Germ, Water Rocket. Angl. Creffori de Fontaine. Gall. 
TETRADYNAMIA. SILIQVOSAE. 363

In agrorum terminis et ad foffarum margines. Fl. Iun. Perennis.

896. Sifymbrium filiquis declinatis, oblongo-ouatis; amplibium.

folioli pinnarifidis, ferratis. erns. Syf. p. $59+$ n. 4 . ROEFM ก. $2-6$.

S? fymbrimm filiquis declinatis oblongo-oustis, foliis pinnatifidis, ferratis, peralis culyce longioribus. LEYS n. ơ 7 .

Var. a) Sifymbrium aquaticum.

B) Sifymbrium terreftre.

Wafferkreffe; Wafferrettig, Sumpthederich; $\beta$ ) Landraucke. Germ. Water Radifh. Angl. Raifort des marais; a) Creffon amphlbie aquatique; $\beta$ ) terrefire. Gall.

In aquis ftagnnntibus et ad earummargines, fre. quens. Fl. Iul. Perennis.

897. Sifymbrium filiquis declinatis oblongo-ouaris, fo- paluftre. liis pinnatifie, ferratis, petalis calyce minoribus. IEYS. n. 6-9. вовHM. n. 2 - 5 .

Sumpflkrefe. Germ. Marjh Water. Creß3. Angl. Creffon des marais. Gall.

In lacubus et ftagnis. Fl. cum priori.

** Siliquis longioribus erectis.

898. Sifynurizm petalis calyce minoribus, foliis de-Sophia. compofito-pinnatis. LINN. Syft. pag. 596 . n. I9. вотнм. п. 280. BLACKW. t. 440. Fl. Dan. t. 528.

Pharm. Soplziae Chirurgorum Semina.

Sophicnkraut; Well-f. Wurmfaamen, großes Befen. krant. Gerin. Flixreeed. Angl. Science des Chirurgiens; Taliftron des boutiques. Gall.

In ruderatis, tectis et ad fepes murosque vbique. Fl. Mai Iun. Perennis.

$V \int$. Dyfenteriam, tam hominum, quam boum Semina curant apud Nericios.

899. Sifymbrium foliis runcinatis, dentatis, nudis, Irio. caule lacui, filiquis eretis. LiNN. Sy凡. p. 596. ח. 2 I. JACQ. Flor. Auftr. Vol. 4. t. 322.

Eryfinn folio lyrato, extimo haftato. вовнM. n, 274 .

Glatte 
364 CLASSIS XV. TETRADYNAMIA. SILIQVOSAE.

Glatte Rauke. Germ. Broad-leaved Rocket, or Hedge Muftard. Angl.

Ad vias, auf den Gonnewitzer Schanzen, et in hortis inter Olera, Fl. Iul. Aug. Perennis.

*** Foliis lanceolatis integris.

Iftictiffi- 900. * Sifymbritum foliis lanceolatis, dentato ferratis mum. caulinis. LINN. Syft. p. 596. JACQ. Flor. Auftr. V. 2. t. 194 .

Draba lutea filiquis ftrictiffmis. C. B. P. p. I 10.

Rauke mit fenkrecht ftehenden Schoten. Germ.

Ad lepes et forfas paffim et in locis ruderatis, haud infrequens fere vbique. Fl. Iun. et Iulio. 


\section{MON A D E L P H I.A}

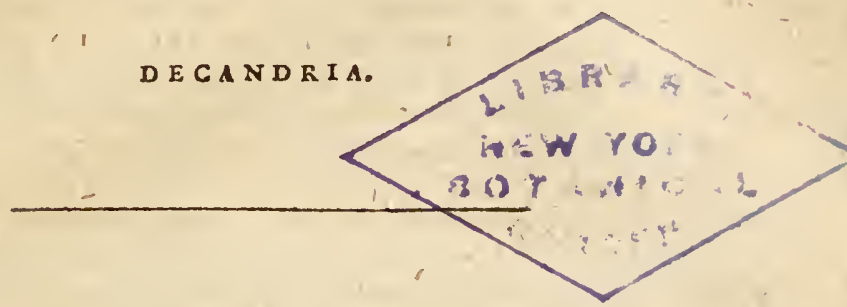

\section{A. FLORE HERMAPHRODITO.}

328. GERANIVM. L. G. 897. Schnabelkraut. Germ. Crane'sbill. Angl. Bec de Grue. Gall. * Stamina 7 antherifera; foliis oppofitis. Her-
bacea.

gor. Geranium calycibus monophyllis, caule carnofo odoratiffibreuifimo, ramis herbaceis longis, foliis cordatis mum. molliflimis. LINN. Syit. p. 614. n. 25. BVRM. Geran. 45 .

Geranium africanum humile, folio fragrantifimo, molli. Dils. Elth. 157. t. 131. f. 138.

Wohlriechender Storchfchnabcl; Mofchatkraut. Germ. Odorant Cran'sbill. Angl. Bec-de-grue très odorant. Gall.

Habitat in Africe et ob foliorum penetrantem et bene fuaueolentem odorem in hortis et ollis valde colitur. Fl. Aeftate. Perennis, 
** Myrrhina: Stam. 5 antherifera. Cal.5-phyllus. Fruct. declinatus.

cicutarium. 902. Geranium pedunculis multifloris, floribus pentandris, foliis pinnatis incifis, obtufis, caule ramofo. IINN. SyRt. p. 6r5.n. 36 . военм. n. 46 I.

Geranium Robertianum. RIV. Irreg.

Wïterichartiges Schnabelkraut; kleiner Storch. fchnabel; Krannichfchnabel. Germ. Hemlock-leated Crane's-bill. Angl. Bec de grue cicutin Gall.

Ad fepes et in agris iner fegetes; ante porrulam Schoenfeldicam etc. frequens. Fior. April. ad Iulium. Annua.

Herbaviridis amuletum in Scania contra febres in. termittentes lauảatur. I.INN. Fl. Suec. p. 24,;.

pufillum. 903: * Geranium pedunculis biforis, petalis ema"ginatis, caule deprefto, foliis reniformibus, palmatis, linearibus, acutis. LiNs. Syft p. 6IR. n. $6 \%$.

Kleinblumiger Storchfchnabel. Germ. Small-flowered Douc's Foot Crane's Bill. Angl. Bec de grue nain. Gail.

In agris et locis arenofis, fterilioribus bei Nauendorf. Fl. aeftate.

phaeum. 90:. * Grranium pedunculis folitariis oppofitionliis, calycibus fubsıifatis, caule erecto, petalis vndulatis. Linn. Sylt. p. 616. n. 48. BvrM. Geraa. 11.

Geranium montanum odoratum, flore purpureo ?. fufco. C. B. P. p. 318.

Schwarzer Storchfchnabel. Germ. Black-flowered Crane's Bill. Angl. Bec de grue livide. Gall.

Sponte crelcit in Alpibus Pannoniae, Heluetiae, aliisque montanis locis, frequentilimum in hortis et ponariis paffim. Perenne,

Obf. 1. Caul. erecti fimplices. Fol. alterna, longe petiolata, fere peltata, orbicuiata, plerumque 5-loba, profunde incifa, dentata; canlina fubferfilia, verius ambitum anguftiora, pedunculis oppofita. Pedunculi et quoque ex-caule fuperne nudiufculo alternant, biflori, bracteis inftructi. Cal.arifati. Cor. Petala aequalia, reuoluta, vel patentia, coloris obfeure purpurei vel fufci. 
MONADELPHIA. DECANDKIA. 367 rem.

Cb. II. Folia rupta ranguineum fundunt liquo-

*** Betrachia: Stam. Io antherifera. Peduncul.2-florus. Perennis.

905. Geranium pedunculis bifloris, foliis fubpeltatis, fyluaticum. quinquelobis incifo ferratis, caule crecto, petalis emarginatis. LINN. Syft. p. 6I6. n. 53. вовнм. n. 458 . BVRM. Geran. 12. Fl. Dan. t. ! 24.

Waldjchuabeliraut. Germ. Mountain Crane's Bill. Angl. Bec de grue forèr Gall.

In pratis fyluaticis et inter arbores frequens im Klein- und froßiölziger Holze, in der Kämmerei bei Nauendorfetc. Fl rul, tug.

806. Geranium pedunculis bifloris, longiffmis, decli- paluftre. natis, pet lis integerrimis, foliis 5 - lobis, incilis. LIN Sylt p. 6:7. n. 5 4. BVRM. Geran. 15.

Gruinalis pratenfis maxima, folio Aconiti minus profunde laciniato. вовнм. n. 45 var.

Sumpfltorchfchnabelkraut; Bruchftorchychnabel Germ. Marfh Crane's, Bill. Angl. Bec de grue des marais. Gall.

In pratis humidis, forfis et dumetis, bei dem $K u h$. thurme, in der Prellheide et alihi. Fl Iul. Aug.

90\%. Geranium pedunculis 2 - floris, foliis fubpeltatis pratenfe.

multipartitis, rugofis acutis; petalis integris. I.INN. Syft. pog. 617. n: 55. воЕнм. n. 459. вVR., Geran. 16.

Var. ß. Geranium batrachoides Gratia Dei Germanorum, flore albo. Tovrn. Inft. p. 207.

Wiefenftorchfchnabelkraut. Germ: Crow-foot Crane's Bill. Angl. Bec de grue de près ou Grace Dieu d'Allemand. Gall.

In pratis humidis, henter dem Kohlgarten, in Ro. fenthale et alibi. Var. $\beta$. in hortis faepe occurrit. Fl. Iun. Iul. Perennis.

Vf. In Chirurgia adhibetur, herbae fuccus recens fusuiter fpirans ad Cancros: Scirrhos et tpoftemata fananda: hinc a Germanis Grazia Dei appellata. 
**** Stamina Io anterifera; pedunculi biflori. Annua.

Robertia-908. Geranium pedunculis bifloris, calycibus pilofis num. decm angulatis. zinN. Syft pag. 6I- n. 60. BVRM. Geran. 18. военм. n. 62. BLAC Kw. t. 480 . Fl. Dan. t. 694 .

Pharm. Geranii Rohertiani Herba.

Ruprechts - Storchfilnabelkraut; Ruprechtskraut; finkcuder Storchfchnabel; ichtkraut; Blutkraut; Gottesgnade. Germ. Herb Robcrt. Angl. Herbe à Robert ou $\mathrm{B}$ c de grue ì Rohert. Gall.

In muris, alnetis et humidioribus inter mufcos: frequentius autem in hortis plurinis. Flor. Mai. Iun. Annua.

Vf. Cimices Herba recens contufa et admo:a pellit. In Haematuria pecorum infulum propinant Paftores. LINN. Fl. Suec, p. 24 l.

iucidum. 909.* Geranium pedunculis bifloris, calycibus pyramidatis angulatis, eleuatis rugofis, foliis :- lobis rotundatis. LINN. Syft. p. 61\% n. 61. bVRM. Geran. 19. Fl. Dan. t. $2 ! 3$.

Geranium lucidum faxatile. C. B. P. p. 3 I8.

Glänzender Storchfchnabel. Germ. Bec de grue lui. fant. Gall.

In Europae nontibus et locis vmbrofis: apud nos contra in hortis frequenter occurrit. Fl. Mai. et Inn. Perenne.

molle. 910: Geranium pedunculis biforis foliisque floralibus alternis, petalis bifidis, calycibus muticis, caule erectiusculo, Linn. Syft. p. 617. n. 62. BVRM. Geran. 21. sCHReb. Spicil. p. 3 ;. n. 955. Fl. Dan. t. 6\%9.

Geranium columbinum villofum petalis 2 - fidis, purpureis. vaild. Parif. 79. t. 15. f. 3 .

iv eiches Schnabelkraut. Germ. Conmon Dove's Foot Crane's Bill. Angl. Bec de grue mollet. Gall.

In pomariis, pratis, ruderatis bei der Leimgrube, ad vias fepesque circa pagos frequens. Fl. Iun. Iul.

Obf. Stipulae bifidae. Folia rotundata, multifida laciniis inaequaliter ob:ufo-diuifis, mollibus. Petala aequalia, bifids. Calyecs hirduti, fubmutici, Corolla breuiores.

911. 
MONADELPHIA. DECANDK:A. 369

911. Gerarimm pedureulis biftoris, folits 5 partito-tri-diffectum.

fidis, peralis emarginatis longitudine calycis, arillis

vilifis. LINN. Syft. pag. $6: 8$, n. 66, вовнм. ก. 463 . BVkм. Geran' i 5 .

Tief cingefchnittenes Schnabelkraut. Germ.' Fagged leavel Dowe's Foot C'rane'sbill. Angl. Bec de gine difféqué. Gall.

in aruis, agris, hinter der Leimgrube porro in hortis s.g. in Horto Bofiano copiofe et ad fepes vbique. F. Iul. Aug.

Oif. Petala pallido-incarnata. Antherae caerilcae.

9i2. Gcraninm pedunculis biforis, foliis longioribus, coltubifoilis quinque - partito-multifidis, arillis glabris, ca- num. lycibus ariftatis. L1NN. Syft. p. 617 . n. 64. 2VRM. n. 22 .

Gernnium columbinum foliis diffectis, pediculis flowirn longiffmis. varlz. Parif 79. t. 15. f. 4 . - Caubenjcinabel. Germ. Bec de grue colombin. Go!l.

In dumetis vimbrofis et ad fepes hortorum paffim reperi: porro in hortis oleraceis aliisque haud infreqnenter mihi occurrit. Fl. Iun. et Iul. Septembr. Semina inaturat.

Obf. Ca!. 5 - phyllus, magnus, laciniis ouatis, 3 ftriis longitudinalibus eminentibus notatis, extus villuiofis, laete viridibus, apice, in ariftam obtufiusculam terminantur, Filam ro, fubulata, alba. Styl. 5. patentes, rubelli. Stipulae fubulatae, bifidae, rubellae, petiolorum bafi inferti. Pedunculi teretes, hirfuti, folia longitudine fuperantes, in 2 pedunculos vnifloros eiusdem longitudinis diuifi. Capf. 5, fubrotundae, glabrae, I - loculares.

913. Geranium pedunculis bifloris, petalis fubintegris Maluncoum. longituline calycis caule proftrato, foliis reniformibus, incifis.-BVRm. Geran. 20., LINN. Sy凡. p. $618 . \mathrm{n}$. 67. Ger. rotundifolium. воЕнM. n. 464. BLACKW. tab. 58.

Pharm. Pedis Columbae Herba.

A a

R̦̣ı!s: 
Runclättriges Schnabelkraut; großer Feldtauben: fulß; Schartenkraut. Germ. Round leaved Dove's Foot; Crane'sbill. Angit. Bec de grue à feuilles rondes oil Vied de Piegonl. Gall.

In agris campis, hortis oleraceis et ad fepes viasque fere vbiq̣ue. F!. aeftate.

\section{***** Staninibus ro antheriferis: Pedunculis

$$
\text { I-floris. }
$$

fanguineum gr.4. Geranitm pedunculis vniloris; foliis quinquepartitis, trifidis, orbiculatis. IINN. Syft. p. 618. n. 70. воегім. n. 360 . evri. Geran. 3 .

Pharn. Sanguinariae Radix.

Bhutiges f. blutrothes Schnabelkraut; Blutreurz; Elutkraut; Nabelwurz: rothe Hiihnere'urz. Germ. Bloody Crane's. bill. Angl. Bcc de grue Janguin. Gall.

in ficcioribus pratis montofisque locis im Bieniz: Item ad viam publicam inter Taucham und der Barmïille nuper reperi. Fl. Iun. Iul. Aug. Perennis.

$V \int$. Flores pabulum apibus falutare.

\section{P O L Y A N D R I A.}

\section{LAVATERA. L. G. 907. Lavatere. Germ.}

thuringich. 915. Lauatcra caule herbaceo, fruetibus denudatis; calycibus incifis. IINN. Syit. p. sz7. sCHREz. Spicil. p. 8. n. 899. JACC. Flor. Auftr. Vol. 4. T. 311 .

Var, $\beta$ ) Malua paluftris mollis et incana, laciniato folio. Rvpp. Ien. p. 15. еvхв. Hal, 207.

Thüringifche f. teutfche Lavatere. Germ. Thuringian Lavatera. Angi.

In durnetis et ad fepes bei Wolkwitz, Ill. b. GLEDIтsCH. olim inuenir, et varietatem ad pagum Hänicleet SCHMEDEL obdermauit. Fl, Iul. Aug. 
MONADELPHIA. POLIAXDRIA. $37 \mathrm{~T}$

330، MALVA. L. G. no6 Pappel. Germ. Mallow. Angl. Mauve. Gall.

916. Malua çule proftrato, foliis cordato-orbiculatis rotundifulias obiotete quinquelobatis; pedunculis fructiferis decilnatis. LINN. Syf. pag. 625. n. 15. ВОЕНM, n. 72 . Fl. Dall. t. 721 .

Var. $\beta$. Malua vulgaris flore minore, folio rotundo.

I. ВAฑH. 2. $9 \div \%$.

Pharm. Maluac Vulgaris Rodix, Herbs.

Rundblêttrige Pappel; Gïnse-Kïfe-Hajen-Feldpappel; Kleine Pappel mit runden Eldirtern. Germ. Common Mallow. Angl Mauve fauvage à fiuillesrondes, ou petite Mauve Jaurige. Gall.

In aggeribus circa vibem; in der Allcc; porro ad vias fepesque copiofiflime etc. Flor. Iun. Iul. Pe:ennis.

$V \int$. Veteres foliis loco Spinaciae cotis vulgó vfi funt in deliciis.

9I. * Malua caule erecto, foliis angulatis crifpis, flo- crifpa ribus axiliaribus glomeratis. LINN. Jyft. pag. 026. n. 22. LEERS Herborn. its.

Malua foliis crifpis. C. B. P. p. 315 .

Kraufe Malue; kraufe Pappel. Germ. Curled-leaved Mallow. Angl. Matzue frifée. Gall.

In cultis oleraceis, bei Sellerhenfin et Stötteritz, in hortulis Pomecrii Grimmerfs, in hortis Pplendidis valde frequens et ad fepes hortorim rufticanorum paffin. Fl. Iul. in Septembr. vsque.

Haec autem fpecies vernacula lingua Tollerkoh aliis appellatur, quia orbes vel patinae his foliis inftruntur. Folia tenella bene fapida ad acetaria $S_{p i-}$ machiae loco adhiberi folcnt.

918. Malua caule erecto, herbaceo, foliis 7 - lobatis, fylueftrís:

acutis; pedunculis petiolisque pilofis. LiNN. Syft.

p. 625. n. 17. BОЕ HM. n. 73. BLACKW. t. 22 ;

Var. «) Malua fore coeruleo

ß) Malua flore albo. 


\section{CLASIS XVI.}

Pharm. Minluae Sylueftris Herba, Radix, Flores, Senina

Wald-1. Roßspappel; große Pappel; Hanf-St. Iohamispappel; W Waldmaluc. Ge1m. IV ild Mapple or Crab. Tree. Angi. Mauve fauvage à fetilles finuées. Gall.

Ad fepes et vias cum priori; porro etiam in pomariis paffim et in fyluis circa Lipfiam fere omnibus frequens. Fl. Iun. - Aug.

Obj. Folin 7-coftata. Cal. exterior ouatuso Cor. caerulei coloris.

matritiana. 919. * Malua caule erecto herbaceo, foliis quinquelobatis obtufis, pedunculis petiolisque golabriusculis. IinN. Syft. p. 626. n. 18.

Malua hederaceo folio. C. B. l'. p. 515 .

Mauritanifihe Malue. Germ. Mauritian Mallowe. Angl. Mauve de la Mauriziane.

In rudera is et reiectamenris hortorum paffim. In. ter olcra atque in hortis fuburbanis rufticanisque frequens. Fl. Iun. in Autumnum vsque.

Olf. Maluae fylucfiri fimilis; fed ab illa differt, foliis 5 - coftatis, calyce exteriore lanceolato. corolla magis ex caerulco-fanguinea, et habitu maiore.

Alcea. 920. Malua caule eręto, foliis multipartitis, fcabriusculis. L1NN. Syft. p. 626. n. 23 . BOEHM. R. 74. BL.ACKW. t. 309 .

Pharm. Alceae Radix.

Sellirißpappel; Siegmarszeurz; Simeonswurz; Wetterrofen; Heraleuchte; Morgenffern, Augennappel. Germ. Common Vervain Mallow. Angl. Mauve Jauvage, ou Alcée. Gall.

In fyluis, dumetis: in collibus circa vrbem et ad vias fere vbique, Fl. Iul. Aug. Perennis.

331. * ALCEA. L. G. 905. Stockrofe. Germ. Holly-
hock. Angl.

tofea. 82r. * Alcea foliis finuato-angulofis, Lisw. Syft. pag: 624.

Pharm. Maluae arboreae Flores.

Ro. 
Rofenpappol; Herhftrofe; Gartenpappel; ErntroSen; Banm-Ilals-Mundrofen; römifche Pappeln; Stockrafe. Germ. Common Holly/rock. Angt. Mauve Rofe; Malue des jardins; Pafjerofe; Rafe d'Outromer, ou de tremier. Gall.

In hortis plurimis copiofe et ad fepes rufticorum pafim. Flo: aeftate. Biennis pafim Perennis.

Olf. Haec planta variis ludit coloribus, ita, vt florem pallidum; luteo-album; flauum; carnofurn; rubrum ; fanguincum; purpureum; atro-purpureum; obfcure bruneum et nigrum, etc, obferuemus. Flores in gargarismatibus adhibentur.

332. * AL.THAEA. L. G. 90.1. Eibifch; Sammetpappeln f. Siegmarsivurz. Germ. Marf h-Mallow.

Angl. Guimauve. Gall.

922. * Althaea foliis fimplicibus tomientofis. LINN. Syft, officinalis.

p. 62.t BLACKW. t. 90 Fl. Dan. t. \30.

Plarm. Althacae Radix, Semina, Herba.

Ibifchiz f. Eibzfch; Heil - Siegmarszenrz. Germ. Mallow of the Shops. Angl. Guimave vulgaire. Gall.

Ad fepes hortorum paflim et in hortis frequentius. Fl. Iul. Aug. Perennis.

Obf. Radix magis mucilaginofa, quam herba. Flores apes frequenter quaerunt.

\section{B. FLORE MONOCLINO.}

333. PINVS. L. G. II75. Fichte; Kiefer. Germ.

* Foliis pluribus ax caden baf vaginali.

923. Pinus foliis geminis primordialibus folitariis, fylueftris. glabris. Linn, Syft. p. 860.

Pinus foliis gemin's conis pyramidatis; fquamis oblongis, obtufis DV Roi B. Il. p. 1.3. BоEIM. n. 687. BLACKIW. T. ISO. CRAM. t. 26 .
A $\approx 3$
Pharm. 
Pham. Pini Turiones, Lignum, Refina.

Wilde gemeine Fichte 1. Kicfer; Fichtbaum; Forren:; Fülere; Kienfore; Fore; Spanholz; Harabaum; zeiluer Zirbelbaum; Kullnbanu; Wirbelbaum; Mädelbaun, Ziegenholz. Germ. Wild Pine-tree; Manured Pine-tree; Scotch Fir. Angl. Pin Janvage, ou Piiz de bois. Gall.

In fyluis tierilicribus, im Linkeler; Macherfchen; Oberluolze; in der Prellheide; in der K.mmerez bei Nauendorf etc. et in montosis copiofe. Fl. Maio.

Ex hac arbore Dalckarlos et alios panem coquere IINN. refert. In Suecia librum recentem initio veris cultello pueri deradunt, et lubenter comedunt. Turiones deftillati fpiritum optimum dant et fragrantiflimum. Porro Sueci cereuifiae frumentihos addere folent. Lignum afteribus, lectis, menfis, ciftis, tignnis, trabibus validis aliisque conficiendis valde vite. Carbonihus Metallargi vintur. Ex radicibus pix producitur. Lapponibus lignum in vfu eft ad foleas SKJi diktas, arcus carinasque traharum. v. LINN. Flor. Lap. I 46. Arbor actatem 400 annorum attin. git.

Strobus. 924. * Pinus foliis quinis margine fcabris, cortice lạeui. IINN. Syft. p. s6o. n. 5. SERT, Lip1.n. 6?.

Pints Strobus foliis quinis, conis oblongis pendulis, fquamis oualibus, planis laxis. bv Ror Harbk.,II. p. $5 \mathrm{r}$.

Pinus canadenfis quinquefolia, floribus albis, co: nis oblongis pendulls, fquamis abieti fere fimilibus. DVHaxi. Arbor. II. p. 12\%.

Larix canadenfis longifimo folio, tovrnef. Inft. p. 506 .

Weymouth, f. Büfchelkiefer. Germ. New , England, or Lord Weymouth's-tree. Angl. Pin blane de Canas da: Pin de Lord Weymoutí. Gall.

Habitat in Virginia, Canada exc. Apud nos in Syluis paffim ante phurimos snnos culta eft, e. g. im Macherfehen Holze, in dor Prellheide auf dem Tiefina feer Antheile: Praeterea quociue in Serto cirça montem Schacekcnberg distum 'et in hortis fuburbanis 
aliisque notiffimis haud infrequens. Flor.' Maio Iunio.

925. * Pinus foliis fafciculatis, obtufis, deciduis : conis Larix, ouato-oblongis, fquamis ouatis, fubfcabris, margine laceris, DV ror Harbk. II. pag. O1. SERT. Lipl. n. 64.

Pinus Larix foliis fafciculatis, obtufis. IINN. Syft. p. 860. n. 7. WILDEN. Prodr. Berol. I1. 700.

Lazix folio deciduo, conifera: bavy. Hift. I. pag. 365. BLACKw. t. 477 .

Larix. C. B. P. p. 497.

Pharm. Terebinzhna $V$ erata.

Lerchenbaun; Lerchentanie; Lorolibaun; Lör. baum; Leerbaum; Lecrkiefer;'Rothbaum; Schösbaun. Gern. Common Larch-tree. Angl. Pin Méleje; Méleze des Alpes; Larche. Gail.

In Europa Auftrali, Sibiria, America feptentrionali proprie habitat: In noftratibus fyluis paffim nune occurrit e. g. in Macherfchen Holze an der Fuhrftraffe cts. in der Prellheide auf don Ticfenfecr Antheil et in Ambulacro bei dem Roßplatze ac in Serto poft Ergaftulum, etc. Fl. April. et Mạio.

Obj. E cortice laefo fịllat fuccus fpiffus, refino. fus, qui facile flommam mouet et arbores incendit. Ligno ad medulla combufto tunc fillat ex fubitantia ligni interiore Gummi rubicundum, ficcum et minus mucilaginofum, quam Gammi arabicum. Hoc autem Gummi gaudet fapore refinofo, plane folubile eft in aqua et Gummi Lariis, aliis autem Gummi Vralenfi appellatur. Infuper Wogulenfes hoc cupide edunt. Vernali tenpore e foliorum faciculis Manna Laricina (Manne de Briançon) colligitur in Ruffia. Lignum praebet durum ad naues, aedificia exftruenda etc, adhibendum: Sub aqua eugdit durius et fere lopideum. 
* Foliis folitariis ex bafi diftinctis.

Alics. 9*6. Pinus foliis folitaris, emarginatis: conis oblongis, erectis: fquamis fubrotundis, planis, hafi acuminalis. Dy roI B. II. p. 95. seRT. Lipl, n. 68.

Pints Picea. linn. Syft. pag. istio. n. 8. boenm. n. 685. (fib Abiete) ELACKw. to ByS. CRAan. to 24.

Pharm. Abietis Turiones, Kefina, Pix - Burgundica.

Wiffe, Sillier, edle Tanne; toxblättrige Tanne; Mafibaun. Germ. Silow-leaved Fir-Tree; Yev-leaved Fir. Angl. Sapin à fauillcs d'If, Faux Sopin. Gall.

In fyluis et ad pagos pafin circa Linklel. Nunc etian in der Allee ante portan Grimmenfem transplantata multisque in hortis priuatis et ante domos rufticorum occurrit.

$V \int$. Liber pueris, vt prioris fpeciei in deliciis eft. Efoliis, more Canadenfium, potum conficere fapidum et falubren Kalmavs docuit. Cortice aedes ftraninis loco teguntur. Lignum leuifimum ad inftrumenta mufica et nauiculas Lapponum portatiles. Cum vern tempeftati humidae exponitur, facile corrum. pit. In igne crepitat. Carbones metallurgis inferuiunt. Rami pro vinculis doliorum. Sadices Iappis ad funes corbesque. Strobili alunt Sciuros, Loxias et Phalaenam. Spiritus e tencllis frondibus fuccedaneum Aquae reginae hungaricae. Exconis oleum, fic ditum, Terebina thimum, producitur.

picea. 927. Pinus foliis folitariis fubulatis, bifariam verfis; conis oblongis, pendulis: fquamis oualibus planis, marginibus vnciulatis lacerisque. DV ro1 B. II. p. 110. SERT. Lipf. ก. 65 .

Pinus Abies. Linn. Syft. p. Sór. n. it. воена. n. 686. вLACKw. tab. 203. cran, tab. 24. Fl. Dan. tab. 192.

Fichte; Roth:Tanne; Harz-Pech-fchrearze Tanne; Fichtianne; fchuearser Tannenvanm; dic fächfiflize Fichte; Rothfichte; Pechboum. Germ. Cosimon Pitch- 
Pitci-tree; Spruce Fir. Angl. Pcue, Peffe, Picen, Sapzin. Gall.

In fyluis, hortis multis et ante portam Grimmenfem. Fl. Mai Iun Arbor.

Vf. Haec fpecies picem praebet ct cum butyro mixta axungi,un vilem. Stolones longi, fed tenues pro Humui perticis, fcandulis; truncivero afferibus, fa. binis et yafis variis apti. Cortex coriis parandis vtilis. Lapponibus radix ad corbes atque funes inferuiter ex tenuiori eiusden cortice nauiculas portatiles conficiunt. Folia cuın auenae feminibus mixta in nonnullis regionibus pabu'um équis. Coni teneriores cum foccharo conditi contra forbutum laudantur. Exhalatio harum arborum phrhificis falutaris.

\section{FLORE DICLINO.}

334. IVNIPERVS. L. G. 1746. Wachholder. Germ. Iuniper-tree. Angl. Genevre. Gall.

928. Innipcrus foliis ternis, patentibus, mucronatis, communis,

bacca longioribus. LINN. Syt. p. 39\%. n. 7. DV ROI B. I. pag. 338 : senT. I.ipf. n. 42. BLACKw. tab. 187 . CRAM. t. 44. DVHAM. Arb. I. p. 321, t. 127.

Pharm. Inniperi Baccae, Lignum, Sumnitates.

Gemeiner 'Wachlolderfrauch; teutfcher Wachlolderfirauch; Hegholder; Wech-f. Reckholder; Rehbaum; Fenerbaun; Kramnctsbeeren; Feldcypreffe; Dürenftaude.-Germ. Common Iuniper. Angl. Geneore, ou Genewrier ordinaire, ou Grand Genewrier. Gall.

Ad fyluarum margines, bei den Univer fitâtsholze et in plurimis hortis fuburbanis paffm mihi occurrit. Fl. Aprili. Frutex.

Vf. Baccae contufae in potum dulcem et diureticum, qui vero genua debilitat, eliguntur; porro fpiritus ab iis defillatione obtinetur. Refina a formicis colleta inter corticem et lignum ex Italia, Hilpania et Africa fub nomine Refinae Sandaracae transportatur. A a 5

Scribae 
Scribae folent puluere Sandaracae chartam rafam fricare, ne atramentum penetret. Infuper in Smolandia aliisque Sueciae prouinciis cereuifiae loco vtuntur infufo Baccarum Iuniperi per totam Aeftatem et Autumnum. lisdem baccis Turdi, Tetraones vẹfeuntur. Baccae quoque pro fuffmigiis in domo, vti etian rami. Cortex ad funes idoneus. E ligno duro, perenni ad palos fepimentorum idoneo grati canthari, pocula etc. conficiuntur. Carbones diutiffme ignem alunt.

Sabina. 929. Inniperus foliis oppofitis erestis, decurrentibus: oppofitionibus pyxidatis. LÍNN. Syft. pag, 894. n. 5 . BORUM. n. 7OE. DV RoI Harbl. I. p. 358. serT. Lipf. n. $: 3$.

Sabina folii Cyprefi. C. B. P. p. 487 . Dүнам. Ar. br. II p. 212. t. 62.

Pharm. Sabinae Herba.

Setuerbaum; Sadebuzun; Raßfchuanabaum. Germ. Common Savin. Angl. Genevrier Sabine; Savinier ou Sabine Gall.

Sponte crefcit in Lufitania, Italia, Heluetia, Sibiria, Olymso. Ararat eic. In noftratibus quoqueregionibus hyeme facile crefcit $t$ t in fere omnibus horris fuburbanis rufticnnisque frequentius culta. Fl. Aeftare trbor humilis.

Olf. Ad fepes viuas valde apta. Tota arbor exhalat odorem fortem et caput grauantem. Sapor eiu dem acris fragmnsque. Herba Sabinac menfes, lochiaque pot ntiffme monet, dehinc teminis calidis valde periculofa. Equis Sabinam oppido conuenire eosque ala. rus et geftientes reddere putant surigae Suecia, a quibus haec arbor ftudiofe quaeritur. Pulvis Sabinat in carie offiun infpergitur et ad porcos venereos tollendos auhibetur.

\section{5.* TAXVS. L. G. 1241. Eibenbaum. Germ. Yew. tręe. Aagl. It. Gall.}

4izcała. 930. * Taxus foliis approxinfatis. Linn. Syft. pag. 895 . Fl. Suec. 12, 916. DV ROI Harbk. II. p. 45 L. 
Tasus. C. B. P. p. 505. BLACKW, t. 512. Ifilder Taxbaum; Bogenbaum; If; Ibe; Ifen; Eibe; Eibenbaum; Eue; Eiben; Ibenbaum; Euen. Ebenbaum; Eyenbaum; veilder teutfcher Iaxus; nordifcher Taxus; ponmorfcher Taxusbaum. Germ. Common Yere; Yew-Gray; Ive; Yo. Angl. If ordintaire. Gall.

Habitat in Europa et America: Apud nos in dumetis pufitim, e. $g$ in Infula ante Horzum IVolkauienfem'atque in hortis fuburbanis, v. c. Bofiano, Winkleriano, Richteriano, Trieriano etc. et quoque alibi. Fl. Mai. Arbor.

Obf. Arbor antiquitus venenata habita foliis lemperuirentibus viridifrmis tecta, topiariis volde apta et ad Tapetzia viua pulcherrima. Baccae certe fufpectae et hominibus lethales. Folia contra pecoribus nocuiffe nonnullorum exempla authorum confirmarunt. Folia in Silefia contra Rabiem caninam adhibentur Lignum rufum, venofum, durum, glaberrimum et valde praeftans atque vtiliffimum ad axes, haftas, ar. cus, cantharos, cochlearia. uIN . Fl. Succ, p. 362 , 


\section{Claffis XVII. \\ D I A D E L P I A.}

, HEXANDRIA.

\section{a) Flores fimplices ringentes.}

336." FVMARIA. L. G. 920. Erdrauch. Germ. Fumatory. Angl. Fumeterre. Gall.

93 I. Fumaria radice bulbola; caule fimplici bracteis maicr. integerrimis, ouato-lanceclatis, floribus breuioribus. ROTнi. Germ, i. p. 300.

Funaria bulbofa caule fimplici, bracteis longitudine florum. LINN. Syft. Ed. R. T. III. pag. 378. n. 4 . var. $\propto$. radice bulboja, cana. военм. ก. з І 2. Fl. Dan. t. 10.5 . GLED. Naturgefch. der einheim. Pfl. pag. 114. tah. 61 .

Var. $x$ Fumaria bulbofa, radice caua, maior, flore rubro. C. B. P. p. 1.a $\{$. BLACKN. t. 5 ił.

B) Fumaria radice tubero!a, maior, flore albo. Pfeudo-Fuinaria. Riv. Tetr. t. -3 .

Pharm Ariftolochiae Canae Radix.

Zwiebelertrauch; Holzuturzel; Donnewwir: Herz. vousz; Hahnenkamm; Fraucnjchïchlein; Taubenkropf. Gèrm. Solid bulbous Fumatory. Var a) Hallow bulbous Fumatory; B) Greater folid-bulbous Fumatory. Angl. Racine creufe; ; $\beta$ ) Fumetcre ayani la raci. ne fafjonée en bulbe. Gall.

In lncis nemorofis. e. g. im Rofenthale, porro ad viam nach den innewitzer Holze. Var. $\alpha$. et $\beta$ ) in Horto Bofiano, hinten an der Lrthmeand; porro quoque inter Gonneweitz, Kajchwitz, Gautch, in der 
Kämmerei bei Nauendorf etc. frequens. Fl. Martio et Aprili.

932. Funaria radice bulbofa, caule fimplici, bracteis Halleri. cuneiformibus apice incifis. WILDEN. Prodr. Berol. n. $70 \%$

Fumaria radice bulbofa, folida, caule fimplici multifolio, bracteis digitatis. Hall. Helver. n. 349 . BOEHM. n. 313. BLACK W. t. 53. .

Fumaria bullofa. Lins Sylt, Ed. R. T. III. p. 378. var. $\beta$. radice bulboja, intermeelía.

Pharm. Arifolochiae Rotundae Vulgaris f. Fabaciae 1. Fumariae Bultiofae Radix.

Kleine Holzueurz; klener knolligter dicktuzurzlichter Erdranch; kleme runde Ofterlucei. Germ. Sualler fold bulbous Funnatniy. Angl. Ariffoloche ronde sommune. Gall.

In locis humidis et nemorofis montofisq̨ue im $R o$. fenthale, hinter dem Lasarethe, poft pagum Eutritfch, vor Pforte auf dem Knabenberge etc. copiole. Flor. Martio in Aprilis medium vsque.

$V \int$. Radix huius fpeciei Kalnuscis fuauiffmum praebet cibum.

b) Caule ramóo.

933. Funaria filiquis linesribus tetragonis, caulibus Capneides. diffufis, acutangulis LINN. Syft. p. 63\% n. 8. SCHREB. Spicil. p. 24. n. 935. RIv. tetr t. 73 .

Gelber Erdrauch. Germ. Yellow Fumatory. Angl. Fumeterre vivace. Gall.

In muris vetuftatis, e. g. in Horto Bofiano in den Mauern des alren Gewächshaufes et ibidem ad muros copiofe. Flor, Maio et per totam fere aeftatem. Perennis.

934. Fumaria pericarpiis monofpermis, racemofis, cau- oficinalis, le diffufo. Linn. Syft. p. 637. n. II, вовнм. n. 3 I I. BLACKW. t. 237. KERN. B. I. p. 46, t. 60. GLED; $N a$ turg. der einl, Pfl. p. IOI, t. 6. 
Fumaria. Riv. Tetrap. Irreg. tab. I.

Pharm Fumariae Semina, Htrba.

Gezeöhnlicher Erdrauch 1. Taúnenkropf; Acker f. Feldraute; Ackerkraut; Alpraute; wilde Raute; Taubenkorbel; Katzenkörbel; Krätzheit; Krätz-f Grind. kraut; Nonncnkraut; Fimftern. Germ. Ramping Fumatory. Angl. Fumetcrre des Boutiques. Gall.

In agris inter fegetes, aruis, aggeribus et ad vias frequens. Flor. Maic et per totain fere aeftatem: Annus.

Vf. Planta smara, corroborans, antacida, Cachecticis, Scorbuticis et Scibiolis etc. vtilis. Pabulum ouibus gratum et falutare eft herba recens.

\section{O C T A N D R I A.}

337. POLYGALA, L. G. 921. Kreuzblume. Germ. Milkwort. Angl. Poligale. Gall.

vulgaris. 935. Polygala floribus criftatis racemofis, caulibus herbaceis, fimplicibus procumbentibus, foliis linearilanceolatis. LINN. Syft. pag. 638. вовнм. n. 253. Fl. Dan. t. 56 .

Poiygala vulgaris. C. B. P. p. 2I5. VAIL L. Parif. $t_{\text {。 }}$ 32. f. 2 .

Var. $\beta$ ) Polygala flore vielaceo.

y) Polygala fore carneo,

d) Polygala flore albo.

ह) Polygala fiore variegato. sif. 161. t. 32 . f. 1 .

६) Polygala maior. C. B. P. p 2r 5. varlz, $\mathrm{Pa}$

Pharm. Polyzalae vulgaris Folia, Radix.

Geneine Kreuzblume; Milchblane; Himmolfarths. Natterblume; Herrgottsbärtlein; Ranifel. Germ. Common Milkwoort. Ang!. Poligale sulgairc. Gall.

In pafcuis et pratis ficcis, e. g. var. $\beta$ ) auf dem $G i$. ckerlingsberge; bei dem Gcfundlbunnen; 'hinter den ileinen Kohlgärten verfus Schönfch et alibi valde frequens; $\gamma$ ) praeprimis bi den Gunndorfer Holze etc. et ad viam ante pägum Sechau/en; $\delta$ ) in limitibus 
agrorum ante pagum Linkel et ad Templunin St. Theclae; $\varepsilon$ ) bei dem. Gefundbrunnen paffim; $\xi$ in :folo pinguiori et locis graminolis vbique. Fl. Maio. in Auguftum vsque.

Obf. Contra Phthifin radix in puluere, vna cum infufo herbae, cum optimo euentu data eft Vindebo. nae. Candon.

\section{DE C A N D R I A.}

b) Flores fimplices papilionacei, leguminofi.

a) Staminibus omnibus bafi connexis.

1) Stigmate imberioi.

338. GENISTA. L. G. 930. Günfter. Germ. Dyer'sBroom. Angl. Genêt. Gall.

\section{* Inermes.}

936. Genifta foliis lanceolatis, glabris, ramis ftriatis, tinctoria. teretibus, ereztis. LINN. Sylt. p. o+5. SERT. Lipf. n. 36.

Genifta foliis confertis, oualibus, acutis, floribus feffilibus, fpicatis. вовнм. п. 323. Fl. Dan. t. 526.

Geniftella. Riv. Tetrap. Irreg, t. 67.

Pharm. Ceniftae tinctorzae Herba, Flores, Semina.

Hohlheide; Mägdekrieg; Färbergiinfter; Färberkraut: Färbeblume; Färberfriemen; Heidefchmuck. Germ. Dyer's Broom, Green-zood; Woad-Waxen. Angl. Genêt des Teinturiers; Herbe aux teintures; Geneftrole. Gall.

In nemoribus mon-ofis et fyluis fterilioribus, im Bieniz; Gunndorfer - und Univerfitats. Macherfchen. Sommerfelder.Grasfelder-Holze; in dem Hegerrafe bei Kriphâne; in der Kammerei bci Nauendorf; in dem Nötzfcher Holze atque in der Prellheide etc. porro in locis elatioribus, e. g. auf den Weinbergen hinter Tauche copiofe. Fl. Iun, in Auguftum vsque. Perennis. 
V). Flores et herba luteo tingunt colore atque pictores ex his colorem Schüttgelb fic dickun pa:ant. Sal Geniftae in hydrope laudatur. Herba pabulum ouibus falutare. - Frutex locum obtinet in fruticetis.

pilora, 937.* Ginifa foliis lanceolatis obtufis, caule tuberculato decumbente. LiNN. Sylt. pag. 645. n. 9. scor. Carn. Ed. II. n. 874. polıich. Palar. n.664.

Genifta inermis, procumbens, folis duris, fubhirfutis, fpicis breuibus foliolis. Hald, Helvet. $n$. 351 .

Chamae - Genifta foliis Geniftae valgaris. C. B. P. p. 395 .

Kleine ranche Erdpfrieme; kleine Mainfrieme; ungarifche Erdpfrieme; kleine Heiden; haviger Ginfter. Germ. Branching Broom; Duarf Bropn of Hungary. Angl. Gênet volu; Gènet branchu ì feuilles de Millepertuis. Gall.

In locis ficcioribus, arenofis elatioribusque, e. g. in der Tieglitz bei. Dïben nuperrime primum detexi. Fl. Maio et Iunio. Semina maturat Augufto.

Obf. Cal. breuis I - phyllus, extus pubefcens, irregulsiter 5 - dentatus: denticulis 2 fuperioribus ouato-acutioribus, magis diftantibus; inferioribus 3 minoribus, omnibus fere ciliatis. Cor. papilionacea: Vexillo lato, reflexo, fubrotundo, obtufo, integerrimo, flauo: Alis 2, quatis, flauis, carina paulo breuioribus, vexilli longitudine. Caul, ramofi, duri, procumbentes, apicem verfus ereeti, $6-7_{-}$- angulis eminentibus fulcisque exarati, tuberculis pluri. mis fparfim obfeif. Fol. e fingulo tuberculo plerumque 3 vel plura egrediuntur, obuerfe-lanceolata, obtula, integerrima, feffilia, vel vix petiolata, fuperne laete viridia, glabra, inferne pilis albelcentibus, tenuioribus fericeis testa. Flores fpicati antrorlum nutantes. Spica racemola, flaua, pedunculis alternis, folitariis, vel 2 ex foliorum alis fafciculatim progredientibus inftruta.

Oly. Flores apes frequenter quaerunt. 
** Spinofae.

938. Ginifta spinis compofitis, ramis foriferis, inerni. Gemanice

bus, foliis lanceolatis. LINN. Syft. pag. 645. n. I2.

BОЕНM. n. 324 .

(ieniftella Spinofa. RIV. Tetrap. Irreg. tab. 67. pul. chre

Srechende Hohlheide; ftech ade Erdpfrieme: kleiner tentfluer 1. ftachlichter Güifter; niedrig ftochende zeutfoine Pficme; fuchlichter Pfriemenkraur; rauke Stach.lufrieme; teut/che Farhcrpfrieme. G rm. German praskly broom; Needle Furwes or duar. Whimme. Angi. Genét d'Allenagne; Petit Genêt epunezix; Genêt. Piquant Gall.

In fyluis fere omnibus crefcit, e.g. im Bieniz, Uniürfiräts - Gunn !orfer - Macherfchen- SommerfeldcrHolze; in dem Hegegrafe bei Kriphäne; in der Kัäm'merei bei Nauendorf; in der Prellheide etc. valde vulgaris. Fl. Iun. et Irl Perennis

Obf. Flores luteo tingunt colore. Herba tenella pabulum bobus, capris ouibusque haud ingratum. Fl. apibus pabulum.

339. * LVPINVS. L. G. 939. Feighohne f. Wolissfchote. irerm. Lupine, Angl. Lupin. Gall.

939: * Lupinus calycibus alternis inappendiculatis: la- alıus. bio fuperiore integro: inferiore tridentato, LINN. Syft. p. 55 - JAHN. n. 10.

I.upinus (latiuus) flore albo, C. B. P. p. 347. kIV. Tetr Irreg. t. 25.

Pharm. Lupini Semina.

Weiffe Feigbohne; weiffe Gartenfeigbohne; Wolfsbohne; große Gartenlupine. Germ. White Lupine. Angl. Lupin blanc. Gall.

In pratis vdis : Schönfcld ibidemque iuxta pifcinam Cel. JAHN ante paucos annos inuenit; in dem Poetengange atque in hortis oleraceis alisque fuburbanis frequentius accurrit. Fl. Iul. Aug. Annua.

Legunin? in Italia inferuiunt cibo. Fabae toftae Caffeae Succedaneum. 
luteus. 9ł0. * Lupinus câjycibus verticillatis appendiculatis labio fuperiore bipartito; inferiore tridentato. LINN. Syft. p. 656 . n. 7 .

Lupinus (fyluefris) fiore luteo, C. B. P. pag. 348. RIV. Tetr. Irreg. t. 26.

Gelbblühende Feigbohne f. Wolfsfchote. Germ. Common Yelloze florcered Lupine. Angl. Lupin jaune. Gall.

Habitat in arenofis Siciliae:

Hofpitatur frequenter in hortis noftratibus, tam fuburbanis, quam rufticanis et oleraceis. Flor. per totam fere aeftatem. Annua.

$O b \int$. Flores fubfeifiles, lutei, fuauem Ipargunt odorem. Brąteae ouatae.

340. ANTHYLLIS. L. G. 936. Wollblume. Germ. Kidney - Vetch. Angl. Vulneraire. Gall.

- Vulneraria, 94I. Anthyllits herbecea, foliis pinnatis, inaequalibus, capitulo duplicato. Linn. Syft. pag. 654. Bоенм. $\mathrm{n}$. 322. KERN. B. I. p. 27. t. 26.

Anthyllis. nIv. Tetrap. Irreg. t. I 8.

Pharm. Vulnerariae Herba.

Wund-f. Beruffraut; Wundblume; Wund-. Ka Ka tzenklee; Hendelweiß; wilde Bohnen. Germ. Yellowflowering IV̈oundwort; Scarlet Kidney-Vetch; Northern Anthyllis or Ladies-Finger. Angl. Vulnéraire ruffique, ou des poifans. Gaill.

In pratis ficcioribus hinter dem, Sandberge bei Rüickmarsdorf; porro quoque in humidis pratis ad Klein- et Großä̈lzig; ad Lindenthain et verfus Kriphäne etc. Fl. Mai, et lun. Perennis.

$V \int$. Herba luteo-croceo inficit colore, quo ruftici fuos veftés tingunt. Infuper ouibus pabulum. Flores exficcatione caerulei euadunt, ficuti Flores Loti corniculati. 
34T. ONON S. L. G. 93. Haufrechel. Germ. ReltHarrow. Angl. Bugrane. Gall.

942. * Ononis Anribus racemofis folitariis; foliis terna. f́pinofa.

tis folirar isque ramis fpinofis. LiNN. Syft p. 651 n. 2. BUETM. n. 2-. VA1. I. RETz Obfrv. B tt. Fsíc. I. p. 3. n. 7. et Fafe. II. p. 21. n. 68. BLACKW. t. 301 . f. 1. Fl. Dan. t. 763 .

Anonis. Riv. Tetrap. Irreg. t. 69.

Stachlichte Hauhechel; Hechelkrant; Stallkraut; Stahliraut; Oclufezkraut; Ochfentrech; Pflugferz; Weibrkrieg. Gerin Common Reft Harrow or Chanmock Ing. Bugrane epincufe Gall.

In locis campentribus t arenolis pareuisque fircis fere vbique, arif der Pfingfirriefe, auf dem Gicicrlingsberge; in limitibus agrorum et Coemeteriis ete. vulgaris. Fl, lun. lug. Perennis.

943. Ononis floribus racemofis, geminatis, foliis ter arusnfis, natis, fuperioribus foli ariis, ramis inemibus, tub-

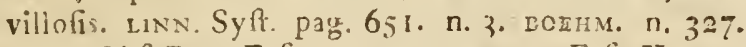
RETZ. Ohf. Bott. Fafc. I. p. 23. n. - S. ei FafC. II. par. 21. n. $6-$ -

Ackerhauhechel ohne Stacheln; Wetzfteinkrat. Gerin. Thornlef. Reft. Harrow. Angl, Bugrane des champs; Arrêt-Boeuf. Gall.

Pharui. Ononidis Radix, Herba.

In iistem locis cum priori immixta reperitur. Fl. Iul. Iug. Perennis.

Olj. Hrec tota priore maior, pallidior, magis fucculenta, hirino odore praedits, nunquam fpinof?, tamen repans. Ararnibus hae. et illa planta inuifa.

$V$ J. Radix in febre hungarica laudatur. Turiones Ononidis Alparagri ad inftar coquuntor in nonnullis reginsibus Decotum herbae equis tfchuria labo* rantib:!s fnlutgr Héba tenel'a ouibus, equis annisque etc. pabulum valde bonum. 


\section{PISVM. L. G. 7 16. Erbfe. Germ. Pea, Angl.} Pois. Gall.

fatium. 94. Pifum petiolis terctibus, ftipulis inferne rotundatis, crenatis, pelunculis multifloris. LINN. Syft. pag. 660, n, I. LOEHM, n. 336, ELACKW, t. 83 .

Pifun aruenfe, C. B. P. p. 342. Pifum, Riv. Tetr. Irieg. t. 36 .

Var. $\beta$ ) Pifum humile caule firmo, tovrnef. Inft. p. 394. Pifurn nanum. RIv. Tetr. Irreg. t. 39 .

y) Pifun fine cortice duriore?

8) Pifum hortenfe maius.

£) Pilum vmbellatum.

3) Pifum maius quadratum.

p. 343 .

p. 342.

n) Pifum aruente fructu cinereo. TovR

6) Pifum áruenfe ex lureo-virefcente. NEF.In-

9) Pifum fructu albo. fit. $p$.

394.

Ervje; zahme Erloge; geneine Feld-1. Gartener bfe; Schotenerbje et immaturae Siliquae Schoten. Germ. Common Garden Pea. Angl. Pois cultivé, ou des jurdins. Var. ß) Zwergcrbfe; Franzerbfe; lileine Zuckcrerbfe; Kruperbfe. Germ. Dwarf Sugar Pea.Angl. Pois nain Jans parchemin. Gall. v) Zuckererbfe. Gęrm. Sugar Pea. Angl. Pois gourmands. Gall. \&) Klankererbje; Fontanellerbfe. Germ. \&) Kronerbfe; Traubcnerbfe; Büfchelerbfe. Germ. Rofe or Crozen Pea. Angl. Pois à couronne. Gall. ६) Hollïndifche Erbfe. Germ. Pcar of Hollande. Angl. Pois d'Hollande. Gall. n) Graue Erbfe.Germ. Gray-Pea. Angl. Pois gris. Gall. b) Felderb $\int e$ : Germ. Pig-Pea. AngL Pois cultivé des champs. Gall. श) Weiffe Felderbje. Germ. Common white Pea. Angl. Pois blane. Gall.

In agris inter legetes var. $n-9$.) paffim occurrunt.' Caeterum omes in agris oleraceis hortisque fere omnibus apud nos frequenter coluntur. Flor. aeftate.

Vf. Siliquae virides' et tenellae facile digeruntur: maturae contra farinam crudam continent et flatus gignunt. 
945. * Pifum petiolis tetraphyllis, fipulis crenatis, aruenfe. pedunculis vniforis. LINN. Syft.p. 66r. n. 2.

Pifun pulchrum, folio angulofo. I. Bavis. 2. pag. $297^{\circ}$

Eeld- f. Ackérerbje; wilde Stockerbfe. Germ. Common Pcafe of the Fields. Angl. Pois dus champs. Gall. In agris cultis praeprimis inter Pifum Satizum et Viciam fatiuam. Fl. Aefate. Annua.

Obf. Ab aliis Ipeciebus facile diftinguitur; videlicet luplici foliorum pare, fipulis emarginatis et flo. ribus folitarie pofitis. вов̈н. tum.

Vf. Siliquae pabulum pecoribus haud ingra,

2. Stigmate probefcente.

343. SPARTIVM. L. G. 929. Pfriemenkraut. Germ. Broom. Angl. Genêt, Gall.

946. Spartiun foliis ternatis folitariisque, ramis inermi- Scoparium. bus, angulatis. LiNN. Syft. p. 644. SCHREe. Spicil.p. 25. n. 938. elackw. t. 244. Fl. Dan. tab. 3I3. DVHa.. Arb. Tom. I. Pl. 84.

Genifta Riv. Tetr. Irreg. t. 65.

Pham. Spartii Scoparii Flores, Semina, Herba.

Günfter; gemeiner Günfter; Pfriemenkraut; BeSem 1? Stechpfriemen; Pfngft- 1. Heidepfrieme; Pfriemenholz; Haafengeil; Reh-Haajenheide; Schachkraut; Frauenfichichel; Bram; Bramkapem; teutfche Kapern. Gern. Common, or Green Broom. Angl. Spartie Genêt ì balais; Genêt commun. Gall.

In remoribus e. $g$. in Pineto ad Lindenthal, in fylvis ad Linkel, Macharn, in der Prellheide; ad Officinam lateritiam Meifodorfieasem; in limitibus agrorum ad Laue et Neuhaufen et in elatioribus bei Gothe et poft vrbem Tauche diatam etc. frequenter creficit. Fl. Maio et Iunio. Perennis.

$V \int$. Flosculi muria et aceto conditi Capparidun fuccedancum. Flores pictoribus colorem praebent flauum. Rami fcopis conficiendis et coriis parandis 
apti. Frutex ob fores palchre luteos magnosque Arborete et Fruticeta ornat.

344. PHASEOIVS. L. G. 940. Bohnen; Phifeolen. Germ. Kidney-Bean. Angl. Hericot. Gall.

vulgaris. 947. Phafeolus canle volubili, racemis multiforis, braEtei, pedictllorum fnlitariis ouatis, leguminibus linearibus. BERG. Mat. Med. IT. p. (101. n. 378 .

Phajeolus.vulgaris caule volubili, floribus racemofis, geminis, hracteis calyce minoribus, leguminibus pendulis. sins. Syft. p. 656. n. I1. военм. n. 344 . RIV. Tetr. Irreg. t. 30 .

Gemeine Bohne; Vitsbohne; welfche Bohne; Gartenfafeolen; großse Schminkbohnen; Schmïikbohnen; Var. B) Stangenbohnen; 1) veiffe Schminkbolunen; 2) Perlbohize; 3) Schwerdbohne; 4) bunte i. fikeckigte Bohne; s) frïhe weiffe Schninkbohne. Germ. Comnon Kidney-Bean; 3) Large'Dutch Kidney Bean. Asigl. Haricot commun Var. 1) Harncot blanc comभunn; 2) Petit Haricot rond blanc; 3, Gros Haricot d'Hollande; 4) Haricot grivelé; $)$ Horicot blanc. Gall.

Obf. Racemi axillares, pubefcentes, folitarii, erecti, multifori, fructihus geminis, pedicellatis. BraCteae folitariae, glabrae, feffiles, ouatae, acutae, apice inflexae. Legumina pendula, fpithamaea, viridia, linearia, rects, dorfo groffius repanda, glabra, ininus oblique et interrupte friato - rugofa, verfus bafin pauiuium attenuata, apice terminata mucrone conico-fubulato, transuerfim compreflo, incuruato. Sem. matura nitida, alba, ex ouato-oblonga, reniformia, hilo albo notata،

puniceus. 948.* Phajeolus caule volubili, racemis multiforis, bracteis pedicellorum ternis lanceolatis, leguminibus acinaciformibus hirtis. BerG. I. c. pag. 6́oz. n, 379 .

Phafeolus indicus, flore corcineo $f$. puniceo. moRIs. Hift. 2. p. 6g. LINN. Spec. Pl. T.II. p. 10 6. n. I. Var. $\beta$.

Phajeolus coccineus, RIV. Tetr, Irreg. t, 29, fig. $\mathrm{x}$. Feure. 


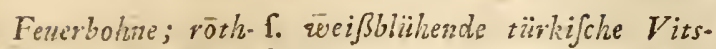
bohne; brafilianifche 1. crabifche Bolnne. Germ. Scarlet Bear. Angl. Haricet d'Efpagne; Haricot ì fleturs pourpres. Gall.

Obj. Racemi axillares, elongati, multifori. Bractere. 3, paruae, lanceolatae, acutae, quartim exteriores reflexae: intermedia erecta, paulo maior, caly. cum vero = oppofitae, calycis bafi vtrinque adnatae, lineari - ouales, calycis longitudine. Legum. pen. dula, acinaciformia, compreffa, vtrinque attenuata, apice acuto, fubtís fulcato, hirfuta, dorfo gibbofa, 3- fperma.

949. * Phajeolus caule fubuolubili, pedunculis axillari- foetidus. bus, quadrifloris, calycibus fuperne truncatis. BERG. "1. c. p. 603 . ก. 380.

Zuckerboline; Spargelboluze. Germ. Sugar Pean. Angl. Haricot fens parcheninis. Gall.

Obf. Pedunc, teretes, axillares, quadriflori, erecti. Brakt, ouatae, ftriatae, glabrae, folitariae, patentes: 2 vero oppofitae, bafi calycis fubiecrae, reflexo-patentes, calyce maiores. Legum. teretiufcula, vtrinque compreffa, apice mucionata. Sem. ouata, ferru. ginea, rotundato-compreffa, glabra, hilo laterali, ob: longo, notata.

Hae omnes tres fpecies commemoratae in India habitant. Apud nos cum varietatibus plurimis in hor: tis oleraceis aliisque fuburbanis rufticanisque etc. frequenter coluntur. Fl. Iùn. Iul. Annuae.

Legumina viridia in culinis iusculis carnium incoquuntur, vel Acetariorum more praeparantur etc.

950. * Plhafeolus caule breui eretiufculo diffufo, pe- nanus dunculis oppofitifoliis, calycis labio fuperiore emarginato, BERG. 1. c. p. 604. n. 381 .

Phafeolus manus caule erecto, laeui, bracteis calyce maioribus; lerruminibus pendulis, compreffis, rugofis. LINN. Syft. p. 656. n. 12. RIv, Tetr. Irreg. t. 29, fig. 2 . 
Zvergbohne; Zuergvitsbolne; Krupvitsbolune;

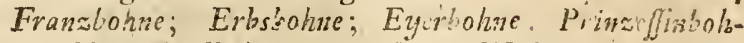
ne: Kleine Pcrlbohne Germ. Duarf Kidney-bean. Angl. Harice naw. Gall.

In Iridia cum prioribus habitat.

In agris oleraceis; hortis fere omnibus valde vulgaris. Fl. Acitate. Annua.

Obf. Pedinc. oppofritolii, ereeti, teretes, pubefcentes, multifiori. Braft. ouatae, acutac, plabrae, ftriatae, patentes, ad pedunculns folitariae, ad calycem cortra oppofitse, calyce longiores. Lutum. carnofa, viridefcentia, linearia, in apicem acumina. tum terminantia: acumine inflexiufculo, coni o, vtrinque fulcato. Scm. 6, ouato-cylindrica, fordide alba, vel alio colore picts, glabra.

In culinis prae aliis maxime adhibentur.

B) Staminibus 9 (inferioribus) connatis, decimo (upremo) libero.

I) Stigmate pubefcente.

345. OROBVS. L. G. 945. Erven; Kichern. Gern. Bitter Vetch. Angl. Orobe, Gall.

vernus, 95 I. Orobus foliis pinnatis ouatis, ftipulis femifagittatis, integerrimis, caule fimplici. LiNn. Syft. p. 664.

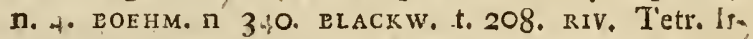
reg. $t$ 58. Orobus.

Pharm. Orobi Farina.

Frïhjährige Erven; Waldkichern; Fafanenkraus. Germ. Vermal Bitter Vetch. Angl. Orobe fauvage, ou printanier. Gall

In nemoribus, in Rofcnthale, vbi forum color valde ludit; porro im Gonncwitzer, Rafchwitzer,

- Zfchocherfchen, Sommerfelder, Univerfitätshnlze, in der $K$ manerei bei Nauendorf et in aliis fyluis copiofe crefcit. Fl April. et Maio. Perennis.

Flos exhilarat fub frondefcentin Coryleta purpureis fpeciofiffinisque floribus. LINN. Herba pabulum bobus, capris et equis haud ingratum. 
952. Orobus foliis pinnatis, lancolatis; ftipulis feni-tuberofus, fogittatis, integerrimis, caule fimplici. LINN. Synt.p. 65 1. n. 5. schreb. Spicil. p. 26. n. 9-10. Fl. Dan. t. 781

Orobus radice tuberola. RIV. Tetrap. Irreg. tab. 59.

Knollige Erven; Bergerife; YFalderlje dur Engländer: Chrifturus; Heiderbfe. Gorm. Tabcrous-rvoted Bitter-Vetch, or Hood or Heazla Peas. Angl. Orobe zuberewx. Gall.

In der Tiglizz bei Düben olim 1ll. schrebervs invenit: nunc quoque in der Kämmerei bo Nazendorf atque im Bienzz paffim reperi, Fl. Maio et lunio. Perennis.

Radices coctae, fapidae et nutrientes, ac pro pane vicario inf"ruire poffunt. $21 \mathrm{~N}$.

953. Orobus caul: ramofo, foliis fexiugis ouato-nb-niger, longis. line. Syft. pag. 662, n. 1O. военм. n. $34 \mathrm{I}$. *

Orobus Viciae folio. RIV. Tetr. Irreg. t. 60.

Schuraze Erven: falfches Süßholz. Germ. Wood: Orobus with Vetch leaves; Vetch-leaved Bitter Vetch. Angl. Orobe noir. Gall.

In fyluis elatioribus im Bieniz, in der Kämmerci paffim. Fl. Iul. Aug. Perennis.

Obf. Ob radicis dulcedinem Glycyrrhiza Syluefris nonnullis appeilatur ct eiusdem herbae radicen fuiffe cibum, a Dione, in Seucri Imperatoris Vita, meinoratum, quo vfi Angli per aliquot dies ab hoftibus preffi, vt famem fitimque tolerarent, fertur. vid. RAI. Hift. 19.

346. LATHYRVS. L. G. 964. Kichern, Platterbfe, Germ, Chichling Vetch. Angl. Vefte.

Gall.

* Pedunculis arifloris.

954. Lathyrus pedunculis vniforis, cirrhis diphyllis te fatiuus

traphyllisque, leguminibus ouatis, compreffis, dorfo bimarginatis. IINN. Syff p. 662, n. 5 . 


\section{4}

Lathyrus Siliqua latiore. RIv. Tetrap. Irreg. tab. 47.

Zucchern, Küchern, weiffe Kichern, italienifche Erb. fen; platter Erbjen; zahwe Platterbfe. Germ. Annual Chichling Vetch.Angl. Geffe cultivée; Nentil de Suiffe. Gall.

In hortis palim et in agris inter Viciam Satiuam fparfim. Fi. Iun. Itil. Annua.

TY. Panis ex feminum farina folummodo confectus albus, leuis, fapidus haberur pro alinento per niciofifimo: fi contra cum Tritici farina mixtus paratur, tunc optimus plerumque et innocuus euadit. Suibus, Gallinis, Columbisque femina effe noxia narrantur. Anferes autem haec auide deuorant et Aues vipabulum plane innoxium. In Helnctia Semina fine detrimento comecuntur et ibidem herbam pecora impune deuorant. vid. ouvernoy Diff. de hoc Lathyro. Bail. 7\%o.

\section{** Pedunculis bifloris.}

odoratus. 955. Lathyorus pedunculis biforis, cirrhis diphyllis, foliolis onato-oblongis, leguminibus hirfutis. IINN. Sylt. p. 663 . n. 10.

a) Siculus. Var. $\approx$ L Lathyrus Siculus Rinini, RVp. Ienenf. p. 210. niv. Tetr. Trreg. t. 36.

B) Zeylani- - B) Iathyrus Zeylanicus, odorato flore amoecus. no ex: albo ct rubro vario. EVRM. Zeyl. 138.

Wohlvieshende Plattcrbje; Gartenwicke; fpanifchè Wicke. Germ. Sweet-fcented Pea. Angl. Gefle odorante. Gall,;

Habitat $\alpha$ ) in Sicilia et $\beta$ ) in Zeylona.

In hortis noftratibus fere vbique colitur ob odorem bene fuaveolentem et fores pulchre varieque pictos. Fl. Aeftate.

Obf. Oeconomi hunc Lathyrum nuper vt pabulum pro pecoribus colendum commendarunt. SCHOLL.

ringitanus. 950́ * Lóthyrns pedunculis bifloris, cirrhis diphyllis: foliolis, alternis, lanceolatis, glabris, ftipulis lunatis. 
LINN. SyR, p. 663. n. I2. JACQ. Hort, t. 76. sCHOLL. Barb. p. 292. n. 104.

Tunitanifche Platterbfe. Germ. Tangiar Chichling $V$ erch. Angl.

Hic Lahyorus, qui in Máuritania fponte crefeit, ob pulchrum fiorum colorem noltrates ornat hortos, vbi frequenter occurrit. Fl. Aeftate. Annua.

957. * Iathyrus pedunculis bifioris, cirrhis polyphyl. Clymenum. lis, ftipulis dentatis. LINN. Syft. p. 663. n. $I_{3}$.

Clymenum hifpanicum, flore vario, filiqua plara. TOVRNEF. InR. p. 396.

Levantifche Platterlys. Germ. Spanifh Chichling. Vetch. Angl. Gcffe Climene, Gall.

Hubitat in Hifponia et Oriente.

In hortis noftratibus nunc frequenter colitur. Fl. Iun. in Auguft. Annia.

Obf Flos inoderus: Vexillo rubro; Alis albidis, Legumina compreffa, plana.

\section{*** Pedunculis multifloris.}

958. Lathyms pedunculis multiforis cirrhis diphyllis, tuberofus. foliolis oualibus intermediis nudis. L1NN. Syft. pag. 663. n. 15.

Lathyrus foliis binatis, radice glandulofa. вовнм. ก. 339 .

Lathyrus aruenfis. Riv. Tetr. Irreg. t. 42.

Knollichtc Plattcrbfe r. Kuchern; Acker-Erdnüffe; Erbelniifje; Erikelnïlfe; Ercieisheln; Erdfeigen; Era. mandeln: Erdnäuschen; Erd Erkelkraut; Knoll. wourz; Grundeicheln; Sand-Saulrod; falch Schweinbrod. Germ. Tuberous rooted Vetch, or Peas Earith Nut. Angl. Geffe tuberenfe; Veffe fauinge; Glands de wrie; Tareole; Tamottcs; Magulfans. Gall.

In agris inter fegetes linter dem brandzorwerke verfus Gonnequitz, et in iisdem locis verfus Scluönfeld et Taucluam etc. Fl. Iul. Aug. Perennis.

$V \int$. Herbam recentem exficcatamque pecora auide d-gुlutiunt; ouibus praecipue falutaris eft Legumina pro vicario pane et in iusculis coquendis adhiberi 
poffint. Radices a fuibus poft meffem diligenter exquiri folent. Tubera huius radicis in Germania inferiore, e.g. in Belgio et quoque in Tataria ab hominibus comeduntur et Solano tubcrofo ibidem fubfti. tuuntur. Radicis puluis cum melle mixtus et ab Apibus deglutitus, foporem ipfis excitare narratur.

pratenfis. $95 \%$. Lathyrus pedunculis multiforis, cirthis diphyllis, fimpliciffimis, foliis lanceolatis. LiNN. Syft. p. 663. ก. 16.

Lathyrus foliis binatis, capreolo non ramolo. bоeим. n. 337. Fl. Dan. t. 52\%. kern. B. II. p. 9I. t. I 16 .

Lathyrus pratenfis. Riv. Tetr. Irreg. t. 43 .

Wiejenkichern f. Platterbfe; Honig-Vogelwicke; Zuckerwicke; gelbo Zaunwicke; galbe Wicks; Wiefenzlatterbfe. Germ. Yellow Chichling Vetch, or Everlafing Taie. Angl. Geffe des près, ou Magjone Gall.

In pratis Schoonfeldicis, in Rofenthale, bei Kleindölzig; boi Lindcnhain; in dunetis ad Lindenau; Gomzlereitz et in fepibus vbique frequens. Fl. Iunio in Auguftum.

$V f$. Flores A pibus pergratum pabulum et in pratis praeftantiffimum pecoribus pabulum. Semina in annonae caritate inferuire poflunt menfis. Culturam huius commendauit SCHRE. III. p. 49.

fylueftris. 960. Lathyrus pedunculis multiforis, cirrhis diphyllis, foliolis enfiformibus, internodiis membranaceis. LIN⿴囗. Syft. p. 663. n. 17. Fl. Dant. t. 525.

Lathyrus fylueftris maior. C. B. P. p. 344.

Lathyrus fyluaticus. kiv. Tetr. Irreg. t. 39.

Waldkichcrn; Waldplatterbfe; Bublerkrant; Buhleierven. Germ. Narrou-leaved Everlafing Pea. Angi. Geffe fanvage. Gall.

In fyluis montofis, in Bicniz paffim mihi occurrit. FI. Iul. Aug. Perennis.

Vf. Herba ficea pabulum babus et ouibus haud ingratum. Semino Equis cibum exhibent bonum. 
96r. Lathyrus pedunculis cirrhis diphyllis, foliolis el- latifolius. lipticis, lanceolatis, internodiis membranaceis. LINN. Syft. p. 663, n. 18. BOEHN. n. 334.

Latlyyins narbonenfis. RIv. Tetr. t. 57 .

Ereitblittrige Kichern; große breitblïttrichte wilde Plattererljen; IVinterwicken; Wolffchoten; Efelsoh. von. Germ. Broad-leaved Everlafing Pea. Angl. $\mathbf{L a}$ grande Geffe; Geffe id feuilles larges. Gall.

In fyluis, im Univerfatï̈sholze; im Bieniz; in fepibus paffin. In hortis quoque frequenter occurrit. Fl. tota aeftate. Perennis.

Obf. Galli hane herbam laudant vt pabulum peco. ribus eximium.

962. * Lathyrus pedunculis multiforis, cirrhis poly-paluftris. phyllis, ftipulis lanceolatis. LIMN. Syft. pag. 663. $\mathrm{n}$. 20. LEYS. ก. 722. Fl. Dan. t. 399.

Lathyrus paluttris, flore Orobi nemorenfis verni. RVPP. Ien..p. 210 . T.I.

Clymenum. TOVRner. t. 218.

Sunpfinichera; Bruch-1. Wafferwicken; wohlriechende Waferweicke. Germ. Marfh Clizchling Vetch. Angl. Gefje des marais. Gall.

In nemoribus paludofis, in Gunindorfer; Grofs-et Kleindölziger; Sleuditzer Holze, et in pratis vliginofis 'bei Schadebach paffim reperi. Flor. Iunio. Iulio.

$V \int$. Flores ab Apibus frequenter inquiruntur. Herba pabulum pecoribus falutare.

347. VICIA. L. G. 947. Wicken. Germ. Vetch. Angl. Vefce. Gall.

* Pedunculis elongatis.

963. * Vicia pedunculis multifloris, petiolis polyphyl- pififormis. lis, foliolis ouatis: infimis feffilibus. IINN. Syft. p. 663. JACQ. Fl. Auftr. V. 4. t. 364.

Pifum fylueftre perenne. C. B. P. pag. 343 .

Cracca flore ochroleuco, RIV. Tetr. t. 52 . 
Erbfenartige Wicke; ungarifche Waldwicke; wilde Erb/e; Darmgichtkraut. Germ. Hungarian Wood Vetch. Angl..

In fyluis elatioribus, im Bieniz fed rarius et in agris cultis inter Pifa pafim. Flor. Iu!. Aug. An. nua.

dumetorum, 964. * Vicia pedunculis multifioris, foiloiis reflexis, ouatis, mucronatis, ftipulis fubdentatis. LINN. Syft. p. $66 \div$ n. 2 .

Vicia maxima dumetorum. C. B. P. p. 345 .

Cracca fyluatica. Riv. Tetr. t. 5 I.

IVlald-f. Heckreicke; große Bergwicke; thüringifche Iricke. Germ. Thuringian Vetch. Angl.

In fylutis montofis im Bieniz pauca fpecimina anno 1789. milhi primum occurrerunt; paffin quoque in agris cultis. Fl. Aeftate.

Obf. Planta magnitudine Pifi. Foliola oblongoouita. Flores purpurei. Stipulae paruae vtrinque acuminatae ferratae.

Craccar 967. Vicia pedinculis multifloris, florihus imbricatis, foliolis lanceoiatis, pubefcentibus, ftipulis integris. inn. Syft. p. 66i. n. 5. вовнм. n. 333. Fl. Dan.t. 80. KERN. B. I. p. 24. t. 23.

Vicia fyluefris śpicata. C. B. P p. $3+5$.

Cracca. Riv. Tetr, t. 49, optime.

Vogelevicke: Vogclheu; Kracke; Krock. Germ. Common Tufted Vetch. Angl. Cracca d'Europe. Gall.

In fyluis et dumetis, pratis aridioribus, im Rofere. thale copiole et in agris inter fegetes frequens. Fior. Iun. Iul. Semina maturat Aug. Septemb. Perennis radix.

Obf. In agris maxime luxuriat, in pratis parua euadit er hirfutior. Rad. fibrofae; caul. - gonus, fulcatus, fubramolus, in dumetis et frugibus erigitur er sitior crefcit.

Equia Serrinibus cito pinguefcunt. LINN. Amoen. Vol. V. p. 360. Boues et Oiles hene refpuunt, niti fame, coasti. Gunner. Semina nigra, cum fe:sle mixta, 
mixta, in annonae caritate panem exhibent haud innoxium. BOEHM.

966. * Vicia pedunculis multiforis, cirrhis polyphyllis; multifora. foliolis caulibus pubefcentibus, ftipulis lemifagittatis, integris, caule pilofis. LEYS. n. 725 .

Vicia multiflora pedunculis fub - 12 - foris, racemofis, foliis inferioribus ouatis, fupremis lanceo. latis, retuis, inferne pubefcentibus, ftipulis integris, filiquis 1 - fpermis. polıtch, Pal. II. p. $30 \% \cdot n$. 683.

Vicia multiflora. C. B..P. p. 34.3 .

Vielblütige Wicke. Germ. Vcfce multiflore. Gall.

In locis lyluaticis in Gonizewitzer Holze paffim, in Bieniz et in dumetis haud infrequens. Fl. Iun. Iul. Semina maturefcunt Aug: et Sept.

Obf. A priore enidenter difert: Pedunculienim ala. res pollicari longitudine circiter, nudi funt, port racentos vnilaterales gerunt, floribus racemo i2-I + - pendulis, imbriatis. Vexillum in hac integrum, in illa contra apice bilobatum; Carina in noftra scuminata, alarum longitudine, in priori obtu\{a. Siliquae breves, latiufculae, comprefise, i-loculares, fenen vnicum modo includentes; in Vicia Cracca contra femina 6-1ofiliquae fingulae continent. Sem. 'crafla fufca, prioris auten nigra.

** Floribus axillaribus, juojejjlibus.

96\%. Vicia leguminibus feffilibus, fúbbinatis', erectis: fatiua. foliolis omnibus fublanceolatis, retufis, emarginatis, fipulis dentatis, femiribus compreffs. LINN. Syft. p. 664. ก. I1. вогнм.п. 328. Rотн. Germ. I. pag. 3 I0.

Vicia. RIv. Tetr. p. 54.

Var, «) Vicia (fatiua) femine albo. I. EAVH. II. 34.

p. 344.

B) Vicia fatiua vulgaris femine nigro. C.B.P. nigra.

Futterwicken ; weiffe 1. fchwarze Futterwicken; wilde Wicken; Feldwicken; Korn-Roß. Saamuicke: 


\section{0

große . zueiblïnige Wicke; St. Chriftophskraut.Germ. Common.cultivated Vetch or Tare. Angl. Veffe cultivée; Veffe des pigcons. Gall.

In agris inter Auenam et Pifum haud infrequenter occurrunt: maxime autem a nofiratibus oeronomis in agris feruntur. Fl. Iun. Iul. 'Semina maturefcunt Iul, et Aug.

VS. Scmina pabulum Equorum conftitunnt vtilifimum: porro isclen delectantur Colunbi 'Iu',ior planta quoque ab Ouibus deuoratur. Farina Ieminum pani inleruire polfit annonae caritate.

suguftifolia. p68. Vicia leguminibus ferilibus fubbinatis, patentibus, foliolis imis retufis emarginatis: fuperiori us lincaribus apice integerrimis, ftipulis dentatis, feminibus globofis. вотн. Germ. I. p. 310.

Vicia filiquis feffilibus, erectis foliis imis, ountis, fuperioribus linearibus. Hall. Helvet. p. 5yъ. вовнм. n. 330 .

Vicia anguftifolia. R̀v. Tetr. t. 55 .

Schmalblâttrige Wickcn. Germ.

- In agris inter fegetes et pratis ficcioribus. Fl.Iun. Iul. Annua.

Haec a Limaeo ad praecedentem relata, a qua ta. men valde differt.

lepium. 969. Vicia leguminibus pedicellatis, fubquaternis, ereatis, foliolis outis integerrimis. LINN. Syf p. 66丸. n. 16. вовнм. n 33 I. Fl. Dan. t. 649. Kern. B. I. p. $31 \cdot$ t. 36

Vicia fepium, Riv. Tetr. t. 56. optime.

Zanmwicke; große Wicke: Domwicke. Germ. Englifh Hedge, or Bufh Vetch. Angl. Veffe des haî̀s. Gali.

In dumetis, ad fepes hortorum rufticanorum, in fyl is pratenfibus intra fruceta, copiofe. Flor. Mai. Iun. Perentis.

Obj. Flores pabulum Apibus eximium. 
970. Vicia caule erecto, petiolis absque cirrhis. Faba. LINN. Sylt. p. 665. n. 19. BOEHM. n. 335. BLACKW. t. 10 .

Var. «) Faba fore-candida, lituris nigris confpiCLO. TOVRNEF. p. $3411^{-}$

Faba niv. Tetr. t. 23. optime.

ß) Faba minor f. equina. C. B. P. p. 338. RIv. Tetr t. 24.

Pharin Fabae Flores, Semina.

Gemeine Gartcnbolne; a) große Bohne; Buffboh ne; großse Gartenbohne; Saubohne; röntifche Bohne; B) Klcine Bohne: Feldbohne, Roj-Lferdebohne; Futzerbohne; kleine teutfche Bohne. Germ. Broad B̈ean; х) Common Garden Bean; Black-bloffoned Bean; $\beta)$ Horfe-bean. Angl. Vefce Feve; Feve de Ma rais; a) Feve de lì gro, e éfpece; $\beta$ ) Petite Feverolle. Gall.

Habitat in Aegypto.

In sgris colirur e. g. verfus Guhlis, Lindenau, Sellcrluaufer, Stötteritz, et fere vbique; in hortis oleraceis pcaeprinis var $x$ ) occurrir. Fl. Iul. et Amg. Sem. marurat Aug. et Septembr.

Semins immatura communiter coquuntur in aqua et parantur cum butyro et petrofelino. In Suecia ficcantur bnec femina im natura que antea aqua feruida citiffime infinduntur atque in vfum hieraa= lem feruantur. Flores ab apibus frequentifime in. quiruntur.

348. * COLVTEA. L. G. 954. Blafenbaum. Germ. Bladder Senna. Angl. Baguenaudier. Gall.

971. * Colutea arborefcens, foliolis obcordato-oblon- hirtutt: gis, ftipulis lan eolatis, racemis hirfu is, leguninibus apice cliufis. Rотн. Germ. I. p. 305.

Colutea arboreficens. LiNN. Syft. pag. 658. SERT. Lipl. n. 16.

Colutea veficaria. C. B. P. p. 396.

Colutea. niv. retr. t. 20 .

Genciner Blafenbaum; baumartige Colutea; Blafent Senne; Schaftinfen. Germ. Commou Bladder Strina. C c Angt. 
Angl. Bagutenaudier en Arbre, ou à veffies; FauxSéné: Séré fartuagro. Gall.

Habitat in Auttria, Helvetia, Gallia, Italia etc.

Apud nos in hortis et in Serto nach den Weinwiintchen; porro verius C'ollegiun Rubrum et poft $E_{r}$ gaftuluni palfim. Porro in Horto Acadenico, Winkleriano, Trieriano, Löhriano aliisque frequens. Fl. Iun. - A ug. Arb. humilis,

orientalis. 972. * Colutea arborefcens, foliis obcordatis rotundatis fubcarnofis, ftipulis minimis denticularibus, racemiş glabris, leguminibus apice fuperne hiantibus. вотн. Germ. I. p. 305.

Colutca foliolis ouatis, integerrimis, caule fruticofo. Mirz. Diet. t. IOO.

Morgenl ändifcher Blafenbaum. Germ. Oriental Bladder Semna. Angl. Baguenaudier d'Orient. Gail.

Habitat in Anglia, G. Narbonenfi, Italia etc.

In locis indicatis cum antecedente frequentius reperitur. Fl. Aeflate. Frutex.

Ohf. 1. Rami minores, expanfi, frueticòfi. Flos ex flauo-rubefcens.

Olis. II. Folia ob Caffiae Senniae adfinitarem faepius huic admiferi folent a Pharmacopolis.

349. ROBINIA. L. G. 953 . Robinie. Gcrm. Robinia, or Falfe Acacia. Angl. Robinier. Gall.

Pfeudo- 973. Robinia racemis pedicellis vniforis, foliis impari* Acacia. pinnatis, ftipulis fpinofis. LINN. Syft. p. 668. n. I. BOEHM. n. 345 . SERT. Lipf. n. $8 \%$.

Pleudo-Acacia. RIv. Tetr. t. 63 .

Gemeine Robmie; Robinienbaum mit großen Blu3. mentrauben; falfcher Acacienlraun; amerikanifcher $\mathrm{f}$. virginifcher Schotendom; wohlriechender Heufchreckenbaum; Courbaril; Süßholzbaum.Germ. Common Baftard-Acacia, or Falle Acacia; White-floivering Robinia; Locuft-tree; Sweet fmelling Locuft. Anol. Robinier Faux Acacia; Faux Acacis; Acacia des Far. diniers; Arbre des Cabarets. Gall. 
In dumetix, fyluis paffim e. $g$. in dumetis poft pagum Stöttritz prope Hortum Weifianum; in Injula ad Groj:zxolkau: in Ambulacris circa Vrbem; in Horto Bofiano et in aliis frequens, Flor. Lunio. Arbor.

Arbor in oeconomia va'de vtilis et commendande eft, quia cito crefcit, animalibus cibum exhibet $+x i^{2}$ mium et lignum praebet vtile ad varia vtenfilia con. ficienda. E lemi ibus oleum in nonnullis regionibus exprimitur. Racemi penduli albi.

2) Stignate imberbi.

ж) Leguminibus snilocularibus, polyjpermis.

350. CICER. L. G. 949. Kichern f. Zifern, Germ. Chich - Peafe. Aiggl. Pois Chiche. Gall.

974. Cicer foliolis ferratis. LINN. Syft. p. 665 ,

Cicer fatiuum. C. B. P. p. $3+7$.

Cicer. R1V. Tetr. t. 19. bene.

Gemeine Kichern; Kichererbfen; Zifererbjen; Kaffeeerbfe; Hidderkopfformige Erbfe. Germ. Common Chich Peafe. Angl. Pois Chiche; Chiche de Bélier. Gall.

In agris inter fegetes et paffim hinc et illinc feritur Fl, aeftate.

Obf. In Hifpania et Italia frequenter coluntur et nomine Caravanzes f. Garavances ibidem in foro venduntur. Komanis olim pro cibo copiofe inferuirunt femina et hodie quoque apud Hifpanos adduntur faturae Olipodrigo iis appellatae. Semina torta Caffeas fuccedaneum bene fapidum, 


\section{GLASIS XVII.}

$35 \mathrm{I}$, CYTISVS. L. G. $05 \mathrm{I}$. Cytifus; Bohnenbaum; Griesfaude. Gorn. Cytifus, or Bafe Trefoiltree. Angl. Cítile. Gall.

Laburnum. 975. Cytifus racenis fimplicibus pendulis, foliolis ouato-oblongis. Livin. Syft. p. 666. n. I. вовнM.n. 325 . sert. Lipf. n. 29. JaCC: Fl. Auftr. Vol, 4. tab. 306.

Laburnum. riv. Tetr. t. 62.

Bohnenbatm; bieitllintrigir Bohnenbann 1. Bohserzifrauch; Baumbohnenftrauch; Alpencytifus; Alpenébenholz; falfcher Ebenkaum; falfches Ebenholz; Linfenbaum; $u$ elfche Linjcn; fpanifche IVeide. Germ. The Laburnum; Common broad-leaved Laburnum; Bean-irce. Angु. Cytife dies Aipes; Ebenierdes Alpes ì feuilles larges. Aubours. Goll.

In dumetis pamers. c. g. poft Siötteritz prope Horium Weifianum, in Serto frequens et in omnibus hortis fplendidis fuburbsnis copiofe occurrit. Fl. Iun. et Iul. Arbor magna.

Oirf. Calyc. 2-labiatus: labio inferiore 3- dentato, fuperiore duobus denticulis inftrueto. Legumina verfus balin refiexa.

Lignum aptum ad manubria conficienda. Flores frequenter quaerunt Apes. Semina inferuire poffunt pabulo pecorum.

352. LOTVS. L. G. 969. Schotenklee, Walzen-

kraut, Germ. Bird's-Foot Trefoil. Angl. Lotier. Gall.

* Leguminibus rarioribus, nec capitulum conftituentibus.

maritmuะ 9:6. * Lotus leguminibus folitariis membranaceoquadrangulis, foliis glabris, bracteis lanceolatis. Linn. Syft. pag. 690. J111N. 11. 15. Fl. Dan, tab. 800.

Mecrualzenkraut. Germ. 'Maritime Bird's-FootTrefoil. Angl. Loticr maritime, ou des mers. Gall. 
In foffis bei dchi fiiffen Wafferbonniez Graben ad Fuappondorf Cel Ializ ante paucos anros inuenit et ad Salinas Ketfchanicrijes anno 17 $13 \%$ quoque reperi. Fl. Iun. Iul. Perennis.

Ob. Diftinguirur a Iublequente: Leguminibus fere omnibus maioribus, foliis magis obtufis, alternis, glabris, laete virentibus; ramis fubhirfutis, caule rigidiore, angulofo.

977. Lotus leguminibus folitariis, membranaceo-qua-filiquofus. drangulis, caulibus procumbentibus foliis fubtus pubelcentilus. LrNe. Syft, p. 6;1. n. 2. вогнat. n. 342. J.ACe. Flor. Auftr. Vol. 4. t. $36 r$.

Lotus tetragonolobus. RIV. Tetr. t. 79.

Hïlfiger f. Wiefenfchotenklee. Gem. Procumbent Meadoze Bird's Foot Trefoil. Angl. Lotier ailé, ou it filiques. Gall.

In pratis bei den Bieniz, porro hinter Groß-et Kleindölzig, bci Kriphine auf dem Behonot, in pratis ad Lindenhain etc. Fl. Iun. Iul.

Ob. Pabulum pecoribus eximium et praeprimis boues vaccaeque hane herbam auide Jeuo. rant.

978. * Lous leguminibus folitariis membranaceo-tetragonoloquadrangulatis, bracteis ouatis. LiNn. Syft. pag.691. ก. 3 .

Lotus ruber filiqua angulofa. C. B. P. pag. $33=$.

Lotus tetragono!obus fiore rubro, RIV. Tetrap. tab. 80.

Spargelerile; viercckichter Schotenklee; Fiiggelerlie; englifice Erije; rother Steinklee, Gern. Square-podded Crimfon Pea; Ininged Pa Bird's Foot Tiefoil. Angl.

In Siciliac collibus proprie habitat. Apud nos in hortis et agris. oleraceis ob flores pulchros feritur; paffim tamen in reicttamentis hortorum quafi fpontanea prouenit, Flor. Iulio in Septembrem vsque. Annụa. 
Legumina inmatura in Anglia Phafeoli more prae. parantur eduntuique.

** Pedunculis multifororis in capitulum.

comicitatus 9\%9. Lotus cspitulis depreflis, caulibus decumbentibus, leguminibus cylindricis, patentibus. Lrin. Syft. p. 692. n. 16. военм. n. 343, schreb. Spicil. p. $27, \mathrm{n}$. 343 .

a) fyluati-
cus.

B) aruenfis

y) tenuifolius.

Var, a) Lotus maior caulibus-erectis.

1 Lotus 5 phyllos, flore maiore luteo fplendente, C. B. P. p. $3: 2$.

Lotus. RIv. Tetr. t. 76 .

B) Locus humilior, caulibus proftrntis.

C. B. P. p. 332 .

Lotus f. Melilotus 5- phyllos minor glahra, Spicil. 1. c. var.

Lotus - phyllos frutefcens, tenuifimis glabris foliis: C. B. P. p. $3: 2$.

Pharm. Loti Sylueftris Flores, Herba.

Gehörnter'Schotenklee; gelber Schoten'lee; galdenzer Klee; Hongklee; fünfblättrichter Klee; giildener Klee; Steinklee; wilder Klee; Hormevicke; gelbe Vo. gelweicke; Frauenfingerkraut; unferer lieben Frauenfchüllein; ß) kleiner Schotenklee; kleiner gelber Honigklee; kleiner geftreckter Hornklee; r fchmalbl ttriges gehörntes Walzenkraut, Germ. Common Englijh Bird's Font Trefoil. Angl: Lotier corniché; Lotier en corne; Trefle jaune. Gall.

In pratis vdis, fyluis, nemoribus et ad forfas fepesque vbique; $\beta$ ) in campeftribus, pratis ficcicribus, pafcuis, verfuris, limitibus, et viis publicis copiofe $; \gamma)$ in pratis. ad Salinas Ketfchauienfes et ad Knappendorf. Fl. Main ad Auguftum. Aug. et Seprembr. Senina maturat.

Obf. Corollae huius odorem fpargunt benc fuaueolentem. Color forum interdum magis aureus obiervatur Exficcati flores virefcunt, vti plantae coloram creruleuin f. Indigo praebentes. Likin. Suec. pag, \$64. 
Vf. Planta recens, vel ficca pabulum pecoribus fuavifimum et falutare. Flores ab Apibus frequentiffme inquiruntur.

353. * GALEGA. L. G. Fleckenkraut; Geilsraute: Germ. Goad's. Rue. Aingl.

980. *alega leguminibus ftrictis, ereatis, foliolis lan. ufficinalis. ceolatis ftriatis nudis. LiNN. Syft. p. 67.9.

Galega vulgaris. C. B. P. p. $35^{2}$.

Galega. RIV. Tetr. t. 72.

Pharm. Galegae Herba.

Geißraute; Pockenraute; Petechienkraut; gewölnn. liches Fleckenkraut; gemeiner Geisklee. Germ. Goat'so Rue of the Shops. Angl. Galega, ou la Rue de Chevre. Gall.

Habitat in Hifpania, Italia, Helvetia.

In noftratibus hortis frequenter occurrit. Fl. Aeftate. Perennis.

In febribus exanthemaicis laudatur herba et infufum Florum coinmendatur vt Anthelminticum prae. ftans. 354. ERVVM. L. G. 948. Linfe. Germ. Tare. Angl. Ers.
Gall.

981. Erunim pedunculis fubbifloris feminibus compref- Lens,

fis conuexis. LinN. Syft, pag. 665, вовнм. n. 326.

Fl. Dan. t. 95 .

Lens vulgaris. C. B. P. p. 346.

Lens, RIv. Tetr. t. 35 .

Var. $\beta$ ) Lens maior. C. B. P. I. c. RIv, Tetrap. tab. 35.

Pharm. Lentivin Semina.

Gemcine Linje; $\beta$ ) Pfenniglinge; franzöfifclize LinSe; große Gartenlinje. Germ. Common. Lentil; $\beta$ ) French Lentil. Angl. Ers ou Lcwtille cultivęe; $\beta$ ). Grande Lentille. Gall.

In agris inter fegetes paflim; praecipue aptem in pagis colitur. Fl. Iun. Iul. Annụa. 
Vf. Semina efculenta, minus nutrientis, difficilius digerenda. Semiria cun Hordeo mixta, peracta termentatione et deftillatione, fpirituin- dant fragran. ten fortemque. Semina pabulum Equis optimum.

wnape- 982. Emman pedunculis fubbifloris, feminibus ginbofis 12uin, quaternis. LINN. Syft. p. 66\%. n. 2. schreb. Spicil. p. 26. n. 937 - (fub Vicia) Fl. Dan. t. 95.

Cracea minor filiquis gemellis. RIv. Tetrap. tab. 53 .

Vievfânige Linfe; glartfchotige Wiclie; Heine glatte Feldwicke; Kleine Linfenwicke; Klene glatie Vogelweicke. Germ Smooth Tare. Angi. Ers, ou Lentille teirafierme. Gall.

In agris er oleraceis cultis vbique. Flor: Iun. Iul. Anกua.

Vf. Plenta recens et ficca gratum exhibet omnibus fere pecudibus pabulum.

hirfutum. 983. Erumm pedunculis multiforis, feminibus globnfis, binis. LINN. Syft. p. 665 . n. 3. вовнM. n. 33 4. (fub Vicia).

Cracca minor. Riv. Tetr. t. 35 .

Rauhe f. Ateiflorflige Linjenwicke; wilde Linfe; zottige Linfe; kleine Vogelwreke; kleme rauhe Feldwiche. Germ. Hairy Tare. Angl. Ers velu. Gall.

In agris inter fegetes fere vbique. Flor. Iun. Iul. Annua.

Planta viridis quoque pabulum pecudum haud ing fimum.

foloniene. 984 . Eraum pedunculis fubbifforis ariftatis, petiolis acuminatis, toliolis obtufis. LINN. Syft. p. $665.11,4$. ВоЕнм. ก. 332 .

Vicia minima Rry. Tetr. to 55 .

Franzöfifche Linfe; Solognifche Linfe-; Frühlingso wicke. Germ. Spring Tarc. Angl.

In apricis ficcioribus, árenofis et in ericetis, auf dem Gickerlingsherge und Mcckerfchen Anger Ce!. DOEHMERYs olim copiofe reperit: ego quoque in agris 
arenofis inter fegetes verfus Gohlis, Eutritfch, Gonstewitz et Schönfeld hinc et illinc vidi. Fl. Mai. Iun. Annua.

Olj. Pabulum pecudibus haud ingratum. Semina Columbis cibus.

98.5. * Emmm pedunculis vniforis folio is intcgerrimis, monanthos. fipulis alternis dentatis. LinN. Hort. Tf́p. pag. 219. n. 7. (iub Vicia) tiusd. Syst. p. 665. n. 5.

Einblunige Linfe. Germ. Oneflowered Lentil. Angl. In agris inter Lentem et Viciun fatiuam paffin. Fl. Iul. Aug. Annua.

Obj. Lente vulgari maior, Cirrhis $2-3-$ fidis fcandens. Foliola $18-20$ - linearia obtufiora. Calyces corolln longe breuiores. Stipulae 2. alternatim maiores, varie figuratae. Pedúnculus - I - forus. Cor. Vexillum compreftum, albidum, friis ex albidoviolaceis piatum. Legum : magnum fubnutans, 2-3fpermum. Sem. comprefla, margine obtufo, nec acuto vti Lentis, magnitudine pifi, alba.

986. * Ermun: germinibus nudato-plicatis, foliis impa- Eruilia. ri pinnatis. Lisn. Syft. p. 665. n. 6.

Eruuru leguminibus pendulis. Hort. Cliff. $37^{\circ}$. İsLl. Helvet. p. 602.

Pharm. Erui Semina." Orobi' Farina.

Eruen; gemeine Erven. Germ. Articulated Eruum, or Bitter Vetch. Angl. Erville d'Orient. Gall.

Proprie habitat in Fallia, Italia, Oriente. In agris inter Legumina fparfin occurrit. Flor. Iunio. Annua.

Obf. Planta ere ta, non fcandens, cirrhis deftitu. ta. Stipul. ouatae; dentatae. Foliola 16-24, lineari-oblonga, obtufa. Petiolus in mucronem terminans. Pedunc. 2-3-florus. Cal. corolla du. plo breuior, dentibus fubaequalibus. Legutil. pendula, $3-4-$ fperma, articulis nodofis intertin Sçn. tubanguloda.

$V \int$. Farina Seminum in nonnullis regionibus infera vit pro fane, quem noxium habent nonnulli. 
355. TRIFOLIVM. L. G. 968. Klee, Germ. Trefoil. Angl. Trefle. Gall.

* Meliloti: Leguminibus uadis, polyfpermis.

Melilotus 987. Trifolizm leguminibus racemofis, nudis difperofticiralıs mis, rugofis, acutis, caule erecto. LiNN. Syft. p.68I.

n. 5. BOEHM. n. 3 I 4 .

Melilotus. Riv. Tetr, t. 6.

Var. a) Melilotus flore luteo, valde odorato. BLACKW, t. 80. f. I.

fig. 2.

B) Mclilotus flore pallido. BLACKw. tab. 80.

Pharm. Meliloti Citrini Flores, Semina.

B) Albi Ilores, Herba.

Gebrïuchlicher Melilotenklee; Stcinklee; teutfcher Steinklec f. Honigklee; Bärklee; gemsiner teut fcher gelber f. weiffer Klee; unfér lieben Frauenfchüchlein. Germ. Common Melilot Trefoil; $\alpha$ et $\beta$ ) Yellow or White-flowered Melilot Trefoil. Angl. Trefle Melilor des bousiques; a et $\beta$ ) Saxifrage jaune, ou blanche. Gali.

In agris et aruis paffim, in pratis, locis limofis in der Leimgrube copiofe; in nemoribus e. g. im Rofenthale, in pafcuis et arenofis frequess; $\beta$ ) in pafcuis poft pagum Wahien et verfus Sckeuditz etc. Fl. Iun. et Iul. Semina maturat Aug. et Sept.

$V \int$. Planta fuaueolens pellit Acoros. Planta emolliens et refoluens, vteri et veficae vitiis dicata. LINN. Vnguentum c floribus et butyro paratum in lippitudine olim commendatum eft. Locis in campeftribus pabulum praebet eximium. Si herba ficca veftimentis interponitur, pellit tineas et fi in lecto difpergitur, cimices.

Melilotus 988. Trifolium fpicis oblongis, leguminibus feminusacrife, dis mucronatis, caule erecto. LiNN. Syft. pag. $687^{\circ}$ ก. 1 .

Lotus hortenfis odorata. C. B. P. p. 33 I. Melilonis caerulea. kiv. Tetr. t. 9. 
Wohlriechender Klee; wohlriechender Steinklee; sahmer Steinklee; Gartcnklee; Siebengezeir; Siebentzett; Schabzunkraut; Schabzüger; Schabzïgerkraut; IVetterkraut; Stundenkraut. Germ. Greater jweet fented Melilot; Sweet Trefoil. Ingi. Trefie Mélilot bleu; Treflé odorant; Trefle musqué; Lotier odorant des jardins. Gall.

In Bohoemia et I.ybia fponte crefcit.

In hortis copiofe occurrit et ibidem quali fpontanea facta eft; in ruderatis et reiezamentis paffim. Fl. Iun Til. Annus.

Folia et Flores caerulei fortem penetrantemque Spargunt odorem. Herba viridis cafeis Schabziger dictis immilcetur ab Helueticis. Flores frequenter quaerunt Apes.

989. * Trifolium leguminibus racemofis, nudis, difper- Melibrus mis, rugofis, obtufis, caule erecto, foliolis integris, italica. LINN. Syft. p. 687 . n. 7 .

Melilotus Italica, folliculis rotundis. C. B. P. pag. $33 \mathrm{r}$.

Melilotus Italica. RIV. Tetr. t. 7 .

Iralienifcher Klee. Germ. Trefle Mélilot d'Italie. Gall.

In Italia habitat.

In hortis noftratibus valde frequenter ac fpontanea occurrit. Fl. Aeftate. Annus.

$V \int$. Flares Tunt pabulum Apibus egregium et haec fpecies onnium Melilotorum praeftantifimum pecoribus proebet pabulum: dehinc copiofius coli meretur.

** Lotoidea: Leguninibus teहtis, polyjpermis.

990. Trifolium capitulis vmbellaribus, leguminibus hybriaum, tetra!permis, caule adfcendente. LINN. Sylt. p. 687 .

D. 12. SCHreB. Spicil. p. 24. n. 936 .

Trifolium flore albo. Riv. Tetr. t. II.

Trifolium orientale altifimum, caule fiftulofo, flo: te albo, vails, Parif. 195. t. 22. f. 5. 
Baftardklee; weiffer hochwachfender Honigklee; weiffer IViefenklee. Germ. Tall Clower. AngI. Trefle hybricle. Gall.

In pratis copiofe et pafcuis e. g. bei dem Brandvorverke et in agris cultis inter Trifolium pratenfeVrbi vicinis frequens. Flor, Iun. Iul. Annua vel Biennis.

repens. 991. Trifolizm capitulis vmbellaribus, leguminibus tetrafpermis, caule repente. LiNN. Sylt. p. 688. n. I3. LOEIIM. n. 320.

Trifolium repens. RIV. Tetr. t. I3. b.

Pharm. Trifolii Albi Flores.

Weiffer Klce; weiffer kriechender Honigklee; Bienenklce; zeciffer Foldklee; zeeiffe Flcifchblume. Germ. White Merdone Trefoil, or Dusch Clover Crecping Trefoil. Angl. Trefle rampant, ou blanc; Triotet. Gall.

In pratis et paícuis ficcioribus et ad femitas vbique frequentifime. Flor. Iun.-Aug. Perennis.

$V \int$. Hrec et prior pabula pecoribus valde eximia. In Islandia caules huius herbae maiores lacti incoquuntur, vel crudi cum butyro et pane comeduntur. Olaffen. *

*** Lagopoda: Calycibus villofis,

rubens. 992.* Trifolitm fpicis villofis longis, corollis monopetalis, caule eręto, foliis ferrulatis. LINN. Syıt.pag. 688. n. 20. JACQ. Fl. Auft. Vol. 4. t. 385.

Trifolium montanum, fpica longifima rubente, C.

B. P. p. 328 .

Großer Bcrggeisklee; röthlichter großer Klee; grof- fer Hafenklce. Germ. Greater Red Trefoil. Angl. Treo fle rougêatre. Gall.

In agris inter legetes et pratis cum Trifol. Sociis inmixtum frequenter occurrit. Flor, Iun. Iul. Perennis.

Obf. Dentes calycis infimi longitudine corollac.

*) Reife durch Island. B. II. p. 206. 
VJ. Haec fpecies omnium equis et pecucibus pabulum delicatifinum et Flores pracprimis ab Apibus inquiruntur.

993. Trifolium fpicis, globofis, fubuillofis, cinctis: pratenfe. ffipulis oppofitis membranaceis: corollis monopetalis. LINN. Syft. p. 688. n. 2 I. BOEHM. n, 31 7. BLACKW. tab. 20 .

Trifolium. RIV. Tetr. t. I I.

Wiefenklee; gemeiner Klee; brauner Wiefenklee; rotker Wiefcrklee; Jpanifcher f. türkifcher Klee; Kiebor f. Klever; Dreiblatt; Himmelsbrodt. Germ. Common purple Meadow Trefoil; Honeyfuckle Trefoil; Ficld Hone?yuckle. Angl. Trejle, on Triolet des près. Gall.

In pratis non rarius et contra faepius in agris colitur. Fl. Iun. in Septembrem vsque. Triennis.

Vf. Pabulum pecoribus faluberrimum. Flosculis ficcatis et in frinam redactis Scoti, necefiniate coacti, pro pane Chambrock (Stampforodt) dizto, vtuntur. Florum capitula viridi tingunt colore veftimenta lanea, quibus Scani frequenter inferuire folent. LiNn. Flor. Scand. $27 \%$.

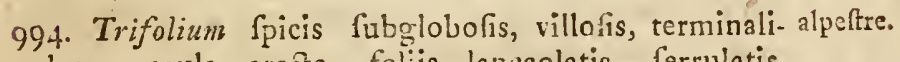
bus; caule erecto, foliis lanceolatis, ferrulatis. LINN. Syft. p. 688. n. 22. BoEIim. n. 318. Fl. Dan. t. 662. JACQ. Fi. Auftr. Vol. 5. t. 433 . Eiusd. Obf. Bott. I. III. p. It. t. $6 \%$.

Trifolium folio longó flore purpureo. RIV. Tetrap. tab. 12.

Alpenklee; großer brauner Klee; purpurfarbiger Bergklee. Germ. Sweedifh Trefoil. Ang. Trefle alpin. Gall.

In fyluis montofis gramineisque elatioribus, im Bieniz frequens; ini Sommerfelder-Macherfchen - Gras. felder Holze paffim. Fl. Iun. Iul. Perennis.

obf. Capitulis 2, terminalibus, ftipulis viridibus, vltimis 'vtrinque lanceolatis, a priori dintinguitur. Villofi Calycis denticuli 4 funt breues, quintus inferior prioribus longior. Corollae cólor ex purpureo 
in rubenten vergens. Legumen leniter compreffum et 1 - fpermum. Ill. JacQvinvs ab hac fpecie Trifolium flexuofum fuum in Flor. Auftr. T. 386 . ob caulem flexuoftum feparat.

a:Lenfe 995. Trifoliun fpicis villofis oualibus, dentibus calycinis fetaceis, villofis, aequalibugs. LINN. Syft.p. , n. 42. BOEHM. n. 321. BLACKW. tab. 450 . Fl. Dan. tab. 724 .

Lagopus. Riv. Tetr. t. 15.

Pharm. Lagopi Flores.

Ackcrklee; Katzenlelee; Hafenklee; Kätzelkraut; Iiafenkraut; Hafenpfötchen; Mützchen. Geru. Harés Foat Trefoil. Angl. Trefle des champs; Pied ou Pat. te de Liévre. Gail.

In agris, aruis, montofis et pafcuis fterilioribus vique copiofe. Fl. Maio-A - Lig A nua.

Obf. Plantam florentem coriis par ndi aptam obfervauit b. Gleditfchius. Semina farinae imuixta panem ex rufo-rubente imbuunt colore.

\section{**** Veficaria; Calycibus inflatis ventricofis.}

fragiferun, 996. Trifolizm fpicis fubrotundis, calycibus infatis bidentatis reflexis, caule repente. LINN. Syft. p. 690. ก. :4. BGE HM. n. 315 .

Trifolium fragiferum folio oblongo. valle. Paril. t. 22. f. $\therefore$.

Erdbeerklee. Germ. Strawberry Trefoil. Angl. Tre. fle à fraifes. Gall.

In pratis, pafcuis pinguioribus, in der Leingrube, bei Klcindiolzig, Rückmarsdorf, Ketfclau, Linden. hain, Kriphäne, in locis aridioribus e. g. bei Sckeudetz et Stahmelv etc. Fl. Iun. Aug. Annua.

Obj. Caul. procumbentes, articulati, ex roiundato - compreffi, glabri.- Fol, alterna, vaginantia, ternata. Foliolis-orbiculato-ouatic, obtufis, ferrulatis, gl:bris, - Pedunculi longi, ereßti, teretes, glabri, florein capitatum, futrotundum, nudum, .gerentes. Cal. trintilofus, portice villofus, antice glaber $5-$ dentatus: denticulis 2 fuperioribus paulo longiori- 
bus, 3 inferioribus breuioribus. Cor. Vexillum obtufum, erectum, limbo emarginato inflexo. Alae obtufae vexillo breuiores. Carina alis breuior. Silicula fubrotunda, glabra, flauefcens, I- locularis, fuperiora verfus longitudinaliter dehifcens, femen I, paruum, fere orbiculatùm, inferne emargina. tum, glabrum includens.

**** Lupulina; Vexillis corollae infexis.

997. Trifolium fpicis fubimbricatis, fubtrifidis, vexil- montanum.

lis fubulatis emarcefcentibus, calyculis nudis, caule erecto. LinN. Syft. pag. 690. n. 40. вовнм. n. 319.

Trifolium folio longiore, flore albo. RIv. Tetrap. tab. I2.

Bergklee; weiffer Bergklee; Spitzklee; weiffer fpitz blättrichter Bergklee. Germ. White Meadoze Trefoil. Angl. Trefle des montagnes. Gall.

In fyluis et locis montofis tenuiori gramine veftitis, in Bieniz, in dens Hegegrafe bei Kriphane, in Nötzfcher-Macherfchen-Grasfelder-Holze, in Vinetis dictis poft Taucham et ibidem anf dem Minneberge, auf den Gonnewitzer Schanzen etc. Flor. Iun. - Aug. Perennis.

$V \int$. In collibus ficcis pabulum pecoribus eft gratum.

998. Trifolium fpicis oualibus, imbricatis; vexillis de- agrarium.

flexis perfiftentibus, calycibus fubpubefcentibus, ftipulis cordatis, ciliatis, foliolo impari petiolato, cau? le diffufo. polt. Palat. Tom. II. p. 342. n. 707 .

Trifolium agrarium fpicis oualibus, imbricatis, vexillis deprefifis perfiftentibus, calycibus nudis, caule erecto. Linn. Syft. pag. 690. n. 4I. вовнм. n. 316. Fl. Dan. t. 5.58 .

Gelber Klee; gelber Katzenklee; großer Hopfenklee; unfer lieben Frausenhopfen. Germ. Hop Trefoil. Angl. Trefle houblonné, ou jaune. Gall.

In agris cultis, copiofe hinter den Kohlgärten nacia Schönfeld $z u$; porro in iisdem locis verfus Stötteritz 
et nach den. Straffenhäuforn und den Gejundbrunnen $z z$; porro in pratis ficcioribus et locis elatioribus arenofisque in der Sandgrube und anf den Sandbergen bei Nauendorf et Rückmarsdorf ctc. Flor. Iun. Iul. Annua.

Ohf. Caul. ereßtufculi, teretes, villof, folitrii. Folia alterna, ternata, foliolis ouatis, obtufis, cilio exiguo terminatis, ftrintis, glabris, verfus apicemle. viter ferrulatis. Stip. ouatae, margine cilistae, reAlexae. Pcdunc. alares, teretiusculi, valde breues. Cal. irrcgulariter 5 - dentatus; denticulis 2 fuper:oribus breuillimis, inferioribus longioribus et villolis, fulcatus. Cor, flava.

$V J$. Pabulum praeprimis ouibus eximitum.

Spadiceum. 999. * Trifolium fpicis oualibus, imbricatis: vexiliis deflexis perfiftentibus; calycibus pilofis; caule erecto. LinN. Syrt. p. 690 . n. 42.

Trifolium montanum lupulinum. C. B. P. pag. 328.

Lupulinum montanum, capitulis fpadiceis. RVPP, Ienenf. p. $207^{\circ}$

Kaftanienbrauner Klee; Schwarabranner Hoṕfenllee. Germ. Trefle paille. Gall.

In pratis montofis, ficcioribusque et in agris ela. tioribus arenofisçue cnm praecedente intermixtum paffim occurrit. Fl. Iun. Iul. Innua

Obf. A priori differt: Caulc magis erecto, folitario: Capitulo ante forefcentiaín villofo: Corolla ferruginea, nec faúa.

procumbens 1000. Trifolinm fpicis oualibus imbricatis, vexillis de. flexis, perfiftentibus, oualibus procumbentibus. s.inN. Sy凡t. p. 090. n. 43. schrez. Spicil. pag. 25. n. 937. Fl. Dant. t. $7 \% 6$.

Niedergeftreckter Klce; gelber Feldklce; lieiner 1 Ho. nigklee. Germ. Trefle conciué. Gall.

In pratis, folo fterili inundato et pafcuis im Oberholze, in der Bürgerauc, ant den it iefen bei Leutfch, Gunndorf, Ehrenberg, in elatioribus, auf dem Bienizezc. Fl. Iun. Iul, 
Olf. tb Agrario differt. Capitulis forum minoribus pauciforis, vexillis snguntioribus, nridis, pallidioribus, minus manifefte itriatis, nec plicatis, eirca frułtum magis conuolutis (et caulibus longis pluribus procumbentibus, paffin vnico ereeto schreb.

I001. Trifolum fpicis fubimbricatis, vexillis defexis filifomc. perfiftentibus, calycilus pedicel!aris, caulibus fiiformibus, pubefcentibus, procumbéntibus. LiNn. Syft.

p. WO. n. 44. L.EYS. n. "45 JAHN. II. I 4.

Trifolium lupulinum minimum. Ra1. Angl. 3. p. 331. t. 14. f. 4. Hall, Opufe. p. 87. etc.

Trifolium luteum, lupulinum minimum. вухв. Hal. p. 325 .

Fadenfürmiger Klee r. ganz kleiner Hopfenklce. Germ. Smal Trefoil. Angl. Trefle filiforme. Gall.

In pratis et pafcuis montofis im Breniz pafim. Fl. Iun. Aug.

Obf. Diftinguitur a praecedenti : Habitu minori, ramis filiformibus, procumbentibus, peduncuos vix capillo aut feta equina craffiores gerentibus; pedun. culis foliis longioribus: Floribus $3-5$, in tatis tepe $12-15$, deflexis: Calycibus $f$ uRum firentibus infidentibus manifeftis et diftinctis pedicellis: foliis emarginatis ftriatisque.

\section{ß) Leguminibus fubbilocularibus.}

35\%. ASTRAGALVS. L. G. 965. Tragant. Germ. Wild Liquorice, or Milkwort. Angl. Aftragale, Adragant, Lall.

1002. * Aftragaltzs caulefcens proftratus, leguminibus Cicer. fubglobofis, inflatis, mucronatis, pilofis. LIN S. Syft. p. 6\$2. n. 13. X.EYS. n. 73ก. JAHN. n. I2. JACQ. Fl. Auftr. Vol, 3. t. 251. KERN. B. I. p. 21, t. I9.

Glaux. RIV. Tetr. t. 108.

Kicher-Tragant; gelber öfterreichifcher Tragant; weilde Kichern. Germ. Yellow jpicked Milk-Vetchlo, Angl, Aftragale à veffies: Gall. 


\section{CLASSIS XVII.}

In locis montofis ad Scopam Cel. Iahu ante paucos annos inuenit, porro quoque im Bicniz, feitreârts Taucla nach der Bahomiilzle in locis elatioribus arenofisque; poft Taucham auf dem Minneberge paftim reperi. Flor. Iun. iul. Perennis.

Obj. Radix longis fibrilluiis in terra repit.

Glycyphyl- roo3. Afragalies cauleícens, proftratus, leguminibus los. fubriquetris arcuatis, foliolis ouslibus, pedunculo longioribus. LIN2. Syft. pag. 6S2, n. I5. BOEHM. n. 350 .

Afragalus. Riv. Tetr. t, 103 .

Pharol. Aftragali Radix.

Süßsholzuiñtriger Tragant; wildes Sïßholz; wild Bockshorn; Chriftianswurzel; Gliedenweich. Germ. Engiifh Wilk-Vetch; Wild Liquorice. Angl. Aftragale régliffier; Régli|le fauvage. Gall.

In pratis et fyluis montofis, im Bieniz, auf den Gonnezeitzer Schanzen et alibi, pafim in hortis. Fl. Iun. Iul. Perennis.

Vf. Herba huius et prioris pabula pecoribus dulcia et Alores $a b$ apibus inquiruntur.

atenarius, roo4. Afralagus caulefcens, ramofus, erectus, tomentofo-albus, foliolis coniplicatis, pedunculis fubquadrifioris. wilden. Prodr. Berol. n. 724 .

Afragalus arenarius. IINN. Syft. pag. $683 \cdot$ n. 28. gañ. n. 13. Fl. Dont. t. 6:4.

Aftragalus incanus paruus noftras. Rar. Angl. 3.p. 326. t. 12. f. 3 .

Sand-Tragant. Germ. Mounzain, or Snall hairy purple Milkwort. Angl. Afragale fablonicre. Gall.

In locis apricis, arenofis ad Scopam frequenter Cel. JAH: annis praeteritis reperit. Flor, Iun. Iul. Annua.

357. GLYCINE. L. G. 942. Glycine. Germ. KidneyBean-Tree. Angl.

Apios. 1005. * Glycine foliis impari pinnatis, ouato-lanceolatis, foliolis feptenis. LINN. Synt. p. $66 \mathrm{I}$. 
Giycine radice tuberofa. Hort. Cliff. $3^{6} 5$. Grow. Virg. $10^{\circ}$.

A pios americana. conN. Canad. 200. t. 201 . KIV. Tetr. t. 102. stiss. Bott 29. t. 29.

Anerikanifche Erdnuj; amerikanifche f. Ateigendo Canadifche Knollivicke; Walderven mit knolligter II ural; Süjhholzwicke. Germ. Weft Indian reild Li. quorice; Knobbed rooted Liguorice-Vetch́; Hopnis; Apios. Angl.

Habirat in Virginia, Canada. In noftratibus hortis e. $\mathrm{g}$. in Hnrto Wmklerinno; in plurimis priuatis; in den Kuchengarten atque in rufticorum hortis palfim. Fi. Augult. Sept. Perennis.

Obf. Plantafeandens, volubilis, obfuos flores pul. chros ornat hortos.

$V \int$. Radices quoad faporem cum Cynara conuenientes paris IncoAmericanis inleruiunt, er Sem na quoque ibidem Piforum more coquuntur comedunturque. Flo. res frequenter quaerunt Apes.

\section{8) Leguminibus articulatis.}

35\%. HEDYS IRV.M. L. G. 96:. Hsilhnenkopf, Schiidkıaut, Süfsklee. Germ Saintfuin. Angl. Saint - foin. Gall.

I006. * Hedvgarum foliis pinnatis, leguminibus articu- coronarium. latis, aculearis, nudis, re itis, caule diffufo. LiN. Syft. p. 67 . n. 54 .

Onobrychis, fernine clypeato afpero, maior. C. B. P. p. 350 .

Sülla; Hahnenkopof; Peltschen; Schildkraut Germ. Common French Honeyfuckle. Angl. Sainfoin d'Ejpagne, Sainfoin à bouquets. Gall.

In Hifpaniae et ltaliae pratis hahitat. Apud nos in hortis fuburbanis et rufticanis valde frequenter veperitur et ab hortulanis foro copiofe venditur. Flor. Aeftate. Perennis.

In Italia pro pabulo pecorum nomine Sulla feritur. 
Orobrychis. 100\%. Hedyfartum folis pinnatis, leguminibus monofpermis alternis, aculeatis, corollarum alis ealycem aequantibus, caule elongato. Linn. Syft. pag. 676 . n. 6I. вовнм. п. 894 JAcC. Fl. Auftr. Vol. 1. t. 38. KERN. B. I. p, ArI. t. 4 .

Onobrychis. niv. Tet". t. 2.

Hahnemkantichen; zahmer Haluncnkopf; türkifcher Klce; Wiedehopfonkraut ; Heiligheu; Stachelshre; das genleine und falfche Saint-Foin; Esparaette. Ferm. Commons Si. Foin, or Efparcette Cocks-Head. Angl. Sainfoin ordinaive; Ejparcoite on Dautphins. Gall.

In campis et locis accliuicribus paffim, in pratis contra frequentius, e. g. Feitwearts poft pagum Altranfaadt, bei Ketfchan prope Machinas Gradatorias; in pratisad Lindeuhain; Wolkau; Friphäne et Zfchepline etc. et quoque in pratorum hortis $v_{0} c$. in Horto Lochriano etc. Flor. Maio - Iul. Annua.

Vf. Pabulum equis iumentisque delicatifimum atque optimum.

359. CORONILLA. L. G. 956. Kronenwicke; Peltfchen. Germ. Jointed Podded Colutea. Angl. Coronille. Gall.。

Emerus. 1008. * Coronilla fruticofa, peduncuiis fubtriforis, co. rollarum vnguibus: calyce triplo longioribus, caute angulato. LiNs. Syft." pag. 669. Eiusd. Fl. Suec, pag. 248.

Coronilla máaior ${ }^{4}$ Riv. Tetr t. 95 .

Skarpionspeltfchen. Germ. Brood-leaved ScorpionSena. Angl. Coroniile pauciflore; Emercs; Séné Baftard; Securidaca ou Baguenaudier des Fardinicrs. 'Gall.

Habitat in Europae auftralis fepibus et fyluis.

Apud nos in Infula ante Hortum ad Croßreölkan:

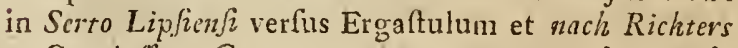
et Curziuffens Garten zu; porro quoque in Hortis fuburbanis fplendidis et alibi valde frequens. Flor. exeanje Vere atque in Autumnum vsque. Frut. 
Obf. Ob fuos fores eleganter luteos, quos fere per 5 menfes fert, fruticeta ornat. Foliajvi purgandi gaudentia pabulum pecoribus falutare.

1009. Coronilla hcrbacea, leguminibus ereŝis; tereti- vatia.

bus; torolis, numerofis, foliolis plurimis, glabris. Iris. Syft. p. 6\%०. n. 9 .

Coronilla, herbacea filiquis articulatis, pendulis flore funuerubente. BoenM. n. 345. KerN. B. I. p. 20. tab. $1 \%$.

Coronilla flore vario. RIv. Tetr t. 94.

Euate Pelffchcu 1. Kronenzeicke; Peltfchonkraut; pourpurbraune Peltfchen; falfches Saintfoin; Vogelevicke; Beilkraut; Schafinfern. Germ. Veritable-flowered Coronilla. Angl. Coronille bigaré ; Fancile. Gall.

In fepibus, dumetis, pratis: e. g. ad Lindenhain in fepulcreto ad Altranftädt; in locis montofis int Bieniz ctc. Fl. Iun. Aug. Annua.

Obf. I. Foliola in petiolo communi infima cauli, vti ftipulae, approximata faepius funt, ficuti in C.coronata aut minima. Canl. proftrati. Peduncul. longitudine foliorum. Murr.

Olf. Il. Galli hane plantam loudant pabulum pecoribus cximium; alii contra narrant hanc non tangere pecora.

359. ORNITHOPVS. L. G. $957^{\circ}$ Vogelfufs. Germ. Dird's - Foat. Angl. Pied d'Oifeau. Gall.

Iо1о. Ornithopus foliis pinnatis, "bractea pinnata, legu- perpufilus. minibus incurtatis. uns. Syft. p. $6 \% 0$.

Ornithopodium foliis pinnatis, vngue filiquae brevi, flore albeftente. вовим. n. 347 . 'Fl. Dain, tab. 730.

Ornithopodium minus. C. B. P. p. 350.

Var. a) Ornirhopodium maius. - ) Ornithopodium radice tuber-) C. B.P. I. c.
culis nodofa.

Winziger Vogelfuß ; kleine Vogelpfote. Germ. Common Bird's Foat. Angit. Petit Pieid d'Oifean. Gall. Dd 3 
In locis arenofis, montofis ïn Bieniz, auf den

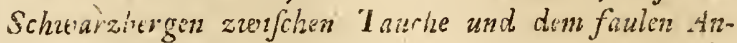
ger, poft Tauchan auf dom Minncberge et ibidem in Vinetis diatis; porro quoque in armis ficcioribusque ad viam verfus Schönfclid, poft pagum Kriphäne ett. vulgaris. Fi. Iun. Aug:

36r. * HIPPOCREPIS. L. G. 958. Hufeifen. Germ. - Horfe-Shoe Vetch. Angl Fer à Cheval, Gall.

comola. rolr. * Hippocrepir leguminibus pedunculatis confer. tis arcuatis; margine exteriore repandis. LINN. Syft. p. $\operatorname{ci}, \mathrm{n} 3$.

Frrum equinim germanicum, filiquis in fummitate. C. B. P p. 246 .

Ferrum quinum comofum. Riv. Tetr. t. 97.

Zopfiges Hufcifen. Germ. Liqurrice Hatchet-Vetch, or Tufted Horje-Shoe-Vetch. Angl. Fer-ì. Cheual vivace, ou en tête. Gall.

In locis montofis im Bieniz nonnulla fpecimina nuper reperi; in montibus autem iuxta Weifjenfels co. piofe crefcit. Fl. Mai. Iun.

362. MEDJCAGO. L. G. 958. Schneckenkraut,

Schreckenklee. Germ. Medick. Angl. Lufer. ne, Gall.

* Floribus fpicatis: Caule facpius erefto, absque ftipulis. \{atiug. Jor2. * Medicago pedunculis 'racemofis, Irguminibus contortis, caule erecto, glabro. LINN. Syft. p. 693.n. 8. LEYS. ก. 75 I. JAHN. n. 16.

Zahne Luzerne f. Schneckenklee; blaucr Schneckenklce; Lucernenklee; Spargel f. ewiger Klee; Hörnerklee; burgundifches Heu; heiliges Heu. Germ.

In locis latioribus et arenofis paffim in collibus circa Vrbem, in der Allee, in der Sandgrube, in Bieiz, frequentius autem in agris colitur. Fl. Iun. Iul. Perennis.

Obf. Pabulum pecorum notifimum er prae. ftantifimum. Solum amat it ile, vbi longas agit radices, per 12 circa snnos viget et quotannis quarer vel quinquies fecari poteft. 
IOI3. Mcalicago pedunculis racemofis, leguminibus falcata. contortis, caule eręto. "tinn. Syft. pag. 693. n. 6. вогем. n. 349 . Fl. Dan. t. 233 .

Falcata. Riv. Tetr. t. 84.

Var. a) Medicago fylueftris floribus ex caeruleovirefcentlbus. violaceis.

B) Medicago floribus partim luteis, partim

r) Medicaga foribus croceis.

Sichelklee; gelber Sichelklee; großser gelber Steinklee; Ackerklce; wildes hciliges Heu; fchwedifches Heu; finvedifche f. teurfche Luzerne. Germ. Yellow Medick. Angi. Luferme jaunc, ou ì faucille. Gall.

Ad fepes et agrorum pratorumque margines paffim; in 1yluis clatioribus, muris vetuftatis, collibus circa Vrbem : in folo arenofo et ficciori e. r. in derSandgrube et ad vias, frequons. Flor. Iun. Iul. Perennis.

Pro foeno in apricis locis glareofis fterilifimis ferenda. uiN. Pabulum pecoribus omnino eft eximium.

Iór4. Mcdicago fpicis oualibus, lemuminibus renifor- Lupulina. mibus monofpermis, caulibus procumbentibus. LINN. Syft, p. 693 . n. 7 - воEIM. n. 348 .

Melilotus minima. niv. Tetr. t. 8 .

Hopfonartiges Schatekculrant; Hopfenfchneckenklee; kleincr Hopfenklee; Hopfuluzcrne. Germ. Delilot Trefoil Angl. Luferne hullonuée. Gall.

In agris, pratis aridioribus, pafcuis et locis arenofis ficcioribusque vbique. Fl. Maio in Autumnum vsque. Annua.

Haec Ipecies minus grata eft pecoribus, quam adfines reliquae; tamen in pratis pabulum eft praeftans.

* Polynuorphac: Pedunculis pauciforis, caule diffufo fipulis munito.

1or 5. Medicago caule diffufo, Ripulis integris, legumi- minima nibis ternaris, cochleatis: aculeis vncinatis. WILD. Prodr. Berol. n. 729 . 
424 Classis XVII. DIADELPHIA. DECANDRIA.

Medicago polynorpha pedunculis multifioris, le: gurrinibus chearis: Ipiculis hamatic, alrersis $\mathrm{x}$ teine donatis, ftipulis integris. - LINN. Syft. pag. $3 y$. 11. v. । ar. $\lambda$ minima. SCHREB. Spicil. pag. 27, n. $9+1$. Fl Dan, t, $21 \mathrm{I}$.

Cochleara echinata minima. kIv. Tetrap. t. gy. et 8o. b

Kleinfter Schneckenklce. Germ. Common Small Mcdick Angl. De li plus petute Luferne polymorphe. Gall.

In agris arennfis montofisque, auj dem Gickerlingsberge, hei Meckern, auf den Sandhergen bei Nonndorf et Rïckmarsdorf, auf dom Bieniz, et ad Deiditz etc. vbique. Fl. Iun.-Aug. Annua. 


\section{Claffis XVIII.}

\section{POL Y A D E L P H I A.}

POLYGINIA.

363. HYPERICVM. L G. 981. Hartheu, Iohannis. kraut. Girm. John's - Wort. Angl. Mille - per-

tuis. Gall.

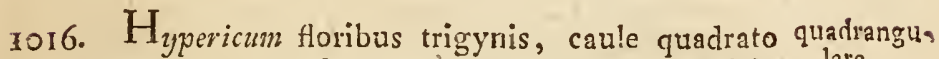
herbaceo. linn. Syft p. $701 . n$. 25. schreb. Spicil. larc. p. 32. n. 950. Fl. Dan. t. 6.70.

Pharm. Hyperici Herba.

Viereckigtes Hartheu; Kuarads-1. Peterskraut; Itagetenfel. Germ St. Peterszeror: Angl. Afcirum, ou Mille-pertuis quadrangulaire. Gall.

In humidis nemorolis ad Zweinauendorf, Delitz, Abtnazendorf, Burghaufen, Somnerfel:, im MacherSchen Holze, in der Kummerei lei Nautendorf, in der. Préllheide auff den Tiefenfeer Antheile etc. copiofe. Fl. Iul. Aug. Perennis.

Olf. In Pharmacopoliis Suecicis indilcriminatim hoc pro $H$. perforato colligitur Hyperci decoetum vinofum in Phthifi pulmonali laudat HELLENivs, *)

x017. Hijpericuni foribus trigynis, caule ancipiti, fo- perôratum, liis obtufis, pelliculo punctatis. LINN. Sylt. p. 701 . ก. 26. 'овен. ก. \$O6. вLACKW. t. 15.

Pharm. Hyperici Herba, Flores, Semina.

Durchlöchertes Iohanniskraut; gemeines durchftock. wes Hartheu; Hexenkraut; Iohannisblut; Iageteufel, Dd 5 Tell-

*) vid. Eiusd. Diff. de Hyperico, Praef. Ill.;v, Limn. Vpẹ, 177 f. 
Tenfelsfucht; St. Konradskrant; unfer Herrgotts: aeunderkraut; Waldkopf. Germ. Common St. Fohn's İort. Angl. Mille-pertuis vulgairc. Herbe de St. Fean.

In collibus circa Vrbem, in Propugnaculo Grimsmenti, auf den Gickerlingsberge; in agris Aterilioribus måcilentisque, bei den Gefundbrunnen, hinter Taucice, bei Skezditz, ad lepes et in dumetis vbique, copiofe. Fl. tota Neftate. Perennis.

Obf. Antherae puncto atro pietae.- Stigmata fanguinea. Flores lutei.

Vf. In tincturis a Ruricolis paffim adhibentur fores, quithus Spiritum frumenti et oleum laete purpureo pingunt colore. Linn. Flores quoque inficiunt Spiritum frumenti ct oleum carmefino colore. Oleum coztum in irsculo fumtum egregium tuffis remedium perhibetur. Vog. Veteribus hoc quoque appellatum eft Fuga Daemonum, quia fpectra et daemones fugare fupertitiofe putant, iuxta verficulum fequentem:

Dof, Hartheu und weiffe Heid, Thun dem Teufel viel leid.

hunifufum, 1018. Hypericum foribus trigynis, axillaribus, folita'riis, caulibus ancipitibus, proftratis filiformibus, foliis glabris. IINN. Syft. p. 70I. n, 27.

Hypericum foliis perforatis, punctis in margine nigris notatis. военм. п. 408. Fl. Dan. t. I 44.

Var. $\beta$ ) Hypericum caule erecto.

Geftrecktes f. liegendes Iohanniskränitlein; kleines Iohamiskraut; Erdlieferlein. Germ. Trailing Fohn's Wort. Angl. Mille-pertuis couché. Gall.

in agris neglectis et pafcuis, auf den Brachfeldern bei dem Gefundbrunnen frequens, in der Lehm- und Saml.grube etc. et var. $\beta$. in agris inter fegetes paffim. Fl. Iun.- Septembr. Annua.

Olf. Folia fubferfilia, non perforata. Flores folitarii, axillares, pedunculis mediocribus furtentantur. 
ro19. Hypericum floribus trigynis, calycibus ferrato- montanum. glandulofis, caule tereti, erecto, foliis ouatis, glabris. LiN. Syft p. -0i. n. 29.

Hypericum foliorum ora punctata, calyce ferrato. BOEHM. n. 107 . Fl. Dan. t. 173 .

Bergjohannisliraut; Hexenhraut; wezches Hartheu. Germ. Mountain, or Imperforate St. Fohits-Wors. Angl. Mille-pertuis des monagnes. Gall.

In fyluis montofis, im Bicniz paffim. Fl.Iul. Aug. Peiennis.

Obf. Coul. ereßtus, teres, glaber, geniculatus. Fol. oppufita, fefijlia, ouata. non perforata, intrgerrima. Flores folitarii ex apice caulis vel ramorum faficulorum ad inftar egrediuntur. Brafteae oppofitae, lanceolatae, margine ciliatae.

1020 Hypericunz foribus trigynis, calycious ferrato- hirfutum. glandulofis, caule tereti eręto, foliis fubouatis fubpubefcentibus. I.INN. SyAt. p. 702. n. 3I. SCHREz. p. 32. n. 451 . Fl. Dant t. 802.

Rauches Iohanniskraut; fteifbortiges Hartheu. Germ. Hairy St. Johas - TVort. Angl. Mille-pertus iclu. Gall.

In nemoribus humidis inz Rofenthale, Gomsewitzer", Gautfizer Holze, porro in fy!uis elatioribus ficcioribusque in Bieniz, ad Zweinancisdorf, Macliern, in der Kanmmerei bei Nauendorf, in der Preilheide auf den Zficenliner Antheile etc. Flor. Iul. Aug. Perennis.

Obj. Caul. hirfutus. Folia punctis deftituta, ouata, coniugata, integerrima, villof́, Panicula multifora caulem terminat Calycis fegmenta ferrata, dentibus glanduliferis oifefra. Petala linfolis nigitis notata. Capj. ouata-oblonga. Semz. rubra.

1021. * Hypericum floribus trigynis, calycibus ferratc- pulchrum. glandulons, caule tereti, folitis amplexicaulibus, cor. datis, glabris LINN. Syft. p. 702. n. 35. Fl. Dan. t. 75.

Hypericum minus ereftum. C. B. P. p. 2‡9. 
428 CIASSIS XVIII. POLYADELPHI, POLYGYNIA.

Schönes Iohanniskraut. Germ. Upright, or Fair, or - beautiful St. Fohn's -Wort. Angl. Mille - apertuis joli ou luifant; Le beau Mille-pertuis. Gall.

In fyluis ficcis elatioribus paffim im Bieniz, fed ra. rius. Fl. Iun. Aug. Perennis.

Obf. Corollae petala flaua, punetis purpurafcentibus phoeniceis Jubtus picta. Canl. erectus, teres, glaber; ex rubello-viridis. Rami oppofiti. Fol. fefflia, cordato-ouata, obtufa, integerrima, deflexa. Flores folitarii, feffiles, alii breniter pedunculati, terminales. 


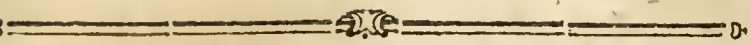

\section{Claffis XIX. \\ S Y N G E N E S I A.}

\section{A. FLORE HERMAPHRODITO.}

\section{AEQVALIS.}

a) Flores femiflofculi: corollis iniformibus, ligulatis.

364. CICHOREVM. L. G. 1000. Wegwart f. Cichorien. Gern. Succory. Angl, Cichorée. Gall.

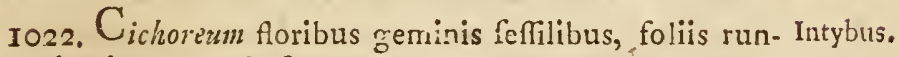
cinatis. LiNN. Syft. p. 722. вов HM. n, 223. вLACKW. t. 177 . et 183 .

Var. $\beta$. Cichoreum fore albo.

Pharm. Cichorei Radix, Flores, Semina, Herba.

Gemeiner Ir egwart; wilde Cichorie; Feldcichorie; Hïndlïufte; Sonnenneendel; Feldfonnemeirbel. Germ. Wild Cichory; Wild Sycory. Angl. Cichorée fauza. ge; Endive commun; Cichorée des boutiques. Gall.

Ad agrorum margines, vias publicas et iuxta fepes vbique: porro in locis campeftribus apricis et in collibus circa Vrbem ambulacrisque etc. copiofe. Flor. Iun. - Sept. Perennis.

$V \int$. Radix fpontanea magis amara praeftat in medicina culta, dulcior vero fatiua, quae in noftratibus hortis oleraceis frequenter occurrit, acetariorum loco in deliciis eft. Radix quoque in taleolas feeta et aere exficcata fuccedaneum Caffeae in multis 
regionihus. Folia tenera fecantur pro fatura herbaria, fapida, amaritie grata.

Endiuia, 1023. Cicliorcunis floribus folitariis pedunculatis, folis integris, crenatis. LINN. Syft. p. -2 2 воЕHM. n. 22s. BLACKW. t. 78. KERN. B. II. p. 86. t. 3 .

Var. a) Cichorium Endiuia foliis oblongo-nuatis, dentaris. SPIELM, Oler. I. p. 53. n, 1 .

Intybus fatiua, latifolia 1. Endiuia vulgaris. C. B. P. p. 125 .

B) Cichorium Endiuia foliis pinnatim laciniatis, laciniis latiufculis hyberna. spielm. 1. c. p. 54 . n. 2. var. $\alpha$.

Intybus crifpa. C. B. P. p. 125. BLACKW. t. 378.

y) Cichorium Endiuia foliis pinnatim laciniatis, neruo euidenter in ramos diuifo viridi. SPIELM. 1. c. p. $5-. \delta$.

Cichorium crifpum, anguftifoliuın. BOERH. Ind. Alt. I. p. 9I.

Pharm. Erdiuiae Semina, Herba.

Andivie f. Endivie; Winterendivie; \&) breitblat. srichte Winterendivie; jchluchte Wintcrendivie; 3 ) seilder Lintcrendivien, gemeine Endive; großkranli. ge Winterendivie; y) kleinkraufigte Wintcrendivie. Germ. Endive; a) Broad. leaved Endive; ;) Curled-leaved Endive; r) Narrov-leaved curlec Endive. Ang!. Endive; Cichorée Endivée, ou douce; a) Scariole ou Scarolle; $\beta$ ) Cichorée blonde frifée; $\gamma) \mathrm{C} i$ chorée de Meaux. Gill.

In hortis et agris oleraceis hae 3 varietates frequenter occurrunt. Annua Biennis.

VJ. Folia acetariorum olerumque more praeparan. tus in culinis et a noftratibus lubenter comeduntur. Haec et antecedens fpecies inter Olera efculenta in Iaponia quoque receptae (unt, *) 
365. HYPOCHAERIS. L. G. 997. Sau- f. Fctkelkraut. Germ. Hauckweed. Angl. Porcelle, Herbe à

l'Epervier. Gall.

1024. * Hypochaeris caule fubnudo: ramo folitario, fo- maculata. liis ouato - oblongis, integris, dentatis. LINN. Syft.p. 72I. n. 48 .

Hieracium alpinum latifolium hirfutie in canum flore magno. C. B. P. p. 128 .

Hieracium alpinum foliis dentatis, fore magno. HaLI. Helvet. p. 760 . t. 24 .

Achyrophoris maculatus, scop, Carn, II. p. 2I6. n. 986.

Pharm. Coftae Herba.

Geflecktes Habichthraut 1. Ferkeikrant; Cofenkraut. Germ. Spotzed Harek-IVeed. Angl. Porcelle tacheté. Gall.

In fyluis pratenfibus vmbrofisque in der Känmerei, bei Machern; in der Tiglize bei Dïben, in Hegegraje bei Kriphâne; in fyluis quoque elatioribus in Bieniz paffim. Fl. Iun. Iul.

$V \int$. Folia coquuntur, vt Brafica, in cibum a Smolandis. Herba recens Equis fapidifima, ficca minus. Linn. *)

1025. * Hypochaeris calycibus oblongis, imbricatis, glabra. caule ramofo, nudo, foliis dentato - finuatis. IIN Syit. p. 721. LEYs. n. 767. Fl. Dan. t. 424.

Hieracium minus, dentis Lionis folio fubafpero.

C. B. P. p. 127 .

Glattes Sau- f. Ferkelkraitt; kleines Ferkelkraut; Schweinscichorien. Germ. Smooth Harek - Weed. Angl. Porcelle douce. Gall.

In pafcuis ficcis hinter Kriphïne an der Prellheide auf clem Tiefinfeer Antlleile atque in campis arenofis paffim. Fl. Iul. Aug.

1026. Hypochaeris foliis runcinatis obtufis, fcabric, ralicata. caule ramofo, nudo, laeui, pedunculis fquamofis. LINN. Syft. p. 721. n. 4. военм, n. 225. Fl. Dan. t. 150. Lang.

") Eiusd. Fl. Sues. p. 271. n. 708 . 
Langwurichtes Ferkelkraut. Germ. Long-rooted Hazek-W'ced. Angl. Porcelle radiqueufe; Herle ì DEpervier. Gall.

In pratis, pafcuis atque fyluis abunde, et cum Crepi Tectorum vbique reperitur. Fl. Iun. Aug.

366. TRAGOPOGON. L. G. 984. Bocksbart. Cicrm. Goat's-Beart. Angl. Barbe de Bouc. Gall.

pratenfe. 1027. Tragopogen calycibus corollae radium aequantibus, foliis integris ftriatis. LINN. yft. p. - -

Tragopogon foliis carinatis, amplexicaulitius, gramineis, flore luteo, вовнM. n. 205. KERN. B.I. p. 49. tab. 66.

Pharm. Barbae Hirci Radix, Herba.

Wilder - gelber Bocksbart; W:efenbocksbart; IVolfsbart; zeilde Hahereenurzel; lofephblume; Morgenftern; wilde Scorzonere. Germ. Yellow Mcadowe Goats-Beard, or Greater Bucks-Beard. Angl. Serfífi, ou Salfifur des près; Barbe de bouc. G:ll.

In pratis et ad vias, pafim im grinmichen $Z_{\text {re }}$ int. ger und auf der $P$ affici, atque in collibus circa Vrbem. Fl. Iun. - Aug. Perennis.

Obf. Planta primo mane euigilat et circa meridiem obdormit; qua de re hae: in Anglia ruricolis appellatur Go at a bed at noon, or Sleep at noon, i. e. vge-

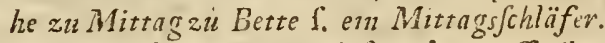

$V \int$. Radices ante caulefentian eff liae Afparagi more coquuntur et cibum exhibent fapidum, gratum atque nutrientem.

porrifoliun. 1028. Tragapogon calycibus corollae radiis longioribus, foliis integris ftrietis, pedunculis fuperne incraffatis, corollulis anguftifimis truncatis. LINN. Syft. p. 710. IEYS. n. 772 . Fl Dain. t. 797 .

Porreyblättrichter Bocksbart: Haferienrzel; blane Habereenrzel; Artiff. Germ. Purple Goat's Ecard. or Salfafy. Angl. Cercifi ou Sallifix commun. Gall.

in collibus circa vrbem paffin et in hortis copiofe. Fl. Iนก. Iแ1. 
SYNGENESIA. AEQYALIS.

Vj Radices ad ncetaria in Angylia adhibentur 'et variis cibis admixtae coquuntui.

367. PICRIS. L. G. 986. Bitterkraut. Germ. Ox-tongue. Angl. Picrid-. Gall.

1029. Picris perianthiis laxis, foliis integris, peduncu- He:actudes lis fquamatis in calycem. LINN. Sy? p q 11 .

Picris calycibus nudis, foliis amplexicanibus, oualibus ror Hu. n. 20 .

Habichekrautähnliches Bitterlvaut f. Coftenkraut. Wallhabichtkrant. Germ. Yellow fuccory, or Rough Haukereed. Angl. Picride Eperviere Gill.

In agris montofis et agrorum marginibus. Flor. Iun. - Aug.

368. TAR AX \CVMk. witden.p. 251. Mönchskopf. Germ. Dandelion. Angl. Piftenlit.

\section{Gall.}

10.30. Taraxacum fquamis calycinis exterionibus refe- ofizinale.

xis, foliis runcinatis acute dentatis glabri. Writes. Prodr. Berol. n. 772. wigg. Primit. n. 5 5. Rot: Germ. 1. p. 33 . воент. n. 218

Hedypnois Taraxacum calyces fquamae exteriores et imae reflexae. scop. Carn. Ed. 2. n $95^{\circ}$.

Lcontodon Taraxacan calycis fquamis inferne refexis, foliis runcinatis, denticulatis, laeuihus. LINN. Syft. pag. 715. вLACKw. t. I. et 5OI. Fl Dan. tab. 573 .

Yar. a) Taraxacum foliis anguftioribus et parun: incifis.

B) Taraxacum foliis angufioribus.

Pharm. Taraxact Radix, Herha.

Gervöhnlicher Lörvenzahn; Butterblume; Dotter. blúme; Hunde'sune ; Hundslattich ; Eyerblume; Möncluskopf; Pappenblume; Pappenkrant: Pfafen. blart; Pfafferediftel; Pfaffenröuriein Röhrleinlrait; Seichllume. Germ. Common Dondelnon. Ang!. Piffenlit commun; Dent déLion. Gall. 
In pratis, pafcuis, verluris, pomariis, fepibus, hortis, nemoribus et locis fterilioribus vbique frequentilfme. Fl. Aeftate tota.

Obf. Pappus longifime ftipitatus fimplex.

Folia primo vcre erumpentia ad Acetaria colliguntur Holmiae, vti apud noftrates. Ob vim diureticsm Eeftiminga vulgo dicitur et a pappis in capitulum colleetis Corona Monachi audit. E radice et herba recenti vernali tempore exprimitur fuccus in cachecticis morbis praeftantifimus. Radices quoque Caffeae fuccedaneum exhibent et florúm capitula claufa Cap.

- paridum more praeparari polfunt.

369. LEONTODON. L. G. 991. Löwenzahn f. Mönchskopf. Germ. Dandelion. Angl. Piffenlit. Gall.

autumnale. 103I. Lèntodion caule ramofo, pedunculis fquamofis, foliis lanceolatis dentatis, integerrimis, g!abris. LINN. Syft. p. 7 I 5. n. 6. BоE⿺M, n. 222. (lub Scor $\approx 0$ mera)

Herlftiözenzahn; fcluvarz f. klein Habichtkraut; klcinblumiges faifches Habichthraut; Hafenlattich. Germ. Autunnal Dandelion. Angl. Piffenlit Autonnc, Gall:

In pafcuis, pratis, hortis, fyluis et ad fepes hortorum frequens. Fl. Iul. - Sept. Perennis.

hifpidum. 1032. Leontodon calyce toto erecto, foliis dentatis, integerrimis, hifpidis; fetis furcatis. Linn. Syft. pag. 715. n. 8. вовнм. п. 217. (fub Taraxaco). Fl. Dan. t. 862 .

Scharfer f. borfigigr Lözeinzahn. Germ. Hifpid Dandelion. Angl, Piffenlit rude. Gall.

In pratis, verfuris an den Teichen bei Lindenau, wach der Tabacksmiizlle et in nemoribus e. g. im Univerfitâtsholze etc. Fl. Iun. Iul. Perennis.

hirtun. 1033. Leontodon calyce toto ere?to, foliis dentatis hirtis, fetis fimpliciflimis. LINN. Syft. p. 715. n. 9 . 
Taraxacum foliis afperrimis, fere fpinofis, pinnato fincatis, pappo plumofo. вовнм. n. $2: 9$.

Struppigter f. ralucher Lözeenzahn. Germ. Rough Dandelion. Angl. Piffenlit heriffe. Gall.

In fyluis, p mariis et ad lepes frequenter. Flor: Iun. Aug. Peremis

Obf. Foli.1 rigidula, quafi arida, laciniis ohliquis. Calycis foliols extrema bafi vtrinque dilatata mediante plica.

\section{SCORZONER 4. L. G. 985. Skorzonere. Germ.}

Vipersor als. Angl. Scorfonére. Gall.

103 4. Scorsonera caule fuhnuda, vniforo, foliis lato- humilis. lancecolatis, nerunfis, pianis. LINN. Sylt p O.n.2. JaHN n. 17. Fl. Dan. t. 8I6. Jace. Flor. Auftr. V. I. t. 36 .

Pharm. Scorzonerae Radix, Herba, Semina.

Wilde niedrige $f$ teutfche Skorzonere; teutfche Skorzonerenwurz; Schlangcuesurz; Schlangenmord; Nattemilch Vipermeurz Germ. Dwarf broad- leaved Viper's. Graß. Ingl. Bombarde, ou la petiteScorfoneve. Gill.

In fyluis elatioribus im Bieniz paffiın, im Hegegrafe bei Kriphanne. Fl. Iun. Iul. Perennis.

$V \int$. Radic:s pratis valde molefte ad cibum aeque ac Dauci et Paftinacae idoneae, et rite ficcatae in puluerem redactae pro pane inferuiunt.

103 ** Scorzonera caule ramofo, foliis amplexicaulibus hifpanica. integris ferrulatis. LINN. Syft. p 7 [1, n, 4. BLACKW. t. 406 .

Scorzonera latifólia finuara. C. B. P. p. 275.

Pharm. Scorzoncrae Radix.

Skorzonere; Salfifi; Schlangenevurzel; Schlangengraß. Germ. Broad finuated-leaved Viper's Grafs. Angi. Scorjonere d'E Jpagne; Salfifi, ou Cerciffd E/pagne. Gall.

In hortis et agris inter olera haud infrequens. Fl. Aeftate, Perennis. 
Vf. Ratices Scorzonerac pariter ac Barbae Hirci in culinis frequenter adhibentur menfisque apponuntu: in aqua elixatae, cum tali embammste, quali vtifolemus ad afparagos. Succus e radice recenter exprelfirs olim commendatus eft contraferpentum ictum.

'anguftifolia. 1036. * Scorzonera foliis fubulatis integris, pedunculo incrafiato, caule bafi villofo. LINN. Syft. p. 711.11, 6 . sc110L. Barb. n. 6ะด.

Scorzonera anguntifolia prima. C. B. P. p. 275.

Schunalbl.ttrige Skor onere. Germ. Narrowe leaved Hungarian Viper's-Graß. Angl. Scorfonere fubulée. Gall.

In fyluis oramine largiore veftitis, in Hegegrafe boi Krip/l.ne, in der Känmmerei bei Naucndorf, paifin. Fl. Iun. - Aug.

Obf. Caul. befi ramofus, caeterum fuperiora verfus fimplex, fere lanuginofus. Folia radicalia latiuscula, bafi lanuginofa; caulina linearia, fubulata. $P_{c}$ dunc. terminales, verfus florem crafliores iplo caule. Corolla lutea fubtus purpurafeens, longitudine calycis.

taciniata. 1037: Scorzonera foliis linearibus dentatis acutis, caule erecto, calycibus Iquamis patulo - mucronatis. LIN⿴囗 Syft. p. 7.11. n. 10.

Scorzonera foliis anguftiffmis, imis rariter femipinnatis, reliquis integris, caule foliofo. вогим. $\mathrm{n}$. 882. Jace. Flor, Auftr. Vol. 4. t. 356.

Zerriffene f. ausgefchnittene Skorzonere. Germ. Fagged-leaved German Vipcr's-Graß. Angl. Scorfonere laciniée. Gall.

In apricis gramine tenui veftiti, vor dem grimmifchen-Thore, dem Gerichte gegen iiber, olim Cel. повнытв invenit; nunc quoque ad Schönfeld, ad vias et alibi vbique, Fl. Iul. Aug. Annua. 
371. CREPIS. L. G. 993. Grundfeite; Pippau. Germ. Baftard-Hackweed. Angl. Crépide. Gall.

1038. * Crepis inuolucris calyce longioribus: fquamis urbati. fetaceis fparfis. IINN. Syft. p. $710 \cdot$ n. 3 .

Hieracium proliferum falcatum. C. B. P. p. 128 .

Bärtiger Pippau; Chriftange. Germ. Yellow -and purple Hureckized. Angl. Crépicie barbue. Gall.

In Siciliae, Mefrnae arenofis et maritimis habitat: In nofratilus contra hortis valde frequens et ibidem nune quafi fponte prouenit; in ruderatis paffim quoque occurrit. Flor. Iun. in Septembiem vsque. Annua.

Obf. Calyx exterior corolla longior. Planta florens Oculus Chrifti appellatur hortulanis.

I039. Crepis foliis lanceolato-runcinatis, leffilibus lae. tectorum. vibus, inferioribus dentatis, L1NN. Syft. pag. 719. n. II. вовим. ก. 213 .

Daclıpippau; kleines Habichthraut. Germ. Smooth fuccory Hawkweed. Angl. Crépide, ou Fufelée des toits. Gaill.

In agris inter legetes, muris, omnibus tectis ét collibus limolis atque in hortis vbique. Fl. Iul. Aug.

1040. Crepis foliis runcinato-pinnatifidis, fcabris: ba- biennis.

fi fuperne dentatis, calycibus muricatis. LINN. Syft. p. 719. n. 12. sCHREB. Spicil. p. 16. n. 918.

Zueijühriger Pipvau f. Gruzdfefe; gelbe Cicho. rien; gentein klein Habichtkraut. Germ. Greateft Hawkiveed: Angl. Crépide verte; Fufelée bifannuelle. Gall.

In pomariis pratis ficcioribus, in collibus circa vrbem et agrorum verfuris. Fl. Iul. Aug. Perennis.

10 1 1. * Crepis foliis radicalibus runcinatis, caulinis Diofcoridis. haftatis; calycibus fubtomentofis. LiNiv. Syft. p. 720 .

n. 14 .

Hieracium maius erectum angufifolium, caule laeui. C. B. P. p. 127 . 
Diofcoridis-Pippau. Germ Common fuccory-leaa' baftard Hazekweed. Angl. Crépidu de Diojcoride Gall.

Ad fepes, in aggeribus et collibus vbique. Flor. Iun. Iul

Obf. Flores lutei, magnitudine Crepidis TeEtorum. Folia radicalia pinnatifida; cauluna inf riora denticulata, luperiora ac ramea contra linearia, integerrima, fefilia, haftata, bafi hinis auriculis eminenibus inftructa, margine paululum reflexa, omnia laete viridia, glabra.

372. CHONDRILLA. L. G. 989. Chondrille. Germ. Gum Succory. Angl. Condrile. Gall.

junces. 1042. Chondrilla foliis radicalibus runcinatis, caulinis linearibus integris. LINN. Syft. pag. 713. вовнм. n, 206. JACQ. Flor. Aultr. Voi. 5. T. $\$ 25$.

Binfenarige Chondrille; Sandhabichtkraut Germ. Rufhy vifcous Gum Succory. Angl. Condrile jonciere. Gall.

In agris cultis eorum pratorumque marginibus, $e$. g. inter Lindenau. et Leutfch durch dem Holze, ad viann mach Burghaufen, hnter dem Bieniz. Flor. Iul. Aug. Perennis.

373. PREN ANTHES. L. G. 990. Hafenftrauch. Germ. Wild Lettuce. Angl. Prenanthe. Gall.

purpurea. 1043. * Prenanthes flofculis quinis, foliis lanceolatis denticulatis. IINN. Syft, pag. 714. Jace. Flor. Auftr. Vol. 4. t. 307.

Prenanthes montana purpureo-caerulea minor. C. B. P. p. 123 .

Purpurrother Hafenftrauch. Germ. Prenanthe purpurine, Gall.

In agris inter fegetes, zwifchen Meckern et Wahreñ paffim mihi occurrit, in fyluis elatioribus umbrofisque im Bieniz, in der Prellherde, pafim. Flor. Iul. Aug. Annua. 
Obf. Antherae cylindricae purpurafcentes, in fe. quente flauac; Styl. I, purpurafcens, in murs!i flauicans. Stigma iterum in noftra purpureum: Ligulae Corollae retrorfun reflexac purpureac, ftriatae, tubo alb:do glabro gaudent.

1044. Prenanthes flosculis quinis, foliis runcinatis. muralis. ! LINN. Syit. pag. 714. SCHREB. Append, n. 1168. Fl. Dant. t. 509.

Pharm. Chondrillae Veterum Herba.

Maucrhirfenffrauch; Maucrjalat; zeild Sonsnerkraut.

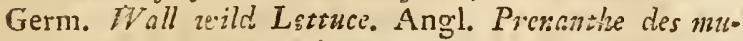
railles. Gall.

In nemoribus vmbrofis, im Linkler Holzc, in Biemiz, im Univerfïtäts - Macherfchın Holze, in der Kämmerei bei Kripluâne etc. copiofe, Fl. Iun. - Aug.

\section{LACTVCA. L. G. 988. Lattich, Salat. Germ. Lettuce. Angl. Laitue. Gall.}

1045. Lactuca foliis rotundatis; caulinis cordatis, cals- fatiur. le corymbofo. EINN. SyR. pag. 7I5. n. 3. военM. $n$. 220. BLACKW. t. 88.

Var. A. Lictuca fatiua. C. B B. p. I22.

B. Laetuca capitata. C. B. P. p. 123 .

I. a) La\&uca capitata, capitibus maioribus viridibus laxis. spieln. p. I4. n. 7.

b) Lactuca capitấ, capitibus maioribus ver. fus marginem maculis rubris $\mathrm{f}_{\text {parfis. SPIEL }}$. pag. 15. ก. 8 .

c) Lactuca capitata, rubro variegata, foliis oblongis. SPIELM. p. 15. n. 9.

d) Lactuca capitata, capitibus magnis viridibus. SPIELM. P. I4. n. 5 .

2. e) LaEtuca capitata, rubro variegata, foliis rotundis. SPIELM. p. 15. n. 10.

f) Lackuca cnpitata, rubro variegata, maculis rubris latioribus. SPIELM, p. 16. n. 12.

3. g) Ląuca capitata, capitibus paruis flauis, SPIELM. P. I3. ก. I,
F e 4
h) La- 
h) Lactuca capitata, capicibus magnis fiauis, foliis rugofis. spielm. p. 13. n. 3 .

i) Lactucn capitata, capitibus magnis flauis, foliis minus bullatis. SPIELM. p. 14. n. 4 .

C. Latuca crifpa. C. B P p. 123.

a) Laftuca capitata crifpa, capitibus viridibus minoribus. SPIELM. p. 16. n. 3 .

b) Lactuca captara crifpa, capiribus maioribus viridibus, sPIELM. p. 16. n. 14.

c) Lastuca capitita, foliis contortis. SPIELM.

p. 17. n. 15 .

Pharm. Laflacae Semina, Herba.

Gemeiner Sallat; Lattich; Gartenfallat. Germ.. Garden Leituce. Angl. Laitue ordinaire. Gall. 1) Gemeiner 1. zalmer Sallat f. Latrich. Germ. Common, or Garden Lettuce, or Lapped Lettuce. Argl. Laitue i conper. Gall. B) Gemeiner Kopffalat. Germ. Cabbage Lettuce. Ang! Lautue pouniér. 'ou en tête. (iall. b) Winterfalat; gelber vinterkopf: Germ. White Daltch Cabbage Lettuce. Angl. La groffc Rouge. Gall. c) Berliner Kopf; Grojadmiralfallat; Frifebuhr; Einer frifst much nicht. Gern. Grand Admiral, or Greetadmirable white Cabbage Lettuce. Angl, Laitue la groffe Allemande, ou Imperale; Ponime de Bolin. d) Grïner Praklfallat. Germ, La Parelfeuje. Gall, e) Fo. rellenkopffullat; Forcllenfallat. Germ. La Sanguine. Gall. f) Rother Winterkopf. Germ. La Pajjion. Gall. g) Friiher Eycrfallat; Montréc; frïher Steinkopf der Strafoburger. Germ. Small early green or white E.sll-Cabbage Lettuce. Angl. Laituc la petite Crêpe, ou petite noire, ou courte; la Bagnolet; Printaniere; Degrcbé; la Crêpe blanche, ou ronde. Gall. h) Gelber Prahlfallat. Germ. George blonde. Gall. i) Großer, gellier, kraufer Montrée. Gern. La grofe George; Laitue verde. Gail. C) Kraufer Sallat. Germ. Curled Letuce; Dwanf curled Lettuce. Angl La cabue, ou la crépue. Gall. a) Kleiner kraufer Sallat. Germ. Petiie Crepe. Gall. b) Grojer kraufer Sallat. Germ. Long curled Lctuce. Angl. La groffe crepe. Gall. c) Kapucinevfallat; Bologneferfallat: Srhraubenfollat Germ. Capuchin Lettuce. Angुl. Laiture la longue Vifféc. Gall. 
In ruderatis aggeribus, collibus circa Vrbem et in agris cultis inter olera paffum varictates autem omnes in hortis et agris oleraceis naxime coluntur. Fl. Aeftare. Annuae vel Eiennes.

Obf. Primo Veue folia Laçucac tenella in cibum iecipiuntur, Germanis Stechfallat, Argentoratenfibus Sir.ufallat, et Gallis Capucine audiunt. Lactuca iam int $r$ antiquifina oleraces enumerata eft. Apud prifos enim Romanos in primariis deliciis fuit faepeque cnenam nchoarunt: Clautere quae coenas Lactuca folebat anorusn, Dic milhi, curnofiras inchoat illa da. pes? Mavtialis. Apud nos herba plerumque comedi folet recens et cruda cum oleo, aceto faieque prac. parats. Coquiturvern paftim ficuti alia olera et tunc tenerrims fit, mirus vero fapida. Caeterum Lactuca facilis digeftionis, et fi vefperi edatur, tunc tranquil. las facit noctes.

246. Lactuca foliis verticillatis carina aculeatis. LINN. Scariola. Syf. p. 713. n. . ВОенM n. 221.

Latuca foliis Entiuiae. C. B. P. p. 122.

Var. a) Lactuca romana foliis meditullio coe. untibus) foliis viridibus. SPIELM. p. $1 \leadsto$. n. I.

b) Lactuca romana, foliis euidenter ad luteunt colorem accedentibus. SP1ELA. p. 17. n. 2.

c) Lactuca romana, foliis ubris maculatis, colore dilutiore. SPIELM. p. 1 . n. 3 .

d) Lafiuca romana, foliis rubro maculatis, maculis magis foturatis. sprezm. p. I8. n. 4.

Wilder Lattich; zelfcher Sallat; Endivienlattich; Bindfallat; Bandfaliat. Germ. Cos Lettuce. Angl. Laitue Scariole. Chicon, ou Laitue Romaine. Gall. Var. a) Grïner Sommercndivienfallat; langer Sommerendivie; Bindlallat; grïner f. gelber welfcher Sallat derStraßhurger. Gerin. Green Cos-Letiuce. Angl. Chin converd, oud'hyucr. Gall. a) Weiffer Sonmerendivien. fallat; weilier Paffeuer. Germ. Verfailles, or Upright white Cos Lettuce. Angl. Chicon blond. Gall. e) Forellen-Bandfullat. Germ. Aleppo Lettuce; Spodded Cos-Letwue. Angl. Chicon pannaché; Flagelle; Laitue de Silcfie. Gall, d) Rother Bandfallat; Bolognefer E $F$. 
rother Sallat. Germ, Red Cos-Lettuce. Angl. Chiconz rouge. Gall.

In iisdem locis cum prioribus praeprimis coluntur. Species ipfa contra in collibus circa Vrbem, ad fepes et agrorum margines haud infrequens. Fl. A eftate. Annua. Vfus vt in antecedente.

virofa $1047^{*}$ * Lactuca foliis horizontalibus carina aculeatis dentibus. L1NN. Syft. p. 7I3. n. 5. Leys. n. 788 .

Pharm. Lactucae virofac Herba.

Gifiiger Lattich; Leberdifel; wilder Sallat. Germ. Laitue vénćrecufe, ou fauvage. Gail.

Ad fepes et in collibus circa Vrbem et ad forfas paffim. Fl. Iun. - Aug.

Obf. Planta narcotica iis excitat ebrietatem, qui lierbain edunt.

faligna. 1048. LaEluca foliis haftato-linearibus ieffilibus, carina aculeatis. LINN. Sylt. p. $7 \$ 3 . n .6$. SCHREe. p. 17. n. 918. JACQ. Flor. Auftr. Vol. 3. t. 250.

Lactuca fylueftris altera, angufto faligno folio, cofta albicante. RVPr. Ien. Ed. Hal. pag. 20\% tab. 4. optima.

Weidenlattich. Germ. Lainue à fevilles de Saule. Ga!l.

In muris collapfis Lipfiae in dem grimwifchen Zwinger prope Templim St. Pauli et in collibus circa Vrbem etc. In fcrobibus inter Lützen et Markranftädt, bei Ketfchau. Fl. Aug. Sept.

375. HIERACIVM. L. G. 992. Habichtkraut. Gerim. Hawkweed. Angl. Eperviere. Gall.

* Scapo nudo vnifloro.

Piloflla, 1049. Hieracium foliis integerrimis, ouatis fubtus tomentofis, ftolonibus repentibus, fcapo vnifloro. LINN. Syft. p. 716. n. 7. BOEIMM. n, 2 II. BLACXW. t. 365 .

Pharm. Auriculae Muris f. Pilofellac Herba. 
Nlein Mäufeöhrchen; gelbes Mänfeöhrlein; kriechende Pilofelle; Nagelkrant. Germ. Conmon creeping Moufe-car. Angt. Epervicre Pilogelle, ou Oreille de Souris, ou de Kat. Gall.

In aridis, ficcis, campeftribus anach Sćluönfold, et collibu, auf dem Gickerlingsberge, int dor Sandzrube, auf den Bergen ante Meckern et alibi copiofe. Fior. Mai. Aug. Perennis.

Huius ridicibus Herbae Coccus adhaerere poloni. cus fertur. LINN.

\section{** Scapo nudo multifloro.}

10:0. Hieraciun foliis integris ounto-oblongis, ftolo. dubium, nibu- repencibus, tcapo nudo multifloro. Lins. Syft. p. 716. n. S. SCHREz. Spicil. p. I6. n. 916.

Ungewiffes f. glattes Häbichthrant. Germ. Monfeear Hurekweed. Ingl. Eperviere doutcufe. Gall.

In nemoribus Aterilibus im Univer fitâtsholze, in Bieniz, im Macherfchen Holze, in der K mmerer bei Naucndorf etc. Pabulum ouibus bonuin Fl. Iun. Iul. Perennis.

1051. Hieracium foliis lanceolatis integris pilofis, fca-cymofum. po fubnudo bafi pilofo, floribus fubumbellatis.' inn. Syft. p. 716. n. 10. военм. n. 210 . Fl. Dan. t. 810.

Langes Habichtkraut. Germ. Cymmofe Harekzeed. Angl. Eperviere ì bouguet. Gall.

In fyluis, im Kleindülaigcr, Skenditzer Holze; in pratorum terminis hinter dem Kollgarten, vor dent $P_{c}$ tersthore bei den Pulverthurme, aut deaz Gounzezvitzer Schanzen et alibi. Fl. Iun. - Aug. Perennis.

1052. * Hieracium foliis integerrimis lanceoiatis, ftolo Auricula, nil us repentibus, feapo nudo multiforo. LINs, Syft. p. "-16. n. 9. LEYS. n. 793 .

Großes Maufeohr. Germ. Narrow-lenved Hawkzeed. Angl. Eperviere oreille. Gall.

In campis, pafcuis et agrorum verfuris frequens, Fl. Mai. - Iul. Annua, 


\section{*** Caule foliofo.}

murorum 10:3. Hieracium caule ramofo, folis radicalibus oua. tis, dentatis; caulino minore. LINN. Syft. p. 7I7. n. 21. ВоЕНМ. ก. 212 . ВТАСКW. t. 538 .

Var. Hieraciun laciniatum, folihs ad bafin longe dentatis.

Pharm. Pulntonariae gallicaé Herba.

Mauerhabichthraut; franzöfifch Lungenklraut. Var. Buchkohl; Buchlattich. Germ. WVall Hawkweed, or Frenil Lungreort. Angl. Epervierc des murailles; ou Pulnozaire des François. Gall.

In muris vbique, porro in Rnfentiale, Gomewitzer-Zfchoclicrifchen liolze etco var. in aggeribus ad Scopam reperi. Fl. Iun. Iul. Perennis.

fyluaticum. $105 \%$ * Hicracinn caule ramofo foliofo; foliis radicalibus ouatis, petiolatis, caulinis feffilibus: pedunculis multiforis. Gouan. illuntr. p. 56. ketz. in Obf. Bo$\tan$. Fafc. I. p. 2\%. n, 90. LIN . Syft. Ed. R. T. III. D. $6+3$. var. 6

Wald Habichthrant. Germ. Epcrviere des foréts. Gall.

In fyluis ficcioribus et elatioribus im Bieniz, Univer:fiatssholze, bei Leutfch et alibi frequens. Fl. Iul. Ang:

paludofum, 1055. Hieracium caule paniculato, foliis amplexicaulibus, dentatis, glabris, calycibus hifipidis. LinN. Syft. p. 717. n. 23 . SChreb. Spicil. p. 16. n. $91 \%$.

Sunipfhabichtkraut. Germ. Succory-leaved Hawekzeeed. Angl. Eperviere de marais. Gall.

In pratis nemorofis et paludofis, in alneto ad Scliönfeld et Abtnanendorf; ad Leutfch; im Univerfitätsholze. Fl. Iun. Iul. Perennis.

Labaudum. 1056. Hicracinui caule eretto multifloro, foliis ouato lanceolatis dentatis femiamplexicaulibus. IINN. Syft. pag. 719. n. 34, военм, n. 208. Fl. Dan, tab. 872 . 
Savoyifches Habiciztkraut; Mein Boręiabichthraut. Germ. Broad-leaved bufhy Haroliwed. Angl. Eperviere de Savoie. Gall.

In fyluis, im Bieniz, in Univer-fitätsholze, im Zfchocherfchen, Gonnezeitzer, Rafchweizzer Holze, in der Kännmerei bei Nauentionf eəc. Flor. Iul. Aug. Perennis.

10.57. Hicracium foliis linearibus fubdentatis, fparfis, vubellatum floribus fubumbellatis. LinN. Syft. pag. 719. n. 35 . воттім. n. 209. Fl. Dan. t. 680 .

Var. a) Hieracium foliis pene ouatis, vix dentatis, caule humili, pene vnifloro. LisN. Syft. Ed. R.T. II. p. 6\$7. riae foliis, ibid.

ß) Hieracium foliis anguftifimis, quafi linea-

Doldenformiges Habichthraut; großes Berghabichtkraut. Germ. Narrouv-leaved buf hy Hazekzeed. Angl. Epervieve en ombelle, ou des bois. Gall.

In pafcuis, dumetis circa pagum Lindenau, auf iten Gonmeneitzer Schanzen, in pratis Kerfchauienfibus; in fyluis, in Univerfitetsholzc, et in hortis pratenfibus; a) in pafcuis ficcis et elatioribus vor der Tabackmïh. le bei dem Gefundbrunnen, im Bieniz. Fl. Iul. Aug. Sept. Perennis. lore.

Vf. Herba lateo eleganti pulchro inficit co-

376. SONCHVS. L. G. 98\%. Gänfediftel. Gernt.

Sow - thiftle. Angl. Laitron, Gall.

1058.* Sonchus pedunculis calycibusque hifpidis fub-paluftris. umbellatis, foliis runcinatis bafi ariftatis. LiNN. Syft.

P. 7I 2. LEYS. D. 798.

Sumpfgänfediftel. Germ. Marfh Soze-thiffle. Ang\%: Lairron des marais. Gall.

In pratis paludofis, ad foffas et fluuiorum ripas frequens. Fl. Iul. Aug. Perennis. 


\section{$46^{\circ}$ cLASSIS XIX.}

aruenfis, 1059. Sonchas pedunculis calycibusque hifpidis fub. umbellatis, fuliis runcinatis, bafi cordatis. IINN. Syft. p. 712. n. 4.

Sonchus foliis femipinnatis, rigidiufculis, calycibus nigris et hifpidis. вовнм n. 14.

Großje Gänfediftel; Ackergänjediftel f. Ackerjonche; Souchenkraut; großser Ackerhafinkohl Grm. Trce Sorv-thifle. Ang!. Laitron des champs. Gall.

In agris inter fegetes frequens prapcipue hinter Lentfch ad Ruckmarsdorf vsque et alibi. Flor. Iul. Aug. Annua.

Obf. Ob radicem repentem agris valde noxia. $\mathrm{Pa}$ bulum Equorum effe gratifimuin et ab Ouibus fuibusque appeti Gunner. notauit 1. c. P. I. p. $5 \%$

oleraceus. ro6o. Sonchus pedunculis tomentofis, caly cibus glabris. LINN. Syft. p. 7 i2. n. 5.

laeuis. Var. $\alpha$ ) Sonchus oleraceus, foliis teneris et laeuibus, calycibus glabris. вогим. n. 216 . вLAckw. tab. I 3 .

afper.

B) Sonchizs oleraceus, foliis amplexicaulibus, rigidiufculis, petiolo foliaceo, lerrato, pinnis triangularibus, ferratis. Fall. Stirp.' n. 21. воЕнм. n. 2 I.5. Fl. Dan. t. 843 .

Pharm. a) Srnchi laenis $\beta$ ) afperi Herba.

Kohlartige Günfodiftel; Saudiftel; Milchdiftel; Le. lerdiftel; Hajenjallat; Saumelke; Gänfemilch; Wachtchveizen; glatter oc'er raucher Hafenkohl. Gern. Smooth Southiftle. Angl. Laitron des jardins, ou Palais de lieure. Gall:

In ruderatis, cultis: Var. $\alpha$ ) praecipue in hortis oleraceis: $\beta$ ) In agris et ad fepes frequens. Fl. Iun. Aug. Annua.

Agris pifis fatis molefus.

$V \int$. Hyemali tempore folia tenera pro acetariis in. feruiunt. Vaccis, Ouibus et Pafferibus canarienfibus gratum eft pabulum. Si Lepores tandem copiofe edunt, caro eorum ingrato gaudet fapore. BOEHM. 
377. LAPSANA. L. G. 998. Rainkohl; Milchen. Germ. Nipple-Wort. Angl. Lampfane.

Gall.

Y06r. Lapfana calycibus fructus angulatis, pedunculis communis. tenuibus, ramofifimis, LiNn. Syít, p. 721. гогнм. n. 203. Fl. Dan. t. 500 .

Geneiner Rainkohl; falfiher Sallat; wildes Sonchenkraut. Germ. Common Nipple-Wort. Argl. Lampfane commune. Gall.

In aruorum terminis et inter olera, copiofe circa Pfaffendorf, et in Syluis im Univerfatâtsholze, 'Rofentthale ctc. Fl. Iun. - Aug. Annua.

V. Pabulum pecoribus et folia iuniora in annonae penuria ad olera paranda vilia.

378. HYOSERIS. L. G. 995. Kranichkraut, Germ. Hyofere. Gall.

1062. Hyojeris caule diuifo nudo, pedunculis incrafla. minima.

tis. LiNn. Syft. p. 72́. вовн. n. 204. Fl. Dan. tab. 201.

Kleinftesf. Ainkendes Kranuichkraut; kleiner Scinzecinejallat; Sandendivien. Germ. Small Swinte's Succory. Angl. Hyofere naine. Gall.

In agris, frequenter nach Schönfeld et circa Gunndorf: in iisdem locis hinter Krzphane et Schöpftadt valde vulgaris. Fl, Iun.-Aug. Annua.

b) Corollis vniformibus, tubulofis.

a) Floribus capitatis.

379. CARLINA. L. G. I008. Eberwurz. Germ.

Carlin - Thifle. Angl. Carline. Gall.

1063. * Carlina caule multifloro, flore breuiore. LINN. acaulis.

Sylt. p. 728. Leys, n. 804.

Plarm. Carlinae f. Cardopatiae Radix. 
Stammloje Eberu:urz; weiffe Ebereeurs; englifche Diftel; wilde Artifchocke. Germ. Durarf Carline Thifle; White-flouered falklejs Carline-Thifle. Angl. Carline faus tige; Camíléon blani, ou Chardonnerette. Gall.

In locis montofis, fterilioribus, anf dem Sandberge vor Nautendorf, porro ad Ruckmiarsubrf, nach $A$ - et Markranftidt et Liitzen; bei Ketfehau; inueni Flor. Iul. Aug.

vulgaris. 1064. Carlina caule multiforo, corymbofo, floribus terminalibus, calycibus radio albo. IINN. Syft. pag. 729. ก. 4. Вовнм. ก. 189.

Pharm. Heracanthae Radix.

Geneine 1. wilde Eberzeurz; Sooct. 1. Dreiniftel; wilder Feldfafran. Germ. Carline - Thiflle. Angl. Carline vulgaire. Gall.

In campis aridioribus et montibus afperis bei Klein$\approx$ fchocher, bei Meisdorf, in Bzeniz et in fepulcreto ad Altranftädt. Fl. Iul. Aug. Perennis.

350. CNICVS. L. G. 1005. Krazkraut. Germ. Foreign-Thiftle, Angl. Cnique. Gall.

oleraceus. 1065. Cnicus foliis pinnatifidis, carinatis, nudis, braCteis concauis, integris." LINN. Syft p. $=27$.

Cricus calyce bracteis cincto: Iquamis ramefo. fpinofis; bracteis concauis, integris, fibcoloatis, foliis glabris, amplexicaulibus, pinnatifidis. WLDEN. Prodr. Berol. n. 797. вовнм. n. 200. Fl. Dan. tab. 860.

Kohlartiges 1. Gelbes Kratzkraut; Graskohl; wilder Suflor; Wieferzkohl f. Wiefentifiel; gellhe Diftel; Kohldiftel. Germ. Round leaven Meridore Cnicus. Angl. Cnichant charnue; Chardon des près; Cniqune des jardins. Gall.

In pratis locisque paludofis, auf den Gerbor-und Schönfelder Wiefen valde frequenter. Fl. Iul. Aug. Perennis.

Vf. Folia Brafficac loco, praccipue in Polfia, in cu. linis adhibentur. 
ro66. Cuicus foliis pinnatifis : pinnis incifis, margine açulis. fpinolis, calyce conico, glabro. WILDEN. Prodr. Berol. n. 800 .

Carduus acaulis, calyce glabro. LiNn. Sylt. pag. 727. n. 3\%. вовнм. n. 196.

Stanmlofe Wiefenkohldiftel. Germ. Dwarf Carline. Thifle. Angl, Chardon-nain. Gall.

In agris et pratis ficcioribus, hinter dem Bieniz, an der Merfeburger Straßse et in pratorum terminis iuxta pagos bei Stötteritz etc. Fl. Iul. Aug. Perennis.

381. CARDVVS. L. G. 1004. Diftel. Germ. Thiftle. Angl. Chardon. Gall.

* Foliis decurrentibus.

I05\%. Carduns foliis decurrentibus, pinnatifidis, hifpi- Isnceolatus, dis, Iaciniis diuaricatis: calycibus ouatis, fpinofis, villofis, caule pilofo. LINN. Syft. p. 724. n. 2. ЕовнM. n. 194.

Lanzenförmige Diftel; Speerdiftel; gemeine Weg. diftel Gerin. Spear Thufle. Angi. Chardon lancéolé ou Cinardon broffe is fleur rouge Gall.

In ruderntis, palcuis et ad viarum publicarum margines vbique. Fl. lul. Aug. Perennis.

Obj. Agris minus gratus.

1068. Carduus foliis femidecurrentibus fpinofis, flori- nutans,

bus cernuis, fquamis calycinis fuperne patentibus. LiNN. Syft. p. 724. n. 4. вовнм. n. 191. Fl. Dan. t. 675.

Ueberhüngende Bifandiftel. Germ. Mufck Thiftle. Angl. Chardon penché, Gall.

in agris'montolis et fterilioribus, in aggeribus circa vrbem, ad vias publicas vbique, circa multos pagos copiofe et in dumetis. Flor. Iun.-Aug Pelennis.

Obf. Haec fpecies quoad corollae colorem inters dum variat, et paffim colore albo et rofeo deprehenditur. 
acanthoides 1069. Carduus foliis decurrentibus finuatis, margine fpinofis; calycibus pedunculatis, folitariis, ereetis, villofis. LIIN. Syft. pag. 721, n. 5. SCHREE. p. 15:-n. 915. JACQ. Flor. Auttr. Vol. 4. t. 349.

Wegedifct; Barenklaudifel. Germ. IVelted Thifle. Angl. Chardon acanthe. Gall.

Ad margines viarum arrozumque, in collibus circa Vrbem et in cultis copiofe. Flor. Iul. Aug. Perennis.

crifpus. 10\%0. Carduns foliis decurrentibus, finuatis: margine fpinofis, floribus aggregatis, terminalibus: fquamis inermibus, fubariftatis, patulis. LiNN. Syft. p. 724 . n. 6. вовнм. n. 192, Fl. Dan. t. 621 .

Var, \&) Carduzus flore albo.

Trraufe 1. gemeinze Diftel; lileine Ackerdiftel; kleine Wegdiffel; Kratzdiftel. Germ. Thiftle upon-Thifte. Angl. Chardon frifé. Gall.

In agris cultis et ad vias frequens rbique. Fl. Iul. Aug. Biennis.

Agris valde moleftus.

paluftris. 1071. Carduns foliis decurrentibus dentatis: margine jpinofis; floribus racemofis, erectis, pedunculis inermibus. LinN. Syft, p. 724. n. S. вовнам. n. 198.

Sumpfdig,tel. Germ. Marjh Thifle. Ang!, Chardon des marais. Gall.

In pratis paludofis et nemoribus frequens. Fl. Iun. Jul. Perennis.

Pratis inuifus. Ex huius altitudine Smolandiac et Wermlandiae ruricolae infequentis hyemis et niuis prognofticon fihi formant. Planta tenella a Smolandis editur. Lins. Flor. Weft. 236.

tuberofus 1072. Carduns foliis fubjecurrentibus, periolatis, fubpinnatifidis, fpinofis, caule inermi, floribus folitariis. zinn. Sy'f. p. 725. n, 19, schreb. Spicil, pag. I5. n. 197.

Knolligte Diftel. Germ. Tuberofe.rooted Thiffle. Angl. Chardon bulbeux. Gail. 
In pratis fubhumidis inter Kleindolzig et Bieniz, in pineto ad Lindenthal; auf dem Behomot, copiofe. Fl. Iul Aug. Perennis. cibo.

$V \int$. Radices nonnullis gentibus inferuiúnt pro

** Folic Jefjilibus.

10-3. Carduus foliis amplexicaulibus, haftato pirnati- marianus. fidis fpinofis, calycibus aphyllis: fpinis canaliculatis, dupicato fpinofis. siNn. Syft. p. 726. воЕнм. n. IY\&. BLACKw. t. “9.

Pharin. Cardui Mariat Herba, Semina.

Murien-1. Frauendift!l; unfer liebon Frauendifel; Siber-Milchdiftl. Germ. Ladies Thiftle, or Milk. Thifle Angl. Marie, ou Chardon de notre Dame, Cizardon laité. Galt.

In cultis frequens et ad fepes bei Gohlis atque in hortis oleraceis. Fl. Iul. Aug. Annua.

1074. * Carduus foliis feffilibus bifariam pinnatifidis: eriophorus. laciniis alternis eretis, calycibus globefis villofis. LiNn. Sylt. p. 726. n. 27. JACQ. Flor. Auftr. Vol. 2. t. 171 .

Carduus capite rotundo tomentofo. C. B. P. pag. 382.

Wollköpfigte Diftel. Germ. Wooly-headed Thiftle. Angl. Chardon cotonneux; Chardon aux Anes. Gall.

In aggeribus circa Vrbem et ad fepes hortorum paltim, in hortis quoque fparfim. Flor. Iul. Aug. Biennis

$V \int$. Capita huius virentia ante florum eruptionem in Gallin et Scotia in culinis praeparantur stque ibidem in deliciis habentur.

1075. Carduus foliis amplexicaulibus lanceolatis den- helenioides. taris: fpinulis inaequalibus, ciliatis dentotis, caule inerini. LINN. Syft. pag, 726. ก. 31. вовнM. 1 . $19 \%$. 
Sibirifche Alantliffel. Germ. Melancholy Thiftle. Angl.

In prato unten am Bicniz et in hortis multis. Fl. Iul. Aug. Perennis.

382. CYNARA. L. G. 100I. Artifchocke. Germ. Artichoke. Angl. Artichaur. Gall.

Scolyıus. 10-6. Cynara foliis fubfpinofis pinnatis indiuifisque, calycinis fquamis ouatis. LiNN. Syft. p. 728. n. I. BОЕНM. n. 199. BLACKW. t. 458 .

Var. ж) Cynara hortenfis aculeata.
\&) Cynara hortenfis non aculeata.) P. 383.

Gemeine Artifchocke; wilde Artifchocke. Var. a) Grüne Gartenartifchocke; $\beta)$ große englifche, gemneine, glarte, runde f. rothe Artifchocke. Germ. French Artichocke; $\alpha)$ Green Artichoke; $\beta$ ) Globe, or red Articho. ke. Angl. Artichaut comman; a) Artichaut vert; Artichaut de Lens à groffe tête; $\beta$ ) Artichaut rouge; Artichaut à la poivrade; Artichaut commun des jardins. Gall.

- In Italiae et Siciliae agris fponte crefcit. In nofrratibus hortis et agris oleraceis vbique maxime co: luntur. Fl. Aug. Sept. Perennis.

$V \int$. Squamae Caly cis ante forefcentiam refectae elixantur in aqua fubfalfa et eduntur vehiculo embammatis. Receptaculum magis carnofum tenerrimum. que, magsis fapidum. Capita virentia eduntur cocta et refrigerata cum oleo, aceto, pipere. In Barbaria vtuntur Arabes et Mauri floribus Cynarae ad Cafeum conficiendum. Corollaè recentis infufum tale communi admixto lac coagulare fertur.

383. ONOPORDON. L. G. IO06. Zellblume; Efelsfurz. Germ. Wolly Thiftle. Angl. Onoporde. Gall.

Acanthium. 1076. Onopordon calycibus fquarrofis: fquamis patentibus, foliis ouato-oblongis, finuatis. LiNn. Syft.p. 728. ВОЕнМ. ก. 186.

Pharm. 
Pharm. Acanthii vulgaris Herba, Semina.

Teutfche Zellblune; woiffe Frausendiftel; wilde Artifchocken; weeiffe Bergdiftel; Ejolsfurz; KrebsKrampfdiftel. Germ. Common IVolly, or Cotton Thifle. Angl. Onoporde, ou Pedane; Pet d'Ane; Grand Chardon de Portugal; ou Epine blanche. Gall.

In ruderatis, aggeribus circa vrbem, prope Alnetum ad Schönfeld, in nemoribus fere omnibus et ad forfas vbique. Fl. Iun. Aug. Perenais.

Agris faepe moleftum.

$V_{j}^{r}$. Succum recenter ex herba expreffum contra cancrum Eller laudat. Radices Romae menfis inferviunt. Thalami et caules iuniores efculenti.

384. SERRATVLA. L. G. IOOS. Scharte. Germ.

Saw - Wort. Aingl. Sarrette, ou Chardon des vigne's. Gall.

1077. Serratula foliis lyrato-pinnatifidis: pinna termi- tinetoria. nali maxima, flosculis conformibus. LINN. Syft. pag. 723. военм. n. 190. Fl. Dan. t. $28 \mathrm{I}$.

Var. ) Serratula foliis inferioribus integris, fuperioribus incifis.

B) Serratula foliis omnibus incifis.

2) Serratula foliis omnibus integris.

Färberfcharte; Wiefent t. Bergfcharte. Germ. Conto mon Sare-Wort. Angl. Sarrette des Teinturiers. Gall.

In pratis humidis, e. g. in Rofenthale, bei dems Kuhthurme et ad K'leindölzig, auf der Behomotsweie/e, im Hegegrafe inter Betulas copiofe, in fyluis mentofis, im Bieniz, porro vor Grasdiorf. Fl. Iul. Aug. Perennis.

$V \int$. Luteo tingit colore, vti Luteola, tinftoribus vfitatiflima.

1078. Serratula foliis dentatis, lanceolatis, fpinolis, ra- aruenfise dice repente. LinN. Syft. p. 724. n. 15. вовнм. n. I95.

Var, a) Serratula flore albo. 
Ackerjchartenkraut; wilel Scharte; Haber-f. Ackerdiftel, Haberdiftel; Saudiftel; Felddrftel; Margentdiftel. Germ. Field Saw - Wort or Way Thifle. Angl. Chardon hémorroidal; Sarrette des Champs; Cinardon des Vignes. Gall.

In agris maxime inter Auenam: var. in lncis limo. fis um die Ziegelfcheune. Flor. Iul. Aug. Annua.

Radix valde repens difficillime exftirpari poteft. Turiones et iuniora folia ab Ouibus auide dezorantur; folia contra adultiora intacta relinquuntur.

385. ARCTIVM. L. G. 1002. Klette. Germ. Burdock.? Angl. Glouteron. Gall.

Lappa. 1079. ArCtiun foliis cordatis, inermibus, petiolatis. inn. Syft. p. 723. BLACKw. tab. i I \% Fl. Dail. tab. 642.

Var. \&) ArẼ tum capitulis glabris maioribus. вовнм. n. 201 .

202.

B) Arglizn capitulis tomentofis. вовнм. n.

Pharm. Bardanae Radix, Herba, Semina.

remeine 1. große Hoffenklette; Klettendiftel. Germ. Common Buridock. Angl. Grande Bardane, ou Barda. ne ordinaire; Glouteron. Gall.

Vf. Caules, antzquam capitula emitrunt, cortice denudati et rite col colti tanquam Afparagi fapiunt et nutriunt. Radix iunior efforta tenera et efculenta fi, more icorzonerae, pro menfa paratur, fatis lapida fit. Capitula ouibus et veftimentis adhaerentia et inuifa. Herba exficcata igni iniecta nirri ad inftar crepitat.

ß) Floribus difcordeis.

386. IVPATORIVM: L. G. IOI 5. Albkraut. Germ. Hemp-Eupatory. Angl. Eupatoire. Gall.

cennabinum 1080. Eupatorium foliis digitatis. unNN. Syft. p. -36.n. 14. BOEHм, n. 185. BLACKw. t. IIO. Fl. Dá, t. $7+5$.

Pharm, 
Pharm. Eupatorii Radix, Herba.

Hanfartiges Albkraut; Waferdofte; Wafichlianf; Leberbaljsm; Tugendblume; Hirfchklee; Kunizundenkraut. Germ. Common Hemp-Agrimonzy. Ang!. Eupatoire cannabine. Gall.

Ad ripas fuftarun vor Nötfich et in locis vmbrofis, an den Grïben hinter Schönfeld, an der Wiefe untenz an Bieniz. Fl. Iun, - Aug. Perennis.

387. BIDENS. L. G. Ior 2. Zweizahn. Germ. WaterHemp.Agrimony. Angl. Bident. Gall.

108r. Bideñs foliis trifidis, calycibus fubfoliofis, femi-triputt ta. nibus erętis. linn. Syft. pag. 732. вовнм. n. 187 . BLACKW. t. 519 .

Dreitheiligter Zweizahn; Fotzenigel; gelb Färberkraut. Germ. Trifil Water-henz-Agrimony. Angl. Bident sulgaire; Bidcut ì fiuilles de Chanvre; Eupasoire aquatique. Gall.

In locis paludofis et foffis vbique. Flor. Iul. Aug. Annua.

$V \int$. Luteo haud ineleganti tingit colore.

1082. Bidens foliis lanceolatis fubintegerrimis, ferfili-minima, bus, floribus feminilusque ereatis. LINN. Syft. pag. 732. n. 2. SCHREe. Spicil. p. I4. n.914. Fl. Dals. tab. 312.

Kleinfer Zweizaln. Germ. Leaft. - Water-HempAgrimony. Angl. Bident tiès petit. Gall.

In agris arenofis nudis zach Schönfeld, in der Thongrube vor dem Petersthore. Flor. Iul. Aug. Annua.

ro83. Bidens foliis lanceclatis amplexicaulibus, fori-cernua. bus cernuis, feminibus ere tis. LINN. Syit. p. $73^{2}$. n. 5. вотнм. n. IfS. Fl. Dan. t. 8.41 .

Höngender Zưeizahn; Wafferzenndkraut; Gabelkraut. Germ. Whole-leaved Water-henp-Agrimony. Angl. Bidcnt penché. Gali.

In locis inundatis et ad fofias auf der Pfingfteriefe, et alibi. Fi. Iul. Aug. Annua. 


\section{S V P E R F L V A.}

a) Floribus difcoidcis; corollulis difformibus, ominibus tubulofis.

388. AKTEMISIA. L. G. 1025. Wermuth. Germ. Mugwort. Angl. Armoife. Gall.

* Procumbentes ante Florefcentiam.

campeftris. I084. Artemi/ia foliis multifidis, linearibus, caulibus procumbentibus, virgatis. LINN. Syft. p. $\div+3 \cdot$ n. 9 . ВОЕНM. n. 160 .

Pharm. Artemifrae campeftris Herba, Semina.

Feldwermuth; wilde Stubrurz. Germ. Common Field Southcrmwood Ang!. 'Armoije champêtre, ou Aurone fauvage. Gall.

In pratis montofis, campoftribus anf dem Gickerlingsberge, auf den Sandberge vor Naucndorf, Rückmarsdorf, in Eieniz. Fl Aug. Sept. Perennis.

VJ. Semina a Gallis in pleuritide ex optato adhibito. Contra vermes feminibus Cynae facile palmam praeripere dicit. LiNN.

** Erectae, herbaceae, foliis compofitis.

pontica. 108\%. * Artemifia foliis multipartitis fubtus tomentofis, florinus fubrotundis, nutantibus: receptaculo nido. IINN. Syft. p. 74+. n. 16. JACQ. Fl. Auftr. Vol. 1. t. 99.

Abfinthium ponticum tentifolium incanum. C. B. P. p. : 38 '

Pharm. Abfinthii Pontici Herba.

Gartenzermuth, rönsifcher f. pontifcher Wormuth. Germ. Pontick Vormielond; True Roman Wormswood. Angl. Armoife Abfinthe pontique; petite Abfinsthe pontique; Pichot encenis Gall

Habltat in Hung $q$ ria, Auftia. Heluetia, Sibiria.

In noftratibus hoitis et agris oleraceis frequenter; ad lepes hortorum et in ruderatis paffin occurrir. F!. Iul, - Sept. Perennis. 
1086. Artmifia foliis compofitis multifidis, floribus Abfynthium fubglobolis, pendulis: receptaculo villolo. LINN. Syf. pag. 74子. n. 20. BOEHM. n. I65. BLACKW. tab. 17.

Hharm. Alyynthii vulgar is Herba.

Gewöhnlicher Wermuth Germ. Common Wormzeood. Ang. Grande Abfinhe; Aluyne Armoife Abfinthe vulgaire Gall.

In ruderatis paffim hinter der Ziegelfcheune et ad pagos frequens: in hortis contra copiofe. Flor. lul. Aug. Perennis.

$V \int$. Si Oues hac herba vefcuntur, eorum_caro amarum habet gufum. Herba pulices fugare fertur Cereuifiis acidis vel vino ipfi afcefcentiam tollit.

I087. Artemifia foliis pinnatifidis, planis incifis, fubtus vulgaris. tomentofis, racemis fimplicibus, recuruatis, florum radio 5- floro. LINN. Syft. p. 744, n. 2 I. BLACKW. t. 431 .

Var. \&) Artemifia flore albo, vel rubro.

Pharm. Artemifiae vubrae 1. albae Herba, Radix.

Gemeiner Beifuf.s; Iohannisgürtel; Gânjekraut. Germ. Common Mugwort. Angl. Armoife vulgaire. Gall.

In verfuris, ad vias, in der Leimgrube in aggeribus circa Vrbem et ad fepes pagorum bei Gonnewitz, Störmthal etc. frequens, Flor. Iul. Aug. Perennis.

$V \int$ Folia in Anfere Troiano infareta faporem ipfi reddunt gratum.

389. TANACETVM. L. G. 1024 Rheinfarn. Germ, Tanfy. Angl. Tanaifie. Gall.

1088. Tanacetum foliis bipinnatis, incifis, ferratis. vuloses LINN. Syft. pag. 742. BOEHM. n. I63. BLACKW. tab. 404

Var. «) Tanacetum foliis crifpis.

Pharm. Tanaceti Herba, Flores, Semina, 
Gewöhnlicher Rheinfarn f. Revierkraut; Wurnfarn; Wurmkraut; Wusrnfaámen; Weinfarrn. Germ. Common Tanfey. Angl. Tanaifie vulgaire, ou Celles de Tanaifie. Gall.

In aggeribus circa vrhen, ad ripos fiuuiorum, ad agrorun-verfuras copiofe in der leimgrube, vor dem Zfchocherfchen Holze, bei der Zuegcljcheune, var. in hortis et alibi. Fl. Iul. Aug. Perennis.

$V \int$ Folia tenella in placertis ex ouis et farina confectis gratifimum exhibere ferculum refert. Lins. Feminas in Weftrobotnia hac planta ante partum vti; Demortuo. rum cadauera hoc ipfa a putredine diutius conleruara Elfdaienfes etiam commemorat LinN. vid. Amoenitt. Vol. I. pag. 529. Flores viridi tingunt colore.

Ealfamita. 1089. Tanacetum foliis ouatis, integris, ferratis. LINN. Syft. p. 742 . n. 7. BLACKw. t. 98 .

Mentha hortenfis corymbifera. C. B. P. p. pag. 226.

Pharm. Balfanitae Herba.

Kofteritrz; Frauenmïnze; Münzbalsan; Frauenkraut; Balfamkrant. Germ. Coftmary. Angl. Tanaife Menthe-coq; Coq-Menthe-Coq; Paté; Herbe au Coq; Coq des jerdins. Gall.

In Europa auftrali habitat.

In noftratibus hortis et in agris oleraceis valde co. litur. Fl. Iul. - Septr. Perennis.

Planta eft amara, quae bene fuaueolento gauảet odore et venenatam opii vim infringit. Folia iuniora tenera apud Batauos laganis immifcentur.

390. CONYZA. L. G. I030. Dürrwuz; Flöhpflanze. Germ. Fleabane. Angl: Conife. Gall.

içuartofa. I090. Conzy a foliis lanceolatis, acutis, caule herbaceo corymbofo, calycibus fquarrofis. LiNn. Syft. p. 752 . mogha. 'n. 181. blackw. t. 102. Fl. Dan. t. IO2.

Sparrichte Dürreturz; Ruhrkraut; gelbe Mïnze. Germ. Plokghman's Spikenard. Angl. Conife vulgai-, re; ou Herbe aux puces. Gall. 
In campeftribus ficcis hinter Kriphäne nací der Prellizcide zu, auf dem Tiefenfeer Antheil, umb das Brandworeerk, vor dem Gerberthore, et in montofis, auf dem Bieniz, Giskerlingsberge. Fl. lul. Aug. Perennis.

$V f$. Culices et pulices pellit herba recens.

391. GNAPHAL VM. L. G. 1026. Ruhrkraut.

Girm. Cudweed. Angl. Immortelle, ou Perliere. Gall.

\section{* Chryfocoma.}

109r. Gnaphalium herbaceum, foliis lanceolatis, infe- arenariuu. rioribus obtufis, corymbo compofito, ciulibus fimplicifimis. LINN. Syft. p. $7+7 \cdot$ n. 26. BOEHM. n. 175 . BLACKw. t. 529. Fl. Dan. t. 6.t1.

Pharm. Stoechadis Citrinae Flores.

Sandruhrkraut; krautartige Sandruhrpjlanze; gelbe Rhein-Mottenblume; Vimterblümchen; Tïnglingsblimchen; Immerfchon; fchöne Liebe; teutfche gelbe Strohblume. Germ. Goldy Locks, or Sand Cudreeed. Angl. Conife; ou Perliere des Sables. Gall.

In campeftribus arenofis et apricis, vor dem Gerberthore et in via nach Schönfeld nach der Mühle zu, auf dem Sandberge hinter den Straffenhaujern, in locis elatioribus aren fis bei Nauendorf, Rückmarsdorf etc. Fl. Iun. - Aug. Perennis.

\section{** Argyrocoma.}

1092. Gnaphalium farmentis procumbentibus, caule dioicum, fimplicifimo, corymbo fimplici, floribus, diuifis. LiNN. Syft. p. 748. n. 45. вовнм. n 174 .

Var. a) Gnaphalium mas flore globofo.

6) Gnaphalium femina flore oblongo.

Pharm. Gnaphalii Flores.

Zweihïufiges Ruhrkrant; Katzenpfötchen; Engelblums; weiß ᄃ. rothes Maufeöhrlein. Germ. Mountain Cud-eed, or Cat's-foot. Angl. Perlere dioique; Pied de Chat. .Gall. 
Iu locis arenofis, elatioribus, im Bieniz, hinter Molkveitz et in campis exaridis :vbique. Flor. Mai. Iun. Annua.

Obf. Quoad colorem facpius variat, ita, vt flores rubri cum albis mixti deprehendantur. Mares calyces fubrotundos, feminae contra fubcylindricos ferunt.

$V f$. Flores cum pane butyraceo vitulis in diarrhoea dantur.

\section{*** Filaginoidea.}

fyluaticum. Ic93. Gnaphalizm caule herbaceo, fimplicifimo, ere. cto; floribus fparfis. LinN. Sylt. pag. 748. n. 50. военм. n. 179. Fl. Dan, r. 254 .

Wald-f. großes Ruhrkraut. Germ. Upright Cudweed. Angl. Perliere des biois. Gall.

In fyluis et nemoribus arenofis frequens. Flor. Iul. Aug.

vliginofun. 1094. Gnaphalium caule herbaceo, ramo diffufo, foribus confectis terminalibus. LIN N. Syft. p. 748. n. 57. военм. n. 180. Fl. Dan. t. 859 .

Sumptrihrikraut 1. Moraftruhrkraut; SchearaesRuhrkraut. Germ. Black-headed Cudwoed. Angl. Perliere des marais. Gall.

In locis inundatis frequens. Flor. Iul. Aug. Annua.

b) Floribus radiatis: Corollulis difformibus, in difco tubulofis; in radio ligulatis.

392. BELLIS. L. G. 1042. Maslieben.-Germ. Daify. Angl. Paquerette. Gall.

perennis. 1095. Bellis feapo nudo. Linn. Syft. p. 770. вовнм. n. 226. BLACK w. t. 200. Fl. Dani. t. 503.

Var. a) Bellis flore toto albo. pureo itriato.

ß) Bellis petalorum difci margine colore pur-

Pharm, 
Pharm. Bellidis minoris Flores.

Maslieben; Gänfe Angerblïmchen ; Margàrethersblümchen; Sonmerthierchen; Tanfendfchönchen.Germ. Commort Daify. Angl. Paquerette vizace, ou petite Marguerite. Gall.

In pafcuis, pratis, pomariis, campis, apricis et gramineis et ad vias vbique frequentiffime. Flor. per totum fere annum. funt.

$V \int$. Folia in annonae caritate ad olera adhiberi por-

393. MATRICARIA. L. G. I049. Mutterkraut. Gcrm. Feverfew. Angh Matricaire. Gall.

1096. Matricaria foliis compofitis, planis: foliolis Parthenium. ouatis incifis, pedunculis ramofis. LINN. Syft. pag. 774. военм. п. 228. в́ACKW. t. 192. Fl. Dare tab. 674 .

Pharm. Matricariae Herba, Flores.

Gewöhnliches Mutterkraut; Metter; Metram; Matronenkraut; Iungferkraut; Fieberkraut; Midchen. blume. Cierm. Common Featherfere. Angl. Matricaire officinale, ou E/pargoutte. Gall.

In ruderatis, pagis et ad fepes paffim in Veneto ad Plaufigg. Fl. Iul. Aug. Perennis.

$V \int$. Vernali tempore herba iunior cum pane butyraceo coméditur in nonnullis regionibus.

1097. Matricaria receptaculis conicis, radiis deflexis, fuaueolens. Iquamis calycinis maigine aequalibus. LiNN. Syft. pag. 774 . n. 3. SCHREB. Spicileg. pag. 47. n: 919.

Wohlriechendes Mutterkraut. Germ. Sieeet-Jcented Feverfew. Angl. Matricaire odorante. Gall.

In ruderatis agris inter fegetes paflim. Flor. Iul. Aug. Annua.

10y8. Matricaria receptaculis conicis, radiis patenti-Chamomilla bus, 1quamis calycinis margine aequalibus. LINN. Syft, p. 774, n, 4. вовнм, n. 23 I. BвLACKW, t. 298.

Pharm. 
Pharm. Chamomillae Nofratis Herba, Flores.

Chamillen; Gamillon; Ramillen; gemeine Kamille; Feldkanille; Richmerey; Römerey; Romey;-Hermchen; Hermel; Hellmerchen; Hermunzel; Kanmelblitme; Laugenblume. Germ. Corn Feverfew. Angl. Camomille commune. Gall.

In agris fecalinis, cultis requietisque et ruderatis locis fere vbique.' Fl. Iun. - Aug. Annua.

$V f$. Pabulum bobus, capris, ouibus gratum. Herba a balneatoribus adhibetur.

Puluis forum Cortici Peruuiano faepe addi folet et contra febres intermittentes, vt ipecificum jsuda. tur remedium.

394. CHRYSANTHEMVM. L. G. 1048. Wucherblume. Germ. Golden Flower. Angl. Grande Marguerite. Gall.

\section{* Leucanthemum, radio albo.}

Leucanthe- 1099. Chryfanthemum foliis amplexicaulibus oblongis: mum. fuperne ferratis: inferne dentatis. IINs. Syft pag. 772. n-5.

Matricaria folis imris petiolatis ad caulem auritis et ferratis. вовнм. n. 2 в в.AC KW. t. $4 \%$

Var. c) Chryfanthemum caule villis canefcente.

B) Chryfantizmum foliis tenuifime incifis.

Pharm. Bellidis maioris et pratenfis Herba, Flo. res.

Iohannisblume, Kinds-op1. Kalbsauge; Kuhblume; große Maslieben; großse Gänfeblume. Germ. Greater Daify, or Common Ox - Eye. Angl. Grande Marguerite, ou Chryfantheme Lencantheme. Gall.

In verfuris, pratis, agris inter fegetes copiofe mach Eutritfch: Var. $\alpha$ ) in aggeribus bei dem Schlo (je, $\beta$ ) auf den Gonneweitzer Schanzen. Flor, Iun. Iul. PeLennis.

inodorum II00. Chrylanthemum foliis pinnatis multifidis, caule ramofo diffufo. LINN. Syft. pag. 7\%2. n. 10. SCHREB. Spicil.p. 17. n. 920. Sub Matricaria. Fl. Dan. t. \$y6. 
Geruchlofe Wucher-f. Iolamishlume; geruchlofe Hundskamille. Germ. Scentleß\} Ox=Eye. Angl.

In agris poft metfem, praecipue in folo arenofo bei Schönfeld, Lindenthal, Leutfci, nací Gonneveizz. F]. Iul. Aug. Annua.

Obf. I. Flores paulo minores, quam in antecedente. Cal. piano - conuexus : fquam is intericribus margine membrana fufca fcariofa vndulata ouais. Flosculi radii $12-16$, albi, tridentati, tubo breni ex'albo-flauefcente gaudent. Difci flores hermaphroditi, tubo albido inftrulti, fuperne flacsi, 5- fidi, regulares. Sem. 4 - gulata, ex fufco-atro, glabra, ad angulos fulcata, apice $;$ denticulis coronata. Rccept. ouato-oblongum, intus caium.

Obf. II. Planta omnis fere odoris expers.

I IøI. Chryfanthenum foliis pinnatis, incifo-ferratis, corymbol caule multifloro. Linn. Syf? p. 772 n. 12. Jace. Fl. fum. Auftr. Vol. 4. t. 379.

Matricaria foliis pinnatis, pinnis femipinnatis, laciniis dentatis, femine coronato, denticulato. вовнм. n. 730 .

Straußartige Wucherblume. Germ. Corynbiferous Daify. Angl. Chryfantheme en corymbe. Gall.

In fyluis montofis im Bieniz aliisque locis ficcioribus atque in hortis paffim. Flor. Iul. Aug. Perennis.

Agris inter fegetes valde molefts.

Obf. Sem. 4- gona calyculo proprio tubulofo, oblique denticulato, coronata. Planta omni odore faporeque caret.

\section{** Chrzffanthemuni radio luteo.}

1102. * Chrufanthemum foliis amplexicaulibus, fuper- fegctum.

ne laciniatis, inferne dentato-ferratis. LINN. Syft. p. 773. n. 17. Leys. n. 844. wilden. Prodr. Berol. n. 837.

Getreide Wucherblume. Germ. Corn Marygold. Angl. Chrufantheme des bles, ou Marguerite dorée. Gall. 
In agris inter fegetes, ruderatis frequens ad Nauendorf, Markranfiüdt et alibi. Flor. Iul. Aug. Septbr. Annua.

Planta agris expellitur ftercoratione autumnali, fe- $^{-}$ gete bienni, occationt quinto die poft feminationem, nouali. Ahlelöf. Praeterea illuminat agros et exhiliarat tranfeuntes floribus luteis egregie folifequiis. Scain. 266.

coronarium. $\mathrm{I1O3}^{*}$ Chryjanthemum foliis pinnatis, incifis, extrorfum latioribus. L1NN. Syft. p. 773, n. 22.

Chryfanthemun foliis Matricariae. C. B. P. pag. 134.

Cretifche Goldblume; Kronenfömige Wucherblume. Germ. Crezan Corn Marygold. Angl."

In Creta et Sicilia fponte crefpit.

In hortis vbique nunc quafi fpontanea fåta. Fl. Iul - Sept.

Olf. Flores vario modo ludunt coloribus.

395. ARNICA. L. G. 1038. Wolverley. Germ. Arnique. Gall.

montana. I Í⿴囗. Arnica foliis ouatis integris; caulinis geminis oppofitis. Linn. Syft. p. 768. Schreb. Spicil. p. 18. n. 922. BLACK w. t. 595. Fl. Dant t. 63.

Pharm. Arnicae Herba, Flores.

Bergevolverley: Fallkraut; Mutter-Engelskraut; Luzianskraut; Bluttrieb; Münchskappe; Verfangkraut. Germ. Plantain-leaved Mountain Anica, or Mountain Leopard's Bane. Angl. Arnique, ou Betoine des Montagnes; Tabac de Vôges, ou Doronic d'Allesmagne. Gall. .

In locis montofis, am Bieniz paffim et copiofe in der Warte ad Tauchan atque in dem Hegegrafe hintev Kriphäne etc. Fl. Iun. Aug. Perennis.

VI. Smolandiae ruftici folia in tabaci penuria huius loco adhibere folent. Arnica $n b$ vim refoluendifanguinem cosgulatum, Panacea Lapfortm, aliis vocatur. Cl. Collin multa inftituit experimenta cum floribus Arnicae et docet hoc fiores vi antifeptica maiore 
maiore gaudere cortice Peruuiano lllos enim laudat in paralyfi, in amaurofi. - Aaskowe quoque curio1a fecit cxperim:nta cum floribus, quibus confirmavit horum vilitatem, in tenuiori cer uista infuforum, in paralyfi, pro potu ordinario atque hoc infufo curavit febres internittentes etc. Hac vero methodo Cęl. BËRgivs fruftra vfus eft, nec puluis Arnicae radicis ei fucceflit in febre quartana. Caprae herbam in deiiciis habent; Boues contra intactam relin. quunt.

396. INVLA. L. G. IO37. Alant. Germ. Elecampane. Angl. Aunée. Gall.

Iro5. Inula foliis amplexicaulibus ouatis rugofis fub Hclenium. tus tomentofis, calycuin fquamis ouatis. LINN. Syft. p. 766 .

After foliis ampléxicaulibus, ex ouatis acuminatis, ora ferrata, flore amplifimo luteo. вовнм. n. 232 . ELACKW. t. 473 .

Pharm. Enulae f. Helenii Radix.

Gemeine Alantwurzel; Glockenwurzel; Helenakraut. Germ. Conmon Elecampane._Angl. Enulée campanne, ou Enule Aunée. Gall.

In pomariis ruftic orum, hortis multis locisque $15 \%$ vaticis, paffim im Univerfitâtsholze. Flor. Iun. Iul. Perennis.

-Vf. Fumus culices pellit, et pabulum equis, capris. Radix imprimis condita, inter expectorantia primaria, valet in Scabie Ouium, uins. Suec. 755 .

I 106. * Inula foliis amplexicaulibus, lanceolatis, fe:ra-britannica. tis, diftinctis fubtus villofis, caule ramofo eręto, villofo. linn. Syrt. pag. 766. n. 5. Jahn. n. 20. Fl, Dan. t. +13 .

Brittifcher Alant. Germ. Britifh Flea-bane. Angl. Enule Bricannique. Gall.

In locis montofis, fterilioribus um den Bieniz paffirt. Fl. Iul. Aug. Perennis. 
dyfenterica. 1107 . Inula foliis amplexicaulibus, cordato-oblongis, caule villofo, paniculato, fquamis calycinis fetaceis. LiNN. Syft. p. 766. n. 6. военм. n. 235. (fub Aftere) Fl. Dan. t. 410 .

Pharm. Conyzae mediae f. Amicae Suedenfis Herba, Flores.

'Purgivender 1. Rublualant; Badekraut; falfch Wohlverley; Hundsauge. Germ. Middle Flca-bane. Angl. Enule dyffentérique, ou Conife des près. Gall.

$V J$. Decoetum herbae Ipecificum, contra dyfentcriam in bello Ruforum cum Perfianis ex optato adhibitum fuife fertur: dudum autem a M. Hofmanno reclamatum. In fcabie etiam laudatur.

pulicaria. 110\%. Inula foliis amplexicanlibus vndulatis, caule proftrato, foribus fubglobofis, radio breuiffimo. LINN: Syft. pag. 766. n. 9. вогнм. n. I 82. (fub Conyza) ELACKW. t. 103. Fl. Dain. t. 613 .

Flähkraut; Chriftinenkraut; kleine Dïrre'urz. Germ. Small Flea-bane. Angl. Enule pulicaire; HerLe du St. Rocke, ou Herbe ausx puces Gail.

In foflis inundatis copiofe ad et poft Lindenan an dim Teiche aliisque locis frequens. Flor. Iul, Ang.

falicina iro9. Inula foliis lanceolatis, recuruis ferrato-fcabris ramis anguftatis, Horibus inferioribus altioribus. IinN. Syft. pag. 767. вовнм. n. 233. (fub Aftere) H. Dan. t. 786 .

Weidenblätrichter Alant; gelbes Bergfternkraut. Germ Willow-leaved Mountain Starwort. Angl. Enule falicine, ou Sauliere Gall.

In locis fterilibus, in der Leimgrabe, et inter frutices in alneto ad Schönfeld etc. Flor. Iun. Iul. Perennis.

In pratis haec minus grata. Solum enim indicat fterile.

hirta. 11 10. Inula foliis feffilibus lanceolatis recuruis fubferra. to - fcabris, caule teretiuf́culo fubpilolo, floribus inferioribus altioribus. LINN. Syf. p 67. n. 15. BOEHM. n. 234. (fub Aftere) JAcQ, Flor, Auftr, V. 4. t. 358. 
Raucher 1. fachlich:blättriger Alant. G:rm. Prick. ly-leaved Starreort. Angl. Enule heriffée. Gall.

In humidioribus ad folfas unten an Biniz, et in Syluis, im Bieniz, in Univerfitätsholze, in dem Hegegrafe- bei Kriphine, hinter Altranftiidt etc. Flor. lul. Aug. Peiennis.

$111 \%$. Inula folis frmlibus lanceolatis recuruis $\mathrm{fca}$ - germaniea. bris, floribus fubtifciculatis LinN. Sy't. pag. 767 . LEYS. ก. X51. Jare. Flor Auftr. V. 2. t. I34.

Teutfcher Alant. Giern. German Starwort. Angl. Enulc Germanique. Galf.

In nemoribus montofis, rarius im Bieniz praeterito anno inueni. Fl, lul. Aug.

397. ERIGERON. L. G 1021. Flöhkraut: Alt. mannskraut. Germ. Fl+a - bane. Angl. Vergeretie. Gall.

I1r. Erigeron caule florihus paniculatis, hirtis, foliis canadenfe. lanceolatis, ciliatis. LINN. Syft. p. 7.34: n. 6 .

Conyza floribus ex alis foliorum paniculatis. BOEHM. ก. I. 4 .

Kanadifches Flöhkraut; weiffe Dïrneurz. Germ. Canada Flea-bane. Angl. Vergerette de Canada. Gail.

In aggeribus et ruderstis circa vrbem, in campis, muris: et copiofe in der Leingrube hinter Altranftadt et alibi frequenter. Fl. Iul. Aug. Annua.

I113. Erigeron pedunculis alternis vnifloris. LINN. Syft. acre. p. 4. ก. 12. Вовнм. ก. 183. (ub Conyza)

Pharm. Conyzae minoris Herba.

Scharfes Flöh-Berufkraut; blaue Dürrwurz; Jcharfes Altmannskraut. Germ. Blue-flowered Flea-bane. Angl. Vergerette Aicre. Gall.

In locis fterilioribus, arenofis, montofis, in der Sandgrabe, bei den Pulverthurme, auf dem Sandberge bei Nauendorf et Ruckmarsdorf, im Bieniz. Fl. lul. Aug Annua.

Herba Ruga IVedelii, qua quidem contra Sodam. vtuntur, RYPP. Ienenf, $1-8$ 
398. SOLIDAGO. L. G. 1035. Goldruthe. Germ. Golden-rod. Angl. Verge dorée. Gall.

Virga aurca. II 14. Solidago caule fubfexuofo angulato, racemis paniculatis, erectis, confertis. EINN. Syft. p. 764. n. I1. воEнM. ก. 236 . BLACKw. tab. 169. Fl. Dan. tab. 663.

Pharm. Virgae Afureae f. Confolidae Saracenicae Ve, terum Herba.

Wahre Goldruthe; gülden Windkraut; St. Peters. ftab. Germ Common Englifh Golden-Rod. Angl. Verge d'or commun, ou Verge dorée. Gall.

In fyluis et ericetis, in fylua Academica, im Bieniz; porro in parcuis inter pagos Schönfeld et Abtnauendorf; porro copiofe ad fofficulas bei Seehaufen, in hortis quoque multis occurrit. Flor. Iul. - Sept. Perennis.

399. CINERARIA. I. G. 1036. Afehenpflanze. Germ. Ragwort. Angl. Jacobée. Gall.

paluftris. in 5. Cineraria floribus corymbofis, folis radicalibus petiolatis lanceolatis ferrato - finuatis; caulinis amplexicaulibus integris. wilden. Frodr. Berol. n. 828 .

Cineraria foribus corymbofis; foliis lato-lanceolatis, dentato-finuatis, caule villofo. LINN. Syft. p. 75. воена. n. 237 . (lub Solidagine) Fl. Dan. tab. 573 .

Var. «) Cineraria foliis integris.

Suspfafchenpflanze. Germ. Marfh hairy-falked Ragwort. Angl.

Ad foffas inter Arundines et Typhas, ; in dem Gerberieaffer, atque in paludibus ad pagum Hohenleine etc. Fl, Iun. Iul, Perennis. 
400. SENECIO. L. G. I033. Kreuzphlanze. Germ. Groundfel. Angl. Seneçon. Gall.

* Floribus flofculofis.

II 6 . Senecio corollis nudis, foliis pinnato finuatis vulgaris. amplexicaulibus, floribus fparfis. LiNN. Syft. p. 756 . n. 9. воЕНм. n. г7О. вLACKW. t. I32. Fl. Dan. tab. 513. KERN. B. I. p. 5I. t. 69.

Pharm. Senecionis Herba.

Gemeine Kreuseurz; Kreuzkraut; gemeine Kreuzpflanze; Goldkraut; Grimmkraut; Gründkraut; Sau1. Spezzeurz; Vogelkraut. Germ. Common Groundfell. Angl. Senzecon vulgaire. Gall.

In ruderatis, agris cultis, hortis in Serto bei und an den Schncckenber $g$ copiofifime, in muris, ad fepes vbique frequentifime. Flor. Vere ineunte in Autumnum vsque.

Furunculis impofita contufa herba medetur apud Helfingos. - Seminibus delectantur Pafferes Canarienfes caueis inclufi.

** Floribus radiatis: radio reuoluto.

II 17. Senecio corollis reuolutis: foliis pinnatifidis, vis- vifcofus. cidis; fquamis calycinis laxis, longitudine perianthii. LINN. Syft. p. $757^{\circ}$ n. 17. БовнM. n. 171 .

Klebrichte Kreuswurz; wollicht Kreuskraut. Germ. Senȩou vifqucux. Gall.

In ruderatis vor dem grimmifchen Thore hinter der Wohnung des Aufpafjers, in muris e. g. im Zuinger zwifchen dem Barfußpförtchen und den Ranftädter Thore, etiamqué circa pagos frequens. Fl. Iun. Iul. Annua.

II 8. * Senecio corollis reuolutis, foliis pinnatifidis. fyluatieus. denticulatis, caule corynibolo, erecto. LINN. Sylt. p. 757. n. 18. LEYS. n. 859. WILDEN. Prodr. Berol, n. 82 . Fl. Dan, t. 869 .

Wald Kreuzwurz. Germ. Seneçon des bois. Gall. 
In nemoribus montofis, humidis im Linkler Hölzgen I!: porluvs inuenit, etiam in der Kämmerei bei Nauendorf et alibi paffim mihi occurrit; porro ad fepes et vias frequens. Fl. Iul. Aug.

*** Floribus radiatis: radio patente, foliis pizazatifidis.

erucanfolius. 1119. Senecio corollis radiantibus, foliis pinnatifdis, dentatis lubhirtis, caule erecto. Link. Syft. p. 737 . n. 26. JAHN. ก." 5 .

Raucksublătivige Krenzueurz. Germ Seneçon à feuillos de Roquette. Gail.

In pratis hinter der Funkenburg et in fyluis copiofe. Fl. Iun. Iul. Perennis.

Iacobaca. 1120. Senecio corollis radinntibus; foliis pinnato-lyra: tis : laciniis lacinulatis, cant eręto. LINN. Syft.pag. 758. n. 31. воЕні ก. 171 .

$\left.\begin{array}{c}\text { Var. a) Tacobaea foliis inftar Erucae la- } \\ \text { ciniatis } \\ \text { B) Iacobaea foliis ad Raphanum ac. } \\ \text { cedentibus. }\end{array}\right\}$ TOVRNo'

Pharm. Tacobene Herbn, Flores.

St. Iacrbsblume; Zehrkraut; Krötenkraut. Germ. Seneçon Zacobée; Herbe de Saint Zaques, ou Arinotje des Fierboriftes. Gall.

In parcuis auf dem Gickerlingsberge et pritis fyluaticis. Var, $\alpha$ ) in fyluis montofis et cedu's: $\beta$ ) in pratis nach dem Kuhthurme, bei dem Gefundbrunnen nach der Tabacksmiiihle $z u$, ad fofficulas et ad margines fyluarum. Fl. Iun - Aug. Perennis.

Vf. Planta viridi f:turato co'ore tingit tota. Atz tamen radix, caulis et folia ante forefcentiam colligenda tunc cum laneis veltinentis coquitur C lor autem a radiis folaribus debilitatur. Vid. A\&. Stockh, Anni 1741. P. 148 . 
**** Foliis radiatis: radio patente, foliis indiuifis.

II2I. Senecio corollis radiantibus, foliis 'enfiformibus paludofus. acute ferratis, fubtus fubuillofis, cauie ftricto. LINN. Syst. pag. 758. n. 39. вовнм. n. 173. Fl. Dan. tab. 38.5 .

Sumpflkreuzuurz. Germ. Marfh Raguort. Angl. Seneçon des marais. Gall.

In pratis vliginofis, ad viam Halenfem et linter Gunndorf. Fl. Iun. Iul. Perennis.

40I. TVSSILAGO. L. G. I032. Huflatig; Rofshuf. Germ. Clot'sfoot. Angl. Pas d'âne.

II 22. Tuffilago fcapo vniforo, imbricato, foliis fubcor-Farfara. datis, angulatis, denticulatis. LINs. Syft. p. 755. n. 7. вовнм. n. $167^{\circ}$. Fl. Dan. t. 595 .

Pharm. Farfarae Radix, Herba, er TuJflaginis Flores.

Gemeiner Huf- f. Brandlattich; Roßhuf; Erdk'ro. ne; Ohmblâtter; Bruftlattich. Germ. Common Clot'sfoot. Anchl. Pas d'ine, ou Taconet. Gall.

In agris humidioribus himer Leatsch, bei Eutritfch am Graben, finter Nauendorf in locis argillaceis, bei Scherbitz atcue in foficulis ad viam publicam verfus Markranfäalt. Fl. Mart. April. Perennis.

Obf. Planta, vbi copiofe crefcit, ibidem folum argillofum atque fimul humidum indicat, vnde aquile. gis fignum. Plin. Figit argillum ad ripas praerun. tas fiuviorum.

$V \int$. Folia iuniora in iusculis vel pulmenti adinftar eduntur a nonnullis gentibus. Folia aëre exficcata Tabaci fuccedaneum. Radix, teftante Cordano, efculenta. Folia et Flores in infufo heticis et iis diarrhoea colliquatiua laborantibus cum euentu optimo dedit Cl. Percival. *) Tuffisfumo foliorum haufto, more tabaci, interdum curata eft apud Suecos. Fomes e radicibus ad excipiendas feintillas praeparari poteft. Flores ab Apious fiequenter quaeruntur.

$$
\mathrm{G} \cong 4
$$

1123.

4) Efjitys, medical anส experimsntal. Vol. II. p. 224. 
hybrida. 1123. Tufjilago thyrfo oblongo, fosculis femineis nudis, piuriuis IINN. Sylt. p. 75 5. 11. 11.

Tuffilago foliis fpicatis, flosculis pauciffinis herma. phroditis. вовнм. п. 169.

Baftard Roßlattich Germ. Long-ftalked ButterBur. Angl. Tufjilage hybride, ougr a nd P'étafitè. Gıll.

In locis humidioribus hinter Eutritfch et alibi. Fl. April. Perennis.

Petafites. II24. Tufjilago thyrfo onato, flosculis femineis nudis paucis. LINN. Syft p. $-5 \delta$ n. I'.

Tufjllago furibus fpicais, ficsculis omnibus her. maphroditis. Вовнм. n. 168. BzACKW. t. 222.Fl. Dan. t. $8+2$.

Pharm. Petafitidis Radix, Flores.

Peftulenzururzl; Srhueeißinurz; großer Huf Roßlattich; Neunkraftreurz; Giftwurz. Germ. Common. Butter-Bur. Angl. Chaperonniere; ou Tufjlage Pétafite; Herbe ou Teigneux. Gall.

In pratis humidis'jpongiolisque locis iuxta flumiorum ripas, in dem Gralicn linter Eutritfcí, bet Kleindölzig et ibidem in multis hortis rufticanis, bei Ket.

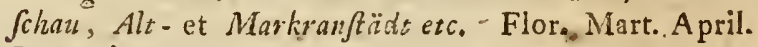
Perennis.

Obf. Gailinaceum genus et minora varia animalcula fub foliis lefe occultant, dum imbres perfundunt terram.

402. ASTER. L. G. I034. Sternblume. Germ. Starwort. Angl. Efpargoute. Gall.

* Herbacei integrifolii; pedunculis nudis.

Tripolium. I125. After foliis lanceolatis integerrimis, carnofis, glabris remis inaequatis, foribus corymbofis. LINN. Syft. pag. 76I.n. 8. SCHREB. Spicil. pag. I8. n. 9 I I. Fl. Dan. t. 615 .

Tripolien 1. Meerfternblume. Germ. Sea Starwort. Angl. After des marais. Gall. 
In locis falfis, e. g. ad falinas Ketfchauienfes frequens. Fi. Iul. Aug. Perennis.

1126. * Afrer foliis lanceolatis, obtufis, fcabris, triner-Amellus. viis, integris, psdunculis nudiufeulis, corymbofis, fquamis calycinis obtulis tiNn. Syft, pag. 761. n. 9. poll. Palat. II. n. 80 r. LEYs. n. 870.

After atticus caerule us valgaris. C. B. P. p. 267.

Virgils Sternblume, blau Stcrukraut. Germ. Blue Italian Starzeort. Angl. Oetl de Chrift. Gall.

Habitat in Europse auftralis collibus.

In hortis fuburbanis rufticanisque vbique frequen. ter in pagis et ad hortorum fepes palfim occurrit et quafi indigena,' Fl. Aug. Sept. Perennis.

Obf. Caul. eseetus, teres, hirfutus, ex viridi rubel. lus, pilofus, fuperiora verfus ramofus. Fol alternis radicalibus et caulinis inferioribus petiolatis, ouatis vel obouatis, integerrimis. ad paffim anteriora verfus crenatis acutis, caulinis furmmis Yeffilibus, omnibus nernofis; laere viridibus, fubpubefcentibus. Flores corymbum formantes. Pedunc alares, alterni, fubfoliofi, vniffori, fcabriufculi. Flosculi Radii ex violaceo-caerulei, patentes. Difci contra lutei.

En etiam flos in pratis, cur nomen Amello. Virg.

** Herbacei integrifolii; pedunculis £quamofis.

I127. After foliis linearibus integerrimis, caule panicu- ericoides. lato, pedunculis racemofis: pedicellis foliofis. LINN. Syst p. 7ór. n. I3.

After ericoides dumofus. Dill. Elth. 40. t. 36 . fig. 40.

Heideariger After-f. Sternblume. Germ. Bufhy Heath-like Starreort. Angl.

In America feptentrionali fponte nafcitur. Apud nos nunc copiofe colitur in hortis et in Horto WVinkleriano, Zörziriano etc et in aliis Vrbi vicinis occurrit, Fl. Aug. Sept. Peremnis. 


\section{4}

acris. I128. After foliis lanceolato-linearibusftrictis, integerrimis, planis, floribus corymbofis, faftigiatis, pedunculis foliofis. LINN. Syft. p.761. n. 17. JAHN.n. 19 .

Scharfes Sternkraut. Germ. Narbonne, or Purple Starvert. Angl. Ajter âcre. Gall.

Ad margines agrorum ad Lefien frequens et alibi. F1. Iul. Aug. Perennis.

Novae An- I 29. * After foliis lanceolatis, alternis, integerrimis, gliae. femiamplexicaulibus, floribus confertis terminalibus, caule hifpido. LinN. Syft. p. 761, n. 20.

After noure angliae altiffimus hirfutus, floribus amplis purpureo coerulaceis. HekM. Par. 98 . t. 98 .

Neuenglandifche Stcrublume. Germ. New England Staruort. Angl.

Habitat in Noua Anglia. In hortis abHortulanis copiofe colitur. Perennis.

Obf. Caul. fufcus. Pedunculi breuilfimi, vt vix apparcant. Flos ex purpureo-violaceus.

*** Herbacei ferratifolii; jedunculis lacuibus.

cordifolius. II30. After foliis cordatis, ferratis, petiolatis, caule corymbofo, pedunculis aphyllis, cautibus lasuibus, LiNN. Syft p. 762. n. 23 .

After latifoliis autumnalis. conn. Canad. 6\% tab. 65.

Herzblïttriges Sterkkraut. Germ. Cordated-leaved Starevort. Angl.

In Afia $\in t$ America feptentrionali habitat.

In hortis valde frequens. Flor. Aug. Sept. Perennis.

Oly. Caul. fublaeuis, fuperne magis ramofus. Fol. radicalia cordata, acute ferrata, fubtus pilofiufcula; Caulina inferiora ouata, ferrata petiolis emarginatis; fuprema fpatulato - lanceolata, amplexicaulia. Panicula corymbofa. Pedunculi nudi. Cal. imbricati: arcti. Radius exalbidus, vix purpurafcens; 12 - petalus.' Fios paruus. 
II3r. * After foliis lanceolatis: inferioribus crenatis, annuus. caule corymbofo, pedunculis nudis; calycibus hemifphaericis. LINN. Syft, p. $762, n, 25$. LEYs. n. $87 \AA$. Fl. Dan, t. \$86.

Tishriges Sterilkraut. Germ. Annual tehite Starwert. Angi. After anmel. Gall.

In locis arenofis, Pterilioribus, frequens in Horto Bofiano, paffim in der Lehm- und Sandgrube. Flor. Iul. Aug.

**** Herbacei ferratifolii, pedunculis Jquamofis.

132. After foliis lanceolatis, fubferratis feffribus, cau- NouiBelgii. le pariculato, ramulis vnifloris, folitariis, calycitus fquarrofis. LiNn. Syft. p. -62 . n. 3 !

After nouse belgiae latifolius vmbellatus, floribus dilu violaceis. HERM. Lugd. 66. t. 67.

Niuholländifcher After. Germ. New-Holland. Starwort. Angl.

In Virginia et Penfyluania habitat. Noftros ornat hortos, vbi in magna copia aunc colitur. Peren. nis.

1132. After foliis ouatis, angulatis, dentatis, petiolatis, Chinenlis. caulibus patentibus, foliofis, terminalibus. LIN Sy. Syf. p. $763 \cdot$ n. 36 .

After chenopodii folio, annuus, fore ingenti fpeciofo. Dizl. Elth. 38. t. 34. f. 3 \%.

Chinefifches Sternkraut; chinefifcher After. Germ.. Chinefe Starwort, or Chinia After. Angl. After de las Chine. Gall.

Habitat in China. In hortis fere omnibus frea quentiffme occurritet ibidem fiore fimplici, feriple. no, vel ex toto pleno, et coloribus permultis ludit.

401,* TAGETES. L. G. I064. Sammtblume. Germ. African Marigold. Angl. Oeillet d'Inde. Gall.

II $34 .{ }^{*}$ Tagetes caule fubdiuilo patulo. Liss. Syft. pag. patula. $770, \pi_{1}, I_{0}$ 
- Tanacetum africanum $\mathrm{f}$. Flos africanus minor. C. B. P. p. I32.

Var. f. Tagetes fore 'pleno.

Weit ausgebreitete $\mathrm{S}$. Kleine afrikaniflhe Sammtblitme; indianifche Nolke: Studcntenblume; Tunefcrblume; Schreiberrofe. Germ. Trench Murigold. Angl. Habitat in Mexico et laponia.

In hortis fere omnibus valde vulgaris. Annua.

ereeta. II 35. * Tagetes caule fimplici erecto, pedunculis nudis vnifloris. LINN. SyR. p. 770. n. 2.

Tanacetum africanum maius, fimplici flore. C. B. P. p. 133 .

Var. $\beta$ ) Tagetes indicus, flore fim-) plici fiftulolo.

y) Tagetes indicus, flore fiftu-

lofo duplicato.

TOVRNEF.

§) Tagetes maximus erectus, flore maximo multiplicato. BAVH. Hift. 3. p. IOO.

Aufrechtfehende Samnitblume; großse faudige Stu. dentenbiume. Germ. African Marigold. Angl.

In Mexico habitat.

In hortis quoque vbique varie figurata et colorata deprehenditur. Flor. Iul, in Autumnum vsque Annua.

Haec et illa fpecies hortulanis communiter appellari folent Flores Africani, quia has plantas ex Africa in Europam Carolus Quinitus primum attulit. - Ob odorem eorum graueolentem fufpectae habentur.

404. HELENIVM. L. G. IO4r. Helenie. Germ. Baftard Sun-Flower. Angl.

autumnale. I 36 . Heleninm foliis decurrentibus ferratis. LINN. Syft. p. 769 .

After luteus alatus. Cornut. Canad. 62.t. 63.

Herbfhelenie; unïchter kleiner Alant; Baftardjonnenblume. Germ. Autumnal Baftard Sun-Flower. Angl.

Habitat in Canada, Florida. 
In hortis, vbi faepe flore pleno ludit, freçuens. Fl. Aug. Sept. Perennis.

405. ANTHEMIS. L. G. I052. Kamille. Germ.

Camomille, Angl. Antemide, ou Camomille.

$$
\text { * Radio discolore 1. albo. }
$$

I 137. * Anthemis foliis pinnato-compofitis, linearibus, nobilis. acutis fubuillolis. Lins. Synt. p. 7̧ó. n. ร. ELACKW.

t. 798 .

Chamaeme! um nobile 1. Leucanthemum odoratius.

C.B. P. p. 135 .

Pharm. Chamonillae Romanae Flores.

Römifche Kamille; edle Chamille. Germ. Swectfented Camomille. Angl. Camomille noble, ou romai. ne, ou des Boutiques. Gall.

In hortis copiofe, paffim in ruderatis et reięamentis hortorum, haud rarius in agris cultis. Fl. Iul. $\left.\mathrm{Se}_{\mathrm{j}}\right) t$. Annua.

VJ. Vires medicae vt in Matricaria Chamomilla. Attamen ex noftra maior olei aetherei copia extrahitur.

II38. Anthemis receptaculis conicis; paleis fetaceis, fe- aruenfis. minibus coronato-marginatis. LINN. Syft. p. $77^{6}$ n. 9. SCHREE. Spicil. pag. 18. ก. 923. (fub Chamaemelo)

Acker-falfche, geruchlofe Kamille; Hundskamille; Kuhdill; Hundsdille; wilde Hermel; Ochfenauge; Rindsange; Mairankraut. Germ. Corn Camomille. Angl. Camonille des champs, ou Antemide champêtre. Gall.

In campis, agris cultis et neglectis vbique copiofe. Fl. Iun. - Aug.

Obf. Flores digito triti odorem fpargunt foeti. dum: Folia iuniora ab Ouibus deuorantur. Apes flores fugiunt.

1039. Anthemis receptaculis conicis, paleis fetaceis, fe-Cotula. minibus, nudis. LINN. Syft. p. 776. n. II. 
Chanacnelum folis plane glabris, pinnis pinnatis, pinnulis latiufculis. вовнат. n. 239 .

Pharm. Cotilae Eoctidae He:ba, Flores.

Stinkende Kanilie; Sinthchanille; Huatds-1. Krö. restill; Gängelropf. Germ. Stinking Maweteced. Angl. Canonille puante: on Marute. Gall.

1. In aruis inter fegetes, anf den Spitälfeldern, ad vias et alibi. Fl. Iun. Iul. Annua.

$V f$. Haec bufones allicit. Pulices fugat et Apibus infenla.

\section{** Radio concolore . luteo.}

tinforia. Iro. Anthemis folis bipinnatis, ferratis, fubtus tomentofis, caule corymbofo. inN. Syft. p. $77^{-} \cdot \mathrm{n} .17^{*}$ SĆRев. Spicil. p. I.5. n. 106 . (fub Chanaeznelo.)

Färberkamille; Gill-Streichblums. Germ. Ox-eye German. Angl. Camomille Oeil de boeuf. Gall.

In locis ficcis, collibus aridis im Bieniz paffim et rarius inter fegetes; frequens vero in multis hortis. Fl. \{ul. Aug. Perennis.

- VJ. Flores luteo inficiunt colore lucido, atque in Suecia valde aefimatur.

406. ACH LLAEA. L, G. I053. Garhen. Germ. Yarrow. Angl. Achilliere, ou Millefeuille. Gall.

\section{* Foliis integris.}

Ptatmica. 1 I 4 T. Achillaea foliis integris lineari-lanceolatis amplexicaulibus ferrulatis. wild. Tr. de Achill pag. 10 . n. 3 .

Achillaca foliis lanceolatis, acuminatis argute ferratis. LinN. Syßt, pag. 777. n. 12. BöHM. n. $24 \mathrm{I}$. BLACK w. t. 276. Fl. Dan. t. 643.

- Pharm. Ptarmicae Radix, Flores, Herba.

Weiffer f. teutfcher Wiefenbertram 1. Dorant; weiffer Rheinfarn; zeslder Dragun; Wiejendragun; Achillenkraut; gemeines Nießkraut. Germ. Common Sneezewert or Goofe Tongue. Ingl. Achillicre Rernutatoire, Ptarmique, ou Herbe à éternuer. Gall. 
In agris, pratis hinter Gunndoif boi der Ziegelfoheune, in fyluaticis pratis in Rofenthale, bei den Gefundbrunzeiz; in dumetis inter prata dir grojen Funkenburg und der Ziegelfcheune. Fl. Jun. - Aug. Perennis.

VJ. Caules iuniores vernoli tempore Acetariis admifcentur in Irlandia. In Sibiria decoctum laudatur is mistu cruento et hamomagia veri laborantibus. Bobus, vaccis, capris, ouibus, fuibus etc. pabulum gratum. *)

\section{** Foliis bipinnatis vel fubbipinnatis.}

IJ 42. Achillaca foliis bipinnatis nudis : laciniis lineari-millefolium. bus dentatis, caulibus fupérne fuleatis. LINN. Syn. pig. 778. n. 18. ВОЕНМ. n, 220. БLАСK. tab. 18. Fl. Dain. t. $73 \%$.

Achillea foliis bipinnatis glabris: pinnarum laciniis linearibus dentatis. wiLDen. Tr. de Achill. ping. 30 . ก. $2 \pi$.

Var. «) Achillaca floribus albido purpureis.

Pharm. Millefolii Herba, Flores.

Gemeine Schafgarbe; Feldgarbe; Schafribbe; TauJendblatt; Karpcukraut. Germ. Common Yarrow, or Milfoil. Var. a) Purple flowering Yarrow. Angl. Achilliere - Millefeuille; Herbe au Charpentier; Herbe aux Voituriers. Gall.

In pratis, verfuris et sd vias vbique. Var. $\alpha$ ) in locis-arenofis, fterilioribus praecipue. Flor. Iun.Aug. Perennis.

Incolae Sueciae praeprimis Dalekarlos Limenfes hac ad cereuifiam citifime inebriantem coquendam vtuntur. LINN.

$V J$. Herba pabulum pecoribus falutare et in - Scabie ouina maxime laudatur.

Ir 43. * Achillaea foliis fubbipinnatis pubefcentibus; nobilis pinnis oblongis, pinnatifidis incifuris aequalibus. wil D. Tr. de Achill. p. 36. n. 25.

*) vid. Gmel. Flor. Sibir. Tom. Il. p. I96, 
Achillea foliis bipinnatis, inferioribus nudis planis, fuperioribus obtulis tomentofis, corymbis conuexis confertifimis. IIN. Syft. pag. 770 n. 19. LEYs. n. gr.

Edle Garben. Germ. Noble, or Sterect Yarroze. Angl. Achilliere noble. Gall.

In locis montofis, fabulofis iuxta lateritiam ad Kleinzfchocher, in Bieniz et in muris paffim. Flor. Iul. Aug.

Obj. Calycibus magis oblongis, cylindricis, rarius albis, difco ochroituco et calycinae fquamae margine minime nigricante, a priori diftinguitur.

${ }_{40} 7^{*}$ ZINNIA. I. G. I056. Zinnien. Germ.

paucitora 1144 * Zinniı floribus fefrilibus. L1NN. Syst. pag. 7 r. ก. 1 .

Rudbeckia foliis oppofitis, ouato acutis, calyce imbricato, radii petalis piftillatis. ziNn. Goeting. pag. 40\%. t. I.

Venigblumige Zinnie. Germ. Yellow'Zinnia. Angl.

Habitat in Pern. In hortis noftratibus haud infrequens. Fl. Aug: Sepr. Annua.

Obf. Caul. teres, erectus, enmpofitus: Fo! op sofita, feffilia, amplexicaulia, cordato-lanceolata, flabia, fubtrineruia, integerrina, margine fcabrà. Cal. cylindricus, terminalis, feffilis, folitarius, gl:bris fquamis rotundatis dente adpreflus. Coroll. lutea, perfiftens. Semb. omnia longa triquetra, in radionuda, in difco contra finplici aut duplici nrina

ta. Rami ex alis foliorum, non flori proximis, cauli fimiles altiores. LINN.

mult?ora I 45. * Zinnia ramis villofis, numerofis, lateralibus primarium fuperantibus. JACQ. Obferv. Bott. II. pag. 19. t. 40.

Zinnia floribus pedunculatis. LIN . Syft. p. $77 \mathrm{I}$.

n. 2. LINN. Fafc. Decad 2: t. 12 .

- Vielblunige Zimnie. Germ. Red Zinnia. 
Habitat in Louifania. Apúd nos in hortis priatis publicisque vbique et fere ibidem fpontanea. Flor. Aug. Sept Innua.

ObF. Caul. teres", erectus, villis pubefcens, paliidovirelcens. Rami omnes ab extremis f liis apicen verfus paulatim incraffantur ibidenque pedunculos formant fiftulofos, ftriatos, leuiter fulcatos, glabriulculos, vnum alterumque pollicen longos, romi czeterum omnes axillares, oppofiti, paffim laterales, rarifime fimplices. Folia ex lanceoiato-ousta, int gerrima, vtrinque feabriulcula, 3 vel 5 neruia, fubpetiolata, opprfita. Calyx ouato-crlindricus e fquamis :6-vel plurimis, arete adpreffis, compofitus. Squamae exteriores breviores pedunculo fittulolo coháerentes, ouatae, concauae, interiores tuhulis flofculorum Radii fubjectae, oblongae, ang:iftiores; caeteruin omnes verlus apicem extrorfun linea lemicirculari et tranfuerfali notatae et quafi unguem reftrentes. Corollae radius flofculis 18 ad 30 numero variis, fentineis, fertilibus, conftans; quorum limbus obuerfe ouatus, obtufus eliarginatus, patens, perfiltens, colore fuperne faturate coccineo, fubtus ex fuluo rubente. Floluli Dilci hermaphroditi, omnes fertiles prinzun interinres exterioribus minores, deinde fucceffiue $\mathbf{e x}$ crefcunt; limbo intundibuliformi, in laciniss 5, breuiffimas, obtufas, lineares diuifo. Stigmata ill radio rubella, in dilco decolora. Hermaphroditis pappus et arifta vnica, paleae oppofita. Pa'eae hermaphroditis membranaceae, epice fufcae Radii Hofculis palese nullae, nec feminibus pappus, 


\section{F R V S T R A N E A.}

408. CENTAVREA. L. G. 1056. Flockenblume-

Gorm. Centaury or Matfellon, Angl. Jacée. Gall.

* Cyani, calycinis Jquamis Serrato ciliatis.

phrygia. 1146. Centamea calycibus recuruato-plumofis, foliis indiuifis, oblongis, feabris. LINN. Syft. p. 785. n. 7. JAHN. n. 21. Fl. Dant. t. 520.

Plirygifche Pflockenblume. Germ. Broad-leaved zeoolly-headed Aufrian Centaury, or Finland Knap. weed. Angl. Centaurée de Phrygie. Gall.

In pratis nemorolis unten am Bieniz et hinter KleinDölzig, bei Kriphäne auf dem Behomot, porro in fepulcreto ad Altranfï̈dt copiofe. Flor. Iul. Aug. Perennis.

montana.' y 47. * Centautrea calycibus ferratis: foliis lanceolatis decurrentibus, caule, fimplicifimo. LINN. Sylt. p. - 785. n. I4. LEYS. n. 880. JACQ. Flor. Aultr. V. 4. T. $37 \mathrm{r}$.

Berg-Flockenblume. Germ. Mountain Blue-Bottle, or Bluie Batchelor's. Angl. Centaurée des montagnes, Bluet grand. Gall.

In fyluis elatioribus fparfin in Bieniz mihi occurrit. Flor. Iul, Aug. Perennis.

Cyants, I 148 . Centaurea calycibus ferratis foliis linearibus integerrimis: infimis dentatis. LinN. Syft. p. 785. n. 15. BOEHM. n. 2-75. BLACKW. t. 270. KERN. B. II, P. 8.t. T. 129.

Pharm. Cyani Flores.

Gemeine Kornblume; Ziegenbon, Zacharias f. Kornflockenblume. Germ. Blue Corn-Bottle, or Blue bottles. Angl. Centạurée Bluët; Caffelunetze Aubifoin. Gall.

In agris inter fegetes praecipue fecalinas vbique frequens. Flor, Iun. Aug. Annua. 
$V \int$ Flores recenter expreffi cum alumine mixti fuccum dant capruleum pro feriptura, Tingit pulchre faccharum cserul.um. LiNn. Suec. p. jol Floribus vtuntur pro condimento tabacum fumantes.

I I Q. Centnurea calycibus ciliatis, fquamis planis, fo-paniculata liis bipinnatis: ramis pinnatifiais linearibus, caule paniculato. LINN. Syft. p. -85 . ก. 16. SCHREB. Spic p. ฯ. n. 925. JACQ. Flor. Auftr. V. 4. t. $\$ 20$. Quafînförnige Flockenblume; kleine Kornblume. Germ White leaved purple panicled Krapeeced, Angl. Centaurée paniculée. Gall.

In agis ad eorum margines et ad vias nach Gohlis, Meckern, Stameln etc. Flor. Iul. Aug. ìnnua.

I150. Centaurea calycibus ciliatis, foliis pinnatifdis, fabiofa. pinnis lanceulatis. LrNw. Syft. p. 336. n, 23. воË́m. n. 883.

Skabiofenartige Flockcnblume; Eifeneurzel, Große Skabiofen; Flockenfkabioje. Germ. Grat Mati-fellon. Angl.

In agris et ad fep s hortosque oleraceos et alibi. Flor. Iun. Inl. Prenenis

Ob. Radix-aratoribus nimis tenax. Semina fero Autumno Pafferibus c bum praebent.

II51. * Centauren calycibus ciliatis: fquamula ouata : nigra. ciliis capillaribus erectis, folis lyrato-angulatis, fleribus flofculofis. LINN. Syft. p. 785 .

Schuearze Flockenblume. Germ. Centaurée noire. Gail.'

In agris elatioribus arenofis, hinter dem Brand. voneverke. Flor. Iul. Auǵ. Perennis.

** Rhapontica: calycinis fquamis aridis feariofis.

I 52. Centaurca calycibus feariofis laceris, foliis Ian-Jacea. ceolatis; radicalibus finuato-dentatis, ramis angulatis. Lins. Syft. p. -8 \%. n. 30. вовमм n. $246 . \mathrm{F}$. Dar. t. 519. Var. Iacea anguftifolia. 
Gemeine Flockenblume; Schwarzes Flockenkraut. Germ. Common Knapweed. Angl. Centaurée Facée, ou Zacée des près, ozl des bois. Gall.

In pratis nemorofis et agris bei dem Brandvorteerke nach Gonnewiz zu, auf den Gerberwiefen, bei, dem Gefundbrunnen et in iapricis vbique. Flor. Iul. Aug. Perennis.

$V \int$. Flores luteo - tinctorii Serratulae fuccedaneum praebent. Folia pecoribus pabulum.

*** Calcitsapac: calycinis fpinis compofitis.

Calcitrapa. $: 1153$. Centaurea calycibus fubdublicato - fpinofis, feffilibus, pinnatifidis, linearibus, dentatis, caule pilofo. LINN. syft. p. 78.7. n. 48, военM. n. 244. Pharm. Calcitrapae Radix.

Wegfterndiftel. Germ. Purple Star Thiftle. Angl. Chaulfe-trape ou Chardon étoilé. Gall.

In campeftribus locis, circa vrbes et pagos paffim. Flor. Iun. Iul. Arnua.

Vf. Agno Pafchali Iudaico vefeebantur cum con. dimento, quod Hebraice פרירים (Merorim), Graece ritxers, in Bibliis Suecicis Bitter Saljo vocatur. (Exod. XII, 8.) Olim in febribus intermittentibus et contra calculos praecipue commendata. vid. SEGUIER 2. P. 154. LIEUTAUD. p. 70\%.

409. COREOPSIS. L. G. IO62. Käpchen; Wanzengeficht. Germ.-Tick-Seed. Angl.

Bidens. 1154. Coreoplis foliis lanceolatis, ferratis, oppofitis, amplexicaulibus. LINN. Syft. p. 782. n. Ir. SCHREB. Spicil. p. 19. n. 924.

Waffer- $r_{0}$ zweijöhriges Wanzengeficht. Germ. Aquatick Tick- - Jeed. Angl.

Ad fortas, in ftagnis et locis paludofis vbique. Flor. Iul. Aug. Annua, 
II55. * Coreopfis foliis fubternatis integerrimis, LINN. tripteris. Syft. p. 782. n. 5. Ejusd Hort. Vpf: p. 269.

Rudbeckia foliis compofitis integris. Roy. Lugdb. $18 \mathrm{r}$.

Hohe virginifche unächte Sternhrautfande; dreifache Coreopfis; Gelbe Veilchen. Germ. Ternate - leazied Coreopjis. Angl.

Habitat in Virginia. - In hortis fere omnibus et in hortulis PomoeriiGrimmenfis verfus Coliegium Rubrum; valde frequens. Fl. Iul. in Septembrem vfque. Perennis radix.

Obf. Caulis humanae altitudinis, laeuis, giaber, articulatus. Folia oppofita, pleraque ternata, faepe quoque in caule ferme pinnata, glabra, foliolis lanceolatis feffilibns, introrfum anguftioribus ad bafin. Calyx calyculo patulo.

410. * RVDBECKIA. L. G. I06!. Amerikanifclie Zwergfonnenblume; Rudbeckie. Germ. Dwarf American Sunflower. Angl-

II 56. * Rudbeckia foliis compofitis, laciniatis, LINN. laciniata. Syit. p. 782 . n. 1 .

Doronicum americanum, laciniato folio.' C. B. P. p. 516.

Aconitum belianthemum canadenfe. corn. Canad. 178 . et 179 .

Großse Rudbeckic; die falfche canadifche Somnenblumenftarde. Germ. Fagged leaued Dwarf Sunfower. Angl.

Habitat in Virginia et Canada.

In hortis fere omnibus fplendidis copiofe et ad hortorum fepes rufticanorum paffim. Flor. Iul. Sept. Perennis.

4II. HELIANTHVS. L. G. ro6o. Sonnenblume. Germ. Sunflower. Angl Soleil. Gall.

II57. Helianthus foliis omnibus cordatis, trineruatis, annums, pedunculis, incrafatis, floribus cernuis. LINN. Syft.

p. 781 . n. I. ВОЕНM, n, 242. 


\section{6}

Fährige $\int$ genteine Sonnenblume; Somnenkrone. Gi rm. Annual Sunflozer. Angl. Soleil annucl; Herbe du Soleil; Couronne du Soleil; Tournefolle. Gall.

In hortis fuburbanis et rufticanis copiofiffme; in aggeribus circa Vrbem, in rudetatis et rejectamentis hortorum haud intiequens. Fl. Iul. in Autumnum vique. A nuts.

Hortos ob varios florum pulchros colores illuminat.

$V f$. Semina oleum praebent praeftars, In nonnullis regionibus haec eduntur pueris. Ex Seminum farina panis cuquitur in Indin Receptarula carnofa Cinarae adinftar praeparantur et lubenter comeduntur. Cemina t fta odoresn Fabis Caffeae fimilem fpargunt et potum exhibent haud ingratum.

multiflorus. II\$8. * Helianthus foliis inferioribus cordatis, trinerua is, fuperioribus ouatis. uIN Syft. p. 78t n. 3 . Heieniun indicun ramofum. C. B. P. p. $2--$.

Viclblumige Sonnenblunte, Kleinere Sonnenblume; gcneine $\mathrm{f}$ befiandige Sonnenbinmenftaude. Gr $\mathrm{rm}$. Commom perturial Sinflower. Angi. Soleil multiftore. Gall.

Habitat in Virginia. in hortis fere vbique, in agris oleraceis, ad lepes hortorum rufticorum paffim. Fi. Iul. - Sept. Perennis.

tuberofus. II 59. Helianthus foliis auato-cordatis, triplineruilis. IINN. Syft. p. 781. n. 4. - BOEHM. n. 243. JACQ. Hort. V. 2. t. $16 \mathrm{I}$.

Knollige Sonnenblunne; Unterartifchocken; Ferufalemsartijchocken; Erilänfel; Erdbirnen melius. Germ. Tuberous Sunfluzeer, or Ferufalem Ari ifhocke. Angl. Solcil Tanpinambour; Poire de terre. Gall.

Ad margines argrolum et ad fofficulas: in agris oleraceis, ruderatis, ad fepes pagorum fr"quens. Praeterea in agris verlus Stötteritz, Scllerhaufen, nack den Straßenhâufernz zu et in agris oleraceis magnis et alibi colitur. Hic rariffime foret. Radix per" nnis.

Vf. Tubera hujus Helianthi, qui in Brafilia habitat, in culinis notiffina, funt et communiter incoquuntur 
quntur carnium jufculis. Haec autem tubera faepe fatus gignunt, qua de re hodie non magis copio fe coluntur. Vbi haec planta crefcit, ibidem ob radicem repentem difficilius eradicari poteft.

\section{N E C E S S A R I A.}

412. FILAGO. L. G. IOZO. Fadenkraut. Germ.

Cotton-wecd. Angl. Herbe à Coton. Gall.

I16o. Filago panicula dichotoma, foribus rotundatis, germanica. axillaribus, hirfutis: foliis acutis. LrNN. Syft. p. 795. n. 2 .

Gnaphalium caule dichotomo, fphaeris floribus in angulo diuifionis feffilibus. вовнм. n., I7 6 .

Teutfches Fadcnkraut; Schinmelkrout; Filzkraut; Engelibïmclex. Germ. Cierman Cotton-zeeed. Angl. Cotioniere commine.' Herbe ì Coton. Gall.

In' agris elatioribus, arenofis, cultis, vor dem Hällijchen Thore nach Gohlis et Eutritjch copiofe. Flor. Iun. Iul. Annua. -

116r. Filago caule fubdichotomo, erecto; floribus montana. conicis terninalibus axillaribusque. LINN. Syft. p. 796. n. 4 .

Gnaphalium caule erecto, ramofo, foliis breuifimis; glomerulis feffilibus diffitis, prope fummitates pofitis. Бовнм. n. $17 \%$.

Berg-Ruhrkraut 1. Fadenkrant. Germ. Mónntain Cotton-zeced. Angl. Cotoniere de montagne. Gall.

In agris lapidefis, montofis bei der Wachsbleiche vor den Hällifchen Thore, in Bieniz, vor Nazezet Rückmarfcludorf etc. Flor. Iun. Iul. Annua.

1162. Filago caule paniculato, floribus conicis latera-aruenfis. libus. Linn. Syft p. 79 ร. n. 6.

Gnaphalinm caule erecto, ramofiffimo, glomerulis florum ad ales longe feffilibus. говим. $\mathrm{n}, \mathbf{1} 77^{\circ}$

Acker Fadenkraut 1. Acker Filakraut, Ackerruhrkraut; grojes Schimmelkraut. Germ. Corn Cottonzeeed. Angl. Cozoniere des champs. Gall. 
In agris arenofís cutis vbique. Flor. cum prioribus Arnua.

Bruta intaetam relinquint herbam.

413. CALENINVLA L. G. 1073. Ringelbiume. Germ. Mrigold. Angl. Souci, Gall.

aruentis, Ix63. Calendula feminibus cymbiformibus, muricatis, incuruatis, extimis ereatis protenfis. LINN. Syft.

p. 791 .

Caltha floribus minimis pallentibus. BoEnM. n. 277.

Feld f. Ackerringelblume, Warscnkraut ; Gilken; Sonnemwende, Hausfonnenewirtel. Germ. Field Marygold. Angl Souci de van ou des champs. Gall.

In agris inter fegetes copiofe. Flor. Iun. Iul. Annua.

$V$. Flores luteo inficiunt colore.

officinalis. 116 * Calendula feminibus cymbiformibus muricatis incuruatis ommibus.' LINN. Sylt. p. 791. n. 3. LEYS. n. 83. BLACKIV. : O5. KERN. B. I. p. 4. t. 6 I.

Pharm Culentalae Herba, Fiores, Semma.

Gereöhnliche Ringelblune; Gold I. Butterblume; IVarzenl raut. Gern. Pot, or Pale -coloured-Marygoll Angl. Souci ou Poucie officinal, ou Souci des Boutralues. Gail.

In cultis, hortis, oleraceis, rejectamentis hortorum e. gr. ii horto Reicheliano, Löhriano etc. et in ruderatis frequens. Flor. Lun. - Sept Annua.

Vf. Corollae radius pigmentum luteuir fucco exprefio cum alumine coeto, praebot. Siccatis corollis Croci loco ruftici pro tinßtura vtuntur ad cibos condindos ob bonum et fragrantem faporem odoremque. 


\section{MON.O G A I A.}

4I4. IASIONE L. G. rogo. Schafsblume, Germ. Shcep's Scabious. Angl.

165. Iafrone foliis lineari-lanceolatis obfolete ferratis; montana. petalis fylo longifim apice glabro breuinribus. rinn. Cliff. 426. Eiusd. Syft. p. 799. вовнм. n. 44. Fl. Dan t. $3 ! 9$.

Berg-Schafblume; Schaafrapunzel; blaue Flocken. blume. Germ. Iafione. Gall

In montibus ficcis et collibus auf dem Gickerlingsberge, im Bieniz, auf ten S:ndbergen od Nauendorf ct Rïckmardorf; auf den Gonnereitzer Schanzen rofinfe et pafin hinter den Staßenh.u fern nach Probft. heide; et in ficcis nicht weit von dem Gefundbrunnen intra frutices. Flor. Iun. - Aug. Perennis.

4I5. VIOL I. L. G. IOg2. Veilchen, Germ. Violet. Angl. Violette. Gall.

\section{* Acaules.}

1166 * Viola scaulis, foliis cordatis, pilofo-hifpidis. hirta Iinn. Syft. p. 802. n. 6. Fl. Dan. t. 618.

Rauches Veilchen Germ. Violette heriffée. Gall.

In pratis hinter 'Reichels Garten, bei dem Brandvorwerke, in Rofenthale etc. Flor. Aprili.

1167 * Tiola acaulis. foliis reniformibus. IIN. Syft. paluftis

p. 802. n. 7. LEYS. 896. Fl Dan. t. 85 .

Sumgefoeilchcu. Germ. Marfh-Violet. Angl. Vio' lette des marais. Gall.

In locis paludofis bei PomfJen et Holzhaufen praete-s: rito anno et n!uper in der Prellheide fub Alnis inueni. Flor. Apr:1. Perennis.

II68. Viola acaulis, foliis cordatis, ftolonibus reptan-odorata tibus, pedunculis, radicatis. LiNs. syft. p. 803. n. 8. вовHA, n. 454. BLACKw, t. 55. Fl. Dan. t. 309 . Vina. Rivis. t. I17. pent.

Pharm. Violae f. Violariae Herba, Flores, Se* mins. 
Märaveilchen; soohlriechende Veilchen; blaue Veilchen; Märziole; Violenkraut. Germ. Marfh purple, or fpring Violet. Angl. Vinlezte de Mars; ouVioletze commune, ou odoranite. Ga!l.

In locis vmbrofis et fyluaticis im Rofenthale mu!tisque hortis ad fepes coñiofiffime. Flor. Mart. Aprili.

Obf. Varietas flore albo faepius in agris verfus Gunndorf et hortis occurrit.

$V \int$. E petalis fyrupus violarum violaceus variis praeparatis pharmaceuticis colorandis aptu's conficitur. Saepius vero adulteratus exftat et e floribus Aquilegiae paratur. Porro faepius in aquarum mineralium examine ad detegendum acidum cum Alcali adhibetur. $A b$ acidis enim rubefcit, ab alcalinis contra viride imbuitur colore.

\section{** Caulefcentes.}

carina. I 169. Viola caule adultiore adfcendente, foliis oblongo cordatis. LINN. Syft. p. 803. n. 9. вовнм, n. 455 .

Violo inodora. Riv. pentap.

Var. \&) Viola folio rotundiore.

B) Viola flore albo.

Pharm. Vioiae Caninae Radix.

Hundeveilchen; Roßseilchen; wilde Veilchen; fri- tes f. Maivitihen. Germ. Dog's Violet. Angl. Vio. lette fauvage. Gall.

In pratis humidis, et apricis, pafcuis, margine fyluarum, in fyluis caeduis, in Rofentizale, in alneto ad Schönfeld et alibi copiole. Flor. April. Iunio.

Olf. I. Ab antecedenti diftinguitur: Defeetu ftolonum, foliis e caule ejusque ramis, nec ex radice ipfa, vt in illa', prodeuntibus; caule ramofo; florum paulo quidem feriore, fed vberiori prouentu; dilntiore colore; odore nullo iofoque fitu: Pedunculi enim, quibus infident flores, ex ramis exeuit, nullo modo e radice. 
Obf. 11. Plantas hújus radicem fub initio lyyemis et vernali tempore effoffam, e terrs ab'utam lenique calore ficcatam, efficifimam effe tentat NIEMEYER. Et quoque ille Vir lalidatus radicis puluerem cum euentu opririo commendat vt lene emeticum. *)

II-o. * Viola caulibus erectis, foliis cordato lanceo- montara. latis. LINN-Sylt. p. 803. n. 10. JAHN, n. 22. Bergueilchen. Germ. Mountain Violet. Angl. Violette de Montagne. Gall.

In locis fubhumidis et nemorofis im Bienz, in fylua ad Scopam paffum. Flor. Maio. Perennis.

*** Stipulis pinnatifidis: ftigmate vrceolato.

II I. Viola caule triquetro diffufo, foliis oblongis in- tricolor. cifis, ftipulis pinnatifidis. LINN. Syft. p. \$03. $\mathrm{n} .17$. воEнм, n. 43. BLACKW. t. 4-. Fl. Dan. t. 623.

Viola tricolor. RIV pent.

Var. a) Viola armenfiss, calyce corollam bicolorem parum excedente. RETz. Flor. Scand. n 962.

B) Viola bicolor Horibus caeruleis et purpu. reis.

Plarm. Trinitatis 1. Violae Tricoloris Herba.

Dreifarbiges Veilchez;. Dreifaltigkeitsblume; je linger je lieber; Garböcklein; Hungerkraut; Sorge; Unnüze Sorge; Freifankraut; Cedenkblïmchen; Gewerlibliumchen; wilde Sicbenfarbenblume; Iefusblïn. crien. Yar. f) Ǩleine Sorge. Germ. Panfies, or Heart's Eafe. Angl. Violette Penfée, ou commun; Violier; Herbe de l' à Trinuté.

Ad margines agrorum et in aruis. var. $\beta$. in hortis cultis occurrit. Flor ab Aprili. et per totam aeftatem. Perennis.

$V f$. Herba in Crufta infantum lactea a Cel. strack, ECCAHDO, aliis nuperrime commendata. Bergius hanc herbam laudat fatis praefans et gratum laxans.

•) Eiusd. Difjert. de Violae caninne in medicina ofu, Goetting. 1785. 40 . 
biccior. 172 . Viola caule triquetro diffufo, folis oblongis incifis, ftipulis dentatis. REYG. Flor. Gedan. p, 215.

Viola pedunculis caulinis angulatis, fipulis oblongis, pinnato-dentatis, foliis olato-oblongis creratis. IINN. Cliff, $4 \div \%$.

Fiola caule procumbente, foliis fub ra,nis laciniatis, flore paru's bicolore. вовнм. n. 456 .

Viola bicolor aruenfis. B. P. 200.

Viola aruenfis. mVRr. Prodr. p. 73.

Viola aruenjis caule inferne angulato, diffufo, foliis oblongis retufis, fipulis pinnatitidis, corolla calycis fere longitudine. WILDEN Prodr Berol. ni. 862.

Viola tricolor LiNn. Syft. Ed. R. III. p. 767. var. «. bicolor.

Vigla bicolor. Riv. pent.

Var. a) Viola foribus albis et luteis.

B) Viola Aoribus luteis et caeruleis.

Zuecifurbiges Veilchen; Stiefmütterchen; Tag und Nacht bibulein. Germ. Violette des champs. Gall.

In agris arenofis vbique. Flor. per tatum fere annum. Annua. Pecora non deuorant herban.

perficifolia, ! I 73. Viola caule erećo, foliis ouato-lanceolatis, ferratis. BOEHM. n. 456 .

Pfrrfchblïtriches Veilchen. Fism. Violette is feuil. les de Perfie. Gall.

In pratis fyluaticis fparfim im Rofenthale et in pafcuis auf der Funkenburg, bei Gonnewitz. Flor. Maio. Perennis.

416. IMPATIENS. L. G. IO93. Springfaamen. Germ. Yellow Balfam, or Quick in hand. Angl: Balfamins. Gall.

* Pedunculis multifloris.

Balfunina. II74. * Impatiens pedunculis vnifloris aggregatis, foliis lanceolatis, fuperioribus alternis, nectariis flore breuioribus. IINN. Syft, p. 80.4. n. 5.

Balfa- 
Baffamina femina. C. B.P. p:306. Baifamina riv. tetr. t. $I \geq 0$.

Balfaminc; Balfankraut. Germ. Common Balfan; Femal Baljame. Angl. Balfamine cultivée. Gall.

In India, Zeylona et Iaponia habitat.

Hortos noftrates ob infignem varietatum numerum ornat atque fplendorem isdem fimul condonat. Fl. Media Aeftate in Autumnum vfque. Anrua.

Ex hujus fucco cum alumine ungues rubros interdum tingunt Iapaneníes. Tivas. Fl. lap. p. 327.

175. Impaticns pedunculis multiforis, folitariis, fo- Noli tanliis ouatis, geniculis caulinis tumentibus. LINN. gere. Syft. p. 804. Fl. Dan. t. 588 .

Balfanina capfula oblonga tenui. Bоenм. n. 310. Impatiens. Riv, tetr. t. $I$.

Spring faame; Springliaut; Ungeduld; Rïhr mich nicht an; wilde Balfanine. Germ. balfanine fauvage ou Mcrucille à Fleur jaune. Gall.

Ad fofficulas in dem Poetentzange, bei Gohlis, Eu. tritfch; et in fyluis humidis e. in der Prellheide, in alneto ad ripam Lupee hinter Neu-Scherbiz. Flor. Iun. Iul. Ferennis.

Capfulae maturae ad attactum femina elaftice explodunt. Bonafias herba aeftate alliciunt et illaqueant Germani. Loefel.

\section{B. FLORE MONOCLINO.}

4I7. * MOMORDICA. L. G. I I9r. Balfamapfel.

Germ. Male Balfam Apple Angl. Pomme de Merveille. Gall.

1176. * Momordica pomis hifpidis, cirrhis nullis. Elateriun. IINN. Sylt. p. 868 .

Cucumis fylueftris afininus dictus, C. B.P.p. 314 . BLACKw. t. IO8.

I. Pharm. Cucumeris Afinini Radix: Elaterii Ex. tractum (viricie). Refina (älba). 
'Wilde Kukumer; Springgurke; Springkürbis; voilde Hundskïrbis; Ejelskürbis f. Gutie; Ejelskukumern. Germ. Wild or Sparkling Cucumber. Angl. Concombre fauvage. Gall.

In Europae auftralis rupibus fponte crefcit. Apud nos in hortis fuburbanis et rufticanis vbique et in rejeßtam ntis hortorum atyue ad f pes pagorum paltim occurrit. Fl. Aeftate, Perennis.

Elaterium a'bum quod e laefis Monordicae Elate-

1 rii pomis emanat, heroicum eft purgars hydragozum in hydrope, ab antiquifimis temporibus adhibiturn, dehirsc a minima dofi incipiendum: tamen Grauidis non propinandum et in hydrope, vi pulfus durus obferuarur et vifcera funt abstructa, hos remedio abfitinendum.

418: CVCVMIS.L. G. Ir03. Gurke f. Kukumern.

Germ. Cucumber. Angl. Concombre. Gall.

Melo. II77. * Cucumis folinrum angulis rotundatis, pomis torulofis. LiNN. Syft. p. 869. n. 6.

Melo vulgaris. C. B. P. p. 320. BLACKw, t. 29. Pharm. Melonis Semina, excorti ata.

Gemcine Melone. Germ. Musk Melon. Angl. Melon commun des jardins. Gall.

Patria, vbi haec planta fponte nafcitur, nondum nota eft. In hortis et agris oleraceis copiofe colitur et varietates plurimas, quae in aëre libero non provéniunt, in Vaporariis et terra praegnante cum magna diligentia colunt Huttulani noftrstes.

$V \int$. Fructus maturus comedi folet crudus, tempore aeftuali, gratus cum odore, tum fapore. Nutrit principio dulci et fimul refrigerat; Immaturus fructus conditur faccharo, vel aceto, pro bellariis. Si cum lale et pipere his fructibus velcamur et vinum bibamus, tunc vim refrigerantem, quae fructu ineft, amitunt. Semina inter 4 frigida majora recenfentur. 
1178. Cucumis foliorum angulis erectis, pomis oblon-fatiuus. gis fcabris. LiNN. Syft. p. 869. n. 9. вовнм. n. 656. BLACKw. t. 4 .

Var. $\propto$ ) Cucumis fatiuus vulgraris. C. B.P. p. 3 ro.

ß) Cucumis fatiuus vulgaris, ma* turo fructu fubluteo. C. B, P.

r) Cucumis fariuus vulgaris, ma- $1 . c$. turo fructu albo.

d) Cucumis fatiuus major. C. P.P.

Pharm. Cucumeris Semina.

Kukunern; Kinmerlinge; Gurken; Gartengurke; zahne Guvke; Gartenkiumnerling; genneine Saatgurke, Germ. Conmon Cucumber; Common prickly Cucumber. Angl. Concombre ordinaire. Gall. Var. a) Gemeine rauche Gurke. Germ. Connucn Gardun Cucumber. Augl. Conconbre commun des jardinis. Galbs ß) Gemeine gelbe Gurke. Germ. Common yellow prickly Cucumber. Angl. Concombre jalin. Gall. r) Geneine weißse Gurke. Germ. White prickly Cusumber. Angl. Concombre blanc. Gall.

In agris oleraceis et hortis cum varietatibus maxime colitur. Fl. Aeftate. Annus.

$V f$. Cucumeres inmaturi in culinis frequentifime vfurpantur. Eduntur nempe crudi, in taleolas feet? addito oleo, aceto, fale et pipere. Si autem fuccus a taleolis exprimitur, indigefti euadunt et cucumerinos generant ructus. Cucumeres viricles recentes in doliis aceto vel fale conditi et perata fermentatio. ne audiunt Saurz Gurken f. Salzgurken. His vero vel crudis vel foli in aqua cum butyro vel quoque addita carne coctis vefci folemus. Cucumeres contra Abortiui (i. e. kleine Pfeffer-f. Gewïrzgurkeni), qui condiuntur vini aceto, pipere et aromatibus, fortem excitant appetitum.

4I9. CVCVRBITA. L. G. I I92, Kürbifs, Germ. Gourd. Angl. Callebaffe. Gall.

1 79. * Cucurbita foliis fubangulatis tomentofis bafi fub- lagenaria. tus biglandulofis, pomis lignofis. LINN. Syft. p. 868. n, I. 
Cucurbita olonga, flore albo, folio molli. C. B. P. p. 313 .

Pharm. Cacurbitae Semina.

Flafchenkürbis; Reulcnliurbis; weichblättriger Kür. bis; Trompecenlürlis i Herkuleskeule; longer Kürlis. Germ. Bottle Gourd; Long Gourd. Angl. Calehaffe des Pélerins; Gourt d'Anerique; Courge des Pelerins.; Flacon. Gail.

I) Iaponia et Amcrica habitst, ex qua in Europam jam dum rranslata eit. In noftracibus hortis hine illincque occurrit. Fil. Aeftate. Annua.

In India orientali ct occidentali cibum per $3-4$ menfes praebent quotidianum. Fructus pro laginis quandoque inleruit in Iaponis. Senina inter IV frigida majora numcrantur.

Pope, IISo. Cucurbita foliis lobatis, pomis laeuibus. IINN, Syf. p. 868. n. 4. ВОЕнм. n. 65 -.

Gemeiner Kürbis; Feldhürbis; Pfebenkürbis; rauchblintriger Kürús ; gemeiner Gartenkürbis. Germ. Common Pompion, or Pumpkitr. Angl. Courge longue; Courge de St. Feasz; Citrouzlle. Gall.

Patria hujus fpeciei adhuc incognita. Caeterum in hortis oleraceis valde coluntur et a ruricolis in fimetis et in hortulis ant domos pagorum frequenter feruntur Fl. Aeftate. Annua.

Vf- Pepones lacte incoquuntur pulmenti adinftar et a vulgo frequenter eduntur. Ex una ejusdem carnis parte et duabus farinae triticeae panem coquunt fapidum nonnulli Turiones caulium tenerrimi squa feruenti perfundi et 'Acetariorum more parari poffunt. Oleum e Seminibus expreffun faporis eft dulcis gratique et in cibis adhibendum.

Citrullus Ir8т. Cucurbita foliis multipartitis. IINN. Syft. p. 868. n. 7. BLACkw! t. I57.

Pharm. Citrulli Semina.

Waffermelone; Angurie; Citrullé. Germ. Water Melon. Angl. Melon d'eau de Cayenne. Paftique Gall

In Calabria, Apulia, Sicilia habitat. 
In hortis et agris oleraceis paffim. Fl. Aeftate: Annus.

$V \int$. Fruetus Citrulli bene maturus editur crudus, vt eximium retigèrans in calore aeftiuo. In regionibus calidis nulius gratior fruetus, qui glaciei ipeciem refert, et fuccum aqueum frigidiufculum praebet. Semina Clinenfés lubenter comedere iolent.

420. BRYONIA L. G. I 194. Zaunrübe. Germ. Briony. Angl. Couleuvrée. Gall.

1132. Bryonia folii's palmatis vtrinque villoio-fcabris, alba.

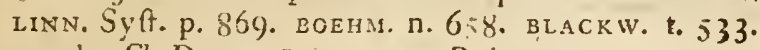
a et b. Fl. Dan. t. 81 . . Kern. B. I. p. 31. t. 32.

Pharm. Bryoniae Radix, Baccae, Sen:ina.

W'eiffe Zaun-1. Gichtriibe; Tenfelskirfche; wilder Zittwer; Stickwurs. Gorm. Red-berried white Briony, or Wilde Hoppe. Ingi. Brione; ou Vigne blanche; ou Couleuvrée. Gall.

In dumetis et hortis oieraceis aliisque ad fepes circa pagos plurimos vulgaris. Flor. Iun. Iul. Perennis.

Vf. Dofis radicis ad maximum 3j raro in fubftan. tia, fed frequentius in decoeto praeferibitur. In morbis hydropicis et conuulfiuis a rufticis frequenter vfurpatur; rarius vero apud Medicos. E radice recenti amylum album, non acre, extraxit Bergius, qued in aqua coetum gelatinsm dedit, gelatinae tritici $f_{1}$ millimam, fapore fubfatuo, miti. 


\section{R Y P T O G A M I A.}

CIASS. II N A EI XXIV.

Ord. I. "F I L I C E S.

a) Frustificationes fpicatac.

42r. EQVISETVM. L. G. 1284. Kannenkraut, Pferdefchwanz. Germ. Horfetait, Angl. Prêle, Gall.

fyluaticum. I183. Equijetum frondibus compofitis, fpica terminali flaccida. Wilden. Prodr. Berol. n. 865 .

Equifetum caule fpicato, frondibus compofitis. LINN. Syft. p. 925. военм, n。 728 .

Waldpferdefchwanz. Germ. Wood Horfe-Tail. Angl. Prêle des bois; Queue de cheval, ou des bois. Gall.

In 1yluis humidioribus, in Zfchocherfchen, Gumndorfer Holze, in der Kämmerci bei Nauendorf. Flor. Aprii, Mai.

arwenfe. 1184 . Equifetum fcapo fructificante nudo; fronde ferili verticillato-ramofa decumbente. wílden. Prodr. Berol, n. 866. Linn. Syft, p. 925.n. 2. вовнм. n. 730. BLACKW. t. $21 \%$ KERN, B. I. P. 25, t. 24.

Pharm. 
Pharm. Equreti minoris Herba.

Ackerjchat theu S. Kandelwifch; Kannenkraut; Zinnkraut; Katzenzagel; Katzeneedel; Rolifchreanz; Reibifch; Preibujch; Gänjekraut. Germ. Corn Horjetail. Angl. Prêle des champs. Gall.

In agris humidioribus vulgare. Flor. Mart. April.

$V \int$. In Suecia pabulum fuibus et in Lapponia ad coria parnda "dhibetur. Oues pregnantes nim um ab hac comedentes abortum faciunt. Bobusintactum perfiftit.

1185. Equifettm caule angulato, frondibus fimplicibus. 'paluftre. LIN N. Syft. p. y25. n. 3. вOEHM. n. “ 31 .

Sumpfinferdefchueanz. Germ. Marrh Horfe-Tail. Angi. Prile des marais. Gall.

in pratis paluciofis et follis ad Schönfeld, $2 m$ Rofenthale frequens. Fl. Mai. Iun.

II86. Equifetum caule ftriato, frondibus fimplicibus. fuuiatile.

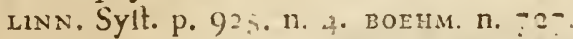

Flufkannenkrait 1. Kandeluifih; Preibufch; Reibijch. Germ. River Horge Tail. Angl Prêle majeure, ou des Riuzeres. Gall.

In foffis ec ad fluuiorum ripas, hinter dem Brandvorwerke, in der Pleiffe. Fl. Maiu.

$V \int$. Vaccis vtilifimum foenum atque lac auget. Equi contra hoc relpeuunt.

I18\% * Equifetum caule fubnudo leui. LiNN. Syft. pag. limofum. 925. n. 5. LEYS. R. 1022.

Thon-Pferdefchtonaz 1, nackendes Wafjerfchaftheu. Germ. Smooth Horfe. Tail. Angl. Prêle limonneufe. Gall.

In locis argillaceis et inundatis vbique frequens. Fl. Maio.

I188. Equifetum caule nudo fcabro, bafi fubracemofo hyemals. LiNn. Syit. p. 925. n. 6. вовнм. n. 329.

Pharm. Equifeti maioris Herba. 
Winter Kandelueifch 1. Pferdefchwanz. Germ. Nough Horfe-tail, or Shave-Graffling. Angl. Pricle diliver. Gail.

In fyluaticis vliginofis, in Bieniz, in der Dïbcnefcher Heide.- Fl. April. Maio.

Vf. Pro infrumentis variis v. g. pétinibus, manubriis, fcipionibus metallisque laeuigandis expoliendisque inferuit, et ad vafa ftannea depurganda in culina valgare.

Infufum aquofun odore faporeue fere infufi Theae Chinenis. Oues abortiunt; Ecuis faiutare; Vaccis noxium, quae dentes amittunt et herbam ore faepius deiiciunt.

422. OPHIOGLOSSVM. L. G. 1288. Natterzunge. Germ. Adder's, Angl. Ophiogloffe.

Gall.

vilgaturn. I189. Ophiogloffum fronde ouata. Linn. Syft. p. 926. военм. n. 726 . вi.ACKW. t. 416 . Fl. Dan. t. 147 .

Pharm. Ophloglogfi Herba.

Gcmeines Natierzinglein; Schlangenzunge. Germ. Adder's Tongue. Angl. Ophioglofje, vulgaire; Langue de ferpent. Gail.

In pafcuis, pratis, locis gramine copiofiore veftitis, limofis; auf dem Gickerlingsberge, auf den Wie- Jen bei den Gefundbrunncn, anf der Wieje unten an Bieniz copiofe. Fl. Mai. Iun.

$V \int$. In India orientali folia leniter cocta eduntur.

423. OSMVNDA. L. G. I 289. Traubenfarn. Germ.

* Scapo infidente canli ad bafin frondis.

T.umaria. I I90. Osmunda fcapo caulino folitario, fronde pinnata, folitaria. LINN. Syft. pag. 927. n, 2, вовнм. n. 725 . BLACKw. t. $420 . F l$. Dan. t. 18.

Pharm. Lunariae Herba. 
Kleine Mondraute; Mondhrant; St. Walpurgiskraut. Gorm. Moon-wort. Angl. Oswnonde lunairc, ou Lunaire commune. Gall.

In pafcuis, pratis et locis elatioribus tenuique gra. mine veftitis ad Rückmarsdorf, Nauendorf porro ad Templum St. Theclae copiofe hoc anno crefcere vidi. Fl. Míai. Iun.

** Fronde ipga frudificationcs ferente.

II91. * Osmunda frondibus bipinnatis, capite racemiferis. LINN. Syft. p. $9=7$. n. I3. LEYS. n. 1026. WILDEN. Prodr. Berol. n. 876. Fl. Dan. t. 217.

Königliche Traubenfarn. Germ. Flowering Fern, or Osmond rogale. Angl. Osmonde, ou Fongere fleuris. Gall.

In fyluis paludofis et ad forias vmbrofas", in der Dübenfchen Heide, inn Univerfitätsholze paffim. Fl. Iun. Iul.

424. STRVTHIOP TERIS. H.ALL. En. Helv, p. I32. Kraftfarrn. Germ.

I192. Struthiopteris frondibus Aterilibus pinnatifidis, pinnulis denfis, oblongis falcatis; frutificationibus maioribus, laxius pinnstis, anguftioribus. Wers. Cryptog. p. $28 \mathrm{I}$.

Osmunda fpicant frondibus lanceolatis pinnatifidis; laciniis confluent? us integerrimis; parallelis. LIN'N. Syft. pag. 928. n. 18. вовнм. n. 724. Fl. Dan. tab. 99.

Kraftfarn; Troßfarn; grof Milakraut; Spikantweiblein;; Kanmfarm. Germ. Rough Spleen, wort. Angl. Osinonde des bois. Gall.

In ericetis et fyluis elationibus in $\operatorname{der}$ Dühenfelsent Heide. Fl. Iun. - Aug.

VJ. Folia, vt Ruppizis refert, cereuifiae addunt non absque fanitatis detrimento nonnullae gentes Germanicae. 
425: IYCOPODIVM. L. G. 1302. Bärlnppen; Kolbenmoos. Girm.

clauatum. IIy3 Lycopodium foliis tparfis filamentofis, fpicis terminalinus pedunculatis gemins. LINN. Syeft. p. $9: 2$. n. вовнм. ก. 732. BLACKw. t. 535. F\%. Dan. tab. 1.26.

Pharm. Mufci Clatuti Herba; Lycopodii Se: mina.

Kezlformige Bärlappen; Holfsklause; Barentappen; Weinkraut; Neunheil; Trutenfuß; Gïrtclkrout; St. Tohamisgürtel; gemeines Kolbemoos 1. azecilolbzger Bärlappen; Tinfilsklait Germ. Plicaire; ou Lycopode commun is poils et rempant. Gall.

In lyluis ficcioribus, pafin $t m$ Univerfitätsholze, et frequens an der Dïbenjchcn Heise, porro in locis catpite tenui vertitis, ericetis. Flor. Iun. Iul. Perennis.

$V \int$. Ad Storeas in paumentis aptum. Spicarum polline phyfici pro fuigur ti ne viuntur. Porro quoque frequens eius vius ad jilu $s \mathrm{~g}$.mmolas isevigandas. Herba fulpenfa in vale vinum corruptum reftituit.

annotinum. I194. * Lycopodium foliis fparfis quinquefaiis fubferratis. furculis annotinis articulatis, fpicis terminalib is, glabris, retis, LINN. Syf. p. 943. n. 11. JAHN. n. 23. Fl. Uan. t, 127.

Wachiolderblâttriger Bärlapp. Germ. Licopode anarinuel ì fenilles de Genevrier. Gall.

In fyluis denfis, in der Dübenfchen Hetde D. Fahn olim inuenit et iple nuperrime quoque ibiden reuif. F1. Ang. Septemb.

$V \int$. Vertes colore inficit fauo.

complana- I195. * Lycopodizun foliis bifariis connatis: fuperficiatum. libus folitariis, fpicis geminis peduncularis. IN Syft. pag. 943. n. 18. Leys. n. 1030. Fl. Dan. tab. 78.

Ebener Bärlappen. Germ. Lycopode aplati, ou Plicaire félaginze. Gall. 
In nemoribus ficcioribus, elatioribus, in der Dü. benfchen Heide. Fl. Iul. Ang.

$V \int$. Fuluo pulcherrimo tingit colore ct rufticis in vfu frequens.

b) Fructificationes frondofae in pagina inferiori.

426. ACKOSTICHVM, L. G, r290. Vollblühende Farren, Gcrm. Acroftique. Gall.

I I96. Acroftichum frondibus nudis linearibus laciniatis. feptentrioLINN. Syft. p. 928. вовнм. n. ZI I. Fl. Dan. t. 6o. Mitternüchtige vollblïhende Farren; grasftenglichtes gefpaltenes Steinfarrenkraut. Germ. Forked, or Horned Fern. Angl. Acroftique feptentrionale. Gall.

In fifuris rupium, cauernis rarius, fed copiofe circa vrbem Grimme fic ditam. Perennis.

427. POLYPODIVM. L. G. 1296. Tüpfelfarn;

Engelfufs. Germ. Polypody. Angl. Polypode. Gall.

* Fronde pinnatifida: lobis coadunatis.

1197. Polypodium frondibus pinnatifidis: pinnis oblongis fubferratis obtufis, radice fquamata. EINN. Syf: vulgare, p. 935. n. 17. воЕнM. ก. 717. ELACKW. t. 215.

Pharm. Polypodii Radix.

Gewölunliche Tüpfelfarn; Engclfüß; Süßjarn; Roßfarn; Baum-Eichen-Steinfarn; veilde Süßwurzcl; weildes Süßhotz; Tropfieurz. Germ. Comnon Polypody, or IVall Fern. Angl. Pclypode ordmaire. Gall.

In petris, fyluis, ad vias rarius et truncos arbornm, im Gumblorfer, im Univerfitâtsholze, aliisque frequens. Fl. Iul, Perennis. 
Thelypteris. 1198. Polypodium frondibus fubbipinnatis: pinnulis integerrimis glomerulis capfularm vndique tectis. WILDEN. Prodr. Berol. n. 88 -.

Polypadiun fronde bipinnata: pinnis pinnatifidis integerrimis fubtis vndigute polline tetis. IINN. Syit. p. 937 . n. ... SCHREB. Spicil. p. 70. n. 719. SCHMID. Icon. p. 45 . T. 3 .

Rund ungekerbtblüttrige Tupfolfarm 1. feines

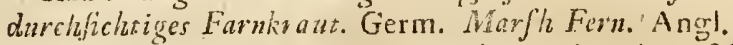

In pratis aquolis vbique, e. $\mathrm{g}$. in pratis Schoenfel. dicis. Fl. Iul. Aug.

criftatum. 1199. Polypodiun frondibus fubbipinnatis: pinnulis oblongis, obtufis ferra:ss: ferraturis ciliatis. glomerulis capfularum duplici ferie difpofitis. T.III. WILD. Prodr. Eerol. n. 885 .

Polypodium frondibus Jubbipinnatis: folits onatoohlongis: pinnis obtufiulculis, apice can!e ferratis. Linn. Syft. p. $437 \cdot n_{\text {, }}+4$. sCHREB. Spicil. pag. 71. n. 10.8 .

Schmalkanmförniges f. graß doppelt gefiedertes Far. renkrant. Germ. Crefted Polypody. Angl. Polypode ì crêze. Galt.

in fyiuis, alnetis ad arborum rerices vor Schonfeld et hinter Kleindölzig. Fior. Iun. Iul. Perennis.

Filix Mas. 1200. Polupodium frondibus bipinnatis: pinnis olotufis crenulatis, ftipite paleaceo. Linn. Sylt.p.937. n. 50. BOE HIM. n. 7 I8. BLACKw. tab. 323. KERN. B. II. p. 87. t. 139.

Pharm. Filicis Radix, Perba.

Mánuliche Tüipfelfarn f. Farrenkraut; IFaldfarn $\mathrm{f}$. Farnirautmännlein. Germ. Common Male Polypody, or Fern. Angl. Fougere nnâle du bois. Gall.

In'fyluis et nemoribus vbique frequens. Flor. Iul. Aug.

Cbf. Flores reniformes. Vim radicis abortiunm experimentis confirmauit Cl. Olzvier. Specifinm 
huius rad cis ad pellendas Taenias iam medicis antiquiffrmis notum fuit.

VJ. Szbirzinfes toliis Lupuli loco sd cereuifiam coquendam vtuntur, vnde gratus odor faporque. In Norwegia obtoeni pentrian pro pabulo pecorum caprarum equorumque inferuit. Herba tota co is parandis vtilis: exficcata Gallis framinis ad inftar; In Anglia cineres exclauatos in globulos formatos dein exficcatos loco faponis exhibent lotrices.

1201. Polypodiun fronde bipinnata : pinnulis lanceola- FilixFoemitis pinnatifidis acutis. LuNN. Syf. pag. 937. n. $5 \mathrm{I}$. na. BOEHM. n. : 19 .

Weiblicher Tüpfelfarn 1. Farronkraut. Germ. Femile Poiypody. Angl. Polypode Fougere femelle. Gall.

In fyluis et nemoribus ad ratices arborum, in alnew, ad Schömfeld, Sylua acadenica alisque. Flor. Iul. Aug Perennis.

Obj. Flores ouati, fubciliati, folitarii.

$V J$. Huius et antecedentis plantae cineres ad fietilia Chinenfum paranda recipiuntur.

1202. Polypodium frondibus fubbipinnatis: pinnulis molle. lanceolatis obtufufculis apice crenulatis. SCHREB. Spicileg. pag 70. 'n. 1027. дотн. Flor. Germ. pag. 449 .

Weicher Tupfelfarn. Germ.

In nemoribus paltim ad arborum radices. Flor. Iul. Aug.

1203. Polypodium frondibus bipinnatis, pinnis lunula. nculeatum. tis ciliato-dentatis, fipite ftrigofo. LINN. Syft. pag. 937. n. 53. ВОЕНM. n. 720 .

Stachlichtblïtriges Farrenkraut. Germ. Prickly - Polvpodz. Angl. Lonkite, ou Polypode is aeguillons. Gail.

In fyluis, alnetis variis et locis paludofis, copiofe in der Dïberzcheri Heide. Fl. aeftate. 
fragile 1204. Polypodium frondibus bipinnatis: foliolis remo. tis : pinnis fubrotundis incilis. LINN. Syft. p. $938 . \mathrm{n}$. 59. Fl. Dan. t. ţor.

Stein-f. Mauerjarnkraut; zerbrechlicher Tüpfel. farn. Germ. Brittle Polypady. Angl. Polypode fragile. Gall.

In vinbrofis montibus et ad radices Quercus mufcofas im Rofenthale, in Univerfititsholze, in der Dübenfcicen Heide et fparfim in murisiuxta pagos. Fl. Iul. Aug.

\section{*** Fronde Jupra decompofita.}

Dryopteris. 1205. Polypodium frondibus fupradecompofitis, foliolis ternis bipinnatis. LINN. Syft. pag. 939. n. 75 . schreb. Spicil. Append n. II 7 .

Dreiâfiger baumförmiger Tüpfelfan; Eicheliarn. Germ. Branched Polypody. Angi. Polypode Dryoptere. Gall.

In fifuris petrarum, an den Brücken von der Ziegelfcheune bis an den Kuhthurm frequens et paffim im Zwinger inter portam Grimmenfem et St. Petri. Fl. Iul. Åug.

428. ASPLENIVM. L. G. I29.5. Milchkraut C. Streifenfarn. Germ. Doradille. Gall.

«) Frondie fimplici.

Scolopen- I205. Afplenium frondibus fimplicibus, cordato-lingudriun. latis, integerrimis, ftipitibus hirfutis. LINN. Syft. p. 932. n. 3 BOEHM. n. Z15. BLACKW. t. I38.

Pharm. Scolopendrii Herba.

Gemeines Hircclzzungen-Milzkraut; Hirfchzunge. Germ. Doradille Scolopendre, ou Langue de Cerf. Gail.

In montofis, afperis et opacis locis ad oras Harcy, niae olim HII. вовнmervs detexit; ad muros bei Grimme ante paucos annos quoque reperi; in-horto Medico,aliisque pafim. 
120-. Afplenium fronde ramofe diuila, angufiore et Gemanilongiore, ioliis rernato connexis, radice cirrlofiore. cum.

GLED ap EOTHM. n. 71 .

A/plenizm caule pinnato, luperioribus fimpliciter dentalis halz. Hift. Helvet. T. III. pag. ห.. n. $16 y 0$. weIs Cryt. p. 2:9.

Adianthum noum Germanicurn Rutae murariae facie. BREYN. Cent. I. p. 19G. T.97.

Grofe Mawerrauthe. Germ.

In locis montofis, vmurofis, denfioribus, auf den Bergen bei Grimmic olim III. BOEHMERvs, inuenit, ad templorum muros pafim.

\section{B) Fronde pinnata.}

1208. Afplenimm frondibus pinnatis, pinnis fubrotundis Trichona, crenatis. LINN. Syft. p. 933. n. 3. BOEmM. n. 716. nes. BLACKw. t. 3 \%. Fl. Dan. t. 19.

Pharm. Trichomanis 1. Adianthi rubri Herba.

Steinmilakraut; rother Steinbreclb; Stcinfeder; rothe Mauerraute; Abton; Wirdertodt, falfch Franenhaar. Germ. Common Maidenhair. Angl. Duradille Politric Gall.

In muris antiquis an den Brücken nach den Kuhthurme copiofe. Fl. Iun. Iul.

\section{r) Fronde pinnata ramofa: Foliis multiplicato- diuifis.}

I209. Afplenium frondibus alternatim decompofitis: Ruta murafoliolis cuneiformibus crenulatis. LINN. Syft. p. 933 . n. 20. вогнм. ก. 712. BLACKw.t. 219. Fl. Dan, tab. x 90.

Pharm. Rutae Murariae f. Paronychiae Herba.

Maucr- C. Steinratite; weiffe Steinaute: Kleines Rauten-Milzkraut. Germ. White Maiden-hoir, or W all Riue. Angl. Doradille des murs, ou Sauve-Vie. Gall.

Ad inuros vetuftos ex corum fifuris circa St. Pauli templum; porro in Zivinger ad erismata intra $e 0$. rum fiRuras; item an der innern Maucr des Ranfïd- 
ter Thores, nach den Schießgraben zu; praeprimis inter portam Halenfern et ergaftulum; denique ad ponticulas coementis conftruétas a lateritiis vsque ad Kuhthurn frequenter occurrit. Flor. iul. in hiemen vsque.

429. PTERIS. L, G. r29r. Flügel- f. Saumfarn. Gicrm.

aquilina. 1210. Pteris frondibus fupradecompolitis : foliolis pinuatis: pinnis lanceolatis: infimis pinnatifidis: fuperioribus minoribus. LINN. Syft, p.931. n. I 7. вовнм. ก. 723. BLACKW. t. 325 .

Adler.Saunfarn; Adlerkraut; Roßfarn; Flïgelfarn; Iefus Chriftueurzel. Germ. Fougére Femelle, ou commine; Bois Boulogne. Gall. .

In fyluis elationibus, agris ferilioribus et ericetis, in Bieniz, im Univer:itïtsholze, in der Kämmorei bei Nattendorf, in der'Prellheide etc. copiofe. Flor. Iul. Aug.

obj. Kodix oblique diffecta, vel fi mauis, Aquilae bicipitis imperialis, imaginem refert.

$V f$. Radix ob odorem graueolentem cimices pellit; herba coriis parandis haud inepta. Folia pro culcetris et equorum ftramentis in Dania inferuiunt. $E$ cineribus squa incoctis globulos in Anglia faciunt lotrices, fmegmatis loco. Ligni inopia ob flammam calidifimam excitantem hanc vfurpant Angli. Decoctum aditringens ad coria paranda, quae Cordzan appellantur, vilk. Fronde: iuniores, foliis nondum ex. plicstis laponenfes edunt, et fere vbique fafciculi cius in taberniş venales exponuntur menfibus Aprili et Maio. Radix lignofa contufa, effufa aqua prima expreffa coquitur et a pauperibus comeditur. тиขNB. Iap. p. 332. 
CRYTOGAMIA. I.I. MTSCI.

Ord. $1 I$.

M V S C I
A FRON D O S I.
a) Periftomate nullo.

430. PHASCVM. IINN. G. 1305. HEDW. G. M. I. Phafcum. Germ. Phalque. Gall.

121r. Phafcum foliis lanceolato-linearibus, fummis c fubulatum. latiufcula bafi fubulatis, rigidis. HeDw. Mufc. Frond. I. p. $95 \cdot$ T. 35.

Pha/cumb ( (ubullatum) caulefcens folits lanceolatolinearibus patulis. schreb. Phafc. p. 8. n. . Eiusd. Spicil. pag. 7I. n. 7 7. тев. Spicil. Goetting. pag. $12 \%$.

Phafcum ( ( ubulatum) acaule, anthera ferfili, foliis fubulato fetaceís patulis. IINN. Syft. pag.-944. n. 3 . военм. n. 777. weis. Crypt. p. 268. Fl. Dan. t. 249. fig. 1. 2 .

Sphagnum acaulon trichodes, Dill. Mufc. p. $25 \mathrm{I}$. t. 32. f. 10.

Pfriemenförmiges Erdphafcum. Germ. Phafque en alêne. Gall.

In agris arēnofis ad Gonnezeitz; pratis pinguibus, e. g. Schoenfeldicis, in Oberholze ad latera forarum et cauorum, porro in Bieniz, bei Meisdorf ad lateritiam. Vernali et autumnali tempore. Thecae Maio et Iunio anni fequentis maturae. Perenne.

1212. * Phafcum humile, foliis fubulato-carinatis, fub. nitidum. fafciatis. HEDIV. Mufc. Frond. I. p. 91. t. 34.

Glïnzendes Erdphafcum. Germ.

Obf. Hanc fpeciem nuporrime in via neglecta pineti ad Lindenthal. Cel, HEDw. detexit. Iun. Iul, thecae maturefcunt. 
piliferum. 1213. Planfam caulefceris, foliis oblongis apice pilife. ris erétis. schree. Phalc. pag. 8. t. 1. f. 6. 7. Eiusd. Spicil, p. 72. n. 1029 .

Haarförmiges Pluafcum. Germ.

In mutis limolis, gregatim viget. Maio calyptra fecedente.

curpidatum. 1214. Phafcum caulefcens, foliis ouatis cufpidatis, patulis: lum in ere is conininentibus SCHREb. Phafe. p. 8. n. 3. T. I. f. 1. 2. Eiusd. Spicil. p. 72. n. 780. WFB. Spicil. Gott. p. 125 .

Phafcum aculon, anthera feffili, foliis oustis, acutis conniuentibus. linn. Syft. p. 94. п. 2. вовнм. n.

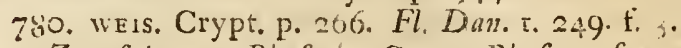
Gail.

Zugefpitztes Phafcuin. Gern. Phafque fans tige.

In agris, hortorum areis, pratis, folo pinguiori, muris argillaceis fere vbique copiofe. Fl. Martio et Autumno.

muticum. I2r 5. Phafcum acaule, foliis ouatis, muticis, concauis conniuentibus. SCHReb. Phafc. p. \$. 11. 4. T. i. f. , $\mathrm{X}$. 12. Eiusd. Spicil. pag. 12. n. 7\%9. wев. Spicil. pag. 126.

Sphagnum acaule bulbiforme minus. Dilt. Mufc. p. 252. t. 32.f 12. LINN. Sp p.I5-O. n. 1. $\beta$. ВОЕНM, n. 7:9. weIs Crypt. p. 2ty.

Stumpfes Phajcum l. Phajcum mit eiförmig ftumpeferz Blattern. Germ.

In muris argillaceis circuli Lipfienfis; fed rarius. Vere et Autuinno.

Obf. A priori differt: Theca feffili, foliis intricatis conniuentibus, nec patulis, muticis, latioribus.

ferratum. 1216. Phafcum acaule, foliis ouato-lanceolatis, planis, ferratis, ereatis. scireb. Plafce pag. 9. n. 5. T II f. 1. 2. Eiusd. Spicil. p. 73. n. 103O. WEE. Spicil, Gctt. p. $12+11.10$ ?

Sägeförmiges Phafcum. Germ. 
In pratis pinguioribus, limofis ad Plifiam. Vere t Autumno.

Obf. Omnium fere mufcorun minimus. Folia apice laciniata: Semina maiora is Polyzrichi maximi. SCHREB.

$121 \%$ * Phafcum foliis trunci minutis difritis: perichse-crípum. tialibus e lata concaua baí longo-acuminatis, inuoluto-contortilibus, HEDW. Muíc. Frond. 1. p. 25. T. IX.

Kranges Phafcum. Germ.

In tumulis Coemeterii nofodochialis, in Horti Apeliani, nunc Reicheliani, ambulacro arcuato et veteranis tulparum cumulis haud infrequenter Cel. HEDW. inuenit. Fl. OAtobr. Novembr. Isnuar. anni fubfequentis thecae maturae.

I218. * Phafcum foliis lanceolatis, lerratis, patentibus, patens. thecae acumine pellucido. Hedw. Mulc. Frond. I p. 28. T. X.

Phafcum mit von einander abftehenden, Blättern 1. flattriges Phafcum. Germ.

In viis vdis, vmbrofis fyluae fic diatae Rofenthal anno $178 \mathrm{I}$ prina vice $H E D W$. vidit; paullo poft in fimilibus locis verfus $Z$ fchocher ei obuiam venit. Flor. Mai. et Iun. Thecae Aug. maturelcunt.

1219. * Phafcum foliis perichaetialibus rectis, thecae pe-curuicelium dunculo incuruato. HEDw. Mufc. Frond. I. pag. 52. T. XI.

Krummhïlfiges Phafcum. Germ.

In areis et arenofis depreffioribus ambulacris horti Reicheliani cum thecis viridibus, Bryo argenteo fatis copiofe commixtum Cel, HEDwrg. inuenit. 
b) Periftomate nuido.

43I. SPHAGNTM. L. G. 1304. HEDW. G. M. 2. Torfmoos. Germ. Shaigne. Gall.

paluktre. 1220. Sphagnun ramis deflexis. IINN. Syft. pag. 944 . BOEYM. n. $77 \div$.

latifolium. Var, $\alpha$ Sphagnum paluftre latifolium. wers. Crypt. p. 263.

Sphagnum paluftre, molle, deflexum, fquamis cymbitormibus. ort. Mufe. 220 t. 32 .

capillaceun

ß) Sphagrum paluftre, capillaceum. weis. Crypt. p. 265.

Sphagnum paluftre molle, deflexum, fquamis capillaceis. dill. Mulc. t. 32, f. 2. LiNN. Sp. Pl. p. 1569 . n. I. var. $\beta$. вовнм. n. 775 .

Breitblättriges 1. haarformiges Sumpt-Torfmoos. Germ.' Sphaigne des marais, out. Moufce aquatıque. Gall.

In ericetis et pafcuis fubhumidis : var. $\alpha$ et $\beta$. in paludibus turfofis poft Schönfeld Cel. HED w. occurrit et in pratis bei Schadebach, in der Prellheide intra Al. nos, copiofiffme obieruaui ete.

VJ. Foeminae Lapponentes pro linteis in curris in: fantum hoc vtuntur.

\section{2. * HEDWIGIA. Hedw. G. M. 3 .}

ciliata. I22 I.* Hedreigia trunco ramificato, foliis nuato-lanceo. latis, concauis, apice diaphano denticulato perigonia* lium ciliato. HEDw. Mufe Frond. I. p. 104. t. 40.

Wimper Hedweigia. Germ.

Non procul a Lipfia, Grimme nimirum, in pe. tris cis Muldam Cel. HEDw. nuperrime inuenit. Fl. Autumno ineunte.

Obf HEDW. perfcrutator mufcorum accuratiffimus dicit hunc inufcum nunquam in arboribus deprehendifre. 
433. GYMNOSTOMVM. HEDw. G. M. 4. Iungfermoos. Germ.

I222. * Gymnoftomun foliis ountis, concauis, piliferis, ouatum, thecis ouatis. HEDW. Mufc Frond. I. p. 16. T. VI.

Eiförmiges Iung fermoos. Germ.

In muris rgillaceis circa Lipfiam vbique crefcic. Initio Maii Opercula cadunt. Ineunte Vere floret.

12.3 Gymnoftomum foliis explanatis oblongis acutis: pyriforme. thecis pyriformibus. wil p. Prodr. Berol. n. 896.

Bryum pyriforme capfulis erectis obouatis, calyptra fubulata furculis acaulibus, foliis ouatis, muticis. LiNn. Syft. p. 749. n, 4. воEнM. n. 743. weis. Crypt. p. 18.3 .

Bryum ferpillifolium capfulis pyriformibus. DIL. Mufc. $3+5$. t. 414 . t. 6 .

Mufcus capillaceus minimus, capituiis pyriformi bus, turgidis. valle. Parif. pag. 129. n. 3. tab. 29. fig. 3 .

Birnförmiges Iungfermoos. Germ. Bri piriforme. Gall.

In humidis ad fofficularum latera atque in locis fylvaticis vbique. April.

1224. Gymnoftomum foliis explanatis apiculatis, thecis truncatio truncatis. HEDw. Mufc. Frond. I. P I3. T. V. Wild. lum. Prodi. Berol. n. $\$ 98$.

Bryum truncatulum antheris erectis fubrotundis: operculo mucronato LINN. Syft. pag. 946. n 20. оена, n, 745. Weis. Crypt. p. I9i. Web. Spicil, p. 109. n. 177. HEDW. 1. c. f. 7.14 . etc.

Bryum exiguum, creberrimis capfulis rufis. DILL. Mufc. $347 \cdot$ t. 45 . f. $\mathrm{r}$.

Mufcus capillaceus omnium minimus. varle. $\mathrm{Pa}$ xif. p. 130. n. 5. t. 26. f. 2.

Abgcftutztes Iungfermoos. Germ. Bri tronque. Gall.

In virgultis et alnetis, campis humidis, ad foflas, fepes et in hortis vbique. Hieme et primo Verecum thecis; initio Veris opercula amittit. 
c) Periftomate figurato: fimplici ordine.

a) Periftomate dentato: denticulis integris.

434. TETRAphis, hedw. G. M.5;

pellucida, 1225. Tetraphis trunco fimplci erecto: foliis ouatoacuminatis, nitidis, pellucentibus. тімм. Fl. Megapl. ก. 727 .

Mnium pellucidum caule fimplici, foliis ouatis. LINN. Syft. p. 946. SCHReb. Spicil. p. 102. n. 1076. wers. Crypt. pag. I6I. schied. Icon. Fafc. I. p. 13. t. 3. Fl. Dan. t. 300 .

Bryum Diaphamum. zoeber. Spicil. p. I2I. n. 190.

Georgia Mnemofymun Ehrhart Hanov. Magaz. I750. 59. St. p. 931.

Durchifchimmerndes Sternmoos. Germ. Mnic transparent. Gall.

In fyluis lignorum putridorum copiofe et olim $D$. Knolle in horto Apclimo, nunc Reicheliano reperit. Martio.

\section{LEERSIA, HEDW. G. M. ?}

vulgatis, 1226. Leerfa furculo fimplici, foliis lanceolatis: thecis cylindricis: calyptris campaniformibus margine integris thecis longioribus. wilden. Prodr. Berol. n. 903.

Leerfa vulgaris calyptra laxa, conica, acquali, vaginulae membranula pileiformi, HEDW. Mufe. Frond. I. p. 46. T. XIII.

Bryum extinctorium capfula ere calyptris laxis aqualibus. LiNs. Syft. pag. 9+8. n. 5. SCHREd. Spiçil. p. 75. n. 1033. WeB. Spicil. p. 98. n. $16 \%$.

Licktfchneusenförmiges Knotenmoos; gemeine Leerfie. Germ. Bri éteignoir. Gall.

In muris argillaceis nach den Kohlgärten et in pagis vicinis; in terra ipfa aridiore an Gickerlingsberge, et Cel, HEDW, in parietibus circa Lipfiam e limo confeEtis, 
ctis, reperit. Ineunte Vere, nempe Aprili viget; Maii vero initio thecae matuae.

I227. Leer:fa furculo ramofo, folis oblongis piliferis; puluinata. thecis fubrotundis nutantibus: calyptris minutis. wiLd. Prndr. Berol. n. gor.

Bryzim pulwinatuin. LIN . Syft. pag. 949. n. 3 I.

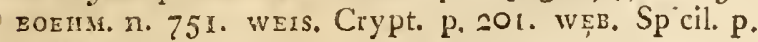
112. n. $1: 0$.

Polfterfömiges 1. Kïffen - Knotenmoos. Germ. Bri coulfinct. Gall.

In tectis ligneis vel framineis, muris et aggeribus copiofe. Vernali tempore viget.

1223. Leerfia trunco ereeto, fimplici divifoque; foliis lanceolata. lanceolato-coniruis, aficulatis, thecis ouatis. HEDw. Mulc. Frond. I. p. 66. T. XXIII.

\section{Lahzetförmige Leirlie. Germ.}

In muris argillaceis, ad aggeres et fupra lapides valde trequens Autumno et primo Vere viget. Initio Moii anni fequentis thecae maturefcunt. Perennis.

436. GRIMMIA. IIE DW. G. M. 8 .

1229. Grimmia foliis ouato-acuminatis, carinatis, pe-apocarpa. rigonialium apice albo, theca oblonga in pedunculo bręuifimo. HEDw. Mufc. Frond. I. pag. 104. Tab. XXXIX.

Grimmia Polyodon furculo ramofo, foliis lanceolatis: thecis onatis terminalibus, feffilibus: operculo acuminato: calyptris glabris minimis. WILD Prodr. Berol. n. yo4.

Bryam apocarpon capfulis feffilibus teminalibus, calyptra minima. LINN. Syft. p. 947 . вовнм. n. -16. LEYs. n. th55. weis, Crypt. pag. 179. Fl. Dar. tab. I 9 .

Fontinalis apocarpa. wzв. Spieileg. pag. 38. n. 116.

Kurvgeftielte Grimmie. Germ. Bri velu, Gall.

TK 2 


\section{CLASIS XX.}

In locis faxofis et apricis, im Bicniz; Cel. HEDW. vero nuperrime paffim ad pifcinam bei Lindenthal et ad ponticulan bei, dem Fuhthurme et alibi reperit. Floret Autumno. Opercula initio Veris cadere folent. Perennis.

437. WEISIA. hedw. G. M. 9. Weifie, Germ.

viridula. 123c. Weifia capiulis erectis : foliis lancedatis acumi- natis imbricato-patulis. L1NN. Fl. Suec. pag. 391.n. 1002. fub Bryo. военм. n. 75 \%. weis. Crypt. pag. 191.

Bryum viridulum. LiNin. Syft. p. 948. п. 2 I.

Bryum paludofum $\beta$. viridulum. weв. Spic. p. I 10. n. 78 .

Grüne Wrifie; blaßgrünes Zwergbryum. Germ. Bri verdozyant. Gall.

In agris ad foffs, ericetis, pratis et viis vbique.

recuruiro-1231. * Weifia foliis lanceolatis, imbricato-patulis, ftra. - theca gracili, operculi roftello recuruato. HEDw. Mufe. Frond. I. p. I9. T. VII. wild. Prodr. Berol. n. gog.

Rückwârtsgefchnäbelte Weifie. Germ.

In locis lapido-fabulofis gregatim ad interftitia bafeos columnae, quam proxime ad pagum Rïickmarsclorf milliaria Merfeburgum verfus, indicat, Cel. HEDWIG detexit. Flor. Iun. Iul. Opercula thecarum mâtura Aug, initio decidunt.

438. ORTHOTRICHVM. HEDW. Mufe. Frond. Vol, II, p. 96. Steiffchopf. Germ.

crifpun. $1232 . *$ Orthotrichum foliis er latiori bafi linearibus, confertis, ficcitate crispis, thecis ex ampliata pedunculi fummitate ouatis. HeDw. Mufc. Frohd. II. p.y6. t. XXXV.

Polytrichum capillaceum crifpum, calyptris acutis pilofifimis. DxLL. Hift. Mufc. 432. t. 35. f. 2.

Polytrickun bryoides. WeIs. Crypt. p. 17\%. var. $\beta$. capillace am.' พЕв, Spicil. p. 39, n. $117^{\circ}$ 

var. $\delta$.

Brywm ftriatum. ziNN. Spec. Pl. pag. I 580. n. 2.

Mufcus capillaceus minimus calyptra villofa. varz L. Parif. p. 433. .. II. t. 27. f. 9 .

Polytrichum friatum capitulo laterali, ouato fubfefrli, foliis integerrimis exappendiculatis, primordialibus gemmofis. Neck. Meth. p. 12I. n. 4.

Kraufer Steiffchof: Germ. Orthotriche frifé. Gall.

Caefpitulis denfis in arborum truncis praecipue Pinus Piceae du Roi pafim in Circulo Lipfienfi occurrit. Veris initio viget; thecae autem Iunio maturae. Perennis.

1233. * Orthotrichum foliis lanceolatis, carinatis, mar-ftriatun. gine reuoluto, patulis fummis apice erofis, calyptrae limbo fubaequali, neDw. Muic. Frond. II.p.99. T. XXXVI.

Bryum friatum. InNN. Spec. pl. n. 1579. n. 2. $\alpha$.

Polytrichum Bryi ruralis facie, capfulis feffilibus. Dil. Hift. Mufc. 430 . t. 55 . f. 8 .

Polytrichum friatum caule ramolo, capfulis fubfeffilibus fparfis, calyptris furfum pilofis. schrez. Spicil. p. 74. n. 736. вовнм, ก. $73^{6}$.

Polytrichum bryoides. WEIs. Crypt. p. 175. var. $\alpha$. ftriatum.

Múfcus apocarpos arboreus ramolus. vailt. Par. p. I 29. n. 6. t. $25 . \mathrm{f} .5$. Gall.

Gefreifter Steiffchopf. Germ. Orthotriche Arié.

Ad truncos arborum fruticumue inn Rofentlale, Streitholze etc. in lepibus, tectis parietibusque lig. neis frequens. Flor. per totum fere annum. Maio et Iun. thecas facit maturns.

1234. * Orthotrichum foliis lanceolato-carinatis, mar-anomalum. gine reuoluto, patulis, theca oblonga, friata, feriftomate interno deftituta, HEDw. Mufc. Frond. II. pag. 102. t. XXXVII. 
Polytrichum Bryi ruralis facie, capfulis feffilibus, minus. dili. Hift. Mufc. 43 i. tab. 1. . f. 9. SCGreb. Spicil. p. 79, n. 737 weis Crypt. p. 176.

Bryum ftriatün. LINN. Spec. pl. 158 8. var. $\beta$.

Mufcus capill ceus minimus acaulos, calypira Priata. vallz. Parif. p 130. n. io. t. 27. f. 10.

In laxis, muris, tectorum tegulis fere vbique; rarius ad arborum truncos. Circa Autumnum viget et Apri: opercula decutit.

Obf. Hae tres fpecies commemoratat, quas linN. et omnes Botanici fub vnico Brio frriato, vt varierstes, comprehenderunt, n fe inaicem diftinguuntur fequente modo: nempe crifpum, foliorum figura ac crifpatura; flriatum, folinrum non crifpatis spiceque eroro; anomalum denique limbo calyptrae crenulato, periftomate interno nuillo et externo dentibus reticuIntim ftriatis.

439. POLITRICHVM. L. G. I3O9. HEDW. M. G. Io. Haarmoos f. Haarkappe. Gorm. Polytric. Gall.

* Thecis cum apophyj.

commune 235 . Polytrichun furculo fimplici prolifero, foliis lineari lane olatis ferrulatis, thecis ablongis tetraëdris; calyptris villofis, WILDEN. Prodr. Berol. n. 9 ro.

Polytrichum commune caule fimplici, capfulis parallelepipedis, foliis ferrulatis acutis. schreb. Spicil. p. 73 . n. 733 .

Polyzrichtin commune, caule finplici, theca parallelepipeda. LinN. Syft. p. 946. вовнм. n. ?33. вLACKw. t. 375 . ก. $=$.

Polytrichum commane a. maius. wers. Crypt. pag. 168.

Pharm. Adiaxzhi aurei Herba.

Gemeines Haarmoos f. Güldenteviederton. Germ. Grand Politric doré, ou Perce moulfề. Gall, 
In ericetis, 'tyluis et ficcioribus pafcuis copiole imb Univerfitätsholze, in alneto ad Schönfold, im Bieniz, in der Prellheidé et alibi. Iunio cum capfulis maturis.

Vf. Weftrogothi fcopas pro furnis ad panificia ex hoc conticere narrant.

1236. Polytrichsan caule fimplici prolifero, foliis linea- iuniperiri-lanceolatis, integerrimis mucronatis, thecis ob. num. longis tetraeddris, calyptris villofis. wILD. Prodr. Berol. n. 9II.

Polytrichum quadrangulare iuniperi foliis breuioribus et rigidioribus. SCHREb. Spicil. pag. 73. n. 734 . воЕнм. n. 73 .'

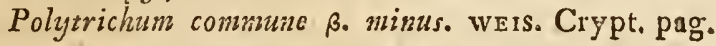
$17 \mathrm{r}$.

IVachholderblättriges Haarmoos f. Goldhaar. Germ.

In pratis et in via ad Schönfeld et Abunaucudorf, in locis ficcioribus et ad arborum radices, in ericetis. Iun. cum capfulis maturis. Menf. April. cum calyptra et thecis immaturis paffim mihi occurrit.

1237. Polytriclaum furculo fimplici, foliis lanceolatis piliferum, integerrimis, piliferis; thecis oblongis tetraëdris; calyptris villofis. wiLden. Prodr. Berol. n. 912.

Polytrichum capfula parallelepipeda; foliis integèrrimis piliferis, caule fimplici. sCHReb. Spicil. P. 74 . n. IOZI.

Polytrichum conmune $\gamma$. villofun. WEIS. 1. c. pag. 372.

Feines Goldhanr; haarforniger Wiederton. Germ.

In editioribus ficcis ad Abtuauendorf, ad: Templam St. Theclae, am Bieniz. Ill, schrebervs olim dete. xit. Autumno et Vere.

Obf. Caule breuiori, fimplici, foliis non ferratis pilo longo erectiufculo cano terminatis differt.

** Thecis absque apopolyys.

1238. Polytrichum foliis obfcure ferratis, theca fubro- nanma tunda, nutante, HeDw. Mufc. Frond. I. p. 35. t. XIII. I K 4 
Polytrichum furculo fimplici, foliis lanceolatis apice fubferratis, thecis fubrotundis: calyptris villotis. wrL. Prodr. Berol. n.913.

Polytrichum caplulis fubrotundis, caule fimplici. hVDS Angl. 400. SCHreb. Spicil. pag. 74. n. 35 . ВOEHM N. 735 .

Polytrichum nanum capfula cylindrica eresta; furculis fimplicibus, breuifimis, foliis ferrulatis. wyss. 1. c. p. $1^{-3}$.

Mnium Polytrichoides calyptra villofa. Lins. SyR. p. $94^{-7}$. Gall.

Niedriges f. Zwerghaarmoos. Germ. Polytric nain.

Ad latera fcrobiculorum arenoforum montis Bieniz BOEHM. SCHRFD. et HEDW. pofterior e $\mathrm{iam}$ in pineto ad I.indenthal, reperirunt. Ineunte vere opercula cum ca. lyptra demittit. Fl. Mai. Iun.

aloides. I2.39. * Polytrichum furculo fimplici foliis lanceolatis, apice ferrulitis, thecis cylindricis: calyptris villofis. wato Prodr.Berol.13.914.

Polytrichum aloides foliis verfus apicem euidenter ferrutatis, theca cylindrica obliquata. HEDw. Mufe. Frond I p. 37. T. XIV.

Mnium Polytrichoides, var. $\beta$. LINN. Syft. Ed. R.IV. .p. 464

Aloefürniges Haarmoos 1. Haarkappe. Germ.

In argillolis ericeris ct ad forfam montis fie dicti Bieniz Cel. HEDw. reperit. Fl. Mai. Martio.

vndulatum. 1240.'Polytrichum foliis lanceolatis, ferratis, vndulatis, patentibus, calyptra ad apicem paraphyfiphora, theca cylindrica, cernua. HeDw. Mufc. Frond. I. pag. 43. T. XVI.

Polytrichin furculo fimplici, foliis lanceolatis ferratis, vndulatis; thecis cylindricis, operculi acumine longe producto: calyptris dimidiatis, glabris. WILD. Prodr. Berol. n. 915.

Bryam vndulatum. LINN. Syf. p.948.n. 10. ВОенM, n. 746. 
Var. $\beta$. Polytrichum thecis foliisque erectioribus. vndulatum HEDW. 1. c. p. 43. T. XVII.f. is. et I 5 . minus.

Bryum foliis luggolis, capitulis erectiufculis. DiLLEN.

Wcllenforminges Knotennoos f. Haarmoos, Haarkappe. Germ. Polytric ondulé. Gail.

In Ciluis, im Rofenthale cuin varietate reperi; porro in pomariis, virgultis copiofe. Iul, et Augufi in:tio fioret., Vere opercula cadunt.

\section{B. Denticulis bifidis.}

440. * SPLACHNVM. HEDw. Mufc, Frond. II. p. 35. Schirmmoos. Germ. Splanc. Gall.

124I. * Splachnum trunco ereßto, fimplici diuifogué, ampullaapophyfi inuerfe ampullaeformi colloque longo viren- :eum. te. HEDW Mufc. Frond. II. p. 4t. T. XIV.

Splachum ampullaceum vinbraculo ampullaceo obconico. IInN Sylt p. 945. Fl. Dan. t. 822.

Flajchenformiges Schirmmoos. Germ. Splanc ampoulé. Gall.

In paludibus caefpitofis turtofis hinter Scliönfeld et proxime ad Taucham inueni. Fl. Iul. Aug.

441. * TRIChOSTO.MVM. hedw. G. M. I. Wimpermoos. Germ.

1242. * Trichoftomum furculo ramofo decumbente, fo- hypnoides. liis oblongis apice piliferis; thecis oblongis; calyp-

- tris integris. WILD. Prodr. Berol. n. 9!6.

Hypnum canefcens a. hivfutum caulibus fubretis; ramis alternis breuibus, foliis piliferis, piiis longis, vagis, fetis breuibus, erectis. wers. Crypt. 'pag. 211.

Bryum hypnoides. IINn. Syft. Ed. R. IV. pag. 477. $\alpha$.

Bryum hypnoides polycephalon lanuginofum montanum. DILL. Mufc. 372 . t. $4 \%$. f. 34 . B.

Raxchharige: Wimpermoos. Germ. 
In fyluis ad arborum truncos pafim. Hyeme. Cap. fulas nondum vidi.

cancfcens :243. Trichoftomum caulibus fubręis, ramis fparfis longioribus, foliis pilofis, fetis longioribus erectis.

Hypnum canefcens ß.pilofum. wers. Crypt. p. 213. WEE. Spicil. p. 8 I. n. 156 .

Bryum hynoides antheris erectis, furculo erectiufculo, ramis lateralibus, breuibus, fertilibus. LIN . Syft. pag. 949. n. 24. scrreb. Spicileg. pag. 77. n. IO34. Fl. Dan. t. 476 .

Weiffes IVimpermoos. Germ. Bri hypnoide. Gall.

In collibus ad Templum St. Theclae. Prino Vere thecae maturae.

pallidum. 1244. Trichoftomm furculo fimplici brcuiffimo, foliis fubulatis, capillaceis, vaginantibus; thecis cylindricis: operculis conicis, calyptris dimidiatis. WILDEN. Prodr. Berol. n. $91 \%$.

Trichoftomum humile, foliis capillaribus, theca ouato-cylindrica: operculo conico. HEDw. Mufc. Frond. I. p. 71. Tab. XXVII. Hall. Hift. n. 1005. fub Eryo.

Bryzum pallidum capfulis vrceolatis, erectis, pectine fpirali, foliis capillaceis, furculis acaulibus, sCHREB. Spicl. p. So. n. $103 \%$.

Blafyieligt IVimper- f. Knotenmoos. Germ.

In nemoribus, im Oberholze, ad latera foftarum Ill. SCHRE 8. et circa montem im Bieniz Cel. Hrow. repierunt. Mai. et Iun. floret. Opercula autem Iul. deiicit.

pufilum. 1245. Trichoftomum furculo fimplici breuifimo, foliis fubulatis vaginantibus; thecis oblongis: operculis conicis: colyptris dimidiatis. Wred. Prodr. Berol. n. 913.

Trichoftomum foliis ex ouato - concauis, bafi fubmlatis, thecis erectis, oblongis. Hedw. Mufc. Frond. I. p. 74. T. XXVIII. 
Selor klcines Haarmoos 1. Wimpcrmoos. Germ.

In locis arerofis, elatioribus, gramine tenui veftitis port hortos oleraceos Cel. IIEDW. anno $17 x+$ primun detexit, paulio poft ad praecipitia fcrobis tenus viam publican Tauchan verfus reuifit. Flor. Autumio et Vere primo opercula deponit. Annuus.

442. * FISSIDENS. HEDW. G. M. I2. Spaltzahn. Gerw.

1246. Fiffidens fronde fimplici pinnata, apice fetifers: bryoides. pinnis oblongis, acutis, thecis oblongis, operculis acutis. wild. Prod:. Berol. n. 919.

Hzpnum bryoides fronde fimplicifima pinnata lan. ceolata apic pedunculifera. IINN. Syft p. 950. n. 4 . schreb. Spicil. p. 85. n. $1055^{2}$. weis. Crypr. p. $21 \%^{\circ}$ wer. Spicil. p. 46. n. 123. Fl. Dan. t 4.3. f. I

Knotenformiges Aftmous f. Spaltzahn. Germ. Hypne bryoide. Gall.

In vmbrofis humidis, folo argillaceo maxime in follis et ambulacris horti Reicheliani, im Rofenthale, Lindenan, Gonnervitz; ad lateritiam Meisdorfanam, in Oberholze. Decemb. cum capfulis.

1247. Fiffidens fronde pinnata fimplici, baî fetifera: taxifolia. pinnis oblongis acutis, thecis oblongis: operculo acuminato. WILD. Prodr. Berol. n. 920.

Fiffrens ixunco fimplici de bafi thecigero, foliis lanceolato-pinnatis. тimi. Fl. Megapol.n. 780.

Hypmm taxifolium. LINN. Syft. pag. 950. ก. 2. schreb. Spicil. p. 86. n. IO5I. Weis. Crypt. p. 2 i 6. web. Spicil. Gott. p. 42. n. 120. Fl. Dait. tab. 473. fig. $\mathrm{I}$.

Taralattriges Aftmoos f. Spaltzahz. Germ. Hypne ì feuilles d'If. Gall.

In fyluaticis humidis im Rofenthale, ad vias vdas, rmbrolas et ad aggeres in fyluis, v. c. in fylua Acr. demica frequens. Fl. Mart, cum thecis. 


\section{$524 \quad$ ELASSIS XX.}

adianthoides 1248. * Fiffidens fronde pinnata fubramofa, medio fetifera; pinnis oblongis acutis; thecis fubcylindricis: operculi acumine breui. wilden. Prodr. Berol. n. 921.

Fifjidens trunco diuifo, erectiufculo, medio thecigero; foliis lanceolato - pinnatis. тімм. Fl. Megapol. I. $75 \mathrm{r}$.

Hypnum adianthoides. Lise. Syft. pag. 950. n. 6. WEB. Spicil. Gott. p. 17. p. 124.

Krautfarnartiges Knotenmoos f. Spaltzahn. Germ. Hypne adiantin. Gall.

In pratis et pafcuis fpongiofis, turfofisque frequens.

donticulatus 1249. Fiffidens fronde pinnata fubfimplici, bafi fetifera: pinnis cuneiformibus acutis, coniugatis; thecis cy. lindricis: operculo obtufo. wisd: Prodr. Berol. n. 922.

Hypnum - denticulatum, fronde pinnata fimplici: pinnis duplicatis bali pedunculiferis. LINN. Syft.pag. 930. n. 3. sCHREB. Spicil. p. 86. n. 772. Wé. Spicil. p. $4.3 \cdot \mathrm{n}, \mathrm{I} 7 \mathrm{I}$.

Mufcus fquamofus non ramofus maior et minor, capitulis incuruis. valle. Parif. t. 29. f. 8 . военM. n. 772.

Gezahnter Spalzzahn. Gern. Hupne denticulé. Gall.

In locis vdis nemorofisque atque in arborum truncis, e. g. in Alneto ad Schönfels, im Rofenthale et alibi frequens. Viget OAtobr. per Hyemem.

Obf. Foliola ouato-triangularia, acuminata, ferie fimplici f. duplici imbricata, bifaria, falcata. Opercula breuia, exacte conica. Surculi fimplices vel ramofi, e centro diffufi, decumbentes.

fiuroides. 1250. Fiffidens furculo fubramofo, foliis imbricatis, outa-lanceolotis, apice piliferis, thecis oblongis, operculo conico. Rотr. Flor. Germ. I. p. 560.

Hypnum fciuroides furculis erectis, ramofis, incurvatis. LINN. Sy?t. P. 952, n. 44. SCHREB. Spicil. p.98. n. 770. военм. n. 770 . weis. Crypt. p. 258 : 
CRYPTOGAMIA. II. MVSCI.

Krummäftiger Eichhornfchwanzaitiger Spaltzahn. Germ. Hypne queue d'ecureuil. Gall.

In arborum vetuftarum truncis in Rofenthale ad Salicum truncos ad Fagos antiquas vor Gunndorf et alibi. Flor. Oetobre in Ver vsque cum thecis.

443.* DICRANVM. hedw. G. M. T3. Gabelzalin.

\section{Germ.}

1251. Dicranum furculo ramofo, foliis oblongis, acu- purpureum. tis, carinatis; thecis fubcylindricis: fetis axillaribus. WILDEN. Prodr. Berol. n. 923.

Dicranum caule dichotomo foliis carinatis ; axilis pedunculiferis, theca cernua. тims. Flor. Megapol. n. 787 .

Mnium purpureum. LiNe. Syft, p. 946. n. ?.

Bryum purpureun capfulis inclinatis ftriatis, operculo conico, foliis linearibus lanceolatis, carinatis, caule fubdiuilo. SCHREB. Spicil. p. 79. n. 738. военм. n. 738 .

Bryum purpureum antheris fubnutantibus axillaribus; caule dichotomo: foliis carinatis. weIs. Crypt. p. 198.

Var. $\beta$. Bryum polytrichoides paluftré, fetis longioribus rubris fericeis. DILx. Mufc. 38\%. tab. 49. fig. 52.

Purpurartiges gabelförmigès Sternmoos; purpurartiger Gabelzahn. Germ. Mnie purpuriti. Gall.

Supra lapides, ad muros, in agris, fyluis, lignis, tectis pagorum ftramineis et fere vbique. Fl, vernali tempore.

1252. Dicranum furculo ramofo, foliis lineari-lancso- feoparium. latis recuruis fecundis, thecis erectis oblongo-cylindricis: operculis conicis acuminatis. wILD. Prodr. Berol. 11. 924.

Dicranum erectum, foliis rigidiufculis fecundis, thecis oblongis cernuis. тाмм. n. 783 . 
Brym fcopairum. LINN. Sy ft. p. 948. n. 9, BOEm, n. 756 . wers. Crypto p. 213 . wer. Spicil. p. 71. л. 145. Fl. Dan. t. U24. f. I.

Befenartiges huotenmoos f. Gabelwahn. Germ.

In fyluis et nemoribus ad aborum truncos vbique. Maitio cum capfulis.

glaucum. 1253. Dicranam furculo ramofo, foliis ouatis, acutis imbricatis; thecis oblongis: operculis acuminatis, recuruis. VILD. Prodr. Berol. n. 926.

Bryum glaucum. LINN. SyR. p. 948. n. II. SCIREB. Spicil. p. 77, n. 739 .

Bryum trichoides, erectis capitulis, albidum fragile. военім. n. 739 .

IIypnum glancum. wers. Crypt. p. 208. WE b.jpicil. p. $75 . \mathrm{n} .150$.

Eifengraues Knotcnmoos; blau angelanfener Gabel. zahn. Germ. Bri glauque. Gall.

In ericetis apricis in bicniz, aiiis Mufcis immix. tum ad arbores. Primo Vere cum thecis.

cirrhatum 1254. Dicranmin foliis capillaceis congeftis, tortilibus, capfulis onato cylindraceis breuiffime ciliatis. HAL.. Hirt. n. 1786. (fub Hypno) scrizes. Spicil. p. 73. n. 748. вогнм. n. ? $\rightarrow$.

Muium cirrhatum. rinn. Syft.p.946. n.9. Fl. Dan。 t. 538 . f. 4 .

Gezackter Gabclsahn. Germ Mnie crêpe, G»ll.

In tectis ftramineis et muris pagorum vicinorum, ad aggeres inter aiios Mufcos. Febr. Martio.

heteromal- I255. Dicranum furculo fubfimplici, foliis fetaceis reIlum. curuis; thecis oustis: 'operculis acuminatis recuruis. wild. Prodr. Berol. n; 925.

Bryum heteromallum valculis erectis, foliis fetaceis fecundis. LINN. Syft. p. 948 . n. I8. SCHREB. Spicil. p 78. n. 1036. Fl Dan, t'. 479. HEDw. Mufc. Frond. II. p. 93. t. XXXIV.

Hypmum hezeromallum foliis capillaribus, heteromallis, capfulis ouaris, operculis ariftatis. WEIs. Crypt. p. 215. WEB. Spicil. p. 72. n. 146. 
Einfeiriger Gabelzahn. Germ. Bri élégant. Gall.

In locis fyluaticis im Oberholze ad aggeres et copiofe ad vallem pifcinae in pineto sd Lindenthal. Septembr. et Oetobr. floret. Vere, praecipue Martio, cum thecis.

1256. Dicranum thecis outis nutantibus, foliis fubula varium. tis, furculo fimpliciffimo, medio pedunculifero. ninn. Syft. p. 929. n. 35. schreb. Spicil. pag. 8I. n. 1041. fub Bryo fimplici.

Veränderlicher Gabelzahn. Germ.

In locis fyluaticis, im Bieniz et agris frequens: hinter der Schönf clder Mïhle, potro verfus Lindenthal in locis gramine copiofiori veftitis Cel. HEDw. deprehendit, Octobr. - Martio cum capfulis.

ஓ) Denticulis ciliatis, tortilibus.

444. * Tortula Hedw. M. G. I 4.

1257. Tortula furculo breuifimo fubdiuifo, foliis oua- muralis. tis acutis, apice piliferis; thecis oblongis: operculis conicis acutis. wild. Prodr. Berol. n. 927.

Bryum murale furculis fimplicibus cefpitofis, foliis piliferis ereßtis; thecis cylindricis erectiufculis. Linn. Syft. pag. 9.48. n. 8. воEHM. n. 7:2. SChreb. Spicil. p. 76. n. 742. we1s. Grypt. p. 189. wЕв. Spicil. p. 100.' n. 169.

Var. $\beta$. Bryum cauliculo breuifimo, foliis ouatolanceolatis, patulis, capfulis ariftatis. HALL. Hift. $n$. 1826. воEHM. n. 747 . SCHREB. n. $7+7$. var.

Mauer - Knotemmoos. Germ. Boi des mures. Gall.

In tegulis, muris, lapidibus vbique; var. in faxis, muris feptentrionalibus, fuburbanis. Martio cum capfulis.

1258. Tortula furculo breuiflimo fimplici, foliis ouatis fubulata. obtufiufculis; thecis cylindraceis, fubulatis; operculo conico; acuto. wild. Prodr. Berol. n. 928. 
Bryum Jubulatum. Linn. Syft.jp. 948. n. 6, вовнм. n. 744. Schreb. Spicil. p. 76. n. 744. weis. Crypt.p. 187. пев. Spicil. p. 9\%. ก. 168.

Pfriemenförmiges Knotenmoos. Germ. Bri fubuls. Gall.

In pratis vliginofis et fyluis humidioribus, im $R o$ fenthale, in alnero ad Schönfeld, poft hunc pagum, in aggeribus e. g. finiftrorfum ad viam nach Gohlis. Aprili cum thecis.

445. * BARIBVLA. HEDW. G. M. I5. Bartmoos.

Germ.

ruralis. 1259. Barbula furculo ramofo, foliis reflexis obouatis, obtufis, apice piliferis; thecis cylindricis: operculis conicis acutis. wrld. Prodr. Berol. n. 929.

Bryum rurale foliis pitiferis recuruatis, thecis cylindricis teretiufculis. LINN. Syft. p.948. n. 7. ВОвHM. n. $7+1$.

Hypnum rurale. weis. Crypt. p. 2 IO. WEB. Spicil. p. 73 . n. I 4.7 .

Feldknotenmoos f. Bartmoos. Germ. Bri ruftique. Gall.

In tectis framineis, muris, ad arborum truncos vbique frequens., Vere cum capfulis.

conuoluta $\mathbf{1} 260$. * Barbula foliis omnibus lanceolatis, perigonialibus obtufis in cylindrum conuolutis. HEDW. Mulc. Frond. I. p. 86. T. XXXII.

Mnium Setaceum. Linn. Syft: p. 946. n. 8.

Borftenartiges Sternmoos S. Bartmoos. Germ. Mnie - fétacé. Gall.

In pratis, ad aggeres, foffas et in muris copiofe. Omni tempore floret. Thecae circa tempus vernale maturéfcunt.

viguiculata, 126r: Barbula foliis lineari-lanceolatis, carinatis, furręitis; perigonialibus mafculi foris cum fafciculo, theca obliqua, furculo fubranofo. HEDw. Mufc: Frond, I. p. 59. t. XXIII. 
Bryum vnguiculatum antheris ereetis oblongis pe. dunculis axillaribus, foliis erectis, acutis, carinatis. LINN. Syft. Ed. R. IV. p. 479. weв. Spicil. p. Iวร. n. $17 \%$.

Bryum vnguiculatnm capfulis vrceolatis, operculo longo obliquo, foliis lanceolatis tortilibus, cauliculis ereßtis. SCHREB. Spicil. p. 79. n. 1037"

\section{Zugefpiztes Bartmogs. Germ.}

In hortorum areis, ad vian nach Gonneveiz, in locis argillaceis, in der Leimgrube, porro in muris argillaceis locisque humilioribus, e. $\mathrm{g}$. in pratis fylusticis gregatim reperitur. Initio Veris praecipue Martio et Aprili opercula cum calyptra deponit. Iul. et Aug. viget.

1262. * Barbula foliis recuruato-patulis, perigoniali- fallax. busque interioribus mafculi exfalciculatis; thecis oblongis; operculo vbique roftrato. HEDW. Mufc. Frond. I. p. 62. T. XXIV.

T.ufchendes Bantmoos. Germ.

In ambulacro fuperiori circulari horti Reicheliani Cel. Hedw. detexit, et nuperrime his locis ipfe deprehendi. Flor. Iul. Aug. et ineunte fubfequentis anni Vere thecae cadunt.

1263. Barbula trunco exigno, foliis patentibus margi- rigida: ne inuolutis, thecis ohlongis erectis. HEDW. Mufc.

Frond. I. p. 65, T. XXV.

Bryum ftellatum acaule, foliis inuolutis, operculis cufpidatis, peetine fpirali. schreb. Spicil. p. 80. n. $10,0$.

Steifes Bartmoos; Sternfömiges Knotenmoos. Germ.

In muris e limo exfruatis, e g. um die Milchingel, ad Schönfeld, Flor. Iunio.

1264. Barbula capfulis obliquis, foliis fubulatis bafi mutabilis. dilatatis vndulatis demun tortilibus, cauliculis ereetis. sCHREB. Spicil. p. 79. ก. 1056. fub Byro crifpo.

Veränderliches Knotenmoos. Germ. 
Ad fortas unten am Bieniz aliisque in locis humidis frequens. Rarifime apud nos tloret.

Obf. Cauliculi humiles foliis e bafi lata, fere fubrotunda, vidulata, fubulatis, acutis, poft exficca. tionem crifpatis laxius praediti. Setae oblongae, virides, bafi rubefcentes. Capfula obliqua: Operculum conicum, acuminatum, rubellum. SCHREB.

\section{d. Periftonate figurato, duplici.}

๙. Periftomate dentato alato. I) denticulis apice. liberis.

446. NECKELIA. HEDW. G. M. I6.

erifpa. 1265. Neckeria furculis ramofis, crectiufculis; foliis diftichis oblongis, obtufis, rugofis; thecis oblongis; operculo roftrato, roftro reflexo. WILDEN. Prodr. Berol. n. 93 r.

Hypnum crifpun furculis ramofis, frondibus fub. pinnatis: foliis vndulatis planis, LiNN. Syft. p. 950. n. 13. WEIS. Crypt. p. 22 r. WEB. Spicil. p. 54. n. 128. Bовнм. n. 764 . Synon. Drel. Gill. 217 .

Kranfe Neckerie. Germ. Hypne crepu. Gall. Ad arborum truncos in ficcioribus.

vitieulofa. 1266. Neckeria furculis ramolis decumbentibus, foliis oblongris, acutis, patulis; thecis oblongis: operculis conicis. WILDEN. Prodr. Berol. n 934.

H'pun viticulofum furculis repentibus; ramis vagis teretibus, ereetis, foliis patulis acuminatis. LINN. Syit. p. 95I. n. 18.. вовнаi. n. 76r. (Syn. Hall.) SCI1REB. p. 94. n. $76 \mathrm{r}$.

Schlankäftige teacholderblättrige Neckerie. Germ. Hypne Sarmentcux. Gall.

In fyluis ad arborum truncos in Rofenthale, im Gonncwizer - Rafchwizer Holze, aliisque frequens. Aprili cum capfulis.

dendroide6. 1267. Neckeria furculo erecto; inferne nudo, fuperne fafciculato, ramofo, foliofo: foliis lineari-lanceola- 
tis, imbricatis; thecis fubcylindricis, ereeis: oper. culis roftello incuruo. WILDEN. Prodr. Berol. $n$. 932:

Hipnun dendroides, furculo ereeto, ramis fafciculatis, terminalibus, fimpliciulculis; thecis eretis. Linn. Sylt. p. 95I. n. 33. вовнM. ח. -69. Veis。 Crypt. p. 245. wez. Spicil. p. 74. n. 148. Fl Dan. t. $82,3$. f. 2 .

Geradiffige baumfömige Neckerie. Germ. Hypne arboré. Gall.

In locis humidioribus, fyluaticis ad radices Alni, porro in pratis et palcuis frequens. Flor. Octobr. in Ver vfque cum thecis.

1168. Neckeria furculis ereatis ramofis, teretibus, fo-curtipendu liofis: foliis oblongo-ouatis, acutis, imbricatis; la. thecis cuatis nutantibus; operculis acuminatis. w'I,DEN. Prodr. Berol. ก. 933.

Hypnum curtipendulum furculis vagis teretibus, foliis ouatis acutis, patulis, perichaetiis longiffunis thecis pendulis. LINN. Syft. p. 952. n 3'́. SCHRER. Spicil. p 101. n. 1075. WEB. Spicil. p. 76. n. I51.

Kis:fielige Neckeric. Germ.

In fyluis ad arborum truncos, im Oberholze, Univerfitätsholze frequens. Aprili cum thecis.

369. Neckeria furculo ramofo, repente, foliis oblon- fericeds gis, fetaceis terminatis, arcte imbricatis ; thecis erectis cylindricis: operculis acuminatis recuruis. WILDEN. n. 938.

Hypnum fericeumi furculo repente, ramis confertis, erectis, foliis fubulatis, thecis erectis. LINN. Syit. p. 9.2, n. 4 1. BОЕНM. n. 759 . Gall.

Seidenartige Neckerie. Germ. Hypone Soyeux.

In fyluis ad terram et atborum truncos vbique copiofe. Martio.

1270. Neckeria furculo ramofo, eresto, foliis lineari-adunca. lanceolatis, falcatis carinatis, apice fetaceis, fecun- 
dis; thecis obliquis, oblongis: operculis conicis, obtufis, wiLDEN. Prodr. Berol. n. 9 ? 7.

Hypmin adancum furculis erectiufculis, fubramo: fis, foliis fecundis, recuruatis, fubulatis. LiNN. Syft. p. 95I. n. 25. SCHRez. Spicil. p. 90. IO56. wers. Crypt. p. 240. weB. Spic. p. 65. n. 'T46.

Krumne Neckerie. Germ. Hypne crochu. Gall.

In fyluis, in Gunndorfer et Klein Dölziger Hol₹e, in Sylua Academica, in pratis vdis Schoenfeldicis frequens. Maio.

\section{LESKEA. HEDW, G. M, 17.}

attentata. $127 \mathrm{I}$. Lefkca furculis ramofifimis, ramis incuruatis apice gracilefeentibus, foliis fecundis, ouatis, carinatis, obtufis; capfulis erectis, cufpidatis. schree. Spicil. p. I00. n. ro73. fub Hypno.

Lefkea attentuata tiunco varie romofo, ramis apice gracilefcentibus incraflatisque, incuruis; foliis ouato acuminatis fecundis; thecis erectis. HEDw. Mufc. Frond. I. p. 33. T. XII.

Ad arborum radices, praecipue ad Carpini Betuli truncos in fyluis, im Rofenthale, ad Gonnezeitz, Rafchreitz frequens. Rarius cum thecis.

complanata. 1272. Lefkea fronde ramofa: foliis diftiehis, imbricatis, acinaciformibus, acuminatis, compreffis, thecis ouatis: operculo conico. SCIREz. Spicil. p. $8 \%$ n. 778. (fub Hypno) Linn. Syft. p. 950. n. 7 .

Hypunu complanatum fronde pinnata ramofa: foliis imbricatis acutis complicatis compreffis. LINN. Syft. p. 650. n. 7. we1s. Crypt. p.218. weB, Spicil. p. 48 . n. 125 .

Ebenes Aftmoos. Germ. Hyjpne aplati. Gall.

Ad truncos arborum vbique, praecipue in fyluis im Rofenthale etc. Primo Vere thecas maturat.

polyantha. 1273. Lefkea furculis ramofis, ramis breniffimis, foliis fubulatis acutis; thecis ohlongis: operculis conicis, obtufis. wilden, Prodr. Berol, n. 942. 
Hypnum polianthos furculis ramolifimis, ramis reAtis, teretibus, multiforis, thesis erectis, oblongis; operculis conicis obtufis. SCHRED. Spic. p. 97. n. 1070.

Hypnum flifolizn furculis vagis ramofifimis; ramis filiformibus; antheris obliquis L1NN. Sylt. p. 952. n. 37 .

Vielblïhendes Afmoos. Germ,

Ad truncos arhorum inprimis Salicum frequens. Hyeme cum thecis.

1274. Lefkea frondibus reptantibus, ramofifimis; ra- myofuroimis teretibus, foliis ouato-lanceolatis arêe imbrica- des. tis pilo tcrminatis; thecis cylindricis. вотн. 1. p. 464 .

Hypnum myofuroides. ıis, Syft. p. 952, n. 46. SCHREe. Spicil. p. 97. n. rogo. WeE, Spic, p. 93. n. 163. var. $\%$ crafitus.

Mâufefchreanzartiges Aftnoos. Gern. Hypne Queuede-rat. Gall.

Ad truncos arborum in Oberholze vulgaris.

I275. Lefkea furculis repentibus, vagis ramofis, foliis paludofa: ouatis, acutis, fecundis; thecis cylindraceis: operculis obtufis. WiLnen. Prodr. Berol. n. $9+3$.

Hyprunn paluftre furculis repentibus, ramis confertis erectis, foliis ouatis fecundis; thecis erectiufcu. lis. IINX. Syft. p. 951. n. 3 I. SCHRED. Spicil. p. I0: n. 1074 .

Hypmim heterophyllam furculo repente fimplici, ramis erectis, fetas fubaequantibus: operculo mucronato. NECK. Meth. p. 168. I1, 21.

Sunzpf Aftmoos. Germ. Hypne de marais, Gall.

In nemoribus paludofis, pratis et ad fublicas putridas ad Plifiam. Autumno cun thecis.

1276. Lefkea fronde ramofa: foliis diftichis imbricatis trichomaacinaciformibus, obtufis: Schreb, fpicil. p. 88. noides. n. 1053 .

Lefliea furculo ramofo: foliis diftichis oblongis, fubulatis, obtufis ; thecis fubcyliridricis, roftello reflexo. wilden. Prodr. Berol. n, 94 I. 
Ad arborum radices truncosque in nemoribus vmbrofis ad cinnewitz, in Rojenthale. Vere cum thecis maturis.

448. HYPNVM. L. G. I312: HEDW. G. M. I8. Aftmoos, Gcrm. Hypne. Gall.

* Frondabus pinnatis.

fyluaticur. 1277. Hypnum fronde pinnata ramofa, procumbente, foliolis acutis, medio pedunculitera, foliolis acutis. IINN. SyAt. p. 950. n. 9. SCIIREB. Spicil, p. $8 \%$ ก. $10 \div 2$.

Wald Aftmoos. Germ. Hypue des forets. Gall.

In aggeribus humidis, vmbrolis ad lateritiam Meusdorfienfein, im Obcrholize.

\section{** Surculis vagis.}

triquetrum. 1278. Hypmum ramis vagis recuruis, foliis ouatis recuruatis patulis. LINN. Sÿft, p. 950. n. 14. воEHM. n. 7ó- schreb. Spicil, p. 90, n, 767.

Dreifchneidiges Aftmoos. Germ. Hypne triangulaire. Gall

n nemoribus ad arborum truncos, e. g. im Rofenthale, ad Connereiz, Rafchwiz, in Klein-und Groß$Z$ fchocherfchen Holse et in pratis multis valde frequens. Hyeme cum captulis.

loreum. 1279. * Hypnum furculis reptantibus, ramis vagis erectis, foliis fecundis: thecis fubrotundis. LINN. Sytt. p. 950. scop. Flor. Can. p. 157. n. I7.

Hypmum loreum montanum, capfulis fubrotundis Dilc. Mufc. p. 305. n. 40.

Langrankig habrblättriges Aftmoos. Germ. Hypwe is courroie. Gall.

In fyluis montofis ad terram, im Bieniz paffin. Aprili cum thecis. 
1280. Hypnum ramis vagis erectiufculis, foliis ouatis, rutabulum. acutis, mucronatis, patulis, operculis conicis. SCHREB. Spicil. p. 90. n. 105\%.

Hypnum ramis vagis fubrepentibus, foliis ouatis mucronatis, imbricatis. L1N. Sy?t. p. 950. n. '50. Fl. Dan. t. 524. f. 2.

Krïckenformiges Bliithen Aftmoos. Germ. Hypne fourgon. Gall.

In nemoribus ad arborum tuncos, in Rofenthaie et aliis vbique frequens. Hyeme cum thecis.

I28I. Hypnum ramis vagis recuruis, folis ouatis lan-ftratum. ceolatís vndique patentibus, operculis mucronatis. SCHREB. Spicil. p.9I. n, 1058.

Geftreiftes Aftmoos. Germ.. Hypne frié. Gall.

In nemoribus vmbrolis, humidis ad arborum truncos, in Rofentluale, in den Wäldchen hinter Sclä̈nfeld, in locis fubudis pafim. Vere cum thecis.

1282. Hypmum furculis ramofis vagis, foliis ouatis, fuitans. acutis, patulis; thecis oblongis: operculis conicis. wiziden. Prodr. Berol. n. 95:.

Hyprum foliis lanceolatis, alternis remotis. LINN. Flor. Suec, n, I034. Scinkeis. Spicil, p.9:. n. 1060.

Platt breites wnd fpiablït:riges Flufs-Aftmoos. Germ.

In aquis ftagnantibas in Tciche vor Meckern, in der Leimgrube, an Gomnezitxer Wege, ad radices Alnorum in pratis Schönfeldicis et alibi copiofe. Rarius floret.

1283. Hypnntan ramis vagis erectis, foliis ouacis, con- piliferum. cauis, obtufis, apice piliferis, operculis cufpidatis. Sснкев. Spicil, p. 91. n. 1059.

Haarförmiges Aftmoos, Germ.

In'nemorolis vmbrofis vdis ad Gonnewiz et Rajch. wiz.

Obf. Hzpno rutabulo fimile eft, fed foliis maris alpreffis, onatis, oninibus fare concauis, per ficcitatem bafi ftriata, integersima', apice rotundo in pilum tenuifimum rectum elongatum terminantibus. 
lutefcens. 1284. Hypnun furculis vagis procumbentibus, foliis ouatis lanceolatis, fubulatis, friatis, capfulis obliquis. hivds. Angl. 421. SCHReb. Spicil. p. 98. n. 1071.

Leuchtutndes Aftmoos. Germ. Hypne luifant. Gall. In pratis et nemoribus ad radices arborum copiofe. Vere cum capfulis.

intricatum 1285. Hypnum furculis repentibus, ramis breuibus: folis laxis lanceolatis acuminatis, thecis obliquis, cernuis, mucrone obliquo, sснгев. Spicil. p..99. n. 1072 .

In nemorofis fyluaticisque: im Rofenthale am Wege ad truncos radicesque arborum; porro in horto Reicheliano, in Sylua Academica, et alibi. Flor. Vérnali tempore.

Indulatum, 1286. * Hypnum furculis ramofis, frondibus fubpinnatis, folitis vndulatis complicatis. LiNN. Sy?t. p. 950. n. 12. Weis. Crypt. p. 220. we B, Spicil. Flor. Götting. p 55. D. I2\%. Gall.

wellcuformiges Aftmoos. Germ. Hypne ondulé.

In fyluis elatioribus, ad radices arborum paffim im Bicniz, in der Prellheide. Cum thecis mihi non ' puiam verit.

\section{*** Surculis pinnatis.}

fiicinum. 1287. Hypnum furculo fimpliciter pinnato, foliis oblongis acuminatis, reflexis, fecundis: thecis lubcylindricis; operculis connuexis. wild. Prodr. Berol, n. 945 .

Hypnum furculis pinnatis; ranulis diftantibus, foliis imbricatis, incuruis, acutis, fecundis. LINN. Syft. p. 950. n. I6. вовнм. n, 771. Weв. Spic. Gott. p. 56 .

Farenkrautartiges Aftmoos. Germ. Hypné Fougere Gall.

In pratis padulofis et follis inundatis vbique, Mart. April, cum thecis. 
I288. Hupnam furculis proliferis plano-pinnatis; pe- proliferum. dunculis aggregatis. Imin. Syf. p. 950.' n. 17. вовн.. n. 756 . weis. Crypt. p. 230 . web. Spicil. p. (: ว. n. 133 .

Sproffendes Aftmoos. Germ. Hypne prolifere. Gall.

- In fyluis et nemoribus inferius ad arborum trun cos copiole. Vere cum thecis.

$V f .4 d$ aedificiorum ligneorum fiffuras obturandas prae calore et frigore, $v t$ in Suecia, et ad filtra latis adhibetur.

1189. Hypnuan furculis plano-pinnatis, continuatis, parietinum. pedunculis aggregatis. LiNn. Syft. p. 950. n. 19. zоена. n. 765 . vets. Crypt. p. 231. web. Gott. p. 61 . n. 134 .

Blaßgrünes bïfchlichtes gefiederites Aftmoos. Germ. Hypue des mures. Gall.

In nernoribus vmbrofis ad arborum radices $i m$ Ro. Jenthale, porro in horto Bofiano in der Tiefe. Febr. Mart. cum thecis.

1290. * Hypnzm furculis fubproliferis, plano-pinnatis delicatulum. cufpidatis, pedunculis aggregatis. LINN. Syft. p. 950. n. 18 .

Hypnum filicinum tamarifei folis minimis non fplendentibus fetis et capfulis ex alis breuioribus. pork. Hift. Mufc. 346. T. 83 . f. 6.

Sehr zartes Aftmoos. Gcrm.

In nemoribus et fyluis e. g. in fylua academica praeterito anno copiofe reperi. Iun. Iul. cum thecis.

I29r. Hypnum furculis fupinnatis decumbentibus:praelongum. ramulis remotis, foliis ouatis, thecis cernuis. LINN. Syft. p. 95 I. n. 20. SCHREB. Spicil. p. 88. n. 1054. WeIs. Crypt. p. 235. WЕв. fpic. p. 62.

Ad arborum emortuorum truncos earumque radices et in terra ipfa argillofa, humida, in horto Reicheliano, im Rofenthale, ad Gonnouti, Rafclizuiz. Hyeme cum thecis. 
Criftáca- 1292. * Hypnum furculis pinnatis: ramulis approxiAtrenfis. matis: apicibus recuruis. LINN. Syft, p. 95I. n. 21. LEYs. n. 1082. Wers. Crypt, p. 233. WEB. Spicil. Fl. Gott. p. 63 .

Gelb. Federbufch-Aftmoos. Germ. Hypne créte. Gall.

In fyluis ficcioribus ad arborum radices in Bieniz pafim. Vere cum thecis.

abistinum. I263 Hypnum furculis pinnatis teretiufculis, remotis, inaequalibus. LIN⿴囗S Syft. p. 95 I, n, 22, SCHRER. Spicil. p. 89. n. 1035 .

Tannenförmig gefiedertes A/tmoos. Germ. Hypne fapinet. Gall.

In pafcuis dridioribus et arenofis, Aterilibus auf den Gickerlingsberge; auf den Wege nach Lindenthal. Rarifime apud nos floret.

$$
\text { **** Foliis reflexis, }
$$

cuprefifor- I294. Hypnum furculis fubpinnatis, foliis fecundis rem.e. curuis, apice fubulatis. LINN. Syft, p. 95I. n. 24 , тоенм. n. 762. Weis. Crypt. p. 234. WER. Fl. Gott. p. 65 . Gall.

Cypreffenartiges Aftmoos. Germ. Hypue Cypres. - In fyluis et nemoribus ad arborum radices, im Rojeathale, fylua Academica etc. frequens. Verc cum thecis.

Schreberi. 1295. Hypnum furculis pinnato-ramofis apice fubula tis, foliis oblongo-acutis laxe imbricatis; thecis oblongis: operculis conicis. WILDEN. Prodr. Berol, ก. 955 .

Hypanum compreffum ramis apice attenuatis; foliis ouato-lanceolstis, fetis elongatis, capfulis inclinatis, ouatis: operculo cenico. schred. Spicil. p. 96. n. 1067.

'ZuJammengepreßstes Aftmoos. Germ. Hypne' com primé. Gall. 
In fyluis, in Breniz copiofe, et nemoribus humidis locisque inundatis im Roferthale, UniverfitätsGonnewizer, Rafchwizer Holze, porro in Alneto ad Schönfcld.

1296. Hypnum furculis ramnfis, foliis lanceolatis acu- fquarrotis, refiexis, thecis oblongis: operculis acutis. wiL- fum. DEN. Prodr. Berol. n. 452.

Hypnum ramis vagis, foliis lanceolatis complicato - carinatis quinqueneruiam recuruatis. LINN. Syft, p. 951. n. 30. sсhreb. Spicil. p. 93. n. 1063. Fl. Dan. t. 535. f. 2.

Sparrigtes Aftmoos: Germ. Hypne rude. Gall.

In neinoribus paludofis ad Gautfch, Zaepen frequens, in pratis im Rojenthale et alibi.

\section{***** Surculis fafciculatis.}

1297. Hypnum furculis ere 2 is, ramis fafciculatis ter-alopecuminalibus, fubdiuifis, thecis fubnutantibus, incli- sun. natis LiNn. Syft, p. 95I. n. 33. вовнм. ก. 769. wEIs. Crypt. p. 246. weB. Fl. Gøtt. p. 74. Fl. Dan. t. 823. f. 2.

Gekrümt:ftiges, baunförmiges Aftmoos. Germ, Hypne Queue - de - renard. Gall.

In fyluis et nemoribus hamidis vmbrofisque ad Gonnezeiz, Gautch, Klein-und Groß-Zfchocher etc.

\section{****** Surculis teretiufeulis.}

3298. Hypnum furculis pinnato-fparfis, fubulatis, foliis purum. ouatis obtufis, conniuentibus. LINN. Syft. p. 952. n. 36. WEIs. Crypt. p. 249. WEB. Fl. Gott. p. 78 . Hypnum ramis teretibus, foliis ouatis, fetis praelongis, capfulis inclinatis ariftatis. SCHREB, Spicil. p. $94 . \pi .1065$.

Rundglatt filuppigt fchlankes Aftmoos. Germ. Hypo ne pur. Gall.

In pratis pafcuis zor denb Ranftädter Thore, in horto Reicheliano, in fyluis et nemoribus, 'im Oberhoh ze. Martio cum thecis. 
Illecebrum. 1299. Hyjnum furculis ramisque vagis teretibus, ere. ciufculis obtufis. LINN. Syft, p. 952. n. 38. SCHREB. Spicil. p. 95. n. 1066. wEB. FI. Gott. p. 78.

IVurmförmiges Afmoos. Germ. Hypme vermicule. Gail.

In pratis et nemoribus, im Nofenthale ad Rafch-

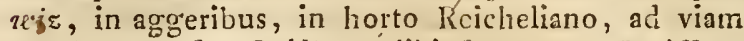
publicam verfus Gohlis et alibi frequens, Rarifine cum thecis.

ripariun. I300. Hypnum furculis teretibus ramofis, foliis acutis patulis diftantibus. LINN. Syft. p. 952. n. 39. SCHRED. Spicil. p. 94. n. 1064. Wris. Crypt p. 250. WEB. Fl. Gott. p. 80. Gall.

Stenglichtes Ufer-Afmoos. Germ. 'Hypne des' riues.

In foffis pratorum Schoenfeldicorum, ad fluuiorum ripas e. g. Pliffam paffim. Cum capfulis Septemb.

Stllatum. 130r. Hypnum furculis erectis, teretibus, foliis ouatis longe mucronatis, erecto patulis, coloratis. SCHREB. Spicil. p. 92. ก. I061.

Sternformiges Aftmoos. Germ.

In pratis paludofis Schoenfeldicis. Iul. cum thecis. Rariffime tamen his regionibus foret.

cufpida- 1302. Hypnum furculis pinnato-ranofis, apice longe tum. cufpidatis, foliis oblongo-acuminatis; thecis cylin. draceis; operculis conicis. wiLDEN. Prodr. Berol. ก. 956 .

Hypnum furculis vagis, apice foliis conuolutis acuminatis. LINN. Syft. p. 952, n. 40. говнм. ก. 765 .

Zugefpiztes Aftmoos. Germ. Hypne pointu. Gall.

In pratis humidis et paludibus mufcofis vlique, Mai. Iun. cum thecis. 


\section{Surculis confertis.}

1303. * Hypmum furculo repente, ramis confertis ere-velutinum. ctis, foliis fubulatis, thecis ouatis fubnutantibus. LINN. Sytt. p. 952. n. 42. wEIs. Crypt. p. 253. WEB. Fl. Gott. p. 66.

Iriechendes harblïtıriges Aftmoos. Germ. Hypue veloutê. Gall.

In fyluis et pomariis ad arborum radices, ad fepes et in caefpitibus frequenter. Hyeme cum capfulis.

1304. Hypnum furculis repentibus, ramis filiformibus: ferpens. foliis oblitteratis, capfulis cylindraceis, mucrone breuifimo recto. schreb. Spicil. p. 99. n. 760. IINN. Sylt. p. 95: n. 43 .

Hypnum furculis repentibus, ramis filiformibus, foliis oblitteratis. LINN. Syft. p. 952, n. 43. . WEIs. Crypt. p. 257. wEB. Fl. Gott. p. 97.

Hypmum repens trichoides, terreftre minimum, capfulis majulculis oblongis erectis. вовнм. п. 760 .

Fafericht kriechendes Aftmoos.' Germ. Hypne traînant. Gall.

Ad fepes, in fyluis et nemoribus ad arborum radices, e. g. im Rofenthale, Streitholze, etc. Vernali tempore cum thecis.

1305. Hypnum furculis erectis, ramulis breuiffmis, nitens." -foliis lanceolatis adpreffis, ftriatis nitentibus, perichaetiis longiffmis, capfulis obliquis. SCHREB. Spic. p. 92. n. I 562. wEB. Fl. Gott. p. 86. n. I59.

Hypnum ramis breuifimis, foliis lanceolatis fubulatis'nitentibus. L.INN. Syft. p. 952. n. 50 .

Glanzendes Aftmoos. Germ. Hypue luifaut. Gall.

In paludibus pratorum Schoenfeldicorum. Aprili cum thecis. 
449. BRYVM. L. G. I3II." HIDW. G. M. I9. Knotenmoos. Germ. Bri. Gall.

* Thecis pedunculatis, creEtis.

androgy- 1306. Fryum furculo ramofo erecto, foliis lanceolatis, num.

patulis; thecis cylindraceis: operculis acuninatis, feta terminali. WILDEN. Prodr. Berol n. 962.

Mnium androgynum caule ranofo androgyno. LINN. Syft. p. 9+6. n. 2. военм. त. 73. Whis. Crypt. p. $16_{3}$.

Bryun androgynum. wiB. Fl. Gott. p. 122.

Zueitterartiges Knotenmoos. Germ. Bri androgyne. Gall.

In pratis et fyluis vliginofis inter alios Mufcos. Martio.

aefiuum, I307. Bryum thecis ereetis, fubrotundis, axillarilus, foliis fubulatis difantibus. LINN. Syft, p. $9.49 \cdot \mathrm{n}$. 26. SChrEb. Spicil. p. 77. n. 1035. wis. Crypt. p. 195 .

Sommer Knotenmos. Germ. Bri d'été. Gall. In humidis limofis, in der Leimgrube et alibi.

\section{* Thecis nutantibus.}

argenteun. 1308 . Bryun capfulis pendulis, furulis cylindraceis, imbricatis laeuibus. LINN. Syft. p. 949. n. 30. BOEHM. n. 749. SCHRFr. Spicil. p. 82. n. IOS9. WT.1s.

- Crypt. p. 299. wEB. Fl, Gott. p. 111. Fl. Dan. t. 880. f. 2.

Silberartiges Knotennoos. Germ. Bri argenté. Gall.

In afferibus, tegulis, muris, locis humidis pinguioribus, ad aggeres foli expofitas, in ollis horto ruin copiofe. Octob. cum thecis.

delicatu- 1309. Bryum foliis lanceolatis, remotis tenerrimis, lum. thecis ouatis, pendulis, operculo obtufo. HEDW. Mulc. Frond. 1. [1. 52, T. XX. 
CKYZTOGAMIA. II. REVCI. 543

Bryum carnen thecis pendulis fubglobofis, foliis acutis aiternis. IINN. Syft. p. 949. n. 34.

Sehr aartes Knotenizoos. Germ. , Bri incarnat. Gall.

In fyluis, campis humidis, im Rofenthale in confortio Phafci pallentis et Gymmoftomi truncatuli. Cel. HEDw. inuenit, porro in fylua academica reperi, aliisque fyluis commune. Aug. foret et Vere primo thecas maturat.

I310. Bryum capfulis pendulis pyriformibus, obtusis: bimum. foliis lanceolatis, alternis, caule rubiginofo. SCHRFB. Spicil. p. 83. n. 10,42.

In pratis paludofis Schoenfeldicis etc. Maio cum capfulis.

450. MNIVM. L. G. I3IO. HEDW. G. M. _c. Sternmoos, Girm. Mnie. Gall.

I3II. Mnium furculo fubramofo erecto, foliis lanceo-fontanum. latis, apice fetaceis incuruis; thecis fubrotundis obliquis: operculo conico vmbilicato obtuto. WiLD:N. Prodr. Berel. n. 965.

Mnium capfulis fubrotundis obliquis, caule fim. plici geminato infexo, IuUs, Angl. 704. LINN. Syft. p. 946. n. 4. wEis. Crypt. p. 1 45. Fl. Dan. t. 298 .

Bryum fontanum. SCHREB. Spicil, p. 75. n. 1032. WEB. Spicil. Gott. p. I20. n. 189.

Brunnen Sternmoos. Germ. Mnie des fontaincs. Gall.

In pratis fpongiofis, paludofis verfus Sclionfeld. Aprili.

Obf. Vbi hic mufcus crefcit, fontes frigidos indicare fertur.

1312. Mnium furculo ramofo dichotomo, foliis fubu-paluftre. latis, acutis, carinatis: thecis oblongis: operculo conico, wildEN. Prodre Berol. n. 966. 


\section{CIASSIS XX.}

Mnium palufre caule dichotomo, foliis fubulatis. LINN. Syft. p. 946, n. 5. SCHREB, Spicil, p, 122, n. 1077. weis. Crypt. p. I65.

Brinum palufire. WEB, Fl. Gott. P. I22. n. I92.

Sumpf Sternnoos. Germ. Mnie des marais Gall.

In pratis paludofis verfus Schönfeld ad Abtnaundorf frequens. Hyeme et Vere.

hornum. 1313. Mnium furculo'fubfimplici, foliis oblongis obtufiufculis; thecis oblongis nutantibus: operculis conuexis: calyptris reetis. wrdLEN. Prodr. Berol. n. 967 .

Mnium hormun thecis pendulis, pedunculo curuato, furculo fimplici, foliis magine fcobris. L1NN. Syft. p. 946. п. 11. (fub Bryo.) weis, Crypt. p. 149.

Bryum horman. Scires. Spicil. p. \$3. n. 1046. \vEB, Fl. Gott.' p. 115 .

In pratis Schoenfeldicis ad Alnorum radices: Flor. Aprili, Maio.

capillare. 13r4. Mnium thecis pendulis, pedunculis longiffmis, foliis ountis fetiferis, carinatis. LINN. Syft. p. 947. n. I2. SCHres. Spicil. p. 82, n. IO4+. (fub Bryo.) Haarfömiges Afmoos. Germ. Mnie chevelu. Gall. Ad vias cauas, latera foffarum, fcrobium, ligna putrefacta, e. g. ad viam publicam vor dem Peters. Thore, in horto Reicheliano. April. Maio.

crudum. I315. Mnium furculo fimplici, foliis lanceolatis acutis; thecis nutantibus ouatis: operculis conicis: calyptris recuruatis. IWLDEN. Prodr. Berol. n. 968.

Mnum trunco fimplici, foliis inferioribus ouatolanceolatis, fummis elongato-linearibus, apice denticulatis: perigonialibus mafculis intimis cuneiformi variis. HEDW. Mufc. Frond. I. p. 99. T. XLVII.

Mnium crudum. LiNN. Syft p. 947. n. 13.

Bryum crudum capfulis oblongis pendulis, foliis acutis pellucidis, ouatis, fummis longioribus lanceolatis. SCHREB, Spicil. p. 83, n, 1045. 
In pratis Schoenfildicis ad Alnorum radices, Mai. Iun. floret et opercula fub Iunii fine decurit. Perennis.

1316. Mnium furculo fimplici, foliis obouatis obtufis: ferpillifothecis nutantibus outis: operculis conicis acutis. linm, wild. Prodr. Berol. in. y69.

Miniun punEtatum capfulis cernuis, pedunculis aggregatis, foliis obouatis integerrimis obtufis pun ctatis. Lisx. Syft. p. y47. n. 16.var. a. Mnii Serpyl. lifolii. (fub Bryo)

Brymm nitidum, ferpilli rotundis foliis, вовнм. n. 755.

Birnum punétanum. schres. Spicil. pag. 85. n. $755^{\circ}$ w) в. Spicil. p. 116.

Getipfeltes Stemnoos. Germ. Mnie ì feritile de Ser. polet. Giall.

In nemorofis vmbrofiset humidis ad radices arborum Salicum, in a!netis ad Gonnereitz, in locis graminofis auf dem Gicherlingsberge. Martio, Aprili.

I31-. Mnium capfulis nutantibus, pedunculis aggra-cufpidatun. gatis, foliis alternis nuatis, acutis, jerratis, LINN. Syft. p. 947. var. 3. Mnii Serpzllifoliz, schieb. Spicil. p. 84. n. 1049. fub Brzgo.

In pratis Schoenfildicis, ad Abtnaucndorf, in Ro. fenthale et in forfis fiequens. Martio, Aprili.

13I8. Mnium furculo fimplici prolifero: foliis obion-rofeun gis acutis, thecis nutantibus oblongis: operculis conuexis, witb. Prodr. Berol, n, 97 I.

Muium capfulis nutartibus, pedunculis aggregatis. foliis rolaceo-congeftis, lanceolatis, acuris.

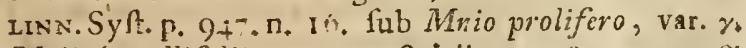
Mnii ferpyillifolii, schreb, Spicil. pag. 84, n. 1048: fub Bryo.

Rofenartiges Stermmoos. Germ.

In pratis in Rofenthale et pomariis frequens. 


\section{$54^{46} \quad$ classis XX.}

ligulatum. 1319. Mnium furculo fubfimplici, foliis oblongo-lanccolatis ferulatis vndulatisquat thecis nutantibus. oblongis: operculis conuexis. witD. Prodr. Berol. $n$. 972.

Mnium capfulis nutantibus, pedunculis aggregatis, foliis obiongis vndulatis, ferratis. SCARZB. Spicil. p. 84. n. I043. LINN. Syft. p. 947. n. 6. var. $\gamma$. fub Dinio undulato.

IVCllenförmiges Sternmoos.

In fyluis in Rofenthale, in pratis Schoenfeldicis, im Oberholze, Linkler Hölzchon et folo humido, paludofo. April. Maio.

casefpititium. 1320. Mniam furculis fubramofis: ramis breuifimis, foliis lanceolatis, apice fetaceis: thecis ouatis, nutantibus: operculis conuexis. wiLD. Prodr. Berol. $n$. 973.

Mnimm thecis pendulis, foliis lanccolatis, acuminato fetaceis, pedunculis longiffimis. L1NN. Syft. p. 949. n. 33. fub Bryo. вовн. n. 753. NEck. Del. Gall. p. 451 . n. I.

Var, a) Mnium furculis difiormibus: thecis longiufculis pedunculisque longioribus.

In fyluis, muris et ficcis fterilioribus, ad fepes frequens. April. Maio.

¿) Periflomate dentato, alato; dentibus apice cohae. rentibus.

451. KOELPEVTERA: HEDW. G. M. 2 I.

hyg:meni- 1321 . Koelreutera furculo fubfimplici, foliis oblongis ca. acuminatis, thecis ouatis nutantibus: operculis planis. "1LD. Prodr. Berol. n. 974.

Koelreutcra trunco exiguo, foliis ouato:lanceolatis, concauis, pedunculo arcuato; theca pyriformi cernua. тімм, n. 853 .

Mnium hygronetricum acaule, theca pendula, calyptra refiexa quadrangulari. Linn. Syft. pag. $9+6$. вовнм. n. 752. fub Bryo. Fl. Dan. t. 648. f. 2.

Bryzum hygrometricum. wEe. Spicil, p. I13. 
CRYPTOGAMIA. II. MVSCI.

Goldgelbes Sternmoos. Germ. Mnie hygronetre. Gall.

In humidis et fyluis gregatim, copiofe in fylua Academica et alibi. April. Maio cun thecis.

ß) Perifomate dentato membranaceo.

452. IVEBERA. HEDW. G. M. 22.

1322. We'era foliis lanceolatis: capfulis oblongis, nu- nutans. tantibus, nenw. Mufc. Frond. I. p. 9. T. IV

Webera furculo finplici, foliis ouato-lanceolatis conniuentibus; thecis cylindraceis operculis conicis mucronatis. wiLD. Prodr Berol, 11. 97\%.

Brznum nutans foliis lanceolatis, lubulatis, "capfulis vrceolatis, cernuis, operculo conico. SCHRtB, Spicil. p. $81, n, 10+3$.

Eryzum aureum. wEs. Flor. Gostting. p. I15. var. ß. maius.

Hangendes Knotennoos. Germ.

Ad latera foflarum arenofarum im Oberinolze Ill. 'SCFREr. in fylua autem Academica, tum ad vallum lacus in pineto ad Lindenthal HEDW. acntillimus naturae perfcrutator reperierunt. Maio foret et Iunio thecas maturat.

1323. Webera caule fimplicifimo, foliis perichaetii ca- pyrifurmis. pillaribus longillimis, recuruis; capfula pyriformi. HEDW. Frnnd. I. p. 5. T. III.

Webera furculo fublimpici, folis linearibus, thecis pyriformihus nutantibus: operculis conicis. wild. Prodr. Berol. n.: 96.

Mnium pyriforme. LINN. Syft. p. 94?. 11. 14. WEIS. Crypt. p. I: $=$.

- Bryzum auretsm. wrB, Fl. Gott. p. I I 4.

Birnfömiges Sternmoos. Germ. Mnie pyriforme. Gall.

In humidis vliginofis, in murorum interttiiis et rupium fifuris copiofe. Iun. Lùl. capfulae maturefcunt et vornali tempore viget. 


\section{8

pomiformis. I324. Ireberafurculo ramofo, folis lineari-lanceolatis, leta terminatis, imbricato patulis, thecis; globofis: operculo plano. WiLd. Prodr. Berol. n. 475.

Bryum pomiforme thecis erectis fphaericis. LINN. Syft. p. 9+7. 1. 3. Dоenai. n. 740. weis, Crypt.pag. 18I. WFr. Fl. Gott. p. II9. Góll.

Apfelformiges Stermoos. Germ. Bri pomiforme.

In fyluis elatioribus, im Bieniz, et paffm in hortorum areis. Aprili cum capfulis.

453. * BARTRAMIA. heDw. Mufc. Frond. II. p. 111 .

Halleriana. $13250^{*}$ * Bartramia foliis e latiori befi longius fubulatis, thecis brewius pedunculatis, oualibus lateralibus. IIEDW. l. C. p. III. T. XL.

Bryzum foliis inollibus fubulatis, fetis breuifimis alaribus. hall. Halvet. n. 1802. T. 45. f. 4. Eiufd. Opulc. p. 269.

In fyluaticis montofis. Cel. HEDw. omnium primo Z firopae in fylua fiudum eiufdem nominis adiacente cletexit. Ego nuperrime in locis montolis faxofis prope vrbem fic diçam Grimme vidi. Flor. Vere primo. Maio vero exeunte fublequentis anni opercu. la deponit.

\section{BVXBAVMA, L. G. 130\%. HEDW. G, M.}

23.

aphylla 326 . Buxbaumia aphylla pedunculato elongato. LiNN. Syft, P. 945. et Linn. jun. Diff, Meth. Mulc, p. 25 . WEB. Fl, Gott. p. 130. Fl. Dan. t. 44 .

Buxbannia aphylia furculis foliisque nullis: theca ouata dimidiata: operculo conico obliquo. WILD. Prodr. Berol. п. 978 .

Buxbania caulefens bulbo villis tecto, scrmat. Dif: de Buxb. 25. n. I. Icon. optim.

Blattloje Buxbaumie. Germ.

In fyluis arenofis praelertim abietinis copiofe. Fl. Autumno in Hyemem vsque. 
I327.*Buxbaumia foliofa furculo nullo, foliis linearibus foliofa. obtufis: theca fefili ounta dimidiata: operculo conico obliquo. wild. Prodr. Berol. n. 979.

Buxbaumia foliofa, acaulis, capfula fubfeffili foliis cincta. LINN. Syft. p. 945. n. 2. et LINN. jun. Difr.p. 33. t. 1. f. .

Buxbaumia feffilis. scumied. Diff. de Buxb. 26. n. 2.

Bryum hallerianuin. NFck. Meth. p. 133. n. 4.4.

Webre diphyfcitm. EHrh. Hanor. Magaz. 1779. I7. St. p. 257.

In fyluaticis vmbrolis praecipue in ambulacro ma. gno abietino poft Breitcnfeld Cel. HeDw. detexit, mi. hique exemplar benigniter communicauit. Aug. Sept. et Hyeme.

\section{\%. Perifiomate dentato, reticulato.}

\section{FONTINAL!S. L. G. 1306. HEDW. G, M. 24. Huilmoos. Germ.}

1328. Fontinalis foliis complicato-carinatis trifariis antipytetica. acutis, thecis lateralibus. LINN. Sy R. p. 945. вовHM. n. $73 \mathrm{r}$.

fontinalis antipyretica furculo ramofo; vago; foliis lanceolatis laxe imbricatis: thecis fubcylindricis: operculis planis mucronatis, WLD. Prod:. Bercl. n. 980.

Kïllchdes Hüdmoos. Germ.

In foris aquofis, pratenfibus in Rofenthale, nach Meckern 2!. Vere floret cum thecis.

1329. * Fontinalis foliis ouatis concsuis trifaris acuris minor. paffim geminis: thecis terminaibus. EINN. Syft. p. 945. n. 2. veB. Spicil. Flor. Gott. 1) 35. n. 113.

Fontinalis triangularis minor, carinata, e cymis capfulifera. Dilu. Hift. Mufc. p. $25 \%$ t. 32. f. 2 .

Kleines Hüllnoos. Germ.

In riuulis bei den Schantergifchen. Guthe, fed rafius Cel, $11 E D W$, reperit. 


\section{6. * MEESIA. HEDW. G. M. 25.}

viginofa، I330. Meefía furculo fubfimplici, foliis oblongo-lanceolatis obtufis, thecis obliquis, pyriformbus: operculis conicis vmbilicatis. wILD. Prodr. Berol. n. 98:.

Meefia foliis lineári lingulatis, obtufis, capfula pyriformi cernua. HeDw. Mufc. Frond. I. pag. 1. Tab. II.

Bryum trichodes an heris erectufculis: ore cilinto absque annulo pedurculo longifimo LINN. Syft. p. 949. *E. Spicileg. Gott. pag. 8\%. Hypnum trichodes.

Bri doré. Gall.

In pratis vliginofis bei Kleindölzig Cel. Hedwr nuperrime detexit. Iunio cum thecis maturis.

\section{B. H E P A T I C I.}

457. IVNGERMANNIA. L. G. I3I3. Iungermannie. Germ.

* Foliis pinnatis foliofis.

afplenoides. 1331. Inngermannia frondibus fimpliciter pinnatis, foliis pinnatis ouatis, fubciliatis. LiNN. Syft. pag. 953. weis: Crypt. p. IIO. wFb. Fl. Gott. pag. 132. Wild. Brodr. Berol. n, 984.

Tungermanizia foliis pinnatis, fubrotundis, ferratis ex apice fioritera. HALl. Hift. Helvet. Tom. III. n. 1868 .

Lichenaftram Afplenii facie pinnis laxioribus. diLL. Muic p. 4 ifa. t. 69 . f. 5 .

Var. B. Inngermannia minor foliis lubrotundis tenuifime denticulatis. micis. Gen. pag. - tab. ¿. f. 2. hall, Enum. Helv, p. 121 , n. 6. военм. 11. -83 .

Lichenaftrum Afplenii facie pinnis confortioribus. DIL. Mufc p. 483 . t. 64 . $f 6$

Milzkrautartige Iungermannie. Germ. Iungermanne afplenoide. Gall. 
In fyluis nemorofis vdis, e. gr. in fylua académica et aliis modo varietatcm reperi, Vere cum th:cis.

1332. Inngermannia fróndibus fimpliciter pinnatis, lan- lanceolata. ceolatis, apice floriferis, foliis infegerrimis. LINN. Syft. p. 953. n. 5. sCirRed. Spicil. p. 103. n. 1079. wers. Crypt. 114. wind. Prodr. Berol. n. 985.

Iungermannia paluftris minima, repens, foliis fubrotundis, denfifimis laete viridibus. Micir. Gen. p.8. t. 5. f. 6. Har L. Enum. Helv. p. 122. n. I1.

Var. $\beta$. Lichenaftrum furculis foliis ac floribus minoribus, foliolis circa thecas tenuioribus crebrioribus. Dill. Mufc. p. 1 6. t. 70. f. 10. C. D.

Hellgrïnse lanzettblättrichte Inngernannie. Germ. Iungermanne lancéolée. Gall.

In terra lubhumida, mifcis veftita, in Oberholze. Var. in terra arenofa, fubhumida, e. g. in agris yerfus Schönfeld copiofe. Vernali tempore.

1333. Inngermannia frondibus fimpliciter pinnatis, fo- bidentata. liis bidentatis, capfulis terminalibus. WiLD. Prodr. Berol. n. 986.

Iangermnnia bidentata furculis procumbentibus ramolis; apicibus floriferis, foliis ouatis bicufpidatis, ftipulis lanceolatis, quadridentatis, sctrer. Spicil.p. 10.4. n. 1081 .

Inngernannia bidentata frondibus fimpliciter pinnatis, medio floriferis, folliis bidentatis. LiNs. Syft. p. 953. n. 6. WeIs. Crypt. p. 115. WEB. Fl. Gott. p. 133.

Var. ß. Iungermannia bidentara minor, repens, fo. liis fubrotundis bifidis, vagina foliorum cylindracea. Micir. Gen. pag. 8. Ord. VI. n. 4. t. 5. f. I3. HaLl. Enum. Helv. p. 123. n. 15. We1s. Crypt. p. IIt.

Lichenaftran pinnulis obtufioribus bifidis minor. Dir.L. Mutc. p. 489 . t. 7 o. f. 12.

Groß oder klein mondfornig cingefchnittene l. zweizähntge Iungermannie., (rern. Iungermanne doubledent. Gall. 
In vmbrofis ad aggeres et fepes in Rofcnthale, im Oberholze vtraque occurrit. Autumno et Vere cun capiulis.

bieurpidata, 1334. Inngermannin frondibus fimpliciter pinnatis, fo. , liis biculpidatis, medio capfuliteris. wal Drodr. Berol. n. $98 \%$.

Iungermannia bicufpidata furculo procumbente, foliis diftichis quadratis bidentatis, ftipulis nulis. SCIHEE. Spicil. p. 105. ח. 1082.

Iungermannia licupidara frondibus fimpliciter pinnatis modiofleriferis, foliis bidentatis. LINN. Sylt. p. 5 4. n. 7. We1s. Crypt. p. II7. weB. Flor. Gottip. 196.

Zueifach gezähnte Iungermannic. Germ.

In fyluis vmbrofis, in Oberholze; in areis horti Reicheliani et locis inundatis, Vere fed rarifime cum captulis.

fcalaris. I335. Inngermannia foliis integerrimis ouatis diftich is extremo caule fetifero. HALL. Hift. Helyet, n. 1858. SCHRE Spicil. p. 103. n. 1078.

Iingermannir Scalaris. Schmivdel de Iungerm. p. \%о. f. XVIJ.

Minzm Trichomanis facie, foliis integris. DILL. Mufc. p. 256. t. 3I. f. 5 .

In folfis in Oberlolze, et ad aggeres.

** Frondibus pinnatis; pinnulis auriculatis fupernè tectis.

Tẹtans, 1336. Inngevmannia furculis decompofitis, medio foriferis, foliis quadratis antice incifis, ftipulis quadrifidis. SCHREB. Spicil. p. IO6. n 1083.

Inngermania reptans frondibus fubtus bipinnatis, apice reptantibus, foliolis quadridentatis. LINN. Sy@t. p 954. n. 14. WeIs. Crypt. p. II Y. WEB. Flor. Gott. p. 1.4.

Kleine kriechende Erdjungermanice. Germ, 
In argaribus vmbrofis vdis in Obcrholie, in, apricis ad Lindenan inter alies iungermanniae mufcoram fpecics. Hyame et Vere cum capfulis.

3337. * Inngermannia frondibus fuprabipinnatis, apice nemorofa. foriferis, foliolis ciliatis. LINN. Syf pag. us3. ก. 2. we1s. Crypt. p. 121. Necker Delic. Gallobelg. pag. 4i)3. n. $1 \times 59$

Iungemannia foliis hipartitis, auriculatis inbricatis fupremis pinnatiferis. IIALI. Hift. Helvet. T. III. p. 8. ก. $185 \%$.

Iungemizannia nemorofa, foliis acutioritus auritis, tenuifime dinticulatis, flore infidente pediculo breviore. MICit. Gen. p. 7. Ord. I. n. 2. t. 5. f. 8. 11ALL. Eivun Helv. p. I 20. n. 2.

Lichenafrian turiculatem, pinnis minoribus cienatis. D1' I.. Mulc p. +90.t. - 1. f. !.

Hellgrïne holblblätrige Haynjungemannic. Germ.

In locis nemorolis vmbrofic er vdis, v. $g$. in fylua Acadernica ad cauas et arbo!um radices Cel, nedW. fed nunquam cum thecis detexir.

\section{*** Frondibus imbricatis.}

I338. Iungermannia furculis repentibus: foliis inferne complanata. auriculatis, duplicato imbricatis, ramis aequalibus. IINN. Syft pag. 9.4. ก. 16. воEнM. ก. 782. weIs. Crypt p. I $24^{\circ}$ WEe, Fl. Gott. p. 146. WILd. Prodr. Berol. n. 988.

-Iungernannia foliis rotundis, alterne imbricatis, caule plano-multiforo, fetis breuifimis. HaLs. Hift. Helv. T. I; I. p. 58 . n. 1860.

Plattchuppigie Iungernannie. Germ. Iungermanne aplatie. Gall.

In fyluis vimbrofis ad arborum truncos valde fre. quenter. Martio cum thecis.

3339. * Iungernannia furculis repentibus, folis infer- dilatata. ne auriculatis duplicato-inbricatis, ramis apice latioribus. linv. Sy?t. p. 954. n.117. scop. Carn. pag. 123. 11. 5. weis. Crypt. p. 126. weB. Fl, Gott, paş; 346. WILD. Prodr. Bcrol. n. 989 . 


$1554 \quad$ CLASSIS XX.

Iungermaniza dilatata furculo reptante imbricato, folis duplici orbiculatis: ramorum apice latiufculo. NECKER. Method. 140. n. 19.

Iungermannia foliis imbricatisalternis, oxbicularis, fetis breuilfmis. HaLL. Hift. Holvet. 'T. III. p. 62. n. 1874

Lichenaftrum imbricatum minus, fquamis conuexo-concauis. DIL. Mufc. p. 49\% t. 72. f. $2 \%$.

Ausgebreitete Inngerizannie. Germ.

In fyluis ad arborum iuniorum truncos et ad Salices in der Milchinfel, paffim in fylua Academica. Vere cum thecis.

tamarififo 1340. Iungermannig furculis decompofitis, apice prolilia. feris foliis fubrotundis fubtus articulatis, ftipulis ouatis emarginatis. SCHREB. Spicil. p. 108. n. 1086. Wild. Prod. Berol. n. 990.

Inngermania tamari/cifolia foliis imbricatis ferie duplici; fuperioribus fubrotundis conuexis obtufis quadiuplo-maioribus. LiNn. Syft. pag. 954. n. 18. weis. Crypt. p. 128 .

Tamarykenblattrige Iungermailie. Germ.

In fyluis, nemoribus ad arborum, praecipue Fagorum truncos. Martio cum capfulis.

platyplsylla. I $_{3} \mathrm{~T}^{*}$ * Iungermannia furculis procumbentibus fubtus imbricatis, foliis cordatis acutis. LINN. Sýf. p. 954. n. I9. Weis. Crypt. pag. I25. Wild. Prodr. Berol. n. 491.

Iungermannia foliis imbricatis lanceolatis, fuperne planis, alternis, inferne concauis, quinquefariis. H.qLe. Hift. Helv. T. III. p. 6r. n. 1872 .

Lichenaftrum Arboris vitae facie, foliis minus rotundis. DILI. Mufe. p. 501. t. 72. f. 32 .

Mufcoides fquamofum maius, atro-virens, foliis fubrotundis. MiCH. Gen. p. 9. Ord. I. n. 2. tab. 6. f. 3. 4.

Große Lebensbaumblättrige Iungermannie. Germ. Iungernanne à feuilles plates. Gall.

In fyluis ad terram et ad arborum maxime Fagorum truncos prope radices. Vere primo cum thecis.

1342 , 
1342. Iungermannia furculis adfcendentibus, foliis di- varia.

Atichis, bilobis fubrotundis integerrimis, lobulis inaequalibus SCHREB. Spicil. p. $10 \div$ n. 1080.

lungcrmanina varia furculis. erectiufculis bifariam imbricatis, foliis bipartitis. L1Nx. Syft. pag. $955^{\circ}$ ก. 22 .

Lichenaftrum foliis variis. DILI. Mufc. 505. t. 73 . f. 3 h. viriet. f. B.

Verïnderliche Inngermannie. Germ.

In fyluis ad terram, im Oberholze.

**** Surculis undique imbricatis : foliolis sparJis.

1343. Iungernannia furculis teretibus, foliis capillace is trichophylla aequalibus. LiNn. Syft. p. 95\%-n.26. sC11ReB. Spicil. p. 10\% n. 108\%. w11s. Crypt. p. 130.

Iungermannia minima foliis capillariter multifidis. IALL. Hit. Helv. T. IIl. p. 63. n. $18 \% 0$.

Haarblätrige Iungemnanne. Germ.

Ad terram rdam inter alios mufcos, pafim im Oberholze et fylua Academica. Rarius cum thecis.

\section{***** Acaules frondibus fimplicibus.}

1344. Inngermannia acaulis, foliolo frondi innato. epiphylla. . LINN. Syft. p. 955 . n. 29. вОЁім. n. 785. wers. pag: I06.

Iungermannia acaulis, foliis reticulato-rugofis, thecis dorfalibus diuergentibus glabris. scop. Carn. p. 122. ก. $Y$.

Iungermannia fronde foliacea, obtufe lobata, ex medio florifera. HALL. Hift. Helv. T. IIT. pag: $6_{3} \cdot n$. I883. SCHREE. Spicil. p. 110. n. 785.

Lichenafrum capitulis rotundis e foliorum medio enafcentibus. Drr.t. Mufc. p. 508. t. 74. f. 4 I.

Hepaticoides Cichorei crifpi folio. vasLl. Parif. p. I00. t. I9. fo 4 .

Langbliatrige Inngermannie. Germ: Iungermanne fo' liacée. Gall. 
In nemoribus ymbrofis ad fofias et riuulos, e. g. ad riuulum hinter dem Bicniz. April. Maio cun 1 thecis.

multifia. 1345. Iungermannia acaulis*, fronde bipinnatifida. IINN. Syft, p. 955. n. 3 i. SCHREв. Spicil. p. I09. n. 1088. wers. Crypt. p. iog.

Lichenaferum ambrofiae diuifura. DILI. Mufc. pag. 511. t. $7: 1$. f. 43 .

Heparica arborum globulifera. vaill. Parif. p. 98. T. XXIII. f. 2, pertinet ad furcatam.

Vielfach enngefchrittene Iungermannic. Germ.

In fyluis vinbrofis ad orbitas humidas pafim im Oberholze. Absque thecis.

furcata. I3:6. Iungermannia acatilis, fronde lineari ramofa; exremitatibus furcatis obtufuiculis. L1NN. Syft. p. 955 . n! 32. воЕнм. n. 78 4. SCIREB. Spicil. p. 109. n. 784. weis. Crypt. p. I08.

Inizgermannia furcata lineari-ramofa, dichotoma bafi capitulifera; primordialibus frondofis terminalibus. Necker. Method. p. 128. n. 3 .

Zuecifach gefpaltene Tungermannie. Germ. Iungermanne fourchue. Gall.

Copiofe ad arborum truncos in fylua Academica et in Oberholze; rarius vero in locis fubhumidis. Vernali tempore cum thecis, fed rarius.

pufilta. 1347 . Iungcrmannia furculis hreuifimis apice foriferis, foliis imbricatis antice crenatis, cauliculo fubtus villofo. Schreb. Spicil. p. 107. n. 1085.

Iunfermannia pufilla acaulis, fronde fubpinnatifida, lobls imbricatis, perichaetiis plicato. IINn. 'Syft. p. 955. n. 33. тімм. Fl. Megapol. n. 881 .

Seir kleine Inngermannie. Germ.

Ad aggeres, in folfis, folo arenolo humido inter vrbem, hortos oleraceos et verfus Schönfeld, ad $L i n$ denau, in Bienis et Oberholse. Aprili cum thecis. 
458. MAKCHANTHA. I. G. 13I5.

134. Marchantia foliis obtufe lobatis; receptaculis poiymorpha planis, orbiculatis. wiL D. Prodr. Berol, n. 996.

Marchantia polymorpha cúlyce communi decemfido. LiNn. Syft. pog.955. Büru. n. 852. weE. Flor. Gott. p. І б́́2.

Marchantia fronce aequabili, cyathis ferratis, bacillis vmbellatis et ftellatis octofidis. I.ALL. Hint. Helv. T. III. p. 66. ก. 1892.

Var, $\alpha$ Marchantia polymorpha frellata pileo laci- ftellata. niato; laciniis teretiufculis, spice dilatatis, fub quibus globuli pilofi. scop. Carn. Ed. 2. n. 1354. WELs. Crypt. p. 152. vild. Prodr. Berol. n. 996. var. $\propto$.

Marchantia pileo itellato, radiis teretibus. Micir. Gen. p. 2. Tab. I. f. 2. HaLl. Enum. Helv. pag. 127.

n. $I$.

Var. $\beta$ ) Marcliantia polynorpha vmbellata recepta- vinbellata. culis decemfidis, laciniis coniuntis, ablongis obtufis. WILd, Prodr. Berol. n. 996 . var. $\beta$.

Marchantia umbellata pileo plano, crenulato, fub quo globuli imberbes. scos. Carn. Ed. 2. n. 1355 . weIs. Crypt. p. 133; var. $\beta$.

Marchantia capitulo non diffeßto. мicn. Gen. p. I. T. I. . 5 .

Lichenis fontani maioris et domeftici minoris. DILL. Mulc. 1. c. Varietates vmbellatae. tab. 76 . f. 6 . C. D. t. $77 \cdot$ f. 7 . D.

Pharm. Hepaticae Fontanae f. Lichenis ftcllati Herba.

Vielgeftaltete Marchantie. Var.- a) langblättrige Sternmarchantie, Steinleberkraut, var. $\beta$ ) kurablattrige Schildnarchantie. Germ. Hepatique des fontaines, ou Marchante étoilée. Gall.

In locis vmbrofis, fubhumidis pratisque; $\mathrm{ad}$ aquarum riuulos, ad muros humidos, e. g. in fepulchreto St. Pauli ad terrem et ad muros et alibi copiofe Vere etgeftate cum thecis.

VJ. In decosto cum lactis fero contra hepatis ob. fructiones; porro etiam in istero et fcorbuto laudatur. 
conica, 1349. Marchantia furculis dichotomis, finuatis, capfu. la conica, fubtus fubquinqueloculari.

Marchazitia conica receptaculo communi quinqueloculari fubouato. LiNN. Syft. p. 955. n. 6. вовнM, n. 853. ScrRed. Spici. p. 54. 1. 853. WEB. Fl. Gott. p. 165 .

Kegelformige Marchantie, Germ. Marchante conique. Gall.

Ad ripas paullo elatiores riuuli prata Schoenfeldi. ca irrigantis, porro ad muros roridos. Maio cum thecis; led rarius.

\section{A L G A E.}

a) Terreftres.

459. ANTHOCEROS. L. G. I 318. Hörneríchorf.

Germ. Anthocere. Gall.

punftatus. 1350. Anthoceros frondibus finuatis, crifpis puntatis. wil. Prodr. Berol. n. 1000.

Anthoceros fronde crilpa finuato - laciniata. SCHREB. Spicil. p. 1 10. n. 1090.

Anthoceros frondihus indiuifis finuatis punctatis. IINN. Syf. pag. 956. тimm. Flor. Megapol. n. 834. Fl. Dan.t. 396 .

Punctirter Hörnerfchorf. Germ. Spatled Anthoccros. Angl. Anthocerer Gall.

In locis fubhumidis ad latera foffarum im Oberholze et alibi. Autumno cum capiulis.

laeuis. I35I. Anthoceros frondibus finuatis laeuibus. WILd. Prodr. Berol. n. 1001.

Anthoceros fronde plana crenata. schmied. Ic. pl. I. p. 71. t. 19." SCHREB. Spicil. p. 110. n. 1089. Anthoceros trondibus indiuifis finuatic laeuibus. IIN N. Syft. p. 956. Fl. Dan. t. 396. SCHMid. Ic. iab. I9.

Glatter Hörnerfchorf; horntragendes Lebermoot. Ge:m. Smooth Anthoceros. Angl, Anthocere-liffe. Gall. 
In agris arenofis humidis vbique circa vrbem; in pratis Schoenfeldicis, et ad Delitz IIl. Pont. reperit. Martio, tum Aug. - Oetobr. cum capíluis.$$
\text { 460. RICCIA. L. G. I317. Riccie. Germ. Riccie. }
$$
Gall.

1352. * Riccia frondibus fupericie papilloís. I1NN. crittallina Syft. p. 956. LeYs. n. 1125. Weis. Crypt. 328. WELd. Prodi. Berol. n. 997.

Lichen paluftris Rutae folio. DiLl. Mufc, p. 535 . , n. 78. f. 1'2.

Rundgefchreift blättrige Riccic. Germ. Riccie crifalline. Gall.

In agris vdiset locis humidis; primo Vere in agris nach Eutrit fch, et polt prata Coriariorum.

1353. * Riccia frondibus glabris bipartitis, acutis. minima. LINN. Sylt. p. 956. wez. Spicil. p. 1 ־0.

Riccia minima nitida; fegmentis acutis. Mrcr. Germ. p. 107 . t. 57 . f. 6 .

Lichen omnium minimus, foliolis fciffis, fuperterram expanfs. Dil.L. Mufc. p. 5.34. t. 78 . f. II.

Kleinfte Ficcie. Gern. Riccie très petit. Gall.

In agris nrenofis, ficcioribus, e. g. in agris Schoentfeldicis aliisque frequenter occurrit.

Obf. Frondes anguftifimae, glabrae, ad apices acutae. Web.

1354. Riccia frondibus glabris canaliculis bilobis obtu- glanea.

fis. LINN. Syft. p. 956. SCHREe. Spicil. pag. III. n. 1091. WeB. Spicil. p. I 72. Wild. Prodr. Berol. n. 998. тIмм. п. 888 . Fl. Dair. 397 f. r.

Var. $\beta$. Riciia glauca, ciliata, frondibus ad margines albis pilis ciliatis. WEB. p. I 43 .

Hepatica paluftris bifurcata, lobis breuioribus carinatis. Valli. Parif. p. 9\%. t. 19. f. 1. Gall.

Blau angelaufene Riccie. Germ. Riccie glauque.

In agris fere vbique, maxime verfus, Gonnereitz, Burghaujen, Wagau, Schönfeld cum Anthocerote 


\section{$560 \quad$ CLASSIS XX.}

vtroque; porro auf den Gickerlingsberge mufcis immixta. Var. in agris ad Gunndorf, Ehienberg collegi Autumno.

Auitans. I $355 . *$ Riccia frondibus dichotomis lineari - filiformibus. innn. Syft. p. 656. Janin. n. 24. wild. Prodr. Berol. n. 999. тімм. п. 830 .

Riccia fuitans fronde dichotoma lineari ramofa: plana; primordialibus obtuís. NeCK. Method. 4I. n. 1 .

Lichenaftrum aquaticum fuitans tenuifolium furca. tum. Disl. Mufc. 231 . t. $7 \%$ f. 47 .

Hepatica paluftris dichotoma, fegmentibus anguftioribus. varle. Paril. p. 98. t. 10. f. 3.

Flußriccie. Germ. Riccie fluttante. Gall.

In lacubus, nec raro in foflis exficeatis et limofis vais inter Lemnas ad Leutfch, Delitz et fere femper Lemnae trifulcae et minori fubtegens, Vere et Autumno.

matans. $13.56 . *$ Riccia frondibus obcordatis ciliatis. LiniN. Syft. p. 956. poli.rer. Palat. Tom. III. Append. p. 319. wЕв, Spicil. Flor. Goetting. p. I74. котн. Fl. Germ. T. I. p. $49 \%$

- Schroimmende Riccie. Germ.

In locis paludolis et pifcinis, in"dem Teiche aufilen Pfingftiviefe, nicht weit von Holse, wo die Gräben find, Cel. Hedwig detexit.

\section{6r. BLASIA. L. G. I3I6. Blafie. Germ. Blafie.} Gall.

pufilla. 135\% * Blafia fronde lohata, lobis fubrotundis, neruis fetiferis, hall. Hift. Tom. III. pag. 57. n. $1 \times 37^{*}$ LiNn. Syft. p. 9*6. LEERS Fl. Heiborn. n- 9,6. web. Spicil. Flor Goetting. p. 169. wrGg. Prim. Flor. Holfat. pag. 83. Fl. Dan, tab. +5 . Icon. scirmid. Dirl. de Blafia.

Sehr kleine Blafie. Germ. Blafie naine. Gall. 
In locis inundatis, vmbrofis, copiofe in fylua $A c a$. demica, et ad vias cruas humidas im Rojerithale paffin. Autumo cum capfulis.

462. PELTIGERA. wiLdFN. Prodr. Berol. p. $34 \%^{\circ}$ Lederficchte. Germ.

I358. Peltigera fronde lata verrucofa, fubtus longis ra- aphthofa. diculis hifuta. norm. Plant. Lichen. Vol. I. Falc. 1. p. 2i. T. VI F. I.

Peltigera fronde obtule lobata, fuperne verrucofa, inferne alba villola. Wilden. Prodr. Berol n, 1002.

Lichen aphthofus coriacelas repens lobatus obtufus planus, verrucis lparfis, pelta marginsli adfcendente. LINN. Syft. p. y6r. n. 75. воЕнм. n. 860. HAG. Hift. Licl. p. 104. n. LII.

Pharm. Mufci cumatilis Herba.

Warzige gemeine Lederflechte. Germ Gren ground Lieverwort. Angl. Lichen ì Aphthe. Gall.

Ad terram in fyluis et agris elatioribus copinie. Hyeme

VS. Rufticolae Vplalienfes infufun cum lacte praeparatum, infantibus aphthis laborantibus praebent, dehinc nomen triuisle ortum. Praeterea egregia gaudet virtute anthelmintica. LINN. Amoen. II. pag. 62. et VII. p. 304.

1359. Peltigera, minima fuhtus venofa; peltis feffilibus venofa. planis orbicuatis. ноғм. Pl, Lichen. Vol. I. Falc. I. p. 3 I. T. VI. t. 2 .

Lichen venofus coriaceus repens lobatus obtufus planus, fubtus venofus, villoius, peltis marginalibus horizontalibus. LiNN. Syft. p. 961 , n 75.5

Lichenoides paruum virefcens, peltis nigricantibus planis. DitI, Mufc. 208. t. 28. f. 0\%. 110.

Kleinfte Schildflechte. Germ. Little dark vein'd Lichen. Angl. Lichen veiné. Gall.

Ad terram humidam in locis vmbrofis et fyluaticis frequens. Hyeme. 


\section{2 classis XX.}

canina. 1360. Peltigera fronde obtule lobata, fubtus venolo. villola, peltis oblongis adfcendentibus. Wred. Prodr. Berol: n, 1003 .

I.ichen caninus coriaceus repens lobatus, obtufus planus fubtus venofus villofus, pelta marginali ad1cendente, LINw. Syft. pag. 961. n. 79. BLCAKw, tab, 336 .

Pharm. Mufci Canini Herba.

Afchgraue Hundslederflechté; Hundsflechte; Hunds. moos; Steinflechte; Erdleberkraut. Germ. Lichen canin, ou de terre, ou Mouffe de chien. Gall.

, Ad terram in fyluis vbique, rarius ad arbores. Hyeme.

$V f$. Sapor Lichenis exficcati eft ingratus mucidusque. Extractum aquofum, odorem balfamicum valde ingratum vetufioris halecis, mephitim referens, fpirat, fapore prinum dulci, deinde amariufculo fubtilițerque acri fere piperino gaudet, Extractum fpirituofum, quod in minoricopia obtinetur, mellei eft odoris minusque acre. Angli hunc Lichenem vtmedicamentum fpecificum in hydrophobia atque rabie canina valde commendant; dehinc in fuis officinis compofitionem quandam nomine Pulueris antiliffi introduxerunt. Haec autem ex duabus Lichenis partibus vnaque parte piperis nigri conftat.

horizóntalis $136 \mathrm{r}$. Peltigera fronde rotunde lobata, fubtus cinereo rufefcente, peltis planifimis.

Lichen horizontalis coriaceus repens planus fubtus auenius, peltis marginalibus horizontalibus. LINN. Syft. pag. 961. 11. 81. SCHREB. Spicileg. pag. 123. n. I116.

Horizontallaufende Lederflechte. Germ.

In fyluaticis vnibrofis ad arborum radices et in cavis frequens in fylua Academica et alibi, Perfi. ftens.

fyluatica, I362. Peltigera fubcoriacea finuato-laciniata, fcabra, peltis adlcendentibus paruis. HoFM. Pl. Lichen. Vol. I. p. 2I. T. IV. f. 2 . 
CRYPTOGAMIA. III: ALAE. $5 G_{3}$

Lichen fyluaticus coriaceus, repens, laciniatus, lacunofus, peltis marginalibus adfcendentibus, LINN. Syli. p. 961 . n. so.

Wraldlederflechte. Germ. Lichen des bois. Gall.

'In lyluis denfioribus vinbrofisque ad radices arbo. rum in fylua Academica valde rara.

Odor poft nultos annos vrinofus, naufeolus prae. fertim exficcatus.

\section{LICHEN. L. G. I3I9. \\ * Foliis imbricatis lincaribus.}

1363. Lichen corniculatus, erectiufculus, leciniis linea- ciliaris. ribus palmstis ciliatis, fcutellis peduncula: is. yofm.l. c, Fafc. I. pag. 16. Tab. III. Fig. 4 (fub Luchenoide).

Lichen ciliaris foliaceus, erectiufulus: laciniis-linear:bus ciliatis, fcutellis pedunculatis, crenatis. LINN. Syft. pag. 954. n. 4\%. воEнM. n. 868. SCHREB. Spicil. n. 126. n. 868 . HaG. Hift. Lichen pag. 81. n. XLII. Fl. Dan. t. 71 :

Augenwimperflechte; gefranzte Banmflechte. Germ. Hairy or Ciliated Lichen. Angl. Lichen cilié. Gall.

Ad truncos omnium fere arborum in fyluis fere omnibus vulgaris. Perfiftens.

Odor in humeztato grauis naufeofus. Quamdiu ficcus eft:Lichen, luteus, fcutellis modo exceptis, cinereus: fi vero humectatus, totus viręfit.

1364. Lichen foliiformis, laciniatus: laciniis adfcen-hifpidus. dentibus femitubulofis, margine hifpicis HOFM. 1 . c. Fafc. I. p. 13. T. III. f. 2. 3. (fub Lichenoide).

Lichen hifpidus foliaceus laciniatus albus: laciniis adfcendentibus obtufis, pilofis, fcutellis feflilibus. scop, Carn. I. p. 110. schreb. Spicil p. 126. n. : 1 :0. et HAGEN. Hift. Lichen, pag. So. n. XLI. (Lichen tenellus).

Lichen hifpidus foliaceus laciniatus albidus: 1aciniis apice obtufis infatis, ciliatis, fcutellis nigris fefffibus. wisd. Prodr. Berol. n. 1024. 
Lichen ciliaris, var, B. albiluls. wers. Crypt. pag. 63.

Haarige Flechte; Kleinfte Baumflechte. Germ.

In truncis arborum e.g. Salicum, Pruni fpinofae et in multis fepibus frequens. Pafiin in lapidibus. Hyeme.

A Lichene ciliari foliis paulio minoribus, tenuioribus, femitubulofis et fcutellis paruis nigrefcentibus, lubpedunculatis, riagis deprefiis et a Lichene ffcllari longioribus exftantibus radiculis et fubfufcis pedunculatisque fcutellis dítinguirur. Color conftanter albus fi: ex albo cinereus in ficca et humeetata planta.

ftellaris. ${ }^{365}$. Fichen imbricatus: foliolis oblongis laciniatis anguftis cinereis, fcute!lis puilis. zINN. Syft. p. 959. n. 45. еоенм. n. 865. SCIIREe. Spicil, p. 127 . n. 865. horm. Enum. Lichen n. 88. T. XIII. f. I. 2.

Var. a) Lichen imbrikatus: fuliclis oblongis laciniatis, laciniis lationibus, fcutellis nigris. ногм. l. c. n. 88. var. B. T. XII\}. f. I.

Var. $\beta)$ Lichcn imbricatus: foliolis anguftioribus, tenuiter laciniatis, fcutellis cinereo-nigris. ноғм.1.c. var. C. T. XIII. fig. l. c.

Lichen orbicularis, foliolis angufioribus, minus laxis, etiam ad margines rádicatis, sсндев. Spicil. 1. c, var. ftellaris.

Stcrnfơnige, Blätterflechte, Germ. Starry Lichen. Angl. Lichcu étoilé. Gall.

Var. $\alpha$. ad arhorum ramos, et $\beta$. in lapidibus, auf alten Schindeldächiem frequens. Hyeme.

ftellari for- I366. Lichcn foliis oblongis planis laciniatis, fcutellis mis. fulcis. ноғм. Enum. Lichen. n. 89.

\section{Sternälnnliche Blâtterflechte. Germ.}

In cortice arborum, praecipue Qnercuum faepius vidi. Perfiftens.

Obj. Foliolis latioribus planis, margine lobatis,' crenulatis, fcutellis fufcis, a priori differt. 
I367. Lichen imbricatus; foliolis lobatis crenatis obtu- puluerulenfis viridibus, polline confperfis, fcutellis nigris, nar- tus. gine crenatis. SCHREs. Spicil. p. 128. n. II23. HоFM. Enum. Lichen. n. 93. T. XII. f. 2. WILD. Prodr. Berol. n. 1015 .

Beftaubte Blätterflechte. Germ.

' In arborum corticibus, 'maxime Salicum, vulgaris.

Obf. Scutellae nigrae, puluere grifeo tećtae, margo crenulatus puluerulentus.

1368. Lichen imbricatus foliolis linearibus diffufs cre-anguftatus. natis, punftis eminentibus nigris. rofM. Enum. Lichen. n. 94. T. X1. f. 2.

Schmale Blätterfiechte. Germ.

In arborum cortice cum priori frequens.

Foliolis femper anguftioribus et fcutellis deftitutis, a priori facile diftinguitur.

\section{** Foliolis imbricatis latioribus.}

1369. Lichen imbricatus, foliolis obfolete multifidis centrifugus. laeuibus fauefcentibus centrifugis, fcutellis rufo-fuf́is. LINN. SyAt. p. 958. n. 34. SCHREB. Spicil.p. 129. n. I 125 . HотM. Enum. Lichen. n. 95. Tab. X. fig. 3.. wild. Prodr. Berol.n. 1016. HaG. Ifift. pag. 6\% n. 33 .

Var. a) Lichen fronde puluerulenta viridi.

Concentrifche Schuppenflechte. Germ. Lichen centrifuge. Gall.

In lapidibus terminalibus maioribus zexifchen dem Berge uid Schönfeld et in aliis frequens. Var. in arborum ramis et lignis putridis ad Breitenfeld.

Cum folution Stanni colorcm exhibet fpadiceo - flavefcentem. Hor

1370. * Lichen foliiformis, imbricatus, laciniatus, ad- fepincola. fcendens, caftaneus, fcutellis concoloribus. HoFm. Lichen. p. 102. T. XVII. f. 1. 11EDw. Mufc. Frond. Vol. II. p. 8. T. II. 
Zainfchuppenflechte. Germ.

Ad arborum trùncos e. g. Crataegi Oxyacanthi, ad Templum St. Thcclae Cel. HEDw. inuenit.

faxatilis, 1371. Lichen imbricatus, foliolis finuatis, fcabris, lacunofis, fcutellis badiis. t.rNn. Syft. pag, 958. n. 35 . военм $n$ 864. wild. Prodr. Berol. n. 1019.

Steinfchupponflechte. Germ. Lichen des roches, out Ufyée du crâne humanz. Gall.

4

Ad arboruni truncos valde frequens : porro in faxis et craniis humanis, äri libero humido longé expofitis. Cum fcutellis rariffime. - Purpureo tingit colore.

pullus. 1372. Lichen imbricatus, foliolis lobatis, oliuaceis, fcutellis integerrimis. sснRев. Spicil. pag. I3I. $\mathrm{n}$. 1127.

Lichen pullus fronde laeui.fcutellifera: germinante diltorta, primordialibus granulofis. NECK. Method. p. 94. n. 63 .

Kleine fchroärzlichte Flechte. Germ.

Ad arborum truncos et in lapidibus paffim.

oiluaceus. 1373. Lichen imbricatus, foliolis lobatis nitidis oliuaceis, fcutellis crenatis. Sснвев. Spicil. pag. I $\mathbf{3} \mathbf{I}$. II 28 .

- Lichcn oliuaceus imbricatus: foliolis lobatis nitidis linidis. IINN. Syft p. 954. n. 37 . Gall.

Olivenfarbene Flechte. Germ. Lichen olivâtre.

\section{In arboribus et lapidibus.}

exifpus. 1374. Lichen imbricatus: foliis lobatis truncatis crenas tis atro-viridibus, fcutellis concoloribus. LINN. Syft. p. 959. n. 40. WIr. Prodr. Berol. n 1013.

Lichen crifpus geiatin ofus, foliis imbricatis lobatis truncatis crenatis atro - viridibus, fcutellis crenulatis. SCHREB. Spicil. p. 127 . n. 1121 .

Gekräufclte Flechte. Germ, 
In muris argiliaceis pagorum e. g. ad Burghaufon; in Horto Reicheliano-ad Tiliae radices. Hyeme et Vere.

Madidus gelatinofus eft; ficcatus vero calcareus. Scutellae badiae.

1375. Lichen imbricatus, foliolis crifpis fuluis; peltis parietinusi concoloribus fuluis. IINN. Syft. pag. 959. n. 43 . военм. n. S6I. Wild. Prodr, Berol. n. 102I.

Wandflechte. Germ. Lichen des murs; Perclle ou Herpetze des murs. Gall.

In arborum truncis, fepibus et parietibus co. piole.

1376. Lichen imbricatus, laciniis anguftis apice infla-phyfodos. tis; \{cutellis pedicellatis. Wild. Prodr. Berol, n. 1020.

Lichen phyfodes imbricatus multifidus: laciniis obtufis fubinflatis. LiNN. Syft. p.959. n. 44. SCHREB, Spicil. p. 129. n. ír24.

Lichen enflé. Gall.

In corticibus arborum frequens. Hyeme.

Obf. Laciniis apice inflatis et fcutellis pedicellatis, a Lichene faxatili diftinguitur.

137.7. Lichen corniculatus decumbens, fubuillofus; la- furfuraceus. ciniis acutis, inferne nigris aculeatis. ноғм. Lichen. Plant. Falc. II. pag. 45 . Tab. IX. f. 2. (fuib Lichenoide).

Lichen furfuraceus foliaceus erectus, laciniatus, fubtus niger puluerulentus, apicibus albidis; fcutellis fufcis concauis. wild. Prodr. Berol. n. 1031 .

Lichen furfuraceus foliaceus decumbens furfuraceus: Irciniis acutis fubtus lacunofis atris. LINN. Syft. p. 960 . n. 53. вовнм. n. 859. Ha G. Hift. Lichen.p. 92. n. XLV.

Kleicuflechte f. graubeftäubte Baumflechte. Germ. Grey-horned branny Lichen. Angl. Lichen à feuilles d'Abjuthe, ou Lichen furfuriacé. Gall. 
In locis fyluaticis ad truncos arborum et rames Fagi, Abietis, copiofe. Cum fcutellis rarius. Vere et Autuinno.

$V \int$. Hic nufcus per multos annos amaritiem fuan retinet, dehinc a nonnullis cortici peruatano fublituitur. Porro colore ex oliuaceo vel viridi-fpaciceo, fine omni addito, pannos imbuit.

calicaris. 1378. Lichen foliaceus, eretus, ramofus, lacunotus, glaber, fcutellis terminalibus, apicibus reflexis corniculatis. wild. Prodr. Berol. n. 1028.

Lichen calicaris foilaceus erectus linearis ramolus, lacunofus, conuexus, mucronatus. LINN. Syft. pag. 960. n. 60. SChrea. Spicil. p. 124. n. 1117 . Hag. Hif́t. Licl. p. 9.5. n. XLVII.

Becherartige Flechtc; gefchnabelte. Baumflechte. Germ. Lichon à gobclets, ou Poulnonette calicaire. Gall.

Ad arborum truncos in Bieniz paffim.

Oly. Scutellis albidis planis a Lichene prunafrvi facile difinguendus.

$V \int$. Pulchrum purpureum dat colorem, fi antea vel in vrina putrefacta, vel in folutione falis alcalivo. latilis açuofa, maceratur, ad praeparationem pulueris cyprii prae aliis valde idoneus.

fraxineug 1379. Lichen foliaceus erectus, oblongus lanceolatus, fublaciriatus, lacunolus, glaber, fcutellis fubpeduncularis. LIN Syft. pag. y60. n. 61. BOEIM. n. $\$ 62$. schreb. Spicil. p. 123. n. 1 I 16. hag. Hift. Lichen.p. 96. n. XLVIII.

Efchen- . Inngblättrige Baumflecinte. Germ. Lzchen de Frêne. Gä!.

Ad arbores, praefertim Salices, Alnos, Fraxinos etc. vbique frequens.

Obf. Qunad magnitudinem folioruin et diuerfam laciniarum formam innumeras praebet varietates.

grunatti. 1380. Lichen foliaceus erectus, laciniatus, fubtus candidus; fcutellis fufcis concauis. wiLD. Prodr. Berol. ก. 1030. 
Lichen prunaftri foligceus erectiufculus, lacunofus: Iubtus tomentofis albus. I.inN. Syft. p. 960. n. 63 . военм, n. 856 . HAG. Hift. Lichen. pag. 97. n. XLIX.

Pflaumenflechte; weiffe Hirgchlornförmige Baumflechte; ueiffes Lungenlraut f. Lungenmoos. Germ. Li. chen de prunelier, ou Orfeille du prunelle. Gall.

Ad arbores naxime Salices et Prunum fpinofam vbique. Vere fed rarius cum fcutellis.

Obf. Sapore gaudet fatuo, in Quercubus vero amaricante. Wurtembergi hunc fub nomine $M u f c i$ Acaciae ad bainea forusque in prolapfin vteri anique, commendant. Caeterum pulchio rubro, vt Lichon calicaris, tingit colore. Pro puluere Cyprio ad dea. bandas crines vtilis.

1381. Lichen foliaceus repens, pallide viridis rugofus, caperatus. inferne ater $\epsilon t$ afper; foliolis rotunde lobaris.

Lichen caperatus pallide viridis rugofus, margine vndulatus. LINN. Syit. p., 60. n. 65. воEнM. n. 863 . SCHRED Spicil. p. 123. n. 863 .

Gerunzelte Flechte. Germ. Lichen froneé.

Aả arbores frequens; paffm in lapidibus et ad mus o lapidolos. Vere. Cum feutellis rarifime.

$V \int$. Cum Virriolo martís ferrugineo tingit colore.

\section{4. * RETICVLALiA. NetzAechte. Germ.}

1382. Reticularia foliacea laciniata; foliolis finuatis, offecinalis. truncatis, reticulato-lacunofis, fcutellis marginalibus. ноғм. 1. с. p. 4. Tab. I. f. 2. (fub Pulmonara reticulata.

Lichen pulmonarizs foliaceus, lacinistus, obtufus, glaber: fupra lacunofus, fubtus tomentofus. Lins:. Syft. pag. 960. n. 52. LOEHM. n. 85\%. Hi G. Hif. Li. chen. p. 88 . n. XLIV. eLACKw. t. 353 .

Pharm. Pulmonariae arboreae Herba.

Lungenflechte f. Lungenkraut; Lungennoos, Banmlungenkraut; Steinalungenkraut. Germ. Common Lungwort. Ancrl. Lichen pulmonaire, ou Herbe aux ponmons. Gall. 
Ad Abietum, Quercuum Fagorumque' truncos et radices in fyluis antiquis vbique.

$V \int$. Sapor eft mucidus, falinus, acris ct amarus; odor vix percipiendus vel nulius. In haemoptoe, vteri, menfium, sluique nimio fiuxu, contra tuffm conuulfuam, phthifin pulmonalem, laudatur. Rufici Sueci ad tuffim pecudum debellandem adhibent. Decoctum cum fero lactis in fcabie. In Sibiria Lupuli loco cereuifiae, quae valde inebriat, incoquitur. Coriis parandis aptus. Lintea amoene-fufco inficit colore durabili. Porro Motacilla Troglodytes nidunı fuum artificiofifimum huius ope Mufci confruere fertur.

verrucofa 1383 * Reticularia foliacea fcrobiculata, foliis fubrotundis, finuatis, fcutellis rufis. Hofm. l. c. p. I. T. I.f. I. (fub Pulmonaria).

Lichen verrucofus, foliaceus repens, fubrotundus, tublobatus crenatus, rugofus, verrucofus, verrucis farinaceis, fcutellis minutifimis fuluis. Hvds. Angl. 2. p. 545 .

Lichen fcrobiculatus, coriaceus repens lobatus, obtufus, fuperne Icrobiculatus verrucofus, inferne villofus, tumoribus albidis. EIGHTF. Scot. 850 .

- Warzige Lungenflechie. Germ. Pitted zearty Lichen. Angl.

In fyluis ad radices arborum frequens.

farinacea. I 384. Reticularia foliacea compreffa erecta ramofa: verrucis marginalibus farinofis. LINN. Syft. p. 960.n. 56. (fub Lichene) schreb. Spicileg. pag. 125. n. I 118.

Lichen farinaceus foliaceus erectus compreffus, ramofus, fárinaceus: lateribus verrucofis. bIN Sy. Syt. p. 827. HAG. Hifl Lichen. p. 93. n. XLVI.

Mehlartige Lungenflechte. Germ. Lichen 'farineux, ou Herpette farineule. Gall.

In Salicibus, Fraxinis, Pinubus aliisque vulgaris.

$\mathrm{Ob}$. $\mathrm{Ob}$ defectum fcutcllarum et praefentiam prominentiarum, polline farinofo praeditarum, ad latera frondis egredientium, hunc ad hoc genus reduxi. 
Vf. Rubrum dat colorem. Parus caudatus nudum ftum hocce L.chene inueftit artificiofum. Zorn.

465. * VMBILICARIA. hofm. Nabelflechte.
Germ.

1385.*Vmbilicaria vmbilicata, gibba, punctata, fubtus miniata. fulva.

Lichen miniatus. LINN. Syft, p. 96= ก. 86. Jace. Mifcell. V. 2. p. 90. t. 10. f. 3 .

Meinnichfarbige Nabelflechte. Germ Lichen farté. Gall.

In locis faxofis et lapidibus paffim. Viget hyeme.

Cum alumine ex hoc obtinuit colorem grifeo- eervinum Cel. Hofmannus.

1386.* Vmlilicaria vmbilicata vndique laeuis, fubtus ni- deufta. gia globofa.

I.ichen deuftuis vmbilicatus vndique laeuis. IINN. Syft p. $962 . \pi$ 90. Шев. Spicil. p. 260.

Lichcn deuftus fronde ficcitate fragili laeui. NECK. Method. p. - 4. n. 36 .

Lichenoides coriaceum cinereum, peltis atris, compreffis. Dilz. Mufc p. 2 Ig. t. 30. f. II 7 .

Verbrannte Nabelfiechte. Germ. Lichen brille. Gall.

In faxis hyemali tempore paffim occurrit.

138?: * Vfrea vmbilicata polyphylla vndique laeuis polyphyllim atro-virens crenata. LINN. Syft. p. y62.n. 91. (fub Lichene). WEB. Spicil. p. 258.

Lichenoides tenue, pullum: foliis vtrinque glabris. silz. Mufc. p. 225. t. 30. f 129 .

Nabelfiechte mit vielen Blättern. Germ. Lichen trèsdécoupé. Gall.

Ad muros fuburbanos et in marmoreis paffim oçcurrit. 
466. CLADONIA. wigG. Primit. 90. Becherflechte, Strauchfiechte. Germ.

* Scyphiferac.

coccifera. I388. Cladonia feyphifera finplex tuberculis coccineis. WILD. Prodr. Berol. n. 104 I.

Var. a) Lichen cocciforus 1cyphifer fimplex, integerrimus, ftypite cylindraceo, tuberculis coccineis. LinN. Syft. p. 963. n. 97. schreb. Spicil. p, I20. n. I I IO. HAG. Hít. Lich. p. I I 8. n. LXII.

Var. $\beta$ ) Lichen fimplex tuberculis feffilibus aut ftipitatis. DILL. p. 82. t. 14. f. 7. A. F. H. I.

Var. $\gamma$ ) Lichen fimplex tubetculis totum difcum replentibus. SCHREB. 1. c var. 2.

Var. 8) Lichen e margine prolifer, tubercuiatus. DilL. 1. c. K. L.

Pharm. Mufci puxidati Herba f. Herba Ignis.

Scharlach rothe Becherflechte; Feuerkraut; Fieberkraut; Ficbernoos. Germ. Lichen coccifére, ou écarlate, Herbe du futu, ou Herpette écarlatize. Gall.

In fteritibus arenofis, ad margines fyluarum, bei dem Univerfitörsholze, in Obcrholze, ad arborum ftipites putrefactas, am Bieniz. Hyeme et Vere.

Cornucopi- 1389. Cladonia fcyphifera, fimplex, folio breuior, tuoides. berculis coccineis. IINN. Syft. p. 963. WeB. Spicil.p. 226. var. g. LEERS n. 981 . LeYs. Ed. I. n. 1023.

Lichen infundibulis proliferis, foliofis et fungofis. HALIr He!v. n. Iy 29.

Coralloides feyphiforme: marginibus radiatis et foliatis. Dill. Nuíc. 85 . t. 4 . f. 9 .

Füllinornähuliche Becherflechte. Germ.

In locis montofis et ericetis paffun in fylua Academica atque im Bieniz.

digitata. T390. Cladonia fcyphifera ramofiffima: ramis cylindricis, caly cibus integris nudofis. LINN. Sytt. pag. 963a We B'. Spicil. p. 225, var. c. fub Lichene. 
Lichcn digitatus ftipite cruftaceo, rămofo; ramulis terminalibus palmatis tuberculatisque. NECK. Method. p. 5\%. ก. 20.

Coralloides ramulofum, tuberculis coccineis. DILL. Hift. p. 95. t. 15. f. 19 . Gall.

Fingerförmige Becherflechtc. Germ. Lichen digité.

In fterilioribus montolis, e. g. im Bieniz paffim occurrit.

1391. Cladonia feyphifera, fubfimplex, tuberculis fu- polymorphá fcis. wits. Prodr. Berol. n. IO+2.

Var. a) Lichen pyxidatus fcypinifer fimplex crenu- pyxidatus. latus, calyce integerimo. hald. Hift. pag. II3. $\mathrm{n}$. 57.

Lichen fquamofus fcypho integerrimo, scop. Carn. p. 370 . n. 6.

Lichen pyxidatus fimplex. wers. Crypt. p. 8 ^.

Var. I. minor, cauliculis breuiffmis, feypho minori. HAG. l. c. var, $\alpha$.

Corollaides fcyphis humilibus intus fufcis. DrLe. Mufc. p. 86. t. 14. f. II.

Var. 2. maior, fcypho infigni. HAG. l. c. var. $\beta$.

Lichen pyxidatus fimplex, tuberculis nullis. SChre . Spicil. p. II 8. n. i icq. var. ${ }^{-}$.

Lichen pyxidatus maior. TOVRN. Init. pæg. 549. t. 325. f. D.

Var. $\beta$ ) Lichen fcyphifer, fimplex, crenulatus, tu: tuberculaberculis fufcis. HaG. Hift. Lich. p. 1 1\%. n. 6r. tus.

Lichen pyxidatus. Linn. Syft. pag. 963, n. 99. SCHREB. Spicil. p. I I8. n. IIOO.

Var. $x$. tuberculis feffilibus. Hag. Hift. p. I I \% var.

ж. SChreb. Spicil. p. JI9. n. 3 .

zichen fquamofus fcyphotuberculofo, scop. Carn.

II. p. 37 I. var. 8 .

Var. 2. tuberculis ftipitatis, rrag. 1, c. var. $\beta$. SCHREb. l. c. var. 4.

Lichen fquamofus, feypho fungifero. scop. 1. c. var. 9.

Var. $\gamma$ Lichen caule fimplici, calyce turbinato: prolifer. centro fimpliciter prolifero, LINN. Syft, Ed. R. T. IV. p. $55^{2}$, SCHREB. l. . . var. 5 .

Vas. 


\section{4

fimbriatus.

Var. ס) Lichen fcyphifer, fimplex, denticulatus, ftipite cylindrico. LINN. Syt. p. y63.n. 100. SCHR:B. Spicil. p. I20. n. III

Pharm. Mufci Pyxidati Herba, Herba Ignis.

Wohlgeftaltete Becherflechte. Var. ' $\alpha$ ) einfache Becherflechte; $\beta$ ) büchfcnformiges Erdmoos; $\gamma$ ) gezähnte Becherflechte. Germ. Var. $\alpha$ ) Lichen pixide, ou Lichen en forme de Boete; $\delta$ ) Lichen, ou Herpette frangée. Gall.

In Bzeniz, im Oberholze, in horto Roicheliano etc. Var. $\beta$ ) in muris argillaceis circa pagos; $\gamma$ ) in terra humida, et ad arborum radices, vti zm Rofenthale, Bieniz, Linkler Holze, et in horto Rercheliano: $\delta$ ) in ramis putredine confumtis, im Rofenthale, Bieniz et alibi fiequentes. Vere, Hyeme et Autumno.

cornuta. I392. Cladonia Icyphifera fimpliciufcula, fubuentrico$\mathrm{fa}$, calycibus integris, LiNn. Syft. pag., $63 . \mathrm{n} .103$. fub Lichene, schR: b. Spicil. p. 120. n. II13. Hag. Hif́. p. 109 . n. 55 .

Var, x) Lichen corniculo fimplici obtulo. Hall, I. c. p. 7 I. n. 1907 .

B) Lichen corniculo fimplici duro fubafpero. HALL. n. IYO5.

r) Lichen corniculo fimplici verrucis obfito. HALL. n. 1905.

Gehörnte Becherflechte. Germ. Lichen cornu. Gall. In ramulis et truncis pritredine confumtis im Rofenticale, fylua Academica, Bieniz et atibi frequenter occurrit. Hyeme et Vere.

deformis, 1393.* Cladonia fcyphifera, fimpliciuícula, fubuentricola : calycibus dentatis. LINN. Sytt. p. 963. n. 104. (ful) Lichene) WEB. Spicil. pag. 2I3. LEERS n. 9i: HAG. Hilt. p. 116. n. LIX.

Lichen corniculo fimplici, maximo, laeui. HaLL. Hift. T. IIl. p. - 1. n. 190).

Ungeftaltete, Becherflechte. Germ.

In ericetis et locis elatioribus, copiofus im Bienie, Univerfitätsholze etc. Hyeme et Vere. 
1394. Cladonia feyphifera fubramofa, radiata, tubercu-radiata. lis fulcis. wild. Prodr. Berol. n. 1043.

Lichen radiatus fcyphifer fubramofus, cylindraceus, elongatus, fcyphis inaequaliter dentatis radiatisque. schreb. Spicil. pag. 122. n. I I I4. IIAg. Hif, Lich. p. I 16. n. LX.

Strahlenförmige Cladonie. Germ.

In fyluis et locis vmbrofis paffim. Vere. Rarius floret.

1395. Cladonia 1cyphifera: Icyphis fimplicibus, foliis foliacea. multifidis fubtus candidis, w1L D. Prodr. Berol. n. I0.44.

Lichen foliaceus foliis adfcendentibus multifido-laciniatis, fubtus niueis fcyphiferis; f'yphulis conicis breuiffimis. SCHRË. Spicil.p. I 22. n. I I I 5 .

Blattertreibende Cladonie. Germ.

In elatioribus fterilibus, in Bieniz, Oberholze, Rofenthale, et "in der Dübenfchen Heide frequens. Vere.

1396. Cladonia fcyphifera dichotomo-ramofa, tuber-gracilis culis fufcis. wiLD, l. c. n. $10+5$.

Lichen gracilis fcyphifer ramofus, denticulatus, filiformis. IINN. Syft, p. 963. n. 101. SCHREB. Spicil.

p. I 2 I. II. I I I2, HAG. Hift. Lich. p. I I2. n. LVI.

Fadenformige . Jchlanke Becherf techte. Germ. Lichen grêle. Gall.

Im Oberholze paffim. Vernali tempore.

T. Si herba maceratur aqua Aluminis cum Vitrio. 1o Martis tunc cinereo tingit colore.

\section{** Fruticulojae.}

1397. Cladonia fruticulofa, ramofiffima, glauca, ramu- rangiferina. lis nutantibus. W1LD. 1. c. n. 1046.

Lichen rangiferinus fruticulofus, perforatus, ra- alpeftris. mofiffimus, ramulis nutantibus. LINN. Syft. p. 963.

n, 106: 
Lichen fruticofus, farinofus, furculis innumeris, nutentibus. hall. Hift. Helvet. III. pag. 78 . n. 1975.

Coralloides montanum, fruticuli Specie, vbique cancicans. dill. Mufc. p. I07. t. I6. f. 29.

fyluaticus $\quad \beta$.Lichen rongiferinus caule ramolo, alis perforatis, ramis capitatis. LINN. Sp. Pl. p. 1620 . n. 66 var. $\beta$. schreb. Spicil. p. II . n. 1105. HaG. Hift. Lich. pag. 127 . n. LXX. var. $\beta$.

Lichen caule fruticolo, foliofo, ramis fubnutantibus, minute multifidis, fungiferis. Hall. i. c. n. 1956.

Coralloides fruticali Ipecie candicans, corniculis rufeicentibus. D1L. Muf́c. p. 110. t. 16. f. 30.

Kraufe Strauchflecintc; Renuthiermons vulgo var. \&) Alipen-et $\beta$ ) Waldrennthierflechte. Germ. Lichen des reunes, ou Coralloide des rennes. Gall.

In fyluis fteriliorlbus et elatioribus ad terram, in Oberholze copiofe, in Atipitibus arborun putridis detruncatis: var. $\beta$ ) im Bicniz paffim occurrit, Vernali tempore viget.

Hae duae varietates quoad habitum, colorem, tuberculoruin megnitudinem et fubfantian differunt. Alpefris enim valde ranofior et maior; fyluatica minor et fimplicior; haec magis rufa, illa contra albicantior: tubercula in priori funtminora : in pofteriore ampliora. Prior eft paullo mollior: pofterior fragilis.

Vf. Eft pabulum hibernum primarium in Lapponia. In hyeme cerui aliaque animaita illo ibidem palcuntur; porro refertur quoque in Carneola in more effe, boues et porcos hoc lichene fnginari. - Heffelins tentauit panem ex hoc Lichene coquere. Ad Cyprium puluerem adhiberi poffe, putat Hallerus.

vncialis. 139. Cladonia fruticulora, virefcens, dichotomo-ramofa, apicibus acutis. WILD. I. c. n. IC 7 .

Lichen vncialis fruticulolus, perforatus, ramulis breuifinis acuris. LIN Syf p?g. 063. n. 107. SCIREB. Spicil. p. I18. n, I 108. HaG. Hift, Lich. pag. 123, n. LXVI, 
Kurzäftige Strauclufflechte. Germ. Lichen d" un pouce. Gall.

Im Oberholze inter antecedenten egrediens. Vere.

139\%. Cladonia fruticulofa, tubulóa, ramofa, ramis furcata. ereetis furcatis. SCEREB. Spicil, p. II7. n. 1106. fub Lich:ne. HaG, Hift, Lich. p. I:5. n. LXVII, t. II. fig. 10.

Gabelfirmige Strauchflechte Germ.

In terilioribus, sxenofo-fabulofis in und am Bie' niz porro quoque im Oberibolze frequens.

I ł00. Cladonia fruticofa, dura, fufco-nigricans, ramo-aculeata. fiffina, fpinofa; furculis furcatis, fpinofis.

Licher uculeatus foliaceus diffufus, comprefrus, ramofiffinus; ramulis furcatis fpinulofis. SCHREB. Spicil. p. I25. n. III\%.

Coralloides aculeatum, fubcompreffum, fufcum, furculis aculeatis, tuberculis radiatis. ноғм. Vol. I. p. 26. Tab. V. fig. 2.

Stachlichte Strutechflechte. Germ.

In ericetis et fyluis inter Lichenes fruticulofos alios-1 que frequens.

Nunquam vidi cum tubérculis.

I 40I. Cladonia fruticulofa ramofa, crufta obdueta, tu-pafchalis. berculis fufcis. WILDEN. 1. c. n. IO49.

Lichen purfschalis fruticulofus folidus tectus foliolis cruftaceis. Linn. Syft. p. 963. n. III. Flor. Dan. tab. I 51 .

Zipreffenförmige Srauthflechte. Germ. Lichen pafcal. Gall.

In locis elatioribus arenofis, inter Hypna, im Bieniz pafim.

1402. Clacionia fruticulofa ramofa, apicibus fimplici-fubulata. bus fubulatis. WILDEN. 1. c. n. 1050 .

Lichen fibsulatus fubdichotomus, ramis finplicibus tubulatis. linn. Syft. p. 963. n. 229, schreb. Spicil. p. $117 . \mathrm{n}, 110 \%$. 

Gall.

Pfriemenartige Strauchflechte. Germ. Lichen alène.

In fyluis, apricis et locis ferilioribus, im Bienis, Obcrholze, in der Dübenfchen Hcide et alibi vulgaris.

467. VERRVCARIA. wiggers Primit. p. 85. Waizenflechte. Germ.

* Tuberculis cauis, puluerc replctis.

kนgora. 1403 . Verrucarin albicans, tuberculis minutiffimis, in liness et punetas confertas difpofitis. WILDEN. 1.c. n. 1092.

Lichen rugofus leprofus albicans, lineolis fimplicibus punetisque nigris conifertis. LINN. Syft. p. 957. ì. S. SCIReb. Spicil. p. I37. n. IItI. hag. Hif. Lichen. p. 46. n. XiI, ногм. Enum. Lich n. 13. T. II. f. 5 .

Runzliche Warzenflechtc. Germ. Wrinkled Lichen. Angl.

Ad arborum naxime Fagorum, Carpinorum etc. cortices im Rofenthale, Bientz etc. copiofiffime.

Olf. Tubercula eculis tantum armatis vifibilia. Lineae atrae et puncta confertifima.

fcripta. I 104. Verrucaria albicans, tuberculis atris planis linegribus varie flexis. WILDEN. I. c. n. 1063 .

Lichen feriptus leprofus albic $n$ s, lineolis nigris, ramis charąteriformibus. LiNn. Syft. Ed R. T.IV. p. 522. SGhreg. Spicil. p. 138. n. 1142 . Hag. Hif. Lich. p. 43. n. X. Hоғм, 1. c. n. I4. Tab. III. fig. 2. a.

Karakteriftifche Warzenflechte. Germ. Littercd Liclıen. Angl. Lichen écrit. Gall.

- In truncis et ramis Quercutm, Fagorum et praeprimis Pyri fylueftris aliarumque arborum vulgaris.

hebsaica, I $405 . *$ Verrucarin albicans, tuberculis planis linearibus, apice diuifis. WILDEN. l, c, n. 1064. 
Lichen hebraicus leprofus albicans, lineolis nigris, diuaricatis. HоFм. 1. c. 11. 15. Tab. III. fig. 2. c.

Rechtweinkelichte Warzenflechte. Germ.

In cortice Quercuum, Fagorum, Abietum aliarumque paffim.

1406. * Verrucaria albicans, tuberculis planis lineari- pulicaria. bus breuiffimis. WILDEN. 1. c, n. 1065.

Lichen pulicaris leprofus albicans lineolis nigris breuiffmis fimplicibus, HoFM. I. c. n. I0. Tab III, fig. $2 \mathrm{f}$,

\section{Flöhformige IVarzenflechte. Germ.}

In cortice Quercumm et Fagorum cum priori immixta.

Obj. Crufta tenuis, fubramola, cinereo-albs.

140\%. Verrucaria leprofa flauefcens, mappiformis, tu- geographiberculis nigris, punctis in lineas curuas notatis. ca.

Lichen geographicus leprofus flauefcens, lineolis nigris, mappam referens. LINN. Syrt. p. 957. n. 2. SCHREB. Spicil. p. I38. n. I I 43. hag. Hift. Lich. p. 45. n. XI. ноғм. 1, c, n. I\%. Tаb. III. f. I. F. Dan.t. 468. f. I.

Landkártenartige Warzenfechte. Germ. Map Lichen. Angl, Lichen géographique. Galh

In lapidibus ad Schönfeld nach dem Berge zu, et in faxis alibi paffim.

1408. * Verrucaria albicans lineolis planis atric ereßtis. typographiWILDEN. 1. c. ח. 1066. Tab. VIII. f. I4. ca.

Buchdrucker - Letterartige Warzenflechte. Germ.

In Ceraforum domefticorum juniorum ramis majoribus et truncis paffim.

Crufta valde tenuis, longiufcula albo-cinerea virefcens.

1409. Verrucaria crufta albicans, tuberculis impreflis pertufa. atris. WILDEN. I. c. n. 1059.

Licha bertufus leprofus, verrucis fubteffelatis lae. uigaris pertufis, poro vno alteroue cylindrico. 
linN. Sylt. p. $95 \%$ n. 7. Hag. Hift. Lich. p. 49. n. XIII. ноғм. I. c. n. is. Tab. III, f. 1.

Sphäria jertafa fubcompolita, aggregata, itregularis, perforata, vireícens. wi IGEL. Obleru. p. 46. n. ๆ. Tal. II. f. I5. WEB. Spicil. p. 282 . ก. 298.

Durchfochene tivarzenflechie. Germ. Porous Warty Lichicn. Angl.

In arborum corticibus, praeprinis in cortice $T_{i}$ liae frequens. Hyeme.

Crufta tenuis, aibicans; recens cinereo-virefcens. Tubercula copiofa, glabra, maxime atia.

colliculofa. isto.* Vermaria leprofa, crufta colliculofa, atra, tuberculis pallidis.

Lichen colliculofur; leprolus cinereo-virefcens, tubercuils albis. norm. 1. c. n. TO. Tab. II. f 2 .

Kleinkörnichee IVarzenfechze. Gom.

In arborum truncis, praecipue Carpini Betuli cortice putrefseto, im Rofenthals paftin.

Crufta recens cinereo-virefcens; ficca plane nigra, cortici firmiter adhaerens.

faginea. Ifrr. Verrucaria crufta albicans, tuberculis planis farinofis concoloribus. WILD. 1. c. n. ro6o.

Lichen faginens leprofus albus, tuberculis albis farinaceis. LINN. Syft. p,957. n. I8. SCHREB. Spicil. p. 135. n. 1136. var, 3. HAG. Hift. Lich. p. 52. n. XXI. ноғм. 1. с. п. 2 I. Tab. II. f. 4.

Var. «. Lichcn orbiculatus; cruftraceus albicans, tuberculis albis farinaceis. SCHRED. Spicil. 1. c. n. I136. ноғм. 1, c. n, 13. Tab. VII. fig. 2 .

Var. $\beta$. Lichen albefcens; cruftaceus cinereus. fcutellis concauis farinaceis albidis. nuDs. Fl. Angl. p. 529. ноғм, 1. с. C. Tab. VII. f. 5.'a.

Var. $\gamma$. Lichen orbiculis poiline amifo, caluis, concauis. Hofs. 1. c. Tab. VII. f. 5. b.

Weiße $\{$. Kalkartige Warzerflechte. Germ. Mealy Beech Lichen. Angl. Lichen des Hêtres. Gally, 
CRYPTOGAMIA. III. $\triangle$ I GAE.

In arboribus variis, praefertim in Fugis, quoque vero haud raro in Quercubus, Tilia aliisque.

Vf. Solutione et maceratione Aluminis dat colo. rém ex rofeo-ferrugineum.

* Tuberculis folidis, terreo grano.is.

I 412. * Virucaria leprofa albefcens; tuberculo cen-Betulina. trali concolori. HODS. Flör. Angl. Ed. If. p. 325. HOFM. 1. c. n. 22.

Weige einhügclichte Birken Warzenflechte. Germ. Birch Lichen. Angl.

In truncis et ramis Betulae albae rarius.

Crufta orbicularis, tenax, alba. Tuberculum folitarium, hemifphaericum, album magnitudine fere feminis Cannabis.

I 113 . Verrucaria crufta fufca, tuberculis planis atris. fufco-atia WILDEN. 1. c. n. 1058 .

Lichen fufco-ater leprofus, fufcus; tuberculis atris. IINN. Syft. p. 95\%. n. 10. SCHREB. Spicil. p. 136. 1). I 138. HAG. Hift. Lich, p. 58. n. XVI. HOF M. 1.

c. n. 25 .

Braunfchearze Warzenflechte. Germ. Black nobb'd fufcous Licher. Angl.

in lapidum generibus fere omnibus, e. g. in dem Schlogle trequens. Vere.

I4I4. * Verrucasia leprofa, crufta albefcente, granulata: graniformis. tuberculis atris. HAGEN. Hilt. Lichen. p. 47 . n. XIII, Tab. r. f. 2. (fub Lichene.)

Körnigte Harzenflechte. Germ.

In afteribus ét lingnis putridis pafim.

I415. Verrucaria leprofa cincreo-virefcens, tubercu- fanguinea. lis atris. LINN. Sylt. p. 957. n. 9. fub. Lichene fanguinario. SChzеE. Spicil. p. I37. n. II千O. HAG. Hift. Lich. p. 47. n. XIV. ноFм. I. c. n. 33. Tab. V. fig 3 .

Schrearze kuglichte Warzenflechte. Germ. Black nobb'd Lichen. Angl. Lichen fanguinaive. Gall. 
In athorum cortice, lignis putridis, copiofe.

Tubercula intus fanguinea.

albo-atra. in 6. Verrucaria leprofa alba, tuberculis nigricantibus. Hогм. l. c. n. 35. fub Lichene.

Weiß fchreâralichte Warzenflechte. Germ. Lichen noir et b!anc. Gall.

In cortice arborum rimofo frequens.

Crufta inaequalis, rimofa; ficca albicans; madida ex glaico-virefcens. Tubercula in ficco nigricantia nebulofa ; in humido nigerrima. v. ноғм. l. c.

mufcorum. I417.*Verrucaria cruftaces, mufco plerumque innafcens, polline cinereo veluti conflata, receptaculis florum nigris. M11 Cr. Gen. p. 98. n. 4I. Gall.

Melichte Wrarzenflechte. Germ. Lichen des moufes.

In mufeorum pratis et arborum corticibus, e. $g$. im Roferthale et Sylua Acadenica paliim.

\section{*** Tuberculis fefjilibus fungofis.}

vernalis. 1418. Verrucaria leprofa, albido-cinerea, tuberculis fubrotundis fufcis.

Lichen veraalis; leprofus albidus, tuberculis fubrotundis ferrugineis. LINN. Syft. p. $95 \%$ n. I r. LEERs Herb. n. 923. HoFM. l. c. n. 47 . Tab. V. f. I. Rofifurbige Warzenflechte. Germ. Vernal Lichen。 Angl.

- In arboirum cortice rimofo et lignis putridis. Vere et Autumno.

Jcmado- r419. Verrucaria crufta glauca-virefens, tuberculis philla. planis carneis fubfffilibus, wILDEN. 1. c. n. ro54.

Lichen ericetorum leprofus candidus, tuberculis carneis. IINN. Syft. Ed. XIII. p. Bo6. var. feffilis. - военм. n. 866. SCHREe. Spicil. p. 134. n. 866 . hag. HiR, Licis. p. 54. n. XXIII.

Fleifchfarbige Warzenflechte. Germ. Lichen des landes. Gall. 
In fyluis humidis in Oberholøe inter Ericam wulsarem et in pafcuis fterilibus, ficcis arenofisque ad Abtnamiorf; porro ad truncos putridos inter $L i$. chenem pyxidatum.

468. TVBercylaria. wiggers Primit, n. 638. Schwammflechte. Germ.

1420. Tubercularia leprola virefcens, tuberculis fub-Sabuletoitipitatis planiufculis atris. SCHREB. Spicil. 1). I34. rum.

n. I 55. (fub Lichene.)

Schrearze Schuvammflechte. Germ.

Ad aggeres fabulolos, et in muris argillaceis.

Tubercula ftipitibus breuillimis ornata et vix vi fibilia.

142I. * Tubercularia crufta glauco-virifcens tubercu- Bacomyess. lis carneis ftipitatis. w1LDEN. 1. c. n. 1052. fub Verrucaria.

Lichen Baeomyces leprofus albicans, tuberculis ftipitatis carneis. linn. Suppl. p. 450. 'schreb. Spicil. p. 134. n. 866. Var. HoFM. 1. c. n. 45. Tab. VIII. tig. 3 .

Fleifchfarbige Scluteammflechte. Germ. Flefh-co. lour'd Mushroom Lichen. Angl.

In locis fterilioribus humidis im Rojenthale paffim. Hyeme, Vere.

$V \int$. Addito vitriolo martis et alumine tingit colore cinereo ceruino. HOFM.

\section{6\%. SCVTELLARIA. SchildRechte. Germ.}

1422. Scutellaria cruftacea cinerea, granofa, Icutellis fcrupofa. immerfis atris, margine crenulato. SCHRER. Spicil. p. 132. n. 1133 . fub Lichere. Hоғм. 1. c. n. $5^{\circ}$. Tab. VI. fig. I.

Lichen ferupolus, pertufus, leprofo cruftaceus, albus, verrucofus, tandem teffelato rimofus, verrucis laeuibus, porro introlabentibus vno pluribusque in fcutellos denique nigricantes, margine fuberenato, jácQ. Collect, Vol, II. p. I81. Tab. XIII, fig. 3 . 
$584 \quad$ - c c LSSIS XX.

Bleifarlige Schildflechte; Farbegechte. Germ.

In muris argillaceis antc portulam Schoenfeldicam.

Vf. Cum vitriolo martis et alumine color obtinetur dilute umbrino grileus. HoFM.

tartarea. 1423. Scutcllaria crufacea, ex albido-virefcens, feutellis flauefcentibus: margine albo. LiNn. Spec. $\mathrm{Hl}$ 1608. LEERS Herb. ก. 936 . HAG. HiR Lich. p. 58. n. XXV. fub Lichene. HOrM. Enum. Lich. p. $\$ 2$.

Lichenoides tartarewn farinaceum, fcutellarum víbone fufco. nill. Mufc. p. 13I. Tab. 18. f. 12. Weißlich grüne Schildfechte. Germ. Lichen tartariux. Gall.

In 6 axis copiole oritur.

Obf. Scutellae valde numerofac, arcte comprefiae; plurimae earum vndulatae viridefentes, margine albo cinetae: adultiores multo euadunt majores rotundiores, poftea magis e flauo colore in fufcum vergunt.

VJ. Weftrogothi ex illo rubrum conficiunt colo. rem, quem lub nomine Boetrelct per totam ob pulchritudinem diuenditant Sueciam. vid. LINN, et KaLM. qui huius deferibunt praeparationern. Cum alumine pantum tingit pallide ex violaceo - purpureo colore; cuin aceto chalyberto pallide rofeo-caineo, nofm.

caerule- 1424. Scutellaria cruftacea, ex albido caerulefcens; fcens. fcutellis concoloribus, magine albo. HAGEN. Hift. Lich. p. 59. n. XXVI. T'ab. I. fig. 5. fub Lichene.

Bläuliche Schildfechte. Germ.

In arborum, maxime Tiliae, cortice.

Byfina. I425. Scutelleria puluerulenta, nigricans, fcutellis minutifimis flauis. Horm. 1. 11. 59. Tab. 10 fig. $\%$. fub Licheme.

Staubartige Schildflechte. Germ.

In afferibus et lignis putrefcentibus.

Crzzita puluerulenta, maculas formans fufco-attas, tenuifimas. Scutellae copiofae, minutae, flauae. noF M. 1. $c$. 
CIYPTOGAMIA. III. ALGAE. $\quad 585$

I426. Scutellaria puluerulenta, glauca, feutellis rubris, Pezizoides. ferratis. HoFM. 1. c. n. 60. Tab. VII. fig. 6.

Kleine gezühnte Schilbjechte. Germ.

Ad terram et in arborum radicibus.

1427. Scutellaria leprof́a lutec-viridis, fcuteliis fuluis. fulua.

SCHREs. Spicil. p. 13\%. n. 1139. (íb Lichene.)

Lichen fuluus cruttaceus flauus, leutellis fuluis. NECK. Del. Gall. p. 502. n. 8.

$\therefore$ Fenergelbe Schilalfechte. Germ.

In arborum truncis, praecipue Salicum annofarum, vulgaris.

1428. * Scutcllaria leprofa, albido - cinerea, fcutellis au- aurantiaca. rantiacis. HoFM. 1. c. n. 55. fub Licíene.

Lichen flano - rubefcens: cruftaceus cinereo-virefcens, fcutellis fauo-rubentibus. IIUds. Flor. Angl. Ed. 2. p. 528 .

Gall.

Orangegelbe Schilaflechte. Germ. Orange Lichen.

In fepibus, truxisque arborum maxime Populi tremuiac aliarumque copiofe. Omni floret tempore.

1329. * Scutellaria crufacea alba, fcutellis cinereis carpinea. I. fefilibus planis, margine niueo. Scop. Carn. Ed I. p. 8 I. n. I6. Vai. b. (fub Lichene.)

Lichen carvineus; leprofus cinereus, tuberculis albidis tugofis. Iris. Syft. Ed. R. Tom. IV. p. 527 . IViße Landikartenäbiliche Schildflechte. Germ. Horn bean Lichen. Angl. Lichcn du charms. Gal!.

In Carpinorum cortice, in Rofenthale. et alibi.

1430. Scuteliaria cruftacea albida, fcutellis confertis angulofa. albidis in tubercula demum abeuntibus, SCHREB. Spicil. p. 136. n. I i 37. fub Lishcne.

Knleine weijse Schildjlichte. Germ.

Ad variarum arborum, e. g. Quercuum, Tiline, etc. cortices et in lapidibus. 


\section{$586 \quad$ cLASSIS XX.}

pallica. 143T. * Scutellaria cruftacea albicans, feutellis pallide rubris, margine albo crenato. Hofm. 1. c. n. 66. Tab. 5. f. 2.

Lichen pallidus cruftaceus cincreus, fcutellis pallide carnein, margine albo. ScHREd. Spicil..p. I33. n. II32. HAG. Hift. Lich, p. 61, n. XXVIII, t. V. fig. 6 .

Lichen crufa tenace, vcrrucofa, cinerea: fcutellis rufis marginatis. HaLt. Hift. Helu. n. 2049.

Blagrothe Schildflechte. Germ.

In arborum corticibus et lignis putridis.

fubfufca. 1432. Scutellaria cruftacea albicans, fcutellis fubfufcis: margine cinereo fubcrenato. LINN. Syft. p. 958. n. 30. SCHREB. Spicil. p. 132. n. II29. fub Lichene. HAG. Hift. Lich, p. 62, n, XXX. HOFM. 1. c. n. 67. Tab. V. fig. 3 .

Braune Schildflechte, Germ. Lichen brun. Gall.

In asborum cortice, tegulis, cippis, paffim lapidibus et alibi frequens. Omni tempore.

atra. I 433: Scutellaria cruftacea albicans, rugofa, fcutellis atris, margine albo fuberenato. HUDS. Angl. Ed. 2 . p. 530. n. 32 . SCTreb. Spicil. p. 132, n. I130. Hofn. 1. c. n. 68. Tab. IV. fig. 4.

Lichers fuofufcus cruftaceus albicans, fcutellis nigris : junioribus lanceolatis cauis. LINN. Syf. Ed. R. Tab. IV. p. 530 .

Lichen nigricans cruftaceus albicans, fcutellis atris, margine cinereo laeuis. NECK. Delic, Galló. p. 504. n. 11. IIAG. Hift. Lich. p. 63. n. XXXI.

Schwirzliche Schildflechte. Germ. Black cupped Lichen. Angl.

In arborum e. g. fagorum cortice, et lapidibus maioribus. Omni tempore.

atrata. 1434. Scutellaria cruftacea, trunco fere per totum fcutellis atris exftructo, difco concolore.

Lichen atratus, trunco mere fcutelliformi, atro, difco concolore Hedw. Mufc. Frond. II. Tab. XXI. a.

Ge. 
Gefchwärzte Schilleflechte. Germ.

In ramulis Taliac Europaeae emortuis, putrilaginofis D. nEDWIG. primum reperit. Omni fere tempore viget.

1435. * Scutellaria albicans, tuberculis puluerulentis, androgyna. fcutellis pallidis; margine albo, crenulato, puluerulento. nоғм. 1. c. n. 70 . Tab. VII. fig. 3 . fub Lichene.

Warzenartige Schildflechte. Germ.

In lingnis et fcanduiis, putridis paffin. Vernali et Autumnali tempore.

$V r$. Cum aqua calcis viuae et vrina colore tingit pallide flawo-carneo.

370. PSORA. нотм. Enum. Lich. P. 57. Schuppenflechte. Germ.

1436. P Jora cruftacea flaua, fcutellis luteis. LiNn. candclaria. Syft. p. 958. n. 22, sснкев. Spicil. p. 132. n. I13!。 ноFм. 1. с. n. 72. Tab. IX. fig. 3. fub Lichene candelario.

Gelbe Schuppenflechte; - blaßgelbe Lichtflechte; Lichtmoos; Mauerkiitze. Germ. Ycllow furinaçeous or cruftet Lichcr. Angl. Lichen jaune, ou des chandclliers, ou Herpette chandelière. Gail.

In parietibus, vetuftis muris, lignis putrefcentibus, cippis, ad arborum cortices; porro fupra faxa ad lapides alibique vulgaris. Hyemali tempore poft pluuiam maxime viget et per totum fare annum.

Vf. Rufici Smolandiae a parietibus hune abradere et linteo inuoluere folent; dehinc luteo tinctum colore excostum cum febo mifcent et candelas, ob :luteum colorem, cereis fimiles, pro diebus feftiuis praeparant. Liss. It. Oeland, p. 39. Cum Sale ammoniaco et alumine colorem dat pallide cinereocarneum; cum alumine et vitriolo martis cinero viridem. HоFм.

In hoc Lichene intra cuculum habitat Phalaenae Lichenellae femina, quae aptera, laeuis, nigra eी. HAG. 
Alauefcens. $143 \%{ }^{*}$ Pfora cruftacea, fisuo-vireícens, fcutellis rufoluteis. Huns, Flor. Angl. Ed. 2. p. 528. fub Lichene. Griugelbe Schuppenflechte. Germ.

In arborum corticibus, afferibus putrefcentibus, parietibus ligno exftructis, muris ctc. copiofe.

Obf. Crufta orbiculari, rugoda, vircicente; fcutellis fufco-fauefcentibus, conuexis, a priori diftinguitur.

Vf. Cum vitriolo martis color obtinetur fpadiceofufcus.

Murorum: I $430^{*}$ * Pfora cruftace imbricata, foliis pulpofis, angufis luteis, fcutellis concoloribus. HoFM. 1. c. n. 80. Tab. IX. fig. 2.

Goldgelve Schuppcnflechâe. Germ.

In muris et tectis vbique. Omni tempore.

VJ. Per fe tingit colore cinereo-coriaceo; cum vitriolo Mart. ochraceo-carnco; cum alumine et vitr. mart. pallicle cincreo-carneo; cum vitr. mart. et aqua vulgari ex cinnamomeo fpadiceo; cum hepate ful- phuris et aceto ciralybeato cinereo violaceo. HOFM.

muralis. 439 . Pfora imbricata, flauo-viref́cens, fcutellis concoloribus demum luteficentibus; margine pallido. scined. Spicil. p. I 30. n. I r26. (fub Lichene.) Horm. 1. c. Tab. IX. fig. I.

Lichen palleicens, cruftaceus albieans, ,fcutellis pallidis. LINN. Syft. p. 958 . n. 28 .

Blade gcllogrïnlichte Mauer Schuppenflechte; Steinkrätze. Germ.

In tectis, fchitteis, tegulis, lapidibus cotaceis, afferibus trabibusque putridis et vbique.

crefia. I 440. * Pfora cruftacea, adpreffa, albido - cinerea, fcutellis concoloribus, tuberculis intermixtis caefiis. moFM. Pl. Lich. Vol. I. p. 37. Tab. VII. fig. I. Ej. Enum. Lich. n. 82. Tab. XII. fig. I.

ITimarlblaue Schuppenflechte; bläulichte Hügelkrïtze. Germ.

In lapidibus, téctis fchifteis, tegulis trabibusque fepimentorum et alibi frequens. 
'Vf. Cum alumine colore tingit grifeo-vmbrino. HOFM.

1441. Pfora imbricata: foliolis oblongis lobatis, inci- granofa. fis, cinereis, laeuibus: fcutellis nigris margine crenulato. SCHREB. Spicil. p. 128. n. 1222. Lichen granefus.

Körnigte Schuppènflechte. Ferm.

In teetis ligneis putridis, et ad Silicum truncos.

1442. * Pfora cruftacea imbricata, orbicularis, fcutel- pallefcens.

lis fufcis: margine crenulato. Hоғм. 1. c. n. 84 . Tab. X. fig. I, 2. fub Lichene.

Lichen pallefcens cruftaceus albicans: fcutellis pallidis. LINN. Sp. Pl, p. I608. n. 15. HAGEN. Tent. p. 6 I. n. 27.

Lichen fronde laciniata apprefia ceruina concolore. HALl. Hilt. Helu. n. 2024 .

Hirfchgraue schuppenflechte. Germ. Päle glaucous Lichen. Gall.

In lapidibus, arborum corticibus, afferibus trábibusque putridis frequenter.

I 443. Pfora cruftacea imbricata, foliolis margine verru- orbicularis. cofis puluerulentis, 1cutellis fufco-nigricantibus. ногм. 1. c. n. 85. Tab. IX. fig. I fub Lichene.

Lichen orbicularis fronde germinante deformi : fcutelifera tuberculata, primordialibus farinofis. NECK. -Method p. 88. n. 57 .

Lichen orbicularis imbricatus: foliolis obtufe multifidis, fcutellis fubfufcis. NEck. Delic. Gallob. p. 509. n. I9.

Lichen puluerulentus foliolis lobatis, crenatis, obtufis, viridibus, polline confperfis: fcutellis nigris, margine crênatis. ScHrEB. Spicil. p. I28. n. I123. HAG. Hift. Lich. p. 66. n. XXXII. t. 11. f. 8.

Kreisfornige Schuppenf lechte. Germ.

In arborum praecipue Carpini et Quercus corticibus. 
Omphalo- 1444. Pfora imbricata: foliolis multifidis glabris obtudes. fis, incanis, punctis vagis eminentibus. IINN. Sylt. p. 959. n. 36. (fub Lichenz.) вовнм. n. 867. HAG. Hift. Lich. p. 72. n. XXXV.

Lichen nigricans omphalodes. vailu. Bot. Par. p. 116. tab. 20. fig. 10 .

Shutioraliche Schuppenfleshte. Germ. Lichen ons. biliqué. Gall.

In lapidibus paffim deprehenditur.

\section{I. VSNEA, поғм. Haarflechte. Germ.}

mollis. I445. * Vfrea fronde articulata, pendula, intus tomertofa: ramis furcatis compreffis, lacunofis, glabris. NECK.-Method. 11. p. 74. n. 35. (lub Lichene.)

Lichen diuaricatus filamentofus, pendulus, angulatus, articulatus, intus tomentolus: ramis diviricatis, peltis orbiculatis feffilibus. LINN. Syft. p. $964 . \mathrm{n}$. I I9. Wer. Spicil. p. 227.

Lichen ramofus, lacunatus, flaccidus. hall. Hift. T. IIT, p. 82, ก. 1975 .

Vjuea mollis, ramis longis compreffis. DILL. Mufe. p. 62. t. I2. fig. 5 .

Weiche voncinandergefperrte Haarflechte. Germ. Lichers écarte. Gâll.

Intra Circuli Linfienjis fyluas ad Abietes paffim.

plicatx. 1446. *Vfizea flimentofa, pendula, ramis implexis, fcutellis radiatis. LINN. Syft. p. 964. n, II6. HAG. Hit. p. 134 . n. 74 .

V- fnea vulgaris loris longis, implexis. DzL. Mufe. p. 56. f. I $\mathrm{r}$.

Pharm. Mufci arborei f. Quercini Herba.

Verworme Haarflechte, Eichenmoos. Germ. Lichen entrelacé. Gail.

In fyluis denfioribus ficcioribusque $a b$ arborum antiquarum, Quercuum et Fagorum ramis pendet frequenter. Omni fere tempore.

VJ. Veteres hunc Lichenem in tuffi conuulfiua et haemorrhagia parium laudarunt, et pinubus betulisque collectam lanam crudam, antea alumine ma- 
CRYPTOGAMIA. III. ALGAE.

ceratam, fi cum aqua coquatur, viridi tingere colore, affirmat kalmivs.

1447. Vfnea filamentofa, pendula, trunco articulsto barbata. glabro, figrillis tenuioribus.

Licken barbatus filamentofus, pendulus fubarticulatus, ramis patentibus. LiNn. Syf. p. 964. 117. SCHREB. Spicil. p. II6. n. I IO4. HaG. Hit. Lich. p. I33. n. LXXIli.

Lang.̈̈rtige Haavflechte. Germ. Lichen barbu, ou Ufnée barbue. Gall.

In locis fyluaticis, in Oberholze, Bieniz, ad Fagos; Quercus etc. paffim.

I448. Vfnea filamentofa, pendula, axillis compreffis. jubata. Lisn. Syft. p. 964. n. I21. (fub Lichene.) schreb. Spicil. p. 115. n, I100. HaG. Hift. Lich. P. I39. n. LXXVIII.

f. 7 .

Vjnea jubata nigrans. DILl. Mufc, 64. t, I2.

Langherabhingende Haarflechte. Germ. Lichen chevelu, ou noir; Ufnée chevelue. Gall.

In Pinubus aliisque arboribus inb Oberholze etc. Vere.

$V J$. Rubro tingit colore.

I449. Vfnea filamentofa, ramofa, diuaricata, decum- chalybeiforbens, implicato - flexuofa. IINN. Syft. p. 96\%. n. mis. 124. Lichen chalybeiformis, SCHRE. Spicil. p. II5. n. IIOI. HaG. Hift, Lich. p. 138. n. LXXVII. Fl. Dan. t. 262 .

Drathformige Haarflechte. Germ. Lichen-fil-deFer. Gall.

Ad Quercuum aliarumque arborum truneos inz Bieniz; in fepimentis ligneis lemiputridis ad Parneck.

1450. Vfnea filamentofa ramofiffima, erecta, tubercu- hirta. lis farinaceis fparfis, LiNN. Syft. p. 964. n. I25. (fub Lichene.) SCHREB. Spicil, p. II6. n.,IIO2. HAG. Hift, Lich, p, I37, n. LXXVI. 
Sträubige f, rauche Haarflechse. Germ. Licnen heriffé ou Ujincé heriffóe. Gall.

In arborum truncis, dumetis, fepibus vique vulgaris.

Pro farcotico egregio et in decoßto ad firmandos pilos commendatur.

nurita. $145 \mathrm{I}$. Vfnea filamentofa ramofa, erecta,' fcutellis ra-, diatis. I.INN. Syft. p. 965. n. I29. (fub Lichene.) SCIIREl. Spicil. p. 116. n. IrO3.

$V$ nnea vulgatirima tenuior et breuior cum orbiculis. DILL. Mulc. 69. t. 13. f. 13.

Pharm. Vfueae carnii humani Herba

Sterntragende Haarflechte. Germ. Lichen fleuri, ou Ufuée flezricic. Gall.

In ramis Pinus aliarumque arbornm emortuis, im Oberholze frequens.

hipporricho-1452. *Vfuea filamentola, teres; nigra, apice diuifa. des.

WILDEN. Prodr. Berol. n. 1038.

Lichen hippo:richodes teres capillaris, niger, fubfurplex, extremitatibus diuifis. WЕв. Spicil. n. 266.

In foliis Pinuum dejeatis in Oberholze, in der. Dïbengfhen Heide copiole Perfiftens. Cum tuberculis rarius.

472. LEPRA. Wiggers. Primit. p. 95. Staubflechte. Gern. Bifre. Gall.

Antiquita- 1453. Lepra puluis ater. WILDEN. 1. c. IO67.

tis.

Lichen antiquitatis puluerulentus ater. SCHRE. Spicil. p. 138. n. 1144. Hag. Hift, Lichen, p. 42. n. IX.

Byjfus Antiquitatis puluerulenta atra. LINN. Syft.

p. 974. n. 8. weis. Crypt. p. I4.

Schwarzgraue Staubflechte. Germ. Crey Rook - Byffus. Angl. Buffe noir. Gall.

Ad faxa, lapides argillchas et muros antiquos fre. quenter. 
1454. Lepra puluis Aauus:

Lepra candelaria. wigg. Primit. n. 1039.

Lichen flauus puluerulentus r̂auus. SCHREB. Spic, p. I 39. n. I 145. Hac. Hift. Lich. 1) 39, n. V.

Byffus candelaris puluerulenta flaua lignis adnafeens, LINN. Syft. p: 974. n. II. weIs. Crypt. p. 15. Flor. Dan. เ. 899 . f. I.

Gilbe Siaulflechte. Germ. Yellow Pozeder Byyjas. Angl. Licher ou Biffe jaune. Gall.

In arborum corticibus, afferibus et ad pariates fere vbique in magna copia.

1455. Lepra puluis inanus.

Lichen incsnus puluerulentus albus, globulis roincann. tundatis. SCHREB. Spicil. P. I 39. n. I I 47. HaG. Hift. Lich. p 35. n. II.

By/jus incanus. LINN. Syft. p.974. ח.13. GLED.

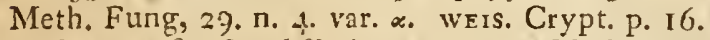

Graurveiße Staubflechte. Germ.' Mealy, Byfus. Angl. Biffe blanc. Gall.

Ad latera foffarum, nach dem Bieniz $\approx u$, porro am das Oberholz et in ambulacris vmbrofis fyluaticis atque hortis.

I456. Lepra puluis fulphureus.

Lichen lutefcens puluerulentus verrucofus, fulphureus, Horm. Enum. Lich. n. 3.

Schwefel 1. blasgelbe Staubflechte. Germ.

In cortice Arborum et aferibus putredine corruptis etc. Autumno et Vere.

1457. Lepra puluis ruber.

rubens.

Var. х. Lichen rubcns, puluerulentus ruber. ноғм. 1. c. n. 5. tab. I. f. 5 .

ß. Lichen croceus puluerulentus croceus. SCFReb. Spicil. p. 139. n. 1416.

Dunkel f. zinnobergelbe Staubflechte. Germ. Lichen rouge, ou fafrane. Gall.

In arborum e.' $\mathrm{g}$. Quercuum etc. corticibus im Rofent/ale; in Querceto vor Markranftïht et alibi. 


\section{4 \\ CLASSIS XX.}

10fea, 1.158. Legrá puluis e glebis maxime fparfis rofeis conftans. Wildir. Prodr. Berol, n. 1072.

Lichen roleus puluerulentus conglomeratus rofeus. schrib. Spicil. p. 1430. n. I150. hofM. 1. c. n. 6.

Rofenfarbige Staubfleckte. Germ.

In cortice Tiliarum Salicumque paffim.

sinnabarina. 1459. * Lepra puluis e glebis cruftaceis cinnabarinis conftans.

Lichen cinnabarinus puluerulentus; crufta glebulofa cinnabsirum, hag. Hift. Lich. p. 4T, n. VII.

Luchen crufta cinnabarina. Halz. Hift. Helu. III. p. 104. n. 2098 .

Zimolingelber Staulf lechre, Germ.

In corticibus arborum variarum e. g. Quercuum, Tiliarum etc. emortuis et afleribus putredine corruptis pafim oritur. Autumno.

cinerea. I46ro. * Lepra puluis obfcure cinerens.

Lichen puluerulentus, cinereus rupes operiens. HAG, Hift, Lich. p. 35. n. III. LINN. Sy凡. p. 974. fub Byflo. котн. Tent. Flor. Germ. p. 490.

Schroarzgraue Siaubflechte. Germ.

In faxis vbique.

ferriginen. 146r. "Lepra puluis cinereo ferrugineus.

Lichen ferruginens puluerulento-crultaceus, rimofus, cinereus. Hozm. l. c. n, 12, tab. 2. fig. 3 .

Graue Staubflechte. Germ.

Ad truncos Salicum, Quercuum, Fagorum aliarumque arborum paffim.

Botryoides: 1462. Lepra puluis e glebis minimis confans, lutëoviridis.

Lichen Botryoides puluerulentus, viridis. HAG. Hift. Lich. p. 40. n. VI, ноғм. 1, c. n. 7. t. I. fig. 2. weis. Crypt. p. 15.

Tremella botryoides. SchrEb. Spicil. p. I41, n. 1153.

Grïne körnigte Staubflechte. Germ. Creen Clufter ByJfus, Angl, Biffe vert. Gall. 
In terre e. g. in der Allee; in variis hortorum recrementis, nec non in fructibus variis; porro ad parietes verfus Septentrionales regiones fpectantes et ad tecka veterana.

1463. Lepra puluis candidus, calcaris indolis.

Lichen lacteus puluerulènto-cruftaceus, albifimus. schreb. Spicil, p. 139. п. I 4 4 . Mag. Hif. Lichen. p. 36. n. 1. п10FM. 1. c. n. 8. tab. I fig. 3.

Byfus la ciea. IINN. Syft. p. $97 \%$ n. 14. weIs. Crypt. p. 17. Flor, Dan. t. 8\%0. f. 4 .

Weißie kalkartige Staubflechte. Germ. Byগe laiteux. Gall.

In corticibus arborum mufcisque variis frequens.

1464. Lepra puluis laete viridis.

Lichen viridis puluerulentus viridis. SCHREB. Spic. lątea. p. I39. n. I 149. HAG. Hit. Lich. p. 40. n. VI. var. $\alpha$.

Byjjus botryoides faturate virens. DILL. Mufc. p. 3. tab. I. fig. 5.

Hellgrüne Staubflechte. Germ.

In Quercuum annofarum etc, cortice pafim.

I46.5. * Lepra puluerulento - cruftacea elegantiflime aeruginofa. viridis.

ByjJus aeruginofa. weis. Crypt. p. 18.

Grïnjpanfarbige Staubflechte. Germ.

Ad truncos putrefcerites Salicum et ad radices Fagorum, Quercuum etc. denudatas frequenter legi.

473. BYSSVS. L. G. I324. Haaraftermoos. Germ.

1466. Bijfus filamentis plumofis natantibus. IINN. Flos Aquae. Syft. p. 974. п. 2 .

Hiutige Vafferblume. Germ. Biffe Fleur-d' eau. Gall.

In aquis ftagrantibus frequens, Viget Aeftate. In exficcatis alba euadit. 


\section{CLASSIS XX.}

feptica. $146 \%$ * Byffus copillacea, mollifîmma, parallela, fragitlifima, pallida. LINN. Syft. p. 973.

Faulichtes Haarafiermoos. Germ. Biffe Septique.

In cellis locisque ä̈ri mephitico expofitis vbique.

phofphorsa. 1468 . Buffus lanuginofa, vioiacea lingnis adnafcens: LINN. SYft. P. 9" - n. 3 .

Buffis capillacea fruetificationibus fparfis, filamentis breuibus integris et tenuiffinis, bafi craffa reptn1te. GLED, Mieth. Fung. p. 22, n, III. BOEHM. n. 878 .

Violettes Haaraftermoos. Germ. Bife phofphore. Gall.

In nemoribus lignis putrefactis et deiectis innafcens praeprimis in putridis Coryli, Aceris, Poptili, Vlmi aliarunque arborum truncis lignisque emortuis et quidem in virgultis omnibasque circa Lipfians fyluis et dumetis frequens. Vere et Autunno.

Noe.u lucet.

cacrulea. 1459 . Buffus capillacea, minima, filamentis fimplicibus, integerrinis, omnium tenuiffmis breuibusque.

By/fus capillaces, caernlea, fuktificationibus fparfis filamentis integerrimis et omniun tenuiffins et breuibus. GLED. Meth. Fing. p. 23. n, III. var, b. Blaues Haaraftcrnoos, Germ.

Mufcis et Ericis obfidet circa pagos Schöifeld, Mockau, Störnthal, Belgershayn, Pomfent, Steinbeck et in Sylua Academica paffim." Vere et Autumno.

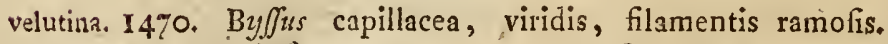
LinN. Syft. p. 974. n. 5. weis. Crypt. p. I2.

By/fus capillacèa, viridis, fructificationibus fparlis, filamentis breuibus tenuifimis, partim fimplicibus, partim ramofis. GLED. Meth. Fung, P. 19. n. I. var. b. вОЕЕМ. ก. 875 . Gall.

Grïnes feideizartiges Haarmoos. Germ. Biffe velours. 
Ad terram vảam perietesque ligneos humidos et muros, faxa, prope terram, atque in hortorum ollis.- Vere èt Autumno.

Obf. A Lepra Botryoide diftinguitur colore magis viridi et ftruatura filamentofa. Weis.

147́x. * Byjfus capillacea, fufco-nigricans mollisque, fufco-nigrifilamentis bifidis vel integris.

Byffus capillacea fufco-nigricans et mollis: fructificationibus fparfis, filamentis breuifimis, partim fimplicibus, partion ramofis. GLEn. Meth. Fung. p. 20 . n. I. var. c.

Schwarsbrannes Haarafiermoos. Germ.

In fyluis ad Vlmbrum, Carpinorum, Quercuum aliarumque cortices, praecipue poft pluuias crebriores.

1472. By乃us capillacea, fructificationibus Iparfis, fila- nigra. mentis integris at productioribus, bafi latifinu. GLED. Meth. Fung. p. 2I. n. II. вовHM. n. 876.

Byfus nigra, velutina. LeERs. Herborn. n. roob. Schwarzes Haarafternoos. Germ. Biffe noir. Gall.

In locis fubterraneis cellis vino cereuifiaeque dicatis, vbi ligna integra, dolia et parietes cellarum obducit, frequenter obferuatur.

1473. Byffus filamentis ramofis fuluis. Hudson. Flor. fulua, Angl. Ed. 2. p. 606.

$B$ by $\int u s$ fructificationibus fparfis, filamentis produftioribus, craffis, bafi latifinma, in plures figuras difci aemulas expanfa. Eied. Meth. Fung. p. 22.

n. II, var. a. ВОЕНМ. n. 877 .

Fenergelies Haaraftermoos. Germ. Biffe jann. Gall.

In lignis putridis aërique humido expofitis, doliis quoque vinariis adnefcens. Hyeme.

1474. By $\int u s$ lanuginofa, albifima filamentis longio-Bombycina. ribus implexis lignis adnafcens. RE'z. Prodr. Flor. Scand. n. 1548 .

$$
\text { P } 3 \text { Byfins }
$$




\section{8}

Byfjus forcofa euanida floccofa niuea. scriper. Spic. p. I 44. n. I 660 . LeERs. Herb. n. Ic05. B. cellaris. WeIs. Crypt. p. Is.

IWeißes Seidenhaaraftermoos. Germ.

In cellis ad dolia, trabes etc. frequens.

corincea. 1475. Buffus perennis denfiffima albicans. SCHREB.

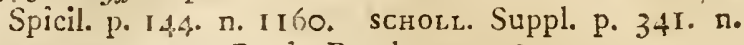
II23. WILDEN. Prodr. Berol. n. I078.

Lederartiges Haaraftemoos. Germ.

In Quercuum annofarum truncis et alibi, paffim.

\section{b. ALGAE AQVATICAE.}

474. CONFERVA. L. G. 1323. Grasleder, Wafferfchlamm. Germ. Conferue. Gall.

a. Filamentis fimplicibus, aequalibus, geniculis. deftitutis.

riuularis. I476. Conferua filamentis fimplicibus, aequalibus, longifínis. zINN. Sylt. p. 972. вогнM. n. 879. Wers. Crypt. p. 20.

- Langes Bachgrasleder 1. Wagferfchlamm. Germ. Coisferue des miffeanx. Gall.

In riuulis lentius fluentibus aquisque ftagnantibus

- frequens. Aeftate.

fontinalis. 1477. Conferua filamentis fimplicifimis, aequalibus digito breuioribus. LINN. Syft. p. 972. n. 2. WEIS. Crypt. p. 21. Flor. Dm. t. 65 I. f. 3 .

Brunnen Grasleder. Germ.

In fontibus limpidis, circa canalium aquam ducentium, et veteratis paffim. Aeftate.

abbreuiata. 147\%. Conferza paluftris, filamentis breuioribus et crafioribus. SCHREB. Spicil. p. 143. d. $1157^{\circ}$ Abgchïrztes Ledergras. Germ.

In forfoculis pratorum ad Abnanendorf et riuulis Calinis Fetfchauienfibus etc. paffim. Aeftate,

b. Fila: 
๖. Filamentis ramofis aequalijus.

I 479. Conferua filamentis aequalibus ramofis, aüreas bullofa. bullas includentibus.' LINN. Sy?t. p. 973. n. 3. schreb. Spicil. p. 142. n. I 56 . Weis. Crypt. p. 22. LEERS. Herb. n. IOIg.

Schauniges Ledergras; Wiefonpelz; Wiefeneratte. Germ. Conferue bulleufe, ou Queue de Renard. Gall.

In forfis paludofis lacubusque copios. Aeftate.

I4SO. * Conferua filamentis acqualibus bafin verfus canalicularamofioribus. LiNn. SyR. p.973. n. 4. Wais, Crypt, ris. P. 23. LEERS. n, 1020 .

Röhren Ledergras. Germ.

In riuulis canalibusque aquam vehentibus. Autumno viget.

'481. Conferza filamentis aequalibus, ramofis exfic-amphibia. catione coeuntibus in aculeos. LINN. Syft. p. 9?3. n. 3. SCIIREB. Spicil. p. 143, n. II 59. weis. Crypt. p. 2.4 .

Schereaninueratte f. Ledergras. Germ.

In folfis humidis ad Ketfchan prope nachinas gradatorias et in locis vdis fere vivique. Aeftate.

\section{c. Filamentis anaftomofantibus.}

I482. * Conferua filamentis reticulatim coadunatis. reticulate. IINN, SyRt. p. 973, n. 11. JAHN. n.,26. WEIs. Crypt. p. 24. LEERS. Herb. n. 1022 . Gall.

Nezförmiges Ledergras. Germ. Conferue en vefeau.

In aquis ftagnantibus ad Leut $\int c h$ et riuulis paffim, Aeftate.

\section{d. Filamentis geniculatis.}

1483. * Conferua filamentis geniculatis, ramulis bre-glomerata. uioribus multifidis. LINN. Syft. p. 973, n, 19. WE1s. Crypt. p. 25. 
Biifchelartiges Ledergras. Germ.

In folfis hinter Mockau et riuulis paffim. Aeftate.

capillaris. 1484 . Conferua filis geniculatis fimplicibus, articulis alternation compreffis. LiNin. Syft. p. 973. n. I4. schreb. Spicil. p. I 43. n. I I58. Leers. Herb. n. 1025.

Haarfömiges Ledergras. Germ. Conferue capillaire. Gall.

In locis vmbrofis ad Pliffae oras et in Atagnis paffin. Aeftate.

farmea. I485. * Conferua filamentis geniculatis ramofifimis e centro confertifimis elongatis viridibus, ramulis confercis tenuifimis. LEYs. Hal, n. 1204.

Mehlartiges Ledergras. Germ.

In riuulis falinis ad Ketfchau dicht bei den Gradierhäufern nuperrime detexi.

475. VLVA. L. G. 1322. Matte, Waffermoos. Germ. Ulue. Gall.

inteftiralis. 1486. * Vlua tubulofa fimplex. LINN. Syft. p. 972. n. 3. JAHN. n. 25. WEIS. Crypt. p. 27.

Darmmatte. Germ. Sea-grafs. Angl. Boyau de chat, ou Fetille de ner; Ulue int fítinale. Gall.

In foltis, lacubus aquisque ftagnatibus vbique, Viget aeftate.

comprafta. 148\%. Vlua tubulofa ramofa, comprefta. Lisn. Syft. p. 972. n. 5. इСнвЕв. Spicil. p. $14 \mathrm{i}$. I. 1154. Platte א. zufammingedrückse Matte. Germ. Aquis falfis, in und bei den Cradierhäufern ad Ketfchau, innata. Aeftate viget. 


\section{F V N G I.}

A. Semina Fungorum externa in Juperficie infera. membranae Fungm obtegentis, aut lansllas, aut tubas formontis, aut Apophyfun ad inftar prodeuntis, reconsista.

476. AGARICVS. I. G. I325. GLED. M. F. G. VI.

BATSCH, El, Fung: G. I. Blätterfchwamm. Germ.

๘. AGARICI VALIDI. Flcifchfchreämme. Germ.

«. Stipite nudo, pileo explanato, conuexo.

1488. Agaricus ftipitatus, pileo campaniformi, albido, extinetolacero, lamellis niueis, ftipite fubbulbolo, fubulato. rius. IINN. Syft. p. 976. n. 22.

Agaricus pileo campanulato in centro depreflo, lamellis tenuioribus, petiolo fulcato, gracili. GLED, M. F. p. 130. n. 27. schazf. t. 36. fub Agar. niueo.

Milchfirbiger Fleifchehwamm; Lichtfchneutzenahnlicher f, weißser kegelförmiger Blätterfchwamm. Germ. Agaric éteiguoir. Gall.

In dumetis, virgultis fyluisque, in Sylua Academica paffim. Augutto in Septembrem vfque.

1489. * Agaricus niueus, Atipite crafio, cylindrico, in-virgineus. tegerrimo. ватsch. El. F. p. 39. n. 2. Tab. III. f. 12 .

Weißer Fleifchfchwanm. Germ.

In fyluis vmorofis denfioribusque in Sylua Academica fparfim. Augufto et Septembri reperi.

1490. Agaricus pileo amoene rofeo, margine pallidiore, fanguineuse ftipite elongato, crafio, niueo in rubellum cadente.

Agaricus fanguineus pileo amoene rofeo, margine pallidiore: lamellis niueis; tipite crafto, niueo, $\mathrm{Pp} 5$ rofee - 
rofeo-rubello. вatsch. El. F. p. 4I. n. 4. Var. $\beta_{*}$ Tab. Iir. f. 13.

Agaricus integer fipitatus lamellis omnibus magnitudine aequalibus. LiNN. Syft. p. 974. n. 3 . SCHAEF. t. 58. et 75 .

Agaricus pileo orbiculari, in margine rugofo et friato; vertice tumido, petiolo breui. GLED. Neth. Fung.'p. 106. ก. it.

Blutfarbiger Fleifchafcheamm; Speytcufel, Germ. Agaric ontier. Fall.

In fyluis denfioribus, in Sylua Academica paffim nuperrime reperi. Aug. et Septembri.

deliciofus. Isqr. Agaricus pileo glabro fubrorido-vifcofo, croceoluteo; lamellis fubconcoloribus, fipite crafio albo. BATsCir. El. Fung. p. 7i. ก. 9.

Agaricus deliciofus Ripitatus, pileo teftaceo, fucco lutefcente. Linn. Syft. p. 975. n. 6.

Agaricus pileo hemifphaerico, in centro deprefro et in margine fornicato, petiolo breui et crafro. GLED. Meth. Fung. p. IOI. n, XT. BOEHM. n. 794. SCHAEF. Tab. II. 65, 220, $22 \mathrm{I}$.

Hierfchling; Reizker; Rietfchen; Herbftling; Tenuling. Germ. Orange Agaric. Angl. Agaric ou Champignon delicieux is fuc jaun. Gall.

In ericetis. im Bieniz, Univerfitätsholze porro circa Pomfen, Steinberg et alibi. Autumno.

Fungus cfeulentus in Suecia valde aeftimatur. Varietaribus ludit plurimis. Lamellae ejusdem vulneratae fundunt fuccum luteum.

vmbilicatus, 1402. *'Agrricus carnofus, pileo candido, centro vmbilicum referente; lamellis concoloribus; ftipite valido, tumido, concolore.

Agaricus candidus ex vna bafi multiplex, pileolo vmbilicato. GLED. Meth. Fung. p. ${ }^{2}$ 13I, n. 77. var. $b$.

Ein wcißlicher Fleifhychwamm wit eincm platten nabelförmagen Huthe. Germ.

In fyluis et ponaris circa Lipfiam et ad arborum radices patrim. Vere et Autumno, 
1493. Agaricus ftipitatus, pileo plano, carneo lacte- laetifuns. fente; lamellis rufis, fipite longo, carneo. LINN. Syft. p. 975. n. 7. еовнM. n. \$I2. SCMAEF, t. 5 . Agaricus fuluesis. Batsci. El. Fung. p. 43. n. II. Hundsreisker; Breitling f. milchigter Blätter. fchramm; Brödling. Germ. Agaric ou Champignon laiteux, ou delicicux à fuc blanc. Gall.

In fyluis im Oberholze; Univerfitätsholze etc. Autumno.

Obf. Pileus in medio depreflus. Stipes bafi tu. midus, validus, Lnc dulce. Fungus ef́culentus.

$V f$. Fungus fapore guadet fuauine reliquis, dehinc coquae noftrates hunc frequentius quaerunt.

1494. * Agaricus pileo glabro ochoraceo, croceo-al- mollis.

bente, campanulato; ftipite elongato, valido, fubconcolore glauco. BatsCH. El, Fung. p. 45. n. 16. Tab. IV. fig. I.t.

Glockigter reeifer Fleifchfchreamm. Germ.

In fyluis vmbrolis, in Univerfitätsholze rarius obuiam iuit. Sept, et Oêtobri.

1495. * Agaricus pilco ouali conico, obtufo, fcabro, Rudolphi. ferrugineo; ftipite elongato, fublineari, lucido fulphurco. вatsch. El. Fung. p. 75. n. 17. Tab. VI. fig. 23 .

Zimmetfarbiger Flcifchfchwamm. Germ.

In fyluis denfioribus locisque gramine veftitis, imb Bieniz et Oberholec. Autumno.

1496. Agaricus pileo fulcefcente conuexo vertici de-violaceus.: preffo, margine violaceo, lamellis violaceis; fipite caerulefcente, bafi-bulbofo. WILDEN. Prodr. Berol. n. I 116 .

Agaricus violaceus ftipitatus, pileo rimofo, margine violaceo, tomentolo; ftipite caerulefcente, lana ferruginea, LINN. Syit. p. 975. n. I I. вовнм. n. 813. SCHAEF. tab. $3 \cdot 3+$ et 56 .

Veilchenblauer Fleifchfchueamm. Germ. Violet Mulst room. Angl. Chanıpignon violet. Gall. 
In fyluis, in Univerfitãtsholze, Oberholze, in Querceto vor Markranftädt frequenter occurrit. Autunino.

Fungus efculentus.

piperatus. I.497. Agaricus ftipitatus pileo planiufculo, lactefcente, margine defiexo; lamellis incarnato-pallidis. ZINN. Syft p. 975. n. 8 .

Agancus pileo puluinato, integerrimo et in centro protundius depreffo, lamellis conuexis, anguftis et compactis; ftipite continuo, cylindraceo et craffo. GLED. Meth. Fung. p. 97. n, X. военм. n. 793.

Agaricus anarus. SC tAEF, t. 83.

Scharfer f. äzender Fleifchjchreamm; Pfefferfchwamm; bitterer f. hândiger Täubling; Bitterling; ächter Kaiforfchreanm. Germ. Agaric poivré, ou Champigaion blane acre. Gall.

In locis ticcicrinus fterilioribusque, pafcuis, pratis Syluisque in Bieniz, Obcrholac paftm. Sept. Oetobri.

Lac fundit copiofum, fed mite. Caro huius fungi acerrimum et feruentifimum edit faporcm. Subftantia, praeprimis corticalis illa carnofa et durior, e qua lac defluit, linguam et fauces vrit. GLED. 1. c.

liuidus. I $498 . *$ Agaricus ftipitatus, pileo "conuexo liuido, lamellis albidis, ftipite longo, albo. HU Dson. Angl. Ed. I. p. 616 .

Agricus pileo orbiculsri, lacero, e luteo pallefcent:, lamellis aureis, ftipite fifulofo\} cylindraceo, tenui GLed. Math. Fung. p. 112. n. XIX. var. a. вOEIMM. ก. 8OI. SCHAEF, t. IL.

Der Flcifchfche anm wit verfhiedcner Farbe. Germ.

In fyluis denfioribuse, in Sylua Acatenica, im Bieniz, in der Prollheide, etc. circa radices arborum mufonfas pallim.

terreus. r 499. * Aguricus pilo obfcure liuido-nigrefeente, fubpilofo, friat:, lamellis canis, ftipite niueo, valido. Batsci. El. Fung. p. 47. n, 22. fub Agar. pullo. SCIYAEF, t. GI.

Agarichis pileolo plano, lacero, angufta, Stipite cy. lindraceo, tenui. GLED. Meth. Fung. p. II2, n. XIX. 
Erdfarbiger Fleifinfchzeamm. Germ.

In faltubus totius circuli Lip̧riae. Autumno paffim occurrit.

1500. * Agaricus fulphureus; pileo fulphureo, fuluo- luteus. que mixto. eatsch. El. Fung. p. 45. n. 14. SChaef. t. $4 \mathrm{I}$.

Goldgelber Fleifchfchreamm. Germ.

In fyluis denfioribus in Oberholae, im Bieniz et .praeprimis in Querceto vor Markrandifadt paflim reperi. Autumno.

\section{B. Bulbofi: faipitibus fericeo - firiatis.}

150I. * Agaricus bulbofus, liuidus, flauens, palli- orichalceus. diffime virens, pileo vifcido, medio ferrugineo; ftipite acute bulbofo, folum flauente; annullo araneofo vna cum lamellis elongatis ferrugineo. ватSCH. Cont. II. p. I. Tab. XXXI. f. 1846 a. b.

MefJing farbener Fleifchfchueanm. Germ.

In fyluis denfioribus, humidis, in Univerfit"ts. holze 1789. Specimina nonnulla reperi. Autumno.

Fungus fufpectus caput grauefcit. Pileus mollis, late expanfus, fuperne vifcidus. Stipes glaber, fericeus, bafi tumidus.

1502. Agaricus bulbofus, liuidus, brunneo-canus; fubferrugiftipite crafto, bulbofo, fere toto in pileun defluente, lamellis oblongis paruis, ferrugineis; fripite pileoque fibrofis. Batsch. Cont. II. p. 7. Tab, XXXI. tig. 186. a. b.

Roftbriunlicher Fleifchfchwanm. Germ.

In locis fyluaticis quoque in Sylua Academica fub fine Augunti mihi obuiam venit.

\%. Stipite fericeo, nec bulbofo, nec fabro.

1503. * Agaricus teftaceus, ftipite furfum incrafato, fe- fufus. riceo, fibrofo; pileo rimofo, glabro, demum ficcitate ochraceo; lamellis pallidis, concoloribus. Batsch. Cont, II, p. 13. Tab, XXXII. f, 189. a-c. 
Kräufelförniger Fleifchfchieamm. Germ.

In fyluis elationibus et pinetis im Oberholze, Bieniz etc. pafîm. Autumno.

peltigerus. I504. * Agaricus paruus, ftipite fericeo-fibrofo, niueo, pileo pallidifine teftaceo. Eatsci. Cont. II. P. 17 . Tab. XXXII. fig. I90. a-c.

Kleinhutiger rother Fleifchfchreamm. Germ.

In fyluis denforibus inter Mufcos varios, in Rocathale paffim. Autumno.

nitens, I 505. * Agaricus pileo cano-oliuacen, fibrillofo, gla* bro, nitente; ftipite fibrofo; breui, niueo, lamellis latis, laxis; pallidis, lenifime oliuaceo-liuefcentibus. Brtsch. Cont. 1I. p. 23. Tab. XXXIII. f. 192. a-d.

Glänzcnd glatter Fleifc!lfchueamm. Germ.

In fyluis et locis arenofis im Oberholze nuperrime detexi. Autunno.

nebuaris. 1506. * Agaricus grifeus pilen obfcuriore glabro; margine inuoluto; ftipite-pallidiore, fibrofo-hifpido, bafi alho-tomentofa; lamellis erga crafium fipitém pileum anguftis, pallidis liuido-ochraceis, ватSCH. Cont. II. p. 25. Tab. XXXII. f. 193. a. b.

Hellgrauer Fleifchforwamm. Germ.

In fyluis acerolis et elatioribus im Bieniz et Ober. holze fparfim. Autumno.

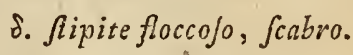

fenefcens. 150\%. * Agaricus ochraceo-ferrugineus, fubfuluellus, mutabilis; ftipite fubbulbofo, obfcuriore, floccis pallidis transuerfe feriatis fquamofo, fubnudo, pileo vario, flauentiore, vifcido; lamellis latis pallidis ferrugineo-fuluellis. Batsch. Cont. I. p. 35. Tab. XXXIV. f. 197. a-d.

Der veralternde Fleifchfchwernm. Germ.

In fyluis acerofis in der Dübenfichen Heide initio Septembris 1789 fiequenter reperi. 
1508. * Agaricus pilco lateritio - carneo, puluinato, laterinusfarto, fubuifcido, ftipite concolore pallidiore, floccofo-alpero, laminis fuluellis anguftis. вatsce. Cont. II. p. 29. Tab. XXXVI. fig 195. a. b.

Ziegelrö̈hlicher Fleifchafchwamm. Germ.

In fyluis acerofis im Oberholze paffim; copiofius vero in der Dïbenfchen Heide. Autumno.

b. AGARICI PVLVINATI. Weich f. Staub-

- fchreämme. Germ.

3509. * Agaricus pileo caftanco-ferrugineo, fubpallido; caftaneus.

ftipite valide albidiore; laminis rubellis. ватsch.

El. Fung. p. I9. n, 30. SCHAEF. t. 8r.

Kafanienbruwner Weichfchreamu. Germ.

In fyluulis denfioribus, in Querceto vor Mark. ranftadt. Septemb. et Oatob. obuiam iuit.

1510. * Agaricus pileo ferrugineo-fufco, fibrclo-ftria- ferrugineus.

to; ftipite fubelongato, valido, pallidiore, fubfquamofo; lamellis pallide rufis. вaтsch. El. Fung, : p. 86. n. 12T. SCHAEF. t. 37.

Rothbrauner Weich/chueamm. Germ.

In fyluis denfioribus humidisque im Univerfetïtsholze paftim. Autumno.

c. AGARICI VOLVÁTL. Eyschwëmme. Germ.

$\alpha$. Stipite bafi et fuperne voluato.

I5 Ir. Agaricus ftipitatus, annullo fixo inuerfo, pileo Mappa. planiufculo flauo, fufco variegato, laminis albis, ftipite bulbofo voluato. wildEN. Prodr. Berol n. 1102.

Agaricus Mappa, pileo flauo cinerafcente, psllido, maculis inaequalibus fufcefcentibus pierumque notato: fipite elongato lamellisque fubconcoloribus albis. вATSCH. Fl, Fung. p. 57, n. 50. SCHAEF. t. 20 .

Gelblicher Eijchreamm. Germ. 
In fyluis arenofis et acerofis in der Dübenfchen Heide palfim. Autumno.

tnufcarius. 1512. Agaricus volua exceptus, pileo conico, in margine ftriato, ftipite annulato, in bafin fquamolotuberofan terminante. GLED. Meth. Fung. p. 82. n. I. ВоЕНм. ก. 786 .

Agaricus mufcarius ftipitatus lamellis dimidiatis folitariis; ttipite voluato; apice dilatato bafi ouato. LINN. Syft, p. $97 \%$. n. 4. M1LL. Gen. t. 78. f. r. SCAAEF. t. $2 \%$. et $=8$.

Agaricus imperialis pileo fruftulis voluae albis in. duratis; ftipite elongato valido lame'isque albis. ватsсн. El. Fung. p. 59. ก. 55 .

Fungus mufcarius miniatus. sterb. p. 2 I5. t. 22. B. c.

Fliegenfchunm. Germ. Agaric aux mouches, on à tête large. Gall.

In pafcuis ericetis elatioribus, fyluis ficcioribus et pinaftretis inter Pinus et Eetulas nafcens. Autumno.

Cum late mufras occiait. Liquamen e contufo fungo parietibus le toque inunctum expellit cimices. Potum ex hoc fungo et Epilobio anguflifolio Kantfchadalonfes parant capur grauefcentem et valde noxium.

aureus, I513. Agaricys fiauus, voluatus; annulo latifimo. IIALL. 1430. LEERS. Herb. n. I062.

Agaricus ampliffima volua exceptus, aureus; pileo hemifphaerico, in margine friato; ftipite craffo, annulo latifimo cincto. GLED. Meth. Fung. p. 85. n. II. var. B. BOEHM, n. 787 . SCHAEF, t. $24 \%$.

Fungus ouinus. STERB. p. 64. t. 4. D. E. F. Goldgelber Eyfchuamm, Kaiferling; Herrenpilz. Germ.

In fyluis ficcioribus inter Betulas et Pinus aliasque arbores e. g. im Oberholze, im Bieriz paffim. Autumno exeunte.

Fungus efculentus. 
1514. Agaricus ftipitatus albus, Aipite cylindraceo, tuberofus. annulato, bafi globofo, pileo magno, plano. LEYs. n. 1211 .

Agaricus volua minore exceptus, pileo orbiculari integerrimo, ftipite annulato, radice tuberofa. GLED. Meth. Fung. p. 86. n. IL. военм, n. 788 .

Kzolligter Ezfchteamm. Germ.

In palcuis, aruis et pomariis, praecipue pof pluuias nach den Gonnewitzer Schanzen hin et alibi frequentor viget. Autumno.

Variat faepe pileo vel albo, vel fufco-albo. Fun. gus efculentus.

X515. Agaricus volua exceptus, pileo hemifphaerico, crenulatus lamellis compactis denticulatis, Ptipite annulato et craffo. GLED. Meth. Fung. p. 9o. n. V. вовнм. ת. $78 \%$.

\section{Gezähnter Eyfchwamm. Germ.}

In campeftribus, pafcuis ficcioribus, ericetis ct pinaftretis; in Sylua Academica, im Oberholze, Bicniz frequens. Autumno.

\section{ß. Stipite bafi voluato.}

2516. Agaricu' volua perfiftente exceptus, pileo forni-formicatus cato, ftipite cylindraceo. CLED. Meth. Fung. p. 92.

11. VI. BOEIM. n. 79I.

Gewölbter Eufchreamm. Germ.

In pafcuis et pratis und den Kuhthurm et bei Lindenau. Autumio.

I517. Agaricus pilen caftaneo - fuluo, margine plicis fimbriatus fimbriatis inftructo, ftipite praelongo, floccis fufcis notato, voluula parua, lamellis pallelcentibus. SCHAEF. t. 95.

Verbrômter Eujchwamm. Germ.

In fyluis vmbrofis, humidis, maxime poft pluuigs oritur. Autumno. 


\section{\%. Sipive fuperne anmulato.}

clypeatus. IzI8. Agaricus fipitatus pileo hemifphaerico vifcido, acuminato, lanellis albis, ftipice longo cylindraceo, albo, bafi ouato. LiNN. Syft. p. 675.n. I8.

Agavicus antiquatus pileo albico fulco-canefcente, pailido, centro fruftulis transuerfis feriatis, difco floccis fparfis vtrisque nigro fufcis variegato; ftipite concolore et 1quamolo, elongato, validiufculo, bali bulbofo, volua lamellisque albis. вarsch. El. Fung. p. $55 \cdot$ ก. 40 .

Agaricus pileo papillari, amplifimo, in margine fornicato, lacero et filamentofo, fipite annulato, procero, inferius tumido, pilei acetabulo inferto. GLED, Meth. Fung. p. 114. n. XX. вовнM. n. 811 . SCHAEF. T. 22, 23.

Fungus coronatus vel marmoreus. STERB, p. 76 . 77. t. 7 . A.

Schiearaflokkiger Ringfchwanm. Germ. Agaric bouslier, ou Champignon armé. Gall.

Ad margines fyluarum ipfisque in fyluis, in Querceto nach Altrandftïlt, im Bieniz, Univerfitäts - et Oberholze etc. Autumno.

Fungus efculentus fub nomine Bubcritze, Bub. litzen colligitur in nonnullis regionibus.

anpetris. I5 I9. Agaribus fipitatus, pileo conuexo fquamato albido, lamellis rufis, LiNN. Sytt. p: $975 \cdot$ n. I1. Fl. Dan. ᄃ. 7 . 4 .

Agaricus pileolo amplo rotundo, fornicato; ftipie breui, annulo permanente cinto. GLaD. Meth. Fung. p. II5. ת. 21. हOEHM. n. SO2. SCHAEF, t. 3 Io et 311 .

Fungus campeftris. STERe. p. 29. t. T. A.

Feld Ringfchwamm; Ehcgürtel; gemeiner Champignon. Germ. Comnon Mushroom. Angl. Agaric champêtre, ou Champignon vulgair, ou de Couche. Gall.

In hortis pinguioribus, locis cultis, fuburbanis, pomariis, pratis, pafcuis, fimetis frequens. Augufto in Octobrem vfque et Vere. 
Fungus efculentus inte: primarios, recens incoquitur variis embammatihus. Conditur quoque aceto vini et per hyemem feruatur.

I520. Agaricus candidus, pileo fornicato, fquamofo; pellicus. ftipite annulato, cylindrico crarroque. GLED. Meth. Fung. p. 1 I $\%$. n. XXI. var. b.

Agaricus pellitus pilen paliide cano, maculis magnis pilofo-fquamiformibus, extrorfum acutis, laxe fparfis, imbricato, radicato; fipite craffufculo, concolore integro, lamellis fubbrunneis. БAтSCH. El. Fung. p. 5j. n. 41. schasf. t. 33.

Fellartig gefekter Ring fchuamin. Germ.

In hortis, fimetariis, pomariis, pratis palcuisque praeprimis polt pluuias. Augufto ad OAtobrem vfque.

Locis ficcis emergens efculentus; humidis autem eft obnoxius.

1521. Agaricus pilei conuexi viridefentis maroine Kremlinga. friato, tipite annulato, bafi-tuberofo. RETz. Prodr. Flor. Scand. n. 1533.

Agaricus delicatus. вatsch. El. Fung. p.43. n. 10. SCHAEF, t. 93 et 94.

Agaricus pileo puluinato, in margine friato, petiolo annulato, ad radicem tuberofo. GLED. Meth. Fung. p. I05, n. XIIL. воEнм. n. 796.

Fungus magnus viridis. STERE. p. 6-. t. 5. C.

Kremling; Grïnling; ein griuner Breitlnng; Koh. lentüubling. Germ.

In pratis, pafcuis circa pagos Lindenum, Leut fch et in fyluis pratenfibus, in Rofenthale, Univerfitäts. holze etc.

Fungus quoad magnitudinem coloremque valde variabilis et efculentus, fucco lncteo et acredine de. fiturus.

1522. Agaricus ftipitatus, pileo flauo, conuexo, la. Georgii. mellis albis. LINN. Syft. p. 973. n. 10.

Agaricus pileolo orbiculari, puluinato, amplo et candido, in margine hirfut et flatelcente; ftipite 
annulato, breui et crafio. GLED. Meth. Fung. p, I I\% n. XXI, var. e. воEHM. n. 803 .

Fungi diui Georgii. STERE. Fung. 32. t. I. G.

Runder Ringfchueanm mit gelbem Huthe; Mayflhwamm; St. Georgenjchuamm; Weifling. Germ. Champignon Georget. Gall.

In palcuis fuburbanis et pratenfibus elatioribus circa Lipfiam, auf den Gonnewitwer Schanzen, umb den Bienza, bei dcm Kuhthmme etc. olim. Ill. b. GLEDITSCHIVs et BOEHMERVs collegerunt; ego vero quoque ad Templam St. Thiclae, im Bicniz etiam, in der Dïbenjchen Heide copiofe reperi. Autumno.

Fungus efculentus.

oczuitans. 1523. "Agaricus pileo fufco-caftaneo, maculis pilofis fubfquamofo; ftipite fubaequali, ralido, fubelongato, concolore, pallidiore; lamellis rofeis, volua albs. BAtsch. El. Fung.p. 55. ก. 45. schaEF. t. 74, Der braune unten röthliche Ringfchuamm. Germ. In locis fyluaticis vmbrofisque, in Sylua Acactemica paffim. Autumno.

d. AGARICI FVGACES. Rußfchreämme. Germ.

fimetarius. I524. Agaricus fipitatus, pileo campanulato, albo fubfquamofo; lamellis nigricantibus; ftipite albo, fiftulofo, annulo fugaci. WILdEN. Prodr. Berol. n. 1096 .

Agaricus fimetarius ftipitatus, pileo campanulato, lacero; lamellis nigris, lateraliter Hexuofis; ftipite fiftulolo. LINN. Syft. p. 976. n. 24. GLED. Meth. Fung. p. 122. n. XXIV. ERIEM. n. SO6. SCHAEF. t. $7 \cdot 8$.

Agaricus Mittella. Batscr.. El. Fung. p. 63. n. 65. Zottiger RußJchueamm; enf örmiger Miftchu:amm; Paddenftuhl. Germ. Agaric des fumiers. Gall.

In agris oleraceis, hortis, fimetis hortorumque ambulacris. Autumno viget.

digitalis. I52.5. * Agraricus pileo femiouato, linido 'canefcente, vertice ferrugineo, Iateribus confertifime friatis, mar- 
margine tenuifime crenulato; lamellis atris; ftipite elongato, albo, valido. BATscr. El. Fung. p. 01. ఐ. 60. Tab. 1. fig. 1. a. b.

Fingerhutformiger Rufschuam. Germ.

In agris fterilioribus tt elatioribus bei Gonnewiz, Schönfeld; porro in pomariis bei Parneck Maio et Iunio 1789 reperi.

1526. Agarieus cefpitofus, pileo ouato, ftriato; lamel-ouatus.

lis defluentibus; fipite cylindraceo, fiftulofo, \&nnulato, longo: annulo fugaci. scop. Carn. Ed I. p. 23. n. 78. et Ed. II. P. 425. n. 1479. GLED. Meth. Fung. p. 123. n, XXIV. var, a. Sciraef. t. 46, $47,216$.

Agaricus Clamaelco. ватвCH. El. Fung. p. 63. ก. 64 .

Euformiger f. hellbläulicher Rußfchteamm. Germ.

In fimetis et ambulacris, in Saliceto bei. Ketfcrias reperi. Autumno.

1527. Agaricas pileo conuexo (vel ouali) campanulato, radians, confertifime ftriato, canefcente, vmbone plano, in-tegro, diftincte circumfcripto et colorato, ftipite elongato, fulcefcente albo. вatsci. El. Fung. p. 61. n. 6I,

Agaricus pileolo in conum acutum faftigiato, pilofo, petiolo in bafi tumido. GLED. Meth. Fung. p. IOS. n. XVI. воEHM. n. 793. SCHAEF. T. 100.

Strahlenformiger Rußjchueamin. Germ.

In pratis, fyluis vmbrolis humidisque, im Rofen. thale, Univerfitatsholze etc. Autumno.

1528. Agaricus ftipitatus, pileo campanulato, cinereo, ftriatus.

ftriato, glabro; lamellis margine crifpis; ftipite fiftulofo, iumson. Angl. Ed 2. p.6r7.

Agaricus ftipitatus, pileo campanulato, ftriato, vertice laeui, petiolo annulato, cylindraceo, fitulofo, in bafin rof̣ratam defínente. GLED. Meth. Fung. p. 89. n. IV. военм. n. 790.

Agaricus fufcens. schaer. Tab. 17,68. 1 Agaricus aqueus. BATsC:x. El. Fung.p. 6r. n. 58 . 
Wafferfarbiger geftrifter. RufSfluzamm; bräunlicher Wafferfchueromm. Germ.

In fimetis fuburbanis, porro ad truncos Salicum corruptos e. g. in Saliceto ad Kietchant; in Rofenthale inter Mufcos Septembr. et Octobri mihi occurrit.

aquofus. 1529. * Agaricus ftipitatus, pileo campanulato, obtufo, fufco-flanefcente; lamellis atro-grifeis; ftipite fiftulofo, grileo, villofo. Hủdson. Angl. Ed. 2. p. 618 .

Agaricus trincornm. SCHAEF. t. 6. Agaricus filcciMeUS. BatsCH. El. Fung. p. 6I. n. $5 \%$.

Walferfarbiger Rufichnvamm. Germ.

In fyluis et hortis ad arborum truncos emortuos frequens. Autumno.

tortus. 1530. * Agaricus pilco connexo-campanulato, lacero, confertifime, frriato-fulcato, fubcarneo; lamellis atris: ftipite elongato, fordide albo, torto, valido. matsch. El. Fung. p. 6r. n. 36. schaef. t. 20 I.

Ruffscheramn mit gevenndenem Stiele. Germ.

In fimetis, ruderibus agrisque nuper ftercoratis enafcitur.

ignorum. I53r. * Agaricus ftipitatus, pileo campanulato, ftriato; lamellis grifeis; ftipite fubulato, albo, WILDEN. Prodr. Berol. n. II 24. SCMAer. t. 66.

Agaricus balanus. ватscr. El. Fung. p. 63. n. 62 . Holz RußJchueamin. Germ.

In lignis putrcfentibus palrim. Autumno.

e. AGARICí PLICATI. Faltenfchwâmme, !Germ.

«. Concolores validiores.

fulphureus, 1532. Agaricus pileo pallido, albo-grifeo, fubfiauente plicis latis plicato, fulcato, conuexo; ftipite elongato, lineari, fulphureo. ватsch. El. Fung. p. 67. ก. 69 .

Agaricus paruus, pileolo hemifplaerico, ftipite cylindraceo, tenui. GLED. Meth. Fung. p. I19. n. 


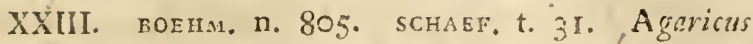
plicatus.

Kraufenfcheramm mit fchuefolgelbein Sticle. Germ.

In fyluis, hortis, paicuis et gramineis, foliis putridis innofeens im Rnfentluale etc. Autumno.

1533. * Agaricus pileo conuexo, conico, plicis latis, aduftus. plicato fulcato, fufco, me:ginem verfus pallente. grifeo; lamellis pallidis atipiteque elongato, lineari fubconcoloribus. вatsch. El. Fung. P. 6\%. п. $\%$. Agaricus brunneus. SCHAEE. t. 32.

Brandfarbiger Kratifcz-1. Faltcnfchetamm. Germ.

Ad arborum truncos deiectos et in arboribus cauis im Rofenthale et in Querceto vor Altrandfä̈dt gregatim crefcit. Autumno.

I534. * Agaricus ftipitatus, pileo campanulato, acuto, conicus. friato, liuido, nitido; lamelis albis, ftipite filtulofo, cinereo, Hudson. Angl. Ed. 2. p. 620.

Agaricus galericulatus. SCHAEF. t. 52. fig. I-6. Kegelförmiger Kraufenfchze'anm. Germ.

Ad Quercmun truncos inter Mulcos in Rofenthale detexi. Octobri.

1535. * Agaricus pileo conico, fubouato, grifeo-Aa-pallácens. vente, albo denfe plicato; lameilis plumbeis, ftipite gracili, fifulofo, longo, albido. ватsсн, El. Fung. p. 69. n. 76. SCHAEE. t. 2 II.

Blaßfarbiger Kranfenfohwanm. Germ.

Ad arborum radices intra Mufcos in fyluis fubur. banis frequens. Vere et Autumno.

I536. * Agaricus pileo conuexo, lateribus plicis latis pilofus. plicato-fulcato, fufco-cinerafcente; lamellis concoloribus, ftipite fliformi, concolore, inferne pilis radicalibus lateralite lannto, вatsci. El. Fung. p. 67. n. 7 T. tab. I. f. 2. a, b.

Kauchficligger Kranfenfchreamn. Germ.

In fyluis vmbrofis ad truncos arborum emortuos earundemque radices. Aeftate et Autumno. 


\section{6}

vmbellife- I537. Agaricus pileo plicato, nembranaceo, lamellis zแs.

bafi latioribus. uinn. Syft. p. 9-6. n. 31 .

Agaricus exiguus, niueus, pileo hemifphaerico, a vertice verfus marginem ftriato; lamelis rarioribus, fipite longiore et tenui. GLED. Meth. Fung. p. 126. n. XXV. var. g. SCHAEF. 309.

Schirmförmiger Kraufenfchwamm. Gern. Agaric ombellifere. Gail.

In deiectis Tiliae, Carpini aliarumque folis femiputridis aliisque recrementis fyluaticis hortenfibusque congeftis gregatim nafcuntur. Autumno.

alliaceus. 5 538. Agaricus pileo conuexo, opaco, fupra fufco, fubtus albo; ftipite fiftulofo, nigro, nudo. JAce. Aufr.t. 82. LiNN. Syft. p. 926, n. 26. SCHAEF. t. 99 .

Agraricus pilco rotundo et integerrimo in vertice alato aut depreffo; lamellis anguftifimis. GLED. Meth. Fung. p. II0. n. XVIII. Бовнм. n. 800.

Agaricus plicatus. nudson. Angl. Ed. 2. p. $62 \mathrm{r}$. n. 43. Agaricns Abietis. Batsch. El. Fung. p. 73. n. 88. tab. III. fig. 10. a-d.

\section{Doonf̧hreamm; Mouceron. Germ.}

In virgultis pafcuis, pomariis, agrorum terminis locisque tenui gramine veftitis, nec non in fyluis ficcioribus, im Oberholze, in der Dïbenfchen Leide. Vere et Autumno.

Fungus efculentus in deliciis habetur. In culinis hic ficcatur fungus et fic viui feruatur per hyemem. inryophyl- I 539 . Agaricus pileo albo-fulphureo, ochraceo ferru-
latus. gineo; ftipite elongato; lamellisque concoloribus.BATSCH. El. Fung. p. 75.'n. 92. SCHAEF. t. 77 .

Nöglcinricehcuder Kraufenjchuamm. Gẹrm.

In fyluis elatioribus et fyluis arenofis, im Bientir rarius. Aeftate.

Fungus efculentus odorem caryophylloram fpirat. BATSCH. 1. C. 


\section{ß. Concolores capillares.}

1540. Agaricus albus, pileo plicato membranaceo, fti- androfnpite nigro. LIN Syf. p. 976. n. 32. ceus.

Agaricus pileo friato, hemifphaerico, paruo; las. meilis paucis anguftifimis; fipite altifimo, capillaceo. Gled. Meth. Fung. p. IOS. n. XV. schaef. t. $23 \%$

Agaricus Pineti. вatsch. El. Fung, p. 73. n. 89. Tab. III. fig. Q.

Fungus pileolo candicante, lamellis paucis, pediculo fufco fplendente. vallz. Parif. p. 69. n. 59. T. XI. f. $2 \mathrm{I}-23$.

Kleiner weißer Lederfchuanm mit fchuearwen har. förmigen Stiel. Germ. Agaric androfacé. Gall.

in pomariis et fyluis ficcioribus ad ligna putrefcentia et intra Mufcos varios im Univerfitâtsholze, in Querceto vor Altrandfädt etc. copiofe. Autumno.

J541. * Agaricus pileo albo, fubfriato, campanifor- Thichopus. mi: lanellis cum procero fetaceo, caudato fipite pariter albis. scop. Carn. Ed. II. n. 1493. JAHN. ก. 27 .

Agaricus exiguus albus, pileo hemifphaerico, ftiv pite fetaceo longifimo, GLED. Meth Fung. p. 120. D. 23. var. b.

In fyluis pratenfibus, in Rofenthale, Univerfitätsholze, intra Mufcos Frondofos varios, vtpote intra Hypra et Nuia; porro in locis vmbrofis alis paffim enafcitur. Autumno.

\section{$\gamma$. Difcolores.}

I542 * Agaricus pileo conuexo, vmbonsto, albo, pal- pratenfis, lide ochraceo grifeoque; ftipite elongato, fubfulcato, concolore, pallidiore; lamellis grifeo-albis. Ratsch. El. Fung. p. 7\%. ก. 100. Tab. If. f. 5 . SCHAEF. t. 220.

Blaffer glockenförniger Lederfchzeamm, Germ. 
In locis gramine veftis, humidis et pratis, im Roferchale paffim. Aug. - Otobr.

fragilis. 1543. Agaricus pileo conico - conueto, vmbilicato, ftriato, glaberrimo, ochracen ferrugineo, fuluente, ftipite lineari, elongato, gracili arcunto, concolore; lamellis pallide fulphureis. гatsch. El. Fúng. p. 74. n. 0,0 .

Agnricus fragilis pileo conuexo, vifcido, pellucido lamellisque luteis, 1tipite nudo. LINN. Syft. p. 976. n. 28. SCHAEF. t. 230 .

Fungus pediculo crocen, fplendoris participe. vaill. Parif. p. 6\%9. n. 58. T. XI. f. I6-I8.

Zerbrechlicher Klciner Lederfohneamm. Germ. Agagaric fragile. Gail.

Ad truncos arborurn emortuos et ligna putrefcentia frequens. Autumno.

In Ruflia hic Fungus editur.

marginatus. I544. * Agaricus pileo ochraceo - fubferrugineo, gilabro mng gine anguftifimo extimo vitra laminas prominulo membranaceo; Atipite fibrillofo, liuidoochraceo, bafi niueo, fuperne annulo fugaci cinto, laminis ochraceo - ferrugineis. ватsch. Cont. II. p. 65 t. XXXVir. f. $20 \%$. c. f.

Zürtoerändeter Lederfchreamm. Germ. bant.
In Sylua Academica menfe Septemb. copiofe vige-

polymor- I545. * Agaricus pileo conico-depreffo, colore mutaphus. bili: fipite varie elongsto, fulco, inferne obfcuriore, fuperne annulo fugaci fubgracili inftrueto, lamellis fufco - ferrugineis.

Agaricus mutabilis." ватsch. Cont II. p. 69. t. XXX̃VIII. f. 208 .

Ververandelnder Lederfcheramm. Germ.

In fyluis humidis et denfioribus, in Sylua Academica et Quercero vor Altrandfátat Septemb. legi.

chryfodon. 1546. * Agaricus albus, pileo margine crenato-dentato et lutefcente, ftipice fuperne infra lamollas lu- 
teo-pruinato, laminis margine fulplureo pruinatis. BATSCF, Cont. II. p. 79. tab. XXXVIII. f. 212 ,

Goldanlanigier Lederfcinuamm. Germ.

In fyluis humidioribus in Rofenthale et $Z$ fchocherfchen Holze Otouris initio nonnulla exemplaria reperi.

547. * Agaricus pileo albo-glaucefente, conuexo, cacfus. oblongo, lamellis fubramofis; ftipite concolare, fubfifulofo. wilden. Prodr. Berol. n. 1113.

Agaricus caefizs. Batsch. Cont. I. P. 113. tab. XVIII. fig. 94 .

Blafsblïulicher zarter Lederfcheramn.

In pinetis, e. $g$. in Lindenthal in foliis Pinus fyluefris putrefactis. Viget Autumni initio.

1548. * Agaricus pileo conico-explanato, plicato-vn-faccharinus. dulato, niueo; laminis paruis concoloribus; ftipite fubulato, albo rubente. вAтsсн. Cont. I. p. 93 . tab. XVIII, f. 83 .

Weißser fchirmförmiger Zart chreamm. Ge:m.

In foliis deicktis, putrelcentibus, in Univerfiätsholze pauca reperi fpecimina. - Septemb.

1549. Agaricus pileo campanulato, friato, pellucido; campanulalamellis adfcendentibus: fipite nudo. LINN. Sy.t. ش. p. 976. ก. 25. Вовнм. ก. 8Iо.

Fungus multiplex obtufe conicus, colore grifeo marino. vaILl. Parif. p. : I. t. Xll. f. I. 2.

Glockenförniger Lederfcheamm. Germ. Agaric cloche. Gall.

In pratis et locis gramine veftitis frequens. Vere.

1550. * Agaricus carneus, leuiter in ochraceum vergens, circumfepileo ante marginem fipitisque medio faepe floccis furfuraceis cineo, laminis ferrugineis. Barsci. Cont. I. p. I 19. n. 98. tab. XIX. fig. 98.

Röthlich flucriger Lederfchweamm. Germ.

In locis fyluaticis, paffim in Rofcntialc, in Querceto vor Altrasdfiait. Autumno. 
enndidus. I55I. * Agaricus albus, fericeo-nitens, vmbonato; fipite validiufcula, foliảo, bafi bulbofo, pileum fuftentante; lamellis lividis, pileo propriis brunnefcentibus. matsch. Cont. I. p. 133. t. XX. f. 106. a - c.

Weifknolliger Lederfchwanm. Germ.

In Oberhole paffirn, in Rofenthalc autem Cel. Batschrvs nuper detexi?.

carbons- 1552. * Agarisus pileo conico-fubouato, acuminato, rius, glabro, liuido, lamellis atris; Itipite lineari, elongato, gracili, oblcuro. вaтsch. El. Fung. p. 69. 11. $7 \pi$.

Var. $\beta$. Agaricus pilco flauente. Schasf, t. 202.

\%. Agaricus pileo ochraceo-fufcefcente, tipite fufco SCHAEF. t. 210.

Kohlenfarbizar Trichier/chueamis mit blaßggelben oder ocherfarbig brainem Huthe und braunem Stiele. Germ.

In fyluis vmbrofis, im Unizerfitätsholze aliisque pafim. Autumino.

f:_AGARICI VNCTVOSI. Fetifchwämme. Germ.

hyacnthus. 1553. * Agarictus pileo conico, vmbonato, luteo; at: rantio (vel fulphureo); ftipite elongato, valido lineari, recto, lamellisque pallidioribus. Batsci. El. Fung. p 8I, tab. VII. f. 28 .

Hyacinthforbiger Fettfhreamm. Germ.

-In fyluis denfioribus, im Univcrfiratsholze paffim. Autumino.

sarneolus. I554. * Agaricus pileo ferrugineo, fuluo, margine luteo; fipite elongato, lineari, valido, Juteo-croceo, lamellis cinereis, pallidirme fufcefcentibus. 3Aт3CH. Ël. Fung. p. 83. n. 1 I6. SCHAEF, t. 49. Karneolfarbiger Fettfihreamm. Germ.

In nemoribus humidioribus im Rofenthale, Zfchoa sherfichn Holise folitarie vel cefpitofe enafeuntur. 
I555. * Agaricus pileo luteo-aurantio, conuexo; fti-vitellinus.

pite lineari, vilido, breuiufuculo, incraflato, concolore, fupra voluam reflexo-patenten albo; lamellis fulphueis. Eatsch. El. Fung. p. 83. n. II7. Agaricus tuberculofus. SCuAEF. t. 79 .

Orangefarbiger Fetschianm. Germ.

In fyluis denfioribus, im Rofenthale, pafim. Autumno,

I556. *Agaricus luteus, pileo conuexo, lamellis con-fimulans, gefto; ftipite nudo, cylindraceo, plenc. scor. Carn. p. 19. n. 25, var. a.

Agaricus ex vna bafi multiplex, pileolo plano, fipite anuulato, cylindraceo. GLED. Meth. Fung. p. 13 I, n. XXVIII.

Agaricus finulans. BAtsch. El. Fung. p. 85. n. I22. SCHAEF. t. 9 .

Rauchficligter Fcttfhuamm mit glattem Huthe. Germ.

Ad truncos Tiliarum, Carpinorum, Quercunmque eic. im Rofentizale et in aliis fuburbanis fyluis, paffin.

I5.5. * Agaricus pileo hemifphaerico, fipiteque fub- coccineus.

fiftulofo coccineo, lamellis aurantiacis. LINN. Sylt. p. 975. n. 2I. JACQ. Mifc. Vol. II. p. I06. SCHAEF。

t. 302 .

Hochrother und gelber Fettfchzanm. Germ.

In Sylua Academica rarius viget. Autumno.

1558. * Agaricus pileo conuexo, luteo, Iamellis vire- falciculariso fcentibus, ftipite flauso. Iídsow. Angl. Ed. II. p. 6 I $5 .$, n. 20 .

Agaricus Fenenfis pileo conuexo-conico, luteo, medio ferrugineo, ftipite elongato, lineari, valido, concolore, fubfquamuloro; volua puluerulenta, Ariata, adnata, brunnea; lamellis oliuaceis. EATSCH. El. Fung. p. 83. n. I13. t. VII. f. 29.

Bündelformiger Fettfchram.' Germ.

Ad arborum praecipue Salicum truncos emortuos copiole et ad terram im Rofenthale et fub liminibus horto. 
hortorum emergens, bei Parmeck nuperrime repieri. Autumio.

Eammans. 1559." Agaricas pileo ferrugineo, maculis pilofis, fquamofo-flammiformibus in fafcias plures appofitis et feriatis fufcis, ftipite valido, lineari, pallido, concolore, furfuraceo - fquarrofo; lanellis fufcis vel brunneis. BATSCH. El. Fung. p. 87. n. 124. t. VII. f. 3०. SCHAEF. t. 209 .

Gefammitir Fettfchwanm. Germ.

In fyluis ad ligna putrefcentia, in Univerfitüts. holze et Rofentlale paffim. Autumno.

fquarofus. 1560. * Agaricus pileo vmbonato lutefcente, fquamofo; fquamis fufcis fquarrofis; ftipite intra annulum fquarrofo, lanteilis pallidis. WildEN. Prodr. Berol.n. I 100. Agaricus fquarrofus. Batscis. El. Fung. p. 86. n. 123. t. VIII. f. 31. - Agaricus floccojus. schaEF. t. 6 . 80 .

Rauchacuppigter Fettchreamm. Germ.

'In fyluis denfioribus, im Univerfitïtsholze pafin, po:ro ad Salicun truncos auf dem Wege nach Schönfeld linker Iland juxta Pilcinam nuperrime inueni. sutumno.

Sphinx. 156r. * Agaricus pileo pallido, medio lutefcente-ferrugineo; fipite opaco, nigro-fufco, torto, cauo lamellis albidis. вAтSCH. Cont. I. p. 145. tab. XXII. f. 112 .

Schrearzftieliger Fettfchreamm. Germ.

In fyluis humidis im Rofenthale et Querceto vor Altrandft.dt pafim mihi occurrit. Septemb.

auriuellus. 1562. * Agaricus ficcus, pileo luteo-ferrugineo, lana mollifima in flammulas denfe inbricatas digefta obducto; ftipite pallide fulphureo: annulo membranaceo ferrugineo; lamellis pallidis, ferrugineo-fufcis. Batscin. Cont. I. p. I 53. tab. XXII. f. I15.

Goldgefamnter Fetticheramm. Germ. 
In locis nemorofis im Rofenthale ante paucos annos detexit Ce? Batscins, egro quoque ibidem revili. A utumno.

\section{g. AGARICI OBLIQVI. Schieffhreamme. Gerrn.}

I563. * Agaricus pileo ferrugineo - fufco, fubfcabro, atro-toconuexo, ftipite breui, crafio, cylindraceo, fub- mentofus. curuato, fufco-atro, tomento denio fcabro; laminis pallide ochraceis, diftincte adnatis. вAтscr. El. Fung. p. 8y. n. I 29. tab. VIII. f. 32 .

Schwerareolligter. Schieffchreamm. Germ.

In fyluis denfioribus ad radices truncosque arborum. Autunino.

1564. * Agaricus pileo conuexo, fragili medio tantum caducus. vmbilicato, cchraceo, margine albente irregulari; ftipite gracili breui vna cum lamellis pallidiore. ватsch. Cont. II. p. 87. tab. XXXIX. f. 2 I5.

Var. $\alpha$. Agaricus pileo margine aequali. Barscr. 1. c. f. 215. a.

ß. Agaricus ftipite abbreuiato. Id. ib. f. 2 I $5, \varepsilon$. Zerbrechlicher 1 . hinfälliger Schieffchwamm. Germ. In fyluis acsrofis im Oberholze, porro quoque in Sylua Academica nuperrime obferuaui. Autumno viget.

1565. * Agaricus pileo craffo puluinato, mergine et obefus, fuperficie inaequali, ochraceo albo, confuente cunı ftipite craffo, breui, carneo - niueo; lamellis pallide ochraceis. Batsch. Cont. II. p. 8\%. tab. XXXIX, f. 2r6. a. b.

Dickfetter Schieffchwamm. Germ.

In locis elatioribus im Bieniz, fed rarius, deprehendi.

1566. * Agaricus pileo lobato fuluello lutidoue; Ati- mefenteri- pite breui valido lamellisque albis. ватsch. El. Fung. cus.

p. 91. n. I32. SCHAEF. t. 43.44.

Gekröfeförmiger Schiefjcieamm. Germ. 
In fyluis humidis, in Rofenthale, Zfchocherifchest Holze; in dumetisibei-Pomfon quoque obuiam iuit. Autumno.

h. AGARICI VENOSI. Aderfchwömme. Germ.

pfeudo-1567. * Agaricas pileo lutefcente, unctuofo, fubcarvnetuofus, neo, conuexo; ftipite valido fubelongato, fuperne - in pileum incrafiato et lamellofo, vna cum lainellis pileo concolore. BATSCH. El. Fung: p. 93. n. $137^{\circ}$ tab. IX. fig: 37 .

Fettiger Aderfchreamm. Germ.

In locis fyluaticis, in Sylua Academica, paffim. Augufto in Olobrem vfque.

Cantharel-1563. Agaricus pileo infundibuliformi, luteo, lamellis lus. venofis, ramofis decurientibus. WILdÉN. Prodr. Berol. n. II I8. Batsch. El. Fung. p. 95. n. 138. tab. IX. fig. 34 .

Agaricus cantharellus fipitatus, lamellis ramofis decurrentibus. IInN. Syft. p; 974. n. 1. Flor. Dan. t. 263. SCH.AEF, t. 82. (fig. male pieta.)

Agaricús luteus, pileo turbinato, in margine an. gulofo, laciniato et varie contorto; lamellis crafis, venofis, ramofis et crifpis. Gled. Meth. Fung. p. I03. n. XII. вовнм. n. 795.

Seeme-leire fungi. STERB. p. 60. t. 4. B. Ausgebreiteter Aderfchwamm; Pfifferling; gelber Pffferling; Eyerfchwamm; Auguffchuamm. Germ. Chantarelle Agaric. Angl. Agaric Chantcrelle. Gall.

In ericetis et fyluis elatioribus, 'im Bieniz. curca págos Pomfen, Steinberg, Grïten aliisque, praepri. mis poft pluuias crebiores. Autumno.

Fungus efculentus, tamen rite praeparandus.

i. AGARICI DIMIDIATI. Halbjchwämme: Germ.

Queicinus, 1569.'Agaricus pileo fuberofo-lignofo, ochraceo-ca* nefcente, pallido, lamellis concoloribus, anaftomofantibus, crebris flexuo!s. вaxsch, El, Fung. p.95. n. 142, Agarie 
Agaricus querínats acaulis, lamellis labyrinthiformibus. LiNN. Syft, p. 976. n. 36 .

Agraricus coriaceus, durus, fefilis, tequamofus et multiplex, lamellis ramofis finuofis et fibi inuicem implexis. GLED. Meth. Fung. p. 134. n. XXX. BOتIMM. n. 8 r.4.

IViflicher Hallofcherannm mit gefchlïngelten Blättchen. Germ. Agaric, ou Champignon de chîne. Gall.

In arborum, praecipue Quercum aliarumque truncis emortuis patridisque frequens. Omni tere tempore.

1500. * Agaricus acaulis, coriaceus, femielliptoidicus, fepiarius. fupra ex flou fufco-nigrefcens, villofus, fafcia marginali albido-flauefecnte; fubtus vna cum lameilis albido - flauens. JACQ. Collect. Vol. I. p. 339. n. CXXIV.

Agaricus flabelliformis, villofus, pileo margine fornicato. GLED. Meth. Fung. p. 133. n. XXIX.

. Agaricus Betulinus. aldion, Flor. Pedemont. T. I. p. 350 . ก. 2742 .

Zain Halbjchzeamm. Germ.

In fyluis denfis fubudisque ad Vlmorzm, Populae, Tremulae aliarumque arborum truncos cmortucs et trabes antiquas. Hyeme et Vere.

1571. Agaricus acaulis, coriaceus, femielliptoidicus, Bctulinus. fupra alhus et villofus; fubtus ex ochraceo-croceus, lamellis reticulatis. JACQ. Collect. Vol. I. p. 338. n. CXX I.

Agaricus betulinus acaulis, villofus, margine ob. tufo, lamellis ramolis anaftomofantibus. LINN. Syft. p. 9-6. n. 37. Flor. Danc t. 7-6. n. 1.

Agaricus feffilis, fquamofus, lobatus et villofus; lamellis diffectis. GLED. Meth. Fung. p. 1+4i n. XXXI. Gall.

Birken Halbchwann. Germ. Agaric de Bouleau.

In fyluis pracipue ad Betularzon adiruminge truncos, in Sylua Academica etiam ing Bienta occurrit etc. Vere et Autumno. 
Habellifú-1572. Agaricus fubacaulis, membranaceo-coriaccus mis. fitpra albus, forniaceo-leprofus, fubtus lameilisquẹ obfolete fauo-argillaceis; fipitulo breui, 1aterali, horizonrali, manubriformi. JAcQ. Collect. Vol. I.

I p. 341.n. CXXY?

Agaricus fiabelliformis, fquamofus, multiplex et candidus, lamelis paucis; petiolo breui, candidoAauefcente. GLeg. Meth. Fung. p. 133. n. XXIX. var, a. SCHAEF. t. $20 \%$.

WVedelförmiger Halbjchueamm. Germ.

Ad emortuos arborum truncos, in Rofenthale et in Sylua Acadenica frequenter. Autumno in Ver vfque fubfequens.

alneus. 1573. Agaricis acaulis. lamellis bifidis puluerulentis. LINN. Syft. p. $77 \%$ n. 38 . WeEg. Obf. 35 . t. 2 . f 6 . Agaricus ferfilis, fquamofus, lobatus et villofus lamellis diffeets. Glen., Meth. Fung. p. I34. n. XXXI. BOEнM. n. 815 . SCHAEF. t. 246.

Weißlichter Halbfcheramm wit zavcithciligen Blättchen. Ferm. Agaric de l'Aune. Gall.

In arborum truncis et lingnis variis emortuis, im Rofenthale. Vere et Autumno.

- chraceus. 1574. Agaricus acaulis ficbelliformis, fupra puluinatus. ochraceus, lamellis albidis margine cinerafcentibus. LINN. Syft. p. 97\% •n. 39. JACQ Mifc. Vol. Il. p. 110. t. 16. f. 2 .

Agaricum cefpitofum, fuluum, Cochlearis $f$. fpatulae forma, hirfutum, ,MICA. GEn. 123. n. 20.t. 65. f. 5. вОЕнм. n. 817. fub Amanita.

Germ.

Spatelformiger und ocherfalbiger Halbfchreamm.

In arborum emortuarum truncis, in Rofentiale alibique paffin. Autumno.

. aneicens. 1575. * Agaricus pileo membransceo, canefcente : ochraceo, pallico-albente, lamellis pallide ochraceis. вatsch. El. Fung, p. 95. n. 139. tab. IX. f. 38 . SCHAEF. t. 213 . A garicus mollis.

Blaßgrịiulichè Hallogcheamm. Germ. 
In truncis Salicum emortuis ad Ketchan I789 reperi.

1576. Agraricus pileo dimidiato, femiorbiculato, fupra villofo-cavillofo-canef́cente, margine infexo, flipitato: la- nefcens. mellis flabslliformibus, multifidis, tranfuerfe pilofis, ex glauco-fufcefeentibus.

Agaricus multifidus dinidiato, fupra canefcentealbus et tomentolo- hirtus; laminis glaucis fubfulvellis, trantuerfe pilofis, fiabelliformiter diuiis, fungum totum conftituentibus, tomento dicto connexis, maceratione fecedentibus, e centro folum exeuntibus, Bàrsci. Cont. l. p. 173. t. XXiV. f. 126 .

Fnngus paruus, lamellatus, punftuli forma, alno adnafcens. vailz. Parif. p. - 0 . n. 63. t. 10. f. 7 . Germ.

Weifrottigter f. fächerförmiger Hallofcheeannm.

In cortice Tiliae Oetobris fine 1789 plura legi fpecinina in horto Löhriano; porro in Rojenthale.

1577. * Agaricus acaulis albidus villofus, lamellis depluens. fufcefcentibus interruptis. waLDE. Prodr. Berol.

n. IOY3.

Agaricus depluens pileo dimidiato, cano fericeo: lamellis fubcarneis, fufco-rubeliis, latls, laxis, quadruplici ordine digeftis. EaTscri. Cont. I. p. 16\%. t. XXIV. f. 122 .

Diinnhüutiger Halbfchevamm. Germ.

In arborum truncis im Rofenthale pafim. Autumno.

477. BOLETVS. L. G. I326. GLED. G. V. BATSCH. G. II. Löcherf́chwamm. Germ.

a. BOLETI SVILLI. Pilze. Germ.

$x_{578}$. Boletus pileo conuexo (vel vndato) fuboblique pel- perennis. tato fufco vel ochraceo, ftipite breui cylindrico, poris ochraceo-albis. вatsCr, El. Fung. p, 103. n. I3. et Cont. I. p. I8I. t, XXV. f. I29. 
Boletus percmins fipitatus perennis, pileo vtrind que planiufculo. LINN. Syf. p. 977. n. I\%.

Boletus tubulis connexis pileo orbiculari et plano, fuperne lineis concentricis ditincto, ceniro excauato; Aipite breui tenci: GLED. Meth. Fung. p. 6\% n. 2. вОEHN1. n. 83O. SCHAEF, t. I25.

Der Pusktfinenanm mit heftändigen Stiele; Heidepilz. Germ. Bulet virace. Gall.

In fabulofis pinaftetis im Oberholze ad arborun radices et vias cauas pallim.

hutcus. 1579. Boletus pileo conuexo vifcido, fufco, poris rotundatis flanis; ftipite cylindrico annulato, WILDEN. Prodr. Berol. 11. i I +3 .

Boletus luteus ftipitatus, pileo puluinato fubuicido, poris rotundatis conuexis flauifimis; fipite albido. LINN. Sylt, p. 978 . n. 16. SCHAEF. t. 114 .

Boletzis pilco hemifphaerico, fuluo et plendente, tubulis anguftifninis, citrinis petiolo gracili concolore. GLED. Meth. Fung. p. 64. n. I. var. c.

Gelber Punktfhreamm; nuh- I Fudenpilz, Kie. ferpilz, Schreeinepilz. Germ. Bolet jaune. Gall.

In fyluis denfioribus, in Sylua Acadenica, im Obcrhol:e aliisque frequens. Autumno.

- In Borufia Rufraque hic fungus frequentius comedi folet, quam in aliis regionibus.

vifcidus. I580. Boletus ftipiratus pileo puluinato, vifcido, poris teretibus conuexis, immerfis, diftinctis, ftipite la.' cero. LINN. Syst. p. $97 \%$. ก. 15.

Boletus pileolo hemifphaerico, fuperne vifcido et fuluo, inferne luteo, petiolo candido-flauefcente, punctis et lituris nigricantibus diftincto. GLED. Meth. Fung. p. 64 . II. var. d. военм. ก. 82 I.

Klebrigcr Punktfhwannn; ein gutor Schueinepilz. Germ. Bolet vifqueux. Gall.

In fyluis pinaftretis, iw Oberholize etc. frequens. Autumno.

Fungum efculentum $R u f j i$ quaerunt. 
15S1. Boletus pileo conuexo, puluinato, glabro, po-bouinus. ris angulatis, itipite attenuato. WILDEN. Prodr. Berol. n. $11+4$.

Bolctus bouinus fipitatus, pileo conuexo, puluirato, 'marginato, poris compofitis, acutis: porulis anguftatis breuioribus. LINN. Syft p.978. n. I 7 .

Boletus pileolo hemifphaerico, tubulis angulatis, petiolo ventricofo, GLED. Meth. Fung. p. 63. n. I. SCHAEF. t. $103 \cdot 10 \%$.

Ka, anienbrauner f. rother Pilz; Kulupilz, Grafepilz, . Sommerpilz. Germ. Bolet pied-de-boenf, ou Ruchin des bocufs. Gall.

In fyluis, in Univerfitâts - Oberholze etc. frequenter occurrit. Autumno.

Fungus efculentus, varietatibus ludit pluribus.

I 582. * Boletus ftipitatus, pileo conuexo glabro, poris crafipes. fubangulatis, ftipite inedio crafínore reticulato.

Bolet:s pileolo hemifphaerico, defuper obfcuro, fubtus e viridi-figuefcente petiolo, ventricofo, obfcuro, bafi in mucronem definente. CLED. Meth. Fung. p. 63. n. I. var. a. SCHAEF. t. 105, 107, 103. Dickftieliger Pilz, et in foro fub nomine Brat. pilze proftant.

In fyluis elatioribus et arenofis im Bieniz, Ober. holze aliisque tyluis ficcioribus.

Fungus efculentus.

1583. Boletus pileo fubhemifphaerico, mediocri, for- bulbofus. dide fufco rubente, glabro, poris angulatis, maioribus, flauefcentibus; ftipite bulbofo, łpbrotundo, craffifino, flauefcente, bafi appendiculato, radicato.

Boletus pileo latifimo, hernilphaerico, defuper ferrugineo rubente, inferne cuin crafio petiobo fubflauo. GLE. Meth. Fung. p. 64. n. I. var.b. вовнм, n. 820. SCHAEF, t. 134,335 .

Ein Punktfhwomm mit dem knolligen Stiele: et a plebeculis vulgo Steimpilze vocantur.

In fyluis ericetis et pafcuis frequens e. $\mathrm{g}$. in Sylua Acadenica alibique Augufto in Septembrem vique.

Fungus efculentus. 


\section{CLASIS XX.}

furpectis. 15 is4: Bolezus pileo magno, craffo, hemifphaerico, fuperius fpadicco fuluefcente, inferius luteo, ftipite crafio e luteo-rubente. GlED. Meth. Fung. p. 66. n. I. var. i. 'BOEHM. n. $\$ 22$;

- Fungus fuillus, perniciofus vulgaris. Caefalp. 617 . Verdanchtiger Punkt fcheamm; Plebeculis appellatur . giftiger Schweizepilz.

In ericetis, fyluis faepius indicatis frequenter obferuatur. Autumno. fubtomen- i5 55 . Boletus pileo flavo, fubtomentofo, poris fuban-
tofus.

gulatis, difformibus, fuluis, planis, ftipite flauo. Iinn. Syit. p. 978, n. 19.

Boletus exiguus coriaceus, fuluus, tubulis mintutifimis, albidis connexis, pilcolo orbiculari, plano, in margine fufco et pilofo; centro depreffo. GLED. Meth. Fung. p. 73 . 11. V. var. a. Gall.

Volligter Punk jchwamm. Germ. Bolet cotonneux.

Ad Vlmorum, Carpinnrim, Almoran aliarumque arborum truncos fenio confeztos aliaque ramenta neglecta, in fyluis Lipfiae fuburbanis frequenter occurrit. Hyeme et Vere.

\section{BOLETI FAVOGINEI, Zellenjchrë̈mme. Germ.}

fubfquámo. 1586. Boletus ftipitatus, niueus: pilei puluinoti cutifus. - - cula tenerrima, breui, squofe fubfufcefcente inque fifumulas difcedente; poris difformibus oblongofublexuofo, JAcQ. Collect. Vol. I. p. 342. n. CXXVI.

Boletus fubquamufus deformis, dilatatus, carneo fuberofus, fubpetiolatus, ochraceus, tergo glabro fubuntuofo, fufcefcente, maculis obfcuris faepe reuolutis fquamofo; tubis latis breuibus, margine acutis, pallidioribus. BATsch. El. Fung. p. $97 \cdot \mathrm{n} \cdot 3$. tab. X. f. 41. - Boletus Fuglaudis: sCHars. t. 110 , 102.

Boletus coriaceus, fquamnfus, fefilis et multiplex, lobis varie diuifis et expanfis, lobulis tenuiffmis; 
connexis angulis. GLED. Meth. Fiung. p. \%o. n. III. BOEHM. n, $8 z+$ et $82 \%$.

Halbfchuppigter Zellenfchreamm, Ge:m, Bolet écail. lean: Goll.

Ad truncos arborum emortuos praecipue in $F *$ glande re $₹$ ia et Salicibus vor cien IVindmialien Thunc a. d. XXI. Augufti 1788 obforuani.

Fungus fufpectus odorem hircinum fpargens.

1587. Boletus coriaceus, poris tenuifimis, ftipite late- Aabeliforrali LEYS. Hal. Fd. 1. n. 1093. mis.

Boletus Aabcilum referens durus, rufo-flauus; in. ferne albus, fipite laterali breuiflimo. GLED. Meth. Fung. p. 8o. n. XII. var. d.

\section{Wedelformiger Zellonfchwanim. Germ.}

Ad Carpinormin; Alnorum, Betmiann Salicum. que truncos in fyluis Lipfienfibus fuburbanis. Au. tumno.

Olf. Stipes valde ludit; mox enim praelongum, mox breuifimum vidi.

I598. Boletus imbricatus, fquamofus, fubftipitatus, intybacens. tubulis minutifmis connexis, lobis fimbriatis ramofo foliaceis. GLED. Meth. Fung. p. 75. ni IX. BOEHM. R. S28. SCHAEF. T. II I, I $27 \cdot$ I 29.

Acfigger Zillenfchreamm; Eichibacafe i Haaferiährlein; Endivinfchuanm; Feisker; Schneepil. Germ.

In fyluis denfioribus et caeduis ad Quercus annofas im Rofenthale et ad alias orbores im Gomereirzer, Gros - Zfchocherfchen - und im Uuiverfitätsholze etc. Autumno.

1589. * Boletus pileo conuexo, peltato, orbiculato, lacteus fufco, fufcefcente; ftipite lineari, valido, diffulo porisque linearibus çatenulatis niueis. B.ATsCH. El. Fung. p. 103 . n. 12. tab. X. fig. 42.

Var. R. Bolutis folitarius, Ripite breui, lineari, B.ATsCH, 1. c. f. 42 .

$\gamma$. Boletus ramofus, fipite elongato, lineari. SCIIAEF. t. $265,266$.

Gcftreifter Punktfinwamm nit weiffen Röhrea. Germ. R. 4 
In fyluis denfioribus ad arbortm truncos, in Sylua Academica pallim obuiam iuit. Autumno.

c. BOLETI RETEPOREI. Halle f. ficllofe Punktfchwömme. Germ.

fomenta- 1590. Boletus acaulis, puluinatus inaequalis obtufus, rius. poris teretihus aequalibus, glaucis. LINN. Sylt. p. 977. n. 4 .

Feuerfangender Punktfchwanm. Germ. Bolet Amadou. Gall.

In arborum truncis im Rofenthale, Univerfitits und Oberholze, Bieniz etc. Omni fere tempore.

igniarius. I59I. Boletus acaulis, puluinatus, laeuis, poris tenuiffimis. LINN. Syft. p. 977 . n. 5 .

Boletus fuhrotundus, petiolo horizontali breuifimo, tubulis tubtilifimis. GLED. Meth. Fung, 2. 78. n. XII.

- вогін, n. 826. schaze. t. 137.138.

Pharm. Bolctus igniarius 1". Agaricus praeparatus.

Gcwöhnlicher Fener - Zunderfchueann. Germ. Aga. ric de chine, ou Bolct ongle de Cheual. Gall.

In ficcioribus fyluis et ericetis ad Betularum et Alnormm, Qucrcuum, Salicum, Fagorumque truncos in Gommewitzer, Gunndorfer Holze; in. Alncto ad Schönfeld, in der Dübenjichen Heide et circa pluri-w mos pagos e. g. Gohlıs, Störnthal, Belgershayn, Pomfen, Steinberg aliosque frequens. Perfiftens.

fubsrofus. 1592. * Boletus acaulis puluinatus, lacuis, poris aclitis, difformibus. LINN. Syft. p.977. П. 8. SCHAEF. t. 136 .

Korkartiger Punktfchwamm. Germ. Bolet liege Gall. In hortis, pomariis et fyluis ad arbores fruticesque et ligna putrefcentia Perfiftens.

Lipfienfis. I593. * Boletis pileo incraffato, fuberofo, dorfo incrementis conuexis et tuberculis gradato, glabro, margine decliui, fafciato. Batsch. Cont. 1. p. 183.

t. XXV. f. I 30. a. b.

Der hökcrigtè zähe Punktfchzeqmm. Germ, 
Cel. Batschivs bunc fungum Septenbris initio 1783 detexit isi Rofenthal, arborum truncis adna- , tuin, vbi quoque hune reuili in magna copia.

1594. Boletus acaulis fafciis difcoloribus, poris albis, verficolor. LINN. Syft. p. $977 \cdot$ ก. 8.

Boletus feffilis, fuperne conuexus, circulis concentricis varians, tubulis connexis, tenuifimis, candidis. GLED. Meth. Fung.p. 68.n. Il. var. b. EOEH. 13. 830 . var. SCHAEF. t. $26 \%, 268$.

Boletus verficolor pileo dilatato, lignofo fuberofo absque nitore, fubtomentofo, falciato; poris albis. BaтsCh. El. Fung. 107. ก. 20.

Streifiger Punktfchueanm mit verfchiedener Farbe. Germ. Bolet azuré. Gall.

In hortis, pomariis et fyluis ad truncos arborum e. g. Ceraforum, Salicim etc. emortuos fruticesque copiofe. Perfiftens.

Color huius fungi valde ludit.

1595. Boletus acaulis, totus albus, fuperne laeuis, po. fuaucolens, ris inaequalibus. WrLden. Prodr. Berol. n. I I39.

Boletus fuaueolens acaulis, fernielliptoidicus, niveus; fupra conuexus, byfino villofus, fubtus tubulofoporofus, poris rotundis anguftatisque, Anifum redolens, falicinus. Jaco. Collect. Vol. IT. p. 14?. n. CLVIII.

Bolezus fuaneolens acaulis, fuperne laevis, falicinus. LiNn. Syft. p. 978. n. 9. SCHAeF. t. 17\%. (male) ensuin. f. $1-4$ (optima.)

Pharm. Fungus Salicis.

Wohlriechender Punktfehreamm; Weidenfchueanun.

\section{Germ.}

In arborum maxime Salicun praeprimis fragilis, vitellinae, amygdalinae etc. truncis emortuis, e. g. ad earum truncos deiectos im Rofenthale plurima legi fpecimina. Viget Autumno et Vere.

Fungus odorem tpargit anifatum fuanifimumque; dehinc inquit $b$. LINN adolefentes hunc inuentum folliciti feruant in marfupio ante pubem pendulo vt gratiorem odorem fpirantes nymphis fuis piacent, o Ridicula venus tibi quąe in exteris regionibus ver:s

$$
\text { Rr } 5
$$

Caf- 


\section{4}

Caffer, Chocolata, conditis et faccharatis, vinis et bellariis, gemmis et margaritis, auro et argento, fcrico et cofmetico, faltationibus et conuenticulis, mufica et comoedis, tibi tufficit hic folus exfuccus fun. gus. In phthifi, morbis fpamodicis hic fungus nuper landatus eít ab xNsin. Difert. de Boleto fuaucolente. Erlang. 734 .

Meculla pa- I596. * Boletus cruftaceus, albus, effufus, difformis. nis.

LINN. Syft. p. 977. n. II. JACQ Mifc. Vol. I. p. I4I.

t. 11 .

Brodkrulumähnlicher Blätterjcluwanm. Germ.

In fyluis dentioribus humidisque e. g. im Rofenthale, Sylua Acadenizica ad arborum truncos palfim.

hepaticus. $159 \%$. Boletns acaulis conuexus, fubulatus, rufus, laevis; poris teretibus, fauis. Hudson. Angl. Ed. I. p. 625. n. 5. Boletns fanguincus. SCH.AeF. t. $116-120$.

Boletus corpore feffili latifino; fiperius lobato; inferitus gibbofo, tubulis agrregatis. GLED. Meth. Fung. p. 77 . n. X. вовті. n. 823.

Leberartiger Punktfcheramm; rothe Hirfchunnge; Blut flintamo Germ.

In fyluis agris Lipfienfibus, im Rofenthale, hinter Leatfcls et Lindenau etc. ad Carpinorum Quercuumque truncos. Autumno.

Fungus efculentutus.

coriaccus. 1508. Bolctis acaulis, coriaceus, conuexus, lobatus, fuluus, laeuis; poris tenuifimis. menson. Angl. Ed. I!. p. 625. n. 4 .

Bolctus coriaceus fquamofus, feffilis et multiplex, lobis varie diuifis et exponfis, tubulis tenuifimis, connexis ançuloirque, Grid. Meth. Fung. p. 70 . ת. III. BOEHM, ก. 829. SCHAEF. А. I3I, I32,

Lederartiger Punktfchwanm. Germ.

In hortis, pomariis fyluisque ad variarum arbo. rum truncos lignaque putrida pafim.

fiftatus. I599. Boletus fafciculatus et fquamofus, tubulis çonnexis minutiflnais; lobis laciniato - fimbriato-criltatis, 
tis. GLed. Meth. Fung. p. 75. i. VIII, вӧIIM. n. $82 ?$.

Ein Punktfcheramm mit Hahnenkammfürnig zertheilten Lappen. Germ.

Ad terminos pratorum verfus agros cum Jafione poft pagos Mockau, Aluzauendort, im Ginindorfor Hölzchen atque an Bieniz paffim obuiam iuit.

1600. Boletus tuberculofus, durus, feflilis ex albo er tubersutocinereo fuluefcens, tubulis minutifinis connexis. fus. GLED. Meth. Fung p. 80, n. XII. var, c. EOEIM. n. 825 .

Hökerigter Punktfchwamm. Germ.

In fyluis, pomariis ad Ceraforum, Malorum alia. rumque truncos et ad ligna putrefcentia o:itur.

178. HYDNUM. L. G. I327. BATSCH. G. III. Stachelfchwamm. Germ. Hydne. Gall.

$$
\text { a. Stipitata. }
$$

I6or. Hydnun fipitatum, pileo fubconuexo, Iqua-imbricatum, mofo; frumis imbricatis fuberectis. WILDEN. Prodr. Berol. n. 11 t6. LINN. Sytt. p. 978. scmaef, t. I fo. Hydnum fubfqusiofun. BATSCH. El. Fung. p. 11 I. ת. 2. tab. X, fig. 43 .

Erinaceus efculentus albus crafus. Mici. p. I32.

t. 72. f. 2. BOEIM. ก. 832.

Gefchupter Stachelfcheramm; braune Hirfchzunge. Germ. Hydne imbrigué, ou ì clsapeaz. Gall.

In fyluis pinaftretis, in Obcrholze parim et in pincto ad Linidential. Autumno.

Fungtis efculentus.

1602. Hydnum Rtipitatum, pileo conuexo, rufo, fub. repardum. tus albo, fipite ad bafin incrafiato. wro. n. 1147 .

Hydmun repandum ftipitatum, pilco conuexo, laeui flexuofo. IIN. Syft. p. 9-8. n. 2. SCHAEF! tab. $14 \mathrm{I}$. 


\section{6,6 \\ c. I A S IS $X X$.}

Boletss pileo puluinato, integerrimo, tubulis connexis, echinato denticulatis. GLED. Meth. Fung. p. 74. n. VI.

Ansgchreiteter röthlichè Stachelfcheamm; Stoppelpilz; YYeißser Süßling. Germ. Hydne finué. Gall.

In fyluis denfioribus, im Univerfizätsholze pafim. Autumno.

Fungus efculentus.

Auriçsl-1603. Hydnnn ftipitatum, pileo dimidiato, hirfuto, pitim. fulco; inferne albicante, ftipite fufco. wrLden. n. 11.48 .

Hydnum Awifcalpium, ftipitatum, pileo dimidiato. LINN. Sylt. p. 978. n. 4. SCHAEE. t. 143.

Evinaceus paruus, hirfutus, ex fulco fuluus, pileo femiorbiculari, ftipite tenuiori, мiсн. N. Pl. G. I32. t. 72 . f. 8. ВСЕHM. n. $83 \mathrm{r}$.

Boletus pileo femiorbiculari, leuiter faftigiato, tubulis connexis, echinato-denticulatis, petiolo prae. alto et tenui. GLED. Meth. Fung. p. $7+$ n. VIf.

Ohrlöfclförmiger Stachelfchueamin mit einem rauchen langen Sticle. Germ. Hydne cure - oreille. Gall.

In fyluis acerofis ibidemque in ftrobulis Pini fylncftris deiectis, im Obcrholze, in Pineto ad Lindenthal, in der Dübenfchen Heide frequens. Vere et Autumno.

zonatum. r6o4. Hydnum pileo conico-excauato, coriaceo, fpadiceo vel nigro-fufcato; ítipite breui, in pileum diffufo, concolore; aciculis grifeo-albis. ватsсн. El. Fung: p. III. n. I. Hydnum cyathiforme. SCHAEF. t. 139 .

Boletus coriaceus, pileolo campanulato, inuerfo, defuper fericeo et fuluo-ferrugineo, lineis concentricis dittincto, tubulis fubtus connexis, eclinato-denticulatis. GLED. Meth. Fung. p. 69. n. II. var. d. DOEIM. n. \$33. var. 2.

Gürtelfürmiger Stachelfluzenmm. Germ.

In fyluis fuburbanis et proximis ceduis e. g. im Rofenthale et Strcitholze olim. b. GLEDitschivs pafim reperit, 
reperit, mihi quoque inb Leurfcluer Holze fed raro occurrit.

1605. Hydnum ftipitatum, gelatinofum, pileo dimi- gelatinodiato fupra glaberrimo. 'I.INN. Syft. p. y73. n. 5. fum. JAC. Flor, Auftr. V.I.I. t. 239. SCHAEF. t. $144,145$. Echinus cryfallinus, gelatinolus. Hall. Hift. T. III. ก. $23 ! 9$.

Gallertartigir Strichelfchzeramm. Germ.

In lingnis putridis et fyluis acerofis pafim in der Dïbenfchen Heide. Autumno.

\section{ß. Sefjilia.}

I606. Hydmum acaule, arcuato-rugofum, tomento-paraficieum. fum. LiNe. Sylt. p. 978. n. 6.

Schuarzer Stuchelfchuanm olne Sticl. Germ.

In ligno putrido, afleribus trabibusque pafim. Perfiftens.

B. Semina Fungorum externa in fuperficic fupera corpus aut conuexum, aut concauum, formante. '

479. PHALLVS. L. G. I 329. 'GlRd. G. IV. ватsch.

G. V. Morchelfchwamm. Cerm. Morchel. Angl. Morille.' Gail.

a. Acaules.

160\%. Phallus conuexus glaber, fubaggregatus oualis acaulis. vel rotundatus, craftus: fupra fufcus, infra albus, radicibus difi pluribus craffis albis. eatscr. El. Fung. p. 129. n. I.

Heluella lamina gyrofa, fubinaєqualis pileoli forma deorfum late et fimbriatim expanfa. GLED, Meth. Fúng. p. 39. n. II. вовнм. n. 843. - Heluella inflata. SCHAEF. t. 153.

Der ungeftielte und blafcnförmige Morchelfchwamm; gemeine Morchel. Cerm. 
In pomariis, pafcuis, fyluis ct ericetis elatioribus pon pluuias. Vere et Autumno.

\section{b. Lobati.}

- oitatus. 1608. Phallus pileo acute-lobato, glabriufculo; tipite elongato Iuperne attenuato inter coltas longitudina. les lacunolo. Batśch. El. Fung. p. I29. n. \&.

Heluella petiolata, lamina in forman capituli deorfum plicato-lacinata et crilpa, petiolo fiftulofo, friato et rimofo. GLED. Meth. Fung. p. 36. n. I. SCHAEF. T. $15 \%$, 162.282.

Falfich Morclaljchacomm; lappigter Morchel-, Jchueamm mit gerippten Stiele. Germ.

In ericetis et fyluis denfioribus, in Univerfitïtoholze aliisque fyluis poft pluuias paffim. Autumno.

Fungus efculentus.

Mitra. 1609. Piballus pileo obtufúfeule lobato, fupra fufco; fipite glabro, integro, incraflato niueo. BAтsch. El. Fung. p. 129. n. 2. (fub Phallo brunneo.) Heluella Mitra pileo defiexo, adneto, lobato, difformi, LINN. Sylt. p. 979 .

Heluella parua, lamina bifulca, in formam capituli duplicis, plani et nonnihii faftigiati deorfum contracti. GLED, Meth. Fung. p. 38 . n. I. vä. c; SCIIAEF, t. $159-16 \mathrm{I}$.

Lapuzger brauncr. Morcheljchuamm; Stockmorchel; Faltermorchel; Bifchofsmütze; Maurache. Germ. Hel'selle mitré. Gall.

In fyluis et ericetis poft pluias hand infrequens.

Fungus efculentus ficcatur et adhibetur vt Phallus ejculentus.

\section{c. Reticulati.}

e`culentus. I6 1o. Phallus pileo ouato, cellulofo, ftipite nudo, rugolo. LINN. Syft. p. 978. DOEHM. n. \$36. SCHAEF. t. $199,298-300$.

Phallus actiminatus pileo ouato, margine adnato conuexo, rugis vndulatis, vndique anaftomofantibus; 
bus; areolis acqualibus; ftipite valido tenuiore. BAtsch. El. Fung. p, 123, n. 9 .

Phallus capitulo faftigiato, fubtus operculato, petiolo nudo. GLED. Meth. Fung. p. 59. n. IV. eOzIri. 11. $83 \%$

Gemeine Morchel; Spitsmorchel; Morchelfchreamm. Germ. Morel. Angl, Morille des ragouts ou comefible. Gall.

In ericetis et fyluis, pomariis et locis pratenfibus elatioribusque, e. g. in Oberholze, bei Pomffen, Steinbeck etc. frequens. Vere in Aefratem vfque.

Fungus efculentus, deliciofus, ficcatus adferuatur et dimenditur in culinis ad perficienda embammata.

16II. Pluallus voluatus, fipitatus, pileo cellulofo. impuảicus. IINN. Syft. p! 9-8. n. 2 .

Phallus voluatus pilco conico, margine libero, crenulato, vertice perforato crafitato, bafi voluato. iatsch. El. Fung. p. 133, n. 10.

Phallus volua exceptus, capituli apice patulo. GLED. Meth. Fung. p. 55. n. II. SCHAEF. t. 190-198.

Der Morcleelfcheeamm nit dcn Eye; ftinkender Morchelfchreann; die rechte Hivfchbrunft über der Erde. Germ. Morille fétide. Gall.

In fyluis humidioribus et alnetis praeprimis ad Alnos emortuos, Aeftate in Autumnum vfque.

480. HELVELLA. L. G. n. I330. GLED. G. III. Faltenfchwamm, Germ.

1612. * Heluella membranacea, multiplex, membra- mefenterinis feffilibus, fimbriato - plicatis. GLED. Meth. Fung. formis. p. 5I. n. IO. STERb. Fung. t. 26. SCHAEr. t. I68. Gekröfeförmiger Faltenfchwamm. Germ.

In fyluis caeduis acerofisque, im Oberholze ad truncos arborum putridos paffim. Autumno.

16r3. Heluella fibrofo-reticulata, nigro-fufca, fibris fubcutanea, rigidis et compreffis. GLED. Meth. Fung. p. 53. n. XII, var.c. scholi. Suppl. Flor, Barb. p. 346, n. 1 I 4 I. Härıti- 
Häutiger Faltenfcheeann. Germ.

In variarum arborum truncis lenio confe tis et coriofis, vbi arkeladhaeret ligno lub cortice e. g. $P i$. nus, Fagi, Carpoini, Salicis et Zuglandis regiac putrefcentis etc. et alibi. Per totum fere annum reperitur.

hirfuta. I6r4. Heluclla explanata, flaua, extus hirfuta. Thedacphora hivfuta. wizdeiv, Prodr. Berol. n. I I 53

Heluella pineti. Lis. Syft. p. 979?

Raucher Faltunflureamin. Germ. Helvelle du Pin. Gall.

Ad lingna putrida paffim. Perfifens.

lacuis. 16I5. Hclacila explanata, laeuis, fordide alba.

Thaclaephora glabra. , wilden. Prodr. Berol. n.

I1 54.

Glatter Faltenfchreanm. Germ.

In lingnis putrefcentibus frequens. Periffens.

Haec et prior nullis gaudent ftipitibus, et loco la: mellorum atque pororuin punctulis conuexis rotundatisqué obfeflae funt.

48I. PEZiZA. L. G. I33 T. GLED. G. VII. BATSCh.

G. IV. Becherfchwamm. Germ. Pezize, Gall.

lacuis. I6r6. Peziza campanulata, feffilis externe viliofa, interne lacuis. wilden. Prodr. Berol. n. I159. (fub Cyatizo.)

Peziza lentifera campanulata lentifera. LINN. Syft. p. 979. SCHAEF. t. 180 et Is't.

Peziza Olla oblongo-campanulata, fubuentricofa, ore marginato, glabro. ватsch. El. Fung. p. 127. ก. $3 \mathrm{I}$.

Glatter f. Topfformiger Becherfchueamm. Germ. Pezize ì lentilles. Gall.

In ligno putrido, hortis, pomariis, areolis et plantis cefpitofis viuentibus paftim. Vere et Autumno. 
16r7. Peziza campanulata externe hirfuta, interne ftriata. friata. WILDEN. Prodr. Bcrol. n. II6o. (fub Cyatho.) Peziza friata campanulata lentifera villofa, interne ftriara. Hudson. Angl. Ed. II. p. 634 n. 2. - Peziza hirfuta conica acuta: margine integro, refto, patens; externe villafa vel hirfuta, obfcura, fufca; interne glabra, ftriata, cana. BATSch. El: Eung. p. 12\% n. 32 .

Peziza feffilis cempanulata, extus pilofa et fufca, intus friata, plumbea, glabra." GLED. Meth. Fung. pi 138. n. I. var. a. bUEHM. n. 847. SCMAEF. t. 178. Geftreifter Becherfchzeamm. Germ.

In hertis et pomariis ad terram intra Mufcos atque in fyluis vmbrofis et ligno putrido poft plunias fre. quens. Autumno.

1618. Peziza cylindrica, integra, glabra, luteo-cylindrica. ochracea.

Cyathus cylindricus arhizus, totus glaber. wrzd. Prodr. Besol. n. I 6 I.

Peziza pysis conico-cylindrica, intezra, glabra fulphurea vel ochracea. вatsch. El. Fung. p. 129.

n. 33 .

Peziza feffilis campanulata, exigua, aurea et glabra, GLED. Meth. Fung. p. 138 . n. I. var. b. sCHAEF.

t. 1 ?9. Peziza crucibuliformis.

Cylinderartiger f. Büchfenfürmiger, Schnelztiegelförmigér. Becherjchuamm. Germ.

In lignis et trabibus putridis paftim. Vere et Autumno.

161 9. * Peziza globofo-campanulata; margine crenato. cupularis. LINN. Sy't. p. 979 .

Peziza fordide alba, acetabulo variabili. Hal Enum. p. 19. ก. 5.

Elutlla corpore hemifphaerico, excauato, externis coftis ramolis et fibi inuicem implexis circumdata ; bafi breuiffima. GLED. Meth. Fung. p. 42. n. VI. Kugelrunder Becher f. Linfenfchwamm. Germ. Pezise en cupule. Gall. 
In fyluis intra Mufos et ad radices arbo:um mu, fcofas innafcitur paffim. Aeftate praeprimis poft pluuias crebrioreș.

ealyculus. r620. * Pc๘iza ftipitata conuexa hemifphaerica patens; ftipite fubelongato, lineari valido, diftin ttc inferto. BATSCH. El. Fung. p. 123. Is. Io. t. XII. f. 5 I.

Langfticliger Becherfshwanm. Germ.

Ad truncos arborum inter Mufcos, inm Rofenthale ad Quercuum truncos paffim vidi.

ealyciformis 1621. * Peziza ftipitata conuexa, intus fufcefcens, extus cinerafcens. WILDEN. Prodr. Berol. n. 1174 .

Peziza calyciformis pileo ochraceo, glabro, fubtus vna cum ftipite, carneo furfurofa. БАтSCH. Cont. p. 195 t. XXVI, fig. $135 . \mathrm{a}-\mathrm{d}$.

Heluella corpore infundibuliformi, intus fufco, extus cinereo, margine tumido, extrorfum reflexo. GLED. Meth. Fung. p. 4I. n. V. var. b.

Oetofpora calyciformir. тімм. Megapol. n. I093. Kelchformiger Napffchwamm. Germ.

In arborum truncis et a amulis Pini deiectis putrefcentibus in Oberholze, Bieniz pafím. Autumno.

tuberofa. 1622. ${ }^{*}$ Peziza trunco tenui elongato, in cyathum extus profunde fufcum, intus palidum exeunte, thecis nudis. HEDW. Mufc. Frond. Vol. II. p. 33. tab, X. B. fub OEiofpora.

Knolligter Becherfchwamm. Germ.

E terra limofa fruticeti pone pratum der großen Funkenburg, April 1/83 prima vice hanc fpeciem enafci Cel. nIED W1Givs vidit.

Callopiana. 1623. Peziza ftipitata, conica, dilatata, patens; ftipite confluente, lineari elongata, fulua, radice tuberofa, cefpitofa. Batsci; Fl. Fung. p.121: n. 15. fub P. Tuba.

Heluella petiolata, tubulofa, margine inaequali, lacero et multifido. GLED. Meth. Fung. p. 40. n. IV. BOEHM. n. 84i. SCHAEF, t. I 7 .

Trompetenförmiger Becherfchwermm. Germ. 
CRYPTOGAMIA. FVNGI.

In fyluis ceduiš denfioribusque, poft pluuias circa Vlmi, Aceris campeftris, Quercus etc. truncos emnrtuos putridosque pafim in Rofentiale, Streitholue, Zfchrcherjchen Holze etc. Autumno.

I621. *-Peziza ftipitata acute conica, patens, ftipite fub- conuiualis. diftineto, lineari breui valida. Estscri. El. Fung. p. I21. n. 26. МICH, t. 85. f. I2.

Pokalförmiger Becherfchneanm. Germ.

In foliis Glecomatis Hederaceae pafim in Rofenthale. Autumno.

482. OCTOSPORA. HEDW. M. Frond. Vol, II. p. 4. Achtfaame. Germ.

\section{a. Stipitatae.}

1625. OEtofpora trunco fimplici, laeui, cartilagineo, variabilis. dilatifime fufco e breui bali anguftata, pedunculum aemulante in cyathum cauum ampliante. HEDw. 1. c. p. 23. Tab. VI. D.

Verïnderlicher Achtfaame. Germ.

In muris argillaceis tectisque ftramineis vetuftatis circa Lip.rae circulum praecipue gregatim obuiam iuit. Aeftate in Autumnuin vfque.

1626. ${ }^{*}$ OEtofpora trunco fimplici, inferne ventricofe an- carnea. guftato inque patellam margine repando dilatato. HEDw. 1. c. p. 25 . Tab. VII. b.

Fleifchfarbiger Achtjaame. Germ.

Ad 2 uercus Roboris truncos in nemore elatiore, praedii haud longe a ciuitate Enlenburg fiti, Gota fic dieti Cel. hedwiglvs detexit. Autumno.

1627.* OEtofpora trunco fimplici, carnofo, elaftico, fum- clafticti mitate denique applanata, nigra, HEDW. l. c. p. 23. Tab. V.E.

$P_{e \sim i z a}$ brinnea interne atra absque nitore, externe rugulofa, fufco-brunnea, carnofa, polymorpha. ватsсн. El. Fung. p. 125. n. 6. tab. XI. fig. 30. SCHAER. t. 158.

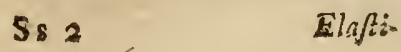




\section{4.}

Elafiffchor f. Schu'arbrauner Achtfáme; braunrandiger, lederartig glänzender Becherfchwamin. Germ.

In truncis deiects putridis et Quercus rimis im Zimmerhofe Febr. 1790 copiofe vidi. Autumno et Hyeme.

violacea: $\left\{623 .{ }^{*}\right.$, OEtofpora trilinearis fimplex; e bafi angufta, elongata eyathiformis, violacea, feminibus rotundis. HEDW. 1. c. p. 27 . t. VIII. A.

Violetfer AchtJaume. Germ.

Ad truncos Salicum putrefactos bei Gohlis et 'Ketfchan frequens. Autumno.

a)bidula. 1620\%" OEiofpora trunco exiguo, pedunculiformi, in patellam conuexo-marginatam terminato, toto laeui, albido. HEDw. l. c. p. 3o. Tab. IX. B.

Weiflichter Achtfaame. Germ.

In ftraminibus muros argillacens contegentibus, extremitatibus vdis fefe offert palfim exeunte Aeftate in Autumnum vfque.

cirrina. 1630. * OEtofpora trilinearis, fimplex, gregaria, bafi contracta tipitiformi in patellam ampliata. HEDW. 1. c. p. 28. tab. VIII. B.

Citronengelber Achitfaame. Germ.

In truncis Quercus deiects putridis et locis vmbrofis nemorofisque, im Rojent/hale et Querceto vor: Markranftâdt paffim. Autumno.

lütefcens. 163r. * OEtoppora trunco exigws, anguftato, pedunculiformi in patellam conuexo-marginatam terminato, to to laeui, lutefcente. HEDW. 1. c. p. 3I. tab. IX. 6 .

Gelblichter Achtfaame. Germ.

In ligno abietino putredine corrupto Ccl. HEDW1G, detexit, ego quoque ad terram in fofficulo linter: den Lazarezhe nuperrime reperi. Autumno.

pyriformis, 1632. ${ }^{*}$ OEtojpora exiguo trunco tenui, patella pyriforŕi, margine albido terminato. HEDW. 1. c. p. 32. tab. X. A.

Birnförmiger Achtjaame, Germ. 
E foliorum alis Mnii ligulati emortuis in horto Bofiano atque in humo fabulofa D. HEDwigivs detexit. Vere.

1633. ${ }^{*}$ OEtofpora trunco e bulbofa bafi gracili, elongato, bulbofa. patella rotundata, exterius albo-punctata, cauitate nigra, terminato. HeDw. l. c. p. 3a. tab. X. C.

Zuviebelartiger Achtfaame. Germ.

Ad fyluarum forfas vdas et ad latera pifcinae pineti ad Lindenithal. Aeftate, copiofius Vere et Autumno.

1634. * OEtofpora trunco coriaceo: breui anguftiore bafi purpuren. in patellam ampliato, extus abfolute purpuream, ficcitate tenerrime ex albido-pupillofam, difco profunde fanguineo. HrDW. l. c. Vol. II. p. 2. tab. XXII. A.

Purpurfarbiger Achtfanme. Gesm.

Supra bafin refidaam truncorum Quercus etc. deiectorum patridorumque haud infrequens Autumno.

1635. OEtofpora laeuis, cinnamomeo rutilans, inferne nana. anguitata, ora incraffata, circulo profundius colorato; feminibus rotundis. HEDW. l. c. p, 29. tab. IX, A.

Zwergartiger Achtfanmo. Germ.

In ciftulis vegetabilium educationi inferuientibus hanc fpeciem e terra propullulantem Cel. HEDWigivs reperit Autumno.

\section{b. Sefjiles.}

1636. * Oetofpora trunco fimplici, orbiculari, extra hirta. fufco rutiante, toto pilofo, difco coccineo, feminibus rotundato - oustis, granulatis. HEDW. l. c. Vol, II. p 17."tab. III. B-

Eluella hemifphaerica, excauata, feffilis et parua, intus coccinea, extus pilofa. GLED. Meth. Fung. p. 48. n. IX, e.

Raucher Acletfaame. Germ.

Ad ligna varia putrefcentia Salicum, Aceris campeftris, Populi nigrae, Alni, Frangulae et in cippis, 


\section{6 \\ c LAs Is XX.}

trabeculis locisque vis vmbrofis frequens. Aeftate et Autumno.

ciliata, $1637^{*}$ * Octofpora feffilis, eeraces, hemifphaerico-concaua, coccinea, oris nigro ciliatis, Jace. Collect. Vol. I. p. $3+6$. n. 129. fub Heluclla ciliari.

Heluella orbicularis excauata, coccinea et feffilis, margine pilofo. GLED. Meth. Fung. p. 48. n. IX. var. $f$.

In fyluis ceduis fuburbanis v. g. im Rofenthale, Schambergifchen Hölzchen aliisque poft pagos Leutfch, Gonnewiz, Gros-et Klein-Zfchocher, im Streitholze ad arborum truncos et ad foueasque frequens. Aeftate in Autumnum vfque.

cochleata, 1638 * Octofpora feffilis, hine finuato-plicata, marginibus acutis erectis. Batsch. El. p. II 7. n. 4. fub Peziza.

Peziza cochleata, turbinata cochleata. LINN. Sylt. p. 979. n. 4 .

Eluella orbicularis, feflilis, excauata, intus coccinea, tota glabra. GLED. Meth. Fung. p. 49. n. IX. var.g. Heluella coccinca. SCHAEF, t. 148 .

Schneckenförmiger Achefaame. Germ. Pezize en coquille. Gall.

In fyluis montofis et fabulofis im Bieniz et Ober halze 1789 pauca detexi fpecimina. Autumno.

eoccinea. 1639. * OĖojpora corpore feffili, orbiculari, concauo, intus extusque coccineo, margine inaequaliter crenulato.' Tab. IV. f. I.

Scharlachfarbiger Achtfaame. Germ.

Ad terram intra Mufcos froudofos in locis elatioribus ficcioribusque enafcitur, et im Bieniz a.d. XVIT. Septemb. 1789. mihi obuiam venit.

Obf. Radices fibrillulofae, breues, albidulae. Genitalia mafcula et feminea detegere non potui. Somina obouata, minutiflima.

5tutellats. 1640. OEtofpora feffilis, patens, carnea, margine acuto, externe pilofa, depreffo-conuexə. BAтSCH. El. 
Fung. p. 123, n. tab. XII. fig. 54, a, b. fub $P e-$ $z i z a$.

OEtofpora fcutellata, planiufcula, margine conuexo pilofo. HEDW. 1. c. p. 10. tab. III.

Peziza fcutellata plana,' margine conuexo, pilofo. LINN. Syft. p. 979- n. 7 .

Eluella orbicularis, minima, feffilis et coccinea, plana, margine ciliato. GLED. Meth. Fung. p. 45. n. VI l. var. b. - Heluella ciliata. schaef, t. 284. Gall.

Schildförmiger Achtfaane. Germ. Pezize en écuffon.

In locis vmbrofis nemorofisque ad truncos putrefcentes im Rofenthale ad truncos deiectos arborum hinter dem Lazarethe, die X. O\&tob. 1789. obuiam iuit; porro quoque ad femites pratorum vdorum ad Scliönfeld, Sellerhaufez Cel. HEDwigivs primum obferuauit. Vere in Autimnum vfque.

164I. ${ }^{*}$ OEtofpora feffilis, elongata, fpathulata, fpathi- leporina. formis, ere ta, inferne cylindrica, anguitior, femiclaufa; fuperne dilatata, oblonga.lateraliter patens tota, ore deorfun in rimam manubrii decurrente. Batsch. El. Fung. p. I 17 * n. 6. fub Peziza.

Peziza Acetabulum eyathiformis; extus angulata venis ramofis. LINN. Syft. p. 979. n. 4.

Eluella corpore hemifphaerico, excauato, externis coltis ramofis et fibi inuicem implexis circumdata, bafi breuịfima. GLED. Meth. Fung. p. 42. n. IV. SCHAEF. t. 156. Gall.

Löffelförmiger Achtsaame. Germ. Pezize en ciboire.

In ficulis mufcofis intra Lipfiae circulum pafim. Aeftate et Autumno.

16.12. * Odoofpora feffilis, intus albida, glabra, extus frubhirfuta. fufca, fubhirfuta, bafi radicata.

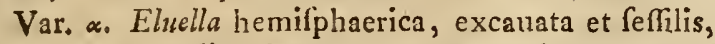
radice longa, GLED. Meth. Fung, p. 46 . n. IX.

B. Eivella hemifphaerica, excauata et feffilis, intus candida, glabra, extus pilofa et Ss 4 - fub- 
fubobfcura. Ejufi. 1. c. n. IX var. a. SCHAEF. t. I $5 \mathrm{I}$.

- Haarigter Achrfaame. Germ.

- Ad truncos Pinas fylueftris emortuos, in der Dïbenfchen Heide pafim. Autumno.

callofa. 1643. " OEtofpora feffilis fubinaequalis ochraceo-canefeens, farta; margine crafto puluinato, vix eminente difco, glabriore. Batsch. Cont. II. p. $95 . t$. XXXIX. f. 219. fub Peziza.

Schwieliger Achtfaame. Germ.

In lignis putridis haud infrequens. Autumno.

haematigına 1644. * OEloppora minuta, fefilis, conuexa, dilute fanguinea. HEDw. Vol. II. p. 17. tab, V.E.

Punktirter Achtfaame. Germ.

In locis fabulofis ad pifcinam poft Lindenthal Cel. HEDwigivs detexit. Autumo.

puftulata, 1645. * OEtofpora minuta, feftilis, forinfecus albo-puftulata. HEDw. I. c. p. 19. tab. VI. A.

Getïpfelter Achrfaame. Germ.

In pineto ad Lindenthal, ibidem ad forlas e pifina aquam deducentes. Autumno.

fpadicea. 1646. " oftofpora fethilis, inaequalis, faturate fpadicea. fuperne nitens, inferne fabra, margine crenulato. BAтsch. Cont. Il. p. 93, tab. XXXIX. fig. 21\%. a. b. fub Pezĩa.

Kaftanienbrauner Achtfaame. Germ.

In lingnis putridis et truncis arborum fenio confe Ris im Rojenthale et Univerfitätsholze pafim obuia. Aeftate.

punice. 1647. * OElofpora feffilis, orbicularis, nitoris expers, fuperne miniata, inferne pallentior farta, margine craffe puluinato, vix eminente, difco concolore: ватscu. Cont. I. p. 97. tab. XXXIX. fig. 220. fub. Peziza.

Coralrother Acht Jaame. Germ. 
In truncis putredine corruptis, in Rofenthale vnica vice pauca inueni fpecimina, exeunte Aeítate.

1648. * Ötofpora atropurpurea, feffilis, reflexa, difco hepatica. faepius fcrobiculo notata. Batsch. Cont. I, p. I99. t. XXVI. f. i 38 . fub Peziza.

Leberfarbener Achtfanme. Germ.

In terra inter Mufcos progrediens, im Rofenthale. fub fine Octobris r 789 reperi.

1649. * Octofpora feffilis, cinerea, reflexa, margine crifpo cinerea. finuato lobato. вatsch. Cont. I. p. 197. t.' XXVI. f. I37. fub. Peziza.

Peziza cinerea feffilis, plana, diaphana, cinerea. wILDEN. Prodr. Berol. n. I I 33.

Afchgrauer Achtfanne. Germ.

In truncis arborum cmortuis pafim. Autumno.

165c. * OEtofpora feffilis, cinerea, planata, tota vel grifea. margine angufto cincta. BATSCH. El. Fung. p. II7.

n. 2. tab. XII. f. 55 .

Grauer Achtfaame. Germ.

Ad truncos Quercunm deiectos im Refenthale fpecimina pauca nuperrime detexi. Autumno.

165r. * OEtGjpora feffilis, plana orbiculata, flaua. WrL- Aaua.

DEN. Prodr. Berol. n. 1175 . fub Pcziza.

Eluella difciformis, feffilis, plana. GLED. Meth. Fung. p. 45. n. VIII. -

Geller Achtfanme. Germ.

In fyluarum locis vmbrofis ad Alnos, Vlmos, $\mathrm{Fa}$. gos, Populos, Salicesqne haud infrequens. Autum. no et Vere.

16.52. * Octojpora feffilis, minima, in patellam fubplana- aurantiaca. tam terininans, surantiaca.

Eluella difciformis, 1clfilis et plana, aurantii coloris. GLED. Meth. Fung. p. 25. n. VIII. var. a.

Pomeranzenfarbiger fichtfaane. Germ.

In Alnorum, Carpinorum, Tiliarmm truncis palfim obuia. Autumno. 
viridans. $1653{ }^{*}$ OEtofpora trunco feffili, conuexo, patelliformi dilute fufeo, margine viridante. HEDW. 1. c. p. 20. tab. VI. B.

Grünrandiger Achtfaame. Germ.

In wuris argillaceis inter Mufcos crefcens, in pago fic diêto Gohlis. Autumno.

uliuacea. $1654{ }^{*}$ OEtofpora interne nigra absque nitore, externe rugulofa, oliuacea, orbicularis, planata, margine angufto, conuexo. вatsch. El. Fung.p. 127. n. 19. tab. XII. fig. 5 1. ful Pezıza. =

Olivengriuner Achtjaame. Germ.

In fyluis ad trunicos emortuos putridosque, in Sylua Academica paffim. Autumno.

niuen. $16550^{*}$ OEtafpora fefilis, niuea, planata, tota vel margine angufto cincts. DATsCH. El. Fung. P. I17. n.I. tab. XII fig $<6$. a. b. fub Peziza.

Schneezeecißer Achtfaame, Germ.

In truncis emortuis putridisque pafim. Autumno:

leweoloma. 1656.* OEtofpora exigua, depreffa, tota miniata, margine niueo, lanulato. HEDw. I. c. p. 13. tab. IV. A. Wezßrändiger Achrfaame. Germ.

In muris argillaceis Mufcis intermixta crefcit. Aeftate exeunte in Autumnum vfque.

afplasula. 165.7. Oetofpora cinnamomea, expanfa, fuperne plana, rugofa, inferne dilutius colorata, HEDW. 1. c. p. I8. tab V. C.

Platter Achatuame. Germ.

In muris argillaceis vetuftis, in Cohlis, Eutritflo alibique. Aucumtso.

guinuta. $16580^{*}$ Ociofpora feffilis, fufca, margine aequali terfo. HEDW. I. c. P, 21. Tab. Vi. C.

Kleiner Achtfanime. Germ.

In i:grits putrefcentibus afferibusque gregatim crefcit. Autumno, 
483. PORONIA, gled. Syft. n. I2I7. Peziza. IINN.

1659. * Poronia minuta, feffilis, leuiter concauo expla- Gleditfchii. nata, fordide flaua, externe rugulofa, patella punEtulis nigris perforata, margine laeui.

Peziza punEtata turbinata, truncata, difco punctata. LiNN. Syft. p. 979.

Eluella turbinata patula, difco foraminibus pertufo, bafi breuifima. GLED. Meth. Fung. p. 4. n. VII.

In pafcuis, ericetis, locis fterilioribus fuper ftercora boum exficcata, vor dcm Petersthore ouf dem Wege nack Schleufg vor den Holze Nouembri 1788 seperi.

Hic fungus pyxidis confperforiae faciem, quam Germavi appellant Sand-oder Streufandbüchfe, haud inepte refert.

\section{Semina Fungorum in fuperficie tota corpus oblongum aut cylindricum, aut clauaefor- mem, formante, externe fita.}

\section{ClaVARIA. L. G. I332. GLED. G. II.}

BATSCH. G. VI. Keulen f. Hörnerfchwamm:

Grrm. Clavaire. Gall.

\section{a. Indiuifas.}

1660. Clauaria clauseformis, fimpliciffma. iINN. Sylt. piftillaris.

p. 980. n. I. SCHAEF. t. I69. f. 3, 10, I2.

Clauaria erecta, parua, luteo - fulca, corpore fimpliciffimo, integro, vertice obtulo, tumido et rugofo. GEED. Meth. Fung. p. 27 . n. I. var. с. воЕнм. ก. 850 . var.

Schwengelförniger f. gelber Keulenfchwamm. Germ. Clavaire en pilon. Gall.

In ericetis ad pagos Pomfen, Steinberg, in Univerfitâtsholze etc. Autumno.

166r. Clauaria fimplicifima clauaeformis dura, nigra. lig:a?a. WIíd: Prodr. Berol. n, I I 76 . 


\section{2}

Clauaria erecta, corpore fimplici, obtufo, integro. Gled. Meth. Fung. p. 26. n. I. eOzHM. n. 850 . SCHAEF. t. I6\%. f. I.

Holz Keulengihreamin., Germ.

Ad ligna putrida in erisetis, fagetis et pinaftetis in der. Dïbenfchen Heide paflim. Aurumno.

Ophioglof- I662. * Clauaria clauata, integerrina comprefra, obtuloides.

$$
\text { fa. HNN. Syft 1\%. } 980 \text {, 1. 5. SCHAEF. t. } 327 \text {. }
$$

Clauaria ophioglogjoides fimplex, 1pathulata, lanceolata, comprefia; glabra. вatsch. El. Fung. p. 13.5. ก. 4 .

Clauaria nigra, corpore fimplicifimo, breui nonnibil rugofo, in bafin tenuillimam longifime pro1) ducto. GLed: Meth. Fung. p. 29). n. i. var. $x$.

Zungenförniger ganz jchwarzer heulenfchwamm. Germ. Cläaire noive. Gall.

In fyluis ficcioribus, elatioribus in Bieniz paffim, in der Dübenfchen Heide fićquentior. Autumno.

Ligula. I663. ${ }^{*}$ Clauaria fimplex, clauata, lutea, fuperne incraf- Sita, inferne tenuis elongata.

7. Clanaria lute - rufa, corpore integro fimplicifimo, tenuifimo et longiffimo. GLeD. Meth. Fung. p. 29. n. I. var. h. SCAAEF. t. I 7 I.

Verlüngerter aungenf örniger Reulenfchuvanm. Germ.

In ericetis ad pagos Ponifcn, Stenberg, Griten etc. inter folia dèiecta putrefcentia atque in lignis putridis, oritur.- - Antunno.

fulua. I664. * Clausric fimplex, leuiter comprefra, vna latere fecundum longitudinen fulcata, ex toto fulua, fifulofa, apicc obtufa, bafi radicata. Tả. IV. f. 3.a. Fentraelber Kenlenfchreamm. Germ.

In locis graminofis, elatioribus, am Bieniz paffim fub fine Otobris 1789 legi.

alba. I665. * Clauaria minima, candida, corporé fimplicifi. mo, obtufo, integro. GLED. Meth. Fung. pag. 29. ก. I' $\operatorname{var}^{\circ}$. 
Ganz ueißer Kenlenfchreamm. Germ.

In locis elatioribus ficcioribusque inter Mufcos in Oberholze pafinn. Autumno.

1666. * Clanaria fimplex, corpore tereti, valido, ci-teres. trini coloris, apice folummodo fufco, bafi paullulum tumida, fibrillulis cbfeffa. Tab. IV. f. 2. a.

Clauaria Jimplici/Jima, fimplicifina, flaus, fubulata, teres, apice fufca. wizden. Prodr. Berol. ก. 1181 .

Ganz runder Keulenfchwamm. Germ.

In locis elatioribus arenofis, gramine tectis im Bicniz eodem tempore curn Cl. fullua reperi.

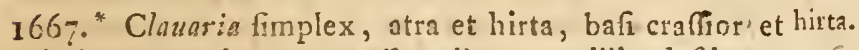

indurata, apice comprefra, albens et villis deftituta.

вatsch. Cont. I. p. 229. tab. XXVIII. fig. I60.

Schearzraucher Kenlenfchzernm. Germ.

In truncis emortuis putridisque, im Rofenthale pauca legi exemplaria. Autumno.

b. Ramofae.

166\%. Clauaria ramofe - cornita, coinprefta. L1NN. Hypoxylon. Sytt. p. 980. n. 7. SChrE B. Spicil. p. I 14. n. 1098. SCHAEF. t. 328. WEIG. Obf. 50. t. 3. f. 5. BATSCH. El. Fung. p. 39. n. 13.

Sphaeria digitata. weB. Spicil. p. 287 . ก. 302.

Schwëizlucher Warzenfchwamm mit weißer Spitze.

Germ. Clauaire comue. Gall.

Ad truncos arborum deiectos putridosque im $R o$ fenthale, porro ad afteres putridos im Zwinger zwi. fchen dem Thomas - und Barfiuffer-Pförtchen, item im Hällifchen Pförtchen linker Hand am Ausgange copiofe Septemb. et Ostobri 1788, 1789, et menie Januar. et Februarii 1790 legi.

1669. Clauaria oblonga teres, věrrucofa, fubnitens et digitata. tota 2tra. ватsCh. El. Fung. p. 137. n, I2.

Clavaria digitata ramofa, lignca, nigra. LINN. Syft. p. 990. n. 6. SCHREB. Spicil. p. 114. n. 1097. WEIG, Obf. 49, t. 3..f. 6 .

Splate- 
Sphacria clauata. web. Spicil. p. 237 . n. 303.

Fingerformiger ganz fchurarzer' Trurzenfchwamn. Germ. Clauaire eligitóe. Gall.

In fyluis ad truncos putridos et alibi e. g. ad afferes putrefcentes, im Zwinger olim $1 l l$. SCHREEervS et Cel. knolne detexerunt, ego quoque d XXX. Ja: nuar. 1790 ibidem zzeifchend dem Thonnas - et BarfüifSer-Pförtchen legi. Autumno et Hyeme.

Obf. Rad. breuis, nullis inftrueta fibrillulis, paffim in corpus compreflum abiens vel pianum vel tortum, quod ex toto nigro extrorfum prueditum colore, porro villis fuligineis, aut vt reetius dicam, quafi fuligine obduttum; interior pars mediatá, alba, ficca vel caerulea. E corpore autem prodeunt rami. duo, paffim tres, quoque nigri coloris, qui crufta tenui albidaque cincti funt et extremitatibus modo bifidi - 4-- fidi, pafim fimplices deprehenduntur. Recens fungus diffectus odorem fpargit vrinolum.

coralloides. 1670. Clauaria ramis confertis ramofiffimis, inaequalibus. LINN. Syft. p.980. n. 9.

Clauaria faftigiata. вAтsCH. El. Fung. p. 137.n. II. tah. XI. f. 48 .

- Clauaria corpore multifido inaequali et ramofífi$\mathrm{mo}$, in apices graciles terminato. GLED. Meth. Fung. p. 3I. n. III. ЕОЕНM. n. $85 \mathrm{I}$.

Coralla - fungus fleuus, varlz. Parif. p. 4I. t. 8. f. 4. SCHAEF, t. 174. 175 .

Korallenartiger Keulenfchwamm; Händling; Händilfchwoannz; Bocksbart; Gelber Geishart; Ziegenbärtchen. Germ. Clavaive Coralloide; Galinole; Barbe de Chevre. Fall.

In fyluis, prnecipue ad earum margines, im Univerfitâtsholze etiamque im Streitholze, porro in der Diibenfchen. Heide frequenter mihi obuiam venit. Aeitate.

Fungus efculentus, qui in culinis fub nomine Barbae Caỹrinae venditur, fere vt Agaricus deliciofus praeparatur, et cicum edit fapidum. - Quoad colorem valde ludit. 
I67r. * Clauaria ramofa inaequalis, corniculata, api-mufcoides. cibus acutis. WILDEN. Prod. n. I184.

Clanaria mufcoides ramis ramolis acuminatis inaequalibus luteis. LINN. Syft. p. 980. n. I3. SCHAEF. tab. $1-3$. Flor. Dan. t. 775 . f. 3 .

Moosartiger Hörnerfchuamm. Germ.

In locis fyluaticis inter Mulcos, im Univerfitütsholze, Oberlsolze, in der Dïbenfchen Heide pafim. Autumno.

1672. * Clauaria fubdiuifa minuta fufcefcens. WiLden. cornea. Prodr. Berol. n. 1185.

Clanaria comea. Batsch. Cont. I. P. 229. tab. XXVIII. f. I 6 r.

Bernfteinfarbiger Hörnerfchreamm. Germ.

In lignis putridis afferibusque putredine corruptis paffim. Autumno.

1673. * Clauaria ramis confertis, ramofifimis, fafti-faftigiata, giatis, obtufis, luteis. LINN. Syft. p, 980. n. Io.

Zugefpitzter Hörnerfchwamm; Bocksburt; Wraldkeulenfchueanun. Gerin.

In lyluis ad truncos radicesque arborum im Univerfititsholze vnica vice obferuiui. Autumio.

Fungus efculentus.

D. Semina Fungorum in cauo peculiari recondita eaque membrana diaphana inuoluto.

485. STEMONITIS. GLED. G, IX. Beutelfchwamin, Germ.

167 t. Stemonitis ftipite nigro; capitulo cylindrico, typhina. fufco-rubente. wigg. Primit, 1 0, n. 1154.

Clathrus nudus fipitatus capitulo oblongo axi longituidinali ałnato. Linn. Syft. p. 979. Flor. Dan. tab. 2 I 6.

Stemonitis petiolata, gregsria, volua fugaci excepta, corpore elongato. GLED. Meth. Fung. p. I4I. $\pi, \mathrm{I}$. ВОЕНM. $\Omega, 83 \%$. 


\section{6}

CLASSIS XY.

Rohrholhenähnlicher Beutelfchreamm; nackter Gitterfchreamm. Germ. Clattre wit. Gall.

In finetis putridis et ad afferes putrefcentes pafim. Autumno et Vere.

fufca. I675. * Stemonitis ftipite nigro, capitulo cylindrico, fufco, maturitate fiffo. wrLden. Prodr. Berol. n. I18.

Clathrus pertufus. BaTsCir. El. Fung. P. I43. n. 4. Erinaceus pertufus. Ejufd. Cont. I. p. 263. tab. XXX. f. 176.

Stemonitis gregaria, petiolata minima, volua fugaci excepta, corpore elongato. GLED. Meth. Fung. p. I4I.n. 1, var. a.

Brauner Beutelfchwamm. Germ.

Ad truncos-Salicum emortuos et in fimetis humido-vaporofis. Autumno et Vere, praeprimis poft plunias crebriores.

erocata. 1676. * Stemonitis tota crocea Atipitata, capitulum cy. lindricum obtufum rudimento voluae circumdatum. wilden. Prodr. Berol. n. I 189.

Erinaceus crocatus, capitulo cylindrico oblongo, cute fugaci, confecto e lana ttipata, molli, elaftica,

1 puluere fuluo-croceo referta; infiftente csiyculi circumfciffo terminali ftipitis validiufculi, vna cum ca- 1yculo fuluo - crocei, nitidiffimi et ftriati. ватsch. Cont. I. p. 265. tab. XXX. fig. I 77.

Safrangelber Stempel.S. Beutellchwamm. Germ.

In ligno putrido et inter Mufcos im Rofonthale nuperrime detexi. 
E. Semina Fungorum in corporis ipsius fubftantia

$$
\text { incluja, et vel }
$$

a) orificio quodam Juperiora verfus aperto effundenda.

486. LYCOPERDON. L. G. I333. GLED. G. X. B̈.тSCy, VIIl. Staubfchwamm. Germ.

a. Solida, fubterranea, radicibus deftituta.

16:7. Lycoperdon globofum, folidiufculum lacerum ceruinum. centro farinifero radice deftitutum. LINN. Syft n. 98 !. n. 2 .

Lycoperdon globofum, cortice granulato, bafi et radice carens. GLED. Meth. Fung. p. I53. n. VII. var. c.

Pharm. Tubera ceruina f. Bületus ceruinus.

Gemeine Hircchtrïffel, Hirfchbrunft muter der Erde. Germ. Vefje-de - Loup du Cerf. Gall.

Ad radices arborum infra terram, in der Diibenfchen-Heide paffim. Autumno in Hyemern vfque.

Cerui, Apri et Lepores fungum festantur et effodiunt ob odorem virofiffimum. RVPP.

1678. Lycoperdon globofum, folidum, muricatum, ra. Tuber. dice deftitutum. LrNn. Syft, p. 98 r. n. 1.

Lycoperdon globofum, fubterraneum, folidum et 'fcabrum bafi et radice carens, capfulis feminalibus magnis. GLED. Meth. Fung. p. I57. n. VIII.

Tuber brumale, pulpa obfcura, odorata. мтссн. Gen. 221. tab. 164 .

Weiße Triiffel; Erdmorchel; Erdgriibling. 'Germ. Truffle. Angl. Truffle commune des ragouts, ou Vefe de Loup Truffe. GaH.

In lyluis fub terra in der Dïbenfchen Heide haud infrequens atque in Oberholze paffim.

Fungus efculentus. 
ß. Pulucrulenta, radicata fupra terram.

Bonifta. 1679. Lycoperdon fubrotundum, lacerato - dehifcens. LINN. Sylt. p. $983 \cdot$ n. 4. вовнм. n. 849.

Lycoperdon globofum, feffile et maximum; glabrum. GLED. Meth. Fung, p. I.43. n. I. et var. a. SCHAEF. t. I9I.

Pharm. Crepizus Lupi f. Fungus Chirurgorum.

Gemeiner Bovift; Woifsfurz; Wolfsgeheul. Germ. Puff-Ball, or Dufty Mufhroom. Angl. Veffe de loup commune. Gall.

In pafcuis, pratis, pomariis, hortis, collibus et ad fyluarum margines frequens. Autumno.

Puluis oculis et ventriculo eft venenum.

eclinatum, 1680. "Lycoperdon feffile, globofo-pyriforme, depreffum, totum pyranidibus validis tetragonis denfiffme muricatum. Batsch. El. Fung. p. I45. n. 5. Lycoperdon cchinus.

Lycoperdon globofum, fefiile et carididum, cortice exteriore in cufpides fubulato-dentatas rigidiufculas et 4-partitas foluto. GLED. Meth. Fung. p. 145. n. I. var. h. SCHAEF, tab, 186.

Zackigzer Bovift ohne Stiel. Gernn.

In fyluis arenofis elatioribusque, im Bieniz, in der Dïbenjchen Heide; porro quoque in pafcuis et ericetis haud infrequens occurrit. Autumno et Vere.

furfura- 68 r. Lycoperdon feffile, globofum, fuperficie furfu. ceum. racea fquamofa. batsch. El. Fung. p. 147. n. 8.

Lycoperton globofum, feffile et candidum, cortice exteriore per totam fuperficiem in furufraceas portiunculas foluto, GLED. Meth. Fung. p. 144. n, I. var. е. вогим. n. 849 , n. I. місн. N.Pl. G. 218 . tab. 97. fig. 6 .

Kleierychuppiger Bovift. Germ.

In palcuis elatioribus ericetisque am Thonberge, in der Sandgrube, vor Mockan etc. paffim; porro in Betulis, Carpinis et Pinubus deiectis. Autunno et Vere. 
1682. Lycoperdon ferile globofum, afperum, fuper-fellatun. ficie fcrobiculata, ftellulis laeuioribus notata. EATSCr. El. Fung. p i $1+5 \cdot$ n. ó.

Lycopcriton fellile, globolum, candidum, cortice exteriore in ftellares portiunculas foluto. GLED. Meth. Fung. pag. I 45 . var. f. BоEнi. n, c. var. 2. AICH. tạb. 79 . f. 3 .

Gerfirmier Bovift. Germ. Veffe de Loup étoilée. Gall.

In palcuis et mufcofis arborum radicibus quoque obuiam init. Autumno.

1683. Lycoperdon fetrile, giobofum, candidum, fu-tefrellatum. perficie externa ter̂́erulis notata.

Lycoperton globofum, fefile, candidum, cortice in arcolas cryitallorum aggregatorum aemulans foluto, GLED. Meth. Fung. p. 145. var. g. воEHM. n。 c. var. 3. SCHAEF, tab, 1 \&̇ं9.

Wïrfelf örmig gezeichneter Bovift. Germ.

In pafcuis et pratenfibus variis circa Lipliam e. $g$. um die Pfingftwiefe und den Bieniz etc. paffim. Autumno.

2684. Lycoperilon fipitatum, fubglobofum, vtrinque gemmatum. fubdeprefum, pyramidibus validis, diftsntibus muricatum; Atipite fubelongato, valido incraflato, difincto lineari. Batscr. El, Fung. p. 147 ก. I4.

Lycoperdon globolum et aculeatum, candidum, bafi longifima, crafta. GLED. Meth. Fung. p. I46. n. I. вовнм. n. c. var. 4. MICH. t. 97. f. I.

Edelfreinförmiger Bovift mit einem langen Stiele. Gerim.

In pafcuis ericetis et fyluis pinaftretis, im Bieniz, Oberholize, in der Dïbenfchen Heide frequens, ad vias qunque publicas arenofas non rarius occurrit. Aùtumno.

1685. Lycoperdon itipitatum, globofum pilofo-hirfu-lanatum. tum, Ripite fubelongato, valido, incraflato, hirto, diftinto, lincari, BAтsCr. El. Fung. p. 147. n. 15. 
Lycoperdon turbinatum, candidum, villofum, bafi longa et crafla, cartice exteriore prorfus fecedente et reflexo. GLED. Meth. Fung. p. 149. var.r. военм, n, c, var. 6. місн. tab. 97. fig. 2.

Wolligter Rovift. Germ.

In ericetis et pafcuis elatioribus juxta femitas, e. g. inter pagos Lez:t fch et Klein-Dölzig etc. Aeftate in Autumnum.

pyriforme. I686.* Lycoperdon ftipitatum, globofum, acuminatum, fcabrum, ftipite incraffato confluente, acumine aperto dehifcens. ватsCh. El. Fung. p. 147. n, 12. SCHAEF, tab. 185.

Lycoperdon pyriforme fipitatum, fubglobofum vmbonatum glabrum, fubrotundo ore. WILDEN. Prodr. Berol. n. I 196.

Birnforniger Bovift. Germ.

In nemoribus, im Rojenthale, Univerfatätsholze, Bieniz paffin. Autumno.

muricatum. 1687.* Lycoperdon feffile, pyriforme, fuperficie externa muricata, fubrotundo ore. WILDEN. Prodr. Berol.

ก. $119 \div$

Lycoperdon muricatum feffile, globofo pyriforme depreffum pyramidibus polyedris muricatum. BATSCH. El. Fung. p. I45. n. 4. SCIIAEF. tab. I84.

Stachlichter Bovift. Germ.

In verfuris argrorum et pafcuis ficcioribus bei Leut fch, Parneck ezc. paffim obuiam iuit. Autumno.

hirtum. I688. * Lycoperdon feffile, deprefium; fuperficie pilofohirta. BatsCh. El. Füng. p. 145. n. 9. мICH. tab. 97. fig. 4 .

Lycoderdon hemifphaericum, niueum, villis longiffimis, tenuifimis et fugacibus obfitum. GLED. Meth. Fung. p. I46. var. g.

Raucher Bovift. Germ.

In pafcuis humidis et pratorum terminis bei Schöhfeld et Lindenau fed rarius reperi. 
r. Pedunculata.

1689. Lycoperdon Aipite Iongo, capitulo globofo, pedunculaglabro; ore cylindrico integerrimo. LinN. Sylt. p. tum.

9.I. n. 9. SCHREB. Spicil. p. 113. n. 1094. TOURN. Inft. n. 563. t. 33. f. E. F.

Lycoperion pedunculatum ftipite integro, capitulo globofo, ore difincte marginato, margine angufto. Batsch. El. Fung. p. 149, n. 19, et Cont. I, p. 241 . tab. XXIX. f. I $6 \%$.

Langfieliger glatter Staubfchwamm. Germ. Vefede - Loup pédunculéc. Gall.

In muris argillaceis paffim. Autumno.

\section{\&. Stellata.}

1690. " Lycoperdon volua fimplici, radiis oblongo-oua- radiatum. tis; acutis, integris, feffle, globofum, ore ftellato. Batsch. El- Fung. p. I5I. ก. 21.

Lycoperdon fellatum volua multifida, capitulo glabro; ore acuminato dentato. LiNn. Syft. p. 981. n. 6. SCHAEF, t. 182. MiсH. tab. 100. fig. 4-6.

Lycopercion globofum et feflile, volua radiata, patente; ore acuminato, dentato. GLED. Meth.Fung. p. I 5 I. n. V.

Großffraliger Sternchwamm mi zerfchlizter Mün. dung. Germ. Vcfje-de-Loup radiće. Gall.

In fyluaticis locis ad mufcofas arborum radices in der Dübenfchen Heide paffim. Autumno et Vere.

169r. Lycoperdon volua fimplici, radiis dilatatis, fif- multifidum. fis, feffile, globofum, ore ftellato. ватsсн. El. Fung. p. I 5 I. n. 24. MICH. t. 100. f. 5.

Lycoperdon multifutum volua multifida patente euanida: radiis ouato - lanceolatis. SCHREb. Spicil. p. II3. n. 1095 .

- Lycoperdan globofum et feffile, ore ftellato, volua radiata, patente; radiis multifidis. GLED. Meth, Fung. p. 152, n. V. yar, b. 
Vielftraliger Sternfchwamm. Germ.

In ericetis et faltu magno verfus Düben; porro in muris argillaceis inter Mufcos paflim obuiam mihi venit. Autumno et Hyeme.

coronarum. 1692, Lycoperdon volua fimplici, radiis ousto-oblongis, acutis, integris, globofum, ore acuminato, fimbriato, ftipite breuifimo, cylindrico gracili ftipitatum. вaтsCr. El. Fung. p. 15I. n. 25. fub Lycop. pedicellato.

Lycoperdon petiolatum, globofum, afperum et paruum, volua radiata, patente, ore denticulis coronato. GLED. Meth, Fung. p. 152. n. V. a. MiCr. t. IOO. f. 2. SCHAEF. t. 183 .

Gekrönter Stcrnfchzeamm. Germ.

In locis-fyluaticis mufcofis circa Betulas, im Bieniz, Univerfitätsholze etc. paflim occurrit. Autumno.

\section{s. Parafitica.}

Epidendrum 1693. Lycoperdon parafiticum feffile, globofum, purpureum, cortice fatifcentis brunelcente, polline feminali liliaceo. JACQ. Collect. I. p. 34\%. n. I32.

Lycoperdon Epidendrum cortice formaque purpurea. LINN. Syft. p. 982. n. 17. вовнм. n. 848 . Flor. Dan. tab. 720 .

Lycoperdon fphaericum, fetfile, ore in apice vel integro, vel inaequali et radiato. GLE1). Meth. Fung. p. T.5O. n. IV. SCHAEF. t. I93.

Blutrother Staubfchteanm. Germ. Veffe-de-Loup pourpre. Gall.

In fyluis et terminis pratorum, variis lignis et truncis putrefactis, nec non in terra intra Mufcos in fyluis frequens. Autumno et Vere.

epiphyllon, 1694 * Iycoperdon aggregatum, parafiticum, ore nultifido, lacero, puluere fuluo. LINN. Syft. p. $98 \mathbf{f}$. Blattlofer Staubjchreamm. Germ. Veffe-de-Loup fauve. Gall. 
In fuperficie inferiori Foliorum Tuffitaginis Petaftidis: in hortis paganis ad Klein-Dölzig', Altranftädt, OÊtobri 1 788. reperi.

I695:* Lycoperton luteum, nitens, fragile, femine fu- luteum. fco-nigro, farinofo-arenaceo. Batsch. El. Fung. p. 155. n. 32 .

Mucor luteus, globofus, in bafi tomentofa feffilis. CLED. Meth. Fung. p. 162. n. IV. var. c.?

Mucor ozatus. SCHAEF. t. 192.

Goldgelber Staulffchreamm. Germ.

In arborum fruticumque truncis emortuis putridisque et foliis putredine corruptis paffim.

I696* Lycoperdon brunneum, induratum, feabrum, verrucofum. РатsCH. El. Fung. P. 155. n. 33.

War enformiger Staubfchwamn. Germ.

In trabibus lignisque putridis pafim. Autumno et Vere.

$1697^{*}$ Lycoperdion gregarium cylindricum rufefcens, veiparium. ore integerrimo fubrotundo, feminibus rufis. wiLDEN. Prodr. Berol, n, 1203.

Lycoperdon vefparium gregarium, cellis denfe connatis, fcariofis, membranaceis, croceo , fuluellis, femen bombycinum faturate croceum continentibus. Batsci, Cont. I. p. 253. t, XXX. f. I 72.

Bienenzelliger rother Wollenfchueann. Germ.

In fyluis ad lingna emortua putridaque paftim. Vere et Autumno.

1698 * Lycoperdon gregarium, globulis fubrotunáis fauogineun luteis, feminibus luteis. wILDEN, Prodr, Berol, n. 1204.

Lycoperdon funogineum gregarium, globulis denfe approximatis veficularibus, femen bombacinum luteum recondentibus. ват SCH. Cont. I. P. 257. tab. XXX. fig. 173 . 
Zellenförmiger geliber Wollenfchwamm. Germ. In truncis putrefcentibus paffim. Autumno.

\section{CARPOBOLVS. мiсн. Gen. $22 \mathrm{I}$.}

albicans. 1699. * Carpobolus volua multifida, fructu globofo ex féminibus combinatis. LinN. Syłt. p. 981 . n. 7. Lycoperdon Carpobolus. MICH, t. 10r. fig. I. - Flor. Dan. t. 895.

Schieffender weißer unächter Sternfchwamm. Germ. $V$ efje-de-Loup Carpobole. Gall.

In lignis putridis im Rofentilale paffim obuiam iuit. Autumno.

488. SPHAERIA. HALl. Hift:T. III, p. I2O. WEs. Spic. p. 28 I. Kugelfchwamm. Germ.

\section{a. Simplices.,}

nitida. 1700. * Sphaeria finplex fubfolitaria, fuboccultata, fplendens, atra: crufta fpathacea, rimofa. WEIG. Obf. p. 45. n. 6. tab. 2. fig. I4. wгв. Spicil. p. 28 I. ก. 297 .

Glänzender Kugelfchwamm. Germ.

In cortice Tiliarum et Fagorum haud infrequenter obuia. Perfiftens.

Crufta ex albido-oliuacea, cui immerguntur fphaerulae atrae, nitidae! WEB.

oliuacea 1 7or. * Sphaeria folitaria oblonga, conuexa, puluerulenta, carne concolore. wilden.- Prodr. Berol. n. $121 \mathrm{I}$.

Olivengrüner Warzenfchwamm. Germ.

In foliis Daturge Stramonii et Cucurbitae Melonis aliarumque plantarum fructibus. Autumno.

Puluis interne contentus oliuaceo gaudet; colore. 
I702. "Sphaeria gregaria, globata, claufa, nigra, ni-globularis. toris expers indurata. Barsch. Cont. I. p. 271. tab, XXX. fig. 180.

Kugelrunder W'arzenfchwamm. Germ.

In lignis deie tis putridis, im Rofenthale paffim obuia. Autumno.

1703. Sphaeria feffilis, fubrotunda, gregaria, nigra, oleracea. crufta rugofa, absque fplendore.

Lycoperdon Brajjicae lubterraneum rugofum, congeftuin. SChreb. Spicil. p. 114. n. 1096. hall. Hift. n. 2178 . Gleichen Abbildd. t. 6.

Kohl WVarzenfchwamm. Germ.

In foliis Bralficae putridis, porro in folfis femiex. ficcatis paffim occurrit. Aeftate in Autumnum vique.

1704. * Sphaeria gregaria, oblonga, nigro - fufca, Bombarda. apice poro tenerrimo femen album exprimente. ватsсh. Cont. I. p. 27 r. t. XXX. f. I81.

Schzearzbrauner Olivengeftalteter Warzenfchwamm. Germ.

In lignis humidis putrefcentibus, in Rofentizale ad Quercus truncos 1pecimina pauca fine OAtobris 1789 legi.

b. Compofitae, f. Sphaerulae plures in vno corpore.

1705. Sphaeria compofita, folitaria, fubpedunculata, tremelloides fubglobofa, purpurea, fubgelatinola. WEIG. Obf. p. 46. n. 8. tab. 3. fig. I.

Tremella pumpurea fubglobofa feffilis, folitaria glabra. linn.' Syft. p. 965. n. IO. schreb. Spicil. p. 112. n. Io97. fub Heluella.

Gallertartiger Kugelfchwamm. Germ. Tremelle pourpre. Gall.

In rimis corticum arborum fruticumque emortuorum e. g. in Oxyacantha, Vlmis, Fagis, Aeşculis, Tilitis etc. copiofe. Hyeme et Vere.

$$
\text { Tt } 5
$$


lycoperdoi 1706. * Sphacria compolita, conuexa, fubfolitaria, des. medulla farinofa, atra. werg. Obf. p.47. n. 10. t. 3. f. 2 .

Lycoperdon variolofum parafiticum, feffile fubrotundatum, cortice exteriore fuluo, deciduo, farina atra, compacta, LinN. Syt. p. 98 I. n. I3.

Boviftahnlicher Kugelfchreamm. Germ. Veffe-de-" Loup variolique. Gall.

Ii rimulis arborum fruticumque emortuis haud infrequens. Autumno ct Vere.

Carpini. I $\% \mathrm{~T}^{*}$ Sphaeria compofita atra, 1piculis minutifimis terminata. поғм. Veget. crypt. p. I. tab. I.

Sphacria fpiculofa, compolita, atra, nitens, cellis in maffum dilatatam colliculatam connatis, colliculo fingulo ftylum acutum atrum exferentibus. Batsch. Cent. I. p. 273. t. XXX fig. 182.

Schwarzer Riffer-Kugelfchwamm. Germ.

In paginis foliorum, praeprimis Carpini ficcorum, in Rofenthale pafim. Vere et Autumno.

maxima 1708. * Sphneria compofira, conuexa, reniformis, nigra. Wев. Spicil. p. $28 \%$. n. 30r. ноғм. Veget. Crypt. p. 3. tab. I. fig. 2. fub Sphateria deufa

\section{Größster Kuge? fchwamm. Germ.}

In fyluis ad truncos emortuos maxime Fagorum. in Rofenthale haud infrequens obuia. Vere ct Autumno.

Aauata, I709. * Sphaeria petiolata, nigra, incrafiata. HoFM. Veget. Crypt. p. I 7. t. I 1. f. 2.

Eingckeulter Kugelfchwamm. Germ.

In lignis putridis Quercuum deiectis; porro in cellis et hortis. Autumno et Vere.

mbra. I710* Sphacria conuexa rubra tota exafperata. WIGG. Primit. $n, 935$.

Rother. Kugelfchwanm. Germ.

In ligno Fagorum et Carpisorum putrido. Au. pumno et Hycme. 
vel ß) Semina Fungorum interna explofione membranulae diffrasta latcraliter eiaculanda.

489. TREMELLA. L. G. I320. Gallerte. Germ.

17II. Tremella fubrotunda, concaua, plicata, nigre- Auricula, fcens. wilden. Projr. Berol, n, 1217.

Peziza Auricula concaua, rugola, auriformis. LINN. Syft p. 979. n. 10.

Eluella fefilis, membranacea rugofa et crifpa, in formam-gyrofan et concauam varie complicata. gied. Meth. Fung. p. 39, n. III. военм. n. 842 。 BLACKW. t. 334.

Pharm. Auricula Fudae.

Ohrenfchreamm 1. Fiudasfchreamm. Germ. Peziz» Oreille. Gall.

In fruticetis et pomariis pratenfibus fyluaticisque, v. g. im Streitholze, Rofenthale, hinter dem Brandvoriverke, in Zjchocherfchen-Gomnereitzer Holze etc. ad Opulos, Corylos, Aceres et Sambucos emortuos et ad alias arbores oritur. Autumno.

1712. Tremella feffilis, fubrotunda, plicata vndulata, Noftec, fufco-virens. HuDson. Angl. Ed. II. p. 564. n. 5.

Tremella Noftoc plicata vndulata. Linn. Syft. p. 965. n. 2. военм. n. 869. (fub Linkia.) SCUREd, Spicil. p. I4I. n. 869. Flor. Dan. tab. 885. fig. I.

Noftock. Germ. Tremelle Noftoc. Gall.

In pratis poft pluuias, praeprimis inter Mufcos frequens. Autumno et Vere.

1713. * Tremella feffilis, fubrotunda, vndulata, ni- arborea. giefeens. Hudson. Angl. Ed. II. p. 563.

Tremiella fagarum feffilis membranacea, difformis, venofo-fubfufca. RETz. Prodr. Flor, Scand. n. I 422.

Basm-Gallerte. Germ.

In arborum ramulis deie tis fepibusque putrefcen tibus paffim. Autumno et Vere. 
mefenteri-1714. Tremella feflilis, fubrotunda, plicató-flaua. formis wilden. Prodr. Berol. n. 1220.

Tremella mefenteriformis in plicas multiplices intorta. Linn, Sýft, p. 965. Jace. Mifcell. Vol. I. p. 142. t. 13.

Eluella membranacea, multiplex, membranis feffilibus, fimbriato plicatis. GLEN. Meth. Fung. p. 51 . n. IX. SCHAEF, t. 168.

Gekröfartige Go?lerte. Germ.

Ad ramenta varia arborum putrida earumque truncos in fyluis ceduis, im Univerfitütsholac, in der Dübenfchen Heide etc. Autumno et Vere.

Globofa. 1715. Tremella fphaerica, veficulis aggregatis. weIs. Crypt. p. 28.

Tremella-granulata gelatinofa, fphaerica, aggregata, viridis. IIUdson. Angl. Eủ. II. p. 566.

Vlua granulata fphaerica, aggregata. LinN. Syft. p. 972. n. 14. SCHREb. Spicil. p. 141 . n. $1155 . \mathrm{Fl}$. Dan. t. 660. f. 2.

Kugelf ormige Gallerte. Germ. Uive en tête. Gall.-

In paludofis et inundatis argillofisque locis inter Gaurfch et Laure, ibidem in argilia tenuifima caerules; porro in fagnis ad Leut/ch, Mark - et Altranftädt, Ketfchau, Lindenthal in argilla alba et alibi. Aeftate.

juniperina. I716. * Tremella feffilis, gelatinofo-pulpofa, fuborbiculata, plicato-crifpa, flamo-rufa, Jace. Collect. Vol. II. p. I 73 . n. 172 .

Tremella juniperina feffilis, membranacea, auriformis, fulua. IINN. Syft. p. 965. n. I. WEB. Spic. p. 277 . n. 297.

Wacholder Gallerte. Germ. Tremelle du Genevrier. Gall.

Ad Juniperos paffim et ad Sabinam Octobri 1789 in Horto Lochriano legi. Autumno et Vere. 
1717. Tremella tuberculofa, folida rugofa. LINN. Syft. verrucofa.

p. $965 . n$. 6. SCHRFB. Spicil. p. I:50. n. II 52.

Tremella fluaiatilis, geiatinofa et tuberculofa. DILl. Mufc. 55. tab. 20. fig. 16.

Gall.

Warzigte Gallerte. Germ. Tremelle verruquenfe.

In ftagnis ad Lindenthal et in variis plantis aqua. ticis fub aqua innaficens.

1718. Tremella terreftris, tenera, crifpa. schreb. Spic. crifpa.

p. 1 40. 11. I $157^{\circ}$. DILL. Mufc. 52, tab. 5C. f. It.

Kraufe Gallerte. Germ.

Ad terram et arborum radices atque in locis fuburbanis poft pluuias.

490. MVCOR, L. G. 1334. Schimmel, Germ.

Moififure. Gall.

a. Perennes.

17 19. Mucor perennis, viridis, foliis furfuraceis, fti- furfuraceus: pite filiformi, capitulo globolo. LINN. Sylt. p. 982. n. 5 .

Lichen capitatus. SCHRER. Spicil. p. I34. n. II34. Kleienartiger Schimmel. Germ. MoifijJure furfuracée. Gall.

In rimis Quercuum et truncis Betularum; porro ad terram in Rofenthale, in Querceto ad Altranftiidt paffrm.

$1720^{*}$ Mucor perennis, ftipite filiformi, nigro; capi- fphaerocetulo globolo, cinereo. LiNN. Syft. p. 982. WЕв, plialus. Spicil. 198. fub Lichene.

Kugelrunder Schimmel. Germ. Moifigjure à tête ronde. Germ.

In parietibus, lignis putridis et lapidibus paffim. Vere et Autumno copiofe. 


\section{b. Fugaces.}

Mucero. r721. Mucor ftipitatus, capfuia globofa. tinn. Sylt. p. 982. n. 7. уовим. n. 874. Flor. Don. t. 467. f. 4. Mucor celpitofus, capitulo fphnerico, pétiolo fetaceo, longitimo. GLed.' Méth. Fung. p. 161, n. 4. м1сн. t. 95. f. I.

Gemciner Schimuncl. Germ, Moififfure grifâtre, Gall.

In variis corporibus putredine corrupiis v. c. pane, cibis farinaceis aliisque efculentis nec non in Cucurbitae, Cerafi, Pruni, Mali fructibus frequenter occurrit.

leprofus. 1722. * Mucor fetaceus, feminibus radicalibus. IINN. Syft. p. 982. n. 9.

Geffeckter Schimninelfchueamm. Germ.

In cellis locisque luffocatis frequens. Autumno.

Slaucus. $1723 .{ }^{*}$ Mucor ftipitatus, capitulo fubrotundo, aggre- gato. LinN. Syft. p. 982, n. 2. Flor. Dan. t. 777. f. 2 .

B. Jus petiolata, fruetificationum lineolis in capitulum radiatum denfe congeftis. GLED. Meth. Fung. p. $24 ;$ n. VI.

Grauer Schimmelfchevanim. Germ. Moififfure glauque. Gall.

In Vlmorum Carpinorumque corticibus et nd varias arborum radices et frußus Cucurbitarum, Dauci, Raphanzi; porro in Cerealiunn fcaphis. Aeftate et Autumno.

Eryinphe. 1724. * Mucor albus, capitulis fufcis, feffilibus. LINN, Syft. p. 98 r. n. 14 .

Honigthau. Germ.

In foliis Humuli; Lamii, Symphti etc. paffim.

Lycogala, 1725. * Mucor capitulo cupreo, gelatinofo, pellucido fugaci, globofo. wiLDen. Prodr, Berol. n. I 233 .

In truncis arborum putridis, im Rofenthale, paf. firn. Autumno.

granufus. 1726. Mucor globofus et cellularis, feffilis; cortice in puluerem, fatifcente. GLED. Meth. Fung. p. I58. n. I. SCHOLz. Suppl. n. II64. 
In terra ipfa recrementis ligneis referta porro in, in lignis e. g. Corylo, Tilia, Populo, Vlıno, Fago etc. poft pluuias maxime oritur. Aeftate.

1727. Mucor fefrilis, fubglobofus, niueus, exiguus, niueus. cortice in puluerem fatifcente. GLED. Meth. Fung.

p. $559 \cdot^{\prime}$ n. II. vâr, b. LEY̧s. n. I 572 .

Schneeweifser Schimmelfchwanm. Germ.

In foliis deiectis, fruticetis et locis humidioribus oritur. Autumno.

491. EMBOLVS. Hall. Hift, n. 2137. Fadenfchimmel: Germ.

1728. * Embolus nigerrima villo albo adfperfus. HaLl. bicolor. Hift. n. c. t. I. fig. I.

Mucor Enbolus feta nigra, villo fufco, LINN. Sy凡t. p. 982, n. 3 .

Zueifarbiger Fadenfchinmel. Germ. Moiffjure velue. Gall.

In lignis putridis, im Rofenthale, paffim occurrit.

\section{MONILIA.}

I729. ${ }^{*}$ Monilia ftipite ramofo, fpicis ternatis, LINN+ eacfpitofa, Sylt. p. 982. n. 12, lub Mucore.

By flus petiolata caefpitofa, fructificationibus in $\mathrm{fpi}$ cam decompofitam digeftis. GLID. Meth. Fung. p. 24 . n. $\mathrm{V}$.

In Vlmo, Carpino et variis corporibus putrefcentibus.

1730. * Monilia ftipitata fpicis digitatis. IINN. Syft. cruftacea. p. 982. n. I I. Lub Mucore. Flor. Dan. t. 897 . f. I. In cibis et fructibus putredine corruptis paffim.

1731. * Monilia lutea, globola, in bafi tomentofa feffi- nidulans. lis. GLED. Meth. Fung. p. 162. n. IV. var. c. fub Murore. इсног, Suppl, n. 1163. 
In lignis putt解is et fruticum ramentis emortuis toto fere anno occurrit.

493. FVLIGO. HALL. Hif. n. 2133 . Rufsfchwann. Gicrm.

feptica. 1732." Fuligo vnetuofa flaua:" uive: Syft. p. 932.n. 15 . BOEHM. n. 8:2. fub Mucore.

Macor cruftaceus, ramofifimus, mollis et fugax crocei coloris. GLED. Meth. Fung. p. 160. n? II. var. d.

Vergänglicher Rußjchwamm. Germ. Moifigfure Jeptiqui: Gall.

In fimetis, vaporariis, deferuefcentibus et pul, vere coriarioruin reiecto circa Lipfiam frequenter occuirrit.

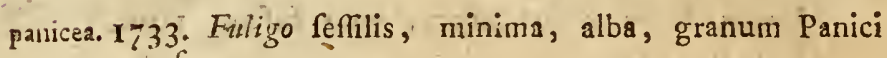
referens.

Mucor aggregatus, fubglobofus, feffilis exiguis et niueus, vertice in puluerem fatifcente. GLED. Meth. Fung. p. 159. n. II. var. b. вовнм. n. 873 .

Hirfenkornâhnlicher Rußfchwanm. Germ.

In foliis deiectis putridis, fruticetis, fyluis et locis fuburbanis humidioribus frequens. Autumno. 


\section{INDEX GENERVM.}

\begin{tabular}{|c|c|c|c|}
\hline \multicolumn{2}{|c|}{ A. } & Anchufa & 109 \\
\hline$A_{\text {cer }}$ & pag. $206 \cdot 208$ & $\begin{array}{l}\text { Andropogon } \\
\text { Androlace }\end{array}$ & $\begin{array}{r}79 \\
114\end{array}$ \\
\hline Achillea & $478-479$ & Anemone & $\begin{array}{r}114 \\
294-296\end{array}$ \\
\hline Acorus & 197 & Anethum & 159 \\
\hline Acroftichum & 503 & Angelica & 152 \\
\hline Actaea & 287 & Anthemis & $477 \cdot 478$ \\
\hline Adonis & 306 & Anthericum & 186 \\
\hline Adoxa & 218 & Antíoceros & 558 \\
\hline Aegopodium & 163 & Anthoxanthum & 14 \\
\hline A elculus & 204 & Anthyllis & 386 \\
\hline Aethufa & 153 & Antirrhinum & $341-343$ \\
\hline Agaricus. & $601-627$ & Aphanes & 108 \\
\hline Agrimonia & 248 & Apium & 162 \\
\hline Agrofte:nma & $240-24 I$ & Aquilegia & 29 I \\
\hline Agroftis & $4 I-44$ & Arabis & 355 \\
\hline Aira & $43-47$ & Aretium & 454 \\
\hline Ajuga & $319-3=0$ & Arenaria & $236 \cdot 237$ \\
\hline Alcea ... & $37^{2}$ & Ariftolochia & 203 \\
\hline Alchemilla & 95 & Arnica & 464 \\
\hline Alifma & 202 & Artemifia & $45^{6}-45 z$ \\
\hline Allium & $179-183$ & Arum & 302 \\
\hline Alopecurus & 40 et $4 I$ & Arundo & 62 et 63 \\
\hline Alfine & 167 & $\Lambda$ fclepias & 134 \\
\hline Althaea & 373 & Afparagus & 189 \\
\hline Alyffum & $346 \cdot 3.77$ & Afperugo & 108 \\
\hline Amaranthus & 172 & Afperula & $91-93$ \\
\hline Amygdalus & 255 & Afplenium & $506-507$ \\
\hline Anagallis & 110 & After & $472-475$ \\
\hline & & $\gamma \mathbf{a}$ & \\
\hline
\end{tabular}


Aftragalus Athamanthae Atriplex Auena

B.

Ballota

Barbula

Bartrammia

Bellis

Berberis

Beta

Betonica

Betula

Bidens

Blafia

Boletus

Borago

Braffica

Briza

Bromus

Bryonia

Bryum -

Bupleurum

Butomus

Buxbaumia

Byffus

C.

Calendula

Callitriche

Caltha

Campanula

Cannabis

Cardamine

Carduus

Carex

Caŕlina

Carpinus

.

p. $417 \cdot 418$

$142-$

175

59.62

$528 \cdot 529$

548

460

177

138

$32 \mathrm{I}$

- 100

455

560

$627-635$

107

355-359

53

56.59

497

$542-543$

147

223

$548-549$

$595-593$

Carpobolus

Carum

Caucalis

Cenntaurea

Centunculus

Ceraftium

Ceratophyllum

Chaerophyllim

Chara

Cheiranthus

Chelidonium

Chenopodium

Chondrilla

Chryfanthemum

Chryfofplenium

Cicer

Cichoreum

Cicuta

Cineraria

Circaea

Ciftus

Cladonia

Clauaria

Clematis

Clinopodium

Cnicns

Colchicum

Colutea

Conarum

Cochlearia

Conferua

488 Conium

2 Conyza

294 Conuallaria

420 et 42 I

158

468

13

288

$572-577$

$65 \mathrm{I} \cdot 655$

I 293

$3+3$

$448 \cdot 449$

- 196

$401-402$

233

$347-348$

$598 \cdot 600$

146

458

$185 \cdot 186$

123-126 Conuolunlus

I I 5

173 Coreopfis - 484 et 485

360-361 Coriandrum

449-4.52 Cornus

153

94

69-77 Coronilla

$420-42 \mathrm{I}$

447-448 Corylus

310 Crataegus 
I NDEX GENERVM.

- 675

Crepis

Cucubalus

Cucumis .

Cucurbita

Cuficuta

Cynara

Cynoglofum

Cynofurus

Cyperus

Cytifus

D.

Daatylis

Daphne

Datura

Daucus

Delphinium

Dianthus

Dicranum

Dictamnus

Digitalis

Dipfacus

Draba

Drofera.

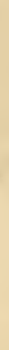

\begin{aligned} 437 & Eupatorium \\ 135 & Eyphorbia \\ $494-495 &$ Euphrafia. \\ $495 \cdot+16 & \\ 56 & \\ -45^{2} & \\$\hline 05 & Fagus \end{aligned}

63 et 67 Feftuca

35 Ficaria

40.t Eilago

Fiffidens

Fontinalis

Fragaria

48 Fraxinus

454

$250-253$

$334-335$

F.

$2 \mathrm{I} 4$ Fritillaria

305

$53-56$

30 [

487

$523 \cdot 524$

544

- 229

189

116 Fuligo 67,2

290-143 Fumaria, is $380-382$

$232-234 \quad G_{*}$

$525-527$

228 Galanthus $\quad 178$

340 Galega $\quad 407$

83 Galeopfis $\quad 323-324$

345 Galium $87-9 x$

170 Genifta $\quad 383 \cdot 385$

Gentiana $\quad 135$

E. Gernnium $\quad 365 \cdot 370$

Geum 282.283

Echium

104 Gladiolus

65 Glaux

Elyınus

Elstine

Embolus

219-120 $\begin{aligned} & \text { Glecoma } \\ & 671 \text { Glycine }\end{aligned}$

$3 \mathrm{~L}$

ข33

313

418

Epilobium

208-2 I I Gnaphalium

498-500 Grimmia

213 Gymnoftomum

4h7 Gypfophila

38

Equifetum

Eriea

Erigeron

Eriophorum

Eruum

Eryngium

407

140 Hedera

Eryfimum

Euonymus -

$352-353$. Hedwigia

129) Hedyfarum

$\mathrm{Vu} 2$

H.

$459-460$

5 I 5

513

23 T

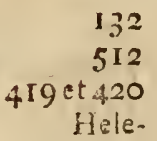


INDEX GENERVM.

Helenium

Helianthus

Heluella

Heracleum

Herniaria

Hefperis

Hieracium

Hippocrepis

Hippophae

Hippuris

Holcus

Holofteum

Hordeum

Hottonia

Humulus

Hydnum.

Hydrocharis

Hydrocotyle

Hyofeyamus

Hyoferis

Hypericum

Hypnum

Hypochaeris

Hyropus

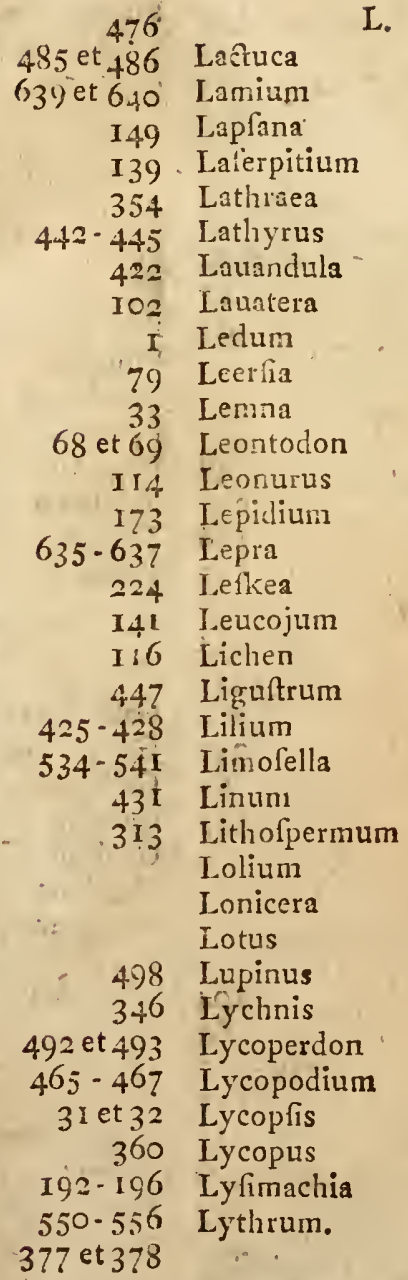

$439-442$

321 et 322

$4+7$

I 52

334

$393-397$

316

$3=0$

227

514 et 515

21 et 22

$43 \div$

312

348 et 349

$592-595$

532 et 533

178

563-569

4

190

338

169

106

65 et 66

I 26 - I 28

404- 406

Iafione

498

385 et 386

Iberis

Impatiens

Inula

Iris

Ifatis

Iuneus

Itngermaninia

Iuniperus

K.

Malua

Marchantia

Koelreutera

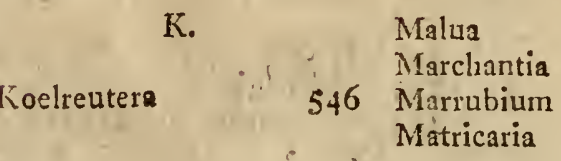

M.

239 et 240

$657: 663$

502

107

12

I I I

$247 \cdot 248$

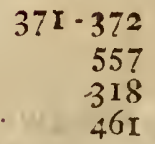

Medicago 
INDEX GENERVM。

\begin{tabular}{|c|c|c|c|}
\hline Medicágo & p. $422-424$ & Orchis & $14-18$ \\
\hline Meefia & 550 & Origanum & 332 \\
\hline Melampyrum & $337-338$ & Ornithogalum & 187 et 188 \\
\hline Melica & 47 & Ornithopus & 421 \\
\hline Meliffa & 333 & Orobanche & 335 et 334 \\
\hline Mentha & $313-316$ & Orobus & $392-393$ \\
\hline Menyanthes & iI 5 & Orthotrichum & $516-517$ \\
\hline Mercurialis & $223 \cdot 224$ & Ofinunda & 500 et $50 \mathrm{r}$ \\
\hline Mefpilus & $262 \cdot 263$ & Oxalis & 243 et 244 \\
\hline Milium & $4 I$ & $x=$ & \\
\hline Mnitam & $543 \cdot 546$ & P. & \\
\hline Momordica & 495 & & \\
\hline Monilia & $67 x$ & Paeonia & $2=20$ \\
\hline Monotropa & 227 & Panicum & $48-49$ \\
\hline Montia & 33 & Papauer. & $284-236$ \\
\hline Mucor & $669-67 \mathrm{I}$ & Parietaria & $1(1) 2$ \\
\hline Myagrum & $345-346$ & Paris & 219 \\
\hline Myolotis & 109 & Parnafia & 168 \\
\hline Myofurus & 172 & Paftinaca & 153 \\
\hline \multirow{3}{*}{$=\quad \mathrm{N}}$. & 314 & $\begin{array}{l}\text { Pedicularis } \\
\text { Peltigera }\end{array}$ & $\begin{array}{c}243 \text { et } 34 \cdots \\
561-56=\end{array}$ \\
\hline & & Peplis & 196 \\
\hline & & Peucedanum & $\quad I 45$ \\
\hline Narciffus & $178 \cdot 179$ & Peziza & $640-643$ \\
\hline Nardus. & 39 & Phalaris & 39 et 40 \\
\hline Neckeria & $530-531$ & Phallus & $637-638$ \\
\hline Nepeta & 326 & Phafcum & $509-511$ \\
\hline Nicotiana & II 7 & Phafeolus. & $390 \cdot 392$ \\
\hline Nigella & 292 & Phellandrium & 1157 \\
\hline \multirow[t]{2}{*}{ Nymphaea } & 289 & Philadelphus & 255 \\
\hline & & Phleum & 64 \\
\hline \multirow[t]{2}{*}{0.} & & Phyteuma & 122 \\
\hline & & Picris & 433 \\
\hline Detofpora & $6 \div 3-65 I$ & Pimpinella & $16 \mathrm{I}$ \\
\hline & $33^{\circ}$ & Pinguicula & 30 \\
\hline Oenanthe & 145 & Pinus & $373-37^{6}$ \\
\hline Denothera & $2 \mathrm{II}$ & Pifun & $388 \cdot 389$ \\
\hline Ononis & 387 & Plantago & $84-86$ \\
\hline Onopordon & 452 & Platanus & 309 \\
\hline Ophioglofum & 500 & Poa & $50 \cdot 5^{2}$ \\
\hline \multirow{2}{*}{ Ophrys } & Iq et 20 & Pollichia & $322-323$ \\
\hline & & Vu 3 & \\
\hline
\end{tabular}


CLASSES GENERVM.

Polycnemum

Polygala

Polygonum

Polypodium.

Polytrichum

Populus

Poronia

Portulaca

Potamogeton

Potentilla

Poterium

Prenanthes

Primula

Pridnella

P. unus

Plora

$P$, teris

$P$ ulmonaria

F'yrola

] ?yrus

Quercus

Q.

R.

Ranunculus

Raphanns

Refeda

Reticularia

Rhamnus

Rhinanthus

Rhus

Ribes

Riccia

Robiniz

Rofa

Rubus

Rudbeckia

Rumex

Ruta
30

382 Sagina

215-218 Sagittaria

503-506 Salicornia

5 I8-520 Salix

220-222 Saluia

$65^{I}$ Sambucus

$2+7$ Samous

97-99 Sanguilorba

280-282 Sanicula

305 Saponaria

439 Satureja

I 3 Satyrium

3 I Saxifraga

$256 \cdot 260$ Scabiola

$587-590$ Scandix

508 Schenchzeria

I 95 Schoenus

226 Schollera

263-265 Scilla

Scirpus

Scleranthus

306

Scorzonera

Scrophularia

Scutellaria $327-328.583-$

$297+30 \mathrm{r}$

35 I. -352

$249-250$

$569-570$

123

336

I 46

130

$559 \cdot 560$ Sherardia

402 Silene

268-276 Sinapis

276.278 Sifymbrium

485 Sium

198-20I Solanum

225 Solidago
S.

$22 \cdot 26$

12

164

I 22

$3^{6}$

$14 \mathrm{I}$

$231 \cdot 232$

' 327

18

$230-23$ I

$8 \mathrm{I}-83$

154

202

$3+$ et 35

213

$+89$

$36-38$

$228 \cdot 229$

$435 \cdot 436$

339

587

65

$244-246$

I $5 \mathrm{I}$

253

$469-47 \mathrm{I}$

20.21

453

' 58

93

$235 \cdot 23^{6}$

$361-362$

$362 \cdot 364$

148

119- 12 I

468

Sonchus 
INDEX GENERYM.

Sonchus

Sorbus

Sparganium

Spartium

Spergula

Sphaeria

Spinacia

Spiraea

Splachnum

Stachys

Staphylea

Statice

Stellaria

Stemonitis

Stipa

Struthiopteris

Symphytum

Syringa
Sphagnum
$445 \cdot 446$ Trientalis

26I Trifolium

77 Triglochin

389 Triticum

24I-242 Trollius

66\$-666 Tropaeolum

5 I 2 Tubercularia

174 Tulipa

265-268 Tumitis

521 Tuffilago

224-226 Typha

167

168

$238 \cdot 239$

655 et 656

44 et 45

501

106

4 et 5 Utricularia

Ulmus

Ulua

Umbilicaria

Urtica

Ufnea
$410-414$

197 et 198 .

67

297

160

583

I $9 \mathrm{x}$

355

$47 \mathrm{r}$ et 472

78

U.

V.

Tagetes

Tanacetưm

Taraxacum.

Taxus

Tetraphis

Teucrium

Thalictrum

Thefium

Thlafpi

Thymus

Tilia

Tordylium

Tormentilla

Tortula

Tragopogon

Trapa

Treniella $667-669$

$475 \cdot 476$

$457-458$

$43 \mathrm{I}$

378

514

$317 \cdot 319$

293

134

349 et 350

329 et $33^{\circ}$

288 et 289

150

278

527

432

93

Vaccinium

Valeriana

Verbafcum

Verbena

Veronica

Verrucaria

Viburnum

Vicia

Vinca

Viola

Vifcum

Vitis

140

600

5 I I

49.

$590 \cdot 592$

I I

2 I I et 2 I 2

29 et 30

118

II

5 - I I

$578-582$

$397-401$

119

$489-492$

IOI

130

W.

Webera

weifia.

547 et 548

516

Z.

Zinnia

480

$\mathrm{vu}_{4}$

INDEX 


\section{N D E X}

NOMINVM' PHARMACEVTICORVM, ANGLORVM, GALLICORVM GERMANORVMQVE.

A.

A bele-tree

Abies

Abrefche

Abfinthe pontique 1085 . vulgaire, 1086,1087 Abfinthium ponticum 1085. vulgare 1086 Abton

Acacia noftras 1208 Acacie, falfche 974. teutfche

Acanthium

658

Acetofa 522

1076

Ackerbremen

ibid.

no. 560 Ackerbrombere ibid, 926 Ackerburzel 632

66 I Ackerdiftel ro78. kleine

Ackererbfe Aclerfodenaut. Ackerfilzkraut ibid. Ackergauch heil $\quad 306$ Ackerholder $\quad 437$ Ackhornkraut Ackerklee 995. 103 I. Ackerknoblinuch - 469 Ackerkohl 8.69. 89I Acetofella

22I Ackerkümmel, fchwarzer Ache

Achillenkraut

624 Achilliere

433

I $14 \mathrm{I}$

Achtfamme $16 \approx 5-1658$

Ackerbacillen

400

Ackerbaldrian 75. gezälinnter

Ackerbecre

76 Ackerröthe

$6 \mathrm{I} 4$ Ackerkuhweizen $\quad 832$ Ackermäufeöhrchen 32 Ackermeyerkraut 260 Ackerneffel 796. kleine todte Ackerrettig 793 869 263 Ackerruhrkraut 
Ackerfalat

Ackerfchaftheu

Ackerfchmielen

75 Alandiftel

1075

1 I84 Alantwurzel

Aekerfenf

Ackerfonche

Ackerfpark

Ackerfteinfaame

I2I Albeerbaum,

891 562. weiffer

1105

Ackerfternkraut

Ackertrefpe

1059

Alcea

fchwarzer

616 Alchemilla

560

293 Alchemiftenkraut ibid.

93 I Alhornbaum 438

Ackerveilchen $1: 1 \% 1172$

Ackerviehgras

Ackervogelkraut

I 16

Alifier des bois

659

Alkirfine

Alleluja

652

Ackerwinde

Ackerwurz

Ackerzwiebel

62

317

Allermannsharnifch

624.625

Acroftique feptentrionale

Allgood f. Aligut.

78

80 Alliaire

486 Allium

872

Alnus

466

I 196

Adder's - Tongue

Alpenklee

285

1189

Adermennig

635

Aderfchwamm, ausgebrei-

Alpentennthiermoos 984

Alpenrennthiermoos 1397

Alpkraut

Alpranken

1080 teter I 568 . fetter 1567

Adianthum aureum 1235 rubrum

1208

Adlerfarn f.kraut 1210

Adlersbecren

659

Aepfelquitte

669

Aefcherwurzel

Aeficulapie, weife

$5 \div 6$

36 I

Affubeere

544

Affodillilie. gelbe 477

Alfine

Alfunach

Altmannsirraut

$36 \mathrm{r}$

Aluyne. I086́

Amandier Pêcher 955

Amourette $\quad 14 \% .149$

Ampfer, gehäufter 518 . kraufer 5I5. rundblättrichter 521. SpitzblättAfrican-Marigold 1 I 35 Agaricus $\quad 148-157$ ? Agaricus praeparatus $15^{\circ}$ Agrimonia

635

Agroftemme des Blés 614

Ahorn

$530-532$

Aigremonie

635

Aiguille du Berger 413

Ail $466-471.273-476$

Airelle rouge

Alant

543 richter 516 . Rumpfblättrichter 519 . wilder 523 . zahmer

$5 \mathrm{I} 3$

Anfelbeerdorn

350

Anagallis

305

Androface

314

Anemone

Anethum

$730-735$ Angelick; kleine falfche 45.5. wilde 409 Angelique 409 Angerblühmchen 1095 Vu 5

Anger? 
Angerkraut

Angurie

Anferina

Antemide champêtre 1138

Antoniuskraut

Apfelbaum, wilder

$$
\text { zahmer }
$$

Aphare des champs

Apios

Apium

Apoftemkiraut

Appeldören

Apple-Quince

Apple - tree, common 668. willing.

Ariftolochia

Arlsbeeren

Armleuchter, gemeiner 6 ftruppigter

667
526

659

1005

433

233

532

669

Avena

Avenette argentée

Augentroftgras

Augenwimperflechte 1363

Augenwurz

Augenzier

Auguftpflaumen

Auguffchwamm

Aulne noir

1107

Aron, gefleckter

Arrête-Boeuf

Arroche 372. 456. 458 .

Arfchröfel

Arsmart

753

943

Aune

Avoine 168. I69. 173.

459

661 $548-551$

Artemifia, alba 1087 . vul-

garis

Artifi

Artifchocke

Arum

Afche

Afchenpflanze

Afh

Afklepiade

Afparagus

Afpen-tree

Afperule

Afphodelus
1084

1028

1076

$\div 53$

561

1115

72

I 34

490

$56 \mathrm{I}$

$-259 \cdot 260$

4) 4

Auricula Iudae I 7 I I. mu. ris

1049

Auronne fauvage 1084

B.

Bachblume

Bachbungen

729

Bachgrasleder, langes $147^{\prime}$

Bachmünze 776. klcine

Bachweide

779

59. 65

400

Badekraut 802.1107.

Bärenfackel $\quad 323$

Bärenklau, unächte $40 \mathrm{I}$

Bärenklaudiftel.

1069

Bären- 
Bärenlauch

Bärklee

4.5 Bafilicum

937 Bafilienminze

$813 \cdot 814$

1193 Baftard-Crefs

778

Bärlappen

Bärtappen

ibid. Baftard-Cyperus 84.85 .

Bärwinde

318

Bärwurz, teutf́che 401 . unächte

391

Baguenodier en arbre $9 ? \mathrm{I}$ des Jardiniers 1008 d'Orient 972 à Pater Nofter

$4 \div I$

Baies de l'Airelle

$5+1$

Baldrian, gebräuchliche 74 unehelicher ibid.

Ballote noire

Balirofen

Balfamine

Balfamita

Balfamkraut

Balfammuinze

Balft ernacken

Bandfalat

806

Bandweide

536

I 74.1175

1080

1174

778

424

1046

Barla caprina 674 hirci

1027

Barbarine d'Orient 810

Baftard - Dittony

Baftard-Hawwe $1038-$

1041

Baftard-Helleborine 50.

5 I

Baftard-Parsley $386-388$.

Baftard-Pimpernel $\quad 40.4$

Baftard - Sun - Flower 1156

Baftardklebrich $\quad 25^{\circ}$

Bathengel - 786

Battate de Virginie $\quad 329$

Bauernborretfch $30 \mathrm{I}$

Bauernkreffe - 864

Bauernlöfleinkraut $\quad 448$

Bauernfenf $\quad 855.856$

Baume $776-778.864$.

Baumfarn

Baumflechte 1363.1364.

Babe de Bouc 1027 de $1377-1379$

Chevre 1670. deChevre, petit

$67+$

Barberry

460

Bardana

1079

Barley

$19=-194$

Bartmoos

$1259-1263$

Bartnelke 386. 359. wilde

Bartisufs

588

Bartfch

265

Baumlungenkrau

1382

Baumwollengras $\quad 98$

Baumwollenweide 60

Baumwurzelfauger $\quad 575$

Bean

$749 \cdot 948 \cdot 970$

Bean-tree

Bear-Breech

975

Beaume

401

Bec de Grue

Beccabunga

822

Bafe-liorehound

$40 I$ Becherblume

$901-914$

Soo Becherflechte $1388-\mathrm{I}_{3} 96$

bafil, bufh $8 \mathrm{I}$. leaft ib. Becherfchwämine 1616fchweet-fcented 813

Batilie, gemeine 813 . Bedeguar kleinfte

1620.1622-1624 686 Beech. 
Beech - tree

760 Berglein

Been blanc

596 Berglilien

Beeren, finnifche

287 Berglinde

715

ichwarze

542 Bergmünze

804

Beerkraut

Behen, weiffer

Beilkraut

Beinwel

Bellbaum

Bell-10wer

Bella Donna

Bellenholz

Bellis maior

- minor

Bendoite

Benedicta

Benedictenkraut

Bengellraut

Bentgras

Berberis

Berberizendorn

Berbisbéere

Berce

Bergbafilien

Bergblume

Bargdiftel

Bergerbfe

Bergladenkraut

Bergfenchel

Bergftachs

Bergguinfel

Berghabichtskraut

635 Bergpeternilie 382 . kleine $596 \quad 1$

I009 Bergofeffer

294 Bergquitten

560 Bergranunkel

383

546

664

$336-340$ 'Bergriedgras

736

$33^{2}$ Bergröthe

28

562 Bergfaniekel

248

I099 Beiglcharte

I093 Bergfchierling

381

$10 ? 7$

418

704. 705 Bergfchnitlauch

468

705 Bergichooten

533

70. Bergfkordien

364 Bergfternkraut, kleines

$107-114$

460

Bergftraufsgras

I 107

ibid. Bergthimion

I 15

itid. Bergveilchen

812

401.402 Bergwicke, grofse

1170

- $\$ 72$ Bergzwiebel

731 Berle

1076 Bertram, 396-398

952 Berufskraut 298. 802.845 .

1161

158 Berufswand

I I 3

360 Bertifwand 298

Befenkraut 862.898 .946$.

73 I Befingkraut, rothes 695

I05I. Beta vulgaris

375

1056 Betoine 789 . d'eau 838 .

Berghenne, fette

$6 \geq 8$

I12 Betonica

Berghirfe

1104

Bergkerbel

419 Bette vulgaire

789

Bergklee

994. 997. Bettelläufe

375

Bergknoblauch

468 Bettlersläufe

$28 \% \cdot 404$

Bergkrefle 835 ,

bittere $890^{\circ}$

Bettlersfeil

510

318

Berglabkraut

248 Betula

284

Berglauch

474 Beutelfchneiderkraut 86 ?

Beu- 
$\begin{array}{lr}\text { Beutelfchwämme } & 1674- \\ & 1676 \\ \text { Beyfurs } & 1087\end{array}$

Bibernell 246. 309. 429---

432. 759

Bident $1081-1083$

Bieberhodlein

Biberklee

Bieberkraut

Bienenbaum

Bienenheide

Bienenklee

Bienenfaug

Bielamdiftel

Bifolium

Rillberry

Bindfalat

Bind - weed

Bingelkraut

Bingenrofe

Binfen 93. 94. $498-508$

Binlengras

Birch-tree

Bird - Cherry - tree

Bird's Foot

Bird's Foot-Trefoil 976--

Bird's Neft

Birghanenfufs

Birke, gemeine

Birkwurz

89-97

284

653

1010

979

49

745

284

695

lirnbaum, gemeiner 666 wilder

Birnquitte

Birth wort

Bifamhanenfufs

Bifamknabenkraut

Bifamkraut

Bifchofsmuitze

Bilhop's - weed

Bilsblume

665

669

526
Biftorta

Bitter - Crcfs

Bitterklee

Bitterkiaut

Bittering:

Bitterfüls

Bitter - Sweat

Bitter-Vetch

Bitterweide

$5+7$

890

316

1039

549. 149 ?

328

ibid.

$95 \mathrm{I}-953$

60

Bitzblume

732

658 .

Black - thorn

542

Black - whortle

Bladder Senna 97 1. Oriental

972

Blätterflechte i $365-$ I 368

Blätterfchwämme 1488 -

$157 ?$

Blanchette

$3 \div 4$

Blafenbaum, gemeiner 97 I morgenländifcher 972 Blafennuls

Blafenlegge

$44 \mathrm{I}$

Blafenfenne

224

Blafie naine

$47 \mathrm{I}$

Blatterkraut

Blattkohl

1357

730. $75^{\circ}$

884

Ble commun noir 832 . rafin 553. de Vache

Blenủe

832

Blette d'Europé

553

Blite

Blodderkirlche

$365 \cdot 369-373$

Bhue grand II 4 . 01553

Blümagekohl

Blütenaftmoos

44 Blumenbinfen

556 Blumengras

1609 Blumenkohl

$60 \% .608$

400 Blutampher

$73^{2}$ Blutauge
553

884

1280

564 884 $5 \mathrm{I} 4$ $-06$

Blut- 
Blutgarbe

552 Borietfch

Blurgras 552. weifies 229 Bluthirfe

Blutkraut 2.46. 293.552 . Blutnufs $633 \cdot 634 \cdot 759 \cdot 908$

Bluttrieb 765

Bluttröpfchen

1104

Blutwurz

293

Bockmelde

914

Bocksbart

$-372$

-1670. 1673 . kleiner 149 rother.

Bockbeere

Bocksbeerenftrauch: 354

Bocksoreilen 46

Bockshorn, wildes $\mathrm{IOO}_{3}$

Bocksknabenkraut 40

Bochspeterlein

429

Bogenbaum

930

Bohne, brafilianifclie 948 gemeine 947 . tuirkifclle $9+8$. wilde

Bohnenbaum

$9+1$

Bohnenkraut

975

Bolirholz

805

Bois boulogne 12 I0. jaune $6 \mathrm{I}$. de Sainte Lucie 652 à fept écorces 672. genti

546

Boletus

I $578-1600$

Boletus ceruinus $\quad 1677$

iginarius

Bollen

Bombarde

Bon-Henri

Bonne Dame

Bonnet de Prêtre

Bonus Henricus

Boom-rofe

Borago

Bornkrefle
1591

472

1034

$3^{64}$

457

387

364

922

295

794
Borfengras, fteifes 99

Borffchwingel $\quad 15 \mathrm{~L}$

Boucage

Bovifte

$429-23^{2}$

$1678-1688$

Bouleau blanc

$25+$

Bouillon

$323 \cdot 324$

Bouquetine, petite 429

Bourdaine

Bourdock

Bourguepine

3.19

Bourrache

1079

$35^{\circ}$

Bourfe à Pafteúr $\quad 867$

Bouton 'd'or

$7+3$

Boyau de chat $\quad 1486$

Brachdiftel.

379

Brätling

Branible

Bramkapern

Branca Vrfina

Brandlattich

1493

Braffica

Braunelle

Braunheil

$690-693$

946

$40 \mathrm{I}$

1122

884

Braunheilig .

$815-817$

815

Braunkohl

775

884

Braunwurzel $325 \cdot 837$ -

839

Braut in Haaren $\quad 724$

Bräunewurzel 262

Breitblatt $53 \mathrm{r}$

Breitling'f. Brödling 1493 ein grüner

$152 \mathrm{r}$

Bremenftrauch

$69 \mathrm{r}$

Brenneffel

283

787

546

Brennwurz

Bris 1226. 1227. 1229.

1 230.1243 .1253 .1255$.

$1257-1289.1300$ -

$1309 \cdot 1314 \cdot 1330$

bris- 


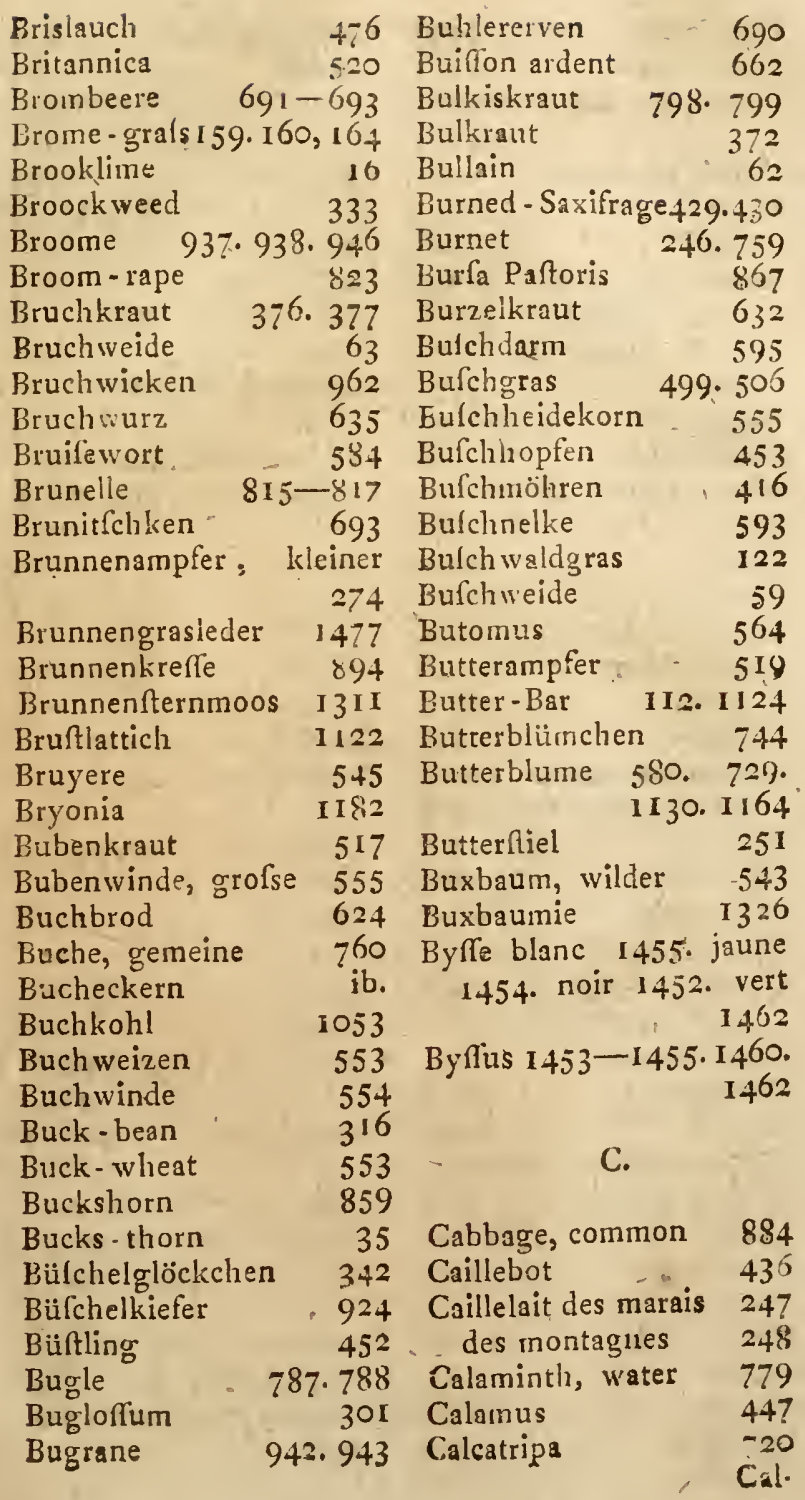


Calcirrapa

1 5 53 Cataputia minor

Calendula I1 64

Cataria

Calebarle - des Pelerins

Cathrinette des bois

04

II 79

Cat's-Fly, german

691

Caméléon blanc

1063

Cat's - Foot

612

Cameline

$853 \cdot 854$

Camerifier

348

Camomille des champs 1138. Oeil de Boeuf 1 I 40 . puante 1139 , romaine

Campanula

Canarienfe

1137

Canary.grafs

Candy - Tuft

Canillée

Connubis

Canneberge

Caprifolium

$336-342$

Caucalier $357 \cdot 388.404$

Cauliflower

Celandine

881

Celori

$28 \% \cdot 712$

Centaurée I146- $1153^{\circ}$

Caprina

Caraways

100

blanc

808

Centaurium minus $\quad 363$

Centaury 363.11.99

Centumnodia $\quad \mathbf{5 5 2}$

Centunkel

2,10

p. $2 \mathrm{I}$

452

544

346

Cepa

Ceraite

4.72

Cerafus

$619-623$

674

Cerciti d'Efpagne 1028

428 Cerefolium 412.414

Cardamine amere 300 . ferfible 897 . velue 888

Cardere

$237-239$

Cardiaca

Cardopatia 768

Carduus Marine

1063

Caret 197-201. 20\%.207

$-211.215-225$

Carex arenaria

198

Cariophillée

Carlina

704

Carline - thiftle 1063--1066

Cerfeuil 412. 414. 416-

Cerifier 652. de Virginie

Chamaeclema $\quad 653$

Chamaedrys $\quad 786$

Chamaepitys $\quad 783$

Chamaras

785

Chanomilla rog8. romana,

1132

Champignon, gemeiner

Carotte fauvage 384

Carrot 382.384 .385

Caruum $\quad 428$

Caryophyllata 704. 705

Cafrelunette

1148

Cafier

354

Carfoleite

877

Cat - Mint

$\$ 04$

1519

Cliampignon de couche I 5 I9. delicieux I49I. laiteux 1493. violet I 496

Chenvre

452

Chaperonniere $\quad 1124$

Chardon 1065-1078.roland 
Chardon à Foulon 236 Cicely, fweet 402. wild Chardonnerete $\quad 1063$

Charme

767 Cichorée douce 1023. fau-

Chataigne d'eau 264. de cheval

528

Chaufie -trape

I 153

Cheidoine-grande 712 . petite :

6,50

Chelidonium maius minus

712 750

Chêne 76r. 762 . petit 786

Chenevis culivée $\quad 452$

Chenuelle

98

Cherry - tree, common 654 cornelian 265

Chervi 399

Chervil horfe $\begin{array}{r}414-420 \\ 528\end{array}$ vage

1022

Cicuta aquatica 423 . terreftris

Cicutaria

392

Cigue d'eau 423.

416

Ciguë d'eau 423. grande

Cimbalaire

392. petite 4 I I.

Cinanchine

$\$ 42$

Cinoglore

Cinquefoil

26 ?

Cireée

Ciffusröslein

Citronenkraut

Chevre-Feuille $345-348$

Chich-Peafe

974

Chiche de Belier

974

Chichling-Vetch 954-959.

962

Clichweed600-602. 604

Chiendent officinel 19!

Chinorrodion

686

Choin

Chondrilla

84.86

Choux

1044

884

Chriftauge 1038

Chriftinenkraut

\section{108}

Citrouille

299
$698-706$

Cive d'Angleterre $\quad 47^{6}$

Cladonia

Clandeftine

$1394-1402$

Clatre nu

814

Clavaire coralloide I670

Chrittohren

356 Cochlearia

Chriftophel

Chriftoph skraut

213

713

cornue 1668 . noire 1662 en pilon

1660

Cleavers

257

Climber

726

Club-Rufh

92

Clufter-Cherry 652.653

Cnichaut charnue 1065

Cob-nut

Cochête

764

$66 \mathrm{I}$

Cochlearia 888

Chriftwurz

967 Colchicum

$95^{2}$ Cole-feed

130

510

832

Chryfantheme 1099. roor Columbines

722

Comaret

783

Chryforplenium $\quad 580$ Concombre ordinaire I 178 Ciboule de St. Jacques fauvage

$117^{6}$

473 Condrille jonciere 1042

Cibouille.

472 
Confanons

709 Couleuvrée

1182

Conferva 1476- I 485

Conife Ilst. des près

I I07. vulgaire I I9O

Conium

392

Confolida maior 294. media 787 . miuor 815 . regalis 720 . farracenica

II 14

Confoude, grande 294

Conuoluulus

318

Conyza media $110 \%$ mi-

nor

I I I 3

Coq des Jardins

1009

Coqueliqot des Jardins

709

Coquelourde $73 \mathrm{I}$. des Jordins

615

Coralloide des rennes 1397

Coreoplis

I 55

Corettier

66 I

Coriander

Corn-Campon

410

614

Corn - Marygold

Cretan

I 102 .

1103

Corne de Cerf deschamps

859

Cornelbaum 265-267

Cornillet 597.599

Cornouillier, ordinaire 265 fanguin

266

Coronille

1008

Cornus

Cofta

Coltenkraut

$265-267$

1024

Coftmary

1025

Cottonier

1089

Cottoniere

763

Cotula fcetida

Couch -grafs

I 162

Coudrier fauvage

I139

I 91

Courbaril

973

Courge de St. Jean 1180. des Pélerins

1179

Couronne imperiale $49 \mathrm{I}$

Couronne du Soleil I 5 ?

Cow-wheat $831-835$

Crab-tree

667

Cracca d'Europe $\quad 965$

Crane's - bill $901-90 \%$

Crannberry

910. 911. 913.914

Crapaudine

544

Crafiula maior -695

Craflula maior 626

Crepide. $1038-\mathbf{1 0 4 I}$

Crepitus Lupi $\quad 1678$

Cré́s 861. 862. 864. 894.

897

Crefion alénois 861 . aquatique 16.894. d'Inde 529. des rochers 5 tio

Crête de $\mathrm{Coq} \quad 824$

Cretelle $\quad$ 880-181

Crow-foot, Globe, $73^{6}$

Crows - foot 859

Cucumber 1176. i 178

Cucumis 1178. afininus

Cucurbita

I 176

Cudweed

Cultrops, water

I 179

274

Cumin des près $\quad 428$

Curage

549

Currant blanc 354 fur $3: 3$

Cyanus

Cydonia

1148

Cynanchica

669

Cynoglofium 262

Cynosbatus

299

Cypergras 87. 88. falches

$-64$ 217 Cy. 
Cyperwurz 84. 86. 88 Dittander $86 \mathrm{I}-863$

\section{D.}

Dachliausuurz 626. 649 .

Dachpippau

Dachskraut

Dachtrefpe

Dactile pelotonnée

Darlitzen

Daffodil

Daify

1039

807

165

I 30

Dock 514. $515.517 \cdot 520$

Docken

Dodder

Dog - weed

520

270

Dog's - Tail - grafs I 80.1 i 1

Dollkraut

Dompte - Venin

Donnerbart 649. kleiner

3I9

Dame d'onze heures
Dammdittel

D́andelion

Danewort

Darmbeeren

Darmmatte

Darmgichtkraut

Dipurit

Daucus

Dauphin cultivé $72 \mathrm{I}$. des bles

Day-Lily 1030-1033

437

654

1486

963

319

$38+$

720

Dead. Nettle

Deckrolir

Degenkraut

Delphinetteroyal

Dentaire

Devil's-Bit

Dictamnus albus

Digitale rouge 840 , rouil. lé

Digitalis

Dill

$8+1$

840

Dill, common

Dillengrafs

Dillkraut

392. 410.426

177

226

723

824

232

578

Donnerdiftel

Donnerkraut

Donnernelken

Donnerreben?

Donnerwurz

Doonfchwamm

Doradille

Dorant, eiffer

Dorlenbaum

Darnapfel

Dornwicken

$63 r$

3:9

636. 6.99

587

$77^{\circ}$

93 I

1.538

Doronic d'Allemagne I 104

Doften, gemeiner 819 . herakleotif́cher $\quad 818$

Dotter, wilder \$54. büfchelförmiger

Dotterblume

Dotterkraut

Dotterweide

Douce amere

Doucette

Douve

Doy's - Onion

Drachenbaum, teutfcher

426

108

226

Diftel $236-238.1063-$

1074
652

Drave printanniere 852

Drehkraut $\quad 403.404$

Dreiblatt

Dreidiftel

316

1064
Drachenwurz $\quad 547$

$x \times 2 \quad$ Drei- 
Dreifaltigkeitsblume I $\mathbf{7}$ I

Dreizack

Dripmadam

5 II Eiche

Dropwort

629 Eichelfarn

Droffelbeeren

674 Eichenfarn

Droue 159. 164. 166. 167 Eichenmoos

Dïkelfpelzen

186

Dïngras

Dïrenftaude

98

628

Dïrwurz 1090. blaue 1 I 13 . kleine 1108, weiffe

Duck's - Meat

1112

Dulcamara

55 Eifenkraut

Durchwachs 393. wilder Eiferich, wilder

761. 762

1205

1197

Eichenmiftel

286

Eichhaale

1446

Einbeer

Einblatt

Eiseiche

Eifenbeerbaum

1588

557

443

761

Eifenhart

328 Eilenwurzel

88I Eiterneffel

Dutch - Medlar

663 Fider-tree

Dutzblume

Dwale

649 Elecampane

332 Elenddiftel

Dyer's - Broom

936

Dyer's-weed

636. 637

Elendsblut

Elime d'Europe 185. des fables

E.

Elifabethblümlein

Eller

184

1150

$3 \mathrm{I}$

282

437

IIO5

379

46

8
$3 I$

3 r

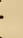


$I N D E X$.

693

Entengrïn

Enula

54 Erdleberkraut

1360

II05 Erdmandeln

Enule

Iro5-IiI Erdmorchel

958

Enzian, 362. Erdphafcum

$16 \div 8$ 1chwarzer

382 Erdpfrieme 937. ftechende

Epenier'des

Eperviere $1049-1057$

Epheu,amerikanifcher 358 . gemeiner

Epi d'eau

Epi - fleuri

357 Erdfpinnenkraut

Erdrauch

938

Epilobe

$271-279$
808

Erdweichfel

Erdweih

$533 \cdot 535$

Erdwinde 3 I 7.843 .844

Epinard cultivé

455 Erica

$93 \mathrm{I}-934$

679

Epine blanche 1076. noi-

Erle 285. 'fchwarze

re 658 . vinette 460

Erntrofen

485

Epithymum

270 Ers

654

585

Epurge

642

Equiletum

Erable

I I 84.1186

Erven

Erville d'Orient

$53 \mathrm{c}-532$ Eryngium

958 Eryfimum

545
349

921

Iirbelnufs

982. 983

951.953

955

379

870

Erbin 1 19-122.124. 126.

Erzengel, weiffer

791

127 Efchdorn

Erbsbohne

950

Efche

530

561

Erbfe, englifche 978. wid-

Efchlauch derkopfförmige 974. Elchröfel

$47 \mathrm{I}$

wilde 963 . zohme 944

Efcallion

659

Elelsfurz

$47 \mathrm{~b}$

Erdäpfel

329.1159

1076

Erdbeere 695. unefsbare Efelsgurke

1176

696 Efelsmilch

Erdbeerpflanze

695 Efelsohren

Erdbirnen

I 59 Efpargoutte

646

Erdeicheln

673 Efparzoutte

753. $96 \mathrm{I}$

1096

1007

770 Efpe

958 Effigbaum

562

Erdfeigen

363 Effigdorn

440

460

750 Elswurzel

Erdgerfte

1678 Efula

30.4

Erdgrübling

1336 Eternue

Erdjungermannie

417 Etiepe

1019 Etoilée

646

Erdkaftanie

Erdkieferlein

Erdkrone

1122

Etran- 
Etrangle - Loup

Everlafing

Eupatoire aquatique 1081 cannabine

Eupatorium

Euphrafia

Eye-bright, of the Shops 825. yellow

Eyenbaum

Eyerblume

Eyerbohne

Eyerfchwamm

Eyfchwärmme I5I I-I5I?

Eyfchwamm, goldgelber

$\mathrm{I}_{5} \mathrm{I} 3$

F.

Fabacia

Fabaria

Face de Loup

Fackelblume

Fadenkraut $1060-\quad 323$

Fadenfchimmel, zweifarbi. - ger

Färb r aum

Färberkamille

Fäberkraut 936. gelbes

I 729

440

I I 40

IOS I

Färberpfrieme 936. teutfche

Färberröthe, kleine

Färberwau

Fallkraut

Faltenmorchel

938

262

636

$\begin{array}{lr}\text { Faltenmorchel } & 1609 \\ \text { Faltenichwämme } & \mathbf{1 5 3 2}-2\end{array}$

Farfara

Earnkraut
I539

1004

$612-$

I6I5

1422

IIS9. IIYO. männliches 1200 . weibliches

I 20 I

Falanenkraut

Faftenblume

Fau au Foyard

Faucile

$95 \mathrm{I}$

3II

761

I009

Faulbaum 349. unächter

Faulweide

652

60

Featherfew, common 1096

Feather-grals

Federba!l

Federgres

Federkohl

I 16

$757 \cdot 758$

I 79

884

Federnelke'592. hohe 593

Feigbohne

93 . 940

Feigwarzenkraut 750.83 ? Feisker

1583

Feldahorn

532.

Feldalyffenkraut, rothes

Feldahorn

795

Feldbacillen

800

400

Feldbinfen

508

Felubirne

665

Feldblume, weific 991

Feldbolnne

Feldeichorie

$9 ! 0$

Feldcyprerfe

1023

Felddiftel

Folddoften

Felderbfe

Feldgras

Feldhirfe

Feldholder

783.928

1078

81)

945. gemeine

944

IO?

293

437

1098

kamil!a

323

Feldkerze

Feldklee, gelber IoIO. weilier

991

Feld- 
Feldknoblauch

Feldkohl

Feldkı appe

Feldkiimmel

Feldkürbis

Feldlilie

Feldmohn

Feldpoley

Feldringlchwamm

Feldröfel

Feldrofe

Feldfafian, wilder ro64

Feldfenf, fchwarzer 89I

Feldfpinat, wilder $\quad 364$

Feldtäfchelkraut

Feldtaubenfufs, grrofser

913

Felduimbaum

Feldwermuth

378

1084

Feldwicke 96\%.982. 9

Feldwinde

Feldzwiebel 485. weife

3 i?

488

Felfenzumpenkraut $\quad 628$

Fenchel 417. 421.427

Feniculum

Fennbeere

427

Fennel-Flower 723. 724

Fennichfegge

Fenouil d'eau 421. commun 427 . de porc 390. des près

391

Fer à cheval vivace IOI I

Ferkelkraut 1024. 1025

Fefcue-grafs 149-I58

Fettblatt

29.

Fette Henne, gelbe 627. weiffe

629

Fettfchwämme 1 553-1562 Feue des maris
Feuerbaum

928 $\begin{array}{lr}\text { Feuerbohne } & 948 \\ \text { Feverfew 1097. 1098 } & \end{array}$

$\begin{array}{lr}\text { Feuerbohne } & 948 \\ \text { Feverfew 1097. 1098 } & \end{array}$

Fenerkraut $533 \cdot 534$. 388

Feuerlilie 494

Feuerfchwamm

I $59 \mathrm{I}$

1456

923

575

316

808. 303.
1096.1388.

Fiebermoos 1388

Fiedelrilmpfchen, $\quad 348$

Figwort, great 827 . vernal 834. Water 838 Filipendel, Waffer 673 Filipendula $\quad 673$

Filix 1200

Filzkraut 270. II60

Fimmel, mein $\quad 452$

Fimftern 934

Fingerhut, rof sarbiger 84 I.

- rother 840 Finkenlaamen 854. kieiner 853 Fir-tree $\quad 923.926$ Fifchkarve $\quad 428$ Fifchmelde $\quad 373$ Fifchmuinze $\quad 77^{6}$ Flachs, gewölınlicher 445 fehr kleiner $447^{\circ}$ wilder

Fiachaufauger $\quad 270$ Flachsdotter 853 Flachsgras $\quad 98$ Flachskraut : 134.846 Flacon II Fladdergras tis: 106 Flambe d'eau 8o, vulgaire 79 
Flammula

Flatterbinfen

728 Foin, St.

Flatterefpe

Fléchiére

499 Foirole IIO?

56I Fontanelerbfe

754 Fool's-Parsley

944

4 I I

Flechte

$1364-1381$

Fleckenkraut 291. 808.980 Foolitones, femal 4I. male

Flegelholz.

Forellenfalat

42

Fleifchblume 6Ir. $83 \mathrm{I}$ -

Fotzenigel

1045

834

Fotzenkraut

1081

Fleifchfchwämme $1488-$

Fotzenzwang

372

I508 Fougere 1200. I20I. com-

Fleau

I82. $\mathrm{I}_{83}$

Fleur mufcuée 556. du fomune

1210 leil

Fliederbaum

714 Fox-glove

760

Fliegenbaum

Fliegenfchwamm

438 Fragaria

840.841

Frambatin du Perou 813

Flitichrofe

I5 I.2 Framboifier à fleurs odo-

813

Flittern

Flix - weed

Flockenblume

709

148

II 2. blaue

Flockenfcabiofe

I 46 -

898 rantes 692, du Mont lda

1165

I 150

Frangula

689

Franzerble

$3+9$

Franzkraut

944

Frau, fchöne

636

Flöhksaut 550 .

Flölıpfeffer

Flöhriedgras

Flötenbaum

Flouvre odorante

Fllower de Luce

Elïgelerbfe

Flutgelfarn

I I I 2

III 3

Frau Venusbad

332

auenbirs

238

549 Frauendiftel 1073. weiffe 197 , 1076

650 Frauenfingerkraut 779 36 Frauenfachs 846 80 Frauenhaar 270. fallches 978

1210

Flufsantmoos

Flufshahnenfufs

I 283

Frauenholz.

I 208

Flulskraut

Flufsriccie $27 \mathrm{I}$

Flutgras, kleines

I 355

Föhre

105

Foeniculum

Fönnich

427

Foin

132. 133

Frauenkrieg

348

289

Frauenmantel 266. kleiner

Frauenmünze 773.1089 Frauensröslein, wildes 597 Frauenfchüchlein

93 I Frauenfpiegel

$3+4$

Fraxinus

Freifamkraut 
French - Willow

Frefswurz

Froment d'été 180 . d'h 53

$$
\text { I oo. rampant }
$$

Fromental

Frofchbifs

Frofchlattich

Froíchlöffel

Frofchpeterlein

Frofchpfeffer

Frofchtatzen

Frue - love

Fuchshödlein

Fuchsriedgras

Fuchsfchwanz

Fuchsiärt, klein

Fuchstraube

Fünfblatt

Fünffingerkraut 700 . 703.

Fuirwitzelbaum

Fuirwitzlein

Fullers - Deazel

Fumaria officinalis

bulbofa $933^{2}$

$$
\text { Salicis }
$$

Fufain des bois

1595

Fufelée bifannuelle des toits

Futterbohne

Futtertrefpe.

Futterwicke

$35^{\mathrm{I}}$

1040

1039

970

166

967

\section{G.}

Gabelkraut

1083

Gabelzahn I 25 I - 1256

Gadelier epineux

356

Gänfearnpfer
I9r Gänleflieder

Gänfefuís

Gänfefutter

Gänfekraut

Gänfekrefte

Gänfekropf

Gänfepappel 98

1009

1058.1059

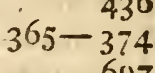

697. 1087.

1184

867

I1 39

98 falfcher

Galega *

Galeopfis

Galgant

Galinen

Galium luteum

84. 96.97

.700

980

798

436

$25 \mathrm{I}$

Gallerte I713-17I8

Gamander 782. gewöhnlicher

786

Gant de notre Dame $34 \mathrm{I}$

Garaffel

Garance de chien"

Garance de chien 162

Garbe

Garböcklein

423

46. common 466. crow

Gartenampfer

469

Gartenbalfam

Gartenbalfam 778

513

Gartenerbfe

Gartengleils

944

944

41 I

Gartenguinu

I 78

Gartenklee

988

Gartenkümmerling II I I

Gartenlinfe $98 \mathrm{r}$

$98 \mathrm{r}$

weifre

$55^{6}$

Gartenmohn ... 7II

$X \times 5$

Gar: 
Gartenmünze 775. rothe Germander 2. 3. 19.785 . 8 788

Gartennelke

Gartenpappel

590 Gerich.

Gartenraute

421

Garcenfalat 569

Gartenfpinat

1045

Gartenwermuth

I 54

Gartenwicke

1085

Gartenyfop

855

Gauchbium

805

Gauchheil

Gauchklee

887.888

Gauchnelke

Grude

Gazon d'Efpagne $305-309$ 624

64 636

Gedenkblümchen

Geduldkraut

444

I I I I

Geisbart 674. gelber 1670

Geisblatt

Geifsfufs

Geisraute

Geisweide

Gelderrofe

Gelenkwurz

$345 \cdot 346$

435

980

67

436

480

Geliy-Flover, fea " 444

Gemüslauch

Genêt $936-93 \% 946$. des

Teinturiers

Genevrier ordinaire fabine

Genickkraut

Genouillet, grand

946

1) 28

929

343

43

Gentian centaurée 786. des

marais

Georgenkraut

Georgenrofen

362

824

$34^{6}$

Georgenfchwamm I522

Geranium

Gerbęrfumach
Gerfch . $43 \mathrm{I}$

192

626

Gefre cultivée 9.54. marais 962. odorante 955. des près 959. fauvage 960 . tubereule

Gewiirzkalmus

958

Gichtblume

Gichtkraut 544. 727.908.

Gichtrofe

Gichtriibe

719

Gierlein

Giftwurz

Gilbkraut

Giliflower

Gilken

Gillblume

Gillis - Flower

1182

Gimpelholz

Giroflée

399

$36 \mathrm{r}$

636

875

1163

1140

590

$43^{6}$

590

Giroflier annuel 876 . blanc 875 . jaune

Glands de terre

874

Glanzgras

9.58

Glaskirfche

Glaskraut Ios ches

Glasfchmalz,krausartiges I

Glafswort I. white

Glaux du bord de 1 a 37

Glaux du bord de là Mer

Glayeul

359

Fleisblume

Gliederlänge

78

740

2.33

Gliederfenden

918 Gliederweich : 1003

440 Gliedkraut - 802.596 
I N DEX.

699

Glitfch

Glocke

Glockenblume

Glockenwurzel

Glouteron

830 Grasblumen $60 \%$ wilde

Graphalium

Goats beard

$1027-1028$

Götzenholz

Gold of Pleafure 853.854

Goldblume 1102.1164

Golghaar

I $236.1237^{\circ}$

Goldhänchen 739 . kleines

Goldhafer

735

Goldkraut

175

Goldlilie

310.1116

Goldmilzkraut, kleines

Goldneffel

579

Goldruthe, wahre II 4

Goldveilchen

580

Goldweide

II 6

Goldwurz 7 I2. wilde 494

Good Henry

Goofe-beiry

$3^{64}$

Goofe - Foot

Goofe-grafs

Gottesgabe

Gottesgnade

Gotteshülfe

Gottesvergels

Gottheil

Gourd, long:

$355 \cdot 356$

366. 367

298. 299

712

908

807

798

815

Gout - wort

1179

435

Grace Dieu d'Allemand

907

Graine de Canarie 100

Grafepilz

Grasglöckchen

Graskohl

Graslauch

Grasleder

587

Gras of Parnaftus

Graflette

Grasw'urzel

Gratecul

$158 \mathrm{E}$

326

1065

Grateron

Green - wood

Gremil

Grenouilet

Grete, faule

Grimmie

Grimmkraut

$467 \cdot 476$

I 477

443

24

19 I

686

Grindkraut 934.1116

Grindwurz

Gripe des champs 206

25 I

986

292. 293

$74 \mathrm{I}$

40 I

1229

I 116

champs 206 noire

24) 7

Gromwell

292

Grosadmiralfalat $\quad 1045$

Groffelier $\quad 353-356$

Grofswedendünk 419

Groundfell

II 6

Gribelnus

763

Grïnkohl 884

Grỉnkraut

454

Grüling

Grünfing I00. 697.698

Grundheil, gelbes 309

Guckuksblume

611

Guckuksbrod - 624

Güldcnklee $\quad 730$

Güldenfteinbrech 580

Gramen, maius 198. mi- Guildenwiederton 1235 nus

I9I Günfel

$787 \cdot 788$

Grapes

352 Günfter $936-938.946 . g e$ meiner 
700

Gürtelkraut

Guéde

Guelderrofe

Gueude de Veau

Gui de Chêne.

Guimauve

Gundelrebe

Gundermanu

Gurifch

Gurken
I193 Händleinkraut 582

886 Härtern 266

436 Haaferkirfche 655

848 Haferfchlehe 657

286 Haferichmirgel 485

922 Haferlchwingel 15 I

770 Haferwurzel, blaue ro28.

ibid. wilde, 1027

435 Hageäpfelf. Hagedorn 660

I178 Hagenbuten $\quad 686$

Hagenweide

Hahnenfuls $297 \cdot 73 \%-746$

Hahnenkämmchen 1007

Haaraftermoos $1467 \cdot 1469$

$147 \mathrm{I}-1475$.

Haarflechte I $445-1452$

Haargras, europäifches

Haarkraut

Haarmoos 1235 - 1240

$$
1245.1470
$$

Haarftrang 390. 391. 074

Haarweide

Haafenampfer

Haafenauge

Haafengeil

Haafenklee 624. 995. groffer

Haafen kraut

Haafenöhrlein

Haafenohr

Haafenpappel

Haafenriedgras

Hafenfalat

Haalenftrauch

Haberdiftel

Habichtikraut 871. 1024. I031. 1039. 1040. 105010.56.

Hackenfehaar

Händelfchwamm
185

749

70

624

704

946

992

995

I 589

147

918

200

1060

1043

1078

Hahnenkamin 829.193 I

Hahnenkopf 1006.100?

Hainbuche

Hair-grafs I I9-I2I. 123 .

124.127.

Ha!blchwämne 1569 -

Halmrüblein

1577

Halskraut 341. 342

Halskrautglöckchen 343

Halsrofen

920

Hammelsmöhren $\quad 424$

Hanebutte $\quad 686$

Haneklötchen $\quad 35 \mathrm{I}$

Hanf. gemeiner 452. wilder

796

Hanfneffel, ächte 797. grof1e 796 . kleine

795

Hanf würger

Hans, klingender 829

Han's - Ear, leaft 395. panifh

Haricot

Harlatier

Harnkraut

Hartgras

364 Hartheu

1670 Harthola
394
$946-950$
661

336.676 .

149

1019: 1020.

.767 
Hartriegel

Harzbaum

Farzeiche

Hafeleiche

Hafelnusftrauch

Hatchet - Vetch

Hauhechel

Hauslaub 649

766 Heidelwinde

923 Heidenlilien

554

76 [ Heidepfrieme

494

762 Heidepilz

946

7678

764 Heidefchmuck 7I4.936

IOI I Heil aller Welt 305.324.

Hausfonnenwirtel

$4+9$

Heilblatt

635

726

Hauswurz, grofse 649 . kleine

$629.63 \mathrm{I}$

Hawk-weed I024-1026.

\section{0: $105 \mathrm{r}$.}

Hawthorn

Hainjungfernmoos

Hazelnut

Heath

Hechelkamm

Hechelkraut

Hechtlack

Heckenbeere

Heckenkirfche, gemeine 34. tortarifche Heckenkürbel

Heckenwinde, grofse 3 I 8 Hecknefiel

Heckrofe

Heckweide

41. 65

Hedera 770 . arborea 357

Hederich 869.873 . fallcher

891. gewölnnlicher 870

Hedge, tack by the 872

Hedge-Muftard

Hedivigie

870

Heide,

ne
Heidekorn 553. wildes 554 Heidekraut, weifses

Heidekrefle

855 rothe

543
Heilgenholz

Heiligheu

Heilkräutlein

Heilwurz

409

510

1007.1012

788

922

Heinrich, böfer 823. guter

Heitz

Helenium 1

364.

694

I 103

Helf kraut

807

714

808.809

Helmkraut

Heluella

I6I 2 - I 1 ?

Helxine

$28 \%$

Hemerocalle jaune $477^{\circ}$ fafranée

478

Hemlock 392. 4 I I - 42 I

Hemp

Hemp. Agrimony 1085-

Henbayne

1083

Henbit 442. great 793

Hep - tree

686

Hepatica 730. alba 443 . fontana 1348. ftellata

122 I 259

Hepatique des bois 259 des fontaines 1348

Heracantha

I 164

$\begin{array}{lll}545 & \text { Herb-Bennet } & 104 \\ 855 & \text { Herb-two-pence } & 310\end{array}$

542. Herba Cathartici, 746. Ig- nis

T388

Herbe 
Herbe à l' Ambaliadeur 322. aux anes 54r. de S. Antoine 533. desAulx 872. au charpentier $87 \mathrm{I}$. II 42 a au chat 804 . au coq $108 \%$. cotton 1160. aux cuilliers $85 \%$. aux écus 310 . à $l$ éfquinancie 262. à éternuer 1141 . de S. Ftienne 34. du Feu 1388 à Gerard 409. 435. aux gueux 726 . aux hemorrhoides $75^{\circ}$. de St. Jaques 1 120. de S. Jean 1017. 1019. à jaunir $63^{6}$. da S. Inuocent 352 . au lait 646 aux mites 326 ' à la paralifie 311 . Paris 557 . aux perles 292. aux poumons I38 $\%$ aux puces 1090. àRobert 908. du S. Roche I IOS. fainte $32 \mathrm{I}$. du fiege 8 ;8. du Sôleil 1157 . aux taureaux 823 . aux Teigneux 1124. aux teintures 936 . de la Trinité 11 I I. au Vent 73 I. aux Viperes 289. aux Voituriers II 42.

Herbftblume

Herbfthelenie

Herbftling

Herbitrofe

Herkuleskeule

Hermlichen $\mathrm{f}$. Helmrichen rogs. wilde

Herniaria

II 38

Herpette chandelière 1436 . ecarlatine 1385 . farineufe
I384. frangée 149I.des mures

1375.

Herrgottsbärtlein $2+6.935$

Herrgottsblatt , $\quad 712$

Herrnblume

Herrnkraut

$4+3$

Herrnlöffelkraut

813

Hetrnpilz

Herrnzipfel.

Herzblümlein

493

Herzfreude

Herzgefpann

1513

Herzkohl

Herzleuchte

Herzpoley 450 295 $26 \mathrm{I}$ 768 884 920 780 Herzröslein 622

Hefpeleinbaum 663 Heu, burgundifches $101 \%$. heiliges 1013 Heurathswurzel 41 Hexenkraut 34. 35. 1017 Himbeerftrauch $\quad 689$ Himmelbeeren ib. Himmelbrod $\quad 993$ Himmelfarthsblume 935 Himmelsbrand Himmelfchlïfrel 311 Himmelthau $\quad 135$ Hind - berry $\quad 89$ Hinfchkraut $\quad 328$

Hirnkraut. 825 II 36 Hirfchbrunft über der Er1491 de I6I1. unter der Er921 de 167 ? I I 79 Hirfchdorn 350 Hirfchheil - 382

Hirfchlholder : $\quad 436$

Hirfchlorn, $\quad 859$

Hirfchhornbaum 720 Hirfchklee 1080

Hirfchkraut 
Hirfchmangol 3

Hirlchpeterlein

29r, Hopfen

Hirfchtrüffel, gemeiner

382 Hopfenklee

453

Hopfenklette

1677 Hopfenlucerne

998. 949

Hirfchwur, gemeine 382 .

Hordeum

1079

1014 kleine

408

Hirfchzunge 1206 . blühende 547 . braune 160 I rothe

1597

Hirfe 106. I 1 2. 293. gewöhnlicher 137 . wilder

$13^{2}$

Hirfegrafs $97.13 \mathrm{I}-134$.

Hirtennadel

413 Horfe = Chefnut

Hirrentäfchelkraut

567 36 i

Hirundinaria

Horehound, black 806. white

Horlitzenbaum

807

Horminum

265

Hornkraut 619-6.67

Hornkïmmel $619-623$

Hornwicise

999

528

Hochkraut

416

593

Hochmuth

Höltgen

6065

Hürnerklee

1012

Horle-tail 2. $1383-1385$

Hottonie

375

Houblon vulgaire $\quad 453$

Hound's tongue, apennine

Hörnerfchorf I350.135I

Hôrnerfchwämme $1671-$ 300. common 299. little blue

$-304$

Houque laineufe $=3 \mathrm{r} . \mathrm{mol}$. - le

1673

Houfe-leek

$23 ?$

Hoflerchen

312 Hoy's Fennel

6.49

Hohlbeere

689

Hohlheide

936

Huck auf die Míăgd

Huckblatt

Hohlwurzel 93I. kleine

Hügelkrätze, bläulichte

932

Hohlzahn

798

Hügelíchilf

$144^{\circ}$

Holderftrauch.

438

Hiillmoos

178

Hollow - root

Holunder

Holzbirne

556

Hündläufte

I328. 1329

1022

$436-439$

Hüneraugenbeere 952

663 Hünerbils 442

Holzwurz

526

Hünerdarm 442. 305. gel-

Holzzwang

626 ber 309 . grolser

595

Honeyfuckle, common french 1006 . field 995 . fly 348. italian 345. tartarian $34 \%$. wild 346 Honigklee 987.9.9 r. 1000 Hiinergift

Hünerkch!

320

Hünermyrrhe

Hünerträubchen

Hufeifen

IOI I

Huflat. 
Huflattich, gemeiner I 22. Iageteufel Io16. 1017 $\begin{array}{llll}\text { grofser } & 1124 & \text { Tafione } & 165\end{array}$

Hundeveilchen : 1169 Tafmin, wilder weiffer 650

Hundsauge 1107 Ibenbauın 930

Hundsbeerfrauch 266 Iberis $66_{3}$

Hundsblume $\quad 1030$ Iberplanze 863 . klsine

Hundsflechte 1360 \$5

Hundsgras $\quad 130$ Ibifch 922

Hundshasrgras $\quad 184$ Ie länger jè freundlicher

Hundshoden $510 \quad 6 i 3$

Hundskamille - I138 Ie länger je lieber 345 .

Hundskohl p. I34 .783. II71. teutfcher

Hundskopf $849 \quad 34^{6}$

Hundskürbis, wilder i 176 Ierufalemsartifchocke I I 59

Hundsmelde $\quad 364$ Ierufalemsblume $\quad 610$

Hundsmilch $\quad 6+4$ Ierufalemskorn! $\quad 388$

Húndsmoos $\quad 1360$ Iefuit's-Nut 264

Hundspeterlein - $4 T^{\prime}$ Iefuitermütze 264

Hundsplaume $\quad 656$ Iefusblümchen I17I

Hundsribbe 243 Iefus Chriftwurzel 1210

Hundsfchädel 845 Igelkraut. 704

Hundszunge $299-30 \mathrm{I}$. It ordinaire 930 kleine 304 Immergrü $\quad 649$

Hungerblümchen 852 Immerichön Io9

Hungerbrod 508 Inber, teutfcher 753

Hungerkraut II I Johannisbeerftrauch, ro-

Hure, nackende 510. Atin- ther 353. fchwarzer 354 kende

Hutzeln

372 Iohannisblume 1099.1100

Hydre cornu

Hyofere, nain

665 Iohannisblut 577.578.

$755 \quad 1077$

Hyofcyamus

Hypericum :

Hy Ropus.

1062

320

1017

771

I.

Jacée dés près

Iacobsea

Iohannisgürtel I087. I 193

Iohanniskorn

188

Iacobsblume

Iacobslauch

Iohanniskraut 753 . $101 \%$ -

Iohannislauch

$102 \mathrm{x}$

Iohannisnufs

476

Iohannispappel

763

918

1152 Iohannsplanze : 626

I120 Iohanniswedel $\quad 674$

ibid. Iolun's - Wort 1018-1020

476

Ione 
I N D EX.

705

Ionc

Ionc fleuri

Ionc odorant

498-503 Kälberkropf

$52+$ Käfekohl

49? Käfepappel

$416-420$

Ionq à mafte

Ionquine

Iofephblume

yo Kätzelkraut

384

916

Ioubarbe 626 - 629.631.

grande

$6+9$ Kaiferling

974

Iris

$79-8$

Kaiferfchwamm

Irrbeere

Iudasfchwamm

322

Iudenkraut

Iudenpilz

17:I Kalbsauge

$\mathrm{SO}_{2}$ Kalbsful's

1573

$15^{-9}$ Kalbsnafe 848.849. kleine

Iünglingsblümchen ro8 I

Julienne 77 . jaune 87 I

Iuly-Flower । $\quad 876$

Iungermannie I 33 I-I 347

Iungfer im Grafe 723. nackende

510

Iungferkraut

1096

Iungfermoos I222-1225

Iungfernblüthe

Iungferngras

448

Iungfernhar

Iungfernkrone

Iungfernftrauch

607

147

327

554

Iungferntritt

Iungfernwein

552

358

Iunggefellenknopf

596

Ivette

783

Iuisquiame noir

320

Iuniperus

928

Ivroie enivrante 187. vace

vi-

Kalinkenbaum

$8+5$

I 497

1099

753

436

Kalmus, falfcher 80. gemeiner

Kameelheu

497

Kameelitroh

Kammfarn ؟. Kraftfarn

I 192

Kammgras, blaues I 81 . gemeines

I 80

Kamillen, gemeine 1098 , geruchlofe 1138. römitche 1137. ftinkende

Kampferkraut, kleines

Kanarienfaame $\quad 100$

Kandelwifch I186. I188

Kannenkraut 2. 1184

Kannenplumpen

Kanntrettig

717

Kapern, teutfche, $\quad \mathbf{7 2 9}$

Kappuskraut - 884

Kapuzinerkreffe $\quad \mathbf{5 2 9}$

Kapuzinerfalat $\quad 1045$

Karpenkraut $\quad 1142$

Karten

$23^{6} .237$

Kaalkraut

824 Kartendiftel, grofse 236 .

Kälberkern

4IS. 420 haarigte

Y y

239

Kar- 
Kartetfchen 236. wahre Kiefer, weymouth 924. $\begin{array}{lllr} & 238 & \text { wilde } & 923 \\ \text { Kartheuferblume } & 585 & \text { Kieferpilz } & \mathbf{5 7 9}\end{array}$

Kartheufernelke, wilde Kienfore

Kartoffein

329

Karve

Kaftánien, Wafter

428

Kirchyfop, wilder

574

Katharinẹnkraut

Kaizbeerenbaum

264

846

Katzenbalfam

655

Katzengeficht

804

Katzenklee 94r. 995. gel-

ber

Katzenkörbel

Katzenkorn

Katzenkraut 804. wildes

$7 \div 6$

Katzenmünze

Katzenpe terlein

Katzenp̧ötchen

Katzentheriak

IKatzenträublein

Katzenwedel

Kellerhals

998

934

195

$8 \% 6$

892

1090

74

630

1184

5.46

Kerbel 40.4.412.418.419

Kerbelkraut

Kerzen

Kerzenkraut

Kéfken

Keulenkürbis

414

324.325

323

439

Keulenfch wämme $1660-$ $160 \%$ korallenartiger

$16 \div 0$

Kichern 954. 958. 959. gemeine

Kichererbfen

974

Kidney - bean', 947. dwarf Kidney-Vetch
974

common

$\checkmark 50$
Kirfchbaum, gemeiner 654 K!affer

Klappernufs

Klapperiofe 709. rothe 7 IO

Klat lehrofe.

Kleber

Klebgrass

709

Klcbliraut

993

Klebnelke 6I2. weife 597

Klee 987-10I2. bitterer 3!6. goldener

Kleicinfechte

Kletten, kleine

979

Klettendifel

1377

257

Klettenkörbel 386

1079
-388

Kiettenkraut

635

Klinker

Klofterbeere

240

Klumperrüben

356

Krumperriben 884

Knabenkraut 4r. 48.626

Knackerbeere

6) 5

Knackerweide

Knapweed II46. II 49

Kinaulgras, gemeines 130 Knawel $577.5-8$.

Knebel, langer 616 Knoblauch, gemeiner 466 . wilder

Knoblauchshederich $8:-2$

Knöterich 551.616.618

Knolldiftel

1072

Knollen

Knollrettig

329

Knollwurz

868

Knopfbinfen

958

498

Knopf- 
Knopfgras

Knopfrofe

Knorpelkraut

Knotenblume

Knotengras.

Knotenkraut $84-\varepsilon \sigma$ ' Kornblume, gemeine I 149

69 I kleine ibid.

77: Korngras.

461 Kornraden

31 Kornrofen 710 blaue 233 .

837 falfche

Knotenmoos I226. 1227. Kornwuth

1248. 1252. 1253.1257. Kornwurz

709

795

1089

1258. 1263.1304. !309. Krähenfufs 743. 859. kleia

1322 ner 245

Knotgrafs 552.german577 Krake : ... 965

IKnützen

Kohernufs

881 Kräizkraut

934

763 . Kranmetsbeeren. 28

Kochapfel, gemeiner 668 Krampfdiftel 1076

Köriginkraut

Königsblume 322

719

Königskerze

323 Krannichkraut , 1062

Königskraut

635 Krannichfchnabel 902

Kohl 755. gemeiner 884. Kratzbeere 690. 69L - wilder 88 I. 885 Kratzdiftel

1070

Kohldiftel

Kohiknoblauch

Koblumangold

Kohlrabi 1065

Kratzkraut, gelbes 1065 470 Krausbeere

291 Krausdiftel

573

Sht Kraufemiline 775.geme

Kohlrube, uber und unter der Frde

884

Kolben, fchmalblättrichte

Kolbengras

228

Kolbenmoos

103: Kraut, weifies'

777

ne

Kraufenfchwämme I532:

Kollerwurz

Kapf kohl

1193

718

.884

589

1045

751

490

Korallenkraut

Korbweide, gemeine 59 .

70

Koriander, gemeiner $4^{10}$

Korn

188
1539

887

884

Kraut, das heilfame $3 ? \mathbf{I}$

Krebsdiftel ... 1076

Krebswurzel

547

Krecken

657

860

Kreen "

88\%. europäilche 863. indianilche 529 Schweine

245

935

Kreutzdorn $28 \% 350$

Y Y 2
Krebsweide : : $=70$ 
Kreutzkraut 642. 8:0. 1116

Kreutzwurz 1117-I121. gemeine Kriechelbaum I I 6

Krötenbinfen

Krötendill 657 505

Krötengras 135.499.505.

Krötenkraut

Krötenmüinze

Kronerble

Kronsbeere

Kronwicke, bunte

Krummhals 296. 297

Küchenfchelle, blaue $73 \mathrm{I}$.

fchwarze 732.Wald 833

Kiihnbaum

923

Kugelfchwämme "I;00.

Kuhblume

$$
1705-1710
$$

Kúlıdill 1099

Kuhdutte

1138

$5 \% 0$

Kubkraut 585

Kulipaftinack

Kuhpilz $\therefore$ 1579. I 58 i

Kuhweitzen 832.834 .835

Kuhwurz

Kümmel, gémeiner

Kümmelfilge

7.53

Kümmelzellen

428 407

Kümmerlingskiaut $\quad 426$

Kürbis

Kürfenmoos

I I 79. II 80

Kukumern

1227 Kunigundenkraut' ' I080

Kunradskraut "
I78. ivilde I $1-6$ 1066
Labkraut I 47-258. wahres

Lachenknoblauch $\quad 475$.

785

Lack, gemeiner $\quad 874$

Lactuca

Lämmerlattich

1045

Lämmerohren

Läuchel

75

Läuchelgras

Läufegras

334 .

872

146

Läufekraut $\quad 849.850$

Ladies. Bedatraw $247 \%-254$

Ladies - Finger $94 \mathrm{I}$

Ladies-Mantle, common

268

Ladies-Smock $887-890$

Ladies-traves

Lâiche noire

47

Laition des champs I059. des jardins 1060. des marais

1058

Laitue à coupér 1045. à feuilles de faule 10.48. fauvage 1047. fcariole

Lambertsnufs

ro46

Lanier des bois 798. rouge

Lainium

792

Lammkraut

791

Laminpette

584

Laınpfane comínune 1069

Landrauke

Langue de Cerf 1205. de chien 249. de ferpent

1189

Lapsthum acutum 5 ? languineum

514

Larch. 
Larch - tree

Larks-fpur, royal 721 . wild

Lafer de Prufie

720

Lattich

Lavatere

Lauch

Lavendel

Laufdiftel

Laugenblume

408

Laureola

Leberbalfam

Leberblume 730. weiffe

443

Leberdiitel 104\%. 1090.

Leberklette $\quad 636$

Lederflechte $1358.13 \%$

Ledergras $117 \% .1179$.

1182.1185.

Leder Chwämme 154 -

I 543 . 1550 . I 55 I. Ledichtblume

725

Leerbaum f. Leerkiefer 925

Leerfie

$1226-1228$

Lehne

$53 \mathrm{I}$

Leimbaum

378

Lein, gewöhnlicher 445 . kleiner wilder

Leinbaum

446

Leinblatt

$53 \mathrm{I}$

Leindotter, kleiner 854 langfchotiger 873. zahmer

353

Leinkraut $\quad 4.6 .597 .598$

Leinfaame

4,45

Lens

987

Lentibulaire

$3 \circ$

Lentille d'eau 55 . cultivée 987. tetrafperme 982 Lerchenbaum

982

Lerchenblume 3 II. 720

Lettuce 1045. 1046.

Leuchte, weiffe 807

Leucojen $873 \cdot 875 \cdot 876$

Lichen ftellatus 1348 .

Lichtmoos $\quad 1430$

Liebäugel 296. 299 .

Liebe, brennende 610

Lierre d' Amerique $35 \%$. ordinaire $35 \%^{\circ}$ terrettre

Lilie, goldgelbe 493. weif́e

492

Lilium album 492. conual. lium

Lilly

Lind - tree

479

Linaria

$492-494$

715

Lin fauvage 846 . d'ufage à filer

Linde, europäifche 715 . kleine 7 I6

Linfe, einblumige 985 . franzöfifche 984. vierfämige 982. wilde 983 Linfen, gemeine 987. wel. fche

Linfenbaum

975

Linfenfchwamm I619

Linlenwicke, kleine 982. fteifborftige $\quad 783$

Linum catharticum 447

Liny, common $\quad 545$

Lions-tail 768

Liquorice, Weft Indian wild 1005. wild 1003

Lis aurange 493 . blanc 492 fauvage

494

Lifchgras 102.182.183.

Lifchkolbe

Liferet

Yy 3

.223

317

Lithoi: 
Liferon des haies

Lithofpermum

Locuft-tree

Löffelkraut

Löwenmaul

Löwenfchwanz

858.859

848.49

768.779

8.3

I.öwentappe

268

Löwenzahn I030-I033

Lolch, ausdauernder 136 . taumel

187

Lonizere, gemeine

Loofe - ftrife; tufted yellow :

Lorenzkraut

Lotier aile 97\%. corniché 970. maritime 9-6. odorant des jardins

Loufewort, marth 850 .

$\therefore$ red

Lucerne, teutfche 1013. zahme

Jucernenklee

Luftwurz

Lunaria

Iungenbiume

Lungenflechte 1383.1384

lungenkraut 290.291. 807 . franzöfifches 10,53 .

Lutugeninoos I382, weiffes

$r 380$

Lungwort 824. narrowleaved 290. fpotted 29I

jupin blanc 938. jaune

Lupulus

940

Luferne houblonné rol 4. jaune IOI3. polymarphe

Luzionskraut

Luzienholz
1015

1104

652
Lycopode annuel II 94 . aplati 1195. commun

I 193

Lycopodium 1193

Lyfinaque des Forêts 30 \%. thyrfifiore

M.

Maarentacken.

286

Msaslieben 1095. groffe

Mache 1009

Macre d'eau

75

Madder, crofs - wort 256

$\because$ round-leaved $\quad 258$

Madenkraut

Madw ort

584

Mäilelbaum - 856.857

Mädchen, fchöne

923

Mädefurs

Mägdekrieg

331

Mägdepalme

$6 ?$

936

327

Mägdel, breune $75 \mathrm{I}$

Mälerkraut $6 \geq 5$

Märzblume, grofse $46 \mathrm{r}$

Märzveilchen 1168

März" urz

Mäufegerfte 195. taube

I $) 6$

Mäufegedärme $\quad 305.4+2$

Mäufegras

Mäuíehafer

450

Mäufcholz

163

328

Mäufeöhrlein, groffes

1052. kleines 1049, rothes und weiffes 1072

Mäufefchwänzchen 450

Mäufezetrig

$4+2$

Magdalenwurzel

74

Magen: 
Magenwurz 753 . weiffes

Marienflachs

I 16.846

Magusfans

Maiblümchen

247

Marienglas

616

958

Marienmäntelchen 269

Maidenhair, common 1208

Marienröslein, weiffes 596 . white wiides

Marienftein

Maien

1209

Majoran, gewöhnlicher

Marient’aränen

612

202 2 820. unächter 813

Maipfrieme, kleine

Maiveilchen

937

Marjolaine common $\$ 20$.

d" Hiver 818

Marjoran

820

Maivurz

I 169

Maroble

807

Mallow, common 916 . curled-leaved 917 . of the fhops 922. vervaing20

Malua arborea $92 \mathrm{r}$. Sylueftris 918. vulgaris 916

Malue, kraufe 91 7 . mauritanifche

Mnndelblume

9เ9

Mandelkraut

Mandelnufs

Mandelpflaune

732

Maronnier d' Inde

Marfh Ciftus

528

Marfh-Marygold $\quad 729$

Marube blanc 807. des marais 32 . puante 806

Marrubium 806

Martagon Liliy $\quad 494$

Marterdorn 673

Marygold Iro2. field I 163

597 pale-coloured' ${ }^{2} 64$

764 Mafie d'eau 227

Mandeliveide

656 Maffern

530

62 Maifette 182

Mangold 291. 303. ge. Mafsholder 532 inciner $\quad 375$ Maltbaum 926

Mannagras

158 Mafkravit

280. $28 \mathrm{I}$

I58 Matricaria

1096

Mannsharnifch

314 Matrifylua

259

Mannstreu

379 Matronenblume

Mapple-tree

Matronenkraut

877

Marchantée étoilće 1348 .

Marchantie, kegelförnige

13.49

Margarethenblimchen 752

Margendiftel

1078

Margendreher

49

Marguerite dorée Iro2. grande 1099.

petite

Matte

I 486. $148 \%$.

Mattenblume

1091

Mattenkümmel

428

Mattfellon, great II 50

Mattweed, imall

99

Mavellen

532

Maucrknotenmoos $\quad \$ 257$

Mauerkrätze $\quad 1436$

rog2 Mauernelke 583

Mariēndiftel

1073

Y y 4

Mauer 
Mauerpfau

Mauerpfeffer, gelber 627 gelinder 631. fcharfer

630

Mauerraute 1209. groffe $120 \%$. rothe

Mouerträubel

Maurache

1208

$63 \mathrm{I}$

1609

Maufohr, glattes $3 \circ 3$. klettenartiges 304 . rauches

Mautzenkraut

302

Mauve ì feuilles rondes 916. à feuilles finuées 918. frilée 917. des jardins.92r. fauvage 920

Mayerhahnenkamin $45 \mathrm{I}$ Mayerraute

ibid.

Maykraut

712

Mayfchwamm

1522

Maw - weed, ftinking I 39

Mazzard

655

Meadow - grafs 137-14t

Meadow-Rue 727.728

Meadow-Sorrel

522

Meadow-fweet

674

Medick, common fnall IOI5. yellow

Medlar, common

Meerampfer

Meerkreuzdorn

Meernelke

Meerrettig

Meerfalzkraut

Meerfandkraut . I78.603

Meerwegetritt

Mehlfâfschen f. Mehlhofen 660

Maierkraut, grofses 252 klein weiffes 249 . rundbiättriges $25 \%$. würgendes
Melampire des bois 835 . des champs 32 à crête 831 . des près 834 . vio. let

833

Melanthium

724

Melde, gefchlitzte $45 \pi^{\circ}$ geftreckre 370 . griune 369. rolenrothe 455 . fpiesblättrige 458 . weit ausgebreitete, 459 . wilde 45 r. zahme $\quad 4.56$

Mélize des Alpes $\quad 925$

Melitot-Trefoil, common

Melilotenklee

987

Melifia

ibid.

Melo

822

Melon commana 177. 1977

I 177

Melon commun $1177 \cdot$ d'eau

$118 \mathrm{I}$

Melone

1177

Mengelwurz, krausblättrige 5 I5. rothblättrige

Ment

Mentha aquatica $772-779$

514
779
776

- - crifpa

775

- - longifolia 772

- - lylueftris 779

Menthaftre

774

Mercurialis , 566

287 Mercury, Day's 565. 444 French 566 860 Merifier 655

I Merk, breitblättriger 396 . Ichmalblättriger $39 \%$. fichelförmiger

400

Merveille à fleur jaune

Mefpilus

1175

Metrạm

663

$10, j 6$

Meyer 
Meyer, groffer 623. kleiner

Meyerdarm

Mezereon

Michaelblume

Milchahorn, grofter $53 \mathrm{I}$. kleiner

Milchbaum

Milchblume

Milchdiftel

Milchglöckchen

wilde

Milchglocken

Milchkraut

Milchpeterling

Milfoil, common I 142

Milic-grafs, ciliated 128 . common

Milisgras

Milium

- - Solis

Miliz, falfcher

Milk - thiftle

Milk - Vetch

Milk-fwort 935. mountain 1004. Sea

139

106 106

292

97

1073

1003

359

Milky - Parsley, caraweyleavéd 407 . marfh 406

Mille-pertuis couché jo I 8 joli 1021 . des montagnes 1019. quadrangulaire 1016. velu 1020. vulgaire

Millefolium

Millet, common

Millet-grafs

1017

I 142

I36

106

Milzkraut 379. gemeines 1206. grofses 1192. kleines

1209

Mint, corn 779. curled 775 . red 778 . round. leaved 774 . water 776

Miroir de Venus 344

Mifpelbaum, gemeiner 663 Miftel, wciffe 286

Mifletoe, common 286

Miftmelde 366 . kleine 372

Miftchwamm 1524

Mithridate-Muftard 865

mountain 866

Mock-Orange $\quad 650$

Möllerbrodt $\quad 655$

Mönchskappe $\quad \mathrm{IIO} 4$

Mönchskopf $\quad 1030$

Mönchsrliabarber 5 r 3.520

Möhren, gemeine 384 . mauritanilche 388 . wilde

424

Mohn, gemeiner $711 . k l e i-$ ner $7^{\circ}$. unächter $70^{\circ}$. wilder

MohrenkümmeI

709

Mohrenweize 832

Mohrrübe, falfche 708

Molene 323

Monatsblume $\quad 316$

Monatsradieschen 868

Mondkraut, kleines 310 .

I 190 . rauches 580

Montien 83

Moon-wort ib.

Moorberry 544

Moorgrafs, Silver-weed

697

Moosheere 544

Moraine grenouilette 568

Moraftlabkraut i 249

Moraftrulirkraut, $\quad 1094$

Morchel, gemeine 1507

1610

Morchelfchwämme $1607^{-}$

1611

$\mathbf{Y} \mathbf{5}$

$\mathrm{Ma}$. 
Morelle à fruit noir grimpante'

Morgeline

Morgenröslein

Morgenftern 920. 1027

Morille fútide 1611. des ragouts

Morfus Diaboli

Mort au chien

Mofchatkraut

Motberwort, englifh

Mottenkraut_324. 326.

Mottenfafran

Mouceron

Mouron 305. 306. d'eau 333 , violet

Moufe-ear, codded 878 . common creeping 1049

Moufe - ear Chickweedor 9

Moufe-tail, fmall $\begin{array}{r}-623 \\ 450\end{array}$

Mousque aquatique 1220

Moufe de chien ' 360

Moutarde blanche 952. des champs 897. noire 893

Mickenfang

612

Münze, gelbe 1090. grolfe 778 . grïne 773 , wilde

Münzbalfóm

$77^{2}$

Müizchen

1089

Mufle de Vèau 849. des bleds 844. des champs

$$
8+7
$$

Munier auriculé 843 . à fenilles de Lievre 842 . rubicond 349 . de Veau

Mugueret

$8+5$

Mugwort 1087
Mullein

Mummeln

$3^{2} 3-320$

Mundrofe

717

$92 \mathrm{I}$

Mures de Renard 601

Mufcus caminus 1360

- clauatus 1193

- cumatilis 1368

- pyxidatus' 1388

Mulhroom, common 1519

Mulk-Crowfoot $\quad 55^{6}$

Muftard, black 893. field syl. white

Muthwille

Mutterblume

588.593.

892
593.

Mutterkraut 359.574.626. 807. 822. 1104. gewöhnliches ro95. wildes 768. wohlriechendes

Myrtillus

1097

$5+2$

\section{N.}

Nabelflechte $1385 . \quad 1386$

Nabelkraut, fchildfürmiges

Nabcliaamen

Nabelwurz

Nachtkerze

380

257

694.914

Nachtfchatten $328-33 \mathrm{I}$.

$837-838$

Nachtviole 44. Frauen.

Nadelliaber

877

Nedelwach

117

118

Nïglein

590

Nägleingras, kleines 136

Nägleinwurzel 704

Nagelkraut

I049

482 Napffchwamm, kelchför- miger

$162 \mathrm{I}$

Na: 
Napus

882 Nicotiana

Narcifie, gemeine, ge!be - 464. weife

Narcifferilauch, kleines

Nardenfaame $\quad 720.725$

Nardet

Narrenhoden 720.725
99

Nafturtium aquaticum $89+$. hortenle 861. indicum

$$
529
$$

Natterblume

935

Natterkopf

Natterkraut, kleines 310

Nattermilch

Natterwurz

Natterzünglein

1034

547

Navet commun 883. fau. vage

Neflier commun 663. de Gesner

$66+$

Neckerie $\quad 1260-1270$

Needle - Furge

938

Nelke, kleine wilde 589

Nelkengras 82. weiffes

Nelkenwurz

622

Nenufar blanc 718. jusu

Nepeta

1717

Neriet

804

Neflel 790-792. brennencie 282 . bunte taube 796. gelbe taube $79 \%$ zweihäufige

283

Nettelkamm

616

Nettle-Hemp, yellow 794

Neunheil

I 193

Neunkraftwurz

1124

Neunfpiten 366

Niederhollunder 437 Oelfenich

Nielle des bleds 6r: des champs 725 . cultivée 724. de Damafcene 723 Niefekraut

631 Nieferurz, falfche 630 . fchwarze 713

Nigella

Night-fhade 328-33I

Nine-Bark

Nipple-wort

672

Nittle, great $106 \mathrm{I}$

Nixblume

Noble Epine 283

Noir prun

Noifettier commun $\quad 765$ des bois

Nonnenkleppel 717.718

Nonnenkraut

Nuilschenfalat 660

Nummularia

Nufs, wellche

Nux aquatica 264 . Iuglan. dis

763

Nymphaea alba 718. lutea

717

O.

Oak-tres, common $76 \mathrm{t}$

Oats 168.16y. 173-176

Ochfenauge

Ochfenbrech

1138

Ochfenweize

942

Ochzenzunge 289.30I

Odermennich 635

Oeil de boeuf I 140. de chat 548. de Chrif 1126

Oeillet $586-594$

Oelfaame

$853 \cdot 882$

Oenanthe aquatique 309 
INDEX.

Oelsnitium

406 Ofeille franche $521 .^{\prime} \mathrm{des}$

Ohmblätter

Ohmkraut

Ohnblatt

Ohrenfchwamm

$575 \cdot 824$

Ohrweide

Oignette

Oignon rouge

Oleander, wilder

One - berry

Ononis

Ophiogloffum

515.1122 .

259

I? I I

66

473

472

523

558

942

I 189

Ophrife double feuille 48 . nid d'oifeals 49. en fpirale

Opoponax

Orach $458.459 .557 . \mathrm{com}-$ mon 268 . garden 456 . ftinking

283

Orant $347-349$. fallcher 844. kleiner 845 . wilder

819

Oreille d'ane 294. de Lievre 393 . de Rat 302 . $10+9$. de Souris 302

Orge diftique 193. groffe 194. des mures i05. (ecale 146 . vulgaire 192

Origanum

Orme fauvage

Ormin des près

378

Orobanche

33

Orobús

Orpin

823

Orquis

Orfeille du prunelle 1380

Orthotriche' frifé 1282. Atrié

1283

Ortie blanche 79 r. brûlante 282. grande 283 . morte brebis 523 . des prés 522

Oifier rouge des vignes

Osmunde des bois 1192. fleuri I 191. lunaire I 190 Oferblume 332.731 .klei-

ne

732

Ofterkerze

323

Ofterluzei, gemeine $\mathbf{5 2 8}$ kleine runde

937

Otterbaum . ' 285

Oiterwurz

Ox - Eye

547

Oxlip

Oxyacantha

1099. I 100

Oxycoccus

312

660

444

Padienftuhl

1524

Paeonia

Pain à Coucou

719

624

Pain - vin

186

Palais de Lievre $\quad 1060$

Palmata

38

Palmweide

69

Panacée des labouriers 799

Pansx gummi

425

Panic glauque 132.manne

335. millet 136 . Pied de Coq 34 . vert 133 . verticillé

131

Panicaut

379

Panicette

132

Papauer album 711. erraticum

Pappel, grofse 918. kraule $91 \%$ lombardifche 563 . lybifche 561. römifche 922.rundblättrichte 916 fchwarze 
Pappel reide

Pappenkraut

Paquerette vivace

Paralyfis

P...relle des jardins

Parietaria

Paris

Parnarte des marais

Paronychia

Parsley, common

Parfnep

Paizenkraut

Pas d'âne

Pasque - Hower, common blue 73 I. finall blackifh. flowered

Paffe d'eau

Pafferage

Paftel des teinturiers

Paftenade

Paftinack, gemeiner

Gummi-425. Kuh - 4ol

Paftinaca

Palique

Patatien

Patience conglomeré 518 . cultivée 513 . d'eau 520 . à écufions 521. frifée 5 I 5 . maritime 5 I 6 . rouge 514 . fauvage 517 . vulgaire

Patientia

Patte de Liévre

Patte d'Oie

Paturin annuel I 4 I. appla. ti 145 . aquatique 137 . des bois 143 . bulbeux I 46. à crêre 144. à feuilles étroites 139 . vulgaire
562 Pavot blane ou noir 7 II.

1030 douteuxy:0.hibride 707

1095 des jardins 71 I. d maf-

3 II fue 708 . fauvage 709

$6.5 \mathrm{I}$

288 Pear-tree, cultivated 666. wild

Peas Eart Nut

665

$65 \mathrm{x}$

Pechnelke 6 II

Pechtanue $\quad 927$

Pediculaire des bois $85 \mathrm{I}$. jaune 829. des marais

850

Peerlaat

421

Peigne de Venus $\quad 4 \mathrm{I} 3$

2 Pellitory 288

863 Pelote de neige 436

586 Pęltichen roc6. bunte Ioog

424 Peltichenkraut rooy

424 Penny-Royal 700

Penfée

$117 \mathrm{I}$

Penfies

ibid.

Peony, officinal $\quad 719$

Peperle

Perce mouffé

417

Percefeuille

1235

Perchepier

393

269

Perelle des murs $\quad \mathbf{1 3 7 5}$

Perfoliatum

393

519 Perlbohne, kleine 950

5I3 Perlgras, gefranztes I 28

995 niederhängendes 129

$364-373$ Perliere des bois 1093 . dioique 1092. des marais rog4 des fables

109 I

Perlkraut, rothes 293

Perfica

Perficaire
651

$548-550$ 
Perficaria vrens

Perfil +34 . laiteux 406 . des montagnes

Pervenche

Pes Columbae

Pefle

Peftilenzwurzel

Petafites

Pet d'Ane

Petechenkraut

Peterlein

Peterfilie, gemeine tolle $4 \mathrm{I} 1$. 'wilde

Peterfilienwurzel

Petersblume

Peterskraut

Petersfchlüflel

Petersftab

Peters - wort

Petrofelinum

Peucedanum

Pcuplier blanc 560 . d'Italie 565 . noir 561 . trem: ble

Pfaffenblate

Pfaffenblut

Pfaffendiftel

Pfaffenhödlein

Pfaffenhütchen

Pfaffenröhrlein

Pfauenfpiegel

Pfaunelke

Pfebenkiurbis

Pfefferkraut

Pfeffermünze

Pfefferfchwamm

Pfefferwurzel.

Pfeitenftrauch

Pfeilkraut
383

327

913

927

1124

ibid.

Jor 6

980
34.4

392

434

832 1030

753

I0 30

750

357

1030

549

593

1180

805

774

1497

429

9. 650

754

Pfennigkraut

pénniglinfe

Pfenniglalat

Pferdeampfer

Pferdebohne

310.864 687.

750

517

970

Pierdegras

231

5SS. 763

Pferdefaamen

$42 \mathrm{I}$

Pferdefchwanz 1183.11 \%6

Pferdelchweif

Pfere .55

Pfifferling, gelber $\quad 1569$

Pfingftpfrieme

Pfingitrofe

Pfirfichbaum

946

Pfirfichkraut

Ptirfichweide

631

550

62

288. 1006 Pflaumen 656. wilde 658

3 II Pfiaumenflechte 1380

I1I4 Pfugltürz

1016 Pfriemengras, binfenarti-

434 ges I 17. haarförmiges

390 99. gefiedertes II $6.7 \mathrm{ar}$ tes

118

Pfriemenholz

5(12 Pfriemenkraut 946. Atachlichtes

Phafce cn âlene

938

Phalaris

12 I I

Pheaiant's Eye

$100-102$

Phellandrium

752

Philadelphe odoranc 650

Pichot encens

1085

Pickelbeere

$5+2$

Picride Eperviere

IO29

Pied d'Alouette 720 de - Chat 1092. de Chevre 409. 435. de Có 134. de Lion 268. d'Oifeau

1010

Pigamon jaune

728

Pilewort 
Pilofella

Pilz, dickftieliger I532 rother

Pilze

Pimperlimpimp I $578-1585$

1581

Pimpernel, blue - flowered 3c6. red 305. yellow

Pimpinella alba

- - italica

- nigra

Pimpernufs

Pine, common ground 783 jagged-leaved ground

782

Pine-tree, wild

923

Pin blanc de Canada 924 . des tois 923 . mélele g:5 fauvage

Pink

923

Pinus

$59 \mathrm{I}$

Pippsu, bärtiger 1038 diofcoridis $104 \mathrm{I}$. zweijähriger

1040

Pifienlit automne $103 \mathrm{I}$ commun 1030. heriffé 1033. rude

Piftacien, wilde

Pitfch-tree

Pitzer, breitblättrichter

370

Pivoine

Plane - tree

Plantago latifolia minor

Plantaginelia

Plantain d'eau 525. lanceo. lée 245 . large $2+1$. des marais $2+4$. mojenne

Platane d'Occident $\begin{aligned} & 242 \\ & 766\end{aligned}$ 361
Plicuire commun II93. felagine

Piatterbfen

$1: 45$

$054-560$

Plockghmann's Spikenard

I I $: 0$

Plompe

Plume - tree

Plumelle des marais

717

6,56

Pockenbiüter

520

930

Pockenraute

Podagraire d'Turope $\$ 35$

Pörfchiohl 884

Poggengras 305

Poherbe d'eau $13 \%$. destriches 138 . des marais 1.42. des près

140

Poire de terre

Poireau

1159

465

Poirée

375

Poirier cultivé 666 . fauvage

667

Pois des champs 945. cultivée

Poivre d'eau

$9+4$

Poleimuinze -so. wilde

Ero

Politric doré 1235. nain

$44 \mathrm{I} 1238$. ondule 1240

Polycneme des champs 77 Polygala

Polypoilium II9?

7 I9 Polypody, branched 1205. 766 I 204 . common II97. $24 \mathrm{I}$ crefted 1199. female 243 1201. male 1200. prickly

1203

Pomme de terre $\quad 329$

Pommeranzenmünze 778 Pommier cultivé 668 . fauvage

667

Pond- 
Pondweed 27I-279.755. Prickenelde

Poplar, black 56́2. 'Lom- Primerole

bardey 563 . trembling 561. white

560

Poppy, biack or white

7 I I. wild

709

Populage des marais 729

Populus

562

Porcelle douce 1025 radi-

queufe

Porreau

Porrey

Porft.

Port - feuille

Portulack

Potelé

Potentille argentée 700

blanche 702. droite 699

printanniere 7o1. rouge

706

Pouliot

$7 \times 0$

Poulmonaire des François

1053

Poulmonette calicaire 1378

Pourpier lauvage 632

Pourpiere

Prausbeere

Prahtnelke 508

543

593

Preibufch

I 181.1186

Prêle des bois II83. des champs I184. d'hiver I 188 timmonneufe I 187 majeure 1 186. des marais.

1185

Prenan the des mures I044. purpurine 1043

Preuftelsbeere
413

627

3 ir

Primevére 3 II . élevée 312. fans tige

Primrofe

313

Primula

313

Prinzeffinbolne

Prinzellinbohne

950

Privet

Prophetenkraut

Provinzrofe

Prunella

681

815

658

ibid.

Pruneola

Prunier domeftique 656 .

fauvage

Ptarmica

Pudding - grafs

Pulegium

657

$11+\mathrm{C}$

780

ibid.

Pulmonaria arborea $13 \% 2$

- - gallica

1053

- maculora $29 r$

Pulfatilla

$73 \mathrm{r}$

- nigricans

732

Pulverholz

359

Pumpkeulen

227

Pumpkin

Pungen, ftrand

I 183

Punktfchwämme 1578 -

I 580 . I 583-I 585 - I 588 .

I 590-1600

Pupleure menu

395

Purgierflachs

Purslane, wild

446

Putier

Pyrafter

632

6.52

665

Pyrola

569 
Q.

Quacking grafs, middle 144. Imall

$147^{\circ}$

Quändel, grofser 810. rómilcher

Queckengras

8 I I

Queckénw urzel, rothe $\mathrm{I}_{4}$ Quecktrefpe

Quellmontie

Quentefeuille

Quercus

Queue de cheval 1183 . de

Renard 9. au pourceau. 390. de Souris

Quickbeam - tree

Quickgrafs

Quince-tree 668. baftard

690

I 9 I

664

Quittenbaum

Quitfchenbeërenbaum 65 s

669

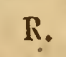

Racine crëufe 93T. fucrée

Raden

399

Radendiftel

Raddilh, horfe

Radieschen

Radifh, common 868. wa. ter

869

Ragwort I II 5. marfh I I 2. I

Regivurzel

41

Raifort commune 868 . des maraisfí96. fauvage 860. 869

Rainfarrn, wilder

697

Rainkohl, gemeiner $106 \mathrm{I}$

Rain veide

Kaiponfe

338
Raiponfette en épi 33.5. à tîtes

Raifin des Dames

Raifinet

Raifon des bois

Tht2

334

352

627

$5+2$

ing

334. fpicked

Ramichelwurzel

Ramfel

Ramfons

Sanunculus

335

$8 \div 2$

$475 \cdot 935$

475

745

734

883

298

868

ibid.

869

Rapunzchen 75 gende 335. kreisrunde

334

Rafenried̦ras $\quad 218$

Rafenfchmielen $\quad 12 \mathrm{I}$

Ralenweide 65

65 ginian flowering 692

Rattenkraut $\quad 326$

Rattenlchwanz 48

Rattle-wort i. $85^{\prime}$

Rauchapfel 319

Rauchlinde $\quad 378$

Raucke, glatte 899. mit fenkrecht ftehenden

Schoten 900: wilde 885

Rave

883

Raupengras $\quad 102$

Raufchbeere $\quad 543$

Raufchgrin $\quad 544$

Raufchwurzel $\quad 87^{2}$

8 Raute, gemeine 568

Z $\%$

Ratz- 
Rauten, fpanifche 638 Raygras, iranzöfifches I 68 Rebendolde Rebhunkraut Reckholder Red-Whorts

Reed-grafs

Rehbeere

Rehheide

Reibifch

Reine des bois 259 . des près

Reitzker

Remors

Rénebre

Rennthiermoos

Renoncle

Renouéc 737-749

Reprife

Releda

Reft - Harrow, common 942. thornlefs

Rettig, Acker \$69. zahmer

Revierkraut 868

Reuille matin I 88

Rhabarber, falfche 644 723 . wilde

Rharbarbre des Moins 573 Rhamnoide à feuilles de Saule

Rheinbeere

Rheinblume

Rheinfarrn I088. weiffer

Rhoeas 287

359

109 I

I $14 \mathrm{I}$ 709

Reis, fchlefifcher

Ribes

Riccie criftalline I 352 , flut tante 1355. glauque 1354. très petit I353 Riebefelftrauch

353

Rieble

Riedgras

Riedítraufsgras

25 ?

Rietfchen

Rindsauge.

IOT-225

I49I

Ringelblume $1_{163}$. gewöhnliche

Ringfỉwämme I5I8-

1525

Rifpengras "I37- 146

liiterfpiel 720

Kitterfporn, gelber 521 . königlicher

Roan - tree -

$72 \mathrm{I}$

Robinie

Rock. Crefs

$66 \mathrm{I}$

Rockenbollen

Rccket, broad-leaved 899. commion Garden 877. Water

395

Rodel, gelber

829

Rodeikraut

$-830$

Röldick

$89 \mathrm{r}$

Röhrenbaum 650

Rölrenlederholz I 4 SO

Röhrleinkraut IO30

Römerey 1098

Rogger

188

Róoggengrás

185

Roggentrefpe

159

Rohr, gemeines

177.

Rohrgras

I $\div 9$

Rohrkolbe, breitblättrige

227

Rollholz

767

Ronce commune. 69r. fremboificre 689. ram- 
pante des rocliers 693

Roqueite faurage 88.5

Ros Solis

Rofa alba 688 Damafcena

$68+$ rubra 6\$5. fylueftris

Role, Damalcener 6it. hundertblätrige $583 . \mathrm{im}$ mergrüne: 82 . wei.

6.

\section{Rofe-Campion}

Rofe de Guelder

Rofe von Jericho

Rofeau

Rofemary, wild

Rofendorn

Rolenholder

Rofenpispel

Robier blane '\&8. canin 68\% de Fra u

Rofsbalfam

Rofsbohne.

7. 2.776

Rofsfarrn

Rolifenchel

II 97.

Rolsgras, weiches

, wolligtes

Róshuf

Rolskaftanie

Rofskü rinel

Rofilattich

Rosuarinus fylueftris 574

Rofsmüinze

Rolsnuls

Rofspappel.

Rofspoley

Rofsriube

Rolsfchwanz

Rofsfcin wanzaum

Rofsweide

Rofswicke

Rothbaum

II 22 .

528

421

II23. II 24

574

$-63$

918

801

243

II 84

929

63

967

925
$40 \% .42 \mathrm{I}$

liothbeinholz

Rothbuche

Rothfichte

Rothgerfte

Rothuurz

Rothkälchenbrodt

Rouvre des

266

760

927

194

694

$3.5 \mathrm{I}$

Ruban d'eau

$4+0$

225

Rubus crefius 690. fiuticoíus 6y1. idaens 689

Ruchin des boeufs $158 \mathrm{I}$ Rudbeckie

Rue de Chêvre 980. jardins

Ruben, rothe 375 . 569

Rubenkerbel

883

Rubfamen 407

Riblaumen 1. Rüben 882

Ribhr mich nicht an $3 I 75$

Rulfer

Ruhrbeerftrauch

$3 \div 8$

Rubriaut $\quad 265$ Ruhrkraut 694. - 1000. I092. grolses $10 \quad 3$ purgierendes 1107 . chwarzes

Rupture-wort $3-6$ - leaft

44 ?

Kulh-grafs $86.93-94$

Rufsfchwämme I 524-I530

1732.1733

Ruta 569. muraria 1209

Rutfchen

498

Rye, common $\quad$ x88

S.

Sanlweide

Saamenkraut

69

Saamkraut 271. $279 \cdot 758$ :

$2 \times 2$

Sanm- 
Saamwicke

Sastgurke

967 Sandhabichtkraut $\quad 1042$

Sabina

Sablonniere

I 178

Sandkraut

$600-604$

920 Sandkreffe

853

Sadebaum

$600-60+$ Sandlilie

Safran, wilder

920

Sandräglein

484

Sage, meadow

510

Sandnelke

444

33. wood Sandpfrieme

594

784 Sandriedgras

II 7

Sagine droite 28I. ram-

Sandruhrkraut

I 98 pante

280 Sandweide

10i) I

Saint Foin I006. 1007
quets 1006 .

Sang de Dragon

Sainfoin à bouquets 1006 .

Sanguinaria

514 ordinaire 1007 Sanguiforba

914

Salbey, wilde

33 Sanikle, Yorkfhire

245

Salbeyweide

66 Sanicula

29

Salep

Salepwurzel

4I Sapin 927. faux

$38 \mathrm{r}$

Salicaria

ib. Saponaria

926

Saliette

$633 \div$ alba

532 Sarbaum

Salix alba

- capreola

- fragilis

- laureola

$7 \mathrm{I}$

63 Sarrette des champs 1078.

Salat, falfcher

Sallow

60 des jardins 805. des

Salomonsfiegel

Salfafy

1061

69

teinturiers

554

Salfifi d'Efpagne $\quad 1035$

480

1028

Salfifix commun 1029. des press.

1027

Salzkraut

359

Sambucus

438

Sammetpappeln

p. 373

Sainmtblume Ir 34 . I 135

Samminelke

Semoskraut

615

Sanamundenkraut

Sandbrodr

Sanddorn

Sinderidivie

333

704

$95 \mathrm{~S}$

287

Sandfeder

Satiraine grenouillette 46

Satureia

Satyrion

805 .

Satyrium

Sauapfel

Saubalg

Saubirne

613 562

Saubohne

Saubrodt

Saudiftel

46

Sauerampfer, franzöfilch

44 52 r. kleiner 523 . wilder 522.

Sauerdorn

465

Sauerklee, gemeiner 624 522

- $t$ : 
Sauermälerkraut
Sauerrach
Sauerfenf
Saufenchel
Sauge lauvage

Saukraut

Saule caffant 63 . commun

7 . helice 65. marceau

64 . nicheur 68 . à oiteil-

les 66. ofier 6r. pleureur 64 . rouge 60 . à trois étamines

Saulöffel

Savorée

Savoyerkohl

Saufamen

Sautodt

Sauwurz

Saw - wort, common 1077

field

Saxifiaga alba

- _ rubra

Saxifrage blanche $58 \mathrm{I}$. cuneiforme 582 . dorée 579. jaune

987

Scabieufe des champs 233 colombaire 234. jaunâtre 235 . fuccife

Scabiofa

Scallion

Sceau de Salomón

Schatampfer

Schafblume

Schafgarbe

Schafgras.

Schafkerbel

Schaflinfen

Schafmäuler

Schafnuts

Schafrapunzel

Schafribbe
232

232

476

480

523

I 165

I 142

149

404

971. 1009

75

763

II 65

I 142
Schafich wingel

I 49

$24 \mathrm{I}$

372

723

326

988 596. 946

Schachtkraut

Schafthalm

Schallkraut

Schalotten

Schalottengras

Schárbocksklee

Scharbockskraut

Scharfkraut, geftrecktes

2

546

$47 \mathrm{I}$

146

316

858

298

Scharlachineffel $\quad \mathbf{7 9 8}$

Seharte 886. wilde 1078

Schartenkraut

Schaumkraut

913

Schaumrösle

Scheere

Scheiskraut

Scheismelde

Schellern

589. 590

Scherte

Schetfchken

596

416

846

376

433

423

438

Scheuchzerie

524

Schibicken

438

Schieffchwämue $\quad 1563-$

1567

Schierling, Berg- 4 I9. gefleckter 392. kleiner 4 II Waffer-

423

Schiefsbeere

349

Schiefspulverholz ibid.

Schildbefenkraut $\quad 85^{6}$

Schildflechte r $422-\mathrm{r} 435$

kleinfte

1359

Schildklee, gelber 1073

Schildkraut 808.809:1006

$\mathrm{Z}=3$

Schilf 
Schilf

I78. I79

I $79-1721$

Schimmelkraut 1 160.groffes

ivurzel

Schnabelkraut

Schnallen

Schimmelfchwämme $r \geq 22$

$1723,1725-1727$

Schirmkrant, europäifches

Schneckenklee,

947

$293 \cdot 480$

102. kleinfter 1015

Schneckenkraut, hopfen-

Schirmmoos

527

Schlaf eere

Schlaf autz

$12+5$

332

686

Schlagkraut

Schlangenäugel

753

Schlangenhaupt artiges

IOI 4

Schrreeballenbaum $\quad 436$

Schnerbinfen, weiffe 507

Schneeglöckchen $46 \mathrm{I}$

Schneepi'z

298

289

Schlangenkraut $547^{\circ}$ klein

Schneetröpfchen

I 585

Schnitikolyl

310. 753

Schlangenlauch

467

Sclinittlauch 476 . wilder

Schlangenwurzel

$54 \%$.

1035

Schlangenzunge

1189

Schleifenblume, kleine 855

Schleifskraut

642

Schlehen 658, rothe 287

Schlottenblume

731

Schliaffelblume, gebröuch .

liche 3II. ftammlofe

313. wilde

Schlifielkra ut

3 I 2

Schnittzwiebel

468

Schnödefenf

$47^{6}$

Schoilliaut, 869

Schöllkraut, grofses 7 I 2

Schönbaum

Schoolskraut

Schotendorn, virzinifcher

Schotendotter.

973

Schotenerbfe

873

Schotenklee.

$9 \div 4$

Schraubenfalat

977

5:4 Schreiberrofe

1045

Schmalzblümchen $\quad \mathbf{7 4 5}$

Schmalzblume

729

Schmalzfternblümchen

Schmarotzerranken

750

Schmeerwurz

270

Schmeerwurzel 6r6. 294 fe

620

Schmelen, blaue 127 gebogene I22.glänzende 12 \% nelkenartige

126

Schinelengras, frühes 125 graues 124 . rohrartiges

Schuppenflechte

II 34

1369 .

Schuppenwurz

144.4

Schufterholz

824

Schuttienf

$35 \mathrm{I}$

Schutenkraut

Schwabenkraut, 884

Schwaden, wilder 158

Schwadengras

I 33

Schwadengriitze, frankfurter -

Schwalbenkraut 712. klei-

nes

750

Schwal- 
Schwalbenwurz 7I2. gemeine Schwamm, feuerfang cnder

I590

Schwammflechte $\quad 1420$.

$142 \mathrm{I}$

Schwammkraut

Schivammledergras

Schwainmwatte

Schwarzdorn

Schwarzhafer

Schwarzkraut

Schwarzkimmel 725 , franzöfifcher 723. zahmer

724

Schwarzweitze

Schwefelwurz

Schweinbrodr, falfch

Schweinemelde

Schweintodt

Schiveinepilz I579.

guter 1580. giftiger

1584

Schweinefalat

1062

Schweinsciciorie 1025

Schweinskreffe $2+5.859$

Schweiswurz

I 124

schwerdboline

947

Schwerdlilie, gelbe 80. fibirilche $8 \%$ tentflie 79 Schwertel, blauer 8I. rother

Schwindelhafer

78

Schwindelkörner

Schwingel, erhabener 152 harter $15 \mathrm{I}$. niederliegender $\mathrm{I} 5 \%$. rohrartiger $\mathrm{I} 53$ rother

Schwulitkraut

Science des Chirurgiens
Scille, fchöne

Scolopendrium

Scordium

Scorpions orifs, field Mouf

489

I 206

785 ear 302. Marfl Moufeear

303

Scorzonera I034. I035

Scrophularia aquatica 838

- - foetida 837

Scrophulaire aquatique 838 grande 837 . jaune 839 . petite,

Scurvy-grafs

750

Sea-Buck-Thorn 28 ?

Sea-gials $\quad 1486$

Sea-Spurry $\quad 603$

Seckelfenf $\quad 865$

Seckelkraue $\quad 867$

Sadum maius 649

- - minus - 630

Secblume, gelbe 717 . weiffe 718

Seeholderkraut $\quad 271$

Seekandel 717.7I8

Seekrappe " I

Seekreuzdorn $\quad 287$

Seelenholz $\quad 348$

Seenelke $4+4$

Seenufs 264

Seerofe, gelbe 717 weiffe

Seeftrandsgras - $\quad 512$

718
512

Segge, entfernte 206. haarförmige

212

Seichblume

1035

Seide, europäifche 270

Seidelbaft. $\quad 546$

I50 Seidenhaaraftermoos 1475
674 Seifenkraut 584 . wildes

674 Seifenkraut $584 . \quad \begin{array}{r}\text { 15ildes } \\ 596\end{array}$

898 Seigle

$2=4$

1:38

Scil. 
Seilweide

\section{70}

Selfheal, common 815 . greater-flowered 816. jagced-leaved

Solin à feuilles de Cherui $40-$ faurage Selleri

Sellerispappel 40.5

433

Séné baftard 1008. fauvage

Seneçon des bois 1118 . à feuilles de Roquette I I 19 . Iacobée 1 I 20 . des marais $12 \mathrm{I}$. 'vifqueux. III 7 . vulgaire 1116 Senevé

Senf, fchwarzer 893. weilfer 842. wilder

Senfkohl

Serpyllum

Serfifi

Service-tree, wild

Sefame d'Allemagne

Sefeli

Seuenbaum

Sheeps - Scabious

Sheeps - Sorrel

Shepered's - Needle

Shepherd's - Purfe

891

879

810

1027

659

833

422

929

I 165

523

413

867

Sherarde des champs 263

Sichelkraut

Sicklewort

Sideritis

400

.787

801

Siebenfarbenblume, wilde

Siebenfingerkraut

Siebengezeit

Siegmarswurz

Siegwurz

Siemeonswurz
Sigillum Salomonis 480 .

Silberbocksbárt $\quad 122$

Silberdiftel

1073

124

$697 \cdot 700$ 560

Silberpappel

Silberweide 71 . kleine 67

Silvie blanche 734. jaune 73.5. des près

Sinapis

Sinau

Sindau

Sinnoriin kleines 327

Sinngrtin, kleines $\quad 327$

Skabiofe, Abbifs - 232. gelblichte 235. 'grolse 100. tauben

234

Skammonie, teutiche 318 Skirrets

Skordie 785. Berg. 786 Skordienkraut 755 . Wald-

Skorodonie 754

Skorpionsmangold 313

Skorpionsfchwanz 304 Skorpionfpelzen $\quad 1008$

Skorzonere, aufgefchnitten'e

Schmalhättrige 1037 teutfche 1036. Skull-cap, fwedif h Snake - ineed

Snap - Dragon, greater 84 574
849 leaft

Sneepilz 848 1588

Snèze - wort, cominon $114 I$. Snow - Drop $\quad 461.4^{62}$ Soft-grafs, meadow 23 I Solanum

$23 I$

Soleil annuel i 57 . multiflore 
fore I158. taupinambour

Sommerbeete

Sommerbuche

Sommerendivienfalat 10,46

Soinmergerfte

Sommerholder

Sommerlinde

Sommerlolch

Sommerpilz

Sommerrettig

Sommerthierchen

Sommertrefpe

Sommerweizen

Sommerzwiebel

Sonchenkraut 1059 . des

Sonchus

Sonnenblümlein

Sonnenblume', gemeine I 57 . vielblumige I I 58 knotige

1159

Sonnenblumenftaude, falfche I I $\mathbf{5 6}$. gemeine 1158 Sonnengünzel

714

Sonnenkrone

1157

Sonnenthau, kleiner 4.49

rundblättriger

Sonnenwende

Sonnenwirbel

Sooddiftel

Sope - wort

Sophia

448

1163

75

1064

Sorbier 659. des chaffeurs

660

Scrbus

$66 \mathrm{I}$

Sorge

II 7 I

Souchet brun 88. jaunâtre

Soude

87

Souci des boutiques 1164 des marais 729. de $\mathrm{Vi}$ -

gne

1163

Sow - thiftle 1058-1060

smack.

Spaltzalin I 246-I25\%

Spanholz

923

Spark, 616. knotiger 6is

Spargel

Spargelbohne

490

949

Spargelklee

1012

Spargenlaame $\quad 724$

Spargoute des champs 616 noueufe

617

Spartium

Spearwort, great 738 . lef-

fer

Spechtwurzel

Speckmelde

737

376

565

Speedwell II-I5. 17. I8.

20. $21.24 \cdot 28$. female

$8+3$

Speerdiftel

1067

Speerhahnenfuls $\quad 738$

Speerkraut, kleines 73 ?

Speichelwurzel $\quad \mathbf{5 5 4}$

Speifekümmel $\quad 428$

Sperberkraut $\quad 246$

Sperberbaum, wilder 659

Sperberkraut

759

Spergel, kleiner weiffer 617 . teutfcher 616 Speyfpettel $\quad 596$

Speyteufel 1490

Speywurz II 6

Sphaigne des marais 1224

Sphondylium - For

Spickantweiblein 1 Iy 2

Spicke 75 [

Spidewort, branching 453

fingle-ftalked 484

Z z 5

Spier- 
Spierfaude

Spiefsbeerholz

Spiefsgras

Spillbaum, - europäifcher

Spillenholz

Spillingr

Spina alba

Spinacia

Spinat, englifcher kohlartiger

Spindle-tree

Spinnblume

Spinnenkraut, äftiges 483

Spiraea

Spitzhafer

Spitzklse

Spitzmorchel

Spitnufs

Spleen - wort

Spornblume

Springauf

Springgras

Springgurke

Springkörner

Springzraut

Springkrerre

Springfaame

Spruce Fir

Spuhlbauin

Spurge 640. 641.

$$
640.648
$$

Spurre 616. doldenförmige

$$
82
$$

Spurrey, curn 6I5. knotted 619. fmall

Squamaria

Squinance - wort

Stabwurz, wilde
617

824

262

1084 - Steinleberkraut

teutfches
Stachelbeere, gemeine 356

haarige

35.5

Stachelhahnenfufs $\quad 746$

Stachelkraut 942

Stacheinuls, fchwimmende

264

Stachelpfrieme rauche 938

Stacheilchwämme $160:-$ 1606

Stahlkraut

$9+2$

942

Stallkraut

947

Stangenbohne

$485-$

4.98

Star - Thifte, purple I I 5.3

Starwort inid. autumnal 4. mountain I Iog. vernal

Staubfechte I 453-1 465

Staubfchwänme I659.

$1693-1696$

Sauliere 1109

Stechapfel, gemeiner $3^{19}$

Stechgünfter

$9+6$

Steckzwiebel

472

Steiffchopf $1232-1234$

Steinbrech, kleiner 582 . rother $6 \% 3.1208$. weiffer

$68 \mathrm{r}$

Steinbrechweiblein $\quad 622$

Steineiche

Steinfarn

$-6 \mathrm{r}$

Steinfarnkraut

1197

Steinfeder

Steinflechte

Steingünzel

I 196

$120 \%$

1360

804

Steinklee, gelber 1013

Steinkraut, beftäubtes 856

85 ?

855

1384

Stein. 
Steinlungenkraut 1382 Stickwurz I182. wilde Steinmilzkraut

Steinmünze

$\begin{array}{rr}1208 & \\ 804 & \text { Stickneffel } \\ 587 & 738\end{array}$

Steinnelke .

Steinpfeffer

Steinpilz

Steinpoley

Steinrate, weiffe 1109

Steinfame 292.293

Steinfchuppenfechte $13 \mathbf{I} \mathbf{I}$

Steinwuizel

635

Stellaire des bois 605 . gra.

587 Stiefmütterchen

1172

630 Stieleiche

1583 tinkbaum

762

Stinkblume

652

Stinkkamille

354

Stinkmelde

II 39

Stipe capillaire II8, jonciere

II?

Stockmorchel I 60 rj minée

607

Stempelfchwamm, 1676

Stendelkraut, grïnes 46 . breitblättriges

Stendelwurz

50

Stepherds - Staff

$5 !-53$

Stockrüben

$8 \times 2$

Stone-Crop, infipid 63 I. rock 628 . wall 620 , white 62 . Yellow

627

Stone - Pink

Stoppelpilz

594

Stopfsloch

1602

Stern sus Bethlehem 485

Sternblürnlein 488. europäifches

527

Sternblume I125-II33

Sternidiftel Yis3

Sternkraut, klein blaues 260. Acker -

263

Sternkrautftaude, unächte I 155

Sternmarchantie 1348 Sternmoos, apfelförmiges

1324 . birnförmiges 1323 borftenartiges -1260 . Brunnen- 331 . durchfchimmerndes 1226. getipfeltes 1316 . goldgelbes 321 I. purpurfarbiges $125 \mathrm{I}$. rofenartiges 13LS. wellenförmiges 1319. Sternpflanze $\quad 606.608$ Sternfchwämme $1690-$

Storchblume

Storchblume 743

393

743

Storchfchnabel gor.kleinblumiger 903 . kleiner 902 glänzender 909 . fchwarzer go.f. ftinkender yo8. weicher 910 Storchfcinnabelkraut go6"-

Stork's - biie 908

Stramonium

413

Strauchflechte 1389 -1402 kraufe

1397

Strauchhopfen $\quad 453$

Straufsgras, auslaufendes III. bicunes 110. federreiches 116 . haarförmiges 112. fehr kleines II 4. rohrartiges 108 . rothes 109. weiffes $\mathrm{I}_{3} 3$ Straw - berry, barren 696 . common

695

Streich- 
Streichblume

II 40

Streichkraut

636

Streifwurz

517

Strenzel, gemeiner

Strohblume

435

Stückbeere

1091

Studentenkraut

Studentenblume

356

988

Studentenröslein, weiffes

1134

443

Succory

1022

Süfsfarrn

1197

Süisholz, falfches

953. wildes 1003 .

Süfsholzbaum

Süfsholzwicke

Sufsling, weiffer

Sumach

Sumpraftmoos

Suinpfbeere

Sumpfdiftel

Sumpfdreizack

Sumpfeinblatt

Sumpfholder

1197

973

1005

1602

440

I 275

Sumpfhahnenfufs $737 \cdot 738$

Sumpfhederich

Sumpflottonie

Sumpfkrefe

Sumpflabkraut

Sumpfmaufeohr

Sumpfmoos

544

107

5 II

443

436

738

Sumpfnabelkiaut,

3 I5

897

2.47

303

1220 förmiges

Sumpfölfenich

Sumpfraucke

Sumpfrodel

Sumpffternmoos

Sumpfraldifroh

Sumpfiwafferftern

Sun-Deew

fchild-

380

706

896

830

I3 12

247

Sun - Flower, a

annual I 157

common prennia! i 58. taberous.

1159

Sureau, commun 438 . à feuilles de Perfile 439. yebie

4.37

Surette 513. des Brebis

Sweet-Biar, common 523

Sweet-Briar, common 675

Sweet Flag

497

Swine's-Creffes $\quad 859$

Swinés-Succory 1062

Swo-thifte, marfh 1058 1mooth 1050. tree 1059

Syccory, Gum 1042. wild

1022. yellow 1029

Sycomore-tree $\quad 530$

T.

Tabac de Vôges $\quad I O_{4}$

Taback, englifcher 322 . gemeiner

321

Tabacum

321

Tabouret

Taconet

867

Täfchelkraut, grofles 864 . kleines

$8: 2$

Täubling, bitterer 1497

Tag und Nacht 833. wild

827

Tagblume

478

Trgeleuchte

825

Tagefchlaf

$73 \mathrm{I}$

Taglichüne

777

Talictruin

728

Talitron des boutiques 898 . commun 728 . à feuilles étroites

Tanie-poifon

Tanacetum.

727

$36 \mathrm{r}$

1088

Tan. 
Tanne, edle 926. rothe

Tannenwedel

Tanner's - Sumach

Tanfay, common

Tanfy, wil.

Taraxacum

- Tareole

Tartoffeln

Taubenbeere

Taubenfuls

Taubenkorn

Taubenkropf

Taubeniclinabel

Taubenfkabiofe

Taubgerfte 103. 187. 195

Taubhafer

Taumelkörbel

Taumellolch

Taupinambour

Taurand, wilder

Taufendblatt

Taufendgüldenkraut 363

Taufenknoten

Taufenkorn 376. kleinftes

447

Taufenfchön, meyerarti-

$$
\text { ges }
$$

Taufendfchönchen 1095

Taxusbaum

Teichfenckel

Teazel, cultivated

Teichkolbe

Teichfchilf

Telephium

Tennegras

Téte de Veau

Teufelsabbils

Teufelsauge

Teufelsband

320. 751
Teufelsdarm

Teufelskirfohe $332.43+8$.

2 Teufelsklaue

1193

Teufelsmarterholz $\quad 348$

Teufelsmettern - 266

697 Teufelsmilch 646. grofse

1030 . 628

958 Teufelspeterlein $\quad 392$

329 Teufelszwirn $\quad 270$

690 Thee, wilder 292

$74 \mathrm{I}$ Therebinthina, 925

186 Theriackwurzel, teutfche

335.93 I $\quad 246 .+29$

912 Thefie à feuilles de Lin

133.360

Thifte $1067-1078$

Thlafpi 864

I87 Thootwort … 824

329 Thorn-Apple 3 r9

807 Thorough-wax, common

I 42 393

Thränenweide 64

Tlumkohl, kleiner 878 . raucher

Thurmkiaut, glattes 878

Thyme, common 8ir. wilu

810

Thymian, gewöhnlicher

930 8II. wilder 810

757 Thymus $81 \mathrm{r}$

238 Tick-Seed II54

228 Tilia 715

77 Till
626

626 Tilleaul $\cdots 716$

552 Tilleul d'Europe 7 I5

848 Timothis:gras 182

232 Tithymale $640.64 \mathrm{r}, 643$.

647

849 Toad - flax, baftard 360 . 
blue 847 . common 846 : lealt $8+5$. ivy -leaved $\delta .42$ Tobaco, common 322 . virginian

Todtenküpfe

321

Todtenkoptbaum

Todienkranz

Töberich

Tölpelgeusbaum

Toligerite

Tollkorn

Tollkraut

Toque blue 808. à fer de fleche

Tordile anthrifque

Torfinoos

Torf w eiderich

Torminge

Tortelle à fleurs che Giroflier

Tournefolle

Tourette, liffe 879. velue

880

Toute Epice

Tower - Muftard, rough 880. fmooth

879

Tragant, fülsholzblättriger

Tragbuche

1000

Trainafle commun

Traubeneiche

Traubenerble 765

552 $76 \mathrm{I}$ Traubenfarrn, königlicher

I i 9 I

Traubenkirfche 652. virginifche

Traubenitock

Trefle alpin 994. blanc 99 I des champs 99 . couché Icos. d'eau 3 I 6 . filifor. ne 1001 . à fraîles 996. hepatique 730 .houblon- né 998. hybride 990. jaune 979. 998. Mclilot des boutiques $98 \%$. Melilot d'Italie 989. de montagne 997 . odorant 988. paille 949. des près .993. rougentre 992. Trefoil $987-1001$. foot 979. marth 316. melilot 1014 Trefpe, gefiederte 167 . gemeine I59. rauche 162. weiche Ito Trefpgras $\quad 160$

Triboule 264

Trichomanes $\quad 1208$

Trichterfchwamm $\quad 1552$

Trifolium fibrinum 316

Trille:

891

Trique madame 629

Tröne

Trollblume

8

Trompetenkürbis 1179

Tropfwurz 389.673 .1197 .

Trulcart des marais $5 \mathrm{LI}$. maritime

$5 \mathrm{I} 2$

Trofsfarrn

- 1192

Trüffel, weiffe 1678

Truffe de Virginie 329

Trufle d'eau $\quad 264$

Truffle commune 1678

Trunkenwaizen $\quad 187$

Tuchmacherdiftel $\quad 236$

Tugendblume : 1080 Tipfelfarrn, baumförmiger I 205. gewöhnlicher 1197 . mäunlicher I200. weiblicher 20 I. weicher I202. zerbrechlicher Ls $\therefore 1204$

Türkifcher Bund 494 Tulpe, 
Tulpe, gefnerifche 4.65. wilde

Tuneferblùme

Tuik's law

Turnep, common

Turfilago

Twalch

Twaybladc

Tyfrelinum

Uferweide

Ulinaria

Ulmbaum

Ulmus

Ulva

Ungeduld

Unholdenkraut

I. $186 . x+87$

Unfer lieben Frauen. Bettfroli Unfer lieben Frauen Birn-
lein 660

660

Unfer lieben Frauen Hand. fchuh

Unfer liebenFrauen-Flachs

Unfer lieben Frauen-Hopfen

998

Unfer liebenFrauen Nachtmantel

268

Unfer lieben Frauen Sch ïchlein $\quad 987$

Unfer lieben Frauen Schülein

Unfers Herrgottslöffel $\$ 48$

Unfers Herrgottswunderkraut

Unterartifchocke 1017

Unvertritt

1159 .

Urtica major 283 . minor

Ufnea Cranii humani 145 I 282 Ufnée barbue 1447. che- velue I 448 " du crane $^{\circ}$ lumain 137 I. flenrie $145 \mathrm{I}$. herifiée $\quad 1450$

$\mathrm{V}$.

Valeriana fylueftris

Valevianedes 74

Valeriane des marais 73

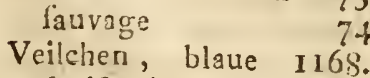
dreifarbize 117 !. fünteckigte 344. gelbe 874. pfirfchblättrige 1173 . rauche I166. wilde I169. wohlriechende I 68 . $z$ weifarbige I 72

Velar.

Velvorte 843 , femell 870 Venusbad 238

Venusblume

Venusfinger

Venusnabel

249

380

Venus's Comb - 413

Venus's Locking-glafs 344

Venuslpiegel $\quad 344$

Venusftiel 413

Verbalcum 323.325

Verbena 3 [

Verfangkraut 1164

Verge dorée I 114 .à pafteur

234

Vergerette âcre JII2. de Canada

Vergue

I I 13 285

Veronica officinalis I4, teucrium

Vergifs mein nicht 303

Vermiculaire brûlante 630

Veronique II - I5. I8. 19.

Verveine

22. 27.

Vefice cultivé.967. feve 970. des haîes 969. multifore 966 ? 
966. Veffe de Loup du Cerf 167\% commune I679. étoilée I 1822 , feuve $169 \%$ pedunculée 1689. truffle

Veffe fauvage I 678

Vetch, birter 986. bufh 969 . cultivated 967. hun garian 963. tuberousrooted 958. tufted 965

Vexierkaftanie

Vexirnelke 528

Vied de Pigeon

Vielgut

615

913

$-382$

Vierling, geftreckter 280 Vigne blanche I 182. cultivée

Vignette

Vinc poifon

Vinca

Vincetoxicum

Viola i I68. canina i 169. Tricolor

Violaria

I 17 L

1168

Viole, gelbe 874 . pfingft-

Violenkraut

872

Violet-Marfh I 67. Days II69. mountain I I7O. fpring

Violette des champs 1172. commun I $17 \mathrm{I}^{\prime}$. à feuilles de Perfie 1 173. heriflée I 166 . des Marais I I67. Ae Mars i i 68. des montagnes 1170 . odo. rantè I-168. fauvage I 169

Violier lauvage

Viorne Obier

874

Viper's-Buglofs

436

289

Viper's - grafis I034-1037

Vifga rifcum

286

Vitis

Vitis Idea

352

Vitsbohne 947. tirkifche

543

Vogelbeere

$9+9$

Volgelfuis, winziger

Vogelheu

Vogelkirfche 652 . ze 655

Vogelknöterich 552 .

Vogelkraut 359. II I6. gemeines 442 . kleines 280 Vogelmeyer, hoher 605 Vogelmilch, doldenartige

488

Vogelneft 49. 387

Vogelpfote, kleine IOIO Vogelfpeierling sbaun 66I Vogelftern, narbonifcher 487

Vogeltodt

392

Vogelwicke 959.965.1009 gelbe 979 . glatte 982 . kleine

Vogelwurz

983

Vogelzunge

Volant d'eau

554

Vulnéraire des poifans $94 \mathrm{I}$

Vulpin

Vuluaria

W. 103-105 372

Wachholderftrauch, teutfcher 928

Wachsblatt, untergetauchtes

Wo 735

735
060

Waid 886. wilder 585

Wake-Robin 753

Wal-wort

Waldaftmoos

437

1277 Wald: 
Waldäpfel.

Waldbibernel

TValdbart

Waldbirne

Waldcymbel

Waldeppich

Walderuen

Waldefche

Waldglocke

Waldhabichtraut 1029

Waldhähnchen $=34 \cdot$ gelbes

.35

Waldhahnenfuls, fülsei

Waldhirfe 106. gelber 834

Waldhirfengras

Waldhopfen

Waldkeulenfchwamm

Waldkicher

Waldkirlchbaum

Waldklette

Waldknabenhraut

Waldknoblauch

Waldkohl

Waldiopf

Waldlabkraut

Waldililie

Waldlinde

Waldmangold

Waldneyerich

Waldmeifter, fürbender 26I. grofser 253. kleiner 262 . wohlriechender

259

Waldnachitchutten $\quad 328$

Waldneflel, gelbe 794 tod. te

Waldplaticrbfe

748

Waldpoley, falicher 821

Waldrapunzel, hohe $33^{6}$

IValdrauch

569

50
Maldraucice

Waldrebe

iividrennthiermoos $13: 5$

Waldriecigras

Walcirodel

IValdichmergel

Waldipargel

Waldftroh

Waldviehgras

Waldwicke

Wald winde

wValdzwiebel

Wallfo: er

Wallnufsheum

Walpurgiskraut

Wal ort

Walzenkraut

Wanzendill

IWanzengeficht

Warzenkraut

Wart - wort

Warzenkraut

222

851

739

$4 y 0$

247

143

96.4

$3 \div 5$

$46 \%$

874

763

1190

437

976.979

410

584

792

644

I1 65

Warzenfchwämme $166 \gamma$. I $69.1701-170.4$.

Wafchwurz

IVaferampfer

584

Wafterandorn, brauner 790

Wafferbeeren

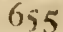

Wafferblume 71\%. häutige

1466. weiffe

Wafferbuche

$7 \times 8$

766

Wafiercypergras 20 i

Wallerdolt

1080

Vaffereppich $\quad 433.740$

Wafierfeder

3 I 5

Wafferfenchel 315. 42 I.

Wafferfilipendel

749

389

Waflertöhkrat $5+8$

Waflerfiofcheppich $\quad 39^{6}$

Wafiergarbe

A a a

315

Wailet- 
Waniergarn

Watterhahnenfurs

Walterhirfe

Waíferholder

Waiterhornliraut

Wafferhornpflanze

Wafferkaftanie

Wafferkreuel

Wafferkrefie

Wafferlack

Wafferlebeikraut

Wafferlilie

Wafteriinfe

Wafferlifch

Waftermännchen

Wafiermangold

Walfermerk

Waffermelone

Waftermühre

Wafrermorelle

Wafternabel

Wafternufs

Wafierpaftinack

Wafferpeterlein

Wanerpfeffer

Wafterpimpinelle, rundblättrige

Waferpoley .

Wafterretig

Wafferrhabarber

Wafferfchaftheu

Wafferfchierling

Wafierfchlamm

Wafierfchlinge

Wafterfchwamm, licher

Wafferfenf

Wafferfteinbrech

Wafferttern .

Warfestulipane

Waftervio!e

Waffervogelkraut
757

74.8

120

436

623

755

264.

559

894.896

$27 \mathrm{I}$

747

717

54 564

718

520

398

1181

718

$3.7 \% \cdot 433$

380

264

396

$397 \cdot 433$

549

333

$77^{6}$

846

520

2. IIS?

423

1476

652

bräun-

I 928

871

389

$3-5$

7 i7

$315.5^{64}$ 509
Wafferwegerich, groffer

Wafferweiderich

525

Wafterwicke

308

962

Wafferwundkraut 1083

Wafferwurzel

705

Water Calthrops

Vater-Gladiole

264

564

Water-Horehound $\quad 32$

Water-Lilly, white 718. yellow

Water-Melon

717

Water - Milfoil, fpicked 357 . verticillated 758

Water-Nabelwort 380

Water-Parinep, common 396. creeping 39s. upright

Water-Pepper

39) 7

Water-Mountain $\quad 52.5$

Water - Speedwell, longlcaved 17 . narrow-leaved.

18

Water-Violet $\quad 380$

Wau 636 .gemeiner 638

Weberdiftel 238

Wechfelknöterich $\quad 548$

Wegdiftel 1069, gemeine 1067. kleine

$10-0$

Wegdorn 350. unbewährter

349

Wegebreit, dreiädrigtes 245. mittleres

242

Wegegras

552

Wegerich; groffer $2.4 \mathrm{I}$. pfriemcnförmiger 245 Wegholder 928

Wegfenf

870

Wegtritt, kleiner $24 \mathrm{I}$. fpitziger

243

Weiberkrieg

942

Weich. 
Weichlchwäınme 1509-

1510

Veichfeln

655

Weide, gelbe 6r. fpanifche 975. weifie

Weidenkraut 633. gelbes

Weidenlattich

Weidenröslein

Weidenfehwamm

Weiderich, gelber 307 . rother 632. weifier 308

Weihernufs

$2^{n} 4$

Wein, greneiner 352, wi!der

Weinhlatt

Weinblume

Weinfarrn

Weinkraut

Weinlauch

Weinraute

Weinrofe

Weinftock

Weifsbaum

Teifsdorn

Weifskraut

Weifsling

Weifswurz

Weitzen

Wellfaamen

358

$53 \mathrm{I}$

$5 \div 1.6 ? 3$

$10: 8$

$73 \mathrm{I} .1193$

469

368

675

3.52

532.560

660

884

1522

450.431

189. 190

897

Werfucide, grofie 69 . kleine

66

Wermuth, gewöinlicher I086. römilcher

Wetterkraut

Wetterrofen

Wetzfteinkraut

Wheat-grafs

1083

98:

$9=0$

943

$18+$

660

$8 \div 2$

Whithlon-gras

Wicke, erbfenartige 963. gelbe 959 . grolle 969
Wiedehopfen'raut 1007

Wiederftols 590 . wilder 597

Wiedertodt

I 208

Wiederton 686. haarförmiger 1237 . weiffer 483

Wiergenftrauch

686

Wielenbertram, weifer I 14 I

Wiefenbockshart IO2?

IViefendiegel

Wiefendiftel

50

106.5

Wiefenflattergras $\quad \mathrm{I}+8$

Wiefenflei!chblume 834

Wiefenfuchsfchwanz 103 .

Wiefengeld

182

Wiefenglückchen $\quad 336$

Witenhaaritrang $\quad 391$

Wiefenhahnenfuls 743

Wiefonkichern

959

829

Wiefenklee, weiffer 990

Wiefenknopf $\quad 246$

Wiefenkönigin $\quad 674$

Wiefenkohl $\quad 1065$

Wiefenkraut 444

Wicfenkreffe 889.empfindliche

$88 ?$

Wiefenkinmel * 428

Wiefenkuhweize 834

Wiefenlauch $\quad 474$

Wifenlifchgras $\quad 182$

Wiefenlolch $\quad 187$

Wiefenölfnich $\quad 407$

Wiefenpelz $1+79$

Wicfenplatterbfe $\quad 959$

Wiefenraute, gelbe 729 .

fchmalblättrige $\quad 727$

Wiefenrodel 820

Wiefenfalbey 33

Wiefenfcharte $10 ? 7$

Wiefenfauerampfer $\quad 522$

Aa 2 
TViefenfchaumkraut 839

IViefenfpargel

Wicfenfchwingel

Wiefenwarte

Wild Buglofs, german 299 finall

Wildemannseras

Wiilow - Herb, bay 535 . greater 310 . hairy 534 . hooded 804 . warih 538 . narrow - leaved $55 \mathrm{I}$. fmooth - leaved 536. ycl. low 307

Willow-tree, Almond lesveat 62 . bay - leaved 60 . crack 63 . golden 61 . pourple 58 rofe 65 . round-leaved 66. fand 67. fmooth 59. weeping 6.1. white

$7 \mathrm{I}$

Wimperinoos $1242 \cdot-1245$

Windahre

Windblume 733 . weiffe 734

Winde

Windhafer

Windröslein $317 \cdot 318$

Winterblïmchen

- Winterendivie

Wintergriin .

Winterkrefle

Winterlinde

Wintermajoran

Winterrettig

Winterroggen

Wintertreipe

Winterweitzen

Winterwicke

Wirbelbaum

Wirbeldoft

Wirfingkohl

Wittwenblume

Woad, Dyers

Wohigemuth

327

$87 \mathrm{I}$

716

$8 \mathrm{IS}$

858

288

286

119

$96 \mathrm{I}$

123

$82 \mathrm{I}$

884

233

$8 \pi 6$

295.819
Wolfshart

Wolfsbaft

Woltbohne

Wolfsfurz

Wolfsfufs

IVolfsgeheul

Wolfseeficht

Wotskirfehe

Woifsklaue

Woltskraut

Wolfsmilch $640.641 .6 \$ 3-$

6,83

Wolfstchote $94 \div .96 \mathrm{I}$

Wolfstrapp 768. falfcher

Wolfswurz

$7: 3$

Wollkrant 323. kteines 324 fchwarzes 715. weilies

Wollenfchwämme r $\begin{array}{r}374 \\ 167\end{array}$ 1698

Wolverley 1104, falfche 1107

Wood - roof, blue 260 . fwedith $=6 \mathrm{I}$. white 259

Wood-Sorrel, common 624. yellow

$6 \approx 5$

Wood-waxen 936

Worm - wood, common ro85.roman $\quad 1086$

Worthle-berry $\quad \mathbf{5 4 3}$

Woundwort 941

Wucherblume, geruchlofe

1 100. krónenförnige I 163 . ftraufsartige I 0 I

Withikraut

Wüterich 392. giftiger 423

Witzerling 42 I

Wundblume 945

Wundkraut 393.941. fettes 626. gülden III 4 . heidnifch 713. kreifend 
Wunnebaum

Wurmfarrn

Wurmkrout

Wurmnefel

Wurmfaame

Wurmwurz

Wuthbeere

\section{Y.}

Yarrow, common 1142, noble

Yew-tree

Yoglknofpe

Igelkopf

Igelkraut

Ypreau

Yfop

Zäpfleinkraut

Zahnlofe

Zahntroft

Zapfenblatt

Zapfenholz

Zartfchwamm, fichirmförmiger

Taunbuche

Zaunling

Zaunreifs

Zaunrübe

Zaunvicke

Zaunvinde

Zehrogras

Zehrwurzel

Zeidelbaft

Zeitlofe

Zeliblume, teutiche 1076

Zellenfchıärnme 1586 -

Zellernurs

Zenigole

Ziegelgerfte

Ziegendill

Ziegenholz

Ziegenklappen

Ziegenkraut

'Ziegenlauch
1143

430

2.26

238

560

771

$3+3$

806

827

$3+1$

349

1548

7ó?

345

257

182

956

318

552

753

546

510

1589

764

70

143

392

$9=3$

316

392. 435

485
204
Zielercrbfen

974

Zigeunerkorn

330

Zigeunerlauch

475

Zimbelblume

50

$8 \div 2$

Zinnie.

Zinnoherblume

Zipfelkraut

Zipollen

Zipparten

Zipperleinkraut

Zirbelbaum, vilder $9=3$

Zirmet, gemeiner $40 \%$.

grofse:

Zittergras

Zitterpappel

Zitterwurz

Zittwer, wilder

Zotterblume

Zuckerboline

Zuckererbfe

Zuckerribchen

$14 .-1,3$

703
1.38

$56 \mathrm{I}$

517

I 182

316

949

$9 \div 4$

399

Zuckerwicke $\quad 959$

Zuckerwurzel

Zürbelnüfe, wilde 14 r

Zumpenkraut, gemeines

626.027 .628

Zunderfchwamm I599

Zweckhol 24?.351

Zweiblatt

43

Zweizahn, dreitheiliger I081. hängender 1083 . kleiner

Zwergbohne

1082

' 2 wergerbfe

Zweroghasmoos

950

$9+4$

1238

Zwergholunder 437

Zwergkifche $\quad 654$

Zwergmifpelbaum 664

Zwetichen 656

Zwiebel, gremeine 472

Zwiebellahnenfufs $\quad 743$

Zwiebelkötengras $\quad 524$

Zwiefelbeerbaum 655 


\section{$A D D E N D A$.}

\section{Ad pag. I2. ante no. 33,}

ofticinalis. 1734.* Saluia foliis lanceolato-ouatis integris crenulatis: floribus ficatis, calycibus acutis. LINN. Syft.p. 68. n. 4. BLACKw. t. 71.

Pharm. aluine Herba.

Gebräuchliche f. rcmeine Salbcy; griine und rothe Salbey; Gartcafalbei. Germ. Green and Red Sage. Angl. Sauge commin. Gall.

In hortis oleraceis et aliis fere omnibus, tam vrbanis, quam rufticanis valde vulgaris. Flor. Aeftate. Perennis.

$V \int$. culinaris notiffmus et praeprimis folia pro ornamentis carnium inferuiunt.

Ad pag. 102. ante ก. 79. 494. Valantia L. G. 1258. Vallantien. Gorm. Vail-
lant. Gall.

Char. Gener. Q Cal. o. Cor. 4- partita. Stam.4. Styl. 2 - fidus. Sém. I. Pift. obfoletuni.

of Cal. o. Cor.3-4-partita. Stam.3-4.

cruciata. 1735. Valantia floribus mafculiṣ quadrifidis, peảnculis diphyllis. LIN. Syft. pag. goo. n. 6. вовнм. n. 7. (fub Galio).

Meicrkraut; gelbe Kreuszeurz; gülden Waldmei. fter. Germ. Groiffette velue. Gall.

In dumetis, foificulis exficcatis ad fepes e. g. hin ter dor Milchinfel; porro ad viam verfus Schönfeld, prope Alnetum; an Gickerlingsberge; in horte Bo. fiano, bei denu alten Gereächshaufe copiofiffume ar alibi valde frequens. Fl. Maio et per totain fere Aeftatem. Annua. 


\section{A D D NDA.}

Herba vulneraria rubro inficit colore animalium ofla et Rubiac Tingorum fubstitui poteft.

$$
\text { Ad pag. I72. polt n. } 45 \mathrm{I} \text {. }
$$

1736. * Awaranthus racemis pentandris compofitis ere fanguin us. ctis: lateralibus patentifimis, foliis ouato-oblongis. LINN. Syft. p. 85 \% n. 18 .

Bluthrothcr Anaranth. Germ.

In reicctamentis hortorum ante pazos paffim et in collibus circa Vrbem; frequentius autem in hortis fuburbanis et ambulacris publicis colitur. Fl. Aug. in Aurunim vique.

$V f$. Folia in nonnullis regionibus olerum more colliguntur coqumn:urque.

1737. * Amarantizus racemis pentandris decompofitis caldatus. cylindricis, pendulis longifimis. LiNn. Syft. p. $85 \%$. n. 2.3 .

Putpurrother f. langrefchüänzter Anaranth, Fuclisfcheranz. Germ. Great Amaranth; Lone - lies a blec. ding. Angl. Pafe velours; Difcipline des Religienfes. Gall.

In iisdem locis cum priori frequenter occurrit et ob longifimos racemos penduliferos, e rubeilo-coccineos noftrates ornat hortos. Floret exeunte Aeflate in Autumnum ferum vsque.

Vf. E Seminibus alicam proparant Rufi.

Ad pag. I33. n. 358 .

Hedera quinquefolia paflom fponte crefcit in Horto Bofano linuten bei dem Geveïchshaufe dicht an den Brunnets.

$$
\text { Ad pag. I3. n. } 33 \text {. }
$$

Saluia prazenfis crefcit copiofe in pratis hinter Altranftïdt.

$$
\text { Ad pag. 17. n. } 43 \text {. }
$$

Orchis milizaris var. manior frequenter habitat in pratis vliginofis bei Schadebach. 
ADDENDA.

Ad pag. 20. 17. 5 I.

Scrapias longifolia occurrit quoque copiofe in pratis humidis ber den Gefundbrumen, atque in pratis fpongiofis bei Sciadebach, hinter Krị̂hânze.

$$
\text { Ad pag. 94. 17. } 264 \text {. }
$$

Trapa natons' copiofifme crefcit in pifcinis der großen Funkenburg.

$$
\text { Ad pag. 95. ad n. } 26 \text {. }
$$

Weiffer Kornelbaun; Hartriegel mit weiffen Becren. Ferm. White berried Cornel. Angl. Counnouilier blanc.

$$
\text { Ad psg. 224. n. } 56 \%
$$

Hydrocharis Morfus Ranae copiofe occurrit in pifcina ante Schönfeld.

$$
\Lambda \mathrm{d} \text { pag. } 232 . \text { n. } 586 .
$$

Diantinus borbatus copiofinme crefcit in locis ficcioribus binuer Kriphäne, dicht an der Prellheide auf tern Tieferefer Antheile.
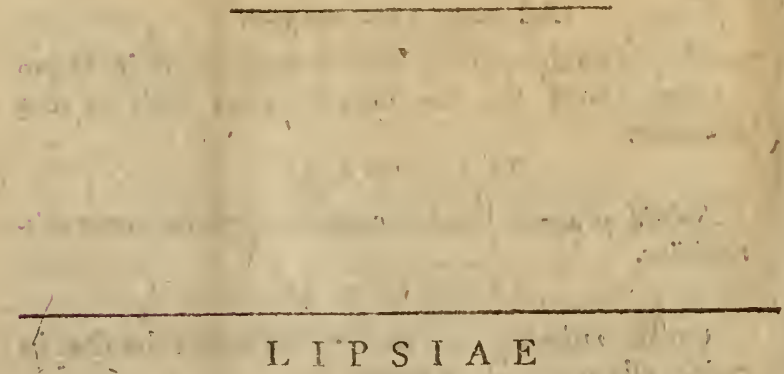

EX OFIICI I A $\$$ I L E KIGIA NA. 



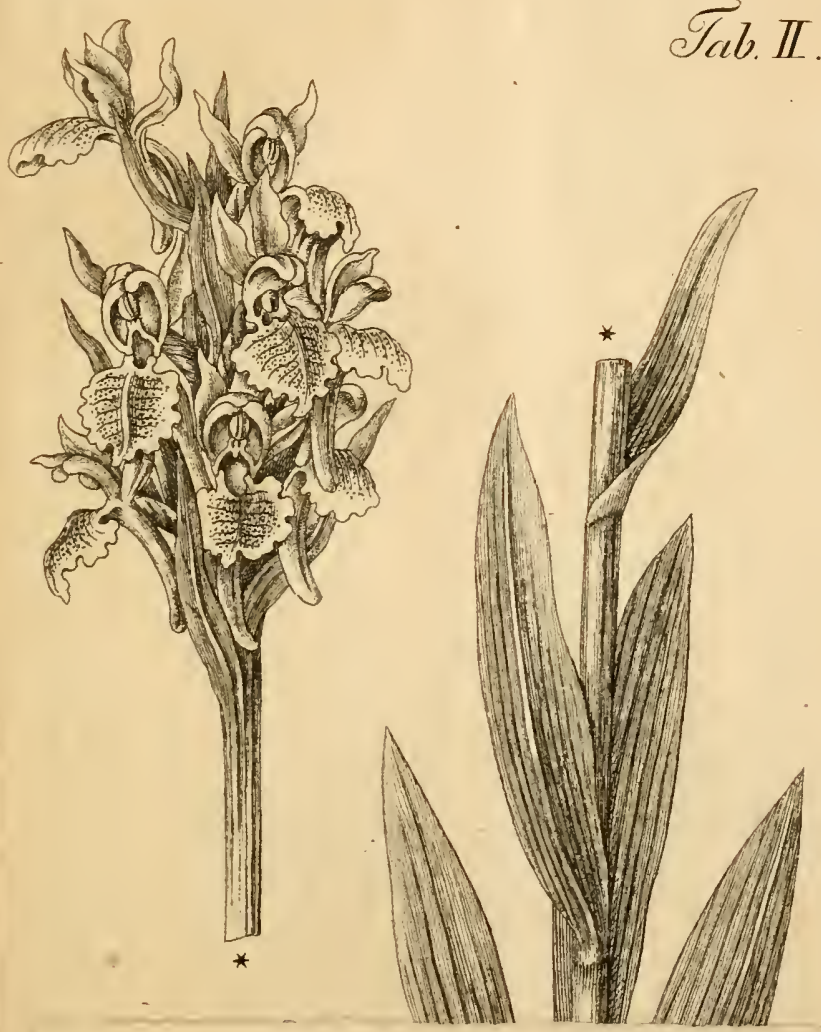




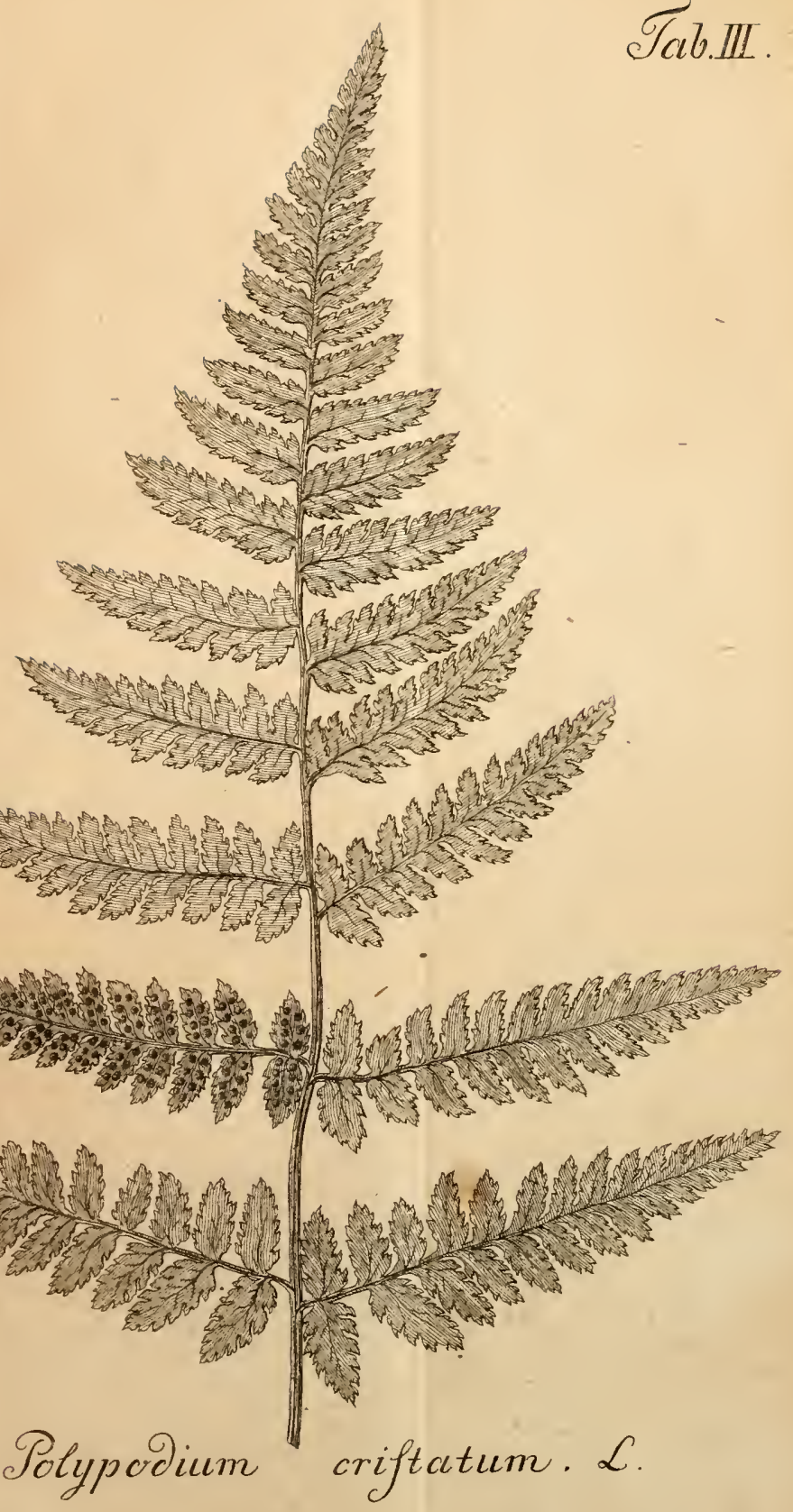





\section{Tab.IV.}
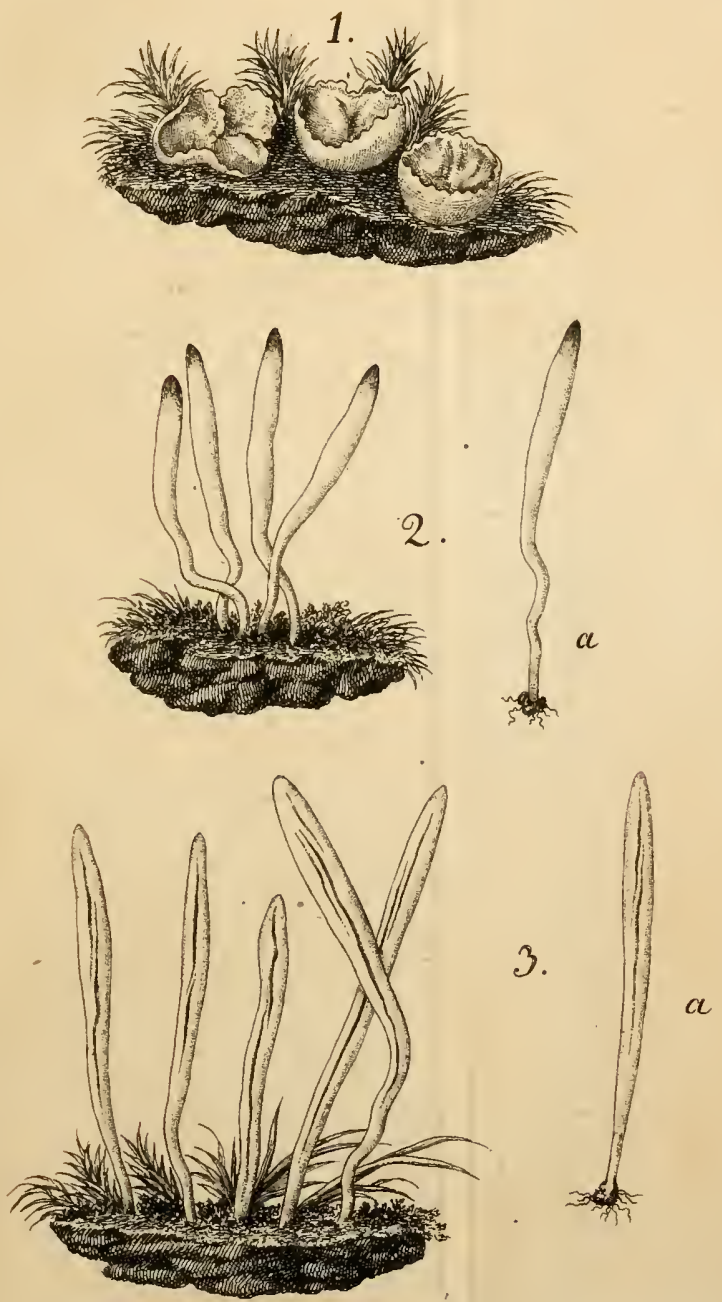

Octofpora coccinea. 2. Clavaria teres.

3. Clavaria fulva. 


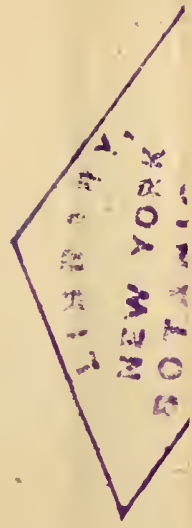



Baumgarten, Johann/Flora lipsiensis : si

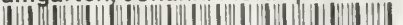

|| || || || ||||||| | | || || || || || || || || 


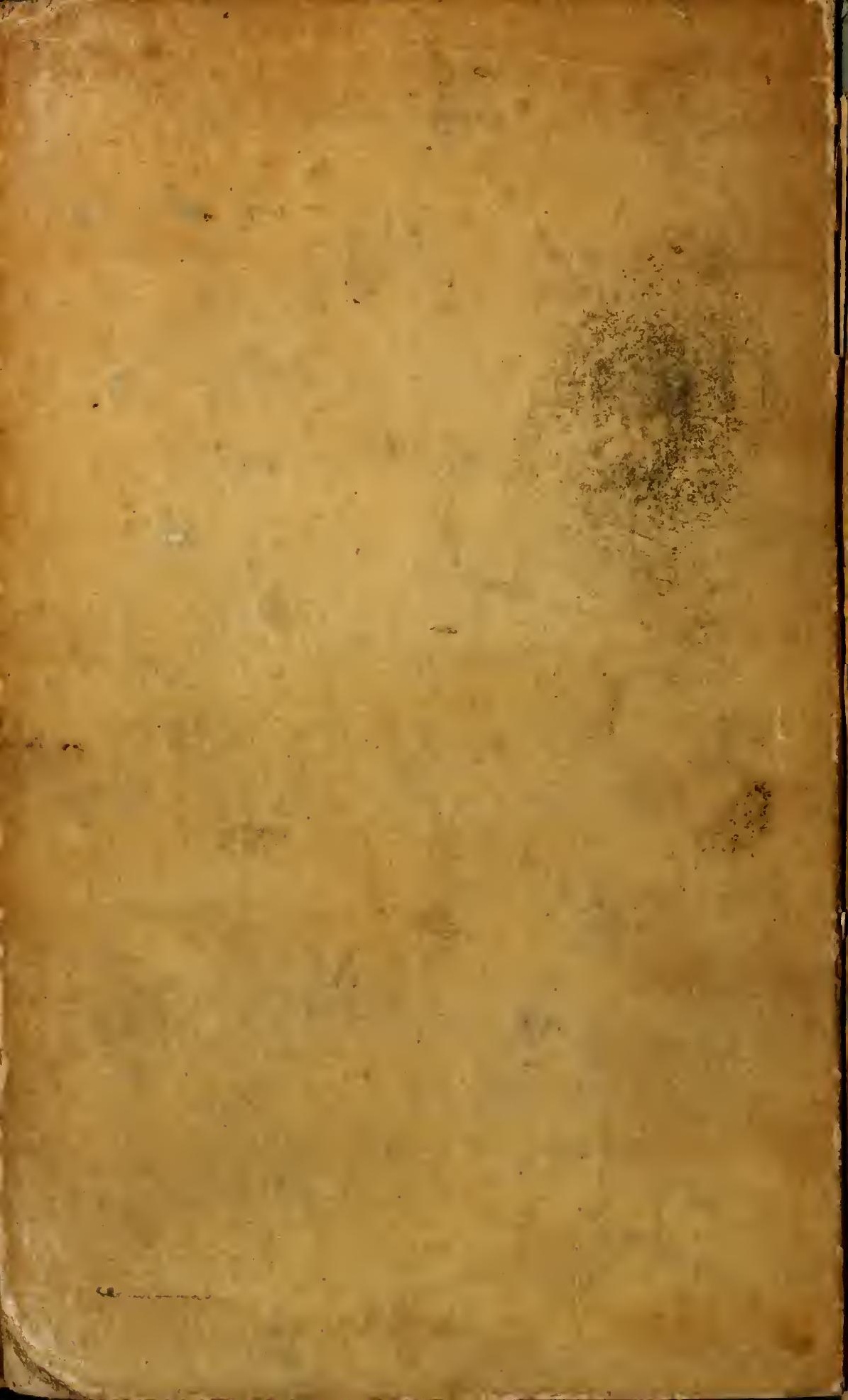

